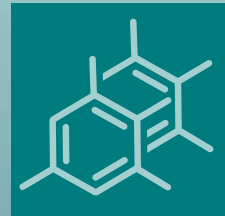

molecules

Amide Bond Activation

Printed Edition of the Special Issue Published in Molecules

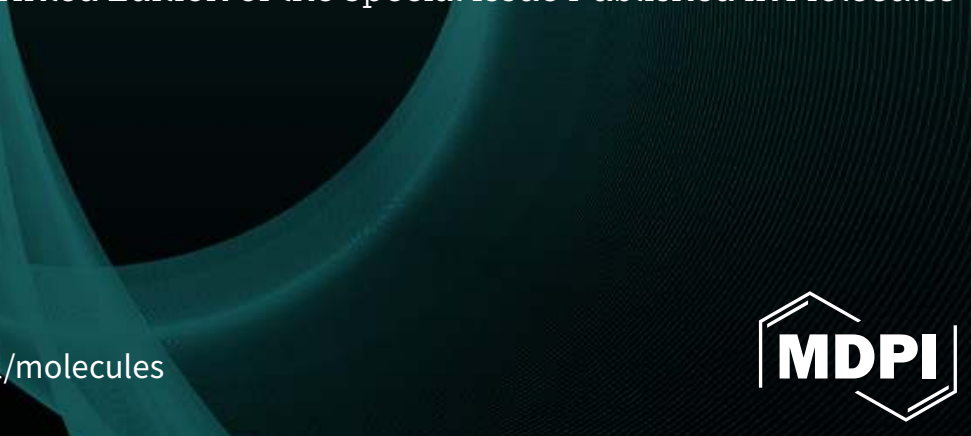


Amide Bond Activation 



\section{Amide Bond Activation}

Special Issue Editor

Michal Szostak

MDPI • Basel • Beijing • Wuhan • Barcelona • Belgrade

\section{MDPI}


Special Issue Editor

Michal Szostak

Rutgers University

USA

Editorial Office

MDPI

St. Alban-Anlage 66

4052 Basel, Switzerland

This is a reprint of articles from the Special Issue published online in the open access journal Molecules (ISSN 1420-3049) from 2018 to 2019 (available at: https://www.mdpi.com/journal/molecules / special_issues/amide_bond_activation)

For citation purposes, cite each article independently as indicated on the article page online and as indicated below:

LastName, A.A.; LastName, B.B.; LastName, C.C. Article Title. Journal Name Year, Article Number, Page Range.

ISBN 978-3-03921-203-3 (Pbk)

ISBN 978-3-03921-204-0 (PDF)

(C) 2019 by the authors. Articles in this book are Open Access and distributed under the Creative Commons Attribution (CC BY) license, which allows users to download, copy and build upon published articles, as long as the author and publisher are properly credited, which ensures maximum dissemination and a wider impact of our publications.

The book as a whole is distributed by MDPI under the terms and conditions of the Creative Commons license CC BY-NC-ND. 


\section{Contents}

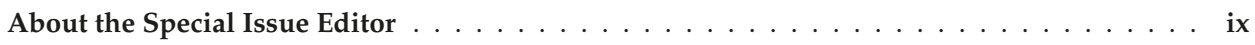

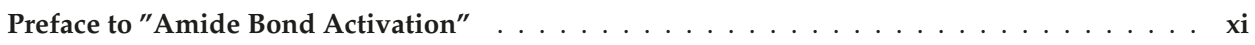

Igor V. Komarov, Aleksandr Yu. Ishchenko, Aleksandr Hovtvianitsa, Viacheslav Stepanenko, Serhii Kharchenko, Andrew D. Bond and Anthony J. Kirby

Fast Amide Bond Cleavage Assisted by a Secondary Amino and a Carboxyl Group-A Model for yet Unknown Peptidases?

Reprinted from: Molecules 2019, 24, 572, doi:10.3390/molecules24030572 . . . . . . . . . . . .

Hengzhao Li, Zemin Lai, Adila Adijiang, Hongye Zhao and Jie An

Selective C-N $\sigma$ Bond Cleavage in Azetidinyl Amides under Transition Metal-Free Conditions Reprinted from: Molecules 2019, 24, 459, doi:10.3390/molecules24030459 . . . . . . . . . . . . 20

Jyunichi Terasawa, Yu Shibata, Miho Fukui and Ken Tanaka

[2+2+2] Annulation of N-(1-Naphthyl)acetamide with Two Alkynoates via Cleavage of Adjacent C-H and C-N Bonds Catalyzed by an Electron-Deficient Rhodium(III) Complex

Reprinted from: Molecules 2018, 23, 3325, doi:10.3390/molecules23123325 . . . . . . . . . . . .

\section{Giovanni La Penna and Fabrizio Machetti}

Understanding the Exceptional Propertiesof Nitroacetamides in Water: AComputational Model Including the Solvent

Reprinted from: Molecules 2018, 23, 3308, doi:10.3390/molecules23123308 . . . . . . . . . . . . . . 41

Jonathan Buchspies, Daniel J. Pyle, Huixin He and Michal Szostak

Pd-Catalyzed Suzuki-Miyaura Cross-Coupling of Pentafluorophenyl Esters

Reprinted from: Molecules 2018, 23, 3134, doi:10.3390/molecules23123134 . . . . . . . . . . . . . 61

Chong-Lei Ji, Pei-Pei Xie and Xin Hong

Computational Study of Mechanism and Thermodynamics of Ni/IPr-Catalyzed

Amidation of Esters

Reprinted from: Molecules 2018, 23, 2681, doi:10.3390/molecules23102681 . . . . . . . . . . . . . . 71

Sungwoo Hong, Zhenghuan Fang, Hoi-Yun Jung, Jin-Ha Yoon, Soon-Sun Hong and

Han-Joo Maeng

Synthesis of Gemcitabine-Threonine Amide Prodrug Effective on Pancreatic Cancer Cells with Improved Pharmacokinetic Properties

Reprinted from: Molecules 2018, 23, 2608, doi:10.3390/molecules23102608 . . . . . . . . . . . . . . 81

Balmukund S. Thakkar, John Sigurd M. Svendsen and Richard A. Engh

Density Functional Studies on Secondary Amides: Role of Steric Factors in Cis/Trans Isomerization

Reprinted from: Molecules 2018, 23, 2455, doi:10.3390/molecules23102455 . . . . . . . . . . . . . . 93

Cheng Chen, Yang Miao, Kimmy De Winter, Hua-Jing Wang, Patrick Demeyere, Ye Yuan and Francis Verpoort

Ruthenium-Based Catalytic Systems Incorporating a Labile Cyclooctadiene Ligand with $N$-Heterocyclic Carbene Precursors for the Atom-Economic Alcohol Amidation Using Amines Reprinted from: Molecules 2018, 23, 2413, doi:10.3390/molecules23102413 . . . . . . . . . . . . . 112 
Weijia Shi and Gang Zou

Palladium-Catalyzed Room Temperature Acylative Cross-Coupling of Activated Amides with Trialkylboranes

Reprinted from: Molecules 2018, 23, 2412, doi:10.3390/molecules23102412 . . . . . . . . . . . . . . 122

Diego Antonio Ocampo Gutiérrez de Velasco, Aoze Su, Luhan Zhai, Satowa Kinoshita, Yuko Otani and Tomohiko Ohwada

Unexpected Resistance to Base-Catalyzed Hydrolysis of Nitrogen Pyramidal Amides Based on the 7-Azabicyclic[2.2.1] heptane Scaffold

Reprinted from: Molecules 2018, 23, 2363, doi:10.3390/molecules23092363 . . . . . . . . . . . . . 132

Sungsoo Kim, Jungyu Kim, Jieun Kim, Daeun Won, Suk-Kyu Chang, Wansik Cha, Keunhong Jeong, Sangdoo Ahn and Kyungwon Kwak

Electronic Effect on the Molecular Motion of Aromatic Amides: Combined Studies Using VT-NMR and Quantum Calculations

Reprinted from: Molecules 2018, 23, 2294, doi:10.3390/molecules23092294 . . . . . . . . . . . . . . 154

Yongjun Bian, Xingyu Qu, Yongqiang Chen, Jun Li and Leng Liu

$\mathrm{K}_{2} \mathrm{~S}_{2} \mathrm{O}_{8}$-Promoted Aryl Thioamides Synthesis from Aryl Aldehydes Using Thiourea as the Sulfur Source

Reprinted from: Molecules 2018, 23, 2225, doi:10.3390/molecules23092225 . . . . . . . . . . . . . 168

Zrinka Rajić, Maja Beus, Hana Michnová, Josipa Vlainić, Leentje Persoons, Ivan Kosalec, Josef Jampílek, Dominique Schols, Toma Keser and Branka Zorc

Asymmetric Primaquine and Halogenaniline Fumardiamides as Novel Biologically Active Michael Acceptors

Reprinted from: Molecules 2018, 23, 1724, doi:10.3390/molecules23071724 . . . . . . . . . . . . . . 178

Jagadeesh Kalepu and Lukasz T. Pilarski

Weinreb Amides as Directing Groups for Transition Metal-Catalyzed C-H Functionalizations

Reprinted from: Molecules 2019, 24, 830, doi:10.3390/molecules24050830 . . . . . . . . . . . . 196

\section{Roman Szostak and Michal Szostak}

Chemistry of Bridged Lactams: Recent Developments

Reprinted from: Molecules 2019, 24, 274, doi:10.3390/molecules24020274 . . . . . . . . . . . . . 218

Sandeep R. Vemula, Michael R. Chhoun and Gregory R. Cook

Well-Defined Pre-Catalysts in Amide and Ester Bond Activation

Reprinted from: Molecules 2019, 24, 215, doi:10.3390/molecules24020215 . . . . . . . . . . . . . 235

Fei Zhao, Pinyi Li, Xiaoyan Liu, Xiuwen Jia, Jiang Wang and Hong Liu

Recent Advances in the Addition of Amide/Sulfonamide Bonds to Alkynes

Reprinted from: Molecules 2019, 24, 164, doi:10.3390/molecules24010164 . . . . . . . . . . . . . . 253

Ervin Kovács, Balázs Rózsa, Attila Csomos, Imre G. Csizmadia and Zoltán Mucsi

Amide Activation in Ground and Excited States

Reprinted from: Molecules 2018, 23, 2859, doi:10.3390/molecules23112859 . . . . . . . . . . . . . 275

\section{Stephen A. Glover and Adam A. Rosser}

Heteroatom Substitution at Amide Nitrogen-Resonance Reduction and HERON Reactions of Anomeric Amides

Reprinted from: Molecules 2018, 23, 2834, doi:10.3390/molecules23112834 . . . . . . . . . . . . . 306 
Sriram Mahesh, Kuei-Chien Tang and Monika Raj

Amide Bond Activation of Biological Molecules

Reprinted from: Molecules 2018, 23, 2615, doi:10.3390/molecules23102615 . . . . . . . . . . . . . . 345

Paola Acosta-Guzmán, Alejandra Mateus-Gómez and Diego Gamba-Sánchez

Direct Transamidation Reactions: Mechanism and Recent Advances

Reprinted from: Molecules 2018, 23, 2382, doi:10.3390/molecules23092382 . . . . . . . . . . . . . . 388

\section{Hideto Miyabe}

Transition-Metal-Free Activation of Amide Bond by Arynes

Reprinted from: Molecules 2018, 23, 2145, doi:10.3390/molecules23092145 . . . . . . . . . . . . . 405

Jean Le Bras and Jacques Muzart

Recent Uses of N,N-Dimethylformamide and N,N-Dimethylacetamide as Reagents

Reprinted from: Molecules 2018, 23, 1939, doi:10.3390/molecules23081939. 



\section{About the Special Issue Editor}

Michal Szostak Szostak received his Ph.D. from the University of Kansas with Prof. Jeffrey Aubé in 2009. After postdoctoral stints at Princeton University with Prof. David MacMillan and the University of Manchester with Prof. David Procter, in 2014, he joined the faculty at Rutgers University. His research group is focused on the development of new synthetic methodology based on transition metal catalysis, amide bond activation, conformational preferences of amides, transition metal-mediated free-radical chemistry, $\mathrm{C}-\mathrm{H}$ activation, and their application to the synthesis of biologically active molecules. He is the author of over 140 peer-reviewed publications. 



\section{Preface to "Amide Bond Activation"}

The amide bond represents a privileged motif in chemistry. A fascinating feature of the amide bond is its innate stability, achieved by delocalization of the nitrogen lone pair into the carbonyl group. In recent years, we have witnessed an explosion of interest in the development of new chemical transformations of amides that defying the conventional knowledge characterizing the amide bond as one of the most robust functional groups in synthetic chemistry. An important trend involves chemoselective activation of the $\mathrm{N}-\mathrm{C}$ amide bond by metal insertion. This thriving class of reactions originated from the classic studies of amide bond destabilization and has already demonstrated the potential to become a widely applicable cross-coupling platform. More generally, $\mathrm{N}-\mathrm{C}$ bond activation emphasizes the significance of ubiquitous amide bonds in participating in a wide range of electrophilic, Lewis acid, radical, and nucleophilic reaction pathways, among other transformations. These methods deliver valuable disconnections by functional group interconversion or the functionalization of amides on a fundamental level. Equally relevant are structural and theoretical studies that provide the basis for chemoselective manipulation of amidic resonance. This monograph on amide bonds offers a broad survey of the recent advances in activation of amides and addresses various approaches in the field.

In closing, I would like to thank all the authors who contributed their excellent work to this monograph. It is beyond any doubt that these interesting articles will inspire future advances in this field.

Michal Szostak

Special Issue Editor 

Article

\title{
Fast Amide Bond Cleavage Assisted by a Secondary Amino and a Carboxyl Group-A Model for yet Unknown Peptidases?
}

\author{
Igor V. Komarov ${ }^{1, *}$, Aleksandr Yu. Ishchenko ${ }^{2}$, Aleksandr Hovtvianitsa ${ }^{2}$, \\ Viacheslav Stepanenko ${ }^{2}$, Serhii Kharchenko ${ }^{2}$, Andrew D. Bond ${ }^{3}$ and Anthony J. Kirby ${ }^{3, *}$ \\ 1 Institute of High Technologies, Taras Shevchenko National University of Kyiv, Vul. Volodymyrska 64/13, \\ 01601 Kyiv, Ukraine \\ 2 Enamine Ltd., Vul. Chervonotkatska 78, 02094 Kyiv, Ukraine; ischa1986@ukr.net (A.Y.I.); \\ cayenestar@gmail.com (A.H.); v.stepanenko@enamine.net (V.S.); serxioharchenko@ukr.net (S.K.) \\ 3 University Chemical Laboratory, Cambridge CB2 1EW, UK; adb29@cam.ac.uk \\ * Correspondence: ik214@yahoo.com (I.V.K.); ajk1@cam.ac.uk (A.J.K.)
}

Academic Editor: Michal Szostak

Received: 14 January 2019; Accepted: 31 January 2019; Published: 5 February 2019

\begin{abstract}
Unconstrained amides that undergo fast hydrolysis under mild conditions are valuable sources of information about how amide bonds may be activated in enzymatic transformations. We report a compound possessing an unconstrained amide bond surrounded by an amino and a carboxyl group, each mounted in close proximity on a bicyclic scaffold. Fast amide hydrolysis of this model compound was found to depend on the presence of both the amino and carboxyl functions, and to involve a proton transfer in the rate-limiting step. Possible mechanisms for the hydrolytic cleavage and their relevance to peptide bond cleavage catalyzed by natural enzymes are discussed. Experimental observations suggest that the most probable mechanisms of the model compound hydrolysis might include a twisted amide intermediate and a rate-determining proton transfer.
\end{abstract}

Keywords: amide hydrolysis; model compound; intramolecular catalysis; twisted amide; protease; intein

\section{Introduction}

Hydrolysis of the 1-azatricyclo[3.3.1.1.7 $]$ decan-2-one (1), which contains an ultimately twisted and $\mathrm{N}$-pyramidalized amide bond, was reported to be very fast and accompanied by the formation of the "dimer" (compound 2) and higher oligomers [1]. The use of a half equivalent of water under certain conditions led almost exclusively to formation of $\mathbf{2}$ (Scheme 1). Apparently, the product of the initial hydrolysis of $\mathbf{1}$-the amino acid 3 -was immediately $N$-acylated by unreacted $\mathbf{1}$, which possesses an extremely electrophilic carbonyl group. In contrast to the twisted and therefore highly reactive amide $\mathbf{1}$, the dimer $\mathbf{2}$ has an essentially unconstrained amide bond: yet we found that it reacted with excess of water at a comparable rate, also giving the amino acid 3 (Scheme 1) [1]. Such a fast amide hydrolysis is unusual; therefore, we decided to study the compound $\mathbf{2}$ in more detail.
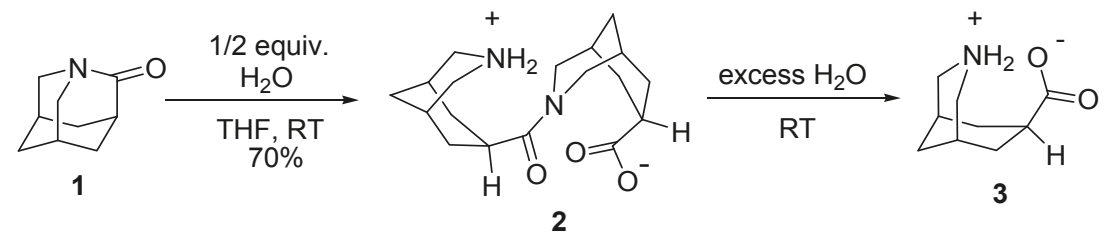

Scheme 1. Formation and hydrolysis of amide 2. 
Examples of amides hydrolysable under mild conditions are rare, but not unknown. Apart from 1 and other similar systems featuring highly deformed amide bonds (see the reviews [2-4]), there are compounds where fast amide bond hydrolysis was suggested to be facilitated by neighboring group assistance (Figure 1 lists some representative examples, [5-13]).<smiles>COC(=O)c1ccccc1C(=O)O</smiles>

$\mathrm{t}_{1 / 2}=550 \mathrm{~min}$

$\left(\mathrm{pH} 1.8,24.8^{\circ} \mathrm{C}[5]\right)$

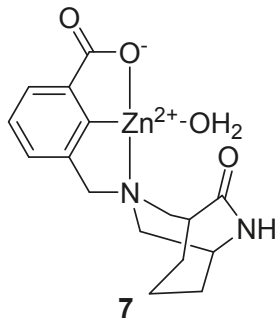

$\mathrm{t}_{1 / 2}=48 \mathrm{~h}$

$\left(\mathrm{pH} 7,50^{\circ} \mathrm{C}[8]\right)$

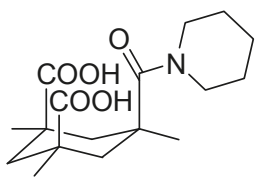

10

$\mathrm{t}_{1 / 2}=3 \mathrm{~min}$

(pD 7.7, $\left.20^{\circ} \mathrm{C}[11]\right)$

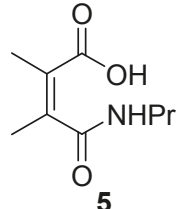

$\mathrm{t}_{1 / 2}=0.6 \mathrm{sec}$

$\left(\mathrm{pH} 3,39^{\circ} \mathrm{C}[6]\right)$<smiles>CC(C)C(C(=O)O)=C(C(=O)N[C@@H](CC(=O)O)C(=O)O)C(C)C</smiles>

$\mathrm{t}_{1 / 2}=42 \mathrm{sec}$

$\left(\mathrm{pH} 3.98,15.5^{\circ} \mathrm{C}[7]\right)$

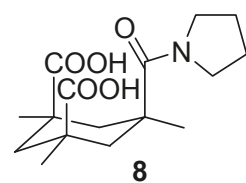

$\mathrm{t}_{1 / 2}=7.7 \mathrm{~min}$ (pD $7.05,21.5^{\circ} \mathrm{C}[9]$ )

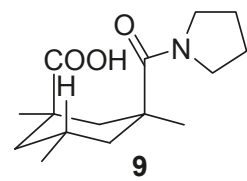

$\mathrm{t}_{1 / 2}=19 \min$ $\left(\mathrm{pD} 6.9,21^{\circ} \mathrm{C}[10]\right)$<smiles>NC(=O)CC1CCC[C@H]2CCC[C@H](O)[C]12</smiles>

$\mathrm{t}_{1 / 2}=21 \mathrm{~min}$ (pD 7, $25^{\circ} \mathrm{C}$ [12])<smiles>CCNC(=O)c1c(C(=O)O)ccc2cccc(C(=O)O)c12</smiles>

12

$\left(\mathrm{pH} 4,35^{\circ} \mathrm{C}\right.$ [13])

Figure 1. Selected compounds reported to undergo unusually fast amide bond hydrolysis in buffered water under mild conditions (indicated in brackets). Values of the half-life, calculated using the measured pseudo-first order rate constants $k_{o b s}$ are listed for each compound.

Compounds like $\mathbf{1}$ and $\mathbf{4 - 1 2}$ should not be regarded simply as chemical curiosities. In fact, most of them were deliberately designed and synthesized to obtain valuable information on the fundamental properties of the amide bond, and to use this information in unraveling the mechanisms of biologically relevant processes involving amide formation and cleavage: particularly mechanisms of protein cleavage catalyzed by proteolytic enzymes. Perhaps most studied in this regard are molecules mimicking the function of the side-chain carboxyl groups in the active sites of aspartic proteases. The first systematic studies with such molecules, later named enzyme models [14], were undertaken back in the 1950s [5,15]. In the following decades many more similar models were discovered. It was demonstrated that one or two carboxyl groups in close proximity to the amide function (as in compounds 4-6, 8-10, 12) catalyzed the amide bond hydrolysis with rates comparable to those of the corresponding enzymatic transformations. Similar work was also published on models of metalloproteases (exemplified here by compound 7), and serine/cysteine proteases (e.g., compound 
11). Although the validity of the enzyme models and their relevance to the natural enzyme mechanisms has been extensively criticized and re-examined (see, for example, $[10,11,16,17]$, there is no doubt that they made important contributions to our understanding of the natural catalytic systems, and will do so in the future.

Moreover, reactive model amides like compounds 1 and 4-12, together with natural systems, inspired many chemists to design selective and efficient non-enzymatic transformations of the amide bond, not limited to hydrolysis. For example, twisting around the $\mathrm{N}-\mathrm{C}$ bond, as a general concept for amide bond activation was ingeniously utilized for the diverse and unprecedented functionalization of amides. Such twisting can be easily achieved either by formation of bridgehead lactams [18], or even by modifying acyclic amides [19] without resorting to polycyclic scaffolds. Notable are the metal-catalyzed $\mathrm{N}-\mathrm{C}$ cross-coupling reactions of the twisted amides, impossible for unconstrained compounds (see recent reviews on this subject, [2,20-22]. Activation by neighboring groups was also used for developing selective amide group cleavage [23] and amine group protection strategies [24,25]. There has also been significant progress towards selective biomimetic metal-ion promoted amide bond cleavage, mimicking metalloproteases and amidohydrolases [23,26-30]. It should be noted, however, that efficient artificial catalytic (in particular, organocatalytic) amide bond transformations characteristic of proteases presents a challenge so far unachieved [31].

In view of the above, compound $\mathbf{2}$ might be regarded as a promising model compound, where the observed fast amide bond hydrolysis under mild conditions could provide new information about the intrinsic reactivity of the amide linkage and its possible catalytic cleavage.

One might hypothesize that the observed fast hydrolysis of $\mathbf{2}$ is facilitated by both carboxyl and secondary amine groups flanking the amide bond. In this paper, we report experimental evidence for this hypothesis, and also discuss the hidden potential of this model system in the study of biochemical transformations and the design of artificial catalytic systems.

\section{Results}

We first wanted to know if the presence of only one functional group, either the amino group or the carboxylate in the structural context of the amide $\mathbf{2}$ is sufficient for the fast hydrolysis of the amide bond. The literature data (e.g., on 5 [6], 9 [10], as well as on the compound described in [32]) clearly demonstrated that a single carboxyl group, if properly placed, can catalyze very fast amide bond hydrolysis intramolecularly, presumably through the proton transfer to the amide bond oxygen and subsequent nucleophilic attack at the $\mathrm{N}-\mathrm{CO}$ bond carbon [6]. Involvement of the basic nitrogen of a neighboring pyrimidine substituent in the hydrolytic cleavage of the amide bond has also been well documented [33].

We synthesized two isostructural analogues of 2, compounds 13 and $\mathbf{1 4}$, one lacking the secondary amino group (bearing the $-\mathrm{CH}_{2}-$ fragment instead), and the other possessing no carboxyl group (with $-\mathrm{CH}_{2}-$ in place of $\left.-\mathrm{CH}(\mathrm{COOH})-\right)$.

Compound 13 was prepared via the bicyclic carboxylic acid 20, synthesized by the method first published in [34] and further refined by us [35]. The acid 20 was converted to the corresponding acid chloride and coupled under the Schotten-Baumann reaction conditions with amino acid 3 (Scheme 2).

The key intermediate in our synthesis of $\mathbf{1 4}$ was the bicyclic amine $\mathbf{2 5}$, which was obtained following the steps described in [36,37] (Scheme 3). N-Cbz-protected amino acid 21 was prepared from 3 (we observed also formation of the side-product 22 during the protection) and coupled with 25 using a standard peptide coupling protocol. Cleavage of the Cbz-protecting group by hydrogenolysis afforded compound $\mathbf{1 4}$. 


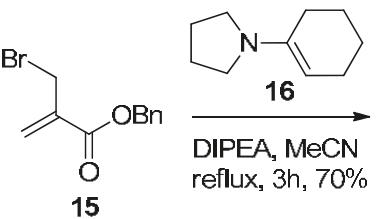

15

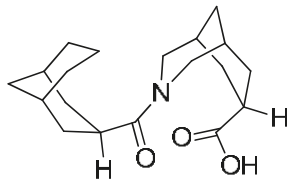

13

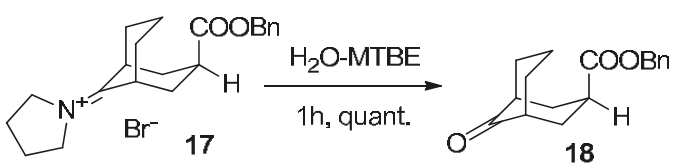

18

2. $\mathrm{NaBH}_{3} \mathrm{CN}, \mathrm{AcCl}$ $\mathrm{MeOH}, \mathrm{O}^{\circ} \mathrm{C}, 0.5 \mathrm{~h}$ then $\mathrm{NaOAc} \cdot 3 \mathrm{H}_{2} \mathrm{O}$ reflux, 3 , quant.
1. $\mathrm{TsSO}_{2} \mathrm{NHNH}_{2}$ $\mathrm{EtOH}$, reflux $0.5 \mathrm{~h}$ quant.

Scheme 2. Synthesis of model compound lacking the amino group.

$$
3 \underset{\mathrm{CbzCl}, \mathrm{NaHCO}_{3}}{\stackrel{\mathrm{H}}{\stackrel{\mathrm{O}-\text { Dioxane, 3h }}{66 \%}}}
$$

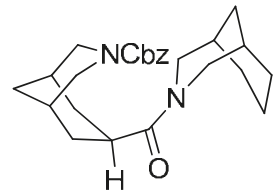

26

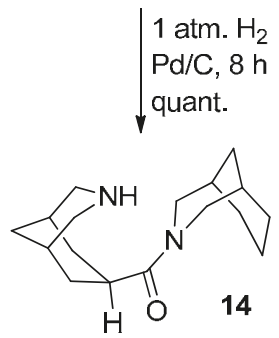<smiles>O=C(O)[C@@H]1C[C@H]2CC[C@H](C2)C1</smiles><smiles>O=CC1C=CCC=C1</smiles>

20

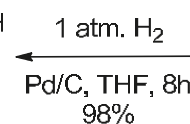

$98 \%$<smiles>CCCC=CC(=O)OBr</smiles>

19
21

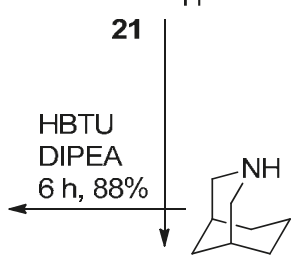

25

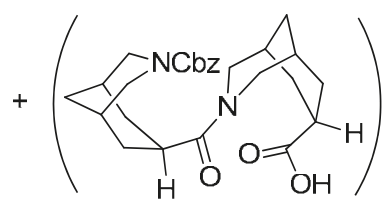

22 (side-product)

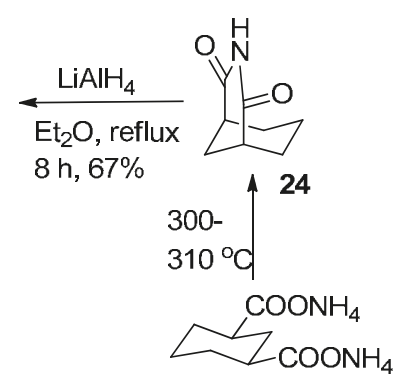

23

Scheme 3. Synthesis of model compound lacking the carboxyl group.

The structure of the amide $\mathbf{1 4}$ was confirmed by comprehensive analysis of its 2D-NMR spectra. The key NOESY correlations, which prove the structure of $\mathbf{1 4}$ in solution are shown in Figure 2 (see also the Supporting Information).

Compound 13 gave single crystals suitable for X-ray structure determination, which showed that the carboxyl group is indeed in close proximity to the amide bond (Figure 3) and might facilitate hydrolysis: as for example, in the known compound 9 [10]. However, neither 13 nor 14 was hydrolyzed at a measurable rate under the conditions used in [1] $\left(0.084 \mathrm{M}\right.$ in acetonitrile- $\mathrm{d}_{3}$ solution in the presence of five equivalents of water), in which compound 2 was reported to be hydrolyzed within days. 
We noted only very slow changes in the solutions of $\mathbf{1 4}$ in the presence of a large excess of water (on standing in a $\mathrm{CD}_{3} \mathrm{CN}-\mathrm{D}_{2} \mathrm{O}$ mixture, $1: 1 v \backslash v$ at $25^{\circ} \mathrm{C}$ ): where formation of insoluble, presumably polymeric material was observed within several weeks. These results are also in agreement with the reported fact [1] that if the carboxyl group in compound 2 is reduced to $\mathrm{CH}_{2} \mathrm{OH}$, the resulting amino alcohol also withstands hydrolysis even during prolonged treatment with excess water. Therefore, one might conclude that the amino and carboxyl groups act together to facilitate the hydrolysis of amide 2 .

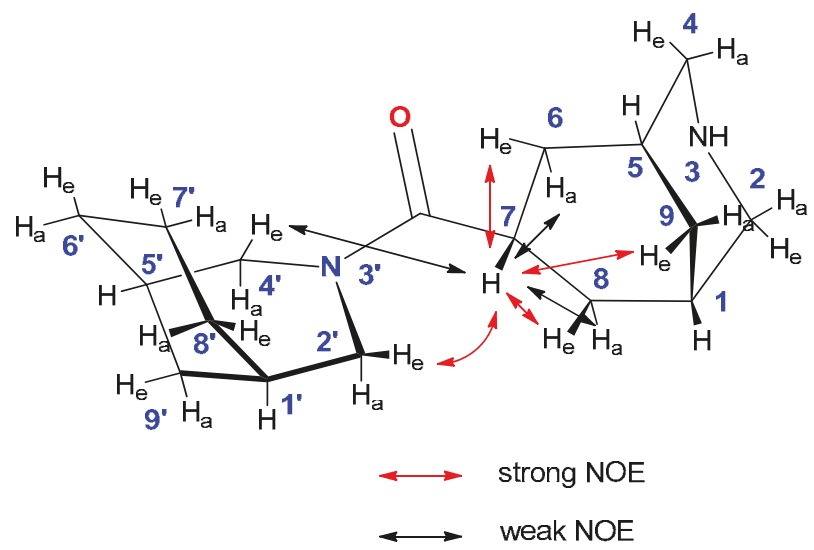

Figure 2. NOE correlations for 7-CH ${ }^{1} \mathrm{H}-\mathrm{NMR}$ peak in the 2D-NOESY spectrum of compound 14.

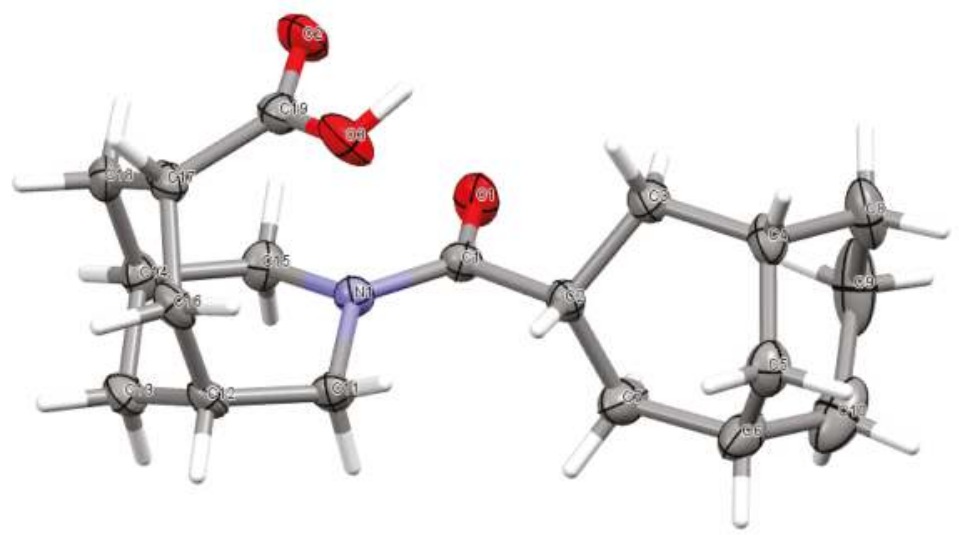

Figure 3. Molecular structure of $\mathbf{1 3}$ (ellipsoids are drawn at the $50 \%$ probability level).

In order to elucidate possible mechanisms for the intramolecular catalysis of the amide bond in 2, we decided to obtain this compound as a hydrochloride by a route different from that shown in Scheme 1 in order to study the rates of its reaction with water in buffers at different $\mathrm{pH}$. We reasoned that the hydrochloride salt would be more stable than the zwitterionic form of 2 obtained directly from 1 , enabling us to purify the compound. The synthetic approach was based on our observation (above) that treatment of the amino acid 3 with $\mathrm{CbzCl}$ gave not only the expected protected compound 21, but also the dimer 22 as a side-product (Scheme 3, in parentheses). Using $\mathrm{Me}_{3} \mathrm{SiCH}_{2} \mathrm{CH}_{2} \mathrm{OCOCl}$ as protecting reagent and varying the reaction conditions, we obtained the dimer 27 in a reasonable yield. Most probably, formation of $\mathbf{2 7}$ proceeded through the activated 
intermediate 28, which reacted with the starting amino acid (Scheme 4). Alternatively, compound 27 could be formed through the twisted amide 1, formed upon activation of the carboxyl group. The twisted amide could acylate unreacted 3 (as shown in Scheme 1), and the dimer 2 produced could then be trapped by the $\mathrm{N}$-protecting reagent. Treatment of 27 with dry $\mathrm{HCl}$ in dioxane afforded the hydrochloride $2 \cdot \mathrm{HCl}$.
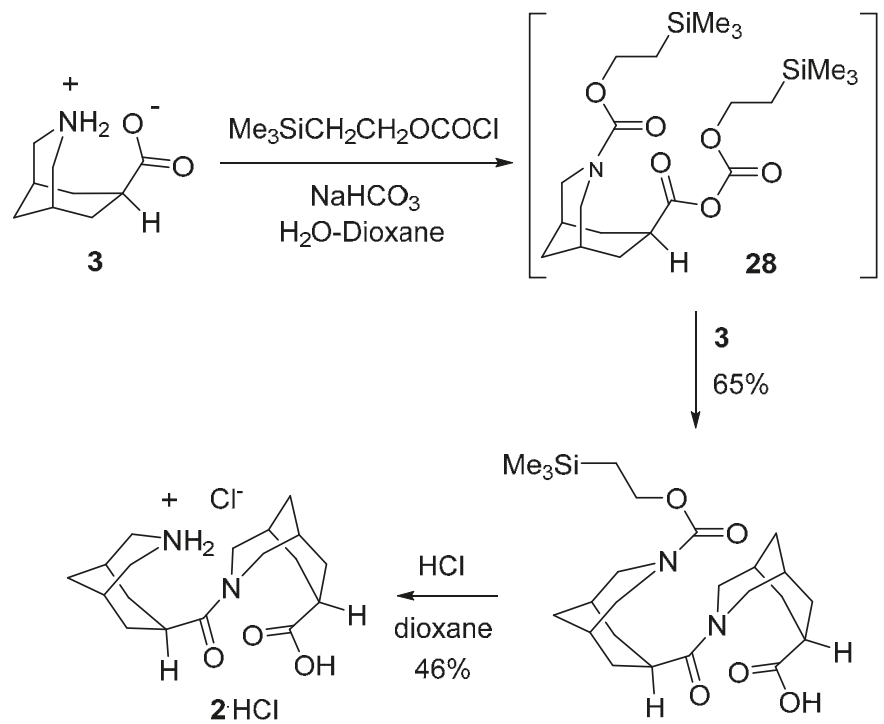

27

Scheme 4. Alternative synthesis of amide 2 (hydrochloride)

Compound $2 \cdot \mathrm{HCl}$ indeed turned out to be quite stable and crystallized from the reaction mixture after the deprotection of $\mathbf{2 7}$ upon addition of diethyl ether. The purity of the obtained $2 \cdot \mathrm{HCl}$ was sufficient to study its hydrolysis in different $\mathrm{D}_{2} \mathrm{O}$ buffers (acetate, $\mathrm{pD} 3.81$ and 4.85; phosphate, $\mathrm{pD}$ 6.68 and 7.95; carbonate, pD 9.45 and 10.68). Progress of the hydrolysis was monitored by ${ }^{1} \mathrm{H}-\mathrm{NMR}$ using unambiguously assigned peaks for the starting compound and its hydrolysis product.

In the acidic acetate buffers (pD 3.81 and 4.85) and in phosphate buffer at $\mathrm{pD} 6.68$, the $2 \cdot \mathrm{HCl}$ hydrolysis product - the amino acid 3 - appeared slowly in the ${ }^{1} \mathrm{H}$ - and ${ }^{13} \mathrm{C}-\mathrm{NMR}$ spectra while the starting amide peaks disappeared. A typical ${ }^{1} \mathrm{H}-\mathrm{NMR}$ data set for the hydrolysis in an acetate buffer is illustrated in Figure 4. The kinetic parameters obtained for the hydrolysis in the acidic-neutral buffers are listed in Table 1 (see also the Experimental section and Supporting Information for the details). As can be seen from the data in Table 1, the pseudo-first order rate constant $k_{\text {obs }}$ of the hydrolytic amide bond cleavage in 2 gradually increases with the $\mathrm{pD}$ values in this $\mathrm{pD}$ range, with the maximum of $1.849 \times 10^{-4} \mathrm{~min}^{-1}$ (half-life $\sim 62.5 \mathrm{~h}, 23^{\circ} \mathrm{C}$ ) in phosphate buffer at $\mathrm{pD} 6.68$.

Table 1. Kinetic parameters for the hydrolysis of $2 \cdot \mathrm{HCl}$ in acidic $\mathrm{D}_{2} \mathrm{O}$ buffers at different $\mathrm{pD}$ values, $23^{\circ} \mathrm{C}$.

\begin{tabular}{cccc}
\hline pD Value & Half-life of $\mathbf{2} \cdot \mathbf{H C l}, \mathbf{m i n}$ & $\boldsymbol{k}_{\text {obs }}, \mathbf{m i n}^{-1}$ & $\log \left(\boldsymbol{k}_{\text {obs }}\right)$ \\
\hline 3.81 & 18,138 & $3.821 \times 10^{-5}$ & -4.418 \\
4.85 & 4668 & $1.485 \times 10^{-4}$ & -3.828 \\
6.68 & 3748 & $1.849 \times 10^{-4}$ & -3.733 \\
\hline
\end{tabular}




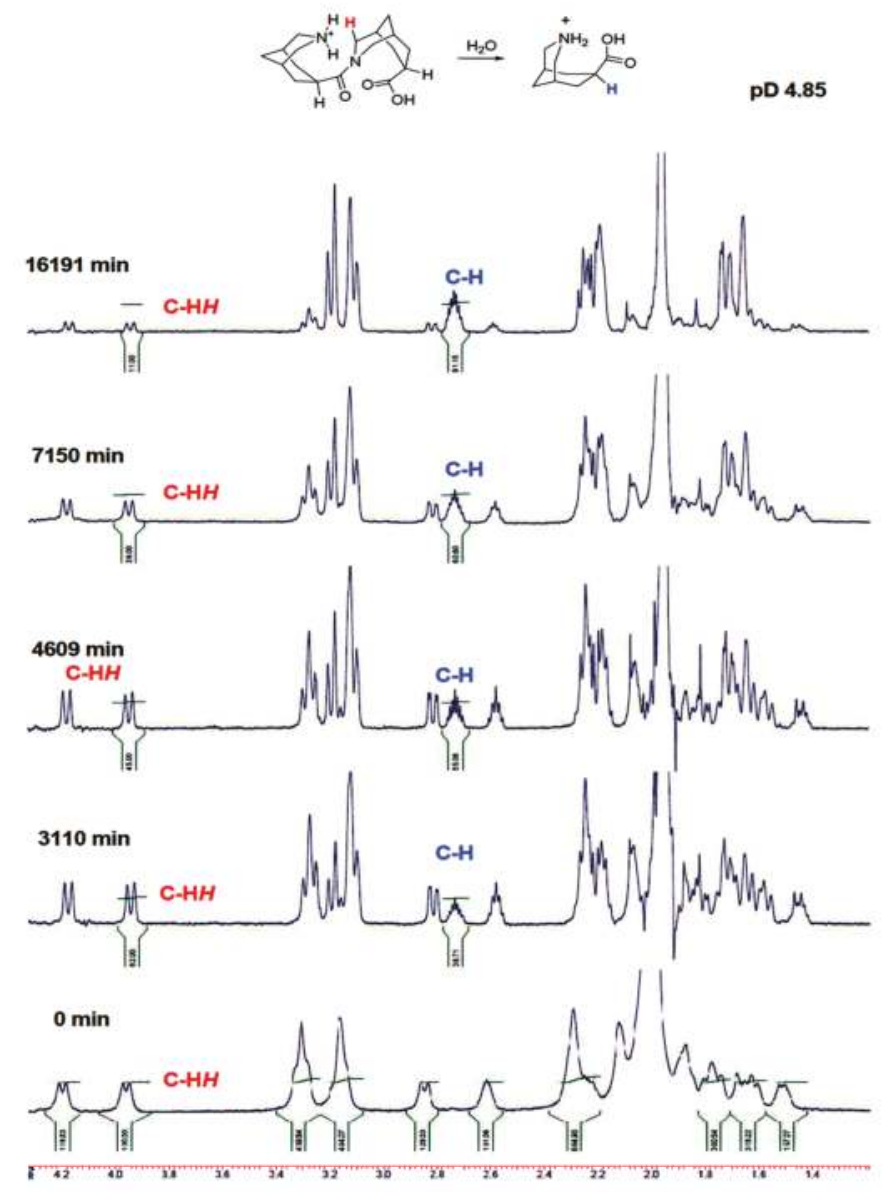

Figure 4. Representative ${ }^{1} \mathrm{H}-\mathrm{NMR}$ spectral data set for hydrolysis of $2 \cdot \mathrm{HCl}$ in acetate $\mathrm{D}_{2} \mathrm{O}$ buffer, $\mathrm{pD} 4.85,23^{\circ} \mathrm{C}$.

Hydrolysis of $2 \cdot \mathrm{HCl}$ in alkaline buffers (phosphate at $\mathrm{pD} 7.95$, carbonate at $\mathrm{pD} 9.45$ and 10.68) was found to become slower as the $\mathrm{pD}$ increased. The kinetic data obtained for this $\mathrm{pD}$ range are shown in Table 2.

Table 2. Kinetic parameters for the hydrolysis of $2 \cdot \mathrm{HCl}$ in alkaline $\mathrm{D}_{2} \mathrm{O}$ buffers at different $\mathrm{pD}$ values, $23^{\circ} \mathrm{C}$.

\begin{tabular}{cccc}
\hline pD Value & Half-life of $\mathbf{2} \cdot \mathbf{H C l}, \mathbf{m i n}$ & $k_{\text {obs }}, \min ^{-1}$ & $\log \left(\boldsymbol{k}_{\text {obs }}\right)$ \\
\hline 7.95 & 18,802 & $3.686 \times 10^{-5}$ & -4.433 \\
9.45 & 91,125 & $7.605 \times 10^{-6}$ & -5.119 \\
10.68 & 126,114 & $5.496 \times 10^{-6}$ & -5.260 \\
\hline
\end{tabular}

Interestingly, at pD 9.45 and 10.68 we observed a duplicated set of the ${ }^{1} \mathrm{H}$ - and ${ }^{13} \mathrm{C}-\mathrm{NMR}$ signals corresponding to the starting amide, suggesting the presence of its two forms in the solutions (Figures S33-S36 in the Supplementary Materials). These two forms were observed immediately after the compound was dissolved (the equilibrium between the forms established faster than we could run the ${ }^{1} \mathrm{H}-\mathrm{NMR}$ spectrum, $2 \mathrm{~min}$ ), and their ratio remained unchanged during the whole 
period of the kinetic measurements ( 2 months). However, the ratio between the forms depended on the $\mathrm{pD}$ of the solutions. The form which was dominant at the $\mathrm{pD} 9.45$ had the chemical shifts of the NMR signals close to those observed for the $2 \cdot \mathrm{HCl}$ in acidic buffers; at the $\mathrm{pD} 10.68$, both forms gave corresponding signals of almost equal intensity; to explain these observations, we suggest the existence of the structures $\mathbf{2} \mathbf{b}^{+-}$and $\mathbf{2}^{-}$in the alkaline solutions (Figure 5).
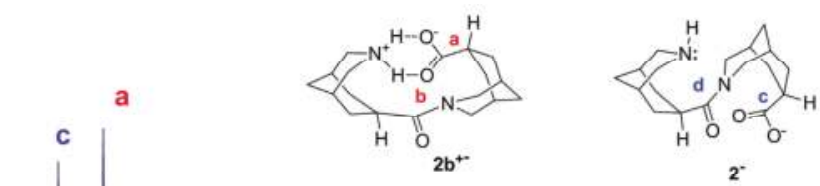

pD 10.68

$$
\mathbf{2}^{-}
$$

b

d
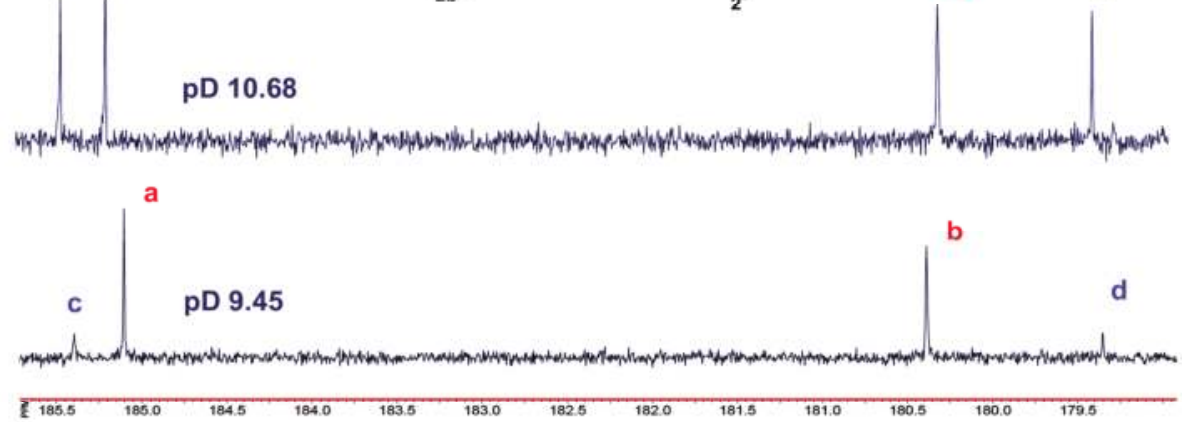

Figure 5. Fragments of ${ }^{13} \mathrm{C}$-NMR spectra of compound 2 in different buffers containing peaks of the carbonyl carbon atoms.

Figure 6 summarizes the kinetic data, showing the $\mathrm{pD}$-rate profile of the amide $\mathbf{2}$ hydrolysis in $\mathrm{D}_{2} \mathrm{O}$. The profile is bell-shaped, with the rate maximum at around neutral $\mathrm{pD}$ at $23^{\circ} \mathrm{C}$.

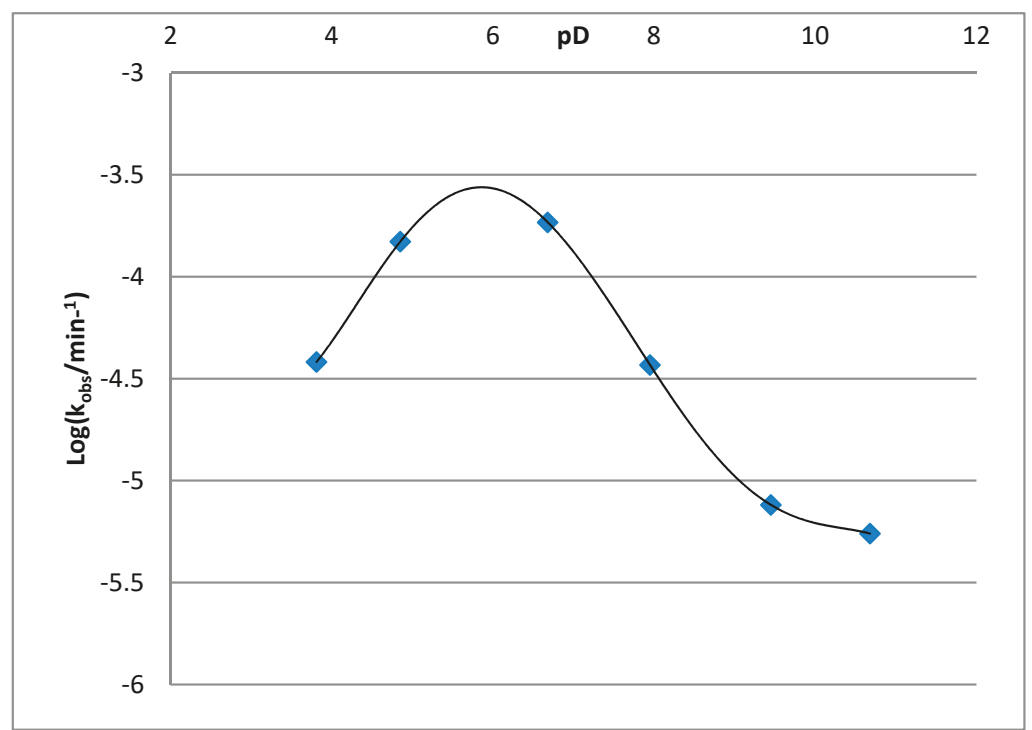

Figure 6. pD-rate profile for the hydrolysis of $2 \cdot \mathrm{HCl}$. 


\section{Discussion}

The bell-shaped rate profile for the hydrolytic cleavage of the amide 2 confirmed our suggestion made using the model molecules 13 and 14: that both amino and carboxyl groups are involved in the hydrolysis. On the basis of our experimental data, one can suggest the equilibria between differently protonated 2 in different buffers, as schematically illustrated in Figure 7. Evidently, the basic nitrogen in 2 is protonated and "switched off" from intramolecular assistance of the amide bond hydrolysis at low pDs (where species $2^{+}$dominate). Similarly, deprotonation of the COOH group "switches off" its involvement in the reaction at high pDs (the equilibria shifting to unreactive $\mathbf{2}^{-}$). There is an alternative explanation of the $\mathrm{pD}$ rate profile- - see the discussion of possible hydrolysis mechanisms below-but in all cases the amino and carboxyl groups should act synergistically.

At the high pDs, another reason for the slowdown of the reaction might be epimerization at the carbon atom next to the carboxyl group. The racemization could also explain the doubling of the signals in the solution of $\mathbf{2}$ in the alkaline buffers. However, we can exclude this possibility: the NMR signal-doubling is observed almost immediately after dissolving the amide 2 in the buffers, and the ratio of the species observed in the NMR spectra is dependent on the $\mathrm{pD}$, but not on time. Epimerization in similar systems is known to proceed much more slowly and under harsher conditions, leading to almost complete conversion of the endo- $\mathrm{COOH}$ epimer to the exo- $\mathrm{COOH}$ epimer [35]. Observation of the two species in the spectra of 2 might be explained by the slow (on the NMR time scale) exchange between the species $\mathbf{2} \mathbf{b}^{+-}$and $\mathbf{2}^{-}$at high pDs (Figure 8 ). This could be confirmed by the fact that one of the species (content increasing with $\mathrm{pD}$, so assigned to $2^{-}$) has the carboxyl group ${ }^{13} \mathrm{C}-\mathrm{NMR}$ resonance at lower field then the other species (tentatively assigned to $\mathbf{2} \mathbf{b}^{+-}$, Figure 8 ), in line with literature data reporting the downfield shift for the $\mathrm{COOH}{ }^{13} \mathrm{C}-\mathrm{NMR}$ peak upon deprotonation [38].

Two types of possible mechanisms of the hydrolysis of 2 can be suggested, if both the amino and carboxyl functions are involved. These mechanisms (which we name $\mathrm{N}$ - and $\mathrm{O}$-mechanisms in order to distinguish them in the following discussion) differ by the roles played by the two functional groups in intramolecular catalysis. The N-mechanism, realizable either through path a or $\mathbf{b}$ (Figure 7) involves a nucleophilic attack of the basic nitrogen atom on the amide bond carbon while the $\mathrm{COOH}$ group acts as a general acid. It might be concerted (path a) or involve formation of a tetrahedral intermediate (TIb, path b), but in both cases should result in formation of the twisted amide 1. Although we did not observe 1 in the reaction mixtures at any pDs by NMR, we know that its hydrolysis will be extremely fast under the reaction conditions used [1], excluding the accumulation of $\mathbf{1}$ in observable concentrations. The O-mechanism (concerted path c or stepwise path d, Figure 7) suggests that the amino and the carboxyl group swap roles in the first step of the reaction: the deprotonated $\mathrm{COOH}$ is now the nucleophile and the protonated amino group acts as the general acid. This possible mechanism would involve formation of the anhydride intermediate A (apart from the tetrahedral intermediate TId in the path d). Degradation of A might again involve the nucleophilic amino group attack at one of the anhydride carbonyls and formation of the twisted amide 1. In all cases the limiting step is the first; the following transformations should be fast-explaining why no intermediates were detected by NMR spectroscopy in the reaction mixtures. In order to prove that the rate limiting step of the hydrolysis (at least at low $\mathrm{pH}$ ) involves a proton transfer, we set up two hydrolysis reactions of $2 \cdot \mathrm{HCl}$ running in parallel with all the conditions but one identical: the solvent for one being $\mathrm{H}_{2} \mathrm{O}$, for the other, $\mathrm{D}_{2} \mathrm{O}$. NMR monitoring of the reaction rates revealed a well-defined isotope effect: the hydrolysis in $\mathrm{H}_{2} \mathrm{O}$ being ca 1.3-1.6 times faster than in $\mathrm{D}_{2} \mathrm{O}$. Figure 9 illustrates the faster appearance of the hydrolysis product in the ${ }^{1} \mathrm{H}-\mathrm{NMR}$ spectra of the reaction mixtures run in the course of the experiment. 


\section{Path a:}

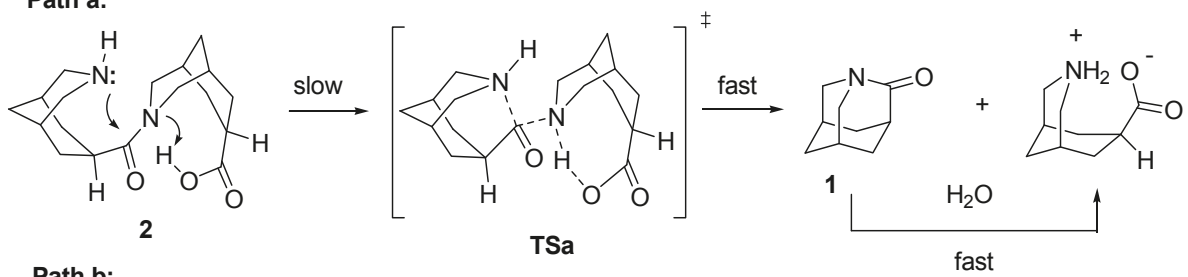

Path b:

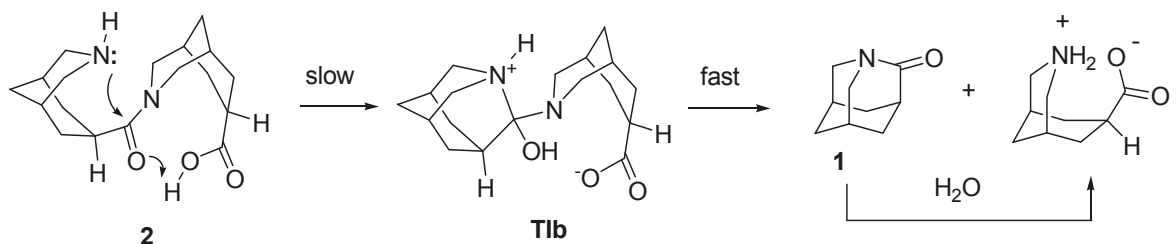

Path c:

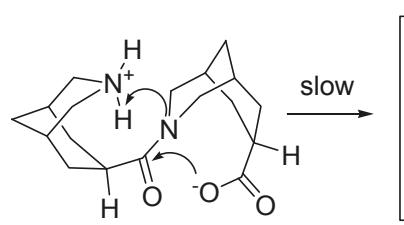

$2 \mathrm{a}^{+-}$

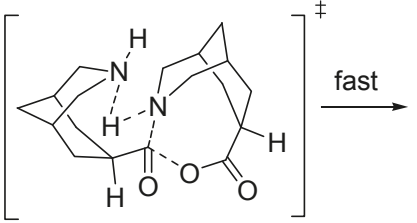

TSc

Path d:

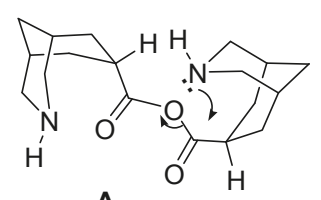

A

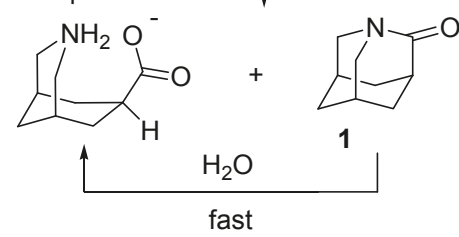

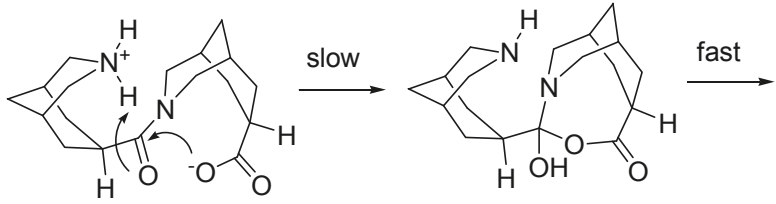

$2 a^{+-}$
TId

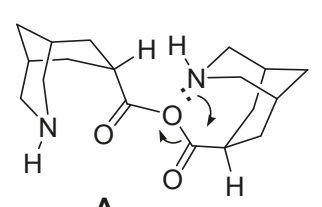

A

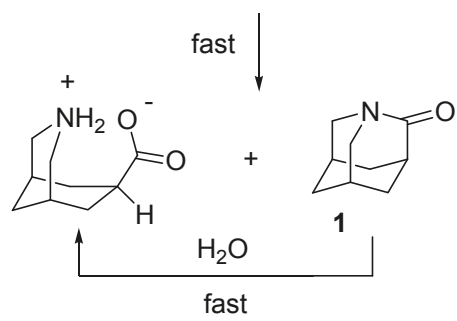

Figure 7. Possible mechanisms of the hydrolysis of the amide 2. 


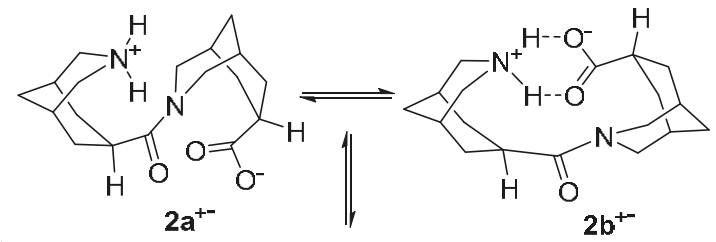

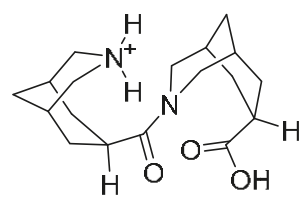

$2^{+}$

Low pH

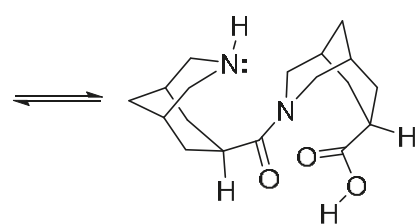

2

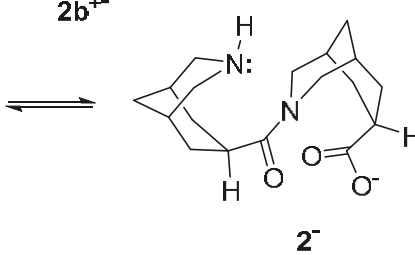

High pH

Figure 8. Equilibria established in solutions of 2 at different $\mathrm{pH}$.

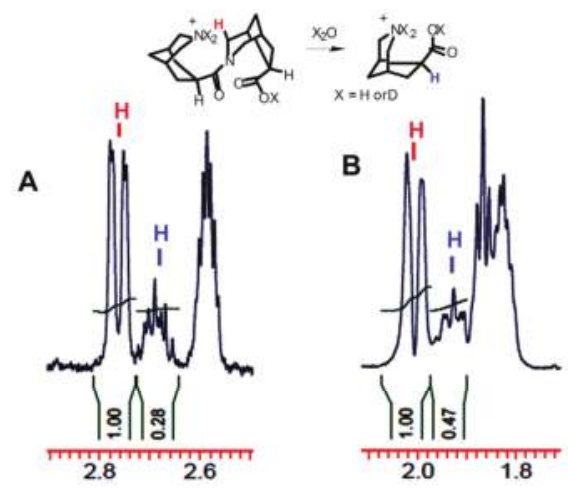

Figure 9. Characteristic regions of the ${ }^{1} \mathrm{H}-\mathrm{NMR}$ spectra illustrating the hydrolysis rates of $2 \cdot \mathrm{HCl}$ in $\mathrm{D}_{2} \mathrm{O}(\mathbf{A})$ and $\mathrm{H}_{2} \mathrm{O}(\mathbf{B})$. After twelve days of reaction.

The fact that we observed none of the possible intermediates makes it difficult to choose between paths a-d based only on our experimental data.

If the amine nitrogen is indeed involved as the nucleophilic center in the intramolecular catalysis of the amide bond cleavage in 2 , this raises an intriguing question: why does nature not utilize nitrogen-based nucleophilic centers in enzymatic hydrolytic cleavage of the amide bond? None of the currently known peptidases (hydrolases acting on amide bonds in protein backbones [39]) utilize an N-nucleophilic attack as a part of their catalytic mechanism [40]. Ubiquitous and long-studied serine and cysteine proteases feature the side-chain - $\mathrm{OH}$ or - $\mathrm{SH}$ nucleophilic groups in their active sites. Similarly, the threonine $-\mathrm{OH}$ group is thought to be involved as a nucleophile in relatively recently discovered threonine proteases [41]. The catalytic mechanisms proposed for both aspartic and metalloproteases involve nucleophilic attack of a water molecule at the scissile amide bond. Finally, the rare glutamic proteases were also suggested to utilize a water molecule as the nucleophile [42]. Even if there are as yet undiscovered "XX-peptidases" (XX designating an N-nucleophile in the active site), they undoubtedly must be rare.

In fact, there are known proteolytic enzymes that cleave peptide bonds with active participation of a nucleophilic nitrogen atom. These enzymes are not peptidases but rather lyases, as their action does not include hydrolysis. The N-nucleophile thought to play the key role in the amide bond cleavage 
is the nominally non-nucleophilic amide nitrogen of the asparagine side chain. Named asparagine peptide lyases, these enzymes were assigned to a "seventh catalytic type of proteolytic enzymes" [43]; many families of this enzyme type are now known. Typical examples are inteins, the protein segments able to mediate their own scission from larger proteins [44,45]. This process, known as protein splicing, involves cleavage of the two amide bonds flanking the inteins, producing the intein-removed proteins built from two remaining $\mathrm{N}$ - and C-extein fragments. Most intein-containing proteins have a conserved asparagine residue at one of the amide-bond cleavage sites. In the key step of the splicing, the asparagine amide is activated for intramolecular nucleophilic attack at its own peptide bond, leading to its cleavage. The chain of molecular events, a part of the mechanism proposed for splicing an intein (SspDnaE) [46] is illustrated in Figure 10.

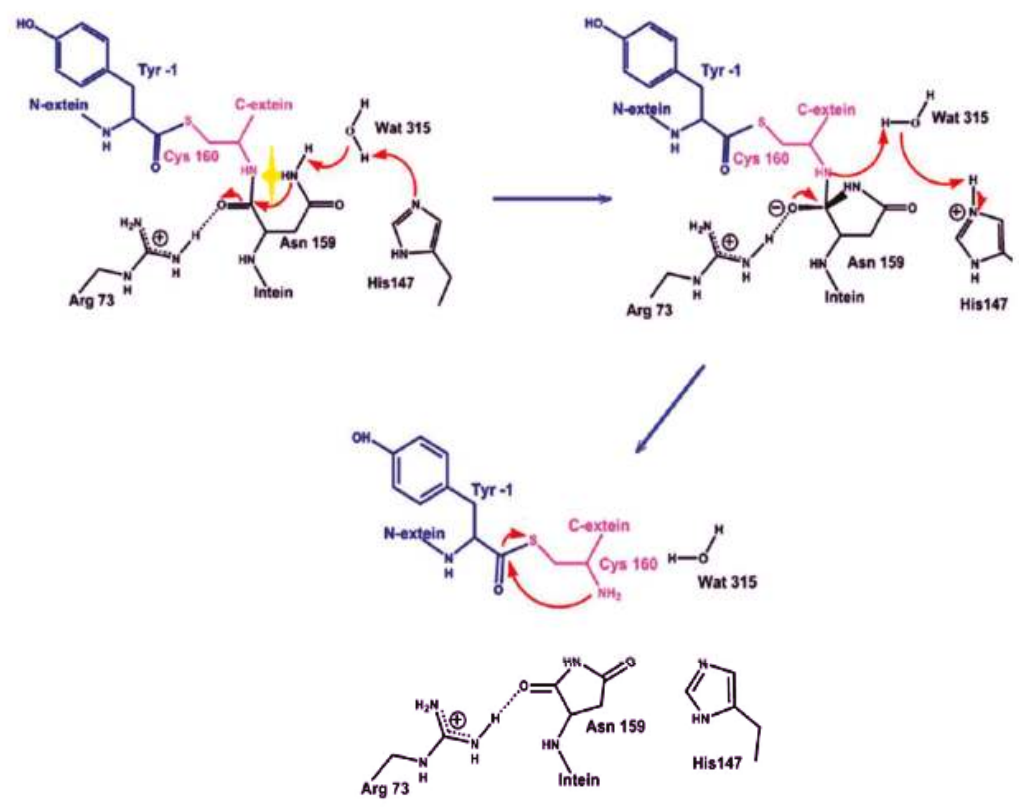

Figure 10. A part of the proposed intein SspDnaE splicing mechanism involving the Asn159 nucleophilic attack (marked with the yellow star) at the nearby amide bond carbonyl. Reprinted from [46] with permission from Elsevier.

Details of the activation of the Asn side chain amide for the nucleophilic attack are not completely understood. This could involve its tautomerization with the formation of a more reactive imidate species [47] or, alternatively, twisting the amide bond, which is known to enhance its nucleophilicity [48]. Interestingly, a mechanism involving the twisted asparagine amide group was proposed for oligosaccharyltransferases, the membrane protein complexes which catalyze asparagine-linked glycosylation [49]. Whatever the mechanism of the amide nucleophile activation, it is clear that nature avoids strong amine nucleophiles in the active sites of the proteolytic enzymes. They are present in a latent form (amide group of Asn) and only generated during the catalysis. It cannot be due to low availability of active $N$-nucleophiles in proteins. The lysine amino group, for example, acts as a nucleophile in ribulose 1,5-bisphosphate carboxylase (Rubisco), the most abundant enzyme on Earth [50]. In the catalytic protein splicing described above, where amide bonds are cleaved, however, the action of the asparagine-derived active nucleophile results in destruction of the enzyme itself. One might even question whether the splicing can be considered as an enzymatic process [43]. 
The prospect of self-destruction could be one of the reasons why natural proteases evolved without $\mathrm{N}$-nucleophiles in the active site.

Our model compound 2 demonstrates that one possible way to avoid self-destruction could be structural constraint holding the intermediate $\mathrm{N}$-acylated species in a twisted conformation, before a water molecule arrives and completes the hydrolysis cycle. There are no reasons to believe that this is impossible in natural catalytic systems, therefore, one might also believe that "XX-peptidases" are yet to be discovered. In any case, in seems worthwhile to design artificial catalytic systems exploiting the $\mathrm{N}$-nucleophiles in the catalytic processes. Such systems could be inspired by known natural enzymes or by model molecules as described in this paper. One important step towards this goal has already been reported by Otaka et al. [51]. They developed a photo-responsive amide cleavage device, mimicking the intein-mediated protein splicing. According to their approach, photo-triggered liberation of the secondary amino group on a modified asparagine fragment activates the asparagine amide for the nucleophilic attack that subsequently cleaves the adjacent peptide bond, as illustrated in Figure 11.
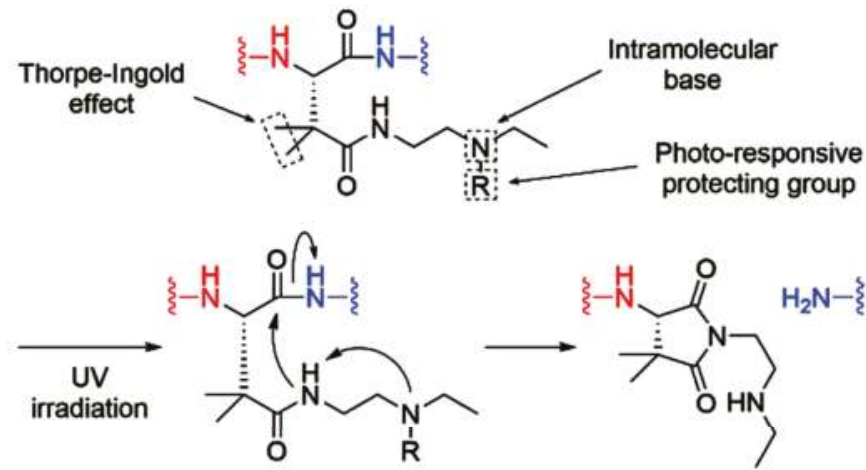

Figure 11. Photoinduced peptide bond cleavage inspired by natural protein splicing. Reprinted with permission from [51]. Copyright 2016 American Chemical Society.

\section{Materials and Methods}

\subsection{General}

Solvents were purified according to standard procedures [52]. Melting points were measured on an automated melting point system and are uncorrected. Analytical TLC was performed using Polychrom SI F254 plates. Column chromatography was performed using silica gel (230-400 mesh) as the stationary phase. ${ }^{1} \mathrm{H},{ }^{13} \mathrm{C}$ NMR and all 2D NMR spectra were recorded at 499.9 or $400.4 \mathrm{MHz}$ for protons and 124.9 or $100.4 \mathrm{MHz}$ for carbon-13. Chemical shifts are reported in ppm downfield from TMS $\left({ }^{1} \mathrm{H},{ }^{13} \mathrm{C}\right)$ as an internal standard. Mass spectra were recorded either on an Agilent $1100 \mathrm{LC} / \mathrm{MSD}$ SL (Agilent, Santa Clara, CA, USA) instrument by chemical ionization (CI) or on a GCMS instrument with electron impact ionization (EI). CHN-analysis was done on an Elementar VarioMICRO Cube analyzer (Elementar, Langenselbold, Germany).

\subsection{Synthetic Procedures}

3-Endo-bicyclo[3.3.1]nonane-3-carboxylic acid (20). This known compound was prepared starting from 1-cyclohexenylpyrrolidine (16) and 2-bromomethyl-acrylic acid benzyl ester (15) on a $0.2 \mathrm{~mol}$ scale in $69 \%$ overall yield following the procedures described in [36] for the analogue, 7-endo-3-(tert-butoxycarbonyl)-3-azabicyclo [3.3.1]nonane-7-carboxylic acid. The ${ }^{1} \mathrm{H}-\mathrm{NMR}$ spectrum of the product corresponded to that described in [53]. White crystals, m.p. $126{ }^{\circ} \mathrm{C}$ (lit. 126.5-127 $\left.{ }^{\circ} \mathrm{C}[52]\right) .{ }^{1} \mathrm{H}-\mathrm{NMR}\left(\delta, \mathrm{CDCl}_{3}, 500 \mathrm{MHz}\right.$ ): 11.78 (broad s, $\left.1 \mathrm{H}, \mathrm{COOH}\right), 2.48$ (h, $\left.6.0 \mathrm{~Hz}, 1 \mathrm{H}, 3-\mathrm{H}\right)$, 
1.9-2.1 (m, 4H), 1.6-1.7 (m, 1H), $1.55(\mathrm{~d}, 13.5 \mathrm{~Hz}, 1 \mathrm{H}), 1.25-1.45(\mathrm{~m}, 7 \mathrm{H}), 1.09$ (d, $13.5 \mathrm{~Hz}, 1 \mathrm{H}) .{ }^{13} \mathrm{C}-\mathrm{NMR}$ ( $\left.\delta, \mathrm{CD}_{3} \mathrm{Cl}, 124.9 \mathrm{MHz}\right): 183.27$ (COOH), 36.56, 32.50, 28.74, 28.48, 24.43, 15.55. LC/MS (CI, neg. scan): $m / z=167.2$; (CI, pos. scan): $m / z=169.2$. Anal. Calc. for $\mathrm{C}_{10} \mathrm{H}_{16} \mathrm{O}_{2}: \mathrm{C}, 71.39 ; \mathrm{H}, 9.59$. Found: $\mathrm{C}, 71.35$; $\mathrm{H}, 9.55$.

3,7'-Endo-3'-(bicyclo[3.3.1]non-3-ylcarbonyl)-3'-azabicyclo[3.3.1]nonane-7'-carboxylic acid (13). Compound $20(266 \mathrm{mg}, 1.6 \mathrm{mmol})$ was dissolved in dry dichloromethane $(0.5 \mathrm{~mL})$ and mixed with oxallyl chloride $(5 \mathrm{mg}, 4 \mathrm{mmol})$. The mixture was stirred under protection from air moisture for $8 \mathrm{~h}$. Then the volatile products were removed under vacuum $\left(0.01 \mathrm{~mm} \mathrm{Hg}, 40{ }^{\circ} \mathrm{C}, 4 \mathrm{~h}\right)$. The residue was dissolved in dioxane $(1 \mathrm{~mL})$ and added dropwise to a solution of the amino acid 3 (prepared as described in [1], $244 \mathrm{mg}$, $1.44 \mathrm{mmol})$ and $\mathrm{Na}_{2} \mathrm{CO}_{3}(0,763 \mathrm{~g}, 7.2 \mathrm{mmol})$ in water $(1 \mathrm{~mL})$ under stirring and cooling by an ice bath. The mixture was stirred for $8 \mathrm{~h}$ at ambient temperature, evaporated on a rotary evaporator, and the residue (the sodium salt of 13 ) crystallized from ethanol. The crystallized and air-dried product was dissolved in a minimum amount of water (approximately $0.4 \mathrm{~mL}$ ) and the solution was acidified by conc. $\mathrm{HCl}$ to afford 13 as a white crystalline material. It was filtered and dried in vacuum $(0.01 \mathrm{~mm}$. $\mathrm{Hg}, 40{ }^{\circ} \mathrm{C}, 4 \mathrm{~h}$ ). $230 \mathrm{mg}, 45 \%$ overall yield. Below, the data for the sodium salt of $\mathbf{1 3}$ (an analytical sample) are listed. m.p. $233^{\circ} \mathrm{C} .{ }^{1} \mathrm{H}-\mathrm{NMR}\left(\delta, \mathrm{D}_{2} \mathrm{O}, 500 \mathrm{MHz}\right): 4.13(\mathrm{~d}, 12.5 \mathrm{~Hz}, 1 \mathrm{H}), 3.82(\mathrm{~d}, 12.5 \mathrm{~Hz}$, $1 \mathrm{H}), 3.01(\mathrm{~d}, 12.5 \mathrm{~Hz}, 1 \mathrm{H}), 2.91(\mathrm{~m}, 1 \mathrm{H}), 2.52(\mathrm{~d}, 12.5 \mathrm{~Hz}, 1 \mathrm{H}), 2.20(\mathrm{~m}, 1 \mathrm{H}), 1.75-2.35(\mathrm{~m}, 8 \mathrm{H}), 1.55-1.75$ $(\mathrm{m}, 3 \mathrm{H}), 1.15-1.45(\mathrm{~m}, 8 \mathrm{H}), 0.95-1.10(\mathrm{~m}, 3 \mathrm{H}) .{ }^{13} \mathrm{C}-\mathrm{NMR}\left(\delta, \mathrm{D}_{2} \mathrm{O}, 124.9 \mathrm{MHz}\right): 184.89,179.73,52.16$, $48.93,37.80,32.41,32.26,32.18,28.79,28.75,28.26,28.05,27.73,26.35,25.58,25.43,24.39,24.11,15.09$. LC/MS (CI, neg. scan): $m / z=318.2$; (CI, pos scan): $m / z=320.2$. Anal. Calc. for $\mathrm{C}_{19} \mathrm{H}_{29} \mathrm{NO}_{3}: \mathrm{C}, 71.44$; H, 9.15; N, 4.38. Found: C, 71.40; H, 9.13; N, 4.39.

7'-Endo-3'-[(benzyloxy)carbonyl]-3-azabicyclo[3.3.1]nonane-7'-carboxylic acid (21). Amino acid 3 (169 mg, 1 $\mathrm{mmol}$ ) and $\mathrm{NaHCO}_{3}(200 \mathrm{mg}, 2.4 \mathrm{mmol})$ were dissolved in water-dioxane mixture $(10 \mathrm{~mL}, 1: 1 \mathrm{v} / \mathrm{v})$. To this solution was added benzyl carbonochloridate (carbobenzoxychloride, $0.2 \mathrm{~mL}$ ) dropwise under stirring. The mixture was stirred for $3 \mathrm{~h}$, and then acidified carefully by $1 \mathrm{~N} \mathrm{HCl}$ till $\mathrm{pH} 2$. The product was extracted with MTBE $(3 \times 50 \mathrm{~mL})$, the combined extracts were dried over $\mathrm{Na}_{2} \mathrm{SO}_{4}$ and evaporated. The product was purified by column chromatography (silica gel, MTBE as an eluent). Analytical sample was prepared by crystallization from diethyl ether. Yield: $200 \mathrm{mg}, 66 \%$. White crystals, m.p. $120{ }^{\circ} \mathrm{C} .{ }^{1} \mathrm{H}-\mathrm{NMR}\left(\delta, \mathrm{CDCl}_{3}, 500 \mathrm{MHz}\right): 10.02$ (br s, $\left.1 \mathrm{H}, \mathrm{COOH}\right), 7.40-7.70(\mathrm{~m}, 5 \mathrm{H}$, arom.), 5.12 (br s, 1H), 4.97 (br s, 1H), 4.03 (br s, 2H), $2.92(\mathrm{~d}, 11.5 \mathrm{~Hz}, 2 \mathrm{H}), 2.60$ (br s, 1H), $2.36(\mathrm{~d}, 13.0 \mathrm{~Hz}, 2 \mathrm{H}), 1.75-2.00$ $(\mathrm{m}, 4 \mathrm{H}), 1.64(\mathrm{~d}, 11.5 \mathrm{~Hz}, 1 \mathrm{H}), 1.54(\mathrm{~d}, 11.5 \mathrm{~Hz}, 1 \mathrm{H}) .{ }^{13} \mathrm{C}-\mathrm{NMR}\left(\delta, \mathrm{CDCl}_{3}, 124.9 \mathrm{MHz}\right): 178.67,156.18$, 136.47, 128.01, 127.72, 127.47, 66.67, 48.70, 36.96, 30.89, 29.26, 26.21. LC/MS (CI, neg. scan): $\mathrm{m} / \mathrm{z}=302.3$; LC/MS (CI, pos. scan): $m / z=304.2$. Anal. Calc. for $\mathrm{C}_{17} \mathrm{H}_{21} \mathrm{NO}_{4}: \mathrm{C}, 67.31 ; \mathrm{H}, 6.98 ; \mathrm{N}, 4.62$. Found: $\mathrm{C}$, $67.36 ; \mathrm{H}, 6.86 ; \mathrm{N}, 4.60$. Chromatographic purification of 21 also yielded a side-product assigned to the structure $22(6 \mathrm{mg})$, on the basis of its ${ }^{1} \mathrm{H}-\mathrm{NMR}$ and MS data.

7,7'-Endo-3'-(\{3-[(benzyloxy)carbonyl]-3-azabicyclo[3.3.1]non-7-yl\}carbonyl)-3'-azabicyclo[3.3.1]no ane-7'-carboxylic acid (22). m.p. $170{ }^{\circ} \mathrm{C}:{ }^{1} \mathrm{H}-\mathrm{NMR}\left(\delta,\left(\mathrm{CD}_{3}\right)_{2} \mathrm{SO}, 500 \mathrm{MHz}\right): 11.63(\mathrm{~s}, 1 \mathrm{H}, \mathrm{COOH})$, 7.20-7.50 (m, 5h, arom.), $5.03\left(\mathrm{~s}, 2 \mathrm{H}, \mathrm{CH}_{2} \mathrm{Ph}\right), 4.11(\mathrm{~d}, 13.0 \mathrm{~Hz}, 1 \mathrm{H}), 3.70-3.90(\mathrm{~m}, 3 \mathrm{H}), 2.93(\mathrm{~d}, 12.0 \mathrm{~Hz}$, $1 \mathrm{H}), 2.55-2.75(\mathrm{~m}, 3 \mathrm{H}), 2.32(\mathrm{~m}, 2 \mathrm{H}), 1.35-1.95(\mathrm{~m}, 13 \mathrm{H}), 1.33(\mathrm{~d}, 12.0 \mathrm{~Hz}, 1 \mathrm{H}), 1.11(\mathrm{~d}, 12.0 \mathrm{~Hz}, 1 \mathrm{H})$, 0.98 (br s, 1H). LC/MS (CI, neg. scan): $\mathrm{m} / \mathrm{z}=453.4$; LC/MS (CI, pos. scan): $\mathrm{m} / \mathrm{z}=455.2$.

3-azabicyclo[3.3.1]nonane (25), 3-azabicyclo[3.3.1]nonane-2,4 dione $\mathbf{2 4}$ (5 g, $32 \mathrm{mmol}$, prepared as described in [35]) was dissolved in THF (100 mL) under an argon atmosphere. Lithium aluminum hydride (3.7 g, $98 \mathrm{mmol}$ ) was added in portions to the solution, which was then refluxed for $5 \mathrm{~h}$ and stirred for an additional $8 \mathrm{~h}$ without heating. The excess of the $\mathrm{LiAlH}_{4}$ was quenched carefully with water, the product was sublimed to afford 25 as a colorless crystalline product, $2.68 \mathrm{~g}, 67 \%$ yield.

All the spectral data were identical to those described in the literature [54]. m.p. $157^{\circ} \mathrm{C}$. For the use in the next step, the amine was converted to its hydrochloride by dissolving in an excess of $1 \mathrm{~N} \mathrm{HCl}$, evaporation in vacuum, co-evaporation with water $(3 \times 20 \mathrm{~mL})$ on a rotary 
evaporator, drying in a desiccator over $\mathrm{P}_{2} \mathrm{O}_{5}$ for $24 \mathrm{~h}$. White crystals (crystallized from isopropanol), 3-azabicyclo[3.3.1]nonanehydrochloride $(25 \cdot \mathrm{HCl}):{ }^{1} \mathrm{H}-\mathrm{NMR}\left(\delta,\left(\mathrm{CD}_{3}\right)_{2} \mathrm{SO}, 500 \mathrm{MHz}\right): 9.81$ (broad s, $1 \mathrm{H}$, NH), 8.08 (broad s, 1H, NH), 3.14 (d, 13 Hz, 2H), 3.03 (d, 13 Hz, 2H), 1.90-2.10 (m, 3H), 1.40-1.80 (m, 7H). ${ }^{13} \mathrm{C}-\mathrm{NMR}\left(\delta,\left(\mathrm{CD}_{3}\right)_{2} \mathrm{SO}, 124.9 \mathrm{MHz}\right): 46.40,29.80,28.96,25.22,19.36$. Anal. Calc. for $\mathrm{C}_{8} \mathrm{H}_{16} \mathrm{ClN}: \mathrm{C}$, 59.43; H, 9.98; N, 8.66. Found: C, 59.40; H, 9.95; N, 8.69.

7-Endo-benzyl 7-(3'-azabicyclo[3.3.1]non-3'-ylcarbonyl)-3-azabicyclo[3.3.1]nonane-3-carboxylate (26). The Cbz-protected amino acid 21 (95 mg, $0.31 \mathrm{mmol}$ ) and DIPEA (81 mg, $0.63 \mathrm{mmol}$ ) were dissolved in acetonitrile $(1 \mathrm{~mL})$. (2-(1H-benzotriazol-1-yl)-1,1,3,3-tetramethyluronium hexafluorophosphate (HBTU, $128 \mathrm{mg}, 0.34 \mathrm{mmol}$ ) was added to the solution under stirring, and the stirring continued for $5 \mathrm{~min}$. Then the mixture was combined with a solution of the amine hydrochloride $(25 \cdot \mathrm{HCl}$, prepared as described above, $61 \mathrm{mg}, 0.37 \mathrm{mmol})$ and DIPEA $(73 \mathrm{mg}, 0.56 \mathrm{mmol})$ in acetonitrile $(1 \mathrm{~mL})$. The resulting mixture was stirred for $8 \mathrm{~h}$, and then evaporated on a rotary evaporator. The residue was applied to a chromatographic column (silica gel) and pure 26 was eluted with hexane-ethylacetate 2:1 $v / v)$. Colorless oil, crystallized on standing, $88 \%$ yield $(112 \mathrm{mg})$. An analytical sample was prepared by crystallization from petroleum ether. m.p. $157^{\circ} \mathrm{C} .{ }^{1} \mathrm{H}-\mathrm{NMR}\left(\delta,\left(\mathrm{CDCl}_{3}, 500 \mathrm{MHz}\right): 7.25-7.45(\mathrm{~m}, 5 \mathrm{H}\right.$, arom.), 5.20 and 5.09 (two d, $2 \mathrm{H}), 4.57(\mathrm{~m}, 1 \mathrm{H}), 4.02(\mathrm{~d}, 12.0 \mathrm{~Hz}, 1 \mathrm{H}), 3.95(\mathrm{~d}, 12.0 \mathrm{~Hz}, 1 \mathrm{H}), 3.88$ (d, $12.0 \mathrm{~Hz}, 1 \mathrm{H}), 3.29(\mathrm{~d}, 12.0 \mathrm{~Hz}, 1 \mathrm{H}), 2.75-2.85(\mathrm{~m}, 3 \mathrm{H}), 2.74$ (broad s, 1H), 1.80-2.15 (m, 7H), 1.50-1.80 (m, 9H), 1.43 (broad s, $1 \mathrm{H}), 1.26(\mathrm{~m}, 1 \mathrm{H}) .{ }^{13} \mathrm{C}-\mathrm{NMR}\left(\delta,\left(\mathrm{CD}_{3}\right)_{2} \mathrm{SO}, 124.9 \mathrm{MHz}\right): 177.47,177.09,136.55,128.15$, 127.56, 127.36, 50.43, 35.75, 32.80, 30.20, 29.51, 29.00, 27.00, 26.21., 26.20, 25.97. LC/MS (CI, pos. scan): $m / z=411.2$. Anal. Calc. for $\mathrm{C}_{25} \mathrm{H}_{34} \mathrm{~N}_{2} \mathrm{O}_{3}: \mathrm{C}, 73.14 ; \mathrm{H}, 8.35 ; \mathrm{N}, 6.82$. Found: C, 73.11; $\mathrm{H}, 8.39 ; \mathrm{N}, 6.80$.

7-Endo-3'-(3-azabicyclo[3.3.1]non-7-ylcarbonyl)-3'-azabicyclo[3.3.1]nonane (14). The Cbz-protected amide 26 (38 mg, $0.1 \mathrm{mmol})$ was dissolved in methanol (3 mL). Palladium on charcoal (10\%, $60 \mathrm{mg})$ was added to the reaction vessel, which was then filled with hydrogen and the mixture was shaken under $1 \mathrm{~atm} \mathrm{H}_{2}$ for $8 \mathrm{~h}$. Then the mixture was filtered, evaporated in high vacuum $(0.01 \mathrm{~mm} \mathrm{Hg})$ without heating. The crude product 14 easily forms the carbonate upon handling on air, therefore it was mixed with $5 \%$ aqueous $\mathrm{NaOH}$ solution $(5 \mathrm{~mL})$ and extracted with dichloromethane $(3 \times 20 \mathrm{~mL})$ under an argon atmosphere. The combined dichloromethane extracts were evaporated in high vacuum without heating, the residue was dried in high vacuum for $5 \mathrm{~h}$. Yellowish oil, $27.6 \mathrm{mg}$ (quantitative yield). ${ }^{1} \mathrm{H}-\mathrm{NMR}\left(\delta, \mathrm{CD}_{3} \mathrm{OD}, 500 \mathrm{MHz}\right): 4.55(\mathrm{~d}, 15.0 \mathrm{~Hz}, 1 \mathrm{H}), 4.08(\mathrm{~d}, 15.0 \mathrm{~Hz}, 1 \mathrm{H}), 3.36(\mathrm{~d}, 15.0 \mathrm{~Hz}, 1 \mathrm{H}), 3.03$ $(\mathrm{m}, 1 \mathrm{H}), 2.85(\mathrm{~d}, 15.0 \mathrm{~Hz}, 1 \mathrm{H}), 2.69$ and 2.61 (two d, $14.5 \mathrm{~Hz}, 4 \mathrm{H}), 1.60-2.20(\mathrm{~m}, 17 \mathrm{H}), 1.55$ and 1.51 (two d, $14.5 \mathrm{~Hz}, 2 \mathrm{H}), 1.46$ (broad s, 1H), 1.38 (d, $14.5 \mathrm{~Hz}, 1 \mathrm{H})$. For the peaks assignments, see Supporting Information. ${ }^{13} \mathrm{C}-\mathrm{NMR}\left(\delta, \mathrm{CD}_{3} \mathrm{OD}, 124.9 \mathrm{MHz}\right)$ : 176.47, 51.81, 51.76, 50.71, 32.61, 31.93, 30.85, 30.36, $28.65,28.25,28.08,26.88,25.64,25.59,20.13$. LC/MS (CI, pos. scan): $m / z=277.2$.

7,7'-Endo-3'-[(3-\{[2-(trimethylsilyl)ethoxy]carbonyl\}-3-azabicyclo[3.3.1]non-7-yl)carbonyl]-3'-azabicyclo[3.3.1] nonane- $7^{\prime}$-carboxylic acid (27). Amino acid 3 (100 mg, $\left.0.59 \mathrm{mmol}\right)$ was suspended in THF $(2 \mathrm{~mL})$ and triethylamine $(120 \mathrm{mg}, 1.2 \mathrm{mmol})$ was added to the suspension under stirring. The mixture was then cooled to $-20{ }^{\circ} \mathrm{C}$ and 2-(trimethylsilyl)ethylcarbonochloridate $(214 \mathrm{mg}, 1.2 \mathrm{mmol}$ ) was slowly added under stirring, keeping the mixture temperature not higher than $-10{ }^{\circ} \mathrm{C}$. After the addition, the mixture was stirred at $-10^{\circ} \mathrm{C}$ for $15 \mathrm{~min}$ and at ambient temperature for $30 \mathrm{~min}$. The mixture was then again cooled in an ice-water bath, and a suspension of $3(100 \mathrm{mg}, 0.59 \mathrm{mmol})$ in a triethylamine $(60 \mathrm{mg}$, $0.6 \mathrm{mmol})$ solution in THF $(2 \mathrm{~mL})$ was added to the stirred mixture in one portion. The resulting mixture was stirred overnight at ambient temperature. The volatile products were removed in vacuum, the residue was triturated with aqueous citric acid solution (5\%). The crude product was extracted with MTBE $(3 \times 50 \mathrm{~mL})$, the combined extracts were evaporated and the residue was purified by reverse-phase HPLC to afford 27 as colorless oil which crystallized on standing. Yield: $178.2 \mathrm{mg}, 65 \%$. m.p. $198{ }^{\circ} \mathrm{C} .{ }^{1} \mathrm{H}-\mathrm{NMR}\left(\delta, \mathrm{CDCl}_{3}, 500 \mathrm{MHz}\right.$ ): 9.83 (br. s, $\left.1 \mathrm{H}\right), 4.36$ (br. s, $\left.1 \mathrm{H}\right), 4.13$ (br. s, 2H), 3.80-4.05 (br. m, 3H), 3.12 (br. s, 1H), 2.65-2.82 (br. m, 5H), 2.53 (br. s, 1H), 2.24 (br. m, 2H), 1.75-2.15 (br. m, 9H), 1.64 (br. s, $1 \mathrm{H}), 1.57$ (br. s, 2H), 1.21 (br. s, $1 \mathrm{H}), 0.98$ (br. m, $2 \mathrm{H}),-0.1$ (br. m, 9H). ${ }^{13} \mathrm{C}-\mathrm{NMR}(\delta$, $\mathrm{CDCl}_{3}, 124.9 \mathrm{MHz}$ ): (all the signals are broadened) 117.72, 117.27, 157.53, 63.64, 50.73, 47.37, 36.83, 
$33.33,33.12,31.31,30.02,29.30,29.05,28.53,27.26,27.07,26.94,26.78,25.81,25.52,25.32,-1.47$. LC/MS (CI, neg. scan): $\mathrm{m} / \mathrm{z}=463.2,454.2,465.2$; (CI, pos. scan): $\mathrm{m} / \mathrm{z}=466.2,467.2,468.2$. Anal. Calc. for $\mathrm{C}_{24} \mathrm{H}_{40} \mathrm{~N}_{2} \mathrm{O}_{5} \mathrm{Si}: \mathrm{C}, 62.03 ; \mathrm{H}, 8.68 ; \mathrm{N}, 6.03$. Found: $\mathrm{C}, 62.08 ; \mathrm{H}, 8.64 ; \mathrm{N}, 6.00$.

7,7'-Endo-3'-(3-azabicyclo[3.3.1]non-7-ylcarbonyl)-3'-azabicyclo[3.3.1]nonane-7'-carboxylic acid hydrochloride (2. $\mathrm{HCl})$. Compound $27(50 \mathrm{mg}, 0.11 \mathrm{mmol})$ was dissolved in a mixture of dry diethyl ether and dichloromethane $(1: 1 v / v, 1 \mathrm{~mL})$ and a solution of $\mathrm{HCl}$ in dry dioxane $(\sim 10 \%, 0.5 \mathrm{~mL})$ was added. The mixture was left standing at ambient temperature for $8 \mathrm{~h}$, the formed white crystals of the product $(2 \cdot \mathrm{HCl})$ were filtered, washed thoroughly with dry diethyl ether on the filter, dried in high vacuum $\left(0.05 \mathrm{~mm} \mathrm{Hg}\right.$ ) for $6 \mathrm{~h}$ at $\left.25^{\circ} \mathrm{C}\right)$. Yield: $18 \mathrm{mg}(46 \%)$. m.p. $198{ }^{\circ} \mathrm{C}$ (with decomposition). ${ }^{1} \mathrm{H}-\mathrm{NMR}(\delta$, $\left.\mathrm{D}_{2} \mathrm{O}, 500 \mathrm{MHz}\right): 4.06$ (d, $\left.13.5 \mathrm{~Hz}, 1 \mathrm{H}\right), 3.85(\mathrm{~d}, 13.5 \mathrm{~Hz}, 1 \mathrm{H}), 3.10-3.33(\mathrm{~m}, 3 \mathrm{H}), 2.90-3.15(\mathrm{~m}, 3 \mathrm{H}), 2.74$ (dd, 13.5 and $2.0 \mathrm{~Hz}, 1 \mathrm{H}), 2.57(\mathrm{~h}, 2.0 \mathrm{~Hz}, 1 \mathrm{H}), 1.85-2.20$ (overlapped $\mathrm{m}, 11 \mathrm{H}), 1.73(\mathrm{dd}, 13.5$ and $3.0 \mathrm{~Hz}$, $1 \mathrm{H}), 1.50-1.70(\mathrm{~m}, 4 \mathrm{H}), 1.34(\mathrm{q}, 3.0 \mathrm{~Hz}, 1 \mathrm{H}) .{ }^{13} \mathrm{C}-\mathrm{NMR}\left(\delta, \mathrm{D}_{2} \mathrm{O}, 124.9 \mathrm{MHz}\right): 180.58,179.33,50.75,49.01$, $48.32,47.98,35.51,29.83,29.26,29.10,28.72,27.11,26.36,26.30,26.28,26.09,23.74,23.39$. Anal. Calc. for $\mathrm{C}_{18} \mathrm{H}_{29} \mathrm{ClN}_{2} \mathrm{O}_{3}$ : C, 60.58; H, 8.19; N, 7.85. Found: $\mathrm{C}, 60.54 ; \mathrm{H}, 8.22 ; \mathrm{N}, 7.83$.

\subsubsection{Kinetic Measurements for Hydrolysis Reaction of Compound 2 in $\mathrm{D}_{2} \mathrm{O}$}

Hydrolysis was carried out at $23{ }^{\circ} \mathrm{C}$ in NMR sample tubes, monitored by ${ }^{1} \mathrm{H}-\mathrm{NMR}$ spectra (recorded by single scans). Six buffer solutions were prepared in $\mathrm{D}_{2} \mathrm{O}$ : acetate buffers ( $\mathrm{pD} 3.81$ and 4.85), phosphate buffers (pD 6.68 and 7.95), and carbonate buffers (pD 9.45 and 10.68); the $\mathrm{pD}$ values were measured at $23^{\circ} \mathrm{C}$ immediately before the measurements. The buffer concentrations were $250 \mathrm{mM}$ in each case, the ionic strengths were adjusted with $\mathrm{NaCl}$ to $1 \mathrm{M}$. The compound $2 \cdot \mathrm{HCl}$ was weighed in an NMR sample tube (5-7 mg), and the measurements started by addition of the corresponding buffer solution to the compound (in the amount to achieve the compound concentration $25 \mathrm{mM}$ ). The content of the tube was vigorously shaken, starting immediately the recording of the time. The first ${ }^{1} \mathrm{H}-\mathrm{NMR}$ spectrum was measured as quickly after the buffer addition as practical ( 2 $\mathrm{min})$, then the spectra were measured at intervals, depending on the reaction progress. The spectra were run as single scans, in order to avoid integral-value distortions due to relaxation effects. The unambiguously assigned non-overlapping peaks of the starting compound and its hydrolysis product were carefully integrated. The complete data sets (Tables S1-S12) were used to build the kinetic curves and calculate $k_{o b s}$ and the half-lives for each compound (see the Supporting Information).

4.2.2. Estimation of the Kinetic Isotope Effect by Comparison of the Hydrolysis Rates of $2 \cdot \mathrm{HCl}$ in $\mathrm{D}_{2} \mathrm{O}$ and $\mathrm{H}_{2} \mathrm{O}$

Two reactions were set up in two NMR sample tubes simultaneously by dissolving $4.2 \mathrm{mg}$ of the 2. $\mathrm{HCl}$ in each tube in $0.5 \mathrm{~cm}^{3} \mathrm{D}_{2} \mathrm{O}$ or $\mathrm{H}_{2} \mathrm{O}$. The ${ }^{1} \mathrm{H}-\mathrm{NMR}$ spectra of the samples were run at intervals (as single scans, in order to avoid integral-value distortions due to relaxation effects). For the spectral measurements in $\mathrm{H}_{2} \mathrm{O}$, excitation sculpting technique [55] was used for the water signal suppression. The unambiguously assigned non-overlapping peaks of the starting compound and its hydrolysis product were carefully integrated. Representative spectra can be seen in Figures S13 and S14.

\subsubsection{X-ray Data for Compound 13}

Crystal Data for $\mathrm{C}_{19} \mathrm{H}_{29} \mathrm{NO}_{3}(M=319.43 \mathrm{~g} / \mathrm{mol})$ : monoclinic, space group $P 2_{1} / c$ (no. 14), $a=6.9409(2) \AA, b=10.8409(3) \AA, c=22.2437(6) \AA, \beta=93.2098(12)^{\circ}, V=1671.11(8) \AA^{3}, Z=4$, $T=180(2) \mathrm{K}, \mu(\mathrm{CuK} \alpha)=0.673 \mathrm{~mm}^{-1}, D_{\text {calc }}=1.270 \mathrm{~g} / \mathrm{cm}^{3}$. The diffraction pattern was indexed as two domains with 19230 measured reflections (domain 1 only), 19298 reflections (domain 2 only) and 3794 reflections (overlapped) $\left(7.96^{\circ} \leq 2 \leq 133.37^{\circ}\right), R_{\text {int }}=0.0399 .2954$ unique reflections were used in all calculations. The final $R 1$ was $0.0599(I>2 \sigma(I))$ and $w R 2$ was 0.1593 (all data). 
CCDC 1884473 contains the supplementary crystallographic data for this paper. These data can be obtained free of charge via https:/ / www.ccdc.cam.ac.uk/structures (or from the CCDC, 12 Union Road, Cambridge CB2 1EZ, UK; Fax: +44 1223 336033; E-mail: deposit@ccdc.cam.ac.uk).

Supplementary Materials: The following are available online. Figures S1-S36, NMR spectra and chromato-mass traces for the compounds described in the main text; Tables S1-S12, Figures S37-S48, kinetic data on the hydrolysis of 2. $\mathrm{HCl}$ in different buffers; Figures S49 and S50, Representative ${ }^{1} \mathrm{H}-\mathrm{NMR}$ data set used for estimation of the kinetic isotope effect on the 2. HCl hydrolysis reaction; Figure S51; The CIF file for compound 13.

Author Contributions: Conceptualization, A.J.K. and I.V.K.; Methodology, A.J.K. and I.V.K.; Formal Analysis, I.V.K., A.Y.I., A.D.B. and A.J.K.; Investigation, I.V.K., A.Y.I., A.H., V.S., S.K. and A.D.B.; Writing: Original Draft Preparation, I.V.K.; Writing: Review \& Editing, A.J.K.; Supervision, A.J.K., S.K. and I.V.K.

Funding: This research received no external funding.

Conflicts of Interest: The authors declare no conflict of interest.

\section{References}

1. Komarov, I.V.; Yanik, S.; Ishchenko, A.Y.; Davies, J.E.; Goodman, J.M.; Kirby, A.J. The Most Reactive Amide As a Transition-State Mimic For cis-trans Interconversion. J. Am. Chem. Soc. 2015, 137, 926-930. [CrossRef] [PubMed]

2. Liu, C.; Szostak, M. Twisted Amides: From Obscurity to Broadly Useful Transition-Metal-Catalyzed Reactions by N-C Amide Bond Activation. Chem. Eur. J. 2017, 23, 7157-7173. [CrossRef] [PubMed]

3. Szostak, M.; Aube, J. Chemistry of bridged lactams and related heterocycles. Chem. Rev. 2013, 113, 5701-5765. [CrossRef] [PubMed]

4. Clayden, J.; Moran, W.J. The Twisted Amide 2-Quinuclidone: 60 Years in the Making. Angew. Chem. Int. Ed. 2006, 45, 7118-7120. [CrossRef] [PubMed]

5. Bender, M.L. General acid-base catalysis in the intramolecular hydrolysis of phthalamic acid. J. Am. Chem. Soc. 1957, 79, 1258-1259. [CrossRef]

6. Kirby, A.J.; Lancaster, P.W. Structure and efficiency in intramolecular and enzymic catalysis. Catalysis of amide hydrolysis by the carboxy-group of substituted maleamic acids. J. Chem. Soc. Perkin Trans. 2 1972, 9, 1206-1214. [CrossRef]

7. Kirby, A.J.; McDonald, R.S.; Smith, C.R. Intramolecular catalysis of amide hydrolysis by two carboxy-groups. J. Chem. Soc. Perkin Trans. 2 1974, 12, 1495-1504. [CrossRef]

8. Groves, J.T.; Olson, J.R. Models of zinc-containing proteases. Rapid amide hydrolysis by an unusually acidic $\mathrm{Zn}^{2+}-\mathrm{OH}_{2}$ complex. Inorg.Chem. 1985, 24, 2715-2717. [CrossRef]

9. Menger, F.M.; Ladika, M. Fast hydrolysis of an aliphatic amide at neutral $\mathrm{pH}$ and ambient temperature. A peptidase model. J. Am. Chem. Soc. 1988, 110, 6794-6796. [CrossRef]

10. Curran, T.P.; Borysenko, C.W.; Abelleira, S.M.; Messier, R.J. Intramolecular acylolysis of amide derivatives of Kemp's triacid: Strain effects and reaction rates. J. Org. Chem. 1994, 59, 3522-3529. [CrossRef]

11. Dougan, M.L.; Chin, J.L.; Solt, K.; Hansen, D.E. Rapid cleavage of cyclic tertiary amides of Kemp's triacid: Effects of ring structure. Bioorg. Med. Chem. Lett. 2004, 14, 4153-4156. [CrossRef] [PubMed]

12. Fernandes, N.M.; Fache, F.; Rosen, M.; Nguyen, P.L.; Hansen, D.E. Rapid Cleavage of Unactivated, Unstrained Amide Bonds at Neutral pH. J. Org. Chem. 2008, 73, 6413-6416. [CrossRef] [PubMed]

13. Souza, B.S.; Mora, J.R.; Wanderlind, E.H.; Clementin, R.M.; Gesser, J.C.; Fiedler, H.D.; Nome, F.; Menger, F.M. Transforming a stable amide into a highly reactive one: Capturing the essence of enzymatic catalysis. Angew. Chem. Int. Ed. 2017, 56, 5345-5348. [CrossRef] [PubMed]

14. Kirby, A.J. Enzyme Mechanisms, Models, and Mimics. Angew. Chem. Int. Ed. 1996, 35, 707-724. [CrossRef]

15. Bender, M.L.; Chow, Y.-L.; Chloupek, F. Intramolecular Catalysis of Hydrolytic Reactions. II. The Hydrolysis of Phthalamic Acid. J. Am. Chem. Soc. 1958, 80, 5380-5384. [CrossRef]

16. Jindal, G.; Warshel, A. Misunderstanding the preorganization concept can lead to confusions about the origin of enzyme catalysis. Proteins 2017, 85, 2157-2161. [CrossRef]

17. Kubyshkin, V.; Budisa, N. Amide rotation trajectories probed by symmetry. Org. Biomol. Chem. 2017, 15, 6764-6772. [CrossRef] 
18. Hu, F.; Nareddy, P.; Lalancette, R.; Jordan, F.; Szostak, M. $\sigma$ N-C Bond Difunctionalization in Bridged Twisted Amides: Sew-and-Cut Activation Approach to Functionalized Isoquinolines. Org. Lett. 2017, 19, 2386-2389. [CrossRef]

19. Meng, G.; Shi, S.; Lalancette, R.; Szostak, R.; Szostak, M. Reversible Twisting of Primary Amides via Ground State N-C (O) Destabilization: Highly Twisted Rotationally Inverted Acyclic Amides. J. Am. Chem. Soc. 2018, 140, 727-734. [CrossRef]

20. Meng, G.; Shi, S.; Szostak, M. Cross-coupling of amides by N-C bond activation. Synlett 2016, 27, 2530-2540. [CrossRef]

21. Dander, J.E.; Garg, N.K. Breaking amides using nickel catalysis. ACS Catal. 2017, 7, 1413-1423. [CrossRef] [PubMed]

22. Adachi, S.; Kumagai, N.; Shibasaki, M. Conquering amide planarity: Structural distortion and its hidden reactivity. Tetrahedron Lett. 2018, 59, 1147-1158. [CrossRef]

23. Wybon, C.C.; Mensch, C.; Hollanders, K.; Gadais, C.; Herrebout, W.A.; Ballet, S.; Maes, B.U. Zn-catalyzed tert-butyl nicotinate-directed amide cleavage as a biomimic of metallo-exopeptidase activity. ACS Catal. 2018, 8, 203-218. [CrossRef]

24. Balachandra, C.; Sharma, N.K. Instability of Amide Bond Comprising the 2-Aminotropone Moiety: Cleavable under Mild Acidic Conditions. Org. Lett. 2015, 17, 3948-3951. [CrossRef] [PubMed]

25. Hutchby, M.; Houlden, C.E.; Haddow, M.F.; Tyler, S.N.; Lloyd-Jones, G.C.; Booker-Milburn, K.I. Switching Pathways: Room-Temperature Neutral Solvolysis and Substitution of Amides. Angew. Chem. Int. Ed. 2012, 51, 548-551. [CrossRef] [PubMed]

26. Milović, N.M.; Kostić, N.M. Palladium (II) complexes, as synthetic peptidases, regioselectively cleave the second peptide bond "upstream" from methionine and histidine side chains. J. Am. Chem. Soc. 2002, 124, 4759-4769. [CrossRef]

27. Hohage, O.; Sheldrick, W.S. Cisplatin mediates selective downstream hydrolytic cleavage of Met-(Gly) n-His segments $(n=1,2)$ in methionine-and histidine-containing peptides: The role of ammine loss trans to the initial Pt-S (Met) anchor in facilitating amide hydrolysis. J. Inorg. Biochem. 2006, 100, 1506-1513. [CrossRef] [PubMed]

28. Rajković, S.; Živković, M.D.; Kállay, C.; Sóvágó, I.; Djuran, M.I. A study of the reactions of a methionine-and histidine-containing tetrapeptide with different Pd (II) and Pt (II) complexes: Selective cleavage of the amide bond by platination of the peptide and steric modification of the catalyst. Dalton Trans. 2009, 39, 8370-8377. [CrossRef]

29. Barrios, A.M.; Lippard, S.J. Interaction of Urea with a Hydroxide-Bridged Dinuclear Nickel Center: An Alternative Model for the Mechanism of Urease. J. Am. Chem. Soc. 2000, 122, 9172-9177. [CrossRef]

30. Uprety, B.; Arderne, C.; Bernal, I. Catalytic Cleavage of the Amide Bond in Urea Using a Cobalt(III) Amino-Based Complex. Eur. J. Inorg. Chem. 2018, 5058-5067. [CrossRef]

31. MacDonald, M.J.; Lavis, L.D.; Hilvert, D.; Gellman, S.H. Evaluation of the Ser-His dipeptide, a putative catalyst of amide and ester hydrolysis. Org. Lett. 2016, 18, 3518-3521. [CrossRef] [PubMed]

32. Menger, F.M.; Ladika, M. Remote enzyme-coupled amine release. J. Org. Chem. 1990, 55, 3006-3007. [CrossRef]

33. Blagoeva, I.B.; Kirby, A.J. Intramolecular nucleophilic catalysis of anilide hydrolysis by pyrimidine nitrogen. J. Chem. Soc. Perkin Trans. 2 1985, 7, 1017-1020. [CrossRef]

34. McEuten, J.M.; Nelson, R.P.; Lawton, R.G. The $\alpha, \alpha^{\prime}$ Annelation of Cyclic Ketones. Synthesis and Conformational Properties of Bicyclo[3.3.1]nonanone Derivatives. J. Org. Chem. 1970, 35, 690-696. [CrossRef]

35. Ishchenko, A.Y.; Yanik, S.; Rusanov, E.B.; Komarov, I.V.; Kirby, A.J. An Expedient and Practical Approach to Functionalized 3-Aza-, 3-Oxa-, and 3-Thiabicyclo [3.3.1] nonane Systems. Synthesis 2015, 47, 367. [CrossRef]

36. Komppa, G. Über ein neues bicyclisches Imin, das Iso-granatanin. Ber. Dtsch. Chem. Ges. 1932, 65, 792-793. [CrossRef]

37. Rossi, S.; Valvo, C. Several derivatives of 3-azabicyclo-(3, 3, 1)-nonane; pharmacological activity. I. Il Farmaco 1957, 12, 1008-1015.

38. Wimley, W.C.; Gawrisch, K.; Creamer, T.P.; White, S.H. Direct measurement of salt-bridge solvation energies using a peptide model system: Implications for protein stability. Proc. Natl. Acad. Sci. USA 1996, 93, 2985-2990. [CrossRef] 
39. Webb, E.C. Enzyme Nomenclature 1992. Recommendations of the Nomenclature Committee of the International Union of Biochemistry and Molecular Biology on the Nomenclature and Classification of Enzymes, 6th ed.; Academic Press: San Diego, CA, USA, 1992; p. 863, ISBN 0122271653.

40. Price, N.; Stevens, L. Fundamentals of Enzymology: The Cell and Molecular Biology of Catalytic Proteins, 3rd ed.; OUP Oxford: Oxford, UK, 2000; p. 496, ISBN 9780198502296.

41. Seemuller, E.; Lupas, A.; Stock, D.; Lowe, J.; Huber, R.; Baumeister, W. Proteasome from Thermoplasma acidophilum: A threonine protease. Science 1995, 268, 579-582. [CrossRef]

42. Fujinaga, M.; Cherney, M.M.; Oyama, H.; Oda, K.; James, M.N. The molecular structure and catalytic mechanism of a novel carboxyl peptidase from Scytalidium lignicolum. Proc. Natl. Acad. Sci. USA 2004, 101, 3364-3369. [CrossRef]

43. Rawlings, N.D.; Barrett, A.J.; Bateman, A. Asparagine peptide lyases: A seventh catalytic type of proteolytic enzymes. J. Biol. Chem. 2011, 286, 38321-38328. [CrossRef] [PubMed]

44. Paulus, H. Protein splicing and related forms of protein autoprocessing. Annu. Rev. Biochem. 2000, 69, 447-496. [CrossRef] [PubMed]

45. Noren, C.J.; Wang, J.; Perler, F.B. Dissecting the chemistry of protein splicing and its applications. Angew. Chem. Int. Ed. 2000, 39, 450-466. [CrossRef]

46. Sun, P.; Ye, S.; Ferrandon, S.; Evans, T.C.; Xu, M.Q.; Rao, Z. Crystal structures of an intein from the split dnaE gene of Synechocystis sp. PCC6803 reveal the catalytic model without the penultimate histidine and the mechanism of zinc ion inhibition of protein splicing. J. Mol. Biol. 2005, 353, 1093-1105. [CrossRef] [PubMed]

47. Liu, Z.; Frutos, S.; Bick, M.J.; Vila-Perelló, M.; Debelouchina, G.T.; Darst, S.A.; Muir, T.W. Structure of the branched intermediate in protein splicing. Proc. Natl. Acad. Sci. USA 2014, 111, 8422-8427. [CrossRef] [PubMed]

48. Kirby, A.J.; Komarov, I.V.; Feeder, N. Synthesis, structure and reactions of the most twisted amide. J. Chem. Soc. Perkin Trans. 2 2001, 4, 522-529. [CrossRef]

49. Lizak, C.; Gerber, S.; Numao, S.; Aebi, M.; Locher, K.P. X-ray structure of a bacterial oligosaccharyltransferase. Nature 2011, 474, 350. [CrossRef] [PubMed]

50. Cleland, W.W.; Andrews, T.J.; Gutteridge, S.; Hartman, F.C.; Lorimer, G.H. Mechanism of Rubisco: The carbamate as general base. Chem. Rev. 1998, 98, 549-562. [CrossRef]

51. Komiya, C.; Aihara, K.; Morishita, K.; Ding, H.; Inokuma, T.; Shigenaga, A.; Otaka, A. Development of an intein-inspired amide cleavage chemical device. J. Org. Chem. 2015, 81, 699-707. [CrossRef]

52. Armarego, W.L.F.; Chai, C. Purification of Laboratory Chemicals, 7th ed.; Butterworth-Heinemann: Oxford, UK, 2013; p. 1024, ISBN 9780123821614.

53. Peters, J.A.; Van Der Toorn, J.M.; Van Bekkum, H. 3, 7-disubstituted bicyclo [3.3.1] nonanes-III: Synthesis and conformation of bicyclo[3.3.1]nonane-3 $\alpha, 7 \alpha$-dicarboxylic acid, its dimethyl ester and some other 3,7-disubstituted bicyclo[3.3.1]nonanes; adamantane as an integrated holding system. Tetrahedron 1975, 31, 2273-2281. [CrossRef]

54. Połoński, T.; Pham, M.; Milewska, M.J. Structure, Conformation, and Stereodynamics of N-Nitroso-2,4-diaryl-3-azabicyclo[3.3.1]nonanes and N-Nitroso-2,4-diaryl-3-azabicyclo[3.3.1]nonan-9- ones. J. Org. Chem. 1996, 61, 3766-3772. [CrossRef]

55. Hwang, T.-L.; Shaka, A.J. Water Suppression that Works. Excitation Sculpting Using Arbitrary Waveform and Pulsed Field Gradient. J. Magn. Res. Ser. A 1995, 112, 275-279. [CrossRef]

Sample Availability: Samples of the compounds 13, 14 are available from the authors.

(C) 2019 by the authors. Licensee MDPI, Basel, Switzerland. This article is an open access article distributed under the terms and conditions of the Creative Commons Attribution (CC BY) license (http:/ / creativecommons.org/licenses/by/4.0/). 


\title{
Communication \\ Selective C-N $\sigma$ Bond Cleavage in Azetidinyl Amides under Transition Metal-Free Conditions
}

\author{
Hengzhao Li, Zemin Lai, Adila Adijiang, Hongye Zhao and Jie An* \\ College of Science, China Agricultural University, No. 2 Yuanmingyuan West Road, Beijing 100193, China; \\ lihengzhao@cau.edu.cn (H.L.); $2016310060420 @$ cau.edu.cn (Z.L.); 2015310060229@cau.edu.cn (A.A.); \\ hongyezhao@cau.edu.cn (H.Z.) \\ * Correspondence: jie_an@cau.edu.cn
}

Received: 6 December 2018; Accepted: 16 January 2019; Published: 28 January 2019

\begin{abstract}
Functionalization of amide bond via the cleavage of a non-carbonyl, C-N $\sigma$ bond remains under-investigated. In this work, a transition-metal-free single-electron transfer reaction has been developed for the $\mathrm{C}-\mathrm{N} \sigma$ bond cleavage of $\mathrm{N}$-acylazetidines using the electride derived from sodium dispersions and 15-crown-5. Of note, less strained cyclic amides and acyclic amides are stable under the reaction conditions, which features the excellent chemoselectivity of the reaction. This method is amenable to a range of unhindered and sterically encumbered azetidinyl amides.
\end{abstract}

Keywords: amides; C-N $\sigma$ bond cleavage; sodium; crown ether

\section{Introduction}

Amide is among the most ubiquitous functional groups [1]. Although the reductive functionalization of amides has been studied extensively, the majority of strategies have focused on the amide reductions via C-O or C-N cleavage, to afford the corresponding amines or alcohols (Scheme 1) [2-11]. Only a few examples were reported for the amide bond functionalization via the selective activation of the non-carbonyl, C-N $\sigma$ bond, despite its considerable potential in the synthesis of amide linkage in both chemistry and biology (Scheme 1) [12,13]. In 2005, Aube and co-workers reported a highly unusual C-N $\sigma$ bond cleavage in a class of specialized bridged lactams under catalytic hydrogenation conditions [14]. The twisted amide bond is the possible reason for the high activities of the $\mathrm{C}-\mathrm{N} \sigma$ bonds in those substrates. Recently, Szostak and co-workers have developed a more general single electron transfer (SET) method for the reductive cleavage of $\mathrm{C}-\mathrm{N} \sigma$ bonds in both planar and pyramidalized amides, using $\mathrm{Tm}_{2}-\mathrm{ROH}$ reagent, which forms from a nonclassical lanthanide (II) iodide [15-18]. Given the high price of thulium, a corresponding SET protocol mediated by cheap electron donor reagents will be more desirable, which is the subject of this work.

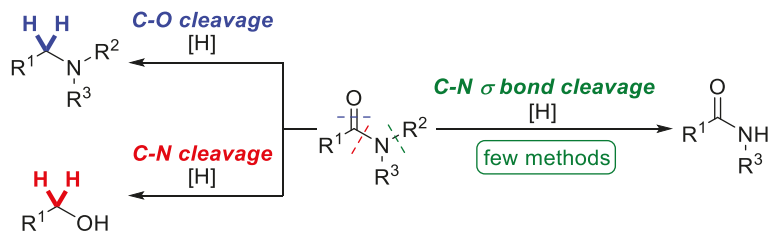

Scheme 1. Reductive functionalization of amides.

Electrides, in which anions are electrons, are a class of useful single electron-donor reagents. Solutions of alkali metal in liquid metals [19], first described by Sir Humphry Davy in 1803 [20], are among the most common electride systems, which have found wide applications in single-electron 
transfer reductions, including the venerable Birch reduction [21-23]. To avoid the hazards that are associated with the usage of liquid ammonia, new methods for the generation of electride salts using alkali metal and crown ethers were developed. However, freshly distilled sodium, potassium mirror, or highly pyrophoric potassium-sodium alloys were required to accelerate the reaction between the alkali metal and crown ethers [24-27]. Previously, our group developed a more practical protocol for the synthesis of electride salts, using sodium dispersions and 15-crown-5 [28]. Sodium dispersion in oil is a bench-stable and commercially available reagent with a high specific surface area [28-32]. The derived electride has already been successfully applied in a chemoselective ammonia-free Birch reduction [28]. However, the application of such an electride in other SET reactions remains under-investigated. Herein, we report the first electride-mediated $\mathrm{C}-\mathrm{N} \sigma$ bond cleavage reaction in pyramidalized azetidinyl amides $\left(\tau=3.3^{\circ} ; \chi_{\mathrm{N}}=32.5^{\circ} ; 4\right.$-TolC $(O)$-azetidine, Winkler-Dunitz parameters [33]), using a cheap sodium dispersion/15-crown-5 reagent system under practical conditions.

\section{Results and Discussion}

Our study began with the optimization of the reaction conditions for the $\mathrm{C}-\mathrm{N} \sigma$ bond cleavage process in azetidinyl amides, using 1a as a model substrate. In the previous work, we have demonstrated that 1a can be converted into the corresponding alcohol via C-N cleavage, using $\mathrm{Na} / \mathrm{EtOH}$ [5]. We hypothesized that the absence of the proton donor would suppress the amide reduction pathway, and lead to the formation of $2 \mathrm{a}$ via the $\mathrm{C}-\mathrm{N} \sigma$ bond cleavage. The initial trial of the reaction, using 5.0 equiv. of sodium dispersions in $\mathrm{Et}_{2} \mathrm{O}$ afforded $\mathbf{2 a}$ in a moderate yield of $50 \%$ with the recovered starting material, accounting for the majority of the remaining mass balance (entry 1, Table 1). By-products derived from the amide reduction were not observed. The yield could be significantly improved by replacing $\mathrm{Et}_{2} \mathrm{O}$ with tetrahydrofuran (THF), a solvent with higher dielectric constant, which indicated that the reaction might go through an outer-sphere electron transfer mechanism (entry 2, Table 1). As electrides are promising electron donors for the outer electron transfer processes, the feasibility of electride derived from sodium dispersions and 15-crown-5 was investigated. When 5.0 equiv. of $\mathrm{Na} / 15$-crown- 5 was employed, satisfactory yields of $2 \mathrm{a}$ were obtained in both $\mathrm{Et}_{2} \mathrm{O}$ and THF (Entries 3 and 4, Table 1). Although Na/15-crown-5/i-PrOH is an effective system for Birch-type reductions, dearomatization was well-suppressed in the absence of a proton donor, and the reduction of the phenyl moiety in 1 a was not observed under the conditions using $\mathrm{Na} / 15$-crown-5 (Entries 3 and 4, Table 1). The reductive C-N $\sigma$ bond cleavage is a two-electron process. However, shortening the amount of $\mathrm{Na} / 15$-crown- 5 to 3.0 equiv. resulted in a much lower yield (entries 5 and 6 , Table 1). Also, shortening the reaction time gave decreased yields (Entries 7 and 8, Table 1).

Table 1. Optimization of selective C-N $\sigma$ bond cleavage in azetidinyl amides by $\mathrm{Na} / 15-\mathrm{crown}-5^{1}$.

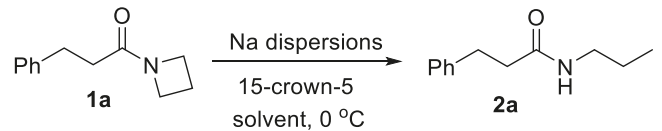

\begin{tabular}{cccccc}
\hline Entry & Sodium Dispersion $^{1}$ (Equiv) & 15-crown-5 (Equiv) & Time & Solvent & Yield (\%) ${ }^{2}$ \\
\hline 1 & 5.0 & 0 & $2.0 \mathrm{~h}$ & $\mathrm{Et}_{2} \mathrm{O}$ & 50 \\
2 & 5.0 & 0 & $2.0 \mathrm{~h}$ & $\mathrm{THF}$ & 67 \\
3 & 5.0 & 5.0 & $2.0 \mathrm{~h}$ & $\mathrm{Et}_{2} \mathrm{O}$ & 79 \\
4 & 5.0 & 5.0 & $2.0 \mathrm{~h}$ & $\mathrm{THF}$ & 80 \\
5 & 4.5 & 4.5 & $2.0 \mathrm{~h}$ & $\mathrm{Et}_{2} \mathrm{O}$ & 65 \\
6 & 3.0 & 3.0 & $2.0 \mathrm{~h}$ & $\mathrm{Et}_{2} \mathrm{O}$ & 56 \\
7 & 5.0 & 5.0 & $1.0 \mathrm{~h}$ & $\mathrm{THF}$ & 71 \\
8 & 5.0 & 5.0 & $10 \mathrm{~min}$ & $\mathrm{THF}$ & 47 \\
\hline
\end{tabular}

THF: tetrahydrofuran. ${ }^{1}$ Sodium dispersions in oil, $33.9 \mathrm{wt} \%$, particle size $5-10 \mu \mathrm{m} .{ }^{2}$ Determined by ${ }^{1} \mathrm{H}-\mathrm{NMR}$. 
Next, the optimized conditions (Entry 4, Table 1) were applied to the selective C-N $\sigma$ bond cleavage reactions. A broad range of aliphatic and aromatic azetidinyl amides were converted into the corresponding secondary $n$-butyl amides at high yields (Figure 1). Both the unhindered (e.g., 1a, $\mathbf{1 g}$, and $\mathbf{1 m})$ and sterically encumbered $(\mathbf{1} \mathbf{h}, \mathbf{1} \mathbf{i}$, and $\mathbf{1} \mathbf{j})$ azetidinyl amides were viable substrates for this reaction. Aromatic rings were stable under the reaction conditions. By-products derived from the Birch-type dearomatization were not detected in any of the tested substrates (1a-1h). Substrate-bearing functional groups, such as methoxy group (1d) and alkene group (1k), were also readily converted into the corresponding $n$-butyl amides without the demethylation of the methoxy group or the reduction of the alkene group. In contrast, chloride (1f) were fully reduced when 8.0 equiv. of $\mathrm{Na} / 15$-crown- 5 was used, which suggested that the potential application of this protocol in dehalogenation reactions. In addition, if the reaction with $1 \mathrm{a}$ was quenched by $\mathrm{D}_{2} \mathrm{O}$, the corresponding deuterium labeled product, 3-phenyl- $\mathrm{N}$-(propyl-3- $d$ )propanamide, was detected, albeit in a low deuterium incorporation. Remarkably, this single electron transfer process is highly selective for azetidinyl amides. Less strained cyclic amides, such as pyrrolidinyl amide 10 and piperidinyl amide $\mathbf{1 p}$, were very stable under the reaction conditions. Acyclic tertiary amide $1 \mathrm{r}$ and secondary amide $1 \mathbf{q}$ also did not undergo the cleavage reaction. Those observations suggested that the large ring strain in a four-membered ring of $25.4 \mathrm{kcal} / \mathrm{mol}$ (cf. aziridines, $27.5 \mathrm{kcal} / \mathrm{mol}$ ) [33] is the possible driving force for the $\mathrm{C}-\mathrm{N} \sigma$ bond cleavage process in azetidinyl amides.

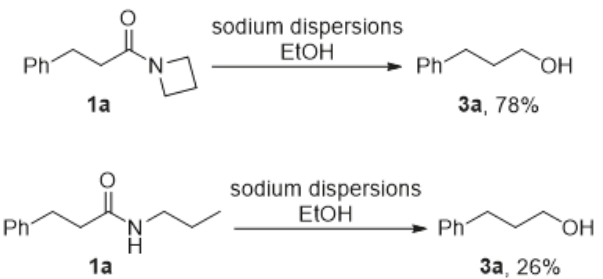

The key processes in this reaction involve the generation of ketyl-type radicals from a reversible electron transfer $(\mathbf{1} \rightarrow \mathbf{4}$, Scheme 2$)$ and the sequential C-N $\sigma$ bond cleavage $(4 \rightarrow 5)$. The control reactions (Equations (1) and (2)) demonstrated that (a) in the presence of EtOH, alcohol 3 was formed as the major product; (b) it was difficult to convert secondary amide 2 to the corresponding alcohol $\mathbf{3}$ using $\mathrm{Na} / \mathrm{EtOH}$. These observations indicated that, in the presence of the proton donor, amide reduction via the C-N cleavage $(\mathbf{4} \rightarrow \mathbf{6} \rightarrow \mathbf{7} \rightarrow \mathbf{3})$ was the dominant pathway. In addition, the ring-opening step $(4 \rightarrow 5)$ was relatively slow, so that the $n$-butyl amides 2 derived from the $\mathrm{C}-\mathrm{N} \sigma$ bond cleavage were not detected in the reaction using $\mathrm{Na} / \mathrm{EtOH}$ (Equation (1)). However, the second electron transfer $(6 \rightarrow 7)$ will be suppressed in the absence of a proton donor, which will alternately lead to the formation of a C-N $\sigma$ bond cleavage product $2(4 \rightarrow 5 \rightarrow 2)$. 


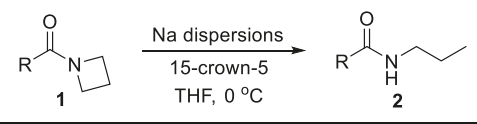

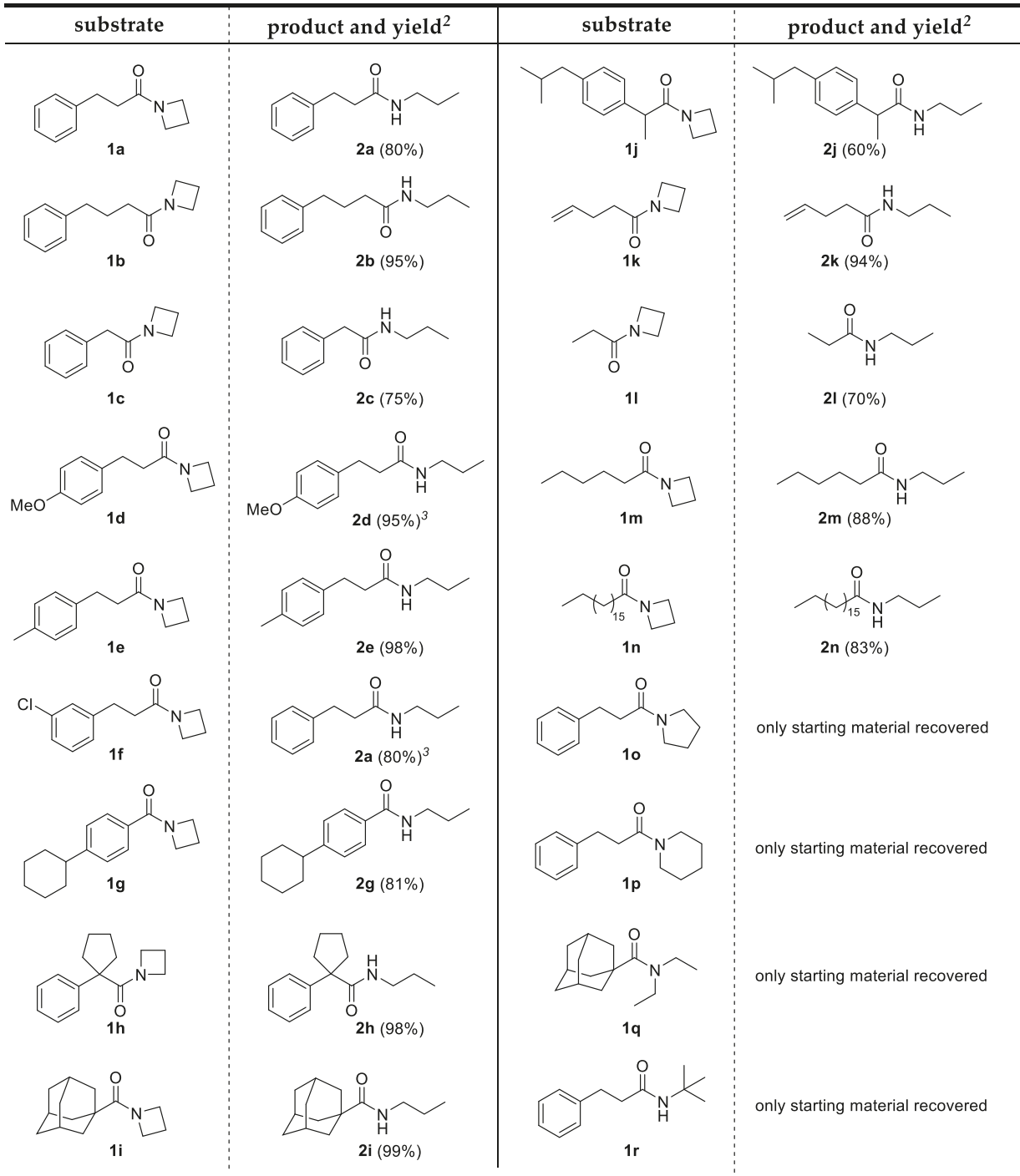

Figure 1. Selective $\mathrm{C}-\mathrm{N} \sigma$ bond cleavage in azetidinyl amides by Na/15-crown- $5{ }^{1} .{ }^{1}$ Conditions: 1 (0.50 mmol, 1.0 equiv.), Na dispersions (5.0 equiv.), 15-crown-5 (5.0 equiv.), THF $(3.0 \mathrm{~mL}), 0{ }^{\circ} \mathrm{C}$. ${ }^{2}$ Isolated yield. ${ }^{3}$ Na dispersions (8.0 equiv.) and 15-crown-5 (8.0 equiv.) were used. 


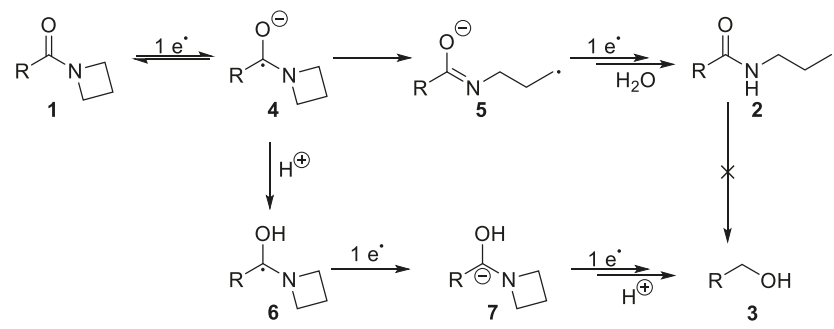

Scheme 2. Proposed mechanism for the C-N $\sigma$ bond cleavage in azetidinyl amides with Na/15-crown-5.

\section{Materials and Methods}

\subsection{General Information}

Glassware was dried in an oven overnight before use. Thin-layer chromatography was carried out on SIL G/UV254 silica-aluminum plates, and plates were visualized using ultraviolet light (254 nm) and $\mathrm{KMnO}_{4}$ solution. For flash column chromatography, silica gel 60, 35-70 $\mu \mathrm{m}$ was used. NMR data was collected at $300 \mathrm{MHz}$. Data was manipulated directly from the spectrometer or via a networked PC with appropriate software. All samples were analyzed in $\mathrm{CDCl}_{3}$. Reference values for the residual solvent were taken as $\delta=7.27\left(\mathrm{CDCl}_{3}\right)$ for ${ }^{1} \mathrm{H}-\mathrm{NMR} ; \delta=77.1\left(\mathrm{CDCl}_{3}\right)$ for ${ }^{13} \mathrm{C}-\mathrm{NMR}$. Multiplicities for coupled signals were designated using the following abbreviations: $\mathrm{s}=$ singlet, $\mathrm{d}=$ doublet, $\mathrm{t}=$ triplet, $\mathrm{q}=$ quartet, $\mathrm{br}=$ broad signal, and are given in $\mathrm{Hz}$.

All solvents and reagents were used as supplied. Amides were prepared by the standard method [33]. $2 \mathbf{g}$ and $\mathbf{2 n}$ are novel compounds, and all the other compounds used in this study have been described in the literature or are commercially available. ${ }^{1} \mathrm{H}$ and ${ }^{13} \mathrm{C}$ NMR spectra of $\mathbf{2 a}-\mathbf{2 n}$, and HRMS of $\mathbf{2} \mathbf{g}$ and $\mathbf{2 n}$ are provided in the Supplementary Materials.

\subsection{Optimization Studies (Table 1)}

To a suspension of $\mathrm{Na}$ dispersion in oil (33.9 wt \%, 1.50-2.50 mmol) in anhydrous solvent $(0.5 \mathrm{~mL})$, 15-crown-5 (0-2.50 mmol) was added under Ar at $0{ }^{\circ} \mathrm{C}$ and stirred vigorously for $5 \mathrm{~min}$. The solution turned dark blue rapidly. A solution of substrate $(0.500 \mathrm{mmol})$ in the same solvent $(2.0 \mathrm{~mL})$ was then added at $0{ }^{\circ} \mathrm{C}$. After $10-120 \mathrm{~min}$, the reaction was quenched by a saturated aqueous solution of $\mathrm{NaHCO}_{3}(2.0 \mathrm{~mL})$, and the reaction mixture was diluted with $\mathrm{Et}_{2} \mathrm{O}(10 \mathrm{~mL})$ and brine $(20 \mathrm{~mL})$. The aqueous layer was extracted with $\mathrm{Et}_{2} \mathrm{O}(2 \times 10 \mathrm{~mL})$, and the organic layers were combined, dried over $\mathrm{Na}_{2} \mathrm{SO}_{4}$, filtered, and concentrated. Then, the sample was analyzed by ${ }^{1} \mathrm{H}-\mathrm{NMR}\left(\mathrm{CDCl}_{3}\right.$, $300 \mathrm{MHz})$ to obtain the yield, using an internal standard $\left(\mathrm{CHCl}_{2} \mathrm{CHCl}_{2}\right)$ and by comparison with corresponding samples.

\subsection{General Procedure for the C-N Bond Cleavage in Azetidinyl Amides}

To a suspension of Na dispersion in oil (33.9 wt \%, 2.50-4.00 mmol) in anhydrous THF (0.5 mL), 15-crown-5 (2.50-4.00 mmol) was added under Ar at $0{ }^{\circ} \mathrm{C}$, and stirred vigorously for $5 \mathrm{~min}$. A solution of the substrate $(0.500 \mathrm{mmol})$ in THF $(2.0 \mathrm{~mL})$ was then added at $0{ }^{\circ} \mathrm{C}$. After $2 \mathrm{~h}$, the reaction was quenched by a saturated aqueous solution of $\mathrm{NaHCO}_{3}(2.0 \mathrm{~mL})$ and the reaction mixture was diluted with $\mathrm{Et}_{2} \mathrm{O}(10 \mathrm{~mL})$ and brine $(20 \mathrm{~mL})$. The aqueous layer was extracted with $\mathrm{Et}_{2} \mathrm{O}(2 \times 10 \mathrm{~mL})$, and the organic layers were combined, dried over $\mathrm{Na}_{2} \mathrm{SO}_{4}$, filtered and concentrated. The crude product was purified by flash chromatography (silica, 0-50\% hexane/EtOAc).

3-Phenyl-N-propylpropanamide (2a) [34]: white solid (76.5 mg, 80\%). ${ }^{1} \mathrm{H}-\mathrm{NMR}\left(300 \mathrm{MHz}, \mathrm{CDCl}_{3}\right) \delta$ 7.32-7.24 (m, 2H), 7.24-7.15 (m, 3H), $5.56(\mathrm{~s}, 1 \mathrm{H}), 3.16(\mathrm{td}, J=7.1,6.9 \mathrm{~Hz}, 2 \mathrm{H}), 2.96(\mathrm{t}, J=7.7 \mathrm{~Hz}, 2 \mathrm{H})$, $2.46(\mathrm{t}, J=7.7 \mathrm{~Hz}, 2 \mathrm{H}), 1.44(\mathrm{~m}, 2 \mathrm{H}), 0.84(\mathrm{t}, J=7.4 \mathrm{~Hz}, 3 \mathrm{H}) ;{ }^{13} \mathrm{C}-\mathrm{NMR}\left(75 \mathrm{MHz}, \mathrm{CDCl}_{3}\right) \delta 172.2,140.9$, $128.4,128.3,126.1,41.2,38.4,31.8,22.7,11.3$. 
4-Phenyl- $\mathrm{N}$-propylbutanamide (2b): colorless oil (97.5 mg, 95\%). ${ }^{1} \mathrm{H}-\mathrm{NMR}\left(300 \mathrm{MHz}, \mathrm{CDCl}_{3}\right) \delta$ 7.33-7.23 (m, 2H), 7.23-7.13 (m, 3H), $5.49(\mathrm{~s}, 1 \mathrm{H}), \delta 3.20(\mathrm{td}, J=7.1,6.5 \mathrm{~Hz}, 2 \mathrm{H}), 2.65(\mathrm{t}, J=7.5 \mathrm{~Hz}, 2 \mathrm{H})$, $2.17(\mathrm{t}, J=7.5 \mathrm{~Hz}, 2 \mathrm{H}), 1.97(\mathrm{~m}, 2 \mathrm{H}), 1.51(\mathrm{~m}, 2 \mathrm{H}), 0.91(\mathrm{t}, J=7.4 \mathrm{~Hz}, 3 \mathrm{H}) ;{ }^{13} \mathrm{C}-\mathrm{NMR}\left(75 \mathrm{MHz}, \mathrm{CDCl}_{3}\right) \delta$ $172.7,141.6,128.6,128.4,126.0,41.3,36.0,35.3,27.2,23.0,11.4$.

2-Phenyl- $\mathrm{N}$-propylacetamide (2c) [35]: white solid (66.5 mg, 75\%). ${ }^{1} \mathrm{H}-\mathrm{NMR}\left(300 \mathrm{MHz}, \mathrm{CDCl}_{3}\right) \delta$ 7.40-7.23 (m, 5H), $5.41(\mathrm{~s}, 1 \mathrm{H}), 3.57(\mathrm{~s}, 2 \mathrm{H}), 83.17(\mathrm{td}, J=7.2,6.2 \mathrm{~Hz}, 2 \mathrm{H}), 1.44(\mathrm{~m}, 2 \mathrm{H}), 0.83(\mathrm{t}, J=7.4 \mathrm{~Hz}$, $3 \mathrm{H}) ;{ }^{13} \mathrm{C}-\mathrm{NMR}\left(75 \mathrm{MHz}, \mathrm{CDCl}_{3}\right)$ 8 171.0, 135.2, 129.5, 129.1, 127.4, 44.0, 41.4, 22.8, 11.3.

3-(4-Methoxyphenyl)-N-propylpropanamide (2d) [34]: white solid (105.1 mg, 95\%). ${ }^{1} \mathrm{H}-\mathrm{NMR}$ (300 $\left.\mathrm{MHz}, \mathrm{CDCl}_{3}\right) \delta 7.11(\mathrm{~d}, J=8.1 \mathrm{~Hz}, 2 \mathrm{H}), 6.82(\mathrm{~d}, J=8.1 \mathrm{~Hz}, 2 \mathrm{H}), 5.53(\mathrm{~s}, 1 \mathrm{H}), 3.77(\mathrm{~s}, 3 \mathrm{H}), 3.16(\mathrm{td}$, $J=6.7 \times 2 \mathrm{~Hz}, 2 \mathrm{H}), 2.90(\mathrm{t}, J=7.5 \mathrm{~Hz}, 2 \mathrm{H}), 2.42(\mathrm{t}, J=7.5 \mathrm{~Hz}, 2 \mathrm{H}), 1.45(\mathrm{~m}, 2 \mathrm{H}), 0.85(\mathrm{t}, J=7.4 \mathrm{~Hz}, 3 \mathrm{H})$; ${ }^{13} \mathrm{C}-\mathrm{NMR}\left(75 \mathrm{MHz}, \mathrm{CDCl}_{3}\right) \delta 172.2,158.1,133.0,129.3,114.0,55.3,41.2,38.9,31.0,22.9,11.3$.

N-Propyl-3-(p-tolyl)propanamide (2e): white solid (100.6 mg, 98\%). ${ }^{1} \mathrm{H}-\mathrm{NMR}\left(300 \mathrm{MHz}, \mathrm{CDCl}_{3}\right) \delta$ $7.18-6.99(\mathrm{~m}, 4 \mathrm{H}), 5.72(\mathrm{~s}, 1 \mathrm{H}), 3.16(\mathrm{td}, J=6.5,6.4 \mathrm{~Hz}, 2 \mathrm{H}), 2.91(\mathrm{t}, J=7.8 \mathrm{~Hz}, 2 \mathrm{H}), 2.44(\mathrm{t}, J=7.8 \mathrm{~Hz}$, $2 \mathrm{H}), 2.30(\mathrm{~s}, 3 \mathrm{H}), 1.45(\mathrm{~m}, 2 \mathrm{H}), 0.85(\mathrm{t}, J=7.4 \mathrm{~Hz}, 3 \mathrm{H}) ;{ }^{13} \mathrm{C}-\mathrm{NMR}\left(75 \mathrm{MHz}, \mathrm{CDCl}_{3}\right) \delta 172.2,137.9,135.6$, $129.1,128.2,41.2,38.6,31.4,22.8,21.0,11.3$.

3-Phenyl-N-propylpropanamide (2a) (derived from 1f) [34]: white solid (76.5 mg, 80\%). ${ }^{1} \mathrm{H}-\mathrm{NMR}(300$ $\left.\mathrm{MHz}, \mathrm{CDCl}_{3}\right)$ 8 7.32-7.24 (m, 2H), 7.23-7.15 (m, 3H), $5.50(\mathrm{~s}, 1 \mathrm{H}), 3.16(\mathrm{td}, J=6.9,6.5 \mathrm{~Hz}, 2 \mathrm{H}), 2.96(\mathrm{t}$, $J=7.7 \mathrm{~Hz}, 2 \mathrm{H}), 2.46(\mathrm{t}, J=7.7 \mathrm{~Hz}, 2 \mathrm{H}), 1.44(\mathrm{~m}, 2 \mathrm{H}), 0.84(\mathrm{t}, J=7.4 \mathrm{~Hz}, 3 \mathrm{H}) ;{ }^{13} \mathrm{C}-\mathrm{NMR}\left(75 \mathrm{MHz}, \mathrm{CDCl}_{3}\right)$ $\delta 172.1,141.0,128.6,128.4,126.3,41.3,38.6,31.9,22.9,11.3$.

4-Cyclohexyl- $N$-propylbenzamide (2g): white solid (99.4 mg, 81\%). ${ }^{1} \mathrm{H}-\mathrm{NMR}\left(300 \mathrm{MHz}, \mathrm{CDCl}_{3}\right) \delta$ 7.73-7.66 (m, 2H), 7.26-7.21 (m, 2H), $6.32(\mathrm{~s}, 1 \mathrm{H}), 3.39(\mathrm{td}, J=7.4,6.5 \mathrm{~Hz}, 2 \mathrm{H}), 2.53(\mathrm{~m}, 1 \mathrm{H}), 1.94-1.73$ $(\mathrm{m}, 5 \mathrm{H}), 1.61(\mathrm{~m}, 2 \mathrm{H}), 1.43-1.22(\mathrm{~m}, 5 \mathrm{H}), 0.96(\mathrm{t}, J=7.4 \mathrm{~Hz}, 3 \mathrm{H}) ;{ }^{13} \mathrm{C}-\mathrm{NMR}\left(75 \mathrm{MHz}, \mathrm{CDCl}_{3}\right) \delta 167.6$, 151.6, 132.4, $127.0(\times 2), 44.5,41.7,34.3,26.8,26.1,23.0,11.5$; HRMS (FTMS-ESI) $m / z:[\mathrm{M}+1]^{+}$calc for $\mathrm{C}_{16} \mathrm{H}_{23} \mathrm{NO} 246.1852$, found 246.1849 .

1-Phenyl-N-propylcyclopentane-1-carboxamide (2h): white solid (113.4 mg, 98\%). ${ }^{1} \mathrm{H}-\mathrm{NMR}(300 \mathrm{MHz}$, $\left.\mathrm{CDCl}_{3}\right) \delta 7.38-7.21(\mathrm{~m}, 5 \mathrm{H}), 5.22(\mathrm{~s}, 1 \mathrm{H}), 3.09(\mathrm{td}, J=7.0,5.9 \mathrm{~Hz}, 2 \mathrm{H}), 2.52-2.41(\mathrm{~m}, 2 \mathrm{H}), 2.06-1.96(\mathrm{~m}$, 2H), $1.89-1.75(\mathrm{~m}, 2 \mathrm{H}), 1.75-1.60(\mathrm{~m}, 2 \mathrm{H}), 1.36(\mathrm{~m}, 2 \mathrm{H}), 0.75(\mathrm{t}, J=7.4 \mathrm{~Hz}, 3 \mathrm{H}) ;{ }^{13} \mathrm{C}-\mathrm{NMR}(75 \mathrm{MHz}$, $\left.\mathrm{CDCl}_{3}\right) \delta 176.4,144.4,128.6,126.8(\times 2), 59.3,41.4,36.9,24.0,22.7,11.1$.

(3r,5r,7r)-N-Propyladamantane-1-carboxamide (2i): colorless oil (109.6 mg, 99\%). ${ }^{1} \mathrm{H}-\mathrm{NMR}(300 \mathrm{MHz}$, $\left.\mathrm{CDCl}_{3}\right) \delta 5.63(\mathrm{~s}, 1 \mathrm{H}), 3.21(\mathrm{td}, J=6.7,6.3 \mathrm{~Hz}, 2 \mathrm{H}), 2.08-2.01(\mathrm{~m}, 3 \mathrm{H}), 1.88-1.82(\mathrm{~m}, 6 \mathrm{H}), 1.76-1.68(\mathrm{~m}$, $6 \mathrm{H}), 1.51(\mathrm{~m}, 2 \mathrm{H}), 0.91(\mathrm{t}, J=7.4 \mathrm{~Hz}, 3 \mathrm{H}) ;{ }^{13} \mathrm{C}-\mathrm{NMR}\left(75 \mathrm{MHz}, \mathrm{CDCl}_{3}\right) \delta 177.7,41.0,40.7,39.4,36.6,28.3$, 23.0, 11.4 .

2-(4-Isobutylphenyl)- $N$-propylpropanamide (2j): colorless oil (74.2 mg, 60\%). ${ }^{1} \mathrm{H}-\mathrm{NMR}(300 \mathrm{MHz}$, $\left.\mathrm{CDCl}_{3}\right) \delta 7.22-7.16(\mathrm{~m}, 2 \mathrm{H}), 7.14-7.08(\mathrm{~m}, 2 \mathrm{H}), 5.41(\mathrm{~s}, 1 \mathrm{H}), 3.53(\mathrm{q}, J=7.2 \mathrm{~Hz}, 1 \mathrm{H}), 3.14(\mathrm{td}, J=7.1$, $5.9 \mathrm{~Hz}, 2 \mathrm{H}), 2.45(\mathrm{~d}, J=7.2 \mathrm{~Hz}, 2 \mathrm{H}), 1.84(\mathrm{~m}, 1 \mathrm{H}), 1.51(\mathrm{~d}, J=7.2 \mathrm{~Hz}, 3 \mathrm{H}), 1.41(\mathrm{~m}, 2 \mathrm{H}), 0.90(\mathrm{~d}, J=6.6 \mathrm{~Hz}$, $6 \mathrm{H}), 0.80(\mathrm{t}, J=7.4 \mathrm{~Hz}, 3 \mathrm{H}) ;{ }^{13} \mathrm{C}-\mathrm{NMR}\left(75 \mathrm{MHz}, \mathrm{CDCl}_{3}\right) \delta 174.5,140.7,138.8,129.6,127.4,46.8,45.1$, $41.3,30.2,22.8,22.4,18.5,11.2$.

$\mathrm{N}$-Propylpent-4-enamide (2k): colorless oil (66.4 mg, 94\%). ${ }^{1} \mathrm{H}-\mathrm{NMR}\left(300 \mathrm{MHz}, \mathrm{CDCl}_{3}\right) \delta 5.82(\mathrm{t}$, $J=8.7 \mathrm{~Hz}, 1 \mathrm{H}), 5.69(\mathrm{~s}, 1 \mathrm{H}), 5.04(\mathrm{dd}, J=18.9,13.6 \mathrm{~Hz}, 2 \mathrm{H}), 3.22(\mathrm{~d}, J=6.8 \mathrm{~Hz}, 2 \mathrm{H}), 2.33(\mathrm{dt}, J=35.4$, $7.5 \mathrm{~Hz}, 4 \mathrm{H}), 1.52(\mathrm{dd}, J=14.5,7.3 \mathrm{~Hz}, 2 \mathrm{H}), 0.92(\mathrm{t}, J=7.2 \mathrm{~Hz}, 3 \mathrm{H}) ;{ }^{13} \mathrm{C}-\mathrm{NMR}\left(75 \mathrm{MHz}, \mathrm{CDCl}_{3}\right) \delta 172.3$, $137.2,115.5,41.336 .0,29.8,22.9,11.4$. 
$\mathrm{N}$-Propylpropionamide (21) [36]: colorless oil (40.3 mg, 70\%). ${ }^{1} \mathrm{H}-\mathrm{NMR}\left(300 \mathrm{MHz}, \mathrm{CDCl}_{3}\right) \delta 5.44$ (s, $1 \mathrm{H}), 3.22(\mathrm{td}, J=7.2,6.5 \mathrm{~Hz}, 2 \mathrm{H}), 2.20(\mathrm{q}, J=7.6 \mathrm{~Hz}, 2 \mathrm{H}), 1.52(\mathrm{~m}, 2 \mathrm{H}), 1.16(\mathrm{t}, J=7.6 \mathrm{~Hz}, 3 \mathrm{H}), 0.93(\mathrm{t}$, $J=7.6 \mathrm{~Hz}, 3 \mathrm{H}) ;{ }^{13} \mathrm{C}-\mathrm{NMR}\left(75 \mathrm{MHz}, \mathrm{CDCl}_{3}\right) \delta 173.7,41.3,29.9,23.0,11.4,10.0$.

$\mathrm{N}$-Propylhexanamide (2m): colorless oil $(69.2 \mathrm{mg}, 88 \%) .{ }^{1} \mathrm{H}-\mathrm{NMR}\left(300 \mathrm{MHz}, \mathrm{CDCl}_{3}\right) \delta 5.64(\mathrm{~s}, 1 \mathrm{H}), 3.21$ $(\mathrm{td}, J=7.2,6.1 \mathrm{~Hz}, 2 \mathrm{H}), 2.16(\mathrm{t}, J=7.8 \mathrm{~Hz}, 2 \mathrm{H}), 1.63(\mathrm{~m}, 2 \mathrm{H}), 1.52(\mathrm{~m}, 2 \mathrm{H}), 1.36-1.26(\mathrm{~m}, 4 \mathrm{H}), 0.96-0.85$ $(\mathrm{m}, 6 \mathrm{H}) ;{ }^{13} \mathrm{C}-\mathrm{NMR}\left(75 \mathrm{MHz}, \mathrm{CDCl}_{3}\right) \delta 173.2,41.2,36.9,31.5,25.6,23.0,22.5,14.0,11.4$.

$\mathrm{N}$-Propylstearamide (2n): white solid (135.1 mg, 83\%). ${ }^{1} \mathrm{H}-\mathrm{NMR}\left(300 \mathrm{MHz}, \mathrm{CDCl}_{3}\right) \delta 5.63(\mathrm{~s}, 1 \mathrm{H}), 3.21$ $(\mathrm{td}, J=6.9,6.5 \mathrm{~Hz}, 2 \mathrm{H}), 2.16(\mathrm{t}, J=7.6 \mathrm{~Hz}, 2 \mathrm{H}), 1.62(\mathrm{~m}, 2 \mathrm{H}), 1.52(\mathrm{~m}, 2 \mathrm{H}), 1.37-1.20(\mathrm{~m}, 28 \mathrm{H}), 0.96-0.82$ $(\mathrm{m}, 6 \mathrm{H}) ;{ }^{13} \mathrm{C}-\mathrm{NMR}\left(75 \mathrm{MHz}, \mathrm{CDCl}_{3}\right) \delta 173.2,41.2,37.0,32.0,29.8(\times 5), 29.7(\times 3), 29.6,29.4(\times 3), 25.9$, 23.0, 22.7, 14.2, 11.4; HRMS (FTMS-ESI) $m / z$ : $[\mathrm{M}+1]^{+}$calc for $\mathrm{C}_{21} \mathrm{H}_{43} \mathrm{NO} 326.3417$, found 326.3408 .

\section{Conclusions}

In summary, a transition metal-free method for the challenging $\mathrm{C}-\mathrm{N} \sigma$ bond cleavage in azetidinyl amides has been developed, using sodium dispersions and 15-crown-5. This practical reaction requires only inexpensive air- and moisture-stable reagents. High yields were obtained across a broad range of aliphatic and aromatic azetidinyl amides. More importantly, full chemoselectivity over the reductive $\mathrm{C}-\mathrm{N} \sigma$ bond cleavage of less strained cyclic amides and acyclic amides was achieved. This work represents the first application of an electride in the $\mathrm{C}-\mathrm{N} \sigma$ bond cleavage in pyramidalized amides. The further application of the electride derived from sodium dispersions and crown ethers in new SET reactions will be the subject of our future research.

Supplementary Materials: The following are available online at http:/ /www.mdpi.com/1420-3049/24/3/459/s1, ${ }^{1} \mathrm{H}$ and ${ }^{13} \mathrm{C}-\mathrm{NMR}$ spectra of $\mathbf{2 a}-\mathbf{2 n}$, and HRMS of $\mathbf{2} \mathbf{g}$ and $\mathbf{2 n}$.

Author Contributions: Conceptualization, J.A. and H.L.; investigation, H.L., Z.L., A.A., and H.Z.; writing, J.A., H.L., Z.L., and H.Z.; supervision, J.A.

Funding: This research was funded by National Key Research and Development Plan of China (grant number 2017YFD0200504) and the National Natural Science Foundation of China (grant numbers 21602248, 21711530213).

Conflicts of Interest: The authors declare no conflict of interest. The funders had no role in the design of the study; in the collection, analyses, or interpretation of data; in the writing of the manuscript, or in the decision to publish the results.

\section{References}

1. Greenberg, A.; Breneman, C.M.; Liebman, J.F. The Amide Linkage: Structural Significance in Chemistry, Biochemistry and Materials Science; Wiley: Hoboken, NJ, USA, 2000.

2. Volkov, A.; Tinnis, F.; Slagbrand, T.; Trillo, P.; Adolfsson, H. Chemoselective reduction of carboxamides. Chem. Soc. Rev. 2016, 45, 6685-6697. [CrossRef]

3. Dub, P.A.; Ikariya, T. Catalytic reductive transformations of carboxylic and carbonic acid derivatives using molecular hydrogen. ACS Catal. 2012, 2, 1718-1741. [CrossRef]

4. Addis, D.; Das, S.; Junge, K.; Beller, M. Selective reduction of carboxylic acid derivatives by catalytic hydrosilylation. Angew. Chemie Int. Ed. 2011, 50, 6004-6011. [CrossRef]

5. Zhang, B.; Li, H.; Ding, Y.; Yan, Y.; An, J. Reduction and reductive deuteration of tertiary amides mediated by sodium dispersions with distinct proton donor-dependent chemoselectivity. J. Org. Chem. 2018, 83, 6006-6014. [CrossRef] [PubMed]

6. Rasu, L.; John, J.M.; Stephenson, E.; Endean, R.; Kalapugama, S.; Clément, R.; Bergens, S.H. Highly enantioselective hydrogenation of amides via dynamic kinetic resolution under low pressure and room temperature. J. Am. Chem. Soc. 2017, 139, 3065-3071. [CrossRef] [PubMed]

7. Tinnis, F.; Volkov, A.; Slagbrand, T.; Adolfsson, H. Chemoselective reduction of tertiary amides under thermal control: formation of either aldehydes or amines. Angew. Chemie Int. Ed. 2016, 55, 4562-4566. [CrossRef] [PubMed] 
8. Mukherjee, D.; Shirase, S.; Mashima, K.; Okuda, J. Chemoselective reduction of tertiary amides to amines catalyzed by triphenylborane. Angew. Chemie Int. Ed. 2016, 55, 13326-13329. [CrossRef]

9. Cabrero-Antonino, J.R.; Alberico, E.; Drexler, H.-J.; Baumann, W.; Junge, K.; Junge, H.; Beller, M. Efficient base-free hydrogenation of amides to alcohols and amines catalyzed by well-defined pincer imidazolyl-ruthenium complexes. ACS Catal. 2016, 6, 47-54. [CrossRef]

10. Szostak, M.; Spain, M.; Eberhart, A.J.; Procter, D.J. Highly chemoselective reduction of amides (primary, secondary, tertiary) to alcohols using $\mathrm{SmI}_{2}$ / amine/ $\mathrm{H}_{2} \mathrm{O}$ under mild conditions. J. Am. Chem. Soc. 2014, 136, 2268-2271. [CrossRef]

11. Das, S.; Wendt, B.; Möller, K.; Junge, K.; Beller, M. Two iron catalysts are better than one: A general and convenient reduction of aromatic and aliphatic primary amides. Angew. Chemie Int. Ed. 2012, 51, 1662-1666. [CrossRef]

12. Hu, F.; Nareddy, P.; Lalancette, R.; Jordan, F.; Szostak, M. $\sigma$ N-C Bond Difunctionalization in Bridged Twisted Amides: Sew-and-Cut Activation Approach to Functionalized Isoquinolines. Org. Lett. 2017, 19, 2386-2389. [CrossRef] [PubMed]

13. Hu, F.; Lalancette, R.; Szostak, M. Structural Characterization of N-Alkylated Twisted Amides: Consequences for Amide Bond Resonance and N-C Cleavage. Angew. Chemie Int. Ed. 2016, 55, 5062-5066. [CrossRef]

14. Lei, Y.; Wrobleski, A.D.; Golden, J.E.; Powell, D.R.; Aubé, J. Facile C-N cleavage in a series of bridged lactams. J. Am. Chem. Soc. 2005, 127, 4552-4553. [CrossRef] [PubMed]

15. Szostak, M.; Spain, M.; Procter, D.J. Uncovering the importance of proton donors in $\mathrm{TmI}_{2}$-promoted electron transfer: facile $\mathrm{C}-\mathrm{N}$ bond cleavage in unactivated amides. Angew. Chemie Int. Ed. 2013, 52, 7237-7241. [CrossRef] [PubMed]

16. Shi, S.; Szostak, M. Synthesis of nitrogen heterocycles using samarium (II) iodide. Molecules 2017, $22,2018$. [CrossRef] [PubMed]

17. Shi, S.; Szostak, R.; Szostak, M. Proton-coupled electron transfer in the reduction of carbonyls using $\mathrm{SmI}_{2}-\mathrm{H}_{2} \mathrm{O}$ : implications for the reductive coupling of acyl-type ketyl radicals with $\mathrm{SmI}_{2}-\mathrm{H}_{2} \mathrm{O}$. Org. Biomol. Chem. 2016, 14, 9151-9157. [CrossRef] [PubMed]

18. Shi, S.; Szostak, M. Aminoketyl radicals in organic synthesis: Stereoselective cyclization of five- and six-membered cyclic imides to 2-azabicycles using $\mathrm{SmI}_{2}-\mathrm{H}_{2} \mathrm{O}$. Org. Lett. 2015, 17, 5144-5147. [CrossRef] [PubMed]

19. Thompson, J.C. Electrons in Liquid Ammonia; Oxford University Press: Oxford, UK, 1976.

20. Thomas, S.J.M.; Edwards, P.P.; Kuznetsov, V.L. Sir Humphry Davy: boundless Chemist, physicist, poet and man of action. Chem. Phys. Chem. 2008, 9, 59-66. [CrossRef]

21. Rabideau, P.W.; Marcinow, Z. The Birch reduction of aromatic compounds. In Organic Reactions; John Wiley \& Sons, Inc.: Hoboken, NJ, USA, 1992; pp. 1-334.

22. Zimmerman, H.E. A mechanistic analysis of the Birch reduction. Acc. Chem. Res. 2012, 45, 164-170. [CrossRef]

23. Cossy, J.; Gille, B.; Bellosta, V. Facile synthesis of spirocyclic systems through the intramolecular addition of ketyl radicals via the sodium/ammonia reduction of $\delta, \varepsilon$-unsaturated carboxylic esters. J. Org. Chem. 1998, 63, 3141-3146. [CrossRef]

24. Dye, J.L. Electrons as anions. Science 2003, 301, 607-608. [CrossRef] [PubMed]

25. Dye, J.L. Electrides: ionic salts with electrons as the anions. Science 1990, 247, 663-668. [CrossRef] [PubMed]

26. Dye, J.L. Compounds of alkali metal snions. Angew. Chemie Int. Ed. English 1979, 18, 587-598. [CrossRef]

27. Jedliński, Z. Novel electron-transfer reactions mediated by alkali metals complexed by macrocyclic ligand. Acc. Chem. Res. 1998, 31, 55-61. [CrossRef]

28. Lei, P.; Ding, Y.; Zhang, X.; Adijiang, A.; Li, H.; Ling, Y.; An, J. A practical and chemoselective ammonia-free Birch reduction. Org. Lett. 2018, 20, 3439-3442. [CrossRef] [PubMed]

29. Ding, Y.; Luo, S.; Adijiang, A.; Zhao, H.; An, J. Reductive deuteration of nitriles: the synthesis of $\alpha, \alpha$-dideuterio amines by sodium mediated electron transfer reactions. J. Org. Chem. 2018, 83, 12269-12274. [CrossRef] [PubMed]

30. Han, M.; Ding, Y.; Yan, Y.; Li, H.; Luo, S.; Adijiang, A.; Ling, Y.; An, J. Transition-metal-free, selective reductive deuteration of terminal alkynes with sodium dispersions and EtOD- $d_{1}$. Org. Lett. 2018, 20, 3010-3013. [CrossRef] 
31. Li, H.; Zhang, B.; Dong, Y.; Liu, T.; Zhang, Y.; Nie, H.; Yang, R.; Ma, X.; Ling, Y.; An, J. A selective and cost-effective method for the reductive deuteration of activated alkenes. Tetrahedron Lett. 2017, 58, 2757-2760. [CrossRef]

32. Han, M.; Ma, X.; Yao, S.; Ding, Y.; Yan, Z.; Adijiang, A.; Wu, Y.; Li, H.; Zhang, Y.; Lei, P.; et al. Development of a modified Bouveault-Blanc reduction for the selective synthesis of $\alpha, \alpha$-dideuterio alcohols. J. Org. Chem. 2017, 82, 1285-1290. [CrossRef]

33. Liu, C.; Achtenhagen, M.; Szostak, M. Chemoselective ketone synthesis by the addition of organometallics to N-Acylazetidines. Org. Lett. 2016, 18, 2375-2378. [CrossRef]

34. Štefane, B.; Polanc, S. hydrogenation of $\mathrm{BF}_{2}$ complexes with 1,3-dicarbonyl ligands. Tetrahedron 2009, 65, 2339-2343. [CrossRef]

35. Ignatenko, V.A.; Deligonul, N.; Viswanathan, R. Branch-Selective Synthesis of Oxindole and Indene Scaffolds: Transition Metal-Controlled Intramolecular Aryl Amidation Leading to C3 Reverse-Prenylated Oxindoles. Org. Lett. 2010, 12, 3594-3597. [CrossRef] [PubMed]

36. Gajda, T.; Zwierzak, A. Phase-transfer-catalysed N-alkylation of carboxamides and sulfonamides. Synthesis 1981, 1981, 1005-1008. [CrossRef]

Sample Availability: Samples of the compounds are not available from the authors

(C) 2019 by the authors. Licensee MDPI, Basel, Switzerland. This article is an open access article distributed under the terms and conditions of the Creative Commons Attribution (CC BY) license (http:/ / creativecommons.org/licenses/by/4.0/). 
Article

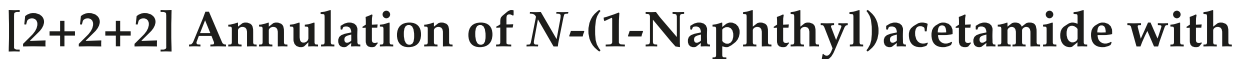 Two Alkynoates via Cleavage of Adjacent $\mathrm{C}-\mathrm{H}$ and C-N Bonds Catalyzed by an Electron-Deficient Rhodium(III) Complex
}

\author{
Jyunichi Terasawa, Yu Shibata *, Miho Fukui and Ken Tanaka * \\ Department of Chemical Science and Engineering, Tokyo Institute of Technology, O-okayama, Meguro-ku, \\ Tokyo 152-8550, Japan; terasawa.j.aa@m.titech.ac.jp (J.T.); mfv1.1.174@gmail.com (M.F.) \\ * Correspondence: yshibata@apc.titech.ac.jp (Y.S.); ktanaka@apc.titech.ac.jp (K.T.); \\ Tel.: +81-3-5734-3631 (Y.S.); +81-3-5734-2120 (K.T.)
}

Academic Editor: Michal Szostak

Received: 21 November 2018; Accepted: 12 December 2018; Published: 14 December 2018

\begin{abstract}
It has been established that an electron-deficient cationic $\mathrm{Cp}^{\mathrm{E}}$-rhodium(III) complex catalyzes the non-oxidative [2+2+2] annulation of $N$-(1-naphthyl)acetamide with two alkynoates via cleavage of the adjacent $\mathrm{C}-\mathrm{H}$ and $\mathrm{C}-\mathrm{N}$ bonds to give densely substituted phenanthrenes under mild conditions (at $40{ }^{\circ} \mathrm{C}$ under air). In this reaction, a dearomatized spiro compound was isolated, which may support the formation of a cationic spiro rhodacycle intermediate in the catalytic cycle. The use of $\mathrm{N}$-(1-naphthyl)acetamide in place of acetanilide switched the reaction pathway from the oxidative $[2+2+2]$ annulation-lactamization via $\mathrm{C}-\mathrm{H} / \mathrm{C}-\mathrm{H}$ cleavage to the non-oxidative $[2+2+2]$ annulation via $\mathrm{C}-\mathrm{H} / \mathrm{C}-\mathrm{N}$ cleavage. This chemoselectivity switch may arise from stabilization of the carbocation in the above cationic spiro rhodacycle by the neighboring phenyl and acetylamino groups, resulting in the nucleophilic $\mathrm{C}-\mathrm{C}$ bond formation followed by $\beta$-nitrogen elimination.
\end{abstract}

Keywords: alkynes; $\mathrm{C}-\mathrm{H}$ bond cleavage; $\mathrm{C}-\mathrm{N}$ bond cleavage; cyclopentadienyl complexes; $\mathrm{N}$-(1-naphthyl)acetamide; rhodium; [2+2+2] annulation

\section{Introduction}

The transition-metal-catalyzed [2+2+2] annulation of three unsaturated compounds is a useful method for the synthesis of six-membered carbocycles and heterocycles [1-9]. For example, the transition-metal-catalyzed $[2+2+2]$ annulation of three alkynes is able to afford densely substituted benzenes with an atom- and step-economical manner [10-14]. For the synthesis of naphthalene derivatives, benzynes have been employed as one of the three alkynes but the use of the benzynes suffers from the redundant precursor synthesis and harsh reaction conditions [15-17]. Alternatively, several examples of the transition-metal-catalyzed oxidative $[2+2+2]$ annulation via cleavage of adjacent two $\mathrm{C}-\mathrm{H}$ bonds of benzenes, in which formally dehydrogenated benzenes are employed as benzyne equivalents, have been reported [18-22]. As such, our research group reported that an electron-deficient cationic $\mathrm{Cp}^{\mathrm{E}}$-rhodium(III) complex, derived from 1 , catalyzes the oxidative tandem [2+2+2] annulation-lactamization of acetanilide (2a) with two alkynoates 3 via cleavage of adjacent two $\mathrm{C}-\mathrm{H}$ bonds at room temperature under air to give densely substituted banzo[cd]indolones 4 a (Scheme 1, top) [23]. In this catalysis, not only acetanilide (2a) but also ortho-substituted acetanilide $\mathbf{2} \mathbf{b}$ was able to react with two alkynoates $\mathbf{3}$ to give the corresponding banzo[cd]indolones $\mathbf{4 b}$ after treatment with $\mathrm{KOH}$ in ethanol (Scheme 1, top) [23]. In this paper, we have established that the electron-deficient cationic $\mathrm{Cp}^{\mathrm{E}}$-rhodium(III) complex is able to catalyze the non-oxidative [2+2+2] annulation of $\mathrm{N}$-(1-naphthyl)acetamide (2c) with two alkynoates 3 via cleavage of the adjacent $\mathrm{C}-\mathrm{H}$ and $\mathrm{C}-\mathrm{N}$ bonds, leading to densely substituted phenanthrenes 5 , under mild conditions 
(at $40{ }^{\circ} \mathrm{C}$ under air) (Scheme 1, middle). Although several examples of the transition-metal-catalyzed decarboxylative and oxidative $[2+2+2]$ annulation of benzoic acids with two alkynoates via cleavage of the adjacent $\mathrm{C}-\mathrm{H}$ and $\mathrm{C}-\mathrm{C}$ bonds, leading to densely substituted naphthalenes, have been reported [24-27], only a single example of the non-oxidative $[2+2+2]$ annulation via cleavage of the adjacent $\mathrm{C}-\mathrm{H}$ and $\mathrm{C}-\mathrm{N}$ bonds, in which the acylamino moiety is employed as a traceless directing group, has been reported in the neutral C $\mathrm{p}^{*}$-rhodium(III) complex-catalyzed synthesis of tetraarylnaphthalenes from $N$-acylanilines and two diarylacetylenes at elevated temperature $\left(110^{\circ} \mathrm{C}\right)$ (Scheme 1, bottom) [28].

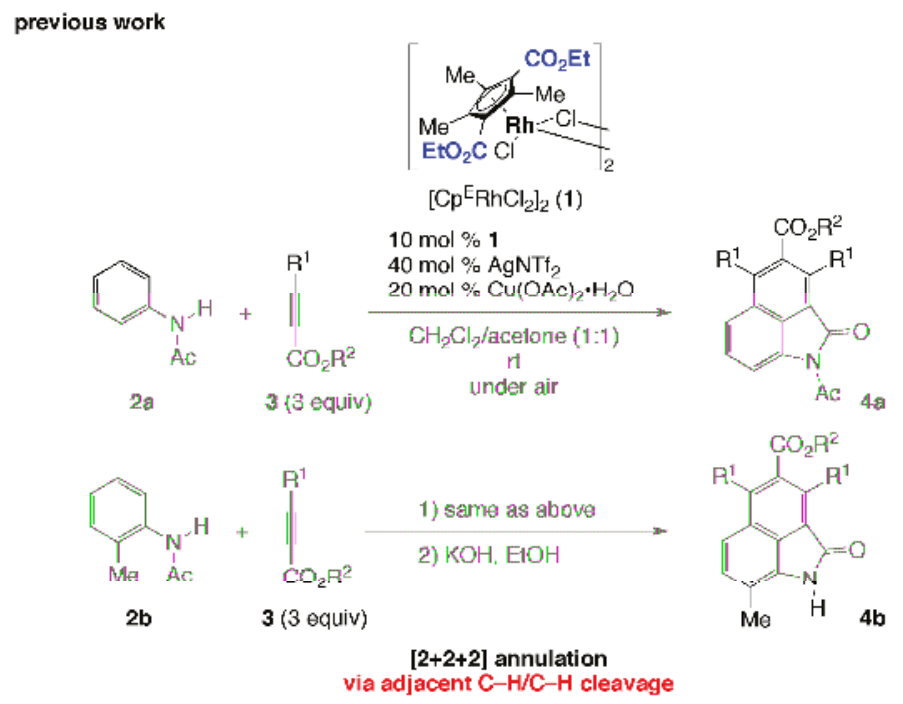

this work

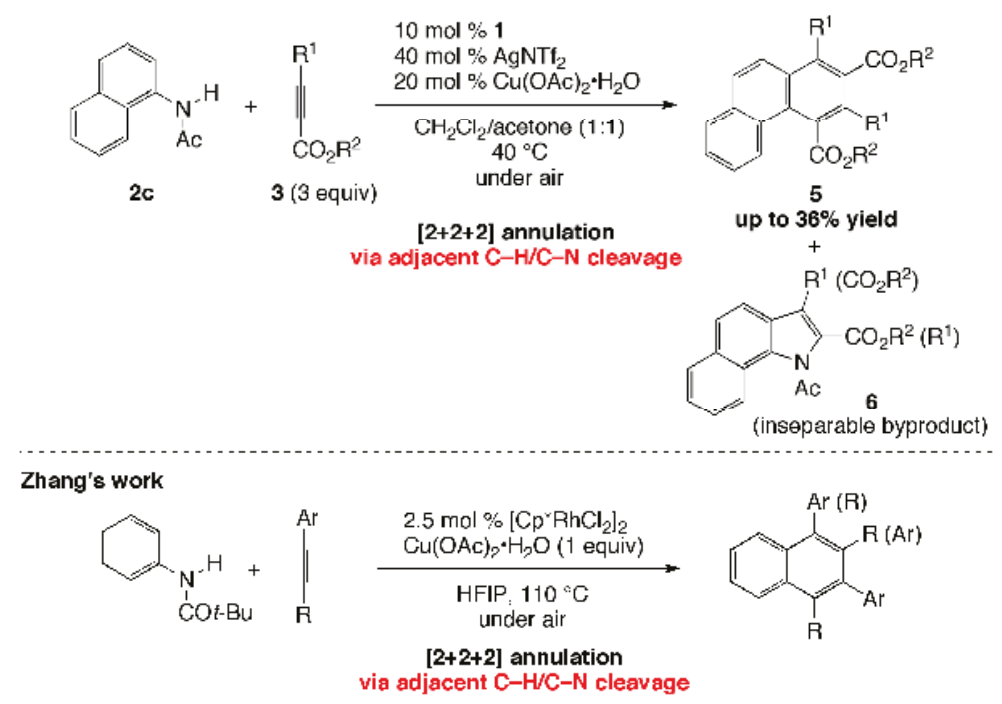

Scheme 1. Cationic $C \mathrm{p}^{\mathrm{E}}$-rhodium(III) complex-catalyzed [2+2+2] annulations of acetanilides $\mathbf{2 a} / \mathbf{2 b}$ and $\mathrm{N}$-(1-naphthyl)acetamide (2c) with two alkynoates 3 via cleavage of adjacent $\mathrm{C}-\mathrm{H} / \mathrm{C}-\mathrm{H}$ and $\mathrm{C}-\mathrm{H} / \mathrm{C}-\mathrm{N}$ bonds, respectively. 


\section{Results}

In the course of our study of the cationic $\mathrm{Cp}^{\mathrm{E}}$-rhodium(III) complex-catalyzed oxidative tandem $[2+2+2]$ annulation-lactamization of acetanilides with two alkynoates, leading to banzo[cd]indolones, the reaction of 2-methyl acetanilide $\mathbf{2} \mathbf{b}$ and ethyl 2-butynoates (3a) was examined. As already shown in Scheme 1, the expected banzo[ $c d$ ] indolones $\mathbf{4 b}$ were generated after treatment with $\mathrm{KOH}$ in ethanol [23]. Surprisingly, the use of $N$-(1-naphthyl)acetamide (2c) in place of $\mathbf{2} \mathbf{b}$ failed to afford the expected naphtho[cd]indolone $4 \mathbf{c a}$. Instead, densely substituted phenanthrene $5 \mathrm{ca}$ was generated as a major product along with a mixture of the corresponding regioisomeric [3+2] annulation products $6 \mathbf{c a} / 6 \mathbf{c a}{ }^{\prime}$ (Scheme 2). In addition to the above products, unidentified oligomerization products derived from $2 \mathrm{c}$ and $3 \mathbf{a}$ were generated as by-products.<smiles>CC#CC(=O)OCC</smiles>

2c

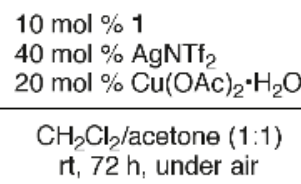<smiles>CCOC(=O)c1c(C)c(C(=O)OCC)c2c(ccc3ccccc32)c1C</smiles>

5 ca $/ 26 \%$<smiles>CCOC(=O)c1c(C)c2ccc3ccccc3c2n1C(C)C</smiles><smiles></smiles>

Scheme 2. Cationic $\mathrm{Cp}^{\mathrm{E}}$-rhodium(III) complex-catalyzed non-oxidative $[2+2+2]$ annulation of $N$-(1-naphthyl)acetamide (2c) with two ethyl 2-butynoates (3a).

Then the screening of the reaction conditions and the acyl groups on the nitrogen of 1-aminonaphthalene was conducted as shown in Table 1. Elevating the reaction temperature $\left(40{ }^{\circ} \mathrm{C}\right)$ slightly increased the yields of $5 \mathbf{c a}$ and $\mathbf{6 c a} / \mathbf{6 c a}$ (entry 2). Increasing the amount of 3a increased the yield of $5 \mathbf{c a}$ and decreased that of $\mathbf{6 c a} / \mathbf{6 c a} \mathbf{c}^{\prime}$ (entry 3). However, this increase was very small, therefore, the conditions of entry 2 were selected as the best conditions. With respect to the acyl groups on the nitrogen of the 1-aminonaphthalene moiety, electron-poor $N$-(1-naphthyl)amide 2d, possessing the highly acidic amide proton, was tested in place of $\mathbf{2} \mathbf{c}$, while no reaction was observed even at $80^{\circ} \mathrm{C}$ (entry 4). Sterically demanding $N$-(1-naphthyl)amide $2 \mathbf{e}$ was also tested with expectation for acceleration of reductive elimination. Unfortunately, the use of 2 e significantly increased the yield of not the [2+2+2] annulation product 5ea but the [3+2] annulation products 6ea/6ea' (entry 5). Finally, the reaction was conducted using the $\mathrm{Cp}^{*}$-rhodium(III) complex instead of the $\mathrm{Cp}^{\mathrm{E}}$-rhodium(III) complex 1, which resulted in significant decrease of the yields of $5 \mathrm{ca}$ and $6 \mathrm{ca} / 6 \mathrm{ca}^{\prime}$ (entry 6 ). 
Table 1. Optimization of reaction conditions for rhodium (III)-catalyzed $[2+2+2]$ annulation of $N$-(1-naphthyl)amides 2 with two ethyl 2-butynoates (3a) ${ }^{a}$.

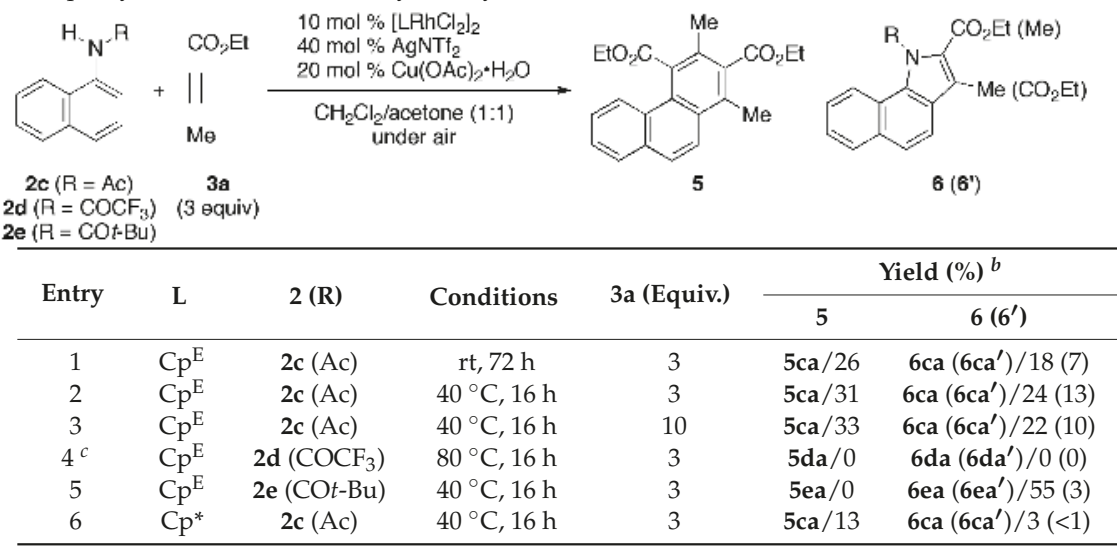

${ }^{a}\left[\mathrm{Rh}_{2}\right](0.020 \mathrm{mmol}), \mathrm{AgNTf}_{2}(0.080 \mathrm{mmol}), \mathrm{Cu}(\mathrm{OAc})_{2} \cdot \mathrm{H}_{2} \mathrm{O}(0.040 \mathrm{mmol}), 2(0.200 \mathrm{mmol}), 3 \mathrm{a}(0.60-2.00 \mathrm{mmol})$, $\mathrm{CH}_{2} \mathrm{Cl}_{2}(1.0 \mathrm{~mL})$ and acetone $(1.0 \mathrm{~mL})$ were used. ${ }^{b}$ Determined by ${ }^{1} \mathrm{H}$ NMR yield using $\mathrm{C}_{6} \mathrm{Me}_{6}$ as an internal standard. ${ }^{c}\left(\mathrm{CH}_{2} \mathrm{Cl}\right)_{2}(2.0 \mathrm{~mL})$ was used.

The scope of the present cationic $\mathrm{CP}^{\mathrm{E}}$-rhodium(III) complex-catalyzed [2+2+2] annulation is shown in Table 2. As with our previously reported cationic $\mathrm{Cp}^{\mathrm{E}}$-rhodium(III) complex-catalyzed oxidative tandem [2+2+2] annulation-lactamization of acetanilides with two alkynoates, leading to banzo[cd]indolones, a wide variety of primary alkyl-substituted alkynoates 3a-e reacted with $N$-(1-naphthyl)acetamide (2c) to give the corresponding [2+2+2] annulation products 5 ca-ce (entries $1-5)$. However, phenyl-substituted alkynoate $3 \mathrm{f}$ failed to afford the corresponding $[2+2+2]$ annulation product $5 \mathrm{cf}$ and gave the corresponding [3+2] annulation product $6 \mathbf{c f}^{\prime}$ in good yield with perfect regioselectivity (entry 6). This product switch is also the same as our previously reported tandem [2+2+2] annulation-lactamization of acetanilide (2a) with 3f [23]. Unfortunately, the use electron-deficient alkynes did not afford the corresponding annulation products at all. For example, the use of ethyl propiolate afforded a complex mixture of products and no reaction was observed when using ethyl 2-butynoate. The structure and regiochemistry of the [2+2+2] annulation product 5ce were unambiguously determined by the X-ray crystallographic analysis as shown in Figure 1.

Table 2. Scope of alkynoates 3 on rhodium(III)-catalyzed [2+2+2] annulation with $N$-(1-naphthyl)acetamide (2c) ${ }^{a}$.
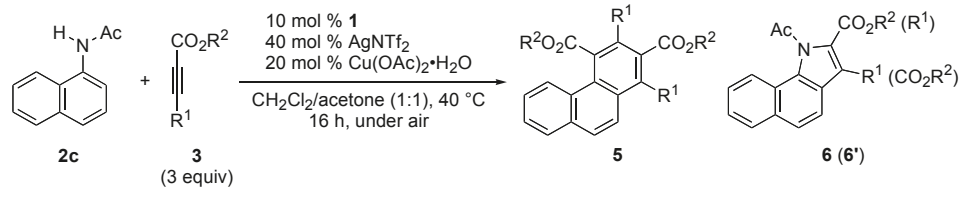

\begin{tabular}{|c|c|c|c|c|c|}
\hline \multirow{2}{*}{ Entry } & \multirow{2}{*}{3} & \multirow{2}{*}{$\mathbf{R}^{1}$} & \multirow{2}{*}{$\mathbf{R}^{2}$} & \multicolumn{2}{|c|}{ Yield (\%) ${ }^{b}$} \\
\hline & & & & 5 & $6\left(6^{\prime}\right)$ \\
\hline 1 & $3 a$ & $\mathrm{Me}$ & Et & $5 \mathrm{ca} / 33$ & $\mathbf{6 c a}\left(\mathbf{6 c a ^ { \prime }}\right) / 22(10)$ \\
\hline 2 & $3 b$ & $\mathrm{Me}$ & $\mathrm{Me}$ & $5 \mathrm{cb} / 30$ & $6 \mathrm{cb}\left(6 \mathbf{b b}^{\prime}\right) / 22(8)$ \\
\hline 3 & $3 c$ & $n$-Bu & Et & $5 \mathrm{cc} / 32$ & $6 \mathrm{cc}\left(6 \mathrm{cc}^{\prime}\right) / 37(7)$ \\
\hline 4 & $3 d$ & $\mathrm{Ph}\left(\mathrm{CH}_{2}\right)_{3}$ & $\mathrm{Me}$ & $5 \mathrm{~cd} / 35$ & $6 \mathrm{~cd}\left(6 \mathrm{~cd} \mathbf{c}^{\prime}\right) / 38(5)$ \\
\hline 5 & $3 e$ & $\mathrm{Cl}\left(\mathrm{CH}_{2}\right)_{3}$ & $\mathrm{Me}$ & 5 ce $/ 36$ & $6 c e\left(6 c e^{\prime}\right) / 31(5)$ \\
\hline 6 & $3 \mathrm{f}$ & $\mathrm{Ph}$ & Et & $5 \mathrm{cf} / 0$ & $6 \mathrm{cf}\left(6 \mathrm{cf}^{\prime}\right) / 0(69)$ \\
\hline
\end{tabular}

${ }^{a} 1(0.020 \mathrm{mmol}), \mathrm{AgNTf}_{2}(0.080 \mathrm{mmol}), \mathrm{Cu}(\mathrm{OAc})_{2} \cdot \mathrm{H}_{2} \mathrm{O}(0.040 \mathrm{mmol}), \mathbf{2 c}(0.200 \mathrm{mmol}), 3(0.600 \mathrm{mmol}), \mathrm{CH}_{2} \mathrm{Cl}_{2}$ $(1.0 \mathrm{~mL})$ and acetone $(1.0 \mathrm{~mL})$ were used. ${ }^{b}$ Determined by ${ }^{1} \mathrm{H}$ NMR yield using $\mathrm{C}_{6} \mathrm{Me}_{6}$ as an internal standard. 


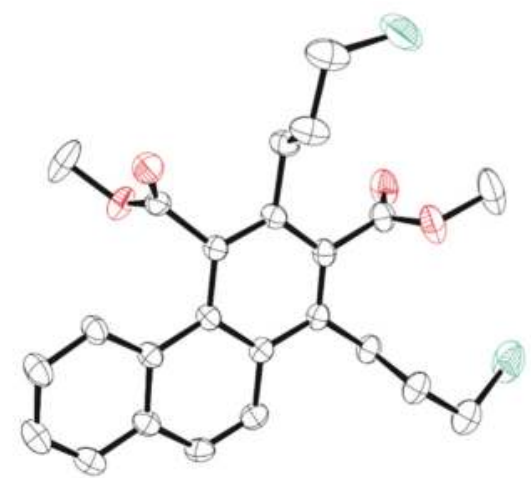

Figure 1. ORTEP diagram of 5ce with ellipsoids at 50\% probability. All hydrogen and disordered atoms are omitted for clarity.

Importantly, an interesting by-product was generated in the reaction of $2 \mathbf{c}$ and $3 \mathbf{a}$ as shown in Scheme 3 . When using 3 equiv of $3 a$, a very small amount of dearomatized spiro compound $7 \mathrm{ca}$ was detected in the crude reaction mixture ( $3 \%$ yield). An isolable amount (13\% yield) of $7 \mathrm{ca}$ was generated when using an excess amount of $\mathbf{3 a}$.

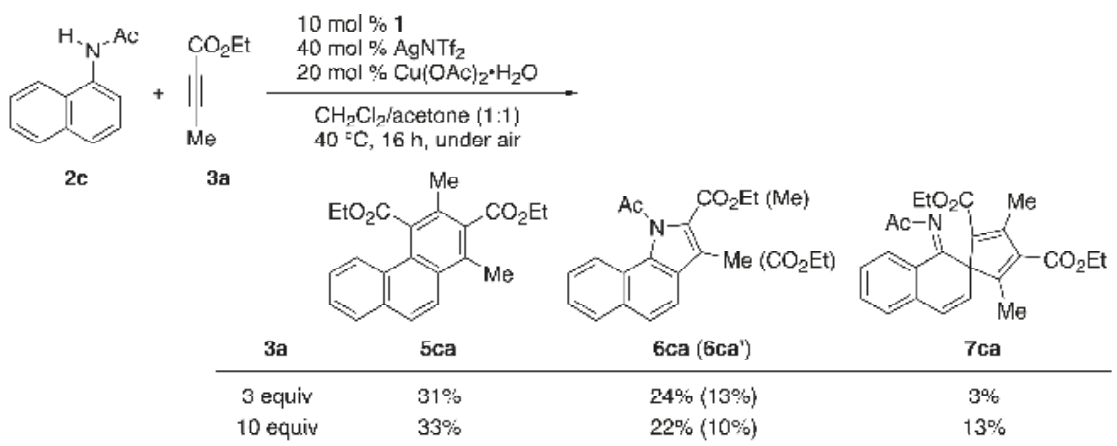

Scheme 3. Formation of dearomatized spiro compound $7 \mathrm{ca}$. The yields were determined by ${ }^{1} \mathrm{H}$ NMR yield using $\mathrm{C}_{6} \mathrm{Me}_{6}$ as an internal standard.

Plausible mechanisms for the formation of $5 \mathrm{ca}, 6 \mathrm{ca}$ and $7 \mathrm{ca}$ from $2 \mathrm{c}$ and $3 \mathrm{a}$ are shown in Scheme 4. First, $\mathrm{C}-\mathrm{H}$ bond cleavage of $\mathbf{2} \mathbf{c}$ by $\mathrm{Cp}^{\mathrm{E}}$-rhodium(III) species $\mathbf{A}$ affords naphthylrhodium B. Next, insertion of 3a into B gives alkenylrhodium C. The subsequent insertion of $3 \mathbf{a}$ into $\mathbf{C}$ gives dienylrhodium $\mathbf{D}$. The second alkyne insertion may not proceed in the case of sterically demanding phenyl-substituted alkynoate $3 \mathbf{f}$, thus generating [3+2] annulation product $\mathbf{6} \mathrm{cf}^{\prime}$ (Table 2, entry 6). Electrophilic metalation of the electron-rich 1-aminonaphthalene ring produces cationic spiro rhodacycle $\mathbf{E}$, in which the carbocation is stabilized by the neighboring phenyl and acetylamino groups. Nucleophilic attack of the dienylrhodium moiety to the electrophilic 1-position of the 1 -aminonaphthalene ring gives $\pi$-pentadienyl complex F [29]. Importantly, nucleophilic attack of the dienylrhodium moiety to the 3-position of the 1-aminonaphthalene ring in spiro rhodacycle $\mathbf{E}^{\prime}$, leading to $\pi$-pentadienyl complex $\mathbf{F}^{\prime}$, would be unfavorable due to the unstable dearomatized quinodimethane structures in $\mathbf{E}^{\prime}$ and $\mathbf{F}^{\prime}$. $\beta$-Nitrogen elimination [30,31] from intermediate $\mathbf{F}$ affords $5 \mathrm{ca}$ and the catalytically active rhodium(III) species A. However, the copper(II) co-catalyst was necessary in order to reoxidize rhodium(I) species generated through the competing oxidative $[3+2]$ annulation giving $\mathbf{6 c a}$. In this reaction, dearomatized spiro compound $7 \mathrm{ca}$ was isolated as a 
by-product. This compound may be generated by reductive elimination and deprotonation from spiro rhodacycle $\mathbf{E}$. Increasing the amount of $3 \mathbf{a}$ may facilitate the reductive elimination, which increased the yield of $7 \mathrm{ca}$. This result may support the intermediacy of spiro rhodacycle $\mathrm{E}$ in the catalytic cycle. Interestingly, the regioselectivity of both the present $\mathrm{Cp}^{\mathrm{E}}$-rhodium(III)-catalyzed $[2+2+2]$ and $[3+2]$ annulations of $N-(1$-naphthyl)acetamide (2c) is opposite to that of our previously reported $\mathrm{Cp}^{\mathrm{E}}$-rhodium(III)-catalyzed [2+2+2] and [3+2] annulations of acetanilides that proceed presumably via alkenylrhodium $\mathrm{G}$ [23], although the reason is not clear at the present stage.

We considered that it is possible to regenerate spiro rhodacycle $\mathbf{E}$ by oxidative addition with a neutral rhodium(I) complex and protonation of $7 \mathrm{ca}$. Therefore, $7 \mathrm{ca}$ was treated with acetic acid and an in situ generated neutral $\mathrm{Cp}^{\mathrm{E}}$-rhodium(I) complex, prepared by the reaction of $\mathbf{1}, \mathrm{AgNTf}_{2}, \mathrm{NaOAc}^{2} \mathbf{2 a}$ and 3a. However, no reaction was observed, thus excluding the intermediacy of $7 \mathrm{ca}$ in the catalytic cycle (Scheme 5).

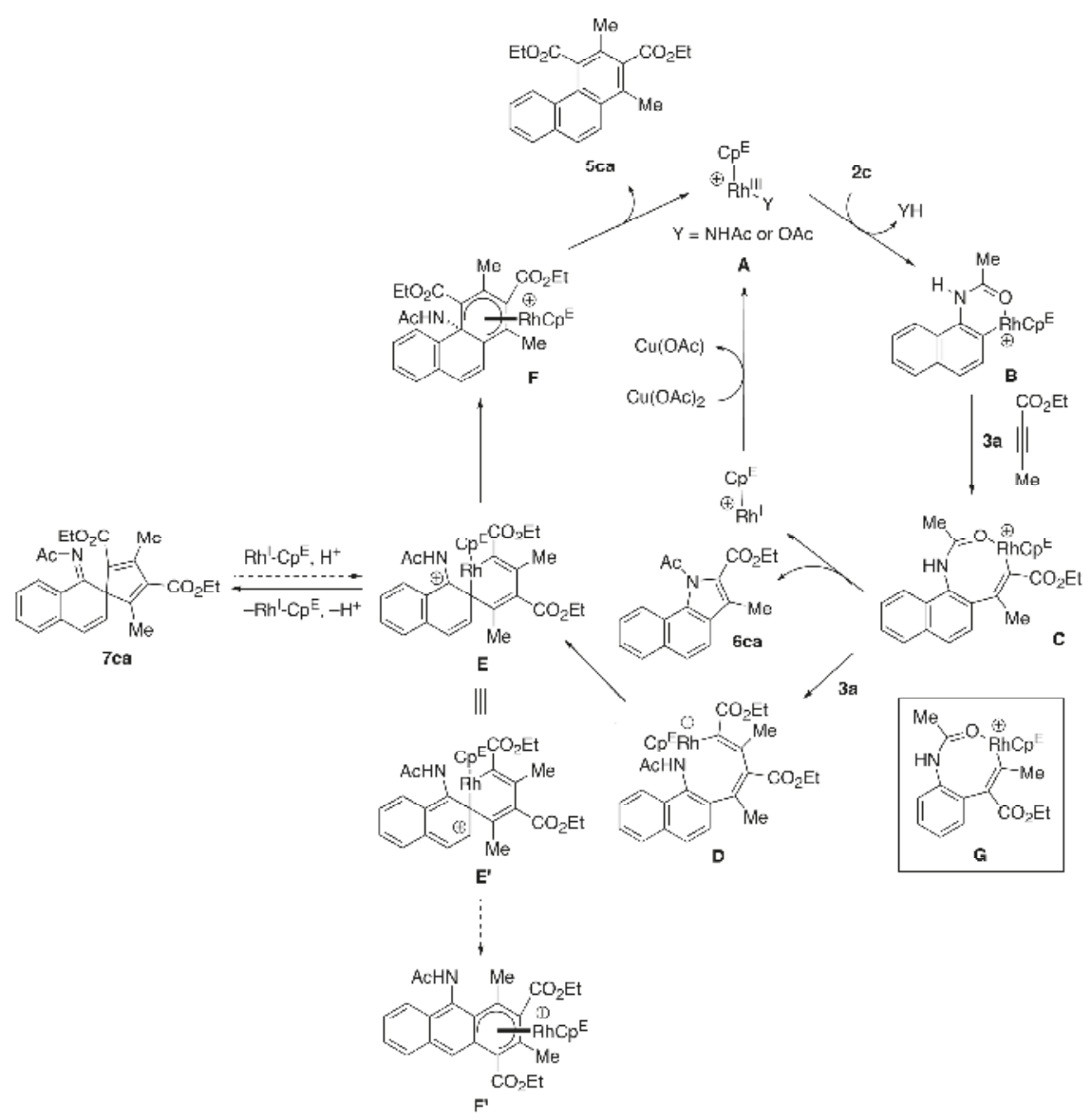

Scheme 4. Plausible mechanisms for formation of $5 \mathrm{ca}, 6 \mathrm{ca}$ and $7 \mathrm{ca}$ from $2 \mathrm{c}$ and $3 \mathrm{a}$. 


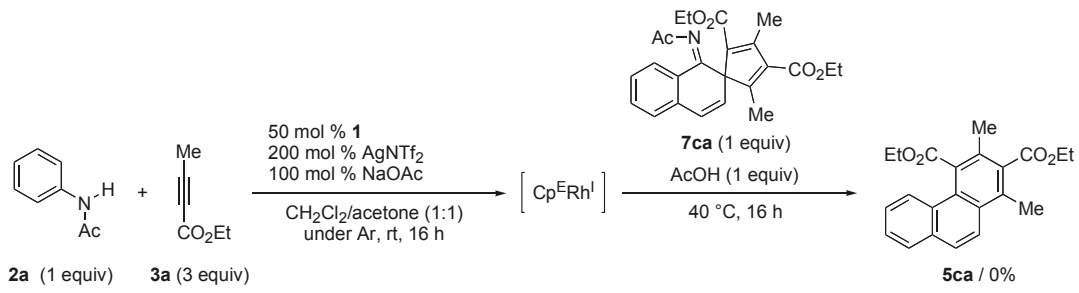

Scheme 5. Reaction of $7 \mathrm{ca}$ with an in situ generated $\mathrm{Cp}^{\mathrm{E}}$-rhodium(III) complex and acetic acid.

\section{Materials and Methods}

\subsection{General Information}

Anhydrous acetone (No. 27,072-5) and $\mathrm{CH}_{2} \mathrm{Cl}_{2}$ (No. 130-02457) were obtained from Aldrich (St. Louis, MO, USA) and Wako (Osaka, Japan) and used as received. Solvents for the synthesis of substrates were dried over Molecular Sieves $4 \AA$ (Wako) prior to use. Anilides 2d [32] and 2e [33] were prepared according to the literature. Internal alkynes $\mathbf{3 d}$ [34] and 3e [35] were prepared according to the literature. All other reagents were obtained from commercial sources and used as received. ${ }^{1} \mathrm{H}$ and ${ }^{13} \mathrm{C}$ data were collected on a Bruker AVANCE III (Billerica, MA, USA) HD 400 (400 MHz) at ambient temperature. HRMS data were obtained on a Bruker micro TOF Focus II (Billerica, MA, USA). A single crystal X-ray diffraction measurement was made on Rigaku XtaLAB mini II diffractometer (Akishima, Japan) using graphite monochromated Mo-K $\alpha$ radiation. All reactions were carried out in oven-dried glassware with magnetic stirring.

3.2. General Procedure for the Rhodium-Catalyzed Annulation of N-(1-Naphthyl)amides with Two Alkynoates $\left(5 c a, 6 c a\right.$ and $6 c^{\prime}$; Table 1 , entry 2)

To a Schlenk tube was added $\mathrm{AgNTf}_{2}(15.5 \mathrm{mg}, 0.040 \mathrm{mmol}),\left[\mathrm{Cp}^{\mathrm{E}} \mathrm{RhCl}_{2}\right]_{2} \mathbf{1}(8.5 \mathrm{mg}, 0.010 \mathrm{mmol})$, $\mathrm{Cu}(\mathrm{OAc})_{2} \cdot \mathrm{H}_{2} \mathrm{O}(4.0 \mathrm{mg}, 0.020 \mathrm{mmol}), \mathrm{N}$-(naphthalen-1-yl)acetamide (2c, $\left.18.5 \mathrm{mg}, 0.100 \mathrm{mmol}\right)$, ethyl 2-butynoate (3a, $33.6 \mathrm{mg}, 0.300 \mathrm{mmol})$, acetone $(0.5 \mathrm{~mL})$ and $\mathrm{CH}_{2} \mathrm{Cl}_{2}(0.5 \mathrm{~mL})$ under air in this order. The mixture was sealed and stirred at $40^{\circ} \mathrm{C}$ under air for 16 hours. The resulting mixture was diluted with ether, filtered through a silica gel pad and washed with ether. The solvent was removed under reduced pressure and the residue was purified by a preparative thin layer chromatography (TLC, hexane $/ \mathrm{AcOEt}=2: 1)$, to give a mixture of $5 \mathbf{c a}, \mathbf{6 c a}$ and $6 \mathbf{c a}^{\prime}$. The yields of $5 \mathbf{c a}(31 \%), 6 \mathrm{ca}(22 \%)$ and $\mathbf{6 c a}^{\prime}(10 \%)$ were determined by ${ }^{1} \mathrm{H}$ NMR with hexamethylbenzene as an internal standard.

\subsection{Product Characterization}

Diethyl 1,3-dimethylphenanthrene-2,4-dicarboxylate (5ca). Analytically pure 5ca was isolated from a mixture of $5 \mathbf{c a}, \mathbf{6 c a}$ and $\mathbf{6} \mathbf{c a}^{\prime}\left(21.8 \mathrm{mg}, 5 \mathbf{c a} / \mathbf{6 c a} / \mathbf{6 c a} \mathbf{c}^{\prime}=45: 41: 14\right)$ by a gel permeation chromatography (GPC). The regiochemistry of the title compound was determined by the NOESY experiment as well as analogy to the ${ }^{1} \mathrm{H}$ NMR chemical shifts of $5 \mathrm{ce}$. Colorless solid, $7.2 \mathrm{mg}, 0.0205 \mathrm{mmol}, 21 \%$ isolated yield, mp 83.8-85.0 ${ }^{\circ} \mathrm{C} ;{ }^{1} \mathrm{H}$ NMR $\left(\mathrm{CDCl}_{3}, 400 \mathrm{MHz}\right) \delta 8.44(\mathrm{~d}, J=8.4 \mathrm{~Hz}, 1 \mathrm{H}), 7.95(\mathrm{~d}, J=9.2 \mathrm{~Hz}, 1 \mathrm{H})$, $7.92-7.87(\mathrm{~m}, 1 \mathrm{H}), 7.79(\mathrm{~d}, J=9.2 \mathrm{~Hz}, 1 \mathrm{H}), 7.63-7.51(\mathrm{~m}, 2 \mathrm{H}), 4.57-7.44(\mathrm{~m}, 4 \mathrm{H}), 2.70(\mathrm{~s}, 3 \mathrm{H}), 2.47(\mathrm{~s}, 3 \mathrm{H})$, $1.95(\mathrm{~s}, 3 \mathrm{H}), 1.44(\mathrm{t}, J=7.1 \mathrm{~Hz}, 3 \mathrm{H}), 1.35(\mathrm{t}, J=7.2 \mathrm{~Hz}, 3 \mathrm{H}) ;{ }^{13} \mathrm{C} \mathrm{NMR}\left(\mathrm{CDCl}_{3}, 100 \mathrm{MHz}\right) \delta 172.0,170.0$, $134.1,133.0,132.3,129.8,129.6,129.5,129.1,128.7,127.8,127.5,127.0,126.3,125.6,122.4,61.8,61.4,17.4$, 17.2, 14.3, 13.9; HRMS (ESI) calcd for $\mathrm{C}_{22} \mathrm{H}_{22} \mathrm{O}_{4} \mathrm{Na}[\mathrm{M}+\mathrm{Na}]^{+} 373.1414$, found 373.1410 .

Ethyl 1-acetyl-3-methyl-1H-benzo[g]indole-2-carboxylate (6ca) and ethyl 1-acetyl-2-methyl-1Hbenzo[g]indole-3-carboxylate (6ca') [36]. An analytically pure mixture of $\mathbf{6 c a}$ and $\mathbf{6} \mathbf{c a}^{\prime}$ was isolated from a mixture of $5 \mathbf{c a}, \mathbf{6 c a}$ and $\mathbf{6} \mathbf{c a}^{\prime}\left(21.8 \mathrm{mg}, \mathbf{5 c a} / \mathbf{6 c a} / \mathbf{6 c a}{ }^{\prime}=45: 41: 14\right)$ by GPC. The regiochemistry of the title compounds was determined by comparison with the ${ }^{1} \mathrm{H}$ NMR chemical shifts of the literature. 
Colorless solid, $7.6 \mathrm{mg}, 0.0257 \mathrm{mmol}, 26 \%$ isolated yield, $6 \mathbf{c a} / 6 \mathbf{c a}^{\prime}=75: 25, \mathrm{mp} 86.1-87.2{ }^{\circ} \mathrm{C} ;{ }^{1} \mathrm{H}$ $\operatorname{NMR}\left(\mathrm{CDCl}_{3}, 400 \mathrm{MHz}\right) \delta$ 6ca: 8.17-8.11 (m, 1H), 7.96-7.90 (m, 1H), $7.67(\mathrm{~d}, J=8.7 \mathrm{~Hz}, 1 \mathrm{H}), 7.59$ $(\mathrm{d}, J=8.7 \mathrm{~Hz}, 1 \mathrm{H}), 7.55-7.48(\mathrm{~m}, 2 \mathrm{H}), 4.43(\mathrm{q}, J=7.1 \mathrm{~Hz}, 2 \mathrm{H}), 2.76(\mathrm{~s}, 3 \mathrm{H}), 2.65(\mathrm{~s}, 3 \mathrm{H}), 2.04(\mathrm{~s}, 3 \mathrm{H})$, $1.45(\mathrm{t}, J=7.1 \mathrm{~Hz}, 3 \mathrm{H}) ; 6 \mathrm{ca}^{\prime}: 8.28(\mathrm{~d}, J=8.7 \mathrm{~Hz}, 1 \mathrm{H}), 7.97(\mathrm{~d}, J=7.9 \mathrm{~Hz}, 1 \mathrm{H}), 7.74(\mathrm{t}, J=7.9 \mathrm{~Hz}, 1 \mathrm{H})$, 7.57-7.44 (m, 3H), 4.50-4.40 (m, 2H), $2.85(\mathrm{~s}, 3 \mathrm{H}), 2.62(\mathrm{~s}, 3 \mathrm{H}), 1.49(\mathrm{t}, J=7.1 \mathrm{~Hz}, 3 \mathrm{H}),{ }^{13} \mathrm{C} \mathrm{NMR}\left(\mathrm{CDCl}_{3}\right.$, $100 \mathrm{MHz}) \delta 177.6,162.3,133.5,129.41,129.36,126.3,126.2,125.8,125.2,124.7,124.4,124.0,123.7,123.2$, $121.8,121.7,121.3,120.8,119.0,61.2,30.0,14.3,10.4$; HRMS (ESI) calcd for $\mathrm{C}_{17} \mathrm{H}_{15} \mathrm{NONa}[\mathrm{M}+\mathrm{Na}]^{+}$ 318.1101, found 318.1115 .

Dimethyl 1,3-dimethylphenanthrene-2,4-dicarboxylate (5cb). The yield of $5 \mathbf{c b}(30 \%)$ was determined by ${ }^{1} \mathrm{H}$ NMR with hexamethylbenzene as an internal standard. Analytically pure $5 \mathrm{cb}$ was isolated from a mixture of $\mathbf{5} \mathbf{c b}, \mathbf{6} \mathbf{c b}$ and $\mathbf{6} \mathbf{c b}^{\prime}\left(19.2 \mathrm{mg}, \mathbf{5} \mathbf{c b} / \mathbf{6} \mathbf{c b} / \mathbf{6} \mathbf{c b}^{\prime}=51: 37: 12\right)$ by GPC. The regiochemistry of the title compound was determined by analogy to the ${ }^{1} \mathrm{H}$ NMR chemical shifts of $5 \mathrm{ce}$. Colorless solid, $8.8 \mathrm{mg}, 0.0273 \mathrm{mmol}, 27 \%$ isolated yield, $\mathrm{mp} 62.8-64.5{ }^{\circ} \mathrm{C} ;{ }^{1} \mathrm{H} \mathrm{NMR}\left(\mathrm{CDCl}_{3}, 400 \mathrm{MHz}\right) ;{ }^{1} \mathrm{H} \mathrm{NMR}$ $\left(\mathrm{CDCl}_{3}, 400 \mathrm{MHz}\right) \delta 8.35(\mathrm{~d}, J=8.4 \mathrm{~Hz}, 1 \mathrm{H}), 7.95(\mathrm{~d}, J=9.1 \mathrm{~Hz}, 1 \mathrm{H}), 7.93-7.87(\mathrm{~m}, 1 \mathrm{H}), 7.79(\mathrm{~d}, J=9.2 \mathrm{~Hz}$, $1 \mathrm{H}), 7.64-7.53(\mathrm{~m}, 2 \mathrm{H}), 4.00(\mathrm{~s}, 3 \mathrm{H}), 3.99(\mathrm{~s}, 3 \mathrm{H}), 2.68(\mathrm{~s}, 3 \mathrm{H}), 2.44(\mathrm{~s}, 3 \mathrm{H}) ;{ }^{13} \mathrm{C} \mathrm{NMR}\left(\mathrm{CDCl}_{3}, 100 \mathrm{MHz}\right) \delta$ $172.4,170.5,133.9,133.1,132.6,129.83,129.79,129.1,129.0,128.8,127.9,127.7,127.1,126.4,125.3,122.3$, 52.7, 52.3 17.5, 17.4; HRMS (ESI) calcd for $\mathrm{C}_{20} \mathrm{H}_{18} \mathrm{O}_{4} \mathrm{Na}[\mathrm{M}+\mathrm{Na}]^{+} 345.1097$, found 345.1101.

Methyl 1-acetyl-3-methyl-1H-benzo[g]indole-2-carboxylate $(\mathbf{6 c b})$ and methyl 1-acetyl-2-methyl-1Hbenzo[g]indole-3-carboxylate $\left(\mathbf{6} \mathbf{c b}^{\prime}\right)$. The yields of $\mathbf{6} \mathbf{c b}(22 \%)$ and $\mathbf{6} \mathbf{c b}^{\prime}(8 \%)$ was determined by ${ }^{1} \mathrm{H}$ NMR with hexamethylbenzene as an internal standard. An analytically pure mixture of $\mathbf{6} \mathbf{c b}$ and $\mathbf{6} \mathbf{c b}^{\prime}$ was isolated from a mixture of $\mathbf{5 c b}, \mathbf{6} \mathbf{c b}$ and $\mathbf{6} \mathbf{c b}^{\prime}\left(19.2 \mathrm{mg}, \mathbf{5 c b} / \mathbf{6} \mathbf{c b} / \mathbf{6} \mathbf{c b}^{\prime}=51: 37: 12\right)$ by GPC. The regiochemistry of the title compounds was determined by analogy to the ${ }^{1} \mathrm{H}$ NMR chemical shifts of $\mathbf{6} \mathbf{c a}$ and $\mathbf{6} \mathbf{c a}{ }^{\prime}$. Colorless solid, $6.0 \mathrm{mg}, 0.0213 \mathrm{mmol}, 21 \%$ isolated yield, $\mathbf{6} \mathbf{c b} / \mathbf{6} \mathbf{c b}^{\prime}=75: 25$, mp 93.7-95.0 ${ }^{\circ} \mathrm{C} ;{ }^{1} \mathrm{H}$ NMR $\left(\mathrm{CDCl}_{3}, 400 \mathrm{MHz}\right)$ 6cb: $\delta 8.17-8.10(\mathrm{~m}, 1 \mathrm{H}), 7.95-7.89(\mathrm{~m}, 1 \mathrm{H}), 7.66(\mathrm{~d}$, $J=8.7 \mathrm{~Hz}, 1 \mathrm{H}), 7.59(\mathrm{~d}, J=8.7 \mathrm{~Hz}, 1 \mathrm{H}), 7.57-7.44(\mathrm{~m}, 2 \mathrm{H}), 3.97(\mathrm{~s}, 3 \mathrm{H}), 2.76(\mathrm{~s}, 3 \mathrm{H}), 2.64(\mathrm{~s}, 3 \mathrm{H}) ; 6 \mathrm{cb}^{\prime}: \delta$ $8.26(\mathrm{~d}, J=8.8 \mathrm{~Hz}, 1 \mathrm{H}), 7.97(\mathrm{~d}, J=8.1 \mathrm{~Hz}, 1 \mathrm{H}), 7.93-7.87(\mathrm{~m}, 1 \mathrm{H}), 7.79(\mathrm{~d}, J=9.2 \mathrm{~Hz}, 1 \mathrm{H}), 7.64-7.53$ $(\mathrm{m}, 2 \mathrm{H}), 4.00(\mathrm{~s}, 3 \mathrm{H}), 3.99(\mathrm{~s}, 3 \mathrm{H}), 2.68(\mathrm{~s}, 3 \mathrm{H}), 2.44(\mathrm{~s}, 3 \mathrm{H}) ;{ }^{13} \mathrm{C} \mathrm{NMR}\left(\mathrm{CDCl}_{3}, 100 \mathrm{MHz}\right) \delta 171.0,136.8$, $134.9,133.6,130.3,130.2,128.7,128.5,125.3,123.4,118.6,118.1,116.3,27.6,9.2$; HRMS (ESI) calcd for $\mathrm{C}_{17} \mathrm{H}_{15} \mathrm{NONa}[\mathrm{M}+\mathrm{Na}]^{+}$304.0944, found 304.0952.

Diethyl 1,3-dibutylphenanthrene-2,4-dicarboxylate (5cc). The yield of $5 \mathrm{cc}(32 \%)$ was determined by ${ }^{1} \mathrm{H}$ NMR with hexamethylbenzene as an internal standard. Analytically pure $5 \mathrm{cc}$ was isolated from a mixture of $5 \mathrm{cc}, 6 \mathrm{cc}$ and $6 \mathrm{cc}^{\prime}\left(40.0 \mathrm{mg}, 5 \mathrm{cc} / 6 \mathrm{cc} / 6 \mathrm{cc}^{\prime}=42: 9: 49\right)$ by GPC. The regiochemistry of the title compound was determined by analogy to the ${ }^{1} \mathrm{H}$ NMR chemical shifts of 5 ce. Pale yellow oil, $11.7 \mathrm{mg}, 0.0269 \mathrm{mmol}, 27 \%$ isolated yield; ${ }^{1} \mathrm{H}$ NMR $\left(\mathrm{CDCl}_{3}, 400 \mathrm{MHz}\right) \delta 8.42(\mathrm{~d}, J=8.6 \mathrm{~Hz}, 1 \mathrm{H}), 7.93$ $(\mathrm{d}, J=9.2 \mathrm{~Hz}, 1 \mathrm{H}), 7.90-7.86(\mathrm{~m}, 1 \mathrm{H}), 7.77(\mathrm{~d}, J=9.1 \mathrm{~Hz}, 1 \mathrm{H}), 7.61-7.56(\mathrm{~m}, 1 \mathrm{H}), 7.55-7.50(\mathrm{~m}, 1 \mathrm{H})$, 4.51-4.43 (m, 4H), 3.04-2.97 (m, 2H), 2.80-2.68 (m, 2H), 1.78-1.64 (m, 4H), 1.55-1.29 (m, 4H), $1.44(\mathrm{t}$, $J=7.1 \mathrm{~Hz}, 3 \mathrm{H}), 1.34(\mathrm{t}, J=7.2 \mathrm{~Hz}, 3 \mathrm{H}), 1.02-0.92(\mathrm{~m}, 6 \mathrm{H}) ;{ }^{13} \mathrm{C} \mathrm{NMR}\left(\mathrm{CDCl}_{3}, 100 \mathrm{MHz}\right) \delta 171.9,170.0$, 137.5, 135.0, 133.7, 132.9, 129.4, 129.2, 129.1, 128.5, 128.1, 127.7, 127.0, 126.1, 125.7, 122.3, 61.7, 61.3, $33.9,33.5,32.1,31.3,23.4,23.3,14.2,13.9,13.83,13.79$; HRMS (ESI) calcd for $\mathrm{C}_{28} \mathrm{H}_{34} \mathrm{O}_{4} \mathrm{Na}[\mathrm{M}+\mathrm{Na}]^{+}$ 457.2349, found 457.2359.

Ethyl 1-acetyl-3-butyl-1H-benzo[g]indole-2-carboxylate (6cc) and ethyl 1-acetyl-2-butyl-1Hbenzo[g]indole-3-carboxylate $(\mathbf{6 c c})$. The yields of $\mathbf{6 c c}(37 \%)$ and $\mathbf{6} \mathbf{c c}^{\prime}(7 \%)$ were determined by ${ }^{1} \mathrm{H}$ NMR with hexamethylbenzene as an internal standard. An analytically pure mixture of $6 \mathrm{cc}$ and $6 \mathrm{cc}^{\prime}$ was isolated from a mixture of $5 \mathrm{cc}, 6 \mathrm{cc}$ and $6 \mathrm{cc}^{\prime}\left(40.0 \mathrm{mg}, 5 \mathrm{cc} / 6 \mathrm{cc} / 6 \mathrm{cc}^{\prime}=42: 9: 49\right)$ by GPC. The regiochemistry of the title compounds was determined by analogy to the ${ }^{1} \mathrm{H}$ NMR chemical shifts of $\mathbf{6 c a}$ and $\mathbf{6} \mathbf{c a}^{\prime}$. Colorless solid, $13.2 \mathrm{mg}, 0.0391 \mathrm{mmol}, 39 \%$ isolated yield, $6 \mathbf{c c} / \mathbf{6 c c ^ { \prime }}=86: 14$, $\mathrm{mp}$ 61.0-62.4 ${ }^{\circ} \mathrm{C} ;{ }^{1} \mathrm{H}$ NMR $\left(\mathrm{CDCl}_{3}, 400 \mathrm{MHz}\right) \delta$ 6cc: 8.16-8.09 (m, 1H), 7.95-7.88 (m, 1H), $7.67(\mathrm{~d}$, $J=8.7 \mathrm{~Hz}, 1 \mathrm{H}), 7.58(\mathrm{~d}, J=8.6 \mathrm{~Hz}, 1 \mathrm{H}), 7.56-7.43(\mathrm{~m}, 2 \mathrm{H}), 4.43(\mathrm{q}, J=7.1 \mathrm{~Hz}, 2 \mathrm{H}), 3.11(\mathrm{t}, J=7.7 \mathrm{~Hz}$, 
2H), $2.77(\mathrm{~s}, 3 \mathrm{H}), 1.75-1.63(\mathrm{~m}, 2 \mathrm{H}), 1.52-1.40(\mathrm{~m}, 2 \mathrm{H}), 1.44(\mathrm{t}, J=7.1 \mathrm{~Hz}, 3 \mathrm{H}), 0.97(\mathrm{t}, J=7.2 \mathrm{~Hz}, 3 \mathrm{H})$; 6cc': $8.30(\mathrm{~d}, J=8.8 \mathrm{~Hz}, 1 \mathrm{H}), 8.00-7.95(\mathrm{~m}, 1 \mathrm{H}), 7.77-7.71(\mathrm{~m}, 2 \mathrm{H}), 7.56-7.43(\mathrm{~m}, 2 \mathrm{H}), 4.50-4.39(\mathrm{~m}, 2 \mathrm{H})$,

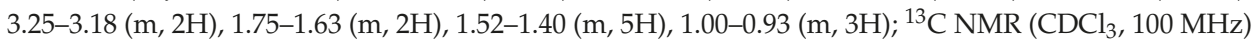
$\delta 177.7,162.2,133.4,131.0,129.4,129.0,126.3,125.7,124.8,123.4,123.1,121.9,121.6,119.1,61.2,33.4$, 30.0, 24.7, 22.9, 14.2, 14.0; HRMS (ESI) calcd for $\mathrm{C}_{21} \mathrm{H}_{23} \mathrm{NO}_{3} \mathrm{Na}[\mathrm{M}+\mathrm{Na}]^{+} 360.1570$, found 360.1575.

Dimethyl 1,3-bis(3-phenylpropyl)phenanthrene-2,4-dicarboxylate (5cd). The yield of 5cd (35\%) was determined by ${ }^{1} \mathrm{H}$ NMR with hexamethylbenzene as an internal standard. Analytically pure $5 \mathrm{~cd}$ was isolated from a mixture of $5 \mathrm{~cd}, 6 \mathrm{~cd}$ and $6 \mathrm{~cd}^{\prime}\left(42.3 \mathrm{mg}, 5 \mathrm{~cd} / 6 \mathrm{~cd} / 6 \mathrm{~cd}^{\prime}=46: 7: 47\right)$ by GPC. The regiochemistry of the title compound was determined by analogy to the ${ }^{1} \mathrm{H}$ NMR chemical shifts of 5ce. Pale yellow solid, $16.4 \mathrm{mg}, 0.0294 \mathrm{mmol}, 29 \%$ isolated yield, $\mathrm{mp} 91.0-92.6{ }^{\circ} \mathrm{C} ;{ }^{1} \mathrm{H}$ NMR $\left(\mathrm{CDCl}_{3}, 400 \mathrm{MHz}\right) \delta 8.30(\mathrm{~d}, J=8.4 \mathrm{~Hz}, 1 \mathrm{H}), 7.89-7.83(\mathrm{~m}, 1 \mathrm{H}), 7.78-7.68(\mathrm{~m}, 2 \mathrm{H}), 7.61-7.44(\mathrm{~m}, 2 \mathrm{H})$, $7.36-7.14(\mathrm{~m}, 10 \mathrm{H}), 3.84(\mathrm{~s}, 3 \mathrm{H}), 3.65(\mathrm{~s}, 3 \mathrm{H}), 3.00-2.90(\mathrm{~m}, 2 \mathrm{H}), 2.78(\mathrm{t}, J=7.2 \mathrm{~Hz}, 2 \mathrm{H}), 2.70(\mathrm{t}, J=7.2 \mathrm{~Hz}$, 2H), 2.70-2.62 (m, 2H), 2.10-1.94 (m, 4H); ${ }^{13} \mathrm{C} \mathrm{NMR}\left(\mathrm{CDCl}_{3}, 100 \mathrm{MHz}\right) \delta 172.2,170.1,141.8,141.6,137.3$, 134.6, 133.5, 132.9, 129.3, 129.2, 128.9, 128.7, 128.6, 128.4, 128.3, 128.2, 128.0, 127.1 126.3, 126.0, 125.8, $125.3,122.1,52.5,52.0,36.4,36.2,33.2,32.6,32.0,30.9$; HRMS (ESI) calcd for $\mathrm{C}_{36} \mathrm{H}_{34} \mathrm{O}_{4} \mathrm{Na}[\mathrm{M}+\mathrm{Na}]^{+}$ 553.2349 , found 553.2354 .

Ethyl 1-acetyl-3-(3-phenylpropyl)-1H-benzo[g]indole-2-carboxylate $(6 \mathrm{~cd})$ and ethyl 1-acetyl-2(3-phenylpropyl)-1H-benzolg]indole-3-carboxylate $\left(\mathbf{6} \mathbf{c d}^{\prime}\right)$. The yields of $\mathbf{6 c d}(38 \%)$ and $\mathbf{6 c d} \mathbf{c d}^{\prime}(5 \%)$ were determined by ${ }^{1} \mathrm{HNMR}$ with hexamethylbenzene as an internal standard. An analytically pure mixture of $6 \mathrm{~cd}$ and $\mathbf{6 c d ^ { \prime }}$ was isolated from a mixture of $5 \mathrm{~cd}, 6 \mathrm{~cd}$ and $\mathbf{6 c d ^ { \prime }}\left(42.3 \mathrm{mg}, 5 \mathrm{~cd} / \mathbf{6 c d} / \mathbf{6 c d} \mathbf{c}^{\prime}=46: 7: 47\right)$ by GPC. The regiochemistry of the title compounds was determined by analogy to the ${ }^{1} \mathrm{H}$ NMR chemical shifts of $\mathbf{6} \mathbf{c a}$ and $\mathbf{6} \mathbf{c a}^{\prime}$. Pale yellow oil, $14.1 \mathrm{mg}, 0.0353 \mathrm{mmol}, 35 \%$ isolated yield, $\mathbf{6} \mathbf{c d} / \mathbf{6} \mathbf{c d}^{\prime}=89: 11 ;{ }^{1} \mathrm{H}$ $\operatorname{NMR}\left(\mathrm{CDCl}_{3}, 400 \mathrm{MHz}\right) \delta 8.15-8.08(\mathrm{~m}, 1 \mathrm{H}), 7.95-7.87(\mathrm{~m}, 1 \mathrm{H}), 7.61-7.54(\mathrm{~m}, 2 \mathrm{H}), 7.53-7.48(\mathrm{~m}, 2 \mathrm{H})$, 7.33-7.26 (m, 2H), 7.25-7.15 (m, 3H), $3.85(\mathrm{~s}, 3 \mathrm{H}), 3.18-3.10(\mathrm{~m}, 2 \mathrm{H}), 2.78-2.72(\mathrm{~m}, 2 \mathrm{H}), 2.76(\mathrm{~s}, 3 \mathrm{H})$, 2.07-1.97 (m, 2H); ${ }^{13} \mathrm{C} \mathrm{NMR}\left(\mathrm{CDCl}_{3}, 100 \mathrm{MHz}\right) \delta 177.6,162.6,142.1,133.4,131.1,129.4,128.5,128.3$, $126.3,125.84,125.80,124.7,123.3,123.2,121.8,121.6,119.0,51.9,35.9,32.5,29.9,24.5$; HRMS (ESI) calcd for $\mathrm{C}_{36} \mathrm{H}_{34} \mathrm{O}_{4} \mathrm{Na}[\mathrm{M}+\mathrm{Na}]^{+} 408.1570$, found 408.1574 .

Diethyl 1,3-dibutylphenanthrene-2,4-dicarboxylate (5ce). The yield of 5 ce (36\%) was determined by ${ }^{1} \mathrm{H}$ NMR with hexamethylbenzene as an internal standard. Analytically pure 5ce was isolated from a mixture of $5 c e, 6 c e$ and $6 \mathrm{ce}^{\prime}\left(42.6 \mathrm{mg}, 5 \mathrm{ce} / 6 \mathrm{ce} / 6 \mathrm{ce}{ }^{\prime}=50: 7: 43\right)$ by GPC. The regiochemistry of the title compound was determined by the X-ray crystallographic analysis as shown in Figure 1. Colorless solid, $13.5 \mathrm{mg}, 0.0284 \mathrm{mmol}, 28 \%$ isolated yield, $\mathrm{mp} 108.1-109.2{ }^{\circ} \mathrm{C} ;{ }^{1} \mathrm{H} \mathrm{NMR}\left(\mathrm{CDCl}_{3}, 400 \mathrm{MHz}\right) \delta 8.34(\mathrm{~d}$, $J=8.4 \mathrm{~Hz}, 1 \mathrm{H}), 7.97(\mathrm{~d}, J=9.2 \mathrm{~Hz}, 1 \mathrm{H}), 7.93-7.88(\mathrm{~m}, 1 \mathrm{H}), 7.82(\mathrm{~d}, J=9.2 \mathrm{~Hz}, 1 \mathrm{H}), 7.65-7.53(\mathrm{~m}, 2 \mathrm{H})$, $4.02(\mathrm{~s}, 3 \mathrm{H}), 3.98(\mathrm{~s}, 3 \mathrm{H}), 3.68(\mathrm{t}, J=6.1 \mathrm{~Hz}, 2 \mathrm{H}), 3.63(\mathrm{t}, J=6.1 \mathrm{~Hz}, 2 \mathrm{H}), 3.24-3.16(\mathrm{~m}, 2 \mathrm{H}), 2.93-2.84(\mathrm{~m}$, 2H), 2.26-2.13 (m, 4H); ${ }^{13} \mathrm{C} \mathrm{NMR}\left(\mathrm{CDCl}_{3}, 100 \mathrm{MHz}\right) \delta 172.0,170.0,136.1,133.9,133.3,133.0,129.6,129.5$, $129.2,128.8,128.6,128.4,127.4,126.6,125.3,121.8,52.8,52.5,45.2,45.0,34.4,33.7,30.1,28.9$; HRMS (ESI) calcd for $\mathrm{C}_{24} \mathrm{H}_{24} \mathrm{Cl}_{2} \mathrm{O}_{4} \mathrm{Na}[\mathrm{M}+\mathrm{Na}]^{+} 469.0944$, found 469.0948 .

Methyl 1-acetyl-3-(3-chloropropyl)-1H-benzo[g]indole-2-carboxylate (6ce) and methyl 1-acetyl-2(3-chloropropyl)-1H-benzo[g]indole-3-carboxylate (6ce'). The yields of $6 \mathrm{ce}(31 \%)$ and $\mathbf{6 c e} \mathbf{c}^{\prime}(5 \%)$ were determined by ${ }^{1} \mathrm{H}$ NMR with hexamethylbenzene as an internal standard. An analytically pure mixture of $6 \mathrm{ce}$ and $\mathbf{6 c e}{ }^{\prime}$ was isolated from a mixture of $5 \mathrm{ce}, 6 \mathrm{ce}$ and $6 \mathrm{ce}^{\prime}\left(42.6 \mathrm{mg}, 5 \mathrm{ce} / 6 \mathrm{ce} / 6 \mathrm{ce}{ }^{\prime}=50: 7: 43\right)$ by GPC. The regiochemistry of the title compounds was determined by analogy to the ${ }^{1} \mathrm{H}$ NMR chemical shifts of $\mathbf{6 c e}$ and $\mathbf{6 c e} \mathbf{c}^{\prime}$. Colorless oil, $8.6 \mathrm{mg}, 0.0240 \mathrm{mmol}, 24 \%$ isolated yield, $6 \mathrm{ce} / \mathbf{6 c e}{ }^{\prime}=83: 17$. ${ }^{1} \mathrm{H}$ NMR $\left(\mathrm{CDCl}_{3}, 400 \mathrm{MHz}\right)$ 6ce: $\delta 8.14-8.07(\mathrm{~m}, 1 \mathrm{H}), 7.96-7.89(\mathrm{~m}, 1 \mathrm{H}), 7.71(\mathrm{~d}, J=8.8 \mathrm{~Hz}, 1 \mathrm{H}), 7.60(\mathrm{~d}$, $J=8.8 \mathrm{~Hz}, 1 \mathrm{H}), 7.58-7.46(\mathrm{~m}, 2 \mathrm{H}), 3.98(\mathrm{~s}, 3 \mathrm{H}), 3.61(\mathrm{t}, J=6.3 \mathrm{~Hz}, 2 \mathrm{H}), 3.32-3.26(\mathrm{~m}, 2 \mathrm{H}), 2.79(\mathrm{~s}, 3 \mathrm{H})$, 2.30-2.13 (m, 2H); 6ce': $\delta 8.76(\mathrm{~d}, J=8.8 \mathrm{~Hz} 1 \mathrm{H}), 8.00-7.97(\mathrm{~m}, 1 \mathrm{H}), 7.77-7.75(\mathrm{~m}, 1 \mathrm{H}), 7.75-7.73(\mathrm{~m}, 1 \mathrm{H})$, 7.58-7.46 (m, 2H), $4.00(\mathrm{~s}, 3 \mathrm{H}), 3.68(\mathrm{t}, J=6.6 \mathrm{~Hz}, 2 \mathrm{H}), 3.37-3.32(\mathrm{~m}, 2 \mathrm{H}), 2.62(\mathrm{~s}, 3 \mathrm{H}), 2.30-2.13(\mathrm{~m}, 2 \mathrm{H})$; ${ }^{13} \mathrm{C}$ NMR $\left(\mathrm{CDCl}_{3}, 100 \mathrm{MHz}\right) \delta 177.5,162.3,133.5,131.1,129.5,126.8,126.5,126.0,125.0,124.6,123.5$, 
123.3, 121.7, $121.60,120.8,118.8,52.1,44.7,33.7,29.9,22.1$; HRMS (ESI) calcd for $\mathrm{C}_{19} \mathrm{H}_{18} \mathrm{O}_{3} \mathrm{NClNa}[\mathrm{M}+$ $\mathrm{Na}]^{+} 366.0867$, found 366.0871 .

Ethyl 2-phenyl-1-pivaloyl-1H-benzo[g]indole-3-carboxylate $\left(\mathbf{6} \mathbf{c f}^{\prime}\right)$. The yield of $\mathbf{6} \mathbf{c f}^{\prime}(69 \%)$ was determined by ${ }^{1} \mathrm{H}$ NMR with hexamethylbenzene as an internal standard. Analytically pure $6 \mathbf{c f}^{\prime}$ was isolated by repeated preparative TLCs. Pale yellow oil, $21.9 \mathrm{mg}, 0.0612 \mathrm{mmol}, 61 \%$ isolated yield; ${ }^{1} \mathrm{H}$ NMR $\left(\mathrm{CDCl}_{3}, 400 \mathrm{MHz}\right) \delta 8.37(\mathrm{~d}, J=8.8 \mathrm{~Hz}, 1 \mathrm{H}), 8.00-7.95(\mathrm{~m}, 1 \mathrm{H}), 7.91-7.86(\mathrm{~m}, 1 \mathrm{H}), 7.78(\mathrm{~d}, J=8.7 \mathrm{~Hz}$, $1 \mathrm{H}), 7.55-7.44(\mathrm{~m}, 7 \mathrm{H}), 4.22(\mathrm{q}, J=7.1 \mathrm{~Hz}, 2 \mathrm{H}), 2.27(\mathrm{~s}, 3 \mathrm{H}), 1.16(\mathrm{t}, J=7.1 \mathrm{~Hz}, 3 \mathrm{H}), 1.17(\mathrm{~s}, 9 \mathrm{H}) ;{ }^{13} \mathrm{C}$ NMR $\left(\mathrm{CDCl}_{3}, 100 \mathrm{MHz}\right) \delta 176.0,164.5,142.4,132.0,131.2,130.8,129.43,129.41,129.3,128.0,126.1,125.2$, 125.0, 124.7, 121.7, 121.3, 120.6, 110.1, 59.9, 29.3, 14.0; HRMS (ESI) calcd for $\mathrm{C}_{23} \mathrm{H}_{19} \mathrm{NO}_{3} \mathrm{Na}[\mathrm{M}+\mathrm{Na}]^{+}$ 380.1257 , found 380.1266 .

Ethyl 3-methyl-1-pivaloyl-1H-benzo[g]indole-2-carboxylate (6ea) and ethyl 2-methyl-1-pivaloyl-1Hbenzo[g]indole-3-carboxylate $\left.(\mathbf{6 e a})^{\prime}\right)$. The yields of $6 \mathbf{e a}(55 \%)$ and $6 \mathbf{6 e}{ }^{\prime}(3 \%)$ were determined by ${ }^{1} \mathrm{H}$ NMR with hexamethylbenzene as an internal standard. An analytically pure mixture of 6ea and $6 \mathbf{e a}^{\prime}$ was isolated by repeated preparative TLCs. Colorless solid; $15.5 \mathrm{~g}, 0.0459 \mathrm{mmol}, 46 \%$ isolated yield, 6ea. mp 128.4-129.5 ${ }^{\circ} \mathrm{C} ;{ }^{1} \mathrm{H}$ NMR $\left(\mathrm{CDCl}_{3}, 400 \mathrm{MHz}\right) \delta 8.24-8.17(\mathrm{~m}, 1 \mathrm{H}), 7.91-7.86(\mathrm{~m}, 1 \mathrm{H}), 7.66(\mathrm{~d}$, $J=8.7 \mathrm{~Hz}, 1 \mathrm{H}), 7.56(\mathrm{~d}, J=8.7 \mathrm{~Hz}, 1 \mathrm{H}), 7.52-7.42(\mathrm{~m}, 2 \mathrm{H}), 4.42(\mathrm{q}, J=7.1 \mathrm{~Hz}, 2 \mathrm{H}), 2.66(\mathrm{~s}, 3 \mathrm{H}), 1.43$ $(\mathrm{t}, J=7.1 \mathrm{~Hz}, 3 \mathrm{H}), 1.17(\mathrm{~s}, 9 \mathrm{H}) ;{ }^{13} \mathrm{C} \mathrm{NMR}\left(\mathrm{CDCl}_{3}, 100 \mathrm{MHz}\right) \delta 187.5,162.9,133.4,131.3,129.1,125.8$, $125.7,125.1,124.7,122.9,122.8,122.4,122.3,119.0,61.2,46.8,28.2,14.3,10.4$; HRMS (ESI) calcd for $\mathrm{C}_{21} \mathrm{H}_{23} \mathrm{NO}_{3} \mathrm{Na}[\mathrm{M}+\mathrm{Na}]^{+} 360.1570$, found 360.1570 .

Diethyl (Z)-1'-(acetylimino)-3,5-dimethyl-1'H-spiro[cyclopentane-1,2'-naphthalene]-2,4-diene-2,4-dicarboxylate (7ca). The yield of $7 \mathrm{ca}(13 \%)$ was determined by ${ }^{1} \mathrm{H}$ NMR with hexamethylbenzene as an internal standard. Analytically pure 7ca was isolated by repeated preparative TLCs. The structure was determined by the HSQC and HMBC analyses. Pale yellow oil, $9.7 \mathrm{mg}, 0.214 \mathrm{mmol}, 11 \%$ isolated yield; ${ }^{1} \mathrm{H}$ NMR $\left(\mathrm{CDCl}_{3}, 400 \mathrm{MHz}\right) \delta 8.08\left(\mathrm{~d}, J=8.0 \mathrm{~Hz}, 1 \mathrm{H}, \mathrm{H}^{h}\right), 7.48\left(\mathrm{td}, J=7.5,1.3 \mathrm{~Hz}, 1 \mathrm{H}, \mathrm{H}^{g}\right), 7.31(\mathrm{td}$, $\left.J=7.7,1.3 \mathrm{~Hz}, 1 \mathrm{H}, \mathrm{H}^{f}\right), 7.28-7.22\left(\mathrm{~m}, 1 \mathrm{H}, \mathrm{H}^{e}\right), 6.79\left(\mathrm{~d}, J=9.4 \mathrm{~Hz}, 1 \mathrm{H}, \mathrm{H}^{d}\right), 5.05\left(\mathrm{~d}, J=9.4 \mathrm{~Hz}, 1 \mathrm{H}, \mathrm{H}^{c}\right)$, $4.31\left(\mathrm{q}, J=7.1 \mathrm{~Hz}, 2 \mathrm{H}, \mathrm{CO}_{2} \mathrm{CH}_{2} \mathrm{CH}_{3}\right.$ on $\left.\mathrm{C}^{2}\right), 4.04\left(\mathrm{q}, J=7.1 \mathrm{~Hz}, 2 \mathrm{H}, \mathrm{CO}_{2} \mathrm{CH}_{2} \mathrm{CH}_{3}\right.$ on $\left.\mathrm{C}^{4}\right), 2.50(\mathrm{~s}, 3 \mathrm{H}$, $\mathrm{CH}_{3}$ on $\left.\mathrm{C}^{3}\right), 2.10\left(\mathrm{~s}, 3 \mathrm{H}, \mathrm{CH}_{3}\right.$ on $\left.\mathrm{C}^{1}\right), 2.01\left(\mathrm{~s}, 3 \mathrm{H}, \mathrm{NCOCH}_{3}\right), 1.36\left(\mathrm{t}, J=7.1 \mathrm{~Hz}, 3 \mathrm{H}, \mathrm{CO}_{2} \mathrm{CH}_{2} \mathrm{CH}_{3}\right.$ on $\left.\mathrm{C}^{2}\right)$, $0.89\left(\mathrm{t}, J=7.1 \mathrm{~Hz}, 3 \mathrm{H}, \mathrm{CO}_{2} \mathrm{CH}_{2} \mathrm{CH}_{3}\right.$ on $\left.\mathrm{C}^{4}\right) ;{ }^{13} \mathrm{C} \mathrm{NMR}\left(\overline{\mathrm{CDCl}_{3}}, 100 \mathrm{MHz}\right) \delta 180.6(\mathrm{NCOMe}), \overline{164.1}\left(\mathrm{C}^{a}\right)$, $164.0\left(\mathrm{CO}_{2} \mathrm{Et}\right), 163.0\left(\mathrm{CO}_{2} \mathrm{Et}\right), 158.7,154.0\left(\mathrm{C}^{e}\right), 136.0\left(\mathrm{C}^{j}\right), 135.1,132.6\left(\mathrm{C}^{h}\right), 132.2,129.9,129.0\left(\mathrm{C}^{c}\right), 127.9$ $\left(\mathrm{C}^{g}\right), 127.8\left(\mathrm{C}^{f}\right), 127.5\left(\mathrm{C}^{d}\right), 127.1\left(\mathrm{C}^{i}\right), 67.7\left(\mathrm{C}^{b}\right), 60.8\left(\mathrm{CO}_{2} \mathrm{CH}_{2} \mathrm{CH}_{3}\right.$ on $\left.\mathrm{C}^{2}\right), 60.1\left(\mathrm{CO}_{2} \underline{\mathrm{CH}}_{2} \mathrm{CH}_{3}\right.$ on $\left.\mathrm{C}^{4}\right)$, $24.5\left(\mathrm{NCO}^{-} \mathrm{H}_{3}\right), 15.1\left(\underline{\mathrm{CH}}_{3}\right.$ on $\left.\mathrm{C}^{3}\right), 14.2\left(\mathrm{CO}_{2} \mathrm{CH}_{2} \underline{\mathrm{C}} \mathrm{H}_{3}\right.$ on $\left.\mathrm{C}^{2}\right), 13.9\left(\underline{\mathrm{CH}_{3}}\right.$ on $\left.\mathrm{C}^{1}\right), 13.5\left(\mathrm{CO}_{2} \mathrm{CH}_{2} \underline{\mathrm{CH}_{3}}\right.$ on $\mathrm{C}^{4}$ ); HRMS (ESI) calcd for $\mathrm{C}_{24} \mathrm{H}_{25} \mathrm{NO}_{5} \mathrm{Na}[\mathrm{M}+\mathrm{Na}]^{+} 430.1625$, found 430.1623 .

The ${ }^{1} \mathrm{H}$ and ${ }^{13} \mathrm{C}-\mathrm{NMR}$ spectra of $5 \mathbf{c a}-5 \mathrm{ce}, 6 \mathbf{c a}-\mathbf{6 c e}, 6 \mathbf{c a}^{\prime}-6 \mathbf{c f}^{\prime}$ and $7 \mathrm{ca}$, and crystal data and data collection parameters of $5 \mathrm{ce}$ are available in Supplementary Materials.

\section{Conclusions}

In summary, we have established that an electron-deficient cationic $\mathrm{Cp}^{\mathrm{E}}$-rhodium(III) complex catalyzes the non-oxidative [2+2+2] annulation of $\mathrm{N}$-(1-naphthyl)acetamide with two alkynoates via cleavage of the adjacent $\mathrm{C}-\mathrm{H}$ and $\mathrm{C}-\mathrm{N}$ bonds to give densely substituted phenanthrenes under mild conditions (at $40{ }^{\circ} \mathrm{C}$ under air). Importantly, a dearomatized spiro compound was isolated in this reaction, which may support the formation of a spiro rhodacycle intermediate in the catalytic cycle. The use of $N$-(1-naphthyl)acetamide in place of acetanilide switched the reaction pathway from the oxidative tandem $[2+2+2]$ annulation-lactamization involving cleavage of adjacent two $\mathrm{C}-\mathrm{H}$ bonds to the non-oxidative $[2+2+2]$ annulation involving cleavage of the adjacent $\mathrm{C}-\mathrm{H}$ and $\mathrm{C}-\mathrm{N}$ bonds. This chemoselectivity switch may arise from stabilization of the carbocation in the above cationic spiro rhodacycle by the neighboring phenyl and acetylamino groups, resulting in nucleophilic attack of the dienylrhodium moiety to this carbocation followed by $\beta$-nitrogen elimination. 
Supplementary Materials: The following are available online: ${ }^{1} \mathrm{H}$ and ${ }^{13} \mathrm{C}$ NMR spectra of $5 \mathrm{ca}-5 \mathrm{ce}, 6 \mathrm{ca}-6 \mathrm{ce}$, $6 \mathbf{c a}^{\prime}-6 \mathbf{c f}^{\prime}$ and $7 \mathrm{ca}$ and crystal data and data collection parameters of $5 \mathbf{c e}$.

Author Contributions: Conceptualization, Y.S. and K.T.; Experiments and analyses, J.T. and M.F.; Writing-Original Draft Preparation, Y.S. and K.T.; Writing-Review \& Editing, K.T.; Visualization, J.T. and Y.S.; Supervision, K.T.; Project Administration, K.T.; Funding Acquisition, Y.S. and K.T.

Funding: This work was supported partly by Grants-in-Aid for Scientific Research (No. JP26102004), for Research Activity Start-up (No. 15H06201) and for Young Scientists (No. 17K14481) from Japan Society for the Promotion of Science (JSPS), Japan. We also thank Umicore for generous support in supplying the rhodium and palladium complexes.

Acknowledgments: We are grateful to Umicore for generous support in supplying the rhodium complex.

Conflicts of Interest: The authors declare no conflict of interest.

\section{References}

1. Pia-Quintana, A.; Roglans, A. Chiral Induction in [2+2+2] Cycloaddition Reactions. Asian J. Org. Chem. 2018, 7, 1706-1718. [CrossRef]

2. Beeck, S.; Wegner, H.A. Thieme Chemistry Journals Awardees-Where Are They Now? Aromaticity as a Source for Strain Energy? Synthesis of Curved Polycyclic Aromatic Structures via [2+2+2] Cycloaddition Reactions. Synlett 2017, 28, 1018-1027. [CrossRef]

3. Domínguez, G.; Pérez-Castells, J. Alkens in [2+2+2] Cycloadditions. Chem. Eur. J. 2016, 22, 6720-6739. [CrossRef]

4. Amatore, M.; Aubert, C. Recent Advances in Stereoselective [2+2+2] Cycloadditions. Eur. J. Org. Chem. 2015, 2015, 265-286. [CrossRef]

5. Satoh, Y.; Obora, Y. Niobium Complexes in Organic Transformations: From Stoichiometric Reactions to Catalytic [2+2+2] Cycloaddition Reactions. Eur. J. Org. Chem. 2015, 2015, 5041-5054. [CrossRef]

6. Tanaka, K. (Ed.) Transition-Metal-Mediated Aromatic Ring Construction; John Wiley \& Sons: Hoboken, NJ, USA, 2013; Part 1; ISBN 978-1-118-14892-1.

7. Broere, D.L.J.; Ruijter, E. Recent Advances in Transition-Metal-Catalyzed [2+2+2]-Cyclo(co)trimerization Reactions. Synthesis 2012, 44, 2639-2672. [CrossRef]

8. Dominguez, G.; Pérez-Castells, J. Recent advances in [2+2+2] cycloaddition reactions. Chem. Soc. Rev. 2011, 40, 3430-3444. [CrossRef]

9. Weding, N.; Hapke, M. Preparation and synthetic applications of alkene complexes of group 9 transition metals in [2+2+2] cycloaddition reactions. Chem. Soc. Rev. 2011, 40, 4525-4538. [CrossRef]

10. Kotha, S.; Lahiri, K.; Sreevani, G. Design and Synthesis of Aromatics through [2+2+2] Cyclotrimerization. Synlett 2018, 29, 2342-2361. [CrossRef]

11. Tanaka, K.; Kimura, Y.; Murayama, K. Enantioselective Helicene Synthesis by Rhodium-Catalyzed [2+2+2] Cycloadditions. Bull. Chem. Soc. Jpn. 2015, 88, 375-385. [CrossRef]

12. Shibata, Y.; Tanaka, K. Rhodium-Catalyzed [2+2+2] Cycloaddition of Alkynes for the Synthesis of Substituted Benzenes: Catalysts, Reaction Scope, and Synthetic Applications. Synthesis 2012, 3, 323-350. [CrossRef]

13. Li, S.; Zhou, L.; Kanno, K.; Takahashi, T. Recent development for enantioselective synthesis of aromatic compounds from alkynes via metallacyclopentadienes. J. Heterocycl. Chem. 2011, 48, 517-528. [CrossRef]

14. Galan, B.R.; Rovis, T. Beyond Reppe: Building Substituted Arenes by [2+2+2] Cycloadditions of Alkynes. Angew. Chem. Int. Ed. 2009, 48, 2830-2834. [CrossRef]

15. Hsieh, J.; Cheng, C. O-Dihaloarenes as aryne precursors for nickel-catalyzed [2+2+2] cycloaddition with alkynes and nitriles. Chem. Commun. 2008, 0, 2992-2994. [CrossRef]

16. Hsieh, J.; Cheng, C. Nickel-catalyzed cocyclotrimerization of arynes with diynes; a novel method for synthesis of naphthalene derivatives. Chem. Commun. 2005, 0, 2459-2461. [CrossRef]

17. Yoshikawa, E.; Radhakrishnan, K.V.; Yamamoto, Y. Palladium-Catalyzed Controlled Carbopalladation of Benzyne. J. Am. Chem. Soc. 2000, 122, 7280-7286. [CrossRef]

18. Zhang, X.; Yu, X.; Feng, X.; Yamamoto, Y.; Almansour, A.I.; Arumugam, N.; Kumar, R.S.; Bao, M. Rhodium-Catalyzed Oxidative Benzannulation of N-Pivaloylanilines with Internal Alkynes through Dual C-H Bond Activation: Synthesis of Highly Substituted Naphthalenes. Chem. Asian J. 2016, 11, 3241-3250. [CrossRef] 
19. He, Z.; Huang, Y. Diverting C-H Annulation Pathways: Nickel-Catalyzed Dehydrogenative Homologation of Aromatic Amides. ACS Catal. 2016, 6, 7814-7823. [CrossRef]

20. Pham, M.V.; Cramer, N. Aromatic Homologation by Non-Chelate-Assisted $\mathrm{Rh}^{\mathrm{III}}$-Catalyzed C-H Functionalization of Arenes with Alkynes. Angew. Chem. Int. Ed. 2014, 53, 3484-3487. [CrossRef]

21. Gao, M.; Lam, J.W.Y.; Liu, Y.; Li, J.; Tang, B.Z. A new route to functional polymers: Atom-economical synthesis of poly(pyrazolylnaphthalene)s by rhodium-catalyzed oxidative polycoupling of phenylpyrazole and internal diynes. Polym. Chem. 2013, 4, 2841-2849. [CrossRef]

22. Song, G.; Gong, X.; Li, X. Synthesis of Quinolines via Rh(III)-Catalyzed Oxidative Annulation of Pyridines. J. Org. Chem. 2011, 76, 7583-7589. [CrossRef]

23. Fukui, M.; Shibata, Y.; Hoshino, Y.; Sugiyama, H.; Teraoka, K.; Uekusa, H.; Noguchi, K.; Tanaka, K. Rhodium(III)-Catalyzed Tandem [2+2+2] Annulation-Lactamization of Anilides with Two Alkynoates via Cleavage of Two Adjacent C-H or C-H/C-O bonds. Chem. Asian J. 2016, 11, 2260-2264. [CrossRef]

24. Honjo, Y.; Shibata, Y.; Kudo, E.; Namba, T.; Masutomi, K.; Tanaka, K. Room Temperature Decarboxylative and Oxidative [2+2+2] Annulation of Benzoic Acids with Alkynes Catalyzed by an Electron-Deficient Rhodium(III) Complex. Chem. Eur. J. 2018, 24, 317-321. [CrossRef]

25. Loginov, D.A.; Muratov, D.V.; Nelyubina, Y.V.; Laskova, J.; Kudinov, A.R. $\mu$-Borole triple-decker complexes as catalysts for oxidative coupling of benzoic acid with alkynes. Structure of a hybrid rhodacyclopentadienyl/borole triple-decker complex. J. Mol. Catal. 2017, 426, 393-397. [CrossRef]

26. Loginov, D.A.; Belova, A.O.; Kudinov, M.R. Rhodacarboranes as catalysts for oxidative coupling of benzoic acid with diphenylacetylene. Russ. Chem. Bull. 2014, 63, 983-986. [CrossRef]

27. Ueura, K.; Satoh, T.; Miura, M. Rhodium- and Iridium-Catalyzed Oxidative Coupling of Benzoic Acids with Alkynes via Regioselective C-H Bond Cleavage. J. Org. Chem. 2007, 72, 5362-5367. [CrossRef]

28. Geng, K.; Fan, Z.; Zhang, A. Available Rhodium-catalyzed oxidative coupling of N-acyl anilines with alkynes using an acylamino moiety as the traceless directing group. Org. Chem. Front. 2016, 3, 349-353. [CrossRef]

29. Saxena, P.; Thirupathi, N.; Nethaji, M. Depalladation of Neutral Monoalkyne- and Dialkyne-Inserted Palladacycles and Alkyne Insertion/Depalladation Reactions of Cationic Palladacycles Derived from $N, N^{\prime}, N^{\prime \prime}$-Triarylguanidines as Facile Routes for Guanidine-Containing Heterocycles/Carbocycles: Synthetic, Structural, and Mechanistic Aspects. Organometallics 2014, 33, 5554-5565. [CrossRef]

30. Aparna, P.S.; Prabha, B.; Prakash, P.; Jijy, E.; Varma, R.L.; Radhakrishnan, K.V. Ruthenium catalyzed desymmetrization of diazabicyclic olefins to access heteroaryl substituted cyclopentenes through $\mathrm{C}-\mathrm{H}$ activation of phenylazoles. Tetrahedron Lett. 2014, 55, 865-868. [CrossRef]

31. Qi, Z.; Li, X. Rhodium(III)-Catalyzed Coupling of Arenes with 7-Oxa/Azabenzonorbornadienes by C-H Activation. Angew. Chem. Int. Ed. 2013, 52, 8995-9000. [CrossRef]

32. Ohtaka, J.; Sakamoto, T.; Kikugawa, Y. A one-pot procedure for trifluoroacetylation of arylamines using trifluoroacetic acid as a trifluoroacetylating reagent. Tetrahedron Lett. 2009, 50, 1681-1683. [CrossRef]

33. Li, X.; Gong, X.; Zhao, M.; Song, G.; Deng, J.; Li, X. Rh(III)-Catalyzed Oxidative Olefination of N-(1-Naphthyl)sulfonamides Using Activated and Unactivated Alkenes. Org. Lett. 2011, 13, 5808-5811. [CrossRef] [PubMed]

34. Mezaki, N.; Yagi, S.; Yoshigami, R.; Maeda, J.; Suzuki, T.; Ohsawa, S.; Tsukamoto, K.; Tanaka, T. Pd-Catalyzed Sulfinylzincation of Activated Alkynes with 1-Alkynyl Sulfoxides as a Sulfinyl Source. J. Org. Chem. 2003, 68, 5550-5558. [CrossRef] [PubMed]

35. Dieter, R.N.; Lu, K. $\alpha$-(N-Carbamoyl)alkylcuprate Chemistry in the Synthesis of Nitrogen Heterocycles. J. Org. Chem. 2002, 67, 847-855. [CrossRef] [PubMed]

36. Patel, P.; Borah, G. Direct Access to Indoles by Ir ${ }^{\mathrm{III}}$-Catalyzed C-H Functionalization of Acetanilides with Diazo Compounds. Eur. J. Org. Chem. 2017, 2271-2279. [CrossRef]

Sample Availability: Samples of the compounds not are available from the authors.

(C) 2018 by the authors. Licensee MDPI, Basel, Switzerland. This article is an open access article distributed under the terms and conditions of the Creative Commons Attribution (CC BY) license (http:/ / creativecommons.org/licenses/by/4.0/). 
Article

\title{
Understanding the Exceptional Properties of Nitroacetamides in Water: A Computational Model Including the Solvent
}

\author{
Giovanni La Penna ${ }^{1, *, \dagger}$ and Fabrizio Machetti ${ }^{2, *, \ddagger}$ \\ 1 Istituto di Chimica dei Composti Organometallici (ICCOM), Consiglio Nazionale delle Ricerche (CNR), \\ via Madonna Del Piano 10, I-50019 Sesto Fiorentino, Firenze, Italy \\ 2 Istituto di Chimica dei Composti Organometallici (ICCOM), Consiglio Nazionale delle Ricerche (CNR), \\ c/o Dipartimento di Chimica "Ugo Schiff" via Della Lastruccia 13, I-50019 Sesto Fiorentino, Firenze, Italy \\ * Correspondence: glapenna@iccom.cnr.it (G.L.P.); fabrizio.machetti@unifi.it or fabrizio.machetti@cnr.it (F.M.); \\ Tel.: +39-055-522-5264 (G.L.P.); +39-055-457-3501 (F.M.) \\ $\dagger$ G.L.P. is associated to the Istituto Nazionale di Fisica Nucleare (INFN), Section of Roma-Tor Vergata, \\ via della Ricerca Scientifica 1, I-00133 Roma, Italy. \\ $\ddagger$ Dedicated to Prof. Francesco De Sarlo on the occasion of his 80th birthday. \\ Academic Editor: Michal Szostak \\ Received: 22 November 2018; Accepted: 10 December 2018; Published: 13 December 2018
}

\begin{abstract}
Proton transfer in water involving $\mathrm{C}-\mathrm{H}$ bonds is a challenge and nitro compounds have been studied for many years as good examples. The effect of substituents on acidity of protons geminal to the nitro group is exploited here with new $\mathrm{p} K_{a}$ measurements and electronic structure models, the latter including explicit water environment. Substituents with the amide moiety display an exceptional combination of acidity and solubility in water. In order to find a rationale for the unexpected $\mathrm{p} K_{a}$ changes in the ( $\left.\mathrm{ZZ}^{\prime}\right) \mathrm{NCO}$ - substituents, we measured and modeled the $\mathrm{p} K_{a}$ with $\mathrm{Z}=\mathrm{Z}^{\prime}=\mathrm{H}$ and $\mathrm{Z}=\mathrm{Z}^{\prime}=$ methyl. The dominant contribution to the observed $\mathrm{p} K_{a}$ can be understood with advanced computational experiments, where the geminal proton is smoothly moved to the solvent bath. These models, mostly based on density-functional theory (DFT), include the explicit solvent (water) and statistical thermal fluctuations. As a first approximation, the change of $\mathrm{p} K_{a}$ can be correlated with the average energy difference between the two tautomeric forms (aci and nitro, respectively). The contribution of the solvent molecules interacting with the solute to the proton transfer mechanism is made evident.
\end{abstract}

Keywords: amides; carbanions; $\mathrm{C}-\mathrm{H}$ acidity; nitro-aci tautomerism; molecular dynamics; density-functional theory

\section{Introduction}

Nitro compounds are useful reagents in synthetic organic chemistry [1]. They are precursors of dipoles in 1,3-dipolar cycloaddition [2-6], a source of carbon nucleophiles in conjugated additions [7,8] and nitro aldol (Henry) reaction [9], and a substrate in Nef reaction [10,11]. In all of these reactions, $\mathrm{C}-\mathrm{H}$ protons geminal to the nitro group are involved. Because of the presence of the nitro group, the above $\mathrm{C}-\mathrm{H}$ protons show a higher degree of acidity (compound 4, Table 1) compared with the $\mathrm{C}-\mathrm{H}$ protons of an aliphatic chain. This feature is due to the ability of the nitro group to stabilize the carbanion in the form of the nitronate anion. The species involved in the nitro compound acidity are depicted in Figure 1 for primary nitro compounds. 


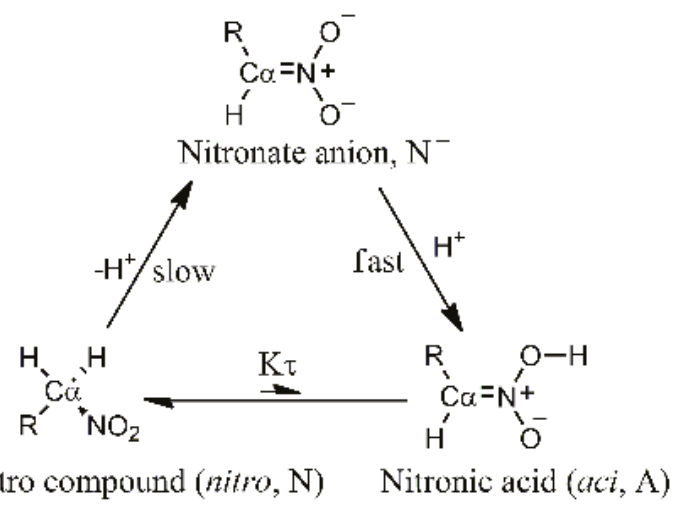

Figure 1. Schematic picture of species involved in the acid-base equilibria of nitro compounds.

An interesting aspect of nitro compounds is their lower proton extraction rate from $\mathrm{C} \alpha$ than that expected from the acidity (Figure 1). This aspect is due to the required conformational rearrangement of the $\mathrm{C} \alpha$ atom (from $s p^{3}$ to $s p^{2}$ ) to delocalize the negative charge of the carbanion to the nitro group [12]. The $\mathrm{p} K_{a}$ of nitronic acid, as it can be derived by kinetic experiments [12], is about 3.5. The issue of the unusual acidity of nitro compounds with labile $\mathrm{C}-\mathrm{H}$ bonds in a geminal position has been the object of experimental and modeling studies for a long time [12-14].

During our work on condensation of nitro compounds with alkenes or alkynes, we became interested in mechanistic aspects of this reaction $[6,15,16]$. We envisaged that acid-base properties of the substrates could be involved. The acidity of nitro compounds is enhanced by electron withdrawing groups such as esters and ketones in geminal position, resembling carboxylic acid in acid strength (compound 5 vs. compounds 6-8, Table 1) [12]. Intramolecular interactions, including hydrogen bonds, stabilize to different extents the species involved.

Therefore, in this work, we complete the list of ionization constants for some nitro compounds, including the nitroacetamides 1-3 (Figure 2), which are the major focus of our study because of the exceptional combination of acidity and solubility of compound $\mathbf{1}$.

Table 1. Apparent ionization constants of primary nitro compounds.

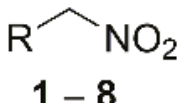

\begin{tabular}{llll}
\hline Compound & $\mathbf{R}$ & $\mathrm{pK}_{\boldsymbol{a}}{ }^{\mathbf{a}}$ & $\mathrm{p} \boldsymbol{K}_{\boldsymbol{a}}{ }^{\mathbf{b}}$ \\
\hline $\mathbf{1}$ & $\mathrm{H}_{2} \mathrm{NCO}$ & $\mathbf{5 . 3 9} ; 5.18[17]$ & 6.20 \\
$\mathbf{2}$ & $\left(\mathrm{CH}_{3}\right) \mathrm{HNCO}$ & $5.46[16]$ & 6.75 \\
$\mathbf{3}$ & $\left(\mathrm{CH}_{3}\right)_{2} \mathrm{NCO}$ & 7.23 & 5.99 \\
$\mathbf{4}$ & $\mathrm{H}$ & $10.7[18]$ & 10.2 \\
$\mathbf{5}$ & $\mathrm{CH}_{3}$ & $8.57[19]$ & 8.49 \\
$\mathbf{6}$ & $\mathrm{CH}_{3} \mathrm{CO}$ & $5.10[20]$ & 5.40 \\
$\mathbf{7}$ & $\mathrm{PhCO}_{\mathbf{8}}$ & $5.19[21]$ & 5.37 \\
\hline
\end{tabular}

a Data reported in the literature and measured (boldface) in this work; ${ }^{\mathrm{b}}$ Data obtained by ACDLabs available from SciFinder ${ }^{\mathrm{TM}}$. 


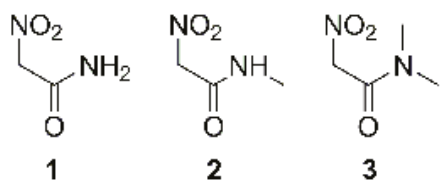

Figure 2. Nitroacetamides studied in this work.

Unexpectedly, nitroacetamides 1-3 show significant change in $\mathrm{p} K_{a}$ values by replacing $\mathrm{N}-\mathrm{CH} 3$ methyl groups in 3 with protons (compounds $\mathbf{2}$ and 1, Table 1). As we show with computational models, those values cannot be easily explained with stabilization factors on nitronate ions. In addition, the prediction of $\mathrm{p} K_{a}$ using a popular software [22], available from the SciFinder ${ }^{\mathrm{TM}}$ database, does not completely agree with the experimental data (Table 1, last column).

To provide a rationale for the effect of amide derivatives on the acidity of $\mathrm{C}-\mathrm{H}$ bonds in geminal position to the nitro group, we present in this work an original model where, in addition to electronic and steric intramolecular effects, the role of the water solvent is included. Electronic effects are included using density-functional theory (DFT) with exchange functional described as in the Perdew-Burke-Ernzerhof (PBE) approximation [23], when dynamical methods are used [24,25], or in the Becke three-parameter Lee-Yang-Parr (B3LYP) approximation [26], when static (or single point) calculations are performed. The models, compared to quantum mechanics/molecular mechanics (QM/MM) techniques [27], allow the study of subtle effects due to charge separation during the addressed reaction [28].

It is found that the solvent exerts an essential effect that opens to a new design strategy for further enhancing this important type of acidity.

\section{Results and Discussion}

Following the analysis first reported in Ref. [19], the "apparent" ionization constant $K^{\prime}$ is a function of the ionization constants of the two tautomeric forms, respectively aci and nitro (see Figure 1):

$$
K^{\prime}=\frac{\left[\mathrm{N}^{-}\right]\left[\mathrm{H}_{3} \mathrm{O}^{+}\right]}{[\mathrm{A}]+[\mathrm{N}]} .
$$

Manipulating the equation above, the apparent $K^{\prime}$ constant can be expressed in terms of the equilibrium constant between the two tautomeric forms $K_{\tau}$ :

$$
K^{\prime}=\frac{K_{N}}{\left(K_{\varnothing}+1\right)} \simeq K_{N}
$$

where $K_{N}$ is the ionization constant of the nitro form (that is the most stable at room conditions) and $K_{\tau}=[\mathrm{A}] /[\mathrm{N}]$. The low ratio between aci and nitro forms $\left(K_{\tau}<<1\right)$ at room conditions in water solution prevents the species from showing the larger acidity of the aci form compared to the nitro. The former is more acidic because the $\mathrm{C}-\mathrm{H}$ bond is always stronger than the $\mathrm{O}-\mathrm{H}$ bond. However, the enhanced chemical properties of rare species present with very low statistical weight in the sample are evident in the measured apparent ionization constant. The stronger acidity of the low-weight aci form is evident when the proton exchange between the aci form and the nitro form is frozen or the kinetics of the aci deprotonation can be separated by measured kinetic data [12]. Hereafter, we indicate $K^{\prime}$ as $K_{a}$.

The prediction of $\mathrm{p} K_{a}$ for the compounds displayed in Figure 2 is a challenging task also for empirical methods, the latter still the more accurate [29]. The application of a popular software [22], available from the SciFinder ${ }^{\mathrm{TM}}$ database, does not agree with the experimental data (see Introduction above) and our work aims at explaining the disagreement in terms of atomistic models. Theoretical and computational methods achieved significant advancement, but reliable applications are still problematic when protons are released by $\mathrm{C}$ atoms, rare species are transiently involved and subtle effects of solvent, especially water, play a role in the thermodynamics of the proton exchange. 
From a microscopic point of view, the contribution of rare acidic forms to the average observed property, that is potentially dominated by low-acidic forms, can be explained if the reactive form is trapped within energy barriers. In this case, the conversion from the rare form to the most stable one is slower than the ionization. The average property, provided by the series of sampled microscopic states, slowly converges with sampling.

Indeed, this effect can be achieved in practice with computational models where the model is constrained towards bound states and cannot escape from one chemical configuration to another. Among these models, the tight-binding method forces the sampling of bound states. In this approximation, the sampling of rare chemical species can last for a long time even if in theory the atoms should rapidly change the valence to reach the most stable configuration. Therefore, despite the many limitations of the tight-binding approximation, it is possible to compare the energy of different bound states, while free energy changes are affected by huge errors. In this case, the average energy can be computed in different samples, each mimicking the metastable equilibrium state of the two different and separated tautomeric forms. Another advantage is the possibility to include explicit water molecules in the modeled sample. In this work, we used the self-consistent charge density-functional tight-binding approximation [30] (DFTB, hereafter).

In order to compare the thermodynamic quantities measured by experiments with results of microscopic models, we make the following assumption in the context of the nitro compounds an object of this study. The larger the statistical weight of the aci form, the larger the acidity of the sample. The tight-binding approximation can be then used to describe realistic configurations with significant statistical weight for each of the two tautomeric forms. Once this goal is achieved, the proton transfer between the two forms can be described with more detailed computational experiments still including the contribution of the solvation layer. The latter task is accomplished here by adding an external empirical potential to a density-functional theory (DFT) approximation of electron density coupled with molecular dynamics (MD) simulations.

\subsection{Tight-Binding Approximation of nitro and aci Forms}

In Table 2, the difference in average energy $\left(\Delta E_{\tau}\right)$ at $T=300 \mathrm{~K}$ and at the water density of bulk water $\left(\rho_{0}=1 \mathrm{~g} / \mathrm{cm}^{3}\right)$ between the two tautomeric forms is reported.

Table 2. Comparison between $\Delta G^{0}(T=298 \mathrm{~K}, P=1$ bar $)$ for ionization of species $\mathrm{RCH}_{2} \mathrm{NO}_{2}$ soluble in water.

\begin{tabular}{lllll}
\hline Compound & $\Delta G^{\mathbf{0}}$ & $\Delta E_{\tau}(\mathrm{DFTB})$ & $\Delta E_{\tau}(\mathrm{DFT})$ & $\Delta G^{\mathbf{0}}$ \\
\hline $\mathbf{1}$ & $30.75 ; 29.55$ & -13 & $-53.85 /-55.70$ & 35.37 \\
$\mathbf{2}$ & 31.15 & -20 & $-65.16 /-73.74$ & 38.51 \\
$\mathbf{3}$ & $\mathbf{4 1 . 2 5}$ & -75 & $-61.54 /-66.73$ & 34.17 \\
$\mathbf{4}$ & 61.04 & -59 & -90.62 & 58.19 \\
$\mathbf{5}$ & 48.89 & -46 & -60.32 & 48.89 \\
$\mathbf{6}$ & 29.10 & -24 & -56.44 & 30.81 \\
$\mathbf{7}$ & 29.61 & -6 & -58.53 & 30.64 \\
$\mathbf{8}$ & $\mathbf{3 2 . 3 0 ; 3 2 . 4 0 ; 3 1 . 7 1}$ & -4 & -60.14 & 32.69 \\
\hline
\end{tabular}

Column 2 is derived from $\mathrm{p} K_{a}$ in Table 1 (boldface values are obtained in this work). Columns 3-4 $\left(\Delta E_{\tau}\right)$ are the difference in average energy between nitro and aci tautomers for the same species. Column 3 is computed in the explicit solvent DFTB model; column 4 is computed in the mean-field solvent DFT model (see Methods for details). Column 5 are values computed from $\mathrm{p} K_{a}$ obtained with SciFinder ${ }^{\mathrm{TM}}$ (Table 1 ). All energy values are in $\mathrm{kJ} / \mathrm{mol}$. DFTB averages are computed at $T=300 \mathrm{~K}$ and with water bulk density at $T=300 \mathrm{~K}$ and $P=1$ bar. In these conditions, root-mean square error on DFTB energy is in the range 105-140 kJ/mol.

These data are compared with the measured ionization free energy change and with the same energy difference computed with an accurate DFT approximation that allows geometry optimization in an implicit model of the water solvent. The final column is the $\Delta G_{0}$ derived from $\mathrm{p} K_{a}$ values predicted 
with an empirical method provided by the SciFinder ${ }^{\mathrm{TM}}$ database. According to a comparison between different prediction methods [29], the ACDLabs [22] method is one of the best performing.

The approximate DFTB model of the electronic structure and the low statistics are not expected to provide agreement between the measured free energy changes (column 2) and the computed energy difference between ionized and neutral species (not shown here). However, it can be noticed that the most acidic species (less positive free energy of ionization, column 2) display the lowest difference in energy of the aci tautomeric form (column 3). With the exception of 6 , the series of substituents displays the correct order for both $\Delta G^{0}$ and $\Delta E_{\tau}$. This rough correlation indicates that the contribution to the apparent acidity due to substituent $\mathrm{R}$ can be ascribed to the increasing statistical weight of the aci form, the latter characterized by large acidity.

The ACDLabs empirical prediction, though it is excellent for the compounds that are presumably tabulated (4-8), fails in predicting the high acidity of compound $\mathbf{1}$ and the decrease of acidity of $\mathbf{3}$ with respect to 1 .

Intramolecular interactions have only a partial role in determining the average energy difference between the two tautomeric forms. This is shown by the values of $\Delta E_{\tau}$ energy difference computed with the more accurate DFT method (column 4 in Table 2). The values are larger in absolute value than the corresponding DFTB estimate, even though they follow approximately the same ordering, with the smallest absolute values corresponding to the most acidic compounds. The range displayed for the amide derivatives is due to the choice of different structures as initial configurations for the geometry optimization. For instance, the lowest energy nitro structure corresponds to an open extended all-trans structure, where there is no interaction between the nitro and the amine group. The aci form is, compared to this extended structure, at the highest energy. On the other hand, when the nitro compound forms intramolecular interactions that favor a closed structure, the aci form is at a lower energy. However, in both cases, the energy difference is larger than when the calculation is performed with a less accurate model, but includes the solvent layer explicitly. Therefore, the inclusion of explicit solvent makes the energy landscape flatter than in the case of a polarizable continuum model for the solvent.

The interplay between intramolecular interactions and interactions with solvent molecules is shown by simulations in the explicit solvent.

In Figure 3, the time evolution of the $\mathrm{N}-\mathrm{C} \alpha-\mathrm{C} \beta-\mathrm{N} \gamma$ dihedral angle is displayed for all the three simulation stages (nitro, aci and ionized forms) for $\mathbf{1}$ and $\mathbf{3}$, performed in the DFTB model. The dihedral angle displays for both compounds large fluctuations when in the nitro form because of the $s p^{3}$ configuration of $\mathrm{C} \alpha$. After the displacement of $\alpha \mathrm{H}$ to the nitro $\mathrm{O}$ atom (in the aci form) and then into the bulk water (ionized form), the molecules are sealed into, respectively, $\mathrm{E}$ and $\mathrm{Z}$ configurations for $\mathbf{1}$ and 3. Despite the conformational freezing, keeping the aci form in the E configuration, the intramolecular $\mathrm{H}-\mathrm{N} \cdots \mathrm{H}_{N}-\mathrm{O}_{N}-\mathrm{N}$ hydrogen bond is not observed. Also in the ionized form, the $\mathrm{O}_{N}$ atoms of the nitro group strongly interact with water molecules in the solvent (see below).

Despite the absence of stable intramolecular hydrogen bonds, there are significant intramolecular interactions in certain compounds. For instance, there is a high persistence of the intramolecular interaction between the $\mathrm{N}-\mathrm{O}$ bond and the amide $\mathrm{H}$ atom when $\mathrm{R}=\mathrm{NH}_{2} \mathrm{CO}$ (1). This interaction keeps the aci form sealed in the $\mathrm{E}$ conformation, the latter more hindered to water access than the aci form of other compounds (see Table 3 and Figure 4 discussed below). The $\mathrm{N}-\mathrm{O} \cdots \mathrm{H}-\mathrm{N}$ interaction displays an angle smaller than $135^{\circ}$, thus being not classified as an hydrogen bond, but rather a strong electrostatic interaction. The proton attached to the nitro group in the aci form when $\mathrm{R}=\mathrm{NH}_{2} \mathrm{CO}$ never interacts with $\mathrm{N}$ and $\mathrm{O}$ of the amide group. The latter atom is always anti to the nitro group with respect to $\mathrm{C} \alpha-\mathrm{C}$ bond. As a consequence of this closed aci form, the anion displays always the strong $\mathrm{N}-\mathrm{O} \cdots \mathrm{H}-\mathrm{N}$ intramolecular electrostatic interaction, while such interaction is not effective in the other substituents. 


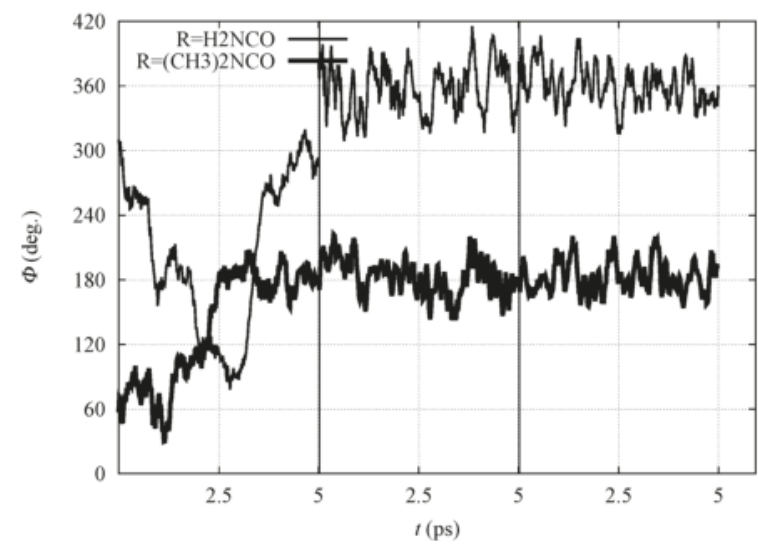

Figure 3. Time evolution of $\mathrm{N}-\mathrm{C} \alpha-\mathrm{C} \beta-\mathrm{N} \gamma$ dihedral angle $(\Phi)$ with $\mathrm{R}=\mathrm{H}_{2} \mathrm{NCO}$ (thin line) and $\left(\mathrm{CH}_{3}\right)_{2} \mathrm{NCO}$ (thick line) within BO-MD simulations performed with the density-functional tight-binding (DFTB) model. Vertical lines separate the simulation of nitro (left), aci (middle) and ionized (nitronate) forms (right), respectively.

Table 3. Hydrogen bond population (\%) for all H-bond donor and acceptor groups in the investigated compounds (residue R, see Table 1).

\begin{tabular}{llrrr}
\hline Compound & $\mathbf{R}$ & nitro & aci & anion \\
\hline $\mathbf{1}$ & $\mathrm{H}_{2} \mathrm{NCO}$ & 287 & 235 & 410 \\
$\mathbf{2}$ & $\left(\mathrm{CH}_{3}\right) \mathrm{HNCO}$ & 257 & 258 & 557 \\
$\mathbf{3}$ & $\left(\mathrm{CH}_{3}\right)_{2} \mathrm{NCO}$ & 170 & 282 & 455 \\
$\mathbf{6}$ & $\mathrm{CH}_{3} \mathrm{CO}$ & 175 & 160 & 426 \\
7 & $\mathrm{PhCO}_{3}$ & 139 & 249 & 359 \\
$\mathbf{8}$ & $\mathrm{CH}_{3} \mathrm{OCO}$ & 170 & 281 & 437 \\
\hline
\end{tabular}

Hydrogen bond is counted when the distance $\mathrm{X} \cdots \mathrm{Y}(\mathrm{X}$ donor, $\mathrm{Y}$ acceptor $)$ is within $0.3 \mathrm{~nm}$ and the $\mathrm{X}-\mathrm{H} \cdots \mathrm{Y}$ angle is between 135 and $180^{\circ}$. Percentage is obtained as the sum of occurrence of hydrogen bonds over all the water molecules in the sample, the two $\mathrm{O}-\mathrm{H}$ bonds in water (when donor), acceptor atoms or $\mathrm{X}-\mathrm{H}$ donating bond of solute, and the configurations collected at $T=300 \mathrm{~K}$ ( 250 configurations within the simulation time $t=5 \mathrm{ps}$ ), finally divided for the number of configurations. Therefore, percentage can be higher than 100 .

These observations indicate that the energy of most of the species reported in Table 2 is also strongly modulated by interactions with the water environment, in addition to the electrostatic intramolecular interactions discussed above. The hydrogen bond population of H-bond donor and acceptor groups is reported in Table 3 and in Figure 4.

In this analysis, all the water molecules $(213,210$ only when $\mathrm{R}=\mathrm{PhCO})$ in the sample are included. From Table 3, it can be observed that the $\alpha \mathrm{H}$ atom forms a significant amount of hydrogen bonds with water molecules ( $\mathrm{C} \alpha-\mathrm{H} \cdots \mathrm{Ow}$, with $\mathrm{Ow}$ the $\mathrm{O}$ atom in water molecules) when $\mathrm{C} \alpha$ is in the nitro form. As a term of comparison, when $\mathrm{R}=\mathrm{CH}_{3}(5$, data not displayed in Table) the probability for $\mathrm{C} \alpha-\mathrm{H}$ and $\mathrm{C} \beta$-H hydrogen bonds with water is, respectively, 23 and $22 \%$.

The $\mathrm{C} \alpha-\mathrm{H} \cdots$ Ow hydrogen bond is lost when the $\mathrm{C} \alpha$ atom is converted into the $s p^{2}$ electronic configuration (aci and nitronate forms). The highest population $\mathrm{C} \alpha-\mathrm{H} \cdots \mathrm{Ow}$ hydrogen bond is observed for $\mathrm{R}=\mathrm{NH}_{2} \mathrm{CO}$ (1) in the nitro form ( $81 \%$, see Figure 4$)$.

The probability of any hydrogen bond with water molecules (both donating and accepting solute hydrogen atoms) reported in Table 3 shows that, for $\mathbf{1}$ and $\mathbf{2}$, and when the solute is neutral, the population of hydrogen bonds has its maximum in the nitro form. The probability is still high when the proton is moved to the aci form. Finally, when the proton is removed from the solute (the negatively charged nitronate form), the probability of hydrogen bonds with the solvent increases, mainly because of the negatively charged nitro group. Looking at the partition of hydrogen bonds (Figure 4), it can 
be noticed that substituents with at least one $\mathrm{N}-\mathrm{H}$ bond are particularly efficient in keeping water molecules structured in the first solvation layer around all the regions of the solute, independently of the tautomeric or protonation form.

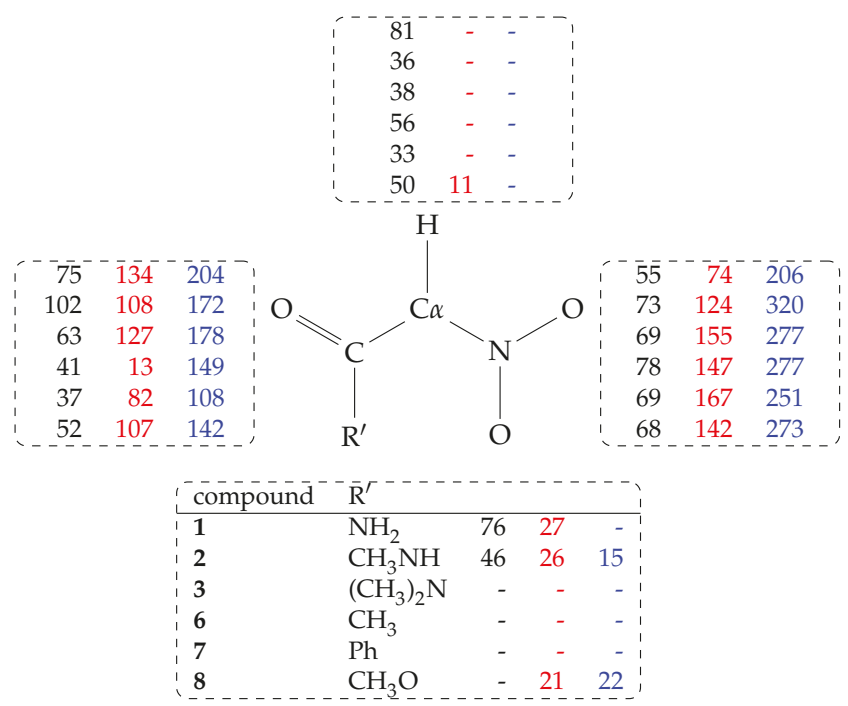

Figure 4. Hydrogen bond population (\%) measured as in Table 3 and distributed over atomic groups in nitro (black, column 1), aci (red, column 2), and nitronate (blue, column 3) species. Lines are in the same order of Table 3. The - symbol indicates no hydrogen bond. Hydrogen bonds are counted for atoms: $\mathrm{C} \alpha-\mathrm{H}$ (top); $\mathrm{CO}$ (left); $\mathrm{NO}_{2}$ (right); $\mathrm{R}^{\prime}$ (bottom).

The water environment around each molecule has different degrees of basicity and, once it is protonated by the $\alpha \mathrm{H}$ extraction, different degrees of acidity towards the solute molecule. To approximately measure acid-base properties of this water environment, $\alpha \mathrm{H}$ is extracted from the solute by moving the atom towards the closest water molecule in the solvent bath. In this condition, the water bath (containing a single $\mathrm{H}_{3} \mathrm{O}^{+}$species) is allowed to give back the proton to the solute. If a short time is provided to the solute, allowing the relaxation of the $\mathrm{C} \alpha$ bond environment, the water bath gives the proton back to other basic groups because, in the tight-binding approximation, the relaxed $s p^{2} \mathrm{C} \alpha$ atom can not form a new $\mathrm{C}-\mathrm{H}$ bond. Remarkably, in most of the cases, the group that is able to host the proton provided by the water bath is the nitro group, thus forming the solute in the aci form. Therefore, this alchemical process mimics a possible pathway for the proton transfer from position $\mathrm{C} \alpha$ to the nitro $\mathrm{O}$ atom, as it is mediated by the water layer around the solute. This simple experiment allows a first exploitation of the mechanism by which the solute can better manifest itself as the more acidic aci form. Interestingly, in some cases $(\mathrm{R}=\mathrm{PhCO})$, the carbonyl oxygen is able to form a transient covalent bond with the proton provided by the water layer.

In Table 4, the times required to transfer the proton from the water layer to one of the oxygen atoms in the solute, producing either the aci or the enolic form, is reported. 
Table 4. Times $(\tau)$ required to transfer the excess proton in the water layer, due to $\alpha \mathrm{H}$ extraction from $\mathrm{C} \alpha$, to $\mathrm{O}$ atoms either in the nitro group or in the carbonyl group (the latter case indicated with an asterisk).

\begin{tabular}{ll}
\hline $\mathbf{R}$ & $\boldsymbol{\tau}(\mathrm{ps})$ \\
\hline $\mathbf{1}$ & $0.28\left(^{*}\right)$ \\
$\mathbf{2}$ & 1.92 \\
$\mathbf{3}$ & - \\
$\mathbf{6}$ & $>5$ \\
7 & $0.14\left(^{*}\right)$ \\
$\mathbf{8}$ & $>5$ \\
\hline
\end{tabular}

Each $\alpha \mathrm{H}$ extraction to the water layer is performed from a selected configuration displaying an approximately zero or $\pi$ dihedral angle for $\alpha \mathrm{H}^{\prime}-\mathrm{C} \alpha-\mathrm{N}-\mathrm{O}$ and a water molecule with Ow within $0.2 \mathrm{~nm}$ from $\alpha \mathrm{H}$. It must be noticed that, when these two conditions are not fulfilled, in most of the cases, the $\alpha$ proton is rapidly given back to $\mathrm{C} \alpha$ because there is no efficient relaxation mechanism for the $\mathrm{H}_{3} \mathrm{O}^{+}$species formed in the water layer.

The formation of the aci form from the reaction between the protonated water environment and the negatively charged form of the solute has different lag-times $\tau$ displayed in Table 4 . In some cases ( 1 and 7 ), the proton is finally bound by the carbonyl oxygen, forming the enolic isomer of the given species. Only in the case of 3 , the proton goes always back to $C \alpha$ because of the strong repulsion between the solute and the close by hydronium species formed by the $\alpha \mathrm{H}$ extraction. Therefore, these data show that, for $\mathbf{1}, \mathbf{2}$ and 7, the pathway for proton exchange between $\mathrm{C}-\mathrm{H}$ bond in the solute and a $\mathrm{O}-\mathrm{H}$ bond in the solvation water layer, followed by the exchange with the $\mathrm{O}-\mathrm{H}$ bond in the solute, is easily found.

The large chance of formation of enolic forms in the case of $\mathbf{1}$ and $\mathbf{7}$ is an indication of the possibility for enolic form as an intermediate in the slow process of $\mathrm{C} \alpha$ deprotonation. A higher probability for enolic form increases the rate for proton release in certain compounds, as observed in the literature [12], because of the $s p^{2}$ pre-organization of C $\alpha$. In the DFTB model investigated here, the enolic form appears, in the more hydrophilic nitro compounds analyzed here, as a second acidic form of the nitro compound, in addition to the aci form. However, in the DFTB model, the mechanism to obtain the enolic form is mediated by the water molecule close to the $\alpha \mathrm{H}$ atom that is extracted.

\subsection{The $\alpha$ H Extraction from the nitro Tautomer and Insertion into the aci Tautomer}

The DFT model of the water solution sample circumvents the limitation of the tight-binding model in oversampling bound states. By using an external force that smoothly extracts one of the $\alpha$ $\mathrm{H}$ atom away from the $\mathrm{C} \alpha-\mathrm{H}$ bond at room thermal conditions, it is possible to break the $\mathrm{C}-\mathrm{H}$ bond, keeping the possibility of forming alternative explicit $\mathrm{H}-\mathrm{O}$ bonds in the first solvent layer of the solute.

The analysis of the change in potential energy along with the $\alpha \mathrm{H}$ extraction in the two extreme cases $\left(\mathrm{R}=\mathrm{H}_{2} \mathrm{NCO}\right.$ and $\left.\mathrm{R}=\left(\mathrm{CH}_{3}\right)_{2} \mathrm{NCO}\right)$ is displayed in Figure 5 (see Methods).

The configurations corresponding to some selected points, indicated by letters a-f and A-F, are displayed in Figures 6 and 7, respectively.

It can be noticed that the compact initial structure of $\mathbf{1}$, where the electrostatic interaction between the amino and nitro groups is effective, is rapidly lost during equilibration, and extended configurations are sampled in the explicit solvent (Figure 6, panel a). During the application of the external force that drives one of the $\alpha \mathrm{H}$ towards the solvent, the more hydrophilic substituent $\left(\mathrm{R}=\mathrm{H}_{2} \mathrm{NCO}\right.$, filled circles in Figure 5) displays the increase in potential energy due to the exchange of the $\mathrm{C}-\mathrm{H}$ bond with a $\mathrm{O}-\mathrm{H}$ bond (Figure $5 \mathrm{c})$. The potential energy is rapidly decreased ( $\sim 150 \mathrm{~kJ} / \mathrm{mol})$, producing configurations with the proton confined within the solute and a water molecule in the first solvation layer (Figure $6 \mathrm{~d}$, the excess proton is on top-right). 
On the other hand, the more hydrophobic substituent $\left(\mathrm{R}=\left(\mathrm{CH}_{3}\right)_{2} \mathrm{NCO}, 3\right.$, circles in Figure 5) displays a fast movement of $\alpha \mathrm{H}$ to the closest water molecule (2.7 $\AA$ compared to 2.0 of 1 ), with a similar increase in potential energy compared to 1 . However, the following relaxation of the charge separation (Figure 7C) does not allow a significant decrease in potential energy. The excess proton (that is visible in panel $\mathrm{C}$ on top of the carbonyl group) displays a high energy and the movement of the excess proton away from the first solvation layer does not produce a significant decrease in potential energy (Figure 7D). The oscillation of potential energy (panels e-f and E-F of Figures 6 and 7, respectively) does not allow for the hydrophobic substituent (circles in Figure 5) the dissipation of potential energy that is allowed for the more hydrophilic one (filled circles in the same figure).

For both the substituents, the aci form is produced during the forced N-O neutralization process (Figures 6 and 7, panels E-F). Nevertheless, the aci form is transient and in rapid exchange with anions displaying hydrogen bonds between the nitro group and water molecules in the first solvation layer.
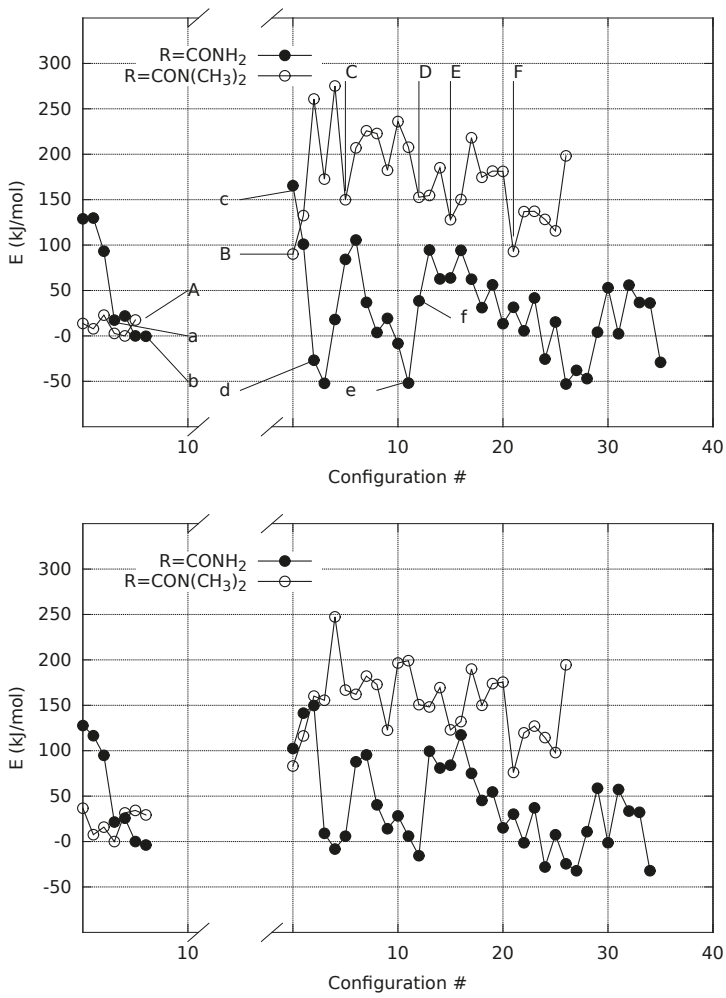

Figure 5. Potential energy with $\mathrm{R}=\mathrm{H}_{2} \mathrm{NCO}$ (filled circles) and $\left(\mathrm{CH}_{3}\right)_{2} \mathrm{NCO}$ (circles) along with the extraction of $\alpha \mathrm{H}$ from the bond with $\mathrm{C} \alpha$ atom. Energy is computed for solute within a distance $\mathrm{O}$ (water)-solute atoms of $4 \AA$ (see Methods). Energy reference is the lowest energy obtained in the initial nitro form for each compound. The gap in the $x$-axis separates nitro (left) from nitronate and aci (right) species. Arrows in the left panel indicate the configurations displayed in Figures 6 and 7. The calculation is performed with plane-wave basis-set and PBE exchange functional (left) and localized Gaussian basis-set with hybrid B3LYP exchange functional (right panel). Points indicated with a-f and A-F are are displayed in Figures 6 and 7, respectively. See text for details. 


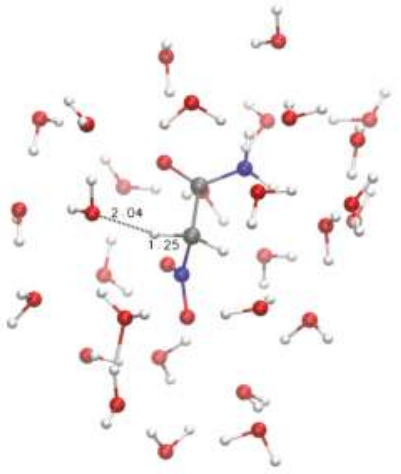

(a)

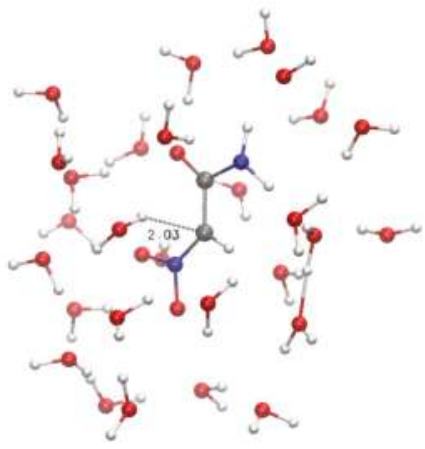

(c)

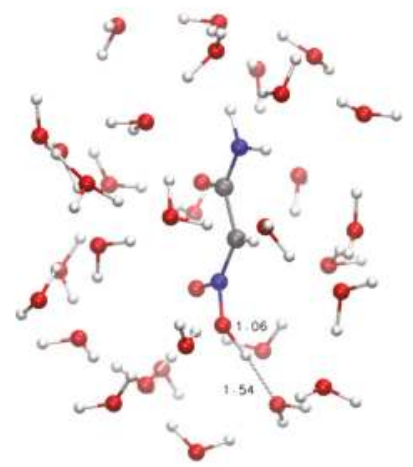

(e)

Figure 6. Structures of samples with $\mathrm{R}=\mathrm{H}_{2} \mathrm{NCO}$ along with proton extraction (Figure 5). Panels (a-f) refer, respectively, to points indicated with a-f in Figure 5. C is gray, $\mathrm{N}$ is blue, $\mathrm{O}$ is red, $\mathrm{H}$ is white. Atomic and bond radii are arbitrary. Some relevant distances are displayed. Explicit bonds are drawn when atoms are closer than 1.6 ̊. The VMD [31] program is used for all molecular drawings. 

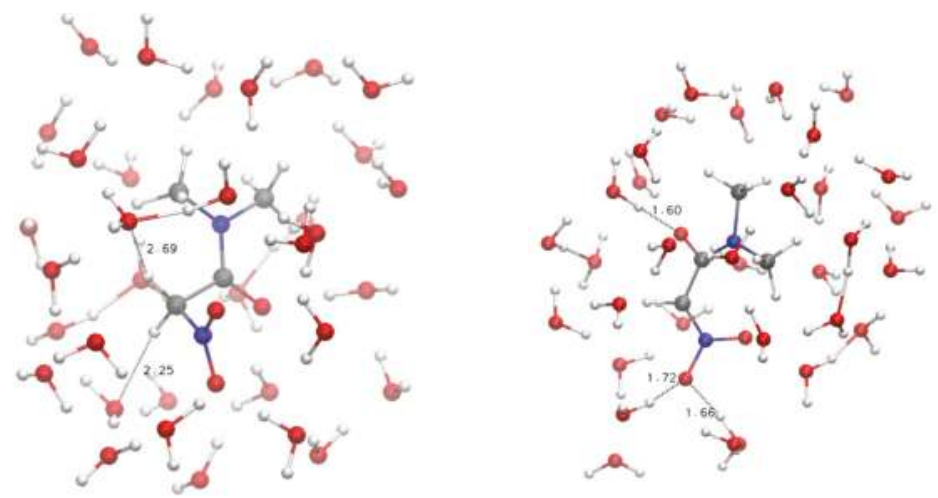

(A)

(B)

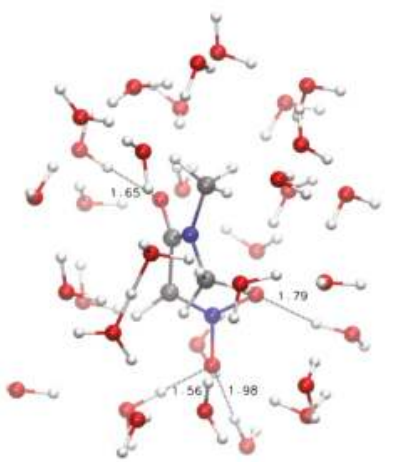

(C)

(D)
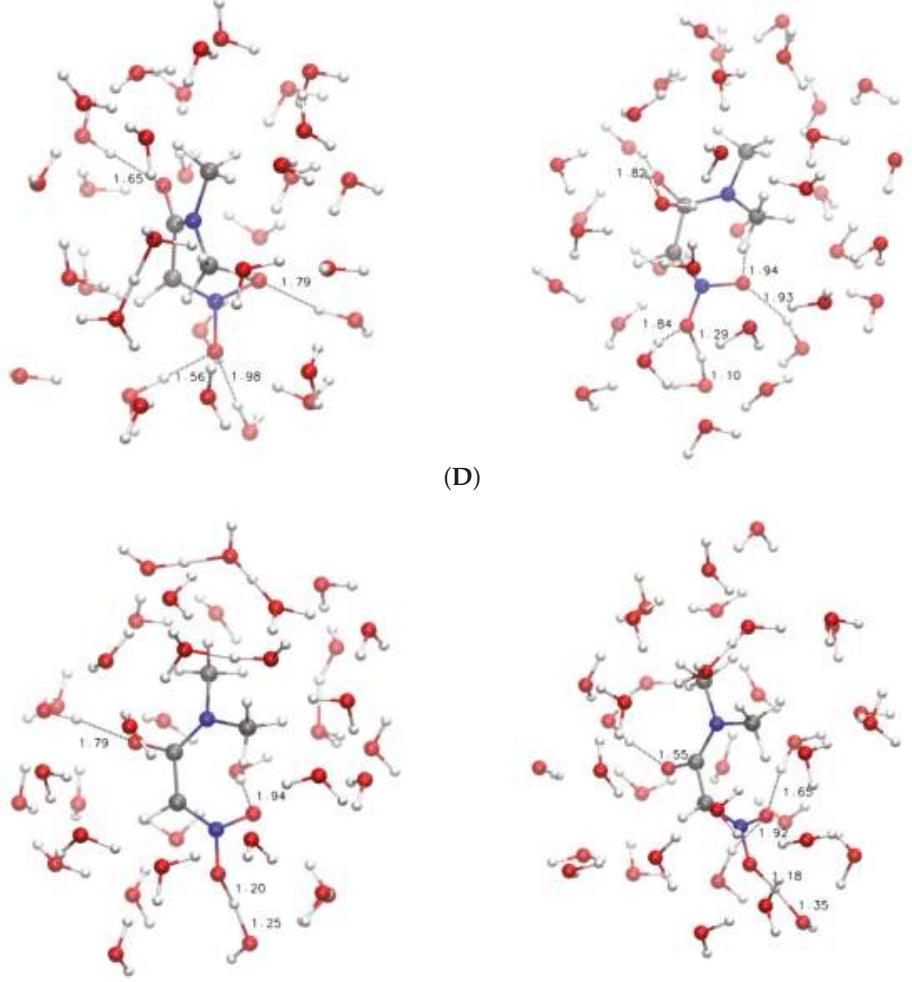

(E)

(F)

Figure 7. The same as Figure 6 when $\mathrm{R}=\left(\mathrm{CH}_{3}\right)_{2} \mathrm{NCO}$. Panels $(\mathrm{A}-\mathrm{F})$ refer, respectively, to points indicated with A-F in Figure 5.

\section{Materials and Methods}

\subsection{Preparation of Nitroacetamides and Determination of Ionization Constants (Apparent $p K_{a}$ )}

Nitroacetamide (1) and N,N-dimethylnitroacetamide (3) have been obtained, respectively, by aminolysis from ethyl nitroacetate [32,33] and methyl nitroacetate [34], following previously reported procedures. 
Ionization constants of nitro compounds $\mathbf{8}, \mathbf{1}$, and $\mathbf{3}$ were determined in water by potentiometric titration using a glass electrode (method of partial neutralization). The values of $\mathrm{pH}$ were determined with CyberScan $510 \mathrm{pH}$ meter produced by Eutech Instruments. Compound $\mathbf{8}$ was used as reference acid and its $\mathrm{pK}_{a}$ was determined to reproduce published results [12] using our procedure.

The values of $\mathrm{p} K_{a}$ were calculated according to the formula:

$$
\mathrm{p} K_{a}=\mathrm{pH}+\log \frac{[\mathrm{HA}]}{[\mathrm{A}]},
$$

where $[\mathrm{HA}]$ is the concentration of non-dissociated nitroacetamide and $[\mathrm{A}]$ is the concentration of its salt.

\subsubsection{Methyl Nitroacetate (8)}

A $0.0100 \mathrm{M}(59.5 \mathrm{mg}$ in $50 \mathrm{~mL})$ solution of methyl nitroacetate $(8)$ (41.0 mL) was titrated with a $0.100 \mathrm{M}$ solution of sodium hydroxyde. Titration data are reported in Table 5.

Table 5. Calculations of the acidity constants of 8 at $T=23^{\circ} \mathrm{C}$ (Table 1), according to the results of one titration. $\mathrm{p} K_{a}=5.70$ as the arithmetic mean of all 12 values in the set.

\begin{tabular}{llll}
\hline $\mathbf{N a O H}(\mathrm{mL})$ & $\log [\mathrm{HA}] /[\mathrm{A}]$ & $\mathrm{pH}$ & $\mathrm{p} \boldsymbol{K}_{\boldsymbol{a}}$ \\
\hline 0.3 & 1.10 & 4.59 & 5.69 \\
0.6 & 0.766 & 4.88 & 5.65 \\
0.9 & 0.551 & 5.12 & 5.67 \\
1.2 & 0.383 & 5.3 & 5.68 \\
1.5 & 0.239 & 5.42 & 5.66 \\
1.8 & 0.106 & 5.59 & 5.70 \\
2.1 & -0.0212 & 5.72 & 5.70 \\
2.4 & -0.150 & 5.84 & 5.69 \\
2.7 & -0.285 & 5.97 & 5.68 \\
3.0 & -0.436 & 6.16 & 5.72 \\
3.3 & -0.615 & 6.33 & 5.71 \\
3.6 & -0.857 & 6.68 & 5.82 \\
\hline
\end{tabular}

\subsubsection{Nitroacetamide (1)}

Run 1: a $0.0100 \mathrm{M}(103.9 \mathrm{mg}$ in $100 \mathrm{~mL})$ solution of nitroacetamide $(\mathbf{1})(48.0 \mathrm{~mL})$ was titrated with a $0.100 \mathrm{M}$ solution of sodium hydroxyde at $T=23^{\circ} \mathrm{C}$. Run 2: the above $0.0100 \mathrm{M}$ solution of nitroacetamide $(\mathbf{1})(44.0 \mathrm{~mL})$ was titrated with a $0.100 \mathrm{M}$ solution of sodium hydroxyde at $T=21^{\circ} \mathrm{C}$. Titration data are reported in Table 6.

Table 6. Calculations of the acidity constants of $\mathbf{1}$ (Table 1), according to the results of two titrations. $\mathrm{p} K_{a}=5.39$ and 5.38 as the arithmetic mean of all eight values in the set Run 1 and Run 2, respectively.

\begin{tabular}{|c|c|c|c|c|c|c|}
\hline \multirow{2}{*}{$\mathrm{NaOH}(\mathrm{mL})$} & \multicolumn{3}{|c|}{ Run 1} & \multicolumn{3}{|c|}{ Run 2} \\
\hline & $\log [\mathrm{HA}] /[\mathrm{A}]$ & $\mathrm{pH}$ & $\overline{\mathrm{p} K_{a}}$ & $\log [\mathrm{HA}] /[\mathrm{A}]$ & $\mathrm{pH}$ & $\mathrm{p} K_{a}$ \\
\hline 0.5 & 0.934 & 4.36 & 5.29 & 0.892 & 4.42 & 5.31 \\
\hline 1.0 & 0.580 & 4.72 & 5.30 & 0.531 & 4.77 & 5.30 \\
\hline 1.5 & 0.342 & 4.96 & 5.30 & 0.286 & 5.02 & 5.31 \\
\hline 2.0 & 0.146 & 5.17 & 5.32 & 0.0792 & 5.26 & 5.34 \\
\hline 2.5 & -0.0362 & 5.37 & 5.33 & -0.119 & 5.48 & 5.36 \\
\hline 3.0 & -0.222 & 5.60 & 5.38 & -0.331 & 5.75 & 5.42 \\
\hline 3.5 & -0.430 & 5.91 & 5.48 & -0.590 & 6.21 & 5.62 \\
\hline 4.0 & -0.699 & 6.42 & 5.72 & - & - & - \\
\hline
\end{tabular}




\subsection{3. $N, N$-Dimethylnitroacetamide (3)}

Run 1: a $0.0100 \mathrm{M}(66.1 \mathrm{mg}$ in $50 \mathrm{~mL})$ solution of N,N-Dimethylnitroacetamide (3) (43.0 mL) was titrated with a $0.100 \mathrm{M}$ solution of sodium hydroxyde at $T=25^{\circ} \mathrm{C}$. Run 2: same as $R$ un 1 at $T=24{ }^{\circ} \mathrm{C}$. Titration data are reported in Table 7.

Table 7. Calculations of the acidity constants of 3 (Table 1), according to the results of two titrations. $\mathrm{p} K_{a}=7.25$ and 7.23 as the arithmetic mean of all 8 values in the set Run 1 and of 13 values in set Run 2, respectively.

\begin{tabular}{|c|c|c|c|c|c|c|c|}
\hline \multirow[b]{2}{*}{$\mathrm{NaOH}(\mathrm{mL})$} & \multicolumn{3}{|c|}{ Run 1} & \multirow[b]{2}{*}{$\mathrm{NaOH}(\mathrm{mL})$} & \multicolumn{3}{|c|}{ Run 2} \\
\hline & Log [HA]/[A] & $\mathrm{pH}$ & $\overline{\mathrm{p} K_{a}}$ & & $\log [\mathrm{HA}] /[\mathrm{A}]$ & $\mathrm{pH}$ & $\mathrm{p} K_{a}$ \\
\hline 0.5 & 0.881 & 6.32 & 7.20 & 0.3 & 1.12 & 6.11 & 7.23 \\
\hline 1.0 & 0.519 & 6.74 & 7.26 & 0.6 & 0.790 & 6.47 & 7.26 \\
\hline 1.5 & 0.271 & 6.99 & 7.26 & 0.9 & 0.577 & 6.69 & 7.27 \\
\hline 2.0 & 0.0607 & 7.2 & 7.26 & 1.2 & 0.412 & 6.86 & 7.27 \\
\hline 2.6 & -0.184 & 7.41 & 7.23 & 1.5 & 0.271 & 6.97 & 7.24 \\
\hline 3.0 & -0.363 & 7.62 & 7.26 & 1.8 & 0.143 & 7.09 & 7.23 \\
\hline 3.5 & -0.641 & 7.91 & 7.27 & 2.1 & 0.0202 & 7.22 & 7.24 \\
\hline 4.0 & -1.12 & 8.41 & 7.29 & 2.4 & -0.101 & 7.34 & 7.24 \\
\hline- & - & - & - & 2.7 & -0.227 & 7.45 & 7.22 \\
\hline - & - & - & - & 3.0 & -0.363 & 7.58 & 7.22 \\
\hline - & - & - & - & 3.3 & -0.519 & 7.73 & 7.21 \\
\hline- & - & - & - & 3.6 & -0.711 & 7.9 & 7.19 \\
\hline- & - & - & - & 3.9 & -0.989 & 8.16 & 7.17 \\
\hline
\end{tabular}

\subsection{Density Functional Tight-Binding (DFTB) Models}

The final goal of our models is to investigate the mechanism of the reactions described in Figure 1, within a density-functional theory (DFT) approximation of electrons in a system composed by the solute nitro compound and a sample of solvent water molecules. To accomplish this task, we apply in this work implementations of DFT suited for systems of several hundreds of atoms (see the next subsection below). Before applying time-consuming DFT models to systems composed of several hundreds of atoms, we applied, to the same systems, semi-empirical models that are as close as possible to the final DFT models, in order to minimize effects due to the transition from the semi-empirical to the DFT models. Therefore, we performed molecular dynamics (MD) simulations in the Born-Oppenheimer (BO) approximation and at room conditions (BO-MD, hereafter) within a semi-empirical Hamiltonian describing atomic cores and valence electrons. The Hamiltonian of the system was based on the self-consistent charge density-functional tight-binding approximation [30] (DFTB), because geometrical parameters (like distances and angles) of minimal energy conformations are consistent with accurate DFT calculations for a large set of organic molecules, both isolated and in condensed phases. We used the DFTB+ code [35] for these simulations. The valence electrons of each atom are represented as $s$ and $p$ orbitals.

We built the solute nitro compounds according to standard geometrical parameters and we merged the resulting solute conformation into a snapshot of the sample of water molecules simulated by MD with the TIP3P interaction potential [36]. This sample is a cubic unit cell with the side of $1.8774 \mathrm{~nm}$ containing 216 water molecules, in a configuration extracted by the MD simulated trajectory in the NVT (constant number of particles, volume, and temperature statistical ensemble with $T=300$ $\mathrm{K}$ and the fixed density of $0.976 \mathrm{~g} / \mathrm{cm}^{3}$. The water molecules with the $\mathrm{O}$ atom closer than $1.2 \AA$ from any solute atom were discarded. The number of discarded water molecules was in the range from $6(\mathrm{R}=\mathrm{COPh})$ to $3(\mathrm{R}=\mathrm{CH} 3 \mathrm{CO})$. As usual, to minimize finite volume effects, periodic boundary conditions are imposed to the system.

The energy of the system was minimized via the conjugate gradient algorithm for 20 steps, in order to reduce the force initially acting on the atoms. Then, the MD simulation in the NVE (constant number of particles, volume, and energy statistical ensemble was performed for 100 steps, starting with 
velocities extracted from a Gaussian distribution at $T=50 \mathrm{~K}$ and with a time-step of $1 \mathrm{fs}$. During this stage, the temperature never reached values larger than $50 \mathrm{~K}$, indicating the absence of close contacts between atoms. The velocity-verlet algorithm was used to integrate the equations of motion [37]. The MD simulation in the NVT statistical ensemble was then performed continuing the trajectory by using the Nosé-Hoover thermostat [38] at $T=150 \mathrm{~K}$ for 1000 steps, followed by 5000 steps (5 ps) at $T=300 \mathrm{~K}$. A unique effective mass corresponding to a coupling constant of $10 \mathrm{THz}$ was used for the thermostat. The second half of the simulation at $T=300 \mathrm{~K}$ ( $2.5 \mathrm{ps})$ was used for analysis, sampling configurations every $20 \mathrm{fs}$.

To account for temperature oscillations affecting energy values, the total energy $H$ was corrected for the thermal contribution of $N_{d e g} R T(t) / 2$, with $N_{d e g}=3 N_{a t}-6, N_{a t}$ the number of atoms in the simulated cell, and $T(t)$ the actual temperature measured in the system at time $t$. Therefore, the corrected total energy $H^{\prime}=H-N_{d e g} R T(t) / 2$ was used for computing the average total energy $E=\left\langle H^{\prime}\right\rangle_{T}$ of each simulated system.

\subsection{Density Functional Theory (DFT) Models}

Car-Parrinello molecular dynamics (CP-MD) simulations [24,25] were performed for models with $\mathrm{R}=\mathrm{H}_{2} \mathrm{~N},\left(\mathrm{CH}_{3}\right) \mathrm{HN}$ and $\left(\mathrm{CH}_{3}\right)_{2} \mathrm{~N}$, starting from the final atomic positions and velocities obtained with the corresponding DFTB model at $T=300 \mathrm{~K}$. The parallel version of the Quantum-Espresso package [39], which incorporates Vanderbilt ultra-soft pseudopotentials [40] and the PBE exchange-correlation functional [23], was used in all CP-MD simulations. Electronic wave functions were expanded in plane waves up to an energy cutoff of $25 \mathrm{Ry}$, while a 250 Ry cutoff was used for the expansion of the augmented charge density in the proximity of the atoms, as required in the ultra-soft pseudopotential scheme. As in the DFTB calculations, periodic boundary conditions were applied in the three directions of space. All calculations were performed under spin-restricted conditions, i.e., with two-electrons effective Kohn-Sham orbitals. The electronic ground state was first calculated using 10 steps of conjugate gradient minimization performed on the dynamic variables representing electrons. Then, the system evolution was followed with $\mathrm{CP}-\mathrm{MD}$, using as initial velocities those obtained with the final DFTB configuration. As in the DFTB BO-MD, we used the velocity-Verlet algorithm for integrating the equations of motion, with a time step of $0.121 \mathrm{fs}$. Empirical dispersive corrections of energy and forces [41,42] were included in the CP-MD simulations to correct for the overestimate of atomic repulsion by the DFT approximation.

We performed CP-MD simulations in the NVT statistical ensemble, with temperature held fixed by a Nosé-Hoover thermostat [38]. The systems were equilibrated for 726 fs (6000 time-steps). After this stage, the simulation was continued in the NPT statistical ensemble. In order to further reduce the overestimate of repulsive forces, possibly producing an unrealistic empty space between solutes and solvent water molecules, a short simulation stage at a pressure slightly larger than room conditions can better settle the water layer around the solute. We performed this step with a short simulation (6000 time-steps) with the same thermostat used in the NVT ensemble and a barostat at $P=10$ bar [43] with an effective mass of $3 / 4 M \pi^{2}, M$ the total mass of the simulation cell. The cell side oscillates around $1.72 \mathrm{~nm}$ in all of the simulations. At the end of this NPT stage, we started manipulating the $\alpha$ $\mathrm{H}$ atoms with external pulling forces (see below), still in the NPT statistical ensemble. At the end of the $\mathrm{H} \alpha$ extraction from $\mathrm{C} \alpha$, the sample volume was kept fixed (NVT ensemble).

\subsection{Pulling $\alpha H$ in DFT Models}

We performed pulling experiments in order to explore possible pathways for the mechanism of $\mathrm{C} \alpha-\mathrm{H}$ bond breaking, together with the formation of $\mathrm{O}-\mathrm{H}$ bonds in the water layer around the solute. After extraction of $\alpha \mathrm{H}$ from the $\mathrm{C}-\mathrm{H}$ bond, the $\mathrm{O}_{N}-\mathrm{H}$ bond formation (with $\mathrm{O}_{N}$ indicating the $\mathrm{O}$ atom in the nitro group) was forced in order to achieve the aci form of the nitro compound (see Figure 1). To accomplish this pathway, we first applied an external mechanical force on the atoms involved in the $\mathrm{C} \alpha-\mathrm{H}$ bonds. When the extraction of $\alpha \mathrm{H}$ into the water sample was achieved, we applied a similar 
external force to the $\mathrm{H}$ atoms in the water sample, potentially binding $\mathrm{O}_{N}$ atoms of the nitro group. With the first pulling experiment, we obtain the nitronate anion from the nitro compound in the nitro form; with the second experiment, we obtain the aci form of the nitro compound starting from the nitronate anion in contact with a protonated sample of water.

As for the first pulling experiment, we defined a collective variable as the $\mathrm{C} \alpha$ coordination number $\mathrm{CN}$ according to the equation below [44]:

$$
\begin{aligned}
C N & =\sum_{i, j} s_{i, j}, \\
s_{i, j} & =1 \text { if } r_{i, j} \leq 0, \\
s_{i, j} & =\frac{1-\left(\frac{r_{i, j}}{\sigma}\right)^{6}}{1-\left(\frac{r_{i, j}}{\sigma}\right)^{12}} \text { if } r_{i, j}>0, \\
r_{i, j} & =\left|\mathbf{r}_{i}-\mathbf{r}_{j}\right|-d_{0},
\end{aligned}
$$

where the index $j$ runs over the $\alpha \mathrm{H}$ (two) atoms of the solute and $i$ indicates $\mathrm{C} \alpha$. The actual value of $C N$ can be therefore manipulated by defining an external force as the derivative of an external harmonic potential $U_{e}=\frac{k}{2}\left(C N-C N_{0}(t)\right)^{2}$. By progressively decreasing $C N_{0}$ with the simulation time $t$, we allow the smooth release (when the target $C N_{0}$ value becomes lower than the actual value of $C N$ ) of one of the two $\alpha \mathrm{H}$ atoms. With this procedure and due to the presence of the explicit water molecules in the model, the $\mathrm{C}-\mathrm{H}$ bond is broken and, when available, a new $\mathrm{O}-\mathrm{H}$ bond is formed in the water layer around the solute. The parameter $d_{0}$ in Equation (4) was set to $1.1 \AA$, while $\sigma$ was $0.2 \AA$ for the first 363 fs and was increased to $0.5 \AA$ for the following $363 \mathrm{fs}$. The parameter $k$ was set to $1255 \mathrm{kcal} / \mathrm{mol}$ in all experiments. The value of $C N_{0}$ is moved from 2 to 1 at the rate of $1 C N$ value in $2000 \mathrm{CP}-\mathrm{MD}$ steps. The pulling of $\alpha \mathrm{H}$ was performed in $726 \mathrm{fs}$ after the equilibration.

As for the second pulling experiment, the index $i$ runs over the $\mathrm{O}_{N}$ atoms of the nitro group, while $j$ runs over all the $\mathrm{H}$ atoms not bound to the solute. The $d_{0}$ parameter was $1.03 \AA$, the latter the equilibrium distance for $\mathrm{O}_{N}-\mathrm{H}_{N}$ measured by DFTB simulations. The $C N_{0}$ parameter was increased from zero to one, at the same speed and after the same equilibration time of the $\alpha \mathrm{H}$ pulling experiment.

\subsection{Analysis}

We computed a mean-field energy for selected configurations along the pathways sampled with $\mathrm{CN}$ manipulations. This calculation is required to correct the energy for contributions due to the periodic boundary conditions and to eliminate thermal fluctuations due to the presence of bulk water around the system of interest (the solute and its hydration layer). From each simulated configuration in the trajectories, we extracted the solute atoms and the water molecules with $\mathrm{O}$ atom within $4 \AA$ from any solute atom. For $\mathrm{R}=\mathrm{H}_{2} \mathrm{NCO}$, the number of extracted water molecules is in the range 25-36. For $\mathrm{R}=\left(\mathrm{CH}_{3}\right)_{2} \mathrm{NCO}$, the same extraction provides a number of water molecules in the range 28-40 because of the larger size of the solute.

When the $\alpha \mathrm{H}$ atom becomes farther than $1.6 \AA$ from any solute atom, then $\alpha \mathrm{H}$ is not assumed as part of the solute. Thus, $\alpha \mathrm{H}$ becomes part of the solvation layer. When the distance between $\alpha \mathrm{H}$ and any water molecule in the layer becomes larger than $1.4 \AA$, then $\alpha \mathrm{H}$ becomes part of the bulk solvent and its energy is estimated according to experimental solvation energy of the proton at room conditions [45]. The number of water molecules in the layer changes from one extracted configuration to another. Therefore, the energy contribution due to the addition or deletion of a number $x$ of water molecules in the layer is computed according to the estimated energy of isolated water molecules and the cohesion energy per water molecule in the layer (see below). These quantities are computed within the same approximations used for the CP-MD trajectories, except as for the following. In the case of energy calculations, the size of the super-cell was chosen as $2.1 \mathrm{~nm}$, i.e., slightly larger than in the $\mathrm{CP}-\mathrm{MD}$ simulations $(1.8774 \mathrm{~nm})$, to achieve better accuracy in total energy. The wavefunction and density energy cut-off were 30 and 300 Ry, respectively. The Makov-Payne 
correction [46], accounting for the energy contribution of collecting the charge in the given periodic super-cell, was always included in the reported energies. The water environment, i.e., the bulk water around each solvated solute, was modeled as a uniform dielectric medium with relative permittivity of 78.3 (pure water at room conditions). In these calculations, a self-consistent DFT approach based on plane-waves representation of effective monoelectronic (Kohn-Sham) states was used in place of the dynamical extended Lagrangian method used in CP-MD simulations. We used the implicit solvation scheme implemented in the Quantum Espresso code [47]. The energy tolerance for energy change was 0.01 Ry. All the calculations reported in this work are performed with the contribution of plane-waves with $K=0$ in the super-cell lattice described by the periodic boundary conditions used, i.e., in the $\Gamma$-point approximation of solid state electron density. Since for water layers the energy minimum cannot be achieved, we performed 30 relaxation steps in the conditions reported above. This number of steps has been found as sufficient to relax most of the vibrational stress in the system.

In order to compare the energy of systems composed of different number of atoms, we used the approximation described below. We first calculated the energy of a single water molecule merged in the dielectric, $E_{w}$, using the same computational conditions of the solvated system (see above). Indicating the different species as in Figure 1, the following equations describe the reaction indicated in the left portion of Figure 1, but including the water layer:

$$
\mathrm{N}\left[n \mathrm{H}_{2} \mathrm{O}\right] \longrightarrow \mathrm{N}^{-}\left[(n-x) \mathrm{H}_{2} \mathrm{O}\right]+\mathrm{H}^{+}+x \mathrm{H}_{2} \mathrm{O}
$$

Here, $n$ indicates the water molecules in the solvation layer of the $\mathrm{N}$ solute, while $n-x$ the number of water molecules in the layer when the nitronate anion $\mathrm{N}^{-}$is formed. The energy change due to the addition or deletion of $x$ water molecules ( $x$ can be a negative number) to the solvation layer is determined by calculating in one single conformation of $\mathrm{R}=\mathrm{CONH} 2$ the energy change to increase the size of the layer from 16 to 30 water molecules. The cohesion energy $E_{c}$ of a single water molecule to the layer is therefore approximated as:

$$
E_{c}=\frac{1}{14}\left[E(n=30)-E(n=16)+14 E_{w}\right],
$$

with $E_{w}$ the energy of the isolated water molecule (see above). We computed this value for a single relaxed configuration of the species $\mathrm{R}=\mathrm{H} 2 \mathrm{NCO}$ in the nitro form. Within this approximation, $E_{c}=-26.0334 \mathrm{~kJ} / \mathrm{mol}$.

Finally, the value of $-1107 \mathrm{~kJ} / \mathrm{mol}$ was used for the solvation energy of $\mathrm{H}_{3} \mathrm{O}^{+}$[45]. No entropic contribution was taken into account in the calculations reported here, except for the empirical value used for $E\left(\mathrm{H}_{3} \mathrm{O}^{+}\right)$.

The final configurations obtained with the DFTB simulations in the nitro and aci forms were optimized in an implicit model for water with more accurate DFT approximations. These calculations were performed with Gaussian 16 package [48], using the B3LYP [26] hybrid approximation for the exchange functional and with the $6-31++G(d)$ basis-set. The PCM method [49] for the implicit water solvation was used. All geometries were optimized according to default "optimization" criteria (Gaussian 16 manual [50]).

\section{Conclusions}

The measurement of apparent ionization constant $\left(\mathrm{p} K_{a}\right)$ for a series of substituted nitromethanes, including the amide moiety (compounds 1-3 in Figure 2), shows the strong effect of hydrophobic and bulky sidechains on the $\mathrm{C} \alpha$ acidity. Models including the water molecules interacting with the solute allow for comparing the contribution of intramolecular interactions with that of interactions with structured water layers. This can answer the question about which of these contributions is more efficient to enhance the acidity of the geminal $\mathrm{C}-\mathrm{H}$ bond. 
In this work, we address the inclusion of explicit water molecules in modeling thermodynamic data for this important deprotonation reaction, involving a $\mathrm{C}-\mathrm{H}$ bond. The reported models, despite the different approximations in the description of ground-state electron density, allow for listing the above observations:

1. The experimental $\mathrm{p} K_{a}$ values approximately follow the statistical weight of the aci (more acidic) form as a reactant, with the weight measured by the energy of the aci form with respect to the low-energy nitro form (Table 2).

2. The extraction of $\alpha \mathrm{H}$ from the $\mathrm{C} \alpha-\mathrm{H}$ bond does not occur necessarily when the molecule populates a closed configuration where the ionized form is stabilized by intramolecular hydrogen-bonds. The work required to extract $\alpha \mathrm{H}$ is related to the availability of water molecules near the solute, rather than on the internal structure of the solute itself.

3. The hydronium species $\left(\mathrm{H}_{3} \mathrm{O}^{+}\right)$formed in the water solvent is different depending on the nitronate species. When the solute is more hydrophilic $\left(\mathrm{Z}=\mathrm{Z}^{\prime}=\mathrm{H}\right)$, the presence of a hydronium close to the solute decreases the potential energy. On the other hand, when the solute is more hydrophobic $\left(\mathrm{Z}=\mathrm{Z}^{\prime}=\mathrm{CH}_{3}\right)$, a hydronium species close to the solute does not decrease the energy compared to a hydronium species completely separated by the solute.

These observations indicate that the nature of the R substituent, enhancing the acidity of $\mathrm{C} \alpha-\mathrm{H}$, should be hydrophilic in order to increase the probability of persistent hydronium species close to the solute. Intramolecular hydrogen bonds and electrostatic interactions enhancing the population of closed configurations do not appear as requirements for the proton release by the $\mathrm{C}-\mathrm{H}$ bond. The presence of the amide moiety as a substituent in the geminal position to the nitro group greatly enhances the $\mathrm{C} \alpha-\mathrm{H}$ acidity, provided the amide substituent is hydrophilic. The further modification of the amide moiety will be the subject of further studies.

Author Contributions: F.M. conceived and designed the experiments; G.L.P. conceived and designed the models; F.M. performed the measurements; G.L.P. applied the molecular models; G.L.P. and F.M. wrote the article together.

Funding: Fondazione Cassa di Risparmio di Firenze, project 2016.0868.

Acknowledgments: Numerical calculations have been made possible through a CINECA-INFN agreement, providing access to resources on Galileo and Marconi at the CINECA (Consorzio Interuniversitario per il Calcolo Automatico dell'Italia Nord Orientale) computational infrastructure. Luca Guideri is acknowledged for carrying out some preliminary experiments.

Conflicts of Interest: The authors declare no conflict of interest.

\author{
Abbreviations \\ The following abbreviations are used in this manuscript: \\ DFT density-functional theory \\ DFTB density-functional tight-binding \\ MD molecular dynamics \\ BO Born-Oppenheimer \\ B3LYP Becke three-parameter Lee-Yang-Parr exchange-correlation functional \\ PBE Perdew-Burke-Ernzerhof exchange-correlation functional \\ PCM polarizable continuum model
}

\title{
References
}

1. Ono, N. The Nitro Group in Organic Synthesis; Organic Nitro Chemistry Series; Wiley-VCH: Weinheim, Germany, 2001.

2. Mukaiyama, T.; Hoshino, T. The Reactions of Primary Nitroparaffins with Isocyanates1. J. Am. Chem. Soc. 1960, 82, 5339-5342. [CrossRef]

3. Basel, Y.; Hassner, A. An Improved Method for Preparation of Nitrile Oxides from Nitroalkanes for In Situ Dipolar Cycloadditions. Synthesis 1997, 309-312. [CrossRef] 
4. Nelson, S.D., Jr.; Kasparian, D.J.; Trager, W.F. The Reaction of $\alpha$-Nitro Ketones with the Ketene-Generating Compounds. Synthesis of 3-Acetyl- and 3-Benzoyl-5- Substituted Isoxazoles. J. Org. Chem. 1972, 37, 2686-2688. [CrossRef]

5. Cecchi, L.; De Sarlo, F.; Machetti, F. Synthesis of 4,5-Dihydroisoxazoles by Condensation of Primary Nitro Compounds with Alkenes by Using a Copper/Base Catalytic System. Chem. Eur. J. 2008, 14, 7903-7912. [CrossRef] [PubMed]

6. Trogu, E.; Vinattieri, C.; De Sarlo, F.; Machetti, F. Acid-Base Catalysed Condensation Reaction in Water: Isoxazolines and Isoxazoles from Nitroacetates and Dipolarophiles. Chem. Eur. J. 2012, 18, 2081-2093. [CrossRef] [PubMed]

7. Ballini, R.; Bosica, G.; Fiorini, D.; Palmieri, A.; Petrini, M. Conjugate Additions of Nitroalkanes to Electron-Poor Alkenes: Recent Results. Chem. Rev. 2005, 105, 933-972. [CrossRef] [PubMed]

8. Ballini, R.; Barboni, L.; Bosica, G.; Fiorini, D.; Palmieri, A. Synthesis of fine chemicals by the conjugate addition of nitroalkanes to electrophilic alkenes. Pure Appl. Chem. 2006, 78, 1857-1866. [CrossRef]

9. Shvekhgeimer, A.M.G. Aliphatic nitro alcohols. Synthesis, chemical transformations and applications. Russ. Chem. Rev. 1998, 67, 35-68. [CrossRef]

10. Noland, W.E. The Nef Reaction. Chem. Rev. 1955, 55, 137-155. [CrossRef]

11. Ballini, R.; Petrini, M. The Nitro to Carbonyl Conversion (Nef Reaction): New Perspectives for a Classical Transformation. Adv. Synth. Catal. 2015, 357, 2371-2402. [CrossRef]

12. Bernasconi, C.F.; Pérez-Lorenzo, M.; Brown, S.D. Kinetics of the Deprotonation of Methylnitroacetate by Amines: Unusually High Intrinsic Rate Constants for a Nitroalkane. J. Org. Chem. 2007, 72, 4416-4423. [CrossRef] [PubMed]

13. Bernasconi, C.F.; Ali, M.; Gunter, J.C. Kinetic and Thermodynamic Acidities of Substituted 1-Benzyl-1-methoxy-2-nitroethylenes. Strong Reduction of the Transition State Imbalance Compared to Other Nitroalkanes. J. Am. Chem. Soc. 2003, 125, 151-157. [CrossRef] [PubMed]

14. Ando, K.; Shimazu, Y.; Seki, N.; Yamataka, H. Kinetic Study of Proton-Transfer Reactions of Phenylnitromethanes. Implication for the Origin of Nitroalkane Anomaly. J. Org. Chem. 2011, 76, 3937-3945. [CrossRef] [PubMed]

15. Trogu, E.; Cecchi, L.; De Sarlo, F.; Guideri, L.; Ponticelli, F.; Machetti, F. Base- and Copper-Catalysed Condensation of Primary Activated Nitro Compounds with Enolisable Compounds. Eur. J. Org. Chem. 2009, 5971-5978. [CrossRef]

16. Guideri, L.; De Sarlo, F.; Machetti, F. Conjugate Addition versus Cycloaddition/Condensation of Nitro Compounds in Water: Selectivity, Acid-Base Catalysis, and Induction Period. Chem. Eur. J. 2013, 19, 665-677. [CrossRef] [PubMed]

17. Horst, G.A.; Mortimer, J.K. Fluoronitroaliphatics. I. The Effect of $\alpha$ Fluorine on the Acidities of Substituted Nitrometanes. J. Am. Chem. Soc. 1966, 88, 4761-4763. [CrossRef]

18. Bernasconi, C.F.; Panda, M.; Stronach, M.W. Kinetics of Reversible Carbon Deprotonation of 2-Nitroethanol and 2-Nitro-1,3-propanediol by Hydroxide Ion, Water, Amines, and Carboxylate Ions. A Normal Brönsted $\alpha$ Despite an Imbalanced Transition State. J. Am. Chem. Soc. 1995, 117, 9206-9212. [CrossRef]

19. Turnbull, D.; Maron, S.H. The Ionization Constants of Aci and Nitro Forms of Some Nitroparaffins. J. Am. Chem. Soc. 1943, 65, 212-218. [CrossRef]

20. Pearson, R.G.; Dillon, R.L. Rates of Ionization of Pseudo Acids. IV. Relation between Rates and Equilibria. J. Am. Chem. Soc. 1953, 75, 2439-2443. [CrossRef]

21. Pearson, R.G.; Anderson, D.H.; Alt, L.L. Mechanism of the Hydrolytic Cleavage of Carbon-Carbon Bonds. III. Hydrolysis of $\alpha$-Nitro and $\alpha$-Sulfonyl Ketones. J. Am. Chem. Soc. 1955, 77, 527-529. [CrossRef]

22. ACD/Labs Percepta Platform: Insight-Driven Decision Support for Teams that Design and Synthesize New Chemical Entities; ACD/Structure Elucidator, version 15.01; Advanced Chemistry Development, Inc.: Toronto, ON, Canada, 2015.

23. Perdew, J.P.; Burke, K.; Ernzerhof, M. Generalized Gradient Approximation Made Simple. Phys. Rev. Lett. 1996, 77, 3865-3868. [CrossRef] [PubMed]

24. Car, R.; Parrinello, M. Unified Approach for Molecular Dynamics and Density-Functional Theory. Phys. Rev. Lett. 1985, 55, 2471-2474. [CrossRef] [PubMed]

25. Marx, D.; Hutter, J. Ab Initio Molecular Dynamics: Basic Theory and Advanced Methods; Cambridge University Press: Cambridge, UK, 2009. 
26. Becke, A.D. Density-functional Thermochemistry. III. The Role of Exact Exchange. J. Chem. Phys. 1993, 98, 5648-5652. [CrossRef]

27. Dreyer, J.; Brancato, G.; Ippoliti, E.; Genna, V.; De Vivo, M.; Carloni, P.; Rothlisberger, U. First Principles Methods in Biology: From Continuum Models to Hybrid Ab initio Quantum Mechanics/Molecular Mechanics. In Simulating Enzyme Reactivity: Computational Methods in Enzyme Catalysis; The Royal Society of Chemistry: London, UK, 2017; pp. 294-339. [CrossRef]

28. La Penna, G.; Andreussi, O. When water plays an active role in electronic structure. Insights from first-principles molecular dynamics simulations of biological systems. In Computational Methods to Study the Structure and Dynamics of Biomolecules and Biomolecular Processes, 2nd ed.; Liwo, A.J., Ed.; Springer series in bio- and neurosystems; Springer-Verlag: Berlin/Heidelberg, Germany, 2019; Volume 1. [CrossRef]

29. Liao, C.; Nicklaus, M.C. Comparison of Nine Programs Predicting pKa Values of Pharmaceutical Substances. J. Chem. Inf. Model. 2009, 49, 2801-2812. [CrossRef] [PubMed]

30. Elstner, M.; Porezag, D.; Jungnickel, G.; Elsner, J.; Haugk, M.; Frauenheim, T.; Suhai, S.; Seifert, G. Self-consistent-charge Density-functional Tight-binding Method for Simulations of Complex Materials Properties. Phys. Rev. B 1998, 58, 7260-7268. [CrossRef]

31. Humphrey, W.; Dalke, A.; Schulten, K. VMD visual molecular dynamics. J. Mol. Graph. 1996, 14, 33-38. [CrossRef]

32. Cecchi, L.; De Sarlo, F.; Machetti, F. 1,4-Diazabicyclo[2,2,2]octane (DABCO) as an Efficient Reagent for the Synthesis of Isoxazole Derivatives from Primary Nitro Compounds and Dipolarophiles: The Role of the Base. Eur. J. Org. Chem. 2006, 4852-4860. [CrossRef]

33. Biagiotti, G.; Cicchi, S.; De Sarlo, F.; Machetti, F. Reactivity of [60]Fullerene with Primary Nitro Compounds: Addition or Catalysed Condensation to Isoxazolo[60]fullerenes. Eur. J. Org. Chem. 2014, 7906-7915. [CrossRef]

34. Ciommer, B.; Frenking, G.; Schwarz, H. Massenspektrometrische Untersuchung von Stickstoffverbindungen, XXXI, Experimentelle und theoretische Untersuchungen zur dissoziativen Ionisierung von $\alpha$-nitro- und $\alpha$-halogen substituierten Acetamiden. Pseudo-einstufige Zerfallsprozesse von Radikalkationen in der Gasphase. Chem. Ber. 1981, 114, 1503-1519. [CrossRef]

35. Aradi, B.; Hourahine, B.; Frauenheim, T. DFTB+, a Sparse Matrix-Based Implementation of the DFTB Method. J. Phys. Chem. A 2007, 111, 5678-5684. [CrossRef]

36. Jorgensen, W.L.; Chandrasekhar, J.; Madura, J.D.; Impey, R.W.; Klein, M.J. Comparison of simple potential functions for simulating liquid water. J. Chem. Phys. 1983, 79, 926-935. [CrossRef]

37. Frenkel, D.; Smit, B. Understanding Molecular Simulation; Academic Press: San Diego, CA, USA, 1996.

38. Nosé, S. A Molecular Dynamics Method for Simulations in the Canonical Ensemble. Mol. Phys. 1984, 52, 255-268. [CrossRef]

39. Giannozzi, P.; Baroni, S.; Bonini, N.; Calandra, M.; Car, R.; Cavazzoni, C.; Ceresoli, D.; Chiarotti, G.L.; Cococcioni, M.; Dabo, I.; et al. QUANTUM ESPRESSO: A Modular and Open-Source Software Project for Quantum Simulations of Materials. J. Phys. Condens. Matter 2009, 21, 395502. [CrossRef] [PubMed]

40. Vanderbilt, D. Soft Self-Consistent Pseudopotentials in a Generalized Eigenvalue Formalism. Phys. Rev. B 1990, 41, 7892-7895. [CrossRef]

41. Grimme, S. Semiempirical GGA-Type Density Functional Constructed with a Long-Range Dispersion Correction. J. Comput. Chem. 2006, 27, 1787-1799. [CrossRef] [PubMed]

42. Barone, V.; Casarin, M.; Forrer, D.; Pavone, M.; Sambi, M.; Vittadini, A. Role and Effective Treatment of Dispersive Forces in Materials: Polyethylene and Graphite Crystals As Test Cases. J. Comput. Chem. 2009, 30, 934-939. [CrossRef] [PubMed]

43. Parrinello, M.; Rahman, A. Polymorphic Transitions in Single Crystals: A New Molecular Dynamics Method. J. Appl. Phys. 1981, 52, 7182-7190. [CrossRef]

44. Barducci, A.; Chelli, R.; Procacci, P.; Schettino, V.; Gervasio, F.L.; Parrinello, M. Metadynamics simulation of prion protein: $\beta$-structure stability and the early stages of misfolding. J. Am. Chem. Soc. 2006, 128, 2705-2710. [CrossRef]

45. Raffa, D.F.; Rickard, G.A.; Rauk, A. Ab Initio Modelling of the Structure and Redox Behaviour of Copper(I) Bound to a His-His Model Peptide: Relevance to the $\beta$-Amyloid Peptide of Alzheimer's Disease. J. Biol. Inorg. Chem. 2007, 12, 147-164. [CrossRef] 
46. Makov, G.; Payne, M.C. Periodic Boundary Conditions in Ab Initio Calculations. Phys. Rev. B 1995, $51,4014$. [CrossRef]

47. Andreussi, O.; Dabo, I.; Marzari, N. Revised Self-Consistent Continuum Solvation in Electronic-Structure Calculations. J. Chem. Phys. 2012, 136, 064102. [CrossRef] [PubMed]

48. Frisch, M.J.; Trucks, G.W.; Schlegel, H.B.; Scuseria, G.E.; Robb, M.A.; Cheeseman, J.R.; Scalmani, G.; Barone, V.; Petersson, G.A.; Nakatsuji, H.; et al. Gaussian 16, Revision A.03; Gaussian Inc.: Wallingford, CT, USA, 2016.

49. Tomasi, J.; Mennucci, B.; Cammi, R. Quantum mechanical continuum solvation models. Chem. Rev. 2005, 105, 2999-3093. [CrossRef] [PubMed]

50. Gaussian 16 On-Line Manual; Gaussian, Inc.: Wallingford, CT, USA, 2016. Available online: http://www. Gaussian.com/keywords (accessed on 25 October 2018).

(C) 2018 by the authors. Licensee MDPI, Basel, Switzerland. This article is an open access article distributed under the terms and conditions of the Creative Commons Attribution (CC BY) license (http://creativecommons.org/licenses/by/4.0/). 


\title{
Communication \\ Pd-Catalyzed Suzuki-Miyaura Cross-Coupling of Pentafluorophenyl Esters
}

\author{
Jonathan Buchspies, Daniel J. Pyle, Huixin He * and Michal Szostak * \\ Department of Chemistry, Rutgers University, 73 Warren Street, Newark, NJ 07102, USA; \\ jonathan.buchspies@gmail.com (J.B.); danielj.pyle@gmail.com (D.J.P.) \\ * Correspondence: huixinhe@rutgers.edu (H.H.); michal.szostak@rutgers.edu (M.S.); \\ Tel.: +1-973-353-5329 (M.S.)
}

Received: 12 October 2018; Accepted: 23 November 2018; Published: 29 November 2018

\begin{abstract}
Although the palladium-catalyzed Suzuki-Miyaura cross-coupling of aryl esters has received significant attention, there is a lack of methods that utilize cheap and readily accessible Pd-phosphane catalysts, and can be routinely carried out with high cross-coupling selectivity. Herein, we report the first general method for the cross-coupling of pentafluorophenyl esters (pentafluorophenyl $=\mathrm{pfp}$ ) by selective $\mathrm{C}-\mathrm{O}$ acyl cleavage. The reaction proceeds efficiently using $\mathrm{Pd}(0) /$ phosphane catalyst systems. The unique characteristics of pentafluorophenyl esters are reflected in the fully selective cross-coupling vs. phenolic esters. Of broad synthetic interest, this report establishes pentafluorophenyl esters as new, highly reactive, bench-stable, economical, ester-based, electrophilic acylative reagents via acyl-metal intermediates. Mechanistic studies strongly support a unified reactivity scale of acyl electrophiles by $C(O)-X(X=N, O)$ activation. The reactivity of pfp esters can be correlated with barriers to isomerization around the $\mathrm{C}(\mathrm{acyl})-\mathrm{O}$ bond.
\end{abstract}

Keywords: Suzuki-Miyaura; cross-coupling; aryl esters; C-O activation; Pd-catalysis

\section{Introduction}

The recent emergence of Suzuki-Miyaura cross-coupling of amide and ester electrophiles by selective $\mathrm{C}(\mathrm{acyl})-\mathrm{X}$ cleavage represents one of the most promising approaches to functionalization of the traditionally inert amide and ester bonds in organic synthesis [1-3]. Although a broad range of amide precursors have been explored [4-8], N.B. benefiting from amide twist [9-13], Pd-catalyzed cross-coupling of esters has received significantly less attention. The seminal study by Newman in 2017 reported the [Pd(NHC)(cin)Cl]-catalyzed cross-coupling of aryl esters at high temperature [14]. Subsequently, we have reported a general method for the cross-coupling of both esters and amides at room temperature [15]. Further studies established that various $\mathrm{Pd}(\mathrm{II})-\mathrm{NHC}$ precatalysts are significantly more reactive after optimizing conditions $[16,17]$. Moreover, Hazari demonstrated the cross-coupling of aryl esters at room temperature conditions using strong bases [18].

This strategy to develop cross-coupling reactions of aryl esters hinges upon ground-state destabilization of the barrier to rotation around the $\mathrm{C}(\mathrm{acyl})-\mathrm{O}$ bond [19]. In contrast to amides, esters feature significant stabilization in the transition state. Given the established capacity of pentafluorophenyl esters as acyl transfer reagents in nucleophilic addition reactions [20-22], we recently questioned whether the ground-state-destabilization principle might enable facile cross-coupling of pentafluorophenyl esters under chemoselective conditions that are inaccessible to the current-stateof-the-art phenolic esters [1-3]. In this Special Issue on Amide Bond Activation, we report the successful realization of this approach, and report the first general method for the cross-coupling of pentafluorophenyl esters by selective $\mathrm{C}-\mathrm{O}$ acyl cleavage. Notable features of our findings include: (1) The first Pd-phosphane-catalyzed Suzuki cross-coupling of esters by C-O activation; (2) unprecedented 
selectivity of the cross-coupling; (3) establishment of the reactivity scale in the cross-coupling of bench-stable acyl electrophiles catalyzed by Pd-phosphanes.

Notably, this study establishes pentafluorophenyl esters as new, highly reactive, bench-stable, economical, ester-based, electrophilic acylative reagents via acyl-metals [1-3]. Considering the versatile role of pfp esters in organic synthesis [20-22], we expect that this approach will find wide application in the development of cross-coupling reactions of bench-stable ester electrophiles by acyl [1] and decarbonylative pathways $[2,7,23,24]$ (Scheme 1$)$.

A: Previous studies

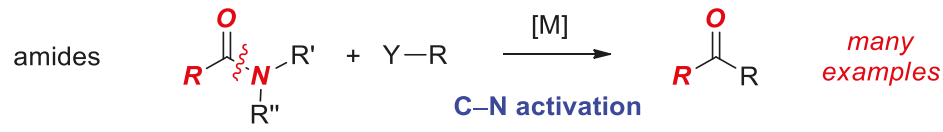

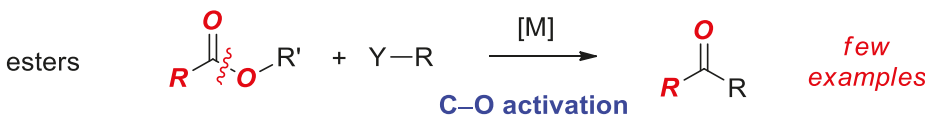

B: This work: the first Suzuki-Miyaura cross-coupling of pfp esters

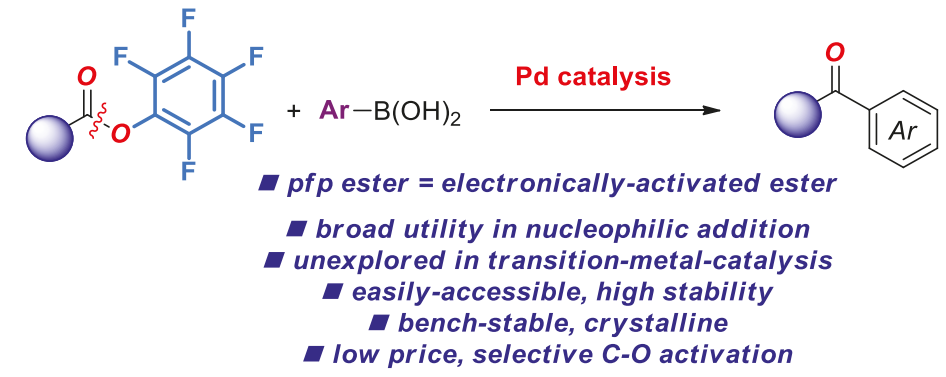

- general guidelines for amide and ester coupling: barrier to isomerization

Scheme 1. Cross-coupling of amides and esters by $\mathrm{C}-\mathrm{N}$ and $\mathrm{C}-\mathrm{O}$ activation.

\section{Results}

Cross-coupling of pentafluorophenyl benzoate with 4-tolyl boronic acid was selected as our model system. From the outset we sought to develop a catalytic system based on phosphane ligands, due to the low price, ready availability and orthogonal selectivity compared to the more $\sigma$-donating NHCs. Selected optimization results are presented in Table 1. As expected, the choice of base (entries 1-6), phosphane ligand (entries 7-12), palladium catalyst (entries 13-15), palladium to ligand ratio (entries 16-18), stoichiometry (entries 19-20) and concentration (entries 21-22) had a major impact on the cross-coupling efficiency. Finally, we established that the optimum conditions involved using $\mathrm{Pd}_{2}(\mathrm{dba})_{3}(3.0 \mathrm{~mol} \%)$ as a catalyst, $\mathrm{PCy}_{3} \mathrm{HBF}_{4}(12 \mathrm{~mol} \%)$ as a ligand, and $\mathrm{Na}_{2} \mathrm{CO}_{3}$ (4.5 equiv) as a base in dioxane at $120{ }^{\circ} \mathrm{C}$ (entry 20). Importantly, under the optimized conditions cleavage of the alternative $\mathrm{O}-\mathrm{C}(\mathrm{Ar})$ bond or nucleophilic addition to the activated pfp group were not observed. To our knowledge, the reaction represents the first example of a Pd-phosphane-catalyzed Suzuki cross-coupling of an ester group by selective $\mathrm{C}-\mathrm{O}$ cleavage $[1-3,23,24]$. It should be noted that all reaction components are easy-to-handle bench-stable solids, which represents a significant practical advantage over related cross-coupling protocols.

With optimized conditions in hand, the scope of the cross-coupling with respect to the boronic acid component was examined (Figure 1). We were pleased to find the reaction readily accommodates a range of electronically-diverse boronic acids, including neutral (3a) electron-rich (3b, 
3c), electron-deficient bearing electrophilic carbonyl (3d), sterically-hindered (3e), as well as fluorinated boronic acids relevant from the medicinal chemistry standpoint (3f-3i).

Table 1. Optimization of the Suzuki-Miyaura cross-coupling of Pfp esters. ${ }^{1}$<smiles>Cc1ccc(C(=O)c2ccccc2)cc1</smiles>

\begin{tabular}{|c|c|c|c|c|c|}
\hline Entry & Catalyst & Ligand & Base & {$[\mathrm{Pd}]: \mathrm{L}$} & Yield (\%) \\
\hline 1 & $\mathrm{Pd}(\mathrm{OAc})_{2}$ & $\mathrm{PCy}_{3} \mathrm{HBF}_{4}$ & $\mathrm{Na}_{2} \mathrm{CO}_{3}$ & $1: 4$ & 52 \\
\hline 2 & $\mathrm{Pd}(\mathrm{OAc})_{2}$ & $\mathrm{PCy}_{3} \mathrm{HBF}_{4}$ & $\mathrm{KHCO}_{3}$ & $1: 4$ & 53 \\
\hline 3 & $\mathrm{Pd}(\mathrm{OAc})_{2}$ & $\mathrm{PCy}_{3} \mathrm{HBF}_{4}$ & $\mathrm{NaHCO}_{3}$ & $1: 4$ & 30 \\
\hline 4 & $\mathrm{Pd}(\mathrm{OAc})_{2}$ & $\mathrm{PCy}_{3} \mathrm{HBF}_{4}$ & $\mathrm{~K}_{2} \mathrm{CO}_{3}$ & $1: 4$ & 12 \\
\hline 5 & $\mathrm{Pd}(\mathrm{OAc})_{2}$ & $\mathrm{PCy}_{3} \mathrm{HBF}_{4}$ & $\mathrm{~K}_{3} \mathrm{PO}_{4}$ & $1: 4$ & 47 \\
\hline 6 & $\mathrm{Pd}(\mathrm{OAc})_{2}$ & $\mathrm{PCy}_{3} \mathrm{HBF}_{4}$ & KF & $1: 4$ & 56 \\
\hline 7 & $\mathrm{Pd}(\mathrm{OAc})_{2}$ & $\mathrm{PPhCy}_{2}$ & $\mathrm{Na}_{2} \mathrm{CO}_{3}$ & $1: 4$ & 60 \\
\hline 8 & $\mathrm{Pd}(\mathrm{OAc})_{2}$ & $\mathrm{PPh}_{2} \mathrm{Cy}$ & $\mathrm{Na}_{2} \mathrm{CO}_{3}$ & $1: 4$ & 5 \\
\hline 9 & $\mathrm{Pd}(\mathrm{OAc})_{2}$ & $\mathrm{PPh}_{3}$ & $\mathrm{Na}_{2} \mathrm{CO}_{3}$ & $1: 4$ & 5 \\
\hline 10 & $\mathrm{Pd}(\mathrm{OAc})_{2}$ & DPPB & $\mathrm{Na}_{2} \mathrm{CO}_{3}$ & $1: 4$ & 13 \\
\hline 11 & $\mathrm{Pd}(\mathrm{OAc})_{2}$ & Xantphos & $\mathrm{Na}_{2} \mathrm{CO}_{3}$ & $1: 4$ & $<5$ \\
\hline 12 & $\mathrm{Pd}(\mathrm{OAc})_{2}$ & $\mathrm{Pt}-\mathrm{Bu}_{3} \mathrm{HBF}_{4}$ & $\mathrm{Na}_{2} \mathrm{CO}_{3}$ & $1: 4$ & $<5$ \\
\hline 13 & $\mathrm{Pd}(\mathrm{dba})_{2}$ & $\mathrm{PCy}_{3} \mathrm{HBF}_{4}$ & $\mathrm{Na}_{2} \mathrm{CO}_{3}$ & $1: 4$ & 23 \\
\hline 14 & $\mathrm{PdCl}_{2}$ & $\mathrm{PCy}_{3} \mathrm{HBF}_{4}$ & $\mathrm{Na}_{2} \mathrm{CO}_{3}$ & $1: 4$ & 25 \\
\hline 15 & $\mathrm{Pd}_{2}(\mathrm{dba})_{3}$ & $\mathrm{PCy}_{3} \mathrm{HBF}_{4}$ & $\mathrm{Na}_{2} \mathrm{CO}_{3}$ & $1: 2$ & 74 \\
\hline $16^{2}$ & $\mathrm{Pd}_{2}(\mathrm{dba})_{3}$ & $\mathrm{PCy}_{3} \mathrm{HBF}_{4}$ & $\mathrm{Na}_{2} \mathrm{CO}_{3}$ & $1: 2$ & 85 \\
\hline $17^{3}$ & $\mathrm{Pd}_{2}(\mathrm{dba})_{3}$ & $\mathrm{PCy}_{3} \mathrm{HBF}_{4}$ & $\mathrm{Na}_{2} \mathrm{CO}_{3}$ & $1: 1$ & 44 \\
\hline $18^{4}$ & $\mathrm{Pd}_{2}(\mathrm{dba})_{3}$ & $\mathrm{PCy}_{3} \mathrm{HBF}_{4}$ & $\mathrm{Na}_{2} \mathrm{CO}_{3}$ & $2: 1$ & 30 \\
\hline $19^{5}$ & $\mathrm{Pd}(\mathrm{OAc})_{2}$ & $\mathrm{PCy}_{3} \mathrm{HBF}_{4}$ & $\mathrm{Na}_{2} \mathrm{CO}_{3}$ & $1: 4$ & 83 \\
\hline $20^{5}$ & $\mathrm{Pd}_{2}(\mathrm{dba})_{3}$ & $\mathrm{PCy}_{3} \mathrm{HBF}_{4}$ & $\mathrm{Na}_{2} \mathrm{CO}_{3}$ & $1: 2$ & 92 \\
\hline $21^{6}$ & $\mathrm{Pd}_{2}(\mathrm{dba})_{3}$ & $\mathrm{PCy}_{3} \mathrm{HBF}_{4}$ & $\mathrm{Na}_{2} \mathrm{CO}_{3}$ & $1: 2$ & 75 \\
\hline $22^{7}$ & $\mathrm{Pd}_{2}(\mathrm{dba})_{3}$ & $\mathrm{PCy}_{3} \mathrm{HBF}_{4}$ & $\mathrm{Na}_{2} \mathrm{CO}_{3}$ & $1: 2$ & 89 \\
\hline
\end{tabular}

${ }^{1}$ Conditions: Ester (1.0 equiv), 4-Tol- $\mathrm{B}(\mathrm{OH})_{2}$ (2.0 equiv), base (2.5 equiv), [Pd] ( $\left.3 \mathrm{~mol} \%\right)$, ligand $(12 \mathrm{~mol} \%)$, solvent $(0.25 \mathrm{M}), 120{ }^{\circ} \mathrm{C}, 15 \mathrm{~h} .{ }^{2}$ [Pd] $(1.5 \mathrm{~mol} \%)$, ligand $(12 \mathrm{~mol} \%), 4-\mathrm{Tol}-\mathrm{B}(\mathrm{OH})_{2}$ (3.0 equiv), base (4.5 equiv). ${ }^{3}[\mathrm{Pd}]$ ( $3 \mathrm{~mol} \%)$, ligand $(6 \mathrm{~mol} \%), 4-\mathrm{Tol}-\mathrm{B}(\mathrm{OH})_{2}$ (3.0 equiv), base (4.5 equiv). ${ }^{4}[\mathrm{Pd}](3 \mathrm{~mol} \%)$, ligand $(3 \mathrm{~mol} \%), 4-\mathrm{Tol}-\mathrm{B}(\mathrm{OH})_{2}$ (3.0 equiv), base (4.5 equiv). ${ }^{5} 4$ - $\mathrm{Tol}-\mathrm{B}(\mathrm{OH})_{2}\left(3.0\right.$ equiv), base $\left(4.5\right.$ equiv). ${ }^{6}$ Dioxane $(0.10 \mathrm{M}) .{ }^{7}$ Dioxane $(0.50 \mathrm{M})$.

We next explored the generality of this cross-coupling with respected to the ester electrophile (Figure 2). Pleasingly, the reaction tolerates electron-deficient substituents $\left(\mathbf{3} \mathbf{f}^{\prime}, \mathbf{3} \mathbf{d}^{\prime}, \mathbf{3} \mathbf{j}\right)$, including electrophilic carbonyls $\left(3 \mathbf{d}^{\prime}, 3 \mathbf{j}\right)$, electron-rich deactivating substituents $\left(3 \mathbf{c}^{\prime}\right)$, sterically-hindered $\left(3 \mathbf{e}^{\prime}\right)$, as well as aliphatic pfp ester precursors (3k). It is worthwhile to note that the reaction proceeded with full selectivity for the cross-coupling of a pfp ester in the presence of an aliphatic ester ( $\mathbf{3} \mathbf{j})$, as expected from the $\mathrm{C}-\mathrm{O}$ isomerization and our design (vide infra) $[15,19]$.

Next, to emphasize the synthetic utility of this transformation, we conducted a series of competition experiments between pfp esters and ester and amide electrophiles previously established in cross-coupling protocols (Scheme 2) [3-8]. Most importantly, as expected on the basis of $\mathrm{C}-\mathrm{O}$ isomerization, the reaction is fully selective for the cross-coupling in the presence of an activated phenolic ester (Scheme 2A). A separate experiment using phenyl benzoate under the optimized conditions for the cross-coupling of pfp esters resulted in a quantitative recovery of $\mathrm{PhCO}_{2} \mathrm{Ph}$. 


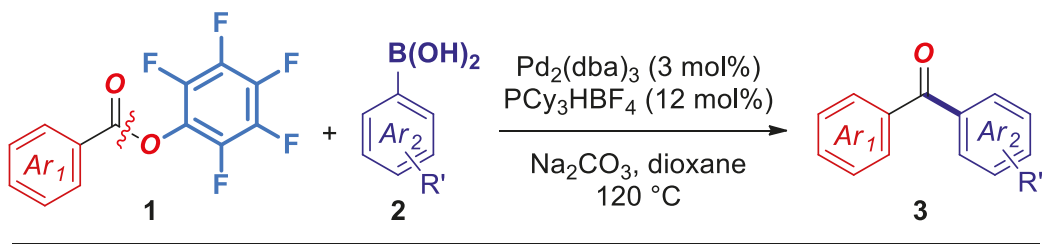<smiles>O=C(c1ccccc1)c1ccccc1</smiles>

3a: $97 \%$ yield<smiles>CC(=O)c1ccc(C(=O)c2ccccc2)cc1</smiles>

3d: $81 \%$ yield<smiles>O=C(c1ccccc1)c1cccc(C(F)(F)F)c1</smiles>

3g: $94 \%$ yield<smiles>Cc1ccc(C(=O)c2ccccc2)cc1</smiles>

3b: $86 \%$ yield<smiles>Cc1ccccc1C(=O)c1ccccc1</smiles>

3e: $82 \%$ yield<smiles>O=C(c1ccccc1)c1ccc(F)cc1</smiles>

3h: $\mathbf{7 8 \%}$ yield<smiles>COc1ccc(C(=O)c2ccccc2)cc1</smiles>

3c: $90 \%$ yield<smiles>O=C(c1ccccc1)c1ccc(C(F)(F)F)cc1</smiles>

3f: $85 \%$ yield<smiles>O=C(c1ccccc1)c1cc(F)cc(F)c1</smiles>

3i: $68 \%$ yield

Figure 1. Boronic acid scope in the Pd-catalyzed cross-coupling of Pfp esters. Conditions: Ester (1.0 equiv), $\mathrm{ArB}(\mathrm{OH})_{2}$ (3.0 equiv), $\mathrm{Na}_{2} \mathrm{CO}_{3}$ (4.5 equiv), $\mathrm{Pd}_{2}(\mathrm{dba})_{3}(3 \mathrm{~mol} \%), \mathrm{PCy}_{3} \mathrm{HBF}_{4}(12 \mathrm{~mol} \%)$, dioxane $(0.25 \mathrm{M}), 120^{\circ} \mathrm{C}, 15 \mathrm{~h}$. See SI for details.
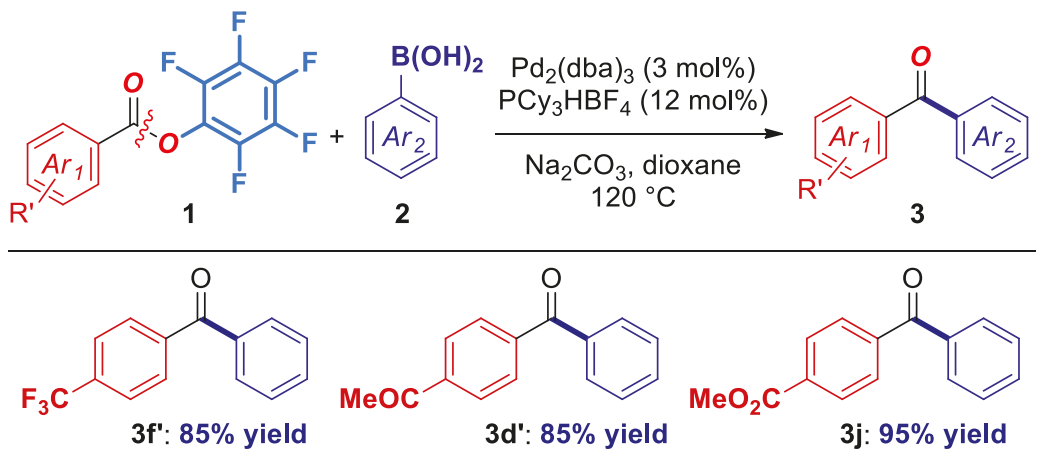<smiles>CC(=O)c1ccc(C(=O)c2ccccc2)cc1</smiles>

$3 e^{\prime}: 90 \%$ yield<smiles>CC(=O)c1ccc(C(=O)c2ccccc2)cc1</smiles><smiles>O=C(c1ccccc1)C1CCCCC1</smiles>

3k: $79 \%$ yield

Figure 2. Ester scope in the Pd-catalyzed cross-coupling of Pfp esters. Conditions: Ester (1.0 equiv), $\mathrm{ArB}(\mathrm{OH})_{2}$ (3.0 equiv), $\mathrm{Na}_{2} \mathrm{CO}_{3}$ (4.5 equiv), $\mathrm{Pd}_{2}(\mathrm{dba})_{3}(3 \mathrm{~mol} \%)$, PCy3HBF4 $(12 \mathrm{~mol} \%)$, dioxane $(0.25 \mathrm{M})$, $120{ }^{\circ} \mathrm{C}, 15 \mathrm{~h}$. See SI for details. 


\section{A: Effect of O-vs. O-activation: pfp vs. Ph}<smiles>Cc1ccc(C(=O)Oc2c(F)c(F)c(F)c(F)c2F)cc1</smiles>

$1 \mathrm{i}$

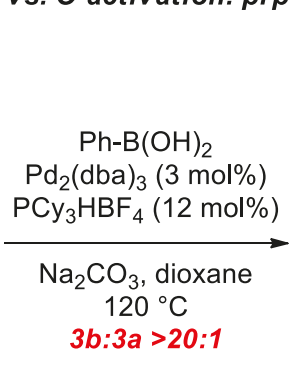

$3 b: 3 a>20: 1$<smiles>Cc1ccc(C(=O)c2ccccc2)cc1</smiles>

$3 a$

$1 \mathrm{~h}: 1 \mathrm{i}$ (2.0 equiv each)

B: Effect of O-vs. N-activation: pfp vs. N-Ts/Ph<smiles>Cc1ccc(C(=O)Oc2c(F)c(F)c(F)c(F)c2F)cc1</smiles>

$\mathrm{Ph}-\mathrm{B}(\mathrm{OH})_{2}$ $\mathrm{Pd}_{2}(\mathrm{dba})_{3}(3 \mathrm{~mol} \%)$ $\mathrm{PCy}_{3} \mathrm{HBF}_{4}(12 \mathrm{~mol} \%)$<smiles>Cc1ccc(C(=O)c2ccccc2)cc1</smiles>

3b<smiles>O=C(c1ccccc1)N([Al])c1ccccc1</smiles>

$\mathrm{Na}_{2} \mathrm{CO}_{3}$, dioxane $120^{\circ} \mathrm{C}$

$3 b: 3 a=1: 1.3$<smiles>O=C(c1ccccc1)c1ccccc1</smiles>

$3 a$

$1 \mathrm{~h}: 1 \mathrm{j}$ (2.0 equiv each)

C: Effect of O-vs. $\mathrm{N}$-activation: pfp vs. $\mathrm{N}$-glutarimide<smiles>Cc1ccc(C(=O)Oc2c(F)c(F)c(F)c(F)c2F)cc1</smiles>

$\mathrm{Ph}-\mathrm{B}(\mathrm{OH})_{2}$ $\mathrm{Pd}_{2}(\mathrm{dba})_{3}(3 \mathrm{~mol} \%)$ $\mathrm{PCy}_{3} \mathrm{HBF}_{4}(12 \mathrm{~mol} \%)$<smiles>Cc1ccc(C(=O)c2ccccc2)cc1</smiles>

3b

$\mathrm{Na}_{2} \mathrm{CO}_{3}$, dioxane

$120^{\circ} \mathrm{C}$

$3 b: 3 a<1: 20$<smiles>O=C(c1ccccc1)c1ccccc1</smiles>

3a

$1 \mathrm{~h}: 1 \mathrm{k}$ (2.0 equiv each)

Scheme 2. Competition experiments.

Furthermore, the reaction is slightly less selective for the cross-coupling of pfp esters cf. N-Ts sulfonamides (Scheme 2B; Ts/Ph:pfp = 1.3:1), whereas full selectivity is observed in the cross-coupling of $\mathrm{N}$-acylglutarimides vs. pfp esters (Scheme 2C; $>20: 1$ ), as expected on the basis of amide bond destabilization $[6,11]$. Overall, the competition experiments demonstrate high chemoselectivity of the cross-coupling of pfp esters, and permit to establish a unified reactivity scale in cross-coupling of esters and amides catalyzed by Pd-phosphanes (Scheme 3). It is well-established that cross-coupling of anilides is performed in the presence of $N, N$-dialkylamides [12].

To gain insight into the reaction mechanism additional experiments were conducted (not shown). (1) Competition experiments with differently substituted pfp esters revealed that electron-deficient arenes are more reactive (4- $\left.\mathrm{CF}_{3}: 4-\mathrm{MeO}>20: 1\right)$; while (2) differently substituted boronic acids revealed 
a small preference for electron-rich boronic acids (4-MeO:4-CF $3=1.1: 1)$. Overall, these findings suggest that $\mathrm{Pd}$ insertion may be the rate limiting step in this reaction.

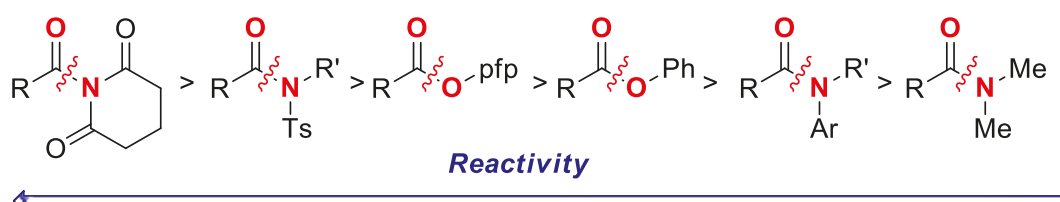

Scheme 3. Reactivity scale in C(acyl)-N and C(acyl)-O Suzuki-Miyaura cross-coupling. Note that thus far only $\mathrm{N}$-Acyl-glutarimides, $\mathrm{N}$-Ts-sulfonamides and $\mathrm{O}$-pfp esters have been shown to react with $\mathrm{Pd}-\mathrm{PR}_{3}$ catalytic systems [1-3]. The reactivity of OPh esters, $\mathrm{N}-\mathrm{Ar}$ amides and N-Me amides is based on Pd-NHC catalysts $[1,15]$.

Finally, we demonstrated that catalytic systems in the Suzuki-Miyaura cross-coupling of pfp esters are not limited to the in situ formed $\mathrm{Pd}(0)$-phosphane catalysts. For example, preformed Pd-phosphane catalysts [25], as well as Pd(II)-NHCs [1], such as $\mathrm{Pd}\left(\mathrm{PCy}_{3}\right)_{2} \mathrm{Cl}_{2}$ and Pd-PEPPSI-IPr afford the coupling product in excellent yields (Scheme 4), highlighting the generality and rich synthetic potential of pentafluorophenyl esters as electrophiles in transition-metal catalysis. Future work will focus on the expansion of the catalyst portfolio in the cross-coupling of activated esters. With the availability of various catalyst systems, the pfp reagents should expand the implementation of ester $\mathrm{C}-\mathrm{O}$ cross-coupling in organic synthesis [14-18].

A: Cross-coupling using preformed Pd-phosphine
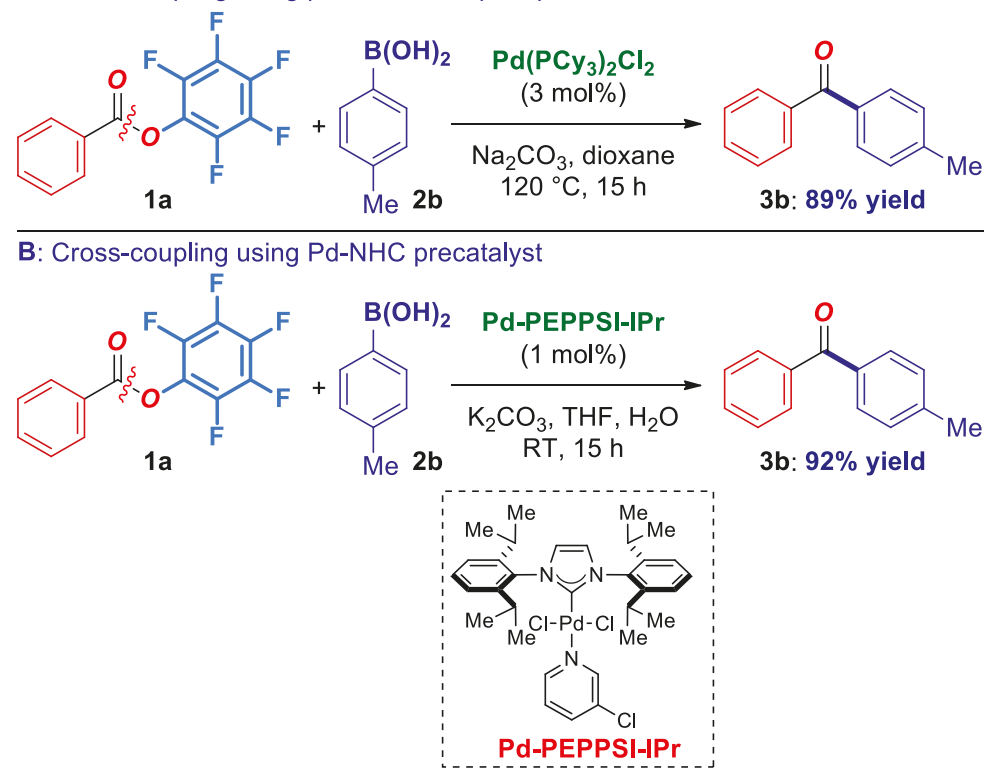

Scheme 4. Cross-coupling using preformed Pd-phosphine and Pd(II)-NHC precatalysts.

\section{Discussion}

In summary, we have reported the Suzuki-Miyaura cross-coupling of pentafluorophenyl esters. The reaction is notable for the first use of Pd-phosphane catalysis in chemoselective Suzuki-Miyaura ester coupling by $\mathrm{C}-\mathrm{O}$ cleavage. Furthermore, this method introduces pfp esters as new, ester-based, electrophilic reagents for transition-metal catalyzed cross-coupling reactions. Given the broad 
utility of pfp esters in nucleophilic addition reactions, we believe that these reagents will find wide application in the cross-coupling chemistry. In particular, this study highlights the utility of ground-state destabilization of acyl electrophiles to achieve chemoselective bond activation. Since pentafluorophenyl esters are easily prepared, bench-stable solids, and highly reactive, these reagents should be considered along phenolic esters in the future development of cross-coupling reactions by acyl [1-3] and decarbonylative pathways $[2,7,23,24]$.

\section{Materials and Methods}

\subsection{General Information}

General methods have been published [13].

\subsection{General Procedure for Cross-Coupling of Pentafluorophenyl Esters}

An oven-dried vial equipped with a stir bar was charged with an ester substrate (neat, 1.0 equiv), boronic acid (typically, 3.0 equiv), sodium carbonate (typically, 4.5 equiv), $\mathrm{Pd}_{2}(\mathrm{dba})_{3}$ (typically, $3 \mathrm{~mol} \%$ ), and $\mathrm{PCy}_{3} \mathrm{HBF}_{4}$ (typically, $12 \mathrm{~mol} \%$ ), placed under a positive pressure of argon, and subjected to three evacuation/backfilling cycles under high vacuum. Dioxane (typically, $0.25 \mathrm{M}$ ) was added with vigorous stirring at room temperature, the reaction mixture was placed in a preheated oil bath at $120^{\circ} \mathrm{C}$, and stirred for the indicated time at $120^{\circ} \mathrm{C}$. After the indicated time, the reaction mixture was cooled down to room temperature, diluted with $\mathrm{CH}_{2} \mathrm{Cl}_{2}(10 \mathrm{~mL})$, filtered, and concentrated. The sample was analyzed by ${ }^{1} \mathrm{H}-\mathrm{NMR}\left(\mathrm{CDCl}_{3}, 500 \mathrm{MHz}\right)$ and GC-MS to obtain conversion, selectivity and yield using internal standard and comparison with authentic samples. Purification by chromatography afforded the pure product.

\subsection{Representative Procedure for Cross-Coupling of Pentafluorophenyl Esters}

An oven-dried vial equipped with a stir bar was charged with perfluorophenyl benzoate (neat, $288.2 \mathrm{mg}, 1.0 \mathrm{mmol}$ ), $p$-tolylboronic acid ( $408.0 \mathrm{mg}, 3.0 \mathrm{mmol}, 3.0$ equiv), $\mathrm{Na}_{2} \mathrm{CO}_{3}(477.0 \mathrm{mg}, 4.5 \mathrm{mmol}$, 4.5 equiv), $\mathrm{Pd}_{2}(\mathrm{dba})_{3}\left(27.5 \mathrm{mg}, 0.03 \mathrm{mmol}, 3 \mathrm{~mol} \%\right.$ ), and $\mathrm{PCy}_{3} \mathrm{HBF}_{4}(44.2 \mathrm{mg}, 0.12 \mathrm{mmol}, 12 \mathrm{~mol} \%$ ) placed under a positive pressure of argon, and subjected to three evacuation/backfilling cycles under high vacuum. Dioxane $(0.25 \mathrm{M})$ was added with vigorous stirring at room temperature, the reaction mixture was placed in a preheated oil bath at $120^{\circ} \mathrm{C}$, and stirred for $15 \mathrm{~h}$ at $120^{\circ} \mathrm{C}$. After the indicated time, the reaction mixture was cooled down to room temperature, diluted with $\mathrm{CH}_{2} \mathrm{Cl}_{2}(10 \mathrm{~mL})$, filtered, and concentrated. A sample was analyzed by ${ }^{1} \mathrm{H}-\mathrm{NMR}\left(\mathrm{CDCl}_{3}, 500 \mathrm{MHz}\right)$ and GC-MS to obtain conversion, yield and selectivity using internal standard and comparison with authentic samples. Purification by chromatography on silica gel (hexanes/ethyl acetate) afforded the title product. Yield $86 \%$ (168.5 mg). White solid. Characterization data are included in the section below.

\subsection{Characterization Data for Products $3 a-3 k$ (Figures 1 and 2)}

Benzophenone (3a). White solid. ${ }^{1} \mathrm{H}-\mathrm{NMR}\left(500 \mathrm{MHz}, \mathrm{CDCl}_{3}\right) \delta 7.83(\mathrm{~d}, J=8.9 \mathrm{~Hz}, 4 \mathrm{H}), 7.62(\mathrm{t}, J=7.4 \mathrm{~Hz}$, $2 \mathrm{H}), 7.51(\mathrm{t}, J=7.6 \mathrm{~Hz}, 4 \mathrm{H}) .{ }^{13} \mathrm{C}-\mathrm{NMR}\left(125 \mathrm{MHz}, \mathrm{CDCl}_{3}\right) \delta 196.75,137.61,132.42,130.07,128.28$.

Phenyl(p-tolyl)methanone (3b). White solid. ${ }^{1} \mathrm{H}-\mathrm{NMR}\left(500 \mathrm{MHz}, \mathrm{CDCl}_{3}\right) \delta 7.81(\mathrm{~d}, J=7.7 \mathrm{~Hz}, 2 \mathrm{H}), 7.75$ $(\mathrm{d}, J=7.5 \mathrm{~Hz}, 2 \mathrm{H}), 7.60(\mathrm{t}, J=7.4 \mathrm{~Hz}, 1 \mathrm{H}), 7.50(\mathrm{t}, J=7.2 \mathrm{~Hz}, 2 \mathrm{H}), 7.31(\mathrm{~d}, J=7.7 \mathrm{~Hz}, 2 \mathrm{H}), 2.47(\mathrm{~s}, 3 \mathrm{H})$. ${ }^{13} \mathrm{C}-\mathrm{NMR}\left(125 \mathrm{MHz}, \mathrm{CDCl}_{3}\right) \delta 196.49,143.22,137.98,134.90,132.14,130.31,129.93,128.97,128.20,21.66$.

(4-Methoxyphenyl)(phenyl)methanone (3c). White solid. ${ }^{1} \mathrm{H}-\mathrm{NMR}\left(500 \mathrm{MHz}, \mathrm{CDCl}_{3}\right) \delta 7.86(\mathrm{~d}, J=8.0 \mathrm{~Hz}$, $2 \mathrm{H}), 7.78(\mathrm{~d}, J=7.6 \mathrm{~Hz}, 2 \mathrm{H}), 7.59(\mathrm{t}, J=7.3 \mathrm{~Hz}, 1 \mathrm{H}), 7.50(\mathrm{t}, J=7.4 \mathrm{~Hz}, 2 \mathrm{H}), 6.99(\mathrm{~d}, J=8.0 \mathrm{~Hz}, 2 \mathrm{H})$, 3.92 (s, $3 \mathrm{H}) .{ }^{13} \mathrm{C}-\mathrm{NMR}\left(125 \mathrm{MHz}, \mathrm{CDCl}_{3}\right) \delta 195.56,163.23,138.30,132.57,131.89,130.17,129.74,128.19$, $113.56,55.51$.

1-(4-Benzoylphenyl)ethan-1-one (3d). White solid. ${ }^{1} \mathrm{H}-\mathrm{NMR}\left(500 \mathrm{MHz}, \mathrm{CDCl}_{3}\right) \delta 8.09(\mathrm{~d}, J=8.2 \mathrm{~Hz}, 2 \mathrm{H})$, $7.89(\mathrm{~d}, J=8.2 \mathrm{~Hz}, 2 \mathrm{H}), 7.83(\mathrm{~d}, J=7.5 \mathrm{~Hz}, 2 \mathrm{H}), 7.65(\mathrm{t}, J=7.4 \mathrm{~Hz}, 1 \mathrm{H}), 7.53(\mathrm{t}, J=7.7 \mathrm{~Hz}, 2 \mathrm{H}), 2.70$ 
(s, 3 H). ${ }^{13}$ C-NMR $\left(125 \mathrm{MHz}, \mathrm{CDCl}_{3}\right) \delta$ 197.52, 195.96, 139.57, 136.92, 133.00, 130.11, 130.05, 128.49, $128.17,26.92$.

Phenyl(o-tolyl)methanone (3e). White solid. ${ }^{1} \mathrm{H}-\mathrm{NMR}\left(500 \mathrm{MHz}, \mathrm{CDCl}_{3}\right) \delta 7.83(\mathrm{~d}, J=7.7 \mathrm{~Hz}, 2 \mathrm{H}), 7.60$ $(\mathrm{d}, J=6.9 \mathrm{~Hz}, 1 \mathrm{H}), 7.49(\mathrm{t}, J=7.6 \mathrm{~Hz}, 2 \mathrm{H}), 7.42(\mathrm{t}, J=7.5 \mathrm{~Hz}, 1 \mathrm{H}), 7.37-7.30(\mathrm{~m}, 2 \mathrm{H}), 7.30-7.27(\mathrm{~m}$, $1 \mathrm{H}), 2.36(\mathrm{~s}, 3 \mathrm{H}) .{ }^{13} \mathrm{C}-\mathrm{NMR}\left(125 \mathrm{MHz}, \mathrm{CDCl}_{3}\right) \delta 198.64,138.63,137.75,136.75,133.14,131.00,130.24$, $130.14,128.52,128.46,125.20,20.00$.

Phenyl(4-(trifluoromethyl)phenyl)methanone (3f). White solid. ${ }^{1} \mathrm{H}-\mathrm{NMR}\left(500 \mathrm{MHz}, \mathrm{CDCl}_{3}\right) \delta 7.93(\mathrm{~d}, J=$ $8.0 \mathrm{~Hz}, 2 \mathrm{H}), 7.84(\mathrm{~d}, J=7.7 \mathrm{~Hz}, 2 \mathrm{H}), 7.79(\mathrm{~d}, J=8.0 \mathrm{~Hz}, 2 \mathrm{H}), 7.66(\mathrm{t}, J=7.4 \mathrm{~Hz}, 1 \mathrm{H}), 7.54(\mathrm{t}, J=7.6 \mathrm{~Hz}$, $2 \mathrm{H}) .{ }^{13} \mathrm{C}-\mathrm{NMR}\left(125 \mathrm{MHz}, \mathrm{CDCl}_{3}\right) \delta 195.53,140.74,136.74,133.73\left(J^{F}=32.5 \mathrm{~Hz}\right), 133.09,130.14,130.11$, $128.54,125.36\left(J^{F}=7.5 \mathrm{~Hz}\right), 123.70\left(J^{F}=273.0 \mathrm{~Hz}\right) .{ }^{19} \mathrm{~F}-\mathrm{NMR}\left(471 \mathrm{MHz}, \mathrm{CDCl}_{3}\right) \delta 63.41$.

Phenyl(3-(trifluoromethyl)phenyl)methanone (3g). White solid. ${ }^{1} \mathrm{H}-\mathrm{NMR}\left(500 \mathrm{MHz}, \mathrm{CDCl}_{3}\right) \delta 8.07(\mathrm{~s}, 1 \mathrm{H})$, $7.98(\mathrm{~d}, J=7.8 \mathrm{~Hz}, 1 \mathrm{H}), 7.85(\mathrm{~d}, J=8.0 \mathrm{~Hz}, 1 \mathrm{H}), 7.80(\mathrm{~d}, J=7.7 \mathrm{~Hz}, 2 \mathrm{H}), 7.63(\mathrm{t}, J=7.6 \mathrm{~Hz}, 2 \mathrm{H}), 7.52(\mathrm{t}$, $J=7.6 \mathrm{~Hz}, 2 \mathrm{H}) .{ }^{13} \mathrm{C}-\mathrm{NMR}\left(125 \mathrm{MHz}, \mathrm{CDCl}_{3}\right) \delta 195.32,138.45,136.92,133.25,133.14,131.17\left(J^{F}=32.7\right.$ $\mathrm{Hz}), 130.16,129.09,128.97\left(J^{F}=7.5 \mathrm{~Hz}\right), 128.71,126.84\left(J^{F}=8.8 \mathrm{~Hz}\right), 123.84\left(J^{F}=272.9 \mathrm{~Hz}\right) .{ }^{19} \mathrm{~F}-\mathrm{NMR}$ $\left(471 \mathrm{MHz}, \mathrm{CDCl}_{3}\right) \delta 62.77$.

(4-Fluorophenyl)(phenyl)methanone (3h). White solid. ${ }^{1} \mathrm{H}-\mathrm{NMR}\left(500 \mathrm{MHz}, \mathrm{CDCl}_{3}\right) \delta 7.90-7.84(\mathrm{~m}, 2 \mathrm{H})$, $7.79(\mathrm{~d}, J=7.7 \mathrm{~Hz}, 2 \mathrm{H}), 7.62(\mathrm{t}, J=6.9 \mathrm{~Hz}, 1 \mathrm{H}), 7.51(\mathrm{t}, J=7.4 \mathrm{~Hz}, 2 \mathrm{H}), 7.18(\mathrm{t}, J=8.2 \mathrm{~Hz}, 2 \mathrm{H})$. ${ }^{13} \mathrm{C}-\mathrm{NMR}\left(125 \mathrm{MHz}, \mathrm{CDCl}_{3}\right) \delta 195.26,165.39\left(J^{F}=254.1 \mathrm{~Hz}\right), 137.51,133.81\left(J^{F}=2.5 \mathrm{~Hz}\right), 132.67\left(J^{F}=\right.$ $8.8 \mathrm{~Hz}), 132.47,129.88,128.36,115.45\left(J^{F}=21.4 \mathrm{~Hz}\right) .{ }^{19} \mathrm{~F}-\mathrm{NMR}\left(471 \mathrm{MHz}, \mathrm{CDCl}_{3}\right) \delta 105.98$.

(3,5-Difluorophenyl)(phenyl)methanone (3i). White solid. ${ }^{1} \mathrm{H}-\mathrm{NMR}\left(500 \mathrm{MHz}, \mathrm{CDCl}_{3}\right) \delta 7.35(\mathrm{dt}, J=40.7$, $18.4 \mathrm{~Hz}, 4 \mathrm{H}), 7.03-6.87(\mathrm{~m}, 1 \mathrm{H}), 6.40(\mathrm{~d}, J=41.0 \mathrm{~Hz}, 2 \mathrm{H}), 6.13(\mathrm{~d}, J=40.9 \mathrm{~Hz}, 2 \mathrm{H}) .{ }^{13} \mathrm{C}-\mathrm{NMR}(125$ $\left.\mathrm{MHz}, \mathrm{CDCl}_{3}\right) \delta 193.95,162.74\left(J^{F}=250.3 \mathrm{~Hz}\right), 162.65\left(J^{F}=251.6 \mathrm{~Hz}\right), 136.40,133.16,129.98,128.59$, $112.96\left(J^{F}=20.1 \mathrm{~Hz}\right), 107.73\left(J^{F}=25.8 \mathrm{~Hz}\right) .{ }^{19} \mathrm{~F}-\mathrm{NMR}\left(471 \mathrm{MHz}, \mathrm{CDCl}_{3}\right) \delta 108.15$.

Methyl 4-benzoylbenzoate (3j). White solid. ${ }^{1} \mathrm{H}-\mathrm{NMR}\left(500 \mathrm{MHz}, \mathrm{CDCl}_{3}\right) \delta 8.17(\mathrm{~d}, J=8.2 \mathrm{~Hz}, 2 \mathrm{H}), 7.87$ $(\mathrm{d}, J=8.2 \mathrm{~Hz}, 2 \mathrm{H}), 7.83(\mathrm{~d}, J=7.5 \mathrm{~Hz}, 2 \mathrm{H}), 7.64(\mathrm{t}, J=7.4 \mathrm{~Hz}, 1 \mathrm{H}), 7.53(\mathrm{t}, J=7.6 \mathrm{~Hz}, 2 \mathrm{H}), 3.99(\mathrm{~s}$, $3 \mathrm{H}) .{ }^{13} \mathrm{C}-\mathrm{NMR}\left(125 \mathrm{MHz}, \mathrm{CDCl}_{3}\right) \delta$ 196.03, 166.32, 141.33, 136.96, 133.22, 132.95, 130.11, 129.78, 129.50, $128.47,52.48$.

Cyclohexyl(phenyl)methanone (3k). White solid. ${ }^{1} \mathrm{H}-\mathrm{NMR}\left(500 \mathrm{MHz}, \mathrm{CDCl}_{3}\right) \delta 7.98-7.96(\mathrm{~d}, J=8.2 \mathrm{~Hz}$, $2 \mathrm{H}), 7.58-7.56(\mathrm{t}, J=7.5 \mathrm{~Hz}, 1 \mathrm{H}), 7.50-7.47(\mathrm{t}, J=7.7 \mathrm{~Hz}, 2 \mathrm{H}), 3.31-3.27(\mathrm{t}, J=11.5 \mathrm{~Hz}, 1 \mathrm{H}), 1.93-1.86$ $(\mathrm{m}, 4 \mathrm{H}), 1.78-1.75(\mathrm{~d}, J=11.7 \mathrm{~Hz}, 1 \mathrm{H}), 1.54-1.49(\mathrm{t}, J=13.4 \mathrm{~Hz}, 2 \mathrm{H}), 1.46-1.39(\mathrm{~m}, 2 \mathrm{H}), 1.34-1.31(\mathrm{~d}, J$ $=12.5 \mathrm{~Hz}, 1 \mathrm{H}) .{ }^{13} \mathrm{C}-\mathrm{NMR}\left(125 \mathrm{MHz}, \mathrm{CDCl}_{3}\right) \delta 203.92,136.38,132.73,128.59,128.27,45.65,29.44,25.98$, 25.88 .

Supplementary Materials: Experimental procedures and characterization data are available online.

Author Contributions: J.B. conducted experimental work and analyzed the data with contributions from D.J.P.; H.H. and M.S. supervised the project, designed experiments to develop this reaction, and wrote the paper.

Funding: This research was funded by Rutgers University and the NSF (CAREER CHE-1650766, CBET 1438493) are acknowledged for support. The $500 \mathrm{MHz}$ spectrometer was supported by the NSF-MRI grant (CHE-1229030).

Conflicts of Interest: The authors declare no conflict of interest.

\section{References}

1. Shi, S.; Nolan, S.P.; Szostak, M. Well-Defined Palladium(II)-NHC (NHC = N-Heterocyclic Carbene) Precatalysts for Cross-Coupling Reactions of Amides and Esters by Selective Acyl CO-X (X= N, O) Cleavage. Acc. Chem. Res. 2018, 51, 2589-2599. [CrossRef] [PubMed]

2. Kaiser, D.; Bauer, A.; Lemmerer, M.; Maulide, N. Amide Activation: An Emerging Tool for Chemoselective Synthesis. Chem. Soc. Rev. 2018, 47, 7899-7925. [CrossRef] [PubMed] 
3. Takise, R.; Muto, K.; Yamaguchi, J. Cross-Coupling of Aromatic Esters and Amides. Chem. Soc. Rev. 2017, 46, 5864-5888. [CrossRef] [PubMed]

4. Liu, C.; Szostak, M. Twisted Amides: From Obscurity to Broadly Useful Transition-Metal-Catalyzed Reactions by N-C Amide Bond Activation. Chem. Eur. J. 2017, 23, 7157-7173. [CrossRef] [PubMed]

5. Meng, G.; Shi, S.; Szostak, M. Cross-Coupling of Amides by N-C Bond Activation. Synlett 2016, 27, 2530-2540. [CrossRef]

6. Meng, G.; Szostak, M. N-Acyl-Glutarimides: Privileged Scaffolds in Amide N-C Bond Cross-Coupling. Eur. J. Org. Chem. 2018, 20-21, 2352-2365. [CrossRef]

7. Liu, C.; Szostak, M. Decarbonylative Cross-Coupling of Amides. Org. Biomol. Chem. 2018, 16. in press. [CrossRef] [PubMed]

8. Dander, J.E.; Garg, N.K. Breaking Amides using Nickel Catalysis. ACS Catal. 2017, 7, 1413-1423. [CrossRef] [PubMed]

9. Meng, G.; Shi, S.; Lalancette, R.; Szostak, R.; Szostak, M. Reversible Twisting of Primary Amides via Ground State $\mathrm{N}-\mathrm{C}(\mathrm{O})$ Destabilization: Highly Twisted Rotationally Inverted Acyclic Amides. J. Am. Chem. Soc. 2018, 140, 727-734. [CrossRef] [PubMed]

10. Szostak, R.; Shi, S.; Meng, G.; Lalancette, R.; Szostak, M. Ground-State Distortion in N-Acyl-tert-butylcarbamates (Boc) and N-Acyl-tosylamides (Ts): Twisted Amides of Relevance to Amide N-C Cross-Coupling. J. Org. Chem. 2016, 81, 8091-8094. [CrossRef] [PubMed]

11. Pace, V.; Holzer, W.; Meng, G.; Shi, S.; Lalancette, R.; Szostak, R.; Szostak, M. Structures of Highly Twisted Amides Relevant to Amide N-C Cross-Coupling: Evidence for Ground-State Amide Destabilization. Chem. Eur. J. 2016, 22, 14494-14498. [CrossRef] [PubMed]

12. Szostak, R.; Meng, G.; Szostak, M. Resonance Destabilization in N-Acylanilines (Anilides): ElectronicallyActivated Planar Amides of Relevance in N-C(O) Cross-Coupling. J. Org. Chem. 2017, 82, 6373-6378. [CrossRef] [PubMed]

13. Liu, C.; Li, G.; Shi, S.; Meng, G.; Lalancette, R.; Szostak, R.; Szostak, M. Acyl and Decarbonylative Suzuki Coupling of N-Acetyl Amides: Electronic Tuning of Twisted, Acyclic Amides in Catalytic Carbon-Nitrogen Bond Cleavage. ACS Catal. 2018, 8, 9131-9139. [CrossRef]

14. Halima, T.B.; Zhang, W.; Yalaoui, I.; Hong, X.; Yang, Y.-F.; Houk, K.N.; Newman, S.G. Palladium-Catalyzed Suzuki-Miyaura Coupling of Aryl Esters. J. Am. Chem. Soc. 2017, 139, 1311-1318. [CrossRef] [PubMed]

15. Lei, P.; Meng, G.; Shi, S.; Ling, Y.; An, J.; Szostak, R.; Szostak, M. Suzuki-Miyaura Cross-Coupling of Amides and Esters at Room Temperature: Correlation with Barriers to Rotation around $\mathrm{C}-\mathrm{N}$ and $\mathrm{C}-\mathrm{O}$ Bonds. Chem. Sci. 2017, 8, 6525-6530. [CrossRef] [PubMed]

16. Shi, S.; Lei, P.; Szostak, M. Pd-PEPPSI: A General Pd-NHC Precatalyst for Suzuki-Miyaura Cross- Coupling of Esters by C-O Cleavage. Organometallics 2017, 36, 3784-3789. [CrossRef]

17. Li, G.; Shi, S.; Szostak, M. Pd-PEPPSI: Water-Assisted Suzuki-Miyaura Cross-Coupling of Aryl Esters at Room Temperature using a Practical Palladium-NHC (NHC $=$ N-Heterocyclic Carbene) Precatalyst. Adv. Synth. Catal. 2018, 360, 1538-1543. [CrossRef]

18. Dardir, A.H.; Melvin, P.R.; Davis, R.M.; Hazari, N.; Beromi, M.M. Rapidly Activating Pd-Precatalyst for Suzuki-Miyaura and Buchwald-Hartwig Couplings of Aryl Esters. J. Org. Chem. 2017, 83, 469-477. [CrossRef] [PubMed]

19. Liebman, J.; Greenberg, A. The Origin of Rotational Barriers in Amides and Esters. Biophys. Chem. 1974, 1, 222-226. [CrossRef]

20. Nicolaou, K.C.; Natarajan, S.; Li, H.; Jain, N.F.; Hughes, R.; Solomon, M.E.; Ramanjulu, J.M.; Boddy, C.N.C.; Takayanagi, M. Total Synthesis of Vancomycin Aglycon. Part 1: Synthesis of Amino Acids 4-7 and Construction of the AB-COD Ring Skeleton. Angew. Chem. Int. Ed. 1998, 37, 2708-2714. [CrossRef]

21. Al-Warhi, T.I.; Al-Hazimi, H.M.A.; El-Faham, A. Recent development in peptide coupling reagents. J. Saudi Chem. Soc. 2012, 16, 97-116. [CrossRef]

22. Specklin, S.; Cossy, J. Chemoselective Synthesis of $\beta$-Ketophosphonates Using Lithiated $\alpha$-(Trimethylsilyl) methylphosphonate. J. Org. Chem. 2015, 80, 3302-3308. [CrossRef] [PubMed]

23. Guo, L.; Rueping, M. Decarbonylative Cross-Couplings: Nickel Catalyzed Functional Group Interconversion Strategies for the Construction of Complex Organic Molecules. Acc. Chem. Res. 2018, 51, 1185-1195. [CrossRef] [PubMed] 
24. Guo, L.; Rueping, M. Transition-Metal-Catalyzed Decarbonylative Coupling Reactions: Concepts, Classifications, and Applications. Chem. Eur. J. 2018, 24, 7794-7809. [CrossRef] [PubMed]

25. Gildner, P.G.; Colacot, T.J. Reactions of the 21st Century: Two Decades of Innovative Catalyst Design for Palladium-Catalyzed Cross-Couplings. Organometallics 2015, 34, 5497-5508. [CrossRef]

Sample Availability: Sample Availability: Not available.

(c) 2018 by the authors. Licensee MDPI, Basel, Switzerland. This article is an open access article distributed under the terms and conditions of the Creative Commons Attribution (CC BY) license (http:/ / creativecommons.org/licenses/by/4.0/). 


\title{
Article \\ Computational Study of Mechanism and Thermodynamics of Ni/IPr-Catalyzed Amidation of Esters
}

\author{
Chong-Lei Ji ${ }^{\dagger}$, Pei-Pei Xie ${ }^{\dagger}$ and Xin Hong * \\ Department of Chemistry, Zhejiang University, Hangzhou 310027, China; \\ chjicl@zju.edu.cn (C.-L.J.); xppyyfd@zju.edu.cn (P.-P.X.) \\ * Correspondence: hxchem@zju.edu.cn; Tel.: +86-571-88273191 \\ + These authors contributed equally to this work.
}

Received: 21 September 2018; Accepted: 12 October 2018; Published: 18 October 2018

\begin{abstract}
Nickel catalysis has shown remarkable potential in amide $\mathrm{C}-\mathrm{N}$ bond activation and functionalization. Particularly for the transformation between ester and amide, nickel catalysis has realized both the forward (ester to amide) and reverse (amide to ester) reactions, allowing a powerful approach for the ester and amide synthesis. Based on density functional theory (DFT) calculations, we explored the mechanism and thermodynamics of $\mathrm{Ni} / \mathrm{IPr}$-catalyzed amidation with both aromatic and aliphatic esters. The reaction follows the general cross-coupling mechanism, involving sequential oxidative addition, proton transfer, and reductive elimination. The calculations indicated the reversible nature of amidation, which highlights the importance of reaction thermodynamics in related reaction designs. To shed light on the control of thermodynamics, we also investigated the thermodynamic free energy changes of amidation with a series of esters and amides.
\end{abstract}

Keywords: amide C-N bond activation; nickel catalysis; amidation; DFT study; reaction thermodynamics

\section{Introduction}

Amide $\mathrm{C}-\mathrm{N}$ bond activation and functionalization provide a powerful strategy to utilize amide as a central synthon [1-6]. Despite the remarkable value of this strategy, the development of amide $\mathrm{C}-\mathrm{N}$ bond activation has progressed slowly due to the resonance nature of amide and the resulting difficulty for bond dissociation [7-16]. Recently, Garg and coworkers discovered the outstanding performance of nickel catalysis for amide $\mathrm{C}-\mathrm{N}$ bond activation [17], leading to the development of a series of exciting Ni-catalyzed cross coupling reactions [18-26]. Szostak and coworkers developed a family of geometrically twisted amides which serves as a powerful synthetic platform [27-39] for both metal-catalyzed and metal-free transformations. Independent studies from Shi, Zou, Rueping, Maiti, Stanley, and Molander also contribute significantly to the synthetic advances involving amide C-N bond activation [40-52].

In addition, amide $\mathrm{C}-\mathrm{N}$ bond activation stimulated the synthetic developments of amide $\mathrm{C}-\mathrm{N}$ bond formation. Szostak and coworkers reported a series of transamidation reactions from twisted amides, which provides a distinctive approach for amide synthesis [39] (Scheme 1a). Garg, Houk, and coworkers discovered that Lewis acid plays an important role on the kinetics and thermodynamics of amidation of ester, which reverses the thermodynamic equilibrium of esterification of amide [53] (Scheme 1b). Newman and coworkers recently disclosed a Ni/IPr-catalyzed amidation of ester under Lewis acid-free conditions [54] (Scheme 1c). This transformation attracts our mechanistic interests [55-66]; particularly for the Lewis-acid free Ni-mediated C-O bond cleavage and C-N bond formation. Here we report a computational study on the mechanism of Ni/IPr-catalyzed amidation of ester and the thermodynamic equilibrium of amidation. 


\section{Szostak et al.}

(a)

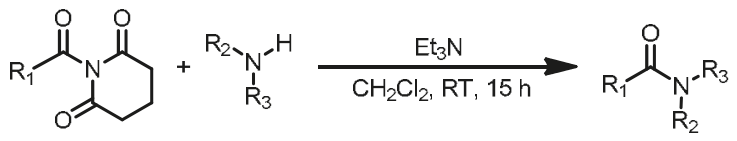

$\mathrm{R}_{1}=$ aryl or $a|k y| ; R_{2}, R_{3}=$ aryl, alkyl, $H$ etc.

\section{Garg et al.}

(b)

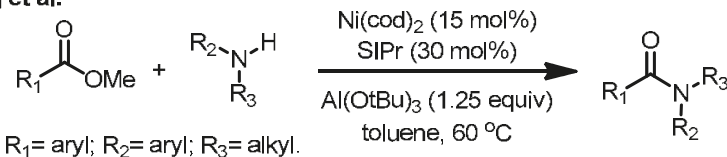

Newman et al.

(c)

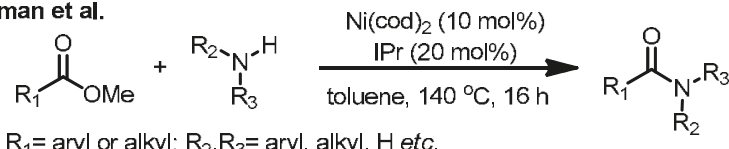<smiles>CC(C)c1cccc(C(C)C)c1N1CCN(c2c(C(C)C)cccc2C(C)C)C1</smiles>

SIPr

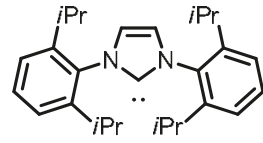

$\mathrm{IPr}$

Scheme 1. (a) Transamidation of $N$-acyl-glutarimides with amines; (b) Ni/SIPr-catalyzed amidation of ester under Lewis acid conditions; and (c) Ni/IPr-catalyzed amidation of ester under Lewis acid-free conditions.

\section{Results and Discussion}

\subsection{Reaction Mechanism of Aromatic Ester}

Using methyl benzoate and morpholine as the model substrates, we first explored the free energy changes of Ni/IPr-catalyzed amidation with aromatic ester. The free energy profile is shown in Figure 1, and the optimized structures of selected species in the catalytic cycle are shown in Figure 2. From the $\mathrm{Ni}(\mathrm{IPr})$ (toluene) complex $\mathbf{1}$ [67], the initial ligand exchange with substrate is exergonic and leads to the substrate-coordinated complex 2. Subsequent oxidative addition via TS3 requires a barrier of $20.4 \mathrm{kcal} / \mathrm{mol}$, which generates the acylnickel species 4.5 then undergoes a facile inner-sphere proton transfer through TS6, and the dissociation of methanol leads to the $\mathrm{LNi}^{\mathrm{II}}$ (acyl)(amino) intermediate 8. From 8, the $\mathrm{C}-\mathrm{N}$ bond formation occurs via the reductive elimination transition state TS9, and the final exergonic product liberation produces the amidation product $\mathbf{1 1}$ as well as regenerates the catalytically active species 2 . We have confirmed the stability of wavefunctions for all $\mathrm{Ni}$ (II) species involved in the catalytic cycle. We were not able to locate the transition states for the ligand exchange steps (4 to 5, 7 to 8) due to the flat energy surface. A series of constrained optimizations were performed to verify the flat energy surface of ligand exchange. Details are included in Supplementary Materials (Figure S1). Based on the DFT-computed free energy changes of the overall catalytic cycle, the on-cycle resting state is the substrate-coordinated complex 2 , and the rate-limiting step is the $\mathrm{C}-\mathrm{O}$ bond activation step via TS3 with an overall barrier of $20.4 \mathrm{kcal} / \mathrm{mol}$. Our computations also suggested that the overall amidation is reversible and almost thermodynamic neutral. The reaction barrier for the reversed transformation from $\mathbf{1 1}$ to 2 is only $20.3 \mathrm{kcal} / \mathrm{mol}$. This corresponds well with the reversible nature of this amidation transformation, as reported by Newman [54]. It should be pointed out the generated methanol may leave the reaction system due to its volatility, which serves as an additional driving force for the amide formation. 


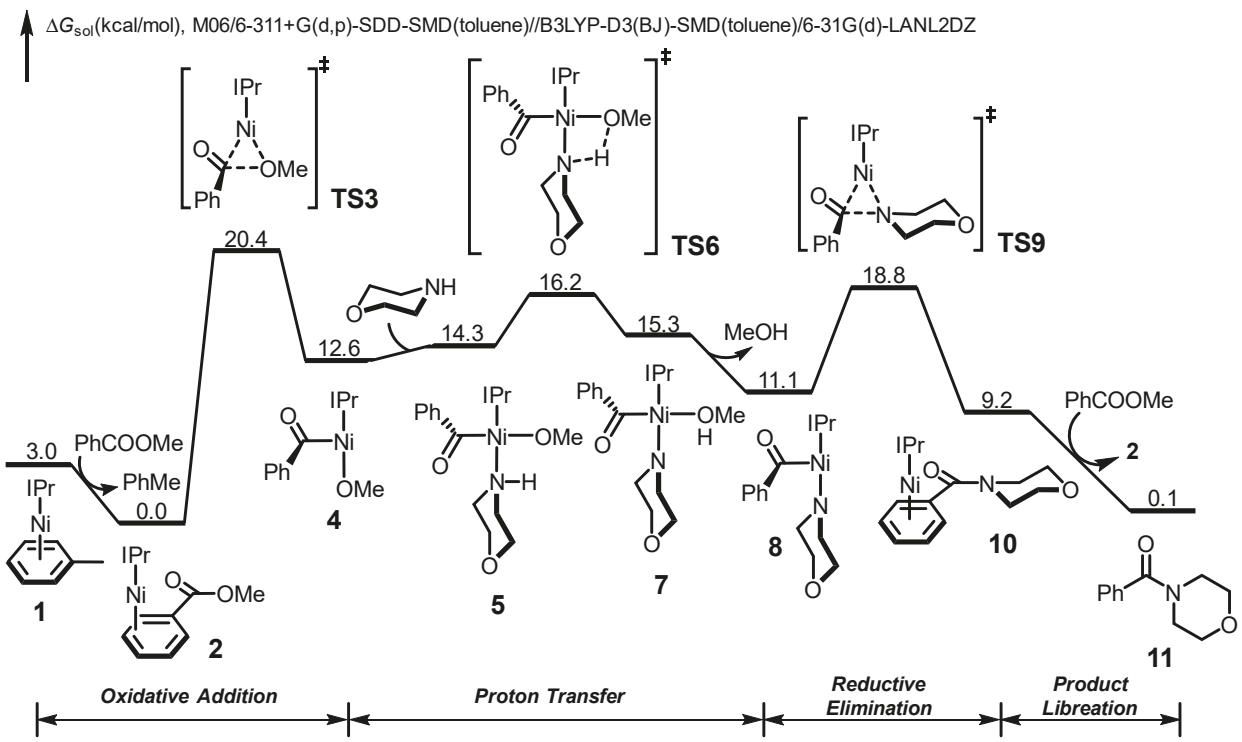

Figure 1. DFT-computed free energy profile of Ni/IPr-catalyzed amidation of aromatic ester.

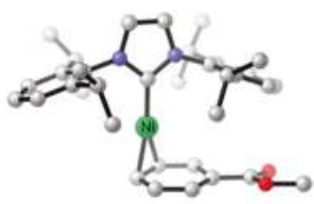

2

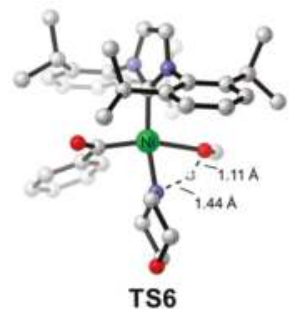

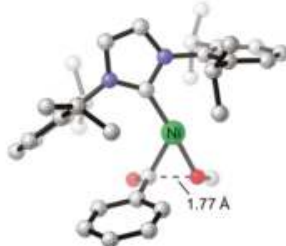

TS3

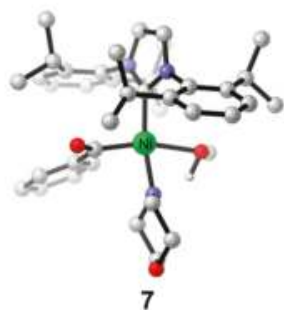

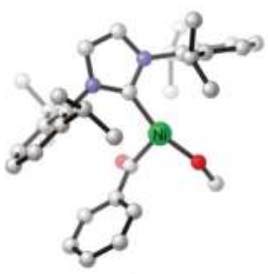

4

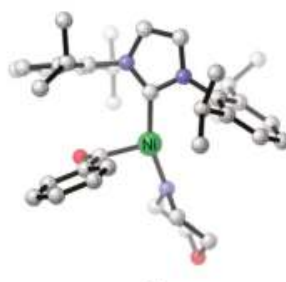

8

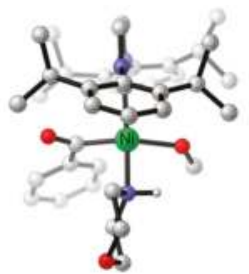

5

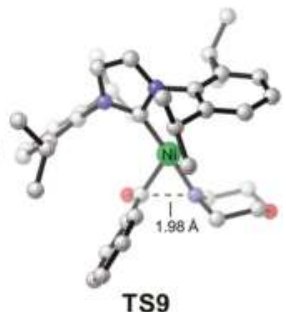

TS9

Figure 2. Optimized structures of selected intermediates and transition states in the catalytic cycle of $\mathrm{Ni} / \mathrm{IPr}$-catalyzed amidation of ester.

\subsection{Reaction Mechanism of Aliphatic Ester}

We next explored the Ni-catalyzed amidation with aliphatic ester, using methyl 3-phenylpropionate as the model substrate. The DFT-computed free energy profile is shown in Figure 3, and the optimized structures of selected species in the catalytic cycle are shown in Figure 4. The reaction mechanism of aliphatic ester is similar to that of aromatic ester, which involves sequential oxidative addition, proton transfer, reductive elimination and product liberation. The resting state is toluene-coordinated complex 1, and the rate-limiting step is the proton transfer step with an overall barrier of $16.9 \mathrm{kcal} / \mathrm{mol}$. The free energy change of the amidation with methyl 3-phenylpropionate is exergonic by $1.8 \mathrm{kcal} / \mathrm{mol}$. Comparing the free energy profiles of aromatic and aliphatic esters, the major difference is the resting 
state and overall reaction barrier. Due to the lack of electron-deficient aromatic functionality in methyl 3-phenylpropionate, the substrate-coordinated complex $\mathbf{1 2}$ is $6.1 \mathrm{kcal} / \mathrm{mol}$ higher in free energy comparing with the toluene-coordinated species 1 . This leads to the low overall barrier of the amidation with aliphatic ester.

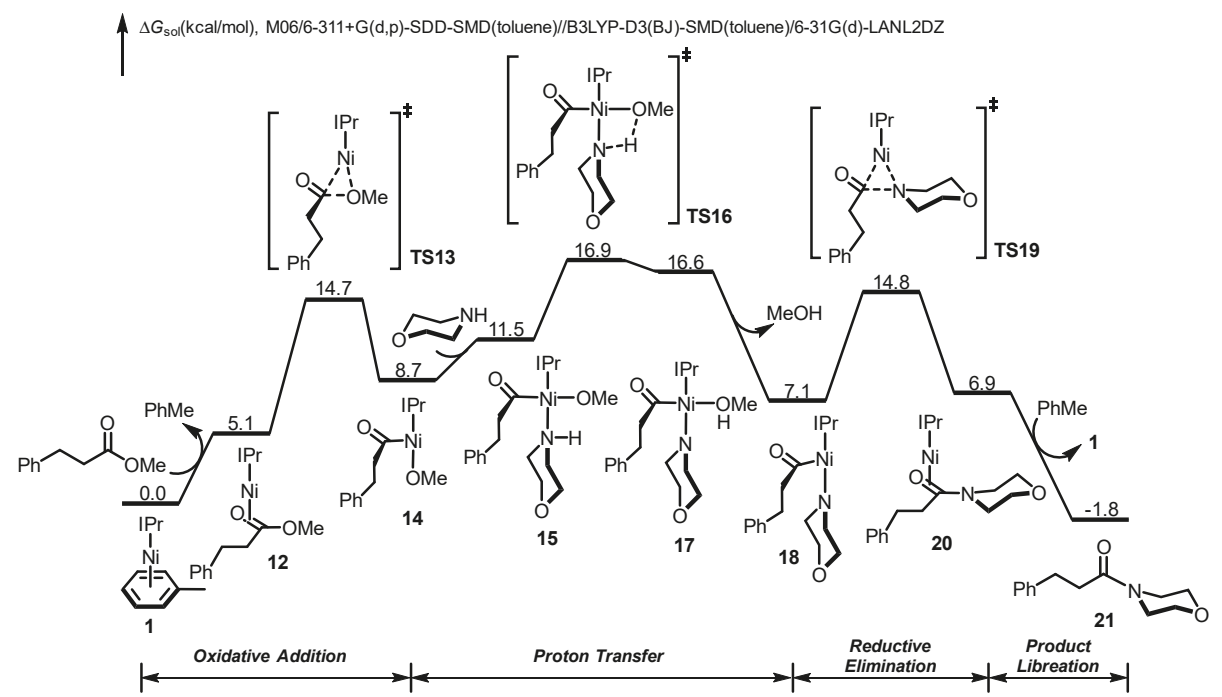

Figure 3. Density functional theory (DFT)-computed free energy profile of Ni/IPr-catalyzed amidation of aliphatic ester.

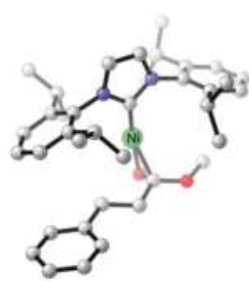

12

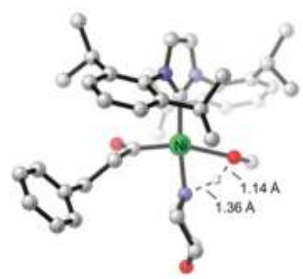

TS16

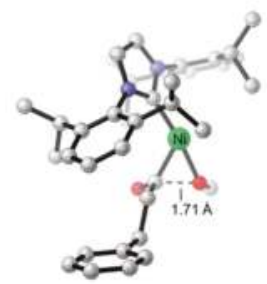

TS13

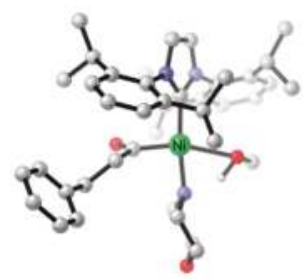

17

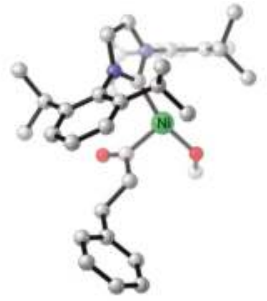

14

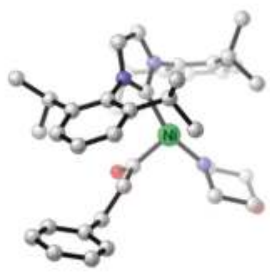

18

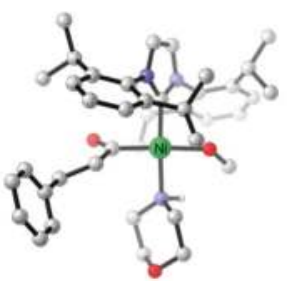

15

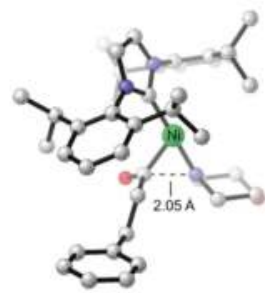

TS19

Figure 4. Optimized structures of selected intermediates and transition states in the catalytic cycle of $\mathrm{Ni} / \mathrm{IPr}$-catalyzed amidation of ester.

\subsection{Reaction Thermodynamics}

Based on the computed free energy profiles of Ni-catalyzed amidation of ester, we noticed that the major bottleneck for this type of transformation is the control of thermodynamics. The thermodynamic 
equilibrium has to be designed cautiously because the overall transformation does not have a strong force, unlike many other organic transformations. Therefore, the synthetic efforts could be unfruitful even the designed amidation or esterification has a surmountable reaction barrier. In order to understand the controlling factors of the thermodynamic equilibrium of amidation as well as provide a general thermodynamic guideline for related reaction designs, we computed the free energy changes with a series of esters and amides. The results are summarized as a heat map in Figure 5. Green represents the thermodynamic equilibrium that favors the formation of ester, and red indicates the opposite trend.

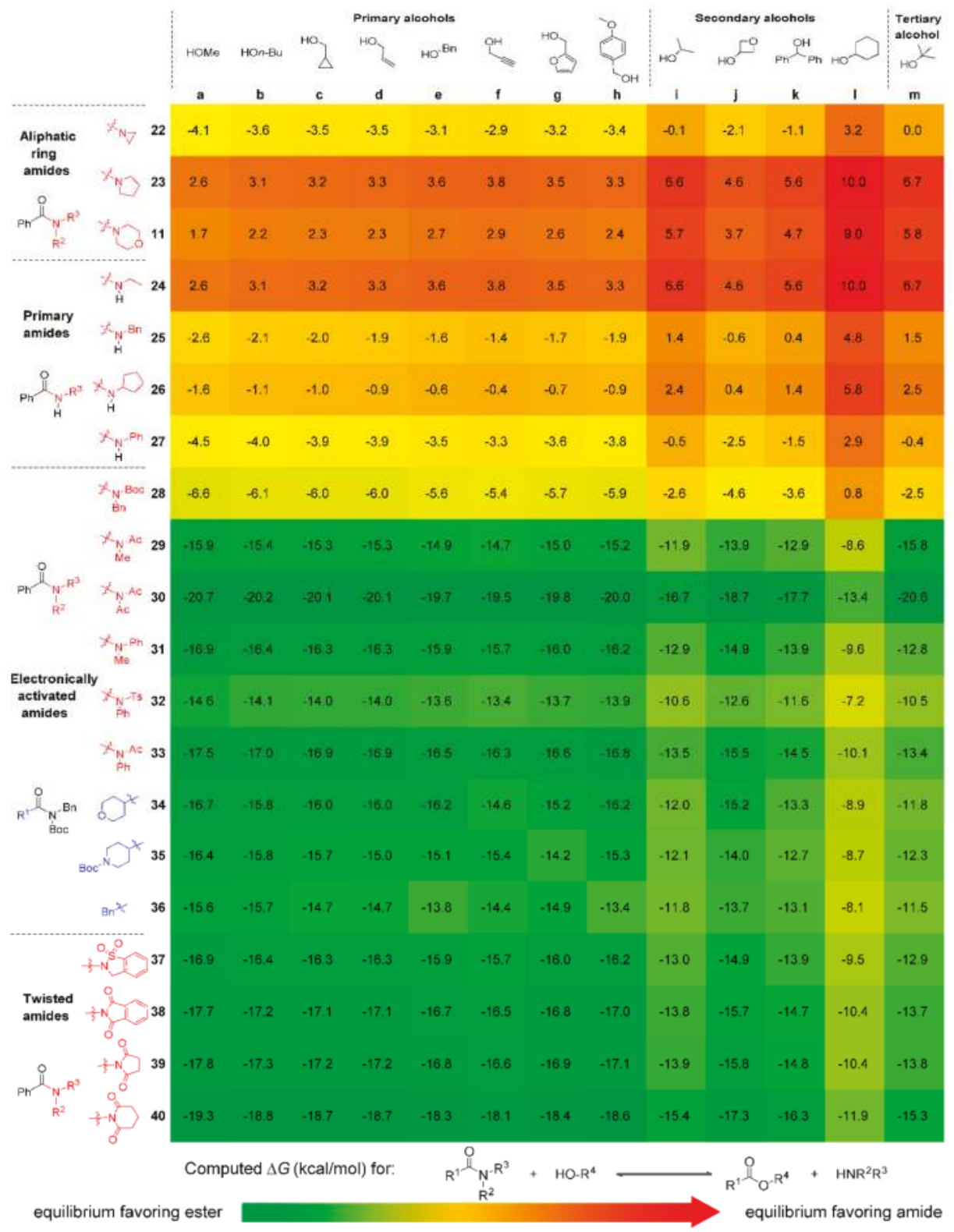

Figure 5. DFT-computed thermodynamics of esterification of amides. 
For the explored esters and amides, the alcohol component (derivatization of ester) have limited effects on the reaction thermodynamics. The effects from the change of primary alcohols are less than $1 \mathrm{kcal} / \mathrm{mol}$ for most amides (a to $\mathbf{h}$ ). Comparing with the primary alcohols, the esters with secondary alcohols are less stable (i to 1 ), especially for cyclohexanol. The thermodynamic equilibrium involving cyclohexanol favors the amide formation the most among all the studied alcohols. This suggest that the cyclohexanol derived esters can be useful substrates for amide synthesis. Interestingly, the tertiary alcohol is not the best alcohol for amide formation, potentially due to the steric repulsions in the corresponding esters.

Unlike the alcohols, the structure of amides has profound effects on the thermodynamic equilibrium of amidation. Without strong electron-activating groups or geometric twisting, amides are more stable than the corresponding esters regardless of the effects from alcohol (23 and 24). This follows the consensus that amide is generally more stable than ester due to the strong resonance nature. However, the electronically activated amides (28-36) and twisted amides (37-40) are significantly less stable in terms of thermodynamics. The equilibrium involving these amides all favor the ester formation, providing significant driving force for amide $\mathrm{C}-\mathrm{N}$ bond activation and functionalization. Based on the computed thermodynamics, we found that the $\mathrm{N}$-substitution has important effect on the thermodynamic stability of amides. This corroborates Szostak's design of twisted amides [27-39], and also highlights the importance of amide design for future synthetic transformations involving amides.

\section{Computational Methods}

All density functional theory (DFT) calculations were carried out using Gaussian16 software package [68]. Geometry optimizations and frequency calculations were conducted using B3LYP [69,70] functional with Grimme's D3(BJ) empirical dispersion correction [71], the LANL2DZ [72] basis set for nickel, and 6-31G(d) basis set for all the other elements. The solvation energy corrections were also included in the geometry optimizations and frequency calculations. Based on the solution phase-optimized geometries, single-point energies were calculated with the M06 [73] functional, the SDD $[74,75]$ basis set for nickel, and 6-311G++ $(\mathrm{d}, \mathrm{p})$ basis set for all other elements. Solvation energies were calculated using the SMD solvation model [76] with toluene as the solvent. No frequency scaling factor was used to calculate Gibbs energy corrections. The 3D diagrams of computed species were visualized using CYLview [77].

\section{Conclusions}

In summary, the mechanism and thermodynamics of Ni/IPr-catalyzed amidation of esters have been explored with DFT calculations. The reaction proceeds via the general cross-coupling mechanism. Nickel catalyst first cleaves the $\mathrm{C}-\mathrm{O}$ bond of ester via oxidative addition, and subsequent proton transfer between $\mathrm{LNi}(\mathrm{acyl})(\mathrm{OR})$ species and amine leads to $\mathrm{LNi}(\mathrm{acyl})(\mathrm{amino})$ intermediate. This intermediate undergoes $\mathrm{C}-\mathrm{N}$ reductive elimination to produce the amidation product. The studied aromatic and aliphatic esters both have fairly low reaction barriers, $20.4 \mathrm{kcal} / \mathrm{mol}$ for methyl benzoate and $16.9 \mathrm{kcal} / \mathrm{mol}$ for methyl 3-phenylpropionate. However, the overall amidation with morpholine is almost thermodynamic neutral. This suggests that the amidation only has limited thermodynamic driving force, and the evaporation of methanol could be critical for productivity. Therefore, the key to reaction success of Ni/NHC-catalyzed amidation of ester is the control of thermodynamic equilibrium.

For the thermodynamic free energy changes of the esterification of amide, the O-substitution of ester has limited effects, and cyclohexanol derivative is the most stable ester among all the studied cases. In contrast to the O-substitution of ester, the $\mathrm{N}$-substitution of amide has profound effects on the thermodynamic stability of amides. Electron-activating groups and geometric twisting can significantly destabilize amides and provide the desired driving force towards the amide $\mathrm{C}-\mathrm{N}$ bond activation. These computations highlight the design of amide for future reaction development involving amide $\mathrm{C}-\mathrm{N}$ bond activation. 
Supplementary Materials: Detailed energies and coordinates of computed saddle points are available online.

Author Contributions: X.H. conceived and designed the research. C.-L.J. and P.-P.X. performed the calculations. All authors analyzed the data and wrote the paper.

Funding: This research was funded by Financial support from Zhejiang University, the Chinese "Thousand Youth Talents Plan", the National Natural Science Foundation of China (NSFC, No. 21702182), and the "Fundamental Research Funds for the Central Universities".

Acknowledgments: Calculations were performed on the high-performance computing system at the Department of Chemistry, Zhejiang University.

Conflicts of Interest: The authors declare no conflicts of interest.

\section{References}

1. Meng, G.; Shi, S.; Szostak, M. Cross-Coupling of Amides by N-C Bond Activation. Synlett 2016, 27, $2530-2540$.

2. Meng, G.; Szostak, M. Palladium-Catalyzed Suzuki-Miyaura Coupling of Amides by Carbon-Nitrogen Cleavage: General Strategy for Amide N-C Bond Activation. Org. Biomol. Chem. 2016, 14, 5690-5707. [CrossRef] [PubMed]

3. Liu, C.; Szostak, M. Twisted Amides: From Obscurity to Broadly Useful Transition-Metal-Catalyzed Reactions by N-C Amide Bond Activation. Chem. Eur. J. 2017, 23, 7157-7173. [CrossRef] [PubMed]

4. Dander, J.E.; Garg, N.K. Breaking Amides using Nickel Catalysis. ACS Catal. 2017, 7, 1413-1423. [CrossRef] [PubMed]

5. Takise, R.; Muto, K.; Yamaguchi, J. Cross-coupling of aromatic esters and amides. Chem. Soc. Rev. 2017, 46, 5864-5888. [CrossRef] [PubMed]

6. Gao, Y.; Ji, C.-L.; Hong, X. Ni-mediated C-N activation of amides and derived catalytic transformations. Sci. China Chem. 2017, 60, 1413-1424. [CrossRef]

7. Wiberg, K.B.; Breneman, C.M. Resonance interactions in acyclic systems. 3. Formamide internal rotation revisited. Charge and energy redistribution along the $\mathrm{C}-\mathrm{N}$ bond rotational pathway. J. Am. Chem. Soc. 1992, 114, 831-840. [CrossRef]

8. Wiberg, K.B. The Interaction of Carbonyl Groups with Substituents. Acc. Chem. Res. 1999, 32, 922-929. [CrossRef]

9. Kemnitz, C.R.; Loewen, M.J. "Amide Resonance" Correlates with a Breadth of C-N Rotation Barriers. J. Am. Chem. Soc. 2007, 129, 2521-2528. [CrossRef] [PubMed]

10. Glover, S.A.; Rosser, A.A. Reliable Determination of Amidicity in Acyclic Amides and Lactams. J. Org. Chem. 2012, 77, 5492-5502. [CrossRef] [PubMed]

11. Szostak, R.; Aubé, J.; Szostak, M. Determination of Structures and Energetics of Small- and Medium-Sized One-Carbon Bridged Twisted Amides using ab Initio Molecular Orbital Methods. Implications for Amidic Resonance along the C-N Rotational Pathway. J. Org. Chem. 2015, 80, 7905-7927. [CrossRef] [PubMed]

12. Hu, F.; Lalancette, R.; Szostak, M. Structural Characterization of N-Alkylated Twisted Amides: Consequences for Amide Bond Resonance and N-C Cleavage. Angew. Chem. Int. Ed. 2016, 55, 5062-5066. [CrossRef] [PubMed]

13. Szostak, R.; Meng, G.; Szostak, M. Resonance Destabilization in N-Acylanilines (Anilides): ElectronicallyActivated Planar Amides of Relevance in N-C(O) Cross-Coupling. J. Org. Chem. 2017, 82, 6373-6378. [CrossRef] [PubMed]

14. Szostak, R.; Szostak, M. N-Acyl-Glutarimides: Resonance and Proton Affinities of Rotationally-Inverted Twisted Amides Relevant to N-C(O) Cross-Coupling. Org. Lett. 2018, 20, 1342-1345. [CrossRef] [PubMed]

15. Bisz, E.; Piontek, A.; Dziuk, B.; Szostak, R.; Szostak, M. Barriers to Rotation in ortho-Substituted Tertiary Aromatic Amides: Effect of Chloro-Substitution on Resonance and Distortion. J. Org. Chem. 2018, 83, 3159-3163. [CrossRef] [PubMed]

16. Meng, G.; Shi, S.; Lalancette, R.; Szostak, R.; Szostak, M. Reversible Twisting of Primary Amides via Ground State N-C(O) Destabilization: Highly Twisted Rotationally Inverted Acyclic Amides. J. Am. Chem. Soc. 2018, 140, 727-734. [CrossRef] [PubMed]

17. Hie, L.; Nathel, N.F.F.; Shah, T.K.; Baker, E.L.; Hong, X.; Yang, Y.-F.; Liu, P.; Houk, K.N.; Garg, N.K. Conversion of amides to esters by the nickel-catalysed activation of amide C-N bonds. Nature 2015, 524, 79-83. [CrossRef] [PubMed] 
18. Weires, N.A.; Baker, E.L.; Garg, N.K. Nickel-Catalysed Suzuki-Miyaura Coupling of Amides. Nat. Chem. 2016, 8, 75-79. [CrossRef] [PubMed]

19. Simmons, B.J.; Weires, N.A.; Dander, J.E.; Garg, N.K. Nickel-Catalyzed Alkylation of Amide Derivatives. ACS Catal. 2016, 6, 3176-3179. [CrossRef]

20. Baker, E.L.; Yamano, M.M.; Zhou, Y.; Anthony, S.M.; Garg, N.K. A Two-Step Approach to Achieve Secondary Amide Transamidation Enabled by Nickel Catalysis. Nat. Commun. 2016, 7, 11554. [CrossRef] [PubMed]

21. Dander, J.E.; Weires, N.A.; Garg, N.K. Benchtop Delivery of Ni(cod) $)_{2}$ using Paraffin Capsules. Org. Lett. 2016, 18, 3934-3936. [CrossRef] [PubMed]

22. Hie, L.; Baker, E.L.; Anthony, S.M.; Desrosier, J.; Senanayake, C.; Garg, N.K. Nickel-Catalyzed Esterification of Aliphatic Amides. Angew. Chem. Int. Ed. 2016, 55, 15129-15132. [CrossRef] [PubMed]

23. Medina, J.M.; Moreno, J.; Racine, S.; Du, S.; Garg, N.K. Mizoroki-Heck Cyclizations of Amide Derivatives for the Introduction of Quaternary Centers. Angew. Chem. Int. Ed. 2017, 56, 6567-6571. [CrossRef] [PubMed]

24. Weires, N.A.; Caspi, D.D.; Garg, N.K. Kinetic Modeling of the Nickel-Catalyzed Esterification of Amides. ACS Catal. 2017, 7, 4381-4385. [CrossRef] [PubMed]

25. Dander, J.E.; Baker, E.L.; Garg, N.K. Nickel-Catalyzed Transamidation of Aliphatic Amide Derivatives. Chem. Sci. 2017, 8, 6433-6438. [CrossRef] [PubMed]

26. Boit, T.B.; Weires, N.A.; Kim, J.; Garg, N.K. Nickel-Catalyzed Suzuki-Miyaura Coupling of Aliphatic Amides. ACS Catal. 2018, 8, 1003-1008. [CrossRef] [PubMed]

27. Meng, G.; Szostak, M. Sterically-Controlled Pd-Catalyzed Chemoselective Ketone Synthesis via N-C Cleavage in Twisted Amides. Org. Lett. 2015, 17, 4364-4367. [CrossRef] [PubMed]

28. Meng, G.; Szostak, M. General Olefin Synthesis by the Palladium-Catalyzed Heck Reaction of Amides: Sterically-Controlled Chemoselective N-C Activation. Angew. Chem. Int. Ed. 2015, 54, 14518-14522. [CrossRef] [PubMed]

29. Meng, G.; Szostak, M. Rhodium-Catalyzed C-H Bond Functionalization with Amides by Double C-H/C-N Bond Activation. Org. Lett. 2016, 18, 796-799. [CrossRef] [PubMed]

30. Shi, S.; Meng, G.; Szostak, M. Synthesis of Biaryls via Nickel Catalyzed Suzuki-Miyaura Coupling of Amides by Carbon-Nitrogen Cleavage. Angew. Chem. Int. Ed. 2016, 55, 6959-6963. [CrossRef] [PubMed]

31. Liu, Y.; Meng, G.; Liu, R.; Szostak, M. Sterically-Controlled Intermolecular Friedel-Crafts Acylation with Twisted Amides via Selective N-C Cleavage under Mild Conditions. Chem. Commun. 2016, 52, 6841-6844. [CrossRef] [PubMed]

32. Shi, S.; Szostak, M. Efficient Synthesis of Diaryl Ketones by Nickel-Catalyzed Negishi Cross-Coupling of Amides via Carbon-Nitrogen Bond Cleavage at Room Temperature Accelerated by Solvent Effect. Chem. Eur. J. 2016, 22, 10420-10424. [CrossRef] [PubMed]

33. Lei, P.; Meng, G.; Szostak, M. General Method for the Suzuki-Miyaura Cross-Coupling of Amides Using Commercially Available, Air- and Moisture-Stable Palladium/NHC (NHC = N-Heterocyclic Carbene) Complexes. ACS Catal. 2017, 7, 1960-1965. [CrossRef]

34. Shi, S.; Szostak, M. Decarbonylative Cyanation of Amides by Palladium Catalysis. Org. Lett. 2017, 19, 3095-3098. [CrossRef] [PubMed]

35. Shi, S.; Szostak, M. Nickel-Catalyzed Negishi Cross-Coupling of N-Acylsuccinimides: Stable, Amide-Based, Twist-Controlled Acyl-Transfer Reagents via N-C Activation. Synthesis 2017, 49, 3602-3608.

36. Lei, P.; Meng, G.; Ling, Y.; An, J.; Szostak, M. Pd-PEPPSI: Pd-NHC Precatalyst for Suzuki-Miyaura Cross-Coupling Reactions of Amides. J. Org. Chem. 2017, 82, 6638-6646. [CrossRef] [PubMed]

37. Liu, C.; Szostak, M. Decarbonylative Phosphorylation of Amides by Palladium and Nickel Catalysis: The Hirao Cross-Coupling of Amide Derivatives. Angew. Chem. Int. Ed. 2017, 56, 12718-12722. [CrossRef] [PubMed]

38. Osumi, Y.; Liu, C.; Szostak, M. N-Acylsuccinimides: Twist-Controlled, Acyl-Transfer Reagents in Suzuki-Miyaura Cross-Coupling by N-C Amide Bond Activation. Org. Biomol. Chem. 2017, 15, 8867-8871. [CrossRef] [PubMed]

39. Liu, Y.; Achtenhagen, M.; Liu, R.; Szostak, M. Transamidation of N-Acyl-Glutarimides with Amines. Org. Biomol. Chem. 2018, 16, 1322-1329. [CrossRef] [PubMed]

40. Hu, J.; Zhao, Y.; Liu, J.; Zhang, Y.; Shi, Z. Nickel-Catalyzed Decarbonylative Borylation of Amides: Evidence for Acyl C-N Bond Activation. Angew. Chem. Int. Ed. 2016, 55, 8718-8722. [CrossRef] [PubMed] 
41. Hu, J.; Wang, M.; Pu, X.; Shi, Z. Nickel-Catalyzed Retro-Hydroamidocarbonylation of Aliphatic Amides to Olefins. Nat. Commun. 2017, 8, 14993. [CrossRef] [PubMed]

42. Li, X.; Zou, G. Acylative Suzuki coupling of amides: Acyl-nitrogen activation via synergy of independently modifiable activating groups. Chem. Commun. 2015, 51, 5089-5092. [CrossRef] [PubMed]

43. Yue, H.; Guo, L.; Lee, S.; Liu, X.; Rueping, M. Selective Reductive Removal of Ester and Amide Groups from Arenes and Heteroarenes through Nickel-Catalyzed C-O and C-N Bond Activation. Angew. Chem. Int. Ed. 2017, 56, 3972-3976. [CrossRef] [PubMed]

44. Srimontree, W.; Chatupheeraphat, A.; Liao, H.; Rueping, M. Amide to Alkyne Interconversion via a Nickel/Copper-Catalyzed Deamidative Cross-Coupling of Aryl and Alkenyl Amides. Org. Lett. 2017, 19, 3091-3094. [CrossRef] [PubMed]

45. Chatupheeraphat, A.; Liao, H.; Lee, S.; Rueping, M. Nickel-Catalyzed C-CN Bond Formation via Decarbonylative Cyanation of Esters, Amides, and Intramolecular Recombination Fragment Coupling of Acyl Cyanides. Org. Lett. 2017, 19, 4255-4258. [CrossRef] [PubMed]

46. Liu, X.; Yue, H.; Jia, J.; Guo, L.; Rueping, M. Synthesis of Amidines from Amides using a Nickel Catalyzed Decarbonylative Amination via CO Extrusion Intramolecular Recombination Fragment Coupling. Chem. Eur. J. 2017, 23, 11771-11775. [CrossRef] [PubMed]

47. Lee, S.; Guo, L.; Yue, H.; Liao, H.; Rueping, M. Nickel-Catalyzed Decarbonylative Silylation, Borylation, and Amination of Arylamides via a Deamidative Reaction Pathway. Synlett 2017, 28, 2594-2598.

48. Lee, S.; Liao, H.; Chatupheeraphat, A.; Rueping, M. Nickel-Catalyzed C-S Bond Formation via Decarbonylative Thioetherification of Esters, Amides and Intramolecular Recombination Fragment Coupling of Thioesters. Chem. Eur. J. 2018, 24, 3608-3612. [CrossRef] [PubMed]

49. Liu, X.; Hsiao, C.; Guo, L.; Rueping, M. Cross-Coupling of Amides with Alkylboranes via Nickel-Catalyzed C-N Bond Cleavage. Org. Lett. 2018, 20, 2976-2979. [CrossRef] [PubMed]

50. Dey, A.; Sasmal, S.; Seth, K.; Lahiri, G.K.; Maiti, D. Nickel-Catalyzed Deamidative Step-Down Reduction of Amides to Aromatic Hydrocarbons. ACS Catal. 2017, 7, 433-437. [CrossRef]

51. Walker, J.A.; Vickerman, K.L.; Humke, J.N.; Stanley, L.M. Ni-Catalyzed Alkene Carboacylation via Amide C-N Bond Activation. J. Am. Chem. Soc. 2017, 30, 10228-10231. [CrossRef] [PubMed]

52. Amani, J.; Alam, R.; Badir, S.; Molander, G.A. Synergistic Visible-Light Photoredox/Nickel-Catalyzed Synthesis of Aliphatic Ketones via N-C Cleavage of Imides. Org. Lett. 2017, 19, 2426-2429. [CrossRef] [PubMed]

53. Hie, L.; Nathel, N.F.F.; Hong, X.; Yang, Y.-F.; Houk, K.N.; Garg, N.K. Nickel-Catalyzed Activation of Acyl C-O Bonds of Methyl Esters. Angew. Chem. Int. Ed. 2016, 55, 2810-2814. [CrossRef] [PubMed]

54. Halima, T.B.; Masson-Makdissi, J.; Newman, S.G. Nickel-Catalyzed Amide Bond Formation from Methyl Esters. Angew. Chem. Int. Ed. 2018, 57, 12925-12929. [CrossRef] [PubMed]

55. Li, Z.; Zhang, S.; Fu, Y.; Guo, Q.; Liu, L. Mechanism of Ni-Catalyzed Selective C-O Bond Activation in Cross-Coupling of Aryl Esters. J. Am. Chem. Soc. 2009, 131, 8815-8823. [CrossRef] [PubMed]

56. Yu, H.-Z.; Fu, Y. Mechanistic Origin of Cross-Coupling Selectivity in Ni-Catalysed Tishchenko Reactions. Chem. Eur. J. 2012, 18, 16765-16773. [CrossRef] [PubMed]

57. Hong, X.; Liang, Y.; Houk, K.N. Mechanisms and Origins of Switchable Chemoselectivity of Ni-Catalyzed $\mathrm{C}$ (aryl)-O and C(acyl)-O Activation of Aryl Esters with Phosphine Ligands. J. Am. Chem. Soc. 2014, 136, 2017-2025. [CrossRef] [PubMed]

58. Lu, Q.; Yu, H.-Z.; Fu, Y. Mechanistic Study of Chemoselectivity in Ni-Catalyzed Coupling Reactions between Azoles and Aryl Carboxylates. J. Am. Chem. Soc. 2014, 136, 8252-8260. [CrossRef] [PubMed]

59. Xu, H.; Muto, K.; Yamaguchi, J.; Zhao, C.; Itami, K.; Musaev, D.G. Key Mechanistic Features of Ni-Catalyzed C-H/C-O Biaryl Coupling of Azoles and Naphthalen-2-yl Pivalates. J. Am. Chem. Soc. 2014, 136, 14834-14844. [CrossRef] [PubMed]

60. Muto, K.; Yamaguchi, J.; Musaev, D.G.; Itami, K. Decarbonylative organoboron cross-coupling of esters by nickel catalysis. Nat. Commun. 2015, 6, 7508. [CrossRef] [PubMed]

61. Li, Z.; Liu, L. Recent advances in mechanistic studies on Ni catalyzed cross-coupling reactions. Chin. J. Catal. 2015, 36, 3-14. [CrossRef]

62. Liu, L.; Chen, P.; Sun, Y.; Wu, Y.; Chen, S.; Zhu, J.; Zhao, Y. Mechanism of Nickel-Catalyzed Selective C-N Bond Activation in Suzuki-Miyaura Cross-Coupling of Amides: A Theoretical Investigation. J. Org. Chem. 2016, 81, 11686-11696. [CrossRef] [PubMed] 
63. Xu, Z.-Y.; Yu, H.-Z.; Fu, Y. Mechanism of Nickel-Catalyzed Suzuki-Miyaura Coupling of Amides. Chem. Asian J. 2017, 12, 1765-1772. [CrossRef] [PubMed]

64. Ji, C.-L.; Hong, X. Factors Controlling the Reactivity and Chemoselectivity of Resonance Destabilized Amides in Ni-Catalyzed Decarbonylative and Nondecarbonylative Suzuki-Miyaura Coupling. J. Am. Chem. Soc. 2017, 139, 15522-15529. [CrossRef] [PubMed]

65. Jiang, Y.-Y.; Liu, T.; Sun, X.; Xu, Z.; Fan, X.; Zhu, L.; Bi, S.-W. Computational study of the mechanism of amide bond formation via CS2-releasing 1,3-acyl transfer. Org. Biomol. Chem. 2018, 16, 5808-5815. [CrossRef] [PubMed]

66. Li, Y.; Zou, L.; Bai, R.; Lan, Y. Ni(I)-Ni(III) vs. Ni(II)-Ni(IV): Mechanistic study of Ni-catalyzed alkylation of benzamides with alkyl halides. Org. Chem. Front. 2018, 5, 615-622. [CrossRef]

67. Saper, N.I.; Hartwig, J.F. Mechanistic Investigations of the Hydrogenolysis of Diaryl Ethers Catalyzed by Nickel Complexes of N-Heterocyclic Carbene Ligands. J. Am. Chem. Soc. 2017, 139, 17667-17676. [CrossRef] [PubMed]

68. Frisch, M.J.; Trucks, G.W.; Schlegel, H.B.; Scuseria, G.E.; Robb, M.A.; Cheeseman, J.R.; Scalmani, G.; Barone, V.; Petersson, G.A.; Nakatsuji, H.; et al. Gaussian 16; Revision A.03; Gaussian, Inc.: Wallingford, CT, USA, 2016.

69. Head-Gordon, M.; Pople, J.A.; Frisch, M. MP2 energy evaluation by direct methods. Chem. Phys. Lett. 1988, 153, 503-506. [CrossRef]

70. Lee, C.; Yang, W.; Parr, R.G. Development of the Colle-Salvetti correlation-energy formula into a functional of the electron density. Phys. Rev. B Condens. Matter Mater. Phys. 1988, 37, 785-789. [CrossRef]

71. Grimme, S.; Antony, J.; Ehrlich, S.; Krieg, H. A consistent and accurate ab initio parametrization of density functional dispersion correction (DFT-D) for the 94 elements H-Pu. J. Chem. Phys. 2010, 132, 154104. [CrossRef] [PubMed]

72. Hay, P.J.; Wadt, W.R. Ab initio effective core potentials for molecular calculations. Potentials for $\mathrm{K}$ to $\mathrm{Au}$ including the outermost core orbitals. J. Chem. Phys. 1985, 82, 299. [CrossRef]

73. Zhao, Y.; Truhlar, D.G. The M06 suite of density functionals for main group thermochemistry, thermochemical kinetics, noncovalent interactions, excited states, and transition elements: Two new functionals and systematic testing of four M06-class functionals and 12 other functionals. Theor. Chem. Acc. 2008, 120, 215-241.

74. Häussermann, U.; Dolg, M.; Stoll, H.; Preuss, H.; Schwerdtfeger, P.; Pitzer, R.M. Accuracy of energy-adjusted quasirelativistic ab initio pseudopotentials. Mol. Phys. 1993, 78, 1211-1224. [CrossRef]

75. Küchle, W.; Dolg, M.; Stoll, H.; Preuss, H. Energy-adjusted pseudopotentials for the actinides. Parameter sets and test calculations for thorium and thorium monoxide. J. Chem. Phys. 1994, 100, 7535-7542. [CrossRef]

76. Marenich, A.V.; Cramer, C.J.; Truhlar, D.G. Universal Solvation Model Based on Solute Electron Density and on a Continuum Model of the Solvent Defined by the Bulk Dielectric Constant and Atomic Surface Tensions. J. Phys. Chem. B 2009, 113, 6378-6396. [CrossRef] [PubMed]

77. CYLview, 1.0b; CYLview 2.0; Universitéde Sherbrooke: Sherbrooke, QC, Canada, 2009.

Sample Availability: Samples of the compounds are not available from the authors.

(C) 2018 by the authors. Licensee MDPI, Basel, Switzerland. This article is an open access article distributed under the terms and conditions of the Creative Commons Attribution (CC BY) license (http:/ / creativecommons.org/licenses/by/4.0/). 
Article

\title{
Synthesis of Gemcitabine-Threonine Amide Prodrug Effective on Pancreatic Cancer Cells with Improved Pharmacokinetic Properties
}

\author{
Sungwoo Hong ${ }^{1,2,+}$, Zhenghuan Fang ${ }^{3, \dagger}{ }^{+}$, Hoi-Yun Jung ${ }^{1,2}$, Jin-Ha Yoon ${ }^{4}$, Soon-Sun Hong ${ }^{3, *}$ \\ and Han-Joo Maeng ${ }^{4, *}$ \\ 1 Center for Catalytic Hydrocarbon Functionalization Institute for Basic Science (IBS), Daejeon 34141, Korea; \\ hongorg@kaist.ac.kr (S.H.); spurs9@kaist.ac.kr (H.-Y.J.) \\ 2 Department and of Chemistry, Korea Advanced Institute of Science and Technology (KAIST), \\ Daejeon 34141, Korea \\ 3 Department of Biomedical Sciences, College of Medicine, Inha University, Incheon 22212, Korea; \\ junghwan110@gmail.com \\ 4 College of Pharmacy, Gachon University, Incheon 21936, Korea; jinha89@daum.net \\ * Correspondence: hongs@inha.ac.kr (S.-S.H.); hjmaeng@gachon.ac.kr (H.-J.M.); \\ Tel.: +82-32-860-3683 (S.-S.H.); +82-32-820-4935 (H.-J.M.) \\ + These authors are equally contributed to this work.
}

Received: 29 August 2018; Accepted: 10 October 2018; Published: 11 October 2018

\begin{abstract}
To investigate the amino acid transporter-based prodrug anticancer strategy further, several amino acid-conjugated amide gemcitabine prodrugs were synthesized to target amino acid transporters in pancreatic cancer cells. The structures of the synthesized amino acid-conjugated prodrugs were confirmed by ${ }^{1} \mathrm{H}-\mathrm{NMR}$ and LC-MS. The pancreatic cancer cells, AsPC1, BxPC-3, PANC-1 and MIAPaCa-2, appeared to overexpress the amino acid transporter LAT- 1 by conventional RT-PCR. Among the six amino acid derivatives of gemcitabine, threonine derivative of gemcitabine (Gem-Thr) was more effective than free gemcitabine in the pancreatic cancer cells, BxPC-3 and MIAPaCa-2, respectively, in terms of anti-cancer effects. Furthermore, Gem-Thr was metabolically stable in PBS (pH 7.4), rat plasma and liver microsomal fractions. When Gem-Thr was administered to rats at $4 \mathrm{mg} / \mathrm{kg}$ i.v., Gem-Thr was found to be successfully converted to gemcitabine via amide bond cleavage. Moreover, the Gem-Thr showed the increased systemic exposure of formed gemcitabine by 1.83-fold, compared to free gemcitabine treatment, due to the significantly decreased total clearance ( 0.60 vs. $4.23 \mathrm{~mL} / \mathrm{min} / \mathrm{kg}$ ), indicating that the amide prodrug approach improves the metabolic stability of gemcitabine in vivo. Taken together, the amino acid transporter-targeting gemcitabine prodrug, Gem-Thr, was found to be effective on pancreatic cancer cells and to offer an efficient potential means of treating pancreatic cancer with significantly better pharmacokinetic characteristics than gemcitabine.
\end{abstract}

Keywords: amino acid transporters; amide bond; gemcitabine prodrug; metabolic stability; pancreatic cancer cells; pharmacokinetics

\section{Introduction}

Gemcitabine (2'-2'-difluorodeoxycytidine, $\mathrm{dFdC})$ is a standard anticancer agent that is used to treat all stages of pancreatic adenocarcinoma [1], and combinations of gemcitabine with other anti-cancer agents, such as erlotinib [2], nab-paclitaxel [3,4] and others have been applied to pancreatic cancer patients. Because gemcitabine has serious toxic effects on the gastrointestinal track [5], and low oral bioavailability (BA), it is administered intravenously [6]. However, gemcitabine is a metabolically unstable drug and has a half-life of only $9 \mathrm{~min}$ in man, probably due to its rapid 
conversion to $2^{\prime}-2^{\prime}$-difluorodeoxyuridine (dFdU) by cytidine deaminase $(\mathrm{CD})$, which is abundant in blood and tissues [7]. This poor metabolic stability and poor compliance has created a clinical need for a gemcitabine prodrug. Several types of prodrugs have been reported, such as valproate amide [8,9], amino acid ester [10,11], aminoacyl amide derivative [12], and L-carnitine amide (OCTN2 targeting) [13] prodrugs.

To maintain the growth and survival of cancer cells during neoplastic transformation, amino acid production is massively increased and as a result, several uptake transporters (e.g., amino acid transporters) are overexpressed. For example, L-type amino acid transporter 1 (LAT-1), a representative amino acid transporter, is overexpressed in various types of cancer cells [14], and interestingly, LAT-1 expression has been consistently reported to be elevated in patients with pancreatic cancer and in transplanted Colo357 cells (a pancreatic cancer cell line) $[15,16]$. Accordingly, LAT-1 has been suggested to be a versatile target for the development of transporter-based drugs [14].

Our research group have been investigating the merits of strategies based on the amino acid transporter-based prodrug approach to overcome the multidrug resistance (MDR) triggered by various efflux transporters like P-glycoprotein (P-gp, MDR1) in cancer cells [17-19]. For example, the addition of amino acids, such as, L-valine (Val) or tyrosine (Tyr), to lapatinib by amide bond formation successfully enhanced the anti-cancer effect of lapatinib in human breast cancer cells (MDA-MB-231 and MCF7) and lung cancer cells (A549), without plasma stability issues, which demonstrated the involvements of amino acid transporters [18]. More recently, the val-modified amide prodrug of doxorubicin (Dox-Val) improved cellular uptake efficiency in MCF7 cells [19]. However, in a rat pharmacokinetic study that demonstrated the conversion of Dox-val to Dox by amide bond cleavage in vivo, the pharmacokinetic properties of the amino acid prodrug examined were limited [19].

Based on the observation that amino acid transporters (e.g., LAT-1) are overexpressed in various cancer cells for their survival, we speculated that amino acid conjugated prodrug of gemcitabine might be an effective way to improve gemcitabine uptake by overexpressing amino acid transporters in pancreatic cancer cells as well as overall physicochemical property. In the present study, we successfully synthesized a threonine-gemcitabine (Gem-Thr) prodrug and investigated its anti-cancer efficacy in pancreatic cancer cells and its in vitro/in vivo metabolic stabilities. In addition, we examined LAT-1 (an amino acid transporter) mRNA/protein expressions in pancreatic cancer cells.

\section{Results and Discussion}

\subsection{Synthesis of Gemcitabine Prodrugs with Amino Acids}

To confirm the validity of the amino acid transporter-based prodrug approach for gemcitabine, we prepared a series of amino acid conjugated gemcitabine prodrugs. As summarized in Figure 1, gemcitabine-amino acid prodrugs 3 were obtained from gemcitabine (1) using a two-step sequence, that is by amide bond formation between gemcitabine (1) and N-Boc-L-amino acid employing 1-hydroxy-1H-benzotriazole (HOBt), 1-ethyl-3-(3-dimethylaminopropyl)carbodiimide and 4-methylmorpholine in DMF/DMSO (3:1), and subsequent Boc deprotection of the resulting compound 2 using hydrochloric acid. In order to avoid potential problems associated with epimerization when using carbodiimides as coupling reagents, HOBt was used as an additive because it enhances the reactivities of activated ester intermediates by facilitating amine approach via hydrogen bonding. To confirm the formation of amide bond, an intermediate of representative compound (Gem-Thr-Boc) was dissolved in DMSO- $d_{6}$. In gemcitabine part, the chemical shift of $\mathrm{CH}(5)$ in oxopyrimidine core showed at $\delta 7.26\left(J_{5,6}=7.6 \mathrm{~Hz}\right)$ as a doublet by ortho coupling with $\mathrm{CH}(6)$ at $\delta 8.27$. The characteristic amide $\mathrm{NH}$ peak was detected at $\delta 10.99$ as a broad singlet, and Boc group of amino acid was appeared at $\delta 1.39$. The side chain of threonine $\mathrm{CH}_{3}$ was appeared at $\delta 1.39$ having a coupling constant $J=6.3 \mathrm{~Hz}$ and $\mathrm{OH}$ group was resonated at $\delta 4.89$. In addition, the MS/MS spectrum showed $[\mathrm{M}+\mathrm{H}]^{+}$at $m / z 465.2$, which confirmed the chemical bond between gemcitabine and $N$-Boc protected threonine. The N-Boc of amino acid was deprotected in acidic conditions to afford the final Gem-Thr product that 
was confirmed by ${ }^{1} \mathrm{H}$ NMR in $\mathrm{CD}_{3} \mathrm{OD}$. The peak of Boc group disappeared and concurrently the side chain of threonine $\mathrm{CH}_{3}$ was detected as a doublet peak at $\delta 7.26(\mathrm{~J}=6.4 \mathrm{~Hz})$. Furthermore, $\mathrm{CH}(5)$ - and $\mathrm{CH}(6)$-peaks of oxopyrimidine remained at $\delta 6.11$ and $\delta 7.85$ coupled as a doublet $\left(J_{5,6}=7.6\right)$.

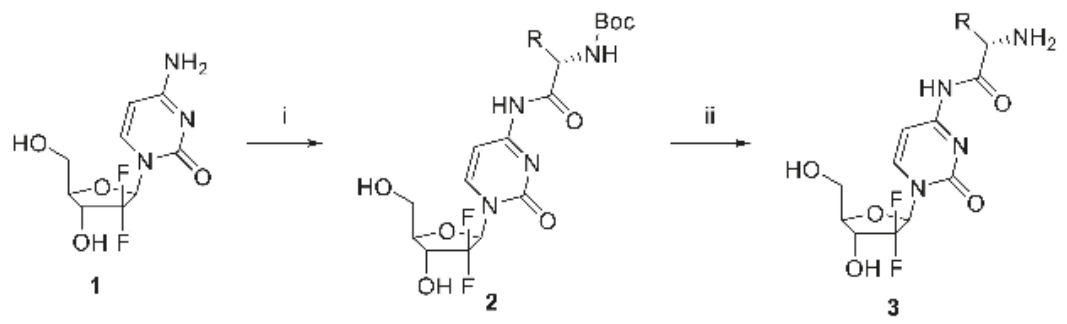

Figure 1. Synthetic scheme of the procedure used to synthesize gemcitabine-amino acid prodrugs. Reagent and conditions were as follows; (i) N-Boc-L-amino acid, 4-methylmorpholine, HOBt, EDCI-HCl, $\mathrm{DMF} / \mathrm{DMSO}=3: 1,55^{\circ} \mathrm{C}, 17 \mathrm{~h}$; (ii) $4 \mathrm{~N} \mathrm{HCl}$ in dioxane, dry $\mathrm{CH}_{2} \mathrm{Cl}_{2}$, r.t. $30 \mathrm{~min}$.

\subsection{Expression of LAT-1 in Pancreatic Cancer Cell Lines}

LAT-1 mRNA and protein levels were detected in the pancreatic cancer cell lines AsPC1, BxPC-3, PANC-1 and MIAPaCa-2. LAT-1 expression was greatest in BxPC-3 (Figure 2). The following studies on anti-cancer effects were performed using BxPC-3 and MIAPaCa- 2 cells. Therefore, this transcriptional activation of LAT-1 might expect to facilitate transport capability of amino acid linked gemcitabine.
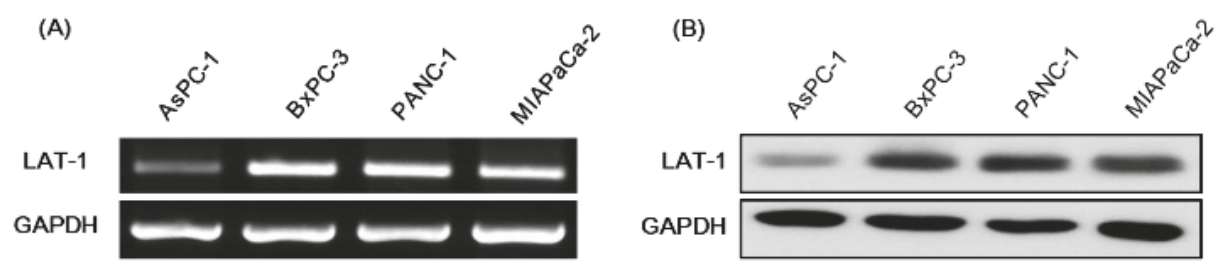

Figure 2. mRNA (A) and protein (B) expressions of LAT-1 in various pancreatic cancer cell lines (AsPC-1, BxPC-3, PANC-1, and MIAPaCa-2). Reverse transcription-PCR and Western blot were performed using gel electrophoresis after purification of DNA from cancer cells.

\subsection{Anticancer Effects of Prodrugs with Amino Acids in Cancer Cells}

We evaluated the cytotoxic effects of gemcitabine derivatives on various cancer cell lines including PDAC (pancreatic ductal adenocarcinoma), and compared results with those of free gemcitabine (Figure 3). In A549 (lung cancer cells) and MDA-MB-231 (breast cancer cells) neither gemcitabine nor gemcitabine derivatives had any significant anti-cancer effect versus vehicle treated controls. However, gemcitabine had significant anti-cancer effects on BxPC-3, MIAPaCa-2 (pancreatic cancer cells) and B16 (melanoma cells). The anti-cancer effects of Gem-Tyr, Gem-Val, Gem-Met, Gem-Ile and Gem-Leu were similar to those of gemcitabine in pancreatic cancer cells, whereas Gem-Thr had the most potent anticancer effect, and this was slightly superior to that of gemcitabine in BxPC-3 cells (Gem-Thr, $44.7 \%$ vs. gemcitabine, $54.1 \%$ of cell viability, $p=0.0464$ ), which was found to overexpress amino acid transporters, including LAT-1 (Figure 3). The introduction of threonine to gemcitabine is likely to be recognized by the LAT-1, which has an important role to influx the drug into the cancer cells. However, addition of some amino acid moieties to gemcitabine did not exert the enhanced cytotoxic effects on the pancreatic cancer cells. Similarly, a valine ester prodrug (Val-SN-38) showed a comparable cytotoxic effect compared to $\mathrm{SN}-38$, an active metabolite of irinotecan, despite an increased intracellular accumulation in MCF cells with amino acid transporters being overexpressed [17]. 


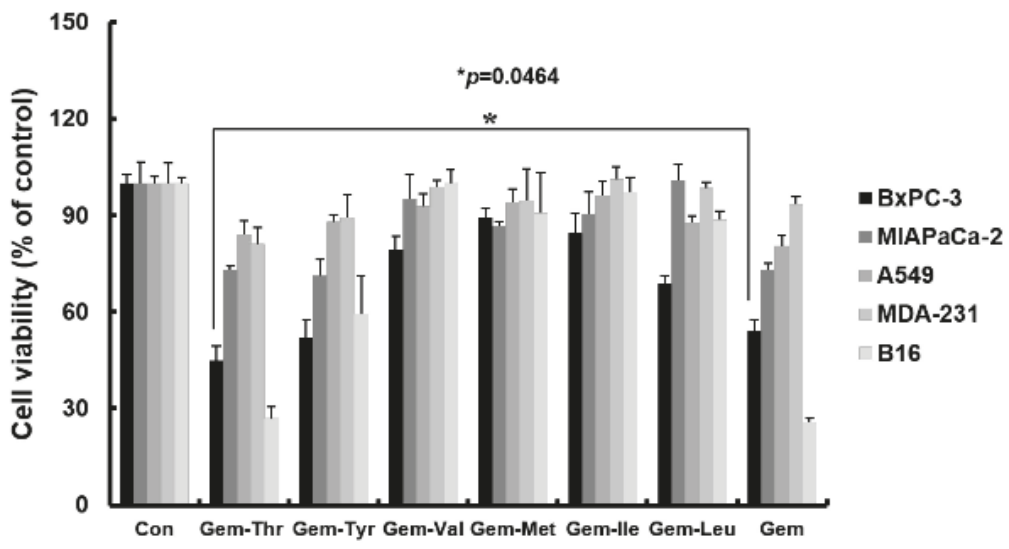

Figure 3. Growth-inhibitory effects of gemcitabine and of its amino-acid-conjugated derivatives on BxPC-3, MIAPaCa-2, A549, MDA-MB-231 B16 cells after exposure to $1 \mu \mathrm{M}$ concentrations for $48 \mathrm{~h}$, as estimated by MTT assay (mean $\pm \mathrm{SD}, n=3$ ). Experiments were performed three times independently. * $p<0.05$, compared with free gemcitabine group.

Additionally, consistent with MTT results, either gemcitabine or Gem-Thr induced apoptosis significantly when we measured cleaved PARP as well as TUNEL positive cells after a $24 \mathrm{~h}$ treatment (Figure 4).

(A)

(B)

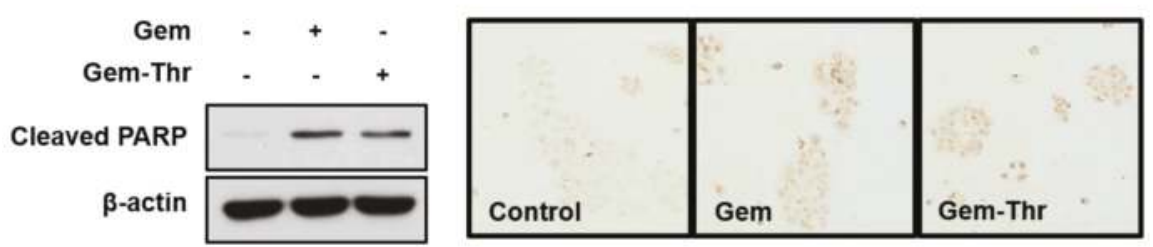

Figure 4. Apoptosis of pancreatic cancer cells by Gemcitabine derivative. After the treatment of gemcitabine and Gem-Thr to BxPC-3 cells for $24 \mathrm{~h}$, cleaved PARP was detected by western blotting (A) and TUNEL assay (B) was performed.

\subsection{In Vitro Plasma Stability of Gem-Thr}

To recognize a substrate by amino acid transporters in cancer cells, the stability of the amide prodrug with amino acid moiety, Gem-Thr, should be first possessed [18]. Thus, the stability of the prodrug was investigated in PBS, rat plasma and liver microsomes for up to $8 \mathrm{~h}$ (Figure 5). Gem-Thr was metabolically stable in PBS (pH 7.4), whereas $20 \%$ of Gem-Thr was metabolized in rat plasma after $8 \mathrm{~h}$, indicating Gem-Thr can be metabolized to gemcitabine by enzymes in plasma. Surprisingly, Gem-Thr was metabolically stable in rat liver microsomal fractions, which contain high levels of cytochrome P450 (CYP) enzymes, indicating the amide bond between gemcitabine and threonine cannot be readily broken via phase I metabolism or enzymes expressed in liver microsomes. This concurs with the results of a previous study on val-lapatinib and tyr-lapatinib, in which amide linkage was found to result in appropriate metabolic stability in vitro [18]. Our results indicate the amino acid moiety of Gem-Thr is likely both stable and recognized by the amino acid transporters in cancer cells. 
(A)

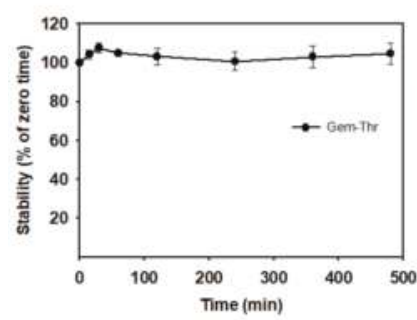

(B)

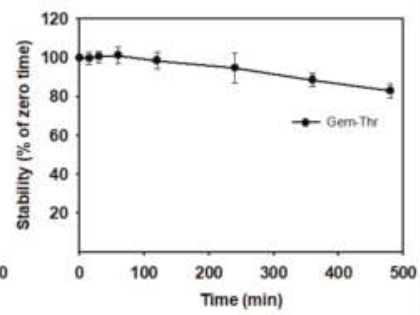

(C)

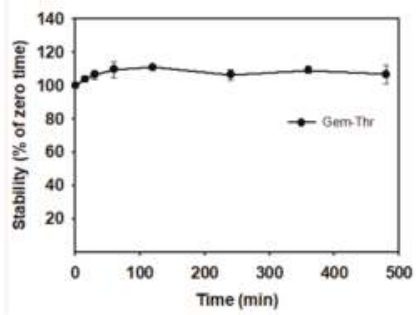

Figure 5. In vitro metabolic stabilities of Gem-Thr in PBS (A), plasma (B) and a liver microsome fraction (C) (mean $\pm \mathrm{SD}, n=3)$.

\subsection{Comparison of Systemic Pharmacokinetics with Free Gemcitabine}

The pharmacokinetic parameters of Gem-Thr and free gemcitabine after intravenous administration in rats are summarized in Table 1. Concentrations of Gem-Thr and gemcitabine and their summed concentrations in plasma were measured and compared to those of animals administered free gemcitabine (Figure 6). After gemcitabine administration at $4 \mathrm{mg} / \mathrm{kg}$, the oral systemic exposure (i.e., AUC) and the measure of drug elimination form the body, $\mathrm{CL}$, were found to be $948.38 \pm 52.04 \mu \mathrm{g} \cdot \mathrm{min} / \mathrm{mL}$ and $4.23 \pm 0.23 \mathrm{~mL} / \mathrm{min} / \mathrm{kg}$, respectively, which concurred with previously reported values [20]. The volume of distribution at steady state $\left(\mathrm{V}_{\mathrm{ss}}\right)$ and average time for a drug molecule to reside in the body, MRT, values for gemcitabine were $2483.64 \pm 867.19 \mathrm{~mL} / \mathrm{kg}$ and $582.06 \pm 177.90 \mathrm{~min}$ (Table 1). After administration of Gem-Thr at $4 \mathrm{mg} / \mathrm{kg}$ i.v., the conversion of Gem-Thr to gemcitabine was found to be probably due to amide bond cleavage, with similar systemic exposure (i.e., AUC) between Gem-Thr and the formed gemcitabine. More importantly, Gem-Thr increased systemic exposure (i.e., the AUC of gemcitabine) by 1.83 -fold versus free gemcitabine, and this was attributed to a significantly lower total CL value $(0.60 \mathrm{vs} .4 .23 \mathrm{~mL} / \mathrm{min} / \mathrm{kg})$ (Table 1). Furthermore, this suggests the amide prodrug approach improves the metabolic stability of gemcitabine in vivo. Other pharmacokinetic parameters, such as, $\mathrm{V}_{\mathrm{ss}}$ and MRT, were also found to be different for Gem-Thr and gemcitabine (Table 1). For example, MRT of gemcitabine for Gem-Thr was greater than that for gemcitabine, indicating that formed gemcitabine from Gem-Thr remains in the systemic circulation longer than free gemcitabine. In a previous study, an amide prodrug of gemcitabine releasing gemcitabine and valproic acid was found to enhance gemcitabine stability by blocking its deamination to uridine, and to prolong systemic exposure as compared with gemcitabine alone [8]. Furthermore, the AUC of sum of Gem-Thr and the gemcitabine (metabolite) was significantly higher (3.62-fold higher) than gemcitabine alone (Table 1). In our previous study, although we first demonstrated the successful conversion and systemic circulation of the active metabolite (doxorubicin) probably occurred due to amide bond cleavage, amide linked doxorubicin/valine failed to improve pharmacokinetic properties including systemic CL [19]. On the other hand, Gem-Thr showed enhanced gemcitabine stability in vivo and an increased AUC and decreased CL versus gemcitabine. This enhanced systemic stability of Gem-Thr is likely to improve gemcitabine uptake by cancer cells and to target amino acid transporters like LAT-1 transporters. 
Table 1. Comparison of pharmacokinetic parameters of Gem-Thr, formed gemcitabine and sum of two species after intravenous administration of Gem-Thr at a dose of $4 \mathrm{mg} / \mathrm{kg}$ with those of free gemcitabine alone at a dose of $4 \mathrm{mg} / \mathrm{kg}$ in rats $(n=3-4)$.

\begin{tabular}{ccccc}
\hline \multirow{2}{*}{$\begin{array}{c}\text { Pharmacokinetic } \\
\text { Parameters }\end{array}$} & \multicolumn{3}{c}{ Gem-Thr (4 mg/kg) } & Free Gemcitabine \\
\cline { 2 - 4 } & Gem-Thr & Gemcitabine & Sum & \\
\hline AUC $(\mu \mathrm{g} \cdot \mathrm{min} / \mathrm{mL})$ & $1713.85 \pm 1082.40$ & $1739.88 \pm 282.00^{*}$ & $3437.92 \pm 1180.56$ & $948.38 \pm 52.04$ \\
Terminal t $\mathrm{H}_{1 / 2}(\mathrm{~min})$ & $236.18 \pm 50.94$ & $666.83 \pm 271.49$ & $537.23 \pm 227.78$ & $532.68 \pm 177.90$ \\
$\mathrm{CL}(\mathrm{mL} / \mathrm{min} / \mathrm{kg})$ & $2.85 \pm 1.33$ & $0.60 \pm 0.10^{*}$ & $1.26 \pm 0.39$ & $4.23 \pm 0.23$ \\
$\mathrm{~V}_{\mathrm{ss}}(\mathrm{mL} / \mathrm{kg})$ & $662.35 \pm 281.40$ & $545.57 \pm 263.01 *$ & $770.96 \pm 435.31$ & $2483.64 \pm 867.19$ \\
MRT $(\mathrm{min})$ & $237.18 \pm 20.87$ & $907.18 \pm 391.68 *$ & $577.36 \pm 212.90$ & $582.06 \pm 177.90$ \\
\hline
\end{tabular}

Administration of dose for Gem-thr was $4 \mathrm{mg} / \mathrm{kg}$, which is equivalent to $2.892 \mathrm{mg} / \mathrm{kg}$ for gemcitabine. Data presents as mean \pm standard deviation (SD). ${ }^{*}$ Significantly different from free gemcitabine group $(p<0.05)$.

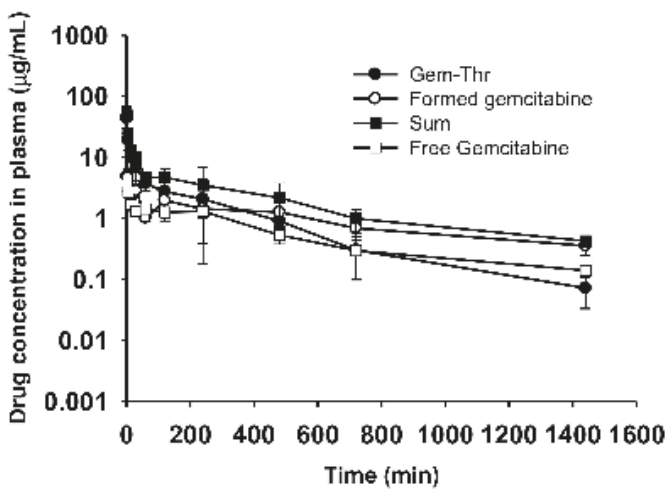

Figure 6. Plasma concentration-time profiles of Gem-Thr (prodrug), formed gemcitabine (metabolite), the sum of Gem-Thr and formed gemcitabine and free gemcitabine. The intravenous pharmacokinetics of Gem-Thr was compared to that of free gemcitabine $(4 \mathrm{mg} / \mathrm{kg}, n=4)$.

\section{Materials and Methods}

\subsection{Materials}

Commercial grade reagents and solvents were used without further purification. Thin layer chromatography (TLC) was performed using precoated silica gel $60 \mathrm{~F}^{254}$ plates and visualized using anisaldehyde solution, heat, and UV light $(254 \mathrm{~nm})$. Flash column chromatography was undertaken on silica gel (400-630 mesh). ${ }^{1} \mathrm{H}$ NMR was recorded at $400 \mathrm{MHz}$ and chemical shifts are quoted in parts per million ( $\mathrm{ppm}$ ) versus an appropriate solvent peak or $2.50 \mathrm{ppm}$ for DMSO- $d_{6}$. The following abbreviations were used to describe peak splitting patterns: $\mathrm{br}=$ broad, $\mathrm{s}=$ singlet, $\mathrm{d}=$ doublet, $\mathrm{t}=$ triplet, $\mathrm{q}=$ quartet, $\mathrm{m}=$ multiplet, $\mathrm{dd}=$ doublet of doublets, $\mathrm{td}=$ triplet of doublets, $\mathrm{ddd}=$ doublet of doublets of doublets. Coupling constants, J, are reported in hertz (Hz). HPLC was conducted using an Agilent HPLC unit equipped with an Agilent Poroshell 120 EC-C18 reverse phase column (4.6 $\times 50 \mathrm{~mm}, 2.7$ Micron) and mass spectroscopy was performed using a quadrupole LC/MS unit.

\subsection{Synthesis and Characterization of DOX-Val}

\subsubsection{General Procedure for Preparing Gemcitabine Derivatives}

To a solution of gemcitabine (1.0 equiv), 1-ethyl-3-(3-dimethylaminopropyl)-carbodiimide hydrochloride (1.3 equiv), 4-methylmorpholine (1 equiv), and 1-hydroxybenzotriazole (1 equiv) in DMF/DMSO (5 mL, 3:1) was added dropwise $N$-Boc protected amino acid (1.1 equiv) at room temperature in a $\mathrm{N}_{2}$ atmosphere. The reaction mixture was then stirred in an oil bath at $55^{\circ} \mathrm{C}$ for $17 \mathrm{~h}$, 
cooled to room temperature and quenched by adding brine $(5 \mathrm{~mL})$. The mixture was then extracted using ethyl acetate $(3 \times 10 \mathrm{~mL})$ and the combined organic layer was washed with $20 \% \mathrm{LiCl}$ solution, saturated $\mathrm{NaHCO}_{3}$ aqueous solution, and brine, dried over $\mathrm{MgSO}_{4}$, and concentrated under reduced pressure. The residue was purified by silica gel column chromatography $(\mathrm{DCM} /$ methanol $=15: 1)$ to afford the desired product 2. To a solution of the mixture of aforementioned intermediate in anhydrous DCM $(1 \mathrm{~mL})$ was added $4 \mathrm{~N} \mathrm{HCl}$ in dioxane $(1 \mathrm{~mL})$. The mixture was then stirred for $12 \mathrm{~h}$ at room temperature, solvent was removed, and the residue was purified by silica gel flash column chromatography $(\mathrm{DCM} /$ methanol $=3: 1)$ to afford the desired product 3 .

3.2.2. (S)-2-Amino- $N$-(1-((2R,4R,5R)-3,3-difluoro-4-hydroxy-5-(hydroxymethyl)tetrahydrofuran2-yl)-2-oxo-1,2-dihydropyrimidin-4-yl)-3-methylbutanamide (Gem-Val)

From the reaction of gemcitabine $(27 \mathrm{mg}, 0.104 \mathrm{mmol}), 21 \mathrm{mg}$ ( $56 \%$ for 2 steps) was obtained. ${ }^{1} \mathrm{H}$ $\operatorname{NMR}\left(400 \mathrm{MHz}\right.$, Methanol- $\left.d_{4}\right) \delta 7.81(\mathrm{~d}, J=7.6 \mathrm{~Hz}, 1 \mathrm{H}), 6.21(\mathrm{t}, J=7.9 \mathrm{~Hz}, 1 \mathrm{H}), 6.04(\mathrm{~d}, J=7.6 \mathrm{~Hz}, 1 \mathrm{H})$, $4.51(\mathrm{~d}, J=7.5 \mathrm{~Hz}, 1 \mathrm{H}), 4.25(\mathrm{td}, J=12.1,8.3 \mathrm{~Hz}, 1 \mathrm{H}), 3.94(\mathrm{dd}, J=12.7,2.5 \mathrm{~Hz}, 1 \mathrm{H}), 3.88(\mathrm{dt}, J=8.4,2.9$ $\mathrm{Hz}, 1 \mathrm{H}), 3.78(\mathrm{dd}, J=12.5,3.2 \mathrm{~Hz}, 1 \mathrm{H}), 2.14(\mathrm{~h}, J=6.8 \mathrm{~Hz}, 1 \mathrm{H}), 1.00(\mathrm{dd}, J=6.8,5.5 \mathrm{~Hz}, 6 \mathrm{H}) ; \mathrm{MS} / \mathrm{MS}$ $m / z 363.1(\mathrm{M}+1)^{+}$.

3.2.3. (2S,3R)-2-Amino- $N-(1-((2 R, 4 R, 5 R)-3,3-$ difluoro-4-hydroxy-5-(hydroxylmethyl)tetrahydrofuran-2-yl)-2-oxo-1,2-dihydropyrimidin-4-yl)-3-hydroxybutanamide2-(4-((pyridin-3-ylmethyl) amino)quinazolin-2-yl)phenol (Gem-Thr)

From the reaction of gemcitabine $(51 \mathrm{mg}, 0.194 \mathrm{mmol}), 24 \mathrm{mg}(34 \%)$ was obtained. ${ }^{1} \mathrm{H}$ NMR $\left(400 \mathrm{MHz}\right.$, Methanol- $\left.d_{4}\right) \delta 7.85(\mathrm{~d}, J=7.6 \mathrm{~Hz}, 1 \mathrm{H}), 6.25-6.16(\mathrm{~m}, 1 \mathrm{H}), 6.11(\mathrm{~d}, J=7.6 \mathrm{~Hz}, 1 \mathrm{H}), 4.67(\mathrm{~d}$, $J=3.9 \mathrm{~Hz}, 1 \mathrm{H}), 4.32-4.19(\mathrm{~m}, 2 \mathrm{H}), 3.98-3.92(\mathrm{~m}, 1 \mathrm{H}), 3.89(\mathrm{dt}, J=8.4,2.9 \mathrm{~Hz}, 1 \mathrm{H}), 3.79(\mathrm{dd}, J=12.6,3.3$ $\mathrm{Hz}, 1 \mathrm{H}), 1.21(\mathrm{~d}, J=6.4 \mathrm{~Hz}, 3 \mathrm{H})$; MS/MS $m / z 365.1(\mathrm{M}+1)^{+}$.

(Gem-Thr-Boc intermediate) ${ }^{1} \mathrm{H}$ NMR (400 MHz, DMSO- $\left.d_{6}\right) \delta 10.99(\mathrm{~s}, 1 \mathrm{H}), 8.27(\mathrm{~d}, J=7.6 \mathrm{~Hz}$, $1 \mathrm{H}), 7.26(\mathrm{~d}, J=7.6 \mathrm{~Hz}, 1 \mathrm{H}), 6.49(\mathrm{~d}, J=8.7 \mathrm{~Hz}, 1 \mathrm{H}), 6.32(\mathrm{~d}, J=6.4 \mathrm{~Hz}, 1 \mathrm{H}), 6.18(\mathrm{t}, J=7.4 \mathrm{~Hz}, 1 \mathrm{H})$, $5.31(\mathrm{t}, J=5.5 \mathrm{~Hz}, 1 \mathrm{H}), 4.89(\mathrm{~s}, 1 \mathrm{H}), 4.25-4.11(\mathrm{~m}, 2 \mathrm{H}), 4.08-4.00(\mathrm{~m}, 1 \mathrm{H}), 3.89(\mathrm{dt}, J=8.5,3.0 \mathrm{~Hz}, 1 \mathrm{H})$, 3.85-3.77 (m, 1H), $3.65(\mathrm{ddd}, J=12.8,6.0,3.2 \mathrm{~Hz}, 1 \mathrm{H}), 1.39(\mathrm{~s}, 8 \mathrm{H}), 1.09$ (d, J = 6.3 Hz, 3H); MS /MS m/z $465.1(\mathrm{M}+1)^{+}$.

3.2.4. (S)-2-Amino- $N-(1-((2 R, 4 R, 5 R)-3,3$-difluoro-4-hydroxy-5-(hydroxymethyl)tetrahydrofuran-2yl)-2-oxo-1,2-dihydropyrimidin-4-yl)-3-(4-hydroxyphenyl)propanamide (Gem-Tyr)

From the reaction of gemcitabine $(22 \mathrm{mg}, 0.083 \mathrm{mmol}), 27 \mathrm{mg}(76 \%)$ was obtained. ${ }^{1} \mathrm{H}$ NMR (400 $\mathrm{MHz}$, Methanol- $\left.d_{4}\right) \delta 7.77(\mathrm{~d}, J=7.6 \mathrm{~Hz}, 1 \mathrm{H}), 7.08(\mathrm{~d}, J=8.5 \mathrm{~Hz}, 2 \mathrm{H}), 6.68(\mathrm{~d}, J=8.5 \mathrm{~Hz}, 2 \mathrm{H}), 6.25-6.13$ $(\mathrm{m}, 1 \mathrm{H}), 5.93(\mathrm{~d}, J=7.6 \mathrm{~Hz}, 1 \mathrm{H}), 4.23(\mathrm{td}, J=12.1,8.2 \mathrm{~Hz}, 1 \mathrm{H}), 3.96-3.90(\mathrm{~m}, 1 \mathrm{H}), 3.87(\mathrm{dt}, J=8.4,2.9$ $\mathrm{Hz}, 1 \mathrm{H}), 3.77(\mathrm{dd}, J=12.6,3.2 \mathrm{~Hz}, 1 \mathrm{H}), 3.09(\mathrm{dd}, J=13.9,6.3 \mathrm{~Hz}, 1 \mathrm{H}), 2.88(\mathrm{dd}, J=13.8,8.2 \mathrm{~Hz}, 1 \mathrm{H})$; $\mathrm{MS} / \mathrm{MS} m / z 427.1(\mathrm{M}+1)^{+}$.

3.2.5. (S)-2-Amino- $N-(1-((2 R, 4 R, 5 R)-3,3-$ difluoro-4-hydroxy-5-(hydroxymethyl)tetrahydrofuran-2yl)-2-oxo-1,2-dihydropyrimidin-4-yl)-4-(methylthio)butanamide (Gem-Met)

From the reaction of gemcitabine ( $38 \mathrm{mg}, 0.146 \mathrm{mmol}), 23 \mathrm{mg}(40 \%)$ was obtained. ${ }^{1} \mathrm{H}$ NMR $(400$ MHz, Methanol- $\left.d_{4}\right) \delta 7.83(\mathrm{~d}, J=7.7 \mathrm{~Hz}, 1 \mathrm{H}), 6.34-6.13(\mathrm{~m}, 1 \mathrm{H}), 5.99(\mathrm{~d}, J=7.6 \mathrm{~Hz}, 1 \mathrm{H}), 4.83-4.73(\mathrm{~m}$, $1 \mathrm{H}), 4.25(\mathrm{td}, J=12.1,8.2 \mathrm{~Hz}, 1 \mathrm{H}), 3.98-3.91(\mathrm{~m}, 1 \mathrm{H}), 3.89(\mathrm{dt}, J=8.4,2.8 \mathrm{~Hz}, 1 \mathrm{H}), 3.78(\mathrm{dd}, J=12.5,3.2$ $\mathrm{Hz}, 1 \mathrm{H}), 2.55$ (ddd, $J=8.4,6.4,3.7 \mathrm{~Hz}, 2 \mathrm{H}), 2.23-2.11(\mathrm{~m}, 1 \mathrm{H}), 2.09(\mathrm{~s}, 3 \mathrm{H}), 2.07-1.89(\mathrm{~m}, 1 \mathrm{H}) ; \mathrm{MS} / \mathrm{MS}$ $m / z 395.1(\mathrm{M}+1)^{+}$.

3.2.6.

(2S,3S)-2-Amino- $N$-(1-((2R,4R,5R)-3,3-difluoro-4-hydroxy-5-(hydroxymethyl)tetrahydrofuran-2yl)-2-oxo-1,2-dihydropyrimidin-4-yl)-3-methylpentanamide (Gem-Ile)

From the reaction of gemcitabine $(29 \mathrm{mg}, 0.110 \mathrm{mmol}), 20 \mathrm{mg}(50 \%)$ was obtained. ${ }^{1} \mathrm{H}$ NMR (400 MHz, Methanol- $\left.d_{4}\right) \delta 7.81(\mathrm{~d}, J=7.6 \mathrm{~Hz}, 1 \mathrm{H}), 6.28-6.14(\mathrm{~m}, 1 \mathrm{H}), 6.02(\mathrm{~d}, J=7.6 \mathrm{~Hz}, 1 \mathrm{H}), 4.54(\mathrm{~d}, J=8.1$ 
$\mathrm{Hz}, 1 \mathrm{H}), 4.25(\mathrm{td}, J=12.0,8.2 \mathrm{~Hz}, 1 \mathrm{H}), 3.98-3.89(\mathrm{~m}, 1 \mathrm{H}), 3.88(\mathrm{dt}, J=8.4,2.9 \mathrm{~Hz}, 1 \mathrm{H}), 3.78(\mathrm{dd}, J=12.5$, $3.3 \mathrm{~Hz}, 1 \mathrm{H}), 1.97-1.83(\mathrm{~m}, 1 \mathrm{H}), 1.58(\mathrm{ddd}, J=13.6,7.6,3.4 \mathrm{~Hz}, 1 \mathrm{H}), 1.32-1.15(\mathrm{~m}, 1 \mathrm{H}), 0.99(\mathrm{~d}, J=6.8 \mathrm{~Hz}$, $3 \mathrm{H}), 0.92(\mathrm{t}, J=7.4 \mathrm{~Hz}, 3 \mathrm{H}) ; \mathrm{MS} / \mathrm{MS} m / z 377.2(\mathrm{M}+1)^{+}$.

3.2.7. (S)-2-Amino-N-(1-((2R,4R,5R)-3,3-difluoro-4-hydroxy-5-(hydroxymethyl)tetrahydrofuran-2yl)-2-oxo-1,2-dihydropyrimidin-4-yl)-4-methylpentanamide (Gem-Leu)

From the reaction of gemcitabine $(19 \mathrm{mg}, 0.073 \mathrm{mmol}), 21 \mathrm{mg}(77 \%)$ was obtained. ${ }^{1} \mathrm{H} \mathrm{NMR}(400 \mathrm{MHz}$, Methanol- $\left.d_{4}\right) \delta 7.81(\mathrm{~d}, J=7.6 \mathrm{~Hz}, 1 \mathrm{H}), 6.26-6.15(\mathrm{~m}, 1 \mathrm{H}), 5.97(\mathrm{~d}, J=7.6 \mathrm{~Hz}, 1 \mathrm{H}), 4.75-4.68(\mathrm{~m}, 1 \mathrm{H}), 4.25$ $(\mathrm{td}, J=12.1,8.2 \mathrm{~Hz}, 1 \mathrm{H}), 3.98-3.91(\mathrm{~m}, 1 \mathrm{H}), 3.88(\mathrm{dt}, J=8.3,2.8 \mathrm{~Hz}, 1 \mathrm{H}), 3.78(\mathrm{dd}, J=12.5,3.2 \mathrm{~Hz}, 1 \mathrm{H})$, $1.77-1.56(\mathrm{~m}, 3 \mathrm{H}), 0.98(\mathrm{~d}, J=6.1 \mathrm{~Hz}, 3 \mathrm{H}), 0.95(\mathrm{~d}, J=6.1 \mathrm{~Hz}, 3 \mathrm{H}) ; \mathrm{MS} / \mathrm{MS} m / z 377.2(\mathrm{M}+1)^{+}$.

\subsection{Characterization of Gemcitabine Prodrugs with Amino Acid}

\subsubsection{Cell Culture}

Human pancreatic cancer cells (MIAPaCa-2, BxPC-3 and AsPC-1) [21], lung cancer cell lines (A549) [22], human breast cancer cell lines (MDA-MB-231) [23] and melanoma cell lines (B16) [24] were purchased from the American Type Culture Collection (Manassas, VA, USA). MIAPaCa-2 and B16-F10 cells were cultured in Dulbecco's modified Eagle's medium (DMEM) supplemented with $10 \%$ heat-inactivated fetal bovine serum (FBS) and 1\% penicillin/streptomycin. Aspc-1, BxPC-3 MDA-MB-231 and A549 cells were cultured in Roswell Park Memorial Institute 1640 (RPMI-1640) medium supplemented with $10 \%$ FBS and 1\% penicillin/streptomycin. FBS and all other reagents used for cell culture were purchased from Invitrogen (Carlsbad, CA, USA). Cultures were maintained at $37^{\circ} \mathrm{C}$ in $95 \%$ air $/ 5 \% \mathrm{CO}_{2}$ humidified atmosphere.

\subsubsection{Reverse Transcription-PCR}

Total LAT-1 RNA was isolated using Trizol reagent and subjected to reverse transcription-PCR (Promega Corp.). The PCR primers used were LAT1, 5'-CCTCTGGGCCTGTTCTCTTG-3' (forward) and 5'-CTTGAGGCATGTCCACCTCC-3' (reverse). PCR reaction of forward and reverse genes was performed using the Ex Taq DNA Polymerase Recombinant (TaKaRa, Tokyo, Japan), with final concentrations of 1X PCR buffer, $2.5 \mathrm{mM}$ of dNTP mixture, $2.5 \mathrm{mM}$ of $\mathrm{MgCl}_{2}, 10$ pmol of each primer in a total reaction volume of $25 \mu \mathrm{L}$ containing $1 \mu \mathrm{L}$ of cDNA. Individual PCR amplification cycle of forward or reverse genes was performed with an initial denaturation step at $94{ }^{\circ} \mathrm{C}$ for $3 \mathrm{~min}$, followed by 35 cycles $\left(94{ }^{\circ} \mathrm{C}\right.$ for $30 \mathrm{~s} ; 55^{\circ} \mathrm{C}$ for $60 \mathrm{~s} ; 72{ }^{\circ} \mathrm{C}$ for $60 \mathrm{~s}$ ), and finally with an elongation step at $72{ }^{\circ} \mathrm{C}$ for $5 \mathrm{~min}$. The DNA products were resolved using gel electrophoresis (1.5\% agarose gel).

\subsubsection{Western Blot Assays}

BxPC-3 cells were washed with DPBS and lysed with RIPA buffer (Biosesang, Seongnam, Korea) containing $150 \mathrm{mM} \mathrm{NaCl}, 1 \%$ Triton X-100, 1\% sodium deoxycholate, 0.1\% SDS, $50 \mathrm{mM}$ Tris-HCl (pH 7.5), 2 mM EDTA ( $\mathrm{pH} 8.0$ ), and Xpert protease inhibitor and phosphatase inhibitor Cocktail (GenDEPOT, Barker, TX, USA). Proteins were separated by $8 \%$ or $15 \%$ SDS-PAGE (sodium dodecylsulfate-polyacrylamide gel electrophoresis) and transferred to polyvinylidene fluoride (PVDF) membranes. Protein transfer was confirmed using a Ponceau S staining solution (AMRESCO, Solon, $\mathrm{OH}, \mathrm{USA})$, and the blots were then immunostained with appropriate primary antibodies (1:1000) and secondary antibodies (1:5000) conjugated to horseradish peroxidase (HRP). Antibody binding was detected using an enhanced chemiluminescence (ECL) reagent (Bio-Rad, Hercules, CA, USA) using primary antibodies specific to proteins of interest, and proteins were detected using X-ray film and enhanced chemiluminescence reagent. Primary antibodies against the following were used: LAT-1, cleaved PARP (Cell Signaling Technologies, Beverly, MA, USA), GAPDH (Abcam, Cambridge, MA, USA), and $\beta$-actin (Sigma Aldrich, St. Louis, MO, USA). Secondary antibodies were purchased from Cell signaling technology. 


\subsubsection{Cytotoxicity Assay in Pancreatic Cells}

Cancer cell viabilities after treatment with gemcitabine or its derivatives were quantified using MTT assay as described previously [25]. Briefly, cells were seeded onto 96-well plates at $3 \times 10^{3}$ cells per well and incubated at $37^{\circ} \mathrm{C}$. The cells were treated with each compound at indicated concentrations for $48 \mathrm{~h}$ and then, $20 \mu \mathrm{L}$ of MTT labeling mixture was added to each well. After incubation for $4 \mathrm{~h}$, optical densities (OD) were determined using a microplate reader by measuring absorbances at $540 \mathrm{~nm}$.

\subsubsection{Terminal Deoxynucleotidyl Transferase-Mediated Nick End Labeling (TUNEL) Assay}

TUNEL assay was conducted with the ApopTag ${ }^{\circledR}$ Peroxidase In Situ Apoptosis Detection Kit (Merck Millipore, Burlington, MA, USA). Briefly, BxPC-3 cells were seeded onto 18-mm cover glasses in medium and grown to $70 \%$ confluence over $24 \mathrm{~h}$. Cells were then treated with $1 \mu \mathrm{M}$ of gemcitabine or Gem-Thr for $24 \mathrm{~h}$, fixed in an ice-cold mixture of acetic acid and ethanol solution, washed with DPBS, TUNEL stained, mounted, and examined under a light microscope for nuclear fragmentation.

\subsection{In Vitro Metabolic Stability of Gem-Thr}

The metabolic stability of Gem-Thr was examined in the presence of PBS (pH 7.4), rat plasma, or liver microsomes as described previously (Maeng et al., 2014). Fresh rat plasma was obtained from sacrificed SD rats (260-280 g) after centrifuging blood (12,000 $\times g, 15 \mathrm{~min})$. Rat liver microsomes were obtained from BD Gentest. Gem-Thr $(10 \mu \mathrm{M})$ was spiked into PBS, blank rat plasma, or liver microsomes ( $1 \mathrm{mg}$ protein $/ \mathrm{mL}$ ) and incubated in a shaking water bath at $37^{\circ} \mathrm{C}$ for $8 \mathrm{~h}$. Aliquots $(50-\mu \mathrm{L})$ were taken after $0,15,30,60,120,240,260$, or $480 \mathrm{~min}$ of incubation, immediately pretreated with ice-cold methanolic solution including the internal standard, vortexed for 3 min and centrifuged $(12,000 \times g, 10 \mathrm{~min})$. Supernatants were stored at $-80^{\circ} \mathrm{C}$ until required for analysis.

\subsection{Systemic Pharmacokinetics Study of Gem-Thr in Rats}

This study was performed in male Sprague-Dawley (SD) rats (Orient Bio, Sungnam, Korea), as described previously [26]. Rats were provided water and food ad libitum and maintained under a 12:12-h light/dark cycle. On the experimental day, a femoral vein and contralateral artery were cannulated using an Intramedic ${ }^{\mathrm{TM}}$ polyethylene tube (PE-50; Becton Dickinson Diagnostics, Sparks, MD, USA) under Zoletil induced anesthesia (50 mg/kg intramuscularly; Virbac, Carros, France). For the intravenous pharmacokinetic study, Gem-Thr or gemcitabine solution were injected into a femoral vein at $4 \mathrm{mg} / \mathrm{kg}$. Blood $(\sim 0.22 \mathrm{~mL})$ was taken from the femoral artery at 0 (blank), 1, 5, 15, $30,60,120,240,480,720$, or $1440 \mathrm{~min}$. To prevent blood loss, the same volume of normal saline was injected intravenously at each time point. Plasma was obtained immediately centrifugation and then stored at $-80^{\circ} \mathrm{C}$ prior to LC-MS/MS.

The pharmacokinetic parameters of Gem-Thr, gemcitabine, Gem-Thr plus gemcitabine, and free gemcitabine were calculated by non-compartmental analysis using WinNonlin (Version 3.1; Pharsight, Mountain View, CA, USA), as described previously (Park et al., 2016).

\subsection{Analysis of Gem-Thr and Gemcitabine by LC-MS/MS}

To determine concentrations of Gem-Thr and gemcitabine in rat plasma, plasma samples were deproteinized by adding two volumes of acetonitrile containing internal standard (phenacetin). After mixing, mixtures were centrifuged at $14,000 \times g$ for $10 \mathrm{~min}$.

Aliquots of supernatants $(2-\mu \mathrm{L})$ were injected into the LC-MS/MS system, which consisted of an Agilent HPLC and an Agilent 6490 QQQ mass spectrometer equipped with an ESI+ Agilent Jet Stream ion source (Agilent Technologies, Santa Clara, CA, USA). The separation of each drug and IS from endogenous plasma substances was achieved on a Synergi Polar-RP 80A column $(150 \times 2.0 \mathrm{~mm}, 4 \mu \mathrm{m}$; Phenomenex, Torrance, CA, USA). The mobile phase consisted of $0.1 \%$ formic acid and acetonitrile $(20: 80, v / v)$ at a flow rate of $0.2 \mathrm{~mL} / \mathrm{min}$. The column and autosampler tray were maintained at 25 and 
$4{ }^{\circ} \mathrm{C}$, respectively. Gemcitabine, Gem-Thr, and the IS were quantified by multiple-reaction monitoring (MRM) in positive electrospray ionization mode. Respective precursor-to-product ion transitions were as follows: Gemcitabine, $264.1 \rightarrow 112.1$, Gem-Thr, 387.1 $\rightarrow 343.2$, and IS (phenacetin), 180.2 $\rightarrow 162.2$. Data acquisition was performed using Mass Hunter software (ver. A.02.00; Agilent Technologies).

\subsection{Statistical Analysis}

Results are expressed as means \pm standard deviations (SDs). Differences between group means were analyzed using the two-tailed Student's $t$-test. Statistical significance was accepted for $p$ values $<0.05$.

\section{Conclusions}

Various amino acid derivatives of gemcitabine were successfully synthesized by forming amide bonds. Of the six derivatives of gemcitabine synthesized, Gem-Thr most effectively killed pancreatic cancer cells, in which LAT-1 was overexpressed. Our in vitro metabolic stability showed Gem-Thr is stable in PBS, plasma and a liver microsomal fraction, which demonstrated Gem-Thr is stable in cancer cells overexpressing amino acid transporter. Interestingly, our systemic pharmacokinetic results suggested that the amide prodrug approach improves the metabolic stability of gemcitabine in our in vivo model due to reduced decreased metabolic clearance. To the best of our knowledge, this is the first report on the cytotoxic effects of an amino acid transporter-targeting gemcitabine prodrug, produced by the introduction of threonine, on pancreatic cancer cells. Although the in vitro anti-cancer effect of Gem-Thr was only slightly superior to that of free gemcitabine, this improved pharmacokinetic property of Gem-Thr may have substantial anti-cancer effects in pancreatic cancer.

Author Contributions: S.H., S.-S.H. and H.-J.M. conceived and designed the experiments; H.-Y.J., Z.F. and J.-H.Y. performed the experiments; S.H., S.-S.H., Z.F. and H.-J.M. analyzed the data; S.H. and S.-S.H. contributed reagents/materials/analysis tools; S.H., S.-S.H. and H.-J.M. wrote the paper.

Funding: This research was supported by Basic Science Research Program through the National Research Foundation of Korea (NRF) funded by the Ministry of Science, ICT and Future Planning (2015R1A1A1A05027671; 2014M3C1A3051476; 2014009392) and Institute for Basic Science (IBS-R010-G1).

Acknowledgments: The authors would like to thank Dr. Kyung Hee Jung for technical assistance on the cytotoxicity assay.

Conflicts of Interest: The authors declare no conflict of interest.

\section{References}

1. Vitellius, C.; Fizanne, L.; Menager-Tabourel, E.; Nader, J.; Baize, N.; Laly, M.; Lermite, E.; Bertrais, S.; Caroli-Bosc, F.X. The combination of everolimus and zoledronic acid increase the efficacy of gemcitabine in a mouse model of pancreatic adenocarcinoma. Oncotarget 2018, 9, 28069-28082. [CrossRef] [PubMed]

2. Moore, M.J.; Goldstein, D.; Hamm, J.; Figer, A.; Hecht, J.R.; Gallinger, S.; Au, H.J.; Murawa, P.; Walde, D.; Wolff, R.A.; et al. Erlotinib plus gemcitabine compared with gemcitabine alone in patients with advanced pancreatic cancer: A phase III trial of the National Cancer Institute of Canada Clinical Trials Group. J. Clin. Oncol. 2007, 25, 1960-1966. [CrossRef] [PubMed]

3. Von Hoff, D.D.; Ervin, T.; Arena, F.P.; Chiorean, E.G.; Infante, J.; Moore, M.; Seay, T.; Tjulandin, S.A.; Ma, W.W.; Saleh, M.N.; et al. Increased survival in pancreatic cancer with nab-paclitaxel plus gemcitabine. N. Engl. J. Med. 2013, 369, 1691-1703. [CrossRef] [PubMed]

4. Ogawa, Y.; Suzuki, E.; Mikata, R.; Yasui, S.; Abe, M.; Iino, Y.; Ohyama, H.; Chiba, T.; Tsuyuguchi, T.; Kato, N. Five Cases of Interstitial Pneumonitis Due to Gemcitabine and Nab-Paclitaxel Combination Treatment in Pancreatic Cancer Patients. Pancreas 2018, 47, e42-e43. [CrossRef] [PubMed]

5. Huang, J.; Robertson, J.M.; Ye, H.; Margolis, J.; Nadeau, L.; Yan, D. Dose-volume analysis of predictors for gastrointestinal toxicity after concurrent full-dose gemcitabine and radiotherapy for locally advanced pancreatic adenocarcinoma. Int. J. Radiat. Oncol. Biol. Phys. 2012, 83, 1120-1125. [CrossRef] [PubMed] 
6. Bender, D.M.; Bao, J.; Dantzig, A.H.; Diseroad, W.D.; Law, K.L.; Magnus, N.A.; Peterson, J.A.; Perkins, E.J.; $\mathrm{Pu}$, Y.J.; Reutzel-Edens, S.M.; et al. Synthesis, crystallization, and biological evaluation of an orally active prodrug of gemcitabine. J. Med. Chem. 2009, 52, 6958-6961. [CrossRef] [PubMed]

7. Beumer, J.H.; Eiseman, J.L.; Parise, R.A.; Joseph, E.; Covey, J.M.; Egorin, M.J. Modulation of gemcitabine $\left(2^{\prime}, 2^{\prime}\right.$-difluoro-2' -deoxycytidine) pharmacokinetics, metabolism, and bioavailability in mice by 3,4,5,6-tetrahydrouridine. Clin. Cancer Res. 2008, 14, 3529-3535. [CrossRef] [PubMed]

8. Wickremsinhe, E.; Bao, J.; Smith, R.; Burton, R.; Dow, S.; Perkins, E. Preclinical absorption, distribution, metabolism, and excretion of an oral amide prodrug of gemcitabine designed to deliver prolonged systemic exposure. Pharmaceutics 2013, 5, 261-276. [CrossRef] [PubMed]

9. Zhang, Y.; Gao, Y.; Wen, X.; Ma, H. Current prodrug strategies, for improving oral absorption of nucleoside analogues. Asian J. Pharm. Sci. 2014, 9, 65-74. [CrossRef]

10. Tsume, Y.; Incecayir, T.; Song, X.; Hilfinger, J.M.; Amidon, G.L. The development of orally administrable gemcitabine prodrugs with D-enantiomer amino acids: Enhanced membrane permeability and enzymatic stability. Eur. J. Pharm. Biopharm. 2014, 86, 514-523. [CrossRef] [PubMed]

11. Song, X.; Lorenzi, P.L.; Landowski, C.P.; Vig, B.S.; Hilfinger, J.M.; Amidon, G.L. Amino acid ester prodrugs of the anticancer agent gemcitabine: Synthesis, bioconversion, metabolic bioevasion, and hPEPT1-mediated transport. Mol. Pharm. 2005, 2, 157-167. [CrossRef] [PubMed]

12. Zhang, D.; Bender, D.M.; Victor, F.; Peterson, J.A.; Boyer, R.D.; Stephenson, G.A.; Azman, A.; McCarthy, J.R. Facile rearrangement of $\mathrm{N} 4$-( $\alpha$-aminoacyl)cytidines to $\mathrm{N}$-(4-cytidinyl)amino acid amides. Tetrahedron Lett. 2008, 49, 2052-2055. [CrossRef]

13. Wang, G.; Chen, H.; Zhao, D.; Ding, D.; Sun, M.; Kou, L.; Luo, C.; Zhang, D.; Yi, X.; Dong, J.; et al. Combination of l-carnitine with lipophilic linkage-donating gemcitabine derivatives as intestinal novel organic cation transporter 2-targeting oral prodrugs. J. Med. Chem. 2017, 60, 2552-2561. [CrossRef] [PubMed]

14. Jin, S.E.; Jin, H.E.; Hong, S.S. Targeting L-type amino acid transporter 1 for anticancer therapy: Clinical impact from diagnostics to therapeutics. Expert Opin. Ther. Targets 2015, 19, 1319-1337. [CrossRef] [PubMed]

15. Kaira, K.; Sunose, Y.; Arakawa, K.; Ogawa, T.; Sunaga, N.; Shimizu, K.; Tominaga, H.; Oriuchi, N.; Itoh, H.; Nagamori, S.; et al. Prognostic significance of L-type amino acid transporter 1 expression in surgically resected pancreatic cancer. Br. J. Cancer 2012, 107, 632-638. [CrossRef] [PubMed]

16. Yanagisawa, N.; Ichinoe, M.; Mikami, T.; Nakada, N.; Hana, K.; Koizumi, W.; Endou, H.; Okayasu, I. High expression of L-type amino acid transporter 1 (LAT1) predicts poor prognosis in pancreatic ductal adenocarcinomas. J. Clin. Pathol. 2012, 65, 1019-1023. [CrossRef] [PubMed]

17. Kwak, E.Y.; Shim, W.S.; Chang, J.E.; Chong, S.; Kim, D.D.; Chung, S.J.; Shim, C.K. Enhanced intracellular accumulation of a non-nucleoside anti-cancer agent via increased uptake of its valine ester prodrug through amino acid transporters. Xenobiotica 2012, 42, 603-613. [CrossRef] [PubMed]

18. Maeng, H.J.; Kim, E.S.; Chough, C.; Joung, M.; Lim, J.W.; Shim, C.K.; Shim, W.S. Addition of amino acid moieties to lapatinib increases the anticancer effect via amino acid transporters. Biopharm. Drug Dispos. 2014, 35, 60-69. [CrossRef] [PubMed]

19. Park, Y.; Park, J.H.; Park, S.; Lee, S.Y.; Cho, K.H.; Kim, D.D.; Shim, W.S.; Yoon, I.S.; Cho, H.J.; Maeng, H.J. Enhanced Cellular Uptake and Pharmacokinetic Characteristics of Doxorubicin-Valine Amide Prodrug. Molecules 2016, 21, 1272. [CrossRef] [PubMed]

20. Zhao, C.; Li, Y.; Qin, Y.; Wang, R.; Li, G.; Sun, C.; Qu, X.; Li, W. Pharmacokinetics and metabolism of SL-01, a prodrug of gemcitabine, in rats. Cancer Chemother. Pharmacol. 2013, 71, 1541-1550. [CrossRef] [PubMed]

21. Son, M.K.; Jung, K.H.; Lee, H.S.; Lee, H.; Kim, S.J.; Yan, H.H.; Ryu, Y.L.; Hong, S.S. SB365, Pulsatilla saponin D suppresses proliferation and induces apoptosis of pancreatic cancer cells. Oncol. Rep. 2013, 30, 801-808. [CrossRef] [PubMed]

22. Pyo, J.S.; Roh, S.H.; Kim, D.K.; Lee, J.G.; Lee, Y.Y.; Hong, S.S.; Kwon, S.W.; Park, J.H. Anti-cancer effect of Betulin on a human lung cancer cell line: A pharmacoproteomic approach using 2 D SDS PAGE coupled with nano-HPLC tandem Mass Spectrometry. Planta Med. 2009, 75, 127-131. [CrossRef] [PubMed]

23. Gu, W.W.; Lin, J.; Hong, X.Y. Cyclin A2 regulates homologous recombination DNA repair and sensitivity to DNA damaging agents and poly (ADP-ribose) polymerase (PARP) inhibitors in human breast cancer cells. Oncotarget 2017, 24, 90842-90851. [CrossRef] [PubMed] 
24. Hatiboglu, M.A.; Kocyigit, A.; Guler, E.M.; Akdur, K.; Nalli, A.; Karatas, E.; Tuzgen, S. Thymoquinone Induces Apoptosis in B16-F10 Melanoma Cell Through Inhibition of p-STAT3 and Inhibits Tumor Growth in a Murine Intracerebral Melanoma Model. World Neurosurg. 2018, 114, e182-e190. [CrossRef] [PubMed]

25. Yun, S.M.; Jung, K.H.; Lee, H.; Son, M.K.; Seo, J.H.; Yan, H.H.; Park, B.H.; Hong, S.; Hong, S.S. Synergistic anticancer activity of HS-173, a novel PI3K inhibitor in combination with Sorafenib against pancreatic cancer cells. Cancer Lett. 2013, 331, 250-261. [CrossRef] [PubMed]

26. Kim, Y.C.; Kim, I.B.; Noh, C.K.; Quach, H.P.; Yoon, I.S.; Chow, E.C.Y.; Kim, M.; Jin, H.E.; Cho, K.H.; Chung, S.J.; et al. Effects of 1 1 ,25-dihydroxyvitamin D3, the natural vitamin D receptor ligand, on the pharmacokinetics of cefdinir and cefadroxil, organic anion transporter substrates, in rat. J. Pharm. Sci. 2014, 103, 3793-3805. [CrossRef] [PubMed]

Sample Availability: Samples of the compounds are available from the authors.

(C) 2018 by the authors. Licensee MDPI, Basel, Switzerland. This article is an open access article distributed under the terms and conditions of the Creative Commons Attribution (CC BY) license (http:/ / creativecommons.org/licenses/by/4.0/). 
Article

\title{
Density Functional Studies on Secondary Amides: Role of Steric Factors in Cis/Trans Isomerization
}

\author{
Balmukund S. Thakkar *, John Sigurd M. Svendsen and Richard A. Engh * \\ Department of Chemistry, UiT The Arctic University of Norway, N-9037 Tromsø, Norway; \\ john-sigurd.svendsen@uit.no \\ * Correspondence: balmukund.thakkar@uit.no (B.S.T.); Richard.Engh@uit.no (R.A.E.); \\ Tel.: +47-96-950-477 (B.S.T.); +47-77-644-073 (R.A.E.)
}

Received: 1 September 2018; Accepted: 21 September 2018; Published: 25 September 2018

\begin{abstract}
Cis/trans isomerization of amide bonds is a key step in a wide range of biological and synthetic processes. Occurring through C-N amide bond rotation, it also coincides with the activation of amides in enzymatic hydrolysis. In recently described QM studies of cis/trans isomerization in secondary amides using density functional methods, we highlighted that a peptidic prototype, such as glycylglycine methyl ester, can suitably represent the isomerization and complexities arising out of a larger molecular backbone, and can serve as the primary scaffold for model structures with different substitution patterns in order to assess and compare the steric effect of the substitution patterns. Here, we describe our theoretical assessment of such steric effects using tert-butyl as a representative bulky substitution. We analyze the geometries and relative stabilities of both trans and cis isomers, and effects on the cis/trans isomerization barrier. We also use the additivity principle to calculate absolute steric effects with a gradual increase in bulk. The study establishes that bulky substitutions significantly destabilize cis isomers and also increases the isomerization barrier, thereby synergistically hindering the cis/trans isomerization of secondary amides. These results provide a basis for the rationalization of kinetic and thermodynamic properties of peptides with potential applications in synthetic and medicinal chemistry.
\end{abstract}

Keywords: density functional theory; cis/trans isomerization; secondary amides; dipeptides; steric effects; tert-butyl; additivity principle

\section{Introduction}

The chemistry of the amide bond has attracted the interest of chemists with diverse specializations. Its unique characteristics arise from the delocalization of electrons from nitrogen to the carbonyl group, which confers a partial double-bond character to the C-N bond and stabilizes a planar geometry with a relatively high energy rotational barrier that hinders the free rotation, giving rise to cis and trans isomers [1-3]. The resonance effect also protects the amide moiety against nucleophilic attacks at the carbonyl carbon (e.g., it is virtually immune to hydrolysis at ambient temperature and $\mathrm{pH}$ in non-enzymatic conditions); hence, it is a common practice to activate amides using Lewis acids for chemical transformation. However, studies on enzymatic hydrolysis of amides have revealed that distortion in the amide bond planarity via C-N bond rotation also results in amide bond activation, increasing susceptibility to nucleophilic attack [4-6]. Cis/trans isomerization is one phenomenon whereby the amide moiety loses its planarity, as significant geometric and hybridizational changes occur throughout C-N bond rotation [7]. Therefore, information regarding the stabilities of cis and trans forms of amides, $\mathrm{C}-\mathrm{N}$ bond rotation in terms of cis/trans isomerization, and relevant energy barriers can be useful for understanding the activation by deformation for a variety of amides, especially peptides.

While $3^{\circ}$-amides (e.g., prolyl peptide bonds) have often been observed to undergo cis/trans isomerization due to small energy differences between cis and trans isomers [8-10], $2^{\circ}$-amides 
also undergo cis/trans isomerization via higher energy states in diverse important phenomena, such as chemo-mechanical cycling of motor proteins [11], the protein folding [12-14] and catalytic activity [15] of enzymes (such as cyclophilin A), cascade dissociation of peptide cation radicals for peptide sequencing [16], and cyclization reactions of peptides (e.g., as in the formation of piperazine-2,5-diones) [17].

With advances in computational capabilities since the 1990s, theoretical studies on trans and cis isomers of $2^{\circ}$-amides and their interconversion have revealed diverse phenomena, such as: effects of pyramidalization of the amide and geometries of transition states [18]; the role of conjugation [19]; simulated solvent effects with molecular dynamics [20]; comparison of theoretically obtained rotational barrier values with experimental values [21,22]; and the generation of ensembles of transition state geometries [23]. Recently, we have conducted theoretical studies [7,24] on secondary amides using density functional methods and molecular dynamics to provide a detailed account of geometry changes during cis/trans isomerization, as well as the effects of solvent models, using glycylglycine methyl ester (GGMe, Figure 1) as an example. We described that cis/trans isomerization can occur via either of the two paths: one via the anti-type transition state, and one via the syn-type transition state (Figure 2). We also showed that the salient features of the cis/trans isomerization remained consistent when the studies were extended from $\mathrm{N}$-methylacetamide to the peptidic scaffolds of GGMe, thus serving as a simple peptide prototype to study conformational flexibilities and complexities relevant to larger molecular backbones. In the present work, we extend our studies to substituted derivatives of GGMe (Figure 1).
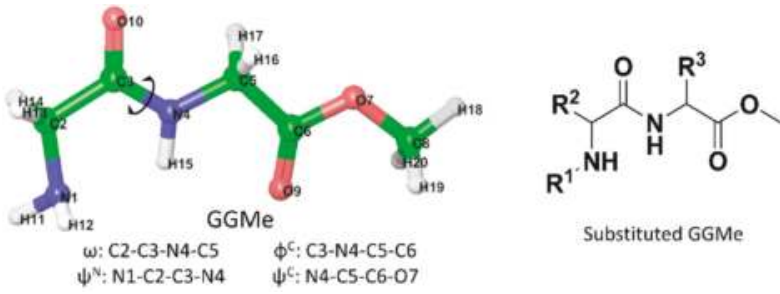

Figure 1. The structures of glycylglycine methyl ester (left) and the substituted GGMe scaffold (right). The relevant dihedral angles are defined by reference to the GGMe atom names (left).

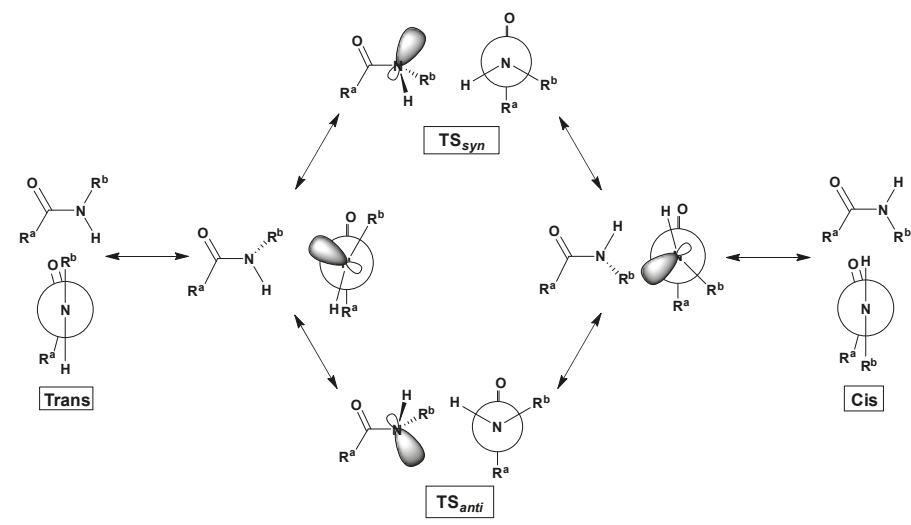

Figure 2. Two paths of cis/trans isomerization via the syn transition state $\left(\mathrm{TS}_{s y n}\right)$ and anti transiton state $\left(\mathrm{TS}_{a n t i}\right)$, respectively. $\mathrm{R}^{\mathrm{a}}$ and $\mathrm{R}^{\mathrm{b}}$ represent substitutions attached to the carbonyl carbon and amide nitrogen, respectively. For simplicity, the rotation is shown only for positive $\omega$ values between $0^{\circ}$ (cis) and $180^{\circ}$ (trans). See [7] for more details.

It has been observed experimentally $[25,26]$ that the steric bulk on both sides of the amide moiety affects the cis/trans isomerization barrier. This demonstrates the key role of amino-acid 
side-chains in peptides in the rate of isomerization and extent of equilibria between the two isomers. Corresponding attempts have been made to tailor the flexibility of the rotamers and overall conformations by introducing constraints, such as intramolecular hydrogen bonding and/or steric bulk around the amide bonds $[27,28]$. In addition to targeted flexibility design, the use of unnatural isomers (especially D-amino acids) and the introduction of $\mathrm{N}$-alkylated chains or functionalities in peptide chemistry for the generation of novel peptidomimetics $[29,30]$ provide further variation of the steric bulk around the peptide bond (as well as diversification towards enzymatic activation). Thus, a systematic theoretical study on the effect of steric bulk on the relative stabilities of trans and cis isomers and their interconversion via cis/trans isomerization is in order.

The diversity of side chains and substitutions, along with their differing extents of steric effects, greatly complicates their study. Bigger and bulkier side chains and substitutions introduce more potential interactions, asymmetry, flexibility, and resonance effects, and hence have prohibitively greater demands for $\mathrm{CPU}$ time for QM studies at higher levels of theory. Hence, a systematic study requires representative substitution group(s) that can serve to introduce simple "bulk", devoid of any resonance or hydrogen-bonding effects. With the A value $>4[31,32]$ and $v_{\text {ef }}$ value $=1.2[33,34]$, the tert-butyl group can therefore be an ideal choice for "bulk". In synthetic chemistry also, it is a common practice to use tert-butyl groups as bulky substitutions to analyze the effect of steric bulk [35-37].

With this background, we present our theoretical assessment of the impact of stereospecific patterns of steric bulk on $\alpha$-carbons and the $\mathrm{N}$-terminal amino group with respect to the geometries of the trans and cis isomers, their relative stabilities, and effects on the cis/trans isomerization barrier.

\section{Results and Discussion}

\subsection{Model Structures}

The GGMe structure was taken as the primary scaffold to introduce bulk at different positions. As shown in Figure 1, among the available three positions for substitutions, two are $\alpha$-carbons of amino acids and are thus chiral centers. In line with the natural amino acids, the default configuration of substitution at $\alpha$-carbons was kept as the $S$-configuration. However, when both chiral centers had substitutions (i.e., where neither $\mathrm{R}^{2}$ nor $\mathrm{R}^{3}$ was hydrogen), the $\mathrm{R}^{2}$ configuration was kept constant $(S)$, and both isomers with different configurations ( $R$ and $S$ ) of $R^{3}$ were included. Hence, along with compounds with the natural $S$-configuration, two compounds with unnatural $R$-configurations at the $\alpha$-carbon were also included. Thus, a total of 10 model structures with different substitution patterns of tert-butyl groups were generated, as summarized in Table 1 and Figure 3.

Table 1. Model structures and their substitutions.

\begin{tabular}{cccc}
\hline Compound $^{\text {a }}$ & $\mathbf{R}^{\mathbf{1}}$ & $\mathbf{R}^{\mathbf{2}}$ & $\mathbf{R}^{\mathbf{3}}$ \\
\hline $\mathrm{N} 0000$ & $\mathrm{H}$ & $\mathrm{H}$ & $\mathrm{H}$ \\
$(\mathrm{GGMe})$ & $\mathrm{H}$ & $\mathrm{H}$ & $S-t-\mathrm{Bu}$ \\
$\mathrm{N} 0010$ & $\mathrm{H}$ & $S-t-\mathrm{Bu}$ & $\mathrm{H}$ \\
$\mathrm{N} 0100$ & $\mathrm{H}$ & $S-t-\mathrm{Bu}$ & $S-t-\mathrm{Bu}$ \\
$\mathrm{N} 0110$ & $\mathrm{H}$ & $S-t-\mathrm{Bu}$ & $\mathrm{R}-\mathrm{t}-\mathrm{Bu}$ \\
$\mathrm{N} 011^{\prime} 0$ & $\mathrm{t}-\mathrm{Bu}$ & $\mathrm{H}$ & $\mathrm{H}$ \\
$\mathrm{N} 1000$ & $t-\mathrm{Bu}$ & $\mathrm{H}$ & $S-t-\mathrm{Bu}$ \\
$\mathrm{N} 1010$ & $t-\mathrm{Bu}$ & $S-t-\mathrm{Bu}$ & $\mathrm{H}$ \\
$\mathrm{N} 1100$ & $t-\mathrm{Bu}$ & $S-t-\mathrm{Bu}$ & $S-t-\mathrm{Bu}$ \\
$\mathrm{N} 1110$ & $t-\mathrm{Bu}$ & $S-t-\mathrm{Bu}$ & $R-t-\mathrm{Bu}$ \\
$\mathrm{N} 111^{\prime} 0$ &
\end{tabular}

a The first, second, and third digits in the name of each compound represent the variants of $R^{1}, R^{2}$, and $R^{3}$, respectively. The fourth digit ( 0 in all) represents methyl ester and is specified in order to enable comparison to future variation at this site. 


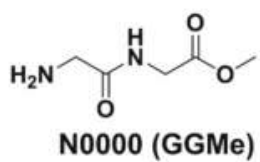<smiles>COC(=O)[C@H](NC(=O)CN)C(C)(C)C[N+](=O)[O-]</smiles><smiles>COC(=O)CNC(=O)C(N)C(C)(C)C</smiles>

N0100<smiles>COC(=O)CNC(=O)CNC(C)(C)C</smiles><smiles>COC(=O)[C@H](NC(=O)C(N)C(C)(C)C)C(C)(C)C</smiles>

N0110<smiles>COC(=O)[C@H](NC(=O)CNC(C)(C)C)C(C)(C)C</smiles><smiles>COC(=O)C(NC(=O)C(N)C(C)(C)C)C(C)(C)C</smiles>

N011'0<smiles>COC(=O)CNC(=O)C(NC(C)(C)C)C(C(C)(C)C)C(C)(C)C</smiles>

N1100<smiles>COC(=O)[C@H](NC(=O)C(NC(C)(C)C)C(C)(C)C)C(C)(C)C</smiles>

N1110<smiles>COC(=O)[C@H](NC(=O)C(NC(C)(C)C)C(C)(C)C)C(C)(C)C</smiles>

N111'0

Figure 3. GGMe and its tert-butyl-substituted derivatives as model dipeptide esters.

\subsection{Trans Geometries}

In both gas and water phases (Figures 4 and 5), the optimized minimum energy geometries of trans isomers showed an interesting blend of peptidic features with many of the characteristics previously observed for GGMe [24]. For example, due to the absence of an amide group at the C-terminal, $\mathrm{C}_{7}$-forms ( $\gamma$-foldings) were not observed and the geometries with unsubstituted chiral carbons showed a preference for the extended planar $\mathrm{C}_{5}$-form [38]. However, the substitutions at chiral carbons introduced peptidic folding. A majority of geometries also showed the presence of a hydrogen bond between the N-terminal amino group and amidic hydrogen [38].

The amide bond planarity is often described quantitatively in terms of the dihedral, $\omega$. The minimum energy geometries showed that the presence of bulky groups on both $\alpha$-carbons can cause distortion in the amide bond planarity beyond $\pm 5^{\circ}$ of ideal perfect planarity (Table 2 ), and therefore can be used as an alternate approach towards acyclic twisted amides in combination with non-covalent bonding strategies.

In order to assess the magnitude of steric factors in terms of energy $\left({ }^{s t} \mathrm{E}\right)$, the energy values calculated based on the additivity principle [31] for tert-butyl-substituted structures ( ${ }^{\text {Add }} \mathrm{E}$ ) were compared with their direct energy estimates for their minimum energy geometries ( $\left.{ }^{\mathrm{opt}} \mathrm{E}\right)$. As explained in Figure 6A, the energy difference between methane and neopentane was taken to represent the additive energy value of tert-butyl substitution on an $\mathrm{sp}^{3}$-carbon $\left(\mathrm{E}_{\mathrm{tb}} \mathrm{C}\right)$, while the energy difference between ammonia and tert-butylamine was taken to represent the additive energy value of tert-butyl substitution on pyramidal $\mathrm{sp}^{3}$-nitrogen of the amino group $\left(\mathrm{E}_{\mathrm{tb}} \mathrm{N}\right)$. Both values were calculated for both gas and water phases (Tables 3 and 4) each. Then, as shown in Figure 6B, the energy value for the optimized minimum energy geometry of N0000 (GGMe), or ${ }^{\text {opt }} \mathrm{E}_{\mathrm{N} 0000}$, was taken as the basis for the calculations of other compounds having tert-butyl substitutions on the $\alpha$-carbon or amino nitrogen. 


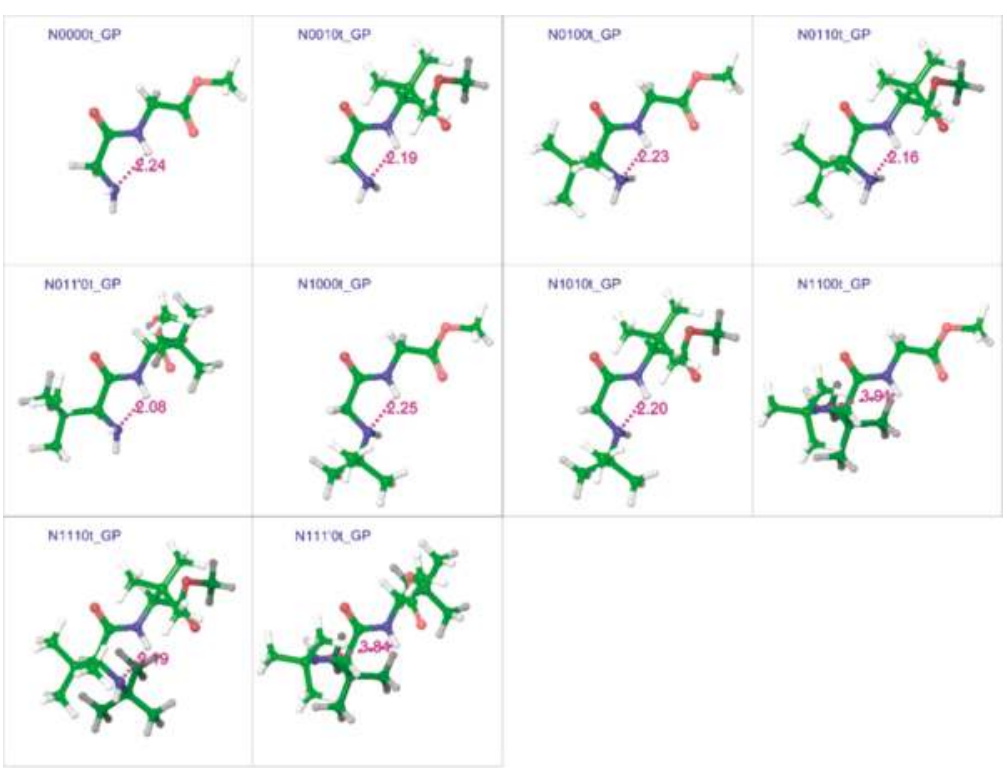

Figure 4. Optimized minimum energy geometries of substituted GGMe derivatives in the gas phase, where all geometries are aligned at the amide moiety. The distance between $\mathrm{N}$-terminal amino nitrogen and amidic hydrogen, in magenta, highlights the presence (or absence when distance $>2.3 \AA$ ) of the $\mathrm{H}$-bond between the two atoms. The " $\mathrm{t}$ " after the compound name indicates the "trans" isomer.

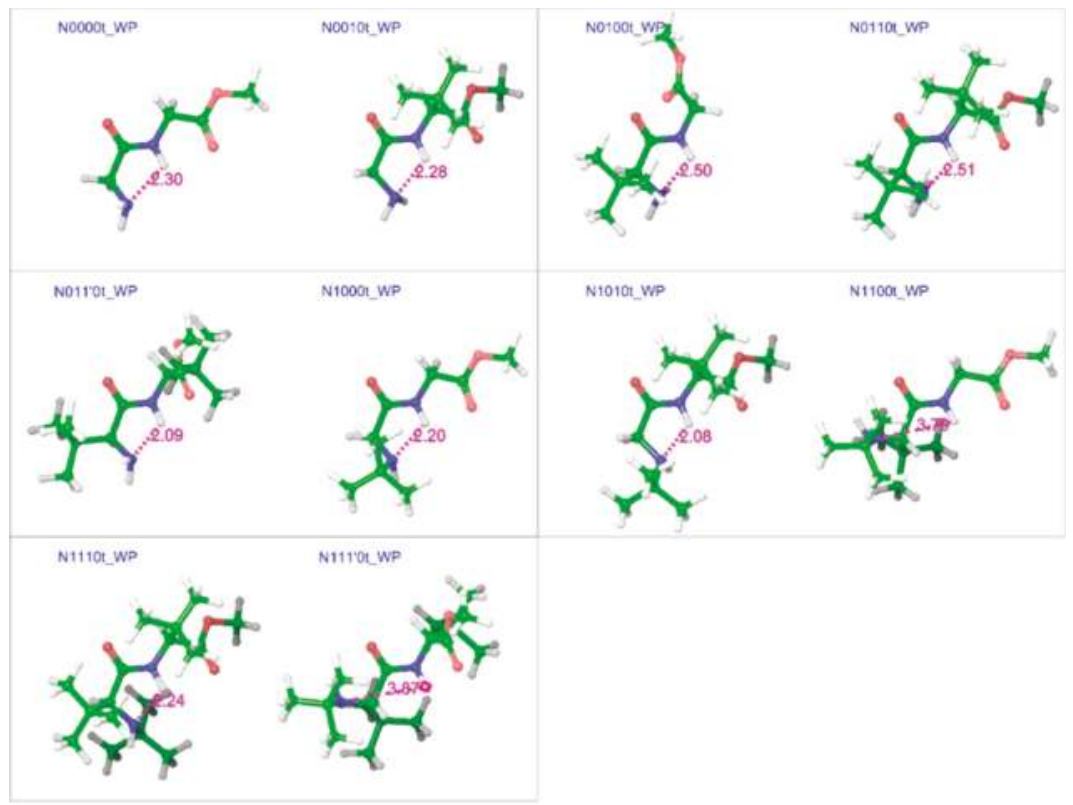

Figure 5. Optimized minimum energy geometries of substituted GGMe derivatives in the water phase, where all geometries are aligned at the amide moiety. The distance between $\mathrm{N}$-terminal amino nitrogen and amidic hydrogen, in magenta, highlights the presence (or absence when distance $>2.3 \AA$ ) of the $\mathrm{H}$-bond between the two atoms. The " $\mathrm{t}$ " after the compound name indicates the "trans" isomer. 
For each compound, the additive energy value ( $\left.{ }^{\text {Add }} \mathrm{E}\right)$ was determined by the addition of corresponding additive energy values of the tert-butyl group $\left(\mathrm{E}_{\mathrm{tb}}\right)$, depending on the atom of attachment (carbon or nitrogen), number of tert-butyl groups, and the phase (gas or water). The steric effect $\left({ }^{\left({ }^{t} \mathrm{E}\right.}\right)$ was calculated as the difference between ${ }^{A d d} \mathrm{E}$ and the energy values for optimized minimum energy geometries of respective compounds $\left({ }^{\mathrm{opt}} \mathrm{E}\right)$ in their respective phase- - that is, the gas or water phases (Tables 5 and 6).

Table 2. Values (in degrees) of different dihedrals for the minimum energy geometries of different compounds in gas and water phases. The presence of bulky groups on both $\alpha$-carbons can cause distortion in the planarity of amide moiety in terms of the $\omega$ dihedral, as highlighted in grey.

\begin{tabular}{ccccccccc}
\hline Compound & \multicolumn{9}{c}{ Gas Phase } & \multicolumn{5}{c}{ Water Phase } \\
& $\boldsymbol{\psi}^{\mathbf{N}}$ & $\omega$ & $\varphi^{\mathrm{C}}$ & $\psi^{\mathrm{C}}$ & $\psi^{\mathbf{N}}$ & $\omega$ & $\varphi^{\mathrm{C}}$ & $\psi^{\mathrm{C}}$ \\
\hline N0000t & 12.8 & 178.3 & 175.6 & -179.3 & 15.2 & 179.2 & 178.5 & -177.4 \\
N0010t & -14.3 & 177.0 & -122.7 & 141.7 & -19.3 & 178.8 & -124.4 & 142.6 \\
N0100t & -22.8 & -179.7 & -173.1 & 178.8 & -40.5 & -177.9 & 66.3 & -146.4 \\
N0110t & -23.8 & 169.5 & -114.3 & 141.2 & -50.8 & 171.3 & -135.3 & 152.0 \\
N011'0t & 14.3 & -178.8 & 123.0 & -140.9 & 13.4 & 178.5 & 127.3 & -143.2 \\
N1000t & -15.6 & -178.0 & -179.1 & 179.6 & 12.7 & 179.5 & 175.3 & -177.3 \\
N1010t & -17.9 & 176.6 & -123.7 & 141.8 & -12.2 & 178.7 & -127.5 & 141.4 \\
N1100t & 140.7 & 177.5 & -175.0 & -179.9 & 134.6 & 174.6 & -163.7 & 171.2 \\
N1110t & -27.1 & 172.5 & -117.0 & 140.5 & -32.7 & 174.2 & -123.1 & 141.1 \\
N111'0t & 143.0 & -169.7 & 127.2 & -145.3 & 148.2 & -173.4 & 136.1 & -147.7 \\
\hline
\end{tabular}

The " $\mathrm{t}$ " after the compound name indicates the "trans" isomer.

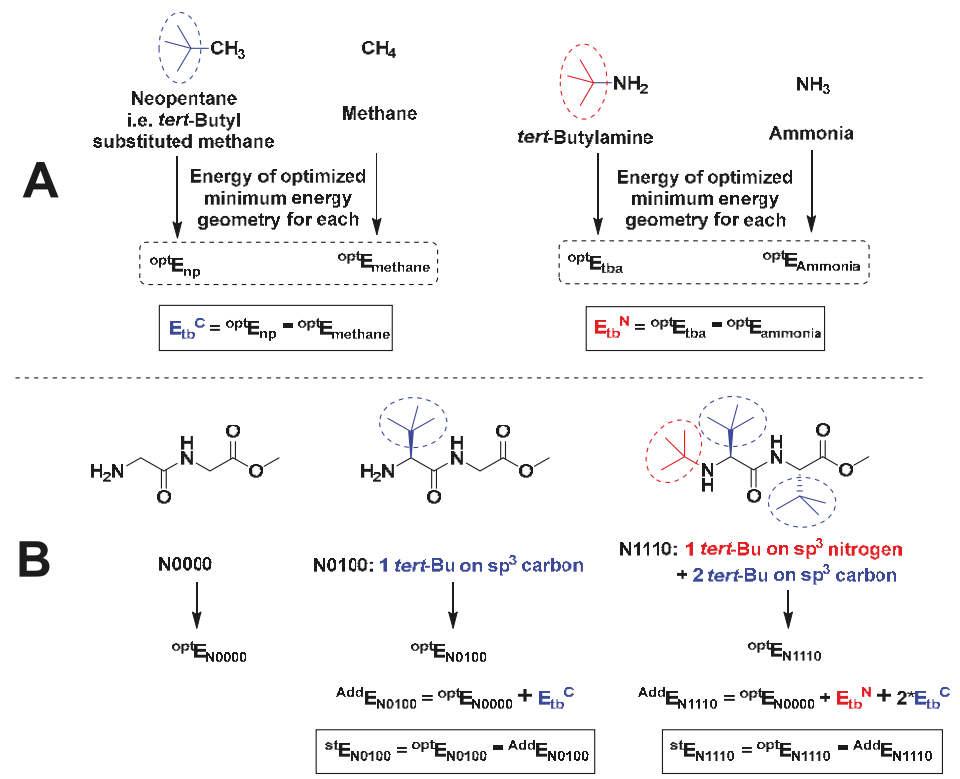

Figure 6. Using the additivity principle: (A) Calculation of the additive energy values of tert-butyl substitution (B) Calculation of the magnitude of the steric effect in terms of energy based on GGMe, explained with examples of N0100 and N1110. 
Table 3. Calculation of tert-Bu additive energy in the gas phase.

\begin{tabular}{cccc}
\hline Compound & ${ }^{\text {opt }} \mathbf{E}$ & Attachment Point & tert-Bu Additive Energy kcal mol ${ }^{-\mathbf{1}}\left(\mathrm{E}_{\mathrm{tb}}\right)$ \\
\hline $\begin{array}{c}\mathrm{NH}_{3} \\
\text { tert }-\mathrm{Bu}-\mathrm{NH}_{2}\end{array}$ & $-35,508.975$ & $\mathrm{sp}^{3}$ nitrogen & $\mathrm{E}_{\mathrm{tb}}{ }^{\mathrm{N}}=-98,709.131$ \\
\hline $\begin{array}{c}\mathrm{CH}_{4} \\
\text { tert }-\mathrm{Bu}-\mathrm{CH}_{3}\end{array}$ & $-25,218.106$ & $\mathrm{sp}^{3}$ carbon & $\mathrm{E}_{\mathrm{tb}} \mathrm{C}=-98,712.134$ \\
\hline
\end{tabular}

Table 4. Calculation of tert-Bu additive energy in the water phase.

\begin{tabular}{cccc}
\hline Compound & ${ }^{\text {opt }} \mathbf{E}$ & Attachment Point & tert-Bu Additive Energy Kcal mol $\mathbf{~ m o n}^{-\mathbf{1}}\left(\mathrm{E}_{\mathrm{tb}}\right)$ \\
\hline $\begin{array}{c}\mathrm{NH}_{3} \\
\text { tert }-\mathrm{Bu}-\mathrm{NH}_{2}\end{array}$ & $\begin{array}{c}-35,514.577 \\
-134,222.223\end{array}$ & $\mathrm{sp}^{3}$ nitrogen & $\mathrm{E}_{\mathrm{tb}}{ }^{\mathrm{N}}=-98,707.646$ \\
\hline $\begin{array}{c}\mathrm{CH}_{4} \\
\text { tert }-\mathrm{Bu}-\mathrm{CH}_{3}\end{array}$ & $-25,436.175$ & $\mathrm{sp}^{3}$ carbon & $\mathrm{E}_{\mathrm{tb}} \mathrm{C}=-98,711.962$ \\
\hline
\end{tabular}

Table 5. Calculation of steric energies in the gas phase.

\begin{tabular}{|c|c|c|c|c|c|}
\hline Compound ${ }^{a}$ & $\begin{array}{c}{ }^{\text {opt }} \mathrm{E} \\
\text { kcal mol }^{-1}\end{array}$ & $\begin{array}{l}\text { No. of } t \text {-Bu on } \\
\mathrm{sp}^{3} \text { Nitrogen }\end{array}$ & $\begin{array}{c}\text { No. of } t \text {-Bu on } \\
\mathrm{sp}^{3} \text { Carbon }\end{array}$ & $\begin{array}{c}{ }_{\text {Add }} \mathrm{E} \\
\mathrm{kcal} \mathrm{mol}^{-1}\end{array}$ & $\begin{array}{c}{ }^{\mathrm{st}} \mathrm{E} \\
\mathrm{kcal} \mathrm{mol}^{-1}\end{array}$ \\
\hline N0000t & $-333,806.071$ & & & $-333,806.071$ & 0 \\
\hline N0010t & $-432,516.46$ & & 1 & $-432,518.205$ & 1.745 \\
\hline N0100t & $-432,515.901$ & & 1 & $-432,518.205$ & 2.304 \\
\hline N0110t & $-531,225.709$ & & 2 & $-531,230.339$ & 4.63 \\
\hline $\mathrm{N} 011^{\prime} 0 \mathrm{t}$ & $-531,225.494$ & & 2 & $-531,230.339$ & 4.845 \\
\hline N1000t & $-432,514.375$ & 1 & & $-432,515.202$ & 0.827 \\
\hline N1010t & $-531,224.575$ & 1 & 1 & $-531,227.336$ & 2.761 \\
\hline N1100t & $-531,222.518$ & 1 & 1 & $-531,227.336$ & 4.818 \\
\hline N1110t & $-629,932.315$ & 1 & 2 & $-629,939.47$ & 7.155 \\
\hline $\mathrm{N} 111^{\prime} 0 \mathrm{t}$ & $-629,931.92$ & 1 & 2 & $-629,939.47$ & 7.55 \\
\hline
\end{tabular}

a The " $\mathrm{t}$ " after the compound name indicates the "trans" isomer.

Table 6. Calculation of steric energies in the water phase.

\begin{tabular}{|c|c|c|c|c|c|c|}
\hline Compound $^{a}$ & $\begin{array}{l}\text { Solvation Energy } \\
\left(\mathrm{kcal} \mathrm{mol}^{-1}\right)\end{array}$ & $\begin{array}{c}\mathrm{opt}^{\mathrm{E}} \\
\mathrm{kcal} \mathrm{mol}^{-1}\end{array}$ & $\begin{array}{c}\text { No. of } t \text {-Bu on } \\
\mathrm{sp}^{3} \text { nitrogen }\end{array}$ & $\begin{array}{c}\text { No. of } t \text {-Bu on } \\
\operatorname{sp}^{3} \text { carbon }\end{array}$ & $\begin{array}{c}{ }_{\mathrm{Add}}^{\mathrm{E}} \\
\mathrm{kcal} \mathrm{mol}^{-1}\end{array}$ & $\begin{array}{c}{ }^{\text {st }} \mathrm{E} \\
\mathrm{kcal} \mathrm{mol}^{-1}\end{array}$ \\
\hline N0000t & -16.33 & $-381,811.506$ & & & $-381,811.506$ & 0 \\
\hline N0100t & -14.86 & $-480,518.077$ & & 1 & $-480,523.468$ & 5.391 \\
\hline N0110t & -16.1 & $-579,224.507$ & & 2 & $-579,235.43$ & 10.923 \\
\hline N011'0t & -12.66 & $-579,225.518$ & & 2 & $-579,235.43$ & 9.912 \\
\hline N1100t & -13.47 & $-579,222.324$ & 1 & 1 & $-579,231.114$ & 8.79 \\
\hline N1110t & -11.49 & $-677,932.254$ & 1 & 2 & $-677,943.076$ & 10.822 \\
\hline $\mathrm{N} 111^{\prime} 0 \mathrm{t}$ & -11.34 & $-677,929.486$ & 1 & 2 & $-677,943.076$ & 13.59 \\
\hline
\end{tabular}

a The " $\mathrm{t}$ " after the compound name indicates the "trans" isomer.

The trend, as shown in Figure 7, suggests that adding a bulky substitution to an $\alpha$-carbon results in a considerable steric effect. The bulky substitution on the $\mathrm{N}$-terminal $\alpha$-carbon has a slightly larger impact than that on the $\mathrm{C}$-terminal $\alpha$-carbon. A bulky substitution on the $\mathrm{N}$-terminal amino nitrogen also leads to a steric effect that is consistently present across corresponding pairs, becoming stronger with bulk on $\alpha$-carbons. This steric effect seen in terms of energies is also reflected in strained geometries, and is stronger when using the polarizable continuum model (the water phase). The comparison between different substitution patterns using the additivity principle provides interesting insights about the importance of the hydrogen bond between the N-terminal amino nitrogen and the amide hydrogen 
for conformational stability. For example, the difference between the stabilities of the minimum energy conformers of N0010 and N0100 in the gas phase is $\sim 0.5 \mathrm{kcal} \mathrm{mol}^{-1}$, but with tert-butyl substitution on the N-terminal nitrogen (N1010 and N1100), the same stability difference increases to $\sim 2.0 \mathrm{kcal} \mathrm{mol}^{-1}$, as N1100 lacks the hydrogen bond (Figure 4). Similarly, in the water phase, the minimum energy geometry of N011'0 is more stable (by $\sim 1 \mathrm{kcal} \mathrm{mol}^{-1}$ ) than that of N0110, while N1110 is more stable (by $\sim 2.7 \mathrm{kcal} \mathrm{mol}^{-1}$ ) than $\mathrm{N} 111^{\prime} 0$. Both of the more stable geometries (N011'0 and N1110) show the presence of the hydrogen bond, while both less-stable geometries lack it (Figure 5). Additionally, as is evident from Figure 8, the tert-butyl groups in the less-substituted N0110 and N011'0 can remain apart, but the same is not possible for the highly substituted geometries of N1110 and N111'0 with their additional bulk on the $\mathrm{N}$-terminal amino nitrogen, ultimately resulting in the higher energy difference.

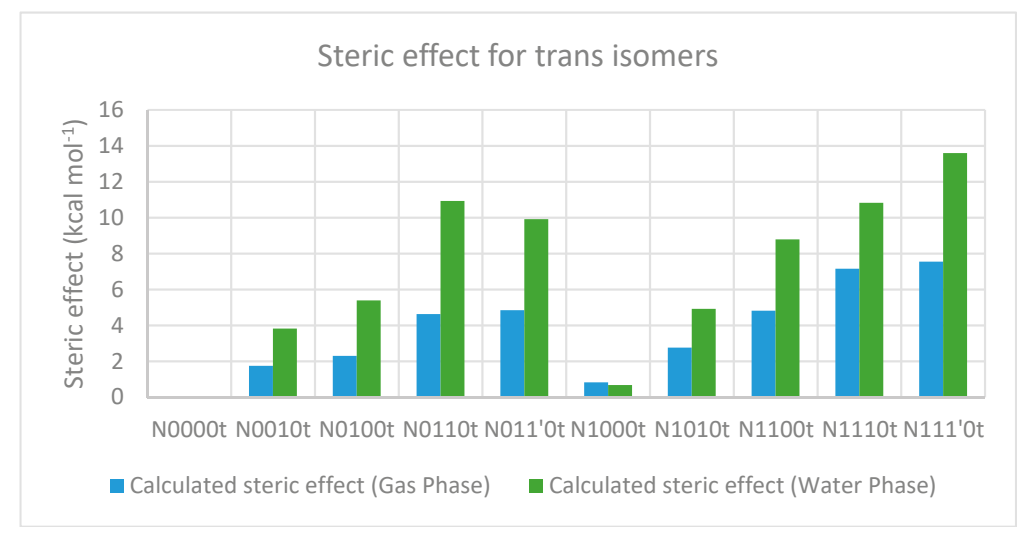

Figure 7. Calculated steric effect for trans-isomers in the gas and water phase, using the additivity principle. The " $\mathrm{t}$ " after the compound name indicates the "trans" isomer.
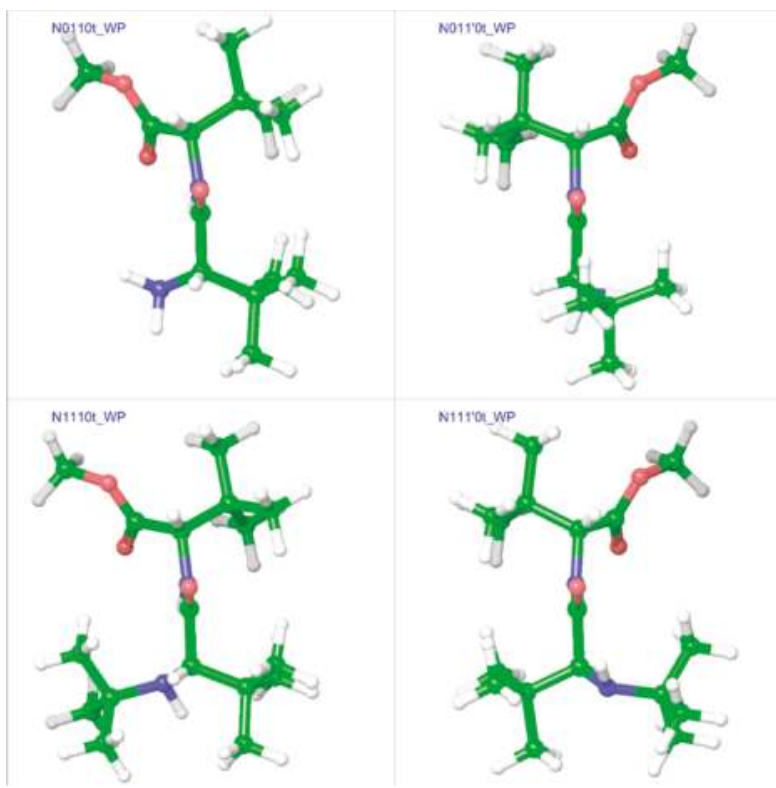

Figure 8. Comparison of minimum energy geometries of N0110, N011' $0, \mathrm{~N} 1110$, and $\mathrm{N}_{111}{ }^{\prime} 0$ in the water phase. The " $\mathrm{t}$ " after the compound name indicates the "trans" isomer. 


\subsection{Cis Geometries}

In line with the trans isomers, the minimum energy geometries of the cis isomers of the compounds in both gas and water phases showed a preference for the extended form at unsubstituted $\alpha$-carbons, but also showed folding at substituted $\alpha$-carbons (Figures 9 and 10). With both $\alpha$-carbons in proximity of each other in the cis-geometries, the impact of steric bulk was evident from the strained geometries. For example, compounds N0010, N0110, and N1110 in the gas phase show similar chain-folding, but the dihedral $\Phi$ for the C-terminal residue shows dramatic changes, while the tert-butyl groups on both $\alpha$-carbons are also forced to come closer (Figure 11). With the tert-butyl group only on the C-terminal $\alpha$-carbon, the dihedral $\Phi$ for N0010 stands at $-115^{\circ}$, which narrows sharply to $-81^{\circ}$ with the addition of a tert-butyl group at the $\mathrm{N}$-terminal $\alpha$-carbon, as both tert-butyl groups try to stay apart ( $2.82 \AA$ ) by pushing the amino and ester moieties towards the other side. However, the repulsion due to another tert-butyl group on the amino nitrogen in N1110 counteracts this and broadens the $\Phi$ to $-87^{\circ}$, in turn "squeezing" the tert-butyl groups on both $\alpha$-carbons even closer ( $2.49 \AA$ ).

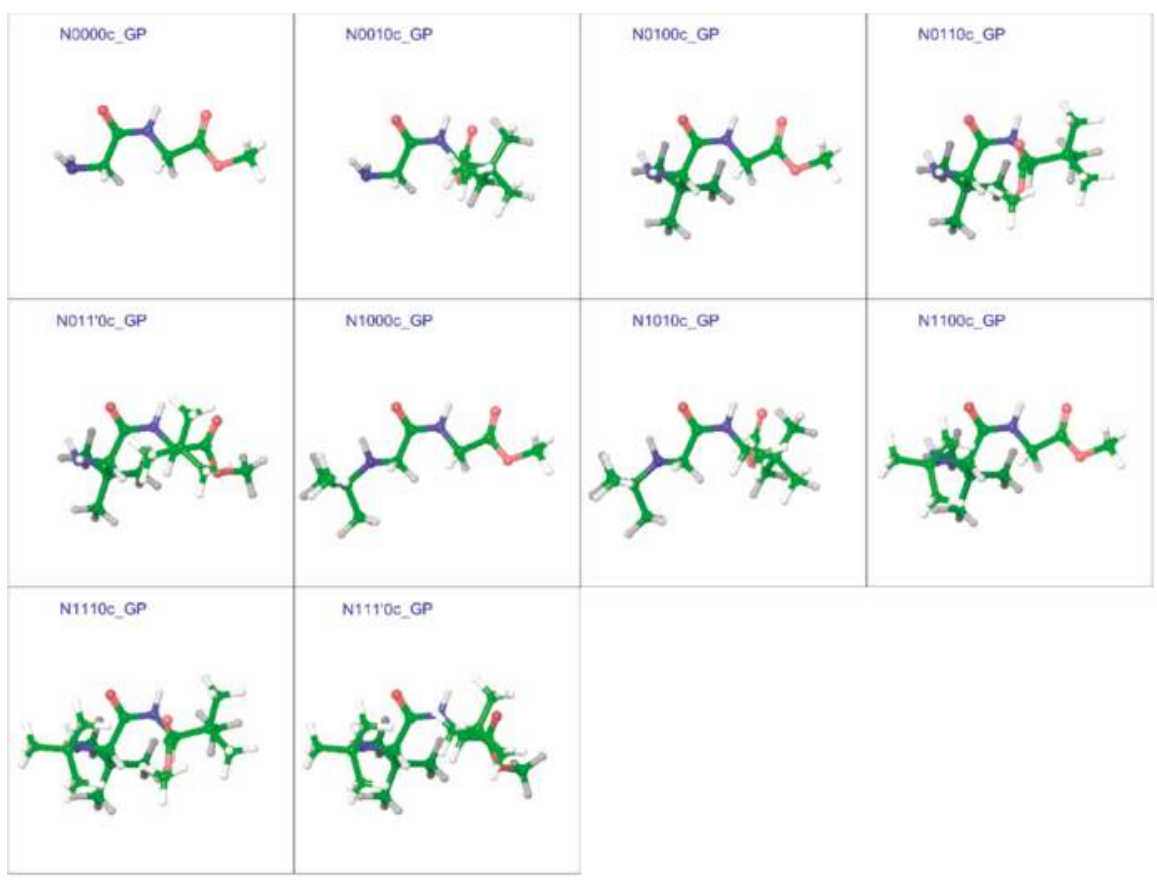

Figure 9. Optimized minimum energy geometries of the cis isomer of the substituted GGMe derivatives in the gas phase; all geometries are aligned at the amide moiety. The " $\mathrm{c}$ " after the compound name indicates the "cis" isomer. 


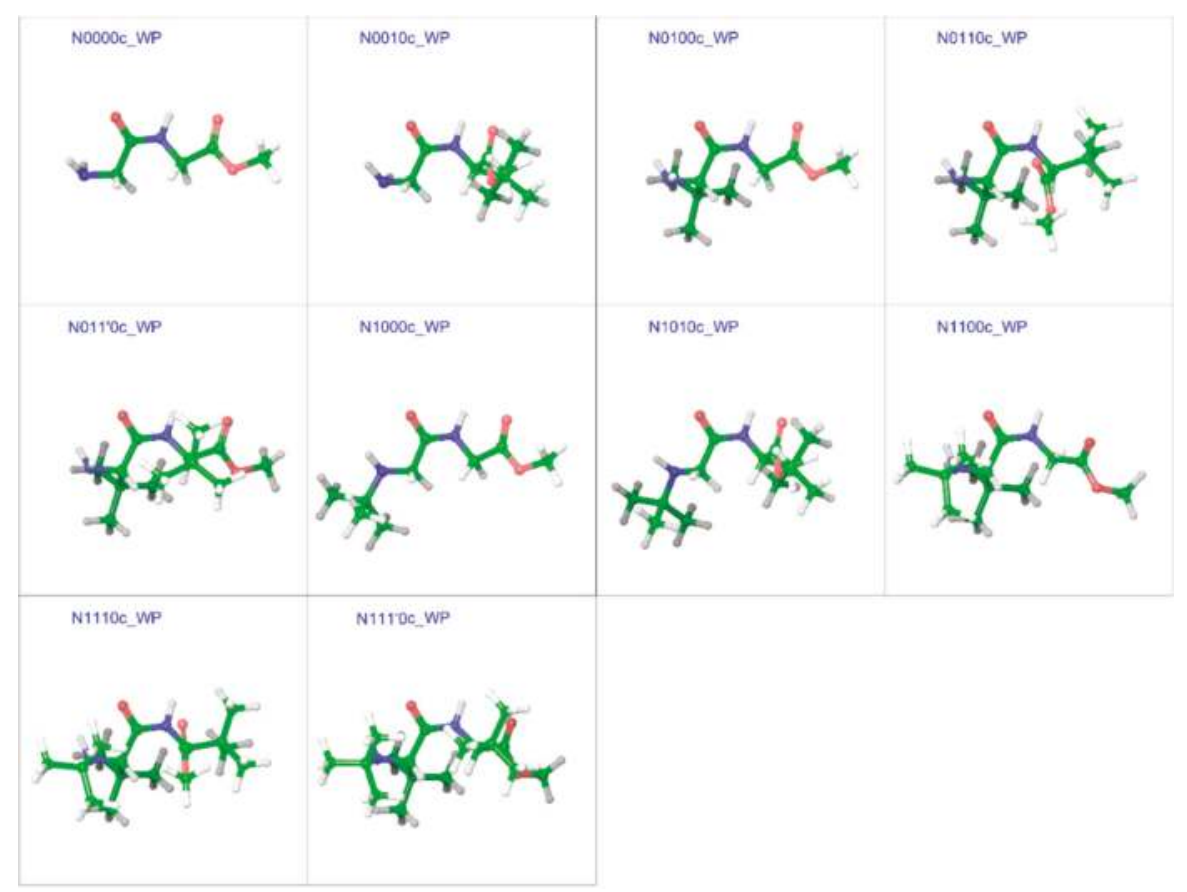

Figure 10. Optimized minimum energy geometries of the cis isomers of the substituted GGMe derivatives in the water dielectric phase; all geometries are aligned at the amide moiety. The " $c$ " after the compound name indicates the "cis" isomer.
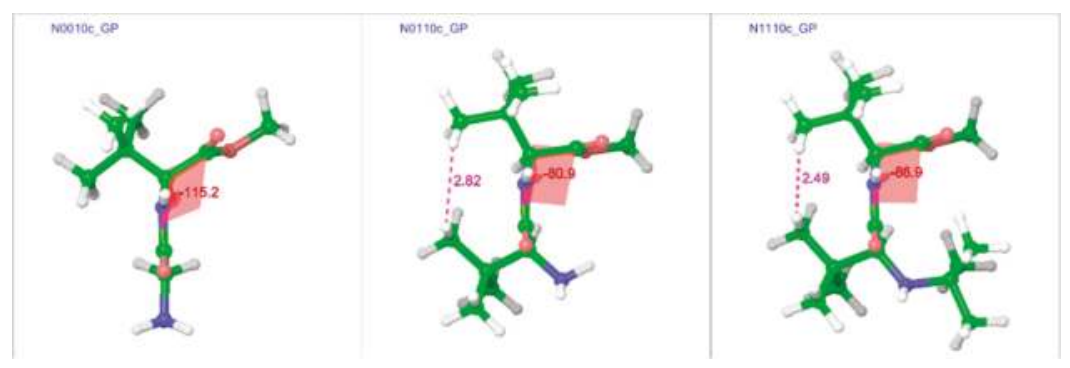

Figure 11. Comparison of cis geometries of N0010, N0110, and N1110 in the gas phase shows increasing strain in the geometries with the successive addition of tert-butyl groups. The " $\mathrm{c}$ " after the compound name indicates the "cis" isomer.

\subsubsection{The Relative Stabilities of Cis vs. Trans Isomers}

Tables 7 and 8 describe the relative energies of the minimum energy cis geometries in gas and water phases, respectively, along with the corresponding Gibbs free energy change estimates. Interestingly, the relative energy values of the minimum energy geometries of most cis isomers (compared to the minimum energy geometries of the trans isomers) were found to be higher in the gas phase than in the water phase (Figure 12). This may be attributed partially to the fact that the trans isomers in the water phase already have much higher energy values than the corresponding gas-phase structures, as revealed in steric-factor calculations using the additivity principle for the trans isomers. Furthermore, the solvation energy values for most cis isomers are higher (i.e., more negative) than corresponding trans isomers by $2-3 \mathrm{kcal} \mathrm{mol}^{-1}$. This indicates better stabilization/solvation of the cis isomers than 
the trans isomers in the water phase, which may, in turn, be attributed to the higher dipole moment of cis isomers compared to trans isomers, as is evident from Figure 13.

Table 7. Dihedral angles (in degree) and relative energies of minimum energy cis isomers in the gas phase.

\begin{tabular}{ccccccc}
\hline Compound $^{\mathbf{a}}$ & $\boldsymbol{\psi}^{\mathbf{N}}$ & $\boldsymbol{\omega}$ & $\boldsymbol{\varphi}^{\mathrm{C}}$ & $\psi^{\mathrm{C}}$ & $\boldsymbol{\Delta} \mathbf{E}^{\mathbf{b}}$ & $\Delta \mathbf{G}^{\mathbf{c}}$ \\
\hline N0000c & 179.9 & 0.1 & -179.9 & 179.8 & 4.63 & 4.92 \\
N0010c & -176.7 & -6.1 & -115.2 & 132.8 & 5.23 & 5.14 \\
N0100c & 130.7 & -2.4 & -178.5 & -179.3 & 5.12 & 4.92 \\
N0110c & 130.0 & -8.5 & -80.9 & 131.9 & 6.17 & 6.07 \\
N011'0c & 131.2 & 0.0 & 127.3 & -136.5 & 4.96 & 5.18 \\
N1000c & -162.2 & 2.1 & -177.6 & 178.5 & 5.02 & 5.77 \\
N1010c & -158.2 & -5.1 & -121.5 & 135.7 & 5.67 & 6.11 \\
N1100c & 137.5 & -6.4 & -175.1 & -178.3 & 5.17 & 5.05 \\
N1110c & 138.9 & -3.5 & -86.9 & 132.0 & 7.52 & 7.71 \\
N111'0c & 140.4 & 6.9 & 104.4 & -143.9 & 7.52 & 7.61 \\
\hline
\end{tabular}

${ }^{a}$ The " $c$ " after the compound name indicates the "cis" isomer. ${ }^{b}$ Gas-phase energy relative to the minimum energy trans geometry, calculated in $\mathrm{kcal} \mathrm{mol}^{-1}$ at the B3LYP/6-311++G(3df,3pd) level. ${ }^{\mathrm{c}}$ Gibbs free energy change at $298.15 \mathrm{~K}$ relative to minimum energy trans geometry, calculated in $\mathrm{kcal} \mathrm{mol}^{-1}$ at the $\mathrm{B} 3 \mathrm{LYP} / 6-31++\mathrm{G}^{* *}$ level.

Table 8. Dihedral angles (in degree) and relative energies of minimum energy cis-isomers in the water dielectric phase.

\begin{tabular}{cccccccc}
\hline Compound $^{\mathbf{a}}$ & Solvation Energy $\left(\mathbf{k c a l ~ m o l}^{-\mathbf{1}}\right)$ & $\boldsymbol{\varphi}^{\mathbf{N}}$ & $\boldsymbol{\omega}$ & $\boldsymbol{\varphi}^{\mathrm{C}}$ & $\boldsymbol{\psi}^{\mathrm{C}}$ & $\Delta \mathbf{E}^{\mathbf{b}}$ & $\boldsymbol{\Delta G}^{\mathbf{c}}$ \\
\hline N0000c & -19.43 & 179.5 & 0.1 & -179.6 & 179.7 & 2.03 & 2.1 \\
N0010c & -17.85 & -163.8 & -0.6 & -129.8 & 144.4 & 2.97 & 2.9 \\
N0100c & -16.88 & 127.5 & -2.1 & -176.4 & -177.4 & 2.11 & 2.3 \\
N0110c & -15.67 & 128.2 & 4.3 & -80.8 & 143.6 & 1.38 & 1.7 \\
N011'0c & -14.7 & 130.7 & 8.3 & 133.4 & -141.9 & 2.80 & 2.4 \\
N1000c & -19.86 & -174.0 & 0.7 & -167.2 & 178.3 & 2.79 & 2.9 \\
N1010c & -18.63 & -159.0 & 0.0 & -128.3 & 143.1 & 3.34 & 3.1 \\
N1100c & -14.35 & 140.1 & 0.7 & 113.8 & -163.8 & 3.92 & 3.7 \\
N1110c & -11.87 & 134.6 & -5.4 & -94.3 & 138.8 & 7.66 & 8.1 \\
N111'0c & -11.76 & 141.2 & 9.5 & 109.1 & -147.5 & 4.86 & 4.94 \\
\hline
\end{tabular}

a The "c" after the compound name indicates the "cis" isomer. ${ }^{b}$ Water phase energy relative to the minimum energy trans geometry, calculated in $\mathrm{kcal} \mathrm{mol}^{-1}$ at the B3LYP/6-311++G(3df,3pd) level. ${ }^{c}$ Gibbs free energy change at $298.15 \mathrm{~K}$ relative to minimum energy trans geometry, calculated in $\mathrm{kcal} \mathrm{mol}^{-1}$ at the B3LYP/6-31++G ** level.

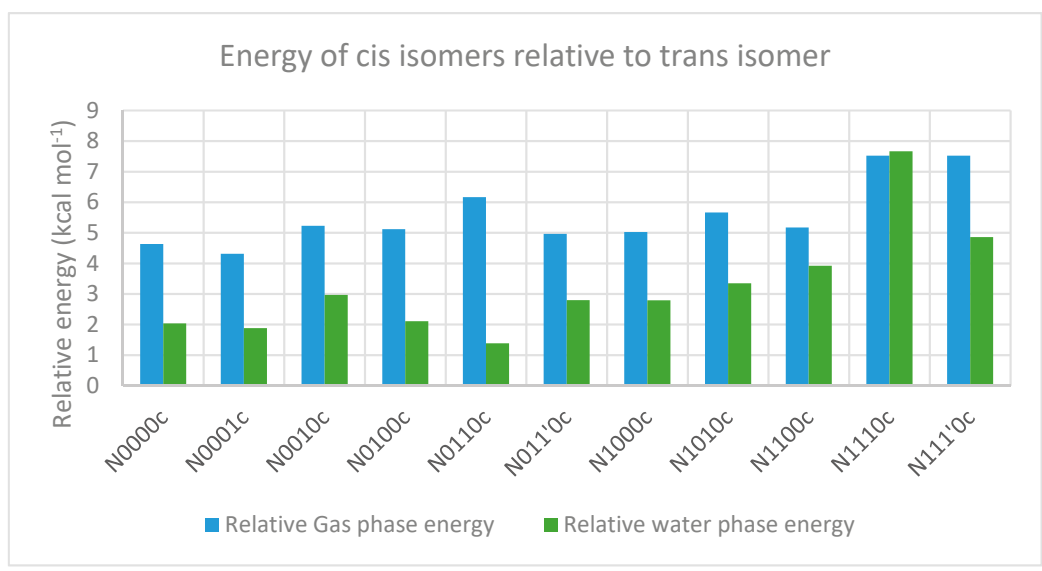

Figure 12. Energies of minimum-energy geometries of cis isomers relative to that of trans-isomers in the gas phase (blue bars) and the water phase (green bars). The " $\mathrm{c}$ " after the compound name indicates the "cis" isomer. 


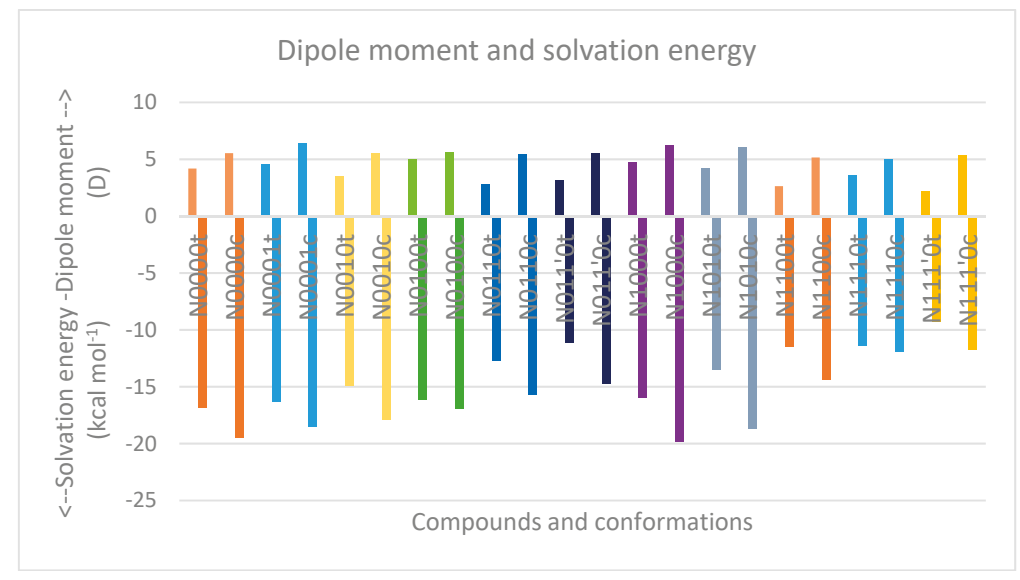

Figure 13. Comparison of the dipole moment and solvation energy for trans and cis isomers (denoted by the " $\mathrm{t}$ " and " $\mathrm{c}$ " after the compound names, respectively).

\subsubsection{The Effect of Bulk on Cis Isomers}

Tables 9 and 10 describe the calculation of steric effects on cis-isomers based on the additivity principle in the gas and water phases respectively, which show a trend similar to that for the trans-isomers (Figure 14), as discussed in Section 2.2.

Table 9. Steric-factor effect on the cis-isomer based on the additivity principle in the gas phase.

\begin{tabular}{|c|c|c|c|c|c|}
\hline$\underset{\mathrm{a}}{\text { Compound }}$ & $\begin{array}{c}{ }^{\text {opt }} \mathrm{E} \\
\mathrm{kcal} \mathrm{mol}^{-1}\end{array}$ & $\begin{array}{l}\text { No. of } t \text {-Bu on } \\
\mathrm{sp}^{3} \text { Nitrogen }\end{array}$ & $\begin{array}{l}\text { No. of } t \text {-Bu on } \\
\mathrm{sp}^{3} \text { Carbon }\end{array}$ & $\begin{array}{c}{ }^{\text {Add }} \mathrm{E} \\
\mathrm{kcal} \mathrm{mol}^{-1}\end{array}$ & $\begin{array}{c}{ }^{\text {st }} \mathrm{E} \\
{\text { kcal } \mathrm{mol}^{-1}}^{-1}\end{array}$ \\
\hline N0000c & $-333,801.441$ & & & $-333,801.441$ & 0 \\
\hline N0010c & $-432,511.233$ & & 1 & $-432,513.575$ & 2.342 \\
\hline N0100c & $-432,510.785$ & & 1 & $-432,513.575$ & 2.79 \\
\hline N0110c & $-531,219.543$ & & 2 & $-531,225.709$ & 6.166 \\
\hline N011'0c & $-531,220.53$ & & 2 & $-531,225.709$ & 5.179 \\
\hline N1000c & $-432,509.352$ & 1 & & $-432,510.572$ & 1.22 \\
\hline N1010c & $-531,218.91$ & 1 & 1 & $-531,222.706$ & 3.796 \\
\hline N1100c & $-531,217.348$ & 1 & 1 & $-531,222.706$ & 5.358 \\
\hline N1110c & $-629,924.792$ & 1 & 2 & $-629,934.84$ & 10.048 \\
\hline $\mathrm{N} 111^{\prime} 0 \mathrm{c}$ & $-629,924.4$ & 1 & 2 & $-629,934.84$ & 10.44 \\
\hline
\end{tabular}

a The "c" after the compound name indicates the "cis" isomer.

Table 10. Steric-factor effect on the cis-isomer based on the additivity principle in the water phase.

\begin{tabular}{|c|c|c|c|c|c|}
\hline$\underset{\mathrm{a}}{\text { Compound }}$ & $\begin{array}{c}{ }^{o p t} \mathrm{E} \\
\mathrm{kcal} \mathrm{mol}^{-1}\end{array}$ & $\begin{array}{l}\text { No. of } t \text {-Bu on } \\
\mathrm{sp}^{3} \text { Nitrogen }\end{array}$ & $\begin{array}{l}\text { No. of } t \text {-Bu on } \\
\mathrm{sp}^{3} \text { Carbon }\end{array}$ & $\begin{array}{c}{ }_{\mathrm{Add}}^{\mathrm{Ad}} \\
\mathrm{kcal} \mathrm{mol}^{-1}\end{array}$ & $\begin{array}{c}{ }^{\text {st }} \mathrm{E} \\
\mathrm{kcal}^{\mathrm{mol}}{ }^{-1}\end{array}$ \\
\hline N0000c & $-333,819.556$ & & & $-333,819.556$ & 0 \\
\hline N0010c & $-432,526.761$ & & 1 & $-432,531.518$ & 4.757 \\
\hline N0100c & $-432,526.055$ & & 1 & $-432,531.518$ & 5.463 \\
\hline N0110c & $-531,233.207$ & & 2 & $-531,243.48$ & 10.273 \\
\hline N011'0c & $-531,232.806$ & & 2 & $-531,243.48$ & 10.674 \\
\hline N1000c & $-432,525.775$ & 1 & & $-432,527.202$ & 1.427 \\
\hline N1010c & $-531,232.932$ & 1 & 1 & $-531,239.164$ & 6.232 \\
\hline N1100c & $-531,228.49$ & 1 & 1 & $-531,239.164$ & 10.674 \\
\hline N1110c & $-629,934.673$ & 1 & 2 & $-629,951.126$ & 16.453 \\
\hline $\mathrm{N} 111^{\prime} 0 \mathrm{c}$ & $-629,934.711$ & 1 & 2 & $-629,951.126$ & 16.415 \\
\hline
\end{tabular}

a The "c" after the compound name indicates the "cis" isomer. 


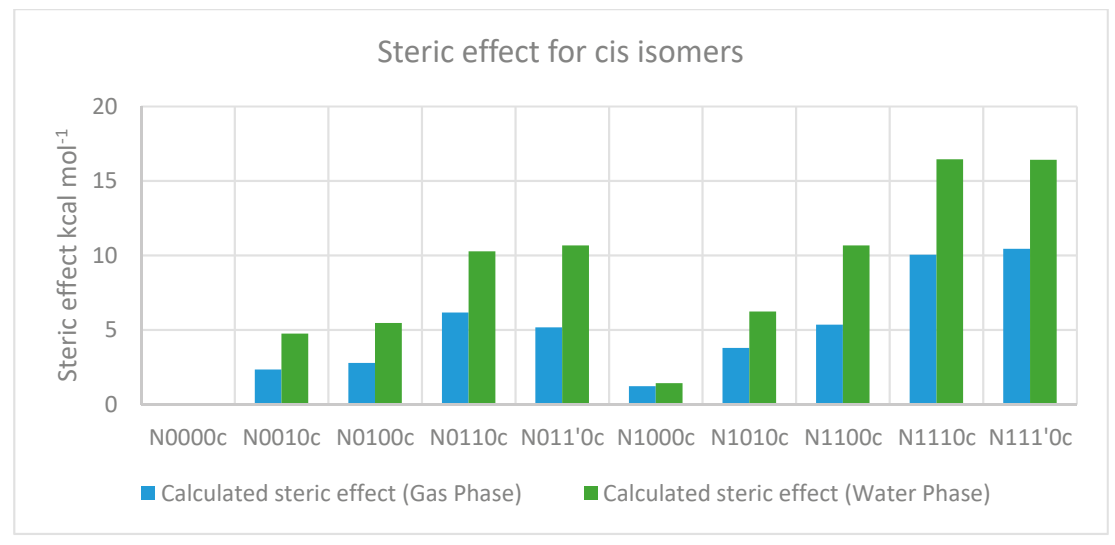

Figure 14. Steric effect for cis-isomers in the gas and water phases using the additivity principle. The "c" after the compound name indicates the "cis" isomer.

\subsection{Cis/Trans Isomerization Barrier}

The calculation of energy barriers for substituted derivatives of GGMe is a complex task. As we have previously reported [7], the existence of multiple rotamers makes it difficult to identify every possible transition state. In the case of GGMe, however, the lack of substitutions on $\alpha$-carbons still significantly simplifies the calculation, as the isomerization study along the rotation coordinate $\omega$ between $180^{\circ}$ and $0^{\circ}$ suffices due to the symmetry. This becomes more complex with the introduction of substitutions and stereospecificity at $\alpha$-carbons, which introduces asymmetry along the rotation coordinates, such as the $\omega$-dihedral, resulting in different energy barriers for rotation along the positive vs. negative directions of rotation, with the simultaneous existence of multiple rotamers. Therefore, the number of possible transition-state conformations increases enormously.

In order to simplify this complex problem, it was necessary to use a specific method to enable comparison among same types of geometries for different compounds. Such a comparison can provide information about the overall effect of substitution patterns, if not for specific conformers. From the examples of $N$-methylacetamide and GGMe [7], it became evident that the energy-barrier geometries obtained with stepwise RCS would provide a reasonably accurate estimation of transition states and corresponding energies. Therefore, we decided to find energy-barrier geometries (EBGs) to estimate energy-barrier values. For compounds without substitutions on the $\alpha$-carbon, the calculation in one direction (between $0^{\circ}$ and $180^{\circ}$, or between $180^{\circ}\left(=-180^{\circ}\right)$ and $360^{\circ}\left(=0^{\circ}\right)$ ) was sufficient. However, for other substituted compounds, calculation in both directions was carried out. Correspondingly, from the trans isomers, syn EBGs were obtained close to $\omega= \pm 60^{\circ}$ and from the cis isomers, anti EBGs were obtained close to $\omega= \pm 120^{\circ}$. Figures 15 and 16 represent the most stable energy barrier geometry for each compound in the gas phase and water phase, respectively.

Tables 11 and 12 describe energy-barrier values corresponding to syn/anti EBGs in the gas phase and water phase, respectively. It is evident that the energy-barrier value strongly depends on the direction of rotation for compounds with substitution on chiral $\alpha$-carbons, and in such cases, the energy difference between the same types of energy-barrier geometries in two different directions of rotation can be significant, from 1 to $6 \mathrm{kcal} \mathrm{mol}^{-1}$. 


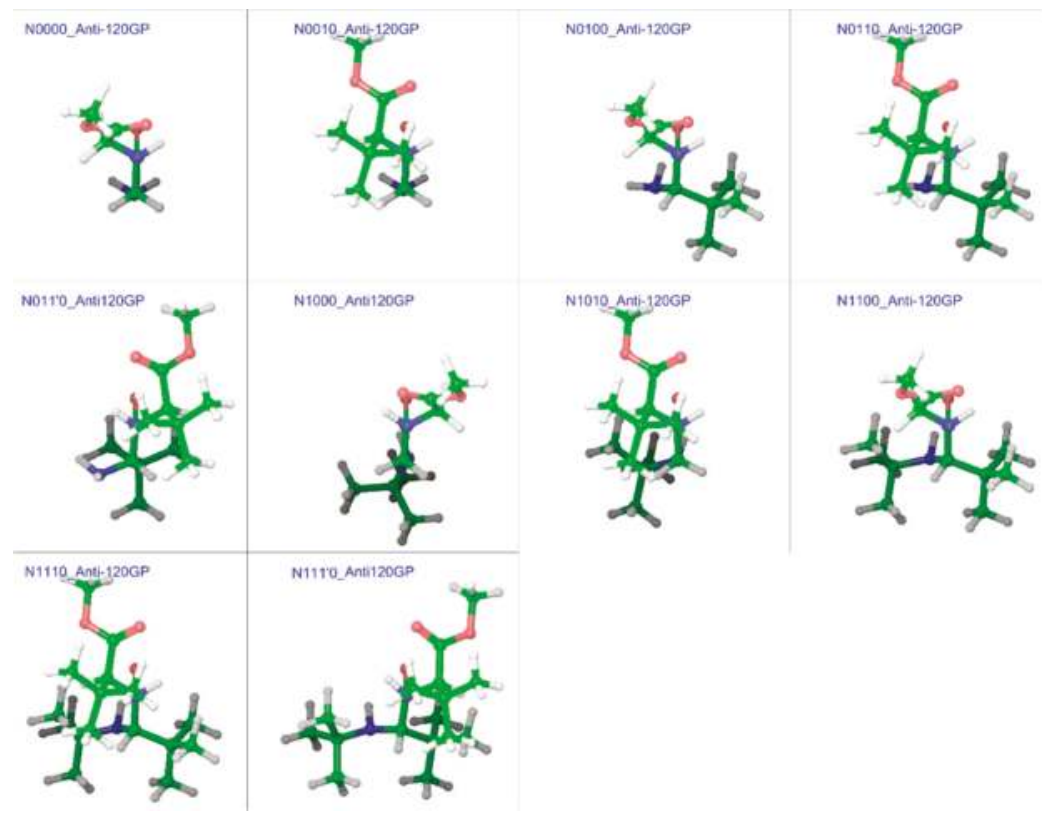

Figure 15. Cis/trans isomerization energy barrier geometries of substituted GGMe derivatives in the gas phase; all geometries are aligned at the amide moiety.

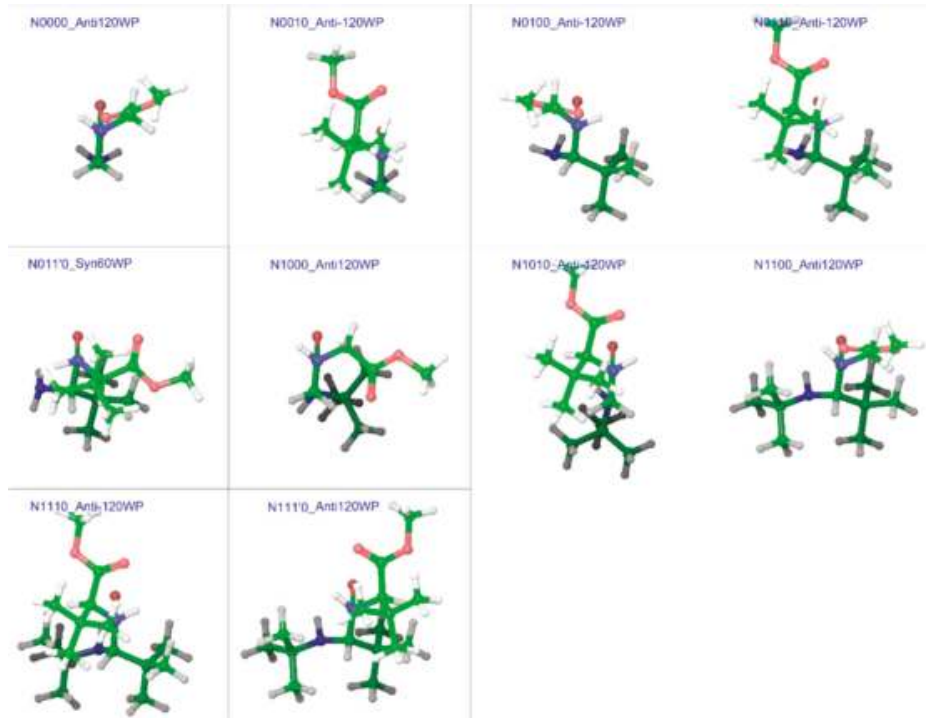

Figure 16. Cis/trans isomerization energy barrier geometries of substituted GGMe derivatives in the water phase; all geometries are aligned at the amide moiety. 
Table 11. Energy-barrier values corresponding to syn and anti EBGs generated from optimized minimum energy trans and cis geometries, respectively, in the gas phase.

\begin{tabular}{|c|c|c|c|c|c|c|c|c|c|}
\hline \multirow{2}{*}{ Compound } & \multicolumn{2}{|c|}{ Anti120GP } & \multicolumn{2}{|c|}{ Anti-120GP } & \multicolumn{2}{|c|}{ Syn60GP } & \multicolumn{2}{|c|}{ Syn-60GP } & \multirow{2}{*}{$\Delta \mathrm{G}_{\mathrm{ef}}$} \\
\hline & $\Delta \mathrm{E}^{\mathrm{a}}$ & $\Delta \mathrm{G}^{\mathbf{b}}$ & $\Delta \mathrm{E}^{\mathrm{a}}$ & $\Delta \mathrm{G}^{\mathrm{b}}$ & $\Delta \mathrm{E}^{\mathrm{a}}$ & $\Delta \mathrm{G}^{\mathrm{b}}$ & $\Delta \mathrm{E}^{\mathrm{a}}$ & $\Delta \mathrm{G}^{\mathrm{b}}$ & \\
\hline N0000 & 19.53 & 13.70 & 19.53 & 13.72 & 25.46 & 19.91 & 25.26 & 19.84 & 13.70 \\
\hline N0010 & 24.22 & 18.34 & 19.34 & 11.93 & 25.22 & 17.86 & 27.99 & 20.23 & 11.93 \\
\hline N0100 & 20.96 & 13.40 & 20.51 & 12.43 & 26.30 & 18.63 & 25.26 & 20.38 & 12.43 \\
\hline N0110 & 25.64 & 18.72 & 19.76 & 12.34 & 23.98 & 17.63 & 28.18 & 22.10 & 12.34 \\
\hline No11'0 & 19.99 & 12.91 & 24.92 & 17.54 & 27.33 & 19.06 & 29.92 & 22.79 & 12.91 \\
\hline N1000 & 19.55 & 11.03 & 19.82 & 11.09 & $\mathrm{ND}^{\mathrm{c}}$ & ND & 25.09 & 19.31 & 11.03 \\
\hline N1010 & 24.33 & 17.92 & 20.10 & 14.82 & 24.95 & 17.65 & 27.80 & 22.20 & 14.82 \\
\hline N1100 & 21.54 & 12.90 & 20.59 & 13.14 & 26.61 & 19.13 & 25.40 & 17.49 & 12.90 \\
\hline N1110 & 26.08 & 17.27 & 20.15 & 11.17 & 28.29 & 20.62 & 34.39 & 28.17 & 11.17 \\
\hline $\mathrm{N} 111^{\prime} 0$ & 21.43 & 12.59 & 26.18 & 17.45 & 30.79 & 22.72 & 23.68 & 14.51 & 12.59 \\
\hline
\end{tabular}

Assuming the minimum-value energy barrier $\left(\mathrm{G}_{\mathrm{eff}}\right)$ to be the "real" barrier, it appears that bulky substitution patterns have no significant effect on the energy barrier values in the gas phase, as even the most substituted compounds N1110 and N111'0 have energy barriers similar to the unsubstituted N0000 (GGMe). However, the effect of stereospecific bulky substitution patterns becomes significant in the water phase, and can show an increase in the energy barrier by up to $4-5 \mathrm{kcal} \mathrm{mol}^{-1}$. Diastereomers N0110 and N011'0 (with S- and R- configuation on the C-terminal $\alpha$-carbon) show a difference of $\sim 5 \mathrm{kcal} \mathrm{mol}^{-1}$. A similar difference is seen also in the case of the other pairs of diastereomers, N1110 and N111'0. Thus, the stereochemistry of substitutions has a profound effect on the energy-barrier heights and can provide an opportunity to control the flexibility selectively. Interestingly, a syn EBG was found to be more stable than both anti EBGs in the case of compound N011'0 in the water phase.

Table 12. Energy-barrier values corresponding to syn and anti EBGs generated from the optimized minimum-energy trans and cis geometries, respectively, in the water phase.

\begin{tabular}{cccccccccc}
\hline \multirow{2}{*}{ Compound } & \multicolumn{2}{c}{ Anti120WP } & \multicolumn{2}{c}{ Anti-120WP } & \multicolumn{2}{c}{ Syn60WP } & \multicolumn{2}{c}{ Syn-60WP } & \multirow{2}{*}{$\boldsymbol{\Delta}$} \\
\cline { 2 - 7 } & $\mathbf{\Delta} \mathbf{E}^{\mathbf{a}}$ & $\boldsymbol{\Delta} \mathbf{G}^{\mathbf{b}}$ & $\boldsymbol{\Delta} \mathbf{E}^{\mathbf{a}}$ & $\boldsymbol{\Delta} \mathbf{G}^{\mathbf{b}}$ & $\boldsymbol{\Delta} \mathbf{E}^{\mathbf{a}}$ & $\boldsymbol{\Delta} \mathbf{G}^{\mathbf{b}}$ & $\boldsymbol{\Delta} \mathbf{E}^{\mathbf{a}}$ & $\Delta \mathbf{G}^{\mathbf{b}}$ & \\
\hline N0000 & 19.18 & 13.82 & 19.18 & 13.74 & 24.29 & 20.07 & $\mathrm{ND}^{\mathrm{c}}$ & $\mathrm{ND}$ & 13.74 \\
N0010 & 25.40 & 20.48 & 19.03 & 13.67 & 29.42 & 23.23 & 24.23 & 20.47 & 13.67 \\
N0100 & 22.45 & 18.28 & 20.66 & 16.24 & 23.31 & 18.6 & 26.09 & 19.91 & 16.24 \\
N0110 & 25.13 & 21.06 & 19.32 & 13.46 & 22.23 & 19.06 & 20.47 & 16.61 & 13.46 \\
N011'0 & 26.44 & 20.83 & 26.55 & 20.67 & 23.39 & 18.55 & 26.51 & 21.71 & 18.55 \\
N1000 & 22.30 & 16.89 & 22.35 & 16.85 & ND & ND & 23.86 & 19.40 & 16.85 \\
N1010 & 26.60 & 20.05 & 19.00 & 12.72 & 29.60 & 23.96 & 24.29 & 19.71 & 12.72 \\
N1100 & 22.54 & 14.06 & 23.71 & 16.92 & 26.50 & 19.28 & 23.04 & 16.86 & 14.06 \\
N1110 & 29.46 & 21.96 & 24.53 & 19.22 & 29.24 & 24.21 & 30.37 & 23.98 & 19.22 \\
N111'0 & 23.15 & 14.50 & 27.71 & 21.34 & 26.65 & 19.74 & 23.78 & 17.50 & 14.50 \\
\hline
\end{tabular}

a Water-phase energy relative to the minimum-energy trans geometry, calculated in $\mathrm{kcal} \mathrm{mol}^{-1}$ at the B3LYP/6-311++G(3df,3pd) level. ${ }^{b}$ Gibbs free energy at $298.15 \mathrm{~K}$ relative to the minimum energy trans geometry, calculated in $\mathrm{kcal} \mathrm{mol}^{-1}$ at the B3LYP $/ 6-31++\mathrm{G}^{* *}$ level. ${ }^{\mathrm{c}} \mathrm{ND}$ : Not determined, assumed similar geometry as for the rotation in the opposite direction due to symmetry.

Overall, bulky substitutions were found to affect cis/trans isomerization in two ways: by making the cis isomer more unstable and thereby shifting the equilibrium towards the trans isomer, and by increasing the reaction barrier height and thereby decreasing the reaction rate. As both effects discourage trans to cis isomerization, compounds with bulky substitutions are expected to take longer and/or require higher temperatures for the same effect. Moreover, as trans to cis isomerization 
is an essential step in the cyclization of dipeptides to piperazine-2,5-diones, it is certain that slow isomerization would also result in decelerated dipeptide cyclization.

\section{Methods}

\subsection{Generation of Structures}

The relevant structures were initially generated as 2D trans isomers using Marvin Sketch 15.6.8, 2015, (ChemAxon, Budapest, Hungary), and were imported to the Maestro [39] module of the Schrodinger suite (Schrödinger, LLC. New York, NY, USA), from which all further studies were performed. The cis geometries were generated by torsional adjustment of the $\omega$ dihedral.

\subsection{Conformational Search}

All trans and cis geometries were subjected to the MacroModel [40] conformational search algorithm, using the MMFFs force-field. From the conformational search output, the geometries within a potential energy of up to $21 \mathrm{~kJ} / \mathrm{mol}$ over the minimum energy geometry were kept.

All further studies were performed using the Jaguar [41,42] program of the Schrodinger suite.

\subsection{Geometric Optimization}

The geometries kept after the conformational search were subjected to geometric optimization at the B3LYP /6-31++ $\mathrm{G}^{* *}$ level with maximum grid density and the "accurate" accuracy level of SCF. Frequency calculation studies were carried out to confirm zero imaginary frequencies for an optimized geometry. For each compound, the most stable geometry (i.e., with the minimum energy) was chosen for further study. Calculations for the water dielectric continuum (water phase) were performed using the same parameters and the additional Poisson Boltzmann Finite (PBF) solvent model. The Cartesian coordinates of the optimized geometries are provided in the supplementary information.

\subsection{Relaxed Coordinate Scan (RCS)}

The optimized minimum energy cis and trans geometries of all compounds were subjected to relaxed coordinate scans (RCS), on the $\omega$ dihedral coordinate at the B3LYP/6-31++ $\mathrm{G}^{* *}$ level with maximum grid density and the "accurate" accuracy level of SCF. The optimized geometry at each step was used to generate the starting geometry for the next step. For water-phase calculations, the Poisson Boltzmann Finite (PBF) solvent model was used. Each RCS was performed in three rounds, with a $15^{\circ}$ step-size for the first round and a $2^{\circ}$ step-size (near the rotation barriers) for the second round. The step-size for the third round (closest to the rotation barrier) was kept at $0.125^{\circ}$ and $0.250^{\circ}$ for the gas and water phase calculations, respectively. Except for compounds with only hydrogens on both chiral $\alpha$-carbons, the relaxed coordinate scan was performed in both directions (positive and negative direction, clockwise and anticlockwise). The syn and anti energy-barrier geometries (EBG) were identified and used as plausible energy-barrier geometries. (Henceforth, EBGs refers to the energy-barrier geometries obtained from RCS). The Cartesian coordinates of the EBGs are provided in the supplementary information.

\subsection{Single-Point Energy Calculations}

Accurate single-point energies were calculated for all optimized and reaction-barrier geometries at the B3LYP/6-311++G(3df,3pd) level with maximum grid density and the "accurate" accuracy level of SCF. Vibrational analyses were carried out at the B3LYP / $6-31++G^{* *}$ level, and the free energy values obtained for $298.15 \mathrm{~K}$ were used to calculate relative Gibbs free energies. For water phase calculations, the Poisson Boltzmann Finite (PBF) solvent model was used. 


\section{Conclusions}

In this work, we conducted a systematic theoretical study of the effects of steric bulk on the relative stabilities with varied substitution patterns on a peptidic scaffold using density functional methods. We used model compounds based on the simple glycylglycine methyl ester peptidic scaffold with patterns of stereospecific substitutions of the tert-butyl group to represent steric bulk. The study establishes how bulky substitutions significantly destabilize the cis isomers and also increase the energy barrier for cis/trans isomerization (especially in the water phase). These effects synergistically discourage the cis/trans isomerization of secondary amides. Therefore, secondary amides with bulky and more substitutions are much less likely to undergo cis/trans isomerization than the unsubstituted or less substituted second amides. Because cis/trans isomerization is an important step in the synthesis of piperazine-2,5-diones via cyclization of dipeptide esters, the rate of reaction for highly substituted dipeptide esters can be expected to be much slower than those with less substitutions. Moreover, for medicinal chemistry purposes, such highly substituted peptidomimetics can be expected to possess a very rigid peptide backbone.

Supplementary Materials: Supplementary Materials are available online.

Author Contributions: Conceptualization, B.S.T.; Formal analysis, B.S.T. and R.A.E.; Funding acquisition, J.S.M.S.; Investigation, B.S.T.; Methodology, B.S.T.; Project administration, R.A.E.; Supervision, J.S.M.S. and R.A.E.; Visualization, B.S.T. and R.A.E.; Writing-original draft, B.S.T.; Writing-review \& editing, J.S.M.S. and R.A.E.

Funding: This research received no external funding.

Acknowledgments: The authors thank Department of Chemistry, UiT The Arctic University of Norway for supporting this research work. The publication charges for this article have been funded by a grant from the publication fund of UiT The Arctic University of Norway. This paper is taken in part from the Ph.D. thesis of B.S.T.

Conflicts of Interest: The authors declare no conflict of interest.

\section{References}

1. LaPlanche, L.A.; Rogers, M.T. Cis and trans Configurations of the Peptide Bond in N-Monosubstituted Amides by Nuclear Magnetic Resonance. J. Am. Chem. Soc. 1964, 86, 337-341. [CrossRef]

2. Ramachandran, G.N.; Mitra, A.K. An explanation for the rare occurrence of cis peptide units in proteins and polypeptides. J. Mol. Biol. 1976, 107, 85-92. [CrossRef]

3. Ramachandran, G.N.; Sasisekharan, V. Conformation of polypeptides and proteins. Adv. Protein Chem. 1968, 23, 283-438. [PubMed]

4. Liu, C.; Szostak, M. Twisted Amides: From Obscurity to Broadly Useful Transition-Metal-Catalyzed Reactions by N-C Amide Bond Activation. Chem. Eur. J. 2017, 23, 7157-7173. [CrossRef] [PubMed]

5. Mock, W.L. Torsional strain considerations in the mechanism of the proteolytic enzymes, with particular application to carboxypeptidase A. Bioorg. Chem. 1975, 4, 270-278. [CrossRef]

6. Mock, W.L. Torsional-strain considerations in enzymology: Some applications to proteases and ensuing mechanistic consequences. Bioorg. Chem. 1976, 5, 403-414. [CrossRef]

7. Thakkar, B.S.; Svendsen, J.-S.M.; Engh, R.A. Cis/Trans Isomerization in Secondary Amides: Reaction Paths, Nitrogen Inversion, and Relevance to Peptidic Systems. J. Phys. Chem. A 2017, 121, 6830-6837. [CrossRef] [PubMed]

8. Stewart, D.E.; Sarkar, A.; Wampler, J.E. Occurrence and role of cis peptide bonds in protein structures. J. Mol. Biol. 1990, 214, 253-260. [CrossRef]

9. Weiss, M.S.; Jabs, A.; Hilgenfeld, R. Peptide bonds revisited. Nat. Struct. Mol. Biol. 1998, 5, 676. [CrossRef] [PubMed]

10. Pal, D.; Chakrabarti, P. Cis peptide bonds in proteins: Residues involved, their conformations, interactions and locations. J. Mol. Biol. 1999, 294, 271-288. [CrossRef] [PubMed]

11. Tchaicheeyan, $\mathrm{O}$. Is peptide bond cis/trans isomerization a key stage in the chemo-mechanical cycle of motor proteins? FASEB J. 2004, 18, 783-789. [CrossRef] [PubMed]

12. Odefey, C.; Mayr, L.M.; Schmid, F.X. Non-prolyl cis-trans peptide bond isomerization as a rate-determining step in protein unfolding and refolding. J. Mol. Biol. 1995, 245, 69-78. [CrossRef] 
13. Vanhove, M.; Raquet, X.; Palzkill, T.; Pain, R.H.; Frère, J.-M. The rate-limiting step in the folding of the cis-Pro167Thr mutant of TEM-1 $\beta$-lactamase is the trans to cis isomerization of a non-proline peptide bond. Proteins Struct. Funct. Bioinform. 1996, 25, 104-111. [CrossRef]

14. Wheeler, K.A.; Hawkins, A.R.; Pain, R.; Virden, R. The slow step of folding of Staphylococcus aureus PC1 $\beta$-lactamase involves the collapse of a surface loop rate limited by the Trans to Cis isomerization of a non-proline peptide bond. Proteins Struct. Funct. Bioinform. 1998, 33, 550-557. [CrossRef]

15. Agarwal, P.K. Cis/trans isomerization in HIV-1 capsid protein catalyzed by cyclophilin A: Insights from computational and theoretical studies. Proteins Struct. Funct. Bioinform. 2004, 56, 449-463. [CrossRef] [PubMed]

16. Ledvina, A.R.; Chung, T.W.; Hui, R.; Coon, J.J.; Tureček, F. Cascade dissociations of peptide cation-radicals. Part 2. Infrared multiphoton dissociation and mechanistic studies of z-ions from pentapeptides. J. Am. Soc. Mass Spectrom. 2012, 23, 1351-1363. [CrossRef] [PubMed]

17. Baldoni, H.A.; Zamarbide, G.N.; Enriz, R.D.; Jauregui, E.A.; Farkas, Ö.; Perczel, A.; Salpietro, S.J.; Csizmadia, I.G. Peptide models XXIX. cis-trans Isomerism of peptide bonds: Ab initio study on small peptide model compound; the 3D-Ramachandran map of formylglycinamide. J. Mol. Struct. THEOCHEM 2000, 500, 97-111. [CrossRef]

18. Wiberg, K.B.; Rablen, P.R.; Rush, D.J.; Keith, T.A. Amides. 3. Experimental and Theoretical Studies of the Effect of the Medium on the Rotational Barriers for $N, N$-Dimethylformamide and $N, N$-Dimethylacetamide. J. Am. Chem. Soc. 1995, 117, 4261-4270. [CrossRef]

19. Lauvergnat, D.; Hiberty, P.C. Role of Conjugation in the Stabilities and Rotational Barriers of Formamide and Thioformamide. An ab Initio Valence-Bond Study. J. Am. Chem. Soc. 1997, 119, 9478-9482. [CrossRef]

20. Mantz, Y.A.; Gerard, H.; Iftimie, R.; Martyna, G.J. Ab Initio and Empirical Model MD Simulation Studies of Solvent Effects on the Properties of N-Methylacetamide along a cis-trans Isomerization Pathway. J. Phys. Chem. B 2006, 110, 13523-13538. [CrossRef] [PubMed]

21. Taha, A.N.; True, N.S. Experimental $1 \mathrm{H}$ NMR and Computational Studies of Internal Rotation of Solvated Formamide. J. Phys. Chem. A 2000, 104, 2985-2993. [CrossRef]

22. Kang, Y.K.; Park, H.S. Internal rotation about the C.-N. bond of amides. J. Mol. Struct. THEOCHEM 2004, 676, 171-176. [CrossRef]

23. Mantz, Y.A.; Branduardi, D.; Bussi, G.; Parrinello, M. Ensemble of Transition State Structures for the Cis-Trans Isomerization of N-Methylacetamide. J. Phys. Chem. B 2009, 113, 12521-12529. [CrossRef] [PubMed]

24. Thakkar, B.S.; Engh, R.A. Comparative conformational analyses and molecular dynamics studies of glycylglycine methyl ester and glycylglycine $N$-methylamide. RSC Adv. 2018, 8, 4445-4453. [CrossRef]

25. Yoder, C.H.; Gardner, R.D. Multiple-substituent parameter analysis of the effects of substituents at nitrogen on the barriers to rotation in amides. J. Org. Chem. 1981, 46, 64-66. [CrossRef]

26. Fischer, G. Chemical aspects of peptide bond isomerisation. Chem. Soc. Rev. 2000, 29, 119-127. [CrossRef]

27. Moure, A.; Sanclimens, G.; Bujons, J.; Masip, I.; Alvarez-Larena, A.; Pérez-Payá, E.; Alfonso, I.; Messeguer, A. Chemical modulation of peptoids: Synthesis and conformational studies on partially constrained derivatives. Chem.-Eur. J. 2011, 17, 7927-7939. [CrossRef] [PubMed]

28. Laursen, J.S.; Engel-Andreasen, J.; Fristrup, P.; Harris, P.; Olsen, C.A. Cis-trans amide bond rotamers in $\beta$-peptoids and peptoids: Evaluation of stereoelectronic effects in backbone and side chains. J. Am. Chem. Soc. 2013, 135, 2835-2844. [CrossRef] [PubMed]

29. Goodwin, D.; Simerska, P.; Toth, I. Peptides as therapeutics with enhanced bioactivity. Curr. Med. Chem. 2012, 19, 4451-4461. [CrossRef] [PubMed]

30. Avan, I.; Hall, C.D.; Katritzky, A.R. Peptidomimetics via modifications of amino acids and peptide bonds. Chem. Soc. Rev. 2014, 43, 3575-3594. [CrossRef] [PubMed]

31. Muller, P. Glossary of terms used in physical organic chemistry (IUPAC Recommendations 1994). Pure Appl. Chem. 2009, 66, 1077-1184. [CrossRef]

32. Hirsch, J.A. Table of Conformational Energies-1967. In Topics in Stereochemistry; Allinger, N.L., Eliel, E.L., Eds.; John Wiley \& Sons, Inc.: Manhattan, NY, USA, 1967; pp. 199-222, ISBN 978-0-470-14710-8.

33. Charton, M. Steric effects. I. Esterification and acid-catalyzed hydrolysis of esters. J. Am. Chem. Soc. 1975, 97, 1552-1556. [CrossRef] 
34. Charton, M. The upsilon steric parameter-Definition and determination. In Steric Effects in Drug Design; Topics in Current Chemistry; Springer: Berlin/Heidelberg, Germany, 1983; pp. 57-91, ISBN 978-3-540-12398-9.

35. Icli, S.; Kandil, K.A.; Thankachan, C.; Tidwell, T.T. Steric Crowding and the Reactivity of Substituted tert-Butyl Perbenzoates. Can. J. Chem. 1975, 53, 979-985. [CrossRef]

36. Marcelin, G.; Brooks, P.R. Steric hindrance in potassium atom-oriented molecule reactions. Methyl iodide and tert-butyl iodide. J. Am. Chem. Soc. 1975, 97, 1710-1715. [CrossRef]

37. Bartell, L.S.; Bradford, W.F. Molecular structures of neopentane and di-tert-butylmethane by vapor-phase electron diffraction. J. Mol. Struct. 1977, 37, 113-126. [CrossRef]

38. Toniolo, C. Intramolecularly hydrogen-bonded peptide conformations. CRC Crit. Rev. Biochem. 1980, 9, 1-44. [CrossRef] [PubMed]

39. Schrödinger Release 2016-1: Maestro; Schrödinger, LLC: New York, NY, USA, 2016.

40. Schrödinger Release 2016-1: MacroModel; Schrödinger, LLC: New York, NY, USA, 2016.

41. Bochevarov, A.D.; Harder, E.; Hughes, T.F.; Greenwood, J.R.; Braden, D.A.; Philipp, D.M.; Rinaldo, D.; Halls, M.D.; Zhang, J.; Friesner, R.A. Jaguar: A high-performance quantum chemistry software program with strengths in life and materials sciences. Int. J. Quantum Chem. 2013, 113, 2110-2142. [CrossRef]

42. Schrödinger Release 2016-1: Jaguar; Schrödinger, LLC: New York, NY, USA, 2016.

(C) 2018 by the authors. Licensee MDPI, Basel, Switzerland. This article is an open access article distributed under the terms and conditions of the Creative Commons Attribution (CC BY) license (http:/ / creativecommons.org/licenses/by/4.0/). 


\title{
Ruthenium-Based Catalytic Systems Incorporating a Labile Cyclooctadiene Ligand with $N$-Heterocyclic Carbene Precursors for the Atom-Economic Alcohol Amidation Using Amines
}

\author{
Cheng Chen ${ }^{1}$, Yang Miao ${ }^{2}$, Kimmy De Winter ${ }^{3}$, Hua-Jing Wang ${ }^{4}$, Patrick Demeyere ${ }^{3}$, \\ Ye Yuan ${ }^{1, *}$ and Francis Verpoort ${ }^{1,2,5,6, *}$ \\ 1 State Key Laboratory of Advanced Technology for Materials Synthesis and Processing, \\ Wuhan University of Technology, 122 Luoshi Road, Wuhan 430070, China; chengchen@whut.edu.cn \\ 2 School of Materials Science and Engineering, Wuhan University of Technology, 122 Luoshi Road, \\ Wuhan 430070, China; miaoyang2018@126.com \\ 3 Odisee/KU Leuven Technology Campus, Gebroeders de Smetstraat 1, 9000 Ghent, Belgium; \\ kimmydewinter@hotmail.com (K.D.W.); patrick.demeyere@odisee.be (P.D.) \\ 4 School of Chemistry, Chemical Engineering and Life Sciences, Wuhan University of Technology, \\ 122 Luoshi Road, Wuhan 430070, China; 18772101949@163.com \\ 5 National Research Tomsk Polytechnic University, Lenin Avenue 30, Tomsk 634050, Russian \\ 6 Ghent University Global Campus, 119 Songdomunhwa-Ro, Yeonsu-Gu, Incheon 21985, Korea \\ * Correspondence: fyyuanye@whut.edu.cn (Y.Y.); francis.verpoort@ghent.ac.kr (F.V.); \\ Tel.: +86-186-358-00380 (Y.Y.); +86-150-7117-2245 (F.V.)
}

Received: 29 August 2018; Accepted: 18 September 2018; Published: 20 September 2018

\begin{abstract}
Transition-metal-catalyzed amide-bond formation from alcohols and amines is an atom-economic and eco-friendly route. Herein, we identified a highly active in situ $\mathrm{N}$-heterocyclic carbene $(\mathrm{NHC})$ /ruthenium $(\mathrm{Ru})$ catalytic system for this amide synthesis. Various substrates, including sterically hindered ones, could be directly transformed into the corresponding amides with the catalyst loading as low as $0.25 \mathrm{~mol} \%$. In this system, we replaced the $p$-cymene ligand of the Ru source with a relatively labile cyclooctadiene (cod) ligand so as to more efficiently obtain the corresponding poly-carbene Ru species. Expectedly, the weaker cod ligand could be more easily substituted with multiple mono-NHC ligands. Further high-resolution mass spectrometry (HRMS) analyses revealed that two tetra-carbene complexes were probably generated from the in situ catalytic system.
\end{abstract}

Keywords: ruthenium (Ru); $N$-heterocyclic carbenes (NHCs); homogeneous catalysis; in situ; amide bonds; synthesis

\section{Introduction}

Amides are a series of fundamental functional structures in nature and biological systems, as well as crucial building blocks for organic synthesis [1-6]. As of late, numerous synthetic methods were reported for the construction of amide bonds. However, they generally suffer from the usage of various stoichiometric additives and the production of unfavorable equimolar byproducts [7-14]. Therefore, green and eco-friendly strategies are highly required for amide synthesis [15]. Recently, a methodology employing transition-metal-based catalytic systems for direct amide synthesis from alcohols and amines was proven to be far more atom-economic and environmentally friendly as the only byproduct is hydrogen [16-22]. Throughout this research, ruthenium $(\mathrm{Ru})$ was most extensively studied [23]. Initially, the Murahashi [24] and Milstein [25] groups pioneered Ru-catalyzed amide 
synthesis in intramolecular and intermolecular manners, respectively. Notably, the Milstein catalyst, a Ru complex bearing a PNN-type pincer ligand, was highly active for this reaction. With a catalyst loading of $0.1 \mathrm{~mol} \%$, various amides could be synthesized from alcohols and amines [25]. Later, great progress was achieved by the Milstein [26-28], Madsen [29-31], Williams [32,33], Hong [34-43], Crabtree [44,45], Albrecht [46], Guan [47,48], Glorius [49], Möller [50,51], Bera [52], Huynh [53], Viswanathamurthi [54-56], Mashima [57], Verpoort [58,59], and Kundu [60] groups. In particular, $\mathrm{Ru}$ combined with $\mathrm{N}$-heterocyclic carbenes (NHCs) attracted more and more interest due to the flexible tunability of the electronic and steric properties of NHCs, which may easily access the optimal structures of the corresponding NHC/Ru complexes [61-63]. Accordingly, a multitude of efficient $\mathrm{NHC} / \mathrm{Ru}$ catalytic systems were discovered for this reaction. Furthermore, considering the merits of the in situ catalytic systems, such as easy operation and convenient investigation of electronically and sterically distinct NHCs, a number of versatile and potent in situ NHC/Ru catalytic systems recently emerged. However, satisfactory yields could only be attained by these reported systems if relatively high Ru loadings of $2.0-5.0$ mol.\% were employed [29,34,36,37,49]. Therefore, the development of more efficient in situ NHC/Ru catalytic systems which can accomplish the formation of amide linkage are urgently required.

In our previous work, the development of various in situ generated ( $p$-cymene)/Ru catalytic systems, which contain benzimidazole-based NHC precursors bearing different electronic and steric properties, was accomplished [58]. Further experiments revealed that two mono-NHC/Ru complexes were observed as major species and two poly-carbene complexes were detected as only minor species (as depicted in Figure 1a) [59]. Herein, we envisioned that replacing the $p$-cymene ligand of the Ru center with a relatively labile cyclooctadiene (cod) ligand could possibly give rise to poly-carbene complexes as a major species (as shown in Figure 1b). Expectedly, the weaker cod ligand could be more easily substituted with multiple mono-NHC ligands. Based on this, an efficient in situ NHC/Ru catalytic system was developed through extensive screening of various conditions. Notably, this system demonstrated excellent catalytic activity for amide synthesis with the applied catalyst loading as low as $0.25 \mathrm{~mol} . \%$. Various amides, including sterically congested ones, were directly synthesized from alcohols and amines in moderate to excellent yields. Furthermore, high-resolution mass spectrometry (HRMS) analyses suggested several Ru species bearing multiple NHC ligands as major species, which was in accordance with our prospection.

(a) Our previous work:

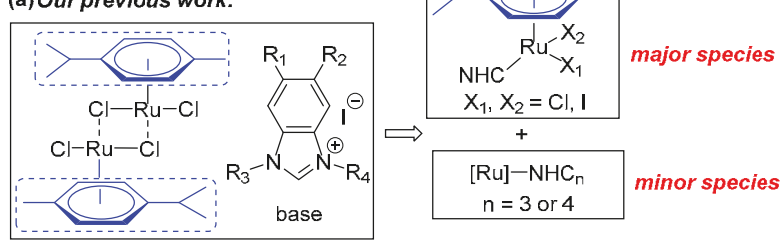

(b) This work:

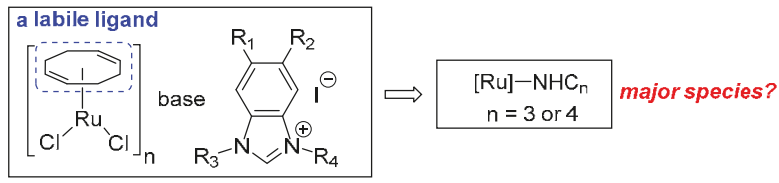

Figure 1. The design strategy of this work.

\section{Results and Discussion}

The reaction of benzyl alcohol (1a) and benzylamine (2a) was selected as a model reaction for the optimization of the reaction conditions. Based on our previous work [59], $0.5 \mathrm{~mol} . \%$ of $\left[\mathrm{RuCl}_{2}(\operatorname{cod})\right]_{\mathrm{n}}$, $2.00 \mathrm{~mol} . \%$ of an NHC precursor, $3.50 \mathrm{~mol} \%$ of $\mathrm{NaH}, 0.5 \mathrm{~h}$ of catalyst generation time, and $16 \mathrm{~h}$ 
of reaction time were originally applied (as listed in Table 1). In the beginning, NHC precursors L1-L6 with different backbone and wingtip substituents were prepared (entries 1-6, Table 1). The first and foremost, $62 \%$ of amide $3 \mathbf{a}$ and $15 \%$ of imine $4 \mathbf{a}$, were obtained with $18 \%$ of $\mathbf{1 a}$ remaining if $\mathbf{L 1}$ was used (entry 1). Electron-deficient precursor L2 gave rise to lower amide content in the product distribution, demonstrating its disadvantage for amide formation (entry 2 vs. entry 1). In the case of an electron-rich NHC precursor (L3), a similar result was obtained compared with L1 (entry 3 vs. entry 1). Moreover, the substituents on the N-terminus of the NHC precursors were adjusted (entries 1, 4-6). With retaining $\mathrm{Me}$ as the substituent for one $N$-terminus, different groups including $\mathrm{Et}, n \mathrm{Pr}$, and $i \operatorname{Pr}$ were introduced for the other terminus. The result was indicative that Et was the optimized group for this reaction (entry 4 vs. entries 1, 5, and 6). After establishing the ideal NHC precursor (L4), we continued the optimization by screening other reaction conditions. It was found that the catalyst generation time was crucial for the catalysis (entries 4, 7-11); 57\% of the amide product could be detected if every substance was added simultaneously (entry 5). As we elongated the period for the in situ catalyst generation from $0 \mathrm{~h}$ to $2.0 \mathrm{~h}$, the yields of 3 a gradually increased (entries 4, 7-10). A further increment of the time led to a similar yield (entry 11 vs. entry 10). Therefore, the ideal duration for the catalyst generation was finalized as $2 \mathrm{~h}$. Next, the ratio of [Ru]: $\mathbf{L} 4: \mathrm{NaH}$ was varied (entries 12-17). It is worth emphasizing that the amount of both $\mathbf{L} 4$ and $\mathrm{NaH}$ changed so as to ascertain three additional equivalents of $\mathrm{NaH}$ to activate $\left[\mathrm{RuCl}_{2}(\mathrm{cod})\right]_{\mathrm{n}}$ for all cases. Without $\mathrm{L} 4$, no amide was formed (entry 12). As the ratio increased from 1:0:3 to 1:5:8, gradually higher yields of 3 a were observed (entries 10, 12-16). However, a higher ratio prompted a reduced yield of $\mathbf{3 a}$ (entry 17 vs. entry 16$)$. Thus, the ratio of 1:5:8 was recognized as the best one (entry 16), and further increasing the reaction time from $16 \mathrm{~h}$ to $36 \mathrm{~h}$ produced $3 \mathrm{a}$ in $93 \%$ yield (entry 18 ).

In order to identify a more active catalytic system, a reduced Ru loading of 0.25 mol. $\%$ was attempted (as listed in Table 2). At the outset, 65\% of 3a was afforded if the loading of the above-optimized catalytic system was directly reduced to $0.25 \mathrm{~mol} \%$ (entry 1 ). In addition, different bases including potassium bis(trimethylsilyl)amide (KHMDS), $\mathrm{KO} t \mathrm{Bu}$, and $\mathrm{Cs}_{2} \mathrm{CO}_{3}$ were exploited instead of $\mathrm{NaH}$ (entries 2-4). Interestingly, compared with $\mathrm{NaH}$, the milder $\mathrm{Cs}_{2} \mathrm{CO}_{3}$ led to an increased yield of 3a (entry 4 vs. entry 1). It was also noticed that the volume of toluene was crucial for the reaction (entries 4-8). Either a more concentrated or diluted solution triggered a lower amide/imine selectivity (entry 5-8 vs. entry 4). Furthermore, the adjustment of the base amounts influenced the reaction (entries 4, 9-12), and $1.75 \mathrm{~mol} \%$ of $\mathrm{Cs}_{2} \mathrm{CO}_{3}$ was found to be optimal for the selective amide formation (entry 10). Therefore, the optimized reaction conditions were identified as $\mathbf{1}(5.00 \mathrm{mmol})$, $2(5.50 \mathrm{mmol}),\left[\mathrm{RuCl}_{2}(\mathrm{cod})\right]_{\mathrm{n}}(0.0125 \mathrm{mmol}), \mathrm{L} 4(0.0625 \mathrm{mmol}), \mathrm{Cs}_{2} \mathrm{CO}_{3}(0.075 \mathrm{mmol})$, toluene $(1.50 \mathrm{~mL})$, reflux, and $36 \mathrm{~h}$ unless otherwise noted.

With the optimized reaction conditions at hand, the substrate scope and limitations of this strategy were further investigated (as depicted in Figure 2). For the sterically non-hindered substrates (1a-1e), the corresponding amides could be obtained in good to excellent yields. If a secondary amine (1f) was employed, tertiary amide $3 \mathrm{f}$ was also given in $80 \%$ yield with $0.5 \mathrm{~mol} \%$ of [Ru]. Expectedly, lactam $3 \mathrm{~g}$ was efficiently afforded from amino alcohol $\mathbf{1 f}$ in an intramolecular pattern. On the other hand, the reactions of benzyl alcohol with substituted benzylamines were evaluated. It seemed that these substituents had no obvious influence on the reactivity, and amides $3 \mathbf{h}-3 \mathbf{k}$ were synthesized in $75-85 \%$ yields. In the case of coupling benzylamine with various benzyl alcohols, a substituent at either the para or meta position resulted in good yields of amides 31-3n. However, an ortho group gave amide 30 in a moderate yield. Apparently, aromatic amines were less reactive, and aniline (2p) produced amide $3 p$ in only $25 \%$ yield. To our delight, this newly developed catalytic system was not as sensitive to steric bulks as our previous systems [58,59]. With an Ru loading of $0.5 \mathrm{~mol} \%$, several sterically hindered substrates could be efficiently transformed into amides $3 q-3 t$. 
Table 1. Optimization of reaction conditions with a catalyst loading of $0.5 \mathrm{~mol} . \%^{a}$.

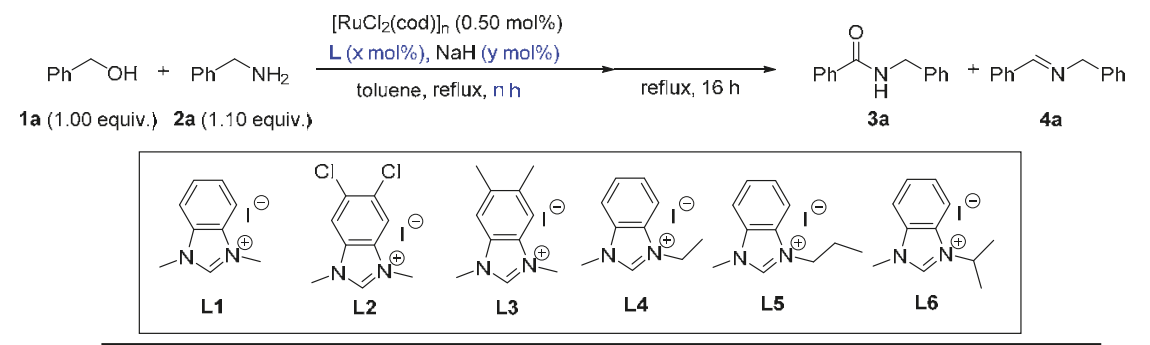

\begin{tabular}{cccccccc}
\hline \multirow{2}{*}{ Entry } & $\mathbf{L}$ & $\mathbf{x}$ & $\mathbf{y}$ & $\mathbf{n}$ & \multicolumn{3}{c}{ Yields $\mathbf{( \% )}^{\boldsymbol{b}}$} \\
\cline { 6 - 8 } & & & & & $\mathbf{3 a}$ & $\mathbf{4 a}$ & Unreacted 1a \\
\hline 1 & L1 & 2.00 & 3.50 & 0.5 & 62 & 15 & 18 \\
2 & L2 & 2.00 & 3.50 & 0.5 & 28 & 30 & 39 \\
3 & L3 & 2.00 & 3.50 & 0.5 & 63 & 15 & 16 \\
4 & L4 & 2.00 & 3.50 & 0.5 & 78 & 10 & 8 \\
5 & L5 & 2.00 & 3.50 & 0.5 & 72 & 12 & 8 \\
6 & L6 & 2.00 & 3.50 & 0.5 & 28 & 30 & 39 \\
7 & L4 & 2.00 & 3.50 & 0.0 & 57 & 10 & 31 \\
8 & L4 & 2.00 & 3.50 & 1.0 & 79 & 6 & 8 \\
9 & L4 & 2.00 & 3.50 & 1.5 & 81 & 5 & 7 \\
10 & L4 & 2.00 & 3.50 & 2.0 & 83 & 4 & 5 \\
11 & L4 & 2.00 & 3.50 & 2.5 & 82 & 4 & 6 \\
12 & L4 & 0.00 & 1.50 & 2.0 & 0 & 19 & 76 \\
13 & L4 & 0.50 & 2.00 & 2.0 & 37 & 10 & 51 \\
14 & L4 & 1.00 & 2.50 & 2.0 & 60 & 11 & 28 \\
15 & L4 & 1.50 & 3.00 & 2.0 & 75 & 7 & 16 \\
16 & L4 & 2.50 & 4.00 & 2.0 & 86 & 4 & 9 \\
17 & L4 & 3.00 & 4.50 & 2.0 & 81 & 6 & 3 \\
$18^{c}$ & L4 & 2.50 & 4.00 & 2.0 & 93 & 5 & $\mathbf{0}$ \\
\hline
\end{tabular}

${ }^{a}$ 1a $(2.50 \mathrm{mmol}), 2 \mathrm{a}(2.75 \mathrm{mmol}),\left[\mathrm{RuCl}_{2}(\mathrm{cod})\right]_{\mathrm{n}}(0.50 \mathrm{~mol} \%), \mathrm{L}(\mathrm{x} \mathrm{mol} . \%), \mathrm{NaH}(\mathrm{y} \mathrm{mol} . \%)$, toluene $(1.25 \mathrm{~mL}), 120{ }^{\circ} \mathrm{C}$, $\mathrm{n} \mathrm{h}$ of catalyst generation time, and $16 \mathrm{~h}$ of reaction time; ${ }^{b}$ NMR yields (average of two consistent runs) using 1,3,5-trimethoxybenzene as an internal standard; ${ }^{c} 36 \mathrm{~h}$ of reaction time.

Concerning the in situ catalytic systems, it is crucial to explore the possible structures of the generated Ru species. As a result, HRMS analyses were performed to clarify this matter (as shown in Figure 3). In accordance with our speculation, no mono-carbene complexes were detected. Instead, two poly-carbene Ru species were observed from the spectrum. [Ru]-1 (corresponding to an isotopic peak at $m / z=812.24209$ ), consistent with an Ru species comprising four-fold NHC ligands, was observed as a major species. Furthermore, another tetra-carbene Ru species, assigned as [Ru]-2 with the isotopic peak at $m / z=793.26709$, was also found as a minor species. Presumably, during exposure to air and/or the HRMS measurements, the Ru centers in [Ru]-1 and [Ru]-2 were oxidized to +3 and +4 , respectively. Unfortunately, attempts to isolate these tetra-carbene complexes were unsuccessful, probably due to the complexity of the in situ catalyst generation. Therefore, it was still unclear whether the high activity of the current catalytic system was attributed to the observed tetra-carbene Ru species or other species. 


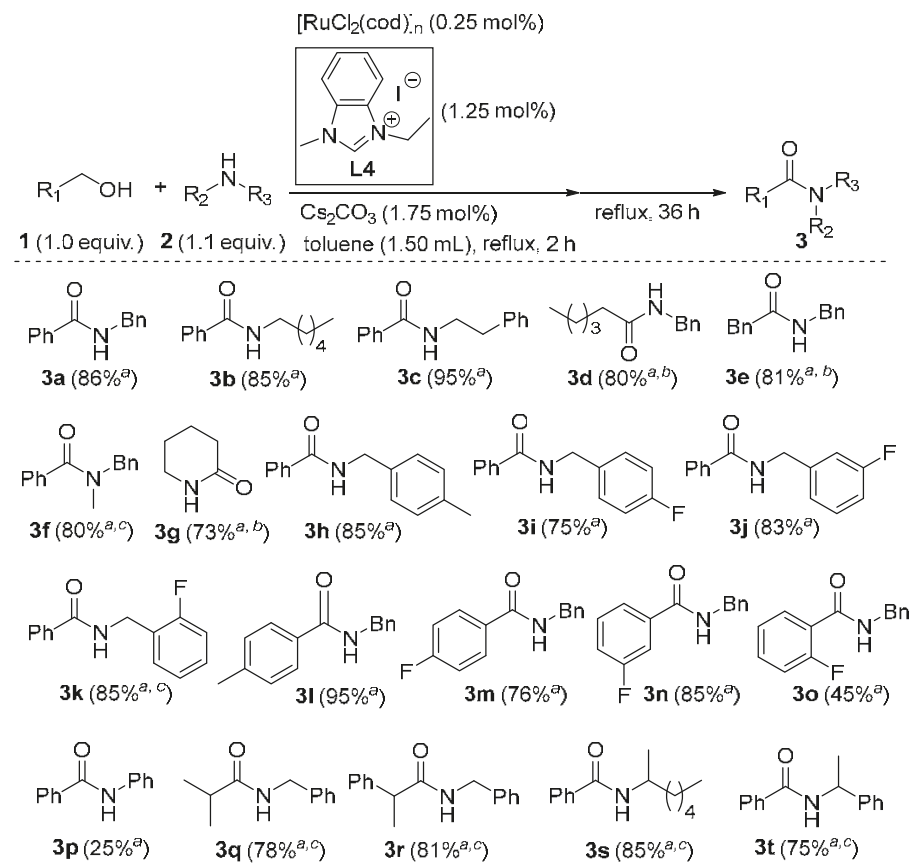

Figure 2. Amide synthesis from various alcohols and amines; ${ }^{a}$ isolated yields (averages of two consistent runs); ${ }^{b}$ in $m$-xylene at reflux; ${ }^{c} 0.5 \mathrm{~mol} . \%$ of $[\mathrm{Ru}]$.

Table 2. Optimization of reaction conditions with a catalyst loading of $0.25 \mathrm{~mol} . \%^{a}$.

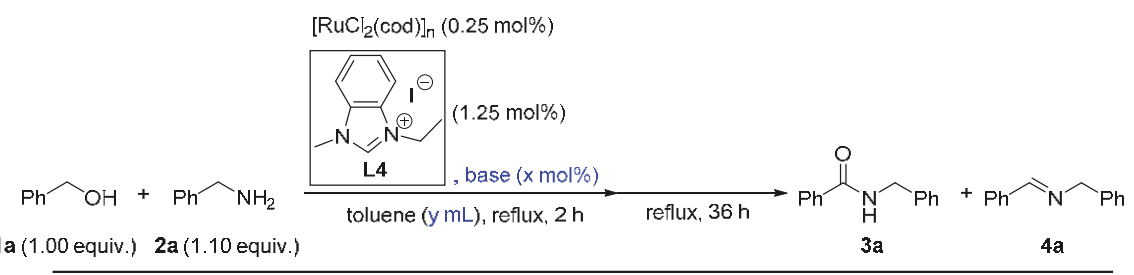

\begin{tabular}{ccccccc}
\hline \multirow{2}{*}{ Entry } & \multirow{2}{*}{ Base } & $\mathbf{x}$ & $\mathbf{y}$ & \multicolumn{3}{c}{ Yields (\%) $\mathbf{~}^{\boldsymbol{b}}$} \\
\cline { 5 - 7 } & & & $\mathbf{3 a}$ & $\mathbf{4 a}$ & Unreacted 1a \\
\hline 1 & $\mathrm{NaH}$ & 2.00 & 1.50 & 65 & 7 & 24 \\
2 & $\mathrm{KHMDS}$ & 2.00 & 1.50 & 27 & 11 & 57 \\
3 & $\mathrm{KO} t \mathrm{Bu}$ & 2.00 & 1.50 & 45 & 15 & 32 \\
4 & $\mathrm{Cs}_{2} \mathrm{CO}_{3}$ & 2.00 & 1.50 & 86 & 7 & 5 \\
5 & $\mathrm{Cs}_{2} \mathrm{CO}_{3}$ & 2.00 & 0.50 & 57 & 18 & 22 \\
6 & $\mathrm{Cs}_{2} \mathrm{CO}_{3}$ & 2.00 & 1.00 & 71 & 13 & 12 \\
7 & $\mathrm{Cs}_{2} \mathrm{CO}_{3}$ & 2.00 & 2.00 & 69 & 16 & 13 \\
8 & $\mathrm{Cs}_{2} \mathrm{CO}_{3}$ & 2.00 & 2.50 & 45 & 38 & 15 \\
9 & $\mathrm{Cs}_{2} \mathrm{CO}_{3}$ & 1.50 & 1.50 & 66 & 15 & 12 \\
$\mathbf{1 0}$ & $\mathrm{Cs}_{2} \mathrm{CO}_{3}$ & $\mathbf{1 . 7 5}$ & $\mathbf{1 . 5 0}$ & $\mathbf{9 0}$ & 7 & $\mathbf{2}$ \\
11 & $\mathrm{Cs}_{2} \mathrm{CO}_{3}$ & 2.25 & 1.50 & 81 & 10 & 8 \\
12 & $\mathrm{Cs}_{2} \mathrm{CO}_{3}$ & 2.50 & 1.50 & 72 & 12 & 15 \\
\hline
\end{tabular}

${ }^{a}$ 1a $(5.00 \mathrm{mmol}), 2 \mathrm{a}(5.50 \mathrm{mmol}),\left[\mathrm{RuCl}_{2}(\mathrm{cod}) \mathrm{n}_{\mathrm{n}}(0.25 \mathrm{~mol} \%), \mathrm{L} 4(1.25 \mathrm{~mol} \%)\right.$, base $(\mathrm{x} \mathrm{mol} . \%)$, toluene $(\mathrm{y} \mathrm{mL}), 120^{\circ} \mathrm{C}$, $2 \mathrm{~h}$ of catalyst generation time, and $36 \mathrm{~h}$ of reaction time; ${ }^{b}$ NMR yields (average of two consistent runs) using 1,3,5-trimethoxybenzene as an internal standard. 


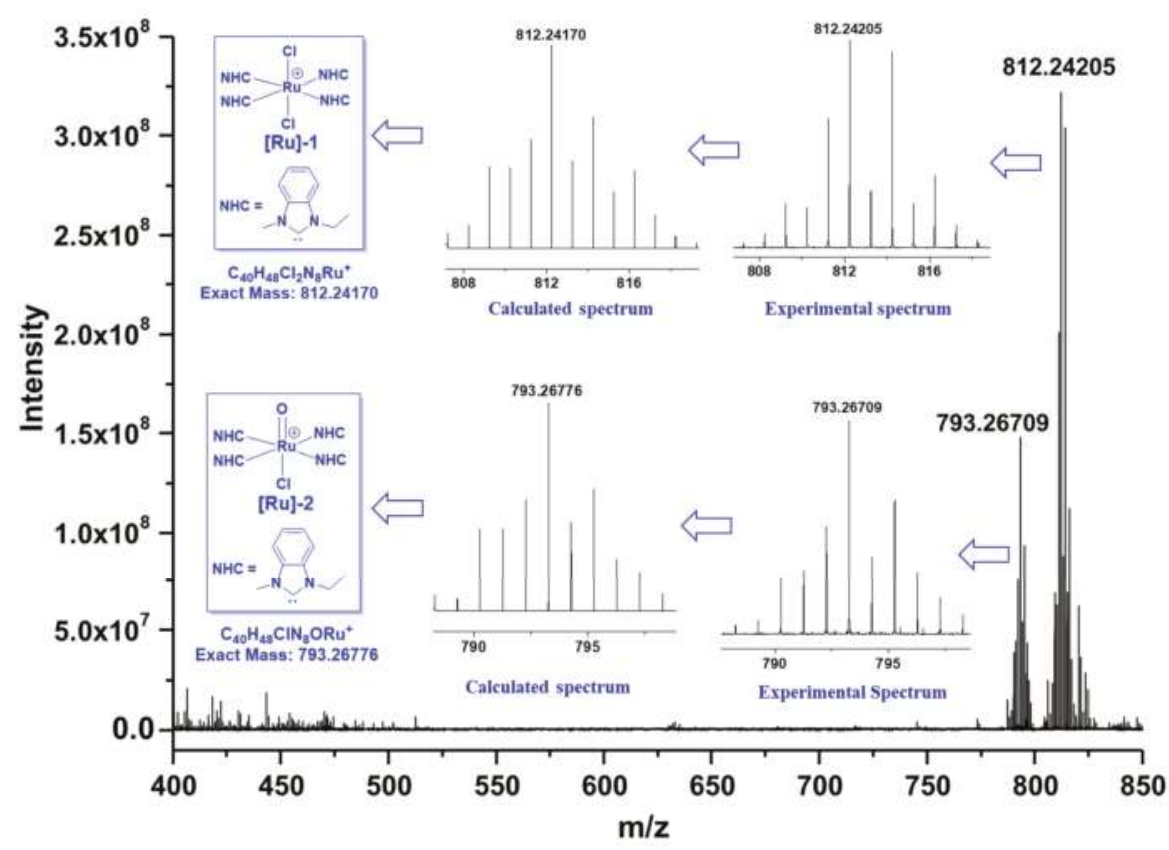

Figure 3. The high-resolution mass spectrometry (HRMS) analyses for the identification of the possible Ru species.

\section{Experimental}

\subsection{General Considerations}

All reactions were carried out using standard Schlenk techniques or in an argon-filled glove box unless otherwise mentioned. All the substrates and solvents were obtained from commercial suppliers and used as received without further purification. ${ }^{1} \mathrm{H}-\mathrm{NMR}$ spectra were recorded on a Bruker Avance 500 spectrometer (Billerica, MA, USA) in $\mathrm{CDCl}_{3}$ or DMSO- $d_{6}$ with TMS as the internal reference, and ${ }^{13} \mathrm{C}-\mathrm{NMR}$ spectra were recorded in $\mathrm{CDCl}_{3}$ or DMSO- $d_{6}$ on a Bruker Avance $500(126 \mathrm{MHz})$ spectrometer. The following abbreviations were used to designate multiplicities: $\mathrm{s}=$ singlet, brs = broad singlet, $\mathrm{d}=$ doublet, $\mathrm{t}=$ triplet, $\mathrm{dd}=$ doublet of doublets, $\mathrm{dq}=$ doublet of quartets, $\mathrm{td}=$ triplet of doublets, $\mathrm{ddd}=$ doublet of doublets of doublets, and $\mathrm{m}=$ multiplet. Melting points were taken on a Buchi M-560 melting point apparatus (Flawil, Switzerland) and were uncorrected. HRMS analyses were done with a Bruker Daltonics microTOF-QII instrument (Billerica, MA, USA). NHC precursors L1-L6 were prepared according to a previous publication [58,59], and all the amide products were identified by spectral comparison with the literature data $[58,59] .{ }^{1} \mathrm{H}-\mathrm{NMR},{ }^{13} \mathrm{C}-\mathrm{NMR}$ data and original spectra of amides $3 \mathbf{a}-\mathbf{3 t}$ could be found in the Supplementary Materials.

\subsection{General Procedure for the Amide Synthesis}

Inside an argon-filled glove box, $\left[\mathrm{Ru}(\mathrm{cod}) \mathrm{Cl}_{2}\right]_{\mathrm{n}}(3.5 \mathrm{mg}, 0.0125 \mathrm{mmol}), \mathbf{L} 4(18.0 \mathrm{mg}, 0.0625 \mathrm{mmol})$, $\mathrm{Cs}_{2} \mathrm{CO}_{3}(28.6 \mathrm{mg}, 0.0875 \mathrm{mmol})$, and dry toluene $(1.50 \mathrm{~mL})$ were added to an oven-dried $25-\mathrm{mL}$ Schlenk flask. The tube was taken out of the glove box and heated to reflux under argon for $2 \mathrm{~h}$. Then, an alcohol $(5.00 \mathrm{mmol})$ and an amine $(5.50 \mathrm{mmol})$ were added, and the mixture was stirred at a refluxing temperature for $36 \mathrm{~h}$. The procedures for calculating the NMR yields were as follows: when the reaction was complete, 1,3,5-trimethoxybenzene $(0.5 \mathrm{mmol}, 84.0 \mathrm{mg})$ and $\mathrm{CHCl}_{3}(1.0 \mathrm{~mL})$ were added to the reaction mixture. Afterward, to an NMR tube was added $0.1 \mathrm{~mL}$ of the above solution and 
$0.4 \mathrm{~mL}$ of $\mathrm{CDCl}_{3}$. The NMR yields were obtained based on the exact amount of 1,3,5-trimethoxybenzene. In order to obtain the isolated yields of the amides, the reaction mixture was cooled down to room temperature, and the solvent was removed under reduced pressure. Finally, the residue was purified by silica-gel flash column chromatography to afford the amides.

\section{Conclusions}

In summary, based on the assumption that the relatively labile cod ligand could be replaced by multiple NHC ligands to obtain versatile and active catalytic systems, we prepared several NHC precursors with distinct electronic and steric properties, then combined them with $\left[\mathrm{RuCl}_{2}(\mathrm{cod})\right]_{\mathrm{n}}$ and a mild $\mathrm{Cs}_{2} \mathrm{CO}_{3}$ to obtain a series of in situ $\mathrm{NHC} / \mathrm{Ru}$ catalytic systems. Through extensive screening of these systems and other conditions, the L4-based NHC/Ru catalytic system exhibited optimal activity for the dehydrogenative amidation of alcohols and amines. Various amides, especially sterically hindered ones, could be afforded in an efficient manner. Notably, the applied catalyst loading was as low as $0.25 \mathrm{~mol} \%$. Further experiments revealed that the higher amount of $\mathbf{L} 4$ compared to Ru probably facilitated the formation of two tetra-carbene species ([Ru]-1 and [Ru]-2), which were observed from HRMS analyses. However, since the in situ catalytic system was relatively complicated, it is still uncertain whether these tetra-carbene Ru species or other species were key catalytic intermediates for this reaction.

Supplementary Materials: Supplementary materials, which contain ${ }^{1} \mathrm{H}-\mathrm{NMR}$ and ${ }^{13} \mathrm{C}-\mathrm{NMR}$ data, as well as spectra of amides $\mathbf{3 a}-\mathbf{3 t}$, are available online.

Author Contributions: C.C., Y.Y and F.V. discussed and designed the whole project together. C.C., Y.M., K.D.W., and H.W. performed the experiments. C.C. and Y.M. wrote the manuscript. Y.Y., F.V. and P.D. revised the manuscript. All authors read and approved the final manuscript.

Funding: This research was supported by the National Natural Science Foundation of China (No. 21502062). F.V. acknowledges the support from the Russian Foundation for Basic Research (No. 18-29-04047) and the Tomsk Polytechnic University Competitiveness Enhancement Program grant (VIU-195/2018).

Conflicts of Interest: The authors declare no conflicts of interest.

\section{References}

1. Humphrey, J.M.; Chamberlin, A.R. Chemical synthesis of natural product peptides: Coupling methods for the incorporation of noncoded amino acids into peptides. Chem. Rev. 1997, 97, 2243-2266. [CrossRef] [PubMed]

2. Bode, J.W. Emerging methods in amide- and peptide-bond formation. Curr. Opin. Drug Discov. Dev. 2006, 9, 765-775. [CrossRef]

3. Cupido, T.; Tulla-Puche, J.; Spengler, J.; Albericio, F. The synthesis of naturally occurring peptides and their analogs. Curr. Opin. Drug Discov. Dev. 2007, 10, 768-783.

4. Valeur, E.; Bradley, M. Amide bond formation: Beyond the myth of coupling reagents. Chem. Soc. Rev. 2009, 38, 606-631. [CrossRef] [PubMed]

5. Ali, M.A.; Punniyamurthy, T. Palladium-catalyzed one-pot conversion of aldehydes to amides. Adv. Synth. Catal. 2010, 352, 288-292. [CrossRef]

6. Pattabiraman, V.R.; Bode, J.W. Rethinking amide bond synthesis. Nature 2011, 480, 471-479. [CrossRef] [PubMed]

7. Han, S.Y.; Kim, Y.A. Recent development of peptide coupling reagents in organic synthesis. Tetrahedron 2004, 60, 2447-2467. [CrossRef]

8. Kohn, M.; Breinbauer, R. The Staudinger ligation-A gift to chemical biology. Angew. Chem. Int. Ed. 2004, 43, 3106-3116. [CrossRef] [PubMed]

9. Montalbetti, C.A.G.N.; Falque, V. Amide bond formation and peptide coupling. Tetrahedron 2005, 61, 10827-10852. [CrossRef]

10. Kolakowski, R.V.; Shangguan, N.; Sauers, R.R.; Williams, L.J. Mechanism of thio acid/azide amidation. J. Am. Chem. Soc. 2006, 128, 5695-5702. [CrossRef] [PubMed] 
11. Lang, S.; Murphy, J.A. Azide rearrangements in electron-deficient systems. Chem. Soc. Rev. 2006, 35, 146-156. [CrossRef] [PubMed]

12. Martinelli, J.R.; Clark, T.P.; Watson, D.A.; Munday, R.H.; Buchwald, S.L. Palladium-catalyzed aminocarbonylation of aryl chlorides at atmospheric pressure: The dual role of sodium phenoxide. Angew. Chem. Int. Ed. 2007, 46, 8460-8463. [CrossRef] [PubMed]

13. Owston, N.A.; Parker, A.J.; Williams, J.M.J. Iridium-catalyzed conversion of alcohols into amides via oximes. Org. Lett. 2007, 9, 73-75. [CrossRef] [PubMed]

14. Chang, J.W.W.; Chan, P.W.H. Highly efficient ruthenium (II) porphyrin catalyzed amidation of aldehydes. Angew. Chem. Int. Ed. 2008, 47, 1138-1140. [CrossRef] [PubMed]

15. Constable, D.J.C.; Dunn, P.J.; Hayler, J.D.; Humphrey, G.R.; Leazer, J.L., Jr.; Linderman, R.J.; Lorenz, K.; Manley, J.; Pearlman, B.A.; Wells, A.; et al. Key green chemistry research areas-a perspective from pharmaceutical manufacturers. Green Chem. 2007, 9, 411-420. [CrossRef]

16. Allen, C.L.; Williams, J.M.J. Metal-catalysed approaches to amide bond formation. Chem. Soc. Rev. 2011, 40, 3405-3415. [CrossRef] [PubMed]

17. Chen, C.; Hong, S.H. Oxidative amide synthesis directly from alcohols with amines. Org. Biomol. Chem. 2011, 9, 20-26. [CrossRef] [PubMed]

18. Gunanathan, C.; Milstein, D. Applications of acceptorless dehydrogenation and related transformations in chemical synthesis. Science 2013. [CrossRef] [PubMed]

19. Gunanathan, C.; Milstein, D. Bond activation and catalysis by ruthenium pincer complexes. Chem. Rev. 2014, 114, 12024-12087. [CrossRef] [PubMed]

20. de Figueiredo, R.M.; Suppo, J.S.; Campagne, J.M. Nonclassical routes for amide bond formation. Chem. Rev. 2016, 116, 12029-12122. [CrossRef] [PubMed]

21. Xiong, X.Q.; Fan, G.M.; Zhu, R.J.; Shi, L.; Xiao, S.Y.; Bi, C. Highly efficient synthesis of amides. Prog. Chem. 2016, 28, 497-506.

22. Gusey, D.G. Rethinking the dehydrogenative amide synthesis. ACS Catal. 2017, 7, 6656-6662.

23. Chen, C.; Verpoort, F.; Wu, Q.Y. Atom-economic dehydrogenative amide synthesis via ruthenium catalysis. RSC Adv. 2016, 6, 55599-55607. [CrossRef]

24. Naota, T.; Murahashi, S.I. Ruthenium-catalyzed transformations of amino-alcohols to lactams. Synlett 1991, 10, 693-694. [CrossRef]

25. Gunanathan, C.; Ben-David, Y.; Milstein, D. Direct synthesis of amides from alcohols and amines with liberation of H-2. Science 2007, 317, 790-792. [CrossRef] [PubMed]

26. Gnanaprakasam, B.; Balaraman, E.; Ben-David, Y.; Milstein, D. Synthesis of peptides and pyrazines from $\beta$-Amino alcohols through extrusion of $\mathrm{H}_{2}$ catalyzed by ruthenium pincer complexes: Ligand-controlled selectivity. Angew. Chem. Int. Ed. 2011, 50, 12240-12244. [CrossRef] [PubMed]

27. Gnanaprakasam, B.; Balaraman, E.; Gunanathan, C.; Milstein, D. Synthesis of polyamides from diols and diamines with liberation of $\mathrm{H}_{2}$. J. Polym. Sci. Part A Polym. Chem. 2012, 50, 1755-1765. [CrossRef]

28. Srimani, D.; Balaraman, E.; Hu, P.; Ben-David, Y.; Milstein, D. Formation of tertiary amides and dihydrogen by dehydrogenative coupling of primary alcohols with secondary amines catalyzed by ruthenium bipyridine-based pincer complexes. Adv. Synth. Catal. 2013, 355, 2525-2530. [CrossRef]

29. Nordstrøm, L.U.; Vogt, H.; Madsen, R. Amide synthesis from alcohols and amines by the extrusion of dihydrogen. J. Am. Chem. Soc. 2008, 130, 17672-17673. [CrossRef] [PubMed]

30. Dam, J.H.; Osztrovszky, G.; Nordstrøm, L.U.; Madsen, R. Amide synthesis from alcohols and amines catalyzed by ruthenium $N$-heterocyclic carbene complexes. Chem. Eur. J. 2010, 16, 6820-6827. [CrossRef] [PubMed]

31. Makarov, I.S.; Fristrup, P.; Madsen, R. Mechanistic investigation of the ruthenium- $N$-heterocyclic-carbene-catalyzed amidation of amines with alcohols. Chem. Eur. J. 2012, 18, 15683-15692. [CrossRef] [PubMed]

32. Watson, A.J.A.; Maxwell, A.C.; Williams, J.M.J. Ruthenium-catalyzed oxidation of alcohols into amides. Org. Lett. 2009, 11, 2667-2670. [CrossRef] [PubMed]

33. Watson, A.J.A.; Wakeham, R.J.; Maxwell, A.C.; Williams, J.M.J. Ruthenium-catalysed oxidation of alcohols to amides using a hydrogen acceptor. Tetrahedron 2014, 70, 3683-3690. [CrossRef]

34. Ghosh, S.C.; Muthaiah, S.; Zhang, Y.; Xu, X.Y.; Hong, S.H. Direct amide synthesis from alcohols and amines by phosphine-free ruthenium catalyst systems. Adv. Synth. Catal. 2009, 351, 2643-2649. [CrossRef] 
35. Zhang, Y.; Chen, C.; Ghosh, S.C.; Li, Y.X.; Hong, S.H. Well-defined N-heterocyclic carbene based ruthenium catalysts for direct amide synthesis from alcohols and amines. Organometallics 2010, 29, 1374-1378. [CrossRef]

36. Muthaiah, S.; Ghosh, S.C.; Jee, J.E.; Chen, C.; Zhang, J.; Hong, S.H. Direct amide synthesis from either alcohols or aldehydes with amines: Activity of $\mathrm{Ru}$ (II) hydride and $\mathrm{Ru}(0)$ complexes. J. Org. Chem. 2010, 75, 3002-3006. [CrossRef] [PubMed]

37. Ghosh, S.C.; Hong, S.H. Simple $\mathrm{RuCl}_{3}$-catalyzed amide synthesis from alcohols and amines. Eur. J. Org. Chem. 2010, 4266-4270. [CrossRef]

38. Zhang, J.; Senthilkumar, M.; Ghosh, S.C.; Hong, S.H. Synthesis of cyclic imides from simple diols. Angew. Chem. Int. Ed. 2010, 49, 6391-6395. [CrossRef] [PubMed]

39. Chen, C.; Zhang, Y.; Hong, S.H. N-heterocyclic carbene based ruthenium-catalyzed direct amide synthesis from alcohols and secondary amines: Involvement of esters. J. Org. Chem. 2011, 76, 10005-10010. [CrossRef] [PubMed]

40. Chen, C.; Hong, S.H. Selective catalytic $\mathrm{sp}^{3}$ C-O bond cleavage with C-N bond formation in 3-alkoxy-1-propanols. Org. Lett. 2012, 14, 2992-2995. [CrossRef] [PubMed]

41. Kim, K.; Kang, B.; Hong, S.H. N-Heterocyclic carbene-based well-defined ruthenium hydride complexes for direct amide synthesis from alcohols and amines under base-free conditions. Tetrahedron 2015, 71, 4565-4569. [CrossRef]

42. Kang, B.; Hong, S.H. Hydrogen acceptor- and base-free $N$-formylation of nitriles and amines using methanol as C-1 Source. Adv. Synth. Catal. 2015, 357, 834-840. [CrossRef]

43. Kim, S.H.; Hong, S.H. Ruthenium-catalyzed urea synthesis using methanol as the C1 source. Org. Lett. 2016, 18, 212-215. [CrossRef] [PubMed]

44. Nova, A.; Balcells, D.; Schley, N.D.; Dobereiner, G.E.; Crabtree, R.H.; Eisenstein, O. An experimental-theoretical study of the factors that affect the switch between ruthenium-catalyzed dehydrogenative amide formation versus amine alkylation. Organometallics 2010, 29, 6548-6558. [CrossRef]

45. Schley, N.D.; Dobereiner, G.E.; Crabtree, R.H. Oxidative synthesis of amides and pyrroles via dehydrogenative alcohol oxidation by ruthenium diphosphine diamine complexes. Organometallics 2011, 30, 4174-4179. [CrossRef]

46. Prades, A.; Peris, E.; Albrecht, M. Oxidations and oxidative couplings catalyzed by triazolylidene ruthenium complexes. Organometallics 2011, 30, 1162-1167. [CrossRef]

47. Zeng, H.; Guan, Z. Direct synthesis of polyamides via catalytic dehydrogenation of diols and diamines. J. Am. Chem. Soc. 2011, 133, 1159-1161. [CrossRef] [PubMed]

48. Oldenhuis, N.J.; Dong, V.M.; Guan, Z. Catalytic acceptorless dehydrogenations: Ru-Macho catalyzed construction of amides and imines. Tetrahedron 2014, 70, 4213-4218. [CrossRef] [PubMed]

49. Ortega, N.; Richter, C.; Glorius, F. N-formylation of amines by methanol activation. Org. Lett. 2013, 15, 1776-1779. [CrossRef] [PubMed]

50. Malineni, J.; Merkens, C.; Keul, H.; Möller, M. An efficient N-heterocyclic carbene based ruthenium-catalyst: Application towards the synthesis of esters and amides. Catal. Commun. 2013, 40, 80-83. [CrossRef]

51. Malineni, J.; Keul, H.; Möller, M. An efficient $N$-heterocyclic carbene-ruthenium complex: Application towards the synthesis of polyesters and polyamides. Macromol. Rapid Commun. 2015, 36, 547-552. [CrossRef] [PubMed]

52. Saha, B.; Sengupta, G.; Sarbajna, A.; Dutta, I.; Bera, J.K. Amide synthesis from alcohols and amines catalyzed by a Ru-II-N-heterocyclic carbene (NHC)-carbonyl complex. J. Organomet. Chem. 2014, 771, 124-130. [CrossRef]

53. Xie, X.K.; Huynh, H.V. Tunable dehydrogenative amidation versus amination using a single ruthenium-NHC catalyst. ACS Catal. 2015, 5, 4143-4151. [CrossRef]

54. Nirmala, M.; Viswanathamurthi, P. Design and synthesis of ruthenium (II) OCO pincer type NHC complexes and their catalytic role towards the synthesis of amides. J. Chem. Sci. 2016, 128, 9-21. [CrossRef]

55. Selvamurugan, S.; Ramachandran, R.; Prakash, G.; Viswanathamurthi, P.; Malecki, J.G.; Endo, A. Ruthenium (II) carbonyl complexes containing bidentate 2-oxo-1,2-dihydroquinoline-3-carbaldehyde hydrazone ligands as efficient catalysts for catalytic amidation reaction. J. Organomet. Chem. 2016, 803, 119-127. [CrossRef]

56. Selvamurugan, S.; Ramachandran, R.; Prakash, G.; Nirmala, M.; Viswanathamurthi, P.; Fujiwara, S.; Endo, A. Ruthenium (II) complexes encompassing 2-oxo-1,2-dihydroquinoline-3-carbaldehyde thiosemicarbazone hybrid ligand: A new versatile potential catalyst for dehydrogenative amide synthesis. Inorg. Chim. Acta 2017, 454, 46-53. [CrossRef] 
57. Higuchi, T.; Tagawa, R.; Iimuro, A.; Akiyama, S.; Nagae, H.; Mashima, K. Tunable ligand effects on ruthenium catalyst activity for selectively preparing imines or amides by dehydrogenative coupling reactions of alcohols and amines. Chem. Eur. J. 2017, 23, 12795-12804. [CrossRef] [PubMed]

58. Cheng, H.; Xiong, M.Q.; Cheng, C.X.; Wang, H.J.; Lu, Q.; Liu, H.F.; Yao, F.B.; Chen, C.; Verpoort, F. In situ generated ruthenium catalyst systems bearing diverse $\mathrm{N}$-heterocyclic carbene precursors for atom-economic amide synthesis from alcohols and amines. Chem. Asian J. 2018, 13, 440-448. [CrossRef] [PubMed]

59. Cheng, H.; Xiong, M.Q.; Zhang, N.; Wang, H.J.; Miao, Y.; Su, W.; Yuan, Y.; Chen, C.; Verpoort, F. Efficient $\mathrm{N}$-heterocyclic carbene/ruthenium catalytic systems for the alcohol amidation with amines: Involvement of poly-carbene complexes? Chem CatChem 2018. [CrossRef]

60. Maji, M.; Chakrabarti, K.; Paul, B.; Roy, B.C.; Kundu, S. Ruthenium(II)-NNN-pincer-complex-catalyzed reactions between various alcohols and amines for sustainable $\mathrm{C}-\mathrm{N}$ and $\mathrm{C}-\mathrm{C}$ bond formation. Adv. Synth. Catal. 2018, 360, 722-729. [CrossRef]

61. Huynh, H.V.; Han, Y.; Jothibasu, R.; Yang, J.A. ${ }^{13}$ C-NMR spectroscopic determination of ligand donor strengths using $N$-heterocyclic carbene complexes of palladium (II). Organometallics 2009, 28, 5395-5404. [CrossRef]

62. Chen, C.; Kim, M.H.; Hong, S.H. N-heterocyclic carbene-based ruthenium-catalyzed direct amidation of aldehydes with amines. Org. Chem. Front. 2015, 2, 241-247. [CrossRef]

63. Kaufhold, S.; Petermann, L.; Staehle, R.; Rau, S. Transition metal complexes with N-heterocyclic carbene ligands: From organometallic hydrogenation reactions toward water splitting. Coord. Chem. Rev. 2015, 304, 73-87. [CrossRef]

Sample Availability: Samples of compounds 3a-3t are available from the authors.

(C) 2018 by the authors. Licensee MDPI, Basel, Switzerland. This article is an open access article distributed under the terms and conditions of the Creative Commons Attribution (CC BY) license (http:/ / creativecommons.org/licenses/by/4.0/). 


\title{
Article \\ Palladium-Catalyzed Room Temperature Acylative Cross-Coupling of Activated Amides with Trialkylboranes
}

\author{
Weijia Shi and Gang Zou * \\ School of Chemistry \& Molecular Engineering, East China University of Science \& Technology, 130 Meilong Rd, \\ Shanghai 200237, China; 10111048@mail.ecust.edu.cn \\ * Correspondence: zougang@ecust.edu.cn; Tel.: +86-021-64253881
}

Received: 23 August 2018; Accepted: 18 September 2018; Published: 20 September 2018

\begin{abstract}
A highly efficient acylative cross-coupling of trialkylboranes with activated amides has been effected at room temperature to give the corresponding alkyl ketones in good to excellent yields by using 1,3-bis(2,6-diisopropyl)phenylimidazolylidene and 3-chloropyridine co-supported palladium chloride, the PEPPSI catalyst, in the presence of $\mathrm{K}_{2} \mathrm{CO}_{3}$ in methyl tert-butyl ether. The scope and limitations of the protocol were investigated, showing good tolerance of acyl, cyano, and ester functional groups in the amide counterpart while halo group competed via the classical Suzuki coupling. The trialkylboranes generated in situ by hydroboration of olefins with $\mathrm{BH}_{3}$ or 9-BBN performed similarly to those separately prepared, making this protocol more practical.
\end{abstract}

Keywords: acylative cross-coupling; trialkylborane; amide activation; palladium; $N$-heterocyclic carbene

\section{Introduction}

Amides are unique and ubiquitous substructures in natural and artificial organic functional molecules, because the strong resonance between the carbonyl and amino groups leads to a highly inert and significantly planar linkage. However, the synthetic utility of amides as an acyl source had remained underdeveloped until the seminal publications in 2015 independently from Garg [1], Szostak [2], and ourselves [3], taking advantage of palladium or nickel catalysis for cleavage of electronically or sterically activated amide C-N bond, and formation of new carbon-carbon or carbon-oxygen bonds. In the past three years, many efforts have been made to expand the scope of amide counterparts, developing a variety of activated amides suitable for the acylative cross-coupling, e.g., $N$-acyl imides [4-6], $N$-Boc and $N$-Ts / Ms amides [7-15], $N$-acylsaccharins [16-20], and amides of heteroaromatic compounds [21,22]. Comparably, the carbon-centered nucleophile counterparts are still rather undeveloped, in particular, with respect to alkyl ones, although alkyl ketones have been widely found in biologically important molecules and synthetic building blocks for fine chemicals. In fact, besides the closely related esters [23-25], there are only two reports on the acylative cross-coupling of amides with alkyl reagents effected by using nickel catalysts. Garg and co-workers reported the first alkylation of amide derivatives by nickel-catalyzed acylative coupling with alkyl zinc reagents in 2016 [26]. Early this year, Rueping and co-workers described the other nickel-catalyzed cross-coupling of B-alkyl-9-BBN with amides [27]. After extension of the nucleophile counterparts from arylboronic acids to cost-effective diarylborinic acids and tetraarylboronates in palladium-catalyzed acylative cross-coupling of amides $[28,29]$, we are interested in the reactivity of trialkylboranes, which could be readily prepared from alkyl Grignard reagents or olefins via hydroboration. Herein we report a highly efficient palladium-catalyzed acylative cross-coupling of activated amides with trialkylboranes at room temperature by using 1,3-bis(2,6-diisopropyl)phenylimidazolylidene (IPr) and 3-chloropyridine (3-ClPy) co-supported palladium chloride, the PEPPSI catalyst developed by Organ et al. [30]. 


\section{Results and Discussion}

Reaction of 4-methoxy-N-methyl-N-tosylbenzamide (1a) with the commercially available triethylborane (2a) $\left(\mathrm{BEt}_{3}, 1 \mathrm{M}\right.$ in $\left.\mathrm{THF}\right)$ was chosen as the model to establish an optimal catalyst system for the acyl alkylation of activated amides (Scheme 1).
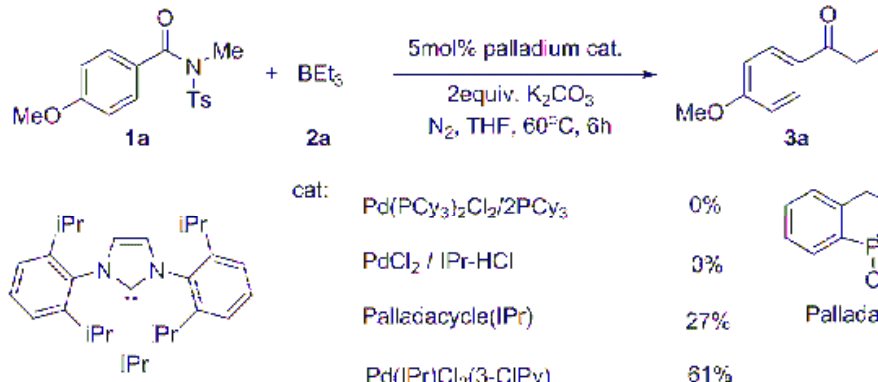

cat:

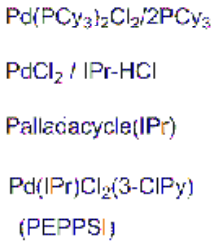

$0 \%$

$3 \%$

$27 \%$

$61 \%$

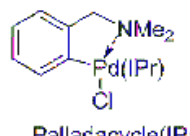

Palladacycle(IP')

(PEPPSI)

Scheme 1. Screening of palladium catalyst for acyl alkylation of amides with alkylboranes.

The catalyst system $\mathrm{Pd}\left(\mathrm{PCy}_{3}\right)_{2} \mathrm{Cl}_{2} / \mathrm{PCy}_{3}$, which we previously established for acylative cross-coupling of amides with aryl boron compounds, was investigated, at first, in the presence of $\mathrm{K}_{2} \mathrm{CO}_{3}$ as base in THF. Unfortunately, palladium black developed immediately upon heating and no reaction was detected after $6 \mathrm{~h}$ at $60{ }^{\circ} \mathrm{C}$, indicating the incompatibility of the $\mathrm{Pd}\left(\mathrm{PCy}_{3}\right)_{2} \mathrm{Cl}_{2} / \mathrm{PCy}_{3}$ system with the high reducing ability of trialkylboranes. We then turned to the sterically demanding $\mathrm{N}$-heterocyclic carbene (NHC) supported palladium catalysts pioneered by Nolan group [31], for example, 1,3-bis(2,6-diisopropylphenyl)imidazolium chloride $(\mathrm{IPr}-\mathrm{HCl}) /$ palladium chloride ( $\left.\mathrm{IPr}-\mathrm{HCl} / \mathrm{PdCl}_{2}\right)$ [32], IPr supported 2-((dimethylamino)methyl)phenyl palladium chloride (Palladacycle(IPr)) [33], and IPr and 3-chloropyridine co-supported PEPPSI catalyst (IPr) $\mathrm{PdCl}_{2}$ (3-ClPy) [30]. Although the $\mathrm{IPr}-\mathrm{HCl} / \mathrm{PdCl}_{2}$ system also rapidly decomposed to palladium black and lost activity, the palladacycle/IPr and PEPPSI catalysts provided the desired cross-coupling product $3 \mathbf{a}$ in $27 \%$ and $61 \%$ yields, respectively, from $1 \mathbf{a}$ with 1.0 equiv $\mathbf{2 a}$ in the presence of 2 equiv $\mathrm{K}_{2} \mathrm{CO}_{3}$. To test if dialkylboranes could be used in the acyl alkylation with amides, we also carried out the model reaction by using diethylborinate $\left(\mathrm{Et}_{2} \mathrm{~B}(\mathrm{OMe}), 1 \mathrm{M}\right.$ in $\left.\mathrm{THF}\right)$ under otherwise identical conditions (Scheme 2). Surprisingly, the C-O cross-coupling product, methyl 4-methoxybenzoate, was obtained in $74 \%$ yield, while the C-C coupling product 3 a was isolated in low $(\sim 5 \%)$ yield, implying a much slower transmetalation of alkyl group from boron to palladium than that of alkoxyl group in dialkylborinates.

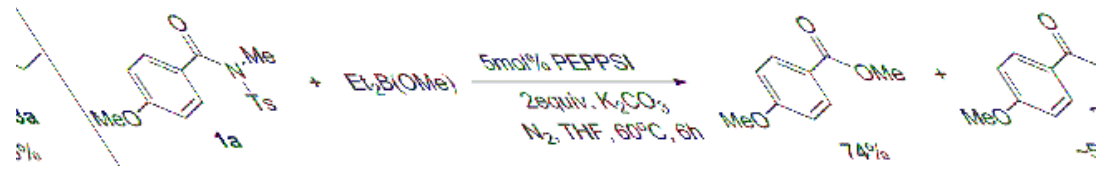

Scheme 2. Unexpected acyl C-O cross-coupling of methyl diethylborinate.

To increase the yield of the desired C-C coupling product in the PEPPSI-catalyzed acyl alkylation of amides, the reaction conditions were optimized with respect to substrate ratio, solvent, base, and reaction temperature, etc. Bases proved to be crucial since no reaction took place in the absence of bases or in the presence of organic base, e.g., $\mathrm{NEt}_{3}$ and pyridine (Table 1, entries 2, 8 and 9). The stronger inorganic bases, $\mathrm{Cs}_{2} \mathrm{CO}_{3}(25 \%)$ and $\mathrm{K}_{3} \mathrm{PO}_{4}(33 \%)$, gave the lower yields of $3 a$ than that of $\mathrm{K}_{2} \mathrm{CO}_{3}$, albeit the reaction proceeded faster while the weaker ones, e.g., $\mathrm{Na}_{2} \mathrm{CO}_{3}, \mathrm{NaOAc}$, and $\mathrm{NaHCO}_{3}$, resulted in recovering most of amide substrate $1 \mathbf{a}$ (Table 1, entries 3-7). The yield of 3a could 
be increased to $80 \%$ with 1.5 equiv $\mathrm{BEt}_{3}$ (Table 1, entry 10). Methyl tert-butyl ether (MTBE) appeared to be the choice of solvent, giving 3 a in $90 \%$ yield (Table 1 , entry 12 ). The reaction occurred even at room temperature and an excellent yield ( $98 \%$ ) for 3a was obtained in $24 \mathrm{~h}$ (Table 1, entry 14). Given the advantages of room temperature organic synthesis [34], we reinvestigated the model reaction in THF or MTBE with $\mathrm{K}_{2} \mathrm{CO}_{3}$ or $\mathrm{K}_{3} \mathrm{PO}_{4}$ as the base (Table 1, entries 15-17). The results confirmed the best performance of the combination of MTBE with $\mathrm{K}_{2} \mathrm{CO}_{3}$.

Table 1. PEPPSI-catalyzed acyl alkylation reaction of amide 1a with triethylborane. ${ }^{a}$

\begin{tabular}{|c|c|c|c|c|c|c|}
\hline Entry & Equiv of 2a & Solvent & Base $^{b}$ & $\mathrm{~T}\left({ }^{\circ} \mathrm{C}\right)$ & Time (h) & Yield $(\%)^{c}$ \\
\hline 1 & 1.1 & THF & $\mathrm{K}_{2} \mathrm{CO}_{3}$ & 60 & 5 & 61 \\
\hline 2 & 1.1 & THF & / & 60 & 5 & $\mathrm{NR}^{\mathrm{d}}$ \\
\hline 3 & 1.1 & THF & $\mathrm{Cs}_{2} \mathrm{CO}_{3}$ & 60 & 5 & 25 \\
\hline 4 & 1.1 & THF & $\mathrm{K}_{3} \mathrm{PO}_{4}$ & 60 & 5 & 33 \\
\hline 5 & 1.1 & THF & $\mathrm{Na}_{2} \mathrm{CO}_{3}$ & 60 & 8 & 15 \\
\hline 6 & 1.1 & THF & $\mathrm{NaHCO}_{3}$ & 60 & 8 & Trace $^{\mathrm{d}}$ \\
\hline 7 & 1.1 & THF & $\mathrm{NaOAc}$ & 60 & 8 & Trace $^{\mathrm{d}}$ \\
\hline 8 & 1.1 & THF & $\mathrm{Et}_{3} \mathrm{~N}$ & 60 & 8 & $\mathrm{NR}^{\mathrm{d}}$ \\
\hline 9 & 1.1 & THF & Pyridine & 60 & 8 & $\mathrm{NR}^{\mathrm{d}}$ \\
\hline 10 & 1.5 & THF & $\mathrm{K}_{2} \mathrm{CO}_{3}$ & 60 & 5 & 80 \\
\hline 11 & 1.5 & Dioxane & $\mathrm{K}_{2} \mathrm{CO}_{3}$ & 60 & 8 & 35 \\
\hline 12 & 1.5 & MTBE & $\mathrm{K}_{2} \mathrm{CO}_{3}$ & 55 & 8 & 90 \\
\hline 13 & 1.5 & $\mathrm{MeCN}$ & $\mathrm{K}_{2} \mathrm{CO}_{3}$ & 60 & 8 & 17 \\
\hline 14 & 1.5 & MTBE & $\mathrm{K}_{2} \mathrm{CO}_{3}$ & $\mathrm{rt}$ & 24 & 98 \\
\hline 15 & 1.5 & MTBE & $\mathrm{K}_{3} \mathrm{PO}_{4}$ & $\mathrm{rt}$ & 24 & 84 \\
\hline 16 & 1.5 & THF & $\mathrm{K}_{2} \mathrm{CO}_{3}$ & $\mathrm{rt}$ & 24 & 82 \\
\hline 17 & 1.5 & THF & $\mathrm{K}_{3} \mathrm{PO}_{4}$ & $\mathrm{rt}$ & 12 & 40 \\
\hline
\end{tabular}

${ }^{\mathrm{a}}$ Reaction was run at $0.5 \mathrm{~mol}$ scale with respect to $1 \mathrm{a}^{\mathrm{b}}{ }^{\mathrm{b}} 2$ equiv base used but no base used in Entry $2{ }^{\mathrm{c}}$ Isolated yield; ${ }^{\mathrm{d}}$ Amide 1a recovered.

Scope and limitations of the PEPPSI-catalyzed room temperature acylative cross-coupling of activated amides with trialkylboranes were briefly explored (Table 2). Influence of the amide structure was investigated at first under the optimized reaction conditions. Similar to tosyl-activated amide 1a, mesyl (Ms, 1b) analog also reacted efficiently to give 3a in 98\% yield, while tert-butyloxycarbonyl (Boc) activated amide (1c) showed comparably lower reactivity (75\%) (Table 2, entries 1 and 2). Reaction of benzamides bearing an electron-withdrawing group, acyl (1e), cyano (1f), or ester (1g), at the para-position of the benzene ring gave the corresponding ketones (3b, 3c, or $3 \mathbf{d}$ ) in $92 \%, 70 \%$, or $91 \%$ yields, respectively, indicating good functional group compatibility of the PEPPSI-catalyzed acyl alkylation (Table 2, entries 4-6). When 4-chloro- $N$-methyl- $N$-tosylbenzamide (1h) was used as the substrate, the desired acylative cross-coupling product 1-(4-chlorophenyl)propanone was not obtained. Instead, double alkylation product 1-(4-ethylphenyl)propanone (3e) was isolated in $47 \%$ yield, which could be increased to $88 \%$ yield with 2.5 equiv BEt 3 (Table 2, entry 7), similar to our previous investigation on the palladium-catalyzed acylative Suzuki coupling of arylboronic acids [3]. A small ortho-substituent at the benzene ring appeared to slightly hamper the coupling. In fact, 1-(o-tolyl)propan-1-one (3f) was isolated in 72\% yield from $N$-methyl- $N$-tosyl-2-methylbenzamide (1i) (Table 2, entry 8). Alkyl amides (1j and $\mathbf{1 k}$ ) reacted similarly to give dialkyl ketones $\mathbf{3 g}$ and $\mathbf{3 h}$ in $95 \%$ and $98 \%$ yields, respectively (Table 2, entries 9 and 10). 
Table 2. Scope and limitations of the PEPPSI-catalyzed acyl alkylation reaction of amides with trialkylboranes ${ }^{\text {a }}$.

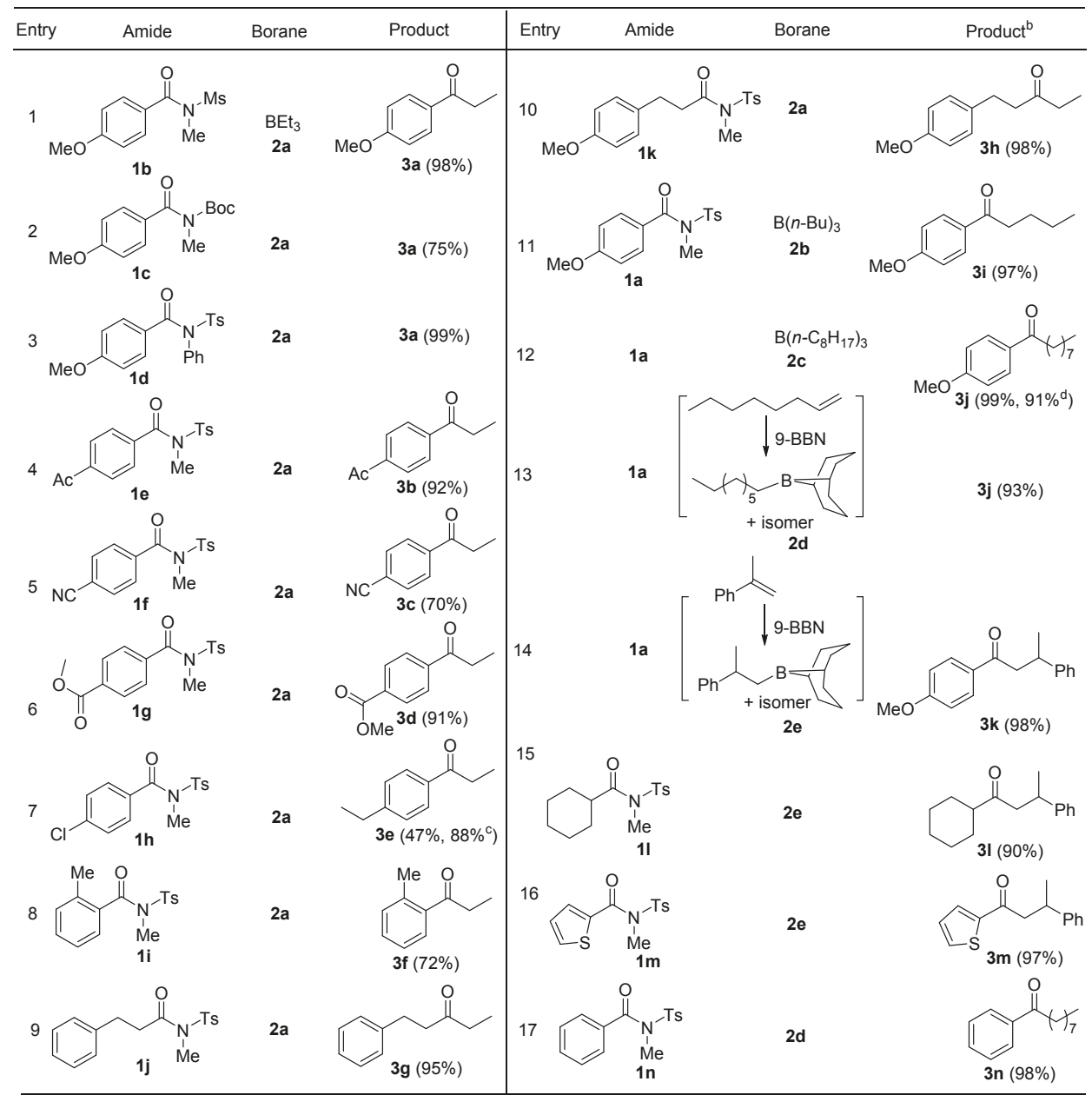

${ }^{a}$ Reaction was run at $0.5 \mathrm{~mol}$ scale with respect to amides with 1.5 equiv trialkylboranes; ${ }^{\mathrm{b}}$ Isolated yield; ${ }^{\mathrm{c}}$ With 2.5 equiv $\mathrm{BEt}_{3} ;{ }^{\mathrm{d}} \mathrm{B}\left(n-\mathrm{C}_{8} \mathrm{H}_{17}\right)_{3}$ and branched isomers in situ generated from hydroboration of octene with 1.0 equiv $\mathrm{BH}_{3}$ in THF at room temperature was used.

$\operatorname{Tri}(n$-butyl)borane (2b) reacted with 1a similarly to triethylborane (2a) while no reaction of tricyclohexylborane was observed, implying the failure of transmetalation of secondary-alkyl group from boron to palladium. Hydroboration of alkenes represents an alternative route to primary alkyl boranes. However, the long-chain primary alkyl boranes prepared by hydroboration of alkenes are generally contaminated by the presence of branched-isomers due to the non-regiospecific addition of B-H to C-C double bonds [35]. Due to the inertness of the secondary-alkyl group in alkylboranes, reaction of 1a with tri(octyl)boranes prepared by hydroboration of 1-octene proceeded comparably to that of tri( $n$-octyl)borane (2c) from Grignard reagent [36], giving $3 \mathbf{j}$ in $91 \%$ and $99 \%$ yields, respectively (Table 2, entry 12). Given the fact that only one primary alkyl group of trialkylboranes is useful in the palladium-catalyzed acylative cross-coupling, it is more practical to use long-chain alkyl boranes prepared by hydroboration of corresponding olefins by dialkylborane, a more stable B-H source, 
e.g., 9-borabicyclo[3.3.1]nonane (9-BBN). Therefore, we further investigated use of B-octyl-9-BBN formed in situ from octene as the trialkylborane counterpart and obtained $3 \mathbf{j}$ in $93 \%$ yield (Table 2, entry 13). $\beta$-Phenyl propiophenones, which show intrinsic deactivation of the lowest and thermally populated $n, \pi^{*}$-triplet excited states in aryl alkyl ketones [37], could be readily obtained in $98 \%$ yield (3k) by the acyl alkylation of amide 1a with B-(2-phenylpropyl)-9-BBN generated in situ from 9-BBN and $\alpha$-methylstyrene. Alkyl and heterocyclic analogs, e.g., 1-cyclohexyl-3-phenylbutanone (31, $90 \%$ ) and 3-phenyl-1-(thiophen-2-yl)butanone (3m, 97\%) could also be prepared efficiently (Table 2, entries 14-16).

However, when amide 1a was subjected to the hydroboration solution of $n$-butyl vinyl ether with 9-BBN the C-O coupling product (vide supra) butyl 4-methoxybenzoate, instead of the desired $\beta$-butoxy-4-methoxypropiophenone, was obtained in $83 \%$ yield, probably due to the facile $\beta$-alkoxy elimination of labile B-(2-butoxyethyl)-9-BBN via intramolecular O-B coordination to B-butoxy-9-BBN for the subsequent $\mathrm{C}-\mathrm{O}$ cross-coupling (Scheme 3).

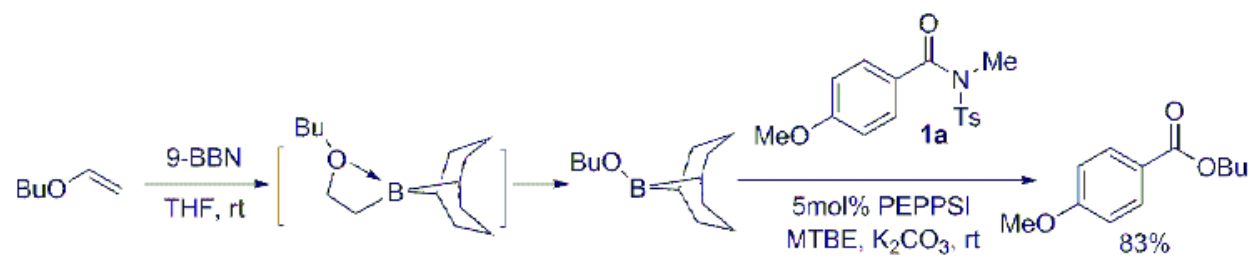

Scheme 3. Formation of borinate and subsequent acyl C-O cross-coupling.

\section{Materials and Methods}

\subsection{General}

Chemicals obtained commercially were used as received. Nuclear magnetic resonance (NMR) spectra were recorded on a Bruker DPX-400 spectrometer (Bruker Co., Billerica, MA, USA) using residue of the deuterated solvent or tetramethylsilane (TMS) as the internal standard (Cambridge Isotope Lab. Inc., Tewksbury, MA, USA). For copies of ${ }^{1} \mathrm{H}$ and ${ }^{13} \mathrm{C}-\mathrm{NMR}$ spectra of the products, please see Supplementary Materials. All products were isolated by flash chromatography using petroleum ether (Sinopharm Chemical Reagent Co. Ltd., Shanghai, China) $\left(60-90{ }^{\circ} \mathrm{C}\right) /$ ethyl acetate (Sinopharm Chemical Reagent Co. Ltd., Shanghai, China) as eluents. Triethylborane (1 M in THF), tributylborane, 9-BBN (1 M in THF) and $\mathrm{BH}_{3}(1 \mathrm{M}$ in THF) were purchased from J\&K chemicals (Beijing, China). Amides [3], PEPPSI catalyst [30], 1,3-bis(2,6-diisopropylphenyl)imidazolium chloride (IPr-HCl) [32], palladacycle (IPr) [33], and tri(n-octyl)borane [36] were prepared according to the procedures reported previously. Solvents, methyl tert-butyl ether (MTBE), tetrahydrofuran (THF), and dioxane were dried over sodium while acetonitrile was distilled over $\mathrm{CaH}_{2}$ prior to use.

\subsection{General Procedure for the PEPPSI-Catalyzed Cross-Coupling of N-Methyl-N-Tosylamides with Trialkylboranes}

A Schlenk tube $(20 \mathrm{~mL})$ charged with amide $(0.5 \mathrm{mmol})$, PEPPSI $(0.025 \mathrm{mmol}, 5 \mathrm{~mol} \%)$, and $\mathrm{K}_{2} \mathrm{CO}_{3}$ ( 2 equiv) was degassed and then refilled with nitrogen, three times. Then, solvent MTBE (6.0 mL) was added via syringe followed by $0.75 \mathrm{~mL}$ (1.5 equiv) borane solution ( $1 \mathrm{M}$ in THF), which was commercially available or was in situ prepared by hydroboration of olefin. The resulted mixture was stirred for $24 \mathrm{~h}$ at room temperature under $\mathrm{N}_{2}$ atmosphere. The reaction was quenched with iced water $(5 \mathrm{~mL})$ and extracted with MTBE $(2 \times 5 \mathrm{~mL})$. The combined MTBE extracts were dried over anhydrous $\mathrm{Na}_{2} \mathrm{SO}_{4}$. After filtration, solvents were removed by rotavapor to afford the crude product, which was purified by flash column chromatography on silica gel using petroleum ether/EtOAc as the eluents.

1-(4-Methoxyphenyl)propanone (3a) [38]: Colorless oil (80.3 mg, 98\%). ${ }^{1} \mathrm{H}-\mathrm{NMR}\left(400 \mathrm{MHz}, \mathrm{CDCl}_{3}\right)$ $\delta$ (ppm): 7.91 (d, J = 8.8 Hz, 2H, Ar), 6.89 (d, J = 8.8 Hz, 2H, Ar), 3.82 (s, 3H, OMe), 2.91 (q, J = $7.2 \mathrm{~Hz}$, 
$\left.2 \mathrm{H}, \mathrm{CH}_{2}\right), 1.18\left(\mathrm{t}, J=7.2 \mathrm{~Hz}, 3 \mathrm{H}, \mathrm{CH}_{3}\right) .{ }^{13} \mathrm{C}-\mathrm{NMR}\left(100 \mathrm{MHz}, \mathrm{CDCl}_{3}\right) \delta(\mathrm{ppm}): 199.34(\mathrm{C}=\mathrm{O}), 163.16$ $\left(\mathrm{C}^{4} \mathrm{Ar}\right), 130.06\left(\mathrm{C}^{2,6} \mathrm{Ar}\right), 129.85\left(\mathrm{C}^{1} \mathrm{Ar}\right), 113.52\left(\mathrm{C}^{3,5} \mathrm{Ar}\right), 55.29(\mathrm{OMe}), 31.26\left(\mathrm{CH}_{2}\right), 8.29\left(\mathrm{CH}_{3}\right)$.

1-(4-Acetylphenyl)propanone (3b) [39]: White powder (80.9 mg, 92\%), mp 69-71 ${ }^{\circ} \mathrm{C} .{ }^{1} \mathrm{H}-\mathrm{NMR}(400 \mathrm{MHz}$, $\left.\mathrm{CDCl}_{3}\right) \delta(\mathrm{ppm}): 8.00(\mathrm{~s}, 4 \mathrm{H}, \mathrm{Ar}), 3.01\left(\mathrm{q}, J=7.2 \mathrm{~Hz}, 2 \mathrm{H}, \mathrm{CH}_{2}\right), 2.62(\mathrm{~s}, 3 \mathrm{H}, \mathrm{Ac}), 1.21(\mathrm{t}, J=7.2 \mathrm{~Hz}$, $\left.3 \mathrm{H}, \mathrm{CH}_{3}\right) .{ }^{13} \mathrm{C}-\mathrm{NMR}\left(100 \mathrm{MHz}, \mathrm{CDCl}_{3}\right) \delta(\mathrm{ppm}): 200.13(\mathrm{C}=\mathrm{O}), 197.46(\mathrm{C}=\mathrm{O}), 139.96\left(\mathrm{C}^{1 / 4} \mathrm{Ar}\right), 139.90$ $\left(\mathrm{C}^{1 / 4} \mathrm{Ar}\right), 128.41\left(\mathrm{C}_{\mathrm{Ar}}\right), 128.07\left(\mathrm{C}_{\mathrm{Ar}}\right), 32.15\left(\mathrm{CH}_{2}\right), 26.81(\mathrm{MeCO}), 7.97\left(\mathrm{CH}_{3}\right)$.

4-Propionylbenzonitrile (3c) [40]: White powder (55.8 mg, 70\%), mp 53-55 ${ }^{\circ} \mathrm{C} .{ }^{1} \mathrm{H}-\mathrm{NMR}(400 \mathrm{MHz}$, $\left.\mathrm{CDCl}_{3}\right) \delta(\mathrm{ppm}): 7.97$ (d, J = 8.4 Hz, 2H, Ar), $7.69(\mathrm{~d}, J=8.4 \mathrm{~Hz}, 2 \mathrm{H}, \mathrm{Ar}), 2.95\left(\mathrm{q}, J=7.2 \mathrm{~Hz}, 2 \mathrm{H}, \mathrm{CH}_{2}\right.$ ), $1.15\left(\mathrm{t}, J=7.2 \mathrm{~Hz}, 3 \mathrm{H}, \mathrm{CH}_{3}\right) .{ }^{13} \mathrm{C}-\mathrm{NMR}\left(100 \mathrm{MHz}, \mathrm{CDCl}_{3}\right) \delta(\mathrm{ppm}): 199.16(\mathrm{C}=\mathrm{O}), 139.64\left(\mathrm{C}^{4} \mathrm{Ar}\right), 132.33$ $\left(\mathrm{C}_{\mathrm{Ar}}\right), 128.23\left(\mathrm{C}_{\mathrm{Ar}}\right), 117.84\left(\mathrm{CN} / \mathrm{C}^{1} \mathrm{Ar}\right), 115.95\left(\mathrm{CN} / \mathrm{C}^{1} \mathrm{Ar}\right), 32.01\left(\mathrm{CH}_{2}\right), 7.75\left(\mathrm{CH}_{3}\right)$.

Methyl 4-propionylbenzoate (3d) [41]: White crystalline powder, $(87.1 \mathrm{mg}, 91 \%), \mathrm{mp} 81-83{ }^{\circ} \mathrm{C} .{ }^{1} \mathrm{H}-\mathrm{NMR}$ $\left(400 \mathrm{MHz}, \mathrm{CDCl}_{3}\right) \delta(\mathrm{ppm}): 8.08$ (d, $\left.J=8.4 \mathrm{~Hz}, 2 \mathrm{H}, \mathrm{Ar}\right), 7.97(\mathrm{~d}, J=8.4 \mathrm{~Hz}, 2 \mathrm{H}, \mathrm{Ar}), 3.92(\mathrm{~s}, 3 \mathrm{H}, \mathrm{OMe})$, $3.05\left(\mathrm{q}, J=7.2 \mathrm{~Hz}, 2 \mathrm{H}, \mathrm{CH}_{2}\right), 1.21\left(\mathrm{t}, J=7.2 \mathrm{~Hz}, 3 \mathrm{H}, \mathrm{CH}_{3}\right) .{ }^{13} \mathrm{C}-\mathrm{NMR}\left(100 \mathrm{MHz}, \mathrm{CDCl}_{3}\right) \delta(\mathrm{ppm}): 200.15$ $(\mathrm{C}=\mathrm{O}), 166.17(\mathrm{OC}=\mathrm{O}), 140.01\left(\mathrm{C}^{1 / 4}{ }_{\mathrm{Ar}}\right), 133.59\left(\mathrm{C}^{1 / 4}{ }_{\mathrm{Ar}}\right), 129.72\left(\mathrm{C}_{\mathrm{Ar}}\right), 127.78\left(\mathrm{C}_{\mathrm{Ar}}\right), 52.35(\mathrm{OMe}), 32.10$ $\left(\mathrm{CH}_{2}\right), 7.96\left(\mathrm{CH}_{3}\right)$.

1-(4-Ethylphenyl)propanone (3e) [42]: Colorless oil $\left(71.1 \mathrm{mg}, 88 \%\right.$, with 2.5 equiv $\left.\mathrm{BEt}_{3}\right) .{ }^{1} \mathrm{H}-\mathrm{NMR}(400$ $\left.\mathrm{MHz}, \mathrm{CDCl}_{3}\right) \delta(\mathrm{ppm}): 7.81(\mathrm{~d}, J=8.4 \mathrm{~Hz}, 2 \mathrm{H}, \mathrm{Ar}), 7.19(\mathrm{~d}, J=8.4 \mathrm{~Hz}, 2 \mathrm{H}, \mathrm{Ar}), 2.90(\mathrm{q}, J=7.2 \mathrm{~Hz}, 2 \mathrm{H}$, $\left.\mathrm{COCH}_{2}\right), 2.61\left(\mathrm{q}, J=7.6 \mathrm{~Hz}, 2 \mathrm{H}, \mathrm{ArCH}_{2}\right), 1.17\left(\mathrm{t}, J=7.6 \mathrm{~Hz}, 3 \mathrm{H}, \mathrm{COCH}_{2} \mathrm{CH}_{3}\right), 1.13(\mathrm{t}, J=7.2 \mathrm{~Hz}, 3 \mathrm{H}$, $\left.\mathrm{Ar} \mathrm{CH}_{2} \mathrm{CH}_{3}\right) .{ }^{13} \mathrm{C}-\mathrm{NMR}\left(100 \mathrm{MHz}, \mathrm{CDCl}_{3}\right) \delta(\mathrm{ppm}): 200.51(\mathrm{C}=\mathrm{O}), 149.71\left(\mathrm{C}^{4} \mathrm{Ar}\right), 134.59\left(\mathrm{C}^{1} \mathrm{Ar}\right), 128.14$ $\left(\mathrm{C}_{\mathrm{Ar}}\right), 127.97\left(\mathrm{C}_{\mathrm{Ar}}\right), 31.60\left(\mathrm{COCH}_{2}\right), 28.85\left(\mathrm{ArCH}_{2}\right), 15.16\left(\mathrm{ArCH}_{2} \mathrm{CH}_{3}\right), 8.27\left(\mathrm{COCH}_{2} \mathrm{CH}_{3}\right)$.

1-(o-Tolyl)propanone (3f) [43]: Colorless oil (53.4 mg, 72\%). ${ }^{1} \mathrm{H}-\mathrm{NMR}\left(400 \mathrm{MHz}, \mathrm{CDCl}_{3}\right) \delta(\mathrm{ppm}): 7.53$ $(\mathrm{d}, J=7.6 \mathrm{~Hz}, 1 \mathrm{H}), 7.29-7.25(\mathrm{~m}, 1 \mathrm{H}, \mathrm{Ar}), 7.16-7.14(\mathrm{~m}, 2 \mathrm{H}, \mathrm{Ar}), 2.82\left(\mathrm{q}, J=7.2 \mathrm{~Hz}, 2 \mathrm{H}, \mathrm{CH}_{2}\right), 2.41$ (s, $\left.3 \mathrm{H}, \mathrm{ArCH}_{3}\right), 1.11\left(\mathrm{t}, J=7.2 \mathrm{~Hz}, 3 \mathrm{H}, \mathrm{CH}_{3}\right) .{ }^{13} \mathrm{C}-\mathrm{NMR}\left(100 \mathrm{MHz}, \mathrm{CDCl}_{3}\right) \delta(\mathrm{ppm}): 205.04(\mathrm{C}=\mathrm{O})$, $138.01\left(\mathrm{C}^{1 / 2} \mathrm{Ar}\right), 137.76\left(\mathrm{C}^{1 / 2} \mathrm{Ar}\right), 131.81\left(\mathrm{C}_{\mathrm{Ar}}\right), 130.97\left(\mathrm{C}_{\mathrm{Ar}}\right), 128.19\left(\mathrm{C}_{\mathrm{Ar}}\right), 125.56\left(\mathrm{C}_{\mathrm{Ar}}\right), 34.64\left(\mathrm{CH}_{2}\right), 21.19$ $\left(\mathrm{ArCH}_{3}\right), 8.31\left(\mathrm{CH}_{3}\right)$.

1-Phenylpentan-3-one (3g) [44]: Colorless oil (77.1 mg, 95\%). ${ }^{1} \mathrm{H}-\mathrm{NMR}\left(400 \mathrm{MHz}, \mathrm{CDCl}_{3}\right) \delta(\mathrm{ppm})$ : 7.33-7.29 (m, 2H, Ph), 7.23-7.20 (m, 3H, Ph), $2.93\left(\mathrm{t}, J=7.6 \mathrm{~Hz}, 2 \mathrm{H}, \mathrm{PhCH}_{2} \mathrm{CH}_{2} \mathrm{CO}\right), 2.76(\mathrm{t}, J=7.6 \mathrm{~Hz}, 2 \mathrm{H}$, $\left.\mathrm{PhCH}_{2}\right), 2.43\left(\mathrm{q}, J=7.2 \mathrm{~Hz}, 2 \mathrm{H}, \mathrm{CO} \mathrm{CH} \mathrm{CH}_{3}\right), 1.07\left(\mathrm{t}, J=7.2 \mathrm{~Hz}, 3 \mathrm{H}, \mathrm{CH}_{3}\right) \cdot{ }^{13} \mathrm{C}-\mathrm{NMR}\left(100 \mathrm{MHz}, \mathrm{CDCl}_{3}\right)$ $\delta(\mathrm{ppm}): 210.61(\mathrm{C}=\mathrm{O}), 141.10\left(\mathrm{C}^{1} \mathrm{Ph}\right), 128.41(\mathrm{Ph}), 128.24(\mathrm{Ph}), 126.00\left(\mathrm{C}^{4} \mathrm{Ph}\right), 43.81\left(\mathrm{PhCH}_{2} \mathrm{CH}_{2} \mathrm{CO}\right)$, $36.05\left(\mathrm{COCH}_{2} \mathrm{CH}_{3}\right), 29.77\left(\mathrm{PhCH}_{2}\right), 7.69\left(\mathrm{CH}_{3}\right)$.

1-(4-Methoxyphenyl)pentan-3-one (3h) [45]: Colorless oil (94.3 mg, 98\%). ${ }^{1} \mathrm{H}-\mathrm{NMR}\left(400 \mathrm{MHz}, \mathrm{CDCl}_{3}\right)$ $\delta(\mathrm{ppm}): 7.09$ (d, $J=8.8 \mathrm{~Hz}, 2 \mathrm{H}, \mathrm{Ar}), 6.81(\mathrm{~d}, J=8.8 \mathrm{~Hz}, 2 \mathrm{H}, \mathrm{Ar}), 3.77(\mathrm{~s}, 3 \mathrm{H}, \mathrm{OMe}), 2.84(\mathrm{t}, J=7.6 \mathrm{~Hz}, 2 \mathrm{H}$, $\left.\mathrm{PhCH}_{2} \mathrm{CH}_{2} \mathrm{CO}\right), 2.64\left(\mathrm{t}, J=7.6 \mathrm{~Hz}, 2 \mathrm{H}, \mathrm{PhCH}_{2}\right), 2.39\left(\mathrm{q}, J=7.6 \mathrm{~Hz}, 2 \mathrm{H}, \mathrm{COCH}_{2} \mathrm{CH}_{3}\right), 1.03(\mathrm{t}, J=7.6 \mathrm{~Hz}$, $\left.3 \mathrm{H}, \mathrm{CH}_{3}\right) .{ }^{13} \mathrm{C}-\mathrm{NMR}\left(100 \mathrm{MHz}, \mathrm{CDCl}_{3}\right) \delta(\mathrm{ppm}): 210.80(\mathrm{C}=\mathrm{O}), 157.85\left(\mathrm{C}^{4} \mathrm{Ar}\right), 133.12\left(\mathrm{C}^{1} \mathrm{Ar}\right), 129.16$ $\left(\mathrm{C}_{\mathrm{Ar}}\right), 113.79\left(\mathrm{C}_{\mathrm{Ar}}\right), 55.17(\mathrm{OMe}), 44.09\left(\mathrm{PhCH}_{2} \mathrm{CH}_{2} \mathrm{CO}\right), 36.08\left(\mathrm{COCH}_{2} \mathrm{CH}_{3}\right), 28.93\left(\mathrm{PhCH}_{2}\right), 7.68\left(\mathrm{CH}_{3}\right)$.

1-(4-Methoxyphenyl)pentanone (3i) [46]: Colorless oil (93.5 mg, 97\%). ${ }^{1} \mathrm{H}-\mathrm{NMR}\left(400 \mathrm{MHz}, \mathrm{CDCl}_{3}\right.$ ) $\delta(\mathrm{ppm}): 7.93(\mathrm{~d}, J=8.8 \mathrm{~Hz}, 2 \mathrm{H}, \mathrm{Ar}), 6.91(\mathrm{~d}, J=9.2 \mathrm{~Hz}, 2 \mathrm{H}, \mathrm{Ar}), 3.85(\mathrm{~s}, 3 \mathrm{H}, \mathrm{OMe}), 2.90(\mathrm{t}, J=7.6 \mathrm{~Hz}$, $\left.2 \mathrm{H}, \mathrm{COCH}_{2}\right), 1.73-1.66\left(\mathrm{~m}, 2 \mathrm{H}, \mathrm{COCH}_{2} \mathrm{CH}_{2}\right), 1.44-1.34\left(\mathrm{~m}, 2 \mathrm{H}, \mathrm{COCH}_{2} \mathrm{CH}_{2} \mathrm{CH}_{2}\right), 0.94(\mathrm{t}, J=7.6 \mathrm{~Hz}$, 3H). ${ }^{13} \mathrm{C}-\mathrm{NMR}\left(100 \mathrm{MHz}, \mathrm{CDCl}_{3}\right) \delta(\mathrm{ppm}): 199.20(\mathrm{C}=\mathrm{O}), 163.23\left(\mathrm{C}^{4}{ }_{\mathrm{Ar}}\right), 130.25\left(\mathrm{C}^{2,6} \mathrm{Ar}\right), 130.11\left(\mathrm{C}^{1} \mathrm{Ar}\right)$, $113.59\left(\mathrm{C}^{3,5} \mathrm{Ar}\right), 55.37(\mathrm{OMe}), 37.95\left(\mathrm{COCH}_{2}\right), 26.68\left(\mathrm{CH}_{2}\right), 22.48\left(\mathrm{CH}_{2}\right), 13.90\left(\mathrm{CH}_{3}\right)$.

1-(4-Methoxyphenyl)nonanone (3j) [47]: Colorless oil (123.0 mg, 99\%, with tri(n-octyl)borane; $115 \mathrm{mg}$, $93 \%$ with hydroboration of octene with 9-BBN; $113 \mathrm{mg}$, 91\% with hydroboration of octene with $\mathrm{BH}_{3}$. ${ }^{1} \mathrm{H}-\mathrm{NMR}\left(400 \mathrm{MHz}, \mathrm{CDCl}_{3}\right) \delta(\mathrm{ppm}): 7.86(\mathrm{~d}, J=9.2 \mathrm{~Hz}, 2 \mathrm{H}, \mathrm{Ar}), 6.84(\mathrm{~d}, J=9.2 \mathrm{~Hz}, 2 \mathrm{H}, \mathrm{Ar}), 3.78(\mathrm{~s}, 3 \mathrm{H}$, $\mathrm{OMe}), 2.82\left(\mathrm{t}, J=7.6 \mathrm{~Hz}, 2 \mathrm{H}, \mathrm{COCH}_{2}\right), 1.63\left(\mathrm{t}, J=7.6 \mathrm{~Hz}, 2 \mathrm{H}, \mathrm{COCH}_{2} \mathrm{CH}_{2}\right), 1.29-1.19\left(\mathrm{~m}, 10 \mathrm{H},\left(\mathrm{CH}_{2}\right)_{5}\right)$, $0.80\left(\mathrm{t}, J=7.2 \mathrm{~Hz}, 3 \mathrm{H}, \mathrm{CH}_{3}\right) .{ }^{13} \mathrm{C}-\mathrm{NMR}\left(100 \mathrm{MHz}, \mathrm{CDCl}_{3}\right) \delta(\mathrm{ppm}): 199.20(\mathrm{C}=\mathrm{O}), 163.23\left(\mathrm{C}^{4} \mathrm{Ar}\right), 130.25$ 
$\left(\mathrm{C}^{2,6}{ }_{\mathrm{Ar}}\right), 130.13\left(\mathrm{C}^{1} \mathrm{Ar}\right), 113.60\left(\mathrm{C}^{3,5} \mathrm{Ar}\right), 55.37(\mathrm{OMe}), 38.26\left(\mathrm{COCH}_{2}\right), 31.79\left(\mathrm{CH}_{2}\right), 29.41\left(\mathrm{CH}_{2}\right), 29.39$ $\left(\mathrm{CH}_{2}\right), 29.14\left(\mathrm{CH}_{2}\right), 24.59\left(\mathrm{CH}_{2}\right), 22.61\left(\mathrm{CH}_{2}\right), 14.05\left(\mathrm{CH}_{3}\right)$.

1-(4-Methoxyphenyl)-3-phenylbutanone (3k) [46]: White powder (125.0 mg, 98\%), mp 84-86 ${ }^{\circ} \mathrm{C} .{ }^{1} \mathrm{H}-\mathrm{NMR}$ $\left(400 \mathrm{MHz}, \mathrm{CDCl}_{3}\right) \delta(\mathrm{ppm}): 7.93(\mathrm{~d}, \mathrm{~J}=8.8 \mathrm{~Hz}, 2 \mathrm{H}, \mathrm{Ar}), 7.34-7.30(\mathrm{~m}, 4 \mathrm{H}, \mathrm{Ph}), 7.23-7.19(\mathrm{~m}, 1 \mathrm{H}, \mathrm{Ph})$, $6.92(\mathrm{~d}, J=8.8 \mathrm{~Hz}, 2 \mathrm{H}, \mathrm{Ar}), 3.86(\mathrm{~s}, 3 \mathrm{H}, \mathrm{OMe}), 3.55-3.47(\mathrm{~m}, 1 \mathrm{H}, \mathrm{CH}), 3.26\left(\mathrm{dd}, J_{1}=16.4 \mathrm{~Hz}, J_{2}=5.6 \mathrm{~Hz}\right.$, $\left.1 \mathrm{H}, \mathrm{CH}_{2}\right), 3.14\left(\mathrm{dd}, J_{1}=16.0 \mathrm{~Hz}, J_{2}=8.4 \mathrm{~Hz}, 1 \mathrm{H}, \mathrm{CH}_{2}\right), 1.34\left(\mathrm{~d}, J=7.8,3 \mathrm{H}, \mathrm{CH}_{3}\right) .{ }^{13} \mathrm{C}-\mathrm{NMR}(100 \mathrm{MHz}$, $\left.\mathrm{CDCl}_{3}\right) \delta(\mathrm{ppm}): 197.59(\mathrm{C}=\mathrm{O}), 163.31\left(\mathrm{C}^{4} \mathrm{Ar}\right), 146.65\left(\mathrm{C}^{1} \mathrm{Ph}\right), 130.28\left(\mathrm{C}_{\mathrm{Ar}} / \mathrm{C}_{\mathrm{Ph}}\right), 130.21\left(\mathrm{C}^{1} \mathrm{Ar}\right), 128.43$ $\left(\mathrm{C}_{\mathrm{Ph}}\right), 126.79\left(\mathrm{C}_{\mathrm{Ph}}\right), 126.15\left(\mathrm{C}_{\mathrm{Ph}}^{4}\right), 113.61\left(\mathrm{C}^{3,5} \mathrm{Ar}\right), 55.37(\mathrm{OMe}), 46.59\left(\mathrm{COCH}_{2}\right), 35.67(\mathrm{CH}), 21.79\left(\mathrm{CH}_{3}\right)$.

1-Cyclohexyl-3-phenylbutanone (31): Colorless oil (103.7 mg, 90\%). ${ }^{1} \mathrm{H}-\mathrm{NMR}\left(400 \mathrm{MHz}, \mathrm{CDCl}_{3}\right) \delta(\mathrm{ppm})$ : 7.33-7.29 (m, 2H, Ph), 7.25-7.19 (m, 3H, Ph), 3.41-3.32 (m, 1H, PhCH), $2.77\left(\mathrm{dd}, J_{1}=16.8 \mathrm{~Hz}, J_{2}=6.4 \mathrm{~Hz}\right.$, $1 \mathrm{H}, \mathrm{CO} \mathrm{CH}), 2.69\left(\mathrm{dd}, J_{1}=16.4 \mathrm{~Hz}, J_{2}=8.0 \mathrm{~Hz}, 1 \mathrm{H}, \mathrm{COCH}_{2}\right), 2.29-2.22(\mathrm{~m}, 1 \mathrm{H}, \mathrm{COCH}), 1.83-1.65(\mathrm{~m}$, $5 \mathrm{H}, \mathrm{Cy}), 1.35-1.17$ (m, 8H, Cy overlapped with $\left.\mathrm{CH}_{3}\right) .{ }^{13} \mathrm{C}-\mathrm{NMR}\left(100 \mathrm{MHz}, \mathrm{CDCl}_{3}\right) \delta(\mathrm{ppm}): 212.83$ $(\mathrm{C}=\mathrm{O}), 146.54\left(\mathrm{C}_{\mathrm{Ph}}^{1}\right), 128.39\left(\mathrm{C}_{\mathrm{Ph}}\right), 126.75\left(\mathrm{C}_{\mathrm{Ph}}\right), 126.11\left(\mathrm{C}_{\mathrm{Ph}}^{4}\right), 51.19(\mathrm{COCH}), 49.10\left(\mathrm{COCH}_{2}\right), 35.02$ $(\mathrm{CH}), 28.22(\mathrm{Cy}), 28.05(\mathrm{Cy}), 25.78(\mathrm{Cy}), 25.61(\mathrm{Cy}), 25.53(\mathrm{Cy}), 21.79\left(\mathrm{CH}_{3}\right)$. HRMS (ESI) $\mathrm{m} / \mathrm{z}$ calcd for $\mathrm{C}_{16} \mathrm{H}_{22} \mathrm{ONa}[\mathrm{M}+\mathrm{Na}]^{+} 253.1568$, found 253.1569 .

3-Phenyl-1-(thiophen-2-yl)butanone (3m) [48]: Colorless oil (111.5 mg, 97\%). ${ }^{1} \mathrm{H}-\mathrm{NMR}\left(400 \mathrm{MHz}, \mathrm{CDCl}_{3}\right.$ ) $\delta(\mathrm{ppm})$ : 7.70-7.69 (m, 1H, thiophenyl), 7.64-7.63 (m, 1H, thiophenyl), 7.36-7.28 $(\mathrm{m}, 4 \mathrm{H}, \mathrm{Ph}), 7.25-7.23$ $(\mathrm{m}, 1 \mathrm{H}, \mathrm{Ph}), 7.14-7.12\left(\mathrm{~m}, 1 \mathrm{H}\right.$, thiophenyl), 3.56-3.51 $(\mathrm{m}, 1 \mathrm{H}, \mathrm{PhCH}), 3.24\left(\mathrm{dd}, J_{1}=16.0 \mathrm{~Hz}, J_{2}=6.0 \mathrm{~Hz}\right.$, $\left.1 \mathrm{H}, \mathrm{CH}_{2} \mathrm{CO}\right), 3.14\left(\mathrm{dd}, J_{1}=15.6 \mathrm{~Hz}, J_{2}=8.4 \mathrm{~Hz}, 1 \mathrm{H}, \mathrm{CH}_{2} \mathrm{CO}\right), 1.38\left(\mathrm{~d}, J=6.8 \mathrm{~Hz}, 3 \mathrm{H}, \mathrm{CH}_{3}\right) .{ }^{13} \mathrm{C}-\mathrm{NMR}$ $\left(100 \mathrm{MHz}, \mathrm{CDCl}_{3}\right) \delta(\mathrm{ppm}): 191.94(\mathrm{C}=\mathrm{O}), 146.18\left(\mathrm{C}^{1}{ }_{\mathrm{Ph}}\right), 144.60\left(\mathrm{C}^{2}\right.$ thiophenyl), 133.56 (thiophenyl), 131.81 (thiophenyl), 128.49 $\left(\mathrm{C}_{\mathrm{Ph}}\right), 128.01$ (thiophenyl), $126.78\left(\mathrm{C}_{\mathrm{Ph}}\right), 126.30\left(\mathrm{C}^{4} \mathrm{Ph}\right), 47.78\left(\mathrm{COCH}_{2}\right), 35.93$ $(\mathrm{CH}), 21.64\left(\mathrm{CH}_{3}\right)$.

1-Phenylnonanone (3n) [47]: Colorless oil (106.8 mg, 98\%). ${ }^{1} \mathrm{H}-\mathrm{NMR}\left(400 \mathrm{MHz}, \mathrm{CDCl}_{3}\right) \delta(\mathrm{ppm}): 7.97-7.95$ $(\mathrm{m}, 2 \mathrm{H}, \mathrm{Ph}), 7.57-7.53(\mathrm{~m}, 1 \mathrm{H}, \mathrm{Ph}), 7.47-7.44(\mathrm{~m}, 2 \mathrm{H}, \mathrm{Ph}), 2.96\left(\mathrm{t}, J=7.6 \mathrm{~Hz}, 2 \mathrm{H}, \mathrm{COCH}_{2}\right), 1.77-1.69$ $\left(\mathrm{m}, 2 \mathrm{H}, \mathrm{COCH}_{2} \mathrm{CH}_{2}\right), 1.39-1.25\left(\mathrm{~m}, 10 \mathrm{H},\left(\mathrm{CH}_{2}\right)_{5}\right), 0.88\left(\mathrm{t}, J=6.8 \mathrm{~Hz}, 3 \mathrm{H}, \mathrm{CH}_{3}\right) .{ }^{13} \mathrm{C}-\mathrm{NMR}(100 \mathrm{MHz}$, $\left.\left.\mathrm{CDCl}_{3}\right) \delta(\mathrm{ppm}): 200.62(\mathrm{C}=\mathrm{O}), 137.05 \mathrm{C}^{1} \mathrm{Ph}\right), 132.83\left(\mathrm{C}^{4} \mathrm{Ph}\right), 128.51\left(\mathrm{C}_{\mathrm{Ph}}\right), 128.02\left(\mathrm{C}_{\mathrm{Ph}}\right), 38.61\left(\mathrm{COCH}_{2}\right)$, $31.81\left(\mathrm{CH}_{2}\right), 29.42\left(\mathrm{CH}_{2}\right), 29.36\left(\mathrm{CH}_{2}\right), 29.15\left(\mathrm{CH}_{2}\right), 24.36\left(\mathrm{CH}_{2}\right), 22.63\left(\mathrm{CH}_{2}\right), 14.08\left(\mathrm{CH}_{3}\right)$.

\section{Conclusions}

In summary, we have developed a highly efficient acylative cross-coupling of trialkylboranes with activated amides by using 1,3-bis(2,6-diisopropyl)phenylimidazolylidene and 3-chloropyridine co-supported palladium chloride, the PEPPSI catalyst, under mild conditions. Bases appeared to play a key role in the reaction, among which $\mathrm{K}_{2} \mathrm{CO}_{3}$ performed best in MTBE at room temperature. The reaction proceeded to give alkyl ketones in good to excellent yields, tolerating a variety of functional groups in the amide counterpart. Unlike the high-order arylboron compounds, in which all the aryl groups react effectively, only one of the three primary alkyl groups in trialkylboranes could be used as alkyl source for the acyl alkylation. The trialkylboranes generated in situ by hydroboration of olefins with $\mathrm{BH}_{3}$ or 9-BBN performed comparably to those separately prepared. This protocol complements ketone synthesis via palladium-catalyzed acylative cross-coupling of amides, providing a feasible access to both monoalkyl and dialkyl ketones.

Supplementary Materials: The following are available online, Figures S1-S28: ${ }^{1} \mathrm{H}$ and ${ }^{13} \mathrm{C}-\mathrm{NMR}$ of products $3 a-3 n$, Figure S29 HRMS of 31 .

Author Contributions: Conceptualization, G.Z.; Investigation, W.S.; Writing-Original Draft Preparation, W.S.; Writing-Review \& Editing, G.Z.Funding: This research was funded by National Natural Science Foundation of China [21472041].

Conflicts of Interest: The authors declare no conflict of interest. 


\section{References}

1. Hie, L.; Nathel, N.F.F.; Shah, T.K.; Baker, E.L.; Hong, X.; Yang, Y.-F.; Liu, P.; Houk, K.N.; Garg, N.K. Conversion of amides to esters by the nickel-catalysed activation of amide C-N bonds. Nature 2015, 524, 79-83. [CrossRef] [PubMed]

2. Meng, G.; Szostak, M. Sterically controlled Pd-catalyzed chemoselective ketone synthesis via N-C cleavage in twisted amides. Org. Lett. 2015, 17, 4364-4367. [CrossRef] [PubMed]

3. Li, X.; Zou, G. Acylative Suzuki coupling of amides: Acyl-nitrogen activation via synergy of independently modifiable activating groups. Chem. Commun. 2015, 51, 5089-5092. [CrossRef] [PubMed]

4. Pace, V.; Holzer, W.; Meng, G.; Shi, S.; Lalancette, R.; Szostak, R.; Szostak, M. Structures of highly twisted amides relevant to amide N-C cross-coupling: Evidence for ground-state amide destabilization. Chem. Eur. J. 2016, 22, 14494-14498. [CrossRef] [PubMed]

5. Osumi, Y.; Liu, C.; Szostak, M. N-Acylsuccinimides: Twist-controlled, acyl-transfer reagents in Suzuki-Miyaura cross-coupling by N-C amide bond activation. Org. Biomol. Chem. 2017, 15, 8867-8871. [CrossRef] [PubMed]

6. Cui, M.; Chen, Z.; Liu, T.; Wang, H.; Zeng, Z. N-Acylsuccinimides: Efficient acylative coupling reagents in palladium-catalyzed Suzuki coupling via C-N cleavage. Tetrahedron Lett. 2017, 58, 3819-3822. [CrossRef]

7. Boit, T.B.; Weires, N.A.; Kim, J.; Garg, N.K. Nickel-catalyzed Suzuki-Miyaura coupling of aliphatic amides. ACS Catal. 2018, 8, 1003-1008. [CrossRef] [PubMed]

8. Hie, L.; Baker, E.L.; Anthony, S.M.; Desrosiers, J.-N.; Senanayake, C.; Garg, N.K. Nickel-catalyzed esterification of aliphatic amides. Angew. Chem. Int. Ed. 2016, 55, 15129-15132. [CrossRef] [PubMed]

9. Lanigan, R.M.; Sheppard, T.D. Recent developments in amide synthesis: Direct amidation of carboxylic acids and transamidation reactions. Eur. J. Org. Chem. 2013, 7453-7465. [CrossRef]

10. Baker, E.L.; Yamano, M.M.; Zhou, Y.; Anthony, S.M.; Garg, N.K. A two-step approach to achieve secondary amide transamidation enabled by nickel catalysis. Nat. Commun. 2016, 7, 11554. [CrossRef] [PubMed]

11. Lei, P.; Meng, G.; Ling, Y.; An, J.; Nolan, S.P.; Szostak, M. General method for the Suzuki-Miyaura cross-coupling of primary amide-derived electrophiles enabled by $[\mathrm{Pd}(\mathrm{NHC})(\mathrm{cin}) \mathrm{Cl}]$ at room temperature. Org. Lett. 2017, 19, 6510-6513. [CrossRef] [PubMed]

12. Shi, S.; Szostak, M. Nickel-catalyzed diaryl ketone synthesis by N-C cleavage: Direct Negishi cross-coupling of primary amides by site-selective N, N-di-Boc activation. Org. Lett. 2016, 18, 5872-5875. [CrossRef] [PubMed]

13. Meng, G.; Szostak, M. Site-selective C-H/C-N activation by cooperative catalysis: Primary amides as arylating reagents in directed C-H arylation. ACS Catal. 2017, 7, 7251-7256. [CrossRef]

14. Liu, C.; Liu, Y.; Liu, R.; Lalancette, R.; Szostak, R.; Szostak, M. Palladium-catalyzed Suzuki-Miyaura cross-coupling of N-mesylamides by N-C cleavage: Electronic effect of the mesyl group. Org. Lett. 2017, 19, 1434-1437. [CrossRef] [PubMed]

15. Wang, C.; Huang, L.; Wang, F.; Zou, G. Highly efficient synthesis of aryl ketones by PEPPSI-palladium catalyzed acylative Suzuki coupling of amides with diarylborinic acids. Tetrahedron Lett. 2018, 59, 2299-2301. [CrossRef]

16. Liu, C.; Meng, G.; Liu, Y.; Liu, R.; Lalancette, R.; Szostak, R.; Szostak, M. N-Acylsaccharins: Stable electrophilic amide-based acyl transfer reagents in Pd-catalyzed Suzuki-Miyaura coupling via N-C cleavage. Org. Lett. 2016, 18, 4194-4197. [CrossRef] [PubMed]

17. Wu, H.; Li, Y.; Cui, M.; Jian, J.; Zeng, Z. Suzuki coupling of amides via palladium-catalyzed C-N cleavage of N-acylsaccharins. Adv. Synth. Catal. 2016, 358, 3876-3880. [CrossRef]

18. Liu, C.; Meng, G.; Szostak, M. N-Acylsaccharins as amide-based arylating reagents via chemoselective N-C cleavage: Pd-catalyzed decarbonylative Heck reaction. J. Org. Chem. 2016, 81, 12023-12030. [CrossRef] [PubMed]

19. Cui, M.; Wu, H.; Jian, J.; Wang, H.; Liu, C.; Daniel, S.; Zeng, Z. Palladium-catalyzed Sonogashira coupling of amides: Access to ynones via C-N bond cleavage. Chem. Commun. 2016, 52, 12076-12079. [CrossRef] [PubMed]

20. Wu, H.; Liu, T.; Cui, M.; Li, Y.; Jian, J.; Wang, H.; Zeng, Z. Rhodium-catalyzed C-H functionalization with N-acylsaccharins. Org. Biomol. Chem. 2017, 15, 536-540. [CrossRef] [PubMed] 
21. Meng, G.; Szostak, R.; Szostak, M. Suzuki-Miyaura cross-coupling of N-acylpyrroles and pyrazoles: Planar, electronically activated amides in catalytic N-C cleavage. Org. Lett. 2017, 19, 3596-3599. [CrossRef] [PubMed]

22. Meng, G.; Lalancette, R.; Szostak, R.; Szostak, M. N-methylamino pyrimidyl amides (MAPA): Highly reactive, electronically-activated amides in catalytic N-C(O) cleavage. Org. Lett. 2017, 19, 4656-4659. [CrossRef] [PubMed]

23. Masson-Makdissi, J.; Vandavasi, J.K.; Newman, S.G. Switchable selectivity in the Pd-catalyzed alkylative cross-coupling of esters. Org. Lett. 2018, 20, 4094-4098. [CrossRef] [PubMed]

24. Liu, X.; Jia, J.; Rueping, M. Nickel-catalyzed C-O bond-cleaving alkylation of esters: Direct replacement of the ester moiety by functionalized alkyl chains. ACS Catal. 2017, 7, 4491-4496. [CrossRef]

25. Chatupheeraphat, A.; Liao, H.-H.; Srimontree, W.; Guo, L.; Minenkov, Y.; Poater, A.; Cavallo, L.; Rueping, M. Ligand-controlled chemoselective $\mathrm{C}(\operatorname{acyl})-\mathrm{O}$ Bond vs $\mathrm{C}(\operatorname{aryl})-\mathrm{C}$ bond activation of aromatic esters in nickel catalyzed C $\left(\mathrm{sp}^{2}\right)-\mathrm{C}\left(\mathrm{sp}^{3}\right)$ cross-couplings. J. Am. Chem. Soc. 2018, 140, 3724-3735. [CrossRef] [PubMed]

26. Simmons, B.J.; Weires, N.A.; Dander, J.E.; Garg, N.K. Nickel-catalyzed alkylation of amide derivatives. ACS Catal. 2016, 6, 3176-3179. [CrossRef]

27. Liu, X.; Hsiao, C.-C.; Guo, L.; Rueping, M. Cross-coupling of amides with alkylboranes via nickel-catalyzed C-N bond cleavage. Org. Lett. 2018, 20, 2976-2979. [CrossRef] [PubMed]

28. Li, X.; Zou, G. Palladium-catalyzed acylative cross-coupling of amides with diarylborinic acids and sodium tetraarylborates. J. Organomet. Chem. 2015, 794, 136-145. [CrossRef]

29. Si, S.; Wang, C.; Zhang, N.; Zou, G. Palladium-catalyzed room-temperature acylative Suzuki coupling of high-order aryl borons with carboxylic acids. J. Org. Chem. 2016, 81, 4364-4370. [CrossRef] [PubMed]

30. O’Brien, C.J.; Kantchev, E.A.B.; Valente, C.; Hadei, N.; Chass, G.A.; Lough, A.; Hopkinson, A.C.; Organ, M.G. Easily prepared air- and moisture-stable $\mathrm{Pd}-\mathrm{NHC}$ (NHC=N-heterocyclic carbene) complexes: A reliable, user-friendly, highly active palladium precatalyst for the Suzuki-Miyaura reaction. Chem. Eur. J. 2006, 12, 4743-4748. [CrossRef] [PubMed]

31. Fortman, G.C.; Nolan, S.P. N-Heterocyclic carbene (NHC) ligands and palladium in homogeneous cross-coupling catalysis: A perfect union. Chem. Soc. Rev. 2011, 40, 5151-5169. [CrossRef] [PubMed]

32. Huang, J.; Nolan, S.P. Efficient cross-coupling of aryl chlorides with aryl Grignard reagents (Kumada reaction) mediated by a palladium/imidazolium chloride system. J. Am. Chem. Soc. 1999, 121, 9889-9890. [CrossRef]

33. Kantchev, E.A.B.; Ying, J.Y. Practical one-pot, three-component synthesis of N-heterocyclic carbene (NHC) ligated palladacycles derived from N,N-dimethylbenzylamine. Organometallics 2009, 28, 289-299. [CrossRef]

34. Brahmachari, G. Room Temperature Organic Synthesis; Elsevier: Amsterdam, The Netherlands, 2015; ISBN 9780128011386.

35. Brown, H.C.; Sharp, R.L. Hydroboration. XXIV. Directive effects in the hydroboration of some substituted styrenes. J. Am. Chem. Soc. 1966, 88, 5851-5854. [CrossRef]

36. Brown, H.C.; Racherla, U.S. Organoboranes. 44. A convenient, highly efficient synthesis of triorganylboranes via a modified organometallic route. J. Org. Chem. 1986, 51, 427-432. [CrossRef]

37. Samanta, S.; Mishra, B.K.; Pace, T.C.S.; Sathyamurthy, N.; Bohne, C.; Moorthy, J.N. $\beta$-Phenyl quenching of triplet excited ketones: How critical is the geometry for deactivation? J. Org. Chem. 2006, 71, 4453-4459. [CrossRef] [PubMed]

38. Rao, M.L.N.; Venkatesh, V.; Banerjee, D. Atom-efficient cross-coupling reactions of triarylbismuths with acyl chlorides under Pd(0) catalysis. Tetrahedron 2007, 63, 12917-12926. [CrossRef]

39. Vu, M.D.; Das, M.; Liu, X.-W. Direct aldehyde $\mathrm{C}_{\mathrm{sp}}{ }^{2}-\mathrm{H}$ functionalization through visible light mediated photoredox catalysis. Chem. Eur. J. 2017, 23, 15899-15902. [CrossRef] [PubMed]

40. Zimbron, J.M.; Seeger-Weibel, M.; Hirt, H.; Gallou, F. Development of a robust and practical process for the Darzens condensation and $\alpha, \beta$-epoxide rearrangement: Scope and limitations of the methodology. Synthesis 2008, 8, 1221-1226. [CrossRef]

41. Liu, M.; Hyder, Z.; Sun, Y.; Tang, W.; Xu, L.; Xiao, J. Efficient synthesis of alkyl aryl ketones \& ketals via palladium-catalyzed regioselective arylation of vinyl ethers. Org. Biomol. Chem. 2010, 8, 2012-2015. [CrossRef] [PubMed]

42. Suchand, B.; Satyanarayana, G. KOtBu-mediated domino isomerization and functionalization of aromatic allylic alcohols. Eur. J. Org. Chem. 2017, 3886-3895. [CrossRef] 
43. Uyanik, M.; Suzuki, D.; Yasui, T.; Ishihara, K. In situ generated (hypo)iodite catalysts for the direct $\alpha$-oxyacylation of carbonyl compounds with carboxylic acids. Angew. Chem. Int. Ed. 2011, 50, 5331-5334. [CrossRef] [PubMed]

44. Li, X.; Li, L.; Tang, Y.; Ling, Z.; Cun, L.; Zhu, J.; Liao, J.; Deng, J. Chemoselective conjugate reduction of $\alpha$, $\beta$-unsaturated ketones catalyzed by rhodium amido complexes in aqueous media. J. Org. Chem. 2010, 75, 2981-2988. [CrossRef] [PubMed]

45. Molander, G.A.; Petrillo, D.E. Suzuki-Miyaura cross-coupling of potassium trifluoroboratohomoenolates. Org. Lett. 2008, 10, 1795-1798. [CrossRef] [PubMed]

46. Colbon, P.; Ruan, J.; Purdie, M.; Xiao, J. Direct acylation of aryl chlorides with aldehydes by palladium-pyrrolidine co-catalysis. Org. Lett. 2010, 12, 3670-3673. [CrossRef] [PubMed]

47. Vautravers, N.R.; Regent, D.D.; Breit, B. Inter- and intramolecular hydroacylation of alkenes employing a bifunctional catalyst system. Chem. Commun. 2011, 47, 6635-6637. [CrossRef] [PubMed]

48. Malanga, C.; Aronica, L.A.; Lardicci, L. Direct $\mathrm{Ni}^{\circ}$ mediated synthesis of ketones from acyl bromides and Grignard reagents. Tetrahedron Lett. 1995, 36, 9185-9188. [CrossRef]

Sample Availability: Samples of the compounds are available from the authors.

(C) 2018 by the authors. Licensee MDPI, Basel, Switzerland. This article is an open access article distributed under the terms and conditions of the Creative Commons Attribution (CC BY) license (http:/ / creativecommons.org/licenses/by/4.0/). 
Article

\title{
Unexpected Resistance to Base-Catalyzed Hydrolysis of Nitrogen Pyramidal Amides Based on the 7-Azabicyclic[2.2.1]heptane Scaffold
}

\author{
Diego Antonio Ocampo Gutiérrez de Velasco ${ }^{1}$, Aoze Su ${ }^{1}$, Luhan Zhai ${ }^{1}$, Satowa Kinoshita ${ }^{1,2}$, \\ Yuko Otani ${ }^{1}$ and Tomohiko Ohwada ${ }^{1, *}$ \\ 1 Laboratory of Organic and Medicinal Chemistry, Graduate School of Pharmaceutical Sciences, \\ University of Tokyo, 7-3-1 Hongo, Bunkyo-ku, Tokyo 113-0033, Japan; daogv1@hotmail.com (D.A.O.G.d.V.); \\ aaronsusu@gmail.com (A.S.); zhailuhanzlh@gmail.com (L.Z.); s.kinoshita13@gmail.com (S.K.); \\ otani@mol.f.u-tokyo.ac.jp (Y.O.) \\ 2 Department of Chemistry, St John's College, University of Cambridge, St John's Street, \\ Cambridge CB2 1TP, UK \\ * Correspondence: ohwada@mol.f.u-tokyo.ac.jp; Tel.: +81-3-5841-4730
}

Academic Editor: Michal Szostak

Received: 25 August 2018; Accepted: 12 September 2018; Published: 15 September 2018

\begin{abstract}
Non-planar amides are usually transitional structures, that are involved in amide bond rotation and inversion of the nitrogen atom, but some ground-minimum non-planar amides have been reported. Non-planar amides are generally sensitive to water or other nucleophiles, so that the amide bond is readily cleaved. In this article, we examine the reactivity profile of the base-catalyzed hydrolysis of 7-azabicyclo[2.2.1] heptane amides, which show pyramidalization of the amide nitrogen atom, and we compare the kinetics of the base-catalyzed hydrolysis of the benzamides of 7-azabicyclo[2.2.1]heptane and related monocyclic compounds. Unexpectedly, non-planar amides based on the 7-azabicyclo[2.2.1] heptane scaffold were found to be resistant to base-catalyzed hydrolysis. The calculated Gibbs free energies were consistent with this experimental finding. The contribution of thermal corrections (entropy term, $-T \Delta S^{\ddagger}$ ) was large; the entropy term $\left(\Delta S^{\ddagger}\right)$ took a large negative value, indicating significant order in the transition structure, which includes solvating water molecules.
\end{abstract}

Keywords: non planar amide; base-catalyed hydrolysis; water solvation; entropy

\section{Introduction}

In non-planar amides, distortion of the amide bond can arise from both twisting about the $\mathrm{C}-\mathrm{N}$ bond and pyramidalization at the nitrogen atom (Scheme 1) [1,2]. These transformations of the amide bond are essentially mutually correlated, and the transition states of the amide rotation involved bond twisting and nitrogen pyramidalization at the same time [3] (see also Reference [4]). The partial double-bond character of planar amides limits rotation about the C-N bond, and this feature also contributes to stabilization, due to electron-delocalization. Decrease in $s p^{2}$ nitrogen character, with increase of $s p^{3}$ character, tends to weaken the C-N bond and increase the electrophilicity of the carbonyl carbon atom [1]. 
(1)

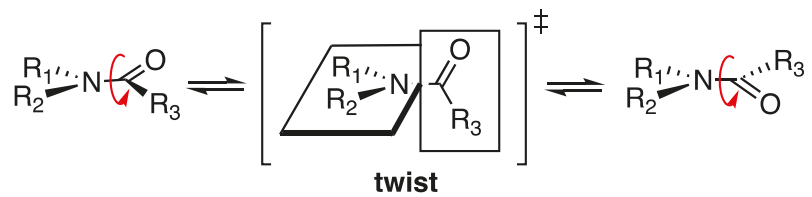

(2)

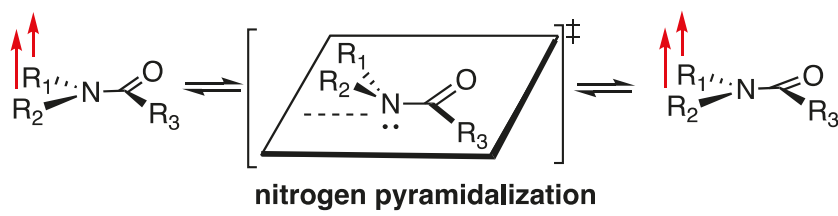

Scheme 1. Amide transformation processes causing non-planarity: (1) N-C bond twisting (rotation) and (2) nitrogen pyramidalization. These transformations are interconnected.

Non-planar amides are usually transitional structures that are involved in amide bond rotation (Scheme 1 (1)) and inversion of the nitrogen atom (Scheme 1 (2)). However, even in ground-minimum structures, amide distortion can be caused by several different factors, as illustrated in Figure 1A lactam ring strain of the nitrogen atom at a bridgehead position [5-8]; Figure 1B steric repulsion between substituents at the carbonyl and nitrogen positions [9]; Figure 1C angle strain at the nitrogen position [10]; Figure 1D bulkiness of substituents at the nitrogen position [11]; Figure 1E anomeric effect [12]; Figure 1F 1,3-allylic strain with respect to the pseudo C-N double bond [4,13]. These compounds are examples of ground-minimum non-planar amides. One of the most significant consequences of losing planarity of amides is an increase in lability: Reduction of the amide resonance exposes the carbonyl functionality to nucleophilic attack and acyl transfer reaction. In particular, hydrolysis by water under both acidic and basic conditions, and even under neutral conditions, is greatly accelerated when planarity is disrupted [5-9].

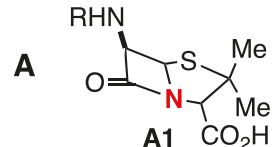

B<smiles>CC(C)(C)C(=O)N1CCSC1=S</smiles>

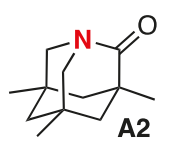

C<smiles>O=C(c1ccccc1)N1CC1</smiles><smiles>O=C1CC2CCC(C1)N2c1ccccc1</smiles>

A3<smiles>CC(=O)N(C)C(C)C12CCC(CC1)C21c2ccccc2-c2ccccc21</smiles><smiles>CN1CCCN(C(=O)C2CCCC2)C1=O</smiles>

A4

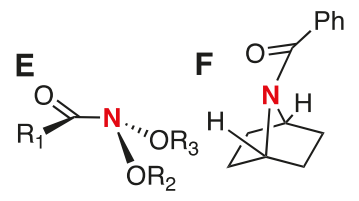

Figure 1. Some examples of non-planar amides.

The torsional angle $(\tau)$ (the mean twisting angle around the C-N bond, see Figure 2) for completely planar amides is $0.0^{\circ}$. It is clear that the $\tau$ angle of ground-minimum non-planar amides can adopt values different from zero. Stable ground-state $\mathrm{N}, \mathrm{N}$-disubstituted tertiary amides, such as benzamide derivatives (1a-1j) can also take non-zero $\tau$ values (Figure 2), as their calculated structures show distortions from planarity $[14,15]$. Some of them $(\mathbf{1} c, \mathbf{1} \mathbf{l}$ and $\mathbf{1 j})$ are activated for facile cleavage of the amide C-N bond in the presence of various catalysts [16-19]. 
<smiles>CN(C)C(=O)c1ccccc1</smiles>

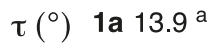<smiles>O=C1N2CCC(C2)N1c1ccccc1</smiles>

$\tau\left({ }^{\circ}\right) 1 \mathrm{~h} 16.5^{\mathrm{a}}$<smiles>CC(C)N(C(=O)c1ccccc1)C(C)C</smiles>

$1 \mathrm{~b} 16.0^{\mathrm{a}}$<smiles>CC1(C)CCCC(C)(C)N1C(=O)c1ccccc1</smiles>

1i $45.6^{b}$<smiles>CC(C)(C)N(C(=O)c1ccccc1)C(C)(C)C</smiles><smiles>O=C(c1ccccc1)N1CC1</smiles><smiles>O=C(c1ccccc1)N1CCC1</smiles><smiles>O=C(c1ccccc1)N1CCCC1</smiles>

1d $21.4^{\text {a }} 1$ e $10.0^{a}$

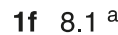<smiles>O=C(c1ccccc1)N1CCCCC1</smiles><smiles>O=C1CCCC(=O)N1C(=O)c1ccccc1</smiles>

1j $68.2^{b}$

Figure 2. Distortion angles $(\tau)$ of ground-state-stable benzoyl amides. ${ }^{a}$ B3LYP/6-31 + G(d) level of theory (Reference [14]). ${ }^{b}$ X-ray data (Reference [15]). Calculated dihedral angle $\tau$. $\tau=\left(\omega_{1}+\omega_{2}\right) / 2$ $\left(\omega_{1}=\angle \mathrm{R}-\mathrm{N}-\mathrm{C}-\mathrm{O}\right.$ and $\left.\omega_{2}=\angle \mathrm{R}-\mathrm{N}-\mathrm{C}-\mathrm{R}^{\prime}\right)[14]$.

Brown proposed a close relationship between nitrogen pyramidalization, $\mathrm{C}-\mathrm{N}$ bond length and kinetic reactivity to hydroxy anion attack [7], based on a comparison of the hydrolysis kinetics of analogous planar (molecule 1k in Figure 3) and non-planar amides (A3 in Figure 3). The base-catalyzed hydrolysis reaction at $25{ }^{\circ} \mathrm{C}$ showed a striking activation by 7 orders of magnitude in passing from the planar to the non-planar structure (see values in Figure 3).

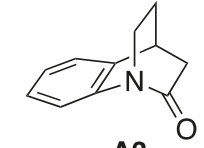

A3<smiles>CC(=O)N(C)c1ccccc1</smiles>

$2.2 \times 10^{-5} \mathrm{M}^{-1} \mathrm{~s}^{-1}$

$\left(\mathrm{NaOH}-\mathrm{H}_{2} \mathrm{O}, 25^{\circ} \mathrm{C}\right)$

Figure 3. Model molecules used by Brown in his comparative kinetics study.

Because of the lability of most non-planar amides in the presence of water [5-9], there have been few applications of these scaffolds (Figure 1) in molecular design. On the other hand, while 7-azabicyclo[2.2.1]heptane amides are highly suspicious of chemical stability, due to nitrogen-pyramidalization [12,13], 7-azabicyclo[2.2.1] heptane amides are of interest, beccause they can be regarded as conformationally constrained $\beta$-proline mimics. Consequently, several derivatives have been synthesized, and helical structures of homooligomers of $\beta$-proline mimics derived from azabicyclo[2.2.1] heptane amide have been reported [20,21]. The helical structures were stable even in the absence of intramolecular hydrogen bonds [22,23]. By introducing suitable bridgehead substituents, either all-cis amide or all-trans amide conformations were obtained. Conformational control favoring the cis-isomer was achieved by introducing substituents at the C-4 bridgehead position (Figure 4(a)). The cis-amide structure is heat-stable and the helical structure remains intact in a variety of solvents (water, alcohol, halogenated solvents and cyclohexane) [24]. On the other hand, conformational control favoring the trans-isomer was achieved by introducing substituents at the C-1 bridgehead position (Figure 4(b)). The trans-amide structure also proved to be heat-stable and the helical structure remained intact in both hydrophilic and hydrophobic solvents [25]. 
(a)

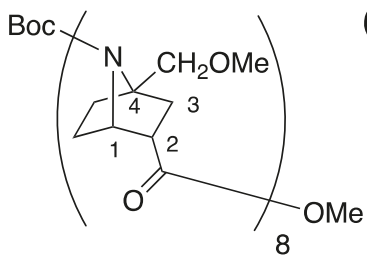

(b)

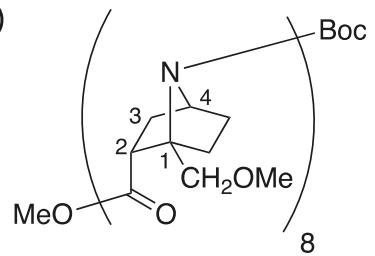

Figure 4. (a) Schematic representation of 7-azabicyclo[2.2.1]heptane amide cis-(S)-8mer. (b) Schematic representation of the trans- $(R)-8$ mer.

In the synthesis of oligomers of 7-azabicyclo[2.2.1] heptane amides (Figure 4) [24,25], acid-catalyzed deprotection of the Boc group was compatible with the amide linkage (Figure 5). Therefore, we thought that the bicyclic amide linkage might be stable under acidic conditions and convectional mild reaction conditions. However, to our knowledge, neither qualitative nor quantitative data about the base-catalyzed hydrolytic reactivity of this system have been reported.

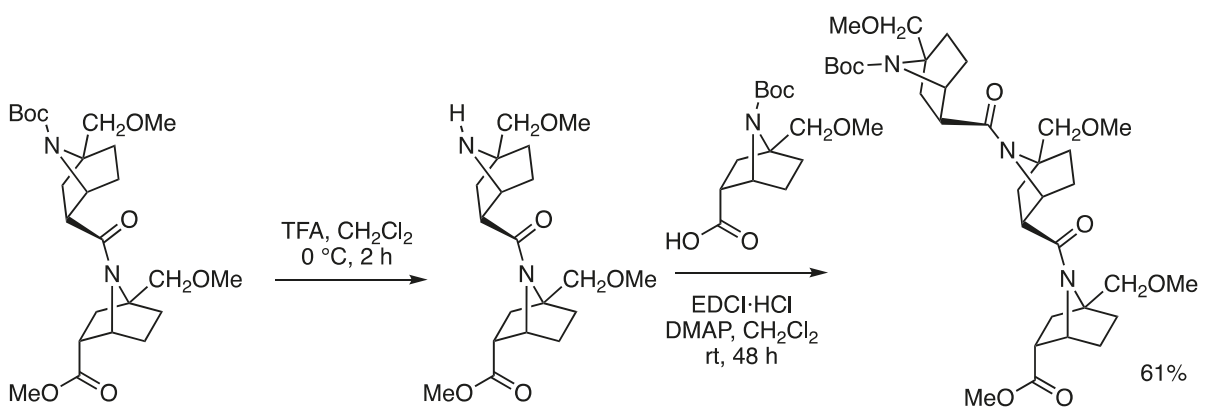

Figure 5. Acidic deprotection procedure in the synthesis of the homooligomers.

Therefore, the aim of the present study is to establish the reactivity profile in the base-catalyzed hydrolysis of this 7-azabicyclo[2.2.1] heptane amide system, which might serve as a model for the enzymatic cleavage of peptide bonds. To this end, kinetic studies of the base-catalyzed hydrolysis of the amide of 7-azabicyclo[2.2.1] heptane benzamides were conducted and the results were compared with reported data for related monocyclic amide compounds. Theoretical calculations were also carried out to aid in understanding the unexpectedly low reactivity.

\section{Results and Discussion}

In order to estimate the strength of amide bonding, we compared the reactivities of planar and non-planar amides, specifically pyrrolidine amides (3a-e) and 7-azabicyclo[2.2.1] heptane amides (4a-e) (Figure 6). We also evaluated the effect of introducing substituents on the bridgehead position of the bicycle (5a-e). We utilized azetidine amides (2a-e) (Figure 6) as reference compounds for non-planar cyclic amides. In general, we found that the base-catalyzed hydrolysis of the bicyclic amides (4 and 5) was rather slow. Among aromatic substituents, we focused on $\mathbf{a}(\mathrm{H}), \mathbf{b}(\mathrm{Cl})$ and $\mathbf{c}\left(\mathrm{NO}_{2}\right)$ (Figure 6), for which the reaction proceeds at acceptable speed, since the reactions in the cases of substituents $d$ $(\mathrm{Me})$ and $\mathbf{e}(\mathrm{MeO})$ are too slow to obtain kinetic data by means of NMR (see below). 
<smiles>[X]c1ccc(C(=O)N2CCC2)cc1</smiles>

2a-e<smiles>[X]c1ccc(C(=O)N2CCCC2)cc1</smiles>

3a-e<smiles>[X]c1ccc(C(=O)N2C3CCC2CC3)cc1</smiles>

4a-e<smiles>[X]c1ccc(C(=O)N2CC3CCC2(COC)C3)cc1</smiles>

5a-c

\section{a: $X=H ; b: X=C l ; c: X=N_{2}$; d X=Me, e: $X=M e O$}

Figure 6. Model molecules used in this study. $N$-Benzoylazetidines (2a-e) and $N$-benzoylpyrrolidines (3a-e) were examined as monocyclic amides. N-Benzoyl-7-azabicyclo[2.2.1] heptanes (4a-e) and $\mathrm{N}$-benzoyl-1-(methoxymethyl)-7-azabicyclo- [2.2.1] heptanes $(\mathbf{5 a}-\mathbf{c})$ were examined as bicyclic amides .

\subsection{Synthesis}

The monocyclic $N$-benzoylazetidines $2 \mathbf{a}-\mathbf{e}$ and $\mathrm{N}$-benzoylpyrrolidines 3a-e were synthesized in a straightforward manner by coupling the corresponding amines with different benzoyl chlorides (Scheme 2). For the synthesis of the azetidine compounds, the chloride salt of the amine was used as the starting material, with 3 equivalents of DIPEA (diispropylethylamine). For the synthesis of pyrrolidine compounds, 1.2 equivalents of DIPEA sufficed. Compounds were obtained in good yields.

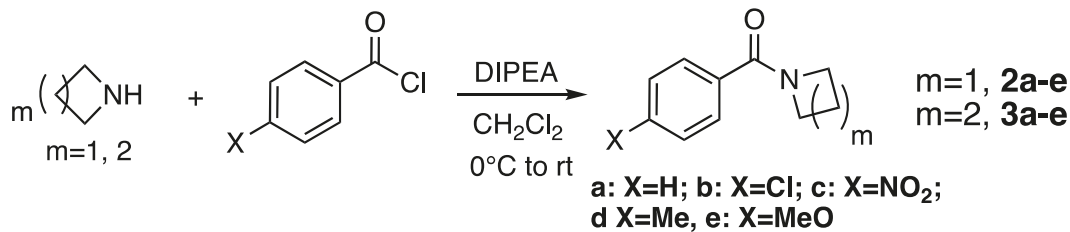

Scheme 2. Synthesis of monocyclic amides 2 and 3.

In addition to the monocyclic amides, we synthesized unsubstituted (4a-e) and substituted (5a-e) bicyclic amides. $\mathrm{N}$-Benzoyl-7-azabicyclo[2.2.1] heptanes were synthesized starting from trans-4-aminocyclohexanol (Scheme 3) [4]. The primary amine was substituted by benzyloxycarbonyl chloride $(\mathrm{ZCl})$, and the hydroxy group was changed to toluenesulfonate in order to facilitate bicycle formation. Coupling of benzoyl chloride or para-substituted benzoyl chlorides gave the bicyclic amides (4a-e).

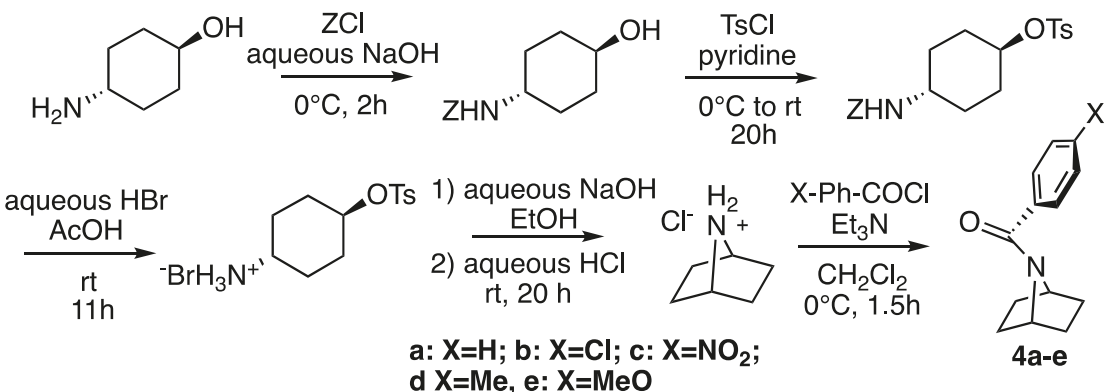

Scheme 3. Synthesis of bridgehead-unsubstituted bicyclic amides 4 . 
A different strategy was followed for the bridgehead-substituted bicyclic amides 5a-c (Scheme 4). The hydroxy group was removed from the previously synthesized monomer scaffold by Barton-McCombie deoxygenation using AIBN and tris(trimethylsilyl)silane (TTMSS) [26]. After that, the bridgehead ester functionality was first reduced to alcohol and then changed to ether. After Boc-deprotection, the compounds were coupled with various para-substituted benzoyl chlorides to afford the bridgehead-substituted bicyclic amides.

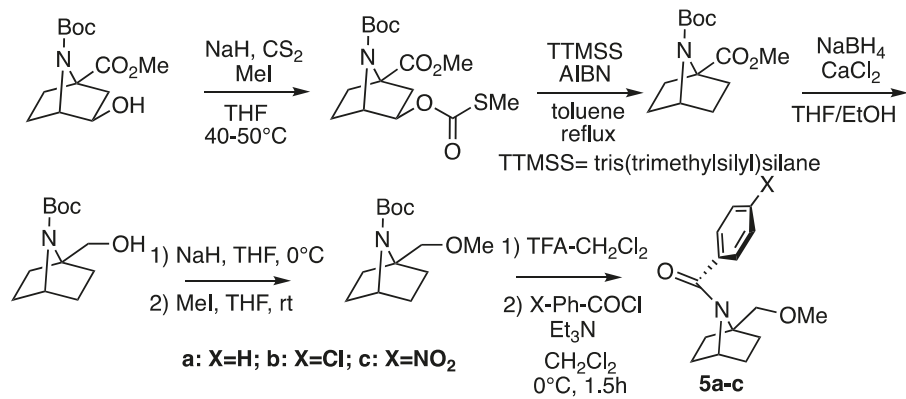

Scheme 4. Synthesis of bridgehead-substituted bicyclic amides 5 .

\subsection{Alkaline Hydrolysis of Planar Amide $3 a$}

In order to assess the chemical reactivities of the non-planar 7-azabicyclo[2.2.1] heptane amides 4 and 5 in alkaline conditions, we first examined the kinetics of the planar amide N-benzoyl pyrrolidine $3 \mathbf{a}(\mathrm{X}=\mathrm{H})$ in order to optimize the reaction conditions, because the hydrolysis of $\mathbf{3} \mathbf{a}$ is expected to be the slowest among these compounds (2, 3, 4 and 5 in Figure 5).

\subsubsection{Optimization of Reaction Conditions}

Given that hydrolysis involves working with water as a solvent, it was necessary to confirm the solubility of the reactants. In order to carry out the reactions, water-miscible co-solvents had to be chosen. In addition, since alkaline conditions entail high concentrations of hydroxide, some solvents (such as ketones or acetonitrile) are unsuitable. The list of possible co-solvents was narrowed down to 1,4-dioxane, methanol, THF and DMSO.

The first attempts at hydrolysis were conducted with $0.15 \mathrm{mmol}(30 \mathrm{mg})$ of N-benzoylpyrrolidine 3a, $100 \mu \mathrm{L}$ of deuterated methanol (as a co-solvent) and $400 \mu \mathrm{L}$ of a solution of $\mathrm{NaOD}$ in $\mathrm{D}_{2} \mathrm{O}(40 w / w \%)$. The procedure was also done using $100 \mu \mathrm{L}$ of deuterated 1,4 -dioxane(1,4-dioxane- $\left.d_{8}\right)$. The samples were heated in a water bath at $37^{\circ} \mathrm{C}$ and subjected to TLC. NMR spectra were recorded after 24 and $48 \mathrm{~h}$. However, no hydrolysis product was detected by ${ }^{1} \mathrm{H}-\mathrm{NMR}$, and no new product appeared on TLC. Thus, the hydrolysis reaction did not proceed at $37^{\circ} \mathrm{C}$. Furthermore, the NaOD solution and the 1,4-dioxane solution separated into two phases.

Next, the concentration of the base was reduced to $0.4 \mathrm{M}$ and that of the reactant to $0.1 \mathrm{M}$ (i.e., a 4-fold excess of base over starting material). The total reaction volume was $1 \mathrm{~mL}$ (100 $\mu \mathrm{L}$ of co-solvent and $900 \mu \mathrm{L}$ of $\left.\mathrm{D}_{2} \mathrm{O}\right)$.

Heating at 50 or $70{ }^{\circ} \mathrm{C}$ was applied, and the hydrolysis of $3 \mathbf{a}$ was monitored by TLC analysis. The reaction proceeded at $70{ }^{\circ} \mathrm{C}$. The starting material was no longer detectable after $48 \mathrm{~h}$, and a single spot corresponding to the hydrolysis product (benzoic acid) appeared. However, at $50{ }^{\circ} \mathrm{C}$ the starting amide 3a was still detectable on the TLC plate after $48 \mathrm{~h}$. In order to assess the working range for the other compounds, a similar test was done at $70^{\circ} \mathrm{C}$ for $p$-nitro derivative $3 \mathrm{c}$ (no spot of the starting material was detected after $5 \mathrm{~h}$ ) and $p$-methoxy derivative $3 \mathbf{e}$ (the starting material was still detected after $65 \mathrm{~h}$ ). Moreover, at the higher temperature, the 1,4-dioxane solution remained monophasic. Therefore, it was decided to work at $70{ }^{\circ} \mathrm{C}$. 
In order to follow the progression of the reaction quantitatively, we recorded NMR spectra of hydrolysis reaction mixtures of $\mathbf{3 a}-\mathbf{e}$ every two $\min$ at $70^{\circ} \mathrm{C}$. Rate constants were calculated from the decrease of the integrals of the reactant (Figure 7).

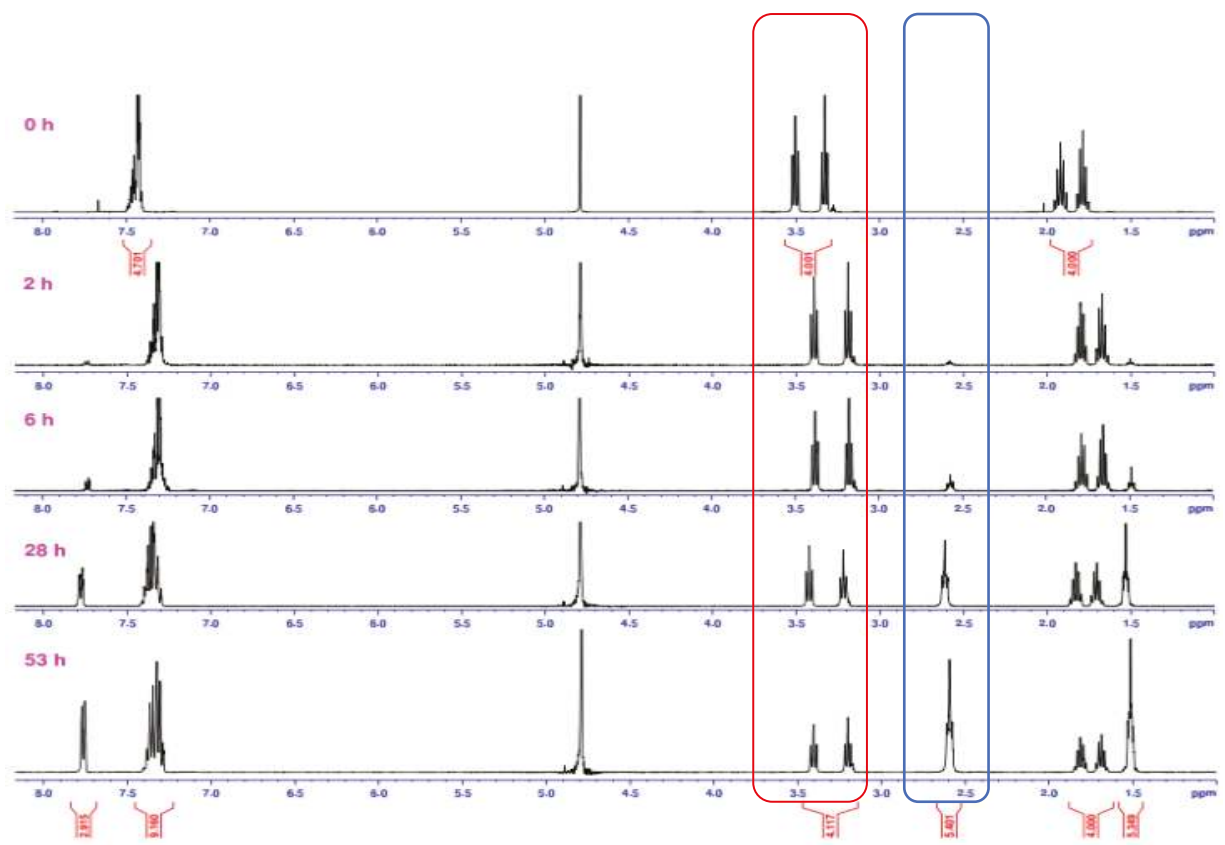

Figure 7. ${ }^{1} \mathrm{H}-\mathrm{NMR}$ monitoring of the hydrolysis of $3 \mathbf{a}$, with $\mathrm{NaOH}$ in $\mathrm{D}_{2} \mathrm{O}$ and 1,4 -dioxane- $d_{8}$ at $70{ }^{\circ} \mathrm{C}$. The intensity of amide peaks decreased (red box) over time, and product signals appeared (blue box).

From the ${ }^{1} \mathrm{H}-\mathrm{NMR}$ integration information we were able to determine the loss of amide over time. Since working with excess deuteroxide anion guarantees pseudo-first-order kinetics, rate constants were calculated using the following first-order equation:

$$
\frac{d[\text { Amide }]}{d t}=-k[\text { Amide }] .
$$

The integration of this rate equation gives the following equation:

$$
\ln [\text { Amide }]=-k t+\ln [\text { Amide }]_{0}
$$

where [Amide] represents the molar concentration (M) of amide, $k$ represents the reaction constant $\left(\mathrm{s}^{-1}\right)$, and $t$ represents time (s). A least-squares plot of the natural logarithm of amide concentration versus time gave a straight line whose slope equals $-k$. The initial amide concentration corresponds to the value of the $y$-intercept.

When either the aromatic protons or the pyrrolidine protons were used as a reference for signal integration, all five pyrrolidine amides $3 a-e$ showed good correlations between concentration and time, and first-order reaction rate constants could be determined (Figure S1). The regression coefficients $\mathrm{R}^{2}$ were high for all five compounds 3a-e (Figure S1). The reaction showed Hammett-like behaviour, that is the hydrolysis proceeded faster when an electron-withdrawing group was present at the para position of the phenyl ring, and slower when an electron-donating group was present. 
Based on these results, we next examined, the hydrolysis of the bicyclic compounds under the same conditions. In order to hydrolyze compounds $4 \mathbf{a}$ and $\mathbf{4 b}$ it was necessary to increase the proportion of 1,4-dioxane from $10 \%$ to $20 \%$. The reaction proceeded smoothly, and the disappearance of the reactants was successfully monitored by NMR. Unfortunately, the bicyclic compounds were not sufficiently soluble under these conditions. Hence, we decided to increase the proportion of co-solvent. The reaction volume was also scaled down from $1 \mathrm{~mL}$ to $500 \mu \mathrm{L}$. Solvent conditions were modified on the basis of an examination of the hydrolysis of the $p-\mathrm{NO}_{2}$-substituted pyrrolidine benzamide $3 \mathrm{c}$ (Table 1).

Table 1. Effect of variations of co-solvent proportions on the hydrolysis rate of 3c.

\begin{tabular}{ccccc}
\hline 1,4-Dioxane- $d_{8} / \mathrm{D}_{\mathbf{2}} \mathrm{O}(\boldsymbol{v} / \boldsymbol{v} \%)$ & $3 \mathrm{c}$ & $\mathrm{NaOD}$ & Temperature & $-\boldsymbol{k}_{\text {obs }}\left(\mathrm{s}^{-\mathbf{1}}\right)$ \\
\hline $25 / 75$ & $0.05 \mathrm{mmol}$ & $0.5 \mathrm{mmol}$ & $70^{\circ} \mathrm{C}$ & $3.0 \times 10^{-4}$ \\
$50 / 50$ & $0.05 \mathrm{mmol}$ & $0.5 \mathrm{mmol}$ & $70^{\circ} \mathrm{C}$ & $9.6 \times 10^{-5}$ \\
$75 / 25$ & $0.05 \mathrm{mmol}$ & $0.5 \mathrm{mmol}$ & $70^{\circ} \mathrm{C}$ & $2.3 \times 10^{-6}$ \\
\hline
\end{tabular}

The sample containing 75\% 1,4-dioxane did not form a homogenous solution even after heating at $70{ }^{\circ} \mathrm{C}$, possibly due to the high $\mathrm{NaOD}$ concentration in the water phase. On the other hand, the use of $25 \%$ 1,4-dioxane resulted in a low $\mathrm{R}^{2}$ value (0.943). Despite these setbacks, it was seen that the reaction proceeds faster in more polar solvent systems. This trend was also seen with other co-solvents (Figure 8). The reaction time was shorter in DMSO- $d_{6}$ than in methanol- $d_{4}$, which in turn was shorter than in 1,4-dioxane. The reaction was also carried out in THF- $d_{8}$, but the compound was not sufficiently soluble even at high temperature. The effect of solvent polarity on the hydrolysis rate can be explained by the fact that the amide bond has a polar nature, and charges develop as the bond is broken. Therefore, more polar solvent systems are better at stabilizing the developing charges in the transition states and the products. Although DMSO is a good solvent, the presence of hydroxide anion can produce the basic dimsyl anion $\left(\mathrm{Na}^{+-} \mathrm{CH}_{2}-\mathrm{SO}-\mathrm{CH}_{3}\right)$ from DMSO. Therefore, we focused on 1,4-dioxane and methanol, rather than DMSO.

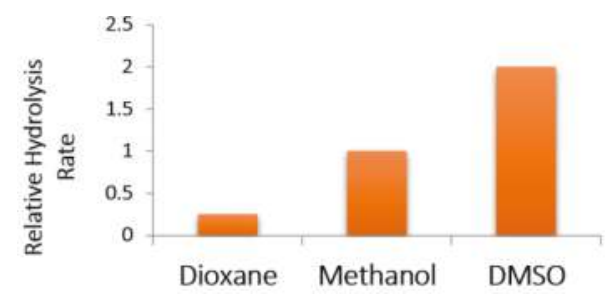

Figure 8. Effect of polarity of the solvent system on the rate of alkaline hydrolysis. Higher polarity of the solvent system accelerates the reaction. The rate of hydrolysis in methanol as a solvent was arbitrarily set at unity (1.0).

\subsubsection{Alkaline Hydrolysis of Amides in Two Solvents}

Finally, the set of conditions, shown in Table 2, was selected for all compounds: $250 \mu \mathrm{L}$ of co-solvent (1,4-dioxane- $d_{8}$ or methanol- $d_{4}$ ), and $250 \mu \mathrm{L}$ of water (total volume $(500 \mu \mathrm{L})$ ), and 10 equivalents of base with respect to the reactant amide. The reaction was carried out at $70{ }^{\circ} \mathrm{C}$. These conditions provided first-order kinetics with respect to amide concentration.

Table 2. Final conditions for alkaline hydrolysis of amide compounds.

\begin{tabular}{ccccc}
\hline Starting Amide & NaOD $40 \%$ wt. & $\mathbf{D}_{\mathbf{2}} \mathbf{O}$ & Co-solvent & Temperature \\
\hline $0.05 \mathrm{mmol}$ & $0.5 \mathrm{mmol}$ & $250 \mu \mathrm{L}$ & $250 \mu \mathrm{L}$ & $70{ }^{\circ} \mathrm{C}$ \\
\hline
\end{tabular}




\subsubsection{Alkaline Hydrolysis in Dioxane}

Several compounds were subjected to NaOD-catalyzed hydrolysis in 1,4-dioxane- $d_{8}-\mathrm{D}_{2} \mathrm{O}(1: 1)$ under the conditions, shown in Table 3. The co-solvent was 1,4-dioxane- $d_{8}$. The plots in Figure S2 are based on the raw data of selected hydrolysis experiments (Figure 9). Hydrolysis was repeated three times for some of the compounds in order to assess the repeatability of the method. It was found that the error when 1,4-dioxane- $d_{8}$ was used as the co-solvent was $\pm 13.8 \%$. Products (carboxylate and amine) were identified by mass spectrometry. NMR monitoring revealed signals corresponding to the reactant and the hydrolysis products in all cases. The ring-opening product of azetidine amide was not detected. As a general trend, base-catalyzed hydrolysis of azetidine amides (2) proceeded more rapidly than that of pyrrolidine amides (3), which in turn were hydrolyzed faster than unsubstituted bicyclic amides (4), while bridgehead-substituted bicycles (5) were least reactive (for example, reaction rate: $2 a>3 a>4 a>5 a ; 2 b>3 b>4 b>5 b ; 2 c>3 c>4 c>5 c)$. The expected Hammett-like trend was observed: The electron-withdrawing substituent $\mathrm{NO}_{2}$ (c) on the phenyl moiety accelerated the reaction.

Table 3. Base-catalyzed hydrolysis rates $\left(-k_{\mathrm{obs}}\right.$ in $\left.\mathrm{M}^{-1} \mathrm{~S}^{-1}\right)$ of amides $\mathbf{2 x - 5 x}(\mathbf{x}=\mathbf{a}-\mathbf{e})$ in two solvent systems. ${ }^{a}$ Average values are shown where possible (see footnotes). Relative reaction rates (referenced to 4) are shown in parentheses.

\begin{tabular}{|c|c|c|c|c|c|c|c|c|}
\hline \multirow[b]{2}{*}{$x=$} & \multicolumn{4}{|c|}{ 1,4-Dioxane- $\mathrm{D}_{2} \mathrm{O}(1: 1), \mathrm{NaOD}, 70{ }^{\circ} \mathrm{C}{ }^{\mathrm{a}}$} & \multicolumn{4}{|c|}{ Methanol- $\mathrm{D}_{2} \mathrm{O}(1: 1), \mathrm{NaOD}, 70^{\circ} \mathrm{C}^{\mathrm{b}}$} \\
\hline & $2 x$ & $3 x$ & $4 x$ & $5 x$ & $2 x$ & $3 x$ & $4 x$ & $5 x$ \\
\hline a (H) & $\begin{array}{c}2.1 \times 10^{-5} \\
(5.8)\end{array}$ & $\begin{array}{c}7.8 \times 10^{-6} \\
(2.2)\end{array}$ & $\begin{array}{c}3.6 \times 10^{-6} \\
(1)\end{array}$ & $\begin{array}{c}6.5 \times 10^{-7} \\
(0.2)\end{array}$ & $1.1 \times 10^{-4}$ & $2.9 \times 10^{-5}$ & ND & ND \\
\hline b $(\mathrm{Cl})$ & $\begin{array}{c}2.3 \times 10^{-4} \\
(82.1)\end{array}$ & $\begin{array}{c}1.8 \times 10^{-5} \\
(6.4)\end{array}$ & $\begin{array}{c}2.8 \times 10^{-6} \\
(1)\end{array}$ & $\begin{array}{c}1.2 \times 10^{-6} \\
(0.4)\end{array}$ & $\begin{array}{c}9.7 \times 10^{-4} \\
(88.2)\end{array}$ & $\begin{array}{c}7.0 \times 10^{-5} \\
(6.4)\end{array}$ & $\begin{array}{c}1.1 \times \\
10^{-5}(1)\end{array}$ & $\begin{array}{c}3.0 \times 10^{-6} \\
(0.3)\end{array}$ \\
\hline $\mathrm{c}\left(\mathrm{NO}_{2}\right)$ & $\begin{array}{c}9.9 \times 10^{-4} \\
(33.0)\end{array}$ & $\begin{array}{c}1.0 \times 10^{-4} \\
(3.3)\end{array}$ & $\begin{array}{c}3.0 \times 10^{-5} \\
(1)\end{array}$ & $\begin{array}{c}3.7 \times 10^{-5} \\
(1.2)\end{array}$ & $\begin{array}{c}6.5 \times 10^{-3} \\
(92.9)\end{array}$ & $\begin{array}{c}4.2 \times 10^{-4} \\
(6.0)\end{array}$ & $\begin{array}{c}7.0 \times \\
10^{-5}(1)\end{array}$ & $\begin{array}{c}4.3 \times 10^{-5} \\
(0.6)\end{array}$ \\
\hline d (Me) & ND & $4.1 \times 10^{-6}$ & NA & NE & ND & $\begin{array}{c}1.7 \times 10^{-5} \\
(4.2)\end{array}$ & $\begin{array}{c}4.1 \times \\
10^{-6}(1)\end{array}$ & NE \\
\hline e $(\mathrm{MeO})$ & ND & $4.8 \times 10^{-6}$ & $\mathrm{NE}$ & NE & ND & $1.9 \times 10^{-5}$ & $\mathrm{NE}$ & NE \\
\hline
\end{tabular}

a Error estimation: $\pm 13.8 \%$ (in the 1,4-dioxane system). (b) Error estimation: $\pm 17.4 \%$ (in the methanol system). $\mathrm{ND}=$ not determined; $\mathrm{NA}=$ not available (due to the solubility problem); $\mathrm{NE}=$ not executable (due to very slow reaction).

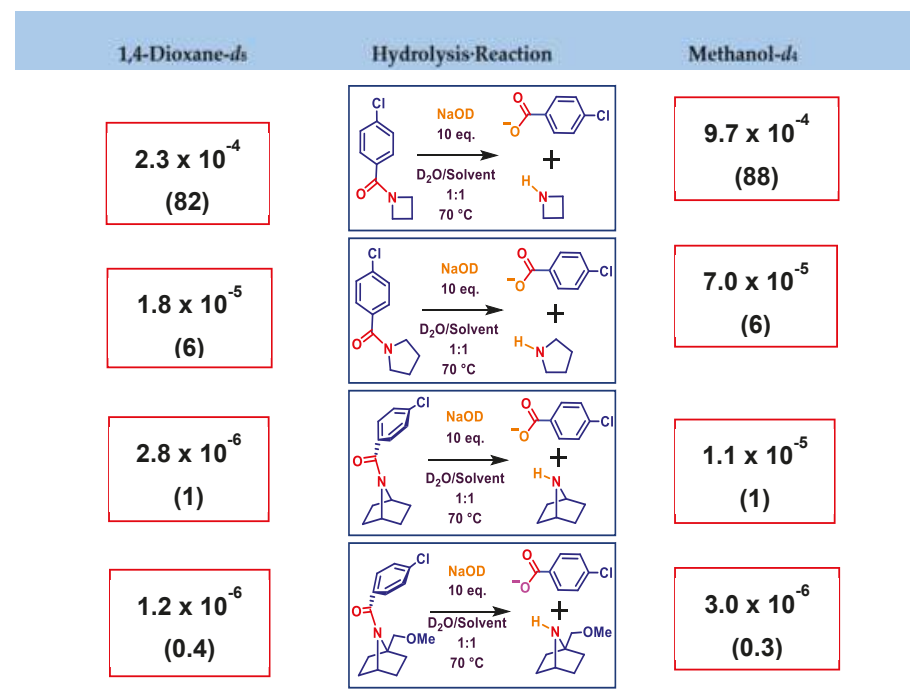

Figure 9. Base-catalyzed hydrolysis rates of $2 c, 3 c, 4 c$ and $5 c$ in two solvent systems (1,4-dioxane and methanol). Values of $-k_{\mathrm{obs}}\left(\mathrm{s}^{-1}\right)$ are shown. Relative reaction rates are shown in parentheses (referenced to 4c). 
For example, $N$-( $p$-nitrobenzoyl-7-azabicyclo[2.2.1] heptane (4c) was hydrolyzed in 1,4-dioxane and $\mathrm{D}_{2} \mathrm{O}$ at a slower rate than the analogous planar monocycle $2 \mathrm{c}(6$ times faster than $3 \mathrm{c})$ or the non-planar monocycle 1c (82-88 times faster than 3c). Moreover, a bridgehead substituent (4c) further slowed the hydrolysis rate (2.3-3.6 times slower than 3c) (Figure 9).

\subsubsection{Alkaline Hydrolysis in Methanol}

Several compounds were subjected to hydrolysis in methanol under the final conditions, shown in Table 3 (methanol- $d_{4}-\mathrm{D}_{2} \mathrm{O}$ 1:1). The co-solvent used in this case was methanol- $d_{4}$. The following plot shows the ${ }^{1} \mathrm{H}-\mathrm{NMR}$ spectral change corresponding to the slow consumption of $5 \mathbf{b}$ in methanol (Figure 10). We could not detect intermediate formation of the methyl ester, which may be formed by the attack of methoxide anion on the amide. Hydrolysis was repeated three times for some of the compounds in order to assess the repeatability of the method. It was found that the error of the method when using methanol- $d_{4}$ as a co-solvent was $\pm 17.4 \%$. Products were identified by mass spectrometry. Signals corresponding to reactants and hydrolysis products were identified in all cases. The ring-opening product of azetidine amide was not detected. Reactivity followed the same trend as in 1,4-dioxane (reaction rate: $\mathbf{2 b}>\mathbf{3 b}>\mathbf{4 b}>5 \mathbf{b}$ ). The reactivity was higher in methanol than in 1,4-dioxane.

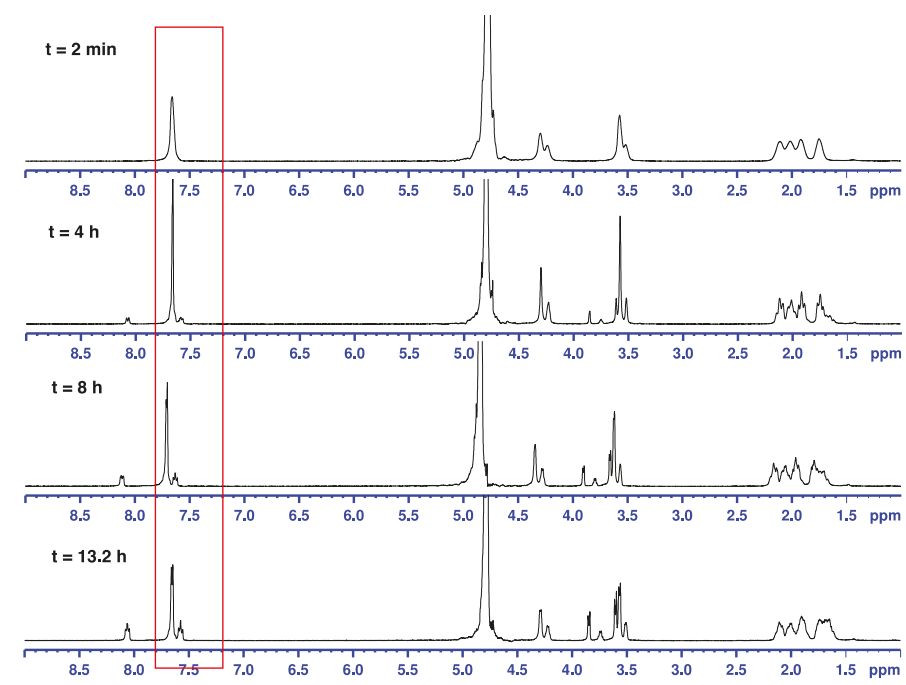

Figure 10. Progress of the hydrolysis of $5 \mathbf{b}$ in methanol- $d_{4} / \mathrm{D}_{2} \mathrm{O}(1: 1)$ at $70{ }^{\circ} \mathrm{C}$, followed by ${ }^{1} \mathrm{H}-\mathrm{NMR}$; the intensity of amide peaks decreased, and new product signals appeared as the reaction progressed (red box).

\subsubsection{Comparison of Kinetic Data}

As shown in Table 3, the same general trend was observed irrespective of the solvent system employed. Azetidine amides (2) were the most reactive, followed by pyrrolidine amides (3), then unsubstituted bicyclic amides (4), and finally bridgehead-substituted bicycles (5) (reaction rate: $2 b>3 b>4 b>5 b$ ). Phenyl substitution had the expected effects (according to the inductive effects) in all series of amides. 


\subsection{Computational Studies}

\subsubsection{Reaction Model}

It was unexpected to find that non-planar amides based on the 7-azabicyclo[2.2.1]heptane scaffold (4) showed such poor susceptibility to base-catalyzed hydrolysis, even upon heating, as compared with the corresponding monocyclic amides (3). Bridgehead substitution of the 7-azabicyclo[2.2.1] heptane amides (5) also decelerated base-catalyzed hydrolysis of the amide as compared with the unsubstituted bicyclic derivative (4). It has been established in previous studies on heavy atom isotope effects that formation of the tetrahedral intermediate is rate-determining in the base-catalyzed hydrolysis of formamide $\left(\mathrm{HCONH}_{2}\right)$ (Scheme 5) [27].

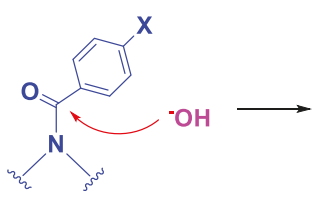

GS

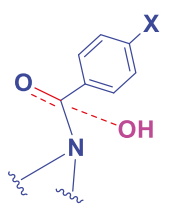

TS1

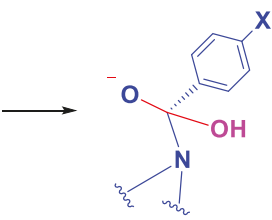

INT1

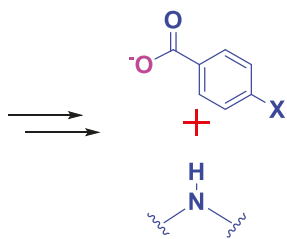

Products

Scheme 5. General reaction path for the base-catalyzed hydrolysis of amides.

While there have been several ab initio and DFT calculation studies of the hydrolysis of planar amides and non-planar amides [28-31], base-catalyzed hydrolysis of amides has been relatively little studied until recently, Further, most studies have focused on rather simple amides, such as formamide, N-methylacetamide, DMF, and DMA (dimethylacetamide) [32]. Here, we aimed to rationalize the observed reactivity trends by computational studies of our more complex reactants and transition structures.

It is known that that explicit water solvation is crucial for the calculation of amide hydrolysis. Xiong and Zhan [32] showed that incorporation of five implicit water molecules is required, and there are two kinds of hydrogen-bonding networks of water in the vicinity of the hydroxy ion $\left({ }^{-} \mathrm{OH}\right)$ and amide group in the presence of five explicit water molecules (Figure 11). These two patterns commonly involve activation of the carbonyl group by hydrogen-bonding of two water molecules to the oxygen atom (increasing its electrophilicity) and hydrogen bonding of three water molecules with the oxygen atom of the hydroxy anion (decreasing its nucleophilicity and at the same time decreasing electronic repulsions). There is a difference in the topology of the hydrogen-bonding networks. Type a is more stable than Type b by approximately 1-2 kcal/mol, but finding a TS of Type a in our experimental amide systems $\mathbf{2}-\mathbf{5}$ was difficult, probably because the Type a hydrogen network is sensitive to the steric interactions encountered in more complicated amide structures (see the detail in the Experimental Section). Therefore, in the present work, we focused on the hydrogen network Type b, which seems relevant to the present compounds.

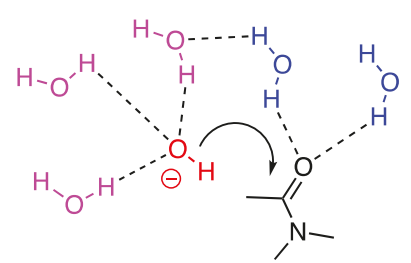

Type a

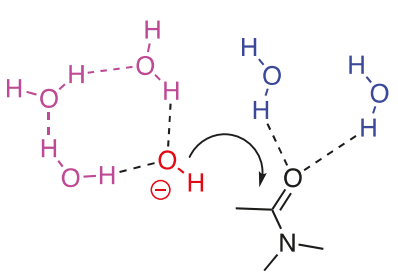

Type b

Figure 11. Two hydrogen network patterns involving five $\mathrm{H}_{2} \mathrm{O}$ molecules in the attack of $\mathrm{OH}$ anion on the amide carbonyl carbon atom [32]. 
Geometry optimizations for the ground states of hydrated reactants (amide and hydroxide anion) and the transition state for the nucleophilic addition of hydroxide anion to the amide carbonyl group were performed in the presence of explicit water molecules at the B3LYP and M06-2X levels of theory with a combination of two basis sets, $6-31+G(d)$ and $6-311++G(d, p)$. Bulk solvation effects (self-consistent reaction field, SCRF) were also incorporated by means of IEFPCM (Polarizable Continuum Model, PCM, using the integral equation formalism variant) and SMD methods in water. Vibrational frequency calculations were performed at the same level of theory. The energies were corrected for the zero-point energies and Gibbs free energy at $25^{\circ} \mathrm{C}(298.15 \mathrm{~K})$, obtained from frequency calculations. Hereafter, we will focus on the calculation values based on M06-2X level with the SMD solvent model. The calculations at the B3LYP level (see Tables S1-S4) were consistent with the trends obtained in the M06-2X calculations.

\subsubsection{Model with Five Explicit Water Molecules}

Transition structures (TSs) for the hydroxide anion-catalyzed hydrolysis of the amides, including five explicit water molecules were identified with M06-2X//6-31+G(d) (Figure 12). As previously described by Xiong and Zhan [32], we calculated the activation Gibbs energies from the energy difference between the TS structures and the summation of the energies of the two reagents, the amide with two hydrogen-bonded water molecules $\left(\operatorname{amide}\left(\mathrm{H}_{2} \mathrm{O}\right)_{2}\right)$ and the hydroxide anion clustered with three water molecules $\left({ }^{-} \mathrm{OH}\left(\mathrm{H}_{2} \mathrm{O}\right)_{3}\right)$ (Scheme 6). We also estimated Gibbs free energies by single-point calculation with M06-2X//6-311++G(d,p) on the basis of the M06-2X//6-31+G(d) optimized structures (Table 4).

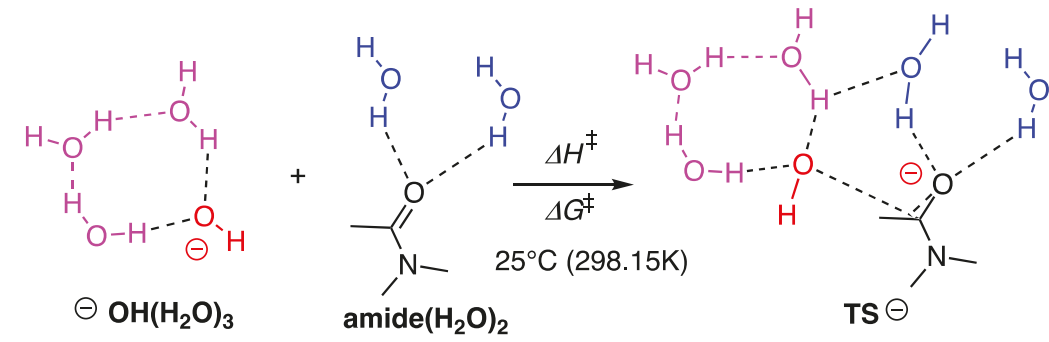

Scheme 6. Model of base-catalyzed hydrolysis reaction of amide.

The contribution of thermal corrections (entropy term, $-T \Delta S^{\ddagger}$ ) was significant. The entropy term $\left(\Delta S^{\ddagger}\right)$ took a large negative value (Table 2), indicating the presence of significant order in the transition structure. Associated water molecules need to rearrange on the surface of the amide, and thus would contribute to this large negative entropy term. A larger free-energy activation barrier was seen for $N$-benzoyl-7-azabicyclo[2.2.1] heptane (4a) than for the monocyclic $N$-benzoylpyrrolidine (3a). The pyramidal amide, the azetidine derivative $2 \mathbf{a}$ has the smallest activation energy. The order of the magnitude of the Gibbs activation energies ( $4 \mathbf{a}>\mathbf{3 a}, \mathbf{5} \mathbf{a}>\mathbf{2 a}$, Table 4$)$ is essentially consistent with the experimental reactivity (Figure 8 and Table 3), with the exception of the bridgehead-substituted bicyclic amide $\mathbf{5} \mathbf{a}$, which is expected to have higher activation energy than $4 \mathbf{a}$. However, we need to make allowance for the simple harmonic oscillator approximation in the thermal energy correction, and also we need to consider that this thermal energy correction is an approximation of the real entropy change in the solvation process.

The enthalpy terms $\left(\Delta H^{\ddagger}\right)$ were underestimated (Table 4$)$, but the order of their magnitudes is also essentially consistent with the experimentally observed hydrolysis rates: $\mathbf{2 a}>\mathbf{3 a}, \mathbf{4 a}, \mathbf{5 a}$. This trend is consistent with the trajectory in the TS structures (Figure 12): The shorter the distance between the amide carbonyl carbon atom and hydroxide oxygen atom (i.e., later the TS), the larger the enthalpy term $\left(\Delta H^{\ddagger}\right)$. 
Table 4. Calculated free energy barrier for the formation of the transition state at $25^{\circ} \mathrm{C}(298.15 \mathrm{~K})$ at the M06-2X/6-31+G(d) and M06-2X/6-311++G(d, p) levels, considering five water molecules. Solvent effect is SMD (solvent $=$ water $^{\text {a }}$.

\begin{tabular}{|c|c|c|c|c|}
\hline Compound & $\begin{array}{c}\Delta H^{\ddagger} \\
\mathrm{kcal} / \mathrm{mol}\end{array}$ & $\begin{array}{c}-T \Delta S^{\ddagger} \\
\mathrm{kcal} / \mathrm{mol}\end{array}$ & $\begin{array}{c}\Delta S^{\ddagger} \\
\mathrm{cal} /(\mathrm{mol} \cdot \mathrm{K})\end{array}$ & $\begin{array}{l}\Delta G^{\ddagger} 25^{\circ} \mathrm{C} \\
\mathrm{kcal} / \mathrm{mol}\end{array}$ \\
\hline \multicolumn{5}{|c|}{ M06-2X/6-31+G(d) SMD=water ${ }^{b}$} \\
\hline $2 a$ & 2.51 & +17.38 & -58.29 & 19.89 \\
\hline $3 a$ & 5.03 & +17.03 & -57.12 & 22.06 \\
\hline $4 a$ & 6.80 & +16.57 & -55.58 & 23.37 \\
\hline $5 a$ & 4.66 & +17.95 & -60.20 & 22.61 \\
\hline \multicolumn{5}{|c|}{ M06-2X/6-311++G(d,p) SMD $=$ water $^{c}$} \\
\hline $2 a$ & 4.26 & +16.16 & -54.20 & 20.42 \\
\hline $3 a$ & 7.13 & +16.03 & -53.76 & 23.16 \\
\hline $4 a$ & 8.80 & +15.76 & -52.86 & 24.56 \\
\hline $5 a$ & 7.50 & +15.44 & -51.79 & 22.94 \\
\hline
\end{tabular}

a Calculation and experimental Gibbs free energy of hydroxide anion-catalyzed hydrolysis of formamide was $21-22 \mathrm{kcal} / \mathrm{mol}[32] .{ }^{\mathrm{b}}$ Full optimizations. ${ }^{\mathrm{c}}$ Single-point calculations.

Other reaction models, a model with four explicit water molecules and a model with implicit water molecules, were also examined and the order of the energy demand is consistent with that of the present five-water model (the results are described in Supporting Information).

Non-planar amides based on the 7-azabicyclo[2.2.1]heptane scaffold were found to be rather inert to base-catalyzed hydrolysis. The calculated Gibbs free energies are also consistent with the experimental results.

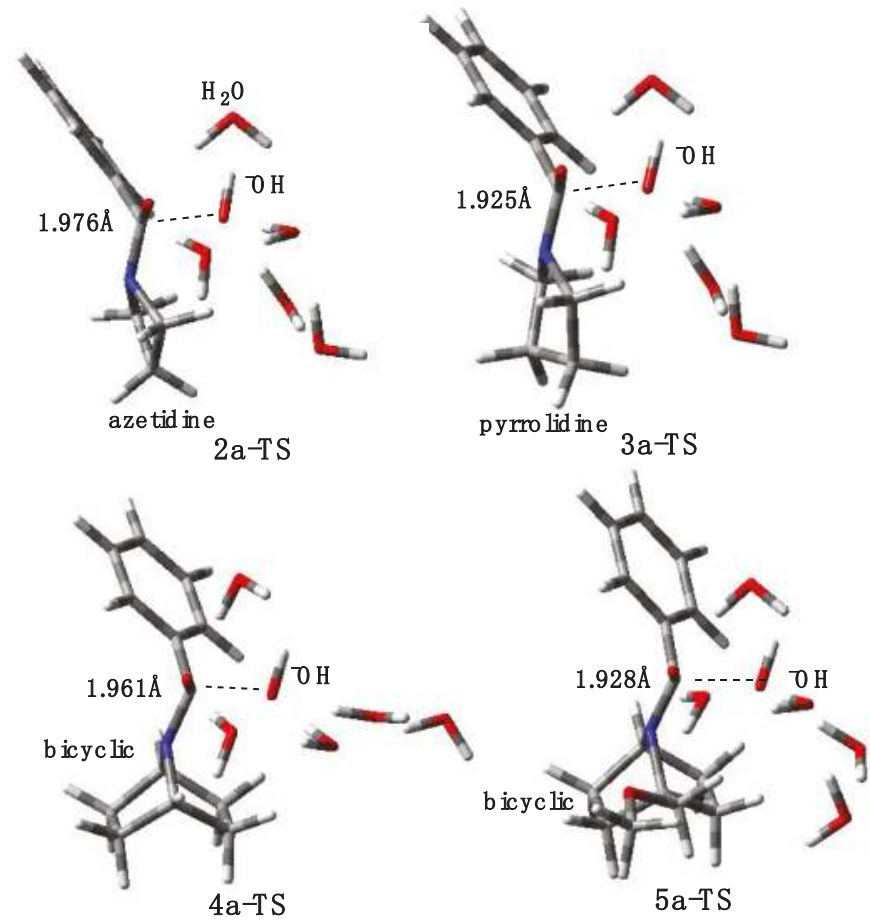

Figure 12. M06-2X/6-31+G(d)-optimized transition structures of hydroxide anion addition to the amide. Distance between the amide carbonyl carbon atom and hydroxide oxygen atom was shown. 
A close scrutiny of the trajectory in the TS (Figure 12) revealed the optimal trajectory for the hydroxide anion attack on the carbonyl group accompanied with hydrating water molecules. The positions of the hydroxy anion were similar in the respective TS structures. In the bicyclic amides (Figure 13, left), the water molecules in the bridgehead-substituted 5a were placed a little further from the amide substrate as compared with those in bridgehead-unsubstituted $4 \mathbf{a}$. A comparison of azetidine $\mathbf{2} \mathbf{a}$ and bridgehead-unsubstituted $\mathbf{4 a}$ also indicated that some of the hydrated waters were placed far from the substrate in the case of $4 \mathbf{a}$ (Figure 13, right). Therefore, these water molecules cannot get close to the substrate, due to greater steric congestion in $\mathbf{4 a}$, as compared with the azetidine (2a). Hydrogen bonding of water molecules stabilized the developing negative charge during the attack of hydroxide anion on the amide carbonyl carbon atom, while the entropy cost compensates for the stabilization. Inefficient hydration is one of the possible reasons that could explain the increase of the activation energy of the bicyclic amides 4 and 5 .

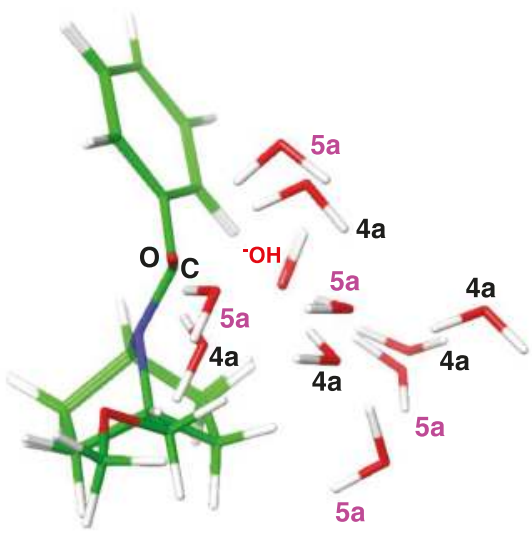

Superimpose of TSs of $4 a$ and $5 a$

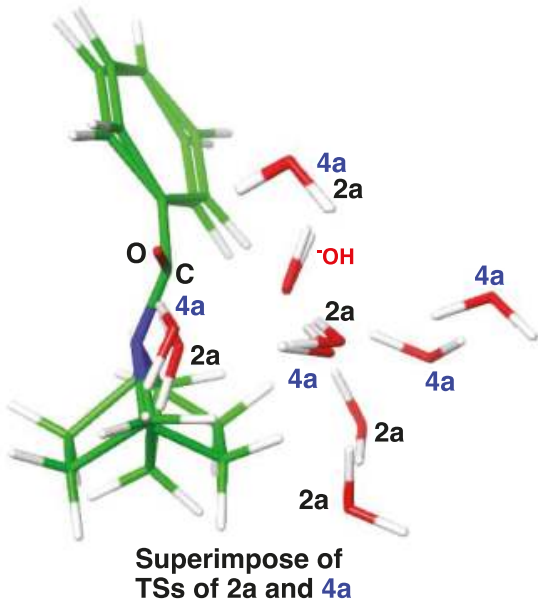

Figure 13. Superimposed TS structures of $\mathbf{4 a}$ and $\mathbf{5 a}$ (left) and $\mathbf{2 a}$ and $\mathbf{4 a}$ (right), showing the disrupted water network in bulky $5 \mathbf{a}$ (left, magenta) and $4 \mathbf{a}$ (right, blue).

\section{Materials and Methods}

\subsection{General Procedures}

All analyzed compounds were synthesized from commercially available reagents. All compounds were purified before use by column chromatography on silica gel (spherical, neutral silica gel $60 \mathrm{~N}$ $(100-210 \mu \mathrm{m})$, Kanto). Characterization was done by multiple techniques. ${ }^{1} \mathrm{H}-(400 \mathrm{MHz})$ and ${ }^{13} \mathrm{C}-$ (100 MHz) NMR spectra were recorded in a $400 \mathrm{MHz}$ Bruker Avance $400 \mathrm{NMR}$ spectrometer at $25^{\circ} \mathrm{C}$. Chemical shifts $(\delta)$ are shown in ppm, and coupling constants are given in hertz. Spectral data was obtained using NMR data processing software Brucker TOP-Spin. The NMR probe temperature was calibrated by the temperature-dependent chemical shift difference in ppm between $\mathrm{OH}$ proton and $\mathrm{CH}_{2}$ proton of ehtyleneglycol [33].

ESI-TOF mass spectra were recorded in a Bruker Daltonics, micrO-TOF-05. Elemental analyses were done by an independent group in this department and were given within a $\pm 0.4 \%$ error range. Melting points were measured with a Yanaco Micro Melting Point Apparatus and are uncorrected. 


\subsection{Synthesis of Amides}

All the amide compounds except $\mathbf{5 a - 5} \mathbf{c}$ have been synthesized previously [12] and stock samples were used for the present work. Some compounds among $\mathbf{2 a} \mathbf{a}-\mathbf{2} \mathbf{e}, \mathbf{3} \mathbf{a}-\mathbf{3 e}$, and $\mathbf{4 a}-\mathbf{4} \mathbf{e}$ were resynthesized, as described below, including the new compounds $\mathbf{5 a - 5}$.

\section{Synthesis of $N$-Benzoylazetidines}

$\mathrm{N}$-Benzoylazetidine (2a). Azetidine chloride (100 mg, $1.1 \mathrm{mmol}$ ) was dissolved in dry $\mathrm{CH}_{2} \mathrm{Cl}_{2}$ $(5 \mathrm{~mL})$ and the solution was cooled to $0{ }^{\circ} \mathrm{C}$. DIPEA $(0.7 \mathrm{~mL}, 2.9 \mathrm{mmol})$ was added, and the mixture was stirred for $10 \mathrm{~min}$. Then, benzoyl chloride ( $186 \mu \mathrm{l}, 1.6 \mathrm{mmol})$ was added slowly to the solution, and stirring was continued for $30 \mathrm{~min}$. The ice bath was removed and the reaction mixture was allowed to cool to r.t., then quenched by pouring it into water. The aqueous and organic layers were separated, and the aqueous phase was extracted with dichloromethane $(3 \times 10 \mathrm{~mL})$. The combined organic phase was washed with $0.5 \mathrm{M} \mathrm{HCl}, 0.5 \mathrm{M}$ aq. $\mathrm{NaHCO}_{3}$ and brine, dried over sodium sulfate, filtered, and evaporated under reduced pressure to afford a yellowish oil. The crude product was purified by open column chromatography (ethyl acetate/DCM, 1:1) to afford $2 \mathbf{a}$ as a transparent oil (130.8 mg, $0.81 \mathrm{mmol}, 76 \%) .{ }^{1} \mathrm{H}-\mathrm{NMR}\left(400 \mathrm{MHz}, \mathrm{CDCl}_{3}\right), \delta(\mathrm{ppm}): 7.616-7.592(\mathrm{~m}, 2 \mathrm{H}), 7.444-7.353$ (m, 3H), 4.296-4.191 (m, 4H), 2.352-2.274 (m, 2H). ${ }^{13} \mathrm{C}-\mathrm{NMR}$ (100 MHz, $\left.\mathrm{CDCl}_{3}\right), \delta(\mathrm{ppm}): 170.39,133.36$, 130.93, 128.40, 127.91, 53.46, 49.01. HRMS (ESI-TOF): $[\mathrm{M}+\mathrm{Na}]^{+}$: Calcd. for $\mathrm{C}_{10} \mathrm{H}_{11} \mathrm{NNaO}^{+}$: 185.0766. Found: 185.0782 .

$\mathrm{N}$-(p-Chlorobenzoyl)azetidine (2b). Azetidine chloride (100 mg, $1.1 \mathrm{mmol})$ was dissolved in dry $\mathrm{CH}_{2} \mathrm{Cl}_{2}(5 \mathrm{~mL})$ and the solution was cooled to $0{ }^{\circ} \mathrm{C}$. DIPEA $(0.7 \mathrm{~mL}, 2.9 \mathrm{mmol})$ was added, and the mixture was stirred for $10 \mathrm{~min}$. 4-Chlorobenzoyl chloride $(205 \mu \mathrm{L}, 1.6 \mathrm{mmol})$ was added slowly, and stirring was continued for $30 \mathrm{~min}$. The ice bath was removed and the mixture was allowed to warm to r.t., then quenched by pouring it into water. The aqueous and organic layers were separated, and the aqueous phase was extracted with dichloromethane $(3 \times 10 \mathrm{~mL})$. The combined organic phase was washed with $0.5 \mathrm{M} \mathrm{HCl}, 0.5 \mathrm{M}$ aq. $\mathrm{NaHCO}_{3}$ and brine, dried over sodium sulfate, filtered, and evaporated under reduced pressure to afford a pale oil. The crude product was purified by open column chromatography (ethyl acetate/DCM, 1:2) to provide $\mathbf{2 b}$ as colorless crystals $(171.9 \mathrm{mg}$, $0.88 \mathrm{mmol}, 82 \%) .{ }^{1} \mathrm{H}-\mathrm{NMR}\left(400 \mathrm{MHz}, \mathrm{CDCl}_{3}\right), \delta(\mathrm{ppm}): 7.587-7.554(\mathrm{~m}, 2 \mathrm{H}), 7.391-7.358(\mathrm{~m}, 2 \mathrm{H})$, 4.309-4.199 (m, 4H), 2.386-2.309 (m, 2H). ${ }^{13} \mathrm{C}-\mathrm{NMR}\left(100 \mathrm{MHz}, \mathrm{CDCl}_{3}\right), \delta$ (ppm): 169.18, 137.08, 131.76, 129.39, 128.70, 53.51, 49.09. HRMS (ESI-TOF): $[\mathrm{M}+\mathrm{Na}]^{+}$Calcd. for $\mathrm{C}_{10} \mathrm{H}_{10} \mathrm{ClNNaO}^{+}: 218.0343$. Found: 218.0360. Anal. Calcd. for $\mathrm{C}_{10} \mathrm{H}_{10} \mathrm{ClNO}$ C, 61.39; H, 5.15; N, 7.16. Found: $\mathrm{C}, 61.02 ; \mathrm{H}, 5.47 ; \mathrm{N}, 6.96$.

$\mathrm{N}$-(p-Nitrobenzoyl)azetidine (2c). Azetidine chloride $(100 \mathrm{mg}, 1.1 \mathrm{mmol})$ was dissolved in dry $\mathrm{CH}_{2} \mathrm{Cl}_{2}(5 \mathrm{~mL})$ and the solution was cooled to $0{ }^{\circ} \mathrm{C}$. DIPEA $(0.7 \mathrm{~mL}, 2.9 \mathrm{mmol})$ was added, and stirring was continued for $10 \mathrm{~min}$. Then, 4-nitrobenzoyl chloride $(186 \mu \mathrm{L}, 1.6 \mathrm{mmol})$ was added slowly, and stirring was continued for $30 \mathrm{~min}$. The ice bath was removed and the mixture was allowed to warm to r.t., then quenched by pouring it into water. The aqueous and organic layers were separated, and the aqueous phase was extracted with dichloromethane $(3 \times 10 \mathrm{~mL})$. The combined organic phase was washed with $0.5 \mathrm{M} \mathrm{HCl}, 0.5 \mathrm{M}$ aq. $\mathrm{NaHCO}_{3}$ and brine, dried over sodium sulfate, filtered, and evaporated under reduced pressure to give a yellow oil. The crude product was purified by open column chromatography (ethyl acetate/DCM, 1:2) to afford $2 \mathrm{c}$ as a yellow solid (172.6 mg, $0.84 \mathrm{mmol}, 78 \%) .{ }^{1} \mathrm{H}-\mathrm{NMR}\left(400 \mathrm{MHz}, \mathrm{CDCl}_{3}\right), \delta(\mathrm{ppm}): 8.268-8.235(\mathrm{~m}, 2 \mathrm{H}), 7.793-7.760(\mathrm{~m}, 2 \mathrm{H})$, 4.311-4.231 (m, 4H), 2.425-2.347 (m, 2H). ${ }^{13} \mathrm{C}-\mathrm{NMR}\left(100 \mathrm{MHz}, \mathrm{CDCl}_{3}\right), \delta$ (ppm): 168.00, 139.22, 131.19, 129.01, 123.76, 53.41, 49.32. HRMS (ESI-TOF): $[\mathrm{M}+\mathrm{Na}]^{+}$Calcd. for $\mathrm{C}_{10} \mathrm{H}_{10} \mathrm{~N}_{2} \mathrm{NaO}_{3}{ }^{+}: 229.0585$. Found: 229.0585.

\section{Synthesis of $N$-Benzoylpyrrolidines}

$\mathrm{N}$-Benzoylpyrrolidine (3a). Pyrrolidine (1 mL, $12.2 \mathrm{mmol})$ was dissolved in dry $\mathrm{CH}_{2} \mathrm{Cl}_{2}(5 \mathrm{~mL})$ and the solution was cooled to $0{ }^{\circ} \mathrm{C}$. DIPEA $(3.4 \mathrm{~mL}, 14.5 \mathrm{mmol})$ was added, and the mixture was stirred 
for $10 \mathrm{~min}$. Then, benzoyl chloride $(1.7 \mathrm{~mL}, 14.75 \mathrm{mmol})$ was added slowly, and stirring was continued for $30 \mathrm{~min}$. The ice bath was removed, and the mixture was allowed to warm to r.t., then quenched by pouring it into water. The aqueous and organic layers were separated, and the aqueous phase was extracted with dichloromethane $(3 \times 10 \mathrm{~mL})$. The combined organic phase was washed with $0.5 \mathrm{M}$ $\mathrm{HCl}, 0.5 \mathrm{M}$ aqeouse solution of $\mathrm{NaHCO}_{3}$ and brine, dried over sodium sulfate, filtered, and evaporated under reduced pressure to give a yellow liquid. The crude product was purified by open column chromatography (ethyl acetate) to afford $3 \mathrm{a}$ as a transparent yellow liquid (1.5530, $8.86 \mathrm{mmol}, 73 \%$ ). ${ }^{1} \mathrm{H}-\mathrm{NMR}\left(400 \mathrm{MHz}, \mathrm{CDCl}_{3}\right), \delta(\mathrm{ppm}): 7.504-7.356(\mathrm{~m}, 5 \mathrm{H}), 3.615(\mathrm{t}, J=6.8 \mathrm{~Hz}, 2 \mathrm{H}), 3.381(\mathrm{t}, J=6.6 \mathrm{~Hz}$, 2H), 1.929-1.804 (m, 4H). ${ }^{13} \mathrm{C}-\mathrm{NMR}\left(100 \mathrm{MHz}, \mathrm{CDCl}_{3}\right), \delta$ (ppm): 169.35, 137.10, 129.51, 128.00, 126.86, 49.33, 45.93, 26.17, 24.21. HRMS (ESI-TOF) $m / z:[\mathrm{M}+\mathrm{Na}]^{+}$Calcd. for $\mathrm{C}_{11} \mathrm{H}_{13} \mathrm{NNaO}^{+}: 198.0890$. Found: 198.0872. Anal. Calcd. for $\mathrm{C}_{11} \mathrm{H}_{13} \mathrm{NO}$ : C, 75.40; H, 7.48; N, 7.99. Found: $\mathrm{C}, 75.21 ; \mathrm{H}, 7.63 ; \mathrm{N}, 7.97$.

$\mathrm{N}$-(p-Chlorobenzoyl)pyrrolidine (3b). Pyrrolidine $(0.5 \mathrm{~mL}, 6.1 \mathrm{mmol})$ was dissolved in $\operatorname{dry} \mathrm{CH}_{2} \mathrm{Cl}_{2}$ $(3 \mathrm{~mL})$ and the solution was cooled to $0{ }^{\circ} \mathrm{C}$. DIPEA $(1.7 \mathrm{~mL}, 7.7 \mathrm{mmol})$ was added, and the mixture was stirred for $10 \mathrm{~min}$. Then, 4-chlorobenzoyl chloride (1.6164 mL, $7.4 \mathrm{mmol}$ ) dissolved in $\mathrm{CH}_{2} \mathrm{Cl}_{2}(2 \mathrm{~mL})$ was added slowly, and stirring was continued for $1 \mathrm{~h}$. The ice bath was removed, and the mixture was allowed to warm to r.t., then quenched by pouring it into water. The aqueous and organic layers were separated, and the aqueous phase was extracted with dichloromethane $(3 \times 10 \mathrm{~mL})$. The combined organic phase was washed with $0.5 \mathrm{M} \mathrm{HCl}, 0.5 \mathrm{M}$ aq. $\mathrm{NaHCO}_{3}$ and brine, dried over sodium sulfate, filtered, and evaporated under reduced pressure to afford a transparent oil. The crude product was purified by open column chromatography (hexane/ethyl acetate) to provide $3 \mathbf{b}$ as a white amorphous solid (444 mg, $2.1 \mathrm{mmol}, 35 \%$ ). m.p.: $62-64{ }^{\circ} \mathrm{C} .{ }^{1} \mathrm{H}-\mathrm{NMR}\left(400 \mathrm{MHz}, \mathrm{CDCl}_{3}\right), \delta$ (ppm): 7.410 (dd; $J=4.3 \mathrm{~Hz}, 1.8 \mathrm{~Hz} ; 2 \mathrm{H}), 7.307(\mathrm{dd} ; J=8.8 \mathrm{~Hz}, 2 \mathrm{~Hz} ; 2 \mathrm{H}), 3.569(\mathrm{t}, J=6.6 \mathrm{~Hz}, 2 \mathrm{H}), 3.349(\mathrm{t}, J=6.6 \mathrm{~Hz}, 2 \mathrm{H})$, $1.930-1.786(\mathrm{~m}, 4 \mathrm{H}) .{ }^{13} \mathrm{C}-\mathrm{NMR}\left(100 \mathrm{MHz}, \mathrm{CDCl}_{3}\right), \delta$ (ppm): 168.48, 135.73, 135.50, 128.63, 128.44, 49.55, 46.25, 26.36, 24.36. HRMS (ESI-TOF): [M + Na] ${ }^{+}$Calcd. for $\mathrm{C}_{11} \mathrm{H}_{12} \mathrm{ClNNaO}^{+}: 232.0500$. Found 232.0517. Anal. Calcd. for $\mathrm{C}_{11} \mathrm{H}_{12} \mathrm{ClNO}$ C, 63.01; $\mathrm{H}, 5.77 ; \mathrm{N}, 6.68$. Found: $\mathrm{C}, 62.95 ; \mathrm{H}, 5.78 ; \mathrm{N}, 6.51$.

$\mathrm{N}$-( $p$-Nitrobenzoyl)pyrrolidine (3c). Pyrrolidine $(0.5 \mathrm{~mL}, 6.1 \mathrm{mmol})$ was dissolved in dry $\mathrm{CH}_{2} \mathrm{Cl}_{2}$ $(5 \mathrm{~mL})$ at $0{ }^{\circ} \mathrm{C}$. DIPEA $(1.7 \mathrm{~mL}, 7.7 \mathrm{mmol})$ was added to the solution, and the mixture was stirred for $10 \mathrm{~min}$. Then, 4-nitrobenzoyl chloride $(1.1301 \mathrm{~g}, 7.4 \mathrm{mmol})$ dissolved in $\mathrm{CH}_{2} \mathrm{Cl}_{2}(10 \mathrm{~mL})$ was added slowly, and stirring was continued for $1 \mathrm{~h}$ at $0{ }^{\circ} \mathrm{C}$. The ice bath was removed, and the mixture was allowed to warm to r.t., then quenched by pouring it into water. The aqueous and organic layers were separated, and the aqueous phase was extracted with dichloromethane $(3 \times 30 \mathrm{~mL})$. The combined organic phase was washed with brine, dried over sodium sulfate, filtered, and evaporated under reduced pressure to give a a yellow liquid. The crude product was purified by open column chromatography (ethyl acetate/acetone 1:1) to afford $3 \mathrm{c}$ as a slightly yellow solid ( $821.6 \mathrm{mg}, 3.7 \mathrm{mmol}$, 61.3\%). m.p.: 78-80 ${ }^{\circ} \mathrm{C} .{ }^{1} \mathrm{H}-\mathrm{NMR}\left(400 \mathrm{MHz}, \mathrm{CDCl}_{3}\right), \delta(\mathrm{ppm}): 8.293-8.207(\mathrm{~m}, 2 \mathrm{H}), 7.698-7.665(\mathrm{~m}, 2 \mathrm{H})$, $3.676(\mathrm{t}, J=7.0 \mathrm{~Hz}, 2 \mathrm{H}), 3.382(\mathrm{t}, J=6.6 \mathrm{~Hz}, 2 \mathrm{H}), 2.039-1.887(\mathrm{~m}, 4 \mathrm{H}) .{ }^{13} \mathrm{C}-\mathrm{NMR}\left(100 \mathrm{MHz}, \mathrm{CDCl}_{3}\right), \delta$ (ppm): 167.61, 143.19, 128.29, 123.84, 49.61, 46.56, 26.52, 24.50. HRMS (ESI-TOF): [M + Na] ${ }^{+} \mathrm{Calcd}$. for $\mathrm{C}_{11} \mathrm{H}_{12} \mathrm{~N}_{2} \mathrm{NaO}_{3}{ }^{+}$: 244.0774. Found: 244.0742. Anal. Calcd. for $\mathrm{C}_{11} \mathrm{H}_{12} \mathrm{~N}_{2} \mathrm{O}_{3}: \mathrm{C}, 59.99 ; \mathrm{H}, 5.49 ; \mathrm{N}, 12.72$. Found: C, 59.82; H, 5.45; N, 12.65.

$\mathrm{N}$-(p-Toluoyl)pyrrolidine (3d). Pyrrolidine $(0.5 \mathrm{~mL}, 6.1 \mathrm{mmol})$ was dissolved in dry $\mathrm{CH}_{2} \mathrm{Cl}_{2}(5 \mathrm{~mL})$ and the solution was cooled to $0{ }^{\circ} \mathrm{C}$. DIPEA $(1.7 \mathrm{~mL}, 7.7 \mathrm{mmol})$ was added, and the mixture was stirred for $10 \mathrm{~min}$. Then, a solution of $p$-tolyl chloride $(975 \mu \mathrm{L}, 7.4 \mathrm{mmol})$ in $\mathrm{CH}_{2} \mathrm{Cl}_{2}(10 \mathrm{~mL})$ was slowly added, and the mixture was stirred for $1 \mathrm{~h}$ at $0{ }^{\circ} \mathrm{C}$. The ice bath was removed, and the mixture was allowed to warm to r.t., then quenched by pouring it into water. The aqueous and organic layers were separated, and the aqueous phase was extracted with dichloromethane $(3 \times 30 \mathrm{~mL})$. The combined organic phase was washed with brine, dried over sodium sulfate, filtered, and evaporated under reduced pressure to provide a yellow liquid. The crude product was purified by open column chromatography (hexane/ethyl acetate 4:1) to afford $3 \mathrm{~d}$ as a white solid $(654.4 \mathrm{mg}$, $3.5 \mathrm{mmol}, 56.8 \%)$. M.p.: $75-76{ }^{\circ} \mathrm{C}$. ${ }^{1} \mathrm{H}-\mathrm{NMR}\left(400 \mathrm{MHz}, \mathrm{CDCl}_{3}\right), \delta(\mathrm{ppm}): 7.438-7.408(\mathrm{~m}, 2 \mathrm{H}), 7.202-7.179(\mathrm{~m}, 2 \mathrm{H}), 3.639(\mathrm{t}, J=7.0 \mathrm{~Hz}$, $2 \mathrm{H}), 3.439(\mathrm{t}, J=6.6 \mathrm{~Hz}, 2 \mathrm{H}), 2.372(\mathrm{~s}, 3 \mathrm{H}), 1.986-1.829(\mathrm{~m}, 4 \mathrm{H}) .{ }^{13} \mathrm{C}-\mathrm{NMR}\left(100 \mathrm{MHz}, \mathrm{CDCl}_{3}\right), \delta(\mathrm{ppm})$ : 
$169.93,139.98,134.52,128.93,127.35,49.75,46.30,26.55,24.59,21.50$ HRMS (ESI-TOF) $m / z:[\mathrm{M}+\mathrm{Na}]^{+}$ Calcd. for $\mathrm{C}_{12} \mathrm{H}_{15} \mathrm{NNaO}^{+}$: 212.1046. Found 212.1036. Anal. Calcd. for $\mathrm{C}_{12} \mathrm{H}_{15} \mathrm{NO}$ : C, 76.16; $\mathrm{H}, 7.99$; N, 7.40. Found: C, 75.80; $\mathrm{H}, 8.09 ; \mathrm{N}, 7.33$.

$\mathrm{N}$-(p-Anisoyl)pyrrolidine (3e). Pyrrolidine $(0.5 \mathrm{~mL}, 6.1 \mathrm{mmol})$ was dissolved in dry $\mathrm{CH}_{2} \mathrm{Cl}_{2}(5 \mathrm{~mL})$ and the solution was cooled to $0{ }^{\circ} \mathrm{C}$. DIPEA $(1.7 \mathrm{~mL}, 7.7 \mathrm{mmol})$ was added, and the mixture was stirred for $10 \mathrm{~min}$. Then, a solution of 4-nitrobenzoyl chloride (1.2573 g, $7.4 \mathrm{mmol})$ in $\mathrm{CH}_{2} \mathrm{Cl}_{2}$ $(10 \mathrm{~mL})$ was slowly added, and stirring was continued for $1 \mathrm{~h}$ at $0{ }^{\circ} \mathrm{C}$. The ice bath was removed, and the mixture was allowed to warm to r.t., then quenched by pouring it into water. The aqueous and organic layers were separated, and the aqueous phase was extracted with dichloromethane $(3 \times 30 \mathrm{~mL})$. The combined organic phase was washed with brine, dried over sodium sulfate, filtered, and evaporated under reduced pressure to provide a yellow liquid. The crude product was purified by open column chromatography ( $n$-hexane/ethyl acetate 1:1) to afford $3 \mathbf{e}$ as a pale-brown solid $(808.3 \mathrm{mg}$, $3.9 \mathrm{mmol}, 65 \%)$. m.p.: $73.5-75.5^{\circ} \mathrm{C} .{ }^{1} \mathrm{H}-\mathrm{NMR}\left(400 \mathrm{MHz}, \mathrm{CDCl}_{3}\right), \delta$ (ppm): 7.515 (ddd, $J=9.2,2.4,2 \mathrm{~Hz}$, $4 \mathrm{H}), 3.832(\mathrm{~s}, 3 \mathrm{H}), 3.634(\mathrm{t}, J=6.4 \mathrm{~Hz}, 2 \mathrm{H}), 3.476(\mathrm{t}, J=6.2 \mathrm{~Hz}, 2 \mathrm{H}), 1.966-1.851(\mathrm{~m}, 4 \mathrm{H}) .{ }^{13} \mathrm{C}-\mathrm{NMR}$ (100 MHz, $\left.\mathrm{CDCl}_{3}\right), \delta$ (ppm): 169.56, 160.93, 129.63, 129.29, 113.55, 55.45, 49.90, 46.44, 26.64, 24.59. HRMS (ESI-TOF) $m / z$ : [M $+\mathrm{Na}]^{+}$Calcd. for $\mathrm{C}_{12} \mathrm{H}_{15} \mathrm{NNaO}_{2}{ }^{+}:$228.0995. Found 228.0993. Anal. Calcd. for $\mathrm{C}_{12} \mathrm{H}_{15} \mathrm{NO}_{2}$ : C, 70.22; $\mathrm{H}, 7.39 ; \mathrm{N}, 6.82$. Found: $\mathrm{C}, 70.01 ; \mathrm{H}, 7.48 ; \mathrm{N}, 6.76$.

\section{Synthesis of $\mathrm{N}$-Benzoylazetidines}

N-Benzoyl-7-azabicyclo[2.2.1]heptane (4a). Trans-4-aminocyclohexyl p-toluensulfonate hydrobromide $(1 \mathrm{~g}, 7.5 \mathrm{mmol})$ was dissolved in ethanol $(110 \mathrm{~mL})$ and water $(30 \mathrm{~mL})$, and then $\mathrm{NaOH} 1 \mathrm{M}(25 \mathrm{~mL})$ was added. The mixture was stirred at room temperature for $20 \mathrm{~h}$, and then quenched by adding $\mathrm{HCl}$ $4 \mathrm{M}$ in 1,4-dioxane (5 mL). Stirring was continued for $20 \mathrm{~min}$ at r.t., and the mixture was evaporated under reduced pressure. $\mathrm{NaOH} 10 \%(10 \mathrm{~mL})$ was added to the residue, and free amide was extracted with ether $(3 \times 30 \mathrm{~mL})$. This solution was evaporated, and the residue was redissolved in $\operatorname{dry} \mathrm{CH}_{2} \mathrm{Cl}_{2}$ ( $30 \mathrm{~mL}$ ). DIPEA ( $2 \mathrm{~mL}, 9.3 \mathrm{mmol}$ ) was added to the resulting solution, and the mixture was stirred for $10 \mathrm{~min}$ at $0{ }^{\circ} \mathrm{C}$. Then, benzoyl chloride $(1.1 \mathrm{~mL}, 9.1 \mathrm{mmol})$ was slowly added. Stirring was continued for $30 \mathrm{~min}$. The ice bath was removed, and the mixture was allowed to warm to r.t. Stirring was continued for $4 \mathrm{~h}$, and then the mixture was quenched by pouring it into water. The aqueous and organic layers were separated, and the aqueous phase was extracted with dichloromethane $(3 \times 50 \mathrm{~mL})$. The combined organic phase was washed with brine, dried over sodium sulfate, filtered, and evaporated under reduced pressure to give a yellow oil. The crude product was purified by open column chromatography $\left(\mathrm{CH}_{2} \mathrm{Cl}_{2}\right.$ /ethyl acetate 9:1) to afford $4 \mathbf{a}$ as a white solid $(52.0 \mathrm{mg}, 35 \%)$. ${ }^{1} \mathrm{H}-\mathrm{NMR}\left(400 \mathrm{MHz}, \mathrm{CDCl}_{3}\right), \delta$ (ppm): 7.813-7.696 (m, 2H), 7.506-7.288 (m, 3H) 4.613-4.460 (m, 1H), 4.121-3.900 (m, 1H), 2.239-1.240 (m, 8H). ESI-HRMS $(m / z)$ : Calculated for $\mathrm{C}_{13} \mathrm{H}_{15} \mathrm{NNaO}^{+}[\mathrm{M}+\mathrm{Na}]^{+}$: 225.1079. Found: 225.1081.

$\mathrm{N}$-(p-Toluoyl)-7-azabicyclo[2.2.1]heptane (4d). Trans-4-aminocyclohexyl p-toluensulfonate hydrobromide $(1 \mathrm{~g}, 7.5 \mathrm{mmol})$ was dissolved in ethanol $(110 \mathrm{~mL})$ and water $(30 \mathrm{~mL})$, and then $\mathrm{NaOH} 1 \mathrm{M}(25 \mathrm{~mL})$ was added. The solution was stirred at room temperature for $20 \mathrm{~h}$, and then quenched by adding concentrated $\mathrm{HCl} 4 \mathrm{M}(5 \mathrm{~mL})$. Stirring was continued for $20 \mathrm{~min}$ at r.t., and then the solution was evaporated under reduced pressure. $\mathrm{NaOH} 10 \%(10 \mathrm{~mL})$ was added to the residue. Free amide was extracted with ether $(3 \times 30 \mathrm{~mL})$, then $\mathrm{HCl}$ in 1,4-dioxane $(1 \mathrm{~mL})$ was added, and the mixture was evaporated. The residue was redissolved in dry $\mathrm{CH}_{2} \mathrm{Cl}_{2}(30 \mathrm{~mL})$. DIPEA $(2 \mathrm{~mL}, 9.3 \mathrm{mmol})$ was added to the resulting solution, and the mixture was stirred for $10 \mathrm{~min}$ at $0{ }^{\circ} \mathrm{C}$. Then, $p$-tolyl benzoyl chloride $(1.6 \mathrm{~mL}, 9.1 \mathrm{mmol})$ was slowly added. Stirring was continued for $30 \mathrm{~min}$. The ice bath was removed, and the mixture was allowed to warm to r.t., and further stirred for $4 \mathrm{~h}$, then quenched by pouring it into water. The aqueous and organic layers were separated, and the aqueous phase was extracted with dichloromethane $(3 \times 30 \mathrm{~mL})$. The combined organic phase was washed with brine, dried over sodium sulfate, filtered, and evaporated under reduced pressure to give a yellow oil. The crude product was purified twice by open column chromatography ( $n$-hexane/ethyl acetate 
(1:1) and dichloromethane/ethyl acetate (9:1)) to afford $4 \mathbf{d}$ as a yellow solid. Recrystallization afforded transparent crystals $(238.6 \mathrm{mg}, 11 \%)$. M.p.: $105-107^{\circ} \mathrm{C} .{ }^{1} \mathrm{H}-\mathrm{NMR}\left(400 \mathrm{MHz}, \mathrm{CDCl}_{3}\right), \delta$ (ppm): 7.449 (d, $J=8 \mathrm{~Hz}, 2 \mathrm{H}), 7.188(\mathrm{~d}, J=8 \mathrm{~Hz}, 2 \mathrm{H}), 4.720$ (br. s, $1 \mathrm{H}), 4.148$ (br. s, $1 \mathrm{H}), 2.377$ (s, 3H), 1.899-1.810 (s, 4H), 1.508-1.466 (m, 4H). ${ }^{13} \mathrm{C}-\mathrm{NMR}\left(100 \mathrm{MHz}, \mathrm{CDCl}_{3}\right), \delta$ (ppm): 169.03, 140.72, 133.50, 128.96, 127.97, 77.36, 30.60, 28.87, 21.56. ESI-HRMS: Calculated for $\mathrm{C}_{14} \mathrm{H}_{17} \mathrm{NNaO}^{+}\left[\mathrm{M}+\mathrm{Na}^{+}\right.$: 238.1202. Found: 238.1217. Anal. Calcd. for $\mathrm{C}_{14} \mathrm{H}_{17} \mathrm{NO}_{2}$ : C, 78.10; H, 7.96; N, 6.51. Found: C, 77.76; H, 7.90; N, 6.58.

\section{Synthesis of N-Benzoyl-1-(Methoxymethyl)-7-azabicyclo[2.2.1]heptanes}

N-Benzoyl-1-(Methoxymethyl)-7-azabicyclo[2.2.1]heptane (5a). Boc-protected 1-(methoxymethyl)-7azabicyclo[2.2.1] heptane $(114.6 \mathrm{mg}, 0.47 \mathrm{mmol})$ was dissolved in a 1:1 mixture of dry $\mathrm{CH}_{2} \mathrm{Cl}_{2}(1 \mathrm{~mL})$ and TFA $(1 \mathrm{~mL})$, and the solution was stirred at room temperature for one $\mathrm{h}$. The solvent was removed in vacuo, and the residue was dissolved in $\mathrm{CH}_{2} \mathrm{Cl}_{2}$. The resulting solution was evaporated again (a total of three times). Finally, the residue was dissolved in dry $\mathrm{CH}_{2} \mathrm{Cl}_{2}(5 \mathrm{~mL})$ and DIPEA (130 $\left.\mu \mathrm{l}, 0.61 \mathrm{mmol}\right)$ was added to the solution. The mixture was stirred for $10 \mathrm{~min}$ at $0{ }^{\circ} \mathrm{C}$, then benzoyl anhydride $(170 \mu \mathrm{L}, 0.9 \mathrm{mmol})$ was slowly added. Stirring was continued for $30 \mathrm{~min}$. The ice bath was removed, and the mixture was allowed to warm to r.t., then quenched by pouring it into water. The aqueous and organic layers were separated, and the aqueous phase was extracted with dichloromethane $(3 \times 10 \mathrm{~mL})$. The combined organic phases were washed with brine, dried over sodium sulfate, filtered, and evaporated under reduced pressure to give a yellow liquid. The crude product was purified by open column chromatography $\left(\mathrm{CH}_{2} \mathrm{Cl}_{2}\right.$ /ethyl acetate 9:1) to afford $\mathbf{5 a}$ as a white solid (520.0 $\mathrm{mg}, 35 \%$ ). M.p.: 53-55 ${ }^{\circ} \mathrm{C} .{ }^{1} \mathrm{H}-\mathrm{NMR}\left(400 \mathrm{MHz}, \mathrm{CDCl}_{3}\right), \delta$ (ppm): 7.524-7.512 (m, 2H), 7.437-7.342 (m, 3H), 4.225 (s, $2 \mathrm{H}), 4.106(\mathrm{t}, J=5 \mathrm{~Hz}, 1 \mathrm{H}), 3.425(\mathrm{~s}, 3 \mathrm{H}), 2.013-1.932(\mathrm{~m}, 2 \mathrm{H}), 1.867-1.771(\mathrm{~m}, 2 \mathrm{H}), 1.728-1.667(\mathrm{~m}$, $2 \mathrm{H}), 1.487-1.425(\mathrm{~m}, 2 \mathrm{H})$. HRMS (ESI-TOF): $[\mathrm{M}+\mathrm{Na}]^{+}$Calcd. for $\mathrm{C}_{15} \mathrm{H}_{19} \mathrm{NNaO}_{2}{ }^{+}[\mathrm{M}+\mathrm{Na}]^{+}: 268.1308$. Found: 268.1312.

$N$-(p-Chlorobenzoyl)-(1-(methoxymethyl)-7-azabicyclo[2.2.1]heptanes (5b). To a solution of the corresponding Boc-protected 1-(methoxymethyl)-7- azabicyclo[2.2.1] heptane (41.2 mg) in dry $\mathrm{CH}_{2} \mathrm{Cl}_{2}$ $(2 \mathrm{~mL})$ was added $3 \mathrm{~mL}$ of TFA. The solution was stirred at room temperature for $2 \mathrm{~h}$ The organic solvent was evaporated, and the residue was dissolved in $10 \mathrm{~mL}$ of $\mathrm{CH}_{2} \mathrm{Cl}_{2}$. Triethylamine $(93.6 \mu \mathrm{L})$ was added at $0{ }^{\circ} \mathrm{C}$, followed by $p$-chlorobenzoyl chloride $(58.8 \mathrm{mg})$. The reaction mixture was stirred for $2 \mathrm{~h}$ at $0{ }^{\circ} \mathrm{C}$, and then poured into saturated aqueous $\mathrm{NaHCO}_{3}$. The whole was extracted with $\mathrm{CH}_{2} \mathrm{Cl}_{2}$ $(30 \mathrm{~mL} \times 3)$. The combined organic layer was dried over $\mathrm{Na}_{2} \mathrm{SO}_{4}$, and the solvent was evaporated. Column chromatography ( $n$-hexane:ethyl acetate $=4: 1)$ of the residue gave $5 \mathbf{b}(47.8 \mathrm{mg}, 77 \%) .{ }^{1} \mathrm{H}$-NMR $\left(400 \mathrm{MHz}, \mathrm{CDCl}_{3}\right), \delta(\mathrm{ppm}): 7.489(2 \mathrm{H}, \mathrm{d}, J=8.4 \mathrm{~Hz}), 7.356(2 \mathrm{H}, \mathrm{d} J=8.0 \mathrm{~Hz}), 4.198(2 \mathrm{H}, \mathrm{s}), 4.087(1 \mathrm{H}$, $\mathrm{m}), 3.423(3 \mathrm{H}, \mathrm{s}), 2.076-1.571(6 \mathrm{H}, \mathrm{m}), 1.568-1.369(2 \mathrm{H}, \mathrm{m}) .{ }^{13} \mathrm{C}-\mathrm{NMR}\left(100 \mathrm{MHz}, \mathrm{CDCl}_{3}\right), \delta(\mathrm{ppm})$ : $169.11,136.37,135.45,129.20,128.43,73.91,68.03,61.37,59.34,32.65,29.59$. HRMS (ESI-TOF): $[\mathrm{M}+\mathrm{Na}]^{+}$ Calcd. for $\mathrm{C}_{15} \mathrm{H}_{18} \mathrm{ClNNaO}_{2}{ }^{+}[\mathrm{M}+\mathrm{Na}]^{+}$: 302.0918. Found: 302.0924. Anal. Calcd. for $\mathrm{C}_{15} \mathrm{H}_{18} \mathrm{ClNO}_{2}$ : $\mathrm{C}$, 64.40; H, 6.49; N, 5.01. Found: C, 64.27; H, 6.52; N, 4.92.

$\mathrm{N}$-(p-Nitrobenzoyl)-(1-(Methoxymethyl)-7-azabicyclo[2.2.1]heptanes (5c). Boc-protected 1-(methoxymethyl)7-azabicyclo[2.2.1]heptane (119.3 mg, $0.49 \mathrm{mmol})$ was dissolved in a 1:1 mixture of dry $\mathrm{CH}_{2} \mathrm{Cl}_{2}(1 \mathrm{~mL})$ and TFA $(1 \mathrm{~mL})$, and the solution was stirred at room temperature for one $\mathrm{h}$. The solvent was removed in vacuo, then the residue was dissolved in $\mathrm{CH}_{2} \mathrm{Cl}_{2}$ and this solution was evaporated again (a total of three times). Finally, the residue was dissolved in dry $\mathrm{CH}_{2} \mathrm{Cl}_{2}(5 \mathrm{~mL})$, DIPEA $(132 \mu \mathrm{L}, 0.63 \mathrm{mmol})$ was added to it, and the mixture was stirred for $10 \mathrm{~min}$ at $0{ }^{\circ} \mathrm{C}$. Then, $p$-nitrobenzoyl chloride $(91.70 \mathrm{mg}$, $0.6 \mathrm{mmol}$ ) was slowly added, and stirring was continued for $30 \mathrm{~min}$. The ice bath was removed, and the mixture was allowed to warm to r.t. Stirring was continued for $5.5 \mathrm{~h}$, and then the mixture was quenched by pouring it into water. The aqueous and organic layers were separated, and the aqueous phase was extracted with dichloromethane $(3 \times 10 \mathrm{~mL})$. The combined organic phase was washed with brine, dried over sodium sulfate, filtered, and evaporated under reduced pressure to give a a yellow liquid. The crude residue was purified by open column chromatography ( $n$-hexane/ethyl acetate 1:1) to afford $\mathbf{5 c}$ as a white solid $(63.9 \mathrm{mg}, 45 \%)$. m.p.: $140-142{ }^{\circ} \mathrm{C} .{ }^{1} \mathrm{H}-\mathrm{NMR}\left(400 \mathrm{MHz}, \mathrm{CDCl}_{3}\right), \delta$ (ppm): 
$8.256(\mathrm{dd}, J=2 \mathrm{~Hz}, 6.8 \mathrm{~Hz}, 2 \mathrm{H}), 7.685(\mathrm{dd}, J=2 \mathrm{~Hz}, 6.8 \mathrm{~Hz}, 2 \mathrm{H}), 4.178(\mathrm{~s}, 2 \mathrm{H}), 4.010(\mathrm{t}, J=4.4 \mathrm{~Hz}$, $1 \mathrm{H}), 3.419(\mathrm{~s}, 3 \mathrm{H}), 2.003-1.961(\mathrm{~m}, 2 \mathrm{H}), 1.873-1.783(\mathrm{~m}, 2 \mathrm{H}), 1.750-1.689(\mathrm{~m}, 2 \mathrm{H}), 1.549-1.487(\mathrm{~m}, 2 \mathrm{H})$. ${ }^{13} \mathrm{C}-\mathrm{NMR}\left(100 \mathrm{MHz}, \mathrm{CDCl}_{3}\right), \delta$ (ppm): 167.52, 148.90, 143.12, 128.68, 123.74, 73.64, 68.66, 61.24, 59.46, 32.79, 29.71. HRMS (ESI-TOF): $[\mathrm{M}+\mathrm{Na}]^{+}$Calcd. for $\mathrm{C}_{15} \mathrm{H}_{18} \mathrm{~N}_{2} \mathrm{NaO}_{4}{ }^{+}[\mathrm{M}+\mathrm{Na}]^{+}: 313.1159$. Found: 313.1169. Anal. Calcd. for $\mathrm{C}_{15} \mathrm{H}_{18} \mathrm{~N}_{2} \mathrm{O}_{4}$ : $\mathrm{C}, 62.06 ; \mathrm{H}, 6.25 ; \mathrm{N}, 9.65$. Found: $\mathrm{C}, 61.92 ; \mathrm{H}, 6.28 ; \mathrm{N}, 9.63$.

\subsection{Kinetic Studies}

Kinetic data were collected by recording the ${ }^{1} \mathrm{H}-\mathrm{NMR}(400 \mathrm{MHz})$ spectra at 2- min intervals. Data were obtained at $70.0^{\circ} \mathrm{C}$ under a $\mathrm{N}_{2}$ flow of $400 \mathrm{~L} / \mathrm{h}$. Deuterated solvents were used for all measurements: Deuterium oxide, $99.9 \%$ D from Wako; methanol- $\mathrm{d}_{4}, 99.8 \% \mathrm{D}$ from Kanto Chemical Co. Inc.; 1,4-dioxane- $\mathrm{d}_{8}, 99 \% \mathrm{D}$ from Cambridge Isotope Laboratories, Inc.; and sodium deuteroxide, $40 \%$ wt. \% in $\mathrm{D}_{2} \mathrm{O}, 99.5 \% \mathrm{D}$ from Sigma-Aldrich, Co. Parameters were set using the reaction solution at room temperature. Reactions were initiated by raising the temperature of the NMR machine. Spectral data were then recorded for at least one half-life. Hydrolysis experiments were repeated three times. Hydrolysis products were identified by comparison of the ${ }^{1} \mathrm{H}-\mathrm{NMR}$ data with those of authentic samples, or by MS-ESI. Pseudo-first-order rate constants $\left(k_{o b s}\right)$ were evaluated by a linear least-squares fitting of a plot of the logarithm of reactant concentration versus time.

\subsection{Computational Studies}

Computational studies were carried out using the Gaussian 09 software package [34]. Geometry optimizations for the model molecules were performed at the M06-2X/6-31+G(d) level with the bulk solvent model SMD (solvent = water) together with explicit water molecules. Vibrational frequency calculations were performed at the same level of theory. Optimized geometries were verified by frequency calculations as minima (zero imaginary frequencies) or transition structures (TS, a single imaginary frequency) (the coordinates, frequency and thermodynamic values are shown in Supporting Information). Intrinsic reaction coordinate (IRC) computations of the transition structures verified the reactants and products in the case of simple amide (formamide and acetamide (data not shown)). In the cases of more realistic substrates ( $2 \mathbf{a}-\mathbf{5 a})$, particularly in combination of the solvent model, the IRC calculations were unsuccessful. In all the transition states the validity of transition state structures was confirmed by inspecting the direction of vibration of the negative frequency, which matched the trajectory of the nucleophilic attack of the hydroxy anion onto the carbonyl carbon atom. Geometry minimization of the transition structures lead to the hydroxide-addition adducts, which also supported the validity of the transition state structures, which represented the trajectory of the nucleophilic attack of the hydroxy anion. We also estimated Gibbs free energies by single-point calculations (frequency calculations) with M06-2X//6-311++G(d,p) for the M06-2X//6-31+G(d)-optimized structures. In these single-point frequency calculations, a single negative frequency was found respectively, which also corresponded to the trajectory of the nucleophilic attack of the hydroxy anion onto the carbonyl carbon atom. The energies were corrected for zero-point energies and Gibbs free energy at $25^{\circ} \mathrm{C}(298.15 \mathrm{~K})$, obtained from frequency calculations. Calculations at the B3LYP level showed similar trends to the M06-2X calculations.

Identification of the transition states structures of the attack of the hydroxide anion to the carbonyl carbon atom of the amide group was carried out in the following multiple procedures: The transition state structures of the attack of the hydroxide anion to the carbonyl carbon atom of the amide were first identified in the absence of the explicit water molecules (data not shown). Addition of explicit water molecules in the arrangement similar to Types a and b (Figure 11) [32], followed by geometry optimization $(\mathrm{OPT}=\mathrm{TS})$. Or we reproduced the TSs of the hydrolysis of formamide and acetamide in the presence of four and five water molecules, respectively, which were consistent with the two hydrogen network models (Types a and b, Figure 11), reported in the previous literature [32]. Then the amide functionality was morphed into the realistic amide substrates $(\mathbf{2} \mathbf{a}-\mathbf{5 a})$. The initial minimum conformation of the neutral amide substrates $(\mathbf{2} \mathbf{a}-\mathbf{5} \mathbf{a})$ were obtained by conformational search in 
Marcomodel software (Schrödinger, LLC, New York, NY, USA), followed by optimization with the DFT methods. The Type a arrangement of waters (Figure 11) did not converge to the optimization or transformed to the Type $b$ arrangement of water molecules. Therefore, we discussed the activation energies on the basis of the Type b hydrogen network model, while the Type a hydrogen network model might be the energy minimum (see the main text).

The change of Gibbs free energy for the reaction was calculated on the basis of the reaction model, shown in Scheme 6. The results of the present calculations (Table 4) were reasonable and reliable, because the present calculations gave the activation energies of similar magnitude to the cases of simple amide: The calculated activation energies of the present amides $\mathbf{2 a - 5 a}$ were in similar magnitude to the calculated and experimental Gibbs free energy change of hydroxide anion-catalyzed hydrolysis of formamide, 21-22 kcal/mol [32], (see also Table 4, footnote a).

\section{Conclusions}

Herein we measured and compared the kinetics of base-catalyzed hydrolysis of non-planar $\mathrm{N}$-benzoyl-7-azabicyclo[2.2.1] heptane amides (4) and related compounds (2, 3 and 5) under pseudo-first-order conditions at $70^{\circ} \mathrm{C}$. Excess sodium deuteroxide was used as the base in two different solvent systems (methanol or 1,4-dioxane in a 1:1 $\mathrm{D}_{2} \mathrm{O}$ solution). Reaction progress was monitored by ${ }^{1} \mathrm{H}$ NMR spectroscopy. Unexpectedly we found that 7-azabicyclo[2.2.1]heptane amides (4) were resistant to base-catalyzed hydrolysis. As a general trend, independently of whether methanol or 1,4-dioxane was used as a co-solvent, it was found that the reactivity of nitrogen-pyramidal azetidine amides (2) was greater than that of the planar pyrrolidine amides (3), followed by unsubstituted bicyclic amides (4), while bridgehead-substituted bicycles (5) were the least reactive (reaction rate: $2 a>3 a>4 a>5 a$, etc.). Phenyl substituents showed the expected electronic trends. We also executed DFT calculations of the rate-determining process, addition of the hydroxide anion to the amide carbonyl group, and found that the experimental kinetic data is consistent with the magnitude of the calculated Gibbs free energies of activation. Our results confirm the stability of the 7-azabicyclo[2.2.1]heptane amides at least at $37^{\circ} \mathrm{C}$. This is important, because it implies that the 7-azabicyclo[2.2.1]heptane amide scaffold is available for practical molecular design, e.g., as an amino acid surrogate.

Supplementary Materials: The following are available online, Supporting Information: Raw kinetic data (Figures S1 and S2), additional calculation data (Tables S1-S5), calculation coordinates, NMR spectra (Figures S3-S5).

Author Contributions: D.A.O.G.d.V.: synthesis of compounds and kinetics measurement, data analysis; A.S.: synthesis of compounds; L.Z.: synthesis of compounds; S.K.: synthesis of compounds; Y.O.: plotting, synthesis, data analysis, funding, writing manuscript; T.O.: plotting, data analysis, calculations, funding, and writing manuscript.

Funding: This work was supported by JSPS KAKENHI Grant Numbers JP 26104508 and 16K08157 (Y.O.) and 26293002 and 18 H02552 (T.O.).

Acknowledgments: The computations were performed at the Research Center for Computational Science, Okazaki, Japan. D.A.O.G.d.V. and A.S. were supported by Japanese Government (MEXT) scholarship.

Conflicts of Interest: The authors declare no conflict of interest.

\section{References}

1. Greenberg, A.; Liebman, J.F. The Amide Linkage Structural Significance in Chemistry, Biochemistry and Materials Science; Wiley: New York, NY, USA, 2000.

2. Fischer, G. Chemical Aspects of Peptide Bond Isomerisation. Chem. Soc. Rev. 2000, 29, 119-127. [CrossRef]

3. Thakkar, B.S.; Svendsen, J.-S.M.; Engh, R.A. Cis/Trans Isomerization in Secondary Amides: Reaction Paths, Nitrogen Inversion, and Relevance to Peptidic Systems. J. Phys. Chem. A. 2017, 121, 6830-6837. [CrossRef] [PubMed] 
4. Otani, Y.; Nagae, O.; Naruse, Y.; Inagaki, S.; Ohno, M.; Yamaguchi, K.; Yamamoto, G.; Uchiyama, M.; Ohwada, T. An Evaluation of Amide Group Planarity in 7-Azabicyclo[2.2.1]heptane Amides. Low Amide Bond Rotation Barrier in Solution. J. Am. Chem. Soc. 2003, 125, 15191-15199. [CrossRef] [PubMed]

5. Bose, A.K.; Manhas, M.S.; Bank, B.K.; Srirajan, V. B-Lactams: Cyclic amides of distinction, chapter 7. In The Amide Linkage Structural Significance in Chemistry, Biochemistry and Materials Science; Greenberg, A., Liebman, J.F., Eds.; Wiley: New York, NY, USA, 2000; pp. 157-214.

6. Komarov, I.V.; Yanik, S.; Ishchenko, A.Y.; Davies, J.E.; Goodman, J.M.; Kirby, A.J. The Most Reactive Amide As a Transition-State Mimic For cis-trans Interconversion. J. Am. Chem. Soc. 2015, 137, 926-930. [CrossRef] [PubMed]

7. Wang, Q.P.; Bennet, A.J.; Brown, R.S.; Santarsiero, B.D. Distorted Amides as Models for Activated Peptide N-C(O) Units. 3. Synthesis, Hydrolytic Profile, and Molecular Structure of 2,3,4,5-Tetrahydro-2oxo-1,5-propanobenzazepine. J. Am. Chem. Soc. 1991, 113, 5757-5765. [CrossRef]

8. Aubé, J. A New Twist on Amide Solvolysis. Angew. Chem. Int. Ed. 2012, 51, 3063-3065. [CrossRef] [PubMed]

9. Yamada, S. Structure and Reactivity of a Highly Twisted Amide. Angew. Chem. Int. Edit. Engl. 1993, 32, 1083-1085. [CrossRef]

10. Alkorta, I.; Cativela, C.; Elguero, J.; Gil, A.M.; Jiménez, A.I. A Theoretical Study of the Influence of Nitrogen Angular Constraints on the Properties of Amides: Rotation/Inversion Barriers and Hydrogen Bond Accepting Abilities of N-Formylaziridine and-Azirine. New J. Chem. 2005, 29, 1450-1453. [CrossRef]

11. Yamamoto, G.; Nakajo, F.; Tsubai, N.; Murakami, H.; Mazaki, Y. Structures and Stereodynamics of N-9-Triptycylacetamide and Its N-Alkyl Derivatives. Bull. Chem. Soc. Jpn. 1999, 72, 2315-2326. [CrossRef]

12. Glover, S.A.; White, J.M.; Rosser, A.A.; Digianantonio, K.M. Structures of N,N-Dialkoxyamides: Pyramidal Anomeric Amides with Low Amidicity. J. Org. Chem. 2011, 76, 9757-9763. [CrossRef] [PubMed]

13. Ohwada, T.; Achiwa, T.; Okamoto, I.; Shudo, K. On the Planarity of Amide Nitrogen. Intrinsic Pyramidal Nitrogen of N-Acyl-7Azabicyclo[2.2.1]heptanes. Tetrahedron Lett. 1998, 39, 865-868. [CrossRef]

14. Mujika, J.I.; Matxain, J.M.; Eriksson, L.A.; Lopez, X. Resonance Structures of the Amide Bond: The Advantages of Planarity. Chem. Eur. J. 2006, 12, 7215-7224. [CrossRef] [PubMed]

15. Bisz, E.; Piontek, A.; Dziuk, B.; Szostak, R.; Szostak, M. Barriers to Rotation in ortho-Substituted Tertiary Aromatic Amides: Effect of Chloro-Substitution on Resonance and Distortion. J. Org. Chem. 2018, 83, 3159-3163. [CrossRef] [PubMed]

16. Clayden, J.; Foricher, Y.J.Y.; Lam, H.K. Intermolecular Dearomatising Addition of Organolithium Compounds to N-Benzoylamides of 2,2,6,6-Tetramethylpiperidine. Eur. J. Chem. 2002, 3558-3565. [CrossRef]

17. Hutchby, M.; Houlden, C.E.; Haddow, M.F.; Tyler, S.N.G.; Llloyd-Jones, G.C.; Booker-Milburn, K.I. Switching Pathways: Room-Temperature Neutral Solvolysis and Substitution of Amides. Angew. Chem. Int. Ed. 2012, 51, 548-551. [CrossRef] [PubMed]

18. Shi, S.; Meng, G.; Szostak, M. Synthesis of Biaryls through Nickel-Catalyzed Suzuki-Miyaura Coupling of Amides by Carbon-Nitrogen Bond Cleavage. Angew. Chem. Int. Ed. 2016, 55, 6959-6963. [CrossRef] [PubMed]

19. Liu, C.; Szostak, M. Twisted Amides; From Obscurity to Broadly Useful Transition-Metal-Catalyzed Reactions by N-C Amide Bond Activation. Chem. Eur. J. 2017, 23, 7157-7173. [CrossRef] [PubMed]

20. Otani, Y.; Futaki, S.; Kiwada, T.; Sugiura, Y.; Muranaka, A.; Kobayashi, N.; Uchiyama, M.; Yamaguchi, K.; Ohwada, T. Oligomers of $\beta$-Amino Acid Bearing Non-Planar Amides Form Ordered Structures. Tetrahedron 2006, 62, 11635-11644. [CrossRef]

21. Hori, T.; Otani, Y.; Kawahata, M.; Yamaguchi, K.; Ohwada, T. Non-planar Structures of Thiomides Derived from 7-Azabicyclo[2.2.1] heptane. Electronically Tunable Planarity of Thioamides. J. Org. Chem. 2008, 73, 9102-9108. [CrossRef] [PubMed]

22. Otani, Y.; Watanabe, S.; Ohwada, T.; Kitao, A. Molecular Dynamics Study of Nitrogen-Pyramidalized Bicyclic ß-Proline Oligomers: Length-Dependent Convergence to Organized Structure. J. Phys. Chem. B 2017, 121, 100-109. [CrossRef] [PubMed]

23. Alemán, C.; Jiménez, A.I.; Cativela, C.; Pérez, J.J.; Casanovas, J. Unusually High Pyramidal Geometry of the Bicyclic Amide Nitrogen in a Complex 7-Azabicyclo[2.2.1]heptane Derivative: Theoretical Analysis Using a Bottom-up Strategy. J. Phys. Chem. B 2005, 109, 11836-11841. [CrossRef] [PubMed] 
24. Hosoya, M.; Otani, Y.; Kawahata, M.; Yamaguchi, K.; Ohwada, T. Water-Stable Helical Structure of Tertiary Amides of Bicyclic $\beta$-Amino Acid Bearing 7-Azabicyclo[2.2.1]heptane. Full Control of Amide Cis-Trans Equilibrium by Bridgehead Substitution. J. Am. Chem. Soc. 2010, 132, 14780-14789. [CrossRef] [PubMed]

25. Wang, S.; Otani, Y.; Liu, X.; Masatoshi, K.; Yamaguchi, K.; Ohwada, T. Robust trans-Amide Helical Structure of Oligomers of Bicyclic Mimics of $\beta$-Proline: Impact of Positional Switching of Bridgehead Substituent on Amide cis-trans Equilibrium. J. Org. Chem. 2014, 79, 5287-5300. [CrossRef] [PubMed]

26. Zhai, L.; Wang, S.; Nara, M.; Takeuchi, K.; Shimada, I.; Otani, Y.; Ohwada, T. Application of C-terminal 7-azabicyclo[2.2.1] heptane to stabilize $\beta$-strand-like extended conformation of a neighboring $\alpha$-amino acid. J. Org. Chem.. Accepted for publication.

27. Marlier, J.F.; Dopke, N.C.; Johnstone, K.R.; Wirdzig, T.J. A Heavy-Atom Isotope Effect Study of the Hydrolysis of Formamide. J. Am. Chem. Soc. 1999, 121, 4356-4363. [CrossRef]

28. Mujika, J.I.; Mercero, J.M.; Lopez, X. Water-Promoted Hydrolysis of a Highly Twisted Amides: Rate Acceleration Caused by the Twist of the Amide Bond. J. Am. Chem. Soc. 2005, 127, 4445-4453. [CrossRef] [PubMed]

29. Gorb, L.; Asensio, A.; Tuñón, I.; Ruiz-López, M.F. The Mechanism of Formamide Hydrolysis in Water from Ab Initio Calculations and Simulations. Chem. Eur. J. 2005, 11, 6743-6753. [CrossRef] [PubMed]

30. Wang, B.; Cao, Z. Mechanism of Acid-Catalyzed Hydrolysis of Formamide from Cluster-Continuum Model Calculations: Concerted versus Stepwise Pathway. J. Phys. Chem. A 2010, 114, 12918-12927. [CrossRef] [PubMed]

31. Matsubara, T.; Ueta, C. Computational Study of the Effects of Steric Hindrance on Amide Bond Cleavage. J. Phys. Chem. A 2014, 118, 8664-8675. [CrossRef] [PubMed]

32. Xiong, Y.; Zhan, C.-G. Theoretical Studies of Transition-State Structures and Free Energy Barriers for Base-Catalyzed Hydrolysis of amides. J. Phys. Chem. A 2006, 110, 12644-12652. [CrossRef] [PubMed]

33. Ammann, C.; Meier, P.; Merbach, A.E. A simple multinuclear NMR thermometer. J. Mag. Reson. 1982, 46, 319-321.

34. Frisch, M.J.; Trucks, G.W.; Schlegel, H.B.; Scuseria, G.E.; Robb, M.A.; Cheeseman, J.R.; Scalmani, G.; Barone, V.; Mennucci, B.; Petersson, G.A.; et al. Gaussian 09, revision D.01; Gaussian, Inc.: Wallingford, CT, USA, 2013.

Sample Availability: Samples of the compounds 2,3 and 4 are available from the authors.

(C) 2018 by the authors. Licensee MDPI, Basel, Switzerland. This article is an open access article distributed under the terms and conditions of the Creative Commons Attribution (CC BY) license (http://creativecommons.org/licenses/by/4.0/). 
Article

\title{
Electronic Effect on the Molecular Motion of Aromatic Amides: Combined Studies Using VT-NMR and Quantum Calculations
}

\author{
Sungsoo Kim ${ }^{1}$, Jungyu Kim ${ }^{2,3}$, Jieun Kim ${ }^{1}$, Daeun Won ${ }^{1}$, Suk-Kyu Chang ${ }^{1}$, Wansik Cha ${ }^{4}$, \\ Keunhong Jeong ${ }^{5, *}$, Sangdoo Ahn ${ }^{1, *}$ and Kyungwon Kwak ${ }^{2,3, *}$ \\ 1 Department of Chemistry, Chung-Ang University, Seoul 156-756, Korea; hesperus86@gmail.com (S.K.); \\ wldms01477@gmail.com (J.K.); panda881020@gmail.com (D.W.); skchang@cau.ca.kr (S.-K.C.) \\ 2 Center for Molecular Spectroscopy and Dynamics, Institute for Basic Science (IBS), Seoul 02841, Korea; \\ kimjoongyu@naver.com \\ 3 Department of Chemistry, Korea University, Seoul 02841, Korea \\ 4 Nuclear Chemistry Research Division, Korea Atomic Energy Research Institute, Daejeon 34057, Korea; \\ wscha@kaeri.re.kr \\ 5 Department of Chemistry, Korea Military Academy, Seoul 01805, Korea \\ * Correspondence: doas1mind@kma.ac.kr (K.J); sangdoo@cau.ac.kr (S.A.); kkwak@korea.ac.kr (K.K.)
}

Received: 6 August 2018; Accepted: 4 September 2018; Published: 8 September 2018

\begin{abstract}
Rotational barrier energy studies to date have focused on the amide bond of aromatic compounds from a kinetic perspective using quantum calculations and nuclear magnetic resonance (NMR). These studies provide valuable information, not only regarding the basic conformational properties of amide bonds but also the molecular gear system, which has recently gained interest. Thus, we investigate the precise motion of the amide bonds of two aromatic compounds using an experimental rotational barrier energy estimation by NMR experiments and a theoretical evaluation of the density functional theory calculation. The theoretical potential energy surface scan method combined with the quadratic synchronous transit 3 method and consideration of additional functional group rotation with optimization and frequency calculations support the results of the variable temperature ${ }^{1} \mathrm{H}$ NMR, with deviations of less than $1 \mathrm{kcal} / \mathrm{mol}$. This detailed experimental and theoretical research strongly supports molecular gear motion in the aromatic amide system, and the difference in kinetic energy indicates that the electronic effect from the aromatic structure has a key role in conformational movements at different temperatures. Our study provides an enhanced basis for future amide structural dynamics research.
\end{abstract}

Keywords: rotational barrier energy; amide bond; nuclear magnetic resonance; kinetic; density functional theory

\section{Introduction}

The amide bond, a basic unit of proteins, has unique steric and energetic characteristics [1,2]. Therefore, studying the dynamics of these bonds is important to understand protein dynamics. Conformational studies of aromatic amide bonds, in particular, have been extensively carried out owing to their potential applications in fields such as asymmetric synthesis, molecular gear systems, single-molecule motors, and single-molecule devices [3].

An aromatic amide has two rotational motions [4] around the central carbonyl group: the rotation around aryl- $\mathrm{CO}$ and the rotation around the $\mathrm{C}-\mathrm{N}$ bond in the amide unit. Therefore, the basic structural change of an aromatic amide involves three bond rotational processes $[4,5]$ that compose the interconversions of the conformers. The two independent rotations of the $\mathrm{C}-\mathrm{N}$ bond or aryl-CO bond interconvert two conformers (exo and endo forms), and the concerted rotation of these bonds 
represents the molecular gear. Both rotations and their three rotational processes $[6,7]$ have received intense interest because rotational dynamics can be applied to single molecule dynamic studies and experimental data on rotational dynamics can be achieved with variable temperature nuclear magnetic resonance (VT-NMR) spectroscopy [8-10] in order to investigate the Gibbs free energy of the concerted $\mathrm{C}-\mathrm{N} /$ aryl-CO bond rotation and/or independent aryl-CO and C-N bond rotation around the carbonyl group on the aromatic amide. These rotations can be controlled through chemical modification of the structure or simple temperature variation [11].

The internal rotation [12] around the $\mathrm{C}-\mathrm{N}$ bond in the amides provides information regarding the conformational characteristics of the backbone of peptides and proteins. There have been many reports concerning determination of the steric effect involving rotational dynamics $[5,6]$, although few of these have discussed electronic effects owing to the difficulty of separately measuring the steric and electronic effects. The other rotational dynamic of aromatic amides, aryl-CO, has been successfully explained in the case of the $\mathrm{C}-\mathrm{C}$ single bond rotational process in $\mathrm{N}$-methylbenzamide [7]. However, the electron-rich aromatic ring in molecular gear studies is usually designed and connected to the $\mathrm{N}$ of amide groups. Thus, the aryl-CO bond is correlated to the $\mathrm{C}-\mathrm{N}$ bond in many experimental studies $[11,13,14]$. It is therefore important to study the electronic effects of aromatic amides, including aryl-CO and C-N bonds, using both theoretical and experimental methods, which will clearly explain the molecular motion. Herein, we use quantum calculations and VT-NMR to investigate the rotational process of aryl-CO and C-N bonds in specifically designed $\mathrm{N}, \mathrm{N}$-diethylamide derivatives.

\section{Results}

\subsection{Interpretation of VT-NMR: Coalescence}

Characterization of $\mathrm{N}, \mathrm{N}$-diethylamide Derivatives (1), (2)

$\mathrm{N}, \mathrm{N}$-diethylamide derivatives (1), (2) were synthesized to measure the rotational barrier of the aryl-CO and C-N bonds (Figure 1). Before we evaluated the rotational barrier using ${ }^{1} \mathrm{H}$ VT-NMR, the $\mathrm{H}$ and Me peaks from two ethyl groups attached to $\mathrm{N}$ were assigned to understand which rotations were occurring. The peaks of chemical shifts in $\mathrm{N}, \mathrm{N}$-diethylpyrene-1-carboxamide (PCDEA) have a similar trend to those in $\mathrm{N}, \mathrm{N}$-diethyl-1-naphthamide (NCDEA) at $25^{\circ} \mathrm{C}$. As shown in Table 1 , the ${ }^{1} \mathrm{H}$ NMR spectrum in NCDEA has two H chemical shift peaks ( $\delta 3.51 \mathrm{ppm}, \delta 3.82 \mathrm{ppm})$, as does the ${ }^{1} \mathrm{H}$ NMR spectrum in PCDEA ( $\delta 3.64 \mathrm{ppm}, \delta 3.89 \mathrm{ppm}$ ). These two peaks occur because two $\mathrm{H}$ atoms are located differently with respect to each aromatic group, resulting in a more de-shielded proton signal when the position is closer to the aromatic group. Similarly, Me peaks are better shielded than H peaks in PCDEA ( $\delta 1.32 \mathrm{ppm}, \delta 1.77 \mathrm{ppm})$ and in NCDEA ( $\delta 0.98 \mathrm{ppm}, \delta 1.34 \mathrm{ppm})$.<smiles>CCN(C(=O)c1cccc2ccccc12)C(C)C</smiles>

N,N-diethyl-1-naphthamide (NCDEA, 1)<smiles></smiles>

N,N-diethylpyrene-1-carboxamide (PCDEA, 2)

Figure 1. Structures of $N, N$-diethylamide derivatives. 
Table 1. Experimental ${ }^{1} \mathrm{H}$ NMR for $N, N$-diethylamide derivatives (aliphatic part only).

\begin{tabular}{ccc}
\hline Compound & Signal & Chemical Shifts $(\delta) /$ ppm \\
\hline NCDEA & $\mathrm{H}$ & $3.51 / 3.82$ \\
NCDEA & $\mathrm{Me}$ & $0.98 / 1.34$ \\
PCDEA & $\mathrm{H}$ & $3.64 / 3.89$ \\
PCDEA & $\mathrm{Me}$ & $1.32 / 1.77$ \\
\hline
\end{tabular}

Line shape analysis of the ${ }^{1} \mathrm{H}$ VT-NMR experiment was applied to evaluate the relative Gibbs free energy difference and the enthalpy difference for aryl-CO and $\mathrm{C}-\mathrm{N}$ rotation. Figure 2 shows that the experimental values are in good agreement with the theoretical analysis. The following (Eyring equation) estimates $\Delta \mathrm{G}^{\ddagger}$ in ${ }^{1} \mathrm{H}$ VT-NMR using the coalescence temperature from the two-site exchange $[9,15]$.

$$
\Delta \mathrm{G}^{\ddagger}=0.01914 \times \mathrm{Tc} \times\left[10.319+\log _{10}\left(\frac{T c}{k}\right)\right],\left(k=\frac{\pi \Delta v}{\sqrt{2}}\right)
$$

In the experiment, the split NMR signals are from two ground states. If their exchange rate constant by rotation is greater than their frequency separation, the peaks are merged into one. Therefore, if two peaks are merged into one peak, the rotational barriers of aryl-CO and C-N and the rate constant are detected by the coalescence temperature. The rate constant $(k)$ has a fast exchange for aryl-CO and C-N rotations.

As the temperature increases, the merging of $\mathrm{H}-\mathrm{H}$ into one relatively sharp peak corresponds to aryl-CO, and merging of Me-Me into one broader peak represents concerted aryl-CO/C-N rotation, which is well supported by a previous extensive theoretical study [16].

NCDEA has two aryl-CO and C-N bond rotations. Two different characteristics are explained by the peak coalescence of the ${ }^{1} \mathrm{H}$ VT-NMR experiment as the temperature increases. The spectra show that aryl-CO rotation represents the broadening signals of $\mathrm{H}-\mathrm{H}$ peaks from $\delta 3.60$ to $\delta 3.80 \mathrm{ppm}$ (Figure 2b). As the temperature increases, the signals of Me-Me from $\delta 1.0$ to $\delta 1.4 \mathrm{ppm}$ are assigned to the $\mathrm{C}-\mathrm{N}$ rotation (Figure 2c). At $65^{\circ} \mathrm{C}$, it is clear that two peaks coalesce in the aryl-CO bond rotation, as shown in Figure 2. On the other hand, the coalescence temperature of the $\mathrm{C}-\mathrm{N}$ rotation is higher than that of the aryl-CO rotation (Table 2).

Table 2. Bond rotation in $N, N$-diethylamide derivatives measured by ${ }^{1} \mathrm{H}$ VT-NMR.

\begin{tabular}{cccccc}
\hline Compound & Coalescing Signals & $\boldsymbol{\Delta} \mathbf{v} / \mathbf{H z}$ & $\mathbf{T}_{\mathbf{c}} /{ }^{\circ} \mathbf{C}$ & $\mathbf{k} / \mathbf{s}^{-\mathbf{1}}$ & $\mathbf{\Delta G}^{\ddagger} / \mathbf{k c a l}^{-\mathbf{m o l}^{-\mathbf{1}}}$ \\
\hline NCDEA & H-H & 175.43 & 60 & 602 & 15.40 \\
NCDEA & Me-Me & 273.93 & 115 & 389 & 18.00 \\
PCDEA & H-H & 219.62 & 57 & 478 & 15.62 \\
PCDEA & Me-Me & 220.28 & 115 & 478 & 17.65 \\
\hline
\end{tabular}

PCDEA exhibits a similar spectral pattern in the ${ }^{1} \mathrm{H}$ VT-NMR experiment. At the coalescence temperature, the chemical shifts representing aryl-CO bond rotation range from $\delta 3.70$ to $\delta 3.90 \mathrm{ppm}$ (Figure 2e), which is similar to the case of NCDEA. C-N bond rotation is shown from $\delta 1.00$ to $\delta 1.50 \mathrm{ppm}$ when coalescence begins, and again, is very similar to that of NCDEA (Figure 2f).

A two-dimensional exchange spectroscopy (EXSY) experiment was performed to confirm the rotational dynamics at high temperatures (Figure S1). The mixing time was $200 \mathrm{~ms}$, and $\omega_{\mathrm{o}} \tau_{\mathrm{c}} \ll 1$ $\left(\omega_{\mathrm{o}}=\right.$ spectrometer frequency in radians; $\tau_{\mathrm{c}}=$ rotational correlation time) was satisfied; thus, the nuclear overhauser effect (NOE) of $\mathrm{H}$ in molecules is not expected to exist [17]. Therefore, the cross-peaks shown in Figure S1 can only be expressed by chemical exchange mechanisms. The 2D EXSY spectrum shows how each bond rotation progresses at three increasing temperatures. 


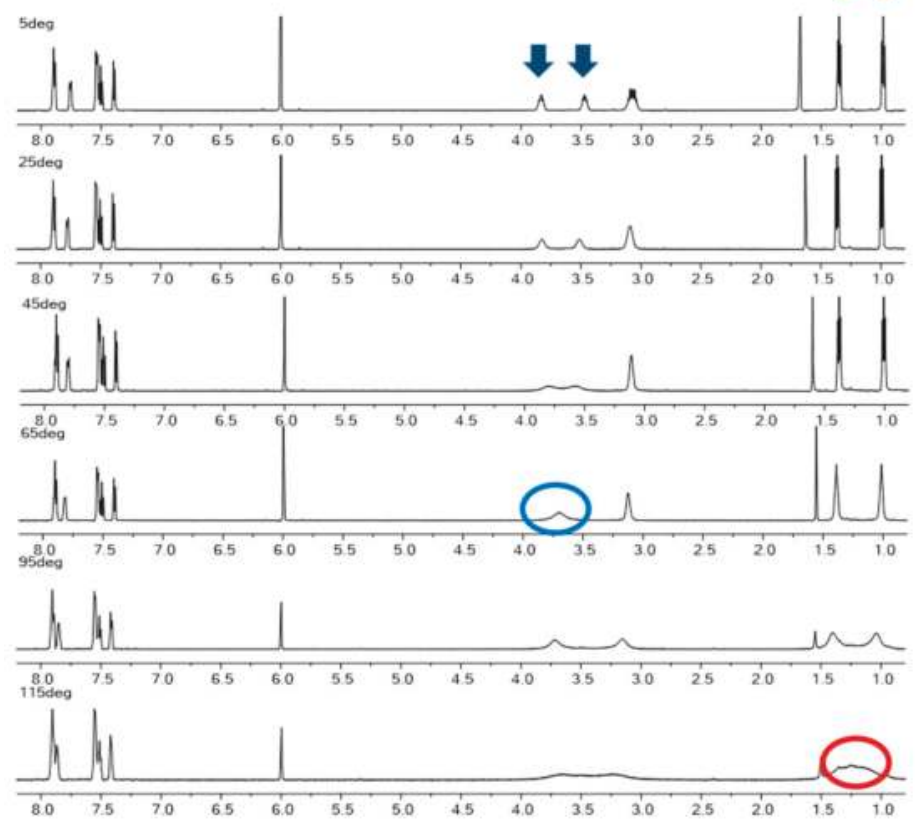

(a)
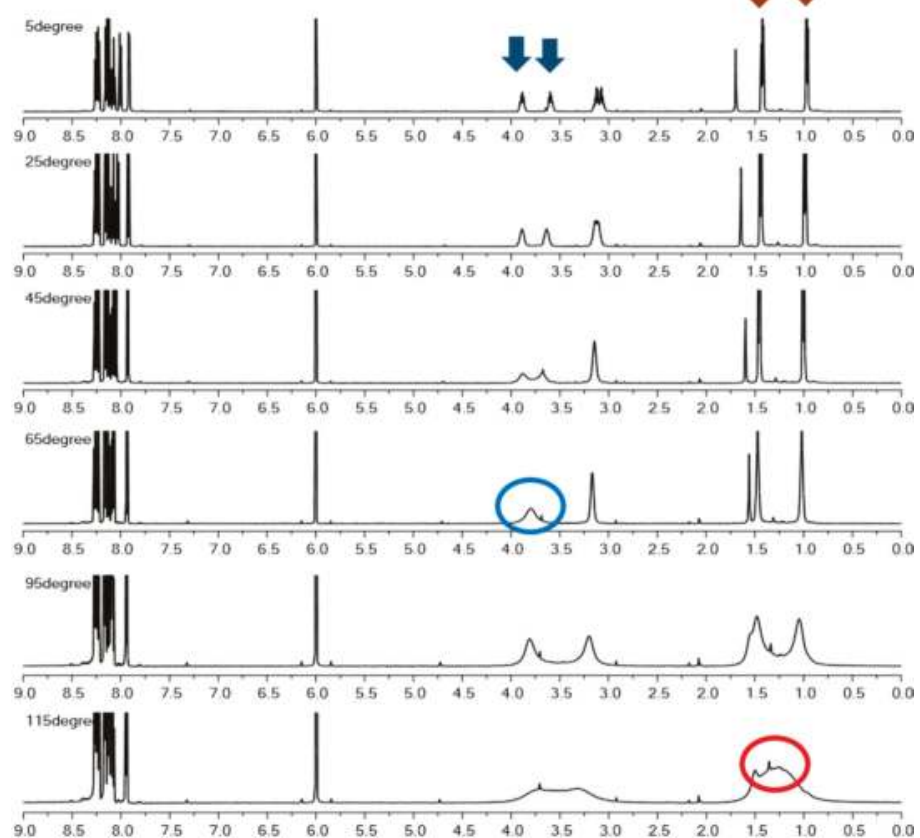

(b)

Figure 2. Cont. 


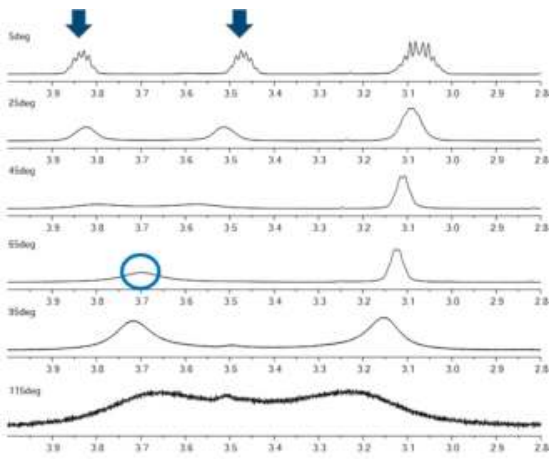

(c)

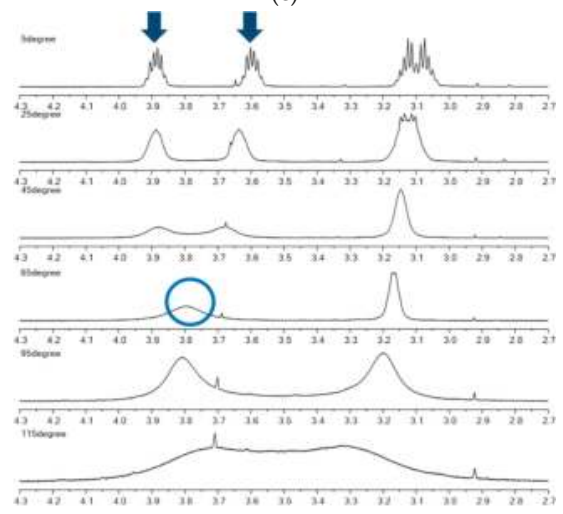

(e)

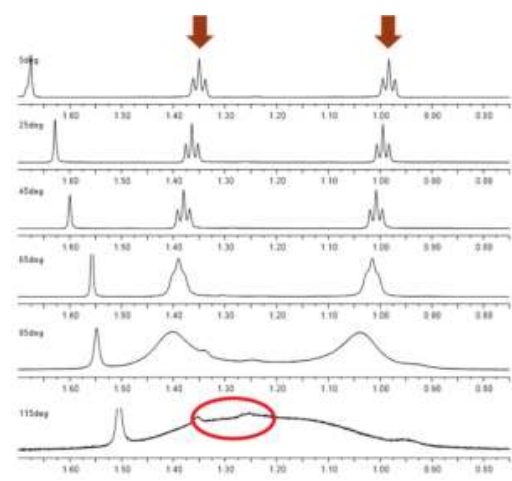

(d)

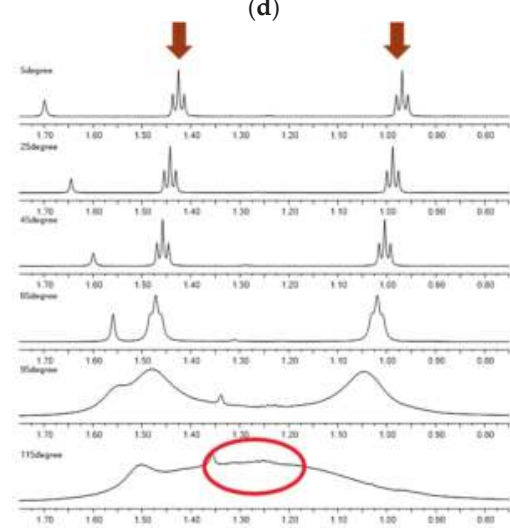

(f)

Figure 2. ${ }^{1} \mathrm{H}$ VT-NMR experiments on NCDEA and PCDEA. Arrows indicate each $\mathrm{H}$ and Me signal in each structure, and circles indicate the merged signals after the temperature increase. (a) Whole spectrum from NCDEA. Arrows indicate split $\mathrm{H}$ and Me signal and circles indicate the merged signal after the temperature increase. (b) Whole spectrum from PCDEA. Arrows indicate split H and Me signal and circles indicate the merged signal after the temperature increase. (c) H-H merges as temperature increases (NCDEA). (d) Me-Me merges as temperature increases (NCDEA). (e) H-H merges as temperature increases (PCDEA). (f) Me-Me merges as temperature increases (PCDEA).

\subsection{Theoretical Calculations}

\subsubsection{One-Dimensional Potential Energy Surface Scan for Aryl-CO and C-N Rotation}

Many potential energy surface (PES) studies have been reported, detailing experimental results that are consistent with the computational analysis of the molecules of interest. Likewise, we investigated the energy based on the geometric optimization of scan coordinates, changing the dihedral angles from $-170^{\circ}$ to $200^{\circ}$ for the C-N bond and aryl-CO bond, respectively, in $N$, $N$-diethylamide derivatives (1), (2). In the ${ }^{1} \mathrm{H}$ VT-NMR results, two types of bond rotation characteristics were detected on aryl-CO and C-N bonds, either simultaneously or separately. NCDEA and PCDEA have discrete values of chemical shifts, as explained previously. The scan coordinates of those molecules on $\mathrm{C}-\mathrm{N}$ and aryl-CO bonds were calculated separately.

When the aryl-CO bond rotates, the diethyl group attached to the $\mathrm{N}$ is directly confronted with the steric effect from the naphthalene (1) and pyrene (2) rings, which increases the optimized energy representing repulsion (Figures S2a and S3a). On the other hand, when concerted aryl-CO and C-N bond rotation occurs, all the diethylamide derivatives manifest a similar tendency for molecular 
orientations and elucidate the concurrent rotations of aryl-CO and C-N bonds; thus, there are two similar transition states (Figures S2b and S3b).

We determined that the PES of the C-N bond rotation of NCDEA and PCDEA indicates that the signals of peak coalescence in VT-NMR show similar chemical shifts. This suggests that the PES of aryl-CO and C-N bond rotations have two ground states, which are enantiomers, and two transition states, indicating that they have two rotational barriers. The Gibbs free energy between the transition state and ground state approximately demonstrates the experimental NMR analysis (Table S1). However, the true transition states would enable a more accurate theoretical description of the actual Gibbs free energy difference.

\subsubsection{Calculated Result for QST3 and Changing Dihedral Angles of Di-ethyl Groups}

Scheme for Interconversion in N,N-Diethylamide Derivatives (1), (2)

Before the transition states were obtained through quadratic synchronous transit 3 (QST3) [18], we obtained the change in dihedral angle of the aryl-CO bond as the dihedral angle of the $\mathrm{C}-\mathrm{N}$ bond increased, or vice versa, by 1D PES analysis. As indicated in Figures 3 and 4, whereas aryl-CO bond rotation is independent of $\mathrm{C}-\mathrm{N}$ rotation, $\mathrm{C}-\mathrm{N}$ bond rotation has an influence on aryl-CO bond rotation in that it experiences concerted rotation with the aryl-CO bond, consistent with previous NMR and calculation results.
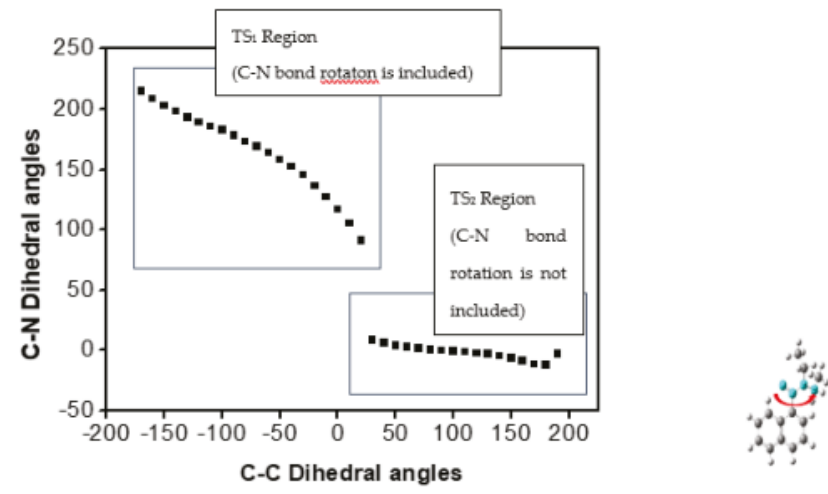

(a) NCDEA
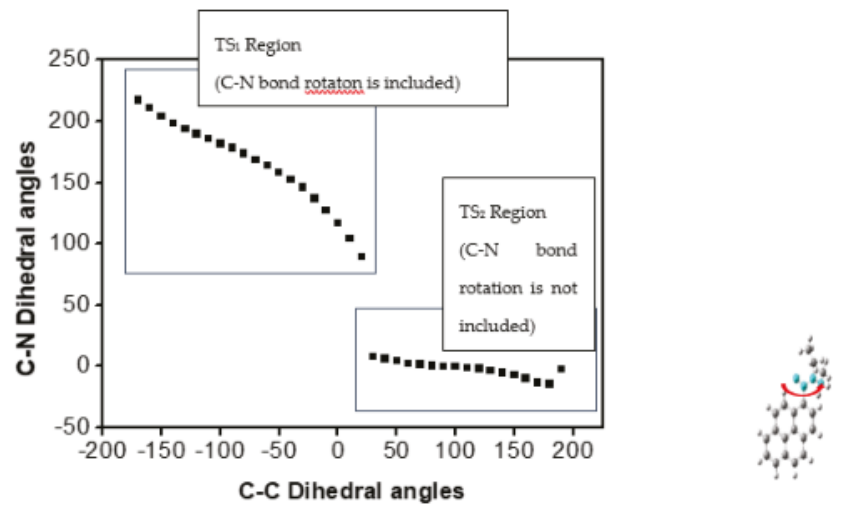

(b) PCDEA

Figure 3. Dihedral angle of C-N bond (highlighted) (Y axis) versus dihedral angle of Aryl-CO bond (Arrowed) (X axis) in (a) NCDEA and (b) PCDEA. 


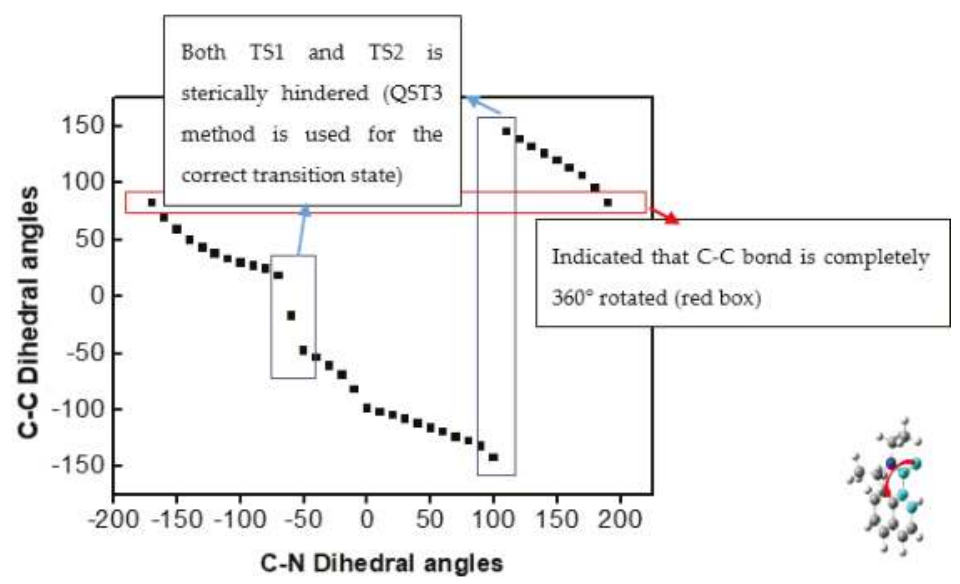

(a) NCDEA

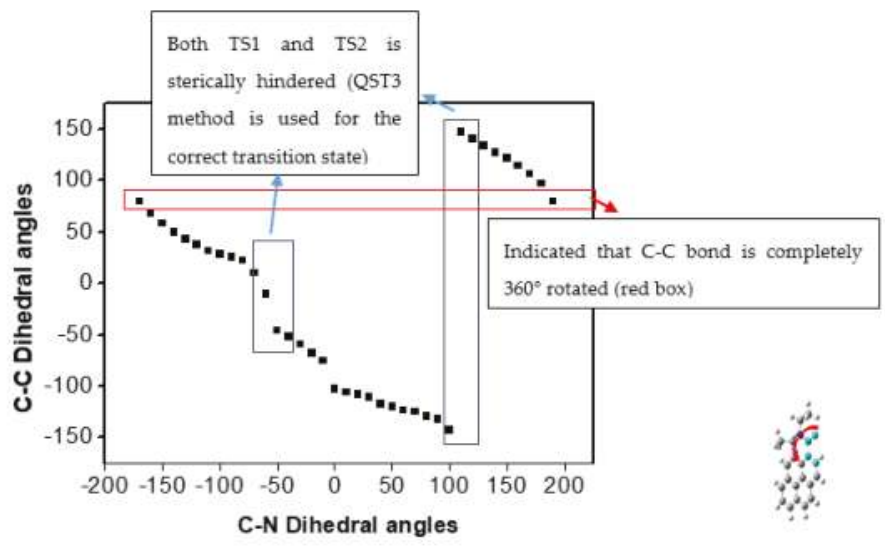

(b) PCDEA

Figure 4. Dihedral angle of Aryl-CO bond (Highlighted) ( $\mathrm{Y}$ axis) versus dihedral angle of C-N bond (Arrowed) (X axis) in (a) NCDEA and (b) PCDEA.

Transition States Optimized through the QST3 Method

The two ground states are two types of structure, i.e., enantiomers, that exhibit the same energy, which is supported by the following energy calculation. Diethyl conformations of the two ground states of $\mathrm{N}, \mathrm{N}$-diethylamide derivatives are in opposite directions if the benzene ring group is considered a mirror plane (Figure S4).

For aryl-CO bond rotation of NCDEA and PCDEA, the barrier of the first transition state (1TS) is different from that of the second transition state (2TS) in that the rotational motion of 1TS in the aryl-CO bond contains $\mathrm{C}-\mathrm{N}$ bond rotation when the PES scan is performed. This originates from the steric hindrance between naphthalene/pyrene rings and diethyl groups, resulting in C-N bond rotation. Thus, we do not have to consider the Gibbs free energy of 1TS (hence QST3-1TS of the aryl-CO bond is not included in Figure S4 or Table S2).

The scan coordinates do not confirm whether the two transition states found in this way are structurally true transition states, which are required for an adequate Gibbs energy difference, even though they have one negative imaginary frequency. Other optimized processes (QST3) for 
finding true transition states are required to subsequently characterize the structure and energy of each state (Figures S2 and S3); these optimized structures also have imaginary frequencies in which the mode corresponds to rotation of the aryl-CO bond and the concerted aryl-CO/C-N bond, respectively (Table S2). The structures of two GSs and one or two TSs for N,N-diethylamide derivatives (1), (2) are expressed as dihedral angles (Schemes S2 and S3) in order to more easily understand the energy difference (Figure S4). Furthermore, the study of intrinsic reaction coordinates analysis is added for confirming the transition state.

Dihedral Angle Change in the Diethyl Conformation of Transition States of the Aryl-CO Bond in NCDEA and PCDEA

Changing the dihedral angles of the diethyl moiety of transition states is necessary for explaining the routes to rotational barriers. As we described earlier, since the 1TS of aryl-CO bond rotation includes C-N rotation, and the increase of activation energy and energy of 1TS in aryl-CO/C-N bond rotation is greater than that of 2TS after the QST3 calculation, we only consider the 2TS of the aryl-CO bond and aryl-CO/C-N bond rotation and make the dihedral angle change for the proper theoretical value consistent with the experimental value. Results of calculations with various dihedral angles are described in detail, and these energy values are very close to the experimental data (Tables S3-S5).

In particular, for the energy value of aryl-CO bond rotation in NCDEA, the theoretical Gibbs free energy value can range from 14.24 to $15.19 \mathrm{kcal} \cdot \mathrm{mol}^{-1}$, a range of less than $1 \mathrm{kcal} \cdot \mathrm{mol}^{-1}$, which is highly consistent with the NMR experimental results; four of the di-ethyl rotation modes, however, do not correspond to aryl-CO bond rotation with more than an imaginary frequency (Table S3).

PCDEA shows a similar tendency in aryl-CO and $\mathrm{C}-\mathrm{N}$ bond rotation to that of NCDEA. It is clear that the value estimated by di-ethyl rotation is similar to the experimental value. The importance of applying the dihedral angle change is thus confirmed; the value of the Gibbs free energy for QST3 optimization is $13.52 \mathrm{kcal} \cdot \mathrm{mol}^{-1}$ and can be increased by di-ethyl rotation to 14.37 and $15.74 \mathrm{kcal} \cdot \mathrm{mol}^{-1}$, values that are only approximately $1 \mathrm{kcal}$ lower than or the same as, respectively, the experimental values (Table S4).

Transition State of the 2D PES

As indicated in the 2D PES scan with frequency calculation in Figure 5, we also investigated independent aryl-CO and C-N dihedral angles for concerted aryl-CO/C-N bond rotation. As shown in Figure 4, as the C-N dihedral angle (X axis) decreases, the aryl-CO (Y axis) increases so that NCDEA and PCDEA have different Gibbs free energies for aryl-CO bond rotation (NCDEA $\triangle G^{\ddagger}: 14.19 \mathrm{kcal}$ and PCDEA $\Delta \mathrm{G}^{\ddagger}: 15.15 \mathrm{kcal}$ ) and $\mathrm{C}-\mathrm{N}$ bond rotation (NCDEA $\Delta \mathrm{G}^{\ddagger}: 17.67 \mathrm{kcal}$ and PCDEA $\Delta \mathrm{G}^{\ddagger}$ : $17.57 \mathrm{kcal})$. This means that $\mathrm{C}-\mathrm{N}$ bond rotation affects the aryl-CO bond rotation, as it is a molecular gear model [3]. On the other hand, aryl-CO bond rotation does not affect $\mathrm{C}-\mathrm{N}$ bond rotation; thus, it rotates independently. This means that the ethyl group connected to the tertiary amine could be sterically hindered by aromatic group when it rotates around. Those results robustly support our previous theoretical and experimental data. Thus, we confirmed via both of Gibbs free energy values (Table 3) and the transition state structures, that the transition state structure of C-N bond rotation is consistent with the structure of the concerted C-N/aryl-CO bond in 2D PES (Tables S6-S10).

Quantum Theory of Atoms in Molecules (QTAIM) Study

The information from the QTAIM study qualitatively supports all the results of this study. The electron density of the C-N/aryl-CO bond in the transition state is generally greater than that of the aryl-CO bond in each structure, demonstrating that the Gibbs free energy of C-N/aryl-CO rotation is greater than that of aryl-CO. Furthermore, the electronic effect from different aryl groups shows the different electron populations on the rotating bonds in the transition state, which reveal the Gibbs free energy difference between NCDEA and PCDEA (Table S11). 
Table 3. Comparison of the relative experimental Gibbs free energy differences to computational results.

\begin{tabular}{|c|c|c|c|}
\hline & & $\begin{array}{c}\text { Variable Temperature } \\
{ }^{1} \mathrm{H} \text { NMR }\end{array}$ & $\begin{array}{l}\text { Theoretical Calculation } \\
\text { (QST3//Di-ethyl Rotation *) }\end{array}$ \\
\hline Compound & Bond & $\Delta \mathrm{G}^{\ddagger} / \mathrm{kcal} \cdot \mathrm{mol}^{-1}$ & $\Delta \mathrm{G}^{\ddagger} / \mathrm{kcal} \cdot \mathrm{mol}^{-1}$ \\
\hline \multirow{2}{*}{ NCDEA } & C-N/aryl-CO & 18.00 & $\begin{array}{c}\text { 1TS: } 20.61 * * \\
\text { 2TS: } 17.13 / / 16.09 \sim 20.04 \\
\text { 2D TS: } 17.67\end{array}$ \\
\hline & aryl-CO & 15.40 & $\begin{array}{c}\text { 1TS: C-N bond rotation is included } \\
\text { 2TS: } 14.24 / / 14.24 \sim 15.19 \\
\text { 2D TS: } 14.19\end{array}$ \\
\hline \multirow{2}{*}{ PCDEA } & $\mathrm{C}-\mathrm{N} /$ aryl-CO & 17.65 & $\begin{array}{c}\text { 1TS: } 19.94 * * \\
\text { 2TS: } 17.04 / / 15.97 \sim 19.92 \\
\text { 2D TS: } 17.57\end{array}$ \\
\hline & aryl-CO & 15.62 & $\begin{array}{c}\text { 1TS: C-N bond rotation is included } \\
\text { 2TS: } 13.52 / / 13.38 \sim 15.74 \\
\text { 2D TS: } 15.15\end{array}$ \\
\hline
\end{tabular}

Di-ethyl rotation * represents energy values between minimum and maximum. ${ }^{* *}$ 1TS showed higher Gibbs free energy than 2TS in QST3, which was not considered for di-ethyl rotation calculation.
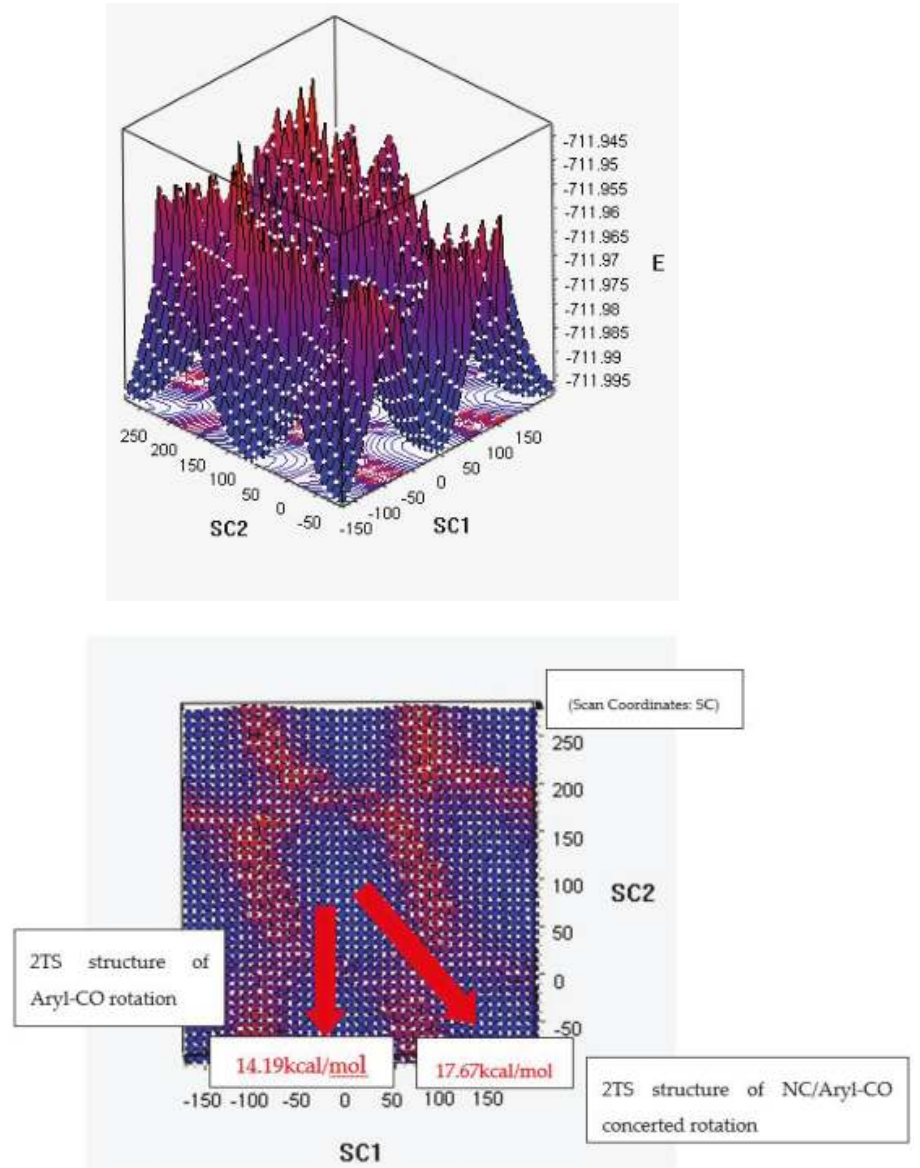

(a) NCDEA (SC1: Ayl-CO rotation, SC2: C-N rotation)

Figure 5. Cont. 

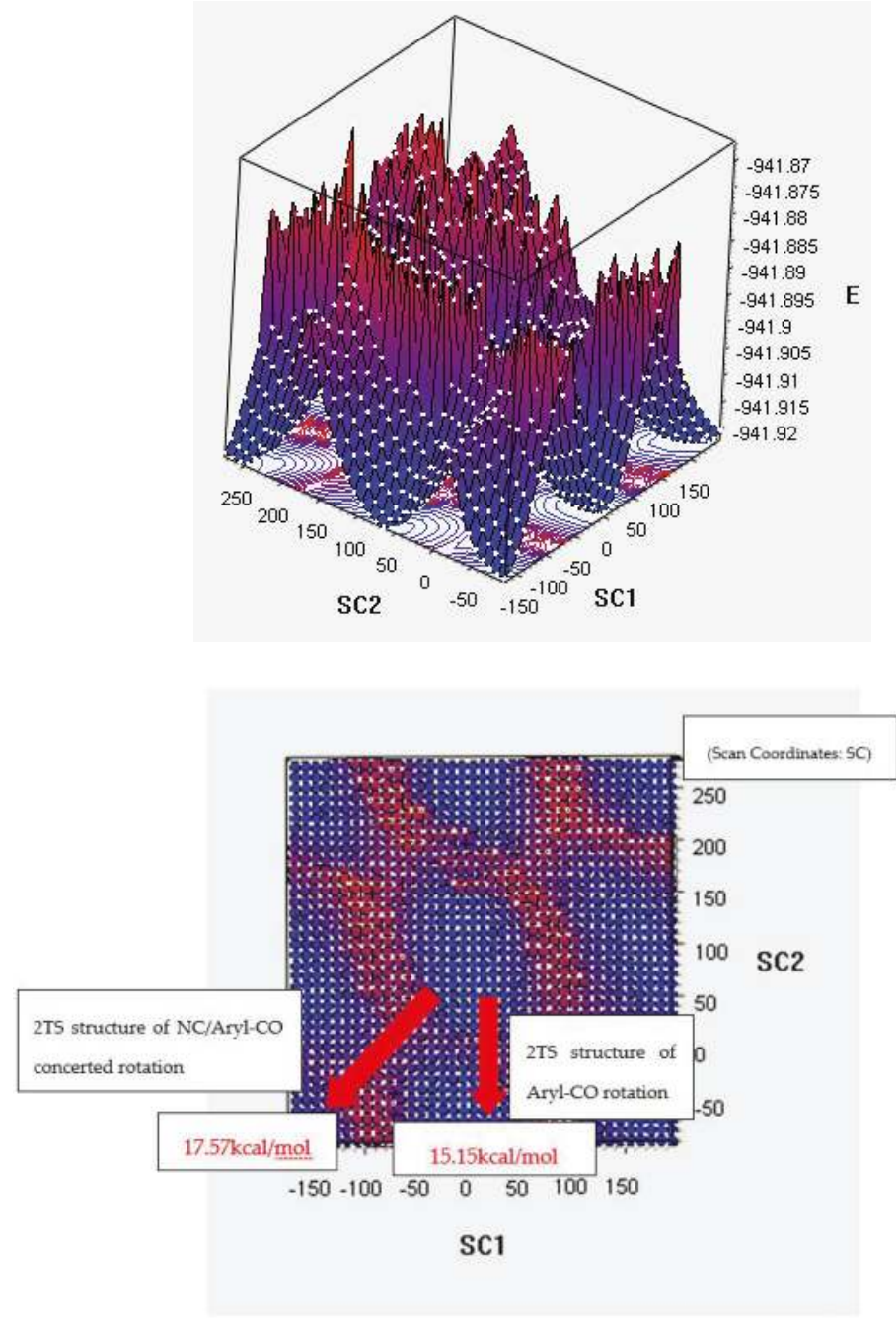

Figure 5. 2D-Potential Energy Surface on Aryl-C = O Dihedral angle and C-N Dihedral angle change of NCDEA (a) and PCDEA (b).

\section{Discussion}

Rotational barrier energy studies of amide bonds of aromatic compounds from a kinetic perspective provide valuable information regarding the basic conformational properties of amide bonds and their molecular gear system, which have been of recent scientific interest. To that end, we investigated rotational barrier energy using two methods to determine the precise motion and theoretical quantum chemical effects using an NMR experiment and density functional theory [19,20]. The theoretical PES scan method, with optimization and frequency calculations suggested by the theoretical study, supports the effect of ${ }^{1} \mathrm{H}$ VT-NMR, which assumes that if the bond rotation is fast enough to break out the double bond characteristic of interest, the two peaks are merged and cannot be distinguished from chemical shifts. Thus, we can predict and evaluate the energy barrier using the Eyring equation $[9,15]$. 
By quantum chemical methods, the PES can be predicted correctly for rotation in a simple system such as ethane $\left(\sim 3 \mathrm{kcal} \cdot \mathrm{mol}^{-1}\right)$ [21]. The PES for diethylamide derivatives, however, has a limitation in explaining the structure of transition states, such that the energy barrier might be miscalculated. This means that the transition states must be re-calculated using QST3 optimization [18], followed by frequency calculation, which shows us that each state has an imaginary frequency. This clearly shows that the transition states assumed to be true demonstrate the rotational energy barriers in the NMR experiment.

The final step, di-ethyl rotations, is required to determine whether each transition states' energy can be varied in the range of several kcals, revealing that the computational result from this step is consistent with energy values from the NMR experiment (Table 3). To further investigate the rotational dynamics, we performed QTAIM studies [22]. The analysis qualitatively supported the Gibbs free energy difference and electronic effect from the different molecular structures. This detailed experimental and theoretical research strongly supports the molecular gear motion for the aromatic amide system and the difference in kinetic energy, provided that the electronic effect from the aromatic structure plays a key part in the conformational movement at different temperatures. Our study provides a basis for future research on amide structural dynamics.

\section{Materials and Methods}

\subsection{Sample Preparation}

We added oxalyl chloride to a mixture of pyrene-1-carboxylic acid and 1-naphthoic acid in methylene chloride and added dimethyl formamide after approximately 1-2 drops [23] (Scheme S1). The mixture was stirred at room temperature to maintain the reaction for approximately $4 \mathrm{~h}$. Once the reaction was completed, the methylene chloride was evaporated, and $1 \mathrm{~h}$ of vacuum was performed. The dried yellow powder was then dissolved in methylene chloride. We added this mixture to a solution of diethylamine and methylene chloride by a dropwise method. This step was followed by extraction with D.W. three times. After sample preparation, we confirmed the product by thin layer chromatography and determined molecular structures with NMR, the results of which were used for data processing.

\subsection{Experimental Methods}

${ }^{1} \mathrm{H}$ NMR spectra were obtained using a Varian VNS 600 spectrometer with a temperature control system. 1,1,2,2-tetrachloroethane- $\mathrm{d}_{2}$ purchased from Euriso-Top was used as the solvent for $N, N$-diethylamide derivatives. Each sample was injected into a 5-mm o.d. NMR tube to be analyzed. The chemical shifts of the spectra were obtained using the solvent peak as a reference.

In the VT-NMR experiment, prior to detection, the samples were left long enough for all samples to be in equilibrium at the designated temperature, so as to increase the reproducibility and accuracy of the results. The experiments were performed in the range of 273-388 K, considering the boiling point of the solvent and the limiting temperature of proton detection. The spectra were typically obtained at intervals of $10^{\circ}$. The interval was $2^{\circ}$ beginning with the coalescence temperature. The possible error range was $\pm 0.5 \mathrm{~K}$.

Two-dimensional exchange spectroscopy (EXSY) [24] was performed at different temperatures for the two $N, N$-diethylamide derivatives (Figure 1) using a normal nuclear Overhauser effect spectroscopy (NOESY) pulse sequence [25].

\subsection{Computational Methodss}

Calculations were performed at the B3LYP/6-311G(d) level by means of the Gaussian 09 software package (Gaussian, Inc., Wallingford, CT, USA) [26]. To find the Gibbs free energy difference between the ground state and transition state, we used density functional theory (DFT) $[19,20,27]$ at the B3LYP/6-311G(d) level [28] with the PCM model [29] (dielectric constant 
$\varepsilon=8.2$ of 1,1,2,2-tetrachloroethane). Gibbs free energy difference was calculated under standard conditions (a temperature of $298.15 \mathrm{~K}$ and a pressure of $1 \mathrm{~atm}$ ).

\subsubsection{D PES Method}

First, the calculations in redundant coordinates were performed at 38 steps of every $10^{\circ}$ increment of the aryl-CO bond and C-N bond in NCDEA and PCDEA. Harmonic vibrational frequencies were calculated for all stationary points. For each optimized state, the frequency analysis showed the absence of imaginary frequencies, whereas each transition state showed a single imaginary frequency [30]. Visual inspection of the corresponding normal mode was used to confirm that the correct transition state had been found.

\subsubsection{QST3 Method and Changing Dihedral Angles of Diethyl Groups Method}

After 1D PES calculations, two assumed transition states of each aryl-CO and C-N bond rotation were re-optimized in QST3 algorithms [18] to confirm transition states. For this calculation, two lowest energy states and an estimated transition state were required. After using the QST3 method, one transition state was calculated. Frequency calculations were also performed to find the imaginary frequency corresponding to bond rotations, meaning that one transition state of those bond rotations could be found.

Diethyl rotations result in a different Gibbs energy barrier; therefore, before we optimized the confirmed transition states for the aryl-CO bond and C-N bond in NCDEA and PCDEA, we prepared for the conformers, of which all the atoms except ethyl were fixed, and the dihedral angles $(\alpha, \beta)$ of C (one ethyl)- $\mathrm{N}-\mathrm{C}$ (the other ethyl)-C (the other ethyl) were $-60^{\circ}, 60^{\circ}$, and $180^{\circ}$, respectively (Scheme S2). Thus, each conformer had nine different combinations (Scheme S2) and was optimized to have stable energy states. Frequency calculations were employed in these nine conformers to find the transition states of the aryl-CO and $\mathrm{N}-\mathrm{C}$ bonds for selecting the optimum Gibbs energy barrier. We also performed intrinsic reaction coordinates of two transition states from QST3 algorithms and the nine conformers from 2 nd transition states in aryl-CO and C-N bond rotations to find actual transition states including one imaginary frequency.

\subsubsection{D PES Method}

The activation energy of aryl-CO and C-N bond rotation can be specifically determined by independently calculating aryl-CO as the $\mathrm{X}$ axis and $\mathrm{C}-\mathrm{N}$ bond as the $\mathrm{Y}$ axis. 2D PESs were calculated for 38 steps of every $10^{\circ}$ increment of aryl-CO and C-N bond rotations. Frequency calculations were performed in an estimated transition state in both NCDEA and PCDEA.

\subsubsection{QTAIM Study}

In order to estimate the electron density on the rotating bonds (aryl-CO and C-N), we performed a QTAIM study using the Multiwfn program [22]. The electron density was calculated at the bond critical point $(\mathrm{CP}(3,-1))$.

Supplementary Materials: The following are available online. Supplementary materials include 3 schemes, 4 figures, and 11 tables. Scheme S1: N,N-diethylamide derivatives (1)-(4) synthesis by Oxalyl Chloride, Scheme S2: Varying the Dihedral angle of C-C-N-C $(\alpha, \beta)$ on Aryl-CO bond and N-C bond, Scheme S3: Angles of Amide Structure, Figure S1: 2D-EXSY spectra of $N, N$-diethylamide derivatives (1),(2), Figure S2: The Potential Energy Surface Graph of Aryl-CO (a) and C-N (b) rotation on NCDEA, Figure S3: The Potential Energy Surface Graph of Aryl-CO (a) and C-N (b) rotation on PCDEA, Figure S4: Structure of ground state and transition states (QST3) of Aryl-CO bond and C-N bond in NCDEA and PCDEA, Table S1: Comparisons of Gibbs Free energy of ${ }^{1} \mathrm{H}$ VT-NMR with those of scan coordinates calculated with the gaussian09 program, Table S2: The imaginary frequency on NCDEA and PCDEA, Table S3: Experimental and Theoretical Gibbs free energy of Aryl-CO bond in NCDEA, Table S4: Experimental and Theoretical Gibbs free energy of Aryl-CO bond in PCDEA, Table S5: Structure data of 2TS (diethyl-rotated conformers) of Aryl-CO bond in NCDEA and PCDEA, Table S6: Structure data of 2TS (diethyl-rotated conformers) of C-N bond in NCDEA, Table S7: Structure data of 2TS (diethyl-rotated conformers) of C-N bond in PCDEA, Table S8: Structure data of 2TS (diethyl-rotated conformers) of C-N bond in NCDEA and 
PCDEA, Table S9: Structure data of TS of the concerted Aryl-CO/C-N bond in NCDEA and PCDEA, Table S10: Structure data of TS of the concerted Aryl-CO/C-N bond of 2D PES in NCDEA and PCDEA, Table S11: Electron density of rotating bonds.

Author Contributions: Conceptualization, S.A. and K.K.; Methodology, X.X.; Software, S.K. and K.J.; Validation, S.K, J.K. (Jieun Kim), D.W., S.K.C., W.C., K.J., S.A. and K.K.; Resources, X.X.; Data Curation, S.K., J.K. (Jieun Kim), D.W., S.-K.C. and W.C., Y.Y. and Z.Z.; Formal Analysis, S.K. and K.J.; Investigation, S.K., J.K. (Jieun Kim)., D.W., S.K.C. and W.C.; Resources, X.X.; Writing-Original Draft Preparation, S.K., J.K. (Junkyu Kim)., D.W. and S.K.C.; Writing-Review \& Editing, S.K., J.K. (Junkyu Kim) and K.J.; Visualization, S.K., J.K. (Junkyu Kim) and K.J.; Supervision, K.J., S.A. and K.K.; Project Administration, S.A. and K.K.; Funding Acquisition, W.C. and K.K.

Funding: This research was funded by the Nuclear Research and Development Program of the National Research Foundation of Korea grant number [NRF-2017M2A8A5014719]. K.K acknowledges support from IBS-R023-D1.

Conflicts of Interest: The authors declare no conflict of interest.

\section{References}

1. Chakrabarti, P.; Dunitz, J.D. Structural characteristics of the carboxylic amide group. Helv. Chim. Acta 1982, 65, 1555-1562. [CrossRef]

2. Hirota, E.; Sugisaki, R.; Nielsen, C.J.; Sørensen, G.O. Molecular structure and internal motion of formamide from microwave spectrum. J. Mol. Spectrosc. 1974, 49, 251-267. [CrossRef]

3. Kottas, G.S.; Clarke, L.I.; Horinek, D.; Michl, J. Artificial molecular rotors. Chem. Rev. 2005, 105, 1281-1376. [CrossRef] [PubMed]

4. Bragg, R.A.; Clayden, J.; Morris, G.A.; Pink, J.H. Stereodynamics of bond rotation in tertiary aromatic amides. Chem. Eur. J. 2002, 8, 1279-1289. [CrossRef]

5. Clayden, J.; Pink, J.H. Concerted rotation in a tertiary aromatic amide: Towards a simple molecular gear. Angew. Chem. Int. Ed. 1998, 37, 1937-1939. [CrossRef]

6. Bragg, R.A.; Clayden, J. Using symmetry to monitor geared bond rotation in aromatic amides by dynamic NMR. Org. Lett. 2000, 2, 3351-3354. [CrossRef] [PubMed]

7. Vargas, R.; Garza, J.; Dixon, D.; Hay, B.P. C( $\left.\mathrm{sp}^{2}\right)-\mathrm{C}(\operatorname{aryl})$ bond rotation barrier in $\mathrm{N}$-methylbenzamide. J. Phys. Chem. 2001, 105, 774-778. [CrossRef]

8. Hammaker, R.M.; Gugler, B.A. An NMR study of hindered internal rotation in $N, N$-dialkyl amides. J. Mol. Spectrosc. 1965, 17, 356-364. [CrossRef]

9. Olsen, R.A.; Liu, L.; Ghaderi, N.; Johns, A.; Hatcher, M.E.; Mueller, L.J. The amide rotational barriers in picolinamide and nicotinamide: NMR and ab initio studies. J. Am. Chem. Soc. 2003, 125, 10125-10132. [CrossRef] [PubMed]

10. Skorupska, E.A.; Nazarski, R.B.; Ciechańska, M.; Jóźwiak, A.; Kłys, A. Dynamic 1 h NMR spectroscopic study of hindered internal rotation in selected $N, N$-dialkyl isonicotinamides: An experimental and DFT analysis. Tetrahedron 2013, 69, 8147-8154. [CrossRef]

11. Ahmed, A.; Bragg, R.A.; Clayden, J.; Lai, L.W.; McCarthy, C.; Pink, J.H.; Westlund, N.; Yasin, S.A. Barriers to rotation about the chiral axis of tertiary aromatic amides. Tetrahedron 1998, 54, 13277-13294. [CrossRef]

12. Kang, Y.K.; Park, H.S. Internal rotation about the C-N bond of amides. J. Mol. Struct. 2004, 676, 171-176. [CrossRef]

13. Clayden, J.; Pink, J.H.; Yasin, S.A. Conformationally interlocked amides: Remote asymmetric induction by mechanical transfer of stereochemical information. Tetrahedron Lett. 1998, 39, 105-108. [CrossRef]

14. Clayden, J.; Johnson, P.; Pink, J.H.; Helliwell, M. Atropisomeric amides as chiral ligands: Using (-)-sparteine-directed enantioselective silylation to control the conformation of a stereogenic axis. J. Org. Chem. 2000, 65, 7033-7040. [CrossRef] [PubMed]

15. Reeves, L.W.; Shaddick, R.C.; Shaw, K.N. Nuclear magnetic resonance studies of multi-site chemical exchange. III. Hindered rotation in dimethylacetamide, dimethyl trifluoro-acetamide, and dimethyl benzamide. Can. J. Chem. 1971, 49, 3683-3691. [CrossRef]

16. Campomanes, P.; Menéndez, M.I.; López, R.; Sordo, T.L. Stereodynamics of bond rotation in tertiary 1-naphthoic acid amides: A computational study. J. Comput. Chem. 2005, 26, 365-373. [CrossRef] [PubMed]

17. Krishnan, V.V.; Thompson, W.B.; Maitra, K.; Maitra, S. Modulations in restricted amide rotation by steric induced conformational trapping. Chem. Phys. Lett. 2012, 523, 124-127. [CrossRef] [PubMed] 
18. Peng, C.; Bernhard Schlegel, H. Combining synchronous transit and quasi-newton methods to find transition states. Isr. J. Chem. 1993, 33, 449-454. [CrossRef]

19. Becke, A.D. Density-functional thermochemistry. III. The role of exact exchange. J. Chem. Phys. 1993, 98, 5648-5652. [CrossRef]

20. Becke, A.D. Density-functional exchange-energy approximation with correct asymptotic behavior. Phys. Rev. A 1988, 38, 3098-3100. [CrossRef]

21. Ercolani, G. Determination of the rotational barrier in ethane by vibrational spectroscopy and statistical thermodynamics. J. Chem. Educ. 2005, 82, 1703. [CrossRef]

22. Lu, T.; Chen, F. Multiwfn: A multifunctional wavefunction analyzer. J. Comput. Chem. 2012, 33, 580-592. [CrossRef] [PubMed]

23. Eor, S.; Hwang, J.; Choi, M.G.; Chang, S.-K. Fluorescent signaling of oxone by desulfurization of thioamide. Org. Lett. 2011, 13, 370-373. [CrossRef] [PubMed]

24. Perrin, C.L.; Dwyer, T.J. Application of two-dimensional NMR to kinetics of chemical exchange. Chem. Rev. 1990, 90, 935-967. [CrossRef]

25. Kumar, A.; Ernst, R.R.; Wüthrich, K. A two-dimensional nuclear overhauser enhancement (2D NOE) experiment for the elucidation of complete proton-proton cross-relaxation networks in biological macromolecules. Biochem. Biophys. Res. Commun. 1980, 95, 1-6. [CrossRef]

26. Frisch, M.J.; Trucks, G.W.; Schlegel, H.B.; Scuseria, G.E.; Robb, M.A.; Cheeseman, J.R.; Scalmani, G.; Barone, V.; Petersson, G.A.; Nakatsuji, H.; et al. Gaussian 09, Revision D.01; Gaussian, Inc.: Wallingford, CT, USA, 2016.

27. Lee, C.; Yang, W.; Parr, R.G. Development of the colle-salvetti correlation-energy formula into a functional of the electron density. Phys. Rev. B 1988, 37, 785-789. [CrossRef]

28. Hehre, W.J.; Ditchfield, R.; Pople, J.A. Self-Consistent molecular orbital methods. XII. Further extensions of gaussian-Type basis sets for use in molecular orbital studies of organic molecules. J. Chem. Phys. 1972, 56, 2257-2261. [CrossRef]

29. Tomasi, J.; Mennucci, B.; Cammi, R. Quantum mechanical continuum solvation models. Chem. Rev. 2005, 105, 2999-3094. [CrossRef] [PubMed]

30. Wigner, E. The transition state method. Trans. Faraday Soc. 1938, 34, 29-41. [CrossRef]

Sample Availability: Samples of the compounds are not available from the authors.

(C) 2018 by the authors. Licensee MDPI, Basel, Switzerland. This article is an open access article distributed under the terms and conditions of the Creative Commons Attribution (CC BY) license (http:/ / creativecommons.org/licenses/by/4.0/). 
Article

\title{
$\mathrm{K}_{2} \mathrm{~S}_{2} \mathrm{O}_{8}$-Promoted Aryl Thioamides Synthesis from Aryl Aldehydes Using Thiourea as the Sulfur Source
}

\author{
Yongjun Bian ${ }^{*}{ }^{\dagger}$, Xingyu $\mathrm{Qu}^{\dagger}$, Yongqiang Chen, Jun Li and Leng Liu \\ College of Chemistry and Chemical Engineering, Jinzhong University, Yuci 030619, China; \\ quxy@jzxy.edu.cn (X.Q.); chenyongqiang@jzxy.edu.cn (Y.C.); hxx406@126.com (J.L.); liuleng@jzxy.edu.cn (L.L.) \\ * Correspondence: yjbian2013@jzxy.edu.cn; Tel.: +86-0351-398-5774 \\ + These authors contributed equally to this work
}

Received: 30 July 2018; Accepted: 29 August 2018; Published: 1 September 2018

\begin{abstract}
Thiourea as a sulfur atom transfer reagent was applied for the synthesis of aryl thioamides through a three-component coupling reaction with aryl aldehydes and $\mathrm{N}, \mathrm{N}$-dimethylformamide (DMF) or $\mathrm{N}, \mathrm{N}$-dimethylacetamide (DMAC). The reaction could tolerate various functional groups and gave moderate to good yields of desired products under the transition-metal-free condition.
\end{abstract}

Keywords: aryl thioamides; thiourea; C-H/C-N activation; C-S formation; transition-metal-free

\section{Introduction}

The synthesis of sulfur-containing organic compounds has received much attention in recent years, due to their wide applications in biology, chemistry, and materials science [1-10]. There are many sulfur reagents for their synthesis, such as $\mathrm{P}_{2} \mathrm{~S}_{5}$ [11], Lawesson's reagent [12], disulfides [13-15], thiols [16-19], sulfonyl hydrazides [20-23], sodium sulfonate [24-28], and elemental sulfur [29-32]. Among them, both $\mathrm{P}_{2} \mathrm{~S}_{5}$ and Lawesson's reagent are the most widely used reagents, and yet they have an obvious drawback of being sensitive to moisture. Therefore, much better sulfur reagents have been pursued by the organic chemists for the past decades [33]. Thioamides, as an important class of sulfur-containing organic compounds, have been synthesized by applying different sulfur reagents as the sulfur source [1,34-39]. For example, Jiang et al. [35] reported that sodium sulfide as a sulfur source was applied for the synthesis of thioamides using aldehydes and $N$-substituted formamides. More recently, a coupling reaction between quaternary ammoniums, $N$-substituted formamides, and sodium disulfide was accomplished for rapid access to aryl thioamides [36]. Thiourea as an inexpensive and easy-to-handle sulfur atom transfer reagent, was used extensively as well, mainly for the synthesis of inorganic metal sulfides [40-42], organic thioethers [43-47], and thioesters [48,49]. As far as we known, a similar reaction using thiourea and aldehydes to prepare thioamides has not yet been introduced. Hence, we want to report a new three-component coupling reaction between aryl aldehydes, thiourea as an effective sulfur source, and DMF or DMAC, for the synthesis of various aryl thioamides.

\section{Results and Discussion}

Initially, we treated the reaction of 4-chlorobenzaldehyde $1 \mathrm{a}$ in $\mathrm{DMF}$ and $\mathrm{H}_{2} \mathrm{O}$ at $125^{\circ} \mathrm{C}$ in the presence of thiourea using the benzoyl peroxide (BPO) as an oxidant. After $24 \mathrm{~h}$, the desired thioamide product $3 a$ was isolated in $58 \%$ yield (Table 1, Entry 1). Subsequently, various oxidants, which are commonly used in C-H activation, such as $p$-benzoquinone (BQ), di-t-butyl peroxide (DTBP), tert-butyl hydroperoxide (TBHP), $\mathrm{K}_{2} \mathrm{~S}_{2} \mathrm{O}_{8}$, or $\left(\mathrm{NH}_{4}\right)_{2} \mathrm{~S}_{2} \mathrm{O}_{8}$, were attempted, to optimize the reaction condition (Table 1, Entries 2-6). Among them, $\mathrm{K}_{2} \mathrm{~S}_{2} \mathrm{O}_{8}$ proved to be best to give the desired thioamide product 3a in $69 \%$ yield (Table 1, Entry 5). For this transformation, $\mathrm{H}_{2} \mathrm{O}$ played an extremely important role. No desired product $3 \mathrm{a}$ was observed when increasing the concentration of $\mathrm{H}_{2} \mathrm{O}$ to $42 \mathrm{M}$ or without 
addition of $\mathrm{H}_{2} \mathrm{O}$ (Table 1, Entries 7 and 9). Slightly enhancing or reducing the loading amount of $\mathrm{K}_{2} \mathrm{~S}_{2} \mathrm{O}_{8}$, the yield of 3a was not obviously changeable (Table 1, Entries 10-11). When the 20\% of $\mathrm{Cu}(\mathrm{OAc})_{2}$ were used as a catalyst, only $54 \%$ yield of 3 a was afforded (Table 1, Entry 12) [36]. To our delight, the yield of $\mathbf{3 a}$ was further promoted to $80 \%$ when 5 equiv. of pyridine (Py) as an additive were added (Table 1, Entry 13) [35].

Table 1. Optimization of reaction conditions ${ }^{\mathrm{a}}$.

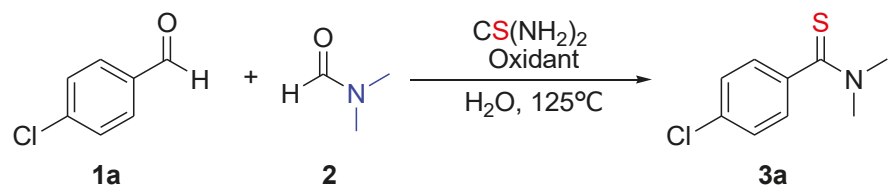

1a

2

$3 a$

\begin{tabular}{cccc}
\hline Entry & Oxidant (Equiv) & Concentration of $\mathbf{H}_{\mathbf{2}} \mathbf{O}(\mathbf{M})$ & Yield $\mathbf{( \% )} \mathbf{b}^{\mathbf{b}}$ \\
\hline 1 & $\mathrm{BPO}(2)$ & 14 & 58 \\
2 & $\mathrm{BQ}(2)$ & 14 & 0 \\
3 & $\mathrm{DTBP}(2)$ & 14 & $<5$ \\
4 & $\mathrm{TBHP}(2)$ & 14 & 20 \\
5 & $\mathrm{~K}_{2} \mathrm{~S}_{2} \mathrm{O}_{8}(2)$ & 14 & 69 \\
6 & $\left(\mathrm{NH}_{4}\right)_{2} \mathrm{~S}_{2} \mathrm{O}_{8}(2)$ & 14 & 55 \\
7 & $\mathrm{~K}_{2} \mathrm{~S}_{2} \mathrm{O}_{8}(2)$ & 42 & $0^{\mathrm{c}}$ \\
8 & $\mathrm{~K}_{2} \mathrm{~S}_{2} \mathrm{O}_{8}(2)$ & 8 & $65^{\mathrm{d}}$ \\
9 & $\mathrm{~K}_{2} \mathrm{~S}_{2} \mathrm{O}_{8}(2)$ & 0 & $0^{\mathrm{e}}$ \\
10 & $\mathrm{~K}_{2} \mathrm{~S}_{2} \mathrm{O}_{8}(3)$ & 14 & 68 \\
11 & $\mathrm{~K}_{2} \mathrm{~S}_{2} \mathrm{O}_{8}(1.8)$ & 14 & 61 \\
12 & $\mathrm{~K}_{2} \mathrm{~S}_{2} \mathrm{O}_{8}(2)$ & 14 & $54^{\mathrm{f}}$ \\
13 & $\mathrm{~K}_{2} \mathrm{~S}_{2} \mathrm{O}_{8}(2)$ & 14 & $80^{\mathrm{g}}$ \\
\hline
\end{tabular}

a Condition: 1a $(0.25 \mathrm{mmol}), 2(9.6 \mathrm{M})$, thiourea $(0.5 \mathrm{mmol})$, oxidant, $\mathrm{H}_{2} \mathrm{O}, 125^{\circ} \mathrm{C}, 24 \mathrm{~h}$. ${ }^{\mathrm{b}}$ Isolated yield. ${ }^{\mathrm{c}} 3.4 \mathrm{M}$ of DMF were used. ${ }^{\mathrm{d}} 11 \mathrm{M}$ of DMF were used. ${ }^{\mathrm{e}} 13 \mathrm{M}$ of DMF were used. ${ }^{\mathrm{f}} 20 \mathrm{~mol} \%$ of $\mathrm{Cu}(\mathrm{OAc})_{2}$ were added. $\mathrm{g} 5$ equiv. of pyridine (Py) were added.

After establishing the optimized conditions, this procedure was applied to access a variety of aryl thioamide derivatives. Several different aryl aldehydes could undergo this transformation smoothly in a mild condition to give the desired products $3 \mathbf{a}-\mathbf{r}$ (Scheme 1). The results indicated that many popular functional groups were well tolerated, such as methyl, methoxyl, chloro, bromo, fluoro, trifluoromethyl, and tert-butyl. Furthermore, the substrate bearing a sensitive hydroxy group, which was generally protected in the presence of an oxidant could be also tolerated in this transformation, and afforded the desired product 30 in $83 \%$ yield. A substituted amino was suitable as well, and gave $88 \%$ yield of $3 p$. The substituents on aromatic aldehydes had a certain influence on this transformation. When the substituents were strong electron-withdrawing groups, either lower yield of desired products, or no desired products were obtained ( $3 \mathbf{j}$ and $\mathbf{3 r}$ ). The desired product $3 \mathbf{m}$ was not afforded possibly due to the steric hindrance. Moreover, our experiments demonstrated that 2-naphthaldehyde was a suitable substrate for this transformation, and gave the desired product $\mathbf{3 q}$ a good yield.

To further expand the substrate scope, some selected heterocyclic aldehydes and an aliphatic aldehyde were examined under the optimal condition (Scheme 2). Generally, five or six members heterocyclic derivatives were suitable for this transformation, such as furan-2-carbaldehyde, thiophene-2-carbaldehyde, and nicotinaldehyde, giving the corresponding thioamide products 3s, 3t, and $3 \mathbf{u} 54 \%, 74 \%$, and 37\% yields, respectively. In addition, aliphatic aldehyde did not accomplish this transformation $(3 \mathbf{w})$.

We attempted to explore the different $N$-substituted formamides for this transformation in additional solvent. No good results were provided when the normal solvents such as $\mathrm{N}$-methyl-2-pyrrolidone (NMP), 1,4-dioxane, 1,2-dichloroethane (DCE), toluene, chlorobenzene (PhCl), dimethyl sulfoxide (DMSO), ethylene glycol, were used (see Supporting Information). Unexpectedly, 
$\mathrm{N}, \mathrm{N}$-dimethylacetamide (DMAC), which was seldom used as an amine source by the acyl C-N bond activation [37], could replace DMF to give the same desired product in good yield. Subsequently, the reactions of aryl aldehydes with thiourea in DMAC were examined under the similar reaction condition (Table 2). The results demonstrated that various groups were tolerated well, such as methyl, chloro, and bromo, and the good yields of the desired products were isolated.<smiles>[R][Y]1ccc2ccc(C=O)cc2c1</smiles>

1<smiles>CCN(C)C(=S)c1ccc(Cl)cc1</smiles>

3a $80 \%$<smiles>COc1ccc(C(=S)N(C)C)cc1</smiles>

3d $68 \%$<smiles>CN(C)C(=S)c1cccc(Cl)c1</smiles>

3 g $73 \%$<smiles>CN(C)C(=S)c1ccc(C(F)(F)F)cc1</smiles>

3j $46 \%$<smiles>Cc1cc(C)c(C(=S)N(C)C)c(C)c1</smiles>

$3 \mathrm{~m} \mathrm{0 \%}$<smiles>CN(C)C(=S)c1ccc(N(C)C)cc1</smiles>

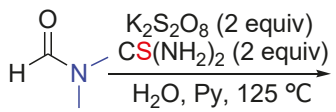

2<smiles>CN(C)C(=S)c1ccccc1</smiles>

3b $72 \%$<smiles>CN(C)C(=S)c1ccc(Br)cc1</smiles>

3e $75 \%$<smiles>CN(C)C(=S)c1cccc(Br)c1</smiles>

3h $74 \%$<smiles>CN(C)C(=S)c1ccc(C(C)(C)C)cc1</smiles>

3k $75 \%$<smiles>CN(C)C(=S)c1ccc(-c2ccccc2)cc1</smiles>

3n $78 \%$<smiles>CN(C)C(=S)c1ccc2ccccc2c1</smiles>

3q $81 \%$<smiles>[R][Y]1=CC=Cc2ccc(C(=S)N(C)C)cc2C1</smiles>

3<smiles>Cc1ccc(C(=S)N(C)C)cc1</smiles>

3c $70 \%$<smiles>CN(C)C(=S)c1ccc(F)cc1</smiles>

3f $80 \%$<smiles>Cc1cccc(C(=S)N(C)C)c1</smiles>

3i $71 \%$<smiles>CN(C)C(=S)c1cc(C(C)(C)C)cc(C(C)(C)C)c1</smiles>

3। $59 \%$<smiles>CN(C)C(=S)c1ccc(O)cc1</smiles>

3o $83 \%$

Scheme 1. The substrate scope of substituted benzaldehydes. Reaction condition: aryl aldehyde 1 ( $0.25 \mathrm{mmol})$, thiourea ( $0.5 \mathrm{mmol}), \mathrm{H}_{2} \mathrm{O}(14 \mathrm{M}), \mathrm{K}_{2} \mathrm{~S}_{2} \mathrm{O}_{8}(0.5 \mathrm{mmol})$ and Py (5 equiv.) in DMF (1.5 mL) at $125^{\circ} \mathrm{C}$ for $24 \mathrm{~h}$ in sealed tube. Isolated yields were given. 


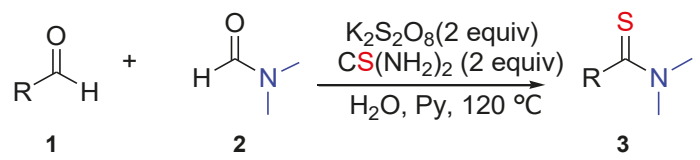<smiles>CN(C)C(=S)c1ccco1</smiles>

(3s $54 \%$ )<smiles>CN(C)C(=S)c1cccs1</smiles>

(3t $74 \%)$<smiles>CN(C)C(=S)c1cccnc1</smiles>

(3u $37 \%$ )<smiles>CN(C)C(=S)c1ccc(-c2ccc3ccccc3n2)s1</smiles><smiles>CN(C)C(=S)C1CCCCC1</smiles>

(3w 0\%)

Scheme 2. The substrate scope of other aldehydes. Reaction condition: aldehyde $\mathbf{1}(0.25 \mathrm{mmol})$, thiourea (0.5 mmol), $\mathrm{H}_{2} \mathrm{O}(14 \mathrm{M}), \mathrm{K}_{2} \mathrm{~S}_{2} \mathrm{O}_{8}(0.5 \mathrm{mmol})$, and Py (5 equiv.) in DMF $(1.5 \mathrm{~mL})$ at $125^{\circ} \mathrm{C}$ for $24 \mathrm{~h}$ in sealed tube. Isolated yields were given.

Table 2. The synthesis of aryl thioamides by DMAC ${ }^{\mathrm{a}}$.

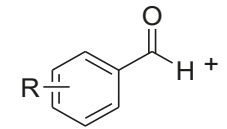

1

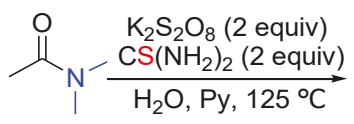

4<smiles>CN(C)C(=S)c1cc[R1]cc1</smiles>

3

\begin{tabular}{ccc}
$\mathbf{1}$ & $\mathbf{4}$ & $\mathbf{3}$ \\
\hline Entry & $\mathbf{R}$ & ${\text { Yield }(\%) \text { of } \mathbf{3}^{\mathbf{b}}}^{\mathbf{4}}$ \\
\hline 1 & $4-\mathrm{Cl}$ & $63(3 \mathbf{a})$ \\
2 & $\mathrm{H}$ & $52(3 \mathbf{b})$ \\
3 & $4-\mathrm{CH}_{3}$ & $55(3 \mathbf{c})$ \\
4 & $3-\mathrm{Br}$ & $48(3 \mathbf{h})$ \\
5 & $3-\mathrm{CH}_{3}$ & $51(3 \mathbf{i})$ \\
6 & $4-\mathrm{Ph}$ & $60(3 \mathbf{n})$
\end{tabular}

a Condition: 1 (0.25 mmol), $4(1.5 \mathrm{~mL})$, thiourea $(0.5 \mathrm{mmol}), \mathrm{K}_{2} \mathrm{~S}_{2} \mathrm{O}_{8}(0.5 \mathrm{mmol}), \mathrm{H}_{2} \mathrm{O}(0.5 \mathrm{~mL}), \mathrm{Py}(1.25 \mathrm{mmol})$, $125^{\circ} \mathrm{C}, 36 \mathrm{~h} .{ }^{\mathrm{b}}$ Isolated yield.

In addition, extremely small amounts of amide products were observed, along with the generation of thioamide products under the optimal condition. So, two control experiments were conducted to explain the tentative reaction mechanism (see Supporting Information). First, no thioamide product was formed in the absence of thiourea, and only trace amounts of amide product were observed. Second, when the $\mathrm{N}, \mathrm{N}$-dimethylbenzamide replacing the benzaldehyde was manipulated under the standard condition, no desired thioamide was observed.

Based on our experimental results and previous reports [35], a proposed reaction mechanism for this transformation is described in Scheme 3. First, an aryl aldehyde undergoes a nucleophilic attack by a dimethylamine, which is from the hydrolysis of DMF, to generate iminium intermediate $\mathbf{A}$. The iminium $\mathbf{A}$ then is directly attacked by thiourea to form the intermediate $\mathbf{B}$, together with the release of urea $[43,47,49]$. Finally, intermediate $\mathbf{B}$ is oxidized by $\mathrm{K}_{2} \mathrm{~S}_{2} \mathrm{O}_{8}$ to afford the desired thioamide product. 


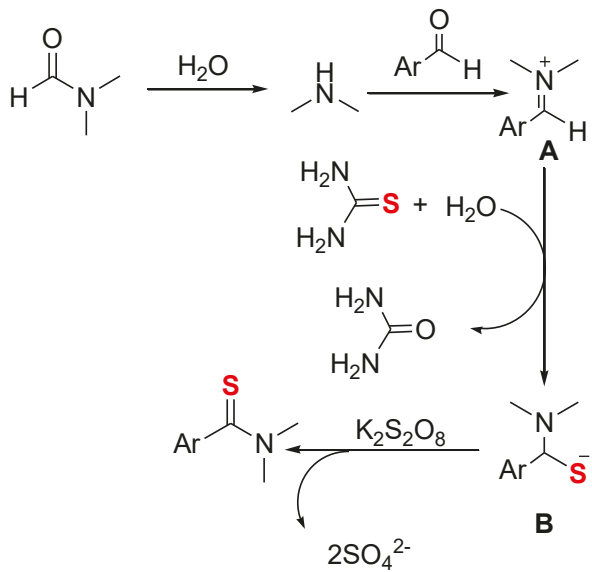

Scheme 3. Plausible reaction pathway.

\section{Materials and Methods}

Unless otherwise stated, all reagents and solvents were purchased from commercial suppliers, and were used without further purification. Reactions were monitored by thin layer chromatography (TLC) analysis on silica gel 60 F254, and visualization was accomplished by irradiation with short wave UV light at $254 \mathrm{~nm}$. ${ }^{1} \mathrm{H}-\mathrm{NMR}$ and ${ }^{13} \mathrm{C}-\mathrm{NMR}$ spectra were recorded on a Bruker Avance 400 or a $500 \mathrm{MHz}$ spectrometer (Bruker, Karlsruhe, Germany), with tetramethylsilane (TMS) as the internal standard. The coupling constants $J$ are given in Hz. Mass spectra were measured with the Thermo Scientific LTQ Orbitrap XL MS spectrometer (Thermo Fisher Scientific, Waltham, MA, USA) or GC-MS QP2010 (Comfort Technology Limited, Kowloon, Hong Kong).

A mixture of aldehyde $\mathbf{1}(0.25 \mathrm{mmol})$, thiourea $(0.5 \mathrm{mmol}), \mathrm{K}_{2} \mathrm{~S}_{2} \mathrm{O}_{8}(0.5 \mathrm{mmol})$, and Py $(1.25 \mathrm{mmol})$ in $2.0 \mathrm{~mL} \mathrm{DMF} / \mathrm{H}_{2} \mathrm{O}(v / v=3: 1)$ was stirred in a sealed tube under air at $125{ }^{\circ} \mathrm{C}$ for $24 \mathrm{~h}$. After the reaction was achieved, the crude mixture was purified by column chromatography (silica gel, EtOAc/petroleum ether) to afford the desired product 3.

4-Chloro-N,N-dimethylbenzothioamide (3a) [35]. ${ }^{1} \mathrm{H}-\mathrm{NMR}\left(\mathrm{CDCl}_{3}, 400 \mathrm{MHz}\right): \delta(\mathrm{ppm}): 7.36-7.33$ (m, 2H), 7.29-7.26 (m, 2H), 3.61 (s, 3H), 3.19 (s, 3H); ${ }^{13} \mathrm{C}-\mathrm{NMR}\left(\mathrm{CDCl}_{3}, 100 \mathrm{MHz}\right): \delta$ (ppm): 199.91, 141.66, 134.60, 128.58, 127.29, 44.18, 43.32; HRMS (ESI) $m / z$ calculated (calcd.) for $\mathrm{C}_{9} \mathrm{H}_{11} \mathrm{ClNS}^{+}(\mathrm{M}+\mathrm{H})^{+}$ 200.02952, found 200.02971 .

N,N-Dimethylbenzothioamide (3b) [35]. ${ }^{1} \mathrm{H}-\mathrm{NMR}\left(\mathrm{CDCl}_{3}, 400 \mathrm{MHz}\right): \delta(\mathrm{ppm}): 7.37-7.30(\mathrm{~m}, 5 \mathrm{H}), 3.62$ (s, 3H), 3.19 (s, 3H); ${ }^{13} \mathrm{C}-\mathrm{NMR}\left(\mathrm{CDCl}_{3}, 100 \mathrm{MHz}\right): \delta$ (ppm): 201.65, 143.69, 128.89, 128.64, 126.04, 44.44, 43.53; GC-MS (EI) m/z (\%) $165.10\left(70, \mathrm{M}^{+}\right), 164.05$ (98), 121.05 (100), 77.00 (46).

4-Methyl-N,N-dimethylbenzothioamide 3c [35]. ${ }^{1} \mathrm{H}-\mathrm{NMR}\left(\mathrm{CDCl}_{3}, 400 \mathrm{MHz}\right): \delta(\mathrm{ppm}): 7.23(\mathrm{~d}, J=8 \mathrm{~Hz}$, $2 \mathrm{H}), 7.16(\mathrm{~d}, J=8 \mathrm{~Hz}, 2 \mathrm{H}), 3.61(\mathrm{~s}, 3 \mathrm{H}), 3.20(\mathrm{~s}, 3 \mathrm{H}), 2.36(\mathrm{~s}, 3 \mathrm{H}) ;{ }^{13} \mathrm{C}-\mathrm{NMR}\left(\mathrm{CDCl}_{3}, 100 \mathrm{MHz}\right): \delta(\mathrm{ppm})$ : 201.55, 140.59, 138.68, 128.89, 125.89, 44.22, 43.35, 21.27; GC-MS (EI) $m / z$ (\%) 179.05 (80, M+). 178.05 (100), 145.10 (50), 135.05 (98), 91.05 (45).

4-Methoxy-N,N-dimethylbenzothioamide (3d) [35]. ${ }^{1} \mathrm{H}-\mathrm{NMR}\left(\mathrm{CDCl}_{3}, 400 \mathrm{MHz}\right): \delta(\mathrm{ppm}): 7.31$ (d, $J=12 \mathrm{~Hz}, 2 \mathrm{H}), 6.87(\mathrm{~d}, J=12 \mathrm{~Hz}, 2 \mathrm{H}), 3.82(\mathrm{~s}, 3 \mathrm{H}), 3.59(\mathrm{~s}, 3 \mathrm{H}), 3.22(\mathrm{~s}, 3 \mathrm{H}) ;{ }^{13} \mathrm{C}-\mathrm{NMR}\left(\mathrm{CDCl}_{3}\right.$, $100 \mathrm{MHz}$ ): $\delta$ (ppm): 201.31, 160.02, 135.82, 127.90, 113.51, 55.40, 44.37, 43.59; GC-MS (EI) m/z (\%) 195.05 $\left(\mathrm{M}^{+}, 84\right), 194.05$ (93), 151.05 (100).

4-Bromo-N,N-dimethylbenzothioamide (3e) [35]. ${ }^{1} \mathrm{H}-\mathrm{NMR}\left(\mathrm{CDCl}_{3}, 400 \mathrm{MHz}\right): \delta(\mathrm{ppm}): 7.53-7.50$ (m, 2H), 7.23-7.19 (m, 2H), 3.60 (s, 3H), 3.19 (s, 3H); ${ }^{13} \mathrm{C}-\mathrm{NMR}\left(\mathrm{CDCl}_{3}, 100 \mathrm{MHz}\right): \delta$ (ppm): 199.79, 142.12, 
131.53, 127.52, 122.73, 44.20, 44.30; GC-MS (EI) m/z (\%) 242.95 (63, $\left.\mathrm{M}^{+}\right), 243.90$ (100), 242.95 (63), 241.90 (92), 200.85 (47), 198.90 (48), 120.00 (54).

4-Fluoro-N,N-dimethylbenzothioamide (3f) [35]. ${ }^{1} \mathrm{H}-\mathrm{NMR}\left(\mathrm{CDCl}_{3}, 400 \mathrm{MHz}\right): \delta(\mathrm{ppm}): 7.32-7.28(\mathrm{~m}, 2 \mathrm{H})$, 7.05-6.99 (m, 2H), $3.58(\mathrm{~s}, 3 \mathrm{H}), 3.16(\mathrm{~s}, 3 \mathrm{H}) ;{ }^{13} \mathrm{C}-\mathrm{NMR}\left(\mathrm{CDCl}_{3}, 100 \mathrm{MHz}\right): \delta(\mathrm{ppm}): 200.19,162.66(\mathrm{~d}$, $J=248 \mathrm{~Hz}), 139.44(\mathrm{~d}, J=4 \mathrm{~Hz}), 128.00(\mathrm{~d}, J=9 \mathrm{~Hz}), 115.33(\mathrm{~d}, J=22 \mathrm{~Hz}), 44.24,43.45$.

3-Chloro-N,N-dimethylbenzothioamide (3g) [35]. ${ }^{1} \mathrm{H}-\mathrm{NMR}\left(\mathrm{CDCl}_{3}, 400 \mathrm{MHz}\right): \delta(\mathrm{ppm}): 7.33-7.25$ (m, $3 \mathrm{H}), 7.20-7.18(\mathrm{~m}, 1 \mathrm{H}), 3.60(\mathrm{~s}, 3 \mathrm{H}), 3.19(\mathrm{~s}, 3 \mathrm{H}) ;{ }^{13} \mathrm{C}-\mathrm{NMR}\left(\mathrm{CDCl}_{3}, 100 \mathrm{MHz}\right): \delta(\mathrm{ppm}): 199.11,144.78$, 134.29, 129.76, 128.63, 125.89, 123.83, 44.18, 43.18; GC-MS (EI) $m / z$ (\%) 200.00 (43), 199.0 (69, $\mathrm{M}^{+}$). 198.00 (100), 165.00 (32), 157.00 (26), 155.00 (74), 111.00 (24).

3-Bromo-N,N-dimethylbenzothioamide (3h) [35]. ${ }^{1} \mathrm{H}-\mathrm{NMR}\left(\mathrm{CDCl}_{3}, 400 \mathrm{MHz}\right): \delta(\mathrm{ppm}): 7.50-7.46$ (m, 2H), 7.27-7.22 (m, 2H), 3.60 (s, 3H), $3.19(\mathrm{~s}, 3 \mathrm{H}) ;{ }^{13} \mathrm{C}-\mathrm{NMR}\left(\mathrm{CDCl}_{3}, 100 \mathrm{MHz}\right): \delta(\mathrm{ppm}): 199.01,144.98$, 131.56, 129.99, 128.68, 124.30, 122.38, 44.19, 43.19; GC-MS (EI) $m / z$ (\%) 244.95 (64), 243.95 (100), 242.95 (65, $\left.\mathrm{M}^{+}\right), 241.95$ (95), 200.90 (43), 198.90 (43), 120.00 (51).

3-Methyl-N,N-dimethylbenzothioamide (3i) [35]. ${ }^{1} \mathrm{H}-\mathrm{NMR}\left(\mathrm{CDCl}_{3}, 400 \mathrm{MHz}\right): \delta(\mathrm{ppm}): 7.34-7.24(\mathrm{~m}, 1 \mathrm{H})$, $7.17(\mathrm{~d}, J=6.0 \mathrm{~Hz}, 2 \mathrm{H}), 7.11(\mathrm{~d}, J=7.5 \mathrm{~Hz}, 1 \mathrm{H}), 3.64(\mathrm{~s}, 3 \mathrm{H}), 3.21(\mathrm{~s}, 3 \mathrm{H}), 2.40(\mathrm{~s}, 3 \mathrm{H}) ;{ }^{13} \mathrm{C}-\mathrm{NMR}\left(\mathrm{CDCl}_{3}\right.$, $100 \mathrm{MHz}): \delta$ (ppm): 201.2, 143.2, 138.0, 129.1, 128.0, 126.1, 122.4, 44.0, 43.0, 21.2.

4-(Trifluoromethyl)-N,N-dimethylbenzothioamide (3j) [35]. ${ }^{1} \mathrm{H}-\mathrm{NMR}\left(\mathrm{CDCl}_{3}, 400 \mathrm{MHz}\right): \delta(\mathrm{ppm}): 7.64(\mathrm{~d}$, $J=8 \mathrm{~Hz}, 2 \mathrm{H}), 7.43(\mathrm{~d}, J=12 \mathrm{~Hz}, 2 \mathrm{H}), 3.63(\mathrm{~s}, 3 \mathrm{H}), 3.18(\mathrm{~s}, 3 \mathrm{H}) ;{ }^{13} \mathrm{C}-\mathrm{NMR}\left(\mathrm{CDCl}_{3}, 100 \mathrm{MHz}\right): \delta(\mathrm{ppm})$ : $199.30,146.56,130.46(\mathrm{q}, J=32.6 \mathrm{~Hz}), 126.02,125.56(\mathrm{q}, J=3.8 \mathrm{~Hz}), 123.73(\mathrm{q}, J=270.5 \mathrm{~Hz}), 44.07,43.09$; GC-MS (EI) $m / z$ (\%) 233.00 (M+ $\left.\mathbf{M}^{+}, 71\right), 232.00$ (100), 199.05 (37), 189.00 (64).

4-tert-Butyl-N,N-dimethylbenzothioamide (3k) [37]. ${ }^{1} \mathrm{H}-\mathrm{NMR}\left(\mathrm{CDCl}_{3}, 400 \mathrm{MHz}\right): \delta(\mathrm{ppm}): 7.38-7.35$ (m, $2 \mathrm{H}), 7.28-7.24(\mathrm{~m}, 2 \mathrm{H}), 3.61(\mathrm{~s}, 3 \mathrm{H}), 3.21(\mathrm{~s}, 3 \mathrm{H}), 1.32(\mathrm{~s}, 9 \mathrm{H}) ;{ }^{13} \mathrm{C}-\mathrm{NMR}\left(\mathrm{CDCl}_{3}, 100 \mathrm{MHz}\right): \delta(\mathrm{ppm})$ : $201.64,151.78,140.49,125.67,125.22,44.27,43.34,34.70,31.23$. GC-MS (EI) $m / z(\%) 221.10\left(70, \mathrm{M}^{+}\right)$, 220.05 (70), 147.05 (24).

3,5-di-tert-Butyl-N,N-dimethylbenzothioamide (31). ${ }^{1} \mathrm{H}-\mathrm{NMR}\left(\mathrm{CDCl}_{3}, 400 \mathrm{MHz}\right): \delta(\mathrm{ppm}): 7.39(\mathrm{t}, J=4 \mathrm{~Hz}$, $1 \mathrm{H}), 7.15(\mathrm{~d}, J=4 \mathrm{~Hz}, 2 \mathrm{H}), 3.63(\mathrm{~s}, 3 \mathrm{H}), 3.16(\mathrm{~s}, 3 \mathrm{H}), 1.33(\mathrm{~s}, 18 \mathrm{H}) ;{ }^{13} \mathrm{C}-\mathrm{NMR}\left(\mathrm{CDCl}_{3}, 100 \mathrm{MHz}\right): \delta(\mathrm{ppm}):$ $202.78,150.70,142.63,122.75,120.13,44.21,43.32,34.92,31.40$. GC-MS (EI) $m / z(\%) 277.15\left(86, \mathrm{M}^{+}\right)$, 276.15 (100), 220.05 (80). HRMS (ESI) $m / z$ calcd. for $\mathrm{C}_{17} \mathrm{H}_{28} \mathrm{NS}^{+}(\mathrm{M}+\mathrm{H})^{+} 278.19370$, found 278.19366.

4-Benzyl-N,N-dimethylbenzothioamide (3n) [38]. ${ }^{1} \mathrm{H}-\mathrm{NMR}\left(\mathrm{CDCl}_{3}, 400 \mathrm{MHz}\right): \delta(\mathrm{ppm}): 7.59-7.56(\mathrm{~m}, 4 \mathrm{H})$, 7.47-7.43 (m, 2H), 7.41-7.34 (m, 3H),3.62 (s, 3H), $3.23(\mathrm{~s}, 3 \mathrm{H}) ;{ }^{13} \mathrm{C}-\mathrm{NMR}\left(\mathrm{CDCl}_{3}, 100 \mathrm{MHz}\right): \delta(\mathrm{ppm})$ : $201.04,142.17,141.56,140.33,128.89,127.69,127.10,127.09,126.39,44.28,43.32$. GC-MS (EI) $m / z$ (\%) $241.05\left(78, \mathrm{M}^{+}\right), 240.05$ (100), 197.00 (58), 181.05 (66), 152.05 (74).

4-Hydroxy-N,N-dimethylbenzothioamide (3o) [35]. ${ }^{1} \mathrm{H}-\mathrm{NMR}\left(\mathrm{CDCl}_{3}, 400 \mathrm{MHz}\right): \delta$ (ppm): 7.21-7.15 (m, 2H), 6.75-6.70 (m, 2H), $5.89(\mathrm{br} \mathrm{s}, 1 \mathrm{H}), 3.59(\mathrm{~s}, 3 \mathrm{H}), 3.21(\mathrm{~s}, 3 \mathrm{H}) ;{ }^{13} \mathrm{C}-\mathrm{NMR}\left(\mathrm{CDCl}_{3}, 100 \mathrm{MHz}\right): \delta(\mathrm{ppm})$ : 200.97, 156. 03, 136. 00, 127.45, 114.85, 43.97, 43.20; GC-MS (EI) m/z (\%) 181.05 (M+ $\left.{ }^{+}, 74\right), 180.05$ (79), 147.10 (31), 137.05 (100).

4-(Dimethylamino)-N,N-dimethylbenzothioamide (3p) [50]. ${ }^{1} \mathrm{H}-\mathrm{NMR}\left(\mathrm{CDCl}_{3}, 400 \mathrm{MHz}\right): \delta$ (ppm): 7.32 (d, $J=8 \mathrm{~Hz}, 2 \mathrm{H}), 7.63(\mathrm{~d}, J=8 \mathrm{~Hz}, 2 \mathrm{H}), 3.59(\mathrm{~s}, 3 \mathrm{H}), 3.28(\mathrm{~s}, 3 \mathrm{H}), 2.99(\mathrm{~s}, 6 \mathrm{H}) ;{ }^{13} \mathrm{C}-\mathrm{NMR}\left(\mathrm{CDCl}_{3}, 100 \mathrm{MHz}\right)$ : $\delta$ (ppm): 201.64, 150.54, 130.30, 127.98, 110.56, 44.19, 43.40, 39.86; GC-MS (EI) $m / z$ (\%) $208.05\left(\mathrm{M}^{+}, 74\right)$, 207.05 (46), 164.05 (100), 148.10 (57).

$\mathrm{N}, \mathrm{N}$-Dimethylnaphthalene-2-carbothioamide (3q) [35]. ${ }^{1} \mathrm{H}-\mathrm{NMR}\left(\mathrm{CDCl}_{3}, 400 \mathrm{MHz}\right): \delta$ (ppm): 7.82-7.81 $(\mathrm{m}, 3 \mathrm{H}), 7.77(\mathrm{~s}, 1 \mathrm{H}), 7.53-7.46(\mathrm{~m}, 2 \mathrm{H}), 7.44-7.41(\mathrm{~m}, 1 \mathrm{H}), 3.64(\mathrm{~s}, 3 \mathrm{H}), 3.19(\mathrm{~s}, 3 \mathrm{H}) ;{ }^{13} \mathrm{C}-\mathrm{NMR}\left(\mathrm{CDCl}_{3}\right.$, $100 \mathrm{MHz}$ ): $\delta$ (ppm): 201.21, 140.60, 128.38, 128.20, 127.75, 126.78, 126.74, 124.73, 123.94, 44.27, 43.31.

N,N-Dimethylfuran-2-carbothioamide (3s) [51]. ${ }^{1} \mathrm{H}-\mathrm{NMR}\left(\mathrm{CDCl}_{3}, 400 \mathrm{MHz}\right): \delta(\mathrm{ppm}): 7.47$ (d, J $=4 \mathrm{~Hz}$, $1 \mathrm{H}), 7.09(\mathrm{~d}, J=4 \mathrm{~Hz}, 1 \mathrm{H}), 6.46(\mathrm{~d}, J=4 \mathrm{~Hz}, 1 \mathrm{H}), 3.56(\mathrm{~s}, 3 \mathrm{H}), 3.45(\mathrm{~s}, 3 \mathrm{H}) ;{ }^{13} \mathrm{C}-\mathrm{NMR}\left(\mathrm{CDCl}_{3}, 100 \mathrm{MHz}\right)$ : 

(70), 73.95 (27).

N,N-Dimethylthiophene-2-carbothioamide (3t) [35]. ${ }^{1} \mathrm{H}-\mathrm{NMR}\left(\mathrm{CDCl}_{3}, 400 \mathrm{MHz}\right): \delta(\mathrm{ppm}): 7.41(\mathrm{dd}, J=4.8$, $0.8 \mathrm{~Hz}, 1 \mathrm{H}), 7.12(\mathrm{dd}, J=4.0,1.2 \mathrm{~Hz}, 1 \mathrm{H}), 6.99-6.97(\mathrm{~m}, 1 \mathrm{H}), 3.58(\mathrm{~s}, 3 \mathrm{H}), 3.45(\mathrm{~s}, 3 \mathrm{H}),{ }^{13} \mathrm{C}-\mathrm{NMR}\left(\mathrm{CDCl}_{3}\right.$, $100 \mathrm{MHz}): \delta$ (ppm):191.63, 145.23, 129.30, 126.50, 126.45, 44.65. GC-MS (EI) $m / z(\%) 171.00\left(77, \mathrm{M}^{+}\right)$, 127.00 (100).

$\mathrm{N}, \mathrm{N}$-Dimethylpyridine-3-carbothioamide (3u) [52]. ${ }^{1} \mathrm{H}-\mathrm{NMR}\left(\mathrm{CDCl}_{3}, 400 \mathrm{MHz}\right): \delta(\mathrm{ppm}): 8.59-8.57$ $(\mathrm{m}, 2 \mathrm{H}), 7.69(\mathrm{dt}, J=8.0,2.0 \mathrm{~Hz}, 1 \mathrm{H}), 7.33-7.30(\mathrm{~m}, 1 \mathrm{H}), 3.63(\mathrm{~s}, 3 \mathrm{H}), 3.23(\mathrm{~s}, 3 \mathrm{H}) ;{ }^{13} \mathrm{C}-\mathrm{NMR}\left(\mathrm{CDCl}_{3}\right.$, $100 \mathrm{MHz}): \delta$ (ppm):197.59, 149.63, 146.19, 133.70, 123.18, 44.25, 43.37. GC-MS (EI) $m / z$ (\%) 166.05 (85, $\left.\mathrm{M}^{+}\right), 165.05$ (88), 149.10 (35), 122.00 (100), 106.05 (38), 78.00 (62).

$\mathrm{N}, \mathrm{N}$-Dimethyl-5-(quinolin-2-yl) thiophene-2-carbothioamide (3v). ${ }^{1} \mathrm{H}-\mathrm{NMR}\left(\mathrm{CDCl}_{3}, 400 \mathrm{MHz}\right): \delta(\mathrm{ppm})$ : $8.15(\mathrm{~d}, J=8 \mathrm{~Hz}, 1 \mathrm{H}), 8.08(\mathrm{~d}, J=8 \mathrm{~Hz}, 1 \mathrm{H}), 7.78(\mathrm{t}, J=8 \mathrm{~Hz}, 2 \mathrm{H}), 7.74-7.69(\mathrm{~m}, 1 \mathrm{H}), 7.59(\mathrm{~d}, J=4 \mathrm{~Hz}$, $1 \mathrm{H}), 7.54-7.49(\mathrm{~m}, 1 \mathrm{H}), 7.19(\mathrm{~d}, J=4 \mathrm{~Hz}, 1 \mathrm{H}), 3.56(\mathrm{~d}, J=40 \mathrm{~Hz}, 6 \mathrm{H}) ;{ }^{13} \mathrm{C}-\mathrm{NMR}\left(\mathrm{CDCl}_{3}, 100 \mathrm{MHz}\right)$ : $\delta$ (ppm): 191.56, 151.54, 148.18, 148.08, 146.86, 136.77, 130.01, 129.37, 127.82, 127.53, 127.40, 126.49, $124.94,117.42,44.54$. HRMS (ESI) $m / z$ calculated (calcd.) for $\mathrm{C}_{16} \mathrm{H}_{15} \mathrm{~N}_{2} \mathrm{~S}_{2}{ }^{+}(\mathrm{M}+\mathrm{H})^{+} 299.06712$, found 299.06706.

\section{Conclusions}

In conclusion, we have demonstrated an efficient and transitional-metal-free method for the synthesis of aryl thioamides derived from aryl aldehydes using thiourea as a sulfur source in the presence of potassium persulfate, in DMF or DMAC. This strategy has the advantages of good functional-group tolerance and gives moderate to good yields of desired products. Further studies on synthetic applications are currently under way.

Supplementary Materials: The following are available online at http://www.mdpi.com/1420-3049/23/9/2225/ s1, Table S1: Screening of various solvents, Figure S1: Three control experiments for mechanism study, 1H-NMR, 13C-NMR, and MS spectrum of 3a-w.

Author Contributions: X.Q. conceived and designed the experiments; Y.B. performed the experiments; Y.C. contributed reagents/materials; J.L. and L.L. wrote the paper.

Funding: This work was supported by Scientific and Technological Innovation Programs of Higher Education Institutions in Shanxi (NO. 2015176), the Doctoral Scientific Research Foundation of Jinzhong University (NO. bsjj2015213 and NO. bsjj2015214) and the Construction plan of the '1331 engineering' photoelectric material innovation team of Jinzhong University.

Conflicts of Interest: The authors declare no conflict of interest.

\section{References}

1. Petrov, K.A.; Andreev, L.N. The Chemical Properties of Thioamides. Russ. Chem. Rev. 1971, 40, 505-524. [CrossRef]

2. Cremlyn, R.J. An Introduction to Organo-Sulfur Chemistry; Wiley \& Sons: New York, NY, USA, 1996.

3. Jiang, W.; Li, Y.; Wang, Z. Heteroarenes as high performance organic semiconductors. Chem. Soc. Rev. 2013, 42, 6113-6127. [CrossRef] [PubMed]

4. Jagodziński, T.S. Thioamides as Useful Synthons in the Synthesis of Heterocycles. Chem. Rev. 2003, 103, 197-228. [CrossRef] [PubMed]

5. Lincke, T.; Behnken, S.; Ishida, K.; Roth, M.; Hertweck, C. Closthioamide: An Unprecedented Polythioamide Antibiotic from the Strictly Anaerobic Bacterium Clostridium cellulolyticum. Angew. Chem. Int. Ed. 2010, 49, 2011-2013. [CrossRef] [PubMed]

6. Shen, C.; Zhang, P.F.; Sun, Q.; Bai, S.Q.; Andy Hor, T.S.; Liu, X.G. Recent advances in C-S bond formation via C-H bond functionalization and decarboxylation. Chem. Soc. Rev. 2015, 44, 291-314. [CrossRef] [PubMed]

7. Anthony, J.E. Functionalized Acenes and Heteroacenes for Organic Electronics. Chem. Rev. 2006, 106, 5028-5048. [CrossRef] [PubMed] 
8. Ashfaq, M.; Shah, S.S.A.; Najam, T.; Ahmad, M.M.; Tabassum, R.; Rivera, G. Synthetic Thioamide, Benzimidazole, Quinolone and Derivatives with Carboxylic Acid and Ester Moieties: A Strategy in the Design of Antituberculosis Agents. Curr. Med. Chem. 2014, 21, 911-931. [CrossRef] [PubMed]

9. Zoumpoulakis, P.; Camoutsis, C.; Pairas, G.; Sokovic, M.; Glamoclija, J.; Potamitis, C.; Pitsas, A. Synthesis of novel sulfonamide-1,2,4-triazoles, 1,3,4-thiadiazoles and 1,3,4-oxadiazoles, as potential antibacterial and antifungal agents. Biological evaluation and conformational analysis studies. Bioorg. Med. Chem. 2012, 20, 1569-1583. [CrossRef] [PubMed]

10. Guo, W.; Fu, Y.Z. A Perspective on Energy Densities of Rechargeable Li-S Batteries and Alternative Sulfur-Based Cathode Materials. Energy Environ. Mater. 2018, 1, 20-27. [CrossRef]

11. Polshettiwar, V. Phosphorus Pentasulfide $\left(\mathrm{P}_{4} \mathrm{~S}_{10}\right)$. Synlett 2004, 12, 2245-2246. [CrossRef]

12. Ozturk, T.; Ertas, E.; Mert, O. Use of Lawesson's Reagent in Organic Syntheses. Chem. Rev. 2007, 107, 5210-5278. [CrossRef] [PubMed]

13. Vásquez-Céspedes, S.; Ferry, A.; Candish, L.; Glorius, F. Heterogeneously Catalyzed Direct C-H Thiolation of Heteroarenes. Angew. Chem., Int. Ed. 2015, 54, 5772-5776. [CrossRef] [PubMed]

14. Jiao, J.; Wei, L.; Ji, X.M.; Hu, M.L.; Tang, R.Y. Direct Introduction of Dithiocarbamates onto Imidazoheterocycles under Mild Conditions. Adv. Synth. Catal. 2016, 358, 268-275. [CrossRef]

15. Rafique, J.; Saba, S.; Rosário, A.R.; Braga, A.L. Regioselective, Solvent- and Metal-Free Chalcogenation of Imidazo[1,2-a] pyridines by Employing $\mathrm{I}_{2} / \mathrm{DMSO}$ as the Catalytic Oxidation System. Chem. Eur. J. 2016, 22, 11854-11862. [CrossRef] [PubMed]

16. Ding, Q.P.; Cao, B.P.; Yuan, J.J.; Liu, X.J.; Peng, Y.Y. Synthesis of thioethers via metal-free reductive coupling of tosylhydrazones with thiols. Org. Biomol. Chem. 2011, 9, 748-751. [CrossRef] [PubMed]

17. Ravi, C.; Mohan, D.C.; Adimurthy, S. N-Chlorosuccinimide-Promoted Regioselective Sulfenylation of Imidazoheterocycles at Room Temperature. Org. Lett. 2014, 16, 2978-2981. [CrossRef] [PubMed]

18. Hiebel, M.A.; Berteina-Raboin, S. Iodine-catalyzed regioselective sulfenylation of imidazoheterocycles in PEG $_{400}$. Green Chem. 2015, 17, 937-944. [CrossRef]

19. Siddaraju, Y.; Prabhu, K.R. Iodine-Catalyzed Cross Dehydrogenative Coupling Reaction: A Regioselective Sulfenylation of Imidazoheterocycles Using Dimethyl Sulfoxide as an Oxidant. J. Org. Chem. 2016, 81, 7838-7846. [CrossRef] [PubMed]

20. Yang, F.L.; Tian, S.K. Iodine-Catalyzed Regioselective Sulfenylation of Indoles with Sulfonyl Hydrazides. Angew. Chem. Int. Ed. 2013, 52, 4929-4932. [CrossRef] [PubMed]

21. Yang, Y.; Zhang, S.; Tang, L.; Hu, Y.B.; Zha, Z.G.; Wang, Z.Y. Catalyst-free thiolation of indoles with sulfonyl hydrazides for the synthesis of 3-sulfenylindoles in water. Green Chem. 2016, 18, 2609-2613. [CrossRef]

22. Singh, R.; Allam, K.B.; Singh, N.; Kumari, K.; Singh, S.K. A Direct Metal-Free Decarboxylative Sulfono Functionalization (DSF) of Cinnamic Acids to $\alpha, \beta$-Unsaturated Phenyl Sulfones. Org. Lett. 2015, 17, 2656-2659. [CrossRef] [PubMed]

23. Senadi, G.C.; Guo, B.C.; Hu, W.P.; Wang, J.J. Iodine-promoted cyclization of N-propynyl amides and N-allyl amides via sulfonylation and sulfenylation. Chem. Commun. 2016, 52, 11410-11413. [CrossRef] [PubMed]

24. Handa, S.; Fennewald, J.C.; Lipshutz, B.H. Aerobic Oxidation in Nanomicelles of Aryl Alkynes, in Water at Room Temperature. Angew. Chem. Int. Ed. 2014, 53, 3432-3435. [CrossRef] [PubMed]

25. Rao, W.H.; Shi, B.F. Copper(II)-Catalyzed Direct Sulfonylation of C( $\left.\mathrm{sp}^{2}\right)-H$ Bonds with Sodium Sulfinates. Org. Lett. 2015, 17, 2784-2787. [CrossRef] [PubMed]

26. Ding, Y.; Wu, W.; Zhao, W.; Li, Y.; Xie, P.; Huang, Y.; Liu, Y.; Zhou, A. Generation of thioethers via direct C-H functionalization with sodium benzenesulfinate as a sulfur source. Org. Biomol. Chem. 2016, 14, 1428-1431. [CrossRef] [PubMed]

27. Xiao, F.; Chen, S.; Tian, J.; Huang, H.; Liu, Y.; Deng, G.J. Chemoselective cross-coupling reaction of sodium sulfinates with phenols under aqueous conditions. Green Chem. 2016, 18, 1538-1546. [CrossRef]

28. Guo, Y.J.; Lu, S.; Tian, L.L.; Huang, E.L.; Hao, X.Q.; Zhu, X.J.; Shao, T.; Song, M.P. Iodine-Mediated Difunctionalization of Imidazopyridines with Sodium Sulfinates: Synthesis of Sulfones and Sulfides. J. Org. Chem. 2018, 83, 338-349. [CrossRef] [PubMed]

29. Zhou, Z.; Liu, Y.; Chen, J.F.; Yao, E.; Cheng, J. Multicomponent Coupling Reactions of Two $N$-Tosyl Hydrazones and Elemental Sulfur: Selective Denitrogenation Pathway toward Unsymmetric 2,5-Disubstituted 1,3,4-Thiadiazoles. Org. Lett. 2016, 18, 5268-5271. [CrossRef] [PubMed] 
30. Ravi, C.; Reddy, N.N.K.; Pappula, V.; Samanta, S.; Adimurthy, S. Copper-Catalyzed Three-Component System for Arylsulfenylation of Imidazopyridines with Elemental Sulfur. J. Org. Chem. 2016, 81, 9964-9972. [CrossRef] [PubMed]

31. Zhang, J.R.; Liao, Y.Y.; Deng, J.C.; Feng, K.Y.; Zhang, M.; Ning, Y.Y.; Lin, Z.W.; Tang, R.Y. Oxidative dual C-H thiolation of imidazopyridines with ethers or alkanes using elemental sulphur. Chem. Commun. 2017, 53, 7784-7787. [CrossRef] [PubMed]

32. Zhu, X.M.; Yang, Y.Z.; Xiao, G.H.; Song, J.X.; Liang, Y.; Deng, G.B. Double C-S bond formation via C-H bond functionalization: Synthesis of benzothiazoles and naphtho[2,1-d]thiazoles from $N$-substituted arylamines and elemental sulfur. Chem. Commun. 2017, 53, 11917-11920. [CrossRef] [PubMed]

33. Bergman, J. Comparison of Two Reagents for Thionations. Synthesis 2018, 50, 2323-2328. [CrossRef]

34. Hurd, R.N.; Delamater, G. The Preparation and Chemical Properties of Thionamides. Chem. Rev. 1961, 61, 45-86. [CrossRef]

35. Wei, J.P.; Li, Y.M.; Jiang, X.F. Aqueous Compatible Protocol to Both Alkyl and Aryl Thioamide Synthesis. Org. Lett. 2016, 18, 340-343. [CrossRef] [PubMed]

36. Zhou, Z.; Yu, J.T.; Zhou, Y.N.; Jiang, Y.; Cheng, J. Aqueous MCRs of quaternary ammoniums, N-substituted formamides and sodium disulfide towards aryl thioamides. Org. Chem. Front. 2017, 4, 413-416. [CrossRef]

37. Xu, K.; Li, Z.Y.; Cheng, F.Y.; Zuo, Z.Z.; Wang, T.; Wang, M.C.; Liu, L.T. Transition-Metal-Free Cleavage of C-C Triple Bonds in Aromatic Alkynes with $\mathrm{S}_{8}$ and Amides Leading to Aryl Thioamides. Org. Lett. 2018, 20, 2228-2231. [CrossRef] [PubMed]

38. Kumar, S.; Vanjari, R.; Guntreddi, T.; Singh, K.N. Sulfur promoted decarboxylative thioamidation of carboxylic acids using formamides as amine proxy. Tetrahedron 2016, 72, 2012-2017. [CrossRef]

39. Nguyen, T.B.; Tran, M.Q.; Ermolenko, L.; Al-Mourabit, A. Three-Component Reaction between Alkynes, Elemental Sulfur, and Aliphatic Amines: A General, Straightforward, and Atom Economical Approach to Thioamides. Org. Lett. 2014, 16, 310-313. [CrossRef] [PubMed]

40. Rao, M.M.; Jayalakshmi, M.; Reddy, R.S. Time-selective Hydrothermal Synthesis of SnS Nanorods and Nanoparticles by Thiourea Hydrolysis. Chem. Lett. 2004, 33, 1044-1045. [CrossRef]

41. Jayalakshmi, M.; Rao, M.M. Synthesis of zinc sulphide nanoparticles by thiourea hydrolysis and their characterization for electrochemical capacitor applications. J. Power Sources 2006, 157, 624-629. [CrossRef]

42. Zhang, K.; Han, Q.; Wang, X.; Zhu, J. One-Step Synthesis of $\mathrm{Bi}_{2} \mathrm{~S}_{3} / \mathrm{BiOX}$ and $\mathrm{Bi}_{2} \mathrm{~S}_{3} /(\mathrm{BiO})_{2} \mathrm{CO}_{3}$ Heterojunction Photocatalysts by Using Aqueous Thiourea Solution as Both Solvent and Sulfur Source. ChemistrySelect 2016, 1, 6136-6145. [CrossRef]

43. Manivel, P.; Prabakaran, K.; Krishnakumar, V.; Khan, F.N.; Maiyalagan, T. Thiourea-Mediated Regioselective Synthesis of Symmetrical and Unsymmetrical Diversified Thioethers. Ind. Eng. Chem. Res. 2014, 53, 7866-7870. [CrossRef]

44. Niu, H.; Xia, C.; Qu, G.; Wu, S.; Jiang, Y.; Jin, X.; Guo, H. Microwave-Promoted "One-Pot" Synthesis of 4-Nitrobenzylthioinosine Analogues Using Thiourea as a Sulfur Precursor. Chem. Asian J. 2012, 7, 45-49. [CrossRef] [PubMed]

45. Firouzabadi, H.; Iranpoor, N.; Gholinejad, M. One-Pot Thioetherification of Aryl Halides Using Thiourea and Alkyl Bromides Catalyzed by Copper(I) Iodide Free from Foul-Smelling Thiols in Wet Polyethylene Glycol (PEG 200). Adv. Synth. Catal. 2010, 352, 119-124. [CrossRef]

46. Mondal, J.; Modak, A.; Dutta, A.; Basu, S.; Jha, S.N.; Bhattacharyya, D.; Bhaumik, A. One-pot thioetherification of aryl halides with thiourea and benzylbromide in water catalyzed by Cu-grafted furfural imine-functionalized mesoporous SBA-15. Chem. Commun. 2012, 48, 8000-8002. [CrossRef] [PubMed]

47. Ma, X.; Yu, L.; Su, C.; Yang, Y.; Li, H.; Xu, Q. Efficient Generation of C-S Bonds via a By-Product-Promoted Selective Coupling of Alcohols, Organic Halides, and Thiourea. Adv. Synth. Catal. 2017, 359, 1649-1655. [CrossRef]

48. Abbasi, M.; Khalifeh, R. One-pot odourless synthesis of thioesters via in situ generation of thiobenzoic acids using benzoic anhydrides and thiourea. Beilstein J. Org. Chem. 2015, 11, 1265-1273. [CrossRef] [PubMed]

49. Swain, S.P.; Chou, Y.; Hou, D. Thioesterifications Free of Activating Agent and Thiol: A Three-Component Reaction of Carboxylic Acids, Thioureas, and Michael Acceptors. Adv. Synth. Catal. 2015, 357, 2644-2650. [CrossRef] 
50. Bezgubenko, L.V.; Pipko, S.E.; Sinitsa, A.D. Dichlorothiophosphoric acid and dichlorothiophosphate anion as thionating agents in the synthesis of thioamides. Russ. J. Gen. Chem. 2008, 78, 1341-1344. [CrossRef]

51. Meltzer, R.I.; Lewis, A.D.; King, J.A. Antitubercular Substances. IV. Thioamides. J. Am. Chem. Soc. 1955, 77, 4062-4066. [CrossRef]

52. Perregaard, J.; Lawesson, S.O. Studies on Organophosphoous Compounds. XI.* Oxidation of Aromatic Compounds with Sulfur in Hexamethylphosphoric Triamide (HMPA). A New Method for Preparation of N,N-Dimethylthiocarboxamides. Acta Chem. Scand. B 1975, 29, 604-608.

Sample Availability: Sample Availability: Not available.

(C) 2018 by the authors. Licensee MDPI, Basel, Switzerland. This article is an open access article distributed under the terms and conditions of the Creative Commons Attribution (CC BY) license (http:/ / creativecommons.org/licenses/by/4.0/). 
Article

\title{
Asymmetric Primaquine and Halogenaniline Fumardiamides as Novel Biologically Active Michael Acceptors
}

\author{
Zrinka Rajić ${ }^{1, *}$, Maja Beus ${ }^{1}$, Hana Michnová ${ }^{2}$, Josipa Vlainić ${ }^{3}$, Leentje Persoons ${ }^{4}$, \\ Ivan Kosalec ${ }^{1}$, Josef Jampílek ${ }^{2}$, Dominique Schols ${ }^{4}$, Toma Keser ${ }^{1}$ and Branka Zorc ${ }^{1, *}$ \\ 1 Faculty of Pharmacy and Biochemistry, University of Zagreb, A. Kovačića 1, 10000 Zagreb, Croatia; \\ mbeus@pharma.hr (M.B.); ikosalec@pharma.hr (I.K.); tkeser@pharma.hr (T.K.) \\ 2 Department of Pharmaceutical Chemistry, Faculty of Pharmacy, Comenius University, Odbojárov 10, \\ 83232 Bratislava, Slovakia; michnova.hana@gmail.com (H.M.), josef.jampilek@gmail.com (J.J.) \\ 3 Laboratory for Advanced Genomics, Division of Molecular Medicine, Rudjer Bošković Institute, \\ Bijenička cesta 54, 10000 Zagreb, Croatia; josipa.vlainic@irb.hr \\ 4 Laboratory of Virology and Chemotherapy, Rega Institute for Medical Research, KU Leuven, Herestraat 49, \\ 3000 Leuven, Belgium; leentje.persoons@rega.kuleuven.be (L.P.); dominique.schols@rega.kuleuven.be (D.S.) \\ * Correspondence: zrajic@pharma.hr (Z.R.); bzorc@pharma.hr (B.Z.); Tel.: +385-1-48-56-202 (Z.R. \& B.Z.)
}

Academic Editor: Michal Szostak

Received: 3 July 2018; Accepted: 11 July 2018; Published: 14 July 2018

\begin{abstract}
Novel primaquine (PQ) and halogenaniline asymmetric fumardiamides $4 a-f$, potential Michael acceptors, and their reduced analogues succindiamides $\mathbf{5 a}-\mathbf{f}$ were prepared by simple three-step reactions: coupling reaction between PQ and mono-ethyl fumarate (1a) or mono-methyl succinate (1b), hydrolysis of PQ-dicarboxylic acid mono-ester conjugates $\mathbf{2} \mathbf{a}, \mathbf{b}$ to corresponding acids $\mathbf{3} \mathbf{a}, \mathbf{b}$, and a coupling reaction with halogenanilines. 1-[bis(Dimethylamino)methylene]-1H-1,2,3-triazolo[4,5-b]pyridinium 3-oxide hexafluorophosphate (HATU) was used as a coupling reagent along with Hünig's base. Compounds 4 and $\mathbf{5}$ were evaluated against a panel of bacteria, several Mycobacterium strains, fungi, a set of viruses, and nine different human tumor cell lines. $p$-Chlorofumardiamide $4 \mathrm{~d}$ showed significant activity against Staphylococcus aureus, Streptococcus pneumoniae and Acinetobacter baumannii, but also against Candida albicans (minimum inhibitory concentration (MIC) $6.1-12.5 \mu \mathrm{g} / \mathrm{mL}$ ). Together with $p$-fluoro and $p-\mathrm{CF}_{3}$ fumardiamides $\mathbf{4 b}, \mathbf{f}$, compound $\mathbf{4 d}$ showed activity against Mycobacterium marinum and $\mathbf{4 b}, \mathbf{f}$ against M. tuberculosis. In biofilm eradication assay, most of the bacteria, particularly S. aureus, showed susceptibility to fumardiamides. $m-\mathrm{CF}_{3}$ and $m$-chloroaniline fumardiamides $4 \mathbf{e}$ and $4 \mathrm{c}$ showed significant antiviral activity against reovirus-1, sindbis virus and Punta Toro virus $\left(\mathrm{EC}_{50}=3.1-5.5\right.$ $\mu \mathrm{M})$, while $4 \mathbf{e}$ was active against coxsackie virus $\mathrm{B}_{4}\left(\mathrm{EC}_{50}=3.1 \mu \mathrm{M}\right) . m$-Fluoro derivative 4 a exerted significant cytostatic activity $\left(\mathrm{IC}_{50}=5.7-31.2 \mu \mathrm{M}\right)$. Acute lymphoblastic leukemia cells were highly susceptible towards $m$-substituted derivatives $4 \mathbf{a}, \mathbf{c}, \mathbf{e}\left(\mathrm{IC}_{50}=6.7-8.9 \mu \mathrm{M}\right)$. Biological evaluations revealed that fumardiamides 4 were more active than succindiamides 5 indicating importance of Michael conjugated system.
\end{abstract}

Keywords: fumardiamide; primaquine; succindiamide; Michael acceptor; biofilm eradication; antibacterial screening; antiviral activity; cytostatic activity

\section{Introduction}

Compounds bearing $\alpha, \beta$-unsaturated carbonyl groups are Michael acceptors capable of conjugate addition, also known as Michael addition. The simplest and the best Michael acceptors are $\alpha, \beta$-unsaturated carbonyl compounds with exposed unsaturated $\beta$-carbon atoms, such as 
exomethylene ketones and lactones or vinyl ketones [1]. These fragments are often used in the design of new anticancer drugs, together with others (6-methylhept-5-ene-1,4-dione, propiolamide, 4-(dimethylamino)but-2-enamide) (Figure 1). They assure the irreversible covalent binding to a cysteine residue of a specific protein and may modulate selectivity and potency of the drug candidate. The targeted covalent modification has emerged as a validated approach to drug discovery with the drug candidate canertinib [2], approved drugs afatinib, neratinib and osimertinib (inhibitors of human epidermal growth factor receptors) and ibrutinib (Bruton's tyrosine kinase inhibitor) [3,4]. A comprehensive review published by Jackson et al. gives an overview of biological activity and applicability of various Michael acceptors [5].

Michael acceptors have been explored in a prodrug strategy for cancer cell-specific targeting. In the review published by Zhang et al., two doxorubicin prodrugs with maleimide moieties have been described [6]. The maleimide component is responsible for the binding to human serum albumin. Once the drug carrier arrives at the targeted cancer tissue, doxorubicin is released from the carrier by the cleavage of hydrazone or glycosidic bond in the acidic environment of cancer cells. The prodrugs demonstrate superior anticancer efficacy than the parent drug.

Michael acceptors are present in other classes of drugs. Examples of such drugs are entacapone (antiparkinsonic) [7], dimethyl fumarate (antipsoriatic; since 2013 used in treatment of multiple sclerosis) [5], rupintivir (experimental antiviral drug against human rhinoviruses) [8], exemestane (cytostatic) [9], and ethacrynic acid (diuretic) [10].

$\alpha, \beta$-Unsaturated carbonyl group is also a motif found in plant and microbial metabolites and their semisynthetic/synthetic derivatives. Many of them are used in clinical practice or are still under the evaluation in clinical trials (vernolepin, helenalin, curcumin, pyrrocidine, fumaric and angelic acid derivatives), but some are classified as toxins [11]. Vernolepin and helenalin are sesquiterpenes with exomethylene lactones responsible for irreversible DNA polymerase inhibition. Pyrrocidine A is a 13-membered macrocyclic alkaloid produced by endophytic fungi, which directly binds to $\mathrm{N}$-acetyl-L-cysteine methyl ester through the Michael-type addition and exerts both antimicrobial and cytostatic effect on leukemia HL60 cells [12]. Angelic acid ester ingenol mebutate has been identified as the most active component of Euphorbia peplus L. latex sap, effective against human nonmelanoma skin cancer [13] and actinic keratosis [14]. A gel formulation of ingenol mebutate has been recently approved for the treatment of actinic keratosis [15] and fumaric acid esters are used for the management of psoriasis $[16,17]$. Curcumin is a symmetric $\alpha, \beta$-unsaturated $\beta$-diketone extracted from Curcuma longa L., a tropical Southeast Asian plant used as a spice and in traditional Indian medicine [18]. Currently, there are 17 open clinical trials involving curcumin, of which mainly evaluate the combination of curcumin with other substances used in anticancer therapy [19].

In this paper, we report design and preparation of novel Michael acceptors, fumaric acid diamides 4a-f. We have chosen $\alpha, \beta$-unsaturated amides because they are less electrophilic than analogous esters and better Michael acceptors [1]. Based on our previous findings [20,21], one of the amide bonds was achieved with a terminal amino group of primaquine $(\mathrm{PQ})$, while the other with halogenanilines (Figure 1). Sharing the same conjugated $\mathrm{C}=\mathrm{C}-\mathrm{CO}$ system and a benzene ring, our compounds are similar to cinnamic acid (trans-3-phenyl-2-propenoic acid) derivatives as well. Taking literature data into account [22-24] and our previous experience with PQ derivatives [20,21,25-28], we have assumed that the designed compounds have a high pharmacological potential. Here we report their synthesis, evaluation of antimicrobial activity on a wide spectrum of bacteria, fungi and viruses, their biofilm eradication ability, and finally, cytostatic activity against several human tumor cell lines. 


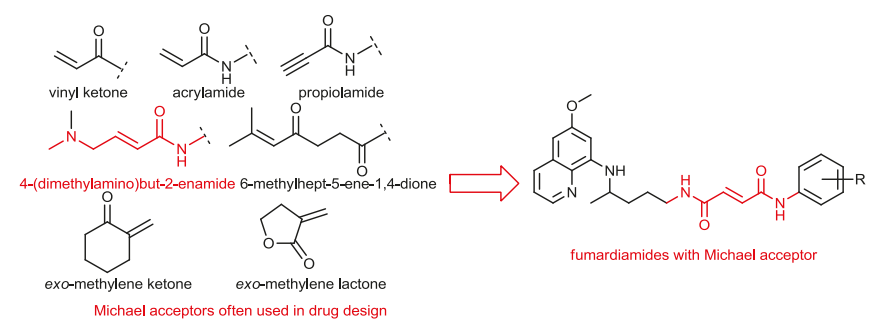

Figure 1. Design of novel fumardiamides.

\section{Results and Discussion}

\subsection{Chemistry}

In this paper, we aimed to prepare and biologically evaluate new Michael acceptors $4 \mathbf{a}-\mathbf{f}$, asymmetric diamides of fumaric acid. To prove the significance of the conjugated Michael system for activity, we have also prepared a series of analogous compounds without a double bond, e.g., a series of succindiamides $\mathbf{5 a}-\mathbf{f}$ (compound $\mathbf{5 a}$ is a reduced derivative of $\mathbf{4 a}, \mathbf{5 b}$ of $\mathbf{4 b}$ etc.). In both series of compounds, one of the amide bonds was achieved with the primary amino group of PQ and the other one with a selected halogenaniline. In the first reaction step, mono-ethyl fumarate (1a) and mono-methyl succinate (1) $\mathbf{1})$ were coupled with PQ to give derivatives $\mathbf{2 a}, \mathbf{b}$ using 1-[bis(dimethylamino)methylene]-1H-1,2,3-triazolo[4,5-b]pyridinium 3-oxide hexafluorophosphate (HATU) as a coupling reagent, along with $N, N$-diisopropylethylamine (DIEA) [29]. However, the transformation of 1a to carboxylic acid chloride and amidation with PQ gave better yields of product $\mathbf{2} \mathbf{a}$. Hydrolysis of $\mathbf{2} \mathbf{a}, \mathbf{b}$ by lithium hydroxide afforded the corresponding acids $\mathbf{3 a}, \mathbf{b}$, which were again coupled with halogenanilines in the presence of HATU/DIEA. The following anilines were used: 3-fluoroaniline, 4-fluoroaniline, 3-chloroaniline, 4-chloroaniline, 3-trifluoromethylaniline and 4-trifluoromethylaniline. Scheme 1 shows the synthetic pathway leading to compounds 4 and 5 .

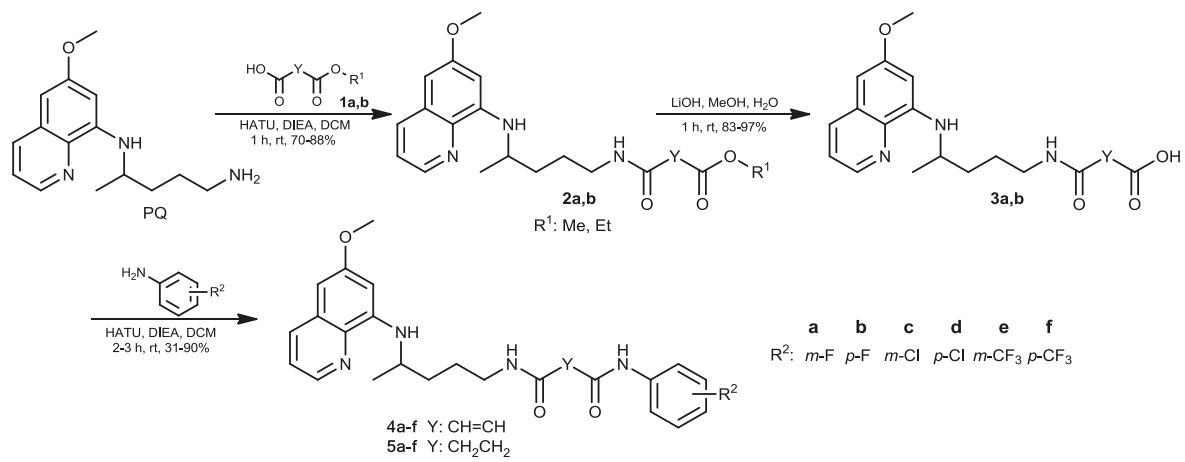

Scheme 1. Synthesis of fumardiamides $\mathbf{4 a}-\mathbf{f}$ and succindiamides $\mathbf{5 a}-\mathbf{f}$.

New compounds are fully characterized by MS, IR, ${ }^{1} \mathrm{H}$ and ${ }^{13} \mathrm{C}$ NMR spectroscopic methods and elemental analyses. Spectral data are consistent with the proposed structures and are given in short in the Materials and Methods and in detail in the Supplementary Material. The presence of carbonyl functional groups in compounds 4 and 5 was indicated by the appearance of strong stretching vibration bands in IR spectra between $v 1677$ and 1628 (amide I) and 1555 and $1515 \mathrm{~cm}^{-1}$ (amide II). PQ residue showed characteristic signals in ${ }^{1} \mathrm{H}$ NMR spectra: hydrogen atom $\mathrm{CH}-15$ occurred between $\delta 8.52$ and 8.55 , methoxy group at $\delta 3.82$, the hydrogen attached to chiral carbon 
$(\mathrm{CH}-10)$ as a multiplet at $\delta 3.57-3.65$, a methyl group at $\delta 1.19-1.22$. NH-1 appeared as a singlet between $\delta 9.98$ and 10.75 ppm, NH-6 as a triplet at $\delta 7.86-8.55$, while NH-12 as a doublet at $\delta 6.11-6.15 \mathrm{ppm}$. ${ }^{13} \mathrm{C}$ spectra showed characteristic PQ signals at $\delta 54.92-54.98$ (methoxy group), 46.19-47.02 (C-10), 38.46-39.23 (C-7), 33.37-33.45 (C-9), 25.70-25.99 (C-8), 20.14-20.21 (C-11) ppm and corresponding signals in aromatic region. Two signals of carbonyl groups in fumardiamides $4 \mathbf{a}-\mathbf{f}$ appeared between 161.17 and $163.34 \mathrm{ppm}$, while in succindiamides $5 \mathbf{a}-\mathbf{f}$ between 170.35 and $171.18 \mathrm{ppm}$. The other two succinic acid carbons (C-3 and C-4) appeared in the aliphatic region between 30.10 and 31.75, and fumaric acid carbons connected by double bond were located very high between 132.11 and 134.66 ppm. $\mathrm{CF}_{3}$ groups in compounds $4 \mathbf{e}, \mathbf{4 f}, \mathbf{5 e}$ and $\mathbf{5 f}$ showed characteristic quartets at 121.32-127.05 with average $J=272 \mathrm{~Hz}$, and the closest C-atom to trifluoromethyl quartets at 124-129 ppm with $J=31 \mathrm{~Hz}$. $m$-Fluorophenyl derivatives $4 \mathbf{a}$ and 5 a showed doublets at $162 \mathrm{ppm}$ and $p$-fluorophenyl derivatives $\mathbf{4} \mathbf{b}$ and $\mathbf{5 b}$ doublets at $158 \mathrm{ppm}$ ( $\mathrm{C}$-atom bearing fluorine) with a similar $J$-coupling constant of $240 \mathrm{~Hz}$, while two neighbouring C-atoms appeared at 105-110 ppm (average $J=21 \mathrm{~Hz}$ ). C-atom substituted with chloro atom appeared at $133 \mathrm{ppm}(m-\mathrm{Cl})$ and $127 \mathrm{ppm}(p-\mathrm{Cl})$. Chemical structures of new compounds were also supported by mass spectroscopy. Molecular ion peaks corresponding to expected relative molecular masses were obtained for all compounds.

Diamides 4 and 5 were subjected to in silico analysis to evaluate the diversity of the set of compounds against topological polar surface area (TPSA) calculations and relevant drug-like properties: number of atoms, molecular weight $(\mathrm{MW})$, partition coefficient $(\log P), \mathrm{H}$-bond donor (HBD), H-bond acceptor (HBA) and molecular refractivity (MR). The parameters are calculated with the Chemicalize.org program [30] and presented in Table S1. All compounds are fully in agreement with the Lipinski and Gelovani rules for prospective small molecular drugs ( $M W \leq 500, \log P \leq 5$, number of H-bond donors $\leq 5$, number of H-bond acceptors $\leq 10, \mathrm{TPSA}<140 \AA^{2}$, MR within the range of 40 and $130 \mathrm{~cm}^{3} / \mathrm{mol}$, the number of atoms 20-70), although $4 \mathbf{e}, \mathbf{f}$ and $\mathbf{5 e , f}$ have the highest permitted relative molecular masses.

\subsection{Biological Evaluation}

\subsubsection{Antibacterial and Antifungal Activity}

The antimicrobial screening was assessed against a panel of Gram-positive bacteria (S. pneumoniae MFBF 10373, S. aureus ATCC 6538, methicillin-resistant S. aureus MRSA 63718, SA 630 and SA 3202, E. faecalis ATCC 29212 and three vancomycin-resistant Enterococci VRE 342 B, 365 and 725 B, B. cereus ATCC 11778, and B. subtilis ATCC 6633), Gram-negative species (P. aeruginosa ATCC 27853, E. coli ATCC 10536, S. marcescens ATCC 10905, P. mirabilis MFBF 10430, A. baumannii MFBF 10913, and S. enteritidis MFBF 11945), four Mycobacterium strains (M. tuberculosis H37Ra, M. smegmatis ATCC 700084, M. kansasii DSM 44162, and M. marinum CAMP 5644) and fungi (two strains of C. albicans ATCC 90028 and CCM 8361, C. krusei CCM 8271, C. parapsilosis CCM 8260 and A. brasiliensis ATCC 16404). The results of the antimicrobial screening of fumardiamides $\mathbf{4} \mathbf{a}-\mathbf{f}$ are presented in Table 1 (the results for inactive fumardiamides and succindiamides $\mathbf{5} \mathbf{a}-\mathbf{f}$ are not shown). In general, Gram-positive bacteria, especially S. pneumoniae and S. aureus ATCC 6538 were susceptible to $\mathbf{4 b} \mathbf{b}-\mathbf{f}$. Compounds $\mathbf{4 a}, \mathbf{b}$ were active against B. cereus as well. However, Gram-negative bacterium A. baumannii was the most susceptible among all tested microorganisms: all compounds, except $m$-fluoro derivative 4 a, showed selective antimicrobial activity against this bacterium strain. Comparison of meta and para derivatives, e.g., a vs. b, c vs. d, e vs. $\mathbf{f}$ revealed that in the most cases $p$-substituted derivatives were more active than the analogous $m$-derivatives. $p$-Chlorofumardiamide $4 \mathbf{d}$ showed significant activity against three bacterial strains (S. aureus, S. pneumoniae and A. baumannii), but also against C. albicans ATCC 90028, with minimum inhibitory concentration (MIC) values ranging from 6.1 to $12.5 \mu \mathrm{g} / \mathrm{mL}$. This compound, together with $p$-fluoro and $p-\mathrm{CF}_{3}$ fumardiamides $4 \mathbf{b}$, $\mathbf{f}$ showed antitubercular activity against $M$. marinum, while $4 \mathbf{b}, \mathbf{f}$ were active against $M$. tuberculosis as well. 


\subsubsection{Biofilm Eradication Assay}

We tested the susceptibility of different bacterial and yeast strains to fumardiamides $4 \mathbf{a}-\mathbf{f}$ and succindiamides $\mathbf{5 a}-\mathbf{f}$ by determining minimum biofilm eradication concentrations (MBECs). The results are presented in Table 2. Again, fumardiamides 4 were much more active than the analogous succindiamides 5 . The most active compounds were $4 \mathrm{a}$ and $\mathbf{4 b}$. Two microorganisms, namely E. faecalis and S. aureus showed high susceptibility to all fumardiamides, while E. coli, S. pneumoniae and $P$. aeruginosa were susceptible to five out of six fumardiamides. A high biofilm eradication potential of fumardiamides might be explained by the reaction of Michael acceptors with cysteine thiol, which could prevent disulfide bond formation. It is a well-known fact that cysteine homeostasis impacts biofilm formation and production of extracellular matrix components, as well as folding and stability of extracytoplasmic proteins [31]. They are also crucial for dental plaque formation, autolysis, extracellular DNA release, genetic competence, bacteriocin production and stabilization of outer membrane porin proteins [32].

\subsubsection{Antiviral Evaluation}

Compounds $\mathbf{4} \mathbf{a}-\mathbf{f}$ and $\mathbf{5} \mathbf{a}-\mathbf{f}$ were evaluated against a broad variety of viral infections including herpes simplex viruses, vaccinia virus, adenovirus-2, human coronavirus (229E), vesicular stomatitis virus, coxsackie virus $B 4$, respiratory syncytial virus, para-influenza- 3 virus, reovirus- 1 , sindbis virus, coxsackie virus B4, Punta Toro virus and yellow fever virus. Only fumardiamides with $m$-chloro and $m$-trifluoromethyl aniline residues, namely $4 \mathbf{c}$ and $4 \mathbf{e}$, showed significant antiviral activity against reovirus-1, sindbis virus and Punta Toro virus with $\mathrm{EC}_{50}=3.1-5.5 \mu \mathrm{M}\left(\mathrm{EC}_{50}=\right.$ concentration required to reduce virus-induced cytopathogenicity by $50 \%$ ). Compound $4 \mathbf{e}$ was also active against coxsackie virus $\mathrm{B} 4\left(\mathrm{EC}_{50}=3.1 \mu \mathrm{M}\right)$. However, their selectivity index $(\mathrm{SI})$, e.g., minimum cytotoxicity concentration (MCC) and $\mathrm{EC}_{50}$ ratio, was quite low (1.8-3.7). Cytotoxicity and antiviral activity of fumardiamides 4a-f in Vero cell cultures are displayed in Table 3 (data for HEL (human erythroleukemia cell line), Hela (cervical carcinoma cell line) and Madin-Darby Canine Kidney cells (MDCK) cultures are not shown, as well as data for inactive succindiamides $\mathbf{5 a}-\mathbf{f}$ ). 

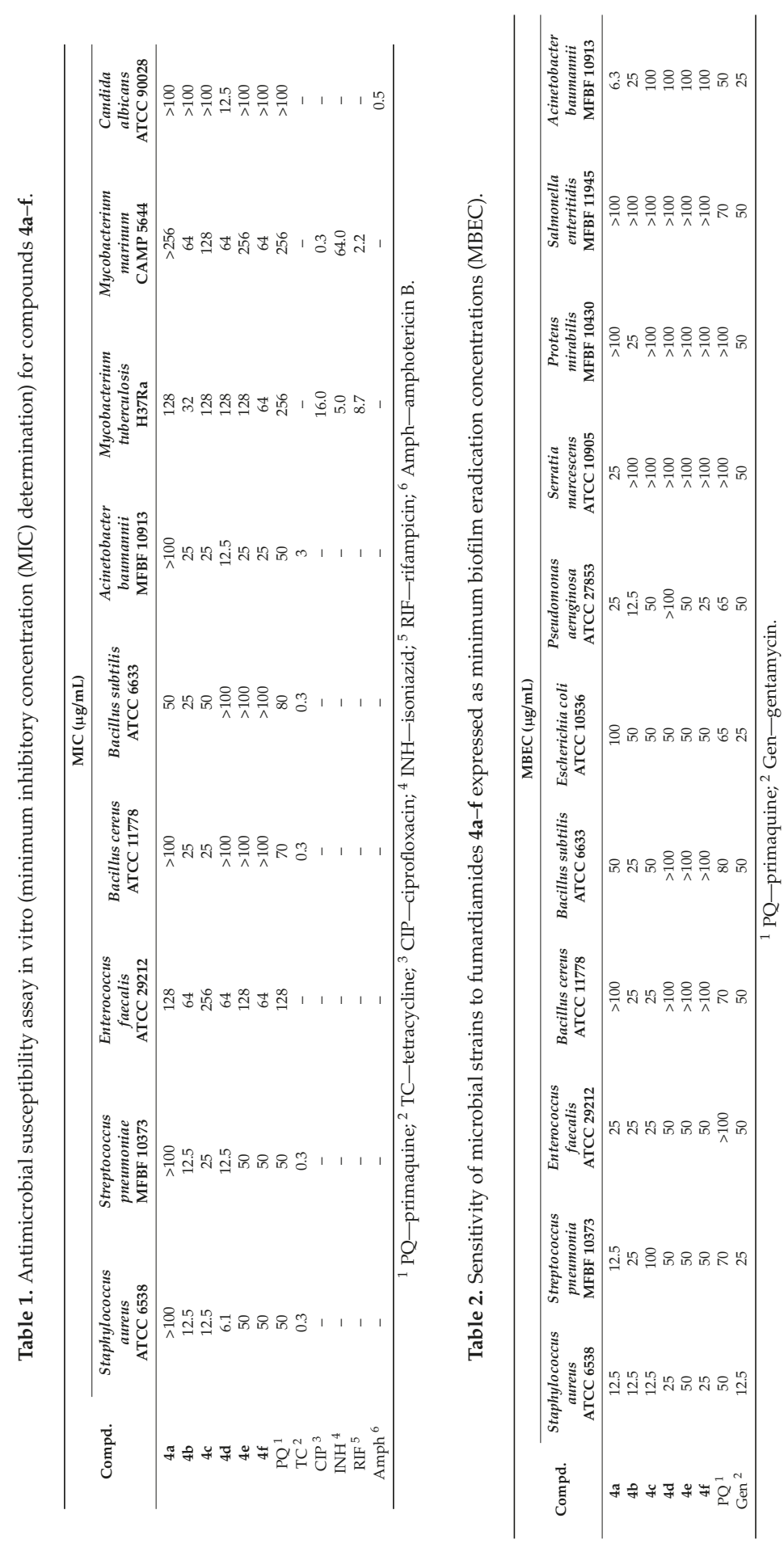
Molecules 2018, 23, 1724

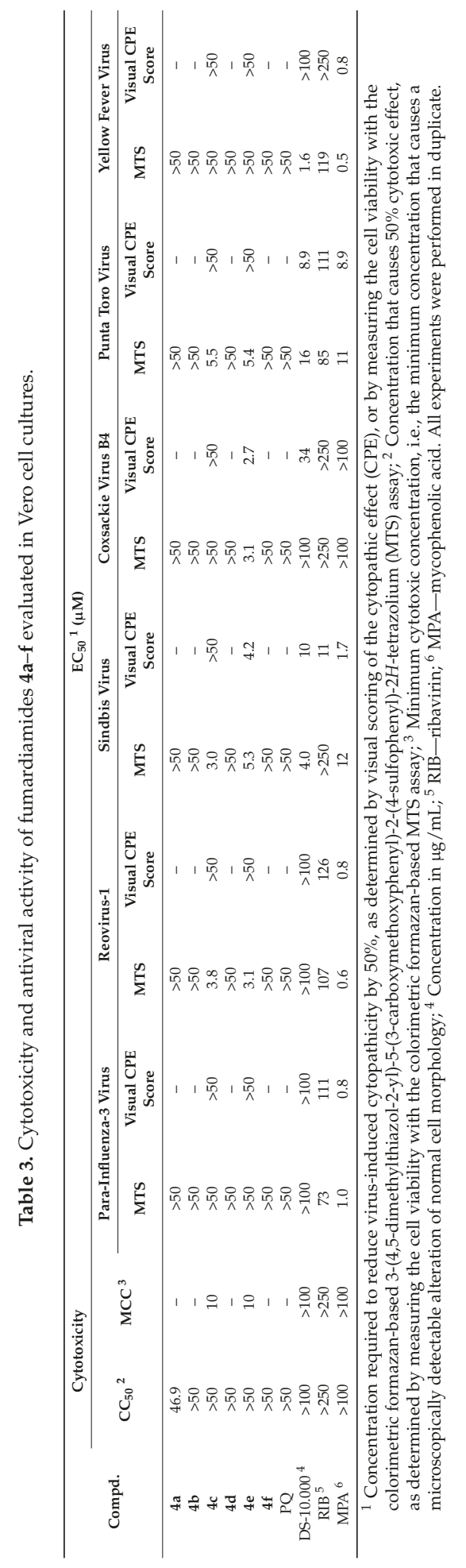




\subsubsection{Cytostatic Activity}

To gain insight into cytotoxicity of newly synthesized compounds $\mathbf{4 a}-\mathbf{f}$ and $\mathbf{5 a}-\mathbf{f}$, their cytostatic activity was evaluated in vitro against a panel of nine different human cancer cell lines, representing various solid tumor types including pancreatic adenocarcinoma (Capan-1), chronic myeloid leukemia (Hap1), colorectal carcinoma (HCT-116), lung carcinoma (NCI-H460), acute lymphoblastic leukemia (DND-41), acute myeloid leukemia (HL-60), chronic myeloid leukemia (K-562), multiple myeloma (MM.1S) and non-Hodgkin lymphoma (Z-138). Succindiamides 5a-f were completely inactive, while free fumardiamides showed activity towards the selected tumor cell lines (Table 4). Fumardiamide $4 \mathbf{a}$ with $m$-fluoroaniline moiety showed cytostatic activity against all tested cell lines, with $\mathrm{IC}_{50}$ values from 5.7 to $31.2 \mu \mathrm{M}\left(\mathrm{IC}_{50}=\right.$ the lowest concentration resulting in $50 \%$ growth inhibition). DND-41 cell line was susceptible to all three $m$-substituted derivatives, e.g., $4 \mathbf{a}, 4 \mathbf{4}$ and $\mathbf{4 f}$ $\left(\mathrm{IC}_{50}\right.$ values between 6.7 and $\left.8.9 \mu \mathrm{M}\right)$. HL-60 and Z-138 cell lines were also susceptible to compound $4 \mathbf{a}$ ( $\mathrm{IC}_{50}$ values 5.7 and $8.4 \mu \mathrm{M}$, respectively).

Table 4. Antiproliferative screening of fumardiamides $4 a-f$ in diverse human tumor cell lines.

\begin{tabular}{|c|c|c|c|c|c|c|c|c|c|}
\hline \multirow{2}{*}{ Compd. } & \multicolumn{9}{|c|}{$\mathrm{IC}_{50}(\mu \mathrm{M})$} \\
\hline & Capan-1 & Hap1 & НСТ-116 & NCI-H460 & DND-41 & HL-60 & K-562 & MM.1S & Z-138 \\
\hline $4 a$ & 16.9 & 19.3 & 22.3 & 15.5 & 6.7 & 5.7 & 31.2 & 13.0 & 8.4 \\
\hline $4 b$ & 50.5 & 66.4 & $>100$ & 29.1 & $>100$ & $>100$ & 70.5 & $>100$ & $>100$ \\
\hline $4 c$ & 69.9 & $>100$ & 73.0 & 43.7 & 8.4 & $>100$ & $>100$ & $>100$ & 46.5 \\
\hline $4 d$ & 91.8 & $>100$ & $>100$ & $>100$ & $>100$ & $>100$ & $>100$ & $>100$ & $>100$ \\
\hline $4 e$ & 56.5 & $>100$ & $>100$ & 34.2 & 8.9 & $>100$ & 71.2 & $>100$ & 68.4 \\
\hline $4 \mathrm{f}$ & 79.4 & $>100$ & $>100$ & $>100$ & $>100$ & $>100$ & $>100$ & $>100$ & $>100$ \\
\hline $\mathrm{PQ}^{1}$ & 18.7 & 42.7 & 30.9 & 52.6 & 11.4 & 2.2 & 35.2 & 28.3 & 7.1 \\
\hline $\mathrm{DXT}^{2}$ & 0.75 & 1.17 & 7.66 & 1.30 & 0.94 & 1.24 & 1.22 & 3.38 & 5.42 \\
\hline $\mathrm{EPEG}^{3}$ & 0.15 & 0.04 & 1.35 & 0.09 & 0.03 & 0.03 & 0.01 & 0.97 & 0.02 \\
\hline STS $^{4}$ & 0.66 & 3.56 & 0.78 & 1.66 & 6.96 & 13.10 & 0.23 & 1.61 & 0.40 \\
\hline
\end{tabular}

\subsubsection{Interaction with Glutathione (GSH)}

Glutathione (GSH) is an important compound present in most mammalian cells, a tripeptide, with the central amino acid cysteine bearing thiol group, which scavenges carcinogenic compounds by conjugate addition and protects from oxidative damage [1]. In the drug development process, it is usual to evaluate the Michael acceptor-GSH interaction [33]. That is why the final step in our research was to study the interaction of fumarmides with GSH. Fumardiamide $4 \mathrm{~b}(1.25 \mu \mathrm{M})$ was incubated with GSH $(125 \mu \mathrm{M})$ in ammonium formate buffer $(\mathrm{pH}=7.4)$ containing $10 \%$ acetonitrile at $37^{\circ} \mathrm{C}$ for $216 \mathrm{~h}$. The MS analysis confirmed the consumption of $4 \mathbf{b}$ with GSH. However, the rate of GSH addition was slow and incomplete, as only $18.3 \%$ of $\mathbf{4 b}$ reacted in the monitored period (See Supporting Material).

\section{Materials and Methods}

\subsection{Chemistry}

\subsubsection{Materials and General Methods}

Melting points were determined on an SMP3 apparatus (Barloworld Scientific, UK) in open capillaries and were uncorrected. IR spectra were recorded on Spectrum One FT-IR (Perkin-Elmer, UK) and UV-Vis spectra on Lambda 20 double-beam spectrophotometers (Perkin-Elmer, UK). NMR ${ }^{1} \mathrm{H}$ and ${ }^{13} \mathrm{C}$ spectra were recorded at $25{ }^{\circ} \mathrm{C}$ on an NMR Avance 600 spectrometer (Bruker, Germany) at 300.13 or 600.13 and 75.47 or $150.9 \mathrm{MHz}$ for ${ }^{1} \mathrm{H}$ and ${ }^{13} \mathrm{C}$ nuclei, respectively. Chemical shifts $(\delta)$ were reported in parts per million (ppm) relative to tetramethylsilane in the ${ }^{1} \mathrm{H}$ and the 
dimethyl sulfoxide residual peak as a reference in the ${ }^{13} \mathrm{C}$ NMR spectra (39.51 ppm). Coupling constants $(J)$ were reported in hertz $(\mathrm{Hz})$. Mass spectra were collected on an HPLC-MS/MS instrument (HPLC, Agilent Technologies 1200 Series; MS, Agilent Technologies 6410 Triple Quad) using electrospray ionization in positive mode. Elemental analyses were performed on a CHNS LECO analyzer (LECO Corporation, USA). All compounds were routinely checked by thin-layer chromatography (TLC) with Merck silica gel 60F-254 glass plates using appropriate solvent systems. Spots were visualized by short-wave UV light and iodine vapour. Column chromatography was performed on silica gel $0.063-0.200 \mathrm{~mm}$. All chemicals and solvents were of analytical grade and purchased from commercial sources. PQ diphosphate, 4-methoxy-4-oxobutanoic acid (mono-methyl succinate), (E)-4-ethoxy-4-oxobut-2-enoic acid (mono-ethyl fumarate), 3-fluoroaniline, 4-fluoroaniline, 3-chloroaniline, 4-chloroaniline, 3-trifluoromethylaniline, 4-trifluoromethylaniline, DIEA, and HATU were purchased from Sigma-Aldrich. PQ was prepared from PQ diphosphate prior to use. All reactions with $P Q$ were run light protected.

\subsubsection{General Procedure for the Synthesis of Esters 2a, $\mathbf{b}$}

PQ-succinamide and fumaramide monoesters $\mathbf{2} \mathbf{a}, \mathbf{b}$ were prepared by condensation of PQ base with mono-methyl succinate (1a) or mono-ethyl fumarate (1b), following the previously described procedure [29].

\subsubsection{General Procedure for the Synthesis of Carboxylic Acids 3a,b}

Carboxylic acids $\mathbf{3} \mathbf{a}, \mathbf{b}$ were prepared by hydrolysis of esters $\mathbf{2} \mathbf{a}, \mathbf{b}$ with lithium hydroxide following the previously described procedure [29].

\subsubsection{General Procedure for the Synthesis of Fumardiamides $4 \mathbf{a}-\mathbf{f}$ and Succindiamides $\mathbf{5 a}-\mathbf{f}$}

A solution of $0.27 \mathrm{mmol}$ of $3 \mathbf{a}$ or $3 \mathbf{b}, 0.068 \mathrm{~g}(0.54 \mathrm{mmol})$ DIEA and $0.103 \mathrm{~g}(0.27 \mathrm{mmol})$ HATU in $6 \mathrm{~mL}$ of dichloromethane was stirred at room temperature. After $10 \mathrm{~min}, 0.297 \mathrm{mmol}$ of the corresponding halogenaniline was added. The reaction mixture was stirred for $2-3 \mathrm{~h}$ at room temperature, evaporated under reduced pressure, dissolved in $8 \mathrm{~mL}$ ethyl acetate and extracted 3 times with water. The organic layer was dried over sodium sulfate, filtered and evaporated under reduced pressure.

(2E)-N-(3-Fluorophenyl)-N'-\{4-[(6-methoxyquinolin-8-yl)amino]pentyl\}but-2-enediamide (4a). From the reaction of $0.096 \mathrm{~g}$ acid $3 \mathrm{a}$ and $0.033 \mathrm{~g}(0.297 \mathrm{mmol}) 3$-fluoroaniline and after purification by column chromatography (mobile phase dichloromethane/methanol 9.5:0.5) and crystallization from ether, $0.041 \mathrm{~g}(34 \%)$ of $4 \mathbf{a}$ was obtained; $\mathrm{mp} 203-204^{\circ} \mathrm{C}$; IR (ATR): $v_{\max } 3388,3319,3269,3080,2961,2935$, 2866, 1630, 1554, 1520, 1452, 1387, 1334, 1201, 1158, 782, $680 \mathrm{~cm}^{-1} ;{ }^{1} \mathrm{H}$ NMR (DMSO- $\left.d_{6}\right) \delta 10.63(\mathrm{~s}, 1 \mathrm{H})$, 8.55-8.53 (dd, $1 \mathrm{H}, J=1.6,4.2), 8.52(\mathrm{t}, 1 \mathrm{H}, J=5.4), 8.09-8.06(\mathrm{dd}, 1 \mathrm{H}, J=1.5,8.3), 7.69$ (d, $2 \mathrm{H}, J=11.7)$, 7.45-7.41 (m, 1H), 7.39-7.36 (m, 2H), 7.06-7.96 (m, 2H), 6.96-6.92 (m, 1H), $6.47(\mathrm{~d}, 1 \mathrm{H}, J=2.4), 6.28(\mathrm{~d}, 1 \mathrm{H}$, $J=2.4), 6.15(\mathrm{~d}, 1 \mathrm{H}, J=8.8), 3.82(\mathrm{~s}, 3 \mathrm{H}), 3.70-3.61(\mathrm{~m}, 1 \mathrm{H}), 3.24-3.18(\mathrm{~m}, 2 \mathrm{H}), 1.74-1.64,1.63-1.52(2 \mathrm{~m}$, $4 \mathrm{H}), 1.22(\mathrm{~d}, 3 \mathrm{H}, J=6.3) ;{ }^{13} \mathrm{C}$ NMR $\left(\right.$ DMSO- $\left._{6}\right) \delta 163.25,162.62,162.09(\mathrm{~d}, J=242.0), 159.00,144.63$, $144.23,140.50$ (d, $J=11.5), 134.79,134.52,134.40,132.28,130.50$ (d, $J=9.5), 129.57,122.09,115.14,110.28$, $106.13(\mathrm{~d}, J=27.2), 96.14,91.62,54.96,46.97,38.95,33.45,25.77,20.21$; MS/MS m/z $451.1(\mathrm{M}+1)^{+}$; Anal. Calcd. for $\mathrm{C}_{25} \mathrm{H}_{27} \mathrm{FN}_{4} \mathrm{O}_{3}: \mathrm{C}, 66.65 ; \mathrm{H}, 6.04 ; \mathrm{N}, 12.44$. Found: $\mathrm{C}, 66.32 ; \mathrm{H}, 6.30 ; \mathrm{N}, 12.49$.

(2E)-N-(4-Fluorophenyl)-N'-\{4-[(6-methoxyquinolin-8-yl)amino]pentyl\}but-2-enediamide (4b). From the reaction of $0.096 \mathrm{~g}$ acid $3 \mathrm{a}$ and $0.033 \mathrm{~g}(0.297 \mathrm{mmol})$ 4-fluoroaniline and after purification by column chromatography (mobile phase dichloromethane/methanol 9.5:0.5) and crystallization from ether, $0.071 \mathrm{~g}(58 \%)$ of $\mathbf{4 b}$ was obtained; $\mathrm{mp} 226-227^{\circ} \mathrm{C}$; IR (ATR): $v_{\max } 3386,3294,3072,2963,2928,2863,1635$, $1548,1513,1452,1391,1330,1212,1160,1051,973,829,673 \mathrm{~cm}^{-1} ;{ }^{1} \mathrm{H}$ NMR (DMSO- $\left.d_{6}\right) \delta 10.49(\mathrm{~s}, 1 \mathrm{H})$, $8.55-8.53(\mathrm{dd}, 1 \mathrm{H}, J=1.6,4.2), 8.52(\mathrm{t}, 1 \mathrm{H}, J=5.4), 8.09-8.06(\mathrm{dd}, 1 \mathrm{H}, J=1.5,8.3), 7.72-7.68(\mathrm{dd}, 2 \mathrm{H}$, $J=5.0, J=8.9), 7.45-7.41(\mathrm{~m}, 1 \mathrm{H}), 7.18(\mathrm{t}, 2 \mathrm{H}, J=8.8), 7.05-6.93(\mathrm{~m}, 2 \mathrm{H}), 6.47(\mathrm{~d}, 1 \mathrm{H}, J=2.1), 6.28(\mathrm{~d}$, 
$1 \mathrm{H}, J=2.1), 6.15(\mathrm{~d}, 1 \mathrm{H}, J=8.8), 3.82(\mathrm{~s}, 3 \mathrm{H}), 3.69-3.61(\mathrm{~m}, 1 \mathrm{H}), 3.24-3.18(\mathrm{~m}, 2 \mathrm{H}), 1.74-1.64,1.63-1.52$ $(2 \mathrm{~m}, 4 \mathrm{H}), 1.22(\mathrm{~d}, 3 \mathrm{H}, J=6.3) ;{ }^{13} \mathrm{C}$ NMR (DMSO- $\left.d_{6}\right) \delta 163.34,162.21,159.00,158.26(\mathrm{~d}, J=240.0), 144.63$, $144.23,135.22,134.79,134.53,133.98,132.52,129.58,122.09,121.05$ (d, $J=7.6), 115.44(\mathrm{~d}, J=21.9), 96.14$, 91.62, 54.96, 46.97, 38.95, 33.45, 25.79, 20.21; MS/MS m/z 451.1 (M+1) ${ }^{+}$; Anal. Calcd. for $\mathrm{C}_{25} \mathrm{H}_{27} \mathrm{FN}_{4} \mathrm{O}_{3}$ : C, 66.65; H, 6.04; N, 12.44. Found: C, 66.47; H, 6.38; N, 12.35 .

(2E)-N-(3-Chlorophenyl)- $N^{\prime}-\{4-[(6-m e t h o x y q u i n o l i n-8-y l) a m i n o] p e n t y l\} b u t-2-e n e d i a m i d e(4 c)$. From the reaction of $0.096 \mathrm{~g}$ acid $3 \mathrm{a}$ and $0.038 \mathrm{~g}(0.297 \mathrm{mmol}) 3$-chloroaniline and after purification by column chromatography (mobile phase dichloromethane/methanol 9.5:0.5) and crystallization from ether, $0.053 \mathrm{~g}(42 \%)$ of $4 \mathrm{c}$ was obtained; $\mathrm{mp} 187-188^{\circ} \mathrm{C}$; IR (ATR): $v_{\max } 3381,3298,3068,2959,2928,2863$, $1635,1591,1521,1465,1419,1386,1331,1210,1163,976,821,783,670 \mathrm{~cm}^{-1} ;{ }^{1} \mathrm{H}$ NMR (DMSO- $d_{6}$ ) $\delta 10.59(\mathrm{~s}, 1 \mathrm{H}), 8.54-8.53(\mathrm{dd}, 1 \mathrm{H}, J=1.5,4.1), 8.50(\mathrm{t}, 1 \mathrm{H}, J=5.5), 8.08-8.06(\mathrm{dd}, 1 \mathrm{H}, J=1.4,8.2)$, $7.90(\mathrm{~s}, 1 \mathrm{H}), 7.51(\mathrm{~d}, 1 \mathrm{H}, J=8.1), 7.43-7.41(\mathrm{~m}, 1 \mathrm{H}), 7.37(\mathrm{t}, \mathrm{H}, J=8.1), 7.16-7.14(\mathrm{dd}, 1 \mathrm{H}, J=1.2, J=8.0)$, $7.00(\mathrm{q}, 2 \mathrm{H}, J=15.1), 6.47(\mathrm{~d}, 1 \mathrm{H}, J=2.4), 6.28(\mathrm{~d}, 1 \mathrm{H}, J=2.3), 6.14(\mathrm{~d}, 1 \mathrm{H}, J=8.8), 3.82(\mathrm{~s}, 3 \mathrm{H}), 3.67-3.63$ $(\mathrm{m}, 1 \mathrm{H}), 3.23-3.20(\mathrm{~m}, 2 \mathrm{H}), 1.73-1.67,1.63-1.53(2 \mathrm{~m}, 4 \mathrm{H}), 1.22(\mathrm{~d}, 3 \mathrm{H}, J=6.3) ;{ }^{13} \mathrm{C}$ NMR (DMSO- $\left.d_{6}\right) \delta$ $163.21,162.60,158.97,144.60,144.19,140.19,134.74,134.50,134.41,133.10,132.19,130.48,129.54,123.45$, $122.03,118.74,117.72,96.11,91.63,54.93,46.98,39.23,33.44,25.72,20.18$; MS/MS m/z $467.0(\mathrm{M}+1)^{+}$; Anal. tCalcd. for $\mathrm{C}_{25} \mathrm{H}_{27} \mathrm{ClN}_{4} \mathrm{O}_{3}$ : C, 64.30; H, 5.83; N, 12.00. Found: $\mathrm{C}, 64.21 ; \mathrm{H}, 6.05 ; \mathrm{N}, 11.78$.

(2E)-N-(4-Chlorophenyl)- $N^{\prime}-\{4-[(6-m e t h o x y q u i n o l i n-8-y l)$ amino]pentyl\}but-2-enediamide $(4 d)$. From the reaction of $0.096 \mathrm{~g}$ acid $3 \mathrm{a}$ and $0.038 \mathrm{~g}(0.297 \mathrm{mmol}) 4$-chloroaniline and after purification by column chromatography (mobile phase cyclohexane/ethyl acetate/methanol 3:1:0.5) and crystallization from ether, $0.062 \mathrm{~g}(49 \%)$ of $4 \mathrm{~d}$ was obtained; $\mathrm{mp} 223-226^{\circ} \mathrm{C}$; IR (ATR): $v_{\max } 3381,3289,3071,2959,2931$, 2864, 1640, 1526, 1452, 1388, 1331, 1210, 1163, 1094, 1049, 973, 822, 787, 686, 631, $507 \mathrm{~cm}^{-1} ;{ }^{1} \mathrm{H}$ NMR $\left(\right.$ DMSO- $\left.d_{6}\right) \delta 10.56(\mathrm{~s}, 1 \mathrm{H}), 8.55-8.53(\mathrm{dd}, 1 \mathrm{H}, J=1.7,4.2), 8.50(\mathrm{t}, 1 \mathrm{H}, J=5.6), 8.09-8.06(\mathrm{dd}, 1 \mathrm{H}, J=1.6$, 8.3), 7.72-7.68 (m, 2H), 7.45-7.37 (m, 3H), 7.06-6.94 (m, 2H), $6.47(\mathrm{~d}, 1 \mathrm{H}, J=2.5), 6.27(\mathrm{~d}, 1 \mathrm{H}, J=2.4)$, $6.14(\mathrm{~d}, 1 \mathrm{H}, J=8.8), 3.82(\mathrm{~s}, 3 \mathrm{H}), 3.69-3.60(\mathrm{~m}, 1 \mathrm{H}), 3.24-3.18(\mathrm{~m}, 2 \mathrm{H}), 1.74-1.64,1.63-1.51(2 \mathrm{~m}, 4 \mathrm{H})$, $1.22(\mathrm{~d}, 3 \mathrm{H}, J=6.3) ;{ }^{13} \mathrm{C}$ NMR (DMSO- $\left.d_{6}\right) \delta 163.29,162.43,159.00,144.63,144.23,137.76,134.79,134.52$, 134.21, 132.38, 129.57, 128.75, 127.36, 122.09, 120.84, 96.14, 91.61, 54.96, 46.97, 38.82, 33.44, 25.77, 20.21; MS/MS m/z 467.0 (M+1) ${ }^{+}$; Anal. Calcd. for $\mathrm{C}_{25} \mathrm{H}_{27} \mathrm{ClN}_{4} \mathrm{O}_{3}: \mathrm{C}, 64.30 ; \mathrm{H}, 5.83 ; \mathrm{N}, 12.00$. Found: $\mathrm{C}, 64.21$; $\mathrm{H}, 5.56 ; \mathrm{N}, 11.83$.

(2E)- $N^{\prime}-\{4-[(6-M e t h o x y q u i n o l i n-8-y l) a m i n o] p e n t y l\}-N-[3-(t r i f l u o r o m e t h y l) p h e n y l] b u t-2-e n e d i a m i d e \quad(4 e)$. From the reaction of $0.096 \mathrm{~g}$ acid $3 \mathrm{a}$ and $0.048 \mathrm{~g}(0.297 \mathrm{mmol})$ 3-trifluoroaniline and after purification by column chromatography (mobile phase dichloromethane/methanol 9.5:0.5) after crystallization from acetone/water, $0.042 \mathrm{~g}$ (31\%) of $4 \mathbf{e}$ was obtained; $\mathrm{mp} 149-150{ }^{\circ} \mathrm{C}$; IR (ATR): $v_{\max } 3399,3357$, 3282, 3094, 2960, 2935, 2867, 1651, 1621, 1563, 1526, 1452, 1388, 1331, 1168, 1122, 973, 893, 788, 694 $\mathrm{cm}^{-1} ;{ }^{1} \mathrm{H}$ NMR (DMSO- $\left.d_{6}\right) \delta 10.75(\mathrm{~s}, 1 \mathrm{H}), 8.55-8.52(\mathrm{~m}, 2 \mathrm{H}), 8.18(\mathrm{~s}, 1 \mathrm{H}), 8.08-8.06(\mathrm{dd}, 1 \mathrm{H}, J=1.1$, 8.2), $7.83(\mathrm{~d}, 1 \mathrm{H}), 7.59(\mathrm{t}, 1 \mathrm{H}, J=7.9), 7.45-7.42(\mathrm{~m}, 2 \mathrm{H}), 7.00-6.98(\mathrm{q}, 2 \mathrm{H}, J=15.1), 6.47(\mathrm{~d}, 1 \mathrm{H}, J$ $=2.4), 6.28(\mathrm{~d}, 1 \mathrm{H}, J=2.0), 6.15(\mathrm{~d}, 1 \mathrm{H}, J=8.7), 3.82(\mathrm{~s}, 3 \mathrm{H}), 3.67-3.63(\mathrm{~m}, 1 \mathrm{H}), 3.23-3.20(\mathrm{~m}, 2 \mathrm{H})$, $1.73-1.67,1.63-1.53(2 \mathrm{~m}, 4 \mathrm{H}), 1.22(\mathrm{~d}, 3 \mathrm{H}, J=6.3) ;{ }^{13} \mathrm{C}$ NMR $\left(\mathrm{DMSO}-d_{6}\right) \delta 163.19,162.81,158.99,144.62$, $144.21,139.54,134.77,134.55,134.52,132.15,130.09,129.56,129.82-129.19$ (q, $J=31.7), 126.73-121.32$ (q, $J=273.3), 122.88,122.07,120.09,115.33,96.13,91.62,54.95,46.19,39.23,33.45,25.76,20.20 ;$ MS $/$ MS m/z 501.1 (M+1) ${ }^{+}$; Anal. Calcd. for $\mathrm{C}_{26} \mathrm{H}_{27} \mathrm{~F}_{3} \mathrm{~N}_{4} \mathrm{O}_{3}: \mathrm{C}, 62.39 ; \mathrm{H}, 5.44 ; \mathrm{N}, 11.19$. Found: C, 62.25; H, 5.76; $\mathrm{N}, 11.08$.

(2E)- $N^{\prime}-\{4-[(6-M e t h o x y q u i n o l i n-8-y l) a m i n o] p e n t y l\}-N-[4-(t r i f l u o r o m e t h y l) p h e n y l] b u t-2-e n e d i a m i d e \quad(4 f)$. From the reaction of $0.096 \mathrm{~g}$ acid $3 \mathrm{a}$ and $0.048 \mathrm{~g}(0.297 \mathrm{mmol})$ 4-trifluoroaniline and after crystallization from ether, $0.046 \mathrm{~g}(34 \%)$ of $\mathbf{4 f}$ was obtained; $\mathrm{mp} 189-191^{\circ} \mathrm{C}$; IR (ATR): $v_{\max } 3387,3309,3071,2963$, 2932, 1636, 1527, 1457, 1417, 1390, 1328, 1213, 1166, 1122, 1065, 970, 832, $681 \mathrm{~cm}^{-1} ;{ }^{1} \mathrm{H}$ NMR (DMSO- $d_{6}$ ) $\delta 10.75(\mathrm{~s}, 1 \mathrm{H}), 8.54-8.53(\mathrm{~m}, 1 \mathrm{H}), 8.51(\mathrm{t}, 1 \mathrm{H}, J=5.3), 8.07(\mathrm{~d}, 1 \mathrm{H}, J=8.2), 7.88(\mathrm{~d}, 2 \mathrm{H}, J=8.5)$, $7.71(\mathrm{~d}, 2 \mathrm{H}, J=8.5), 7.43-7.41(\mathrm{~m}, 1 \mathrm{H}), 7.07-6.99(\mathrm{q}, 2 \mathrm{H}, J=15.1), 6.47(\mathrm{~d}, 1 \mathrm{H}, J=2.2), 6.28(\mathrm{~d}, 1 \mathrm{H}$, 
$J=2.2), 6.14(\mathrm{~d}, 1 \mathrm{H}, J=8.7), 3.82(\mathrm{~s}, 3 \mathrm{H}), 3.67-3.63(\mathrm{~m}, 1 \mathrm{H}), 3.23-3.20(\mathrm{dd}, 2 \mathrm{H}, J=6.1,12.1), 2.59(\mathrm{t}, 2 \mathrm{H}$, $J=7.0), 1.73-1.67,1.61-1.53(2 \mathrm{~m}, 4 \mathrm{H}), 1.22(\mathrm{~d}, 3 \mathrm{H}, J=6.3) ;{ }^{13} \mathrm{C}$ NMR $\left(\mathrm{DMSO}-d_{6}\right) \delta 161.17,162.83,158.97$, $144.60,144.17,142.28,134.72,134.66,134.50,132.11,129.53,126.95-121.55(q, J=271.6), 126.11-126.04$ (q, $J=3.0), 124.02-123.39$ (q, $J=31.7), 122.02,119.26,96.10,91.63,54.92,46.96,38.80,33.43,25.70,20.17$; MS/MS m/z 501.1 (M+1) ${ }^{+}$; Anal. Calcd. for $\mathrm{C}_{26} \mathrm{H}_{27} \mathrm{~F}_{3} \mathrm{~N}_{4} \mathrm{O}_{3}$ : C, 62.39; $\mathrm{H}, 5.44 ; \mathrm{N}, 11.19$. Found: $\mathrm{C}, 62.17$; $\mathrm{H}, 5.61 ; \mathrm{N}, 11.40$.

$N$-(3-Fluorophenyl)- $N^{\prime}-\{4-[(6-m e t h o x y q u i n o l i n-8-y l) a m i n o] p e n t y l\} b u t a n e d i a m i d e(5 a)$. From the reaction of $0.097 \mathrm{~g}$ acid $3 \mathbf{b}$ and $0.033 \mathrm{~g}(0.297 \mathrm{mmol}) 3$-fluoroaniline and after purification by column chromatography (mobile phase dichloromethane/methanol 9.5:0.5), $0.077 \mathrm{~g}(63 \%)$ of $5 \mathbf{a}$ was obtained; mp 140-142 ${ }^{\circ} \mathrm{C}$; IR (ATR): $v_{\max } 3391,3283,3145,3080,2959,2926,1744,1646,1615,1555,1507,1387$, $1224,1202,1167,1157,838,815,786,681 \mathrm{~cm}^{-1} ;{ }^{1} \mathrm{H}$ NMR (DMSO- $\left.d_{6}\right) \delta 10.13(\mathrm{~s}, 1 \mathrm{H}), 8.54-8.53(\mathrm{dd}, 1 \mathrm{H}$, $J=1.7,4.2), 8.08-8.06(\mathrm{dd}, 1 \mathrm{H}, J=1.6,8.3), 7.86(\mathrm{t}, 1 \mathrm{H}, J=5.6), 7.60-7.58(\mathrm{~m}, 1 \mathrm{H}), 7.43-7.41(\mathrm{~m}, 1 \mathrm{H})$, $7.31-7.27(\mathrm{~m}, 2 \mathrm{H}), 6.85-6.81(\mathrm{~m}, 1 \mathrm{H}), 6.47(\mathrm{~d}, 1 \mathrm{H}, J=2.5), 6.26(\mathrm{~d}, 1 \mathrm{H}, J=2.5), 6.11(\mathrm{~d}, 1 \mathrm{H}, J=8.7)$, $3.82(\mathrm{~s}, 3 \mathrm{H}), 3.64-3.59(\mathrm{~m}, 1 \mathrm{H}), 3.10-3.03(\mathrm{~m}, 2 \mathrm{H}), 2.55(\mathrm{t}, 2 \mathrm{H}, J=7.2), 2.37(\mathrm{t}, 2 \mathrm{H}, J=7.2), 1.67-1.63$, $1.55-1.45(2 \mathrm{~m}, 4 \mathrm{H}), 1.19(\mathrm{~d}, 3 \mathrm{H}, J=6.3) ;{ }^{13} \mathrm{C}$ NMR $\left(\right.$ DMSO- $\left.d_{6}\right) \delta 170.86,162.10(\mathrm{~d}, J=240.1), 158.98$, $144.61,144.19,141.03(\mathrm{~d}, J=13.1), 134.75,134.51,130.19(\mathrm{~d}, J=9.0), 129.55,122.05,114.55,109.22(\mathrm{~d}, J=$ 20.1), 105.61, 96.07, 91.59, 54.94, 46.99, 38.46, 33.38, 31.75, 30.16, 25.95, 20.15; MS/MS m/z 453.3 (M+1)+; Anal. Calcd. for $\mathrm{C}_{25} \mathrm{H}_{29} \mathrm{FN}_{4} \mathrm{O}_{3}: \mathrm{C}, 66.35 ; \mathrm{H}, 6.46 ; \mathrm{N}, 12.38$. Found: $\mathrm{C}, 66.25 ; \mathrm{H}, 6.50 ; \mathrm{N}, 12.20$.

$N$-(4-Fluorophenyl)- $N^{\prime}-\{4-[(6-m e t h o x y q u i n o l i n-8-y l) a m i n o] p e n t y l\} b u t a n e d i a m i d e(5 b)$. From the reaction of $0.097 \mathrm{~g}$ acid $3 \mathbf{b}$ and $0.033 \mathrm{~g}(0.297 \mathrm{mmol})$ 4-fluoroaniline and after purification by column chromatography (mobile phase dichloromethane/methanol 9.5:0.5) and crystallization from ether, $0.098 \mathrm{~g}(80 \%)$ of $\mathbf{5 b}$ was obtained; $\mathrm{mp} 118-120^{\circ} \mathrm{C}$; IR (ATR): $v_{\max } 3391,3283,3145,3080,2959,2926$, $1744,1646,1615,1555,1507,1387,1224,1202,1167,1157,838,815,786,681 \mathrm{~cm}^{-1} ;{ }^{1} \mathrm{H}$ NMR (DMSO-d 6 ) $\delta$ $9.98(\mathrm{~s}, 1 \mathrm{H}), 8.55-8.53(\mathrm{dd}, 1 \mathrm{H}, J=1.6,4.2), 8.09-8.06(\mathrm{dd}, 1 \mathrm{H}, J=1.5,8.3), 7.87(\mathrm{t}, 1 \mathrm{H}, J=5.5), 7.62-7.57$ $(\mathrm{m}, 2 \mathrm{H}), 7.45-7.40(\mathrm{~m}, 1 \mathrm{H}), 7.14-7.08(\mathrm{~m}, 2 \mathrm{H}), 6.47(\mathrm{~d}, 1 \mathrm{H}, J=2.4), 6.26(\mathrm{~d}, 1 \mathrm{H}, J=2.4), 6.12(\mathrm{~d}, 1 \mathrm{H}$, $J=8.8), 3.82(\mathrm{~s}, 3 \mathrm{H}), 3.65-3.57(\mathrm{~m}, 1 \mathrm{H}), 3.10-3.04(\mathrm{~m}, 2 \mathrm{H}), 2.54(\mathrm{t}, 2 \mathrm{H}, J=7.1), 2.37(\mathrm{t}, 2 \mathrm{H}, J=7.0)$, $1.69-1.59,1.58-1.43(2 \mathrm{~m}, 4 \mathrm{H}), 1.19(\mathrm{~d}, 3 \mathrm{H}, J=6.3) ;{ }^{13} \mathrm{C}$ NMR (DMSO- $\left.d_{6}\right) \delta 170.96,170.35,159.00,157.72$ (d, $J=246.3), 144.63,144.22,135.76,134.79,134.52,129.57,122.09,120.53$ (d, $J=7.8), 115.14$ (d, $J=22.1$ ), 96.09, 91.58, 54.97, 47.00, 38.48, 33.39, 31.66, 30.34, 25.99, 20.17; MS/MS m/z 453.4 (M+1)+; Anal. Calcd. for $\mathrm{C}_{25} \mathrm{H}_{29} \mathrm{FN}_{4} \mathrm{O}_{3}$ : C, 66.35; H, 6.46; N, 12.38. Found: C, 66.53, H, 6.29; N, 12.55 .

$\mathrm{N}$-(3-Chlorophenyl)- $\mathrm{N}^{\prime}$-\{4-[(6-methoxyquinolin-8-yl)amino]pentyl\}butanediamide (5c). From the reaction of $0.097 \mathrm{~g}$ acid $3 \mathbf{b}$ and $0.038 \mathrm{~g}(0.297 \mathrm{mmol}) 3$-chloroaniline and after purification by column chromatography (mobile phase cyclohexane/ethyl acetate/methanol 3:1:0.5) and crystallization from ether, $0.062 \mathrm{~g}(49 \%)$ of $5 \mathrm{c}$ was obtained; $\mathrm{mp} 156-158^{\circ} \mathrm{C}$; IR (ATR): $v_{\max } 3390,3287,3242,3180,3102$, 3074, 2962, 2922, 2856, 1738, 1650, 1612, 1591, 1572, 1539, 1516, 1422, 1388, 1202, 1066, 816, 787, 698, 682 $\mathrm{cm}^{-1} ;{ }^{1} \mathrm{H}$ NMR (DMSO- $\left.d_{6}\right) \delta 10.11(\mathrm{~s}, 1 \mathrm{H}), 8.54-8.53(\mathrm{dd}, 1 \mathrm{H}, J=1.6,4.2), 8.08-8.06(\mathrm{dd}, 1 \mathrm{H}, J=1.6$, 8.3), $7.86(\mathrm{t}, 1 \mathrm{H}, J=5.5), 7.81(\mathrm{t}, 1 \mathrm{H}, J=2.0), 7.43-7.41(\mathrm{~m}, 2 \mathrm{H}), 7.31-7.28(\mathrm{~m}, 1 \mathrm{H}), 7.07-7.05(\mathrm{~m}, 1 \mathrm{H})$, $6.47(\mathrm{~d}, 1 \mathrm{H}, J=2.5), 6.25(\mathrm{~d}, 1 \mathrm{H}, J=2.5), 6.11(\mathrm{~d}, 1 \mathrm{H}, J=8.2), 3.82(\mathrm{~s}, 3 \mathrm{H}), 3.63-3.59(\mathrm{~m}, 1 \mathrm{H}), 3.10-3.03(\mathrm{~m}$, $2 \mathrm{H}), 2.55(\mathrm{t}, 2 \mathrm{H}, J=7.1), 2.37(\mathrm{t}, 2 \mathrm{H}, J=7.2), 1.67-1.63,1.56-1.44(2 \mathrm{~m}, 4 \mathrm{H}), 1.19(\mathrm{~d}, 3 \mathrm{H}, J=6.3) ;{ }^{13} \mathrm{C} \mathrm{NMR}$ $\left(\right.$ DMSO- $_{6}$ ) $\delta 170.89,170.85,158.98,144.60,144.19,140.73,134.77,134.49,132.97,130.29,129.55,122.51$, 122.06, 118.31, 117.19, 96.08, 91.59, 54.95, 46.99, 38.46, 33.38, 31.74, 30.16, 25.96, 20.16; MS/MS m/z 469.2 $(\mathrm{M}+1)^{+}$; Anal. Calcd. for $\mathrm{C}_{25} \mathrm{H}_{29} \mathrm{ClN}_{4} \mathrm{O}_{3}: \mathrm{C}, 64.03 ; \mathrm{H}, 6.23 ; \mathrm{N}, 11.95$. Found: $\mathrm{C}, 63.91 ; \mathrm{H}, 6.33 ; \mathrm{N}, 11.70$.

$N$-(4-Chlorophenyl)- $N^{\prime}$-\{4-[(6-methoxyquinolin-8-yl)amino]pentyl\}butanediamide (5d). From the reaction of $0.097 \mathrm{~g}$ acid $3 \mathbf{b}$ and $0.038 \mathrm{~g}(0.297 \mathrm{mmol}) 3$-chloroaniline and after purification by column chromatography (mobile phase dichloromethane/methanol 9.5:0.5) and crystallization from ether, $0.076 \mathrm{~g}(60 \%)$ of $5 \mathbf{d}$ was obtained; $\mathrm{mp} 152-153^{\circ} \mathrm{C}$; IR (ATR): $v_{\max } 3390,3287,3242,3180,3102,3074$, 2962, 2922, 2856, 1738, 1650, 1612, 1591, 1572, 1539, 1516, 1422, 1388, 1202, 1066, 816, 787, 698, 682 $\mathrm{cm}^{-1} ;{ }^{1} \mathrm{H}$ NMR (DMSO- $d_{6}$ ) $\delta 10.07$ (s, $\left.1 \mathrm{H}\right), 8.55-8.53(\mathrm{dd}, 1 \mathrm{H}, J=1.5,4.2), 8.10-8.07(\mathrm{dd}, 1 \mathrm{H}, J=1.4$, 
8.3), $7.88(\mathrm{t}, 1 \mathrm{H}, J=5.4), 7.61(\mathrm{~d}, 2 \mathrm{H}, J=8.9), 7.45-7.41(\mathrm{~m}, 1 \mathrm{H}), 7.32(\mathrm{~d}, 2 \mathrm{H}, J=8.9), 6.48(\mathrm{~d}, 1 \mathrm{H}, J=2.3)$, $6.26(\mathrm{~d}, 1 \mathrm{H}, J=2.3), 6.13(\mathrm{bs}, 1 \mathrm{H}), 3.81(\mathrm{~s}, 3 \mathrm{H}), 3.63-3.57(\mathrm{~m}, 1 \mathrm{H}), 3.09-3.03(\mathrm{~m}, 2 \mathrm{H}), 2.55(\mathrm{t}, 2 \mathrm{H}, J=7.4)$, $2.39(\mathrm{t}, 2 \mathrm{H}, J=7.0), 1.70-1.59,1.58-1.43(2 \mathrm{~m}, 4 \mathrm{H}), 1.19(\mathrm{~d}, 3 \mathrm{H}, J=6.3) ;{ }^{13} \mathrm{C}$ NMR (DMSO- $\left.d_{6}\right) \delta 170.92$, $170.64,159.01,144.55,144.18,138.28,134.89,134.42,129.59,128.51,126.33,122.09,120.37,96.19,91.63$, 54.98, 47.02, 38.47, 33.37, 31.73, 30.23, 25.98, 20.15 (11); MS/MS m/z 469.3 (M+1) ${ }^{+}$; Anal. Calcd. for $\mathrm{C}_{25} \mathrm{H}_{29} \mathrm{ClN}_{4} \mathrm{O}_{3}: \mathrm{C}, 64.03 ; \mathrm{H}, 6.23 ; \mathrm{N}, 11.95$. Found: $\mathrm{C}, 64.35 ; \mathrm{H}, 6.57 ; \mathrm{N}, 12.13$.

$N^{\prime}-\{4-[(6-M e t h o x y q u i n o l i n-8-y l) a m i n o] p e n t y l\}-N$-[3-(trifluoromethyl)phenyl]butanediamide (5e). From the reaction of $0.097 \mathrm{~g}$ acid $3 \mathbf{b}$ and $0.048 \mathrm{~g}(0.297 \mathrm{mmol})$ 3-trifluoromethylaniline and after purification by column chromatography (mobile phase dichloromethane/methanol 9.5:0.5) and crystallization from ether, $0.122 \mathrm{~g}(90 \%)$ of $\mathbf{5 e}$ was obtained; $\mathrm{mp} 146-149^{\circ} \mathrm{C}$; IR (ATR): $v_{\max } 3394,3302,3263,3216,3164$, $3097,2963,2928,2859,1651,1617,1562,1518,1450,1389,1331,1265,1173,1127,1064,894,816 \mathrm{~cm}^{-1} ;{ }^{1} \mathrm{H}$ NMR (DMSO- $\left.d_{6}\right) \delta 10.26(\mathrm{~s}, 1 \mathrm{H}), 8.54-8.53(\mathrm{dd}, 1 \mathrm{H}, J=1.6,4.2), 8.11(\mathrm{~s}, 1 \mathrm{H}), 8.08-8.06(\mathrm{dd}, 1 \mathrm{H}, J=1.6$, 8.3), $7.88(\mathrm{t}, 1 \mathrm{H}, J=5.5), 7.74(\mathrm{~d}, 1 \mathrm{H}, J=8.1), 7.52(\mathrm{t}, 1 \mathrm{H}, J=8.0), 7.43-7.41(\mathrm{~m}, 1 \mathrm{H}), 7.36(\mathrm{~d}, 1 \mathrm{H}, J=7.8)$, $6.47(\mathrm{~d}, 1 \mathrm{H}, J=2.5), 6.25(\mathrm{~d}, 1 \mathrm{H}, J=2.5), 6.11(\mathrm{~d}, 1 \mathrm{H}, J=8.7), 3.82(\mathrm{~s}, 3 \mathrm{H}), 3.63-3.58(\mathrm{~m}, 1 \mathrm{H}), 3.10-3.04(\mathrm{~m}$, $2 \mathrm{H}), 2.57(\mathrm{t}, 2 \mathrm{H}, J=7.2), 2.41(\mathrm{t}, 2 \mathrm{H}, J=7.2), 1.67-1.63,1.56-1.44(2 \mathrm{~m}, 4 \mathrm{H}), 1.19(\mathrm{~d}, 3 \mathrm{H}, J=6.3) ;{ }^{13} \mathrm{C} \mathrm{NMR}$ (DMSO-d $d_{6}$ ) $\delta 171.11,170.84,158.98,144.61,144.19,140.03,134.75,134.50,129.83,129.55,129.67-129.04$ (q, $J=31.9), 126.81-121.40$ (q, $J=269.8), 122.33,122.05,119.14,114.88,96.06,91.58,54.94,46.98,38.46$, $33.38,31.72,30.11,25.96,20.14 ; \mathrm{MS} / \mathrm{MS} \mathrm{m} / z 503.3(\mathrm{M}+1)^{+}$; Anal. Calcd. for $\mathrm{C}_{26} \mathrm{H}_{29} \mathrm{~F}_{3} \mathrm{~N}_{4} \mathrm{O}_{3}: \mathrm{C}, 62.14 ; \mathrm{H}$, 5.82; N, 11.15. Found: C, 62.25; H, 5.99; N, 11.08 .

$N^{\prime}-\{4$-[(6-Methoxyquinolin-8-yl)amino]pentyl\}-N-[4-(trifluoromethyl)phenyl]butanediamide (5f). From the reaction of $0.097 \mathrm{~g}$ acid $3 \mathbf{b}$ and $0.048 \mathrm{~g}(0.297 \mathrm{mmol}) 4$-trifluoromethylaniline and after purification by column chromatography (mobile phase dichloromethane/methanol 9.5:0.5), $0.068 \mathrm{~g}$ (50\%) of $\mathbf{5 f}$ was obtained; mp 163-165 ${ }^{\circ} \mathrm{C}$; IR (ATR): $v_{\max } 3387,3287,3256,3198,3123,3071,2963,2925,2859,1652,1614$, $1547,1515,1452,1419,1389,1327,1264,1169,1124,1064,846,784 \mathrm{~cm}^{-1} ;{ }^{1} \mathrm{H}$ NMR (DMSO-d $\left.d_{6}\right) \delta 10.31$ $(\mathrm{s}, 1 \mathrm{H}), 8.54-8.52(\mathrm{dd}, 1 \mathrm{H}, J=1.5,4.2), 8.09-8.06(\mathrm{dd}, 1 \mathrm{H}, J=1.5,8.3), 7.89(\mathrm{t}, 1 \mathrm{H}, J=5.3), 7.79(\mathrm{~d}, 2 \mathrm{H}$, $J=8.5), 7.63(\mathrm{~d}, 2 \mathrm{H}, J=8.7), 7.44-7.40(\mathrm{~m}, 1 \mathrm{H}), 6.47(\mathrm{~d}, 1 \mathrm{H}, J=2.4), 6.25(\mathrm{~d}, 1 \mathrm{H}, J=2.4), 6.11(\mathrm{~d}, 1 \mathrm{H}$, $J=8.7), 3.82(\mathrm{~s}, 3 \mathrm{H}), 3.65-3.57(\mathrm{~m}, 1 \mathrm{H}), 3.09-3.04(\mathrm{~m}, 2 \mathrm{H}), 2.59(\mathrm{t}, 2 \mathrm{H}, J=7.0), 2.40(\mathrm{t}, 2 \mathrm{H}, J=7.0)$, $1.71-1.58,1.57-1.43(2 \mathrm{~m}, 4 \mathrm{H}), 1.19$ (d, 3H, $J=6.2) ;{ }^{13} \mathrm{C}$ NMR (DMSO- $\left.d_{6}\right) \delta 171.18,170.86,158.99,144.61$, $144.20,142.83$, 134.77, 134.51, 129.55, 125.95, 127.05-121.68 (q, $J=274.2), 123.15-122.52(\mathrm{q}, J=28.2)$, 122.06, 118.69, 96.08, 91.59, 54.95, 46.99, 38.47, 33.38, 31.79, 30.10, 25.96, 20.14; MS/MS m/z 503.3 (M+1) ; Anal. Calcd. for $\mathrm{C}_{26} \mathrm{H}_{29} \mathrm{~F}_{3} \mathrm{~N}_{4} \mathrm{O}_{3}: \mathrm{C}, 62.14 ; \mathrm{H}, 5.82 ; \mathrm{N}, 11.15$. Found: $\mathrm{C}, 62.39 ; \mathrm{H}, 5.76 ; \mathrm{N}, 11.41$.

\subsection{Biological Evaluation}

\subsubsection{In Vitro Antibacterial Susceptibility Assay (MIC Determination)}

(a) Staphylococci and Enterococci: The synthesized compounds were evaluated for in vitro antibacterial activity against representatives of multidrug-resistant bacteria and clinical isolates of methicillin-resistant Staphylococcus aureus (MRSA) 63718, SA 630 and SA 3202, that were obtained from the National Institute of Public Health (Prague, Czech Republic). S. aureus ATCC 29213 was used as a reference and quality control strain. In addition, all the compounds were tested for their activity against vancomycin-susceptible Enterococcus faecalis ATCC 29212 as a reference strain and three isolates from American crows of vanA-carrying vancomycin-resistant E. faecalis (VRE) 342B, 368 and 725B [34]. Ampicillin (Amp) and ciprofloxacin (CIP) (Sigma-Aldrich, St. Louis, MO, USA) were used as standards. Prior to testing, each strain was passaged onto nutrient agar (Oxoid, Basingstoke, UK) with $5 \%$ of bovine blood, and bacterial inocula were prepared by suspending a small portion of the bacterial colony in sterile phosphate-buffered saline ( $\mathrm{pH} 7.2-7.3)$. The cell density was adjusted to $0.5 \mathrm{McF}$ arland units using a densitometer (Densi-La-Meter, LIAP, Riga, Latvia). This inoculum was diluted to reach the final concentration of bacterial cells $5 \times 10^{5} \mathrm{CFU} / \mathrm{mL}$ in the wells. The compounds were dissolved in DMSO (Sigma-Aldrich, St. Louis, MO, USA), and the final concentration of DMSO in the Cation Adjusted 
Mueller-Hinton (CaMH) broth (Oxoid) for Staphylococci or brain-heart infusion for Enterococci did not exceed $2.5 \%$ of the total solution composition. The final concentrations of the evaluated compounds ranged from 256 to $0.008 \mu \mathrm{g} / \mathrm{mL}$. The broth dilution micro-method, modified according to NCCLS (National Committee for Clinical Laboratory Standards) guidelines [35] in MH broth for Staphylococcus strains and CaMH for Enterococcus strains, was used to determine MIC. Drug-free controls, sterility controls, and controls consisting of $\mathrm{MH}$ and CaMH broths and DMSO alone were included. The determination of results was performed visually after $24 \mathrm{~h}$ of static incubation in darkness at $37^{\circ} \mathrm{C}$ in an aerobic atmosphere.

(b) Other Gram-positive (Streptococcus pneumoniae MFBF 10373, Bacillus cereus ATCC 11778, and Bacillus subtilis ATCC 6633) and Gram-negative bacteria species (Pseudomonas aeruginosa ATCC 27853, Escherichia coli ATCC 10536, Serratia marcescens ATCC 10905, Proteus mirabilis MFBF 10430, Acinetobacter baumannii MFBF 10913, and Salmonella enteritidis MFBF 11945): Serial microdilution broth assay was used to determine MIC of compounds $\mathbf{4 a}-\mathbf{f}$ and $\mathbf{5 a}-\mathbf{f}$ [36]. Cell suspensions were prepared from stock cultures using phosphate-buffered saline (PBS) (Gibco Laboratories, USA) pH 7.4 and adjusted to 0.5 McFarland units using a nephelometer (ATB 1550, BioMérieux, France). Stock solutions of the tested compounds were prepared in DMSO $(10 \mathrm{mg} / \mathrm{mL})$. Testing was performed using serial dilution in microtiter flat-bottom 96-well plates with compounds ranging from 100 to $0.78125 \mu \mathrm{g} / \mathrm{mL}$. After inoculation $\left(10^{7} \mathrm{CFU} / \mathrm{mL}\right)$ and incubation $\left(18 \mathrm{~h}, 35^{\circ} \mathrm{C}\right.$, aerobically in darkness), MICs for bacterial species were determined by addition of $0.5 \mathrm{mg} / \mathrm{mL}$ TTC (2,3,5-triphenyl-2H-tetrazolium chloride). The absorbance was recorded at $540 \mathrm{~nm}$. As a positive quality control (susceptibility of strains) tetracycline hydrochloride (TC) (Sigma-Aldrich) was added into wells. MICs were determined as non-linear regression using GraphPad Prism as the lowest concentrations resulting in 50\% growth inhibition of growth in comparison to control.

(c) Mycobacteria: Mycobacterium tuberculosis H37Ra ATCC 25177 was grown in Middlebrook broth (MB), supplemented with Oleic-Albumin-Dextrose-Catalase (OADC) supplement (Difco, Lawrence, $\mathrm{KS}, \mathrm{USA})$ and mycobactin $\mathrm{J}(2 \mu \mathrm{g} / \mathrm{mL})$. At $\log$ phase growth, a culture sample $(10 \mathrm{~mL})$ was centrifuged at 15,000 rpm/20 min using a bench-top centrifuge (MPW-65R, MPW Med Instruments, Poland). Following removal of the supernatant, the pellet was washed in fresh Middlebrook 7H9GC broth and re-suspended in fresh, ODAC-supplemented MB $(10 \mathrm{~mL})$. The turbidity was adjusted to match McFarland standard No. $1\left(3 \times 10^{8} \mathrm{CFU}\right)$ with MB broth. A further 1:20 dilution of the culture was then performed in MB broth. The antimicrobial susceptibility of $M$. tuberculosis was investigated in a 96-well plate format. In these experiments, sterile deionised water $(300 \mu \mathrm{l})$ was added to all outer-perimeter wells of the plates to minimize evaporation of the medium in the test wells during incubation. Each evaluated compound $(100 \mu \mathrm{L})$ was incubated with $M$. tuberculosis $(100 \mu \mathrm{l})$. Dilutions of each compound were prepared in duplicate. For all synthesized compounds, final concentrations ranged from $1000 \mu \mathrm{g} / \mathrm{mL}$ to $8 \mu \mathrm{g} / \mathrm{mL}$. All compounds were dissolved in DMSO, and subsequent dilutions were made in supplemented MB. The plates were sealed with parafilm and incubated at $37^{\circ} \mathrm{C}$ for 7 days. Following incubation, $10 \%$ of alamarBlue (Difco, Lawrence, KS, USA) was mixed into each well, and readings at $570 \mathrm{~nm}$ and $600 \mathrm{~nm}$ were taken, initially for background subtraction and subsequently after $24 \mathrm{~h}$ reincubation. The background subtraction is necessary for strongly coloured compounds, where the colour may interfere with the interpretation of any colour change. For non-interfering compounds, a blue colour in the well was interpreted as the absence of growth, and a pink colour was scored as growth.

The evaluation of the in vitro antimycobacterial activity of the compounds was additionally performed against $M$. smegmatis ATCC 700084, M. marinum CAMP 5644 and M. kansasii DSM 44162. The broth dilution micro-method in Middlebrook 7H9 medium (Difco, Lawrence, KS, USA) supplemented with ADC Enrichment (Becton, Dickinson and Comp.) was used to determine MIC as previously described [37]. The compounds were dissolved in DMSO (Sigma-Aldrich), and the final concentration of DMSO did not exceed $2.5 \%$ of the total solution composition. Final concentrations of the evaluated compounds ranging from $256 \mu \mathrm{g} / \mathrm{mL}$ to $0.125 \mu \mathrm{g} / \mathrm{mL}$ were obtained by twofold 
serial dilution of the stock solution in a microtiter plate with sterile medium. Bacterial inocula were prepared by transferring colonies from culture to sterile water. The cell density was adjusted to 0.5 McFarland units using a densitometer (Densi-La-Meter, LIAP, Riga, Latvia). The final inoculum was made by 1:1000 dilution of the suspension with sterile water. Drug-free controls, sterility controls and controls consisted of medium and DMSO (Sigma-Aldrich, St. Louis, MO, USA) alone were included. The determination of results was performed visually after 3 days of static incubation in darkness at $37^{\circ} \mathrm{C}$ in an aerobic atmosphere for M. smegmatis, after 7 days of static incubation in darkness at 37 ${ }^{\circ} \mathrm{C}$ in an aerobic atmosphere for $\mathrm{M}$. kansasii and after 21 days of static incubation in darkness at $28^{\circ} \mathrm{C}$ in an aerobic atmosphere for M. marinum. Ciprofloxacin (CIP), rifampicin (RIF) and isoniazid (INH) (Sigma-Aldrich, St. Louis, MO, USA) were used as the standards.

\subsubsection{In Vitro Antifungal Susceptibility Testing}

Microdilution method was used for testing the antifungal activities of newly synthesized compounds against Candida albicans CCM 8261 and ATCC 90028, C. krusei CCM 8271, C. parapsilosis CCM 8260 (Czech Collection of Microorganisms, Brno, Czech Republic) [38]. Tested compounds were diluted in RPMI-1640 (Sigma) broth to concentrations 128-0.016 $\mu \mathrm{g} / \mathrm{mL}$. Flucytosine (FLU) (Sigma) and amphotericin B (Amph) were used as positive controls. The plates were inoculated by an inoculum prepared in RPMI-1640 broth. The final concentration of fungal cells was $5 \times 10^{2}-2.5 \times 10^{3} \mathrm{CFU} / \mathrm{mL}$ in each well. The plates were incubated at $37^{\circ} \mathrm{C}$ for 24 (C. albicans, C. krusei) or 48 (C. parapsilosis) hours. Drug-free controls were included. MIC was defined as $80 \%$ or greater $\left(\mathrm{IC}_{80}\right)$ reduction of growth in comparison with the control [35].

MIC determination for Aspergillus brasiliensis was performed in RPMI 1640 broth with glutamine supplemented with $2 \%$ glucose, following the same scheme as for bacteria, procedure b). After incubation period $\left(48 \mathrm{~h}, 35^{\circ} \mathrm{C}\right.$, aerobically in dark), XTT ( $2 \mathrm{H}$-tetrazolium, 2,3-bis(2-methoxy4-nitro-5-sulfophenyl)-5-[(phenylamino)carbonyl]-hydroxide) (10 mg/mL) in combination with menadione $(1 \mathrm{mg} / \mathrm{mL}$ in acetone) $(7: 1, v / v)$ was added [36]. Absorbance was read at $540 \mathrm{~nm}$. Amph was used as a positive control and solvent and media (no microorganisms added) as negative controls.

\subsubsection{Minimum Biofilm Eradication Assay}

Biofilm eradication screening was performed on the following microorganisms: S. aureus ATCC 6538, S. pneumoniae MFBF 10373, E. faecalis ATCC 29212, B. cereus ATCC 11778, B. subtilis ATCC 6633, E. coli ATCC 10536, P. aeruginosa ATCC 27853, S. marcescens ATCC 10905, P. mirabilis MFBF 10430, S. enteritidis MFBF 11945, A. baumannii MFBF 10913, and C. albicans ATCC 90028. MBECs of fumardiamides $\mathbf{4 a - f}$ and succindiamides $\mathbf{5 a - f}$ were determined as follows [39]. Each well (96-well plate) was filled with $100 \mu \mathrm{l}$ of bacterial $\left(10^{7} \mathrm{CFU} / \mathrm{mL}\right)$ or yeast $\left(5 \times 10^{6} \mathrm{CFU} / \mathrm{mL}\right)$ suspension. When the inhibition of yeast biofilm formation was tested, the wells were pre-treated with fetal bovine serum (FBS) $(250 \mu \mathrm{l}$ per well). Negative controls contained broth only. Positive controls were performed using standard antimicrobial drugs gentamycin (Gen) and Amph, respectively. The plates were covered and incubated aerobically for $24 \mathrm{~h}$ (bacteria) or $48 \mathrm{~h}$ (yeast) at $37^{\circ} \mathrm{C}$. Following incubation period, each well was aspirated, washed three times and vigorously shaken to remove all non-adherent bacteria/yeast. The remaining attached cells were fixed with methanol (15 $\mathrm{min})$ and the plates were left to dry overnight. Formed biofilm was stained with crystal violet (1\%, $5 \mathrm{~min})$. Excess stain was rinsed by placing the plate under running tap water and the plates were left to dry. Adherent cells were solubilized using ethanol. The absorbance was read at $570 \mathrm{~nm}$. The MBEC value represents the lowest dilution of a compound at which bacteria fail to grow.

\subsubsection{Antiviral Evaluation}

Antiviral activity of compounds $\mathbf{4} \mathbf{a}-\mathbf{f}$ and $\mathbf{5 a}-\mathbf{f}$ was determined as described previously [40]. Cytotoxicity and antiviral activity assay towards herpes simplex virus (HSV) strains HSV-1 KOS, HSV-2 G, HSV-1 TK-KOS ACVr, vaccinia virus, adenovirus-2, human coronavirus (229E) in HEL 
cell cultures, vesicular stomatitis virus, coxsackie virus B4, respiratory syncytial virus in Hela cell cultures, para-influenza- 3 virus, reovirus- 1 , sindbis, coxsackie virus B4, Punta Toro virus, yellow fever virus in Vero cell cultures, while influenza A/H1N1 A/Ned/378/05, influenza A/H3N2 A/HK/7/87 and influenza B B/Ned/537/05 viruses in Madin-Darby Canine Kidney (MDCK) cell cultures were performed. On the day of the infection, growth medium was aspirated and replaced by serial dilutions of the test compounds. Virus was then added to each well, diluted to obtain a viral input of $100 \mathrm{CCID}_{50}\left(\mathrm{CCID}_{50}\right.$ being the virus dose that is able to infect $50 \%$ of the cell cultures). Mock-treated cell cultures receiving solely the test compounds were included, to determine their cellular cytotoxicity. After 3 to 10 days of incubation the virus-induced cytopathicity was determined by visual scoring of the cytopathic effect (CPE) (light microscopic evaluation of the virus-induced CPE and inhibition of evaluated compounds), as well as by measuring the cell viability with the colorimetric formazan-based MTS assay (3-(4,5-dimethylthiazol-2-yl)-5-(3-carboxymethoxyphenyl)-2-(4-sulfophenyl)-2H-tetrazolium). All experiments were performed in duplicate. Antiviral activity was expressed as $\mathrm{EC}_{50}$. The activities were compared with the activities of the parent drug PQ, DS-10.000 (dextran sulfate, approx. MW = 10.000) and standard antiviral drugs: ribavirin (Rib), mycophenolic acid (MPA), brivudin, cidofovir, acyclovir, gancyclovir, zalcitabine, alovudine, UDA, zanamivir, amantadine and rimantadine.

\subsubsection{Cytostatic Activity}

Cytostatic activity was evaluated in vitro on nine different types of human tumor cell lines: Capan-1, Hap1, HCT-116, and NCI-H460, as well as hematological tumors such as DND-41, HL-60, K-562, MM.1S and Z-138 as described previously [41]. All human tumor cell lines were acquired from the American Type Culture Collection (ATCC, Manassas, VA, USA), except for the DND-41 cell line which was purchased from the Deutsche Sammlung von Mikroorganismen und Zellkulturen (DSMZ Leibniz-Institut, Braunschweig, Germany) and the Hap1 cell line which was purchased from Horizon Discovery (Waterbeach, UK). Capan-1, Hap1, HL-60, K-562, Z-138, MM.1S and DND-41 were cultured in Iscove's Modified Dulbecco's Medium (IMDM, Gibco Life Technologies, Gaithersburg, MD, USA), HCT-116 were grown in McCoy's 5A Medium (Gibco Life Technologies) and NCI-H460 were cultured in RPMI (Gibco Life Technologies). All media were supplemented with 10\% FBS (HyClone, GE Healthcare Life Sciences, USA). Adherent cell lines HCT-116, Hap1, NCI-H460, and Capan-1 cells were seeded at a density between 400 and 1250 cells per well, in 384-well, black-walled, clear-bottomed tissue culture plates (Greiner Bio-One, Kremsmünster, Germany). After overnight incubation, cells were treated with test compounds at four different concentrations ranging from 100 to $0.8 \mu \mathrm{M}$. Suspension cell lines HL-60, K-562, Z-138, MM.1S, and DND-41 were seeded at densities ranging from 3000 to 10,000 cells per well in 384-well, black-walled, clear-bottomed tissue culture plates containing test compounds at the same four concentrations. The plates were incubated and monitored at $37^{\circ} \mathrm{C}$ for $72 \mathrm{~h}$ in an IncuCyte (Essen BioScience Inc., Ann Arbor, MI, USA) for real-time imaging. Images were taken every $3 \mathrm{~h}$, with one field image per well under $10 \times$ magnification. All compounds were tested with duplicate data points and averaged. The activities were compared with the activities of the parent drug PQ and standard anticancer drugs docetaxel (DXT), etoposide (EPEG) and staurosporine (STS).

\subsubsection{Interaction with Glutathione (GSH)}

Fumardiamide $4 \mathrm{~b}(1.25 \mu \mathrm{M})$ was incubated with GSH $(125 \mu \mathrm{M})$ in ammonium formate buffer $(\mathrm{pH}=7.4)$ containing $10 \%$ acetonitrile at $37^{\circ} \mathrm{C}$ for $216 \mathrm{~h}$ [33]. The progress of the reactions was monitored with the percent of remaining fumardiamide determined by MS using an internal standard ( $N$-(benzyloxy)- $N^{\prime}-\{4-[(6-$ methoxyquinolin-8-yl)amino]pentyl\}butanediamide). Aliquots of the reaction mixture (taken after 0, 4.5, 26, 52, 124 and 216 h) were analysed with Synapt G2-Si ESI-QTOF-MS system (Waters, Milford, USA). The aliquots were diluted 10 times with acetonitrile and sprayed at a flow rate of $50 \mu \mathrm{L} / \mathrm{min}$ using the fluidics system of the instrument. MS conditions were set as follows: positive ion mode, capillary voltage $3 \mathrm{kV}$, sampling cone voltage $10 \mathrm{~V}$, source temperature 
$120^{\circ} \mathrm{C}$, desolvation temperature $350{ }^{\circ} \mathrm{C}$, desolvation gas flow $800 \mathrm{~L} / \mathrm{h}$. Mass spectra were recorded from $100-1000 \mathrm{~m} / \mathrm{z}$ at a frequency of $1 \mathrm{~Hz}$. Data were acquired and analysed with Waters MassLynx v4.1 software.

\section{Conclusions}

Twelve novel PQ-derivatives of diamide type were designed and synthesized. These compounds differ in the type of spacer and/or halogen atom in aniline region. Compounds $\mathbf{4 a -} \mathbf{f}$ are fumardiamides and $5 \mathbf{a}-\mathbf{f}$ succindiamides. Compounds $\mathbf{4 a}, \mathbf{b}, \mathbf{5 a}, \mathbf{b}$ are fluoro, $4 \mathbf{c}, \mathbf{d}, \mathbf{5 c}, \mathbf{d}$ chloro and $4 \mathbf{e}, \mathbf{f}, 5 \mathbf{e}, \mathbf{f}$ are trifluoroderivatives. All new compounds were screened for antibacterial, antitubercular, antiviral and cytostatic activity as well as biofilm eradication ability. In all biological assays, fumardiamides 4 were superior to succindiamides 5, which indicates that the double bond conjugated to the carbonyl was important for the activity. With their high bioactivity, low cytotoxicity and convenient drug-like properties, $p$-substituted derivatives $4 \mathbf{b}, \mathbf{d}, \mathbf{f}$ provide a strong basis for further research and optimization of novel agents useful in the treatment of bacterial and biofilm-associated infections, while $m$-substituted derivatives $\mathbf{4 a}$, c,e could be potential leads for the development of antitumor agents.

Supplementary Materials: The following are available online: Table S1. Properties of novel compounds calculated with Chemicalize.org program. The Lipinski and Gelovani parameters; Table S2. Analytical and spectral data of compounds $\mathbf{4 a - f}$ and $\mathbf{5 a}-\mathbf{f}$; Table S3. ${ }^{1} \mathrm{H}$ and ${ }^{13} \mathrm{C}$ NMR spectra of amides $\mathbf{4 a}-\mathbf{f}$ and $\mathbf{5 a}-\mathbf{f}$; Table S4. Interaction of fumardiamide $\mathbf{4 b}$ with GSH; Figure S1. Interaction of fumardiamide $\mathbf{4} \mathbf{b}$ with GSH ( $)$. Control: ( $N$-(benzyloxy)- $N^{\prime}-\{4-[(6-m e t h o x y q u i n o l i n-8-y l)$ amino]pentyl\}butanediamide) $(\bullet)$. Spectra of all compounds.

Author Contributions: Conceptualization, Z.R. and B.Z.; Synthesis and characterization of compounds M.B., Z.R.; Antibacterial, antifungal and biofilm eradication assay, H.M., J.V., I.K., J.J.; Antiviral and cytostatic evaluaton, L.P., D.S.; Interaction with GSH T.K.; Writing of Manuscript, Z.R. and B.Z.

Funding: This work has been fully supported by the Croatian Science Foundation (project IP-09-2014-1501), University of Zagreb (support for 2017), Comenius University in Bratislava (grant UK/229/2018), Faculty of Pharmacy of Comenius University in Bratislava (grant FaFUK/9/2018) and SANOFI-AVENTIS Pharma Slovakia, s.r.o.

Conflicts of Interest: The authors declare no conflicts of interest.

\section{References}

1. Clayden, J.; Greeves, N.; Warren, S. Organic Chemistry, 2nd ed.; Oxford University Press: New York, NY, USA, 2012.

2. Smaill, J.B.; Rewcastle, G.W.; Loo, J.A.; Greis, K.D.; Chan, O.H.; Reyner, E.L.; Lipka, E.; Showalter, H.D.; Vincent, P.W.; Elliott, W.L.; et al. Tyrosine kinase inhibitors. 17. Irreversible inhibitors of the epidermal growth factor receptor: 4-(phenylamino)quinazoline- and 4-(phenylamino)pyrido[3,2- $d$ ]pyrimidine-6-acrylamides bearing additional solubilizing functions. J. Med. Chem. 2000, 43, 1380-1397. [CrossRef] [PubMed]

3. Minami, Y.; Shimamura, T.; Shah, K.; LaFramboise, T.; Glatt, K.A.; Liniker, E.; Borgman, C.L.; Haringsma, H.J.; Feng, W.; Weir, B.A.; et al. The major lung cancer-derived mutants of ERBB2 are oncogenic and are associated with sensitivity to the irreversible EGFR/ERBB2 inhibitor HKI-272. Oncogene 2007, 26, 5023-5027. [CrossRef] [PubMed]

4. Baselga, J.; Coleman, R.E.; Cortés, J.; Janni, W. Advances in the management of HER2-positive early breast cancer. Crit. Rev. Oncol. Hematol. 2017, 119, 113-122. [CrossRef] [PubMed]

5. Jackson, P.A.; Widen, J.C.; Harki, D.A.; Brummond, K.M. Covalent modifiers: A chemical perspective on the reactivity of $\alpha, \beta$-unsaturated carbonyls with thiols via hetero-Michael addition reactions. J. Med. Chem. 2017, 60, 839-885. [CrossRef] [PubMed]

6. Zhang, X.; Li, X.; You, Q.; Zhang, X. Prodrug strategy for cancer cell-specific targeting: A recent overview. Eur. J. Med. Chem. 2017, 139, 542-563. [CrossRef] [PubMed]

7. Compound Summary for CID 5281081. Available online: https://pubchem.ncbi.nlm.nih.gov/compound/ entacapone\#section=Top (accessed on 25 May 2018). 
8. Matthews, D.A.; Dragovich, P.S.; Webber, S.E.; Fuhrman, S.A.; Patick, A.K.; Zalman, L.S.; Hendrickson, T.F.; Love, R.A.; Prins, T.J.; Marakovits, J.T.; et al. Structure-assisted design of mechanism-based irreversible inhibitors of human rhinovirus $3 \mathrm{C}$ protease with potent antiviral activity against multiple rhinovirus serotypes. Proc. Natl. Acad. Sci. USA 1999, 96, 11000-11007. [CrossRef] [PubMed]

9. Buzdar, A.U.; Robertson, J.F.; Eiermann, W.; Nabholtz, J.M. An overview of the pharmacology and pharmacokinetics of the newer generation aromatase inhibitors anastrozole, letrozole, and exemestane. Cancer 2002, 95, 2006-2016. [CrossRef] [PubMed]

10. Somberg, J.C.; Molnar, J. The pleiotropic effects of ethacrynic acid. Am. J. Ther. 2009, 16, 102-104. [CrossRef] [PubMed]

11. Dawson, R.M. The toxicology of microcystins. Toxicon 1998, 36, 953-962. [CrossRef]

12. Eusugi, S.; Fujisawa, N.; Yoshida, J.; Watanabe, M.; Dan, S.; Yamori, T.; Shiono, Y.; Kimura, K.; Pyrrocidine, A. A metabolite of endophytic fungi, has a potent apoptosis-inducing activity against HL60 cells through caspase activation via the Michael addition. J. Antibiot. 2016, 69, 133-140. [CrossRef]

13. Ramsay, J.R.; Suhrbier, A.; Aylward, J.H.; Ogbourne, S.; Cozzi, S.J.; Poulsen, M.G.; Baumann, K.C.; Welburn, P.; Redlich, G.L.; Parsons, P.G. The sap from Euphorbia peplus is effective against human nonmelanoma skin cancers. Br. J. Dermatol. 2011, 164, 633-636. [CrossRef] [PubMed]

14. Lebwohl, M.; Swanson, N.; Anderson, L.L.; Melgaard, A.; Xu, Z.; Berman, B. Ingenol mebutate gel for actinic keratosis. N. Engl. J. Med. 2012, 366, 1010-1019. [CrossRef] [PubMed]

15. Picato®gel-FDA. Available online: https://www.accessdata.fda.gov/drugsatfda_docs/label/2012/ 202833lbl.pdf. (accessed on 9 June 2018).

16. Sebök, B.; Bonnekoh, B.; Geisel, J.; Mahrle, G. Antiproliferative and cytotoxic profiles of antipsoriatic fumaric acid derivatives in keratinocyte cultures. Eur. J. Pharmacol. 1994, 270, 79-87. [CrossRef]

17. Smith, D. Fumaric acid esters for psoriasis: A systematic review. Ir. J. Med. Sci. 2017, 186, 161-177. [CrossRef] [PubMed]

18. Kocaadam, B.; Şanlier, N. Curcumin, an active component of turmeric (Curcuma longa), and its effects on health. Crit. Ver. Food Sci. Nutr. 2017, 57, 2889-2895. [CrossRef] [PubMed]

19. Seca, A.M.L.; Pinto, D.C.G.A. Plant secondary metabolites as anticancer agents: Successes in clinical trials and therapeutic application. Int. J. Mol. Sci. 2018, 19, 263. [CrossRef] [PubMed]

20. Pavić, K.; Perković, I.; Cindrić, M.; Pranjić, M.; Martin-Kleiner, I.; Kralj, M.; Schols, D.; Hadjipavlou-Litina, D.; Katsori, A.-M.; Zorc, B. Novel semicarbazides and ureas of primaquine with bulky aryl or hydroxyalkyl substituents: Synthesis, cytostatic and antioxidative activity. Eur. J. Med. Chem. 2014, 86, 502-514. [CrossRef] [PubMed]

21. Perković, I.; Antunović, M.; Marijanović, I.; Pavić, K.; Ester, K.; Kralj, M.; Vlainić, J.; Kosalec, I.; Schols, D.; Hadjipavlou-Litina, D.; et al. Novel urea and bis-urea primaquine derivatives with hydroxyphenyl and halogenphenyl substituents: Synthesis and biological evaluation. Eur. J. Med. Chem. 2016, 124, 622-636. [CrossRef] [PubMed]

22. Guzman, J.D. Natural cinnamic acids, synthetic derivatives and hybrids with antimicrobial activity. Molecules 2014, 19, 292-349. [CrossRef] [PubMed]

23. Kakwani, M.D.; Suryavanshi, P.; Ray, M.; Rajan, M.G.R.; Majee, S.; Samad, A.; Devarajan, P.; Degani, M.S. Design, synthesis and antimycobacterial activity of cinnamide derivatives: A molecular hybridization approach. Bioorg. Med. Chem. Lett. 2011, 21, 1997-1999. [CrossRef] [PubMed]

24. De, P.; Baltas, M.; Bedos-Belval, F. Cinnamic acid derivatives as anticancer agents-a review. Curr. Med. Chem. 2011, 18, 1672-1703. [CrossRef] [PubMed]

25. Pavić, K.; Perković, I.; Gilja, P.; Kozlina, F.; Ester, K.; Kralj, M.; Schols, D.; Hadjipavlou-Litina, D.; Pontiki, E.; Zorc, B. Design, synthesis and biological evaluation of novel primaquine-cinnamic acid conjugates of amide and acylsemicarbazide type. Molecules 2016, 21, 1629. [CrossRef] [PubMed]

26. Pavić, K.; Perković, I.; Pospíšilová, Š.; Machado, M.; Fontinha, D.; Prudêncio, M.; Jampilek, J.; Coffey, A.; Endersen, L.; Rimac, H.; et al. Primaquine hybrids as promising antimycobacterial and antimalarial agents. Eur. J. Med. Chem. 2018, 143, 769-779. [CrossRef] [PubMed]

27. Vlainić, J.; Kosalec, I.; Pavić, K.; Hadjipavlou-Litina, D.; Pontiki, E.; Zorc, B. Insights into biological activity of ureidoamides with primaquine and amino acid moieties. J. Enzyme Inhib. Med. Chem. 2018, 33, 376-382. [CrossRef] [PubMed] 
28. Levatić, J.; Pavić, K.; Perković, I.; Uzelac, L.; Ester, K.; Kralj, M.; Kaiser, M.; Rottmann, M.; Supek, F.; Zorc, B. Machine learning prioritizes synthesis of primaquine ureidoamides with high antimalarial activity and attenuated cytotoxicity. Eur. J. Med. Chem. 2018, 146, 651-667. [CrossRef] [PubMed]

29. Beus, M.; Rajić, Z.; Maysinger, D.; Mlinarić, Z.; Antunović, M.; Marijanović, I.; Fontinha, D.; Prudêncio, M.; Held, J. SAHA-primaquine hybrids (sahaquines) as potential anticancer and antimalarial compounds. Chem. Open, submitted.

30. Chemicalize, 2017, ChemAxon Ltd. Available online: http:/ /www.chemicalize.org (accessed on 5 April 2018).

31. Hufnagel, D.A.; Price, J.E.; Stephenson, R.E.; Kelley, J.; Benoit, M.F.; Chapman, M.R. Thiol starvation induces redox-mediated dysregulation of Escherichia coli biofilm components. J. Bacteriol. 2018, 200, e00389-17. [CrossRef] [PubMed]

32. Lee, S.F.; Davey, L. Disulfide bonds: A key modification in bacterial extracytoplasmic proteins. J. Dent. Res. 2017, 96, 1465-1473. [CrossRef] [PubMed]

33. Flanagan, M.E.; Abramite, J.A.; Anderson, D.P.; Aulabaugh, A.; Dahal, U.P.; Gilbert, A.M.; Li, C.; Montgomery, J.; Oppenheimer, S.R.; Ryder, T.; et al. Chemical and computational methods for the characterization of covalent reactive groups for the prospective design of irreversible inhibitors. J. Med. Chem. 2014, 57, 10072-10079. [CrossRef] [PubMed]

34. Oravcova, V.; Zurek, L.; Townsend, A.; Clark, A.B.; Ellis, J.C.; Cizek, A. American crows as carriers of vancomycin-resistant enterococci with vanA gene. Environ. Microbiol. 2014, 16, 939-949. [CrossRef] [PubMed]

35. Clinical and Laboratory Standards Institute. Performance Standards for Antimicrobial Susceptibility Testing; The 8th informational supplement document; CLSI: Wayne, PA, USA, 2012; M100-S22.

36. EUCAST, European Committee on Antimicrobial Susceptibility Testing. Determination of minimum inhibitory concentrations (MICs) of antibacterial agents by broth micro dilution. EUCAST Discussion Document. Clin. Microbiol. Infect. 2013, 9, 1-10.

37. Schwalbe, R.; Steele-Moore, L.; Goodwin, A.C. (Eds.) Antimicrobial Susceptibility Testing Protocols; CRC Press: Boca Raton, FL, USA, 2007.

38. Sheehan, D.J.; Espinel-Ingroff, A.; Steele, M.; Webb, C.D. Antifungal susceptibility testing of yeasts: A brief overview. Clin. Infect. Dis. 1993, 17, 494-500. [CrossRef]

39. Stepanović, S.; Vuković, D.; Hola, V.; Di Bonaventura, G.; Djukić, S.; Cirković, I.; Ruzicka, F. Quantification of biofilm in microtiter plates: Overview of testing conditions and practical recommendations for assessment of biofilm production by Staphylococci. APMIS 2007, 115, 891-899. [CrossRef] [PubMed]

40. Tzioumaki, N.; Manta, S.; Tsoukala, E.; Vande Voorde, J.; Liekens, S.; Komiotis, D.; Balzarini, J. Synthesis and biological evaluation of unsaturated keto and exomethylene D-arabinopyranonucleoside analogs: Novel 5-fluorouracil analogs that target thymidylate synthase. Eur. J. Med. Chem. 2011, 46, 993-1005. [CrossRef] [PubMed]

41. Li, Q.; Lescrinier, E.; Groaz, E.; Persoons, L.; Daelemans, D.; Herdewijn, P.; De Jonghe, S. Synthesis and biological evaluation of pyrrolo[2,1-f][1,2,4] triazine C-nucleosides with a ribose, $2^{\prime}$-deoxyribose, and 2',3'-dideoxyribose sugar moiety. ChemMedChem. 2018, 13, 97-104. [CrossRef] [PubMed]

Sample Availability: Samples of all compounds are available from the authors.

(C) 2018 by the authors. Licensee MDPI, Basel, Switzerland. This article is an open access article distributed under the terms and conditions of the Creative Commons Attribution (CC BY) license (http:/ / creativecommons.org/licenses/by/4.0/). 


\title{
Weinreb Amides as Directing Groups for Transition Metal-Catalyzed C-H Functionalizations
}

\author{
Jagadeesh Kalepu and Lukasz T. Pilarski * \\ Department of Chemistry-BMC, Uppsala University, BOX 576, 75-123 Uppsala, Sweden; \\ jagadeesh.kalepu@kemi.uu.se \\ * Correspondence: lukasz.pilarski@kemi.uu.se \\ Academic Editor: Michal Szostak \\ Received: 28 January 2019; Accepted: 15 February 2019; Published: 26 February 2019
}

\begin{abstract}
Weinreb amides are a privileged, multi-functional group with well-established utility in classical synthesis. Recently, several studies have demonstrated the use of Weinreb amides as interesting substrates in transition metal-catalyzed C-H functionalization reactions. Herein, we review this part of the literature, including the metal catalysts, transformations explored so far and specific insights from mechanistic studies.
\end{abstract}

Keywords: $\mathrm{C}-\mathrm{H}$ functionalization; directing groups; amides; transition metals; catalysis

\section{Introduction}

The pursuit of efficient methods for the direct, catalytic substitution of otherwise inert C-H bonds in organic molecules has become a major area of research focus in recent years [1]. Tremendous advances have been made in the development of previously impossible transformations [2-5], mechanistic understanding [6-9], milder and safer protocols [10], and selectivity [11-14]. The ubiquity of $\mathrm{C}-\mathrm{H}$ bonds in organic molecules makes their regioselective activation and substitution particularly attractive, but also challenging. To this end, the use of directing groups-parts of an organic substrate that can coordinate to and position a metal center over the desired C-H bond-has met with enormous success [15]. The use of ortho-directing groups especially has provided the basis of many new homogeneous catalytic C-H functionalization reactions [16]. Directing groups able to deliver meta $[17,18]$ and para [19] selectivity in C-H functionalization catalysis have also been described, although the generality of that approach is still some way off in the future.

Ideally, directing groups should not require separate and/or laborious installation/removal or otherwise be inutile in later steps of a synthesis. It is preferable that they should either be part of the desired target compound or that they could be converted to another useful group once their role during the $\mathrm{C}-\mathrm{H}$ functionalization step is over. A plethora of strategies to realize the latter objective has been pursued. The invention of various removable or modifiable [20-22], traceless [23], or otherwise transient [24-29] directing groups has formed a sizeable category in and of itself within the field of $\mathrm{C}-\mathrm{H}$ functionalization catalysis.

Amides are an incomparably important class of compounds. The development of methods for their selective synthesis and derivatization is, therefore, a key pursuit in synthetic methodology. That the amide group can serve as a ligand for transition metals enables various new approaches to this via catalytic C-H functionalization [30]. Most commonly, the amide group has been called upon to direct the catalytic substitution of neighboring Ar-H bonds but, as discussed below, they also enable $\mathrm{C}\left(\mathrm{sp}^{3}\right)-\mathrm{H}$ bond manipulation.

$N$-methoxy- $N$-methyl amides (1, Figure 1), or Weinreb amides [31], are a valuable branch of the amide family. They provide the 'textbook' route to mono-addition products (especially ketones and aldehydes) via nucleophilic attack on the carbonyl group. Such attacks give rise to stable 
five-membered tetrahedral cyclic intermediates (2) to which a second addition ("over-addition") is precluded. Weinreb amides may be prepared with ease from carboxylic acids or their chlorides, esters, aldehydes or ketones [32].

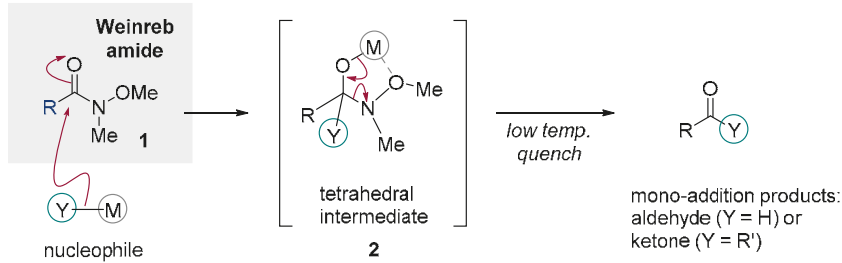

Figure 1. The 'textbook' application of Weinreb amides: generation of mono-addition products resulting from nucleophilic attack on their carbonyl groups.

That Weinreb amides can also steer the regioselectivity of transition metal-catalyzed C-H functionalizations (Figure 2) qualifies them as noteworthy multi-functional directing groups. Remarkably, and despite the various synthetic advantages of this (for example that it can obviate the need for lithiation strategies and make available previously impossible reactions), Weinreb amides have only recently attracted attention as substrates for $\mathrm{C}-\mathrm{H}$ functionalization. In part, this is due to the amide oxygen's weaker coordination ability to most transition metal centers. The latter has presented a challenge to the development of their use in $\mathrm{C}-\mathrm{H}$ functionalization reactions, although many carbonyl-directed reactions are now known [33].

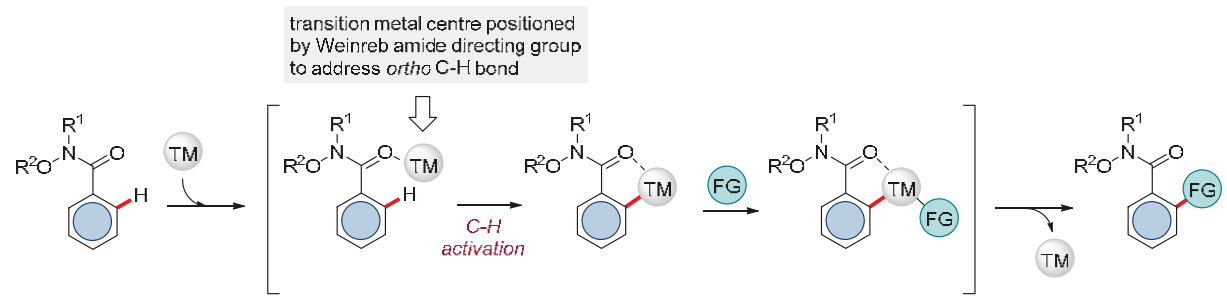

Figure 2. A generic representation of a Weinreb amide-directed catalytic $\mathrm{C}-\mathrm{H}$ functionalization $(\mathrm{TM}=$ transition metal).

This review describes progress in the use of Weinreb amides as directing groups in catalytic C-H functionalization. A variety of reactions falls under this category. We have chosen to group these according to the transition metal center responsible for the $\mathrm{C}-\mathrm{H}$ functionalization catalysis, rather than the overall transformation, in order to maximize the ease of comparison between researchers working in similar areas, and to track the different rates at which progress has occurred and insights in to the underlying mechanisms. Overwhelmingly, the focus of the studies reviewed herein falls on the utility of Weinreb amides as directing groups for the $\mathrm{C}-\mathrm{H}$ functionalization step. Therefore, whilst several publications describe subsequent manipulation of the Weinreb amide group, this is usually to illustrate the possibility, rather than a key development. We have opted therefore not to include many examples of the latter; we take the possibility of a posteriori conversion of Weinreb amides using conventional approaches (e.g., to ketones or aldehydes), for the most part, to be a safe assumption.

\section{Ru-catalyzed Reactions}

The versatility of $\mathrm{Ru}$, as well as its considerably lower price compared to other 2nd and 3rd-row transition metals, make it an appealing candidate around which to develop economical C-H functionalization methodology [34,35]. Moreover, considerable advances have been made in Ru-catalyzed C-H functionalization directed by weakly coordinating groups, including amides [33]. 
In 2013, Ackermann and co-workers described the Weinreb amide-directed C-H ortho-oxygenation of arenes 3 using a $\mathrm{Ru}(\mathrm{II})$-based system [36]. [ $\mathrm{RuCl}_{2}$ ( $p$-cymene) $]_{2}$ served as the catalyst precursor and $\mathrm{PhI}(\mathrm{OAc})_{2}$ as the most effective oxidant. Representative results from the study are shown in Scheme 1a.

A. Representative scope of Ru(II)-catalyzed C-H ortho-oxygenation of Weinreb amides:

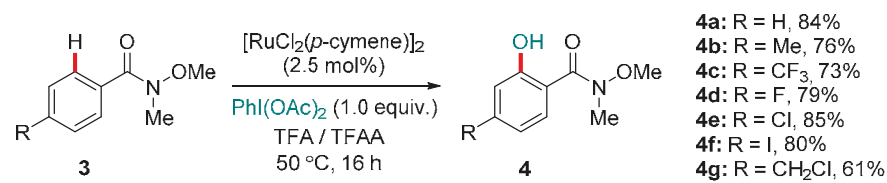

B. Reduction of the Weinreb amide directing group to the corresponding aldehyde:

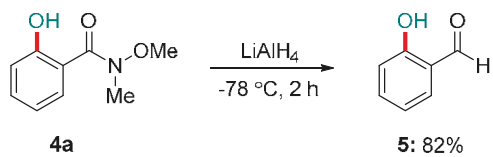

Scheme 1. $\mathrm{Ru}(\mathrm{II})$-catalyzed $\mathrm{C}-\mathrm{H}$ oxidation of arenes directed by a Weinreb amide group. (a) Representative scope of the reaction with respect to arene substituents; (b) Reduction of the Weinreb amide to reveal aldehyde functionality.

The reaction showed a high selectivity for mono-oxygenated products 4 , a preference for electron-rich substrates in competition experiments, and a kinetic isotope effect (KIE) of $k_{\mathrm{H}} / k_{\mathrm{D}}=3.0$ [6]. The authors proposed that an irreversible C-H activation event was a key step en route to the products. It is notable that the $N$-alkyl substituent could also be varied substantially without any loss of reaction efficiency. The Weinreb amide group could be reduced in high yield (4a to 5) to reveal the corresponding aldehyde (Scheme 1b). A single Weinreb amide substrate was also shown to work as part of a study by Jeganmohan and co-workers on the ortho-directed C-H benzoyloxylation of various amides. The reaction system closely resembled that reported above by Ackermann, except for the use of $\left(\mathrm{NH}_{4}\right) \mathrm{S}_{2} \mathrm{O}_{8}$ as the terminal oxidant, higher temperatures and use of 1,2-dichloroethane as solvent [37].

Subsequently, Das and Kapur produced a report demonstrating the Ru-catalyzed olefination of various amides, including Weinreb amide-decorated arenes [38]. The protocol closely resembles the Pd-catalyzed oxidative Heck reaction [39] (also known as the Fujiwara-Moritani reaction) and other related Ru-catalyzed C-H alkenylations [34]. However, for the majority of their entries (selected examples are shown in Scheme 2a), the authors observed cleavage of the Weinreb amide $\mathrm{N}-\mathrm{O}$ bond; $\mathrm{N}$-methyl amides were obtained as the main products. It is instructive to consider the proposed mechanism, an adapted version of which is shown in Scheme $2 \mathrm{~b}$. Presumably, the $\mathrm{N}-\mathrm{O}$ bond serves as an oxidant with $\mathrm{Cu}(\mathrm{OAc})_{2} \cdot \mathrm{H}_{2} \mathrm{O}$ as the carboxylate source to facilitate repeated C-H functionalization [40] The use of similar "internal oxidant" strategies in C-H functionalization, including using $\mathrm{N}$-methoxy amides, has been recently reviewed by Cui and co-workers [41]. Exceptions wherein the $\mathrm{N}-\mathrm{O}$ bond was preserved presumably resulted from $\mathrm{Cu}$ (II) (or $\mathrm{Cu}$ (III) species arising via disproportionation) outcompeting $\mathrm{N}-\mathrm{O}$ as an internal oxidant. The importance of such examples is under-appreciated, in our view. That an exogenous oxidant may divert reactivity away from damaging a group under otherwise identical conditions is a key aspect of modulating functional group tolerance; a factor that will govern the extent to which $\mathrm{C}-\mathrm{H}$ activation-and other catalytic methods-gain acceptance as generalizable routes to construct molecular complexity.

Das and Kapur reported that five-membered cyclic amides of the type $7(n=0)$ typically underwent $\mathrm{N}-\mathrm{O}$ bond cleavage, affording ring-opened products. To prevent this, and thereby retain the Weinreb amide functionality, they subsequently sought to show that $\mathrm{N}-\mathrm{O}$ bond cleavage could be prevented through judicious substrate design [42]. Increasing the Weinreb amide size to six- and seven-membered rings $(7, n=1$ or 2 , respectively) rendered the $\mathrm{N}-\mathrm{O}$ bond cleavage energetically 
unfavorable. Under otherwise unchanged conditions, the oxidative $\mathrm{C}-\mathrm{H}$ olefination afforded products 8 (Scheme 3), restoring $\mathrm{Cu}(\mathrm{II})$ to its role as the terminal oxidant. Further manipulation of the cyclic Weinreb amide moieties in 8 , for example in their conversion to the corresponding aldehyde or ketones, was demonstrated to proceed in high yield.

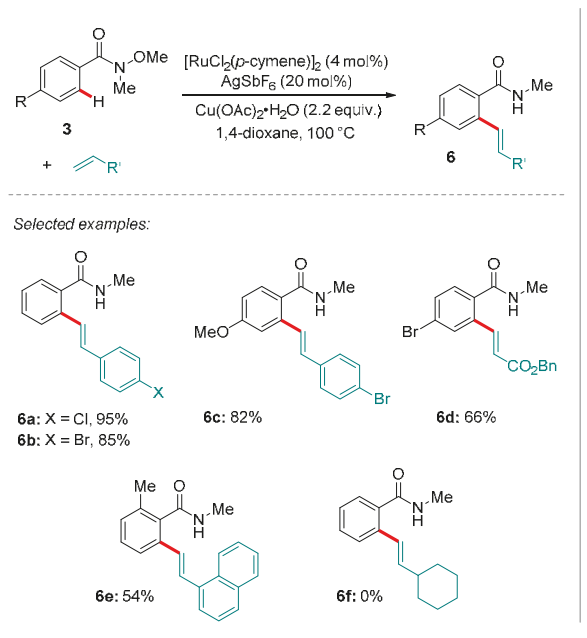

(a)

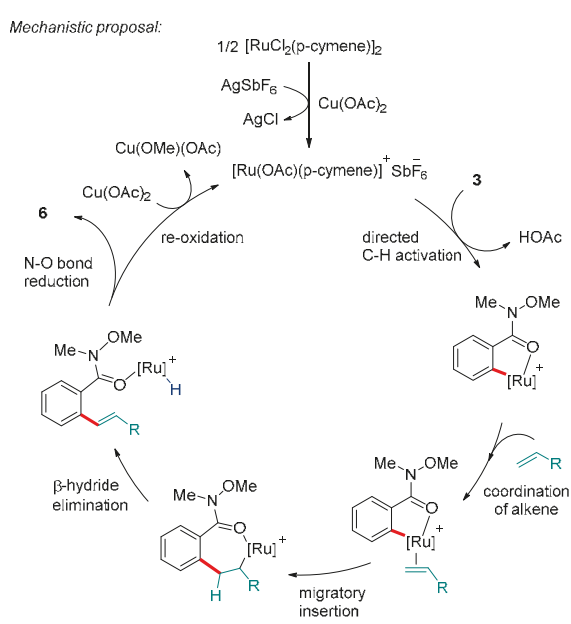

(b)

Scheme 2. $\mathrm{Ru}(\mathrm{II})$-catalyzed oxidative $\mathrm{C}$-H ortho-alkenylation of Weinreb amides; selected products and proposed mechanism.
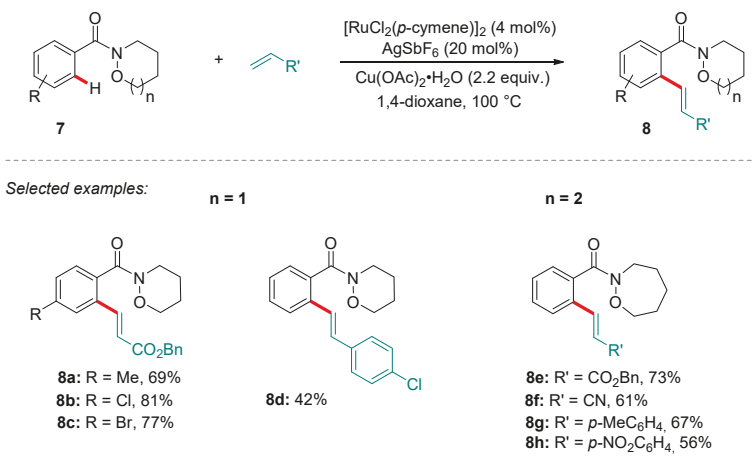

Proposed intermediates:

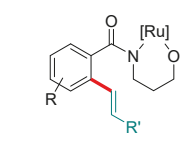

9a

6-membered ruthenacycle (accessible)

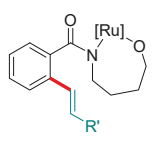

$9 b$

7-membered ruthenacycle (disfavored)

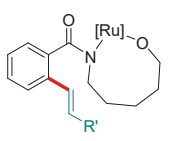

$9 \mathrm{c}$

8-membered ruthenacycle (disfavored)

Scheme 3. Ru-catalyzed C-H olefination using directed by cyclic Weinreb amides without N-O bond cleavage. Putative intermediates $\mathbf{9 a}-\mathbf{c}$ are suggested to arise from the insertion of $\mathrm{Ru}$ into the substrate $\mathrm{N}-\mathrm{O}$ bond. 
An explanation for the greater relative stability of the 6- and 7-membered cyclic Weinreb amide groups in this protocol was proposed: In the course of the reaction, oxidative addition of the Ru center to the $\mathrm{N}-\mathrm{O}$ bond would furnish intermediates of type $\mathbf{9}$. Of these, only the formation of $9 \mathrm{a}$ would be favorable; the 7 - and 8-membered ruthenacycles ( $9 \mathbf{b}$ and $9 \mathbf{c}$, respectively) are presumably too high in energy to be accessed.

\section{Co-catalyzed Reactions}

The expense and eventual scarcity of second- (4d) and third-row (5d) transition metals has, in recent years, motivated a shift towards exploring the potential of their more abundant first-row (3d) cousins for catalytic $\mathrm{C}-\mathrm{H}$ functionalization [43]. Cobalt stands out in this context as a comparatively cheap, abundant option that comes with a proven track record in broad areas of homogenous catalysis, including several industrially important reactions [44-46].

In 2013, Yoshino and Matsunaga disclosed the first C-H ortho-directed functionalization catalyzed by $\mathrm{Cp}^{*} \mathrm{Co}(\mathrm{III})$ species $[47,48]$. In a subsequent study on the Co-catalyzed $\mathrm{C}-\mathrm{H}$ allylation of aryl purines and benzamides using allylic alcohol, they demonstrated the new reaction also on Weinreb amide 3a [49]. Here, the bench-stable complex $\mathrm{Cp}^{*} \mathrm{Co}(\mathrm{CO}) \mathrm{I}_{2}$, which was previously shown by Matsunaga and Kanai to be highly efficient for indole $\mathrm{C} 2-\mathrm{H}$ amidation [50], served as the pre-catalyst (Scheme 4). Hexafluoroisopropanol (HFIP) [51,52] was needed for the C-H allylation, as were acetate salts. The authors interpreted the latter as an indication that the $\mathrm{C}-\mathrm{H}$ activation proceeded via a Concerted-Metalation-Deprotonation (CMD) mechanism [53], as has been elucidated in more detail for second row transition metals $[8,40,54]$. The moderate yield of product $9 a$ in this reaction was attributed to the weaker coordinating ability of the Weinreb amide group compared to its simpler benzamide relatives or, indeed, to that of the purine $\mathrm{N}_{\mathrm{sp}}^{2}$ centers.

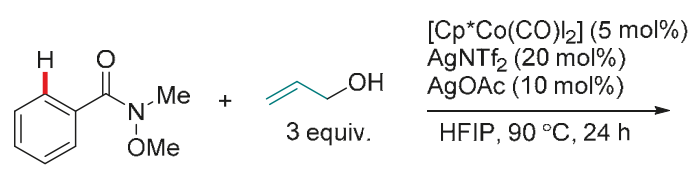

$3 a$

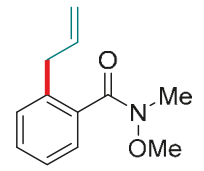

9 a, $44 \%$

Scheme 4. An initial example of the Weinreb amide-directed Co(III)-catalyzed ortho-C-H allylation.

In a later study, the group published a considerably expanded range of Co-catalyzed $\mathrm{C}-\mathrm{H}$ functionalizations using aromatic Weinreb amides (Scheme 5) [55]. These included C-H allylation using allylic carbonates (Scheme 5A), C-H alkenylation under oxidative conditions (Scheme 5B), C-H iodination using $\mathrm{N}$-iodosuccinimide (Scheme 5C) [56] and C-H amidation using dioxazolones (Scheme 5D). These systems relied on similar combinations of $\left[\mathrm{Cp}{ }^{*} \mathrm{Co}(\mathrm{CO}) \mathrm{I}_{2}\right]$ pre-catalyst, a cationic silver additive $\left(\mathrm{AgNTf}_{2}\right.$ or $\left.\mathrm{AgSbF}_{6}\right)$ and $\mathrm{AgOAc}$. Unlike in the Ru-catalyzed case (see Scheme 2), the $\mathrm{N}-\mathrm{O}$ bond of the Weinreb amide moiety was preserved. Competition and kinetic isotope exchange experiments showed that the $\mathrm{C}-\mathrm{H}$ activation event in the case of the allylation reaction was both rate-limiting and all but irreversible, supplying further evidence for the CMD pathway Yoshino and Matsunaga proposed in their earlier study [49]. Their proposed mechanism for the Co(III)-catalyzed $\mathrm{C}-\mathrm{H}$ allylation is shown in Figure 3. In related recent work, Whiteoak and Hamilton have elucidated the mechanistic details governing the oxidative Co-catalyzed C-H alkenylation of amides, and specifically whether and why alkyl or alkenyl products are obtained depending on the choice of alkene substrate [57]. 


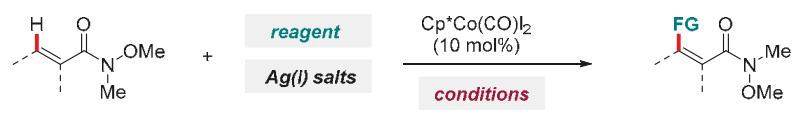

3

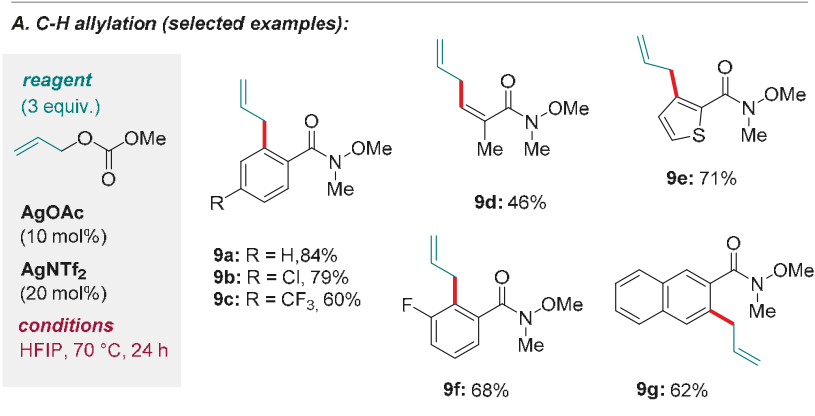

B. C-H alkenylation (selected examples):

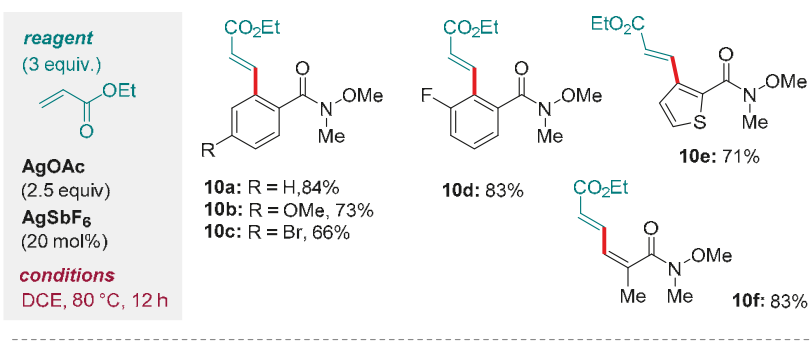

\section{C-H iodination (selected examples):}
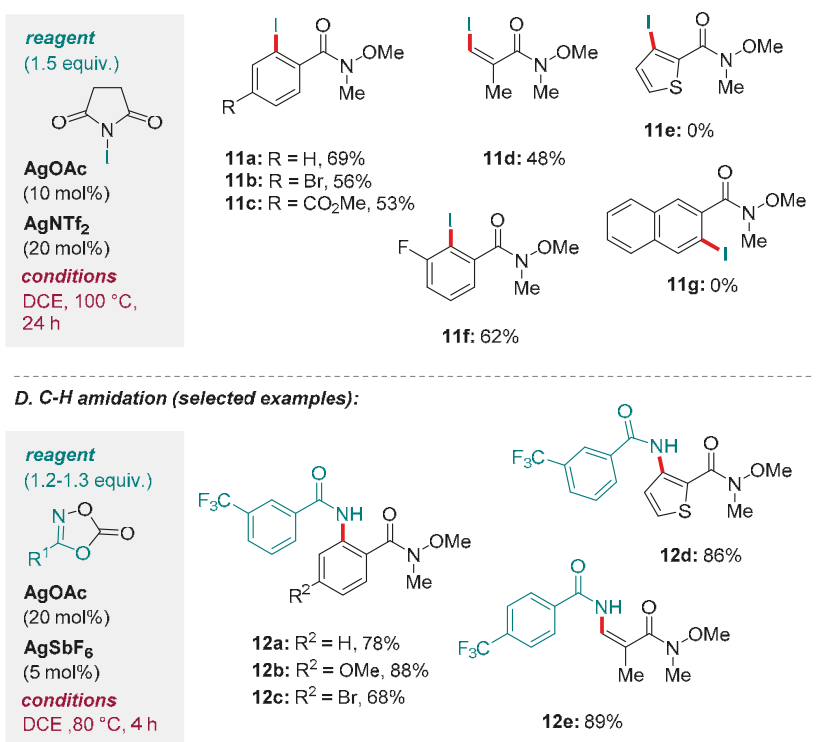

Scheme 5. Selected examples of C-H transformations enabled by a Co(III)-catalyzed system. 


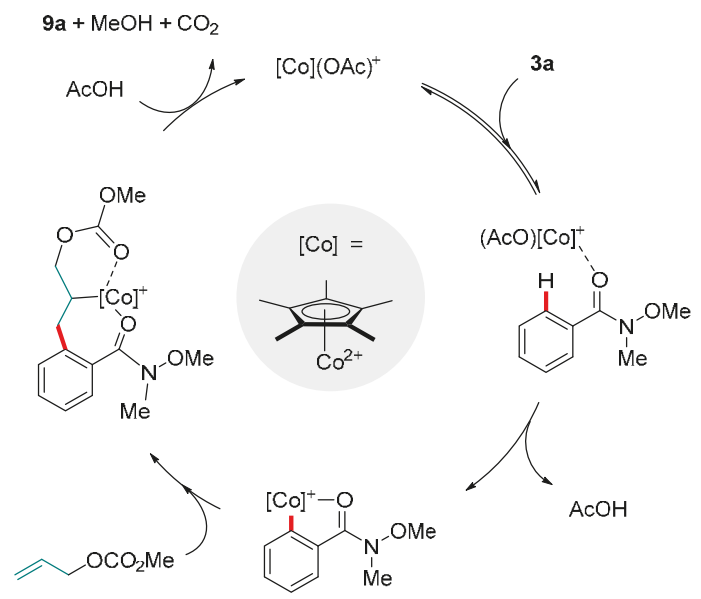

Figure 3. A mechanism proposed by Yoshino and Matsunaga for the Co(III)-catalyzed C-H allylation of Weinreb amides.

The relevance to wider synthetic contexts of the transformations reported by Yoshino and Matsunaga was demonstrated through the conversion of the Weinreb amide group in their various products to the corresponding ketones, aldehydes and alkenes. This thus delivers several motifs whose preparation might otherwise be longer and more demanding.

\section{Pd-catalyzed Reactions}

Palladium is perhaps the most firmly established metal for coupling chemistry [58-62], and this has translated to its high level of popularity for C-H functionalization reactions [16,63-66]. Many Pd-based catalysts are well-defined $[67,68]$, permitting systematic tuning of their properties, and are understood, most usually, to work via $\mathrm{Pd}(0) / \mathrm{Pd}(\mathrm{II})$ or $\mathrm{Pd}(\mathrm{II}) / \mathrm{Pd}(\mathrm{IV})$ manifolds $[62,64,66]$. Despite the prevalence of many ortho-directing groups, including several closely related amides [30], there have been relatively few examples of Pd-catalyzed reactions using Weinreb amides.

In 2015, Wang and co-workers reported the first Weinreb amide-directed C-H functionalization catalyzed by Pd. The reaction took place between either aryl Weinreb amides 3 (Scheme 6a) or benzyl amides 13 and iodoarenes using $\mathrm{Pd}(\mathrm{OAc})_{2}$ as the pre-catalyst in DCE solvent [69]. Both Weinreb types showed high tolerance towards electron-donating and electron-withdrawing substituents, as well as halogens (e.g., the bromide in $\mathbf{1 5 d}$ ). However, benzyl amides showed considerably worse mono-selectivity, except if meta substituents were present (e.g., 15c and 15d) presumably to impart steric hindrance.

(a)

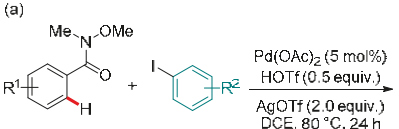

3

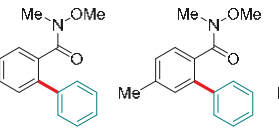

14a: $91 \%(5 \%)$

14b: $93 \%(6 \%)$

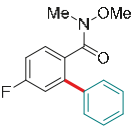

14c: $71 \%$ (8\%)

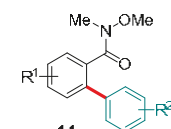

14

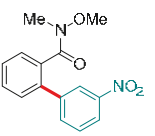

14d: $96 \%$

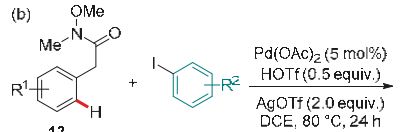

13
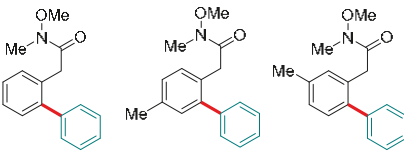

15c: $81 \%$
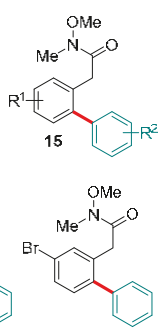

15d: $72 \%$

Scheme 6. Pd-catalyzed C-H arylation of (a) aryl and (b) benzyl amides. Yields in parentheses refer to the amount of di-arylated products detected. 
Figure 4 shows one of the proposed mechanisms, adapted for the specific case of substrate $3 \mathbf{a}$. A kinetic isotope effect (KIE) of 1.1 suggested that the C-H activation step itself (forming 16 from 3 ) was not rate-determining. Oxidative addition of the aryl iodide to $\mathbf{1 6}$ was postulated to form $\mathbf{1 7}$ from which the product 14a is formed via reductive elimination. The authors reported that AgOTf, as well as acting as an oxidant, was crucial for the reaction and hypothesized that in situ generated $\mathrm{Pd}(\mathrm{OTf})_{2}$ is a key aspect of the catalytic cycle. (We note that the various roles Ag plays in Pd-catalyzed reactions have recently been reviewed by Pérez-Temprano and co-workers [70].)

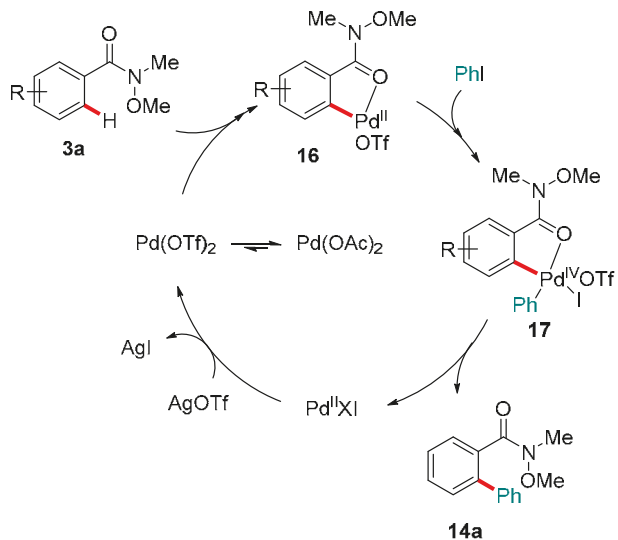

Figure 4. Mechanism proposed by Wang and co-workers for the C-H ortho-arylation of Weinreb amides proceeding via $\mathrm{Pd}(\mathrm{IV})$ intermediates.

To the best of our knowledge, the only other example of a Pd-catalyzed Weinreb amide-directed $\mathrm{C}-\mathrm{H}$ arylation comes from a single entry in a study by Bhanage and workers on the use of anilines as arylating reagents for N-methoxybenzamides (Scheme 7) [71]. Conditions were largely analogous to those described for Wang's reaction above, with the principal exception that aniline underwent in situ oxidation using ${ }^{t} \mathrm{BuONO}$ to generate the electrophilic coupling partner. However, the yield for the Weinreb amide specifically was low, indicating that although this approach holds some promise, it is harder to optimize for the Weinreb amide compared to the using more conventional coupling partners.

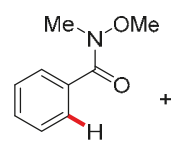

$3 a$

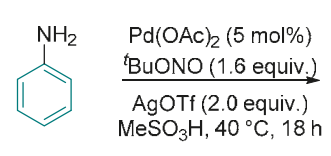

$\mathrm{MeSO}_{3} \mathrm{H}, 40^{\circ} \mathrm{C}, 18 \mathrm{~h}$

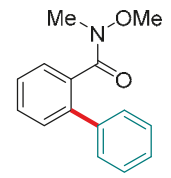

14a: $21 \%$

Scheme 7. Bhanage's C-H arylation using aniline as the electrophile source.

Also in 2015, Yu and co-workers described conditions for the efficient alkenylation and acetoxylation of Weinreb amides (Scheme 8) [72], overcoming the additional entropic penalty imposed by the extra methylene unit present in the directing group (and thus the challenge of forming seven-membered palladacyclic intermediates). In keeping with related protocols reported by Yu and co-workers, the presence of Ac-Gly-OH was found to be crucial to facilitate the $\mathrm{C}-\mathrm{H}$ functionalization step [73].

$\mathrm{Yu}$ and co-workers found the olefination reaction to have moderate to excellent yields, exclusively mono C-H olefination with ortho and meta-substituted benzyl Weinreb amides, but reduced selectivity if the substituents were positioned para with respect to the directing group (Scheme 8). 


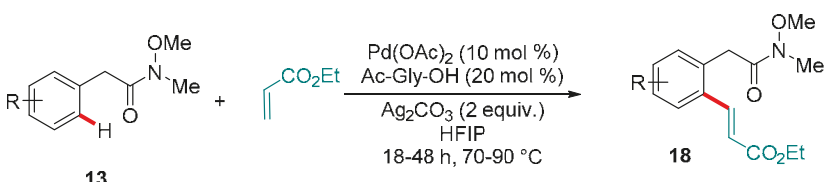

13

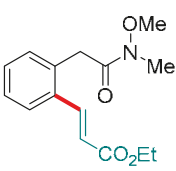

$18 \mathrm{a}$

$29 \%(58 \%)$

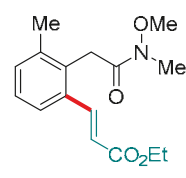

$18 \mathrm{~b}$<smiles>CCOCCc1cc(C)ccc1CC(=O)N(C)C</smiles>

$18 \mathrm{c}$ $20 \%(47 \%)$<smiles>CCOC(=O)C=Cc1cccc(C(F)(F)F)c1CC(=O)N(C)C</smiles>

$18 d$

$92 \%$

Scheme 8. Yu and co-workers' protocol for the oxidative ortho C-H acetoxylation of benzylic Weinreb amides. Yields in parentheses refer to the amount of di-olefinated products detected.

The acetoxylation of benzyl amides (Scheme 9) used $\mathrm{PhI}(\mathrm{OAc})_{2}$ as the oxidant in the presence of either $\mathrm{Ac}_{2} \mathrm{O}$ or tert-butyl peroxyacetate $\left(\mathrm{MeC}(\mathrm{O}) \mathrm{OO}^{t} \mathrm{Bu}\right)$. Yields and tolerance towards various substituents were good (examples 19a-c). Furthermore, it was possible to expand the scope by an extra methylene unit (i.e., the reaction can proceed with good efficiency via an 8-membered palladacycle) to give product $19 \mathrm{~d}$.<smiles>[R]OC(=O)Cc1ccccc1</smiles>

13

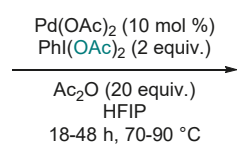

$18-48 \mathrm{~h}, 70-90^{\circ} \mathrm{C}$

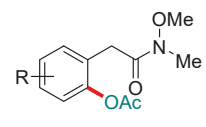

19<smiles>COC(=O)Cc1ccccc1OC(C)=O</smiles>

$70 \%(22 \%)$<smiles>CON(C)C(=O)Cc1c(OC(C)=O)cccc1[N+](=O)[O-]</smiles>

$19 \mathrm{~b}$
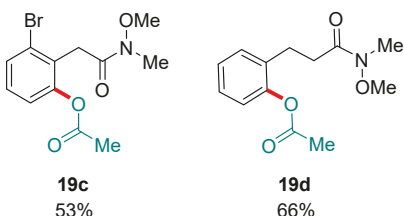

Scheme 9. Yu and co-workers' protocol for the oxidative ortho $\mathrm{C}-\mathrm{H}$ acetoxylation of benzylic Weinreb amides. Yields in parentheses refer to the amount of di-acetoxylated products detected.

The introduction of halogens to organic substrates is an inherently valuable pursuit in methodology development, owing the great versatility of C-halogen bonds in synthesis [74]. In 2017, the group of Kapur disclosed the Pd-catalyzed $\mathrm{C}-\mathrm{H}$ halogenation (iodination, bromination and chlorination) of Weinreb amides (Scheme 10) [75]. The reaction relied on a combination of $\mathrm{Pd}(\mathrm{OAc})_{2}$ and $\mathrm{Cu}(\mathrm{OTf})_{2}$ with $\mathrm{N}$-halo-succinimide (NXS; $\mathrm{X}=\mathrm{I}, \mathrm{Br}$ or $\mathrm{Cl}$ ) as the halogen source. The reaction worked well with a variety of substituents, except for nitro groups, which switch off the reaction from either of the ortho or para position. 


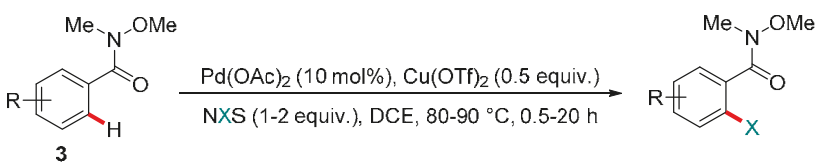<smiles>[X]c1ccccc1C(=O)N(C)OC</smiles><smiles>[X]c1cc(F)ccc1C(=O)N(C)OC</smiles><smiles>[X]c1cc(Cl)ccc1C(=O)N(C)OC</smiles><smiles>COc1cccc(C(=O)N(C)OC)c1Br</smiles>
11a: I $(68 \%)$
20a: $\operatorname{Br}(81 \%)$
21a: $\mathrm{Cl}(62 \%)$

20d: $64 \%$

Scheme 10. Kapur and co-workers' reaction for the ortho $\mathrm{C}-\mathrm{H}$ halogenation of aromatic Weinreb amides.

Mechanistic studies suggested that the C-H activation step was irreversible, but not rate-limiting. The catalytic cycle (Figure 5) was proposed to proceed via a route closely related to that of the corresponding arylation reaction (Figure 4, above): carbonyl directed cyclometallation to give 22 precedes oxidative addition into NXS, the latter of which produces $\mathrm{Pd}(\mathrm{IV}$ ) species 23 (a bimetallic Pd(III) species [76-79] — not shown—is also possible). Thereafter, reductive elimination releases the desired product.

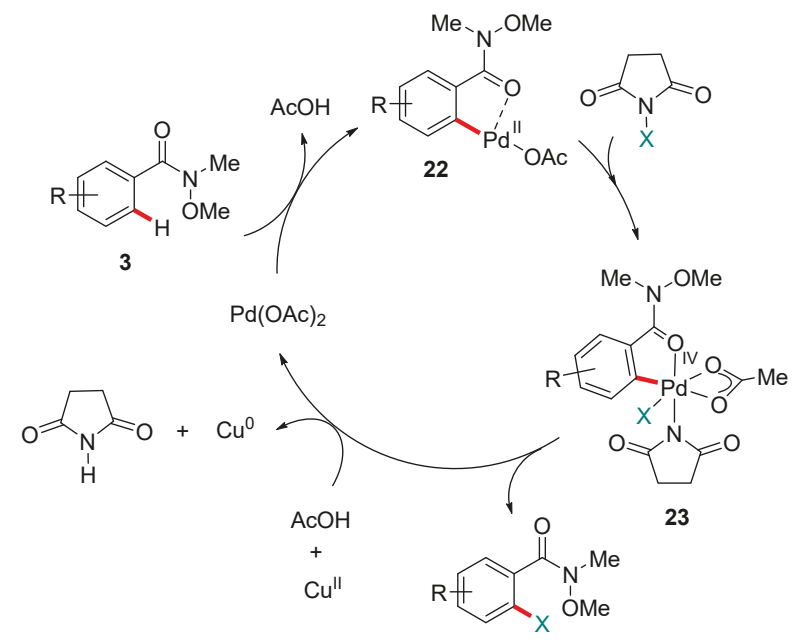

Figure 5. An adapted version of the mechanism proposed by Kapur and co-workers for the Pd-catalyzed ortho C-H halogenation of aromatic Weinreb amides. $\mathrm{X}=\mathrm{Cl}^{-}, \mathrm{Br}^{-}$or $\mathrm{I}^{-}$.

2018 saw Yu and co-workers extend the utility of the Weinreb amide directing group further [80]. This time, the $\mathrm{Yu}$ group used it as the basis for directing Pd-catalyzed $\mathrm{C}_{\mathrm{sp}}{ }^{3}-\mathrm{H}$ arylation of alkyl groups (Scheme 11). The discovery of general and efficient methods that allow selective substitution of $\mathrm{C}\left(\mathrm{sp}^{3}\right)-\mathrm{H}$ at transition metal centers is a long-standing challenge. For Pd, progress has been notably rapid in in the past few years [63,81-83], and its various aspects have been reviewed recently $[65,84,85]$. 


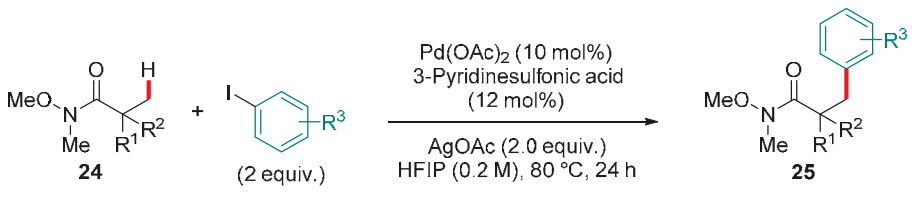

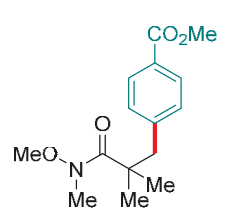

25a: $61 \%(15 \%)$

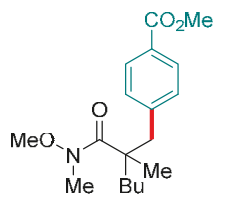

25b: $63 \%(5 \%)$

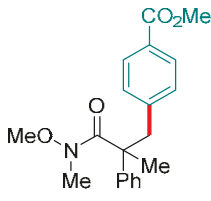

25c: $59 \%$
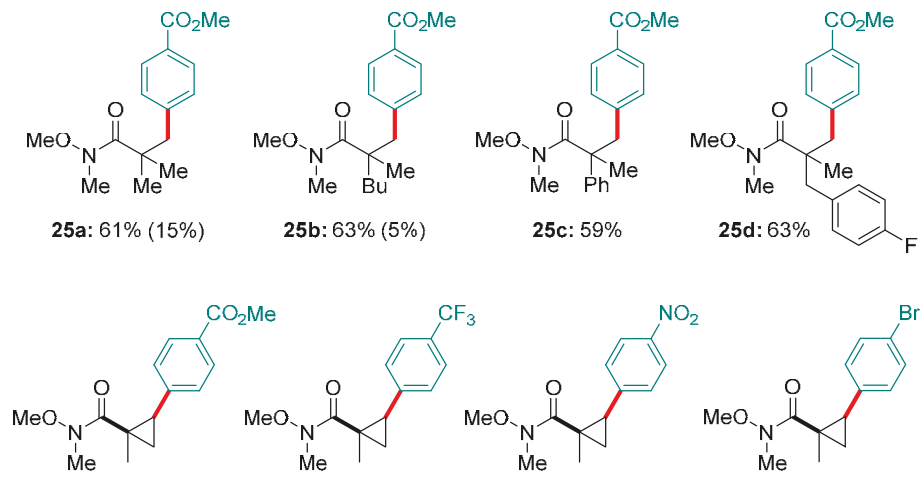

25e: $97 \%$

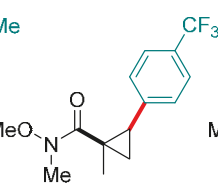

25f: $86 \%$

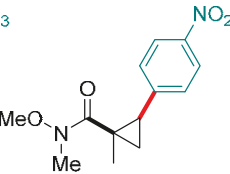

25g: $83 \%$

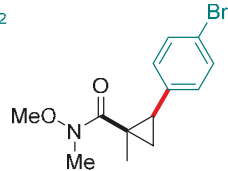

25h: $80 \%$

Scheme 11. Selected scope from Yu and co-workers' Pd-catalyzed C $\left(\mathrm{sp}^{3}\right)$-H arylation protocol enabled by Weinreb amide directing groups.

$\mathrm{Yu}$ and co-workers found that the inclusion of 3-pyridinesulfonic acid was crucial to the reaction, both Weinreb and other amides. Computational studies at the DFT level revealed that 3-pyridinesulfonic acid stabilizes cationic Pd intermediates during the reaction and that it promotes the dissociation of acetate ligands, which is required for the $\mathrm{C}\left(\mathrm{sp}^{3}\right)-\mathrm{H}$ bond cleavage to occur [80].

\section{Rh-catalyzed Reactions}

The first two decades of this century have seen an explosion of interest in the use of Rh(III) catalysts for selective C-H functionalization. Substantial progress has been made in both scope $[86,87]$ and attendant mechanistic understanding [7,88-90]. As part of their efforts to answer key questions relating to the regioselectivity of $\mathrm{Rh}(\mathrm{III})$-catalyzed transformations, Rovis and co-workers reported in 2013 an intramolecular alkene hydroarylation directed by Weinreb amide $\mathbf{2 6}$ in excellent yield (Scheme 12) [91].

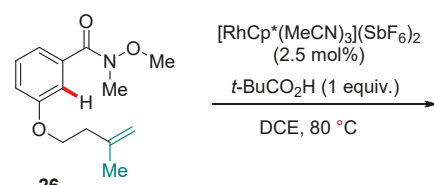

26

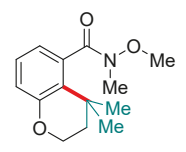

$91 \%$

Scheme 12. A Rh(III)-catalyzed, Weinreb amide-directed alkene hydroarylation.

Wang and co-workers reported a closely-related but more elaborate system, involving $\mathrm{Cu}(\mathrm{OAc})_{2}$ as a catalytic oxidant regenerated under air to retain olefin functionality at the end of a cycle coupling aromatic Weinreb amides with alkenes (Scheme 13) [92]. An ample scope demonstrated the reaction's tolerance towards various functional groups, including halogens, various ortho-substituents and a range of electron-donating and electron-withdrawing groups. Competition experiments revealed that electron-rich arenes reacted faster than their electron-poor counterparts. 


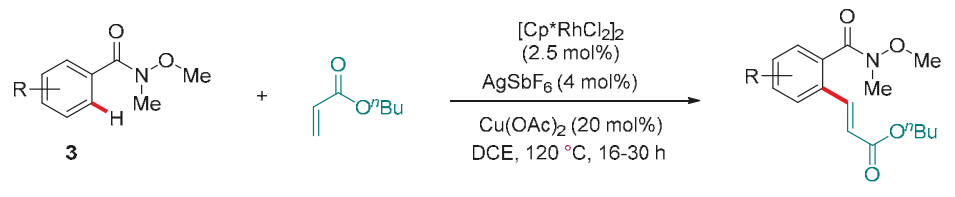<smiles>COC(=O)CCc1cc(Br)ccc1C(=O)N(OC)OC</smiles>

10g: $86 \%$ a,b<smiles>COC(=O)/C=C/c1cccc(OC)c1C(=O)N(OC)OC</smiles>

10h: $78 \%$<smiles>CCOC(=O)C=Cc1cccc(C)c1C(=O)N(OC)OC</smiles><smiles>COC(=O)/C=C/c1cc(OC(C)=O)ccc1C(=O)N([O-])OC</smiles>

10i: $96 \%$ 10j: $84 \%$<smiles>CCOC(=O)/C=C/c1cc(C#N)ccc1C(=O)N([O-])OC</smiles>

10k: $89 \%^{a}$<smiles>[Y10]N(OC)C(=O)c1ccc(C)cc1/C=C/C(=O)OCC</smiles>

10I: $85 \%$<smiles>CCOC(=O)/C=C/c1cc(-c2ccccc2)ccc1C(=O)N(OC)OC</smiles>

$10 \mathrm{~m}: 74 \%^{a, b}$

Scheme 13. Selected examples from Wang and co-workers' oxidative Rh-catalyzed C-H alkenylation directed by Weinreb amides. ${ }^{a}\left[\mathrm{Cp}^{*} \mathrm{RhCl}_{2}\right]_{2}(2.5 \mathrm{~mol} \%)$ and $\mathrm{AgSbF}_{6}(10 \mathrm{~mol} \%)$ loadings were used. ${ }^{\mathrm{b}}$ A reaction temperature of $130^{\circ} \mathrm{C}$ was used.

The mechanism proposed by Wang and co-workers (Figure 6) involved coordination of the $\mathrm{Rh}(\mathrm{III})$ center to the carbonyl moiety of the Weinreb amide, insertion of the alkene to the rhodacyclic intermediate (27), $\beta$-hydride elimination and regeneration of the active catalyst by $\mathrm{Cu}(\mathrm{OAc})_{2}$.
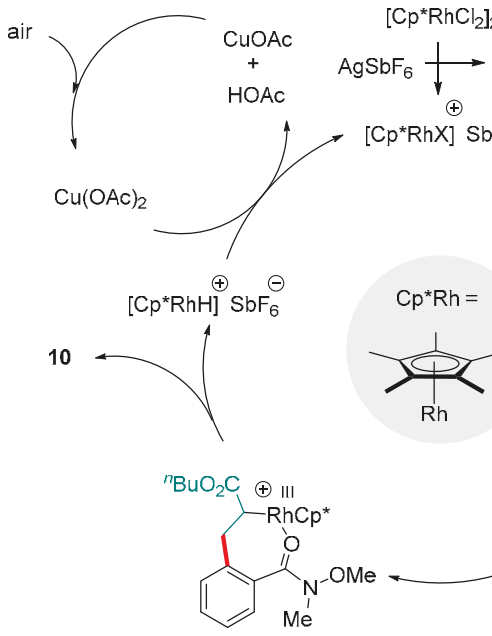

29
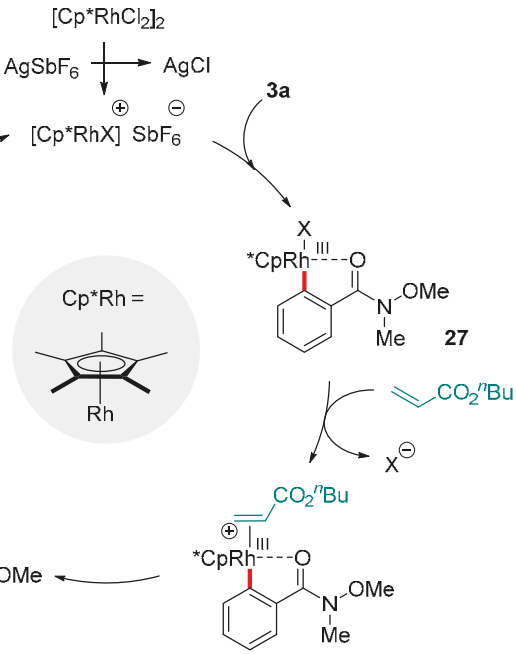

28

Figure 6. An adapted version of the mechanism proposed by Wang and co-workers for the oxidative C-H alkenylation of aromatic Weinreb amides catalyzed by $\mathrm{Rh}(\mathrm{III})$. 
Whilst, strictly speaking, it represents a slight departure from the current focus on the Weinreb amide group, it is noteworthy that a very closely related class of substrates, has been used extensively wherein their $\mathrm{C}(\mathrm{O}) \mathrm{NH}-\mathrm{OMe}$ bond as an "internal oxidant" for transition metal centers. Thus, $\mathrm{C}-\mathrm{H}$ functionalization reactions may be performed without exogenous oxidants. This strategy has worked with a number of transition metals, $\mathrm{Rh}(\mathrm{I} / \mathrm{III})$ catalytic cycles have dominated in this area [41].

In 2018, Qin and co-workers disclosed a near identical set of conditions to those used by Wang above, but using ethenesulfonyl fluoride (ESF) as the alkene coupling partner and 1,4-dioxane as the solvent [93]. However, the Qin group further observed that increasing the loading of $\mathrm{AgSbF}_{6}$ to 1 equivalent favored the formation of cyclic lactones. Residual water introduced from the hygroscopic $\mathrm{AgSbF}_{6}$ was proposed to promote the in situ hydrolysis of the Weinreb amide group to account for the lactone formation, though mechanistic work proved inconclusive. In switching away from Weinreb amides to $\mathrm{N}$-methoxybenazmides ( $\mathrm{ArC}(\mathrm{O}) \mathrm{NH}-\mathrm{OMe})$, Qin and co-workers were able to cause a similar oxidative cyclization involving insertion of the ESF double bond into the amide N-H unit.

Recent years have witnessed the rediscovery and subsequent explosion of interest in functionalizations enabled by photoredox catalysis. The photoexcitation of transition metal complexes serves as a greener and more economically viable method of generating radical intermediates able to initiate a wide range of valuable reactions [94-98]. One application of this is the replacement of terminal oxidants with lighter loadings of a photocatalyst whose oxidative power is obtained via photoexcitation. Rueping and co-workers applied this strategy to demonstrate that the oxidative alkenylation of aromatic amides, including Weinreb amides, is viable using a manifold analogous to that described by Wang's group (see above), but driven by a visible light-regenerated Ru-based photocatalyst, $\left[\mathrm{Ru}(\mathrm{bpy})_{3}\right]\left[\mathrm{PF}_{6}\right]_{2}$ (Scheme 14) $[99,100]$. The protocol is notable not just for its efficiency and high functional group tolerance, but also for the fact that it could be extended to other amides as well as a variety of olefin substrates (various groups $R^{2}$ ).

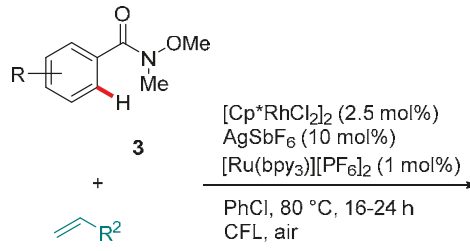

(2 equiv.)

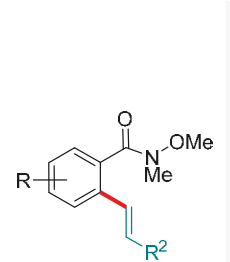

10

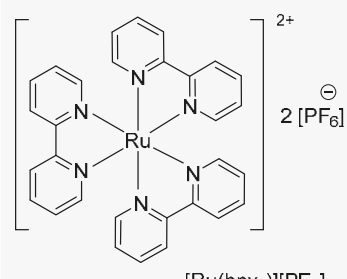

$\left[\mathrm{Ru}\left(\mathrm{bpy}_{3}\right)\right]\left[\mathrm{PF}_{6}\right]_{2}$

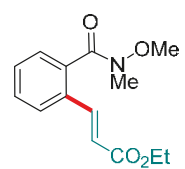

10a: $96 \%$<smiles>COC(=O)COCc1cc(Cl)ccc1C(=O)N(C)OC</smiles>

10n:84\%<smiles>COC(=O)c1ccccc1/C=C/OCCO</smiles>

100: $69 \%$

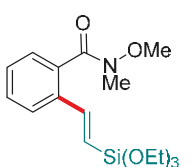

10p: $47 \%$

Scheme 14. Rh-catalyzed olefination of aromatic Weinreb amides enabled by Ru photocatalysis.

The catalytic cycle proposed by Rueping and co-workers closely resembles to that of Wang: ortho-rhodation of 3 to give 29 coordination and insertion of the olefin (complex 30 to 31 ) and $\beta$-hydride elimination to form the hydride intermediate 32 and the product (Figure 7). Reductive loss of the hydride and re-oxidation to $\mathrm{Rh}(\mathrm{III})$, however, is mediated by the photo-excited $[\mathrm{Ru}(\mathrm{bpy}) 3]^{2+\cdot}$ species, of which only a $1 \mathrm{~mol} \%$ loading is required. 

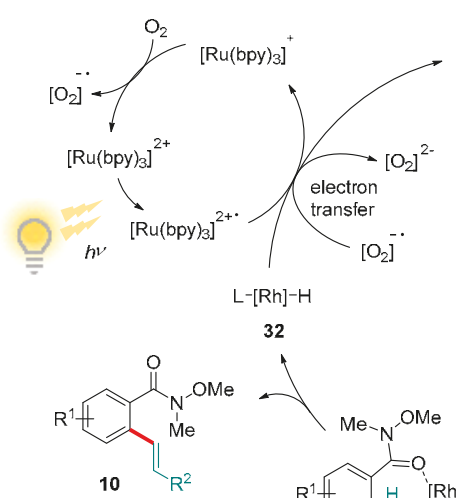

32
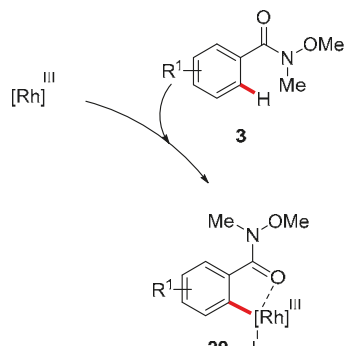

29 L

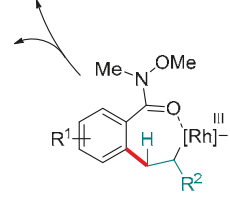

31

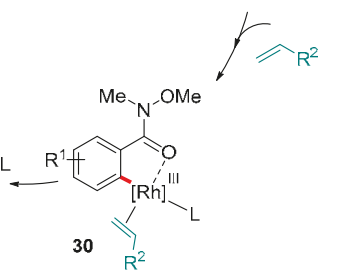

Figure 7. Mechanism proposed by Rueping and co-workers for the oxidative $\mathrm{C}-\mathrm{H}$ olefination of aromatic Weinreb amides catalyzed by $\mathrm{Rh}(\mathrm{III})$ in the presence of a Ru photocatalyst.

\section{Ir-catalyzed Reactions}

Boronates rank amongst the most versatile of groups; they may be converted to an extraordinarily broad range of functionality through a many different mechanisms [101-103]. Moreover, recent years have seen boronate-based methodology emerge as the basis of automated synthesis, which holds enormous potential to streamline the synthesis of many complex (hetero)aromatic and olefinic molecules [104-107]. Such advantages render especially important methods that allow the regioselective introduction of boronates to organic substrates. Amongst these, Ir-catalyzed C-H borylation ranks as one of the mildest and most enabling, as it is amenable to regiocontrol through sterics $[108,109]$, directing groups (both to the ortho [110-115] and para [116] positions) and/or the inherent electronic properties [117-119] of a substrate.

Krska, Maleczka and Smith have demonstrated [120] that Weinreb amides rank amongst groups that competently direct Ir catalysts towards ortho-C-H borylation (Scheme 15). Although only a single entry using a Weinreb amide was reported in their Communication, the success of the reaction (a high yield and regioselectivity) was representative, suggesting that other advantages of the method, such as the high functional group tolerance, could easily be paired with the Weinreb amide functionality. Conditions for this transformation deviated little from those commonly used for Ir-catalyzed C-H borylation more generally: $[\operatorname{Ir}(\mu-\mathrm{OMe})(\mathrm{COD})]_{2}$ as the pre-catalyst with dtbtpy as a ligand and $\mathrm{B}_{2}(\mathrm{pin})_{2}$ as the boron source. The corresponding mono-borylated product, 33 was reported to form in $84 \%$ yield.

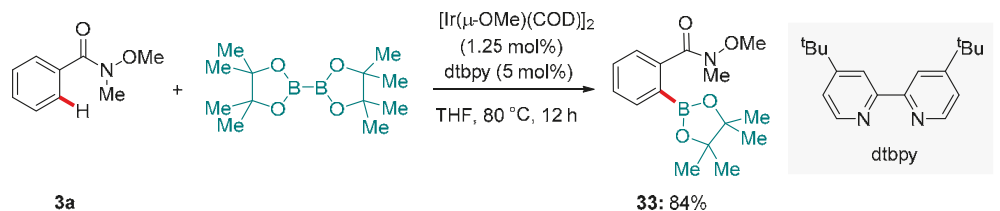

Scheme 15. Ir-catalyzed ortho-C-H borylation of an arene using the Weinreb amide as a directing group.

Enantioselective $\mathrm{C}-\mathrm{H}$ functionalization marries the benefits of directly substituting a $\mathrm{C}-\mathrm{H}$ bond with with establishing a new stereocenter in the product. This pursuit continues to inspire a growing body of research [121]. In 2015, Yamamoto and Shirai described an Ir-catalyzed protocol for the asymmetric intermolecular hydroarylation of arenes directed by oxygen based directing 
groups [122]. Although the scope included only a single example exploiting a Weinreb amide directing group (the transformation of 34 to 35), this entry was representative both in terms of yield and selectivity (Scheme 16). Enantioselectivity was induced using the bidentate bis(phosphoramidite) ligand $(R, R)$-S-Me-BIPAM ligand (36) and the $\mathrm{N}-\mathrm{O}$ bond was preserved in the product.

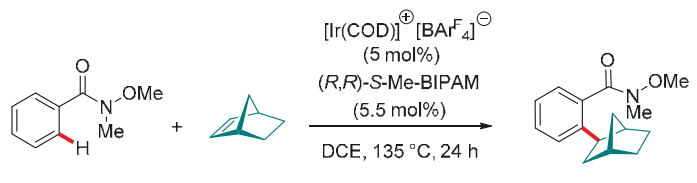

34

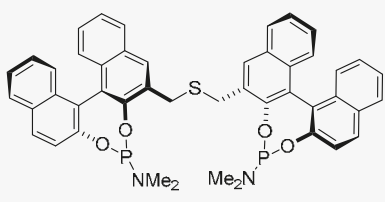

$(R, R)$-S-Me-BIPAM

36
35: $64 \%, 99 \%$ ee

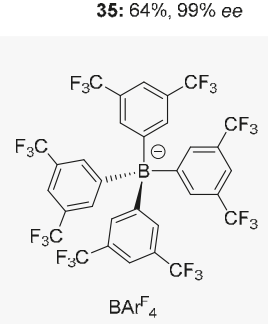

$\mathrm{BAr}_{4}$

Scheme 16. Ir-catalyzed enantioselective C-H hydroarylation of an olefin, directed by a Weinreb amide.

Most recently, the group of Martín-Matute has developed an Ir(III)-catalyzed C-H ortho-iodination of various amides [123]. The scope includes a strong focus on Weinreb amides. Their reaction used $\left[\mathrm{Cp} * \operatorname{Ir}\left(\mathrm{H}_{2} \mathrm{O}\right)_{3}\right]\left[\mathrm{SO}_{4}\right]$ as the catalyst precursor, and $\mathrm{N}$-iodo-succinimide (NIS) as the halogenating reagent in the presence of trifluoroacetic acid. Selected examples are shown below (Scheme 17). It is notable that Weinreb amides returned only the mono-iodinated products 11; a result only tertiary amides gave (primary and secondary amides gave at least small amounts of di-iodination). Whilst the substrate scope included a broad range of functional groups, substituents positioned ortho to the directing group at the outset restricted reactivity, presumably by imposing prohibitive amounts of steric hindrance.

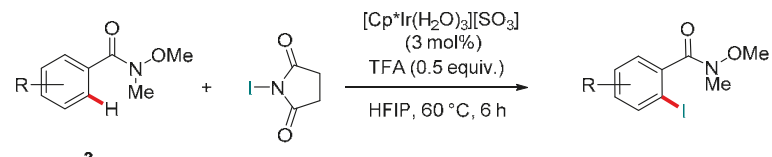<smiles>[R]c1ccc(C(=O)N(C)OC)c(I)c1</smiles>

$11 \mathrm{~b}, \mathrm{R}=\mathrm{Br}, 88 \%$ 11c, $\mathrm{R}=\mathrm{CO}_{2} \mathrm{Me}, 78 \%$ $11 \mathrm{~h}, \mathrm{R}=\mathrm{F}, 77 \%$<smiles>CON(OC)C(=O)c1cc(C)ccc1I</smiles>

11j: $92 \%(9: 1)^{\mathrm{a}}$<smiles>[R]c1cccc(I)c1C(=O)N(C)OC</smiles>

$11 \mathrm{k}: \mathrm{R}=\mathrm{H}, 92 \%$ 11I, $\mathrm{R}=\mathrm{Me}, 0 \%$ $11 \mathrm{~m}, \mathrm{R}=\mathrm{Cl}, 0 \%$

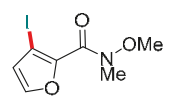

11n: $69 \%$

Scheme 17. Ir-catalyzed C-H iodination of Weinreb amides developed by the Martín-Matute group. ${ }^{\text {a }}$ Ratio of isomers is indicated in parenthesis; the major isomer is shown.

The authors also performed a robustness screen $[124,125]$ to identify the reaction's tolerance towards various functional groups. To this end, various small molecules with different functional groups were added to the reaction mixture to see how the reaction would be affected. Tolerance towards several common functional groups, including ketones amides, carboxylic acids and alkyl halides proved excellent. Aldehydes and alkenes returned less satisfactory results, however. Mechanistically, 
the reaction was proposed to follow a pathway closely related to that of Martín-Matute and co-workers' recently published Ir-catalyzed C-H ortho-iodination of aryl carboxylic acids [126]. The acid additive is understood to play a dual role: 1) activation of NIS via protonation of its carbonyl group and 2) by encouraging the dissociation of the iodinated product from the Ir center. Indeed, Martín-Matute and co-workers found in their optimization study on amides that lowering the amount of acid additive favored the formation of di-iodinated products for non-tertiary amides.

\section{Conclusions}

The Weinreb amide is a privileged functional group in organic synthesis that enables otherwise impossible transformations. Recent developments have seen $\mathrm{C}-\mathrm{H}$ functionalization methodology greatly expand the range of chemical contexts in which its advantages may be exploited. Challenges remain, however. Presently, Weinreb amides are rarely explored as a substrate class in their own right; they are most often presented as specialized examples in studies describing a more general scope, typically amidst other amides. Thus, it is usual that only the simplest examples of Weinreb amides are demonstrated to work under newly developed reaction conditions. This is at least a little unfair since, as some of the examples described above demonstrate, Weinreb amides may return different results to other amides, for example by virtue of the reactivity of their N-O bond. Weinreb amides might, in this sense, be considered hitherto as "sleeper" substrates.

Despite this, it is evident that Weinreb amides can direct a wide range of $\mathrm{C}-\mathrm{H}$ functionalization reactions catalyzed by transition metals. C-H functionalization, and catalytic methodology in general, is undergoing a shift of emphasis towards the use of less "endangered" [127,128], especially first-row transition elements for catalysis [43]. However, their use with Weinreb amides is rare. For example, to the best of our knowledge, no Weinreb amide-directed C-H functionalization reactions catalyzed by $\mathrm{Mn}, \mathrm{Fe}$ or Ni have yet been reported.

Finally, it is unfortunate that the preponderance of conditions used for Weinreb amide directed $\mathrm{C}-\mathrm{H}$ functionalization involve toxic halogenated solvents. Increasing legislative pressure is being brought to bear on this problem, with a particular focus against 1,2-dichloroethane (DCE) [129], which features in many of the reactions discussed above. We look forward to the use of Weinreb amides under greener conditions [130-132].

Acknowledgments: We thank the Wenner-Gren Foundation for funding (JK).

Conflicts of Interest: The authors declare that no conflicts of interest exist.

\section{References}

1. Crabtree, R.H.; Lei, A. Introduction: CH Activation. Chem. Rev. 2017, 117, 8481-8482. [CrossRef] [PubMed]

2. Yang, Y.; Lan, J.; You, J. Oxidative C-H/C-H Coupling Reactions between Two (Hetero)arenes. Chem. Rev. 2017, 117, 8787-8863. [CrossRef] [PubMed]

3. Park, Y.; Kim, Y.; Chang, S. Transition Metal-Catalyzed C-H Amination: Scope, Mechanism, and Applications. Chem. Rev. 2017, 117, 9247-9301. [CrossRef] [PubMed]

4. Murakami, K.; Yamada, S.; Kaneda, T.; Itami, K. C-H Functionalization of Azines. Chem. Rev. 2017, 117, 9302-9332. [CrossRef] [PubMed]

5. Sandtorv, A.H. Transition Metal-Catalyzed C-H Activation of Indoles. ACS Catal. 2015, 357, $2403-2435$. [CrossRef]

6. Simmons, E.M.; Hartwig, J.F. On the Interpretation of Deuterium Kinetic Isotope Effects in C-H Bond Functionalizations by Transition-Metal Complexes. Angew. Chem. Int. Ed. Engl. 2012, 51, 3066-3072. [CrossRef] [PubMed]

7. Qi, X.; Li, Y.; Bai, R.; Lan, Y. Mechanism of Rhodium-Catalyzed C-H Functionalization: Advances in Theoretical Investigation. Acc. Chem. Res. 2017, 50, 2799-2808. [CrossRef] [PubMed]

8. Davies, D.L.; Macgregor, S.A.; McMullin, C.L. Computational Studies of Carboxylate-Assisted C-H Activation and Functionalization at Group 8-10 Transition Metal Centers. Chem. Rev. 2017, 117, 8649-8709. [CrossRef] [PubMed] 
9. Balcells, D.; Clot, E.; Eisenstein, O. C-H Bond Activation in Transition Metal Species from a Computational Perspective. Chem. Rev. 2010, 110, 749-823. [CrossRef] [PubMed]

10. Gensch, T.; Hopkinson, M.N.; Glorius, F.; Wencel-Delord, J. Mild metal-catalyzed C-H activation: Examples and concepts. Chem. Soc. Rev. 2016, 45, 2900-2936. [CrossRef] [PubMed]

11. Hartwig, J.F.; Larsen, M.A. Undirected, Homogeneous C-H Bond Functionalization: Challenges and Opportunities. ACS Cent. Sci. 2016, 2, 281-292. [CrossRef] [PubMed]

12. Brückl, T.; Baxter, R.D.; Ishihara, Y.; Baran, P.S. Innate and Guided C-H Functionalization Logic. Acc. Chem. Res. 2012, 45, 826-839. [CrossRef] [PubMed]

13. Ping, L.; Chung, D.S.; Bouffard, J.; Lee, S.G. Transition metal-catalyzed site- and regio-divergent C-H bond functionalization. Chem. Soc. Rev. 2017, 46, 4299-4328. [CrossRef] [PubMed]

14. Saint-Denis, T.G.; Zhu, R.-Y.; Chen, G.; Wu, Q.-F.; Yu, J.-Q. Enantioselective C(sp3)-H bond activation by chiral transition metal catalysts. Science 2018, 359, eaao4798. [CrossRef] [PubMed]

15. Sambiagio, C.; Schönbauer, D.; Blieck, R.; Dao-Huy, T.; Pototschnig, G.; Schaaf, P.; Wiesinger, T.; Zia, M.F.; Wencel-Delord, J.; Besset, T.; et al. A comprehensive overview of directing groups applied in metal-catalysed C-H functionalisation chemistry. Chem. Soc. Rev. 2018, 47, 6603-6743. [CrossRef] [PubMed]

16. Lyons, T.W.; Sanford, M.S. Palladium-Catalyzed Ligand-Directed C-H Functionalization Reactions. Chem. Rev. 2010, 110, 1147-1169. [CrossRef] [PubMed]

17. Dey, A.; Agasti, S.; Maiti, D. Palladium catalysed meta-C-H functionalization reactions. Org. Biomol. Chem. 2016, 14, 5440-5453. [CrossRef] [PubMed]

18. Leitch, J.A.; Frost, C.G. Ruthenium-catalysed $\sigma$-activation for remote meta-selective C-H functionalisation. Chem. Soc. Rev. 2017, 46, 7145-7153. [CrossRef] [PubMed]

19. Dey, A.; Maity, S.; Maiti, D. Reaching the south: Metal-catalyzed transformation of the aromatic para-position. Chem. Commun. 2016, 52, 12398-12414. [CrossRef] [PubMed]

20. Rousseau, G.; Breit, B. Removable Directing Groups in Organic Synthesis and Catalysis. Angew. Chem. Int. Ed. 2011, 50, 2450-2494. [CrossRef] [PubMed]

21. Yadav, M.R.; Rit, R.K.; Shankar, M.; Sahoo, A.K. Reusable and Removable Directing Groups for $\mathrm{C}\left(\mathrm{sp}^{2}\right)-\mathrm{H}$ Bond Functionalization of Arenes. ASIAN J. Org. Chem. 2015, 4, 846-864. [CrossRef]

22. Zhang, F.; Spring, D.R. Arene C-H functionalisation using a removable/modifiable or a traceless directing group strategy. Chem. Soc. Rev. 2014, 43, 6906-6919. [CrossRef] [PubMed]

23. Font, M.; Quibell, J.M.; Perry, G.J.P.; Larrosa, I. The use of carboxylic acids as traceless directing groups for regioselective $\mathrm{C}-\mathrm{H}$ bond functionalisation. Chem. Commun. 2017, 53, 5584-5597. [CrossRef] [PubMed]

24. Gandeepan, P.; Ackermann, L. Transient Directing Groups for Transformative C-H Activation by Synergistic Metal Catalysis. Chem 2018, 4, 199-222. [CrossRef]

25. Ihara, H.; Koyanagi, M.; Suginome, M. Anthranilamide: A Simple, Removable ortho-Directing Modifier for Arylboronic Acids Serving also as a Protecting Group in Cross-Coupling Reactions. Org. Lett. 2011, 13, 2662-2665. [CrossRef] [PubMed]

26. Ihara, H.; Suginome, M. Easily Attachable and Detachable ortho-Directing Agent for Arylboronic Acids in Ruthenium-Catalyzed Aromatic C-H Silylation. J. Am. Chem. Soc. 2009, 131, 7502-7503. [CrossRef] [PubMed]

27. Ihara, H.; Ueda, A.; Suginome, M. Ruthenium-catalyzed C-H Silylation of Methylboronic Acid Using a Removable \&alpha;-Directing Modifier on the Boron Atom. Chem. Lett. 2011, 40, 916-918. [CrossRef]

28. Yamamoto, T.; Ishibashi, A.; Suginome, M. Regioselective Synthesis of o-Benzenediboronic Acids via Ir-Catalyzed o-C-H Borylation Directed by a Pyrazolylaniline-Modified Boronyl Group. Org. Lett. 2017, 19, 886-889. [CrossRef] [PubMed]

29. Zhao, Q.; Poisson, T.; Pannecoucke, X.; Besset, T. The Transient Directing Group Strategy: A New Trend in Transition-Metal-Catalyzed C-H Bond Functionalization. Synthesis 2017, 49, 4808-4826. [CrossRef]

30. Zhu, R.-Y.; Farmer, M.E.; Chen, Y.-Q.; Yu, J.-Q. A Simple and Versatile Amide Directing Group for C-H Functionalizations. Angew. Chem. Int. Ed. 2016, 55, 10578-10599. [CrossRef] [PubMed]

31. Nahm, S.; Weinreb, S.M. N-methoxy-n-methylamides as effective acylating agents. Tetrahedron Lett. 1981, 22, 3815-3818. [CrossRef]

32. Nowak, M. Weinreb Amides. Synlett 2015, 26, 561-562. [CrossRef]

33. De Sarkar, S.; Liu, W.; Kozhushkov, S.I.; Ackermann, L. Weakly Coordinating Directing Groups for Ruthenium(II)- Catalyzed C-H Activation. Adv. Synth. Catal. 2014, 356, 1461-1479. [CrossRef] 
34. Arockiam, P.B.; Bruneau, C.; Dixneuf, P.H. Ruthenium(II)-catalyzed C-H bond activation and functionalization. Chem. Rev. 2012, 112, 5879-5918. [CrossRef] [PubMed]

35. Ruiz, S.; Villuendas, P.; Urriolabeitia, E.P. Ru-catalysed C-H functionalisations as a tool for selective organic synthesis. Tetrahedron Lett. 2016, 57, 3413-3432. [CrossRef]

36. Yang, F.; Ackermann, L. Ruthenium-Catalyzed C-H Oxygenation on Aryl Weinreb Amides. Org. Lett. 2013, 15, 718-720. [CrossRef] [PubMed]

37. More, N.Y.; Padala, K.; Jeganmohan, M. Ruthenium-Catalyzed C-H Benzoxylation of tert-Benzamides with Aromatic Acids by Weak Coordination. J. Org. Chem. 2017, 82, 12691-12700. [CrossRef] [PubMed]

38. Das, R.; Kapur, M. Fujiwara-Moritani Reaction of Weinreb Amides using a Ruthenium-Catalyzed C-H Functionalization Reaction. Chem. Asian J. 2015, 10, 1505-1512. [CrossRef] [PubMed]

39. Ferreira, E.M.; Zhang, H.; Stoltz, B.M. Oxidative Heck-Type Reactions (Fujiwara-Moritani Reactions). In The Mizoroki-Heck Reaction; Oestreich, M., Ed.; Wiley: Chichester, UK, 2009.

40. Ackermann, L. Carboxylate-Assisted Transition-Metal-Catalyzed C-H Bond Functionalizations: Mechanism and Scope. Chem. Rev. 2011, 111, 1315-1345. [CrossRef] [PubMed]

41. Mo, J.; Wang, L.; Liu, Y.; Cui, X. Transition-Metal-Catalyzed Direct C-H Functionalization under External-Oxidant-Free Conditions. Synthesis 2015, 47, 439-459. [CrossRef]

42. Das, R.; Kapur, M. Product Control using Substrate Design: Ruthenium-Catalysed Oxidative C-H Olefinations of Cyclic Weinreb Amides. Chem. Eur. J. 2016, 22, 16986-16990. [CrossRef] [PubMed]

43. Gandeepan, P.; Müller, T.; Zell, D.; Cera, G.; Warratz, S.; Ackermann, L. 3d Transition Metals for C-H Activation. Chem. Rev. 2018. [CrossRef] [PubMed]

44. Moselage, M.; Li, J.; Ackermann, L. Cobalt-Catalyzed C-H Activation. ACS Catal. 2016, 6, 498-525. [CrossRef]

45. Gao, K.; Yoshikai, N. Low-Valent Cobalt Catalysis: New Opportunities for C-H Functionalization. Acc. Chem. Res. 2014, 47, 1208-1219. [CrossRef] [PubMed]

46. Yoshikai, N. Development of Cobalt-Catalyzed C-H Bond Functionalization Reactions. Bull. Chem. Soc. Jpn. 2014, 87, 843-857. [CrossRef]

47. Yoshino, T.; Ikemoto, H.; Matsunaga, S.; Kanai, M. Cp*CoIII-Catalyzed C2-Selective Addition of Indoles to Imines. Chem. A Eur. J. 2013, 19, 9142-9146. [CrossRef] [PubMed]

48. Yoshino, T.; Ikemoto, H.; Matsunaga, S.; Kanai, M. A Cationic High-Valent Cp*CoIII Complex for the Catalytic Generation of Nucleophilic Organometallic Species: Directed C-H Bond Activation. Angew. Chem. Int. Ed. Engl. 2013, 52, 2207-2211. [CrossRef] [PubMed]

49. Bunno, Y.; Murakami, N.; Suzuki, Y.; Kanai, M.; Yoshino, T.; Matsunaga, S. Cp*CoIII-Catalyzed Dehydrative C-H Allylation of 6-Arylpurines and Aromatic Amides Using Allyl Alcohols in Fluorinated Alcohols. Org. Lett. 2016, 18, 2216-2219. [CrossRef] [PubMed]

50. Sun, B.; Yoshino, T.; Matsunaga, S.; Kanai, M. Air-Stable Carbonyl(pentamethylcyclopentadienyl)cobalt Diiodide Complex as a Precursor for Cationic (Pentamethylcyclopentadienyl)cobalt(III) Catalysis: Application for Directed C-2 Selective C-H Amidation of Indoles. Adv. Synth. Catal. 2014, 356, 1491-1495. [CrossRef]

51. Colomer, I.; Chamberlain, A.E.R.; Haughey, M.B.; Donohoe, T.J. Hexafluoroisopropanol as a highly versatile solvent. Nat. Rev. Chem. 2017, 1, 0088. [CrossRef]

52. Wencel-Delord, J.; Colobert, F. A remarkable solvent effect of fluorinated alcohols on transition metal catalysed C-H functionalizations. Org. Chem. Front. 2016, 3, 394-400. [CrossRef]

53. Planas, O.; Chirila, P.G.; Whiteoak, C.J.; Ribas, X. Current Mechanistic Understanding of Cobalt-Catalyzed C-H Functionalization. Adv. Organomet. Chem. 2018, 69, 209-282. [CrossRef]

54. Gorelsky, S.I.; Lapointe, D.; Fagnou, K. Analysis of the Concerted Metalation-Deprotonation Mechanism in Palladium-Catalyzed Direct Arylation Across a Broad Range of Aromatic Substrates. J. Am. Chem. Soc. 2008, 130, 10848-10849. [CrossRef] [PubMed]

55. Kawai, K.; Bunno, Y.; Yoshino, T.; Matsunaga, S. Weinreb Amide Directed Versatile C-H Bond Functionalization under (eta(5)-Pentamethylcyclopentadienyl)cobalt(III) Catalysis. Chem. Eur. J. 2018, 24, 10231-10237. [CrossRef] [PubMed]

56. Kuhl, N.; Schröder, N.; Glorius, F. Rh(III)-Catalyzed Halogenation of Vinylic C-H Bonds: Rapid and General Access to Z-Halo Acrylamides. Org. Lett. 2013, 15, 3860-3863. [CrossRef] [PubMed] 
57. Chirila, P.G.; Adams, J.; Dirjal, A.; Hamilton, A.; Whiteoak, C.J. Cp*Co(III)-Catalyzed Coupling of Benzamides with $\alpha, \beta$-Unsaturated Carbonyl Compounds: Preparation of Aliphatic Ketones and Azepinones. Chem. Eur. J. 2018, 24, 3584-3589. [CrossRef] [PubMed]

58. Johansson Seechurn, C.C.C.; Kitching, M.O.; Colacot, T.J.; Snieckus, V. Palladium-Catalyzed Cross-Coupling: A Historical Contextual Perspective to the 2010 Nobel Prize. Angew. Chem. Int. Ed. Engl. 2012, 51, 5062-5085. [CrossRef] [PubMed]

59. Wu, X.-F.; Neumann, H.; Beller, M. Synthesis of Heterocycles via Palladium-Catalyzed Carbonylations. Chem. Rev. 2013, 113, 1-35. [CrossRef] [PubMed]

60. Wang, D.; Weinstein, A.B.; White, P.B.; Stahl, S.S. Ligand-Promoted Palladium-Catalyzed Aerobic Oxidation Reactions. Chem. Rev. 2018, 118, 2636-2679. [CrossRef] [PubMed]

61. Ruiz-Castillo, P.; Buchwald, S.L. Applications of Palladium-Catalyzed C-N Cross-Coupling Reactions. Chem. Rev. 2016, 116, 12564-12649. [CrossRef] [PubMed]

62. Sehnal, P.; Taylor, R.J.K.; Fairlamb, I.J.S. Emergence of Palladium(IV) Chemistry in Synthesis and Catalysis. Chem. Rev. 2010, 110, 824-889. [CrossRef] [PubMed]

63. Timsina, Y.N.; Gupton, B.F.; Ellis, K.C. Palladium-Catalyzed C-H Amination of C $\left(\mathrm{sp}^{2}\right)$ and C( $\left(\mathrm{sp}^{3}\right)-\mathrm{H}$ Bonds: Mechanism and Scope for N-Based Molecule Synthesis. ACS Catal. 2018, 8, 5732-5776. [CrossRef]

64. Topczewski, J.J.; Sanford, M.S. Carbon-hydrogen $(\mathrm{C}-\mathrm{H})$ bond activation at PdIV: A Frontier in $\mathrm{C}-\mathrm{H}$ functionalization catalysis. Chem. Sci. 2015, 6, 70-76. [CrossRef] [PubMed]

65. He, J.; Wasa, M.; Chan, K.S.L.; Shao, Q.; Yu, J.-Q. Palladium-Catalyzed Transformations of Alkyl C-H Bonds. Chem. Rev. 2017, 117, 8754-8786. [CrossRef] [PubMed]

66. Bonney, K.J.; Schoenebeck, F. Experiment and computation: A combined approach to study the reactivity of palladium complexes in oxidation states 0 to iv. Chem. Soc. Rev. 2014, 43, 6609-6638. [CrossRef] [PubMed]

67. Valente, C.; Çalimsiz, S.; Hoi, K.H.; Mallik, D.; Sayah, M.; Organ, M.G. The Development of Bulky Palladium NHC Complexes for the Most-Challenging Cross-Coupling Reactions. Angew. Chem. Int. Ed. Engl. 2012, 51, 3314-3332. [CrossRef] [PubMed]

68. Hazari, N.; Melvin, P.R.; Beromi, M.M. Well-defined nickel and palladium precatalysts for cross-coupling. Nat. Rev. Chem. 2017, 1, 0025. [CrossRef] [PubMed]

69. Wang, Y.; Zhou, K.; Lan, Q.; Wang, X.-S. Pd(II)-catalyzed C-H arylation of aryl and benzyl Weinreb amides. Org. Biomol. Chem. 2015, 13, 353-356. [CrossRef] [PubMed]

70. Mudarra, Á.L.; Martínez de Salinas, S.; Pérez-Temprano, M.H. Beyond the traditional roles of Ag in catalysis: The transmetalating ability of organosilver(i) species in Pd-catalysed reactions. Org. Biomol. Chem. 2018, 17, 1655-1667. [CrossRef] [PubMed]

71. Yedage, S.L.; Bhanage, B.M. Palladium-Catalyzed Deaminative Phenanthridinone Synthesis from Aniline via C-H Bond Activation. J. Org. Chem. 2016, 81, 4103-4111. [CrossRef] [PubMed]

72. Li, G.; Wan, L.; Zhang, G.; Leow, D.; Spangler, J.; Yu, J.-Q. Pd(II)-Catalyzed C-H Functionalizations Directed by Distal Weakly Coordinating Functional Groups. J. Am. Chem. Soc. 2015, 137, 4391-4397. [CrossRef] [PubMed]

73. Engle, K.M.; Wang, D.-H.; Yu, J.-Q. Ligand-Accelerated C-H Activation Reactions: Evidence for a Switch of Mechanism. J. Am. Chem. Soc. 2010, 132, 14137-14151. [CrossRef] [PubMed]

74. Das, R.; Kapur, M. Transition-Metal-Catalyzed Site-Selective C-H Halogenation Reactions. Asian J. Org. Chem. 2018, 7, 1524-1541. [CrossRef]

75. Das, R.; Kapur, M. Palladium-Catalyzed, ortho-Selective C-H Halogenation of Benzyl Nitriles, Aryl Weinreb Amides, and Anilides. J. Org. Chem. 2017, 82, 1114-1126. [CrossRef] [PubMed]

76. Powers, D.C.; Lee, E.; Ariafard, A.; Sanford, M.S.; Yates, B.F.; Canty, A.J.; Ritter, T. Connecting Binuclear Pd(III) and Mononuclear Pd(IV) Chemistry by Pd-Pd Bond Cleavage. J. Am. Chem. Soc. 2012, 134, 12002-12009. [CrossRef] [PubMed]

77. Powers, D.C.; Benitez, D.; Tkatchouk, E.; Goddard, W.A.; Ritter, T. Bimetallic Reductive Elimination from Dinuclear Pd(III) Complexes. J. Am. Chem. Soc. 2010, 132, 14092-14103. [CrossRef] [PubMed]

78. Powers, D.C.; Ritter, T. Bimetallic Pd(III) complexes in palladium-catalysed carbon-heteroatom bond formation. Nat. Chem. 2009, 1, 419. [CrossRef]

79. Powers, D.C.; Geibel, M.A.L.; Klein, J.E.M.N.; Ritter, T. Bimetallic Palladium Catalysis: Direct Observation of Pd(III)-Pd(III) Intermediates. J. Am. Chem. Soc. 2009, 131, 17050-17051. [CrossRef] [PubMed] 
80. Park, H.; Chekshin, N.; Shen, P.-X.; Yu, J.-Q. Ligand-Enabled, Palladium-Catalyzed $\beta-C(s p 3)-H$ Arylation of Weinreb Amides. ACS Catal. 2018, 8, 9292-9297. [CrossRef]

81. Willcox, D.; Chappell, B.G.N.; Hogg, K.F.; Calleja, J.; Smalley, A.P.; Gaunt, M.J. A general catalytic $\beta$-C-H carbonylation of aliphatic amines to $\beta$-lactams. Science 2016, 354, 851-857. [CrossRef] [PubMed]

82. Zhu, R.-Y.; Li, Z.-Q.; Park, H.S.; Senanayake, C.H.; Yu, J.-Q. Ligand-Enabled $\gamma$-C(sp3)-H Activation of Ketones. J. Am. Chem. Soc. 2018, 140, 3564-3568. [CrossRef] [PubMed]

83. Zhu, R.-Y.; He, J.; Wang, X.-C.; Yu, J.-Q. Ligand-Promoted Alkylation of C(sp3)-H and C(sp2)-H Bonds. J. Am. Chem. Soc. 2014, 136, 13194-13197. [CrossRef] [PubMed]

84. Baudoin, O. Ring Construction by Palladium(0)-Catalyzed C(sp3)-H Activation. Acc. Chem. Res. 2017, 50, 1114-1123. [CrossRef] [PubMed]

85. Baudoin, O. Transition metal-catalyzed arylation of unactivated C(sp3)-H bonds. Chem. Soc. Rev. 2011, 40, 4902-4911. [CrossRef] [PubMed]

86. Chatani, N.; Rej, S. Rh-Catalyzed Removable Directing Group Assisted sp2 or sp3-C-H Bond Functionalization. Angew. Chem. Int. Ed. 2018. [CrossRef]

87. Colby, D.A.; Bergman, R.G.; Ellman, J.A. Rhodium-Catalyzed C-C Bond Formation via Heteroatom-Directed C-H Bond Activation. Chem. Rev. 2010, 110, 624-655. [CrossRef] [PubMed]

88. Vásquez-Céspedes, S.; Wang, X.; Glorius, F. Plausible Rh(V) Intermediates in Catalytic C-H Activation Reactions. ACS Catal. 2018, 8, 242-257. [CrossRef]

89. Davies, D.L.; Ellul, C.E.; Macgregor, S.A.; McMullin, C.L.; Singh, K. Experimental and DFT Studies Explain Solvent Control of C-H Activation and Product Selectivity in the Rh(III)-Catalyzed Formation of Neutral and Cationic Heterocycles. J. Am. Chem. Soc. 2015, 137, 9659-9669. [CrossRef] [PubMed]

90. Li, J.; Qiu, Z. DFT Studies on the Mechanism of the Rhodium(III)-Catalyzed C-H Activation of N-Phenoxyacetamide. J. Org. Chem. 2015, 80, 10686-10693. [CrossRef] [PubMed]

91. Davis, T.A.; Hyster, T.K.; Rovis, T. Rhodium(III)-catalyzed intramolecular hydroarylation, amidoarylation, and Heck-type reaction: Three distinct pathways determined by an amide directing group. Angew. Chem. Int. Ed. 2013, 52, 14181-14185. [CrossRef] [PubMed]

92. Wang, Y.; Li, C.; Li, Y.; Yin, F.; Wang, X.-S. Rhodium-Catalyzed C-H Olefination of Aryl Weinreb Amides. Adv. Synth. Catal. 2013, 355, 1724-1728. [CrossRef]

93. Wang, S.-M.; Li, C.; Leng, J.; Bukhari, S.N.A.; Qin, H.-L. Rhodium(iii)-catalyzed Oxidative Coupling of N-Methoxybenzamides and Ethenesulfonyl fluoride: A C-H Bond Activation Strategy for the Preparation of 2-Aryl ethenesulfonyl fluorides and Sulfonyl fluoride Substituted $\gamma$-Lactams. Org. Chem. Front. 2018, 5, 1411-1415. [CrossRef]

94. Wang, C.-S.; Dixneuf, P.H.; Soulé, J.-F. Photoredox Catalysis for Building C-C Bonds from C(sp2)-H Bonds. Chem. Rev. 2018, 118, 7532-7585. [CrossRef] [PubMed]

95. Shaw, M.H.; Twilton, J.; MacMillan, D.W.C. Photoredox Catalysis in Organic Chemistry. J. Org. Chem. 2016, 81, 6898-6926. [CrossRef] [PubMed]

96. Romero, N.A.; Nicewicz, D.A. Organic Photoredox Catalysis. Chem. Rev. 2016, 116, 10075-10166. [CrossRef] [PubMed]

97. Lang, X.; Zhao, J.; Chen, X. Cooperative photoredox catalysis. Chem. Soc. Rev. 2016, 45, 3026-3038. [CrossRef] [PubMed]

98. Prier, C.K.; Rankic, D.A.; MacMillan, D.W.C. Visible Light Photoredox Catalysis with Transition Metal Complexes: Applications in Organic Synthesis. Chem. Rev. 2013, 113, 5322-5363. [CrossRef] [PubMed]

99. Fabry, D.C.; Rueping, M. Merging Visible Light Photoredox Catalysis with Metal Catalyzed C-H Activations: On the Role of Oxygen and Superoxide Ions as Oxidants. Acc. Chem. Res. 2016, 49, 1969-1979. [CrossRef] [PubMed]

100. Fabry, D.C.; Zoller, J.; Raja, S.; Rueping, M. Combining rhodium and photoredox catalysis for C-H functionalizations of arenes: Oxidative Heck reactions with visible light. Angew. Chem. Int. Ed. 2014, 53, 10228-10231. [CrossRef] [PubMed]

101. Fyfe, J.W.B.; Watson, A.J.B. Recent Developments in Organoboron Chemistry: Old Dogs, New Tricks. Chem 2017, 3, 31-55. [CrossRef]

102. Xu, L.; Zhang, S.; Li, P. Boron-selective reactions as powerful tools for modular synthesis of diverse complex molecules. Chem. Soc. Rev. 2015, 44, 8848-8858. [CrossRef] [PubMed] 
103. Lennox, A.J.J.; Lloyd-Jones, G.C. Selection of boron reagents for Suzuki-Miyaura coupling. Chem. Soc. Rev. 2014, 43, 412-443. [CrossRef] [PubMed]

104. Lehmann, J.W.; Blair, D.J.; Burke, M.D. Towards the generalized iterative synthesis of small molecules. Nat. Rev. Chem. 2018, 2, 0115. [CrossRef] [PubMed]

105. Li, J.; Grillo, A.S.; Burke, M.D. From Synthesis to Function via Iterative Assembly of N-Methyliminodiacetic Acid Boronate Building Blocks. Acc. Chem. Res. 2015, 48, 2297-2307. [CrossRef] [PubMed]

106. Li, J.; Ballmer, S.G.; Gillis, E.P.; Fujii, S.; Schmidt, M.J.; Palazzolo, A.M.E.; Lehmann, J.W.; Morehouse, G.F.; Burke, M.D. Synthesis of many different types of organic small molecules using one automated process. Science 2015, 347, 1221-1226. [CrossRef] [PubMed]

107. Woerly, E.M.; Roy, J.; Burke, M.D. Synthesis of most polyene natural product motifs using just 12 building blocks and one coupling reaction. Nat. Chem. 2014, 6, 484. [CrossRef] [PubMed]

108. Hartwig, J.F. Borylation and Silylation of C-H Bonds: A Platform for Diverse C-H Bond Functionalizations. Acc. Chem. Res. 2011, 45, 864-873. [CrossRef] [PubMed]

109. Mkhalid, I.A.; Barnard, J.H.; Marder, T.B.; Murphy, J.M.; Hartwig, J.F. C-H activation for the construction of C-B bonds. Chem. Rev. 2010, 110, 890-931. [CrossRef] [PubMed]

110. Smith, M.R.; Bisht, R.; Haldar, C.; Pandey, G.; Dannatt, J.E.; Ghaffari, B.; Maleczka, R.E.; Chattopadhyay, B. Achieving High Ortho Selectivity in Aniline C-H Borylations by Modifying Boron Substituents. ACS Catal. 2018, 8, 6216-6223. [CrossRef] [PubMed]

111. Li, H.-L.; Kanai, M.; Kuninobu, Y. Iridium/Bipyridine-Catalyzed ortho-Selective C-H Borylation of Phenol and Aniline Derivatives. Org. Lett. 2017, 19, 5944-5947. [CrossRef] [PubMed]

112. Chattopadhyay, B.; Dannatt, J.E.; Andujar-De Sanctis, I.L.; Gore, K.A.; Maleczka, R.E.; Singleton, D.A.; Smith, M.R. Ir-Catalyzed ortho-Borylation of Phenols Directed by Substrate-Ligand Electrostatic Interactions: A Combined Experimental/in Silico Strategy for Optimizing Weak Interactions. J. Am. Chem. Soc. 2017, 139, 7864-7871. [CrossRef] [PubMed]

113. Hale, L.V.A.; Emmerson, D.G.; Ling, E.F.; Roering, A.J.; Ringgold, M.A.; Clark, T.B. An ortho-directed C-H borylation/Suzuki coupling sequence in the formation of biphenylbenzylic amines. Org. Chem. Front. 2015, 2, 661-664. [CrossRef]

114. Crawford, K.M.; Ramseyer, T.R.; Daley, C.J.A.; Clark, T.B. Phosphine-Directed C-H Borylation Reactions: Facile and Selective Access to Ambiphilic Phosphine Boronate Esters. Angew. Chem. 2014, 53, 7589-7593. [CrossRef] [PubMed]

115. Kawamorita, S.; Ohmiya, H.; Hara, K.; Fukuoka, A.; Sawamura, M. Directed Ortho Borylation of Functionalized Arenes Catalyzed by a Silica-Supported Compact Phosphine-Iridium System. J. Am. Chem. Soc. 2009, 131, 5058-5059. [CrossRef] [PubMed]

116. Hoque, M.E.; Bisht, R.; Haldar, C.; Chattopadhyay, B. Noncovalent Interactions in Ir-Catalyzed C-H Activation: L-Shaped Ligand for Para-Selective Borylation of Aromatic Esters. J. Am. Chem. Soc. 2017, 139, 7745-7748. [CrossRef] [PubMed]

117. Tajuddin, H.; Harrisson, P.; Bitterlich, B.; Collings, J.C.; Sim, N.; Batsanov, A.S.; Cheung, M.S.; Kawamorita, S.; Maxwell, A.C.; Shukla, L.; et al. Iridium-catalyzed C-H borylation of quinolines and unsymmetrical 1,2-disubstituted benzenes: Insights into steric and electronic effects on selectivity. Chem. Sci. 2012, 3, 3505-3515. [CrossRef]

118. Larsen, M.A.; Hartwig, J.F. Iridium-Catalyzed C-H Borylation of Heteroarenes: Scope, Regioselectivity, Application to Late-Stage Functionalization, and Mechanism. J. Am. Chem. Soc. 2014, 136, 4287-4299. [CrossRef] [PubMed]

119. Hartwig, J.F. Regioselectivity of the borylation of alkanes and arenes. Chem. Soc. Rev. 2011, 40, $1992-2002$. [CrossRef] [PubMed]

120. Ghaffari, B.; Preshlock, S.M.; Plattner, D.L.; Staples, R.J.; Maligres, P.E.; Krska, S.W.; Maleczka, R.E.; Smith, M.R. Silyl Phosphorus and Nitrogen Donor Chelates for Homogeneous Ortho Borylation Catalysis. J. Am. Chem. Soc. 2014, 136, 14345-14348. [CrossRef] [PubMed]

121. Newton, C.G.; Wang, S.-G.; Oliveira, C.C.; Cramer, N. Catalytic Enantioselective Transformations Involving C-H Bond Cleavage by Transition-Metal Complexes. Chem. Rev. 2017, 117, 8908-8976. [CrossRef] [PubMed]

122. Shirai, T.; Yamamoto, Y. Cationic Iridium/S-Me-BIPAM-Catalyzed Direct Asymmetric Intermolecular Hydroarylation of Bicycloalkenes. Angew. Chem. Int. Ed. 2015, 54, 9894-9897. [CrossRef] [PubMed] 
123. Erbing, E. Development of New Efficient Iridium-Catalyzed Methods for the Construction of Carbon-Heteroatom Bonds. Ph.D. Thesis, Stockholm University, Stockholm, Sweden, 2018.

124. Collins, K.D.; Glorius, F. A robustness screen for the rapid assessment of chemical reactions. Nat. Chem. 2013, 5, 597-601. [CrossRef] [PubMed]

125. Gensch, T.; Teders, M.; Glorius, F. Approach to Comparing the Functional Group Tolerance of Reactions. J. Org. Chem. 2017, 82, 9154-9159. [CrossRef] [PubMed]

126. Erbing, E.; Sanz-Marco, A.; Vázquez-Romero, A.; Malmberg, J.; Johansson, M.J.; Gómez-Bengoa, E.; Martín-Matute, B. Base- and Additive-Free Ir-Catalyzed ortho-Iodination of Benzoic Acids: Scope and Mechanistic Investigations. ACS Catal. 2018, 8, 920-925. [CrossRef]

127. Egorova, K.S.; Ananikov, V.P. Which Metals are Green for Catalysis? Comparison of the Toxicities of Ni, Cu, $\mathrm{Fe}, \mathrm{Pd}, \mathrm{Pt}, \mathrm{Rh}$, and Au Salts. Angew. Chem. Int. Ed. 2016, 55, 12150-12162. [CrossRef] [PubMed]

128. Hayler, J.D.; Leahy, D.K.; Simmons, E.M. A Pharmaceutical Industry Perspective on Sustainable Metal Catalysis. Organometallics 2019, 38, 36-46. [CrossRef]

129. Sherwood, J. European Restrictions on 1,2-Dichloroethane: C-H Activation Research and Development Should Be Liberated and not Limited. Angew. Chem. Int. Ed. 2018, 57, 14286-14290. [CrossRef] [PubMed]

130. Clarke, C.J.; Tu, W.-C.; Levers, O.; Bröhl, A.; Hallett, J.P. Green and Sustainable Solvents in Chemical Processes. Chem. Rev. 2018, 118, 747-800. [CrossRef] [PubMed]

131. Wilson, K.L.; Murray, J.; Sneddon, H.F.; Wheelhouse, K.M.P.; Watson, A.J.B. Connecting the Dots: Method Development Using Sustainable Solvents. Chem 2017, 3, 365-368. [CrossRef]

132. Welton, T. Solvents and sustainable chemistry. Proc. R. Soc. A Math. Phys. Eng. Sci. 2015, 471. [CrossRef] [PubMed]

(C) 2019 by the authors. Licensee MDPI, Basel, Switzerland. This article is an open access article distributed under the terms and conditions of the Creative Commons Attribution (CC BY) license (http:/ / creativecommons.org/licenses/by/4.0/). 


\title{
Chemistry of Bridged Lactams: Recent Developments
}

\author{
Roman Szostak ${ }^{1}$ and Michal Szostak ${ }^{2, *}$ \\ 1 Department of Chemistry, Wroclaw University, F. Joliot-Curie 14, 50-383 Wroclaw, Poland; \\ roman.szostak@chem.uni.wroc.pl \\ 2 Department of Chemistry, Rutgers University, 73 Warren Street, Newark, NJ 07102, USA \\ * Correspondence: michal.szostak@rutgers.edu; Tel.: +1-973-353-5329
}

Academic Editor: Michal Szostak

Received: 28 December 2018; Accepted: 10 January 2019; Published: 12 January 2019

\begin{abstract}
Bridged lactams represent the most effective and wide-ranging method of constraining the amide bond in a non-planar conformation. A previous comprehensive review on this topic was published in 2013 (Chem. Rev. 2013, 113, 5701-5765). In the present review, which is published as a part of the Special Issue on Amide Bond Activation, we present an overview of the recent developments in the field of bridged lactams that have taken place in the last five years and present a critical assessment of the current status of bridged lactams in synthetic and physical organic chemistry. This review covers the period from 2014 until the end of 2018 and is intended as an update to Chem. Rev. 2013, 113, 5701-5765. In addition to bridged lactams, the review covers recent advances in the chemistry of bridged sultams, bridged enamines and related non-planar structures.
\end{abstract}

Keywords: amide bond; bridged lactams; twisted amides; amides; Winkler-Dunitz parameters; $\mathrm{N}-\mathrm{C}$ activation; hypersensitivity; nitrogen heterocycles; distortion; bridged sultams

\section{Introduction}

The amide bond is arguably the most important linkage in chemistry and biology [1]. Typical amide bonds are planar as a result of amidic resonance $\left(\mathrm{n}_{\mathrm{N}} \rightarrow \pi^{*} \mathrm{C}=\mathrm{O}\right.$ conjugation, $\left.15-20 \mathrm{kcal} / \mathrm{mol}\right)$ (Figure 1A) [2].

A: Amide bond resonance

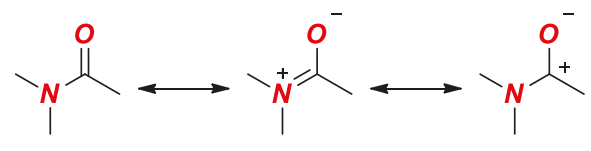

B: Types of non-planar amide bonds

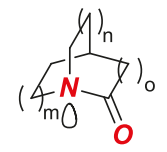

a) steric
restriction<smiles>[R8]C(=O)N([R2])OC</smiles>

b) steric repulsion<smiles>[R]C(=O)N1CCCCC1</smiles>

c) conformational effects<smiles>[R]C(=O)N([Y])OC</smiles>

d) electronic effects

Figure 1. (A) Amide Bond Resonance. (B) Types of Distorted Amide Bonds.

The redesign of the amide bond geometry through structural and electronic changes of substituents comprising the amide bond has had a profound impact on the physico-chemical properties of amides [3-6]. The alteration of the amide bond geometry generally leads to a reversal of traditional 
properties of amides, such as lower barrier to cis-trans rotation, increased length of the $\mathrm{N}-\mathrm{C}(\mathrm{O})$ bond, favored protonation at the nitrogen atom, and increased reactivity in nucleophilic addition and hydrolysis [3-6]. The geometric and structural changes of the amide bond are an established technique to affect properties of amide bonds in biology and medicinal chemistry [7-10], while recent advances in selective metal insertion into the amide bond driven by its distortion represent a thriving and general concept in organic synthesis [11,12]. In general, amide bond distortion can be achieved by four methods (Figure 1B): (1) steric restriction, (2) steric repulsion, (3) conformation effects, and (4) electronic effects. Out of these methods, the most effective one by far is steric restriction. Typically, steric restriction involves constraining the amide bond in a rigid bicyclic ring system with a nitrogen atom positioned at a bridgehead position. This allows one to constrain the typical planar amide bond in a non-planar conformation with the magnitude of distortion principally controlled by the type of ring system (Figure 2). To date, bridged lactams represent the only method that has allowed for a substantial distortion, exceeding $60 \%$ of the maximum theoretical value of the amide bond $[3-6,11,12]$.

A: Winkler-Dunitz distortion

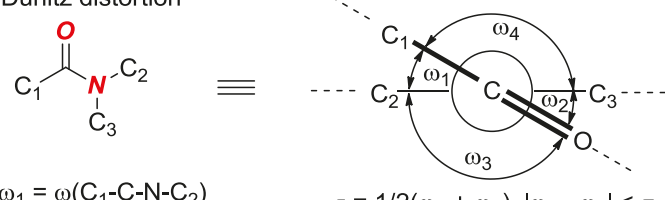

$\omega_{2}=\omega\left(\mathrm{O}-\mathrm{C}-\mathrm{N}-\mathrm{C}_{3}\right)$

$\tau=1 / 2\left(\omega_{1}+\omega_{2}\right),\left|\omega_{1}-\omega_{2}\right|<\pi$

$\omega_{3}=\omega\left(\mathrm{O}-\mathrm{C}-\mathrm{N}-\mathrm{C}_{2}\right)$

$\omega_{4}=\omega\left(\mathrm{C}_{1}-\mathrm{C}-\mathrm{N}-\mathrm{C}_{3}\right)$

$\chi_{N}=\left(\omega_{2}-\omega_{3}+\pi\right)=\left(\omega_{4}-\omega_{1}+\pi\right)$

$\chi_{\mathrm{C}}=\left(\omega_{1}-\omega_{3}+\pi\right)=\left(\omega_{4}-\omega_{2}+\pi\right)$

additive parameter $=\left(\tau+\chi_{N}\right)$

B: Activation of the amide bond by $\mathrm{N}-/ \mathrm{O}$-protonation

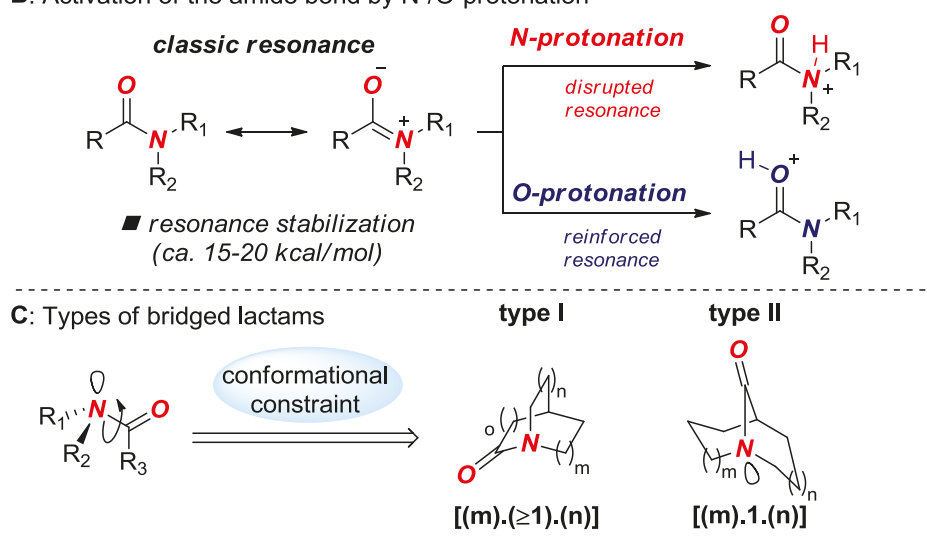

Figure 2. (A) Winkler-Dunitz Distortion. (B) Activation of the Amide Bond by N-/O-Protonation.

(C) Types of Bridged Lactams.

Amide bond distortion is measured by Winkler-Dunitz parameters: $\tau$ (twist angle), $\chi_{N}$ (pyramidalization at $\mathrm{N}$ ) and $\chi_{\mathrm{C}}$ (pyramidalization at $\mathrm{C}$ ) [13] as well as by changes in $\mathrm{N}-\mathrm{C}(\mathrm{O})$ and $\mathrm{C}=\mathrm{O}$ bond lengths (Figure $2 \mathrm{~A}$ ). Amide bond distortion leads to a change of thermodynamic $\mathrm{N}$-/O-protonation aptitude, which is a key effect that controls the reactivity of non-planar amide bonds (Figure 2B) [11]. The properties of amide bonds in bridged lactams are further amplified by a type of bridged lactam scaffold (Figure 2C). In general, bridged lactams are classified into amides in which the $\mathrm{N}-\mathrm{C}(\mathrm{O})$ bond is placed on a one-carbon bridge or on a larger bridge, with the former enjoying additional stabilization through transannular scaffolding effects. 
In this review, published as a part of the Special Issue on Amide Bond Activation, we present an overview of the recent developments in the field of bridged lactams and present a critical assessment of the current status of bridged lactams. This review covers the period from 2014 until the end of 2018 and is intended as an update to the previous comprehensive review on topic, Chem. Rev. 2013, 113, 5701-5765 [3]. In addition to bridged lactams, the review covers recent advances in the chemistry of bridged sultams, bridged enamines and related non-planar structures. For additional coverage, the reader is referred to previous reviews on bridged lactams [4-6]. It is our hope that the review will serve as a useful reference for chemists involved in various aspects of activating the amide bond and stimulate further research in this area.

\section{Synthesis, Properties and Reactivity of Bridged Lactams}

Recent advances in the field of bridged lactams include: (1) identification of the additive Winkler-Dunitz parameter, (2) synthesis of extremely twisted non-stabilized amides, (3) synthesis of novel bridged lactams, and (4) new examples of reactivity of non-planar amides.

In 2015, we have identified the additive Winkler-Dunitz distortion parameter $\left(\Sigma \tau+\chi_{N}\right)$, sum of twist and pyramidalization at nitrogen angles, as a more accurate prediction of the structural and energetic properties of non-planar amides than either twist or pyramidalization alone (Figures 3 and 4) [14,15]. A computational study to determine the effect of amide distortion on $\mathrm{N}$-/O-protonation using a set of lactams comprehensively covering the entire distortion range (Figure 3) revealed a linear correlation between the composite Winkler-Dunitz parameter $\left(\Sigma \tau+\chi_{\mathrm{N}}\right)$ and $\mathrm{N}$-/O-protonation aptitude (Figure 4) [14]. Our subsequent study demonstrated that the additive Winkler-Dunitz parameter $\left(\Sigma \tau+\chi_{N}\right)$ gives linear correlations vs. structural and other energetic parameters (resonance energies, atomic charges, frontier molecular orbitals, infrared frequencies) [15].

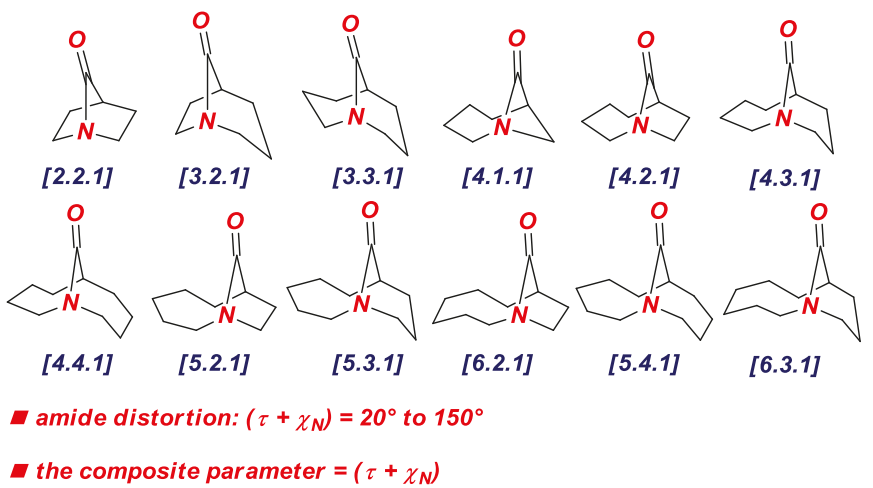

Figure 3. Additive Winkler-Dunitz Distortion Parameter: Sum of Twist Angle and Nitrogen Pyramidalization $\left(\Sigma \tau+\chi_{N}\right)$. 


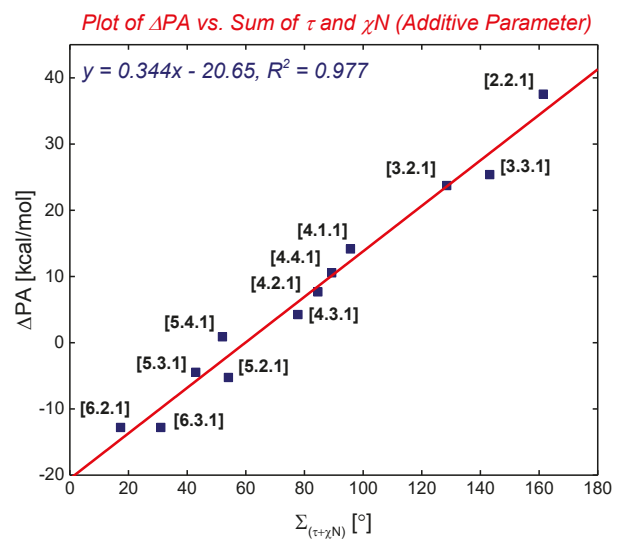

Figure 4. Plot of $\triangle \mathrm{PA}(\mathrm{PA}=$ Experimental Protonation Affinity) to the Sum of Twist and Pyramidalization at Nitrogen Angles (Additive Winkler-Dunitz Parameter: $\Sigma \tau+\chi_{\mathrm{N}}$ ). Note that $\left(\Sigma \tau+\chi_{N}\right)$ gives linear correlations vs. structural and other energetic parameters. See [15]. Also note comprehensive studies [16-18].

Since (1) amide bond distortion typically hinges upon both twist and pyramidalization, and (2) the additive Winkler-Dunitz parameter gives a more accurate prediction of geometric changes of the amide bond, this parameter should be routinely reported to describe structural variations of all non-planar amide bonds. Recently, we have utilized the additive Winkler-Dunitz parameter $\left(\Sigma \tau+\chi_{\mathrm{N}}\right)$ to determine the origin of high twist and $\mathrm{N}$-/O-protonation aptitude of Tröger's base twisted amides (Figure 5) [19]. Perhaps surprisingly, we found that although Tröger's base twisted bis-amides are among the most twisted amides synthesized and structurally-characterized to date (vide infra), these amides are less effective in probing $\mathrm{N}$-protonation than less twisted in this series 1-azabicyclo [3.3.1] nonan-2-one derivatives.

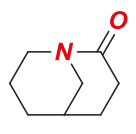

[3.3.1] monoamide monoamide<smiles>O=C1CCN2CCC1C2</smiles>

[3.3.1]

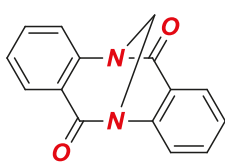

[3.3.1]

Tröger's base bis-amide<smiles>O=C1CCN2CCN1CCC2=O</smiles>

[3.3.2]

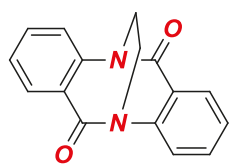

[3.3.2]

Tröger's base bis-amide

- high distortion

$\left(\tau+\chi N=100^{\circ}\right)$

- not ideal for $N$ protonation

Figure 5. Additive Winkler-Dunitz Distortion Parameter in Tröger's Base Twisted Amides.

In 2016, the extremely twisted 7-hypoquinuclidonium tetrafluoroborate was reported by Stoltz and co-workers (Figure 6) [20]. The group has impressively exploited the intramolecular Aubé-Schmidt reaction to access the [2.2.1] bridged scaffold. This unconventional amide bond forming strategy represents a general approach to this and another extremely twisted amide, 2-quinuclidonium tetrafluoroborate (see Figure 6, box) [21], in the absence of nucleophiles that would likely decompose both compounds. It should be noted that the target twisted amide was isolated as a $\mathrm{HBF}_{4}$ salt or $\mathrm{BF}_{3}$ 
complex. The latter compound was fully characterized by X-ray crystallography, revealing one of the most twisted amide bonds isolated to date $\left(\tau=90.0^{\circ}, \chi_{\mathrm{N}}=69.8^{\circ} ; \mathrm{N}-\mathrm{C}(\mathrm{O})=1.526 \AA, \mathrm{C}=\mathrm{O}=1.186 \AA\right.$ ).

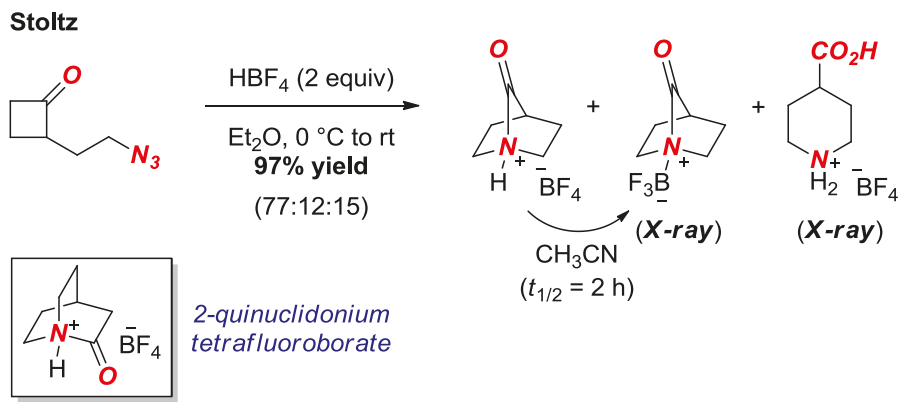

Figure 6. Synthesis of 7-Hypoquinuclidonium Tetrafluoroborate.

It is now well-established that $N$-coordination of the amide bond increases twist and pyramidalization (vide infra). Thus, with the exception of a structurally-unique 1-adamantan-2-one derivatives (see below), there are no examples of unconstrained structurally-characterized amides with a combined Winkler-Dunitz parameter $\left(\Sigma \tau+\chi_{N}\right)$ exceeding $100^{\circ}$ in the neutral form.

In 2016, the synthesis of another extremely twisted amide was reported by Komarov, Kirby et al. (Figure 7) [22]. These researchers achieved the synthesis of the parent 1-aza-2-adamantanone via a route consisting of thermal amidation of the $N$-Boc protected amino acid. Previous calculations showed a significant stabilizing effect of the methyl groups in the trimethyl twisted amide derivative (see Figure 7, box) [23]. The parent 1-aza-2-adamantanone was fully characterized after protonation as $\mathrm{HBF}_{4}$ salt $\left(\tau=88.1^{\circ}, \chi_{\mathrm{N}}=58.0^{\circ} ; \mathrm{N}-\mathrm{C}=1.508 \AA, \mathrm{C}=\mathrm{O}=1.186 \AA\right)$. Furthermore, the authors obtained the $X$-ray structure of the $\alpha$-monomethylated 1-aza-2-adamantanone in a neutral form $\left(\tau=90.0^{\circ}\right.$, $\chi_{\mathrm{N}}=61.8^{\circ} ; \mathrm{N}-\mathrm{C}=1.448 \AA, \mathrm{C}=\mathrm{O}=1.201 \AA$ ). Similar to the [2.2.1] amide synthesized by the Stoltz group (cf. [2.2.2] amide), the parent 1-aza-2-adamantanone was found to be more reactive in reactions with nucleophiles than the previous "most twisted amide" 3,5,7-trimethyl-1-azaadamantan-2-one [24].

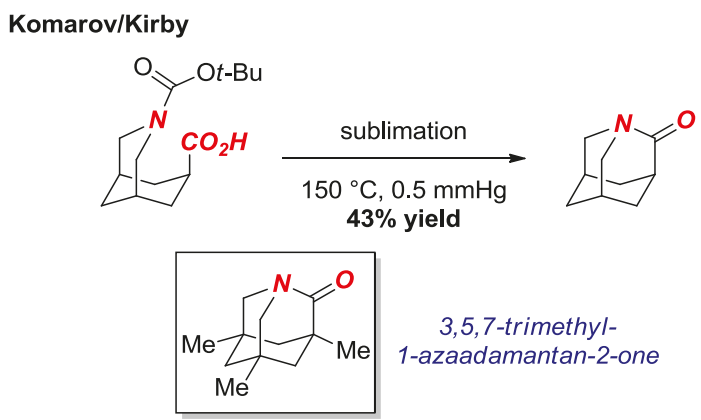

Figure 7. Synthesis of Parent 1-Azaadamantan-2-one.

In 2017, Greenberg and co-workers reported an interesting study of a silicon-containing twisted amide in a [3.3.3] scaffold (Figure 8) [25]. Heteroatom-containing derivatives of bridged lactams have received considerable attention as a means of facilitating the synthesis and tuning properties of the twisted amide bond. Through computations, the authors demonstrated that the nitrogen atom in 1-methyl-4-silatranone would be more similar to a lactam rather than a silatrane with a long intramolecular N-Si bond (N-Si = $2.902 \AA$ vs. 1 -methylsilatrane, N-Si = 2.466 ̊). Although 
the attempted synthesis via condensation of $\left(\mathrm{HOCH}_{2} \mathrm{CH}_{2}\right)_{2} \mathrm{~N}\left(\mathrm{COCH}_{2} \mathrm{OH}\right)$ with various silanes was unsuccessful, the study lays a foundation for the synthesis of silicon-containing twisted amides.

\section{Greenberg}

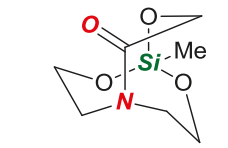

1-methyl-4-silatranone

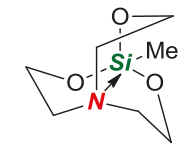

1-methyl-4-silatrane

Figure 8. Computational Study of 1-Methyl-4-Silatranone.

In 2016, we reported the first examples of structurally-characterized $N$-alkylated bridged lactams (Figure 9) [26]. N-Alkylation significantly increased amide bond distortion $\left(\tau=44.0^{\circ}, \chi_{N}=58.3^{\circ}\right.$; $\mathrm{N}-\mathrm{C}=1.554 \AA, \mathrm{C}=\mathrm{O}=1.192 \AA$ ). Furthermore, we demonstrated that $N$-coordination activated the twisted amide bond towards $\sigma \mathrm{N}-\mathrm{C}$ bond activation by Pd-catalyzed hydrogenation.

\section{Szostak}

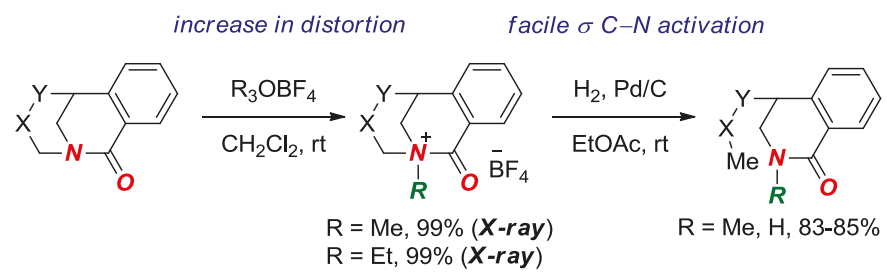

Figure 9. N-Alkylation of Bridged Lactams as a Trigger for $\sigma \mathrm{N}-\mathrm{C}$ Bond Activation.

Transition-metal-free $\sigma \mathrm{N}-\mathrm{C}$ bond activation in bridged lactams was reported by our group in 2017 (Figure 10) [27]. Facile assembly of the twisted amide scaffold by intramolecular Heck reaction, followed by $N$-alkylation and selective $\sigma$ bond cleavage established a "sew-and-cut" approach to complex isoquinoline-2-ones by a formal di-functionalization of the $\mathrm{N}-\mathrm{C}$ amide bond. The reactivity was correlated with amide bond twist in that less distorted amides were found unreactive. Given the utility of mild difunctionalization methods in organic synthesis, twisted lactams are attractive intermediates for the synthesis of nitrogen-containing heterocycles by this approach.

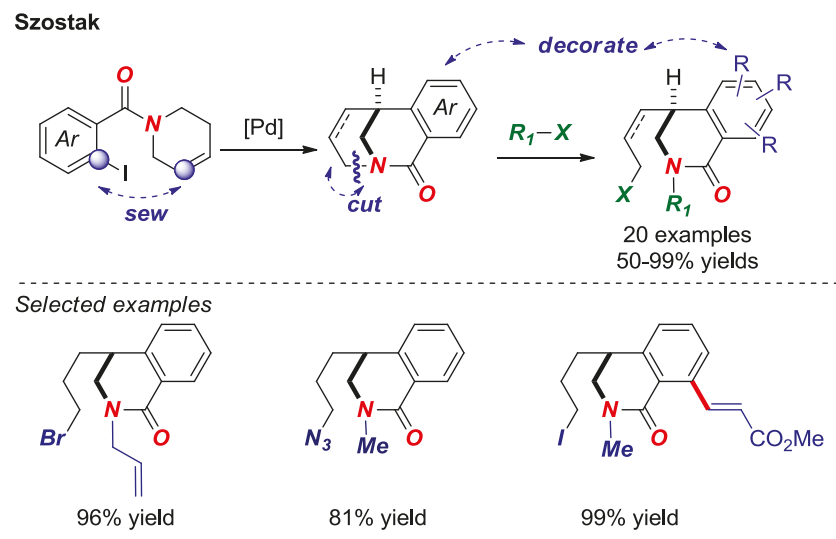

Figure 10. Sew-And-Cut of Bridged Lactams by a Transition-Metal-Free $\sigma$ N-C Bond Activation. 
In 2018, Marsden, Nelson and co-workers reported the synthesis of a set of bridged lactams with [3.3.1] and [4.3.1] scaffolds as part of their research on fragment-based drug discovery (Figure 11) [28]. This approach nicely utilizes the presence of an additional heteroatom in the twisted amide structure to facilitate the synthesis of starting materials. The cyclization was carried out according to the established lactamization protocol mediated by $\mathrm{Bu}_{2} \mathrm{SnO}$ [29]. Due to the unique shape diversity, bridged lactams hold a significant potential as unexplored scaffolds in drug discovery.

\section{Marsden/Nelson}<smiles>[R]OC(C)CC([R])C1CN(C(=O)OCc2ccccc2)CCC1=O</smiles>

$\mathrm{n}=1,2, \mathrm{R}=\mathrm{Me}, \mathrm{Et}$

$X R^{\prime}=\mathrm{CH}_{2}, \mathrm{NBn}, \mathrm{NMe}, \mathrm{NCbz}, \mathrm{NCOR}, \mathrm{NSO}_{2} \mathrm{Ar}, \mathrm{NCH}_{2} \mathrm{CN}$

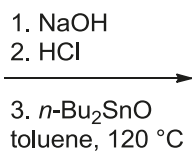

toluene, $120^{\circ} \mathrm{C}$

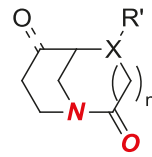

11 examples
Selected examples<smiles>[R]N1CC(=O)N2CCCC1C2</smiles>

$\mathrm{R}=\mathrm{Bn}, 46 \%$

$\mathrm{R}=\mathrm{Me}, 45 \%$

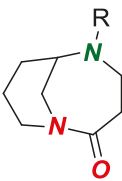

$\mathrm{R}=\mathrm{Bn}, 59 \%$

$\mathrm{R}=\mathrm{Cbz}, 52 \%$

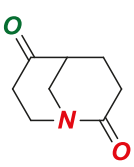

$57 \%$<smiles>[R]C(=O)N1CCN2CCCC1C2</smiles>

$\mathrm{R}=\mathrm{CH}_{2} \mathrm{OMe}$,

$\mathrm{n}=1,63 \%$

$\mathrm{R}=\mathrm{Me}, \mathrm{n}=2,35 \%$

Figure 11. Fragment-Based Drug Discovery using Bridged Lactams.

In 2017, Stoltz and co-workers reported the synthesis of a bridged hydantoin by asymmetric $\alpha$-allylation, Ru-catalyzed olefin isomerization, oxidative cleavage, Curtius rearrangement and $\mathrm{N}$-cyclization onto the isocyanate (Figure 12) [30]. The cyclization is performed by the same mechanism as reported previously by Brouillette [31]; however, the method avoids the use of toxic lead acetate. The bridged hydantoin was fully characterized by X-ray crystallography $\left(\tau=36.4^{\circ}, \chi_{\mathrm{N}}=50.2^{\circ}\right.$; $\mathrm{N}-\mathrm{C}(\mathrm{O})=1.404 \AA ; \mathrm{C}=\mathrm{O}=1.210 \AA$ ). This research illustrates one of the few methods for the synthesis of an enantioenriched twisted amide bond.

\section{Stoltz}
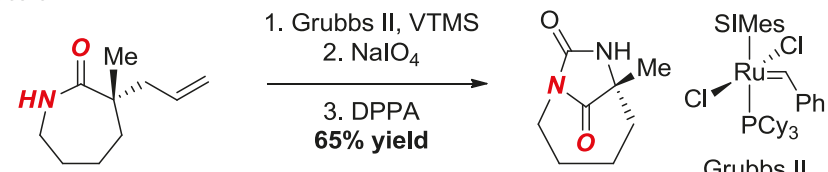

Grubbs II
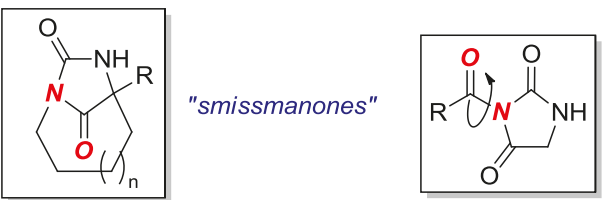

twisted acyclic hydantoins

Figure 12. Synthesis of a Bridged Hydantoin. VTMS = Vinyloxytrimethylsilane. DPPA = diphenyl phosphoryl azide. SIMes = 1,3-Bis(2,4,6-trimethylphenyl)-2-imidazolidinylidene.

Bridged hydantoins of this type were originally proposed by Smissman as potential anticonvulsants (Figure 12, box) [32]. Our group has recently reported the structural characterization of related acyclic twisted $N$-acyl-hydantoins (Figure 12, box) [33]. 
In 2017, Gouverneur, Cvengros and co-workers reported the synthesis of ethano Tröger's base twisted bis-amides (Figure 13) [34]. Their approach involves one-step oxidation of the ethano-Tröger's base precursors under the conditions reported earlier by Wärnmark (Figure 13, box) [35]. The ethano Tröger's base twisted bis-amide is significantly twisted $\left(\tau=29.8^{\circ}, \chi_{N}=45.5^{\circ} ; \mathrm{N}-\mathrm{C}(\mathrm{O})=1.401 \AA\right.$, $\mathrm{C}=\mathrm{O}=1.215 \AA$ ). The advantage of this method is rapid access to a twisted amide bond; however, our study suggests that the presence of the fused aromatic ring is detrimental to the $\mathrm{N}$-protonation reactivity in this class of twisted amides [19].

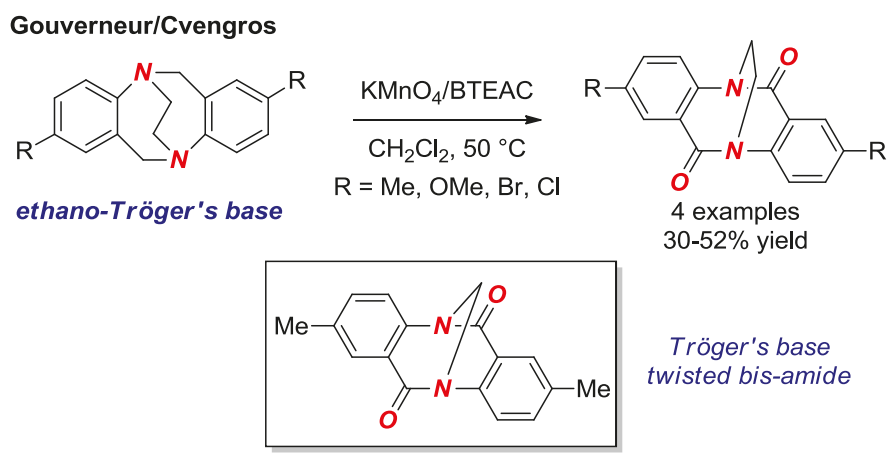

Figure 13. Synthesis of Ethano Tröger's Base Twisted Amides. BTEAC = Benzyltriethylammonium Chloride.

Satyanarayana and Helmchen reported asymmetric synthesis of bridged lactams in [3.3.1] and [4.3.1] scaffolds using Ir-catalyzed allylic amination as an enantioselectivity determining key step (Figure 14) [36]. With allylic amines in hand, the synthesis was completed by well-established amidation/Heck cyclization sequence. The structure of one of the lactams in the [3.3.1] series was confirmed by X-ray crystallography $\left(\tau=30.8^{\circ}, \chi_{N}=52.7^{\circ} ; \mathrm{N}-\mathrm{C}(\mathrm{O})=1.393 \AA, \mathrm{C}=\mathrm{O}=1.218 \AA\right.$ ).
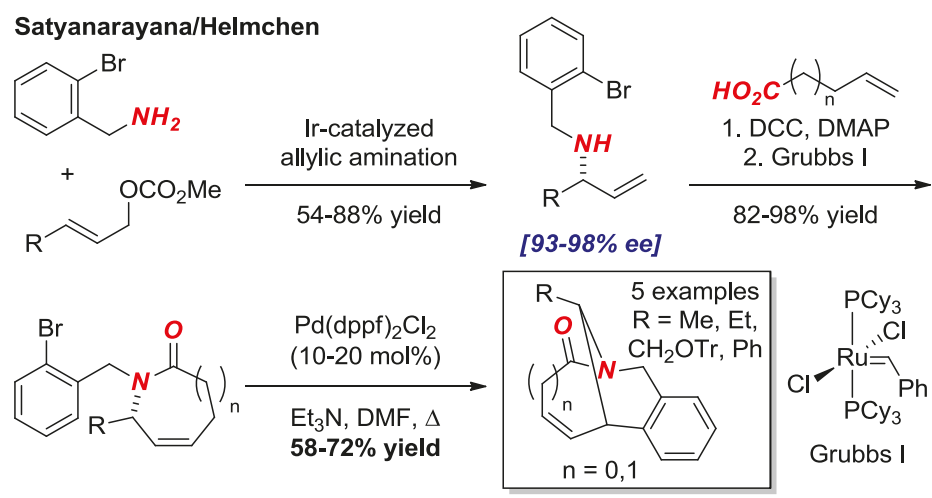

Figure 14. Enantioselective Synthesis of Bridged Lactams by Allylic Amination.

An inventive strategy for the synthesis of bridged lactams in the [5.3.1] and larger scaffolds was reported by Liu and co-workers (Figure 15) [37]. The authors developed a new process for radical aryl migration with chirality transfer to form macrocyclic ketones. As an application of this method, they subjected several azido-ketones to the transannular Aubé-Schmidt rearrangement, resulting in the formation of bridged lactams in 40-63\% yields. Nevertheless, bridged lactams with the overall sum of carbon atoms forming the bridged structure of ten or more, are similar in properties to planar amides. 


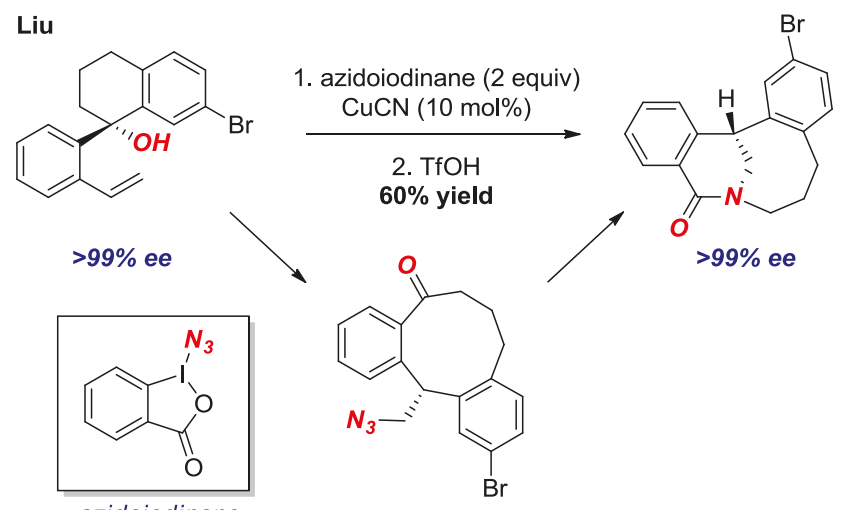

Figure 15. Enantioselective Synthesis of Bridged Lactams by Radical Aryl Migration.

\section{Bridged Sultams}

Bridged sultams (bridged sulfonamides) have attracted significant attention due to a wide range of biological activities of the sulfonamide bond [38]. In contrast to bridged lactams, constraining a sulfonamide bond in rigid bicyclic ring systems is easily possible due to the lack of $\mathrm{Nlp}$ to $\mathrm{SO}_{2}$ conjugation (Nlp = nitrogen lone pair) [39]. Such bridged sultams are not hyper-reactive to hydrolysis and besides applications in medicinal chemistry have been used as template in stereoselective synthesis enabled by rapid scission of the $\mathrm{N}-\mathrm{SO}_{2}$ bond [3].

In 2017, Evans and co-workers in the continuation of their studies on bridged sultams reported an improved method for the synthesis of saturated sultams via intramolecular reductive Heck reaction (Figure 16) [40]. The use of a single Pd catalyst and a broad substrate scope are noteworthy features of this method. One of the saturated sultams in a [3.2.1] scaffold was characterized by $\mathrm{X}$-ray crystallography $(\theta=328.7 ; \mathrm{N}-\mathrm{S}=1.643)$. The same group reported a bromonium-triggered 1,2-Wagner-Meerwein rearrangement of benzofused bridged sultams (not shown) [41].

\section{Evans}<smiles></smiles>

$\mathrm{R}=\mathrm{H}, \mathrm{OMe}, \mathrm{Cl}, \mathrm{NH}_{2}, \mathrm{NO}_{2}$

$\mathrm{R}^{\prime}=\mathrm{H}, \mathrm{Me}, \mathrm{C}(\mathrm{Me})=\mathrm{CH}_{2}$

Selected examples $(X=B r)$

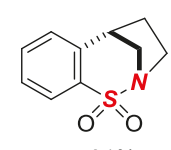

$91 \%$

${ }^{*} 55 \% \mathrm{X}=\mathrm{Cl}$<smiles>Nc1ccc2c(c1)[C@H]1CCN(C2)S1(=O)=O</smiles>

$65 \%$
1. $\mathrm{Pd}(\mathrm{OAc})_{2}(10 \mathrm{~mol} \%)$ $\mathrm{PPh}_{3}(20 \mathrm{~mol} \%)$ $\mathrm{K}_{2} \mathrm{CO}_{3}, \mathrm{DMF}, 110^{\circ} \mathrm{C}$

2. $\mathrm{NH}_{4} \mathrm{HCO}_{2}, 80^{\circ} \mathrm{C}$ $\mathrm{X}=\mathrm{Br}, \mathrm{Cl}$<smiles>[R]Cc1cccc2c1S(=O)(=O)N1CCC2([R])C1</smiles>

14 examples $43-93 \%$ yields

Figure 16. Synthesis of Saturated Bridged Sultams via Intramolecular Heck Reaction/Reduction. 
In 2017, Das and co-workers nicely exploited intramolecular $S_{N}$ Ar-type cyclization to form bridged benzothiaoxazepine-1,1-dioxides in a [4.3.1] scaffold (Figure 17) [42]. An advantage of this method is a rapid, telescoped, three-step synthesis of bridged sultams from the corresponding $\mathrm{N}$-aryl-2-fluorobenzenesulfonamides and trans-2,3-epoxy cinnamyl tosylates. One of the sultams was fully characterized by X-ray crystallography $(\theta=342.0 ; \mathrm{N}-\mathrm{S}=1.668)$. The authors have also developed an enantioselective variant by using a chiral trans-2,3-epoxy cinnamyl alcohol.

Das
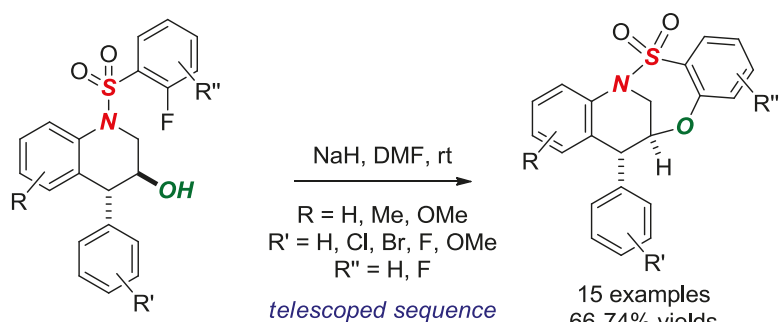

15 examples $66-74 \%$ yields

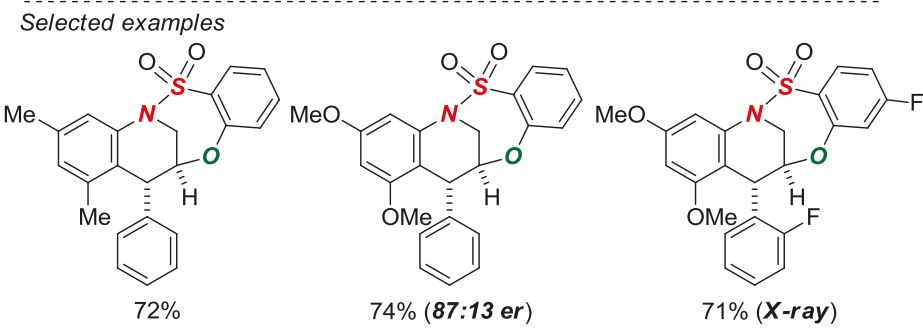

Figure 17. Synthesis of Bridged Benzothiaoxazepine-1,1-dioxides via $\mathrm{S}_{\mathrm{N}} \mathrm{Ar}$ Cyclization.

One example of an "apex-type" bridged sultam in a [3.2.1] scaffold was reported by Sokolov and co-workers (Figure 18) [43]. The X-ray structure demonstrated significant pyramidalization of the nitrogen atom $(\theta=325.5 ; \mathrm{N}-\mathrm{S}=1.668)$.

\section{Sokolov}<smiles>CC(=O)CS(=O)(=O)Nc1ccccc1/C=C/OC(C)=O</smiles>

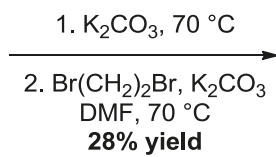

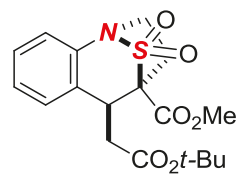

Figure 18. Synthesis of an Apex Bridged Sultam via 1,4-Addition.

\section{Application in Natural Product Synthesis}

Bridged lactams continue to serve as useful intermediates in the total synthesis of natural products [3]. In general, recent applications hinge upon the increased electrophilicity of the carbonyl group and increased nucleophilicity of the nitrogen atom of the amide bond rendered possible by geometric distortion.

In 2015, Zhu and co-workers reported selective reduction of the more twisted amide bond in scholarisine G (Figure 19A) [44]. The enamine was obtained after dehydration of the intermediate hemiaminal. The $\mathrm{X}$-ray structure of scholarisine $\mathrm{G}$ showed a significantly distorted $\mathrm{N}$-aryl amide bond $\left(\tau=21.9^{\circ}, \chi_{\mathrm{N}}=32.0^{\circ} ; \mathrm{N}-\mathrm{C}(\mathrm{O})=1.373 \AA, \mathrm{C}=\mathrm{O}=1.223 \AA\right.$ ) vs. the aliphatic amide bond $\left(\tau=2.9^{\circ}\right.$, $\chi_{\mathrm{N}}=19.9^{\circ} ; \mathrm{N}-\mathrm{C}(\mathrm{O})=1.352 \AA, \mathrm{C}=\mathrm{O}=1.227 \AA$ ). It is also possible that the selective reduction in this case 
can be explained by the exclusive stability of the five-membered ring lactams and by the fact that the six-membered lactam is an anilide. In contrast, Dai exploited the higher basicity of the oxygen atom in the aliphatic amide bond in a structurally-related leuconoxine to selectively maneuver reduction of the more electron-rich amide bond through electrophilic pathway (Figure 19B) [45].

A. Zhu
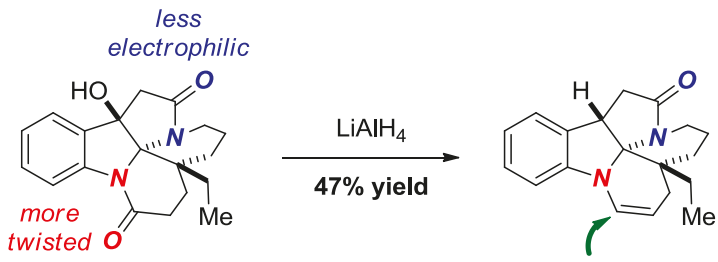

scholarisine G

only lactam reduced

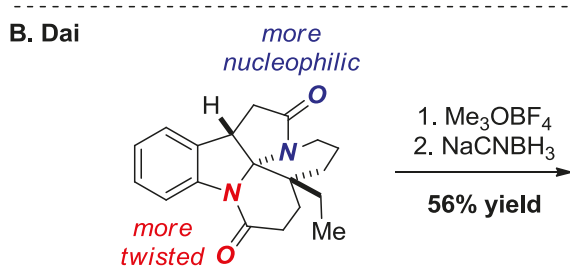

leuconoxine

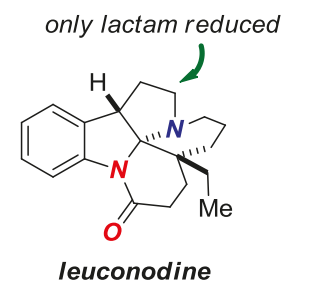

Figure 19. Reduction of a Bridged Lactam in Scholarisine G (A) and Leuconoxine Alkaloids (B).

A total synthesis of 3-O-demethylmacronine, an Amaryllidaceae alkaloid, utilizing a lactam-to-lactone rearrangement of a twisted amide was reported by Banwell and co-workers (Figure 20) [46]. This elegant method capitalized on the high basicity of the twisted amide nitrogen atom to form the acylium ion, which underwent trapping with a pendant hydroxyl group under mild conditions.
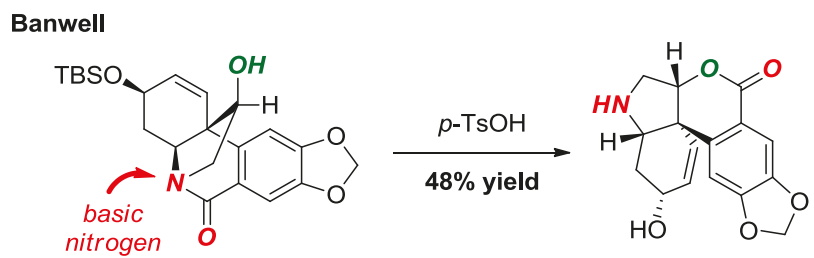

Figure 20. Lactam-to-Lactone Rearrangement of a Bridged Lactam in Haemanthidine Alkaloids.

Landais and co-workers reported a total synthesis of eucophylline, a dimeric terpene indole alkaloid, taking advantage of a high electrophilicity of the carbonyl group in a [3.3.1] bridged lactam scaffold (Figure 21) [47]. Bridged lactams are known to readily condense with amines to form amidines. In this approach, condensation of the twisted amide bond with aniline afforded a bridged amidine, which provided the key disconnection to the eucophylline core. 


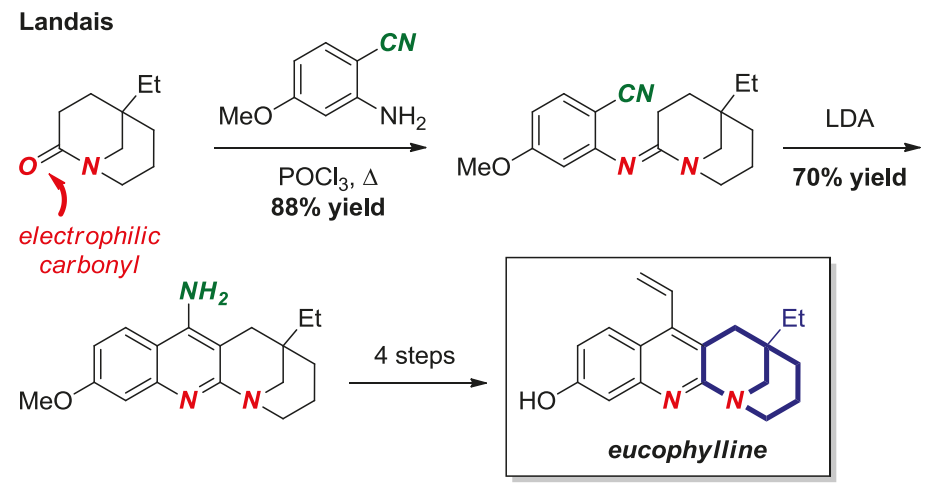

Figure 21. Bridged Amidine from a [3.3.1] Bridged Lactam in the Synthesis of Eucophylline.

\section{Miscellaneous Examples}

In 2015, Wang, Yu and co-workers reported the synthesis of bridged enamines via Au-catalyzed spiro-cyclization of 2-propargyl- $\beta$-tetrahydrocarbolines (Figure 22) [48]. In these heterocycles, the resonance interaction between Nlp and $\pi$ electrons of the double bond is inhibited, resulting in a nucleophilic nitrogen atom.

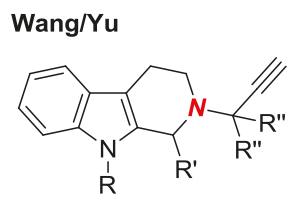

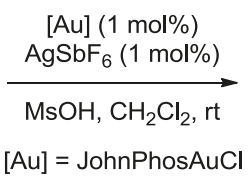

$[\mathrm{Au}]=\mathrm{JohnPhosAuCl}$

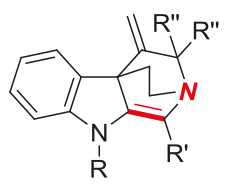

11 examples $76-97 \%$ yields

Figure 22. Synthesis of Bridged Enamines via Gold-Catalyzed Spriocyclization.

In their studies on the Witkop cyclization, Gaich and co-workers reported the synthesis of macrocyclic amides supported by the indole ring (Figure 23) [49]. The structure of one of the amides was confirmed by $X$-ray crystallography and showed a significantly distorted amide bond $\left(\tau=32.3^{\circ}\right.$, $\chi_{\mathrm{N}}=0.0^{\circ} ; \mathrm{N}-\mathrm{C}(\mathrm{O})=1.353 \AA, \mathrm{C}=\mathrm{O}=1.227 \AA$ ).
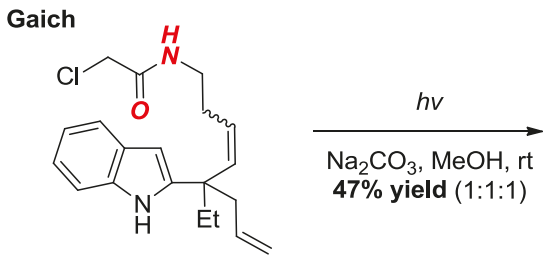

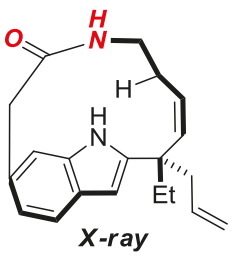

+2 other isomers

Figure 23. Synthesis of a Macrocyclic Lactam via Witkop Cyclization.

Yudin and co-workers developed several elegant methods for site-specific incorporation of amino acids [50], peptide sequencing [51] and conformational control [52] of cyclic peptides based on the twisted amide electrophilic sites (Figure 24). In their approach, the integration of a highly strained and $\mathrm{N}$-pyramidalized aziridinyl ring allows for selective $\mathrm{N}-\mathrm{C}(\mathrm{O})$ cleavage and amino acid incorporation, 
while the strained aziridinyl ring provides a handle for further functionalization by aziridine-ring opening with nucleophiles.
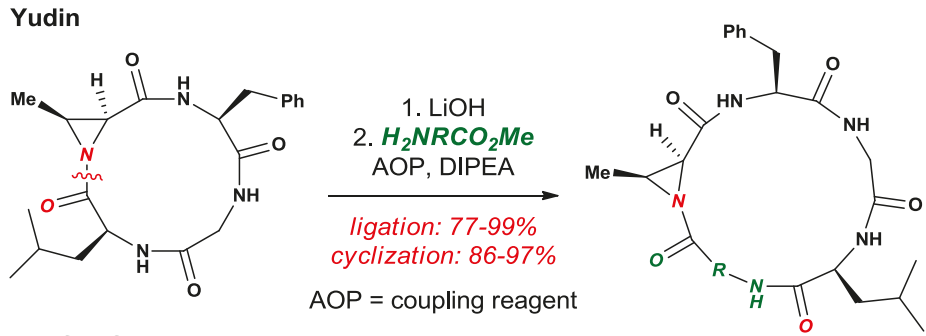

$\mathrm{R}=\mathrm{Gly}$, Sar, Ala, Leu, Val, Phe, Tyr, Trp, Aze, $\beta$-Ala, N $\alpha$-Ac-Lys

Gly-Gly, Phe-D-Pro, Gly-Phe-D-Pro, Ala-Phe-D-Pro

Figure 24. Cyclic Twisted Amide-Containing Tetrapeptides.

Several additional studies on non-planar amides have been reported. Computational studies on ion-pair interactions in Kirby's amide $\mathrm{HBF}_{4}$ salts [53] and $N$-protonation of twisted amides by HF and $\mathrm{HCl}[54]$ were reported by Panday. Mykhailiuk and co-workers reported selective $\sigma \mathrm{N}-\mathrm{C}$ bond scission in strained acyclic amides [55]. Stereoselective C-O bond cleavage in pyramidalized diketopiperazines induced by amide bond distortion was reported by Jahn and co-workers [56]. Intramolecular hydrogen bonding to electron-deficient oxygen in $\mathrm{N}$-pyramidalized bicyclic amides was reported by Otani, Ohwada and co-workers [57]. Excellent reviews on the role of amide bond activation in biological molecules [58], amidicity [59], and heteroatom substitution at amide nitrogen [60] have been published. Additional studies on the properties of amides have been reported [61,62]. Recent relevant studies on acyclic non-planar amides should also be noted [11,12,63-66].

\section{Conclusions}

In summary, we have reviewed recent advances in the area of bridged lactams. This field continues to provide the most effective and wide-ranging method to achieve non-planarity of the amide bond. The main progress in the last five years includes: (1) identification of the additive Winkler-Dunitz parameter as a straightforward and accurate descriptor of the structural and energetic properties of the non-planar amide bond, and (2) the synthesis of extremely twisted bridged lactams in both quinuclidone and adamantanone series. Recently reported examples of novel bridged lactam scaffolds, divergent $\mathrm{N}-\mathrm{C}$ cleavage reactivity and applications in the total synthesis of natural products are also worth noting.

Despite the considerable progress that has been made, the area is far from being mature. The recent remarkable progress in the chemistry of acyclic twisted amides has underlined the benefits of using conformational restriction (i.e., bridged lactams) to achieve non-planarity, but also brought to light the deficiencies of bridged lactams, and non-planar amide bonds in general. Most important is that except for the structurally-limited 1-aza-2-adamantanones there is a complete lack of isolated and fully characterized unhindered bridged lactams with a combined Winkler-Dunitz parameter $\left(\Sigma \tau+\chi_{\mathrm{N}}\right)$ exceeding $100^{\circ}$ in the neutral form (or in other words merely $60 \%$ of the maximum theoretical distortion). It is beyond belief that the area has progressed so little since the first conception of a bridged lactam bond by Lukeš in 1938 .

Further, very little is known about the stability of bridged lactams and, by extension, of non-planar amides. It is now safe to assume that a range of distortion of $\left(\Sigma \tau+\chi_{\mathrm{N}}\right)$ ca. $70-80^{\circ}$ gives isolable lactams. However, this stability range has only been tested in a very limited set of lactams.

Even less is known about the generality of amide bond distortion, properties and structures across different sets of non-planar amides. This research is hindered by the very few types of non-planar bridged lactams that have been described to date. The recent example of Tröger's base twisted amides 
is as a good case in point [19]. Despite significant amide bond distortion, these lactams do not protonate readily as a consequence of Nlp conjugation onto the aromatic ring.

Another issue involves the reactivity of non-planar amides. Almost all research thus far has focused on simple hydrolytic stability and nucleophilic addition studies. At present, only one type of potentially very synthetically appealing metal-catalyzed $\sigma \mathrm{N}-\mathrm{C}$ bond activation has been reported, and the mechanism of this transformation is unknown.

The importance of the amide bond and the continuous role of twisted amides in chemistry and biology have served as a powerful stimulus for fundamental research on bridged lactams. Given the obvious possibilities for applications of non-planar amide bonds, future studies are expected to have a broad impact beyond this important research area.

Author Contributions: The manuscript was written through the contributions of all authors.

Funding: Rutgers University, the NSF (CAREER CHE-1650766) and the Wroclaw Center for Networking and Supercomputing are gratefully acknowledged for support of our research program.

Conflicts of Interest: The authors declare no conflict of interest.

\section{References}

1. Greenberg, A.; Breneman, C.M.; Liebman, J.F. The Amide Linkage: Structural Significance in Chemistry, Biochemistry, and Materials Science; Wiley: New York, NY, USA, 2000.

2. Pauling, L. The Nature of the Chemical Bond; Oxford University Press: London, UK, 1940.

3. Szostak, M.; Aubé, J. Chemistry of Bridged Lactams and Related Heterocycles. Chem. Rev. 2013, 113, 5701-5765. [CrossRef] [PubMed]

4. Szostak, M.; Aubé, J. Medium-Bridged Lactams: A New Class of Non-Planar Amides. Org. Biomol. Chem. 2011, 9, 27-35. [CrossRef] [PubMed]

5. Lease, T.G.; Shea, K.J. A Compilation and Analysis of Structural Data of Distorted Bridgehead Olefins and Amides. In Advances in Theoretically Interesting Molecules; JAI Press Inc.: Greenwich, CT, USA, 1992.

6. Hall, H.K., Jr.; El-Shekeil, A. Anti-Bredt bridgehead nitrogen compounds in ring-opening polymerization. Chem. Rev. 1983, 83, 549-555.

7. Poland, B.W.; Xu, M.Q.; Quiocho, F.A. Structural Insights into the Protein Splicing Mechanism of PI-SceI. J. Biol. Chem. 2000, 275, 16408-16413. [CrossRef] [PubMed]

8. Romanelli, A.; Shekhtman, A.; Cowburn, D.; Muir, T.W. Semisynthesis of a segmental isotopically labeled protein splicing precursor: NMR evidence for an unusual peptide bond the N-extein-intein junction. Proc. Natl. Acad. Sci. USA 2004, 101, 6397-6402. [CrossRef] [PubMed]

9. Shemella, P.; Pereira, B.; Zhang, Y.M.; Van Roey, P.; Belfort, G.; Garde, S.; Nayak, S.K. Mechanism for Intein C-Terminal Cleavage: A Proposal from Quantum Mechanical Calculations. Biophys. J. 2007, 92, 847-853. [CrossRef] [PubMed]

10. Lizak, C.; Gerber, S.; Michaud, G.; Schubert, M.; Fan, Y.Y.; Bucher, M.; Darbare, T.; Aebi, M.; Reymond, J.L.; Locher, K.P. Unexpected reactivity and mechanism of carboxamide activation in bacterial N-linked protein glycosylation. Nat. Commun. 2013, 4, 2627. [CrossRef] [PubMed]

11. Pace, V.; Holzer, W.; Meng, G.; Shi, S.; Lalancette, R.; Szostak, R.; Szostak, M. Structures of Highly Twisted Amides Relevant to Amide N-C Cross-Coupling: Evidence for Ground-State Amide Destabilization. Chem. Eur. J. 2016, 22, 14494-14498. [CrossRef] [PubMed]

12. Shi, S.; Nolan, S.P.; Szostak, M. Well-Defined Palladium(II)-NHC (NHC = N-Heterocyclic Carbene) Precatalysts for Cross-Coupling Reactions of Amides and Esters by Selective Acyl CO-X (X=N, O) Cleavage. Acc. Chem. Res. 2018, 51, 2589-2599. [CrossRef] [PubMed]

13. Winkler, F.K.; Dunitz, J.D. The non-planar amide group. J. Mol. Biol. 1971, 59, 169-182. [CrossRef]

14. Szostak, R.; Aubé, J.; Szostak, M. An Efficient Computational Model to Predict Protonation at the Amide Nitrogen and Reactivity along the C-N Rotational Pathway. Chem. Commun. 2015, 51, 6395-6398. [CrossRef] [PubMed]

15. Szostak, R.; Aubé, J.; Szostak, M. Determination of Structures and Energetics of Small- and Medium-Sized One-Carbon Bridged Twisted Amides using ab Initio Molecular Orbital Methods. Implications for Amidic Resonance along the C-N Rotational Pathway. J. Org. Chem. 2015, 80, 7905-7927. [CrossRef] [PubMed] 
16. Greenberg, A.; Venanzi, C.A. Structures and energetics of two bridgehead lactams and their N- and O-protonated forms: An ab initio molecular orbital study. J. Am. Chem. Soc. 1993, 115, 6951-6957. [CrossRef]

17. Greenberg, A.; Moore, D.T.; DuBois, T.D. Small and Medium-Sized Bridgehead Bicyclic Lactams: A Systematic ab Initio Molecular Orbital Study. J. Am. Chem. Soc. 1996, 118, 8658-8668. [CrossRef]

18. Morgan, J.; Greenberg, A. Novel bridgehead bicyclic lactams: Molecules predicted to have O-protonated and N-protonated tautomers of comparable stability; hyperstable lactams and their O-protonated tautomers. J. Chem. Thermodyn. 2014, 73, 206-212. [CrossRef]

19. Szostak, R.; Szostak, M. Tröger's Base Twisted Amides: High Amide Bond Twist and N-/O-Protonation Aptitude. J. Org. Chem. 2019, in press. [CrossRef] [PubMed]

20. Liniger, M.; VanderVelde, D.G.; Takase, M.K.; Shahgholi, M.; Stoltz, B.M. Total Synthesis and Characterization of 7-Hypoquinuclidonium Tetrafluoroborate and 7-Hypoquinuclidone BF 3 Complex. J. Am. Chem. Soc. 2016, 138, 969-974. [CrossRef] [PubMed]

21. Tani, K.; Stoltz, B.M. Synthesis and structural analysis of 2-quinuclidonium tetrafluoroborate. Nature 2006, 441, 731-734. [CrossRef] [PubMed]

22. Komarov, I.V.; Yanik, S.; Ishchenko, A.Y.; Davies, J.E.; Goodman, J.M.; Kirby, A.J. The Most Reactive Amide As a Transition-State Mimic For cis-trans Interconversion. J. Am. Chem. Soc. 2015, 137, 926-930. [CrossRef]

23. Morgan, K.M.; Rawlins, M.L.; Montgomery, M.N. Influence of methyl substituents on the stability of 1-aza-2-adamantanone, Kirby's most twisted amide. J. Phys. Org. Chem. 2005, 18, 310-314. [CrossRef]

24. Kirby, A.J.; Komarov, I.V.; Wothers, P.D.; Feeder, N. The Most Twisted Amide: Structure and Reactions. Angew. Chem. Int. Ed. 1998, 37, 785-786. [CrossRef]

25. Morgan, J.P.; Weaver-Guevara, H.M.; Fitzgerald, R.W.; Dunlap-Smith, A.; Greenberg, A. Ab initio computational study of 1-methyl-4-silatranone and attempts at its conventional synthesis. Struct. Chem. 2017, 28, 327-331. [CrossRef]

26. Hu, F.; Lalancette, R.; Szostak, M. Structural Characterization of N-Alkylated Twisted Amides: Consequences for Amide Bond Resonance and N-C Cleavage. Angew. Chem. Int. Ed. 2016, 55, 5062-5066. [CrossRef] [PubMed]

27. Hu, F.; Nareddy, P.; Lalancette, R.; Jordan, F.; Szostak, M. $\sigma$ N-C Bond Difunctionalization in Bridged Twisted Amides: Sew-and-Cut Activation Approach to Functionalized Isoquinolines. Org. Lett. 2017, 19, 2386-2389. [CrossRef] [PubMed]

28. Hassan, H.; Marsden, S.P.; Nelson, A. Design and synthesis of a fragment set based on twisted bicyclic lactams. Bioorg. Med. Chem. 2018, 26, 3030-3033. [CrossRef] [PubMed]

29. Steliou, K.; Poupart, M.A. Reagents for organic synthesis. Part 3. Tin-mediated esterification in macrolide synthesis. J. Am. Chem. Soc. 1983, 105, 7130-7138. [CrossRef]

30. Liniger, M.; Liu, Y.; Stoltz, B. Sequential Ruthenium Catalysis for Olefin Isomerization and Oxidation: Application to the Synthesis of Unusual Amino Acids. J. Am. Chem. Soc. 2017, 139, 13944-13949. [CrossRef]

31. Brouillette, W.J.; Jestkov, V.P.; Brown, M.L.; Akhtar, M.S.; DeLorey, T.M.; Brown, G.B. Bicyclic Hydantoins with a Bridgehead Nitrogen. Comparison of Anticonvulsant Activities with Binding to the Neuronal Voltage-Dependent Sodium Channel. J. Med. Chem. 1994, 37, 3289-3293. [CrossRef]

32. Smissman, E.E.; Matuszak, A.J.; Corder, C.N. Reduction of Barbiturates Under Hydroboration Conditions. J. Pharm. Sci. 1964, 53, 1541-1542. [CrossRef]

33. Szostak, R.; Liu, C.; Lalancette, R.; Szostak, M. Twisted N-Acyl-hydantoins: Rotationally Inverted Urea-Imides of Relevance in N-C(O) Cross-Coupling. J. Org. Chem. 2018, 83, 14676-14682. [CrossRef]

34. Pereira, R.; Pfeifer, L.; Fournier, J.; Gouverneur, V.; Cvengroš, J. Twisting the ethano-Tröger's base: The bisamide. Org. Biomol. Chem. 2017, 15, 628-633. [CrossRef] [PubMed]

35. Artacho, J.; Ascic, E.; Rantanen, T.; Karlsson, J.; Wallentin, C.J.; Wang, R.; Wendt, O.F.; Harmata, M.; Snieckus, V.; Wärnmark, K. Twisted Amide Analogues of Tröger's Base. Chem. Eur. J. 2012, 18, 1038-1042. [CrossRef] [PubMed]

36. Satyanarayana, G.; Helmchen, G. Enantioselective Syntheses of Bicyclic Lactams Based on Iridium-Catalyzed Asymmetric Allylic Substitution and Heck Cyclization. Eur. J. Org. Chem. 2014, 2242-2252. [CrossRef]

37. Li, L.; Li, Z.L.; Wang, F.L.; Guo, Z.; Cheng, Y.F.; Wang, N.; Dong, X.W.; Fang, C.; Liu, J.; Hou, C.; et al. Radical aryl migration enables diversity-oriented synthesis of structurally diverse medium/macro- or bridged-rings. Nat. Commun. 2016, 7, 13852. [CrossRef] [PubMed]

38. Drews, J. Drug Discovery: A Historical Perspective. Science 2000, 287, 1960-1964. [CrossRef] [PubMed] 
39. Paquette, L.A.; Leit, S.M. The First Examples of Bridgehead Bicyclic Sultams. J. Am. Chem. Soc. 1999, 121, 8126-8127. [CrossRef]

40. Khalifa, A.; Conway, L.; Geoghegan, K.; Evans, P. Ammonium formate-based one-pot reductive Heck reactions for the construction of cyclic sulfonamides. Tetrahedron Lett. 2017, 58, 4559-4562. [CrossRef]

41. Geoghegan, K.; Smullen, S.; Evans, P. Halonium Ion Triggered Rearrangement of Unsaturated BenzoAnnulated Bi- and Tricyclic Sulfonamides. J. Org. Chem. 2013, 78, 10443-10451. [CrossRef]

42. Borgohain, H.; Devi, R.; Dheer, D.; Borah, B.J.; Shankar, R.; Das, S.K. Synthesis of Tetrahydroquinoline-Embedded Bridged Benzothiaoxazepine-1,1-dioxides. Eur. J. Org. Chem. 2017, 6671-6679. [CrossRef]

43. Grosheva, D.S.; Rassadin, V.A.; Sokolov, V.V. A Route to Benzo-Annelated $\delta$-Sultams through Michael Cyclization. Eur. J. Org. Chem. 2015, 2015, 1355-1363. [CrossRef]

44. Xu, Z.; Wang, Q.; Zhu, J. Total Syntheses of (-)-Mersicarpine, (-)-Scholarisine G, (+)-Melodinine E, (-)-Leuconoxine, (-)-Leuconolam, (-)-Leuconodine A, (+)-Leuconodine F, and (-)-Leuconodine C: Self-Induced Diastereomeric Anisochronism (SIDA) Phenomenon for Scholarisine G and Leuconodines A and C. J. Am. Chem. Soc. 2015, 137, 6712-6724. [PubMed]

45. Yang, Y.; Bai, Y.; Sun, S.; Dai, M. Biosynthetically Inspired Divergent Approach to Monoterpene Indole Alkaloids: Total Synthesis of Mersicarpine, Leuconodines B and D, Leuconoxine, Melodinine E, Leuconolam, and Rhazinilam. Org. Lett. 2014, 16, 6216-6219. [CrossRef] [PubMed]

46. Ma, X.; Gao, N.; Banwell, M.G.; Carr, P.D.; Willis, A.C. A Total Synthesis of ( \pm )-3-O-Demethylmacronine through Rearrangement of a Precursor Embodying the Haemanthidine Alkaloid Framework. J. Org. Chem. 2017, 82, 4336-4341. [CrossRef] [PubMed]

47. Hassan, H.; Mohammed, S.; Robert, F.; Landais, Y. Total Synthesis of ( \pm )-Eucophylline. A Free-Radical Approach to the Synthesis of the Azabicyclo[3.3.1]nonane Skeleton. Org. Lett. 2015, 17, 4518-4521. [PubMed]

48. Zhang, L.; Wang, Y.; Yao, Z.J.; Wang, S.; Yu, Z.X. Kinetic or Dynamic Control on a Bifurcating Potential Energy Surface? An Experimental and DFT Study of Gold-Catalyzed Ring Expansion and Spirocyclization of 2-Propargyl- $\beta$-tetrahydrocarbolines. J. Am. Chem. Soc. 2015, 137, 13290-13300. [CrossRef] [PubMed]

49. Pfaffenbach, M.; Roller, A.; Gaich, T. Synthesis of Indolophanes by Photochemical Macrocyclization. Chem. Eur. J. 2016, 22, 8444-8447. [CrossRef]

50. White, C.J.; Hickey, J.L.; Scully, C.C.G.; Yudin, A.K. Site-Specific Integration of Amino Acid Fragments into Cyclic Peptides. J. Am. Chem. Soc. 2014, 136, 3728-3731. [CrossRef]

51. Zaretsky, S.; Rai, V.; Gish, G.; Forbes, M.W.; Kofler, M.; Yu, J.C.Y.; Tan, J.; Hickey, J.L.; Pawson, T.; Yudin, A.K. Twisted amide electrophiles enable cyclic peptide sequencing. Org. Biomol. Chem. 2015, 13, 7384-7388. [CrossRef]

52. Chung, B.K.W.; White, C.J.; Scully, C.C.G.; Yudin, A.K. The reactivity and conformational control of cyclic tetrapeptides derived from aziridine-containing amino acids. Chem. Sci. 2016, 7, 6662-6668. [CrossRef]

53. Pandey, K.K. Theoretical insights into structure, bonding, reactivity and importance of ion-pair interactions in Kirby's tetrafluoroboric acid salts of twisted amides. RSC Adv. 2015, 5, 105668-105677. [CrossRef]

54. Pandey, K.K. Does hydrohalic acid HX (X=F, Cl) form true N-protonated twisted amide salts? Effects of anions on the ion-pair interactions and on the amide moiety in N-protonated tricyclic twisted amide salts. New J. Chem. 2016, 40, 7831-7839. [CrossRef]

55. Artamonov, O.S.; Slobodyanyuk, E.Y.; Volochnyuk, D.M.; Komarov, I.V.; Tolmachev, A.A.; Mykhailiuk, P.K. Synthesis of Trifluoromethyl-Substituted 3-Azabicyclo[n.1.0]alkanes: Advanced Building Blocks for Drug Discovery. Eur. J. Org. Chem. 2014, 46, 3592-3598. [CrossRef]

56. Amatov, T.; Jangra, H.; Pohl, R.; Cisařová, I.; Zipse, H.; Jahn, U. Unique Stereoselective Homolytic C-O Bond Activation in Diketopiperazine-Derived Alkoxyamines by Adjacent Amide Pyramidalization. Chem. Eur. J. 2018, 24, 15336-15345. [CrossRef]

57. Wang, S.; Taniguchi, T.; Monde, K.; Kawahata, M.; Yamaguchi, K.; Otani, Y.; Ohwada, T. Hydrogen bonding to carbonyl oxygen of nitrogen-pyramidalized amide-Detection of pyramidalization direction preference by vibrational circular dichroism spectroscopy. Chem. Commun. 2016, 52, 4018-4021. [CrossRef]

58. Mahesh, S.; Tang, K.C.; Raj, M. Amide Bond Activation of Biological Molecules. Molecules 2018, $23,2615$. [CrossRef] [PubMed]

59. Kovács, E.; Rózsa, B.; Csomos, A.; Csizmadia, I.G.; Mucsi, Z. Amide Activation in Ground and Excited States. Molecules 2018, 23, 2859. [CrossRef] [PubMed] 
60. Glover, S.A.; Rosser, A.A. Heteroatom Substitution at Amide Nitrogen-Resonance Reduction and HERON Reactions of Anomeric Amides. Molecules 2018, 23, 2834. [CrossRef]

61. Morgan, K.M.; Ashline, D.J.; Morgan, J.P.; Greenberg, A. Electrospray Ionization (ESI) Fragmentations and Dimethyldioxirane Reactivities of Three Diverse Lactams Having Full, Half, and Zero Resonance Energies. J. Org. Chem. 2014, 79, 517-528. [CrossRef]

62. Glover, S.A.; Rosser, A.A. HERON reactions of anomeric amides: Understanding the driving force. J. Phys. Org. Chem. 2015, 28, 215-222. [CrossRef]

63. Szostak, R.; Shi, S.; Meng, G.; Lalancette, R.; Szostak, M. Ground-State Distortion in $\mathrm{N}$-Acyl-tert-butyl-carbamates (Boc) and $\mathrm{N}$-Acyl-tosylamides (Ts): Twisted Amides of Relevance to Amide N-C Cross-Coupling. J. Org. Chem. 2016, 81, 8091-8094. [CrossRef]

64. Meng, G.; Shi, S.; Lalancette, R.; Szostak, R.; Szostak, M. Reversible Twisting of Primary Amides via Ground State N-C(O) Destabilization: Highly Twisted Rotationally Inverted Acyclic Amides. J. Am. Chem. Soc. 2018, 140, 727-734. [CrossRef] [PubMed]

65. Szostak, R.; Szostak, M. N-Acyl-Glutarimides: Resonance and Proton Affinities of Rotationally-Inverted Twisted Amides Relevant to N-C(O) Cross-Coupling. Org. Lett. 2018, 20, 1342-1345. [CrossRef] [PubMed]

66. Liu, C.; Shi, S.; Liu, Y.; Liu, R.; Lalancette, R.; Szostak, R.; Szostak, M. The Most Twisted Acyclic Amides: Structures and Reactivity. Org. Lett. 2018, 20, 7771-7774. [CrossRef] [PubMed]

(C) 2019 by the authors. Licensee MDPI, Basel, Switzerland. This article is an open access article distributed under the terms and conditions of the Creative Commons Attribution (CC BY) license (http:/ / creativecommons.org/licenses/by/4.0/). 


\title{
Review \\ Well-Defined Pre-Catalysts in Amide and Ester Bond Activation
}

\author{
Sandeep R. Vemula, Michael R. Chhoun and Gregory R. Cook * \\ Department of Chemistry and Biochemistry, North Dakota State University, Fargo, ND 58108-6050, USA; \\ sandeepreddy.vemula@ndsu.edu (S.R.V.); michael.chhoun@ndsu.edu (M.R.C.) \\ * Correspondence: gregory.cook@ndsu.edu; Tel.: +1-701-231-7413 \\ Academic Editor: Michal Szostak \\ Received: 3 December 2018; Accepted: 2 January 2019; Published: 9 January 2019
}

\begin{abstract}
Over the past few decades, transition metal catalysis has witnessed a rapid and extensive development. The discovery and development of cross-coupling reactions is considered to be one of the most important advancements in the field of organic synthesis. The design and synthesis of well-defined and bench-stable transition metal pre-catalysts provide a significant improvement over the current catalytic systems in cross-coupling reactions, avoiding excess use of expensive ligands and harsh conditions for the synthesis of pharmaceuticals, agrochemicals and materials. Among various well-defined pre-catalysts, the use of $\mathrm{Pd}(\mathrm{II})-\mathrm{NHC}$, particularly, provided new avenues to expand the scope of cross-coupling reactions incorporating unreactive electrophiles, such as amides and esters. The strong $\sigma$-donation and tunable steric bulk of NHC ligands in Pd-NHC complexes facilitate oxidative addition and reductive elimination steps enabling the cross-coupling of broad range of amides and esters using facile conditions contrary to the arduous conditions employed under traditional catalytic conditions. Owing to the favorable catalytic activity of Pd-NHC catalysts, a tremendous progress was made in their utilization for cross-coupling reactions via selective acyl $\mathrm{C}-\mathrm{X}(\mathrm{X}=\mathrm{N}, \mathrm{O})$ bond cleavage. This review highlights the recent advances made in the utilization of well-defined pre-catalysts for $\mathrm{C}-\mathrm{C}$ and $\mathrm{C}-\mathrm{N}$ bond forming reactions via selective amide and ester bond cleavage.
\end{abstract}

Keywords: pre-catalysts; palladium catalysis; amide bond activation; ester bond activation; cross-coupling

\section{Introduction}

Transition metal-catalyzed cross-coupling reactions to form $\mathrm{C}-\mathrm{C}$ and $\mathrm{C}-\mathrm{N}$ bonds are a mainstay of organic synthesis for a wide range of academic and industrial applications [1-6]. Due to their wide applicability, these reactions have become a critical arsenal for synthetic chemists and have clearly changed retrosynthetic analysis of complex targets. Since their discovery in the late 1960s, palladium catalyzed cross-coupling reactions has been considerable and continues to be a focus of organometallic research [7-14]. The most active Pd catalysts for cross-coupling reactions involve the use of strong donor ligands to reach a high degree of efficiency. In fact, one of the major advancement in cross-coupling reactions is the synthesis and utilization of specialized electron-rich phosphines and $\mathrm{N}$-heterocyclic carbenes (NHC) for the development of active catalytic systems expanding the substrate scope with lower catalyst loadings and milder conditions $[15,16]$. However, the monetary costs of these specialized ligands are often comparable to the Pd precursor. Therefore, the traditional route of addition of excess ligand for generating the active $\operatorname{Pd}(0)$ becomes unattractive $[15,17]$. Furthermore, in many cross-coupling reactions, the optimal $\mathrm{Pd}$ to ligand ratio is $1: 1$, with the active species proposed to be a monoligated $\operatorname{Pd}(0)$. Therefore, the use of well-defined $\mathrm{Pd}(\mathrm{II})$ pre-catalysts to facilitate cross-coupling reactions is highly desirable, as they can generate mono ligated active $\operatorname{Pd}(0)$ catalysts in 
solution. Since Herrmann reported that Pd-NHC complexes efficiently catalyzed Heck reaction [18], these complexes found a widespread use for various cross-coupling reactions incorporating previously unreactive coupling partners (Figure 1) [19].

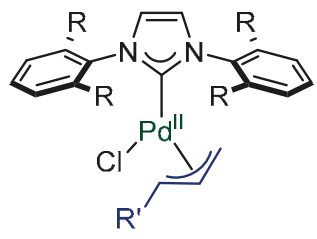

Nolan precatalyst

Active for:

- Suzuki-Miyaura coupling

- Kumada coupling

- Negishi coupling

- Buchwald-Hartwig amination

- $\alpha$-arylation reactions

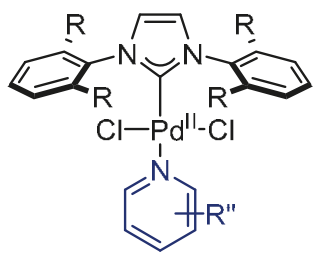

\section{Organ precatalyst}

Active for:

- Suzuki-Miyaura coupling

- Kumada coupling

- Negishi coupling

- Buchwald-Hartwig amination

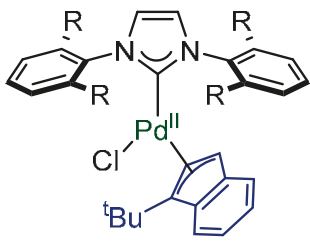

Hazari precatalyst

Active for:

- Suzuki-Miyaura coupling

- Buchwald-Hartwig amination

Figure 1. Overview of cross-coupling reactions catalyzed by $\mathrm{Pd}(\mathrm{II})-\mathrm{NHC}$ pre-catalysts.

Although various electrophiles are employed in cross-coupling reactions for the construction of $\mathrm{C}-\mathrm{C}$ and $\mathrm{C}-\mathrm{N}$ bonds, there is immense interest in increasing the substrate scope to include a wide range of cross-coupling partners $[1,4,20]$. In recent years, tremendous progress was made to incorporate stable, unreactive, carboxylic acid derivatives, such as amides and esters, in cross-coupling reactions to

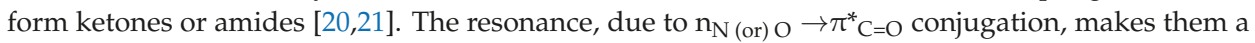
complicated reacting partner in cross-coupling reactions, requiring a high activation energy for the $\mathrm{N}$ or $\mathrm{O}-\mathrm{C}(\mathrm{O})$ bond scission. Destabilization strategies increasing the steric bulk on the amide nitrogen independently developed by the laboratories of Garg [22], Szostak [23], and Zou [24] provide a basis for the development of acyl cross-coupling of amides. Various Pd and Ni catalyst systems with phosphine and NHC ancillary ligands are shown to be effective in utilizing amides and esters as coupling partners in Suzuki-Miyaura coupling and Buchwald-Hartwig amination reactions. However, in this review, we will focus only on describing the recent advances made in the cross-coupling of amides and esters using well-defined pre-catalysts. The individual sections in this review are organized according to the pre-catalysts employed [Pd(allyl)(NHC)Cl, and Pd-PEPPSI] for cross-coupling of amides and esters.

\section{Pd(allyl)(NHC)Cl Pre-Catalysts in Suzuki-Miyaura Cross-Coupling of Amides and Esters}

With a wide functional group tolerance and less sensitivity toward air and moisture, palladium is by far the most commonly used metal for catalysis of cross-coupling reactions. Among the various pre-catalysts developed in the past decade, there is considerable interest and improvement in pre-catalysts based on $\eta^{3}$-allyl ligands. Aside from the inherent advantages associated with NHC ligands (i.e., strong $\sigma$-donation, tunability, sterics), Nolan demonstrated that $\eta^{3}$-allyl and $\eta^{3}$-cinnamyl pre-catalysts with bulky NHC ligands also exhibit high stability toward air and moisture allowing for easy storage and handling $[15,25,26]$. Furthermore, the commercial availability and ease of synthesis made them an important class of catalysts for reaction screening. The strong $\sigma$-donating nature of NHC facilitates the activation of stable and unreactive bonds. Specifically, the $[\mathrm{Pd}($ cinnamyl)(L)Cl] scaffold $\left(\mathrm{L}=\mathrm{IPr}^{*}\right.$ or $\left.\mathrm{IPr}^{*} \mathrm{OMe}\right)$ was incorporated into several highly active catalysts for difficult cross-coupling reactions, such as the synthesis of tetra-ortho-substituted biaryls using Suzuki-Miyaura coupling [27], Buchwald-Hartwig reactions with secondary amines [28], as well as the use of amides and esters as electrophiles in Suzuki-Miyaura coupling and Buchwald-Hartwi aminations. Figure 2 lists selected and active Pd(allyl)NHC pre-catalysts that were employed for the cross-coupling of amides and esters [19]. 


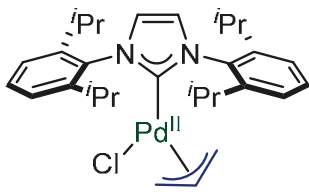

[Pd(IPr)(allyl)Cl]

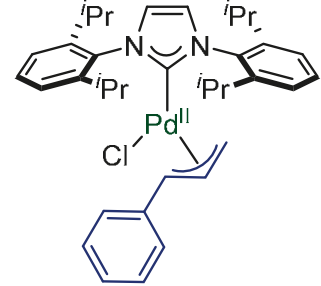

[Pd(IPr)(cinnamyl)Cl]

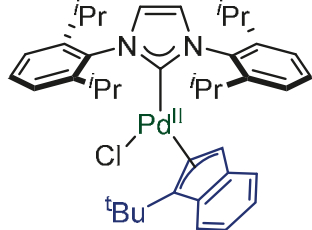

$[\mathrm{Pd}(\mathrm{IPr})($ indenyl)Cl]

Figure 2. $\mathrm{Pd}($ allyl)NHC pre-catalysts employed in the cross-coupling of amides.

\subsection{Pd(allyl)(NHC)Cl Pre-Catalysts in Suzuki-Miyaura Cross-Coupling of Amides}

Given the key role of the amide bond in nature, development of new methods to functionalize amides via $\mathrm{C}-\mathrm{N}$ bond activation became an active area of research. Mechanistically, activation of the $\mathrm{C}-\mathrm{N}$ amide bond proceeds through ground-state destabilization (twisting) of the amide bond by steric and/or electronic factors, allowing a facile insertion of a metal into the $\mathrm{C}-\mathrm{N}$ bond, furnishing the acyl-metal intermediate facilitating coupling reactions [29-31]. Scheme 1 lists various substituents on amide nitrogen employed for the destabilization.<smiles>O=C1CCCC(=O)N1C(=O)c1ccccc1</smiles>

N-Acylglutarimide<smiles>[R]N(C(=O)c1ccccc1)S(C)(=O)=O</smiles>

N-Mesyl amides<smiles>O=C1C=CC(=O)N1C(=O)c1ccccc1</smiles>

N-Acylsuccinimide<smiles>O=C(c1ccccc1)N1C(=O)c2ccccc2S1(=O)=O</smiles>

N-Acylsaccharins<smiles>[R]N(C(=O)OC(C)(C)C)C(=O)c1ccccc1</smiles><smiles>[R7]N([3H])C(=O)c1ccccc1</smiles>

$N$-Boc amides

$N$-Tosyl amides<smiles>O=C(c1ccccc1)n1cccc1</smiles>

N-Acylpyrroles<smiles>CN(C(=O)c1ccccc1)c1ncccn1</smiles>

N-Methylamino pyrimidyl amides (MAPA)

Scheme 1. Selected $\mathrm{N}$-substituents employed for amide C-N bond destabilization.

In 2015, the utilization of amide bond for the Suzuki-Miyaura cross-coupling was reported by Zou and coworkers employing $N$-phenyl- $N$-tosyl substituted amides [24]. The report showcased the effect of substituent electronics on the destabilization of amide resonance facilitating the metal insertion in to the amide $\mathrm{C}-\mathrm{N}$ bond. Although the methodology showed good functional group tolerance, it suffered from high catalyst loadings and stringent reaction conditions (Scheme 2).<smiles>[R]C(=O)N([3H])Pc1cccc([Hg])c1</smiles>

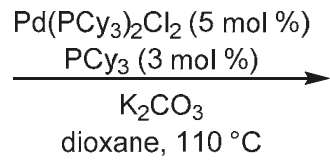<smiles>[R]C(=O)c1ccc([R])cc1</smiles>

$35-98 \%$ Yield 28 examples

Scheme 2. Suzuki-Miyaura cross-coupling of $N$-phenyl- $N$-tosyl substituted amides.

In the same year, Szostak and coworkers employed a rather different approach of sterically controlled amide bond destabilization using a variety of $N$-substituted amides and found the best 
results to be $\mathrm{N}$-glutarimide [23]. The methodology provided inherent steric advantages for amide bond distortion, thereby providing a milder reaction conditions and high functional group tolerance (Scheme 3). But the utilization of large excess of expensive ligand (1:4 ratio of $\mathrm{Pd}(\mathrm{OAc})_{2}$ to $\mathrm{PCy}_{3} \mathrm{HBF}_{4}$ ), and applicability to only highly twisted $N$-glutarimide amides restricted the practical applications of the methodology.<smiles>[R]C(=O)N1C[CH+]CCC1=O</smiles>

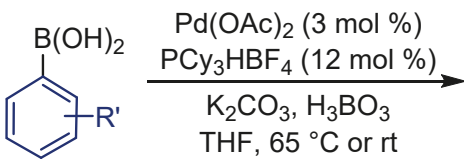<smiles>[R]C(=O)c1ccc(C)cc1</smiles>

\section{up to $98 \%$ Yield} 62 examples

Scheme 3. Suzuki-Miyaura cross-coupling of sterically substituted twisted amides.

It was not until recently that a more general method incorporating all classes of amides under milder conditions was developed. In 2017, Szostak and coworkers reported the versatility of $[\mathrm{Pd}(\mathrm{IPr})($ cinnamyl)Cl], a well-defined pre-catalyst in the Suzuki-Miyaura cross-coupling of amides under operationally simple conditions (Scheme 4) [23]. The methodology is highly significant, as it promoted the $\mathrm{C}-\mathrm{N}$ amide bond activation of various amides, including $\mathrm{N}$-glutarimide, $\mathrm{N}$-Boc-carbamate, and $\mathrm{N}$-toluenesulfonamide, under the same reaction conditions with similar yields of the ketone product. The method also showed high functional group tolerance for both reacting partners. The use of easily prepare and common protecting groups ( $N$-Boc and N-Ts amides) for cross-coupling is appealing, as it brings the amide bond cross-coupling closer to general practical use. As stated previously, it was proposed that strong $\sigma$ donation of the NHC facilitates oxidative addition, while flexible steric bulk around Pd promotes reductive elimination, triggering high reactivity even with less activated amide precursors.

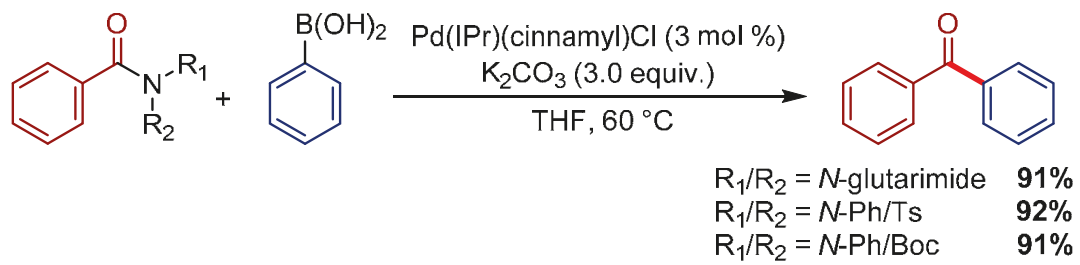

Scheme 4. Application of $\mathrm{Pd}($ cinnamyl)(IPr)Cl in amide bond cross-coupling.

While nonplanar amides were found to be very effective and well-documented for cross-coupling reactions by steric distortion, the resonance destabilization of corresponding planar amides was not well developed. To incorporate planar amides for cross-coupling reactions, Szostak and coworkers utilized $N$-acylpyrroles and $N$-acylpyrazoles in Suzuki-Miyaura cross-coupling reactions (Scheme 5) [32]. They found delocalization of $\mathrm{N}_{\mathrm{lp}}$ into the $\pi$-electron system of the pyrrole/pyrazole ring to be sufficient to selectively insert palladium into the amide $\mathrm{C}-\mathrm{N}$ bond in the absence of steric distortion. The extensive optimization emphasized the importance of well-defined $[\mathrm{Pd}(\mathrm{cinnamyl})(\mathrm{IPr}) \mathrm{Cl}]$ producing ketone in good yields compared to traces of product formation with the traditional catalyst/ancillary ligand system. 


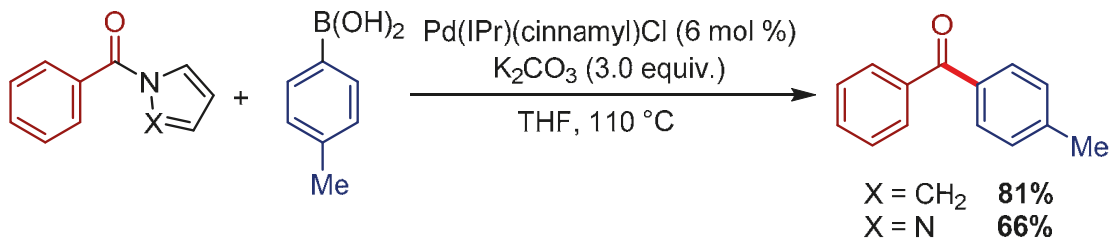

Scheme 5. Cross-coupling of planar amides catalyzed by well-defined Pd(cinnamyl)(IPr)Cl.

Compared to both traditional Pd/phosphine catalyst systems or Pd/ancillary NHC catalytic systems, well-defined $[\mathrm{Pd}($ cinnamyl)(IPr)Cl] offers both practical advantages and high activity in cross-coupling reactions of amides. In fact, the high catalytic activity of [ $\mathrm{Pd}(\mathrm{cinnamyl})(\mathrm{IPr}) \mathrm{Cl}]$ can be evident by its ability to convert $N$-alkyl- $N$-aryl amides to corresponding ketones. In 2017, Szostak and coworkers introduced $\mathrm{N}$-methylaminopyrimidyl amides (MAPA) as highly reactive, electronically activated amides for $\mathrm{C}-\mathrm{N}$ bond cleavage (Scheme 6) [33,34].

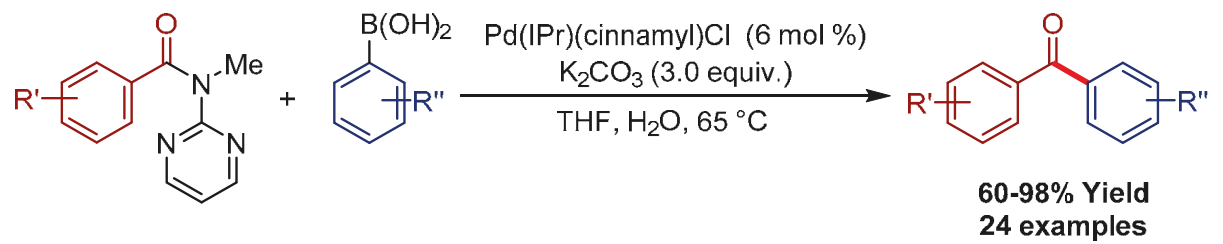

Scheme 6. Pd(cinnamyl)(IPr)Cl catalyzed Suzuki-Miyaura cross-coupling of $N$-alkyl- $N$-aryl amides.

Interestingly, Suzuki-Miyaura cross-coupling of both the sterically distorted and/or electronically distorted amides were found to be reactive under similar reaction conditions, further demonstrating how the well-defined nature of a catalyst can enhance the overall catalytic activity and reactivity compared to traditional usage of excess ancillary ligand. This is highly beneficial, as it allows chemists to screen minimal conditions to optimize methodology for new classes of amides with similar distortion angles or resonance energies. In fact, Zeng and coworkers, on their quest to incorporate commercially available and inexpensive $\mathrm{N}$-acylhydantoins as amide electrophiles, have also used similar conditions for the formation of ketones indicating the versatility of $\mathrm{Pd}(\mathrm{allyl})(\mathrm{NHC}) \mathrm{Cl}$ pre-catalysts with different substituted amides (Scheme 7) [35].<smiles>[R]Oc1cccc(C(=O)N2C(=O)NC(C)(C)C2=O)c1</smiles>

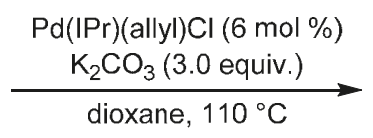<smiles>[R]c1ccc(C(=O)c2ccc([R6])cc2)cc1</smiles>

Scheme 7. Pd(allyl)(IPr)Cl catalyzed Suzuki-Miyaura cross-coupling of $N$-acylhydantoins.

Although the reported methods to incorporate amide bonds in cross-coupling reactions is quite promising, the synthetic modifications to activate amide bond can impede overall synthetic utility. On the other hand, use of $\mathrm{N}, \mathrm{N}$-di-Boc-activated amides would be highly beneficial, allowing direct engagement of most ubiquitous primary amides. Szostak and coworkers developed a new catalytic system based on $[\mathrm{Pd}(\mathrm{IPr})(\mathrm{cinnamyl}) \mathrm{Cl}] / \mathrm{KF}$ for the selective insertion of metal into acyl amide bond (cf. $N$-carbamate bond) [36]. The addition of 5.0 equiv of water was found to be critical for the cross-coupling of di-boc amides, as is evident from decreased yields or no reaction in the absence of water (Scheme 8). 


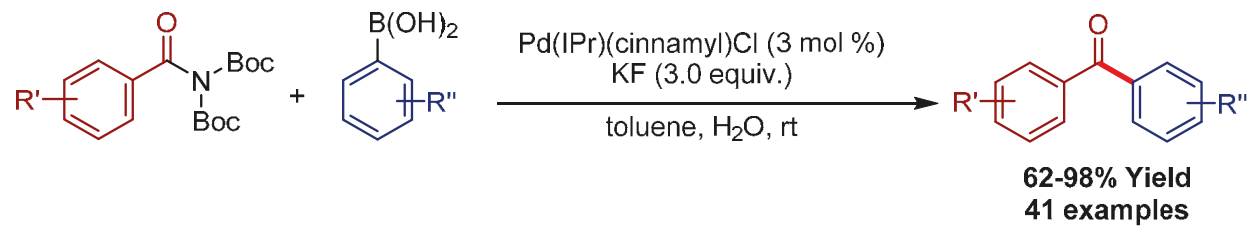

Scheme 8. Direct cross-coupling of N,N-di-Boc-amides under Pd(IPr)(cinnamyl)Cl catalysis.

The high catalytic activity of $\mathrm{Pd}(\mathrm{IPr})($ cinnamyl)Cl allowed for the cross-coupling to be conducted at ambient temperature with even lower catalyst loadings. The robust nature of $\mathrm{Pd}(\mathrm{IPr})(\mathrm{cinnamyl}) \mathrm{Cl}$ also allowed them for the gram scale conversion of primary amides to ketones with just $0.5 \mathrm{~mol} \%$ of catalyst with a TON of 1220, further increasing the practicality of amide cross-coupling (Scheme 9) [36]. In fact, the high catalytic activity of Pd-IPr complexes also allowed Szostak and coworkers to use easily accessible $\mathrm{N}$-acyl amides for the cross-coupling reaction with the highest reported TON (3500), compared to the corresponding traditional Pd-phosphine catalytic systems [37].

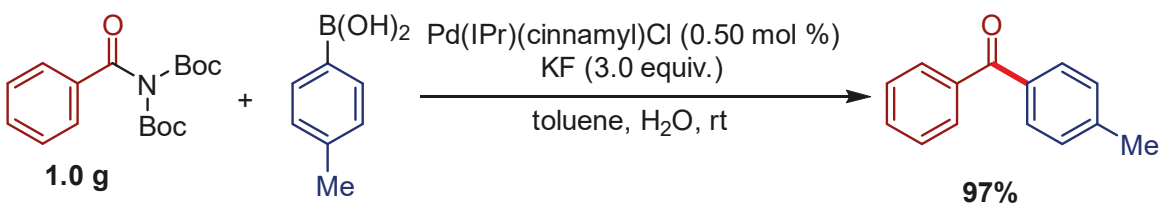

Scheme 9. Scale-up study in direct cross-coupling of $N, N$-di-Boc-amides under $\operatorname{Pd}(\operatorname{IPr})($ cinnamyl) $\mathrm{Cl}$ catalysis.

Recently, employing standard reaction conditions of amide Suzuki-Miyaura cross-coupling under well-defined Pd-NHC catalysis (i.e., $\mathrm{Pd}(\mathrm{IPr})\left(\right.$ cinnamyl) $\left.\mathrm{Cl} / \mathrm{K}_{2} \mathrm{CO}_{3} / \mathrm{THF}\right)$, Szostak and coworkers also realized challenging $\mathrm{C}\left(\mathrm{sp}^{2}\right)-\mathrm{C}\left(\mathrm{sp}^{3}\right)$ couplings using $\mathrm{N}, \mathrm{N}$-di-Boc-amides and $\mathrm{B}$-sp ${ }^{3}$ alkyl reagents (Scheme 10) [38]. Various substituents on the amide bonds, such as $\mathrm{N}$-glutarimide, $\mathrm{N}$-Ph- $\mathrm{N}$-Boc, and $\mathrm{N}-\mathrm{Ph}-\mathrm{N}-\mathrm{Ms}$ were also found to be reactive under identical conditions albeit at a higher temperature.

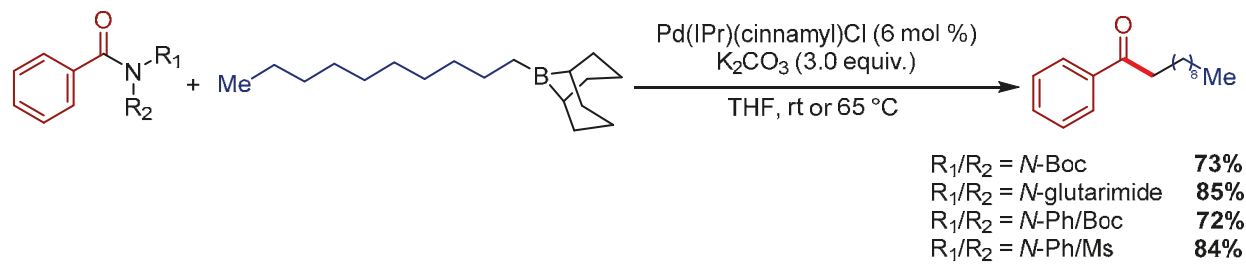

Scheme 10. $\mathrm{Pd}(\mathrm{IPr})($ cinnamyl) $\mathrm{Cl}$ catalyzed alkylation of amides by $\mathrm{C}-\mathrm{N}$ bond cleavage.

\subsection{Pd( $\eta^{3}$-1-t-Bu-indenyl) (NHC)Cl Pre-Catalysts in Suzuki-Miyaura Cross-Coupling of Amides}

The high reactivity of $[\mathrm{Pd}($ allyl $)(\mathrm{NHC}) \mathrm{Cl}]$ pre-catalysts stems from maintaining the optimal 1:1 Pd to ligand ratio and the fast reduction of $\mathrm{Pd}(\mathrm{II})$ to active $\mathrm{Pd}(0)$ [15]. It is now widely accepted that base mediated activation of $[\mathrm{Pd}(\mathrm{allyl})(\mathrm{NHC}) \mathrm{Cl}]$ pre-catalysts forms the active ligated $\operatorname{Pd}(0)$ catalyst in solution [34]. However, elegant studies by Hazari and coworkers observed a deleterious comproportionation pathway under catalytic conditions to form $\mathrm{Pd}(\mathrm{I}) \mu$-allyl dimers (Scheme 11) [39,40]. Based on extensive mechanistic investigation, they proposed two strategies to develop even more active catalysts: (1) Increase the barrier to comproportionation between $\mathrm{Pd}(0)$ and $\mathrm{Pd}(\mathrm{II})$, and (2) develop systems that undergo faster activation so that all of $\mathrm{Pd}(\mathrm{II})$ is converted to $\mathrm{Pd}(0)$ before comproportionation. 


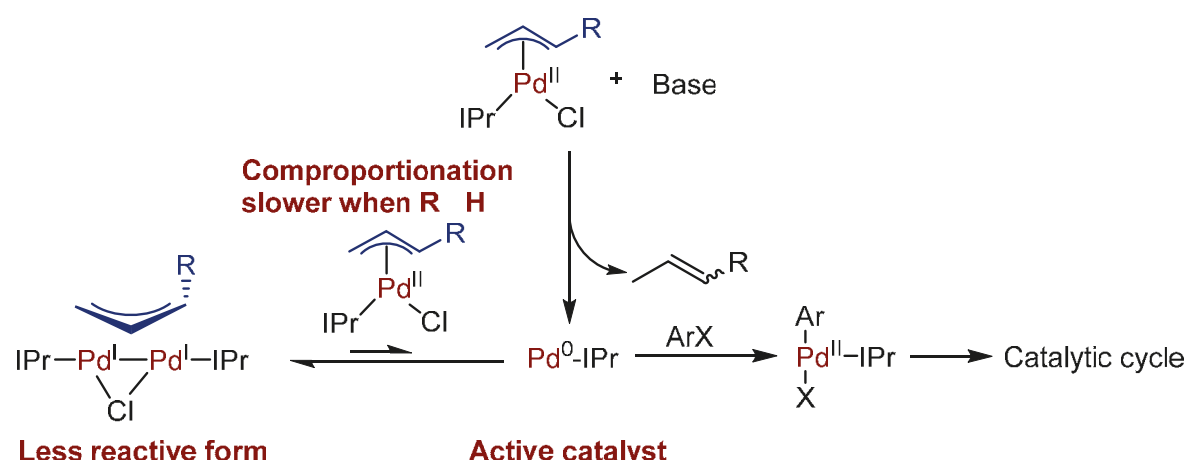

Less reactive form

Active catalyst

Scheme 11. Activation/deactivation pathway during $\mathrm{Pd}($ allyl)(NHC)Cl pre-catalyst activation.

The mechanistic insights on the deactivation pathway led the Hazari group to discover $\mathrm{Pd}\left(\eta^{3}-1-t-\mathrm{Bu}\right.$-indenyl)(NHC)Cl (Hazari catalyst), a highly efficient pre-catalyst for cross-coupling reactions [41]. As a major advance in Pd-NHC precatalysts, the inability of ( $\eta^{3}-1-t$-Bu-indenyl) (NHC)Cl to generate unreactive $\mathrm{Pd}(\mathrm{I})$ dimers significantly improved its activity for cross-coupling reactions. In 2017, Szostak and coworkers utilized [Pd(indenyl)(IPr)Cl] for the development of Suzuki-Miyaura cross-coupling of $\mathrm{N}-\mathrm{Ph}-\mathrm{N}$-Boc amides under otherwise standard conditions of amide cross-coupling reaction $\left(\mathrm{K}_{2} \mathrm{CO}_{3} / \mathrm{THF}\right.$, Scheme 12) [42]. The unprecedented reactivity of Hazari catalyst by suppressing the deactivation pathway led the amide cross-coupling reaction to occur at room temperature under glovebox-free conditions, increasing the operational simplicity and practicality of the reaction. This reaction is notable as the first example of Suzuki-Miyaura cross-coupling of an amide at room temperature with excellent yield of ketone product. The robust nature of the pre-catalyst allowed the Szostak group to develop the first direct one-pot activation/cross-coupling of secondary amides.

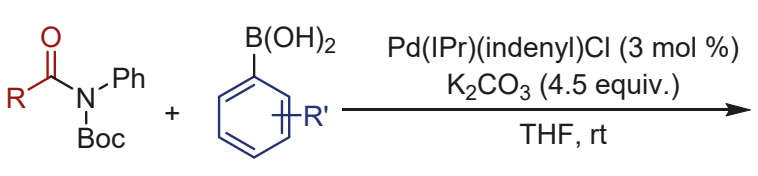<smiles>[R]C(=O)c1ccc(CCCCC)cc1</smiles>

$42-98 \%$ Yield 18 examples

Scheme 12. $\mathrm{Pd}(\operatorname{IPr})($ indenyl) $\mathrm{Cl}$ catalyzed Suzuki-Miyaura coupling of amides at room temperature.

\subsection{Pd(allyl)(NHC)Cl Pre-Catalysts in Suzuki-Miyaura Cross-Coupling of Esters}

The ubiquitous nature of ester bonds attracted the interest of chemists for their synthetic manipulation into useful products. In recent years, the direct use of aromatic esters in cross-coupling reactions to form biaryls or ketones has been demonstrated as a promising area of research [20]. The selective cleavage of ester bonds offers significant advantages in multistep synthesis as they are robust to a range of reaction conditions and can only be activated under specific conditions. Although activation of aryl C-O bonds to form biaryls via decarbonylation is well-documented $[43,44]$ the corresponding synthesis of ketones is still in its infancy. In 2017, Newman, Houk and coworkers reported the first-time utilization of aryl esters as acyl equivalents for the formation of ketones (Scheme 13) [45]. The exceptional bulkiness of NHC ligand on the catalyst hindered the decarbonylation step facilitating ketone formation over the well-known biaryl formation. 


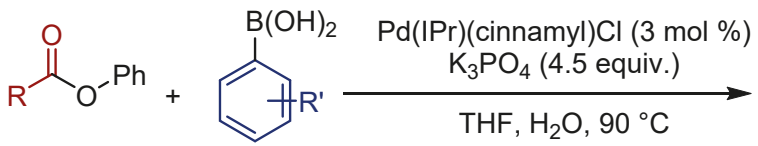<smiles>[R]C(=O)c1ccccc1</smiles>

\section{$30-95 \%$ Yield \\ 30 examples}

Scheme 13. $\mathrm{Pd}(\mathrm{IPr})($ cinnamyl) $\mathrm{Cl}$ catalyzed Suzuki-Miyaura cross-coupling of aryl esters.

Optimization studies demonstrated the importance of well-defined pre-catalysts for successful ketone formation (Table 1). When Pd catalysts in combination with excess ancillary ligand were used, very low yield of the product was obtained (Table 1, entry 1-4). On the contrary, when the metal to ligand ratio was decreased to the optimal 1:1 ratio, a substantial increase in the product formation was observed (Table 1, entry 5). Further improvement was reported when a preformed well-defined $\mathrm{Pd}(\mathrm{IPr})($ cinnamyl) $\mathrm{Cl}$ was used as the catalyst, forming the cross-coupled product in $95 \%$ yield, highlighting the importance of well-defined pre-catalysts as compared to traditional catalyst/ligand system (Table 1, entry 6).

Table 1. Optimization study for the Suzuki-Miyaura cross-coupling of aryl esters.

\begin{tabular}{cccc}
\hline & \\
\hline
\end{tabular}

Very recently, as an improvement from their work on $\mathrm{C}\left(\mathrm{sp}^{2}\right)-\mathrm{C}\left(\mathrm{sp}^{2}\right)$ cross-coupling of esters, the Newman group reported a $\mathrm{C}\left(\mathrm{sp}^{2}\right)-\mathrm{C}\left(\mathrm{sp}^{3}\right)$ cross-coupling of aryl esters with alkyl-BBN to form aryl-alkyl ketones [46]. This reaction is particularly challenging, as alkyl boron reagents, in general, are reluctant to undergo transmetallation relative to their aryl counterparts and the intermediacy of alkylmetal species are prone to $\beta$-hydride elimination. However, the strong $\sigma$-donation and bulky nature of NHC in precatalysts, enabled the reaction to proceed to form ketones. On the contrary, when they employed $\mathrm{Pd}$-ancillary phosphine catalyst conditions, biaryls were formed via decarbonylation and reductive elimination (Scheme 14).

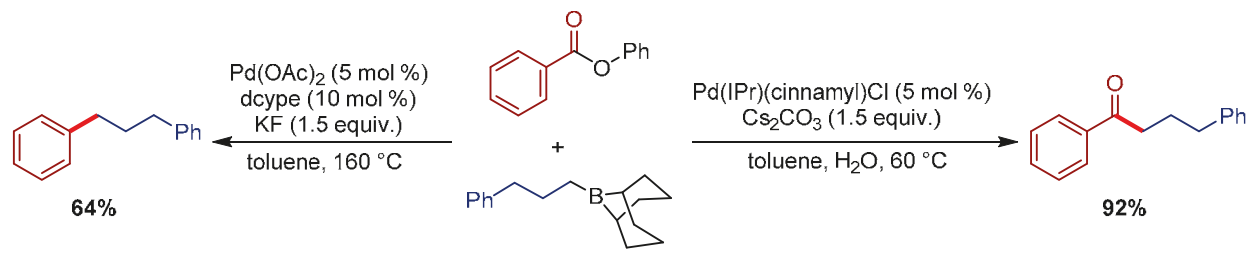

Scheme 14. Suzuki-Miyaura coupling of aryl esters with alkyl-BBN. 


\subsection{Pd( $\eta^{3}-1-t-B u$-indenyl) (NHC)Cl Pre-Catalysts in Suzuki-Miyaura Cross-Coupling of Esters}

The Hazari catalyst, a highly active catalyst for amide bond cross-coupling, was also found to be very effective in Suzuki-Miyaura cross-coupling of aryl esters. In 2017, Szostak and coworkers reported the first room temperature Suzuki-Miyaura cross-coupling of esters by selective C-O bond activation to give biaryl ketones (Scheme 15) [42]. Interestingly, only a small variation in the amount of base from the conditions employed for amide cross-coupling enabled the cross-coupling of esters.

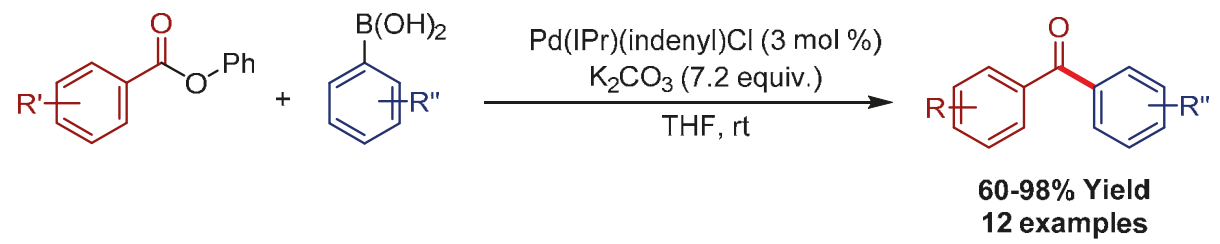

Scheme 15. Suzuki-Miyaura cross-coupling of aryl esters catalyzed by Pd(indenyl)(IPr)Cl.

An advancement in the cross-coupling of aryl esters catalyzed by Pd(indenyl)(IPr)Cl was reported by Hazari and coworkers (Scheme 16) [47]. The use of potassium hydroxide base allowed them to develop even milder reaction conditions with lower catalyst loadings (1.0 mol \%), and shorter reaction times (6 h to $16 \mathrm{~h})$.

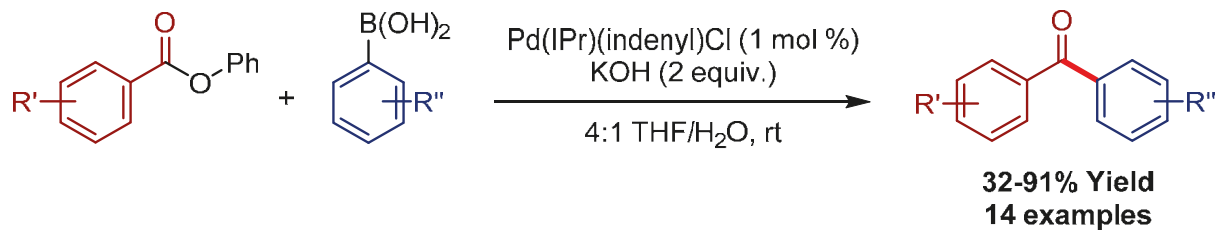

Scheme 16. Hazari protocol for the Suzuki-Miyaura cross-coupling of aryl esters catalyzed by $\mathrm{Pd}($ indenyl)(IPr)Cl using hydroxide bases.

\section{Pd(allyl)(NHC)Cl Pre-Catalysts in Buchwald-Hartwig Amination of Amides and Esters}

\subsection{Pd(cinnamyl)(IPr)Cl Pre-Catalyst for the Transamidation of Amides}

The excellent reactivity of $\mathrm{Pd}($ cinnamyl)(IPr) $\mathrm{Cl}$ pre-catalysts in amide $\mathrm{C}-\mathrm{N}$ activation to form acyl-metal species is highly significant, as it can potentially undergo cross-coupling reactions with any nucleophile. In 2017, Szostak and coworkers realized the acyl-metal reaction with other nucleophiles when they reported the first general method for Buchwald-Hartwig amination of acyl-metal species with amines under Pd-NHC catalysis (Scheme 17) [48]. The protocol offered advantages in efficient cross-coupling of both alkyl, aryl, and sterically hindered anilines. The method also showed a broad scope with respect to both the amine and amide components.

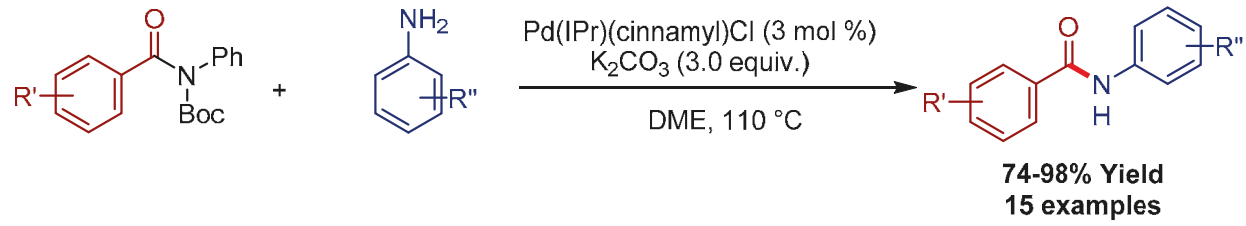

Scheme 17. $\mathrm{Pd}(\mathrm{IPr})($ cinnamyl) $\mathrm{Cl}$ catalyzed transamidation of amides. 


\subsection{Pd(allyl)(IPr)Cl Pre-Catalyst for the Transamidation of Esters}

Newman and coworkers reported the first example of Pd-NHC catalyzed amide bond formation directly from aryl esters and anilines. Similar to their observation in Suzuki coupling of aryl esters, a well-defined preassembled NHC-ligated catalyst was essential, as separated components resulted in reduced yields [45]. They found the use of a mild carbonate base and the presence of water was essential for higher conversion, forming the transamidated product in good yields (Scheme 18). The mildness of the protocol was showcased by the reaction of proline ester with anilines and the aminated product was formed with minimal loss of enantiopurity.

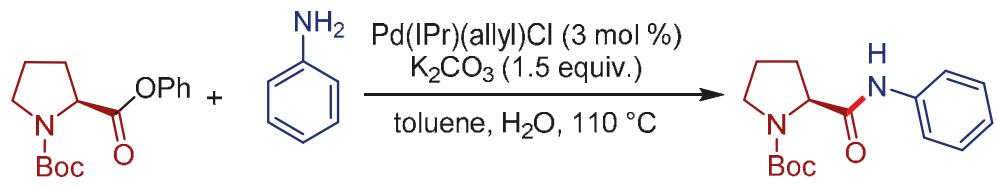

$82 \%, 96: 4$ e.r

Scheme 18. $\mathrm{Pd}(\mathrm{allyl})(\mathrm{IPr}) \mathrm{Cl}$ catalyzed amidation of proline esters.

\subsection{Pd(indenyl)(SIPr)Cl Pre-Catalyst for the Transamidation of Esters}

Given the exceptional catalytic activity of $\mathrm{Pd}($ indenyl)(IPr)(Cl) for Suzuki-Miyaura reactions involving aryl esters, Hazari and coworkers also explored Buchwald-Hartwig amination of aryl esters. Using $1 \mathrm{~mol} \%$ of $\mathrm{Pd}$ (indenyl)(SIPr)(Cl) (SIPr = 1,3-bis(2,6-diisopropylphenyl)imidazolidin-2-ylidene) as the pre-catalyst, they were able to couple phenyl benzoate and aniline in essentially quantitative yield at $40{ }^{\circ} \mathrm{C}$, using a 4:1 $\mathrm{H}_{2} \mathrm{O} / \mathrm{THF}$ solvent mixture (Scheme 19) [47]. They also found that the coupling was highly sensitive to the ligand used, with SIPr affording the best yields, whereas other NHC or phosphine ligands were ineffective.
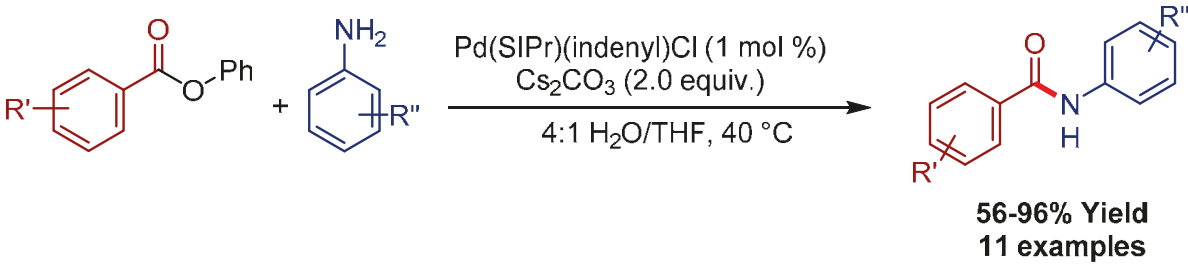

Scheme 19. $\mathrm{Pd}$ (indenyl)(SIPr)Cl pre-catalyst for the Buchwald-Hartwig amination of aryl esters.

\section{Pd-PEPPSI Pre-Catalysts in the Suzuki-Miyaura Cross-Coupling of Amides and Esters}

The last two decades saw tremendous growth in the development of highly active, generally applicable, and functional group-tolerant catalytic systems employing NHC ligands. One highly active well-defined pre-catalyst system is Pd-PEPPSI (pyridine-enhanced pre-catalyst preparation, stabilization and initiation), developed by the Organ group [49]. As Figure 1 illustrates, Pd-PEPPSI catalysts found their use in various cross-coupling reactions, such as Suzuki-Miyaura, Negishi, Kumada-Tamao-Corriu, and Buchwald-Hartwig aminations [50]. As with all the Pd-NHC precatalysts, Pd-PEPPSI has two major components: The bulky NHC ligand, which contains strong $\sigma$-donor properties which help promote the oxidative addition, and the sterics aid reductive elimination. The second component, the pyridine, often referred as a "throw away ligand," aids not only in the synthesis of pre-catalyst, but also increases the stability of the isolated complexes (Figure 3). The easy synthesis, high stability toward air and moisture and the exceptional reactivity of Pd-PEPPSI complexes led synthetic chemists to utilize these pre-catalysts in the cross-coupling of difficult and unreactive electrophiles, such as amides and esters (vide infra). 


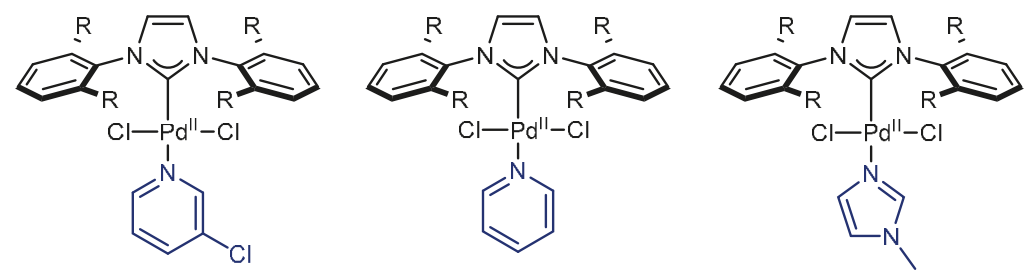

Figure 3. Well-defined Pd-PEPPSI pre-catalysts employed in the cross-coupling reactions.

\subsection{Pd-PEPPSI Pre-Catalysts in the Suzuki-Miyaura Cross-Coupling of Amides}

Szostak and coworkers were the first to report the use of Pd-PEPPSI pre-catalysts in Suzuki-Miyaura cross-coupling of amides [51]. In agreement with high catalytic activity of in situ generated Pd-NHC complexes, identical reaction conditions could be employed for the cross-coupling of various destabilized amides (Scheme 20).

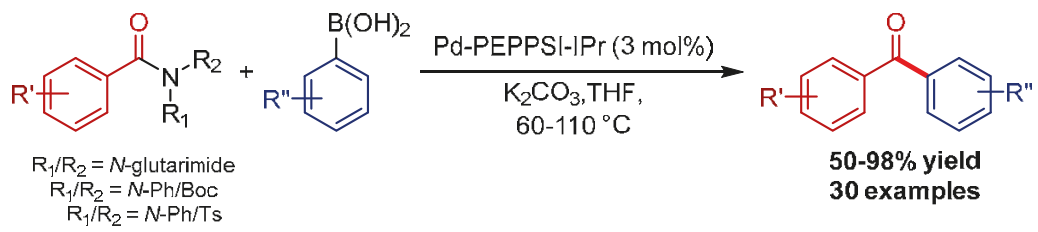

Scheme 20. Pd-PEPPSI catalyzed Suzuki-Miyaura cross-coupling of amides.

In accordance with the amide $\mathrm{C}-\mathrm{N}$ bond destabilization, kinetic studies with $\mathrm{N}$-glutarimide, $\mathrm{N}-\mathrm{Ph}-\mathrm{N}-\mathrm{Ts}$, and $\mathrm{N}-\mathrm{Ph}-\mathrm{N}$-Boc amides showed similar reactivity to their cross-coupling reactivity scale with $\mathrm{N}$-glutarimide being the fastest and $\mathrm{N}$-Ph- $\mathrm{N}$-Ts being the slowest [52]. The kinetic data between Pd-PEPPSI and $\mathrm{Pd}(\mathrm{IPr})($ cinnamyl) $\mathrm{Cl}$ precatalysts under identical conditions suggested tha while the reaction rates of $N$-glutarimide and $N$-Ph- $N$-Boc amides were higher with Pd-PEPPSI, $N$-Ph- $N$-Ts amides are shown to have faster reaction rates under $\operatorname{Pd}(\operatorname{IPr})($ cinnamyl)Cl catalysis (Figure 4) [19]. The data is highly beneficial, as it provides a general idea for chemists to choose from both the catalyst systems for different type of amides employed in cross-coupling reactions.
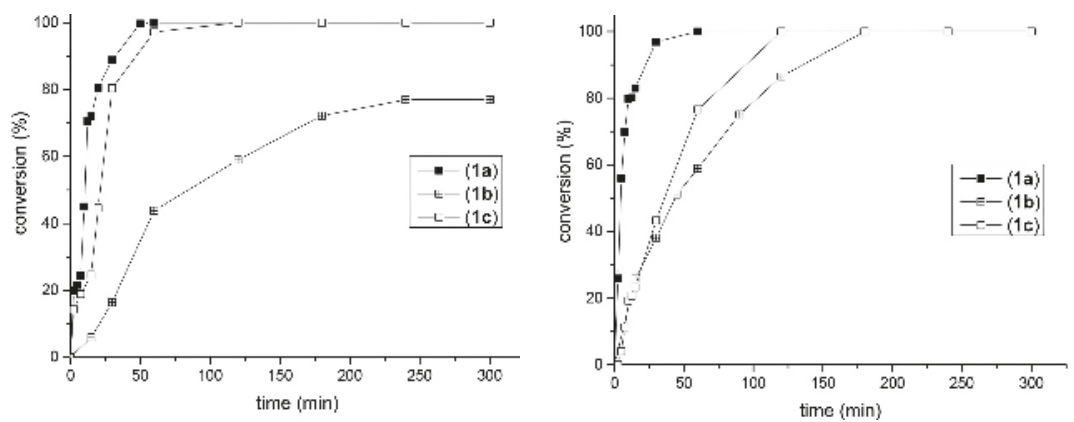

Figure 4. Kinetic study displaying the conversion percentage over time of Pd-PEPPSI (left), and $\mathrm{Pd}(\mathrm{IPr})($ Cinnamyl)Cl (right) pre-catalysts. Activated amides used were $\mathrm{N}$-Glutarimide (1a), $\mathrm{N}-\mathrm{Ph}-\mathrm{N}$-Ts (1b), and N-Ph-N-Boc (1c). Reprinted with permission from J. Org. Chem. 2017, 82, 6638-6646. Copyright 2017 American Chemical Society.

Very recently, Zou and coworkers reported the Suzuki-Miyaura cross-coupling of less reactive $N$-alkyl- $N$-Ts amides with diarylborinic acids under Pd-PEPPSI catalysis (Scheme 21) [53]. The use of 
stable diarylborinic acids was advantageous, as it extended nucleophile counterparts in cross-coupling reactions. Under otherwise standard reaction conditions of amide cross-coupling reactions, they were successful in cross-coupling less reactive $N$-Me- $N$-Ts amides to form ketone products. Notably, no reaction ensued under Pd/phosphine catalysis and only low Pd-PEPPSI catalyst loadings (1.0 mol \%) were needed, highlighting the high activity of Pd-NHC pre-catalysts. The protocol also offered a broad functional group tolerance, with both electron donating and electron withdrawing groups on both coupling partners.

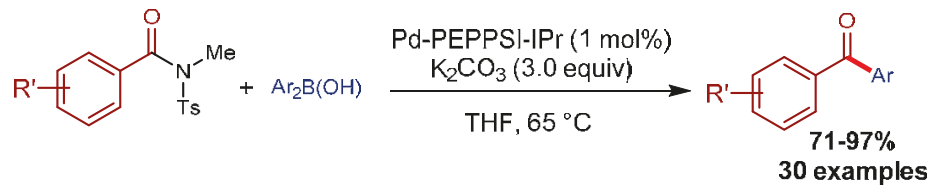

Scheme 21. Pd-PEPPSI catalyzed Suzuki-Miyaura cross-coupling of amides with diarylborinic acids.

Zou and coworkers further advanced the Suzuki-Miyaura coupling of amides to form alkyl ketones using trialkylboranes as coupling partners under Pd-PEPPSI catalysis [54]. Although Pd/phosphine catalysis proved ineffective, $5 \mathrm{~mol} \%$ of Pd-PEPPSI was very effective in transforming $N$-Me-N-Ts amides to form alkyl ketones (Scheme 22). Unlike the high-order arylboron compounds, in which all the aryl groups react effectively, only one of the three primary alkyl groups in alkylboranes could be used as alkyl source for the acyl alkylation.

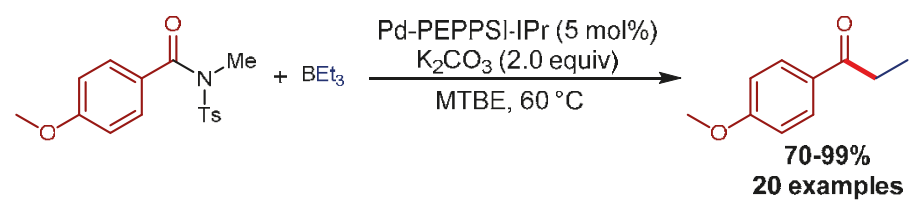

Scheme 22. Pd-PEPPSI catalyzed alkylation of $N$-Me- $N$-Ts amide.

Wang, Liu, and coworkers recently reported a new series of Pd-NHC pre-catalysts using various $N$-heterocycles [55] as "throwaway ligands" with benzothiazole being the most effective for the Suzuki-Miyaura cross coupling of $N$-succinimide amides (Scheme 23) [56]. Change in the "throw-away ligand" was found to have a profound effect on the overall yield of the reaction, with benzothiazole ligand outperforming traditional 3-chloro pyridine ligand.

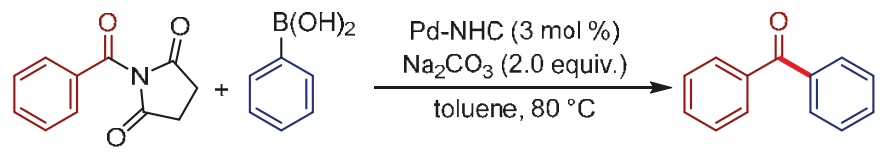

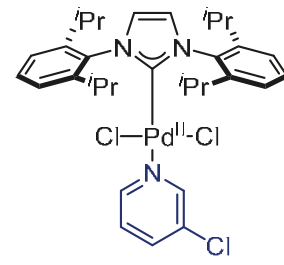

Yìeld: $85 \%$

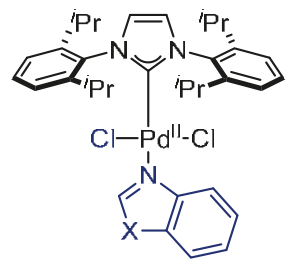

$X=0,41 \%$

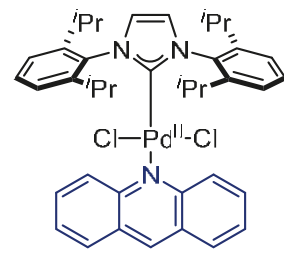

$51 \%$

Scheme 23. NHC-Pd(II) catalyzed acylative Suzuki-Miyaura cross-coupling of amides 


\subsection{Pd-PEPPSI Pre-Catalysts in the Suzuki-Miyaura Cross-Coupling of Esters}

Pd-PEPPSI pre-catalysts were also found to be effective in catalyzing the cross-coupling of esters. In most cases, the reactivity was comparable to that of $[\mathrm{Pd}(\operatorname{IPr})($ cinnamyl)Cl]. Szostak and coworkers reported a direct Suzuki-Miyaura cross-coupling of aryl esters under Pd-PEPPSI catalysis and found that the rates were similar to those reported for the cross-coupling of $\mathrm{N}-\mathrm{Ph} / \mathrm{Boc}$, and $\mathrm{N}-\mathrm{Ph} / \mathrm{Ts}$ amides under identical reaction conditions (Scheme 24) [57].

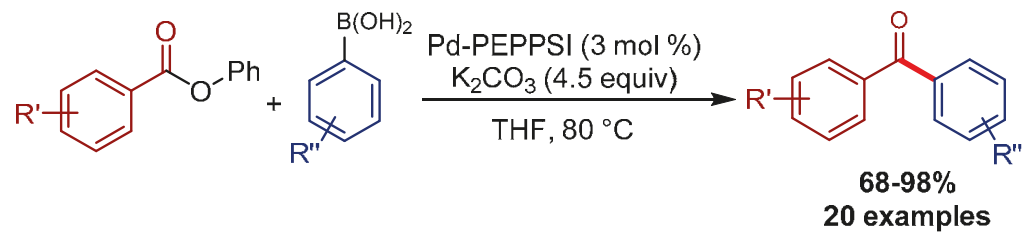

Scheme 24. Pd-PEPPSI catalyzed Suzuki-Miyaura cross-coupling of aryl esters.

To further advance cross-coupling of esters, and to find a more general method, Szostak and coworkers reported a water assisted Suzuki-Miyaura cross-coupling of aryl esters at room temperature (Scheme 25) [58]. They demonstrated that the addition of water (5.0 equiv) was able to facilitate the reaction under very mild reaction conditions with only $1 \mathrm{~mol} \%$ catalyst loading and at room temperature.

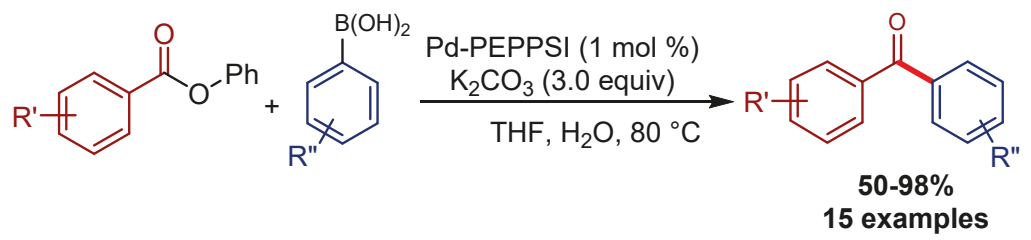

Scheme 25. Water assisted, Pd-PEPPSI catalyzed Suzuki-Miyaura coupling of esters.

To elucidate the role of water additive, they subjected the Pd-PEPPSI pre-catalyst under optimized reaction conditions without the coupling partners to observe the formation of hydroxide dimer, $[\mathrm{Pd}(\mu-\mathrm{OH}) \mathrm{Cl}(\mathrm{IPr})]_{2}$ in appreciable $32 \%$ yield (Scheme 26$)$.

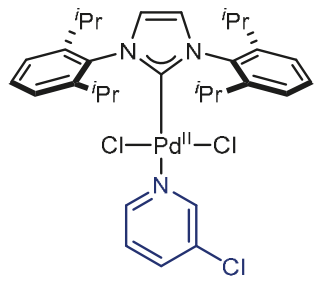

Pd-PEPPSI-IPr

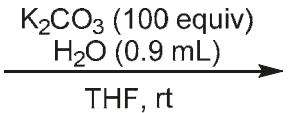

Scheme 26. Synthesis of Pd(II) hydroxide dimer formation from Pd-PEPPSI.

They also performed kinetic studies to probe the catalytic activity of preformed dimer and observed faster reaction rates compared to the Pd-PEPPSI conditions. Notably, negligible product formation in the absence of water additive indicated the importance of Pd-hydroxide dimer formation prior to the reduction of $\mathrm{Pd}(\mathrm{II})$ to active $\mathrm{Pd}(0)$ species (Figure 5). This protocol has also allowed the first achievement of a TON > 1000 in the Suzuki-Miyaura cross-coupling of aryl esters. 

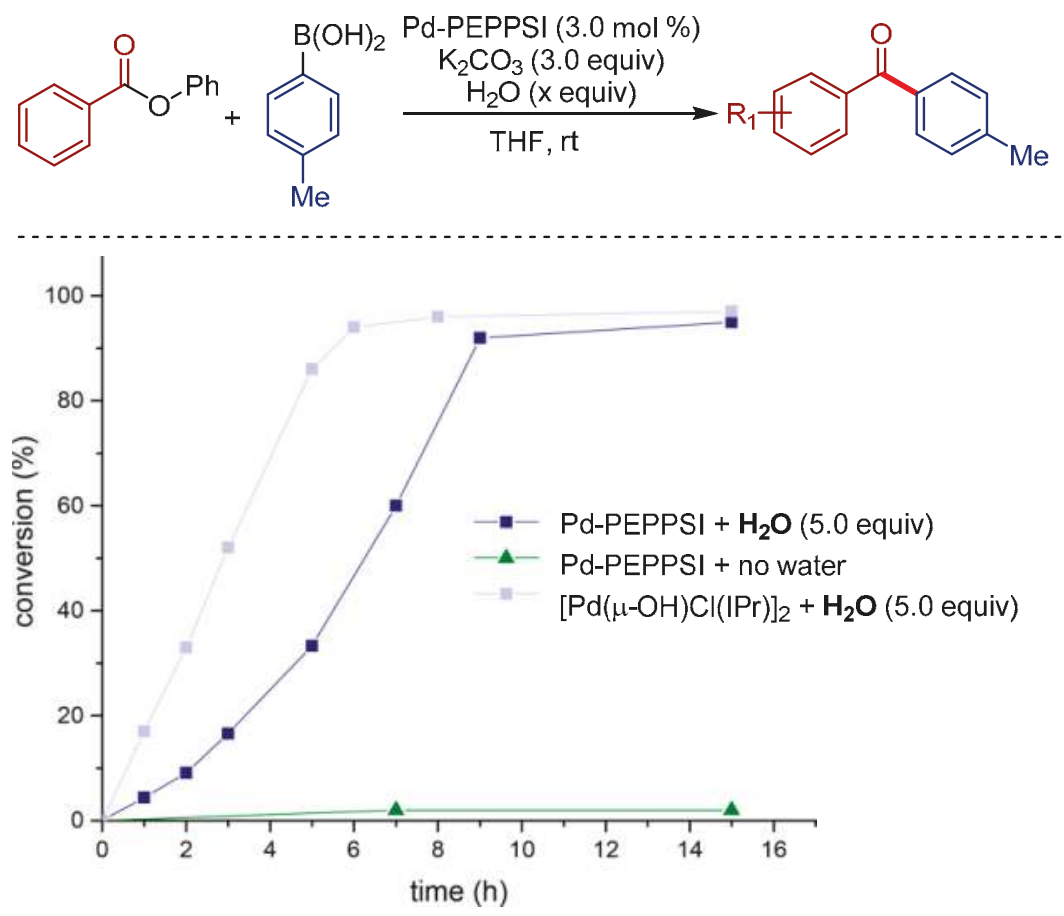

Figure 5. Kinetic profile of aryl ester cross-coupling under Pd-PEPPSI catalysis Reprinted with permission from Adv. Synth. Catal. 2018, 360, 1538-1543. Copyright (C) 2018 John Wiley and Sons.

Very recently, while preparing this manuscript, Szostak and coworkers reported Suzuki-Miyaura cross-coupling of esters using pentafluorophenyl substituents. Although the reported method was primarily focused on the utilization of traditional Pd-ancillary phosphine catalysis, the high catalytic activity of Pd-PEPPSI catalysts allowed them to use even milder conditions with better yields [59].

\section{Pd-PEPPSI Pre-Catalysts in Buchwald-Hartwig Amidation of Esters and Amides}

Szostak and Shi also reported the first Pd-PEPPSI catalyzed Buchwald-Hartwig amination of phenyl esters and activated amides. In their work, they reported the chemo-selective acyl $\mathrm{C}-\mathrm{O} / \mathrm{C}-\mathrm{N}$ amination with anilines using the Pd-PEPPSI pre-catalyst [60]. Phenyl esters, $\mathrm{N}-\mathrm{Ph}-\mathrm{N}$-Boc, and $\mathrm{N}-\mathrm{Ph}-\mathrm{N}$-Ts amides were successfully converted to amides with excellent yield. However, conditions reported were harsher than conditions reported for ketone synthesis (Scheme 27).

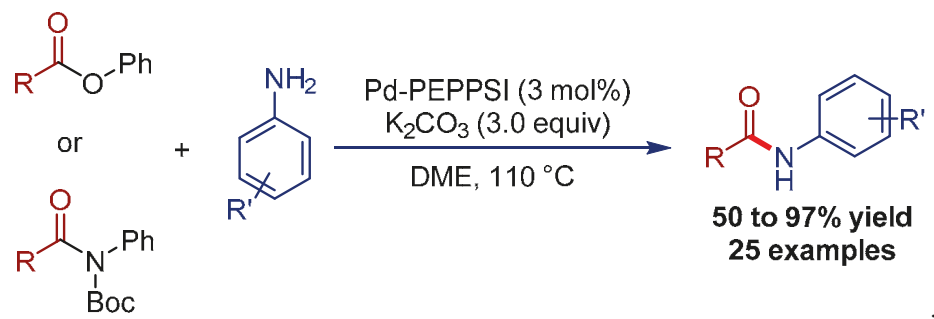

Scheme 27. Pd-PEPPSI catalyzed Buchwald-Hartwig amination of amides and esters. 


\section{Palladium(II)/N-Heterocyclic Carbene-Catalyzed Direct C-H Acylation of Heteroarenes with $\mathrm{N}$-Acylsaccharins}

Following up on the work from the Szostak group, Gandhi and coworkers reported the use of pyrene based Pd-PEPPSI catalysts (Figure 6) with wingtip substituents, such as Ar/alkyl and alkyl groups for the cross-coupling of $\mathrm{N}$-acylsaccharin amides with azoles and azole derivatives [61].
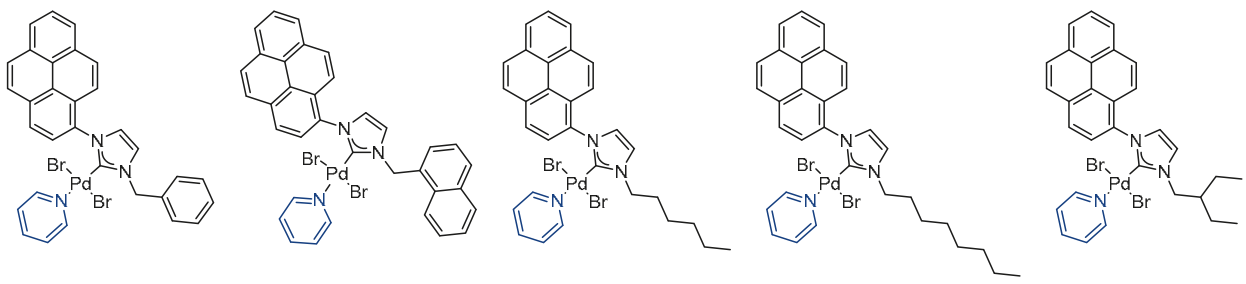

Figure 6. Pyrene based Pd-PEPPSI catalysts employed in the cross-coupling reactions.

$\mathrm{N}$-acyl saccharin, a commonly used twisted amide, was used to accomplish the difficult cross coupling reactions incorporating amide bond cleavage and $\mathrm{C}-\mathrm{H}$ activation reactions. The work focused on the cross-coupling of $\mathrm{N}$-functionalized saccharins with benzoxazole and its derivatives through a C-H activation process (Scheme 28). Not surprisingly, other activated amides such as $\mathrm{N}$-aryl- $\mathrm{N}$-Ts were found ineffective, resulting in no product.

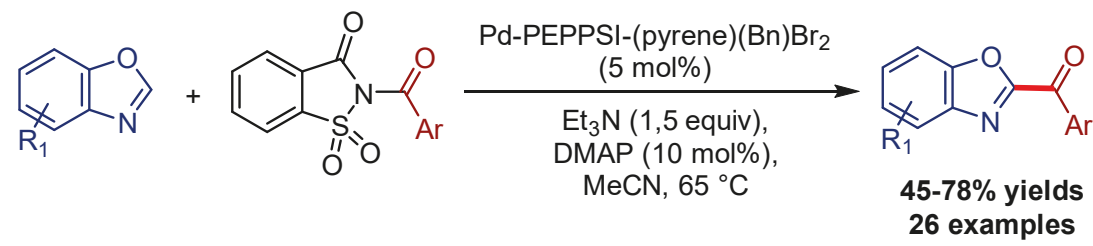

Scheme 28. Pd-PEPPSI-pyrene pre-catalysts in the C-H acylation of benzoxazole.

\section{Conclusions}

In summary, the use of well-defined $\mathrm{Pd}(\mathrm{II})$-NHC pre-catalysts offers significant advantages over the traditional approach of adding extra ligand to standard Pd catalysts. In the past few years, these catalysts were found to be exceptional in enabling the cross-coupling reactions of amides and esters via $\mathrm{C}-\mathrm{N}(\mathrm{O})$ bond activation to form ketones and amides. The easy preparation, commercial availability, and stability toward air and moisture of the pre-catalysts facilitate the development of operationally simple and practical cross-coupling methods. The strong $\sigma$-bond donating nature of NHC ligands increases the reactivity of Pd center toward oxidative addition of difficult electrophiles, such as amides and esters, increasing the scope and generality of the cross-coupling reactions. Further exciting developments are expected in this relatively new area of employing amides and esters as acyl electrophiles, with recent breakthroughs enabled by $\mathrm{Pd}(\mathrm{II})-\mathrm{NHC}$ catalysis.

Author Contributions: S.R.V., M.R.C. collected the literature references. S.R.V., M.R.C., and G.R.C. contributed to the manuscript writing.

Funding: This research was funded by the generous financial support from North Dakota State University and a pilot project grant from NIH NIGMS P30 GM103332, NSF-ND-EPSCoR Track 1 Grant Award IIA-1355466.

Conflicts of Interest: The authors declare no conflict of interest. 


\section{References}

1. Alberico, D.; Scott, M.E.; Lautens, M. Aryl-Aryl Bond Formation by Transition-Metal-Catalyzed Direct Arylation. Chem. Rev. 2007, 107, 174-238. [CrossRef] [PubMed]

2. Stuart, D.R.; Fagnou, K. The Catalytic Cross-Coupling of Unactivated Arenes. Science 2007, 316, 1172-1175. [CrossRef]

3. Kumar, D.; Vemula, S.R.; Cook, G.R. Merging C-H Bond Functionalization with Amide Alcoholysis: En Route to 2-Aminopyridines. ACS Catal. 2016, 6, 3531-3536. [CrossRef]

4. Park, Y.; Kim, Y.; Chang, S. Transition Metal-Catalyzed C-H Amination: Scope, Mechanism, and Applications. Chem. Rev. 2017, 117, 9247-9301. [CrossRef] [PubMed]

5. Kumar, D.; Vemula, S.R.; Balasubramanian, N.; Cook, G.R. Indium-Mediated Stereoselective Allylation. Acc. Chem. Res. 2016, 49, 2169-2178. [CrossRef] [PubMed]

6. Kumar, D.; Vemula, S.R.; Cook, G.R. Recent Advances in the Catalytic Synthesis of $\alpha$-Ketoamides. ACS Catal. 2016, 6, 4920-4945. [CrossRef]

7. Kumar, D.; Vemula, S.R.; Cook, G.R. Highly Chemo- and Regioselective Allylic Substitution with Tautomerizable Heteroarenes. Green Chem. 2015, 17, 4300-4306. [CrossRef]

8. Vemula, S.R.; Kumar, D.; Cook, G.R. Palladium-Catalyzed Allylic Amidation with N-Heterocycles via Sp 3 C-H Oxidation. ACS Catal. 2016, 6, 5295-5301. [CrossRef]

9. Satoh, T.; Miura, M. Catalytic Direct Arylation of Heteroaromatic Compounds. Chem. Lett. 2007, 36, $200-205$. [CrossRef]

10. Tamao, K.; Sumitani, K.; Kumada, M. Selective Carbon-Carbon Bond Formation by Cross-Coupling of Grignard Reagents with Organic Halides. Catalysis by Nickel-Phosphine Complexes. J. Am. Chem. Soc. 1972, 94, 4374-4376. [CrossRef]

11. Corriu, R.J.P.; Masse, J.P. Activation of Grignard Reagents by Transition-Metal Complexes. A New and Simple Synthesis of Trans-Stilbenes and Polyphenyls. J. Chem. Soc. Chem. Commun. 1972, 144a. [CrossRef]

12. Milstein, D.; Stille, J.K. A General, Selective, and Facile Method for Ketone Synthesis from Acid Chlorides and Organotin Compounds Catalyzed by Palladium. J. Am. Chem. Soc. 1978, 100, 3636-3638. [CrossRef]

13. Miyaura, N.; Yamada, K.; Suzuki, A. A New Stereospecific Cross-Coupling by the Palladium-Catalyzed Reaction of 1-Alkenylboranes with 1-Alkenyl or 1-Alkynyl Halides. Tetrahedron Lett. 1979, 20, 3437-3440. [CrossRef]

14. Trost, B.M.; Fullerton, T.J. New Synthetic Reactions. Allylic Alkylation. J. Am. Chem. Soc. 1973, 95, $292-294$. [CrossRef]

15. Marion, N.; Nolan, S.P. Well-Defined N-Heterocyclic Carbenes-Palladium(II) Precatalysts for Cross-Coupling Reactions. Acc. Chem. Res. 2008, 41, 1440-1449. [CrossRef] [PubMed]

16. Valdés, H.; Canseco-González, D.; Germán-Acacio, J.M.; Morales-Morales, D. Xanthine Based N-Heterocyclic Carbene (NHC) Complexes. J. Organomet. Chem. 2018, 867, 51-54. [CrossRef]

17. Hazari, N.; Melvin, P.R.; Beromi, M.M. Well-Defined Nickel and Palladium Precatalysts for Cross-Coupling. Nat. Rev. Chem. 2017, 1, 0025. [CrossRef]

18. Herrmann, W.A.; Elison, M.; Fischer, J.; Köcher, C.; Artus, G.R.J. Metal Complexes of N-Heterocyclic Carbenes-A New Structural Principle for Catalysts in Homogeneous Catalysis. Angew. Chem. Int. Ed. English 1995, 34, 2371-2374. [CrossRef]

19. Shi, S.; Nolan, S.P.; Szostak, M. Well-Defined Palladium(II)-NHC Precatalysts for Cross-Coupling Reactions of Amides and Esters by Selective N-C/O-C Cleavage. Acc. Chem. Res. 2018, 51, 2589-2599. [CrossRef]

20. Takise, R.; Muto, K.; Yamaguchi, J. Cross-Coupling of Aromatic Esters and Amides. Chem. Soc. Rev. 2017, 46, 5864-5888. [CrossRef]

21. Vemula, S.R.; Kumar, D.; Cook, G.R. N-Boc-Glycine-Assisted Indium-Mediated Allylation Reaction: A Sustainable Approach. Tetrahedron Lett. 2015, 56, 3322-3325. [CrossRef]

22. Hie, L.; Fine Nathel, N.F.; Shah, T.K.; Baker, E.L.; Hong, X.; Yang, Y.-F.; Liu, P.; Houk, K.N.; Garg, N.K. Conversion of Amides to Esters by the Nickel-Catalysed Activation of Amide C-N Bonds. Nature 2015, 524, 79-83. [CrossRef] [PubMed]

23. Meng, G.; Szostak, M. Sterically Controlled Pd-Catalyzed Chemoselective Ketone Synthesis via N-C Cleavage in Twisted Amides. Org. Lett. 2015, 17, 4364-4367. [CrossRef] [PubMed] 
24. Li, X.; Zou, G. Acylative Suzuki Coupling of Amides: Acyl-Nitrogen Activation via Synergy of Independently Modifiable Activating Groups. Chem. Commun. 2015, 51, 5089-5092. [CrossRef] [PubMed]

25. Marion, N.; Navarro, O.; Mei, J.; Stevens, E.D.; Scott, N.M.; Nolan, S.P. Modified (NHC)Pd(Allyl)Cl (NHC = $\mathrm{N}$-Heterocyclic Carbene) Complexes for Room-Temperature Suzuki-Miyaura and Buchwald-Hartwig Reactions. J. Am. Chem. Soc. 2006, 128, 4101-4111. [CrossRef] [PubMed]

26. Navarro, O.; Marion, N.; Mei, J.; Nolan, S.P. Rapid Room Temperature Buchwald-Hartwig and Suzuki-Miyaura Couplings of Heteroaromatic Compounds Employing Low Catalyst Loadings. Chem. A Eur. J. 2006, 12, 5142-5148. [CrossRef]

27. Chartoire, A.; Lesieur, M.; Falivene, L.; Slawin, A.M.Z.; Cavallo, L.; Cazin, C.S.J.; Nolan, S.P. [Pd( $\left(\mathrm{Pr}^{*}\right)($ Cinnamyl)Cl]: An Efficient Pre-Catalyst for the Preparation of Tetra-Ortho-Substituted Biaryls by Suzuki-Miyaura Cross-Coupling. Chem. A Eur. J. 2012, 18, 4517-4521. [CrossRef]

28. Chartoire, A.; Frogneux, X.; Nolan, S.P. An Efficient Palladium-NHC (NHC=N-Heterocyclic Carbene) and Aryl Amination Pre-Catalyst: [Pd(IPr*)(Cinnamyl)Cl]. Adv. Synth. Catal. 2012, 354, 1897-1901. [CrossRef]

29. Szostak, M.; Aubé, J. Chemistry of Bridged Lactams and Related Heterocycles. Chem. Rev. 2013, 113, 5701-5765. [CrossRef]

30. Liu, C.; Szostak, M. Twisted Amides: From Obscurity to Broadly Useful Transition-Metal-Catalyzed Reactions by N-C Amide Bond Activation. Chem. A Eur. J. 2017, 23, 7157-7173. [CrossRef]

31. Meng, G.; Shi, S.; Lalancette, R.; Szostak, R.; Szostak, M. Reversible Twisting of Primary Amides via Ground State $\mathrm{N}-\mathrm{C}(\mathrm{O})$ Destabilization: Highly Twisted Rotationally Inverted Acyclic Amides. J. Am. Chem. Soc. 2018, 140, 727-734. [CrossRef] [PubMed]

32. Meng, G.; Szostak, R.; Szostak, M. Suzuki-Miyaura Cross-Coupling of N-Acylpyrroles and Pyrazoles: Planar, Electronically Activated Amides in Catalytic N-C Cleavage. Org. Lett. 2017, 19, 3596-3599. [CrossRef] [PubMed]

33. Meng, G.; Lalancette, R.; Szostak, R.; Szostak, M. N-Methylamino Pyrimidyl Amides (MAPA): Highly Reactive, Electronically-Activated Amides in Catalytic N-C(O) Cleavage. Org. Lett. 2017, 19, 4656-4659. [CrossRef] [PubMed]

34. Li, G.; Lei, P.; Szostak, M.; Casals-Cruañas, E.; Poater, A.; Cavallo, L.; Nolan, S.P. Mechanistic Study of Suzuki-Miyaura Cross-Coupling Reactions of Amides Mediated by [Pd(NHC)(Allyl)Cl] Precatalysts. ChemCatChem 2018, 10, 3096-3106. [CrossRef]

35. Luo, Z.; Liu, T.; Guo, W.; Wang, Z.; Huang, J.; Zhu, Y.; Zeng, Z. N -Acyl-5,5-Dimethylhydantoin, a New Mild Acyl-Transfer Reagent in Pd Catalysis: Highly Efficient Synthesis of Functionalized Ketones. Org. Proc. Res. Dev. 2018, 22, 1188-1199. [CrossRef]

36. Lei, P.; Meng, G.; Ling, Y.; An, J.; Nolan, S.P.; Szostak, M. General Method for the Suzuki-Miyaura Cross-Coupling of Primary Amide-Derived Electrophiles Enabled by $[\mathrm{Pd}(\mathrm{NHC})(\mathrm{Cin}) \mathrm{Cl}]$ at Room Temperature. Org. Lett. 2017, 19, 6510-6513. [CrossRef] [PubMed]

37. Liu, C.; Li, G.; Shi, S.; Meng, G.; Lalancette, R.; Szostak, R.; Szostak, M. Acyl and Decarbonylative Suzuki Coupling of N -Acetyl Amides: Electronic Tuning of Twisted, Acyclic Amides in Catalytic Carbon-Nitrogen Bond Cleavage. ACS Catal. 2018, 8, 9131-9139. [CrossRef]

38. Meng, G.; Szostak, M. Palladium/NHC (NHC = N -Heterocyclic Carbene)-Catalyzed B-Alkyl Suzuki Cross-Coupling of Amides by Selective N-C Bond Cleavage. Org. Lett. 2018, 20, 6789-6793. [CrossRef]

39. Hruszkewycz, D.P.; Balcells, D.; Guard, L.M.; Hazari, N.; Tilset, M. Insight into the Efficiency of Cinnamyl-Supported Precatalysts for the Suzuki-Miyaura Reaction: Observation of Pd(I) Dimers with Bridging Allyl Ligands During Catalysis. J. Am. Chem. Soc. 2014, 136, 7300-7316. [CrossRef]

40. Hruszkewycz, D.P.; Guard, L.M.; Balcells, D.; Feldman, N.; Hazari, N.; Tilset, M. Effect of 2-Substituents on Allyl-Supported Precatalysts for the Suzuki-Miyaura Reaction: Relating Catalytic Efficiency to the Stability of Palladium(I) Bridging Allyl Dimers. Organometallics 2015, 34, 381-394. [CrossRef]

41. Melvin, P.R.; Nova, A.; Balcells, D.; Dai, W.; Hazari, N.; Hruszkewycz, D.P.; Shah, H.P.; Tudge, M.T. Design of a Versatile and Improved Precatalyst Scaffold for Palladium-Catalyzed Cross-Coupling: ( $\eta$-1- t Bu-Indenyl) 2 ( $\mu-\mathrm{Cl}) 2$ Pd 2. ACS Catal. 2015, 5, 3680-3688. [CrossRef]

42. Lei, P.; Meng, G.; Shi, S.; Ling, Y.; An, J.; Szostak, R.; Szostak, M. Suzuki-Miyaura Cross-Coupling of Amides and Esters at Room Temperature: Correlation with Barriers to Rotation around $\mathrm{C}-\mathrm{N}$ and $\mathrm{C}-\mathrm{O}$ Bonds. Chem. Sci. 2017, 8, 6525-6530. [CrossRef] [PubMed] 
43. Ishizu, J.; Yamamoto, T.; Yamamoto, A. Selective Cleavage of C-O Bonds In Esters Through Oxidative Addition To Nickel(0) Complexes. Chem. Lett. 1976, 5, 1091-1094. [CrossRef]

44. Yamaguchi, J.; Muto, K.; Itami, K. Recent Progress in Nickel-Catalyzed Biaryl Coupling. Eur. J. Org. Chem. 2013, 2013, 19-30. [CrossRef]

45. Ben Halima, T.; Vandavasi, J.K.; Shkoor, M.; Newman, S.G. A Cross-Coupling Approach to Amide Bond Formation from Esters. ACS Catal. 2017, 7, 2176-2180. [CrossRef]

46. Masson-Makdissi, J.; Vandavasi, J.K.; Newman, S.G. Switchable Selectivity in the Pd-Catalyzed Alkylative Cross-Coupling of Esters. Org. Lett. 2018, 20, 4094-4098. [CrossRef]

47. Dardir, A.H.; Melvin, P.R.; Davis, R.M.; Hazari, N.; Mohadjer Beromi, M. Rapidly Activating Pd-Precatalyst for Suzuki-Miyaura and Buchwald-Hartwig Couplings of Aryl Esters. J. Org. Chem. 2018, 83, 469-477. [CrossRef]

48. Meng, G.; Lei, P.; Szostak, M. A General Method for Two-Step Transamidation of Secondary Amides Using Commercially Available, Air- and Moisture-Stable Palladium/NHC (N-Heterocyclic Carbene) Complexes. Org. Lett. 2017, 19, 2158-2161. [CrossRef]

49. Valente, C.; Çalimsiz, S.; Hoi, K.H.; Mallik, D.; Sayah, M.; Organ, M.G. The Development of Bulky Palladium NHC Complexes for the Most-Challenging Cross-Coupling Reactions. Angew. Chem. Int. Ed. 2012, 51, 3314-3332. [CrossRef]

50. Froese, R.D.J.; Lombardi, C.; Pompeo, M.; Rucker, R.P.; Organ, M.G. Designing Pd-N-Heterocyclic Carbene Complexes for High Reactivity and Selectivity for Cross-Coupling Applications. Acc. Chem. Res. 2017, 50, 2244-2253. [CrossRef]

51. Lei, P.; Meng, G.; Ling, Y.; An, J.; Szostak, M. Pd-PEPPSI: Pd-NHC Precatalyst for Suzuki-Miyaura Cross-Coupling Reactions of Amides. J. Org. Chem. 2017, 82, 6638-6646. [CrossRef] [PubMed]

52. Pace, V.; Holzer, W.; Meng, G.; Shi, S.; Lalancette, R.; Szostak, R.; Szostak, M. Corrigendum to: Structures of Highly Twisted Amides Relevant to Amide N-C Cross-Coupling: Evidence for Ground-State Amide Destabilization. Chem. A Eur. J. 2017, 23, 3496. [CrossRef] [PubMed]

53. Wang, C.; Huang, L.; Wang, F.; Zou, G. Highly Efficient Synthesis of Aryl Ketones by PEPPSI-Palladium Catalyzed Acylative Suzuki Coupling of Amides with Diarylborinic Acids. Tetrahedron Lett. 2018, 59, 2299-2301. [CrossRef]

54. Shi, W.; Zou, G. Palladium-Catalyzed Room Temperature Acylative Cross-Coupling of Activated Amides with Trialkylboranes. Molecules 2018, 23, 2412. [CrossRef] [PubMed]

55. Vemula, S.R.; Kumar, D.; Cook, G.R. Bismuth-Catalyzed Synthesis of 2-Substituted Quinazolinones. Tetrahedron Lett. 2018, 59, 3801-3805. [CrossRef]

56. Wang, T.; Guo, J.; Wang, H.; Guo, H.; Jia, D.; Zhang, W.; Liu, L. N-Heterocyclic Carbene Palladium(II)-Catalyzed Suzuki-Miyaura Cross Coupling of N-Acylsuccinimides by C-N Cleavage. J. Organomet. Chem. 2018, 877, 80-84. [CrossRef]

57. Shi, S.; Lei, P.; Szostak, M. Pd-PEPPSI: A General Pd-NHC Precatalyst for Suzuki-Miyaura Cross-Coupling of Esters by C-O Cleavage. Organometallics 2017, 36, 3784-3789. [CrossRef]

58. Li, G.; Shi, S.; Lei, P.; Szostak, M. Pd-PEPPSI: Water-Assisted Suzuki-Miyaura Cross-Coupling of Aryl Esters at Room Temperature Using a Practical Palladium-NHC (NHC=N-Heterocyclic Carbene) Precatalyst. Adv. Synth. Catal. 2018, 360, 1538-1543. [CrossRef]

59. Buchspies, J.; Pyle, D.J.; He, H.; Szostak, M. Pd-Catalyzed Suzuki-Miyaura Cross-Coupling of Pentafluorophenyl Esters. Molecules 2018, 23, 3134. [CrossRef]

60. Shi, S.; Szostak, M. Pd-PEPPSI: A General Pd-NHC Precatalyst for Buchwald-Hartwig Cross-Coupling of Esters and Amides (Transamidation) under the Same Reaction Conditions. Chem. Commun. 2017, 53, 10584-10587. [CrossRef]

61. Karthik, S.; Gandhi, T. Palladium(II)/ N-Heterocyclic Carbene-Catalyzed Direct C-H Acylation of Heteroarenes with N -Acylsaccharins. Org. Lett. 2017, 19, 5486-5489. [CrossRef] [PubMed]

Sample Availability: Samples of the compounds are not available from the authors. 


\title{
Recent Advances in the Addition of Amide/Sulfonamide Bonds to Alkynes
}

\author{
Fei Zhao ${ }^{1}$, Pinyi Li ${ }^{1}$, Xiaoyan Liu ${ }^{1}$, Xiuwen Jia ${ }^{1}$, Jiang Wang ${ }^{2,3}$ and Hong Liu ${ }^{2,3, *}$ \\ 1 Antibiotics Research and Re-evaluation Key Laboratory of Sichuan Province, Sichuan Industrial Institute of \\ Antibiotics, Chengdu University, 168 Hua Guan Road, Chengdu 610052, China; zhaofei@cdu.edu.cn (F.Z.); \\ pinyiLi19950206@126.com (P.L.); 19940826097@163.com (X.L.); jiaxiuwen2018@126.com (X.J.) \\ 2 State Key Laboratory of Drug Research and CAS Key Laboratory of Receptor Research, Shanghai Institute of \\ Materia Medica, Chinese Academy of Sciences, 555 Zuchongzhi Road, Shanghai 201203, China; \\ jwang@simm.ac.cn \\ 3 University of Chinese Academy of Sciences, No.19A Yuquan Road, Beijing 100049, China \\ * Correspondence: hliu@simm.ac.cn; Tel.: +86-021-5080-7042
}

Academic Editor: Michal Szostak

Received: 11 December 2018; Accepted: 27 December 2018; Published: 4 January 2019

\begin{abstract}
The addition of amide/sulfonamide bonds to alkynes is not only one of the most important strategies for the direct functionalization of carbon-carbon triple bonds, but also a powerful tool for the downstream transformations of amides/sulfonamides. The present review provides a comprehensive summary of amide/sulfonamide bond addition to alkynes, including direct and metal-free aminoacylation, based-promoted aminoacylation, transition-metal-catalyzed aminoacylation, organocatalytic aminoacylation and transition-metal-catalyzed aminosulfonylation of alkynes up to December 2018. The reaction conditions, regio- and stereoselectivities, and mechanisms are discussed and summarized in detail.
\end{abstract}

Keywords: amide bond; sulfonamide bond; alkynes; addition reaction; aminoacylation; aminosulfonylation

\section{Introduction}

The addition of atom-atom bonds to alkynes has become an important strategy for the functionalization of carbon-carbon triple bonds [1-16]. These intermolecular and intramolecular addition reactions provide a facile and efficient access to highly functionalized alkenes and cyclic compounds, respectively, in a high atom- and step-economic manner. Considering the large occurrence of amide/sulfonamide motifs in natural products and pharmaceutical agents, the addition of amide/sulfonamide bonds to alkynes, namely aminoacylation/aminosulfonylation of alkynes, is particularly important. Because they allow the direct downstream transformations of amides/sulfonamides by the insertion of carbon-carbon triple bonds into the amide/sulfonamide bonds, they thus produce more complex and skeletally different addition molecules (Scheme 1). In addition, the aminoacylation/aminosulfonylation of alkynes also constitutes a tool for the structural modification of compounds carrying amide/sulfonamide bonds, especially for peptides, which are an important class of drugs used in the clinic [17-19]. Besides, amide/sulfonamide bond addition to alkynes, which constructs one $\mathrm{C}-\mathrm{C} / \mathrm{S}$ and one $\mathrm{C}-\mathrm{N}$ bond in a single step featuring high atom- and step-economy, is in accordance with the concept of "green and sustainable chemistry".

It should be noted that the addition of amide/sulfonamide bonds to alkynes has not been reviewed before. Moreover, amide/sulfonamide bond addition to alkynes has achieved many important developments in recent decades, especially in transition-metal-catalyzed and organocatalytic processes. Therefore, a review focused on the aminoacylation/aminosulfonylation of alkynes 
would enrich the knowledge of synthetic chemists who are interested in amide/sulfonamide bond activation. The aim of the present review is to provide a systematical and comprehensive summary on the addition of amide/sulfonamide bonds to alkynes, including direct and catalyst-free aminoacylation, based-promoted aminoacylation, transition-metal-catalyzed aminoacylation, organocatalytic aminoacylation, and transition-metal-catalyzed aminosulfonylation of alkynes up to December 2018. We hope this review will serve as a handy reference for chemists interested in the addition of amide/sulfonamide bonds to alkynes, and will encourage further developments in this field in overcoming the remaining challenges.

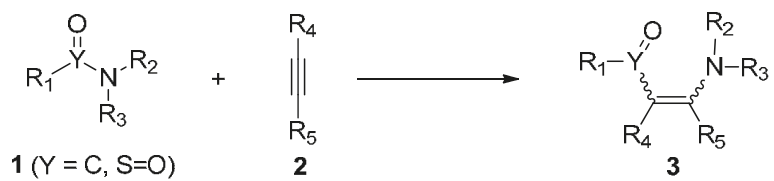

Scheme 1. The addition of amide/sulfonamide bonds to alkynes.

\section{Addition of Amide Bonds to Alkynes}

\subsection{Direct Addition of Amide Bonds to Alkynes without Catalysts and Additives}

The first example of amide bond addition to alkynes was a catalyst- and additive-free process as reported by Eğe's group in 1976 [20]. They found the treatment of active 2-phenylpyrazolidin-3-ones 4 with dimethyl acetylenedicarboxylate 5 in $\mathrm{CH}_{3} \mathrm{CN}$ under reflux led to the formation of the interesting ring expansion products 1,2-diazepin-5-ones 6 , albeit with unsatisfactory selectivities and yields (Scheme 2). The main byproducts of this reaction were the cis- and trans- Michael-type addition products. Besides, this transformation was strongly influenced by the solvent used. Polar but nonprotic solvents such as acetone and acetonitrile gave the best results while few products were obtained in protic solvents such as ethanol. Similar results were also observed in Svete and Stanovnik's research on the addition reactions between 5,5-dimethyl-2-(1H-indenyl-2)-3-pyrazolidinones 7 and acetylenedicarboxylates 8 (Scheme 3) [21]. A plausible reaction mechanism was outlined in Scheme 4. The Michael addition of N1 of the pyrazolidinones to acetylenedicarboxylate generates the carbanionic intermediate 11, which attacks the carbonyl group across the ring to give the bicyclic amino-acetal intermediate 12. The following ring opening of 12 affords the zwitterionic intermediate 13, which undergoes ring expansion to produce the addition products 6 .
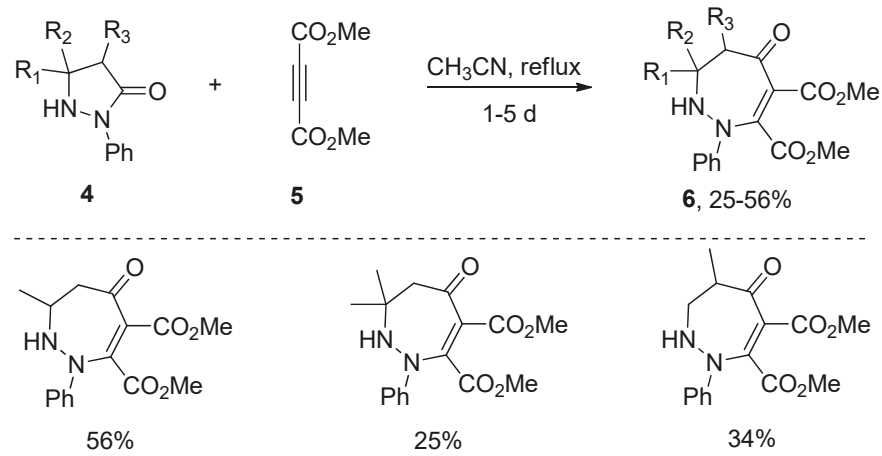

6, $25-56 \%$

Scheme 2. Insertion of 2-phenylpyrazolidin-3-ones into amide bonds. 
<smiles>CC1(C)CC(=O)N(N2C=Cc3ccccc3C2)N1</smiles>

7<smiles>[R]C#CCO[R]</smiles>

8<smiles>[R]OC(=O)C1=C(C(=O)O)C(=O)CC(C)(C)NN1C1=Cc2ccccc2C1</smiles>

9 (minor)

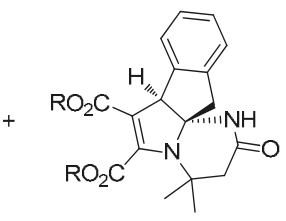

10 (major)

Scheme 3. Catalyst- and additive-free amide bond addition to alkynes.

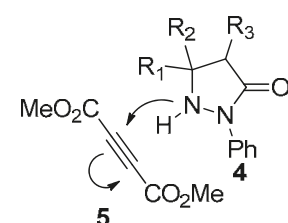

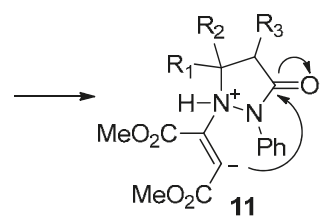

11

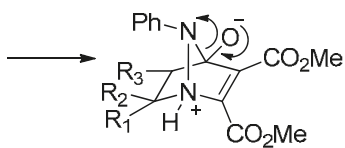

12<smiles>[R]C1C(=O)C(C(=O)OC)=C(C(O)OC)N(Pc2ccccc2)NC1([R])[R]</smiles>

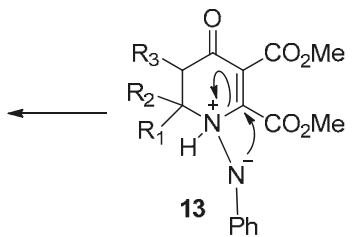

Scheme 4. Proposed mechanism for the insertion of 2-phenylpyrazolidin-3-ones into amide bonds.

In contrast, Hanack's group developed a more general and practical addition of amide bonds to carbon-carbon triple bonds without any catalysts and additives in 1989 [22]. Amides 15 were directly added to alkynyl trifluoromethyl sulfones $\mathbf{1 4}$ to afford the cis-adducts $\mathbf{1 6}$ with excellent regioselectivity and good yields, despite the fact that a long reaction time was required (Scheme 5). This protocol showed advantages such as simple operation, broad substrate scope, and the avoidance of metals and additives. A plausible mechanism was proposed in Scheme 6. The Michael reaction of nitrogen atom of the amides to alkynyl trifluoromethyl sulfones yields a zwitterion 17, which undergoes cyclization to form intermediate 18. The subsequent rupture of the carbon-nitrogen bond of $\mathbf{1 8}$ gives the products $\mathbf{1 6}$. The regio- and stereoselectivity observed in this reaction could be well explained by this mechanism.

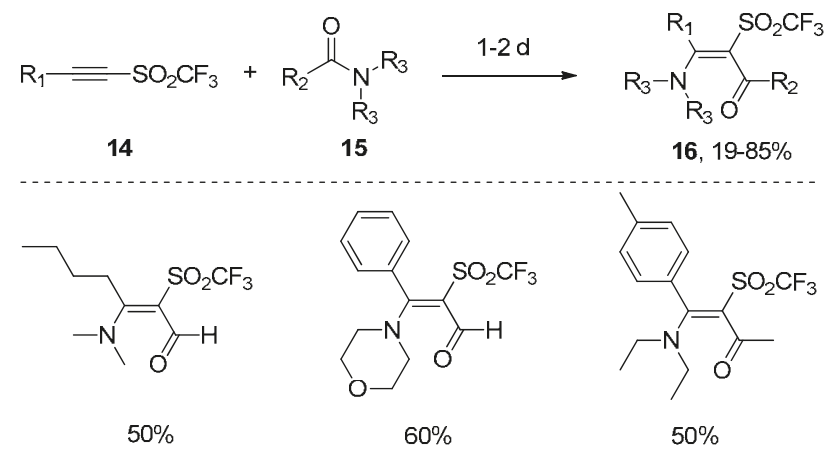

Scheme 5. Direct aminoacylation of alkynyl trifluoromethyl sulfones. 


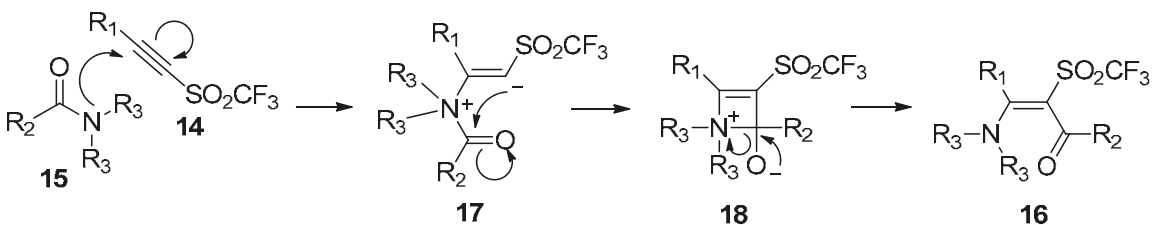

Scheme 6. Proposed mechanism for the direct aminoacylation of alkynyl trifluoromethyl sulfones.

What seems particularly interesting is the addition of 1,1'-carbonyldiimidazole (CDI) 19 to alkynoic acids 20 with the release of $\mathrm{CO}_{2}$, as reported by Knölker and co-workers in 1993 (Scheme 7) [23]. This reaction proceeded well under mild conditions to provide the E-adducts 23 in moderate yields. The reaction of CDI 19 with alkynoic acids 20 generated intermediate 21 and imidazole 22 with the release of $\mathrm{CO}_{2}$, and the subsequent addition of the imidazole 22 to the electron deficient alkyne 21 stereoselectively produced the products 23 .

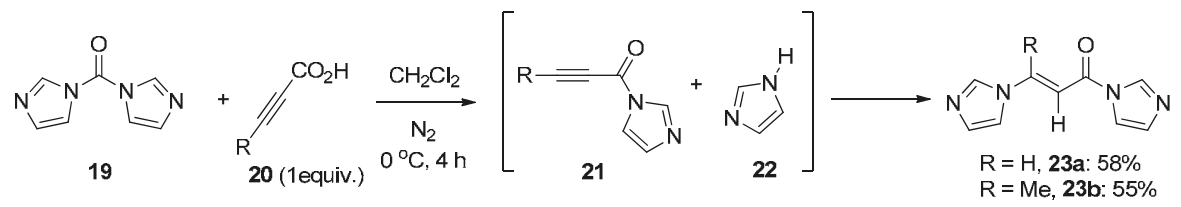

Scheme 7. Direct addition of $1,1^{\prime}$-carbonyldiimidazole to alkynes.

\subsection{Base-Promoted Addition of Amide Bonds to Alkynes}

In 1987, Suzuki and Tsuchihashi disclosed a sequential process for the preparation of enaminones 27 through the insertion of lithium (triphenylsilyl)acetylide into amides (Scheme 8) [24]. Acyclic amides reacted smoothly to give the E-enaminones in high yields, while lower yields of the desired ring expansion products were obtained when cyclic amides were used as the substrates. It is worth noting that the triphenyl group on silicon was essential for the transformation as other silylacetylides failed to give the enaminone products. The possible reaction pathway may involve the initial formation of the silylalkynone, the subsequent Michael addition of in situ-formed lithium amide and the final protiodesilylation.

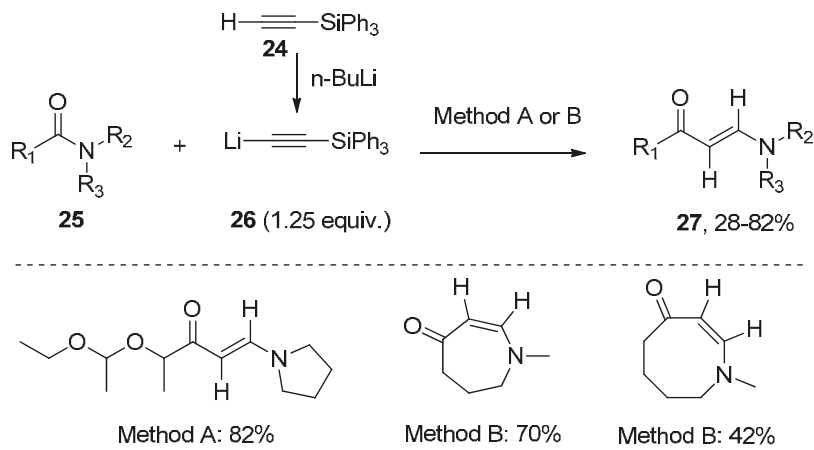

Scheme 8. The insertion of lithium (triphenylsilyl)acetylide into amides. Method A: THF, $-45{ }^{\circ} \mathrm{C}, 5 \mathrm{~h}$, then quenching with MeOH. Method B: $\mathrm{BF}_{3} \cdot \mathrm{OEt}_{2}\left(1.2\right.$ equiv.), THF:Hexane $=1: 5(v / v),-45^{\circ} \mathrm{C}, 5 \mathrm{~h}$, then quenching with $50 \%$ aqueous TFA.

Subsequently, Jeong et al. successfully realized the addition of Weinreb amides 29 to the carbon-carbon triple bond of trifluoropropynyl lithium 30 in a one-pot two-step pathway [25-27], 
providing a $Z / E$ mixture of $\beta$-trifluoromethyl enaminones 34 in moderate yields (Scheme 9). It should be noticed that an excessive amount of trifluoropropynyl lithium was required to consume Weinreb amides completely. The reaction temperature had a decisive impact on the outcome of this transformation since quenching the reaction with $\mathrm{H}_{2} \mathrm{O}$ at room temperature failed to give the enaminones but gave recovery of Weinreb amides. Besides, the use of $N, N$-dimethylbenzamide instead of $N$-methoxy- $N$-methylbenzamide under optimal conditions did not provide the desired product at all, only the recovery of starting material. This indicated that the $N$-methoxy group in Weinreb amides played an indispensable role in this reaction. The proposed mechanism involved the key intermediate 31, which was formed from the addition of trifluoropropynyl lithium with Weinreb amides. Then 31 was quenched by $\mathrm{H}_{2} \mathrm{O}$ to give the ynone intermediate 32 , which rapidly reacted with $N$-methoxy- $N$-methylamine 33 generated from the reaction to give the products 34 . The $N$-methoxy group in Weinreb amides was essential because the oxygen could coordinate with the lithium cation to stabilize the key intermediate 31. Particularly, the fact that trapping 31 with trimethylsilyl chloride afforded the corresponding siloxane derivative in a high yield further demonstrated the mechanism.

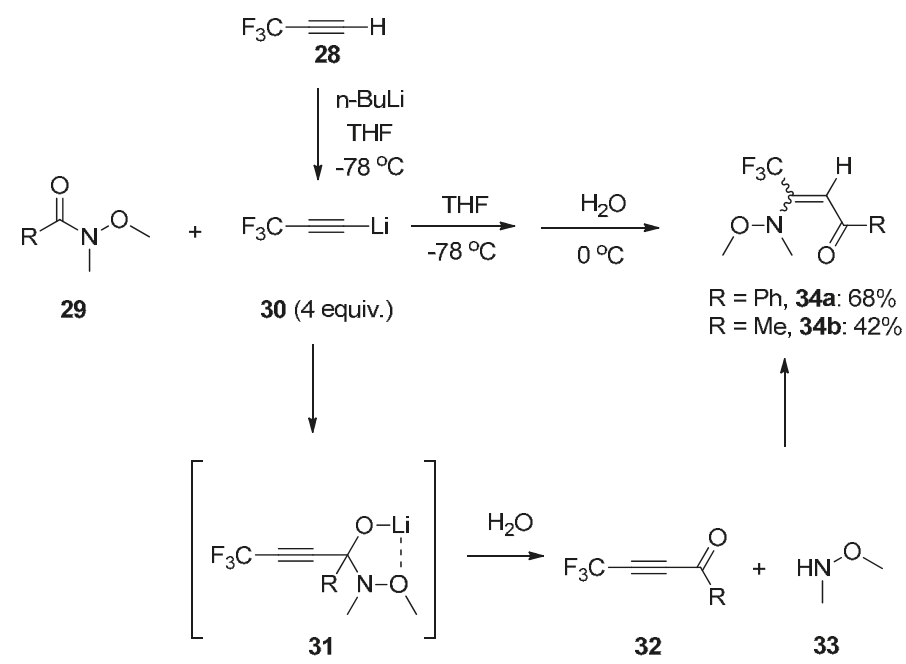

Scheme 9. Addition of Weinreb amides to trifluoropropynyl lithium.

Soon afterwards, the group of Nielsen reported the insertion of sodium acetylide of ethyl propynoate 35 into Weinreb amides 29 to produce the 1,2-addition products 37 as the major products (Scheme 10a) [28]. The selectivity of the 1,2-addition products 37 over 1,1-addition products 38 depended on the $\mathrm{R}$ group of the Weinreb amides. Substrates with bigger R substituents showed higher selectivity than those with smaller ones. For example, substituents such as phenyl showed excellent selectivity, providing the 1,2-addition adduct as the single product in high yield. However, substrates carrying bulky substituents such as tert-butyl or 2,4-dimethoxyphenyl did not undergo this transformation. Notably, the tertiary enaminones 37 preferentially adopted $E$-geometry in all cases, suggesting the 1,2-addition reactions proceeded in a highly trans-selective manner. In addition, the $\beta$-enaminoketoesters 37 were employed by the authors to react with hydrazines 39 under microwave irradiation to construct pyrazoles 40 through a regioselective cyclocondensation (Scheme 10b). Similarly, Choudhury's group reported a one-pot sequential process consisting of nucleophilic substitution of the lithiated acetylides with Weinreb amides, and a following Michael reaction of the extruded $N$-methoxy- $N$-methylamine to a carbon-carbon triple bond after quenching with saturated $\mathrm{NH}_{4} \mathrm{Cl}$, producing the $E$ - $\beta$-enamino ketones 43 as the single geometrical isomer in high yields (Scheme 11) [29]. 


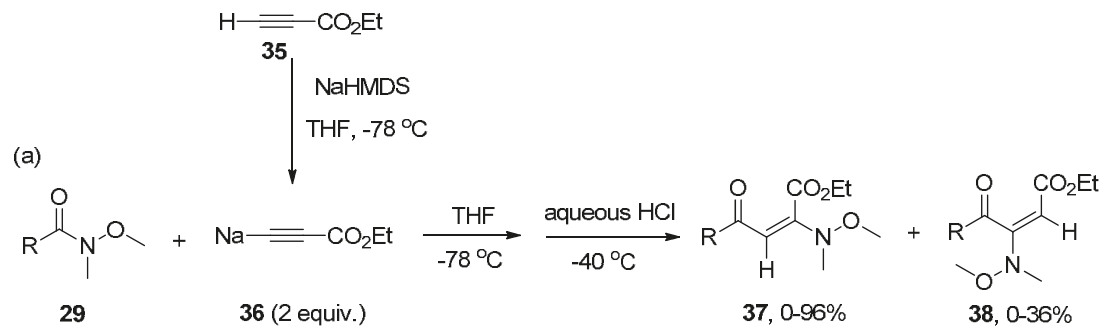

$\mathrm{R}=\mathrm{Me}, 37 \mathrm{a}, 31 \% ; 38 \mathrm{a}, 33 \%$

$\mathrm{R}=\mathrm{Et}, \mathbf{3 7 b}, \mathbf{4 1 \%} ; \mathbf{3 8 b}, 34 \%$

$\mathrm{R}=\mathrm{Bn}, 37 \mathrm{c}, 44 \% ; 38 \mathrm{c}, 30 \%$

$\mathrm{R}=i-\mathrm{Pr}, 37 \mathrm{~d}, 52 \% ; 38 \mathrm{~d}, 36 \%$

$\mathrm{R}=\mathrm{Ph}, \mathbf{3 7 e}, 96 \% ; 38 \mathrm{e}, 0 \%$

$\mathrm{R}=4-\mathrm{NO}_{2}-\mathrm{C}_{6} \mathrm{H}_{4}, 37 \mathrm{f}, 75 \% ; 38 \mathrm{f}, 0 \%$

$\mathrm{R}=4-\mathrm{MeO}-\mathrm{C}_{6} \mathrm{H}_{4}, 37 \mathrm{~g}, 72 \% ; 38 \mathrm{~g}, 0 \%$

$\mathrm{R}=2,4-\mathrm{Cl}_{2} \mathrm{C}_{6} \mathrm{H}_{3}, 37 \mathrm{~h}, 60 \% ; 38 \mathrm{~h}, 0 \%$

(b)
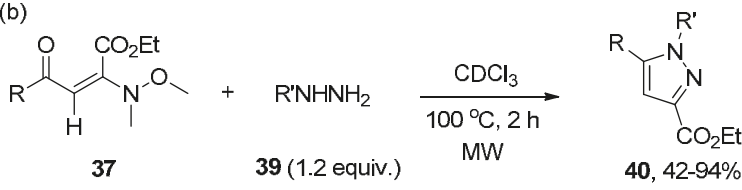

40, $42-94 \%$

Scheme 10. (a) Insertion of sodium acetylide of ethyl propynoate into Weinreb amides. (b) Synthesis of pyrazoles employing $\beta$-enaminoketoesters.

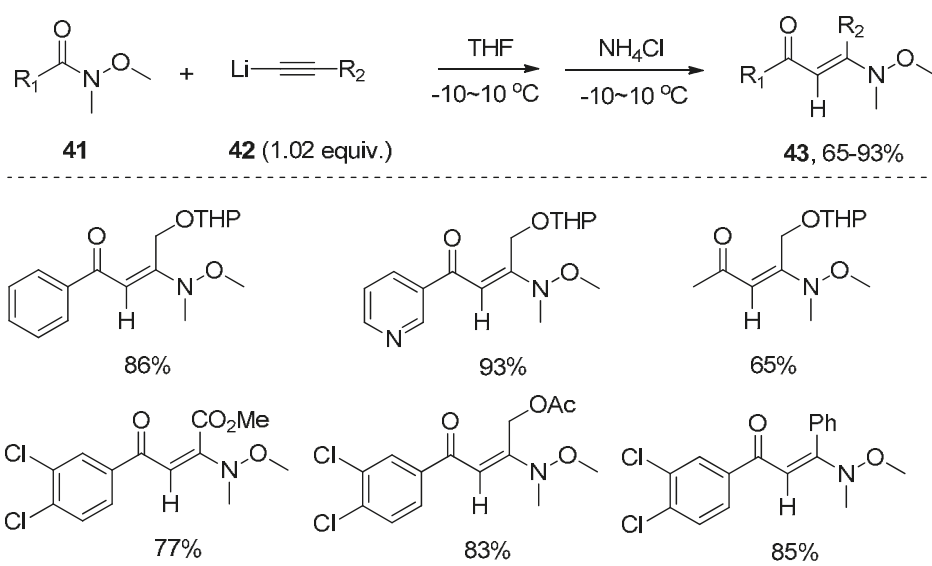

Scheme 11. One-pot sequential transformation of Weinreb amides to enamino ketones.

Very recently, Li and co-workers reported the addition of the amide bond of imides 45 to the carbon-carbon triple bond of alkynones 44 under basic conditions (Scheme 12) [30]. This addition reaction proceeded smoothly with the addition of a base such as $\mathrm{K}_{2} \mathrm{CO}_{3}$ in DMSO at high temperature, affording the corresponding tetra-substituted enamides $\mathbf{4 6}$ in good yields. Although this transformation suffered from unsatisfactory stereoselectivities, excellent regioselectivities were observed. The acyl group and amide group were dominantly located at the $\alpha$-position and $\beta$-position of the carbonyl, respectively. Interestingly, in the reactions of alkynones 47 bearing an ortho-bromo-substituted aryl ring, highly functional chromones $\mathbf{4 8}$ were selectively formed in good to high yields via the $\mathrm{O}$-cyclization pathway (Scheme 13). Control experiments showed that the base played an important role. It could deprotonate the imides $\mathbf{4 5}$ to form a nitrogen anion, which undergoes a Michael-type addition to the alkynones 49 to produce the anion intermediate 50 . Then intermediate 50 undergoes an intramolecular nucleophilic addition/ring-opening sequence to provide intermediate 52. Hydrolysis of intermediate 52 generates enamides $46(X=H)$, or imine-enamine 
tautomerization of intermediate $\mathbf{5 2}$ followed by nucleophilic aromatic substitution $\left(\mathrm{S}_{\mathrm{N}} \mathrm{Ar}\right)$ to give the chromones $48(\mathrm{X}=\mathrm{Br})$ (Scheme 14).

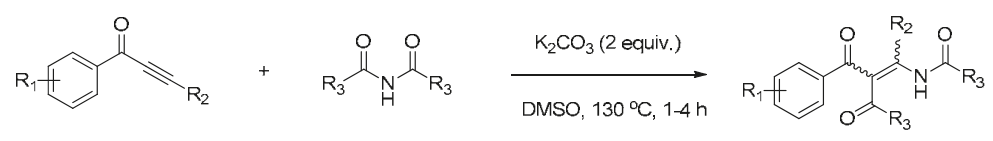

44

45 (2 equiv.)

\section{6, up tp $85 \%$}<smiles>O=C(NC(C(=O)c1ccccc1)c1ccccc1)c1ccccc1</smiles>

$80 \%$

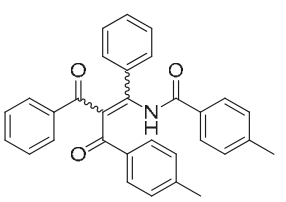

$64 \%$

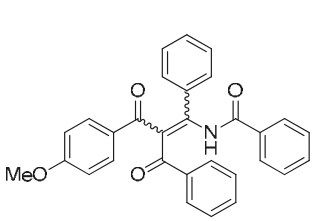

$67 \%$

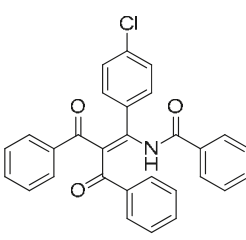

$58 \%$

Scheme 12. Addition of imides to alkynones promoted by $\mathrm{K}_{2} \mathrm{CO}_{3}$ to synthesize enamides.
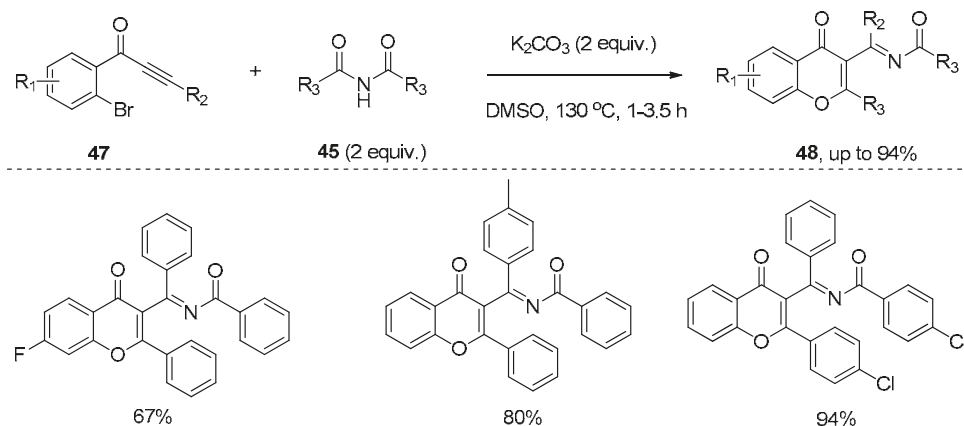

45 (2 equiv.)

48, up to $94 \%$

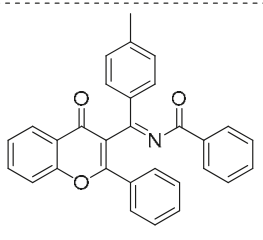

$80 \%$

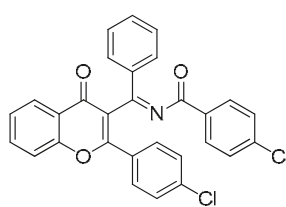

$94 \%$

Scheme 13. Addition of imides to alkynones promoted by $\mathrm{K}_{2} \mathrm{CO}_{3}$ to synthesize chromones.<smiles></smiles>

45

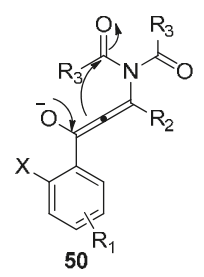

50

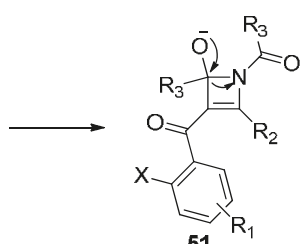

51<smiles>[R]C(=O)N=C([R])c1c([R])oc2cc([R])ccc2c1=O</smiles>

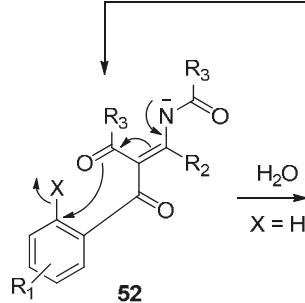<smiles></smiles>

Scheme 14. Proposed catalytic cycle for the addition of imides to alkynones promoted by $\mathrm{K}_{2} \mathrm{CO}_{3}$.

Soon afterwards, $\mathrm{Li}$ and co-workers presented the insertion of alkynones 53 into the amide bond of amide 54 promoted by $\mathrm{Cs}_{2} \mathrm{CO}_{3}$ (Scheme 15), providing the functionalized enaminones 55 with high 
stereoselectivity and excellent regioselectivity [31]. It should be noted that the combination of $\mathrm{Cs}_{2} \mathrm{CO}_{3}$ and 1,10-phenanthroline hydrate (Phen $\left.\cdot \mathrm{H}_{2} \mathrm{O}\right)$ is essential to obtain good yields in a short reaction time. The authors hypothesized that 1,10-phenanthroline hydrate may act as a metal ion chelator, which increased the basicity of $\mathrm{Cs}_{2} \mathrm{CO}_{3}$ to accelerate the reaction. Similarly, 3-carbonyl-4-quinolinones 58 were selectively formed via a subsequent $N$-cyclization pathway in the cases of alkynones $\mathbf{5 6}$ bearing an ortho-bromo-substituted aryl ring (Scheme 16). The proposed reaction mechanism is outlined in Scheme 17. The Michael-type addition of amides 57 to alkynones 59 under basic conditions yields an allenol intermediate $\mathbf{6 0}$. The subsequent intramolecular nucleophilic addition gives a highly reactive cyclobutenol intermediate $\mathbf{6 1}$, which undergoes ring opening to produce a formal alkyne insertion intermediate $\mathbf{6 2}$. Then intermediate $\mathbf{6 2}$ undergoes imine-enamine tautomerization to provide intermediate 63 , which undergoes a nucleophilic aromatic substitution $\left(\mathrm{S}_{N} \mathrm{Ar}\right)$ to afford the quinolinone products $64(\mathrm{Y}=\mathrm{Br})$. In contrast, the protonation of intermediate 62 or 63 leads to the formation of the enaminone products $65(\mathrm{Y}=\mathrm{H})$.

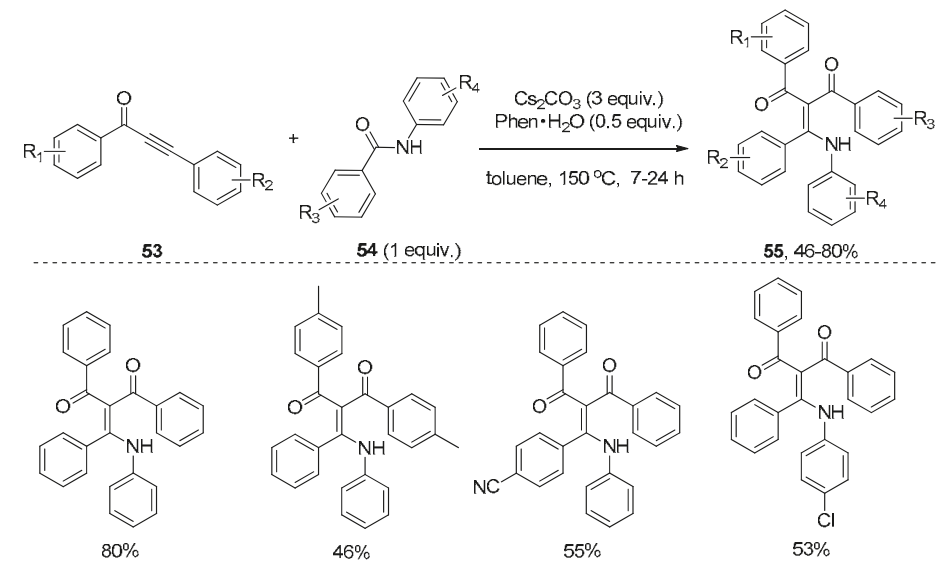

Scheme 15. Insertion of alkynones into amides to synthesize enaminones promoted by $\mathrm{Cs}_{2} \mathrm{CO}_{3}$.

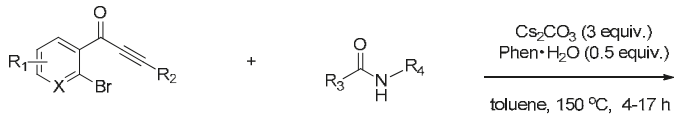

56 57 (1 equiv.)

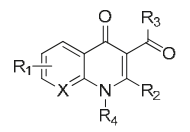

58, up to $82 \%$
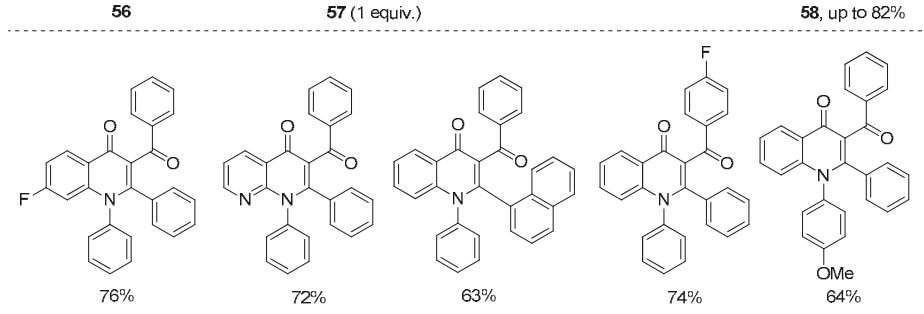

Scheme 16. Insertion of alkynones into amides to synthesize quinolinones promoted by $\mathrm{Cs}_{2} \mathrm{CO}_{3}$. 


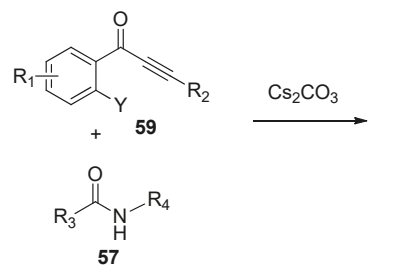<smiles>[R]CC(C)C(=O)c1ccccc1[Y]</smiles>

60

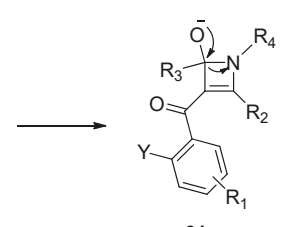

61

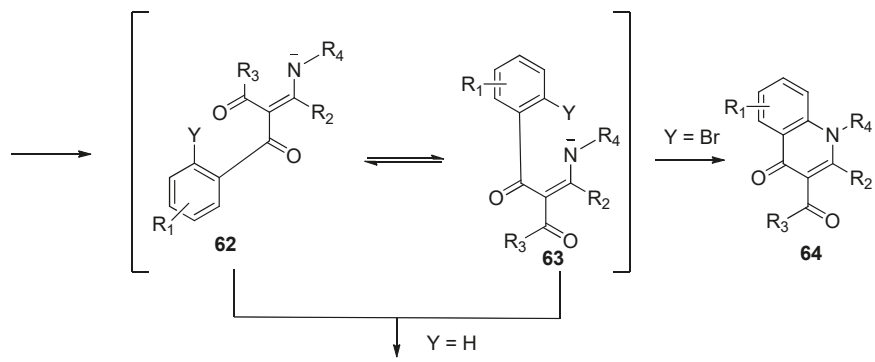<smiles>[R]NC([R])=C(C([R])=O)C(=O)c1ccccc1</smiles>

Scheme 17. Proposed reaction mechanism for the insertion of alkynones into amides promoted by $\mathrm{Cs}_{2} \mathrm{CO}_{3}$.

\subsection{Transition-Metal-Catalyzed Addition of Amide Bonds to Alkynes}

In 2004, Yamamoto's group reported the platinum catalyzed synthesis of highly functional indoles through an intramolecular amide $\mathrm{C}-\mathrm{N}$ bond addition to alkynes with the [1,3]-migration of acyl groups (Scheme 18) [32]. $\mathrm{PtCl}_{2}$ showed the highest catalytic activity compared with other platinum catalysts such as $\mathrm{PtCl}_{2}\left(\mathrm{CH}_{3} \mathrm{CN}\right)_{2}, \mathrm{PtBr}_{2}$, and $\mathrm{Pt}\left(\mathrm{PPh}_{3}\right)_{4}$. Various ortho-alkynylanilides 66 bearing diverse alkyl or aryl groups at $\mathrm{R}_{1}$ could be converted into the corresponding indole products 67 with good to high yields with $\mathrm{PtCl}_{2}$. Notably, a variety of acyl groups could undergo intramolecular [1,3]-migration to give 3-acyl-indoles 67 . The main drawback of this method is that the desired products 67 are together with deacylated byproducts 68 in most cases. Based on the results of deuterium-labeling experiments and crossover experiments, the authors proposed a catalytic cycle of this intramolecular aminoacylation of alkynes. As shown in Scheme 19, coordination of alkyne moiety to $\mathrm{PtCl}_{2}$ yields the $\pi$-complex 69 , followed by nucleophilic attack of nitrogen to the alkyne, affording the zwitterionic intermediate 70. An intramolecular [1,3]-migration of the acyl group then gives intermediate $\mathbf{7 1}$, which affords the product and regenerates the catalyst. The 3-deacylated byproducts 68 may attribute to the deacylation which takes place through the protonolysis of the $\mathrm{C}-\mathrm{Pt}$ bond of intermediate $\mathbf{7 0}$. 


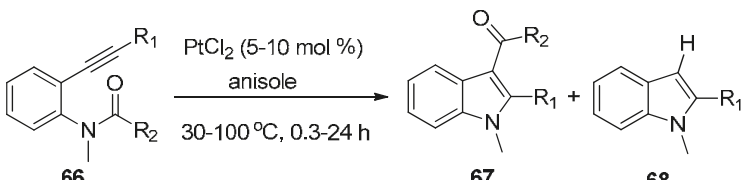

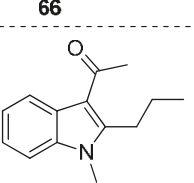

$96 \%, 67 a: 68 a=9: 1$<smiles>CCCc1c(C(=O)c2ccccc2)c2ccccc2n1C</smiles>

$75 \%, 67 \mathrm{~g}: 68 \mathrm{~g}=13: 1$<smiles>CC(=O)c1c(-c2ccc(C(F)(F)F)cc2)n(C)c2ccccc12</smiles>

$93 \%, 67 e: 68 e=4: 1$<smiles>Cn1c(-c2ccccc2)c(C(=O)Cc2ccccc2)c2ccccc21</smiles>

$87 \%, 67 \mathrm{~h}: 68 \mathrm{~h}=4: 1 \quad>99 \%, 67 \mathrm{i}: 68 \mathrm{i}=100: 0$

Scheme 18. $\mathrm{PtCl}_{2}$-catalyzed intramolecular aminoacylation of alkynes.

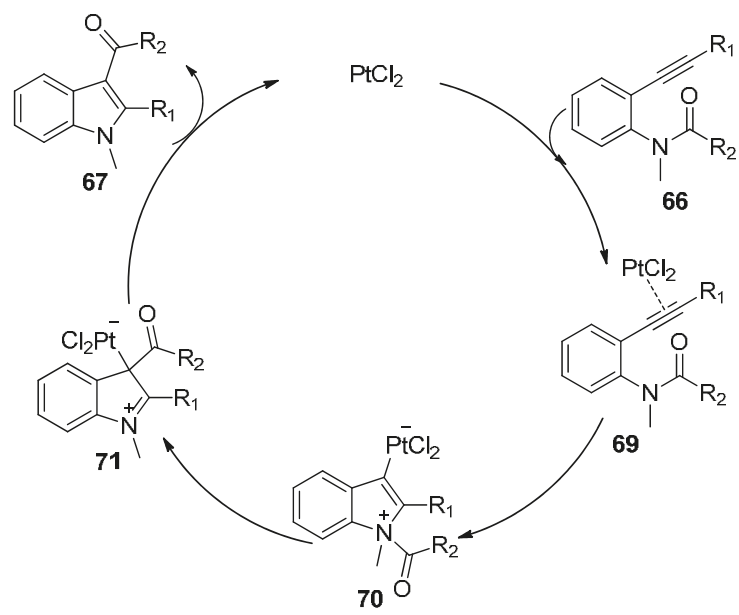

Scheme 19. Proposed catalytic cycle of $\mathrm{PtCl}_{2}$-catalyzed intramolecular aminoacylation of alkynes.

Encouraged by the excellent catalytic performance of platinum catalysts towards the intramolecular aminoacylation of alkynes, Nakamura's group further studied similar reactions using ortho-alkynylphenylureas or ortho-alkynylphenyl carbamates as substrates (Scheme 20) [33]. The reactions of ortho-alkynylphenylureas 72 having a carbamoyl group attached to the nitrogen atom proceeded successfully under the catalysis of $\mathrm{PtI}_{4}$, providing the desired indole-3-carbamides 73 in moderate to high yields along with the 3-protonated byproducts 68 . Interestingly, ortho-alkynylphenyl carbamates 74 could be converted into the corresponding indole-3-carboxylates 75 in good yields without the generation of 3-protonated byproducts 76 . The authors proposed a similar mechanism to that of Yamamoto's group [32]. They assumed the generation of the 3-protonated byproducts 68 in the reactions of ortho-alkynylphenylureas $\mathbf{7 2}$ may be attributed to protodemetalation of intermediate 78 by a proton from the methyl moiety of intermediate 79, which was extruded in the reaction (Scheme 21). Notably, this work proved that amide and ester groups could be used as the migrating groups, thus 
providing an efficient method to synthesize indole-3-carbamides/carboxylates which could not be prepared via Friedel-Crafts electrophilic substitution into the C3-position of the indole ring.<smiles>[R]C#Cc1ccccc1N([R2])C(=O)N(C)CC</smiles><smiles>[R]OC(=O)N(C)c1ccccc1C#CCCC</smiles>

$\mathrm{PtCl}_{2}$ or $\mathrm{PtCl}_{4}(10 \mathrm{~mol} \%)$

$\mathrm{EA}, 100^{\circ} \mathrm{C}, 14-16 \mathrm{~h}$

74

EA, $100^{\circ} \mathrm{C}, 2-48 \mathrm{~h}$

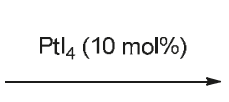

$\mathrm{R}=\mathrm{Me}, \mathbf{7 5 a}: 74 \%$

$\mathrm{R}=\mathrm{Ph}, \mathbf{7 5 b}: 80 \%$

73 (up to $83 \%$ )<smiles>[R]c1c(C(=O)N(C)C)c2ccccc2n1C</smiles>

68 (up to $56 \%$ )<smiles>CCCc1cc2ccccc2n1C</smiles>

76 (not detected)

Scheme 20. Platinum-catalyzed intramolecular carboamination.

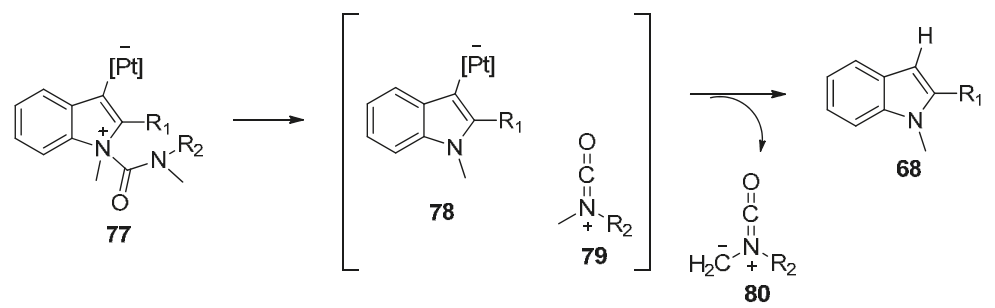

Scheme 21. Proposed pathway for the generation of 3-protonated byproducts.

In 2007, Nakamura's group revealed that $\mathrm{PdBr}_{2}$ could also catalyze the intramolecular amide $\mathrm{C}-\mathrm{N}$ bond addition to alkynes (Scheme 22), affording the indole adduct 82 from ortho-alkynylanilide 81 in 52\% yield [34]. Encouraged by the catalytic performance of $\mathrm{PdBr}_{2}$ towards the intramolecular aminoacylation of alkynes, Liu's group further screened a series of palladium complexes. They found that $\mathrm{PdCl}_{2}\left(\mathrm{CH}_{3} \mathrm{CN}\right)_{2}$ showed excellent catalytic activity (Scheme 23) [35]. Substrates 83 with alkyl/aryl groups at $\mathrm{R}_{1}$ furnished the corresponding products 84 in good to excellent yields. The protocol was also compatible with substrates 83 bearing electron-donating substituents, halides, and electron-withdrawing substituents at $\mathrm{R}_{2}$, which produced the corresponding products 84 in high yields. In addition, the reactions of substrates 83 with different alkyl substituents at $R_{3}$ also took place smoothly, providing the desired products 84 in high yields. More importantly, various acyl and amide groups could migrate smoothly and be conveniently introduced at the C3-position of indoles.

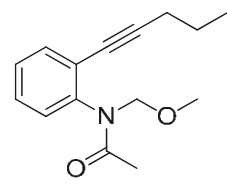

81

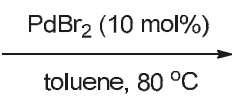

Scheme 22. $\mathrm{PdBr}_{2}$-catalyzed intramolecular aminoacylation of alkynes. 
<smiles>[R]C#Cc1cc[R]([R])cc1N([R3])C([R4])=O</smiles>

83

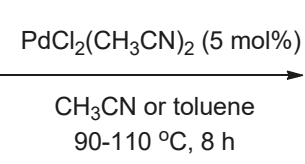

$90-110^{\circ} \mathrm{C}, 8 \mathrm{~h}$<smiles>[R]C(=O)c1c([R])n([R3])c2cc[R1](C)cc12</smiles>

$84,26-99 \%$<smiles>CCCCc1c(C=O)c2cc(OC)ccc2n1C</smiles>

$99 \%$ $97 \%$<smiles>CCCCc1[nH]c2ccccc2c1C=O</smiles>

$93 \%$<smiles>CCCCc1c(C(C)=O)c2ccccc2n1C</smiles>

$85 \%$

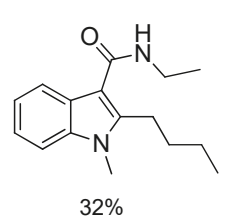

$32 \%$<smiles>CCC1Cc2c(c3ccccc3n2C)C(=O)C1(C)C</smiles>

$26 \%$
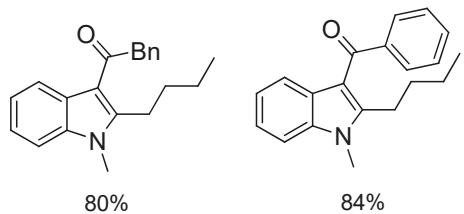

Scheme 23. $\mathrm{PdCl}_{2}\left(\mathrm{CH}_{3} \mathrm{CN}\right)_{2}$-catalyzed intramolecular aminoacylation of alkynes.

Subsequently, Liu and coworkers further extended their palladium catalytic system to the synthesis of 3-diketoindoles 86 from ortho-alkynyl- $N$ - $\alpha$-ketoacylanilines 85 via the intramolecular amide bond addition to alkynes (Scheme 24) [36]. Notably, this addition reaction proceeded smoothly to give the high functional 3-diketoindoles 86 with the [1,3]-migration of $\alpha$-ketoacyl groups, which were used as migrating groups for the first time. Compared with previously reported protocols such as Friedel-Crafts acylation [37], Glyoxylation/Stephens-Castro coupling sequence [38], and the oxidative cross-coupling of indoles [39-41], which achieved the synthesis of 3-diketoindoles through the modification of the indole ring, but suffered from poor selectivity, operational complexity, the requirement of strict exclusion of moisture, limited substrate scope and low atom economy, this new method successfully prepared 3-diketoindoles via the construction of an indole ring with valuable features such as operational simplicity, high atom economy, broad substrate scope and high yields. Interestingly, a 3-diketoindole dimer $\mathbf{8 8}$ was synthesized in a high yield when substrate $\mathbf{8 7}$ was subjected to the optimal reaction conditions (Scheme 25). Finally, the authors proposed a reaction mechanism which is similar to that proposed by Yamamoto's group [32]. 


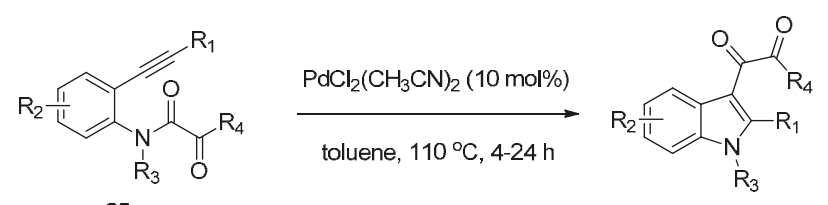

85

86, 60-99\%

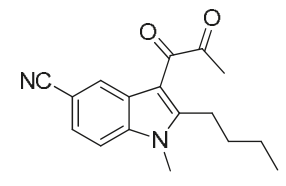

$83 \%$<smiles>CCCCc1c(C(=O)C(=O)CC)c2ccccc2n1C</smiles>

$90 \%$<smiles>CCCCc1c(C(=O)C(C)=O)c2cc(C(F)(F)F)ccc2n1C</smiles>

$80 \%$<smiles>CCCCc1c(C(=O)C(C)=O)c2ccccc2n1Cc1ccccc1</smiles>

$93 \%$

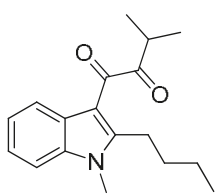

$87 \%$

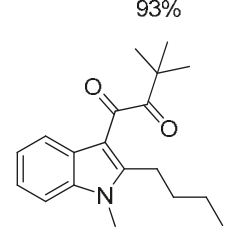

$85 \%$

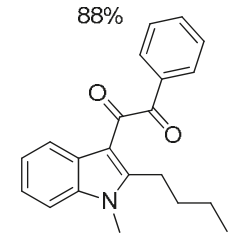

$85 \%$

Scheme 24. $\mathrm{PdCl}_{2}\left(\mathrm{CH}_{3} \mathrm{CN}\right)_{2}$-catalyzed synthesis of 3-diketoindoles via the intramolecular amide bond addition to alkynes.<smiles>CC(=O)C(=O)N(C)c1ccccc1C#CCCCCCC#Cc1ccccc1N(C)C(=O)C(C)=O</smiles>

87
$\mathrm{PdCl}_{2}\left(\mathrm{CH}_{3} \mathrm{CN}\right)_{2}(10 \mathrm{~mol} \%)$

toluene, $110^{\circ} \mathrm{C}, 4 \mathrm{~h}$

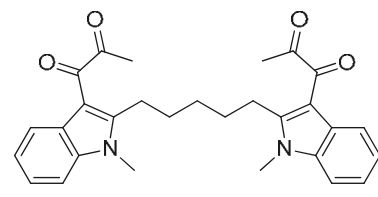

88, $90 \%$

Scheme 25. $\mathrm{PdCl}_{2}\left(\mathrm{CH}_{3} \mathrm{CN}\right)_{2}$-catalyzed synthesis of 3-diketoindole dimer via the intramolecular amide bond addition to alkynes.

Ruthenium complexes were also found to be efficient catalysts for the intramolecular amide bond addition to alkynes, as was reported by Li's group in 2012 (Scheme 26) [42]. Their study showed that $\left[\mathrm{RuCl}_{2}(p \text {-cym) }]_{2}\right.$ displayed the highest catalytic activity, with which ortho-alkynylanilides 83 could undergo intramolecular annulation through amide bond addition to the alkyne moiety to synthesize highly functional indoles $\mathbf{8 4}$. A variety of substrates $\mathbf{8 3}$ carrying diverse functional groups such as olefin, ester, aldehyde were well tolerated and could be converted into the corresponding indole products 84 in moderate to high yields. Despite the fact that a longer reaction time was required compared with platinum or palladium catalytic systems, it is worth noting that no 3-deacylated indoles were observed in all examples. However, the main shortcoming of this method is that unsatisfactory yields were obtained when bigger acyl groups such as acetyl were employed as the migrating groups. Based on the mechanistic study results with deuterium-labeling experiments, the authors hypothesized that the reaction mechanism may involve the complexation of substrates with ruthenium catalyst, the subsequent oxidative addition of ruthenium catalyst across the amide bond, the following addition of the N-Ru bond to carbon-carbon triple bonds, and the final reductive elimination to produce the products and regenerate the catalyst (Scheme 27). 
<smiles>[R]C#Cc1cc[R]([R])cc1N([R3])C([R4])=O</smiles>

83<smiles>Cn1c(C2CC2)c(C=O)c2ccccc21</smiles>

$82 \%$<smiles>Cn1c(-c2ccccc2)c(C=O)c2cc(C(F)(F)F)ccc21</smiles>

$98 \%$
$\left[\mathrm{RuCl}_{2}(p-\mathrm{cym})\right]_{2}(3 \mathrm{~mol} \%)$

DCE, reflux, $40 \mathrm{~h}$<smiles>[R]C(=O)c1c([R])n([R3])c2cc[R]#cc12</smiles>

$84,30-99 \%$<smiles>[13CH2]n1c(C2=CCCCC2)c(C=O)c2ccccc21</smiles><smiles>O=Cc1c(-c2ccccc2)n(Cc2ccccc2)c2ccccc12</smiles>

$30 \%$<smiles>Cc1ccc2c(c1)c(C=O)c(-c1ccccc1)n2C</smiles>

$84 \%$

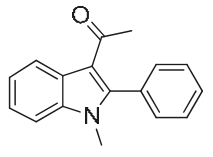

$57 \%$

Scheme 26. $\left[\mathrm{RuCl}_{2}(p-c y m)\right]_{2}$ catalyzed intramolecular aminoacylation of alkynes.

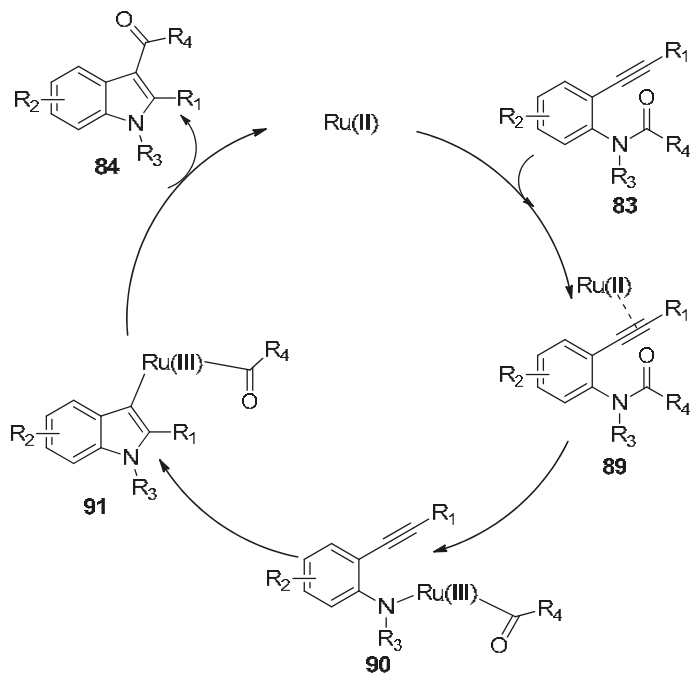

Scheme 27. Possible mechanism of $\left[\mathrm{RuCl}_{2}(p-\mathrm{cym})\right]_{2}$ catalyzed intramolecular aminoacylation of alkynes.

\subsection{Addition of Amide Bonds to Alkynes through Organocatalysis}

In addition to the metal-catalyzed processes, methods utilizing organocatalysis, which feature advantages such as low cost, environmental economy, and the avoidance of metal contamination, have also been developed in recent years. What seems particularly interesting is the insertion of an electron-deficient alkyne 5 into the amide bond of an acyl-onio salt 92 (Scheme 28), as reported by Weiss and Huber [43]. This reaction could be achieved in the presence of a catalytic amount of small organic molecules such as $\mathrm{PPh}_{3}$ or DMAP, providing the desired $\beta$-oniovinylation products 93 in good yields. The stereochemistry of this process depends on the reaction conditions, preferentially $E$ or Z-stereochemistry was observed, and the Z-isomer is the thermodynamically more stable isomer. More importantly, the onio substituent in the products 93 could be selectively replaced by a number of nucleophiles, such as anilines, phenols, and thiophenols, to prepare Michael systems with donor 
functions in the $\beta$-position, which could be further converted into quinolones, thiochromones, and pyrazoles by intramolecular cyclization. The authors proposed a catalytic cycle for this organocatalytic process. Taking the transformation catalyzed by $\mathrm{PPh}_{3}$ as the example (Scheme 29), the conjugate addition of $\mathrm{PPh}_{3}$ to alkyne 5 produces the zwitterionic intermediate 94 , which attacks the electrophilic carbonyl center of 92 to provide intermediate 95 with liberation of 4-dimethylaminopyridine (DMAP). Then intermediate 95 reacts with the liberated DMAP to give the products 93 and regenerates the catalyst.<smiles></smiles><smiles>CC(C)(C)O[Na]</smiles>

92

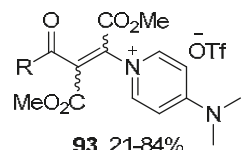

$93,21-84 \%$

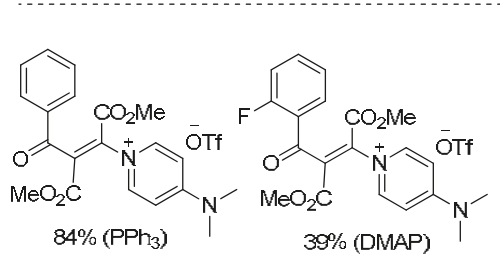

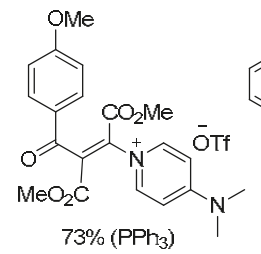

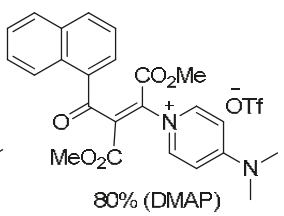

Scheme 28. The addition of amide bonds of acyl-onio salts to alkynes through $\mathrm{PPh}_{3}$ or 4-dimethylaminopyridine (DMAP) organocatalysis.

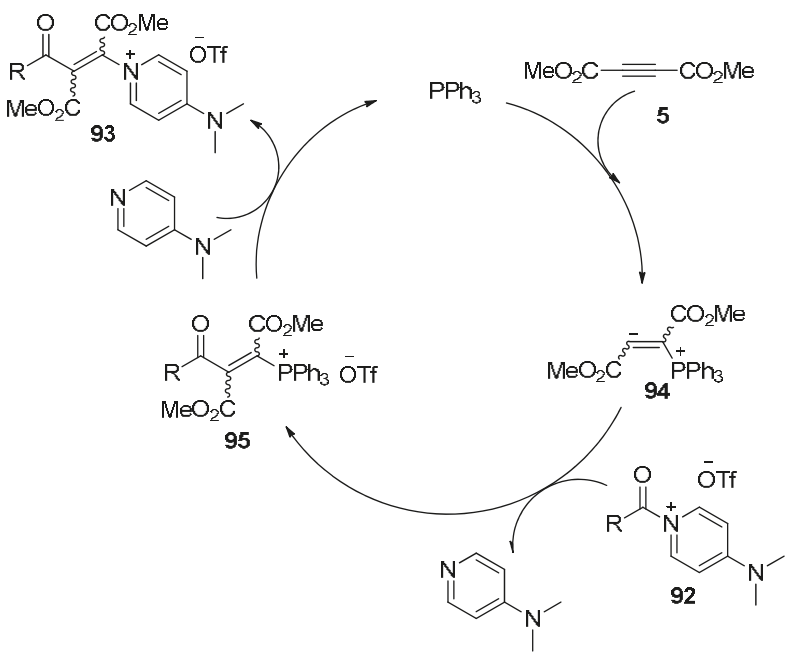

Scheme 29. Proposed catalytic cycle for the addition of amide bond of acyl-onio salts to alkynes.

Recently, Doi's group reported an example of amide addition to alkynes through tertiary amine organocatalysis (Scheme 30) [44]. They found that $o$-alkynoylaniline derivatives 96 could undergo intramolecular aminoacylation of the carbon-carbon triple bonds successfully under the catalysis of 9-azajulolidine (9-AJ) to afford the 3-acyl-4-quinolinones 97 in moderate to good yields with excellent regioselectivity. Notably, a variety of acyl groups including ester groups could act as migrating groups to be transferred to the C3-positon of the quinolinones. Particularly, the synthesis of pyrrolyl 4-quinolinone alkaloid, quinolactacide, and its analogues were successfully achieved by the authors employing this organocatalytic process. Finally, a plausible reaction mechanism was outlined in 
Scheme 31. 1,4-addition of 9-AJ to substrates 96 takes place at first, and the subsequent nucleophilic attack of the resulting anion to the acyl group provides intermediate $\mathbf{9 8}$, which could be converted into the intermediate 99. Then the acyl group in allenolate 99 could be transferred to the C3-position, thus leading to the formation of enone 100, which undergoes 6-endo cyclization to provide the products 97 with the regeneration of $9-\mathrm{AJ}$.<smiles>[R]C(=O)[N+]([O-])c1ccccc1C(=O)C#Cc1ccccc1</smiles>

96<smiles>COC(=O)c1c(-c2ccccc2)n(C(=O)OC(C)(C)C)c2ccccc2c1=O</smiles>

93\%

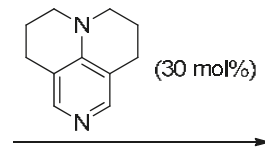

DMF, $30^{\circ} \mathrm{C}, 3-120 \mathrm{~h}$<smiles>[R]C(=O)c1c(-c2ccccc2)n(C(=O)OCc2ccccc2)c2ccccc2c1=O</smiles>
97, $25-93 \%$<smiles>COc1ccc(C(=O)c2c(-c3ccccc3)n(C(=O)OCc3ccccc3)c3ccccc3c2=O)cc1</smiles><smiles>CC(C)(C)OC(=O)n1c(-c2ccccc2)c(C(=O)C(C)(C)C)c(=O)c2ccccc21</smiles>

$56 \%$

Scheme 30. The 9-azajulolidine-catalyzed intramolecular amide addition to alkynes.

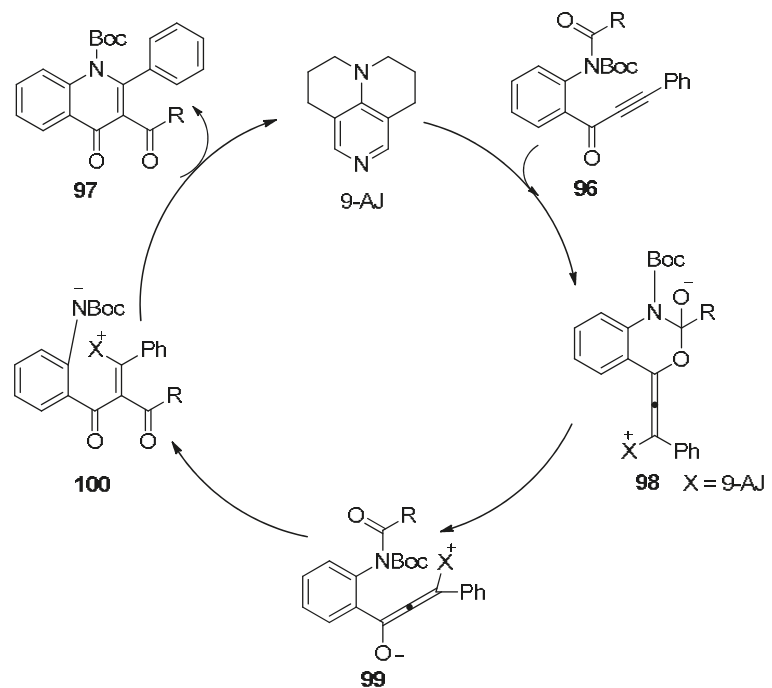

Scheme 31. Proposed mechanism for the 9-azajulolidine-catalyzed intramolecular amide addition to alkynes.

\section{Transition-Metal-Catalyzed Addition of Sulfonamide Bonds to Alkynes}

The group of Nakamura reported the first example of the addition of sulfonamides to alkynes in 2007. As shown in Scheme 32, ortho-alkynyl- $N$-sulfonylanilines 101 could undergo the intramolecular aminosulfonylation of carbon-carbon triple bonds successfully under the catalysis of $\mathrm{AuBr}_{3}$ to give the 3-sulfonylindoles 102 in good to high yields [45,46]. Although small amounts of 4- and 6-sulfonylindoles were obtained as the byproducts in some examples, this process provides a facile and efficient method for the synthesis of 3-sulfonylindoles, which cannot be synthesized directly from the corresponding unsubstituted indoles by electrophilic substitution because the electrophilicity of the 
sulfonyl groups is much lower than that of the acyl groups and halogens $[47,48]$. Interestingly, when 2-alkynyl-6-methoxy- $N$-sulfonylanilines 105 were employed as the substrates, this transformation could also occur under the catalysis of $\mathrm{InBr}_{3}$. However, the intramolecular aminosulfonylation products 106 were obtained as minor products, whereas 6-sulfonylindoles 107 were observed as the major products (Scheme 33). The reaction mechanism of this process may involve the initial coordination of the catalyst to the alkyne moiety, subsequent nucleophilic attack of the nitrogen atom to the carbon-carbon triple bond, the following migration of the sulfonyl group to the C3-position of the indole skeleton, and the final generation of the products with elimination of the catalyst (Scheme 34).

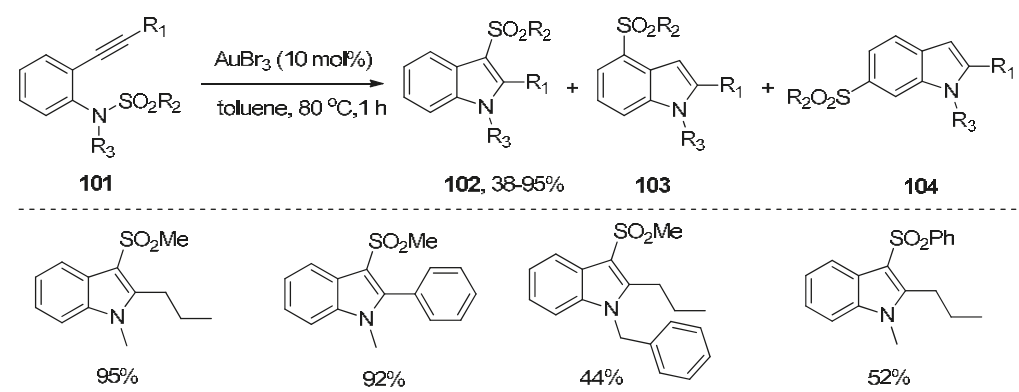

Scheme 32. $\mathrm{AuBr}_{3}$-catalyzed intramolecular aminosulfonylation of alkynes.

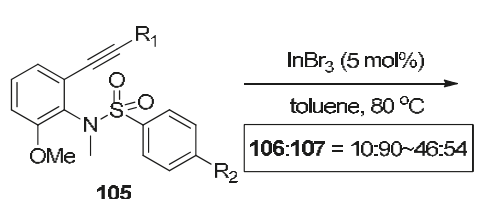

105

$\mathrm{R}_{1}=n \mathrm{Pr}, \mathrm{R}_{2}=\mathrm{Me}, 106 \mathrm{a}: 107 \mathrm{a}=13: 87,95 \%$

$\mathrm{R}_{1}=n \mathrm{Pr}, \mathrm{R}_{2}=\mathrm{MeO}, 106 \mathrm{~b}: 107 \mathrm{~b}=16: 84,99 \%$

$\mathrm{R}_{1}=n \mathrm{Pr}, \mathrm{R}_{2}=\mathrm{H}, 106 \mathrm{c}: 107 \mathrm{c}=22: 78,98 \%$

$\mathrm{R}_{1}=n \mathrm{Pr}, \mathrm{R}_{2}=\mathrm{NO}_{2}, 106 \mathrm{~d}: 107 \mathrm{~d}=34: 66,99 \%$

$R_{1}=$ cyclohexyl, $R_{2}=$ Me, 106e:107e $=13: 87,97 \%$<smiles>[R]c1ccc(S(=O)(=O)c2c([3H])n(C)c3c(OC)cccc23)cc1</smiles>

106 (minor)

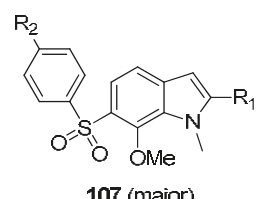

107 (major)

$R_{1}=P h, R_{2}=M e, 106 f: 107 f=10: 90,99 \%$

$\mathrm{R}_{1}=\rho-\mathrm{MeOC}_{6} \mathrm{H}_{4}, \mathrm{R}_{2}=\mathrm{Me}, 106 \mathrm{~g}: 107 \mathrm{~g}=15: 85,98 \%$

$\mathrm{R}_{1}=p-\mathrm{CF}_{3} \mathrm{C}_{6} \mathrm{H}_{4}, \mathrm{R}_{2}=\mathrm{Me}, 106 \mathrm{~h}: 107 \mathrm{~h}=17: 83,88 \%$

$R_{1}=H, R_{2}=M e, 106 i: 107 i=46: 54,73 \%$

Scheme 33. $\mathrm{InBr}_{3}$-catalyzed intramolecular aminosulfonylation of alkynes.

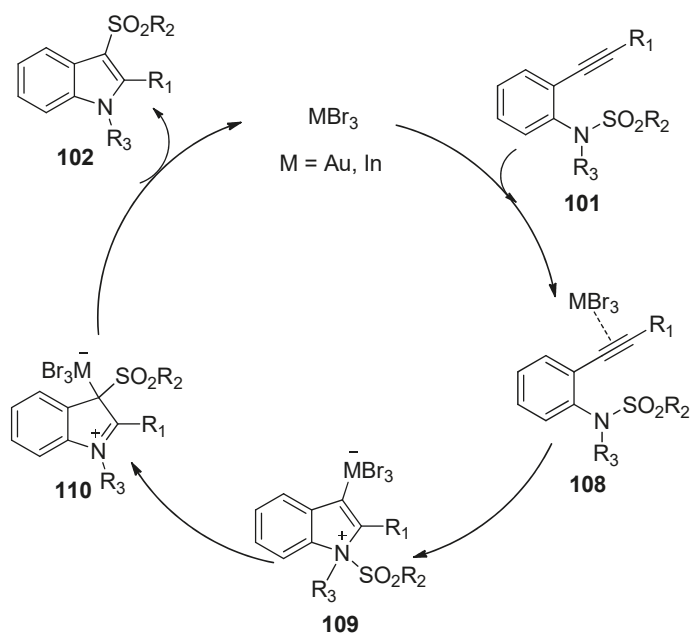

Scheme 34. Proposed mechanism for $\mathrm{AuBr}_{3} / \mathrm{InBr}_{3}$-catalyzed intramolecular aminosulfonylation of alkynes. 
Subsequently, Chan's group presented a gold-catalyzed domino aminocyclization/1,3-sulfonyl migration of $\mathrm{N}$-substituted $\mathrm{N}$-sulfonyl-aminobut-3-yn-2-ols 111 to synthesize highly functional pyrroles 112 (Scheme 35) [49]. A screening of gold catalysts disclosed that the NHC ( $\mathrm{N}$-heterocyclic carbene)-gold(I) complex $\mathbf{1 1 3}$ was found to be the most effective catalyst for this intramolecular aminosulfonylation of alkynes. It could catalyze the conversion of various substrates $\mathbf{1 1 1}$ carrying electron-withdrawing, electron-donating, and sterically demanding groups to the corresponding pyrroles $\mathbf{1 1 2}$ in moderate to high yields. It is worth noting that this method provides an efficient and convenient tool to prepare penta-substituted highly functional pyrroles. The mechanism of this transformation is outlined in Scheme 36. The coordination of gold cation to the alkyne moiety of the substrates gives intermediate 114, which undergoes a nucleophilic attack of the nitrogen atom to the alkynes to produce intermediate 115. At this juncture, dehydration of intermediate 115 yields cationic pyrrole-gold adduct 116, subsequent 1,3-sulfonyl migration of intermediate 116 then results in deauration with the regeneration of the gold catalyst and delivery of the products 112. Alternatively, intermediate 115 could undergo the deaurative 1,3-sulfonyl migration first to afford intermediate 117, which undergoes dehydrative aromatization to produce the products $\mathbf{1 1 2}$.
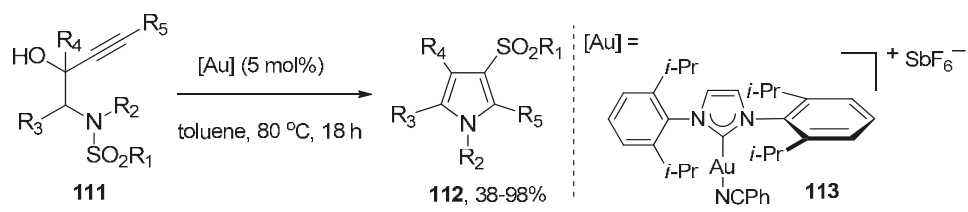

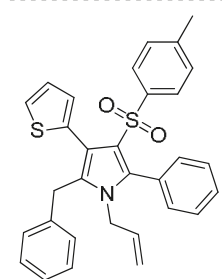

$52 \%$

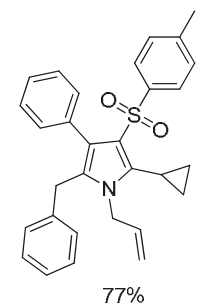

$77 \%$

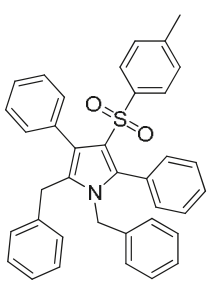

$60 \%$

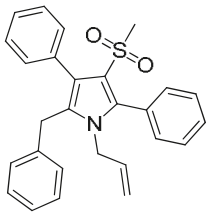

$43 \%$

Scheme 35. Gold-catalyzed intramolecular aminosulfonylation of $N$-substituted $N$-sulfonyl-aminobut3-yn-2-ols.
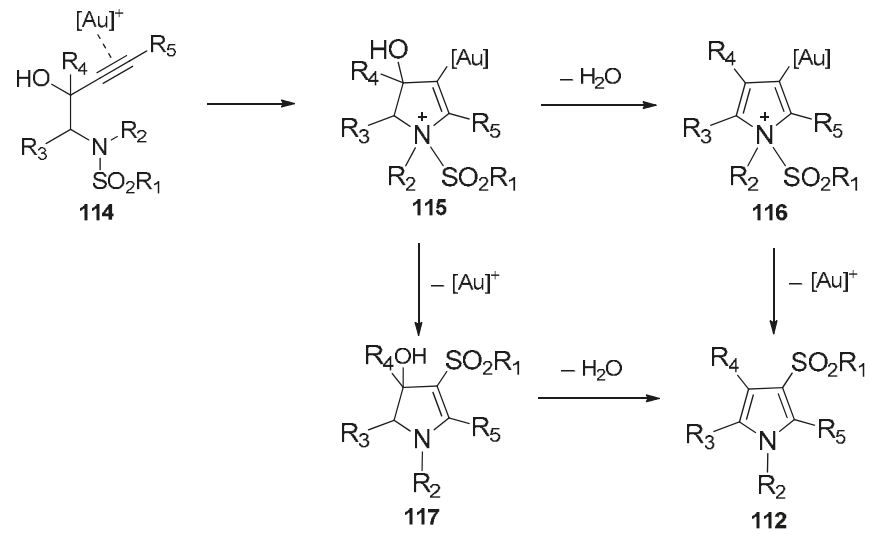

Scheme 36. Possible reaction mechanism for gold-catalyzed intramolecular aminosulfonylation of $\mathrm{N}$-substituted $\mathrm{N}$-sulfonyl-aminobut-3-yn-2-ols. 
Soon afterwards, Liu's group reported a more general and efficient intramolecular aminosulfonylation of alkynes to synthesize 3-sulfonylindoles 119 through palladium catalysis (Scheme 37) [35,50]. The reactions took place smoothly with $\mathrm{PdCl}_{2}\left(\mathrm{CH}_{3} \mathrm{CN}\right)_{2}$ in $\mathrm{CH}_{3} \mathrm{CN}$ at $90^{\circ} \mathrm{C}$ to afford 3-sulfonylindoles $\mathbf{1 1 9}$ as the single products without the generation of 4- and 6-sulfonylindole regioisomers, which were obtained as the byproducts in the gold- and indium-catalyzed process. In addition, this protocol features broad substrate scope, good functional group tolerance, and moderate to high yields, thus providing a practical access to functional 3-sulfonylindoles. A plausible mechanism, which is similar to gold- or indium-catalyzed aminosulfonylation of alkynes [45,46], was also proposed by the authors.

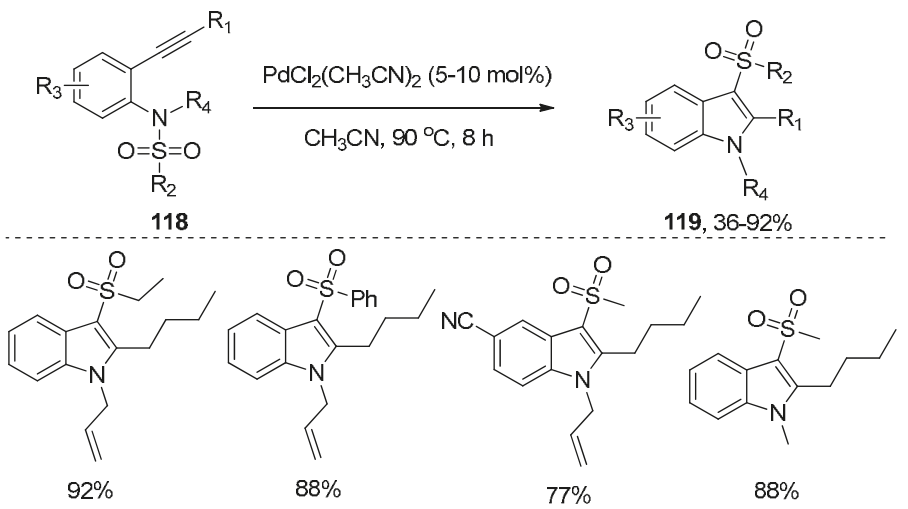

Scheme 37. $\mathrm{PdCl}_{2}\left(\mathrm{CH}_{3} \mathrm{CN}\right)_{2}$-catalyzed intramolecular aminosulfonylation of alkynes.

\section{Conclusions and Perspectives}

In this review, we presented a summary of the addition of amide/sulfonamide bonds to alkynes, which has emerged as a highly important tool to functionalize carbon-carbon triple bonds. The aminoacylation/aminosulfonylation of alkynes, which is characterized by high atom- and step-economy in an environmentally-friendly manner, has also become a remarkable method for the downstream transformations of amide/sulfonamides compounds. Notably, the intramolecular aminoacylation/aminosulfonylation of alkynes has provided a facile and efficient protocol for the synthesis of valuable heterocycles such as chromones, quinolinones, indoles, and pyrroles. Despite the remarkable achievements made, there are at least three areas where some critical advances are necessary to make the aminoacylation/aminosulfonylation of alkynes more general and powerful: (a) the intermolecular addition of unactivated amide/sulfonamide bonds to alkynes is still in high demand; (b) as the reported metal-catalyzed process employed expensive metals, the development of cheap metal catalysis as well as organocatalysis, will be a good direction to take; (c) the exploration of tandem reactions involving aminoacylation/aminosulfonylation of alkynes will continue to drive this field considering their efficiency and step-economy in constructing complex heterocyclic compounds.

Author Contributions: F.Z. wrote the manuscript; P.L. and X.L. collected the literature references; X.J. and J.W. drew the schemes and contributed to the editing; H.L. conceived this review and made major revisions and edits.

Funding: This research was funded by National Natural Science Foundation of China (grant 21602022, 81620108027 and 21632008), Sichuan Science and Technology Program (grant 2018JY0345) and Chengdu University New Faculty Start-up Funding (grant 2081915037).

Acknowledgments: F.Z. gratefully acknowledge the support from 1000 Talents Program of Sichuan Province and Chengdu Talents Program.

Conflicts of Interest: The authors declare no conflict of interest. 


\section{References}

1. Irvine, G.J.; Lesley, M.J.G.; Marder, T.B.; Norman, N.C.; Rice, C.R.; Robins, E.G.; Roper, W.R.; Whittell, G.R.; Wright, L.J. Transition metal-boryl compounds: Synthesis, reactivity, and structure. Chem. Rev. 1998, 98, 2685-2722. [CrossRef] [PubMed]

2. Marder, T.B.; Norman, N.C. Transition metal catalysed diboration. Top. Catal. 1998, 5, 63-73. [CrossRef]

3. Han, L.B.; Tanaka, M. Transition metal-catalysed addition reactions of $H$-heteroatom and inter-heteroatom bonds to carbon-carbon unsaturated linkages via oxidative additions. Chem. Commun. 1999, 395-402. [CrossRef]

4. Beletskaya, I. Element-element addition to alkynes catalyzed by the group 10 metals. Chem. Rev. 1999, 99, 3435-3461. [CrossRef] [PubMed]

5. Suginome, M.; Ito, Y. Transition-metal-catalyzed additions of silicon-silicon and silicon-heteroatom bonds to unsaturated organic molecules. Chem. Rev. 2000, 100, 3221-3256. [CrossRef] [PubMed]

6. Ishiyama, T.; Miyaura, N. Chemistry of group 13 element-transition metal linkage-The platinum- and palladium-catalyzed reactions of (alkoxo)diborons. J. Organomet. Chem. 2000, 611, 392-402. [CrossRef]

7. Suginome, M.; Ito, Y. Stereoselective accesses to enantioenriched allyl-, allenyl-, and propargyl-silanes via Si-Si bond activation by palladium-isocyanide catalysts. J. Organomet. Chem. 2003, 685, 218-229. [CrossRef]

8. Dembitsky, V.M.; Ali, H.A.; Srebnik, M. Recent developments in bisdiborane chemistry: B-C-B, B-C-C-B, B-C $=\mathrm{C}-\mathrm{B}$ and B-C $\equiv \mathrm{C}-\mathrm{B}$ compounds. Appl. Organomet. Chem. 2003, 17, 327-345. [CrossRef]

9. Ishiyama, T.; Miyaura, N. Metal-catalyzed reactions of diborons for synthesis of organoboron compounds. Chem. Rec. 2004, 3, 271-280. [CrossRef]

10. Beletskaya, I. Element-element additions to unsaturated carbon-carbon bonds catalyzed by transition metal complexes. Chem. Rev. 2006, 106, 2320-2354. [CrossRef]

11. Shimizu, M.; Hiyama, T. Polyborylated reagents for modern organic synthesis. Proc. Jpn. Acad. Ser. B 2008, 84, 75-85. [CrossRef]

12. Miyaura, N. Metal-catalyzed reactions of organoboronic acids and esters. Bull. Chem. Soc. Jpn. 2008, 81, 1535-1553. [CrossRef]

13. Takaya, J.; Iwasawa, N. Catalytic, direct synthesis of bis(boronate) compounds. ACS Catal. 2012, 2, $1993-2006$. [CrossRef]

14. Zhao, F.; Jia, X.; Wang, D.; Fei, C.; Wu, C.; Wang, J.; Liu, H. Research progress in metal-catalyzed addition of carbon-hetero bonds to alkynes. Chin. J. Org. Chem. 2017, 37, 284-300. [CrossRef]

15. Zhao, F.; Jia, X.; Li, P.; Zhao, J.; Zhou, Y.; Wang, J.; Liu, H. Catalytic and catalyst-free diboration of alkynes. Org. Chem. Front. 2017, 4, 2235-2255. [CrossRef]

16. Miyabe, H. Transition-metal-free activation of amide bond by arynes. Molecules 2018, 23, 2145. [CrossRef] [PubMed]

17. Fosgerau, K.; Hoffmann, T. Peptide therapeutics: Current status and future directions. Drug Discov. Today 2015, 20, 122-128. [CrossRef] [PubMed]

18. Lau, J.L.; Dunn, M.K. Therapeutic peptides: Historical perspectives, current development trends, and future directions. Bioorg. Med. Chem. 2018, 26, 2700-2707. [CrossRef]

19. Henninot, A.; Collins, J.C.; Nuss, J.M. The current state of peptide drug discovery: Back to the future? J. Med. Chem. 2018, 61, 1382-1414. [CrossRef]

20. Eğe, S.N.; Carter, M.L.C.; Spencer, R.L.; Nordman, C.E.; Friedman, H.Z. Formation and acid-catalyzed rearrangement of 1,2-diazepin-5-ones. J. Chem. Soc. Perkin Trans. 1976, 1, 868-876. [CrossRef]

21. Turk, C.; Svete, J.; Stanovnik, B.; Golič, L.; Golobič, A.; Selič, L. Unusual reactions of 5,5-dimethyl-2(indenyl-2)-3-pyrazolidinone with acetylenedicarboxylates. Org. Lett. 2000, 2, 423-424. [CrossRef] [PubMed]

22. Hanack, M.; Wilhelrn, B. Addition of carboxamides to alkynyl trifluoromethyl sulfones. Angezw. Chem. Int. Ed. Engl. 1989, 28, 1057-1059. [CrossRef]

23. Knölker, H.J.; El-Ahl, A.A. Imidazole derivatives, part VIII. Stereoselective formation of 1-[(E) 3-(1-imidazolyl)-2-alkenoyl]imidazoles. Heterocycles 1993, 36, 1381-1385. [CrossRef]

24. Suzuki, K.; Ohkuma, T.; Tsuchihashi, G. Preparation of enaminones by two-carbon homologation of amides with lithium (triphenylsilyl)acetylide. J. Org. Chem. 1987, 52, 2930-2932. [CrossRef]

25. Jeong, I.H.; Jeon, S.L.; Min, Y.K.; Kim, B.T. A novel approach to $\beta$-trifluoromethyl enaminones. Tetrahedron Lett. 2002, 43, 7171-7174. [CrossRef] 
26. Jeong, I.H.; Jeon, S.L.; Kim, M.S.; Kim, B.T. New approaches to $\beta$-trifluoromethylated enone derivatives. J. Fluorine Chem. 2004, 125, 1629-1638. [CrossRef]

27. Jeon, S.L.; Kim, J.K.; Son, J.B.; Kim, B.T.; Jeong, I.H. One pot synthesis of novel $\alpha, \beta$-dichloro$\beta$-trifluoromethylated enones and their application to the synthesis of trifluoromethylated heterocycles. J. Fluorine Chem. 2007, 128, 153-157. [CrossRef]

28. Persson, T.; Nielsen, J. Synthesis of $N$-methoxy- $N$-methyl- $\beta$-enaminoketoesters: New synthetic precursors for the regioselective synthesis of heterocyclic compounds. Org. Lett. 2006, 8, 3129-3222. [CrossRef]

29. Choudhury, A.; Breslav, M.; Grimm, J.S.; Xiao, T.; Xu, D.; Sorgi, K.L. A facile one-pot synthesis of acyclic $\beta$-enamino ketones, an important class of versatile synthetic intermediates. Tetrahedron Lett. 2007, 48, 3069-3072. [CrossRef]

30. Zheng, Z.; Wang, Y.; Xu, M.; Kong, L.; Wang, M.; Li, Y. Transition-metal-free insertion reactions of alkynes into the C-N r-bonds of imides: Synthesis of substituted enamides or chromones. Chem. Commun. 2018, 54, 6192-6195. [CrossRef]

31. Zheng, Z.; Tao, Q.; Ao, Y.; Xu, M.; Li, Y. Transition-metal-free aminoacylation of ynones with amides: Synthesis of 3-carbonyl-4-quinolinones or functionalized enaminones. Org. Lett. 2018, 20, 3907-3910. [CrossRef]

32. Shimada, T.; Nakamura, I.; Yamamoto, Y. Intramolecular C-N bond addition of amides to alkynes using platinum catalyst. J. Am. Chem. Soc. 2004, 126, 10546-10547. [CrossRef]

33. Nakamura, I.; Sato, Y.; Konta, S.; Terada, M. Platinum-catalyzed consecutive C-N bond formation-[1,3] shift of carbamoyl and ester groups. Tetrahedron Lett. 2009, 50, 2075-2077. [CrossRef]

34. Nakamura, I.; Mizushima, Y.; Yamagishi, U.; Yamamoto, Y. Synthesis of 2,3-disubstituted benzofurans and indoles by $\pi$-Lewis acidic transition metal-catalyzed cyclization of ortho-alkynylphenyl $\mathrm{O}, \mathrm{O}$ - and $\mathrm{N}, \mathrm{O}$-acetals. Tetrahedron 2007, 63, 8670-8676. [CrossRef]

35. Zhao, F.; Zhang, D.; Nian, Y.; Zhang, L.; Yang, W.; Liu, H. Palladium-catalyzed difunctionalization of alkynes via C-N and S-N cleavages: A versatile approach to highly functional indoles. Org. Lett. 2014, 16, 5124-5127. [CrossRef] [PubMed]

36. Wu, C.; Zhao, F.; Shu, S.; Wang, J.; Liu, H. Palladium-catalyzed intramolecular addition of C-N bond to alkynes: A novel approach to 3-diketoindoles. RSC Adv. 2015, 5, 90396-90399. [CrossRef]

37. Okauchi, T.; Itonaga, M.; Minami, T.; Owa, T.; Kitoh, K.; Yoshino, H. A general method for acylation of indoles at the 3-position with acyl chlorides in the presence of dialkylaluminum chloride. Org. Lett. 2000, 2, 1485-1487. [CrossRef] [PubMed]

38. Merkul, E.; Dohe, J.; Gers, C.; Rominger, F.; Müller, T.J.J. Three-component synthesis of ynediones by a Glyoxylation/Stephens-Castro coupling sequence. Angew. Chem. Int. Ed. 2011, 50, 2966-2969. [CrossRef]

39. Wu, J.C.; Song, R.J.; Wang, Z.Q.; Huang, X.C.; Xie, Y.X.; Li, J.H. Copper-catalyzed C-H oxidation/cross-coupling of $\alpha$-amino carbonyl compounds. Angew. Chem. Int. Ed. 2012, 51, 3453-3457. [CrossRef]

40. Tang, R.Y.; Guo, X.K.; Xiang, J.N.; Li, J.H. Palladium-catalyzed synthesis of 3-acylated indoles involving oxidative cross-coupling of indoles with $\alpha$-amino carbonyl compounds. J. Org. Chem. 2013, 78, 11163-11171. [CrossRef]

41. Gao, Q.; Zhang, J.; Wu, X.; Liu, S.; Wu, A. Direct regioselective oxidative cross-coupling of indoles with methyl ketones: A novel route to C3-dicarbonylation of indoles. Org. Lett. 2015, 17, 134-137. [CrossRef] [PubMed]

42. Wu, C.Y.; Hu, M.; Liu, Y.; Song, R.J; Lei, Y.; Tang, B.X.; Li, R.J.; Li, J.H. Ruthenium-catalyzed annulation of alkynes with amides via formyl translocation. Chem. Commun. 2012, 48, 3197-3199. [CrossRef] [PubMed]

43. Weiss, R.; Bess, M.; Huber, S.M.; Heinemann, F.W. Nucleophilic $\beta$-Oniovinylation: Concept, mechanism, scope, and applications. J. Am. Chem. Soc. 2008, 130, 4610-4617. [CrossRef] [PubMed]

44. Saito, K.; Yoshida, M.; Uekusa, H.; Doi, T. Facile synthesis of pyrrolyl 4-quinolinone alkaloid quinolactacide by 9-AJ-catalyzed tandem acyl transfer-cyclization of o-alkynoylaniline derivatives. ACS Omega. 2017, 2, 4370-4381. [CrossRef]

45. Nakamura, I.; Yamagishi, U.; Song, D.; Konta, S.; Yamamoto, Y. Gold- and indium-catalyzed synthesis of 3- and 6-sulfonylindoles from ortho-alkynyl-N-sulfonylanilines. Angew. Chem. Int. Ed. 2007, 46, 2284-2287. [CrossRef] [PubMed] 
46. Nakamura, I.; Yamagishi, U.; Song, D.; Konta, S.; Yamamoto, Y. Synthesis of 3- and 6-sulfonylindoles from ortho-alkynyl- $N$-sulfonylanilines by the use of Lewis acidic transition-metal catalysts. Chem. Asian J. 2008, 3 , 285-295. [CrossRef] [PubMed]

47. Williams, T.M.; Ciccarone, T.M.; MacTough, S.C.; Rooney, C.S.; Balani, S.K.; Condra, J.H.; Emini, E.A.; Goldman, M.E.; Greenlee, W.J.; Kauffman, L.R.; et al. 5-Chloro-3-(phenylsulfonyl)indole-2-carboxamide: A novel, non-nucleoside inhibitor of HIV-1 reverse transcriptase. J. Med. Chem. 1993, 36, 1291-1294. [CrossRef]

48. Silvestri, R.; Martino, G.D.; Regina, G.L.; Artico, M.; Massa, S.; Vargiu, L.; Mura, M.; Loi, A.G.; Marceddu, T.; Colla, P.L. Novel Indolyl Aryl Sulfones Active against HIV-1 Carrying NNRTI Resistance Mutations: Synthesis and SAR Studies. J. Med. Chem. 2003, 46, 2482-2493. [CrossRef]

49. Teo, W.T.; Rao, W.; Koh, M.J.; Chan, P.W.H. Gold-catalyzed domino aminocyclization/1,3-sulfonyl migration of $\mathrm{N}$-substituted $\mathrm{N}$-sulfonyl-aminobut-3-yn-2-ols to 1-substituted 3-sulfonyl-1H-pyrroles. J. Org. Chem. 2013, 78, 7508-7517. [CrossRef]

50. Wu, C.; Zhao, F.; Du, Y.; Zhao, L.; Chen, L.; Wang, J.; Liu, H. Highly selective intramolecular addition of C-N and S-N bonds to alkynes catalyzed by palladium: A practical access to two distinct functional indoles. RSC Adv. 2016, 6, 70682-70690. [CrossRef]

(C) 2019 by the authors. Licensee MDPI, Basel, Switzerland. This article is an open access article distributed under the terms and conditions of the Creative Commons Attribution (CC BY) license (http:/ / creativecommons.org/licenses/by/4.0/). 


\title{
Amide Activation in Ground and Excited States
}

\author{
Ervin Kovács ${ }^{1}$, Balázs Rózsa ${ }^{2}$, Attila Csomos ${ }^{3}$, Imre G. Csizmadia ${ }^{4}$ and Zoltán Mucsi ${ }^{4,5, *}$ \\ 1 Institute of Materials and Environmental Chemistry, Research Centre for Natural Sciences, \\ Hungarian Academy of Sciences, Budapest H-1117, Hungary; kovacs.ervin@ttk.mta.hu \\ 2 Laboratory of 3D Functional Imaging of Neuronal Networks and Dendritic Integration, Institute of \\ Experimental Medicine, Hungarian Academy of Sciences, Budapest H-1083, Hungary; rozsabal@koki.hu \\ 3 Institute of Chemistry, Eötvös University, Budapest H-1117, Hungary; csomosattila@caesar.elte.hu \\ 4 Department of Chemistry, University of Toronto, Toronto, ON M5S 3H6, Canada; icsizmad@hotmail.com \\ 5 Department of Chemistry, Femtonics Inc., Budapest H-1094, Hungary \\ * Correspondence: zoltanmucsi@gmail.com or zmucsi@femtonics.eu; Tel.: +36-20-441-6971
}

Academic Editor: Michal Szostak

Received: 4 October 2018; Accepted: 31 October 2018; Published: 2 November 2018

\begin{abstract}
Not all amide bonds are created equally. The purpose of the present paper is the reinterpretation of the amide group by means of two concepts: amidicity and carbonylicity. These concepts are meant to provide a new viewpoint in defining the stability and reactivity of amides. With the help of simple quantum-chemical calculations, practicing chemists can easily predict the outcome of a desired process. The main benefit of the concepts is their simplicity. They provide intuitive, but quasi-thermodynamic data, making them a practical rule of thumb for routine use. In the current paper we demonstrate the performance of our methods to describe the chemical character of an amide bond strength and the way of its activation methods. Examples include transamidation, acyl transfer and amide reductions. Also, the method is highly capable for simple interpretation of mechanisms for biological processes, such as protein splicing and drug mechanisms. Finally, we demonstrate how these methods can provide information about photo-activation of amides, through the examples of two caged neurotransmitter derivatives.
\end{abstract}

Keywords: amide; activation; amidicity; carbonylicity; transamidation; acyl transfer; excited state

\section{Introduction}

The amide functional group is one of the most generally used moieties both in synthetic organic chemistry and bioorganic chemistry [1-5]. They have been known and studied for more than a century and can be commonly found in peptides/proteins and biologically active compounds, as well as in a broad range of synthetic drugs and toxins as a key functionality [1,6-9]. In general, when speaking of amides, the idea of a stable, unreactive group comes in our minds, however, they can play a significant role as reactants in a vast number of processes.

The wide variability in their reactivity can be attributed to the possibility of fine-tuning the bond strength. This can be controlled by attached substituent groups at the carbon and nitrogen atoms. The correlation between poor reactivity and planarity $[10,11]$ of amides was proposed firstly by Pauling and later it was understood as being a result of the strength of the resonance-stabilized amide $\mathrm{C}-\mathrm{N}$ bond [12]. Pauling predicted that a typical planar amide exhibits approximately $40 \%$ partial double-bond character, which renders the amide bond one of the most solid and least reactive functional groups (Figure 1) $[13,14]$. For example, the conjugation of an amide bond, which is traditionally specified as $\mathrm{n}(\mathrm{N}) \rightarrow \pi^{*}(\mathrm{C}=\mathrm{O})$, in formamide results in resonance energy (RE) of $91.29 \mathrm{kcal} \mathrm{mol}^{-1}[15,16]$. In contrast to that, embedding the amide bond into a rigid bicyclic frame with nitrogen at the ring fusion, significantly modifies the degree of the resonance, therefore increasing the instability of the strained amide bond, for example in $\beta$-lactam antibiotics [17-19]. More intense conjugation implies a 
larger contribution of resonance stabilization, which increases the system stability thus lowering the reactivity and vice versa. In other words, the extent of conjugation predetermines chemical reactivity of the amides [20].

Amides can readily be cleaved by enzymes such as protease $[15,16]$, but synthetically it is difficult to selectively break the carbon-nitrogen bond [21-31]. How can nature solve a problem easily, that is so hard for us? The answer is hidden in the process of activation of the unreactive group.

Organic chemists and "Nature" have developed methods to activate stable amide bonds, to make possible various reactions. Numerous examples of these can be found in the field of synthetic organic chemistry and biochemistry. The amide activation is typically based on the lowering of the amidic character by forcing the amide group to lose its conjugation. This can be achieved by substituent groups, as well as by forcing them into an inflexible structure. Moreover, as Thakkar et al. have described, the presence of the cis or trans isomer in the planar character of the amide bond in stable geometries can also influence the overall reactivity [32]. In connection with special chromophores, amide bonds can also be activated under excitation, as was demonstrated in some earlier studies [33-35]. Some of these processes include amidation, transamidation, reduction, coupling reactions by transition metallic complexes, and spontaneous or enzymatic hydrolysis.

The aim of our paper is to characterize the activity of amides using the amidicity and carbonylicity concepts and to demonstrate possibilities to increase or decrease their activity based on the bond strength [14]. In this work, using quantum chemical computation by using Gaussian 09 [36] at B3LYP / 6-31G(d,p) level of theory [37], we reevaluated the data reported in the literature for reactivity of amide bonds. Here we reinterpreted some selected well-known compounds and reactions using the simple rule of amidicity, which can estimate the direction and rate of similar reactions involving more complex reactants.

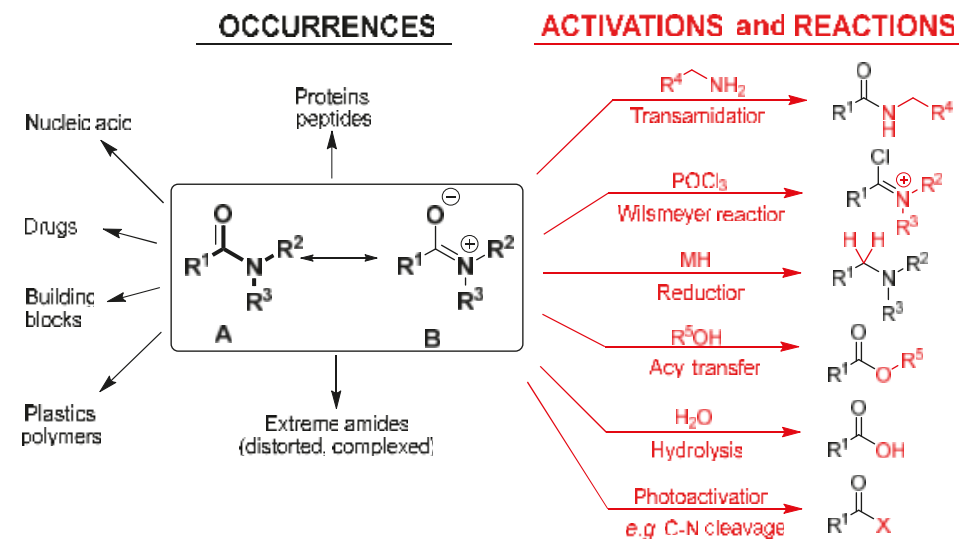

Figure 1. Contributing resonance structures of an amide bond (in the box). The occurrences (left) of the amide functionality and their typical reactions (right).

\section{Discussion}

The amide group can be described generally by its resonance structures (A and B in Figure 1), where the nitrogen lone electron pair is delocalized between the nitrogen and the neighboring carbonyl. The condition of this phenomenon is a planar structure of the amide group. For the resonance structure B (Figure 1), the nucleophilic attack to the group is far less possible, thus making a general amide a resistant and unreactive group. The chemical and biochemical stability and reactivity is determined by the contribution of the minor resonance structure (B in Figure 1), in which formally a double bond is formed between the carbon and nitrogen atoms. These characteristics can be represented on a wide spectrum. 
Earlier, the strength of a given amide bond was successfully characterized and the reactivity of different amides was made comparable to each other by creating the so called linear "amidicity scale" (Figure 2B) [27]. Analogously, a linear "carbonylicity scale" (Figure 2A) was also constructed, extending the group of amides toward the entire world of carbonyl compounds, making all of them comparable [20]. Other methods, such as carbonyl substitution nitrogen atom replacement $[6,38,39]$ and transamidation (TA) [14] which also aim to measure the amide stabilization energy, were also published in the literature. Using this scale, we are able not only to explain the reactivity of the amide bond, but also predict the effect of different substituents on the bond strength. Predicting amide bond strength effectively gives us the opportunity to activate or reactivate the desired amide bond. Manipulating the amidicity of a selected amide of a molecule has numerous synthetic applications. Also, calculating the amidicity—in other words, estimating the activity of the amide bond in biochemical compounds-may clarify the mechanism of action in which they are involved.

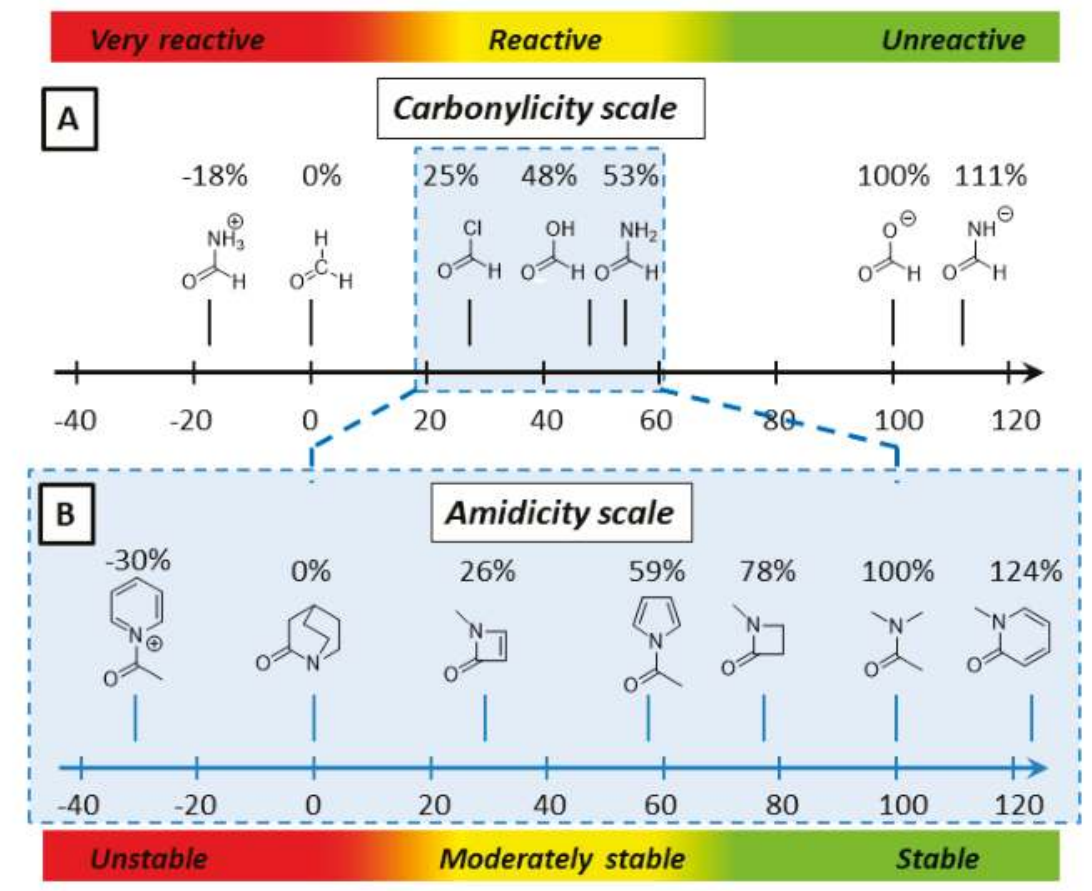

Figure 2. Typical carbonyl and amide compounds represented on the carbonylicity (A) and amidicity (B) scales. The direction of reactivity and stability increase are shown by red and green strips, respectively.

\subsection{Amidicity Scale $(A M \%)$ and Carbonylicity Scale $(C A \%)$ and Their Resonance Enthalpies $\left(H_{R E}\right)$}

The "amidicity scale" [27] quantifies the amide bond strength on a linear scale (Figure 3A), based on the computed enthalpy of hydrogenation $\left(\Delta \mathrm{H}_{\mathrm{H} 2}\right)$ of the examined compound. A few examples positioned on the scale demonstrate the wide variety of amides. The scale is based on two specifically chosen reference compounds: A1 and B1 (Figure 3A). Compound aza-adamantane-2-on (A1 in Figure 3A) represents the lack of amidic charater, while dimethylacetamide (B1 in Figure 3A) corresponds to the perfect amide bond. In the structure of A1, the planar geometry is missing, due to the forced arrangement of the bridged $\mathrm{N}$ atom. To create the amidicity scale (AM\%), the enthalpy of hydrogenation $\left(\mathrm{H}_{\mathrm{H} 2}\right)$ of compounds $\mathrm{A} 1$ and $\mathrm{B} 1$ was calculated Equations (1) and (2) and amidicity was defined using a linear fit to these points. The enthalpy of hydrogenation for $\mathrm{A} 1\left(\Delta \mathrm{H}_{\mathrm{H} 2}[\mathrm{~A}]\right)$ 
is considered to have a $0 \% \mathrm{AM} \%$ value, while that for $\mathrm{B} 1\left(\Delta \mathrm{H}_{\mathrm{H} 2}[\mathrm{~B}]\right)$ is considered to have a $100 \%$ $\mathrm{AM} \%$ value.

$$
\begin{gathered}
\Delta H_{H 2}[\mathrm{~A}]=H[\mathrm{~A} 2]-\left\{H[\mathrm{~A} 1]+H\left[\mathrm{H}_{2}\right]\right\}=-44.62 \mathrm{~kJ} \mathrm{~mol}^{-1} \\
\Delta H_{H 2}[\mathrm{~B}]=H[\mathrm{~B} 2]-\left\{H[\mathrm{~B} 1]+H\left(\mathrm{H}_{2}\right)\right\}=34.88 \mathrm{~kJ} \mathrm{~mol}^{-1}
\end{gathered}
$$

As specified before, the carbonylicity scale (CA\%) [20] quantifies the conjugation of the carbonyl group on a linear scale (Figure 3B), based on computed enthalpy of hydrogenation $\left(\Delta \mathrm{H}_{\mathrm{H} 2}\right)$ of the examined carbonyl group (Equations (3) and (4)). Analogously to amidicity, the carbonylicity scale is also based on two specifically chosen reference compounds, $\mathrm{C} 1$ (formaldehyde; CA $\%=0 \%$ ) and D1 (formate; $C A \%=100 \%$ ) and defined using a linear fit to these points. Also, note that the amidicity scale is a defined section of the carbonylicity scale as it is represented on Figure 2, and differs only in the reference compunds chosen.
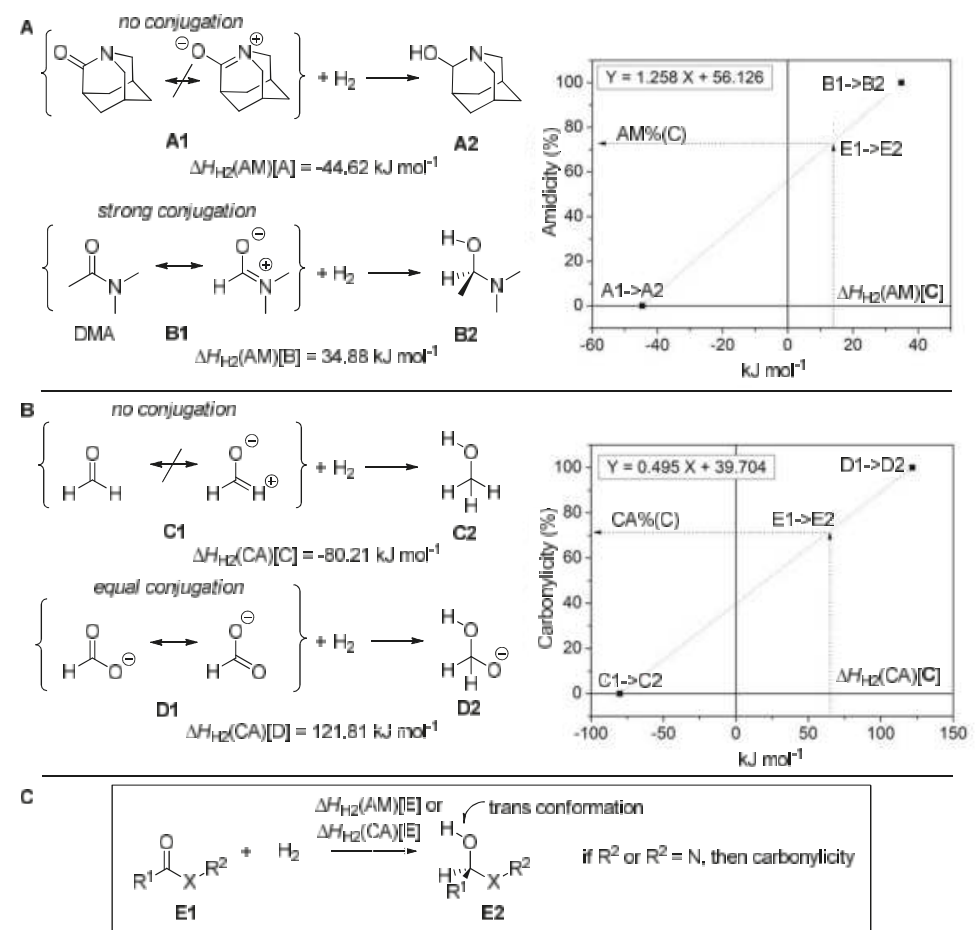

Figure 3. The definition of the amidicity (A) and carbonylicity (B) percentage based on the enthalpy of hydrogenation $\left(\Delta \mathrm{H}_{\mathrm{H} 2}\right)$ of the carbonyl group of a general carbonyl compound E1 (C). The two specifically chosen reference structures and their hydrogenation are also illustrated as A1 and B1 for amidicity (AM\%; top) as well as $\mathrm{C} 1$ and D1 for carbonylicity (CA\%; bottom). Values were obtained from the B3LYP/6-31G $(\mathrm{d}, \mathrm{p})$ geometry-optimized structures. In structure $\mathrm{E} 2$, the $\mathrm{O}-\mathrm{C}-\mathrm{X}-\mathrm{R}_{2}$ and the $\mathrm{H}-\mathrm{O}-\mathrm{C}-\mathrm{X}$ dihedral angles are chosen to be in the anti orientation.

$$
\begin{aligned}
& \Delta H_{\mathrm{H} 2}[\mathrm{C}]=H[\mathrm{C} 2]-\left\{H[\mathrm{C} 1]+H\left(\mathrm{H}_{2}\right)\right\}=-80.21 \mathrm{~kJ} \mathrm{~mol}^{-1} \\
& \Delta H_{\mathrm{H} 2}[\mathrm{D}]=H[\mathrm{D} 2]-\left\{H[\mathrm{D} 1]+H\left(\mathrm{H}_{2}\right)\right\}=121.81 \mathrm{~kJ} \mathrm{~mol}^{-1}
\end{aligned}
$$

The linear fits are described by two pairs of fitting parameters, the slope $\left(\mathrm{m}_{\mathrm{AM}}\right.$ and $\left.\mathrm{m}_{\mathrm{CA}}\right)$ and the intercept $\left(\mathrm{b}_{\mathrm{AM}}\right.$ and $\left.\mathrm{b}_{\mathrm{CA}}\right)$. The values (AM\% and $\mathrm{CA} \%$ ) for a desired amide or carbonyl bond can be easily calculated with the help of Equations (6) and (8), for a known enthalpy of hydrogenation, $\Delta \mathrm{H}_{\mathrm{H} 2}$, 
from Equation (5). Both the amidicity and carbonylicity values can be transformed to the resonance enthalpy $\left(\mathrm{H}_{\mathrm{RE}}\right.$ [E]; Equations (7) and (9)), which helps to estimate the energy benefit coming from the resonance inside the group. Neither of these scales is limited to values between $0 \%$ and $100 \%$; in extreme cases the bond is weaker than $\mathrm{A} 1$ or $\mathrm{C} 1$ and stronger than $\mathrm{B} 1$ or D1, so they may display values outside of the aformentioned range. The amidicity scale can be considered as a sub-section of the carbonylicity scale.

$$
\begin{gathered}
\Delta H_{\mathrm{H} 2}[\mathrm{E}]=H[\mathrm{E} 2]-\left\{H[\mathrm{E} 1]+H\left(\mathrm{H}_{2}\right)\right\} \\
A M \%[\mathrm{E}]=m_{\mathrm{AM}} \Delta H_{\mathrm{H} 2}[\mathrm{E}]+b_{\mathrm{AM}} \\
H_{\mathrm{RE}}[\mathrm{E}]=A M \% / m_{\mathrm{AM}} \\
C A \%[\mathrm{E}]=m_{\mathrm{CA}} \Delta H_{\mathrm{H} 2}[\mathrm{E}]+b_{\mathrm{CA}} \\
H_{\mathrm{RE}}[\mathrm{E}]=C A \% / m_{\mathrm{CA}}
\end{gathered}
$$

\subsection{Transamidation and Transacylation Reactions in Synthetic Organic Chemistry}

The amidicity value is useful to predict the outcome of a general transamidation reaction (Figure 4, top). The amidicity change $\Delta \mathrm{AM}$ in Equation (10) or the change in stabilization enthalpy $\left(\Delta \mathrm{H}_{\mathrm{RE}}\right.$ in Equation 12) leads to a thermodynamic selection rule, allowing for the reactions to be categorized as being either thermodynamically favorable or unfavorable. Generally, $\Delta \mathrm{H}_{\mathrm{RE}}$ is proportional with the entalpy change of the transamidation reaction. The lower the amidicity value of the chosen group, the greater reactivity it has towards nucleophylic reagents, like amines. The direction of the transamidation reactions can be predicted by comparing the sum of amidicities on the product and reactant sides. If the amidicity value increases, the reaction is energetically favoured in the given direction. If the difference is a negative value, the reaction is not driven forward. If there are different possible reaction routes, the one with the greater increase in amidicity is favored. The amidicity value is also capable of predicting the most active amide group in a molecule. Such a thermodynamic selection rule may also be used to predict the selectivity of a reaction in the presence of competing amide functionalities. This principle is illustrated as being operative in cases of different reactions. However, it should be mentioned that reactions may have several other parameters that determine if a reaction can proceed or not, such as steric hinderance, kinetic consequences, side reactions and the role of the leaving group on the acyl group. These amidicity and carbonylicity values describe only the thermodynamic background and not the kinetic aspect of a reaction.

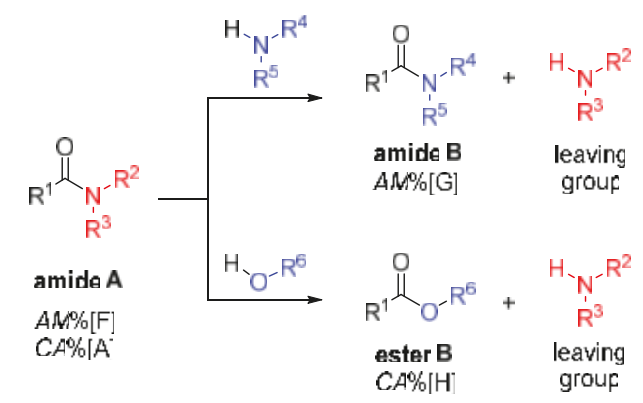

Figure 4. General transamidation reaction and the amidicity (AM\%) and carbonylicity (CA\%) percentages of the amides examined.

$$
\begin{gathered}
\Delta A M=A M \%[\mathrm{G}]-A M \%[\mathrm{~F}] \\
\Delta C A=C A \%[\mathrm{H}]-C A \%[\mathrm{~F}] \\
\Delta H_{\mathrm{TA}} \approx \Delta H_{\mathrm{RE}}=H_{\mathrm{RE}}[\mathrm{B}]-H_{\mathrm{RE}}[\mathrm{A}]
\end{gathered}
$$


On the basis of the exploratory screening of the literature, four cases were defined (Figure 5) [40]. Cases I and II (one-step processes) are both thermodynamically favored yet differ in reaction barrier height. Reaction barriers in case I are low [41], while those of case II are high, with the latter requiring a suitably chosen Lewis acid catalyst $\left(\mathrm{AlCl}_{3}, \mathrm{BF}_{3}, \mathrm{TiCl}_{4}, \mathrm{HCl}\right.$, etc. $)$ to proceed normally [42,43]. This amine exchange reaction is sometimes carried out in a closed autoclave at high temperature by using the salt of the amine in the presence of $\mathrm{BF}_{3}$ [44], often to convert simple urea to a substituted one. In contrast to that, both cases of III and IV (two-step processes) are thermodynamically unfavorable, requiring the activation of either the reacting amide (case III) or the reacting amine. In case III, the amide is effectively destabilized, so activated by nitrosation, nitration, or acylation step [ $\mathrm{N}$-activation by activating group (AG), case III, Figure 5]. This activation is manifested as an increase in the energy level of the starting state, wherein the activated amide intermediate provides a thermodynamically favorable and rapid transamidation process.

In case IV ( $N$-deprotonation), a theoretically thermodynamically unfavorable transamidation, which may proceed in the presence of a strong base ( $\mathrm{NaH}$ or $\mathrm{NaOR}$ ). The product monosubstituted amide forms and stays in its deprotonated form $\left(-\mathrm{CO}-\mathrm{NHR}^{4}\right)$ and the starting amide is disubstituted non-deprotanable (-CO-NR ${ }^{1} \mathrm{R}^{2}$, amide). Therein, the forming amide-anion intermediate is stabilized by the deprotonation. In this case, an originally thermodynamically unfavorable transamidation process involves a thermodynamically favorable reversible subprocess, which finally finishes irreversibly by protonation in the acidic work-up.

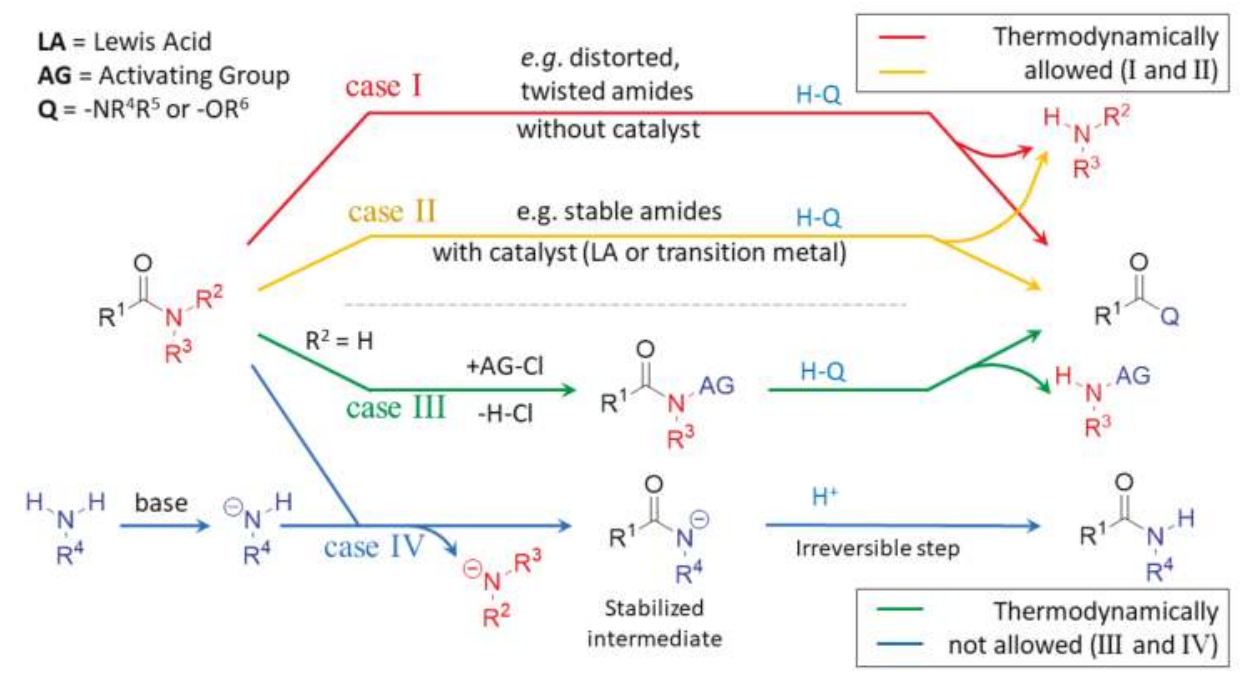

Figure 5. The classification of the acyl transfer and transamidation reactions into four cases (case I, II, III and IV), interpreted by amidicity (AM\%) and carbonylicity (CA\%) values.

2.2.1. Examples of the Thermodynamically Allowed Transamidation Reactions (case I and II)

Transamidation Processes of Simple Amide Compounds

In order to illustrate the essence of the transamidation reaction, we are demonstrating this concept by simple amides and amines. Unsubstituted amides, such as $\mathbf{1}$ and $\mathbf{2}$ in Figure 6, exhibit a moderately reduced value of amidicity (Figure 6) relative to mono-substituted or di-substituted amides, such as 3 and 4 (97-103\%; Figure 6) [40], so one may therefore predict a transamidation process between them. Mono- and di-substituted amines (e.g., dimethylamine) are shown to react readily with formamide (1) at RT $\left(25^{\circ} \mathrm{C}\right)$ or above without any additional activation (case I). However, the transamidation reaction of acetamide (2) required elevated temperature and the presence of $\mathrm{AlCl}_{3}$ as a Lewis acid activator in 
order to attain an acceptable reaction rate (case II). The harsh conditions are explained by the high activation energy of the sterically hindered reaction center [40].
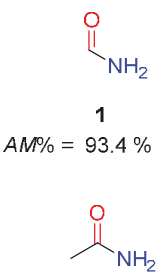

2

$A M \%=96.1 \%$

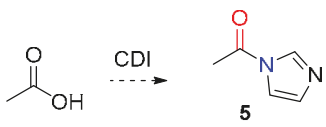

$A M \%=59.0 \%$

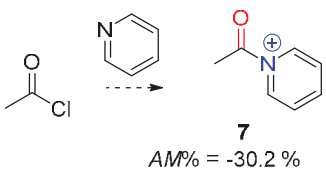

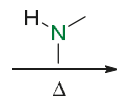

$\Delta$

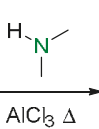

$96.8 \%$

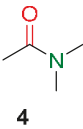

$100.0 \%$
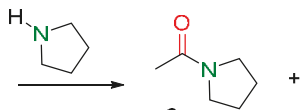

$106.3 \%$
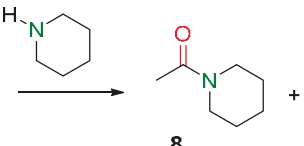

$100.2 \%$ $\triangle A M=3.4 \%$

$\Delta A M=3.9 \%$

$\mathrm{NH}_{3}$

$\mathrm{NH}_{3}$

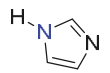

$\Delta A M=+47.3 \%$

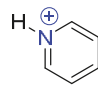

$\Delta A M=+130.4 \%$

Figure 6. Examples for transamidation involving secondary amine, with the corresponding amidicity values computed at B3LYP/6-31G(d,p) level of theory.

Compound 5 represents mild acylating agents (Figure 6) taking part readily in transamidation reactions with amines (e.g., pyrrolidine), forming amide 6 beside imidazole as a side-product. The synthesis of 5 can be carried out simply by means of the corresponding acid and carbonyl diimidazole (CDI) reagent. The increased acylating potency $(\mathrm{AM} \%=59 \%)$ of 5 can be attributed to the competition for the $\mathrm{N}$ atom lone pair between the imidazole aromatic ring and the carbonyl group of the amide. This phenomenon decreases the amidicity percentage of 5 to a value as low as $59 \%$ compared to normal amides. During the acylation reaction $\mathbf{5} \rightarrow \mathbf{6}$, the amidicity value increased significantly, providing the main driving force for this transamidation reaction. Compound 7 (Figure 6) exhibits an extremely low amidicity percentage $(-30.2 \%)$, making this molecule an excellent acylating agent, which can be prepared in situ from $\mathrm{AcCl}$ and pyridine. Consequently, 7 readily furnishes the acylation with an amine (e.g., piperidine), resulting in product 8 . Here, the reaction is motivated by the extremely large change in amidicity ( $\triangle \mathrm{AM}$, Figure 6) even at low temperature $[24,31,40,45]$.

Amidicity value is also able to explain the inactivity and resistance of some commonly used organic amide solvents, For example, $\mathrm{N}, \mathrm{N}$-dimethylformamide (DMF, AM $\%=100 \%$ ) and $\mathrm{N}$-methylpyrrolidinone $(\mathrm{NMP}, \mathrm{AM} \%=136 \%)$ exhibit extremely high amidicity values.

When dissolving any amine in these species, no reaction occurs between them due to the negative $\triangle \mathrm{AM}$, which makes them unfavorable for taking part in any reaction even at high temperature $[24,31,40,45]$.

Transamidation and Acyl Transfer Processes of N-Phenylamides.

In the literature, there are numerous examples where acylated $\mathrm{N}$-alkyl anilines are reacted by amines or alcohols in the presence of transition metal catalysts (Pd, Ni, etc.). In these cases, the $\mathrm{N}$-alky-anilids exhibit moderately low amidicity values, due to the dual effect of the phenyl ring. The phenyl ring suffers some steric hindrance and competes with the non-bonding electron-pair of 
the $\mathrm{N}$ atom against the acyl group at ones. In retrospect, it appears that the transamidation and acyl transfer reaction can occur without any catalyst, although, in the literature at different times, both of these types of reactions were reported as new approaches. Initially, these were reported to proceed without catalyst in the 1960's [46-49]. However, analogue reactions were highlighted later as a novel approach in the presence of Ni or Pd catalysts. Authors called these reactions new, cross-coupling reactions of $\mathrm{N}$-Ar amides (anilides), as reported by Garg et al. [50]. The reactivity of theses aromatic amides, under Ni-catalyzed esterification (Ni/SIPr) was rationalized by the concept of so called "barrier-free" rotation around the N-CO bond [51]. Analogues transacylation reaction with alcohol in the presence of Pd catalyst was also reported [52]. However, the earlier metal or catalyst-free transamidation solutions have subsequently been reinvestigated and rereported as new results [53]. This apparent confusion can be easily resolved by comparing the difference of amidicity values between the aromatic amides (anilids) with aliphatic amides, which thermodynamically allows such transamidation or acyl transfer reaction.

A simple, but illustrative example can be found in the literature, which describes an intramolecular transamidation, where two amine-anilides $(\mathbf{9 , 1 1})$ rearrange to aniline-alkyl-amide products $(\mathbf{1 0 , 1 2}$; in Figure 7) without any catalyst. The positive changes in amidicity values as well as the exothermic enthalpy changes undoubtedly prove the efficiency of these reactions $[46,54,55]$. Other creative synthetic applications, taking advantage of the $N$-phenyl-acyl activation, were also developed for the synthesis of large lactams [53].

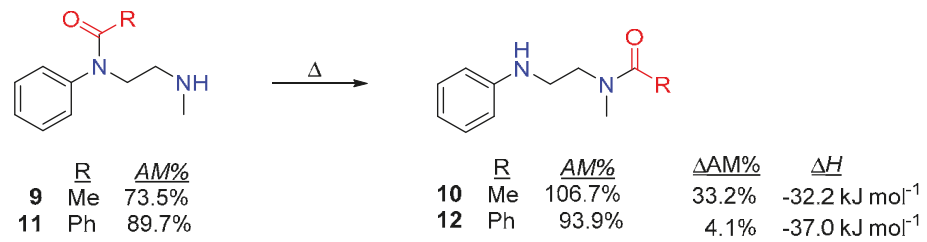

Figure 7. Typical example of intramolecular transamidation rearrangement, with the corresponding amidicity values $(\mathrm{AM} \%)$ as well as amidicity $(\triangle \mathrm{AM})$ and enthalpy change $(\Delta \mathrm{H})$, computed at B3LYP/6-31G(d,p) level of theory.

Acyl Transfer Reactions of Distorted or Twisted Amides

The structural distortion of an amide bond significantly modulates the degree of the amidic resonance, typically by lowering its amidicity/carbonylicity value [56,57]. The two classic twisted bridged lactams (aza-bicycloheptanone 13 [17], penicillin scaffold-penam 14 [58-60]) were synthetized more than 75 years ago. More than six decades later, this was followed by the preparation of 15 (in 1998) and its aromatic derivatives [61-64]. The aza-adamantane analogue 16 (in 2006 [65]), as well its substituted derivatives [66-68] made the series complete. These compounds furnish fully perpendicular arrangement within the amide bonds, resulting in high reactivity similar to that of ketones (Figure 8).

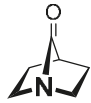

13

$10 \%$

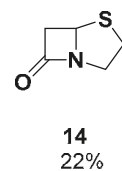

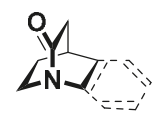

15 and derivatives $17.1 \%$

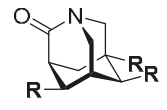

$16 \mathrm{R}=\mathrm{H}, \mathrm{Me}$

$0.0 \%$ if $\mathrm{R}=\mathrm{H}$ (by definition)

Figure 8. Typical examples of synthetized twisted amides (13-16) with the corresponding amidicity computed at B3LYP/6-31G(d,p) level of theory.

At first, we should clarify the difference between the distorted and twisted amides (Figure 9). Updating a previous nomenclature $[6,69]$, the distorted amides reflect some steric hindrance or ring 
strain in their entire structures, but they already possess significant conjugation, with mentionable amidicity values. Here the amides are almost planar. In contrast, twisted amides may be described by a near perpendicular amine plane to the carbonyl plane with pyramidalized $\mathrm{N}$ atom, where the whole structure itself is not distorted or hindered (Figure 9).

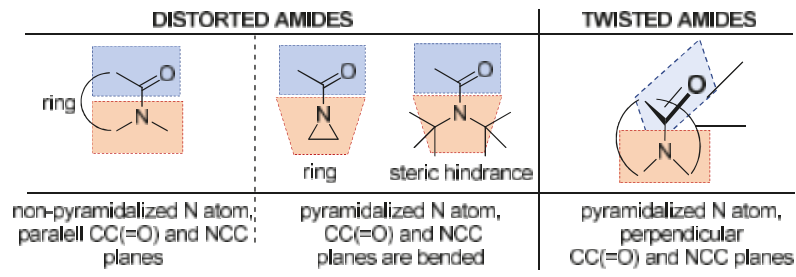

Figure 9. Redefined difference between the distorted and twisted amides. Distorted amides suffer steric hindrance or ring stress with pyramidalized or non-pyramidalized $\mathrm{N}$ atom. Twisted amides do not exhibit any strain, with perpendicular, non-overlapping amide planes. The carbonyl and amide planes are illustrated by the parallel- or perpendicularly-oriented blue and orange colors.

Recently, twisted and distorted amide bonds have slowly found real application as a potent reagent in the mainstream of general organic chemistry. This reagent advances the highly reactive $\mathrm{N}-\mathrm{C}$ amide bond in metal-free as well as transition metal catalyzed cross-coupling reactions yielding various carbonyl derivatives.

Distorted ring-amide can be represented generally by the correlation between the cleavage of lactam rings and the ring size. In Figure 10 and the corresponding Table 1 we summarize the possible alcoholysis of four to seven-membered lactams $(n=1-4)$ to open chain amino ester in the light of the calculated carbonylicity values. It is important to clarify, that the CA\% values are corrected with ring strain as described. The smallest ring-sized lactam (17a; $\mathrm{n}=1$ in Figure 10) has relatively low carbonylicity value $(40.5 \%)$, which may be due to the insignificant conjugation and not only to the ring strain (Table 1). Thus, 17a can transform to the corresponding open-chain amino ester 18a, already having a normal value (ca. 56\%; Figure 10, Method-A). Generally, five- and six-membered rings $(\mathbf{1 7 b}, \mathrm{n}=2$ and $\mathbf{1 7 c}, \mathrm{n}=3)$ are the most stable among the small ring lactams, so one-step alcoholysis reactions are not allowed. More precisely, for five-member ring lactam $\mathbf{1 7 b}$ this one-step process toward $\mathbf{1 8 b}$ is forbidden due to the negative change of the carbonylicity value $(\triangle \mathrm{CA}=-3 \%)$, while in the case of six-member lactam the ring opening process $(\mathbf{1 7 c} \rightarrow \mathbf{1 8 c})$ exhibits an almost neutral change $(\triangle \mathrm{CA}=+1 \%)$. In these cases, a more complicated multi-step processes $(\mathbf{1 7} \rightarrow \mathbf{1 9} \rightarrow \mathbf{2 0} \rightarrow \mathbf{1 8}$; Method-B) should be used to cleave the lactam ring effectively. In this longer process, the hydrolysis with $\mathrm{NaOH}$ is allowed due to the increasing CA\% $(\mathbf{1 9 b}, \mathbf{c})$. The acid chloride formation $(\mathbf{2 0 b}, \mathbf{c})$ activates their functionalities, which easily transform to the desired ester $\mathbf{1 8 b}$,c. Finally, the seven membered lactam $(17 \mathrm{~d} ; \mathrm{n}=4)$ has a slightly lower carbonylicity value $(53 \%)$, which allows a moderate potency to transform it to $\mathbf{1 8 b}$ in alcohol in one step, with slightly increasing $\Delta \mathrm{CA}$. It should be mentioned that the longer procedure $\mathbf{1 7} \rightarrow \mathbf{1 9} \rightarrow \mathbf{2 0} \rightarrow \mathbf{1 8}$ is available for all ring sizes.

Table 1. The calculated carbonylicity values (CA\%) of compounds $\mathbf{1 7 a}-\mathbf{d}$ and $\mathbf{1 8 a}-\mathbf{b}$ and the carbonylicity changes $(\triangle \mathrm{CA})$ for ring-opening alcoholysis depending on the ring size.

\begin{tabular}{ccccc}
\hline State & $\mathbf{n = 1}(\mathbf{a})$ & $\mathbf{n}=\mathbf{2}(\mathbf{a})$ & $\mathbf{n}=\mathbf{3}(\mathbf{a})$ & $\mathbf{n}=4 \mathbf{( a )}$ \\
\hline Start (CA $\%) 17$ & $46.5 \%$ & $60.3 \%$ & $55.2 \%$ & $53.4 \%$ \\
Product (CA $\%) 18$ & $56.2 \%$ & $56.1 \%$ & $56.1 \%$ & $56.2 \%$ \\
$\Delta$ CA & $+10.7 \%$ & $-4.2 \%$ & $+0.9 \%$ & $+2.8 \%$ \\
Method & A or B & only B & $\mathrm{A}^{1}$ or B & A or B \\
\hline
\end{tabular}

${ }^{1}$ Extremely slow reaction. 


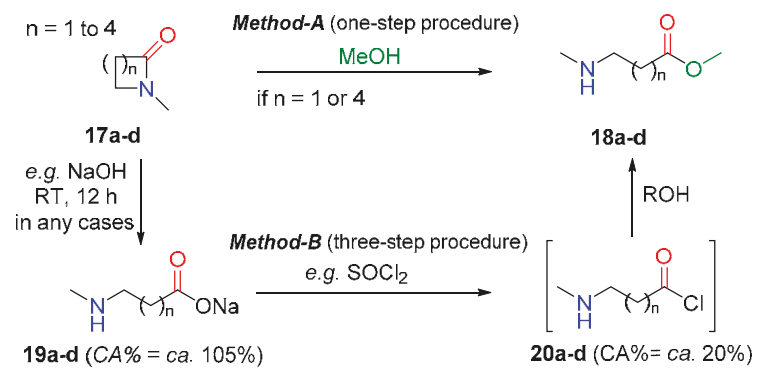

Figure 10. One step (Method-A; top) and multi-step (Method-B, bottom) procedures to transform cyclic amide (lactam) with various ring sizes to amino ester (for the corresponding carbonylicity values computed at B3LYP/6-31G(d,p) level of theory; see Table 1). The carbonylicity values for 19 and 20 are average values.

Some examples of sterically hindered amides were reported [70-72] to exhibit moderately low amidicity and carbonylicity values. One representative example is 21, where the amide functionality is sterically hindered and, hence, distorted. Here, somewhat decreased carbonylicity makes the reaction possible with alcohol (for example $\mathrm{MeOH}$ ) to yield an ester (22), as published earlier (Figure 11, top) [73]. Another example shows that a twisted amide (e.g., 23), having an extremely low amidicity value, readily cleaves its $\mathrm{CO}-\mathrm{N}$ bond by $\mathrm{MeOH}$, resulting an open-chain amino-ester (24), as shown in Figure 11 (bottom). In both cases, the thermodynamic driving force can be easily explained by the positive change in carbonylicity $[74,75]$. The combination of the twisted amide and acyl-anilide concepts are also exemplified, where these amides furnish effective alcoholysis analogously to the previous cases $[73,76]$.

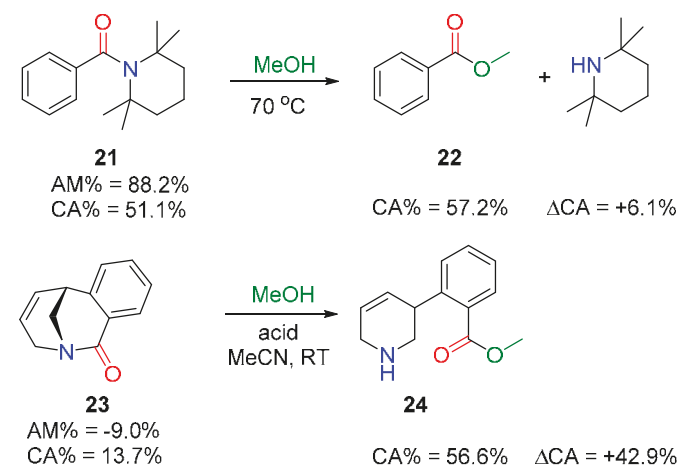

Figure 11. Relevant examples for acyl transfer reactions in the cases of distorted (21) and twisted amides (23) resulting esters (22 and 24), explained by the change in carbonylicity (CA\%) with the corresponding carbonylicity and amidicity values computed at B3LYP/6-31G $(d, p)$ level of theory.

\subsubsection{Transamidation Reaction via Activated Amides (case III)}

Non-strained secondary amides (e.g., N-metylacetamide; 25) exhibit approximately $100 \%$ amidicity, so are typically not able to take part in transamidation reactions. For instance, the reaction between 25 and dimethylamine, yielding theoretically dimethyl acetamide (26), is not beneficial, due to the slightly smaller amidicity [40]. From the perspective of practicing chemists, there was a synthetic demand to activate and use these amides as reagents. To activate these resistant secondary amides, their high amidicities should be decreased by an activating group. Numerous methods were developed 
in recent decades and presented in the literature, summarized in Figure 12. All these solutions involve a preliminary activation step.

The introduction of $N$-nitroso (27) [77,78], N-nitro (28) [79], N-(tosyl) (29) [80], N(trifluoromethanesulfonyl) (30) [80], or $N$-acyl (31) [81-83] amides are the most relevant examples. The following step describes how these activated amides (27-31) could react with, e.g., dimethylamine, to yield the desired and exemplified amide product 26 . The byproducts of these reactions are typically good leaving groups. The most significant amidicity decrease can be measured for $\mathbf{2 8}$ and $\mathbf{3 0}$, producing the most reactive acylating agents $[79,80]$. The $N$-BOC-N-methyl-acetamide 31 was prepared in a previous step from 25 by $(\mathrm{BOC})_{2} \mathrm{O}$ reagent $[82,83]$, a process known as $N$-Boc activation. Other, bisacyl and triacyl substituted amides (such as succinimide [84] and phthalimide derivatives [85]) may also behave as good transamidating agents in the presence of an amine. In all cases, the listed $\Delta \mathrm{AM}$ values were large enough to provide enough driving force to convert to the desired product 26 [40].
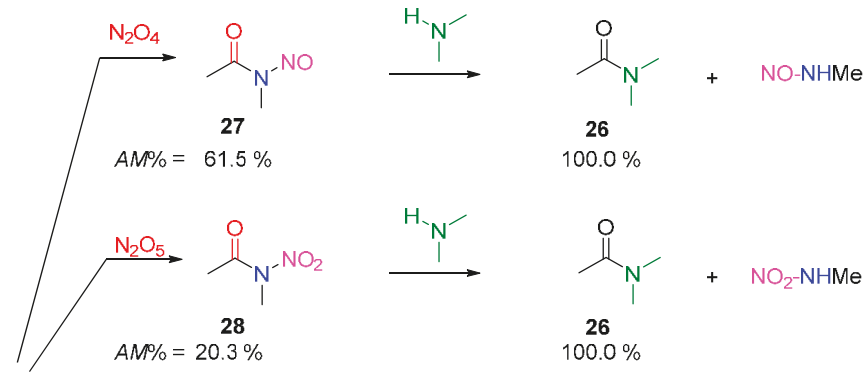

$\triangle A M=38.5 \%$
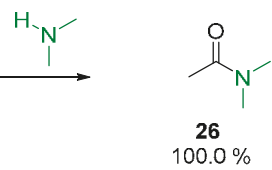

$+\mathrm{NO}_{2}-\mathrm{NHMe}$

$$
100.0 \%
$$

$\triangle A M=79.7 \%$
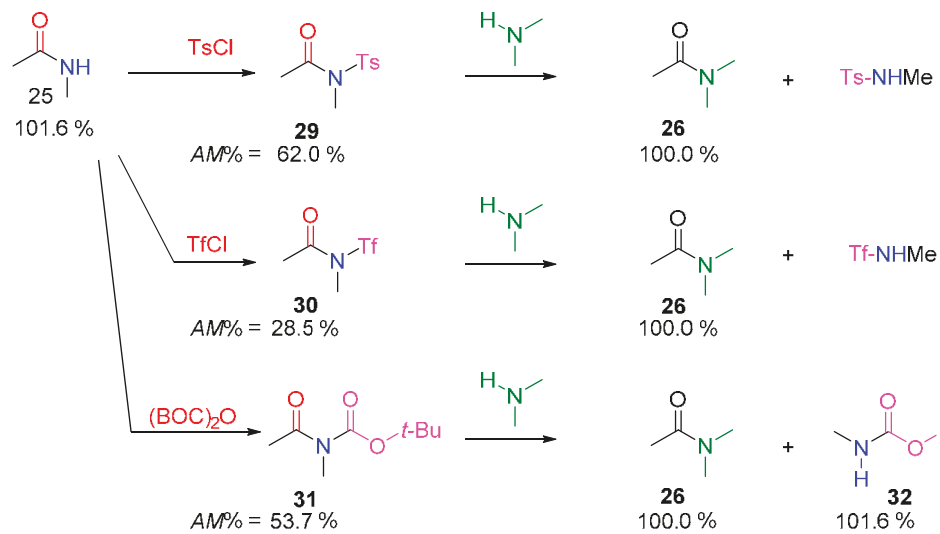

$+\quad \mathrm{Tf}-\mathrm{NHMe}$

$\triangle A M=71.5 \%$
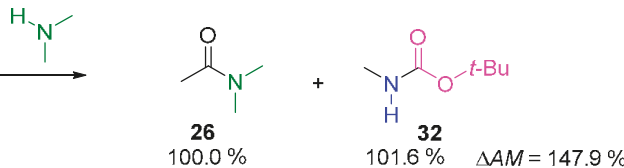

Figure 12. Some representative examples of amide activations (case III), using various reagents with the corresponding amidicity values computed at B3LYP/6-31G $(\mathrm{d}, \mathrm{p})$ level of theory. Ts = $p$-toluenesulfonyl; $\mathrm{Tf}=\mathrm{CF}_{3} \mathrm{SO}_{2}-; \mathrm{BOC}=t-\mathrm{BuO}-\mathrm{CO}-$

Finally, a good example can be found for the transition metal catalyzed transamidation, where $N$-alkyl-benzamide (e.g., 33) was transformed to dialkyl derivatives (e.g., 34a). The authors previously reported that 33 could not be transformed to 34 a directly, even in the presence of an active transition metal catalyst (Ni/SIPr), without providing any theoretical interpretation. However, the amidicity concept is able to highlight the thermodynamic background of the process failure, due to the unfavorable amidicity change $(\triangle A M=-16.4 \%$ in Figure 13). Nevertheless, with the activation of the amide by BOC group (35), the progress occurs smoothly to product $34 \mathrm{a}$, in the presence of $\mathrm{Ni} / \mathrm{SIPr}$ catalyst. It seems reasonable to conclude that when the transamidation reaction exhibits positive amidicity change (as in $35 \rightarrow 34$ ), the transition metal catalyst or any other catalyst may help. 
However, when the reaction is substantially endothermic (as in $\mathbf{3 3} \rightarrow \mathbf{3 4 a}$ ), the reaction will not take place even if catalyst is used.

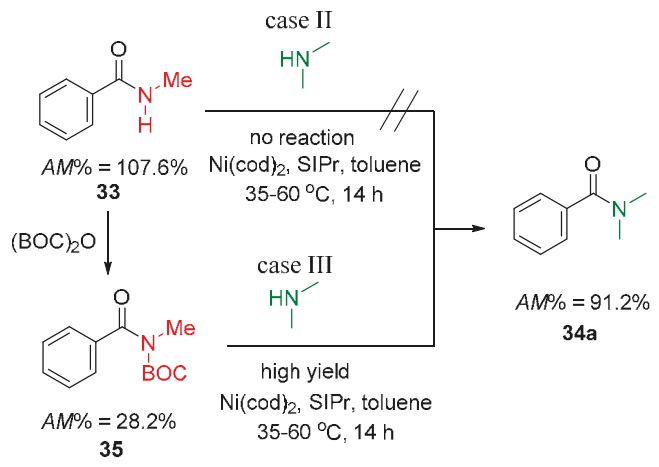

Figure 13. Exemplified transamidation reaction of 33 (case III) with $(33 \rightarrow 35)$ and without amide activation. The corresponding amidicity values were computed at B3LYP/6-31G $(\mathrm{d}, \mathrm{p})$ level of theory. $\mathrm{BOC}=t$-BuO-CO-; $\mathrm{cod}=1,5$-cyclooctadiene; $\mathrm{SIPr}=1,3$-bis(2,6-diisopropylphenyl)imidazole-2-ylide .

Analogues reactions can be found in the literature, where variously substituted amide compounds are used as a reagent to convert them to ester derivatives with the corresponding alcohol. Some examples are summarized in Figure 14, where substituted benzamide derivatives (33-34a,b) could be converted to 22 . Clearly, these reactions can occur, if the carbonylicity difference is favorable. In the case of the transformation of $33(\mathrm{R}=\mathrm{H})$ to 22 , the reaction is forbidden due to the negative change in carbonylicity, with or without catalyst (Figure 14). The transformation of 34a to 22 is theoretically possible, but the reaction condition applied in the publication was not harsh enough to be effective (Figure 14, case II). In the case of Ph substituents (35), however, maintaining low amidicity value is sufficient to enable the acyl transfer in the presence of Ni/SIPr catalyst [50]. Finally, 33 can transform to 22 effectively by the activation method with (BOC) $)_{2} \mathrm{O}$ reagent (Figure 14, case III). The prepared active intermediate $\mathbf{3 4 b}$, having a low amidicity value, finally can be transformed to the ester product, in the presence of $\mathrm{Ni} / \mathrm{SIPr}$ catalyst.

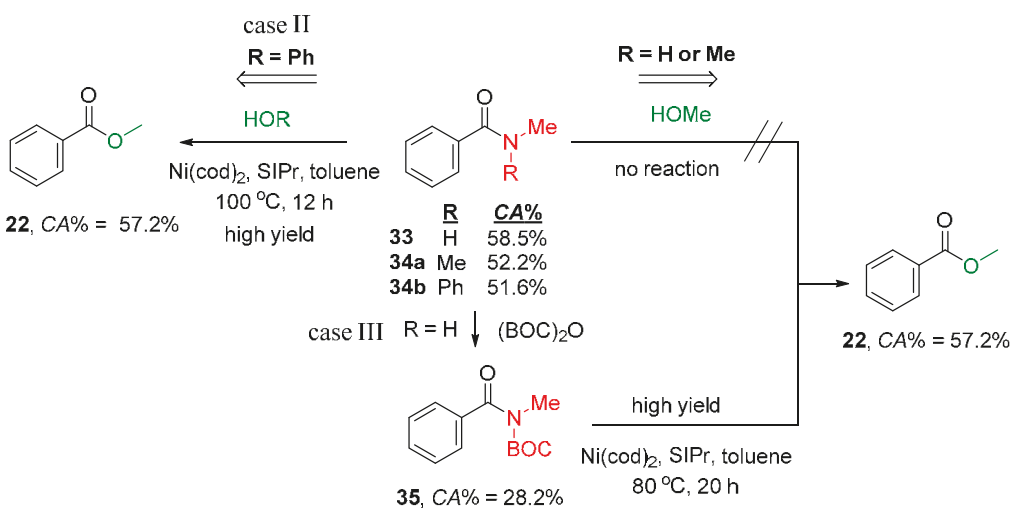

Figure 14. Exemplified acyl transfer reaction (case II and case III) with and without amide activation in the presence of catalyst. The corresponding carbonylicity values were computed at B3LYP/6-31G $(\mathrm{d}, \mathrm{p})$ level of theory. BOC $=t-\mathrm{BuO}-\mathrm{CO}-; \mathrm{cod}=1,5$-cyclooctadiene; $\mathrm{SIPr}=1,3-\mathrm{bis}(2,6-$ diisopropylphenyl)imidazole-2-ylide. 
From these examples it becomes clear that there is no fundamental difference between transamidation reaction and other transacylation, because in both cases there is an acyl migration. However, for historical reasons, the transamidation and acyl transfer processes are still distinguished in the literature. Needless to say, all of these conclusions are true when the heteroatom is sulfur.

The reverse pathway with different substituent patterns, the transacylation from ester to amide, was also described in the literature in the presence of Ni/SIPr catalyst [86-88].

\subsubsection{Activated Transamidation Reaction via Product Stabilization [case IV]}

Because of its high amidicity value, $N, N$-dimethyl formamide (DMF; Figure 15) can be considered an unreactive amide. In contrast to this, deprotonated amides, such as 36, possess even higher amidicity values $(>150 \%)$ than tertiary amides. In strongly basic conditions, deprotonated amides (36) should, therefore, be more favorable than non-deprotonable DMF. A good example is found in the literature, where aniline derivatives $37 \mathrm{a}-\mathrm{c}$ can be deprotonated by $\mathrm{NaH}$ or $\mathrm{NaOMe}$, generating their corresponding anion form of $38 \mathrm{a}-\mathrm{c}$. The product amide anions $36 \mathrm{a}-\mathrm{c}$ were formed at elevated temperature (Figure 15) [36,89-91]. During the workup process, an aqueous acid was used to acidify and precipitate the neutral product $39 \mathbf{a}-\mathbf{c}$ in an irreversible way. The procedure as a whole is a thermodynamically forbidden transformation $(38+\mathrm{DMF} \rightarrow 39)$, due to the lower amidicity of the product $39 \mathrm{a}-\mathrm{c}$. Nevertheless, only the reversible subprocess of $\mathbf{3 8}+\mathrm{DMF} \rightarrow \mathbf{3 6}$ (in green box, Figure 15) is favorable. Overall, the driving force of this subprocess is controlled by the high $\triangle \mathrm{AM}$, so this formylation reaction is rapid, making this reaction practical [40].

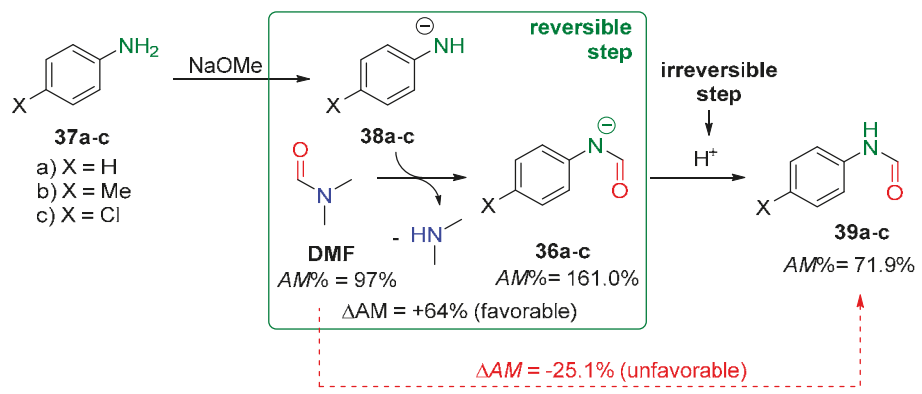

Figure 15. An example for case IV transamidation reaction with the corresponding amidicity values computed at B3LYP/6-31G(d,p) level of theory. The green box illustrates the thermodynamically favorable subprocess, while the red arrow shows the overall unfavorable reaction.

The use of the amidicity change $(\triangle \mathrm{AM})$ leads to a quasi-thermodynamic selection rule, allowing the reactions to be categorized as being either thermodynamically favorable or unfavorable. This simple rule of amidicity-change may be used to predict the selectivity of a reaction, where two competing functional groups are involved. Such an example is presented, where two types of amino groups are attached in one molecule (40). As one may predict by the amidicity change, only the alkyl amine group will react with formamide, yielding 41 exclusively with high yields in one step (Figure 16). The other isomer amide $\mathbf{4 2}$ and the diacylated 43 , including anilid type amide, could not be detected in the reaction mixture, as the amidicity change simply predicted [40]. 


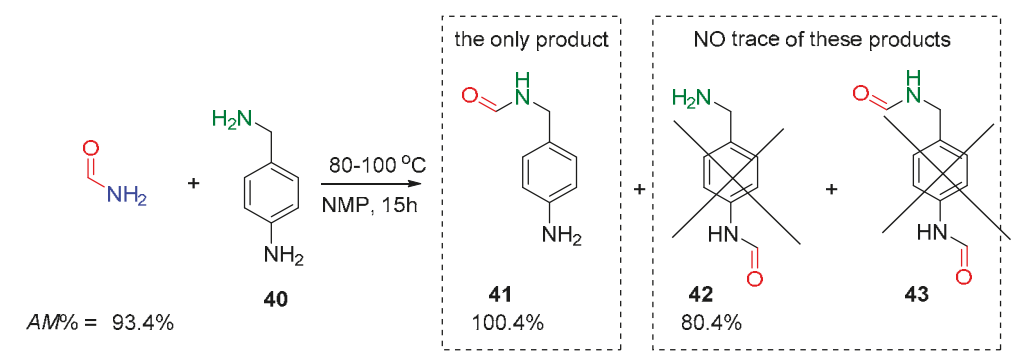

Figure 16. Selectivity of transamidation reaction of $N, N$-dimethylformamide (DMF) and compound 40, having two types of amino groups. The three possible products $41-43$ are shown. The corresponding amidicity values were computed at B3LYP/6-31G(d,p) level of theory.

\subsection{Amide Reduction via Amide Activation}

An unprecedented number of examples can be found in the literature to reduce amides to substituted amines, using numerous reduction agents (most generally metal hydrides). The situation is illustrated by a few selected citations $[31,69,92-97]$. Strong reduction agents are a common feature of these methods, since generally amides are very resistant against reduction. Consequently, these methods are typically not applicable to carry out selective reactions. This extreme resistance can be explained by the strong conjugative interaction within the structure of amide, exhibited by their high amidicity values. Among the reduction agent $\left(\mathrm{LiAlH}_{4}\right.$ or $\left.\mathrm{BH}_{3}\right)$, the complex and highly active metal hydrides may have the most significant synthetic importance to obtain various amines.

However, selective examples can be found in the literature in which one of the amide groups was reduced selectively in one molecule, while keeping the other amide or other sensitive groups of the molecule untouched [98-101]. This was achieved by the activation of the selected amide group by an appropriate $\mathrm{N}$-substituting activating group. The following example illustrates this methodology in Figure 17, among other examples. The case of the exemplified diketopiperazine derivative 44 [101] includes two unequal but very similar amides, $\mathrm{A}$ and $\mathrm{B}$, from the aspect of amidicity. If one tries to reduce this compound 44 by $\mathrm{LiAlH}_{4}$, both the amides A and B will be reduced to piperzine derivative 45. From this reaction it would become clear for a practicing chemist, that no possibility exists of finding a selective reducing agent to obtain piperazidone derivative 46 . In the case of adding only one equivalent of reductive agent, a complex mixture of partially reduced forms can be observed.

However, analogously to case III reactions in the previous section, the secondary amide-A was acylated by $\mathrm{BOC}_{2} \mathrm{O}$ reagent, which resulted in a triacylated intermediate 47 . In this structure, the amidicity of the acylated amide $\mathrm{A}$ is lowered to $34.6 \%$, while that of amide B increased slightly. The carbonyl of the BOC group (amide-C) is as high as $109.1 \%$, which exhibits large resistance to reduction. The lowered amidicity of the amide-A provides not only higher reactivity with the metal hydride, but allows the application of significantly weaker reducing agent, such as $\mathrm{NaBH}_{4}$. This reagent is soft enough to avoid the reduction of amide- $\mathrm{B}$ and $\mathrm{C}$. In the first reduction step, amide-A is reduced only to hydroxy amine intermediate 48 , protected by the BOC group, but with increased amidicity for amide-C. This intermediate $\mathbf{4 8}$ was transformed finally to the desired product $\mathbf{4 6}$ by a consecutive deprotection and reducing steps. This compound later proved to be an excellent building block in drug research. This method is not limited only to six-member diketopiperazines, but it can also be generalized for even open chain systems [101]. 


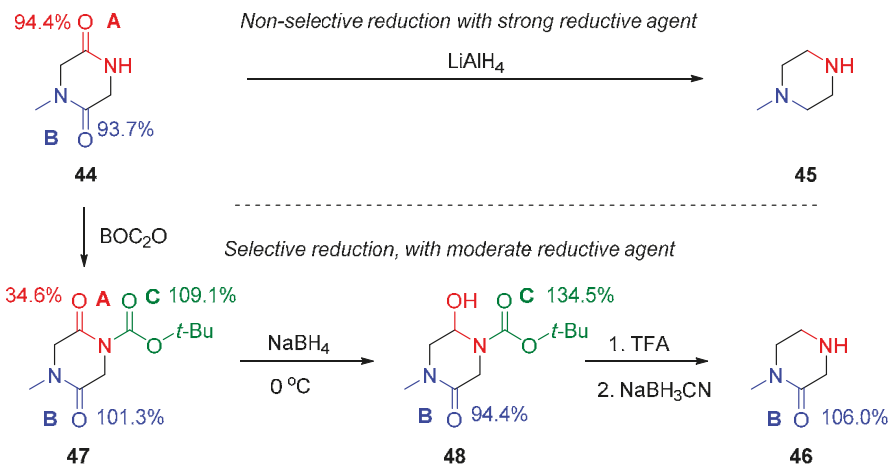

Figure 17. The non-selective and selective reduction of the amide bonds in a diketopiperazine derivative 44, including amide-A and B, to yield 45 and $\mathbf{4 6}$. The corresponding amidicity values were computed at B3LYP/6-31G $(\mathrm{d}, \mathrm{p})$ level of theory.

\subsection{Amide Reaction in the Biochemistry}

Natural products are very precisely assembled from selected molecular components in unique arrangements. They typically exhibit very effective and targeted mechanisms of actions in numerous biological processes. There is an observably large difference in complexity, activity and efficiency of human-designed compounds [102] and nature's biomolecules, such as dinucleotide coenzymes (NAD and FAD) [103], calicheamicin- $\gamma 1$ [102,104,105], duocarmycin [106-108], syringolin A [18], aflatoxin B [18], and penicillin [109]. Biochemical processes also take advantage of the selectivity of acyl transfer reaction and amide activation, so three representative examples are presented in this section.

\subsubsection{Cross-Linking in the Blood Clotting Process}

The first example is taken from the multistep process of blood clotting [110-112]. In this case, in the final, thirteenth step (Figure 18) of the entire complex process, the two final protein intermediates 49 and 50 are linked to each other via a new side-chain amide bond [112].

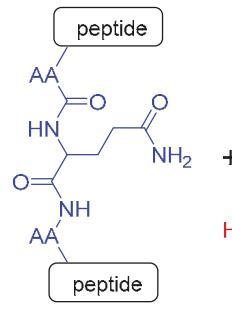

49

$A M \%=96.0 \%$

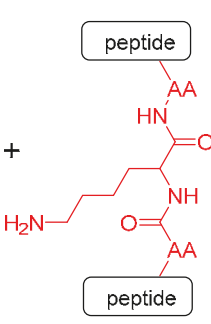

50

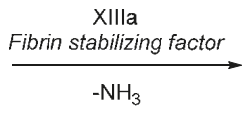

$\triangle A M=5 \%$

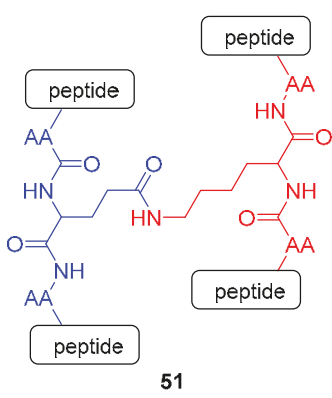

$A M \%=101.0 \%$

Figure 18. The final step of the blood clotting process from the aspect of amidicity change, catalyzed by the transamidinaze enzyme. The corresponding amidicity values were computed at B3LYP/6-31G $(\mathrm{d}, \mathrm{p})$ level of theory.

This creates a molecular polymeric net (51), which forms a barrier against bleeding. Analyzing the process from the aspect of amidicity values (Figure 18), this transamidation reaction is spontaneous. The process takes part between a glutamine side chain amide (blue) and a lysin side chain amine (red). 
The amidicity change is predicted to be slightly positive $(\Delta \mathrm{AM})$, because the initial $96.0 \%$ amidicity of the glutamine side chain amide is increased to $101 \%$ as the new amide is formed, not requiring additional activation. This small change in amidicity provides a driving force for this bioreaction, but it is not enough to exhibit the measurable high reaction rate at body temperature. Consequently this process is catalyzed by an enzyme fibrin stabilizing factor or transglutaminase [112,113]. Moreover, the releasing ammonia also makes the process irreversible.

\subsubsection{Intein-Mediated Protein Splicing}

Intein-mediated protein splicing is a biologically important process (Figure 19) [114-117], where a small but defined part of the protein $\mathbf{5 2}$, intein (53), is cut out specifically from the middle of a protein. Meanwhile, the two remaining parts, called exteins, are linked to each other, forming a new protein 54 via a new peptide bond. Protein splicing is so rapid that the precursor protein is rarely observed in native systems. It was shown that the process is auto-catalytic and folding-dependent [118-120]. The N-extein residues play unique and important roles in protein splicing [120]. The intein peptide sequence is supposed to contain no sufficient information originating from an external source [114-117].

From the chemical aspect, here two amides are involved in transamidation process rather than an amide and an amine shown previously [33]. The intein and the C-terminal extein residue contain sufficient information for splicing in proteins, which involves four basic chemical steps. In the first step of the mechanism [114-117], the serine or cysteine residue, at the N-terminal border of the intein, attacks the neighboring peptide bond forming an intermediate 55 , which in a subsequent step rearranges to 56 and 57 . In the final step, the intein leaves the native sequence resulting in the edited protein 54 . Taking into account only the starting and ending state, the overall process exhibits a large negative $\triangle \mathrm{AM}$ value $(-45 \%)$, which may suppose an endothermic reaction. One may argue that the exothermic refolding of the instantly cut intein sequence provides additional driving force, covering the energy demand of the overall amidicically unfavorable process. Moreover, the N-extein-intein amide linkage is a typically distorted amide (blue in Figure 19.) due to the folding, resulting in lower amidicity, which could initiate the acyl migration (blue arrow).

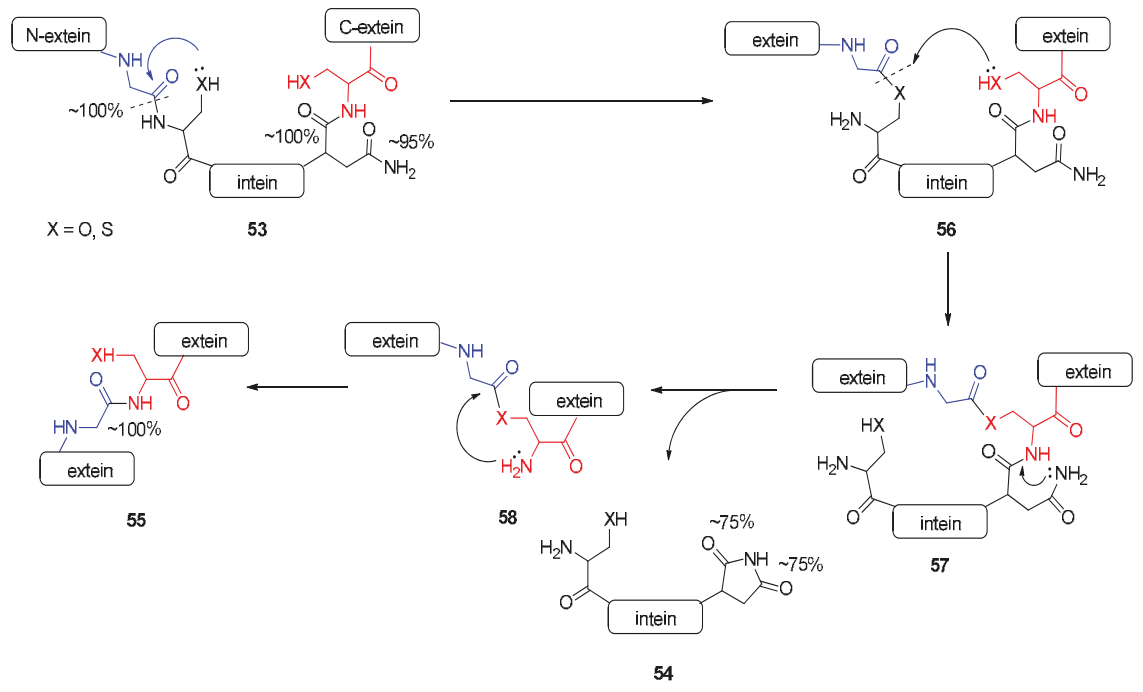

Figure 19. The mechanism of action of protein splicing as a special type of transamidation reaction. 


\subsubsection{Penicillin}

One of the most important small biogen amides is penicillin (58), produced by the Penicillium genus, which is considered to be one of the great discoveries of the 20th century $[121,122]$. This antibiotic inhibits penicillin binding proteins, such as transpeptidase, by blocking their serine residue via acylation in gram-positive bacteria. In this way, bacterial cell wall synthesis stops, leading to deadly susceptibility to osmotic effects and cell bursting. This bacterial enzyme plays a crucial role in transferring the D-Ala-D-Ala dipeptide into the bacterial cell wall synthesis as illustrated by Figure 20. The perennial war between bacteria and fungus led to the evolution of $\beta$-lactam related antibiotics, and resulted in many variants, of which cephalosporine [123] and thienamycin $[124,125]$ are just two examples.

During the last century, resistant bacteria strains have developed some defending mechanisms against intensively and overused $\beta$-lactam antibiotics. Consequently, antibiotic research is once again at the forefront of drug research. The $\beta$-lactamase enzyme is synthesized by resistant bacteria for deactivation of penicillin-type compounds in order to avoid their lethal effects [122,126-129]. Regardless, continued characterization of the $\beta$-lactam structure and mechanism aids in the understanding and design of novel antibiotics with desired effects and great precision [126].
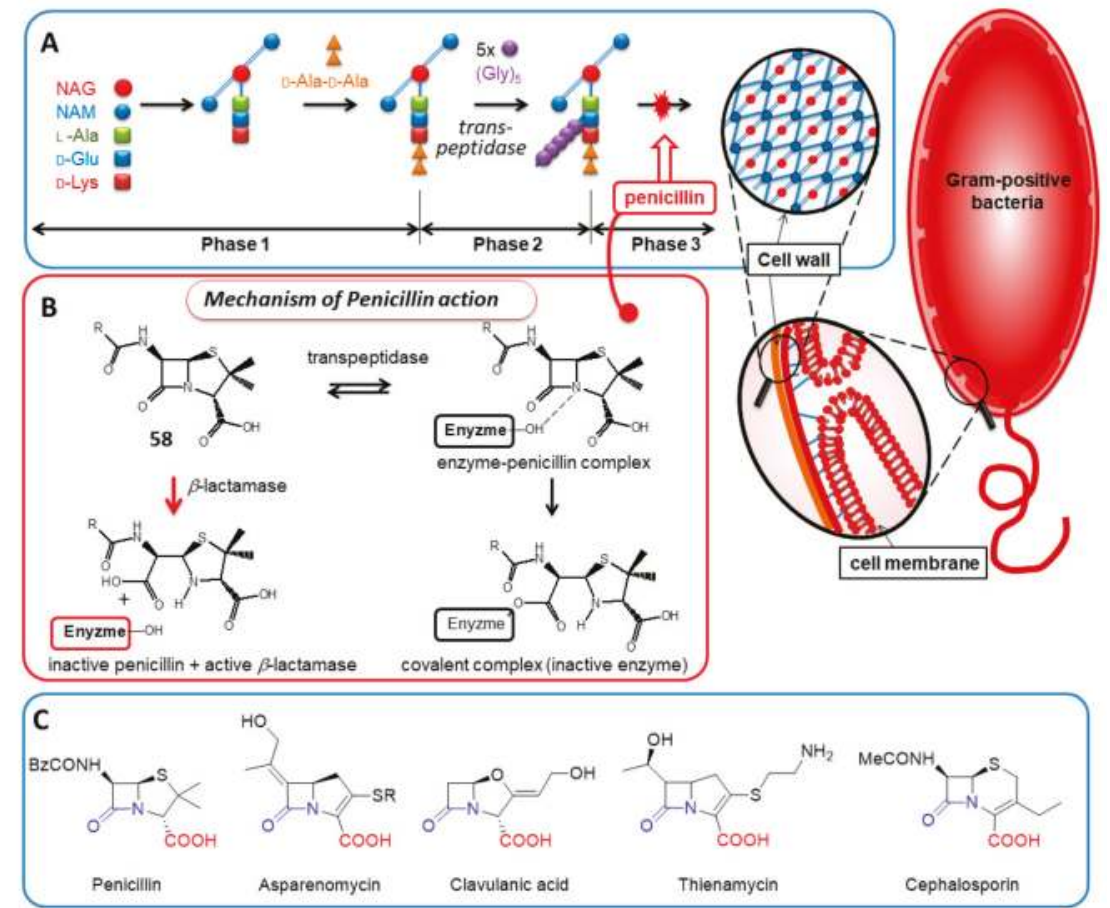

Figure 20. (A) The schematic mechanism of biological action of the penicillin antibiotic in the course of cell wall synthesis. (B) Penicillin inhibits transpeptidase enzyme by bonding covalently to the serine side-chain producing non-hydrolysable enzyme-substrate complex, blocking irreversibly the enzyme activity. (C) Some representative examples of $\beta$-lactam antibiotics. Their common feature is the strained $\beta$-lactam ring neighbouring a carboxylic functionate, which are both essential for the antibiotic activity. $\mathrm{NAG}=\mathrm{N}$-acetylglucoseamine; $\mathrm{NAM}=\mathrm{N}$-acetylmuramic acid.

Since the discovery of penicillin's chemical structure [18,129], the way this molecule avoids the aqueous hydrolytic effects in body fluid, while immediately awakening its hidden ability to acylate 
the transpeptidase's serine side-chain oxygen, has remained a mystery $[130,131]$. Recently, bacterial resistance has been investigated intensively, wherein penicillin hydrolysis was studied [131-135], and on the bases of this mechanism its activity was understood [132-134]. The "strange" fused $\beta$-lactam-type structure [132] was dedicated to explain its strength as an acylating agent completely, approximated earlier to that of acyl chlorides $[133,134]$. In organisms, however, such a strong acylating agent should decompose quickly before reaching its destination, e.g., the transpeptidase enzyme of the bacteria.

Previously, it was shown that the unexpected stability of penicillin can be attributed to its deprotonated form (59 in Figure 21), which is the dominant component of the neutral aqueous environment [60]. According to the new, higher level quantum chemical calculations at MP2(full)/DGDZVP, the amidicity value [40] of the anion form was found to be higher ( $\mathrm{AM} \%=71.7 \%$ ) than the neutral form (58), referring to the more stable amide bond in the anionic form. However, when the penicillin reached its target enzyme, the transpeptidase, it gets protonated (59 in Figure 21) by the enzyme. The forming neutral form of penicillin (58) immediately lowers its amidicity to $22.1 \%$, so it has been triggered for the reaction. Finally, the $\mathrm{H}$ atom on the carboxylic acid group can also easily turn back to the pyramidaziled amid $\mathrm{N}$ atom, forming an H-bond. This conformational change turns on the final, superactive form of the molecule (60 in Figure 21), reflected by the extremely low amidicity $(\mathrm{AM} \%=-8.7 \%)$. This form instantaneously makes a covalent enzyme-drug complex, and knocks out the enzymatic activity. This carboxylic function makes the molecule a well-designed acylating bacteria killer, because it also acts as a bait for the essential bacterial enzyme. In this way, penam scaffold antibiotics are practically self-activating selective hitmen against bacteria. In summary, penicillin provides an interesting example of a controlled protonation and conformation-dependent amide bond activation.

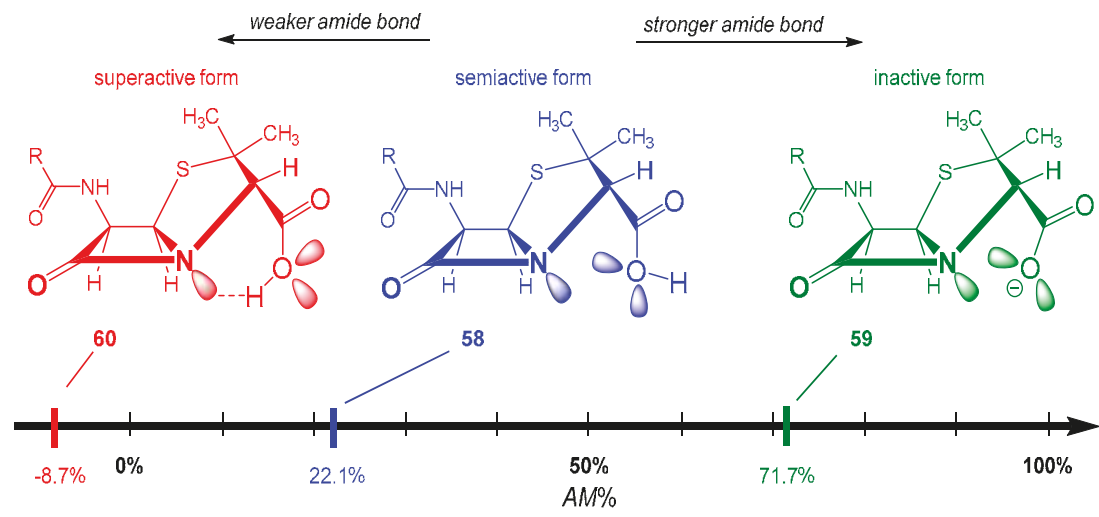

Figure 21. The amidicity scale [MP2(full)/DGDZVP], showing the reactivity of the carbonyl group for the three different forms of penicillin molecule $(58,59$ and 60$)$, depending on its protonation degree as well as its conformation. The electron repulsion between the $\mathrm{COO}-$ group and the $\mathrm{N}$ atom is illustrated by the lone pairs. This strengthening of the amide bond in 59 (larger amidicity) decreases reactivity with respect to 58 . In form 60 , the internal $\mathrm{H}$-bond withdraws density from the amide bond, weakening it (extremely low amidicity) leading to extremely high reactivity toward nucleophiles.

\subsection{Amide Activation in Excited State.}

The electronic excitation of the chromophore functionality is able to transfer the energy toward a neighboring amide bond, resulting in an amide activation and in an increased reactivity of the amide bond, which is utilized for various processes [33]. Photocleavage (also known as uncaging) is based on this phenomenon, providing a methodology to release selectively a bioactive compound from its covalently bonded cage-form in a localized volume. Otherwise, the cage scaffold should effectively 
block the activity of the bonded biomolecule, but undergoes efficient removal after excitation of the moiety, through the scissile bond. Until now, numerous cage molecules have been developed (Figure 22); however, nitro-indoline and coumarine scaffolds are the most popular of these, and are usually linked with glutamate as excitatory neurotransmitter [136,137].

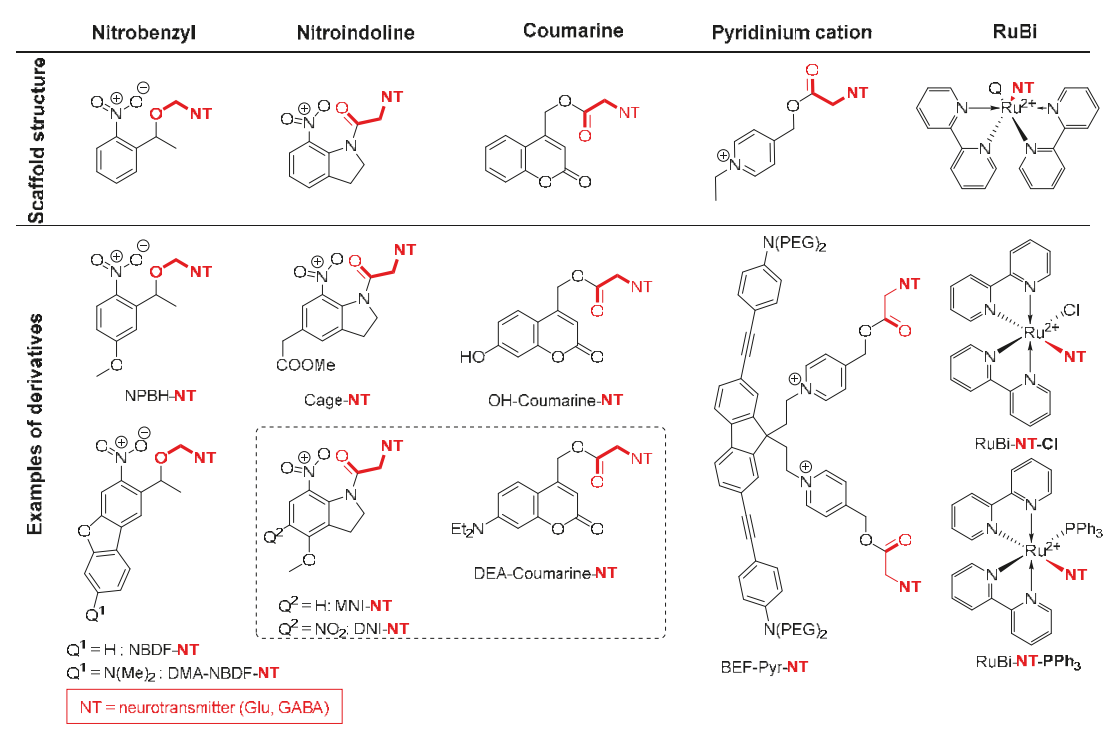

Figure 22. Collection of the most prominent cage-scaffolds (top) and some derivatives (bottom). $\mathrm{NT}=$ neurotransmitter. Compounds in the box are the subject of discussion.

\subsubsection{Photochemical Release of Glutamate from MNI-Glu and DNI-Glu at Excited State}

The most popular cage compounds, 5-mono-nitro-indoline (MNI) and 5,7-dinitro-indoline (DNI), have proved their effectiveness during the last decade and have been widely applied in numerous neuroscientific papers. Due to the large number of scientific results, in this paragraph we focus only on DNI-Glu and MNI-Glu [138]. MNI-Glu and DNI-Glu fulfill the main requirements for an ideal cage compound, including an efficient uncaging process with relatively high chemical yield, rapid two-photon induced release (quantum yield 8.5\%) [139], low spontaneous hydrolysis rate, (Figure 23) and low biochemical side effects [140]. These properties were demonstrated to be useful in neurophysiological experiments.

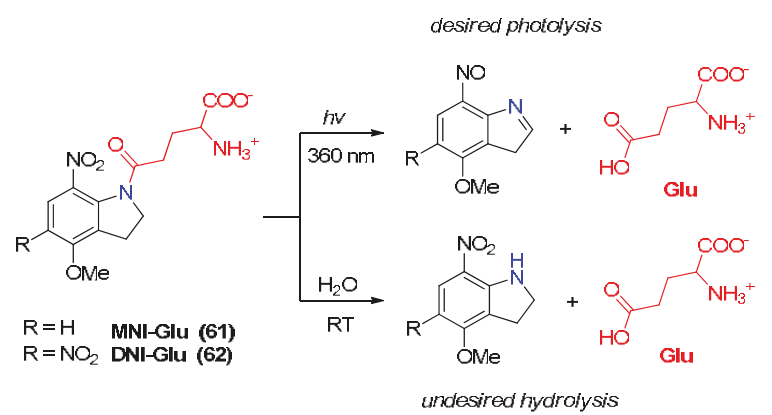

Figure 23. Chemical structures of MNI-Glu $(\mathrm{R}=\mathrm{H})$ and DNI-Glu $\left(\mathrm{R}=\mathrm{NO}_{2}\right)$ and their photochemical reactivity (top) and hydrolytic reactivity (bottom). 
The reaction mechanisms of the desired photochemical glutamate release of MNI-Glu (61) and DNI-Glu (62) were studied and compared on quantum chemical bases using GAUSSIAN 09 software [141] (Figures 24 and 25). Their reaction profile proved to be identical, but the energy values varied in a significant range (4-10 kJ/mol). Here, only the photochemical reaction of DNI-Glu (62) will be presented. The photocleavage of DNI-Glu (62) starts from the initial state A(S0) and follows the sequence of $\mathrm{A} \rightarrow \mathrm{B} \rightarrow \mathrm{C} \rightarrow \mathrm{D} \rightarrow \mathrm{E} \rightarrow \mathrm{F} \rightarrow \mathrm{G}$. The inadvertent ground state hydrolysis in aqueous media $(\mathrm{A} \rightarrow \mathrm{I})$ also plays an important role during the applications, but will not be discussed here.

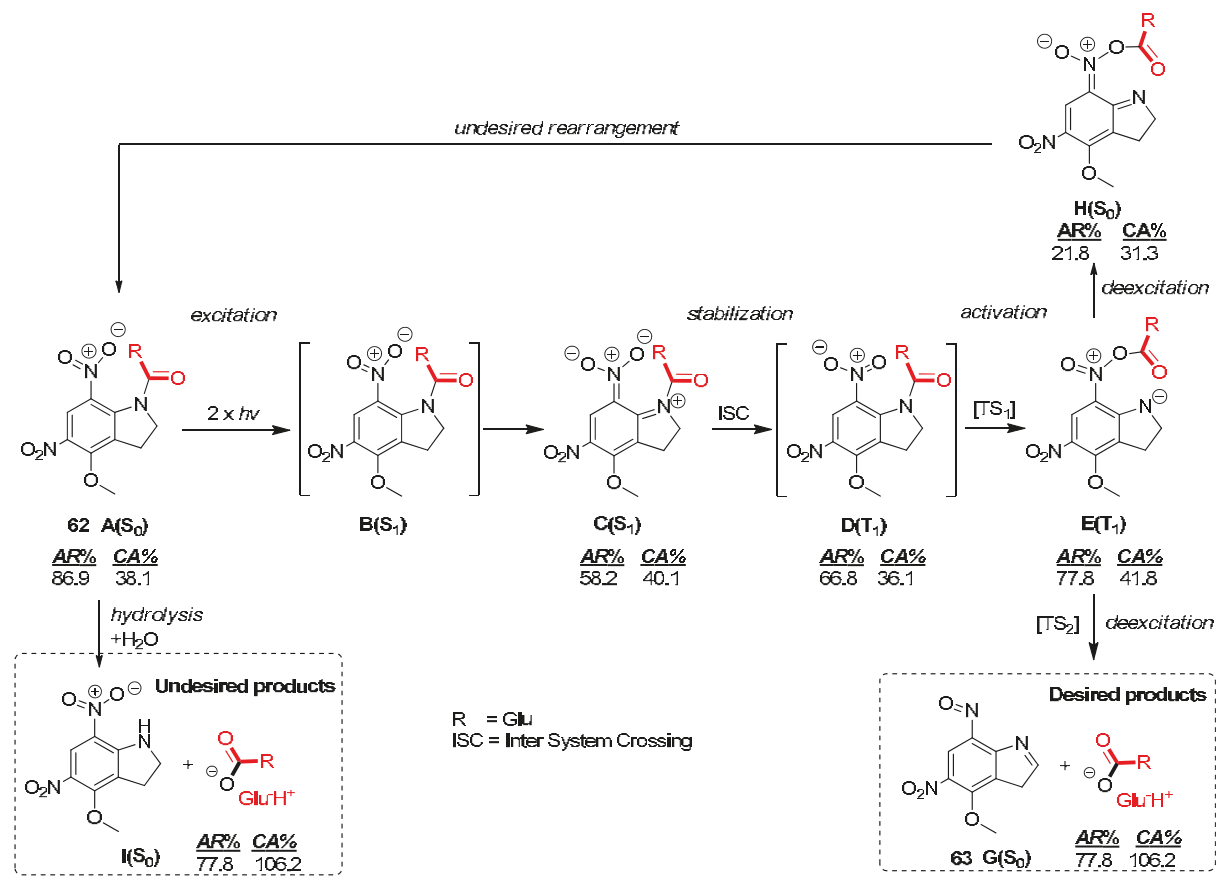

Figure 24. Quantum chemical modelling of the photochemical reactions as well as the simplified mechanisms of ground state hydrolysis for DNI-Glu (62). The aromaticity (AR\%) of the benzene ring and carbonylicity of the carbonyl functionality along the mechanism are computed at B3LYP/6-31G(d,p)//PCM(water) level of theory [37].

After the excitation of the aromatic antenna moiety of DNI-Glu $\left[62 ; \mathrm{A}\left(\mathrm{S}_{0}\right) \rightarrow \mathrm{B}\left(\mathrm{S}_{1}\right)\right]$ the structure follows a vibrational relaxation $\left[\mathrm{B}\left(\mathrm{S}_{1}\right) \rightarrow \mathrm{C}\left(\mathrm{S}_{1}\right)\right]$. The high energy excited singlet state $\mathrm{C}\left(\mathrm{S}_{1}\right)$ tends to transform to a triplet state $\mathrm{D}\left(\mathrm{T}_{1}\right)$ via an intersystem crossing (ISC) process. The triplet state intermediate takes part in an acyl transfer reaction, where the acyl group migrates from the indoline $\mathrm{N}$ atom to one of the $\mathrm{O}$ atoms of the nitro group through a low energy barrier (TS1). This process finally results in an unusually stable triplet state $\left[\mathrm{E}\left(\mathrm{T}_{1}\right)\right]$. Here, the mechanism may proceed in two different directions. The desired product state, including the free glutamate [Product $1 ; \mathrm{G}\left(\mathrm{S}_{0}\right)$ ], is achieved by the $\mathrm{N}-\mathrm{O}$ bond cleavage at stage $\mathrm{E}\left(\mathrm{T}_{1}\right)$ through $\mathrm{TS} 2$, leading to a relatively high energy state $\mathrm{F}\left(\mathrm{T}_{1}\right)$. Finally, the deexcitation to ground state $\left[\mathrm{G}\left(\mathrm{S}_{0}\right)\right]$ results in the final products. However, due to the relative stability of the triplet state $\mathrm{E}\left(\mathrm{T}_{1}\right)$, it can undergo a deexcitation process to give a very reactive species $\mathrm{H}\left(\mathrm{S}_{0}\right)$, which can return to the starting state $\mathrm{A}\left(\mathrm{S}_{0}\right)$. 


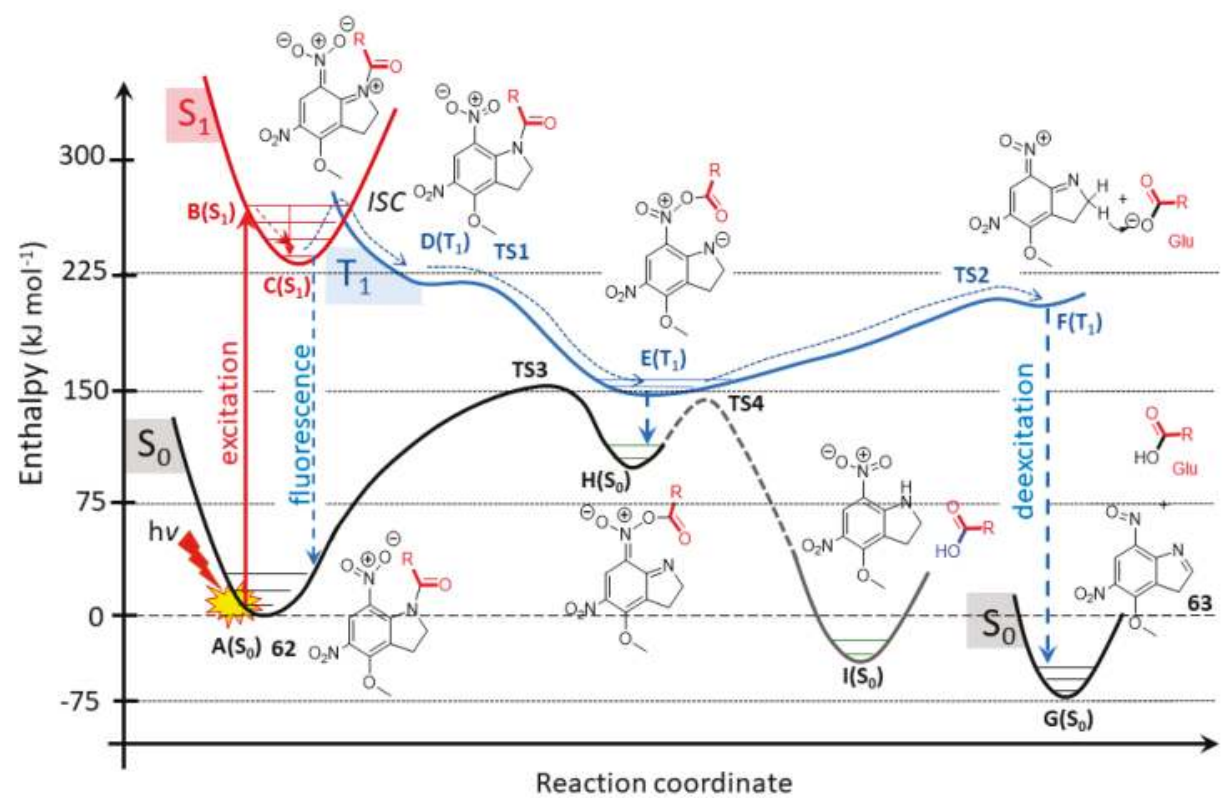

Figure 25. Quantum chemical modelling of the potential enthalpy profile of the singlet (red), triplet (blue) and ground state (black) mechanism for DNI-Glu (62) at B3LYP/6-31G(d,p)//PCM(water) level of theory. For detailed data see [138].

It is possible to explain the overall process by means of systems chemistry. Through the change in the aromaticity (AR\%) [142] and carbonylicity (CA\%) values [computed at B3LYP/6-31G(d,p)// $\mathrm{PCM}$ (water)] it is possible to understand how the electron distribution follows the energetic changes in the triplet excited as well as the ground state during the photochemical process. DNI-Glu (62) is composed of an aromatic ring and a carbonyl group (Figure 24), characterized by values of AR\% and $\mathrm{CA} \%$. During the excitation $\left[\mathrm{A}\left(\mathrm{S}_{0}\right)\right] \rightarrow\left[\mathrm{C}\left(\mathrm{S}_{1}\right)\right]$ the aromaticity is significantly reduced $(\mathrm{AR} \%$ : $86.9 \% \rightarrow 58.2 \%$ ), while the carbonylicity value remained relatively constant $(\mathrm{CA} \%: 38.1 \% \rightarrow 40.1 \%$ ). After intersystem crossing (ISC) from singlet to triplet excited state $\left[C\left(S_{1}\right)\right] \rightarrow\left[D\left(T_{1}\right)\right]$, the molecule tries to regain its stability by slightly increasing its aromaticity (AR\%: $58.2 \% \rightarrow 66.8 \%$ ) at the expense of carbonylicity (CA\%: $40.1 \% \rightarrow 36.1 \%$ ). The reduced $\mathrm{CA} \%$ in state $\mathrm{D}\left(\mathrm{T}_{1}\right)$ indicates that the amid group is already triggered and favors the next intramolecular rearrangement. This results in a relatively stable triplet state molecule $\mathrm{E}\left(\mathrm{T}_{1}\right)$ with an increased aromaticity $(77.8 \%)$ as well as carbonylicity $(41.8 \%)$. Subsequently, an endothermic cleavage of the $\mathrm{N}-\mathrm{O}$ bond leads to stage $\mathrm{F}\left(\mathrm{T}_{1}\right)$, then to the product $63 \mathrm{G}\left(\mathrm{S}_{0}\right)$, recovering finally both the $\mathrm{AR} \%$ and $\mathrm{CA} \%$ after a de-excitation. During the deexcitation from state $\mathrm{E}\left(\mathrm{T}_{1}\right)$ to the ground state $\mathrm{G}\left(\mathrm{S}_{0}\right)$, the rearranged molecule loses a lot of stabilization energy, represented by the sharp decreases of AR\% (21.8\%) and CA\% (31.3\%), summarized in Figure 24.

The photochemical uncaging process of DNI-Glu is an excellent example of how the electronic excitation of an aromatic moiety can activate a neighboring amide group, leading to an acyl transfer reaction.

\subsubsection{Photochemical Release of Glutamate from Coumarin-Caged Transmitters at Excited State}

The neurotransmitter derivatives of coumarin-4-yl-methyl have been developed as a new class of efficient caging scaffolds and were applied successfully to mask the biologically active amino, carbonyl [143] and hydroxyl compounds via carbamate [144-146] or carbonate [33] linkers. 
Some phosphate [56,147-155], carboxylate [56,155,156], sulfate [154], sulfonate [154] and diol [157] functionalities were also been protected by various coumarin derivatives (Figure 26) [33].

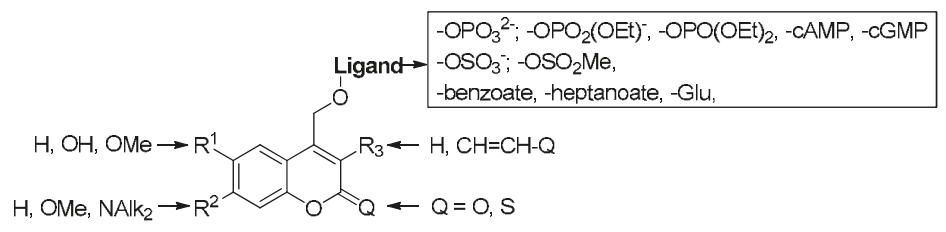

Figure 26. Some examples of cage compounds based on various coumarin scaffolds.

The photochemical mechanism of diethyl coumarin-Glu cage compound (64) has been studied and are reported here by quantum theory (Figure 27) at B3LYP / 6-31G(d,p//PCM(water) level of theory. The mechanism and the corresponding enthalpy reaction profile are shown in Figure 28. After the absorption of photon (excitation) by the ground state of coumarin $64\left[\mathrm{~A}\left(\mathrm{~S}_{0}\right)\right]$, it reaches its excited singlet state $\mathrm{B}(\mathrm{S} 1)$. During the vibrational relaxation process at singlet excited state, the molecule reaches its lowest vibrational energy level $\mathrm{C}(\mathrm{S} 1)$. The molecule tends to deexcite back to its ground state $\left[\mathrm{A}\left(\mathrm{S}_{0}\right)\right]$ by means of emission (fluorescence) or non-radiative processes. However, some of the excited singlet molecule C(S1) transforms to its triplet state D(T1) via an intersystem crossing (ISC, in Figure 28). In that $\mathrm{C}(\mathrm{S} 1)$ state, the molecule goes through a conformational change, finding the perpendicular arrangement of the side chain carbamate to the aromatic ring as the energy optimum $\mathrm{E}\left(\mathrm{T}_{1}\right)$. After a relatively high enthalpy TS $\left[34.5 \mathrm{~kJ} \mathrm{~mol}^{-1} ; \mathrm{F}\left(\mathrm{T}_{1}\right)\right]$, the $\mathrm{CH}_{2}-\mathrm{O}$ bond is cleaved heterolytically, forming a triplet state coumarin cation $\left(65,\left[\mathrm{G}\left(\mathrm{T}_{1}\right)\right]\right)$ and a ground state carbamate anion derivative $\left(66, \mathrm{~S}_{0}\right)$. The formation of the real solvent-separated ions is an energy demanding process (estimated as high as $+265.4 \mathrm{~kJ} \mathrm{~mol}^{-1}$ ), so before the ion-pair separation, the positively charged coumarin scaffold deexcites to its ground state and reacts with a water molecule immediately, resulting in coumarin alcohol [66; $\left.\mathrm{S}_{0}(\mathrm{H})\right]$. At the same time, the carbamate derivative 66 yields the desired amino neurotransmitter (in the present cases, $\mathrm{Me}-\mathrm{NH}_{2}$ ), while it loses $\mathrm{CO}_{2}$. Notably, the overall enthalpy change is endothermic with respect to the starting material in its $\mathrm{S}_{0}$ state, however, the reaction is greatly exothermic with respect to the reactant first excited state $\mathrm{S}_{1}[\mathrm{~B}]$ or $\mathrm{S}_{1}[\mathrm{C}]$.

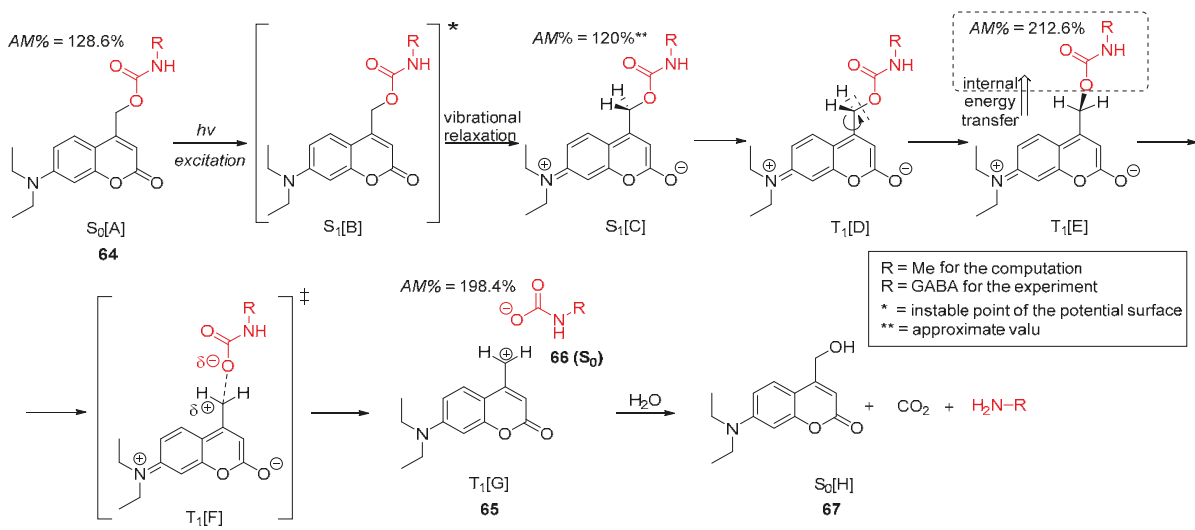

Figure 27. Mechanism of the photochemical initiated scission of coumarin-caged model compound 64 to products $66+67$ by an internal energy transfer, computed at B3LYP/6-31G(d,p)//PCM(water) level of theory. The amidicity values (AM\%) are also shown for some structures. 


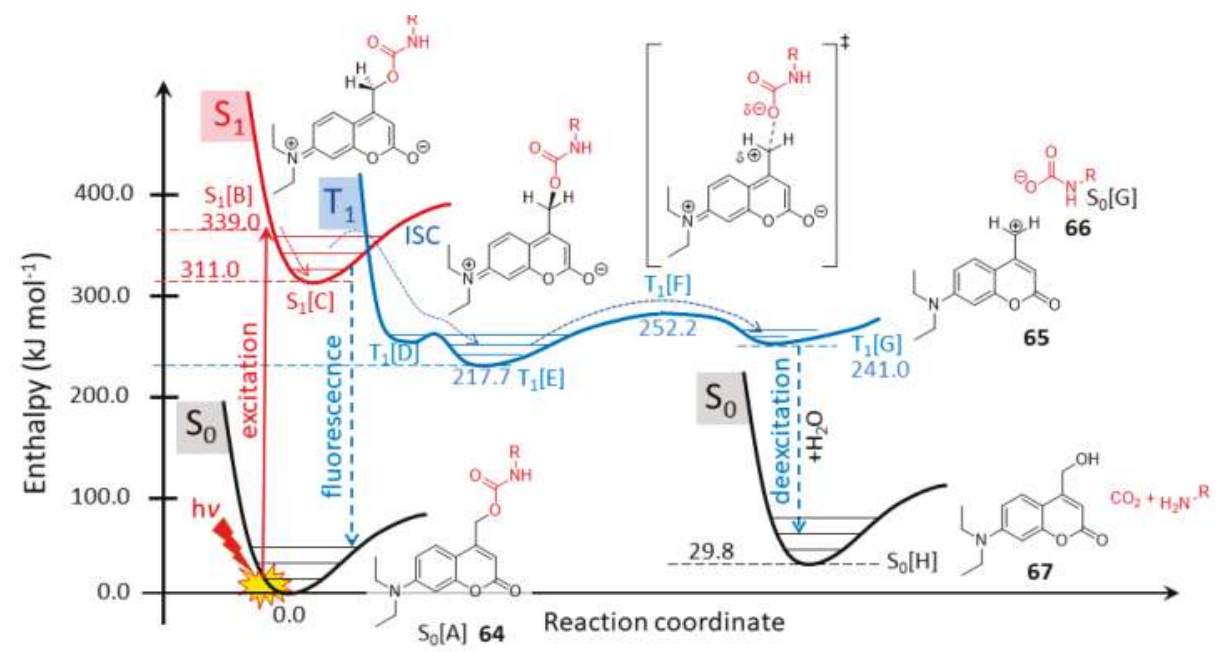

Figure 28. Reaction enthalpy $\left(H\right.$ in $\left.\mathrm{kJ} \mathrm{mol}^{-1}\right)$ profile of the photochemical initiated scission of coumarin-caged model compound 63 to $65+\mathbf{6 6}$, computed at B3LYP/6-31G(d,p)/ PCM(water) level of theory.

During the photochemical reaction, the original high amidicity value $(\mathrm{AM} \%=128.6 \%)$ remains nearly constant in its $S_{1}$ state, but in its subsequent triple state $\left(T_{1}\right)$ its amidicity increased to an unprecedently high value $(212.6 \%)$, which indicates that the carbamate functionality became a good leaving group, allowing the C-O dissociation. Finally, the forming of ground state carbamate 66 also exhibits a high value. It appears that there has been an internal energy transfer from the excited aromatic ring to the carbamate group. This means that amide, in fact, is stabilized and not activated, as might have been supposed from the study of DNI-Glu in the previous section.

\section{Materials and Methods}

All computations were carried out using the Gaussian09 program package (G09) [141]. Geometry optimizations and subsequent frequency analyses were carried out on selected amide-containing systems from which the values for the enthalpy of hydrogenation $\left(\Delta H_{\mathrm{H} 2}\right)$ were extracted. Computations were carried out at B3LYP/6-31G(d,p) level of theory [37]. Method and basis sets were chosen for their reliability in the characterization of amidicity [40] and carbonylicity [20], in agreement with works published earlier. The vibrational frequencies were computed at the same levels of theory as those used for geometry optimization, in order to properly confirm all structures as residing at minima on their potential energy hypersurfaces (PESs). In some cases, the acetonitrile or water solvent was considered by the default IEF-PCM (integral equation formalism polarizable continuum medium) method.

\section{Conclusions}

In general, amide groups have been considered to be very stable and functional for many years, due to their extensive conjugation of the $\pi$ electron system consisting of the four $\pi$ electrons. Due to this characteristic, amides can be found frequently in natural or human-made molecules as stable linkages between functioning building blocks, maintaining them for hundreds of years. During synthetic work, they are often and willingly used to inactivate a part of a given molecule as a protecting group. However, as was earlier revealed, the chemistry of the amide bond can be tricked, turning up their reactivity and forming a reactive functional group. 
In this paper we showed that there is a semi-quantitative rule to predict the outcome of an acyl transfer or transamidation reaction. This thermodynamic selection rule indicates the driving force of amide reactions based on amidicity or carbonylicity values, numerically measuring the amide bond strengths, namely the stabilization enthalpies, toward providing a simple and reliable protocol for practicing chemists. The change of amidicity or carbonylicity in the course of a reaction revealed that the process is favorable or unfavorable (Figure 29).

The amidicity-based classification of the acyl transfer reactions was demonstrated with a few case examples. Spontaneous processes suppose that the reagent amide exhibits an originally lowered amidicity value, typically by distortion or twisting. If the starting amide exhibits high amidicity it should be lowered by an amide activation. We have shown that it can be achieved by chemical activating groups or photoexcitation, to initiate the acyl exchange. Analogues activation was also used for selective amide reduction. This ON/OFF function of amides can also be revealed in natural biochemical processes, demonstrated by penicillin, blood clotting and intein-mediated protein splicing.

\section{REAGENT AMIDE}

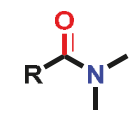

Moderate or Iow $A M \%$

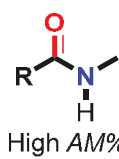

$$
\begin{aligned}
& \begin{array}{c}
\text { Chemical } \\
\text { activation }
\end{array} \\
& \underset{\text { 1. substituent }}{\text { modification }} \\
& \begin{array}{l}
\text { 2. neighboring } \\
\text { group effect }
\end{array}
\end{aligned}
$$

Direct process distortion or twist

\section{$\mathrm{H}-\mathbf{Q}$}$$
\mathbf{R}
$$

\section{PRODUCT}

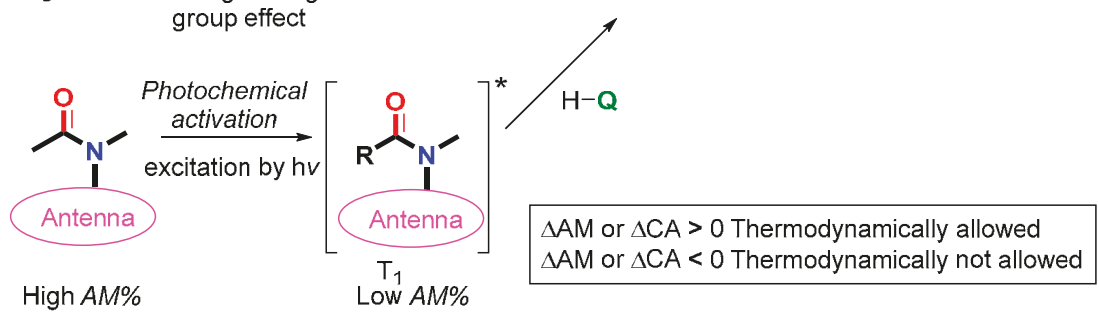

Figure 29. Summary of the amide activation processes. $\mathrm{T}_{1}=$ triplet state; $\mathrm{AM} \%=$ amidicity; $\mathrm{CA} \%=$ carbonylicity.

Author Contributions: Author Contributions: conceptualization, E.K., A.C., I.G.C. and Z.M.; methodology, Z.M.; software, Z.M.; validation, E.K., A.C. and I.G.C.; formal analysis, E.K., A.C. and I.G.C.; investigation, Z.M.; writing-original draft preparation, Z.M.; writing—review and editing E.K., A.C., I.G.C. and Z.M.; visualization A.C. and Z.M.; supervision I.G.C. and B.R.; financing B.R.; project administration, Z.M.

Funding: This project was supported by National Research, Development and Innovation Fund of Hungary, financed under the [KFI_16-1-2016-0177; NVKP_16-1-2016-0043, OTKA PD128612] funding scheme.

Conflicts of Interest: The authors declare no conflict of interest.

\section{References}

1. Pattabiraman, V.R.; Bode, J.W. Rethinking amide bond synthesis. Nature 2011, 480, 471-479. [CrossRef] [PubMed]

2. Mahesh, S.; Tang, K.; Raj, M. Amide Bond Activation of Biological Molecules Sriram. Molecules 2018, $23,2615$. [CrossRef] [PubMed]

3. Figueiredo, R.M.; Suppo, J.; Campagne, J. Nonclassical Routes for Amide Bond Formation. Chem. Rev. 2016, 116, 12029-12122. [CrossRef] [PubMed] 
4. Acosta-Guzmán, P.; Mateus-Gómez, A.; Gamba-Sánchez, D. Direct Transamidation Reactions: Mechanism and Recent Advances. Molecules 2018, 23, 2382. [CrossRef] [PubMed]

5. Valeur, E.; Bradley, M. Amide bond formation: Beyond the myth of coupling reagents. Chem. Soc. Rev. 2009, 38, 606-631. [CrossRef] [PubMed]

6. Greenberg, A.; Breneman, C.M.; Liebman, J.F. The Amide Linkage: Structural Significance in Chemistry, Biochemistry, and Materials Science; Wiley-VCH: New York, NY, USA, 2003; ISBN 978-0-471-35893-0.

7. Pauling, L.; Corey, R.B.; Branson, H.R. The structure of proteins: Two hydrogen-bonded helical configurations of the polypeptide chain. Proc. Natl. Acad. Sci. USA 1951, 37, 205-211. [CrossRef] [PubMed]

8. Hughes, A.B. (Ed.) Amino Acids, Peptides and Proteins in Organic Chemistry; Wiley-VCH: Weinheim, Germany, 2011; ISBN 978-3-527-32102-5.

9. Kaspar, A.A.; Reichert, J.M. Future directions for peptide therapeutics development. Drug Discov. Today 2013, 18, 807-817. [CrossRef] [PubMed]

10. Pauling, L. The nature of the chemical bond. Application of results obtained from the quantum mechanics and from a theory of paramagnetic susceptibility to the structure of molecules. J. Am. Chem. Soc. 1931, 53, 1367-1400. [CrossRef]

11. Pauling, L. The Nature of the Chemical Bond; Oxford University Press: London, UK, 1940.

12. Greenberg, A.; Breneman, C.M.; Liebman, J.F. (Eds.) Amide Linkage: Structural Significance in Chemistry, Biochemistry, and Materials Science; Wiley-VCH: New York, NY, USA, 2000.

13. Wiberg, K.B.; Breneman, C.M. Resonance Interactions in Acyclic Systems. 3. Formamide Internal Rotation Revisited. Charge and Energy Redistribution along the C-N Bond Rotational Pathway. J. Am. Chem. Soc. 1992, 114, 831-840. [CrossRef]

14. Glover, S.A.; Rosser, A.A. Reliable determination of amidicity in acyclic amides and lactams. J. Org. Chem. 2012, 77, 5492-5502. [CrossRef] [PubMed]

15. Van Vranken, D.; Weiss, G.A. Introduction to Bioorganic Chemistry and Chemical Biology; Garland Science (Taylor \& Francis): Oxford, UK, 2013; ISBN 978-0815342144.

16. Brix, K.; Stöcker, W. Proteases: Structure and Function; Brix, K., Stöcker, W., Eds.; Springer: Berlin, Germany, 2013; ISBN 978-3-7091-0885-7.

17. Lukes, R. Sur une nouvelle application de la règle de bredt. Collect. Czechslovak Chem. Commun. 1938, 10, 148-152. [CrossRef]

18. Woodward, R.B.; Neuberger, A.; Trenner, N.R. The Chemistry of Penicillin; Clarke, H.T., Johnson, J.R., Robinson, R., Eds.; Princeton University Press: New Jersey, NJ, USA, 1949.

19. Wasserman, H.H. Chemistry: Synthesis with a twist. Nature 2006, 441, 699-700. [CrossRef] [PubMed]

20. Mucsi, Z.; Chass, G.A.; Viskolcz, B.; Csizmadia, I.G. Quantitative scale for the extent of conjugation of carbonyl groups: "Carbonylicity" percentage as a chemical driving force. J. Phys. Chem. A 2008, 112, 9153-9165. [CrossRef] [PubMed]

21. Kemnitz, C.R.; Loewen, M.J. "Amide resonance" correlates with a breadth of C-N rotation barriers. J. Am. Chem. Soc. 2007, 129, 2521-2528. [CrossRef] [PubMed]

22. Mujika, J.I.; Matxain, J.M.; Eriksson, L.A.; Lopez, X. Resonance structures of the amide bond: The advantages of planarity. Chem.-Eur. J. 2006, 12, 7215-7224. [CrossRef] [PubMed]

23. Bechara, W.S.; Pelletier, G.; Charette, A.B. Chemoselective synthesis of ketones and ketimines by addition of organometallic reagents to secondary amides. Nat. Chem. 2012, 4, 228-234. [CrossRef] [PubMed]

24. Mujika, J.I.; Mercero, J.M.; Lopez, X. Water-promoted hydrolysis of a highly twisted amide: Rate acceleration caused by the twist of the amide bond. J. Am. Chem. Soc. 2005, 127, 4445-4453. [CrossRef] [PubMed]

25. Wang, B.; Cao, Z. Acid-catalyzed reactions of twisted amides in water solution: Competition between hydration and hydrolysis. Chem.-Eur. J. 2011, 17, 11919-11929. [CrossRef] [PubMed]

26. Cho, S.J.; Cui, C.; Lee, J.Y.; Park, J.K.; Suh, S.B.; Park, J.; Kim, B.H.; Kim, K.S. N-Protonation vs O-Protonation in Strained Amides: Ab Initio Study. J. Org. Chem. 1997, 62, 4068-4071. [CrossRef]

27. Mucsi, Z.; Tsai, A.; Szori, M.; Chass, G.A.; Viskolcz, B.; Csizmadia, I.G. A Quantitative Scale for the Extent of Conjugation of the Amide Bond. Amidity Percentage as a Chemical Driving Force. J. Phys. Chem. A 2007, 111, 13245-13254. [CrossRef] [PubMed]

28. Morgan, J.; Greenberg, A.; Liebman, J.F. Paradigms and paradoxes: O- and N-protonated amides, stabilization energy, and resonance energy. Struct. Chem. 2012, 23, 197-199. [CrossRef] 
29. Morgan, J.; Greenberg, A. Novel bridgehead bicyclic lactams: (A) Molecules predicted to have O-protonated and N-protonated tautomers of comparable stability; (B) hyperstable lactams and their O-protonated tautomers. J. Chem. Thermodyn. 2014, 73, 206-212. [CrossRef]

30. Tinnis, F.; Volkov, A.; Slagbrand, T.; Adolfsson, H. Chemoselective Reduction of Tertiary Amides under Thermal Control: Formation of either Aldehydes or Amines. Angew. Chem. Int. Ed. 2016, 55, 4562-4566. [CrossRef] [PubMed]

31. Szostak, M.; Spain, M. Highly Chemoselective Reduction of Amides (Primary, Secondary, Tertiary) to Alcohols using SmI2/Amine/ $\mathrm{H}_{2} \mathrm{O}$ under Mild Conditions. J. Am. Chem. Soc. 2014, 136, 2268-2271. [CrossRef] [PubMed]

32. Thakkar, B.; Svendsen, J.; Engh, R. Density Functional Studies on Secondary Amides: Role of Steric Factors in Cis/Trans Isomerization. Molecules 2018, 23, 2455. [CrossRef] [PubMed]

33. Klán, P.; Šolomek, T.; Bochet, C.G.; Blanc, A.; Givens, R.; Rubina, M.; Popik, V.; Kostikov, A.; Wirz, J. Photoremovable protecting groups in chemistry and biology: Reaction mechanisms and efficacy. Chem. Rev. 2013, 113, 119-191. [CrossRef] [PubMed]

34. Ellis-Davies, G.C.R. Caged compounds: Photorelease technology for control of cellular chemistry and physiology. Nat. Methods 2007, 4, 619-628. [CrossRef] [PubMed]

35. Mayer, G.; Hechel, A. Biologically active molecules with a "light switch". Angew. Chem. Int. Ed. 2006, 45, 4900-4921. [CrossRef] [PubMed]

36. Kotsuki, H.; Iwasaki, M.; Nishizawa, H. A new powerful method for the transformation of lactams into $\omega$-amino-carboxamides under high pressure conditions. Tetrahedron Lett. 1992, 33, 4945-4948. [CrossRef]

37. Becke, A.D. Density-functional thermochemistry. III. The role of exact exchange. J. Chem. Phys. 1993, 98, 5648-5652. [CrossRef]

38. Greenberg, A.; Moore, D.T.; DuBois, T.D. Small and medium-sized bridgehead bicyclic lactams: A systematic ab initio molecular orbital study. J. Am. Chem. Soc. 1996, 118, 8658-8668. [CrossRef]

39. Greenberg, A.; Venanzi, C.A. Structures and Energetics of Two Bridgehead Lactams and Their N- and O-Protonated Forms: An ab Initio Molecular Orbital Study. J. Am. Chem. Soc. 1993, 115, 6951-6957. [CrossRef]

40. Mucsi, Z.; Chass, G.A.; Csizmadia, I.G. Amidicity change as a significant driving force and thermodynamic selection rule of transamidation reactions. A synergy between experiment and theory. J. Phys. Chem. B 2008, 112, 7885-7893. [CrossRef] [PubMed]

41. Lukács, A.; Szabó, L.; Hazai, L.; Szántay, C.; Mák, M.; Gorka, Á.; Szántay, C. Seven-membered ring formation through Grewe-cyclization. Tetrahedron 2001, 57, 5843-5850. [CrossRef]

42. Sibi, M.P.; Hasegawa, H.; Ghorpade, S.R. A convenient method for the conversion of N-acyloxazolidinones to hydroxamic acids. Org. Lett. 2002, 4, 3343-3346. [CrossRef] [PubMed]

43. Galat, A.; Elion, G. The Interaction of Amides with Amines: A General Method of Acylation. J. Am. Chem. Soc. 1943, 65, 1566-1567. [CrossRef]

44. Sowa, F.J.; Nieuwland, J.A. Organic Reactions with Boron Fluoride. XIV. The Reaction of Amides with Acids and Amines. J. Am. Chem. Soc. 1937, 59, 1202-1203. [CrossRef]

45. Varga, T.R.; Nemes, P.; Mucsi, Z.; Scheiber, P. A concise synthetic pathway towards 5-substituted indolizidines. Tetrahedron Lett. 2007, 48, 1159-1161. [CrossRef]

46. Wright, W.; Brabander, H.; Hardy, R. Notes- The Rearrangement of N-(Methylaminoalkyl)anilides. J. Org. Chem. 1961, 26, 2120-2123. [CrossRef]

47. Kano, S.; Ebata, T.; Shibuya, S. Intra- and Intermolecular Nucleophilic Cleavage of the Amide Bond of b-Laactams. Chem. Pharm. Bull. 1979, 27, 2450-2455. [CrossRef]

48. Wade, P.C.; Vogt, B.R.; Toeplitz, B.; Puar, M.S.; Gougoutas, J.Z. 1,2,4-Triazolo- and 1,2,5-triazino[4,3d][1,4]benzodiazepinone ring systems: synthesis and barrier to ring inversion. J. Org. Chem. 1979, 44, 88-99. [CrossRef]

49. Kano, S.; Ebata, T.; Denta, Y.; Hibino, S.; Shibuya, S. Formtion of Some Heterocycles through Ring Transformation of 1-Arylazetidin-2-ones. Heterocycles 1977, 8, 411-416. [CrossRef]

50. Hie, L.; Fine Nathel, N.F.; Shah, T.K.; Baker, E.L.; Hong, X.; Yang, Y.F.; Liu, P.; Houk, K.N.; Garg, N.K. Conversion of amides to esters by the nickel-catalysed activation of amide C-N bonds. Nature 2015, 524, 79-83. [CrossRef] [PubMed] 
51. Itai, A.; Toriumi, Y.; Tomioka, N.; Kagechika, H.; Azumaya, I.; Shudo, K. Stereochemistry of N-methylbenzanilide and benzanilide. Tetrahedron Lett. 1989, 30, 6177-6180. [CrossRef]

52. Jin, Y.; Chen, M.; Ge, S.; Hartwig, J.F. Palladium-Catalyzed, Enantioselective $\alpha$-Arylation of $\alpha$-Fluorooxindoles. Org. Lett. 2017, 19, 1390-1393. [CrossRef] [PubMed]

53. Di Gregorio, G.; Mari, M.; Bartolucci, S.; Bartoccini, F.; Piersanti, G. Divergent reactions of oxindoles with amino alcohols: Via the borrowing hydrogen process: Oxindole ring opening vs. C3 alkylation. Org. Chem. Front. 2018, 5, 1622-1627. [CrossRef]

54. Reverdito, A.M.; Orelli, L.; Dalmaso, M.; Perillo, I.; Fernández, B.M. Synthesis and hydrolysis of substituted tetrahydropyrimidinium salts. Behaviour of the degradation products on varying pH. J. Heterocycl. Chem. 1991, 28, 273-281. [CrossRef]

55. Milos, S.; Hejtmánková, L.; Hanusek, J.; Machác, V. Synthesis and Ring Transformation of Substituted S-(1-Phenylpyrrolidine-2-ones-3-yl) isothiuronium Salts to Substituted. J. Heterocycl. Chem. 2002, 39, 1105-1107. [CrossRef]

56. Schade, B.; Hagen, V.; Schmidt, R.; Herbrich, R.; Krause, E.; Eckardt, T.; Bendig, J. Deactivation Behavior and Excited-State Properties of (Coumarin-4-yl)methyl Derivatives. 1. Photocleavage of (7-Methoxycoumarin-4-yl)methyl-Caged Acids with Fluorescence Enhancement. J. Org. Chem. 1999, 64, 9109-9117. [CrossRef]

57. Liu, C.; Szostak, M. Twisted Amides: From Obscurity to Broadly Useful Transition-Metal-Catalyzed Reactions by N-C Amide Bond Activation. Chem.-Eur. J. 2017, 23, 7157-7173. [CrossRef] [PubMed]

58. Borthwick, A.D.; Davies, D.E.; Exall, A.M.; Livermore, D.G.; Sollis, S.L.; Nerozzi, F.; Allen, M.J.; Perren, M.; Shabbir, S.S.; Woollard, P.M.; et al. 2,5-Diketopiperazines as potent, selective, and orally bioavailable oxytocin antagonists. 2. Synthesis, chirality, and pharmacokinetics. J. Med. Chem. 2005, 48, 6956-6969. [CrossRef] [PubMed]

59. Matulenko, M.A.; Lee, C.H.; Jiang, M.; Frey, R.R.; Cowart, M.D.; Bayburt, E.K.; DiDomenico, S.; Gfesser, G.A.; Gomtsyan, A.; Guo, Z.Z.; et al. 5-(3-Bromophenyl)-7-(6-morpholin-4-ylpyridin-3-yl)pyrido[2,3-d] pyrimidin4-ylamine: Structure-activity relationships of 7-substituted heteroaryl analogs as non-nucleoside adenosine kinase inhibitors. Bioorg. Med. Chem. 2005, 13, 3705-3720. [CrossRef] [PubMed]

60. Mucsi, Z.; Chass, G.A.; Ábrányi-Balogh, P.; Jójárt, B.; Fang, D.C.; Ramirez-Cuesta, A.J.; Viskolcz, B.; Csizmadia, I.G. Penicillin's catalytic mechanism revealed by inelastic neutrons and quantum chemical theory. Phys. Chem. Chem. Phys. 2013, 15, 20447-20455. [CrossRef] [PubMed]

61. Blackburn, G.M.; Skaife, C.J.; Kay, I.T. Strain effects in acyl transfer reactions. J. Chem. Res. Synopses 1980, 9, 294-295.

62. Wang, Q.P.; Bennet, A.J.; Brown, R.S.; Santarsiero, B.D. Distorted amides as models for activated peptide $\mathrm{N}-\mathrm{C}=\mathrm{O}$ units. 2. The synthesis, hydrolytic profile, and molecular structure of 3,4-dihydro-2-oxo-1,4propanoquinoline. Can. J. Chem. 1990, 68, 1732-1739. [CrossRef]

63. Wang, Q.P.; Bennet, A.J.; Brown, R.S.; Santarsiero, B.D. Distorted Amides as Models for Activated Peptide N-C(O) Units. 3. Synthesis, Hydrolytic Profile, and Molecular Structure of 2,3,4,5-Tetrahydro-2-oxo-1,5propanobenzazepine. J. Am. Chem. Soc. 1991, 113, 5757-5765. [CrossRef]

64. Somayaji, V.; Brown, R.S. Distorted Amides as Models for Activated Peptide N-C=0 Units Produced during Enzyme-Catalyzed Acyl Transfer Reactions. 1. The Mechanism of Hydrolysis of 3,4-Dihydro-2oxo-1,4-ethanoquinoline and 2,3,4,5-Tetrahydro-2-oxo-1,5-ethanobenzazepine. J. Org. Chem. 1986, 51, 2676-2686. [CrossRef]

65. Tani, K.; Stoltz, B.M. Synthesis and structural analysis of 2-quinuclidonium tetrafluoroborate. Nature 2006, 441, 731-734. [CrossRef] [PubMed]

66. Kirby, A.J.; Komarov, I.V.; Feeder, N. Synthesis, structure and reactions of the most twisted amide. J. Chem. Soc. Perkin Trans. 2 2001, 522-529. [CrossRef]

67. Kirby, A.J.; Komarov, I.V.; Feeder, N. Spontaneous, millisecond formation of a twisted amide from the amino acid, and the crystal structure of a tetrahedral intermediate [1]. J. Am. Chem. Soc. 1998, 120, 7101-7102. [CrossRef]

68. Kirby, A.J.; Komarov, I.V.; Wothers, P.D.; Feeder, N. The Most Twisted Amide: Structure and Reactions. Angew. Chem. Int. Ed. 1998, 37, 785-786. [CrossRef]

69. Andersson, P.G.; Munslow, I.J. (Eds.) Modern Reduction Methods; Wiley-VCH: New York, NY, USA, 2008; ISBN 978-3-527-31862-9. 
70. Levkoeva, E.I.; Nikitskaya, E.S.; Yakhontov, L.N. Reaction of 2-quinuclidones with and without C-N bond breaking. Dokl. Akad. Nauk 1970, 192, 342.

71. Von Pracejus, H.; Kehlen, M.; Kehlen, H.; Matschiner, H. Neues zur sterischen mesomeriehinderung bei lactamen vom typ des $\alpha$-chinuclidons. Tetrahedron 1965, 21, 2257-2270. [CrossRef]

72. Werstiuk, N.H.; Brown, R.S.; Wang, Q. An AM1 calculational study of the protonation and reactions of 3,4-dihydro-2-oxo-1,4-ethanoquinoline, 3,4-dihydro-2-oxo-1,4-propanoquinoline, 3,3,4,5-tetrahydro-2-oxo1,5-ethanobenzazepine, 3,3,4,5-tetrahydro-2-oxo-1,5-propanobenzazepine, and N-methyl-4-b. Can. J. Chem. 1996, 74, 524-532. [CrossRef]

73. Hu, F.; Lalancette, R.; Szostak, M. Structural Characterization of N-Alkylated Twisted Amides: Consequences for Amide Bond Resonance and N-C Cleavage. Angew. Chem. Int. Ed. 2016, 55, 5062-5066. [CrossRef] [PubMed]

74. Hutchby, M.; Houlden, C.E.; Gair Ford, J.; Tyler, S.N.G.; Gagné, M.R.; Lloyd-Jones, G.C.; Booker-Milburn, K.I. Hindered ureas as masked isocyanates: Facile carbamoylation of nucleophiles under neutral conditions. Angew. Chem. Int. Ed. 2009, 48, 8721-8724. [CrossRef] [PubMed]

75. Hutchby, M.; Houlden, C.E.; Haddow, M.F.; Tyler, S.N.G.; Lloyd-Jones, G.C.; Booker-Milburn, K.I. Switching pathways: Room-temperature neutral solvolysis and substitution of amides. Angew. Chem. Int. Ed. 2012, 51, 548-551. [CrossRef] [PubMed]

76. Somayaji, V.; Skorey, K.I.; Brown, R.S. Molecular Structure of and Its Reaction with Alcohols as a Model for the Acylation Step of the Serine Proteases. J. Org. Chem. 1986, 51, 4866-4872. [CrossRef]

77. Garcia, J.; González, J.; Segura, R.; Urpí, F.; Vilarrasa, J. Reaction of N-Nitroso- and N-Nitro-N-alkylamides with Amines. J. Org. Chem. 1984, 49, 3322-3327. [CrossRef]

78. Garcia, J.; Vilarrasa, J. New synthetic "tricks" using old reagents. A mild method for the conversion of RCONHR' to RCONHR". Tetrahedron Lett. 1982, 23, 1127-1128. [CrossRef]

79. Hendrickson, J.B.; Bergeron, R. Trifumides: New Acylating Ard Triflating Reagents. Tetrahedron Lett. 1973, 14, 4607-4610. [CrossRef]

80. Bon, E.; Bigg, D.C.H.; Bertrand, G. Aluminum Chloride-Promoted Transamidation Reactions. J. Org. Chem. 1994, 59, 4035-4036. [CrossRef]

81. Shah, K.R.; Blanton, C.D.W. Reaction of Maleimides and Ethyl 3-Aminocrotonates. A Reinvestigation Leading to an Improved Synthesis of Pyrrolo[3,4-c]pyridines. J. Org. Chem. 1982, 47, 502-508. [CrossRef]

82. Davidsen, S.K.; May, P.D.; Summers, J.B. Di-tert-butyl N-Acylimidodicarbonates as Isolable Acylating Agents: Mild Conversion of Primary Carboxamides to Substituted Amides. J. Org. Chem. 1991, 56, 5482-5485. [CrossRef]

83. Shapiro, G.; Marzi, M. Facile and Selective O-Alkyl Transesterification of Primary Carbamates with Titanium(IV) Alkoxides. J. Org. Chem. 1997, 62, 7096-7097. [CrossRef] [PubMed]

84. Goodman, C.A.; Eagles, J.B.; Rudahindwa, L.; Hamaker, C.G.; Hitchcock, S.R. Synthesis, X-ray crystallography, and reactions of $\mathrm{N}$-acyl and N-carbamoyl succinimides. Synth. Commun. 2013, 43, 2155-2164. [CrossRef]

85. Goodman, C.A.; Hamaker, C.G.; Hitchcock, S.R. Synthesis and evaluation of some variants of the Nefkens' reagent. Tetrahedron Lett. 2013, 54, 6012-6014. [CrossRef]

86. Ji, C.-L.; Xie, P.-P.; Hong, X. Computational Study of Mechanism and Thermodynamics of Ni/IPr-Catalyzed Amidation of Esters. Molecules 2018, 23, 2681. [CrossRef] [PubMed]

87. Li, Z.; Zhang, S.L.; Fu, Y.; Guo, Q.X.; Liu, L. Mechanism of Ni-catalyzed selective C-O bond activation in cross-coupling of aryl esters. J. Am. Chem. Soc. 2009, 131, 8815-8823. [CrossRef] [PubMed]

88. Yu, H.; Fu, Y. Mechanistic origin of cross-coupling selectivity in Ni-catalysed Tishchenko reactions. Chem.-Eur. J. 2012, 18, 16765-16773. [CrossRef] [PubMed]

89. Stach, H.; Hesse, M. Synthesis of macrocyclic compounds by ring enlargement. Tetrahedron 1988, 44, 1573-1590. [CrossRef]

90. Süsse, M.; Hájícek, J.; Hesse, M. Studies on the Carbon Zip Reaction of 2-OxocycIoalkane-l-carbonitriles. Helv. Chim. Acta 1985, 68, 1986-1997. [CrossRef]

91. Askitoglu, E.; Guggisberg, A.; Hesse, M. N-substituted 3-aminopropanenitriles and 2-aminoacetonitriles asSchiff-base equivalents. Helv. Chim. Acta 1985, 68, 750-759. [CrossRef]

92. Seyden-Penne, J. Reductions by the Alumino and Borohydrides in Organic Synthesis; Wiley-VCH: New York, NY, USA, 1997; ISBN 978-0-471-19036-3. 
93. Hudlicky, M. (Ed.) Reductions in Organic Chemistry; John Wiley \& Sons: New York, NY, USA, 1984.

94. Trost, B.M.; Fleming, I. (Eds.) Comprehensive Organic Synthesis; Pergamon: Oxford, UK, 1991.

95. Gribble, G.W. Sodium borohydride in carboxylic acid media: A phenomenal reduction system. Chem. Soc. Rev. 1998, 27, 395. [CrossRef]

96. Reeves, J.T.; Tan, Z.; Marsini, M.A.; Han, Z.S.; Xu, Y.; Reeves, D.C.; Lee, H.; Lu, B.Z.; Senanayake, C.H. A practical procedure for reduction of primary, secondary and tertiary amides to amines. Adv. Synth. Catal. 2013, 355, 47-52. [CrossRef]

97. Simmons, B.J.; Hoffmann, M.; Hwang, J.; Jackl, M.K.; Garg, N.K. Nickel-Catalyzed Reduction of Secondary and Tertiary Amides. Org. Lett. 2017, 19, 1910-1913. [CrossRef] [PubMed]

98. Ortín, I.; González, J.F.; de la Cuesta, E.; Avendaño, C. Synthesis of a novel tetrahydroisoquinoline pentacyclic framework. Tetrahedron 2009, 65, 2201-2211. [CrossRef]

99. Ortín, I.; González, J.F.; de la Cuesta, E.; Manguan-García, C.; Perona, R.; Avendaño, C. Pyrazino[1,2b]isoquinolines: Synthesis and study of their cytostatic and cytotoxic properties. Bioorganic Med. Chem. 2008, 16, 9065-9078. [CrossRef] [PubMed]

100. Valente, M.W.N.; Williams, R.M. The Concise and Versatile Synthesis of Epi-malbrancheamide and Structurally Related Analogs. Heterocycles 2006, 70, 249-259. [CrossRef]

101. Lee, B.H.; Clothier, M.F. Selective reduction of secondary amides to amines in the presence of tertiary amides. Tetrahedron Lett. 1999, 40, 643-644. [CrossRef]

102. Zein, N.; Sinha, A.M.; McGahren, W.J.; Ellestad, G.A. Calicheamicin gamma 1I: An antitumor antibiotic that cleaves double-stranded DNA site specifically. Science 1988, 240, 1198. [CrossRef] [PubMed]

103. Zein, N.; Poncin, M.; Nilakantan, R.; Ellestad, G. Calicheamicin gamma 1I and DNA: Molecular recognition process responsible for site-specificity. Science 1989, 244, 697-699. [CrossRef] [PubMed]

104. Boger, D.L.; Garbaccio, R.M. Shape-dependent catalysis: Insights into the source of catalysis for the CC-1065 and duocarmycin DNA alkylation reaction. Acc. Chem. Res. 1999, 32, 1043-1052. [CrossRef]

105. Boger, D.L.; Johnson, D.S. CC-1065 and the duocarmycins: Understanding their biological function through mechanistic studies. Angew. Chem. Int. Ed. 1996, 35, 1438-1474. [CrossRef]

106. Boger, D.L.; Boyce, C.W.; Garbaccio, R.M.; Goldberg, J.A. CC-1065 and the duocarmycins: Synthetic studies. Chem. Rev. 1997, 97, 787-828. [CrossRef] [PubMed]

107. Groll, M.; Schellenberg, B.; Bachmann, A.S.; Archer, C.R.; Huber, R.; Powell, T.K.; Lindow, S.; Kaiser, M.; Dudler, R. A plant pathogen virulence factor inhibits the eukaryotic proteasome by a novel mechanism. Nature 2008, 452, 755-758. [CrossRef] [PubMed]

108. Crawford, J.M.; Thomas, P.M.; Scheerer, J.R.; Vagstad, A.L.; Kelleher, N.L.; Townsend, C.A. Deconstruction of iterative multidomain polyketide synthase function. Science 2008, 320, 243-246. [CrossRef] [PubMed]

109. Bud, R. The fall of a wonder drug. Nature 2007, 446, 981. [CrossRef]

110. Palta, S.; Saroa, R.; Palta, A. Overview of the coagulation system. Indian J. Anaesth. 2014, 58, 515-523. [CrossRef] [PubMed]

111. Adams, R.L.C.; Bird, R.J. Review article: Coagulation cascade and therapeutics update: Relevance to nephrology. Part 1: Overview of coagulation, thrombophilias and history of anticoagulants. Nephrology 2009, 14, 462-470. [CrossRef] [PubMed]

112. Hoffman, R.; Benz, E.; Shattil, S.; Furie, B.; Cohen, H. (Eds.) Hematology: Basic Principles and Practice, 4th ed.; Elsevier: Philadelphia, PA, USA, 2005; ISBN 978-0443079542.

113. Griffin, M.; Casadio, R.; Bergamini, C.M. Transglutaminases: Nature's biological glues. Biochem. J. 2002, 368, 377-396. [CrossRef] [PubMed]

114. Kane, P.; Yamashiro, C.; Wolczyk, D.; Neff, N.; Goebi, M.; Stevens, T. Protein splicing converts the yeast TFP1 gene product to the 69-kD subunit of the vacuolar $\mathrm{H}(+)$-adenosine triphosphatase. Science 1990, 250, 651-657. [CrossRef] [PubMed]

115. Anraku, Y.; Mizutani, R.; Satow, Y. Protein splicing: Its discovery and structural insight into novel chemical mechanisms. IUBMB Life 2005, 57, 563-574. [CrossRef] [PubMed]

116. Hirata, R.; Ohsumi, Y.; Nakano, A.; Kawasaki, H.; Suzuki, K.; Anraku, Y. Molecular Structure of a Gene, VMA1, Encoding the Catalytic Subunit of $\mathrm{H}+$-Translocating Adenosine Triphosphatase from Vacuolar Membranes of Saccharomyces cerevisiae. J. Biol.Chem. 1990, 265, 6726-6733. [PubMed]

117. Gimble, F.S.; Thorner, J. Homing of a DNA endonuclease gene by meiotic gene conversion in Saccharomyces cerevisiae. Nature 1992, 357, 301-306. [CrossRef] [PubMed] 
118. Kawasaki, M.; Makino, S.I.; Matsuzawa, H.; Satow, Y.; Ohya, Y.; Anraku, Y. Folding-dependent in vitro protein splicing of the Saccharomyces cerevisiae VMA1 protozyme. Biochem. Biophys. Res. Commun. 1996, 222, 827-832. [CrossRef] [PubMed]

119. Kawasaki, M.; Nogami, S.; Satow, Y.; Ohya, Y.; Anraku, Y. Identification of three core regions essential for protein splicing of the yeast Vma1 protozyme. A random mutagenesis study of the entire VMA1- derived endonuclease sequence. J. Biol. Chem. 1997, 272, 15668-15674. [CrossRef] [PubMed]

120. Kawasaki, M.; Satow, Y.; Ohya, Y.; Anraku, Y. Protein splicing in the yeast Vma1 protozyme: Evidence for an intramolecular reaction. FEBS Lett. 1997, 412, 518-520. [CrossRef]

121. Walsh, C. Molecular mechanisms that confer antibacterial drug resistance. Nature 2000, 406, 775. [CrossRef] [PubMed]

122. Dennis, C. The bugs of war. Nature 2001, 411, 232. [CrossRef] [PubMed]

123. Theilgaard, H.B.A.; Kristiansen, K.N.; Henriksen, C.M.; Nielsen, J. Purification and characterization of delta-(L-alpha-aminoadipyl)-L-cysteinyl-D-valine synthetase from Penicillium chrysogenum. Biochem. J. 1997, 327, 185-191. [CrossRef] [PubMed]

124. Huffman, G.W.; Gesellchen, P.D.; Turner, J.R.; Rothenberger, R.B.; Osborne, H.E.; Miller, F.D.; Chapman, J.L.; Queener, S.W. Substrate Specificity of Isopenicillin N Synthase. J. Med. Chem. 1992, 35, 1897-1914. [CrossRef] [PubMed]

125. Roach, P.L.; Clifton, I.J.; Fülöp, V.; Harlos, K.; Barton, G.J.; Hajdu, J.; Andersson, I.; Schofield, C.J.; Baldwin, J.E. Crystal structure of isopenicillin $\mathrm{N}$ synthase is the first from a new structural family of enzymes. Nature 1995, 375, 700. [CrossRef] [PubMed]

126. Voet, D.; Voet, J.G. Biochemistry, 3rd ed.; John Wiley \& Sons, Inc.: Hoboken, NJ, USA, 2004.

127. Cohen, M.L. Changing patterns of infectious disease. Nature 2000, 406, 762. [CrossRef] [PubMed]

128. Smaglik, P. Antibiotic resistance must be monitored, US Senate is told. Nature 2000, 407, 437. [CrossRef] [PubMed]

129. Nogrady, T. Medicinal Chemistry A Biochemical Approach; Oxford University Press: New York, NY, USA, 1985.

130. Sheehan, J.C. The enchanted Ring: The Untold Story of Penicillin; The MIT Press: Cambridge, MA, USA, 1982; ISBN 9780262192040.

131. Johnson, J.R.; Woodward, R.B.; Robinson, R. The Chemistry of Penicillin; Clarke, H.T., Ed.; Princton University Press: Princton, NJ, USA, 1949; ISBN 9780691627489.

132. Woodward, R.B. Recent advances in the chemistry of natural products. Science 1966, 153, 487-493. [CrossRef] [PubMed]

133. Newton, G.; Abraham, E.P. Cephalosporin C, a New Antibiotic containing Sulphur and D- $\alpha$-Aminoadipic Acid. Nature 1955, 175, 548. [CrossRef] [PubMed]

134. Tally, F.P.; Jacobus, N.V.; Gorbach, S.L. In vitro activity of thienamycin. Antimicrob. Agents Chemother. 1978, 14, 436-438. [CrossRef] [PubMed]

135. Johnston, D.B.R.; Schmitt, S.M.; Bouffard, F.A.; Christensen, B.G. Total Synthesis of ( \pm )-Thienamycin. J. Am. Chem. Soc. 1978, 100, 313-315. [CrossRef]

136. Araya, R. Input transformation by dendritic spines of pyramidal neurons. Front. Neuroanat. 2014, 8, 1-18. [CrossRef] [PubMed]

137. Granger, A.J.; Nicoll, R.A. Expression mechanisms underlying long-term potentiation: A postsynaptic view, 10 years on. Philos. Trans. R. Soc. Lond. B Biol. Sci. 2014, 369, 1-6. [CrossRef]

138. Pálfi, D.; Chiovini, B.; Szalay, G.; Kaszás, A.; Turi, G.F.; Katona, G.; Ábrányi-Balogh, P.; Szori, M.; Potor, A.; Frigyesi, O.; et al. High efficiency two-photon uncaging coupled by the correction of spontaneous hydrolysis. Org. Biomol. Chem. 2018, 16, 1958-1970. [CrossRef] [PubMed]

139. Papageorgiou, G.; Ogden, D.; Kelly, G.; Corrie, J.E.T. Synthetic and photochemical studies of substituted 1-acyl-7-nitroindolines. Photochem. Photobiol. Sci. 2005, 4, 887-896. [CrossRef] [PubMed]

140. Warther, D.; Gug, S.; Specht, A.; Bolze, F.; Nicoud, J.F.; Mourot, A.; Goeldner, M. Two-photon uncaging: New prospects in neuroscience and cellular biology. Bioorg. Med. Chem. 2010, 18, 7753-7758. [CrossRef] [PubMed]

141. Frisch, M.J.; Trucks, G.W.; Schlegel, H.B.; Scuseria, G.E.; Robb, M.A.; Cheeseman, J.R.; Scalmani, G.; Barone, V.; Mennucci, B.; Petersson, G.A.; et al. Gaussian 09, Revision D.01; Gaussian, Inc.: Wallingford, CT, USA, 2009. 
142. Kovács, E.; Sághy, P.; Turczel, G.; Tóth, I.; Lendvay, G.; Domján, A.; Anastas, P.T.; Tuba, R. Metathesis of renewable polyene feedstocks-Indirect evidences of the formation of catalytically active ruthenium allylidene species. J. Organomet. Chem. 2017, 847, 213-217. [CrossRef]

143. Lu, M.; Fedoryak, O.D.; Moister, B.R.; Dore, T.M. Bhc-diol as a photolabile protecting group for aldehydes and ketones. Org. Lett. 2003, 5, 2119-2122. [CrossRef] [PubMed]

144. Montgomery, H.J.; Perdicakis, B.; Fishlock, D.; Lajoie, G.A.; Jervis, E.; Guy Guillemette, J. Photo-control of nitric oxide synthase activity using a caged isoform specific inhibitor. Bioorg. Med. Chem. 2002, 10, 1919-1927. [CrossRef]

145. Takaoka, K.; Tatsu, Y.; Yumoto, N.; Nakajima, T.; Shimamoto, K. Synthesis and photoreactivity of caged blockers for glutamate transporters. Bioorg. Med. Chem. Lett. 2003, 13, 965-970. [CrossRef]

146. Takaoka, K.; Tatsu, Y.; Yumoto, N.; Nakajima, T.; Shimamoto, K. Synthesis of carbamate-type caged derivatives of a novel glutamate transporter blocker. Bioorg. Med. Chem. 2004, 12, 3687-3694. [CrossRef] [PubMed]

147. Givens, R.S.; Matuszewski, B. Photochemistry of Phosphate Esters: An Efficient Method for the Generation of Electrophiles1. J. Am. Chem. Soc. 1984, 106, 6860-6861. [CrossRef]

148. Furata, T.; Torigai, H.; Sugimoto, M.; Iwamura, M. Photochemical Properties of New Photolabile cAMP Derivatives in a Physiological Saline Solution. J. Org. Chem. 1995, 60, 3953-3956. [CrossRef]

149. Hagen, V.; Bendig, J.; Frings, S.; Wiesner, B.; Schade, B.; Helm, S.; Lorenz, D.; Benjamin Kaupp, U. Synthesis, photochemistry and application of (7-methoxycoumarin-4-yl)methyl-caged 8-bromoadenosine cyclic 3',5'-monophosphate and 8-bromoguanosine cyclic 3',5'-monophosphate photolyzed in the nanosecond time region. J. Photochem. Photobiol. B Biol. 1999, 53, 91-102. [CrossRef]

150. Eckardt, T.; Hagen, V.; Schade, B.; Schmidt, R.; Schweitzer, C.; Bendig, J. Deactivation behavior and excited-state properties of (coumarin-4-yl)methyl derivatives. 2. Photocleavage of selected (coumarin-4yl)methyl-caged adenosine cyclic 3',5'-monophosphates with fluorescence enhancement. J. Org. Chem. 2002, 67, 703-710. [CrossRef] [PubMed]

151. Geißler, D.; Kresse, W.; Wiesner, B.; Bendig, J.; Kettenmann, H.; Hagen, V. DMACM-caged adenosine nucleotides: Ultrafast phototriggers for ATP, ADP, and AMP activated by long-wavelength irradiation. ChemBioChem 2003, 4, 162-170. [CrossRef] [PubMed]

152. Hagen, V.; Frings, S.; Wiesner, B.; Helm, S.; Kaupp, U.B.; Bendig, J. [7-(Dialkylamino)coumarin-4yl]methyl-caged compounds as ultrafast and effective long-wavelength phototriggers of 8-bromo-substituted cyclic nucleotides. ChemBioChem 2003, 4, 434-442. [CrossRef] [PubMed]

153. Furuta, T.; Takeuchi, H.; Isozaki, M.; Takahashi, Y.; Kanehara, M.; Sugimoto, M.; Watanabe, T.; Noguchi, K.; Dore, T.M.; Kurahashi, T.; et al. Bhc-cNMPs as either water-soluble or membrane-permeant photoreleasable cyclic nucleotides for both one- and two-photon excitation. ChemBioChem 2004, 5, 1119-1128. [CrossRef] [PubMed]

154. Geißler, D.; Antonenko, Y.N.; Schmidt, R.; Keller, S.; Krylova, O.O.; Wiesner, B.; Bendig, J.; Pohl, P.; Hagen, V. (Coumarin-4-yl)methyl esters as highly efficient, ultrafast phototriggers for protons and their application to acidifying membrane surfaces. Angew. Chem. Int. Ed. 2005, 44, 1195-1198. [CrossRef] [PubMed]

155. Hagen, V.; Dekowski, B.; Nache, V.; Schmidt, R.; Geißler, D.; Lorenz, D.; Eichhorst, J.; Keller, S.; Kaneko, H.; Benndorf, K.; Wiesner, B. Coumarinylmethyl esters for ultrafast release of high concentrations of cyclic nucleotides upon one- and two-photon photolysis. Angew. Chem. Int. Ed. 2005, 44, 7887-7891. [CrossRef] [PubMed]

156. Furuta, T.; Wang, S.S.-H.; Dantzker, J.L.; Dore, T.M.; Bybee, W.J.; Callaway, E.M.; Denk, W.; Tsien, R.Y. Brominated 7-hydroxycoumarin-4-ylmethyls: Photolabile protecting groups with biologically useful cross-sections for two photon photolysis. Proc. Natl. Acad. Sci. USA 1999, 96, 1193-1200. [CrossRef] [PubMed]

157. Lin, W.; Lawrence, D.S. A strategy for the construction of caged diols using a photolabile protecting group. J. Org. Chem. 2002, 67, 2723-2726. [CrossRef] [PubMed]

(C) 2018 by the authors. Licensee MDPI, Basel, Switzerland. This article is an open access article distributed under the terms and conditions of the Creative Commons Attribution (CC BY) license (http:/ / creativecommons.org/licenses/by/4.0/). 


\title{
Heteroatom Substitution at Amide Nitrogen-Resonance Reduction and HERON Reactions of Anomeric Amides
}

\author{
Stephen A. Glover * and Adam A. Rosser \\ Department of Chemistry, School of Science and Technology, University of New England, Armidale, NSW 2351, \\ Australia; arosser3@une.edu.au \\ * Correspondence: sglover@une.edu.au
}

Received: 6 October 2018; Accepted: 24 October 2018; Published: 31 October 2018

\begin{abstract}
This review describes how resonance in amides is greatly affected upon substitution at nitrogen by two electronegative atoms. Nitrogen becomes strongly pyramidal and resonance stabilisation, evaluated computationally, can be reduced to as little as 50\% that of $\mathrm{N}, \mathrm{N}$-dimethylacetamide. However, this occurs without significant twisting about the amide bond, which is borne out both experimentally and theoretically. In certain configurations, reduced resonance and pronounced anomeric effects between heteroatom substituents are instrumental in driving the HERON (Heteroatom Rearrangement On Nitrogen) reaction, in which the more electronegative atom migrates from nitrogen to the carbonyl carbon in concert with heterolysis of the amide bond, to generate acyl derivatives and heteroatom-substituted nitrenes. In other cases the anomeric effect facilitates $S_{N} 1$ and $\mathrm{S}_{\mathrm{N}} 2$ reactivity at the amide nitrogen.
\end{abstract}

Keywords: amide resonance; anomeric effect; HERON reaction; pyramidal amides; physical organic chemistry; reaction mechanism

\section{Introduction}

Amides are prevalent in a range of molecules such as peptides, proteins, lactams, and many synthetic polymers [1]. Generically, they are composed of both a carbonyl and an amino functional group, joined by a single bond between the carbon and nitrogen. The contemporary understanding of the resonance interaction between the nitrogen and the carbonyl in amides is that of an interaction between the lowest unoccupied molecular orbital (LUMO) of the carbonyl, $\pi^{*} \mathrm{C}=\mathrm{O}$, and the highest occupied molecular orbital (HOMO) of the amide nitrogen $\left(\mathrm{N} 2 \mathrm{p}_{\mathrm{z}}\right.$ ) (Figure 1). This molecular orbital model highlights the small contribution of the carbonyl oxygen to the LUMO, which indicates that limited charge transfer to oxygen occurs, in line with the resonance model presented in Figure 2, which signifies that charge at oxygen is similar to that in polarized ketones or aldehydes and nitrogen lone pair density is transferred to electron deficient carbon rather than to oxygen. The major factor in the geometry of amides, and the restricted rotation about the amide bond, is the strong $\pi$-overlap between the nitrogen lone pair and the $\mathrm{C} 2 \mathrm{p}_{\mathrm{z}}$ component of the LUMO, which dominates the $\pi^{*} \mathrm{C}=\mathrm{O}$ orbital, on account of the polarisation in the $\pi_{\mathrm{C}=\mathrm{O}}[2,3]$. 


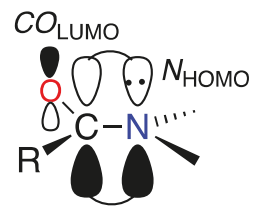

Figure 1. The interaction between the nitrogen highest occupied molecular orbital (HOMO) and the carbonyl lowest unoccupied molecular orbital (LUMO) in amides.<smiles>CC(=O)NCCCCC(N)=[OH+]</smiles>

Figure 2. Resonance hybrid contributions in amides, showing that the majority of charge transfer occurs between nitrogen and carbon.<smiles>CC(=O)N(C)C</smiles>

1<smiles>[R]C(=O)[N+]([Y])([Y])[O-]</smiles>

2<smiles>[R]C(=O)N(C)C</smiles>

3

a: $\mathrm{R}=\mathrm{H}$

b: $R=M e$<smiles>[R]C(=O)N(C)OC</smiles>

4

a: $\mathrm{R}=\mathrm{H}$

b: $\mathrm{R}=\mathrm{Me}$

b: $X=O A c, Y=O R \quad g: X=O R, Y=O^{-}$

c: $X=Y=O R \quad h: X=O R, Y=N$

$\mathrm{d}: \mathrm{X}=\mathrm{OR}, \mathrm{Y}=\mathrm{NR}_{2} \quad$ i: $\mathrm{X}=\mathrm{NR}_{2}, Y=\mathrm{SR}$

e: $X=O R, Y=S R \quad j: X=C l, Y=S R$

Amide resonance can be diminished by limiting the overlap between the nitrogen lone pair, $\mathrm{n}_{\mathrm{N}}$, and $\pi_{\mathrm{C}=\mathrm{O}}^{*}$ orbitals. In most instances, this can occur by twisting the amino group about the $\mathrm{N}-\mathrm{C}(\mathrm{O})$ bond and/or pyramidalising the nitrogen, which amounts to introducing " $\mathrm{s}$ " character into the $\mathrm{N} 2 \mathrm{p}_{\mathrm{z}}$ orbital.

Computational modelling of $\mathrm{N}-\mathrm{C}(\mathrm{O})$ rotation and nitrogen pyramidalisation in N,N-dimethylacetamide 1, at the B3LYP/6-31G(d) level, illustrates the energetic changes (Figure 3) [4]. Distortion of the amide linkage can be quantified by Winkler-Dunitz parameters $\chi$ and $\tau$, where $\chi=60^{\circ}$ for a fully pyramidal nitrogen, and $\tau=90^{\circ}$ for a completely twisted amide where the lone pair orbital on nitrogen is orthogonal to the $\mathrm{C} 2 \mathrm{p}_{\mathrm{z}}$ orbital $[5,6]$. Deformation from the non-twisted, $\mathrm{sp}^{2}$ planar ground state (Figure 3a) through rehybridisation of nitrogen to $\mathrm{sp}^{3}$ (Figure $3 \mathrm{~b}$ ) is accompanied by an increase in energy $\left(\sim 27 \mathrm{~kJ} \mathrm{~mol}^{-1}\right)$, but the majority of amide resonance remains intact. A much larger increase in energy $\left(\sim 100 \mathrm{~kJ} \mathrm{~mol}^{-1}\right)$ results from twisting the $\mathrm{N}-\mathrm{C}(\mathrm{O})$ bond through $90^{\circ}$ whilst maintaining sp ${ }^{2}$ planarity at nitrogen (Figure $3 \mathrm{~d}$ ), and as the nitrogen is allowed to relax to $\mathrm{sp}^{3}$ hybridisation (Figure $3 \mathrm{c}$ ), a fully twisted amide devoid of resonance is obtained. The loss of $\sim 31 \mathrm{~kJ} \mathrm{~mol}^{-1}$ in this final step is indicative of the concomitant twisting and pyramidalisation observed in a variety of twisted amides. 


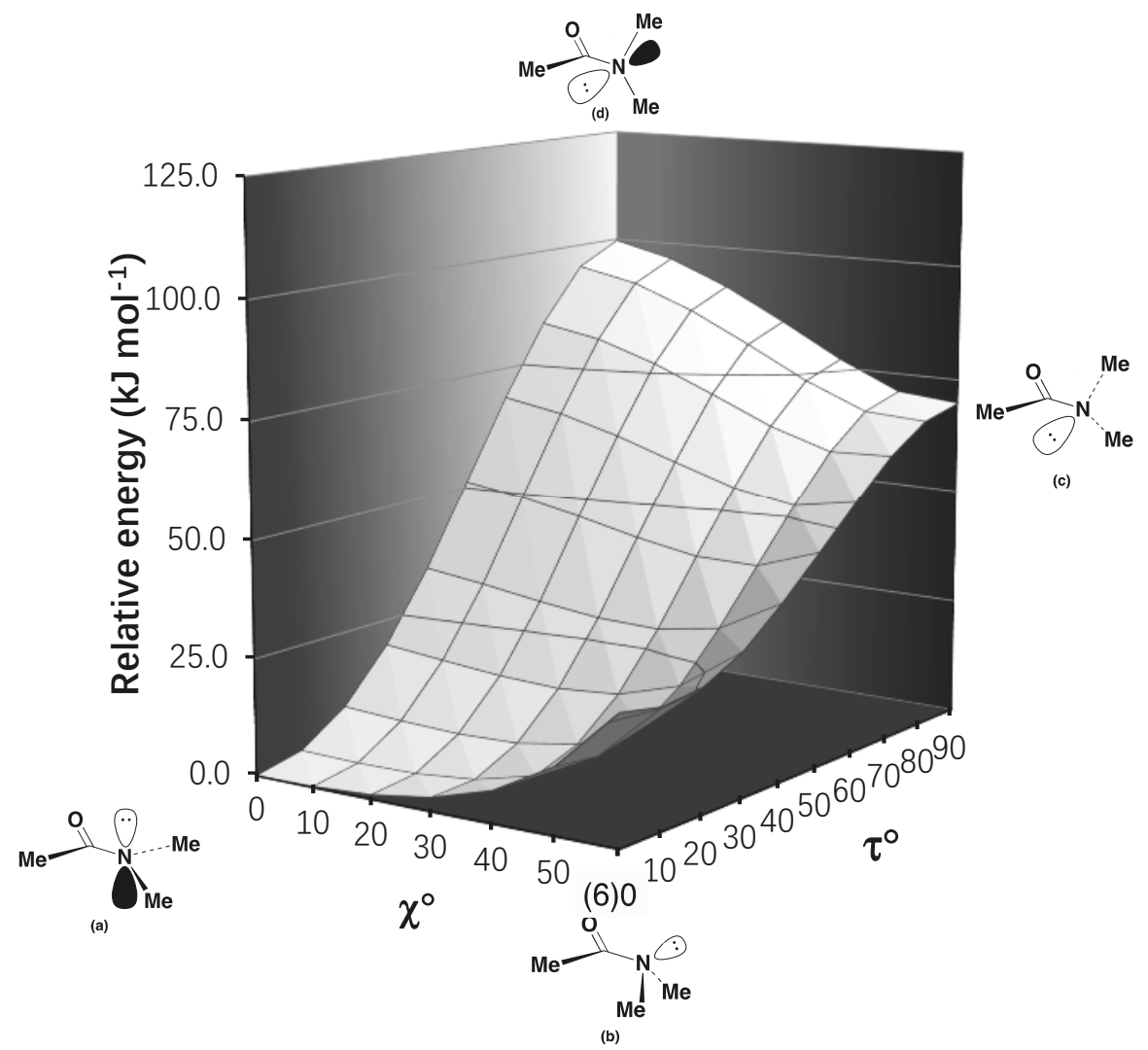

Figure 3. A B3LYP/6-31G(d) generated energy surface for the deformation of the amide moiety in $\mathrm{N}, \mathrm{N}$-dimethylacetamide 1 [4]. $\chi$ and $\tau$ are Winkler-Dunitz parameters for pyramidalisation and twist, respectively [5,6]. (a) The ground state planar structure for $N, N$-dimethylacetamide; (b) untwisted system with $\mathrm{sp}^{3}$ hybridised nitrogen; (c) $90^{\circ}$ rotation about $\mathrm{N}-\mathrm{C}(\mathrm{O})$, whilst maintaining $\mathrm{sp}^{3}$ hybridisation at nitrogen; and (d) the fully twisted moiety, $90^{\circ} \mathrm{N}-\mathrm{C}(\mathrm{O})$ rotation and $\mathrm{sp}^{2}$ hybridised nitrogen.

Typically, amides exhibit restricted rotation about the $\mathrm{N}-\mathrm{C}(\mathrm{O})$ bond, in the order of $67-84 \mathrm{~kJ} \mathrm{~mol}^{-1}$, along a sigmoid pathway with little change in energy upon moderate pyramidalisation $\left(\chi=0-40^{\circ}\right)$ and minor twisting $\left(\tau=0-20^{\circ}\right)$. Clearly, rotation without pyramidalisation is energetically unfavourable and many examples of twisted amides are testament to this. The shift to $\mathrm{sp}^{3}$ hybridisation at the amidic nitrogen is clearly demonstrated when twisting of the $\mathrm{N}-\mathrm{C}(\mathrm{O})$ bond is geometrically enforced by tricyclic and bicyclic bridged lactams [7-13]. Kirby's "most twisted amide" 1-aza-2-adamantanone, synthesised in 1998 [10,12], and Tani and Stoltz's 2-quinuclidone, synthesised in 2006 [14], exemplify the fully twisted amide, geometrically and chemically. Intramolecular steric hindrance is another source of non-planar twisted amides $[15,16]$, as exemplified by the thioglycolurils $[17,18]$ and other systems. Ring strain in nontwisted amides, such as 1-acylaziridines [19,20] and N-acyl-7-azabicyclo[2.2.1] heptanes [21-24] can result in pyramidality at the amide nitrogen, despite retaining a noticeable $\mathrm{n}_{N}-\pi^{*} \mathrm{C}=\mathrm{O}$ interaction.

The structural changes accompanying the loss of amide resonance include the lengthening of the $\mathrm{N}-\mathrm{C}(\mathrm{O})$ bond and minor shortening of the $(\mathrm{N}) \mathrm{C}=\mathrm{O}$ bond. Comparing the fully twisted 1-aza-2-adamantanone to an analogous unstrained tertiary $\delta$-lactam, the $\mathrm{N}-\mathrm{C}(\mathrm{O})$ bond shortens from $1.475 \AA$ to $1.352 \AA$, and the $(\mathrm{N}) \mathrm{C}=\mathrm{O}$ bond lengthens from $1.196 \AA$ to $1.233 \AA[12,25]$. Spectroscopically 
and chemically, the amide carbonyl trends towards ketonic behaviour at large twist angles. In tricyclic 1-aza-2-adamantanone, the carbonyl carbon ${ }^{13} \mathrm{C}$ NMR resonance is at $200.0 \mathrm{ppm}$ and the IR carbonyl vibrational frequency $\left(1732 \mathrm{~cm}^{-1}\right)$ is significantly higher than regular amides $\left(1680 \mathrm{~cm}^{-1}\right)[10,12]$.

\section{Properties of Anomeric Amides}

\subsection{Structural Properties}

Another way in which amides may be dispossessed of their planarity and resonance is through bisheteroatom-substitution by electronegative heteroatoms at the amide nitrogen in 2 . We named this class 'anomeric amides' on account of the pronounced anomeric effects that can and do occur between the heteroatoms [26-35]. However, the physical, theoretical, and chemical properties of various congeners differ from those of conventional primary, secondary, and tertiary alkylamides.

Electronegative atoms demand an electron density redistribution which is facilitated by a shift in the hybridisation at nitrogen towards $\mathrm{sp}^{3}$, in accordance with Bent's rule $[36,37]$. Reduced $\mathrm{n}_{\mathrm{N}}-\pi^{*} \mathrm{C}=\mathrm{O}$ overlap due to pyramidalisation (Figure 4) together with the increased ' $2 \mathrm{~s}$ ' character of the lone pair on nitrogen results in structural, electronic, spectroscopic, and chemical differences in comparison to traditional amides. Their unique properties of have been reviewed in recent years [31,35].

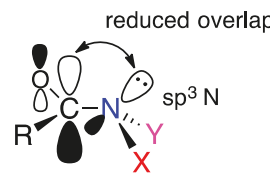

Figure 4. Reduced $\mathrm{n}_{\mathrm{N}}-\pi^{*} \mathrm{C}=\mathrm{O}$ overlap due to pyramidalisation.

Much of our interest into, and indeed the discovery of, anomeric amide chemistry emanates from our investigations of the biological activity, structure, and reactivity of $N$-acyloxy- $N$-alkoxyamides (NAA's) 2b [31,38-49] a class of anomeric amides. Readily synthesised by treatment of $N$-alkoxy- $N$-chloroamides $\mathbf{2} \mathbf{a}$, themselves a form of anomeric amide, with silver or sodium carboxylate salts in anhydrous solvents $[45,46,48,49]$, NAA's are direct-acting mutagens which react with nucleophilic centres in DNA [31,39-46,49,50]. Additionally, they react with a variety of nucleophiles to produce other congeners, including, reactive anomeric amides in the form of $N$-alkoxy- $N$-aminoamides 2d [44,47,51] and $N$-alkoxy- $N$-thioalkylamides 2e [52]. We have also encountered several anomeric reactive intermediates through reactions of $N$-acyloxy- $N$-alkoxyamides: reaction of $\mathbf{2} \mathbf{b}$ with base generates $N$-alkoxy- $N$-hydroxamate anions $2 \mathrm{~g}$ [45] and reaction with azide ultimately generates 1-acyl-1-alkoxydiazenes, which are aminonitrenes $\mathbf{2 h}$ [53,54]. We have generated $N, N$-dialkoxyamides 2c in related studies by solvolysis of $N$-alkoxy- $N$-chloroamides $2 \mathbf{a}$ in aqueous alcohols and through the reaction of hydroxamic esters with hypervalent iodine reagents in appropriate alcohols $[30,55,56]$. Other anomeric amides of theoretical interest to us are $N$-amino- $N$-chloroamides $2 \mathbf{f}$ [34], as well as $N$-amino- $N$-thioalkylamides $\mathbf{2} \mathbf{i}$ and $N$-chloro- $N$-thioalkyamides $\mathbf{2} \mathbf{j}$.

The impact of heteroatom substitution at amide nitrogen is clearly demonstrated by comparing $N, N$-dimethylacetamide $\mathbf{1}$ to $N$-methoxy- $N$-methylacetamide $3 \mathbf{b}$ and $N, N$-dimethoxyacetamide $4 \mathbf{b}$. In 1996, we reported on the B3LYP/6-31G(d) theoretical properties of the corresponding formamides 3a and 4a [27]. The substitution of hydrogen by methoxyl in 3a led to an increase in $\mathrm{N}-\mathrm{C}(\mathrm{O})$ bond length from $1.362 \AA$ to $1.380 \AA$ and a second substitution at nitrogen in 4 a resulted in a similar increase to $1.396 \AA$; the carbonyl bond contracted marginally by $0.006 \AA$. Nitrogen in $N$-methoxy- $N$-methylformamide and $N, N$-dimethoxyformamide becomes distinctly pyramidal with average angles at nitrogen of $\sim 114^{\circ}$. With similar degrees of pyramidality $\left(\chi_{N}\right)$, the increased $N-C(O)$ bond length in $N, N$-dimethoxyformamide could not solely be attributed to deformation at nitrogen. Energetic lowering of the lone pair electrons is also responsible for reduced overlap with the adjacent $\mathrm{C} 2 \mathrm{p}_{\mathrm{z}}$ orbital. This is dramatically exemplified by the rotational barriers for $N, N$-dimethylformamide, 
$N$-methoxy- $N$-methylformamide, and $N, N$-dimethoxyformamide, which were computed to be of the order of 75, 67, and $29 \mathrm{~kJ} \mathrm{~mol}^{-1}$, respectively [27].

Deformation energy surfaces for $N$-methoxy- $N$-methylacetamide $3 \mathbf{b}$ and $N, N$-dimethoxyacetamide $4 \mathbf{b}$, for comparison with that of $N, N$-dimethylacetamide 1, are depicted in Figure 5 . In contrast to $N, N$-dimethylacetamide (Figure 3 ), the lowest energy forms clearly deviate from planarity at nitrogen with $\chi_{0}$ in the region of $40^{\circ}$ and $50^{\circ}$, respectively. In both structures, the highest point corresponding to $\chi=0^{\circ}, \tau=90^{\circ}$ is metastable, and the planar fully twisted, and therefore nonconjugated forms, relax to fully pyramidal conformations $\left(\tau=90^{\circ}, \chi=60^{\circ}\right)$, the energy of which reflects the B3LYP /6-31G(d) barriers to amide isomerisation in each case, which are approximately 67 and $44 \mathrm{~kJ} \mathrm{~mol}^{-1}$, respectively. While the energy lowering for $N$-methoxyacetamide is modest, the attachment of two electronegative oxygens to the amide nitrogen radically lowers the isomerisation barrier by some 29 to $33 \mathrm{~kJ} \mathrm{~mol}^{-1}$. Inversion barriers at nitrogen are low on account of the gain in resonance stabilisation in the planar form, though the barrier is higher for $N, N$-dimethoxyacetamide where the resonance capability would be less and a six $\pi$-electron repulsive effect would operate; planarisation in the hydroxamic ester is less costly than in $N, N$-dimethoxyacetamide ( 6.3 vs. $14.6 \mathrm{~kJ} \mathrm{~mol}^{-1}$, respectively).

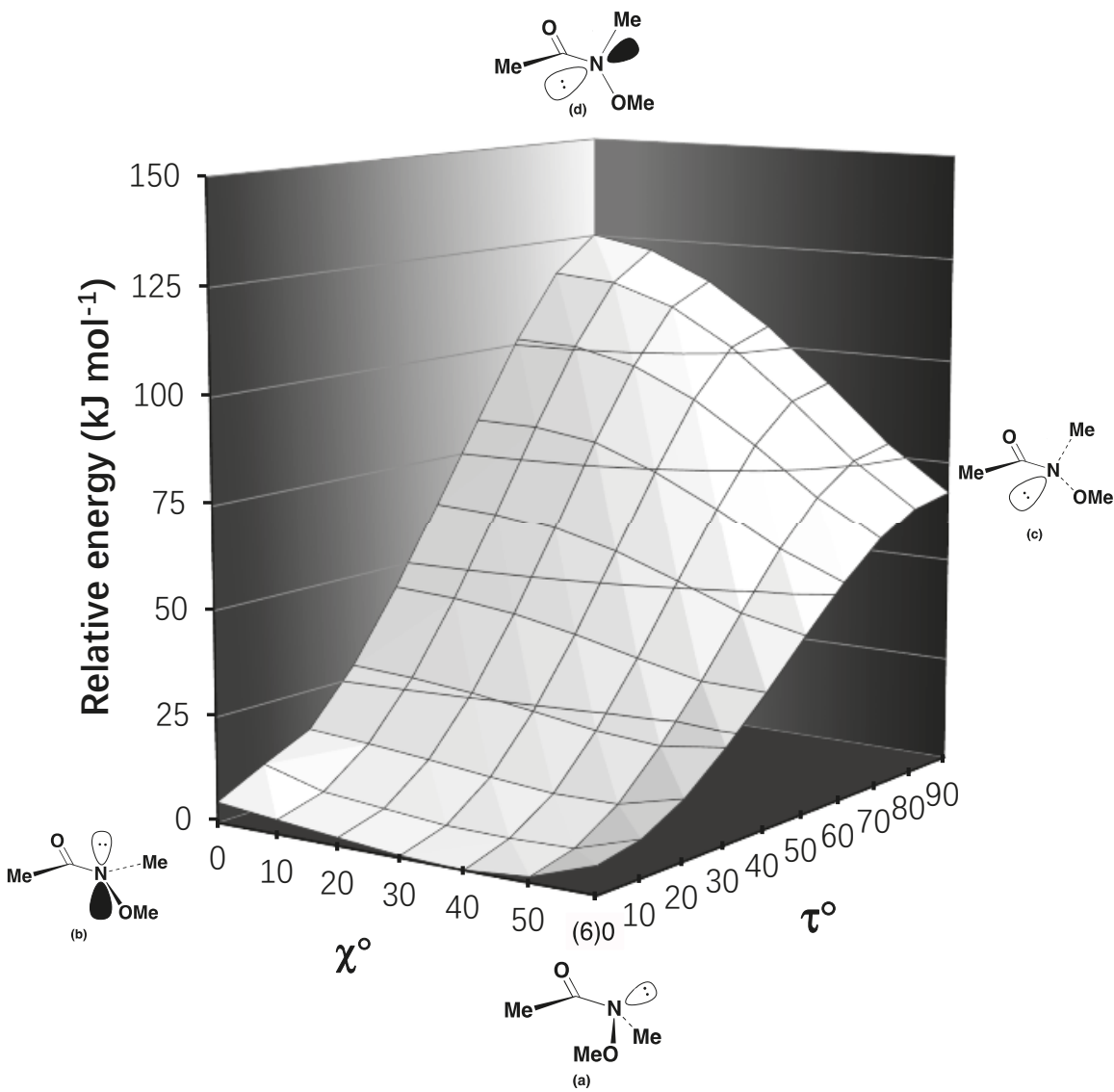

(A)

Figure 5. Cont. 


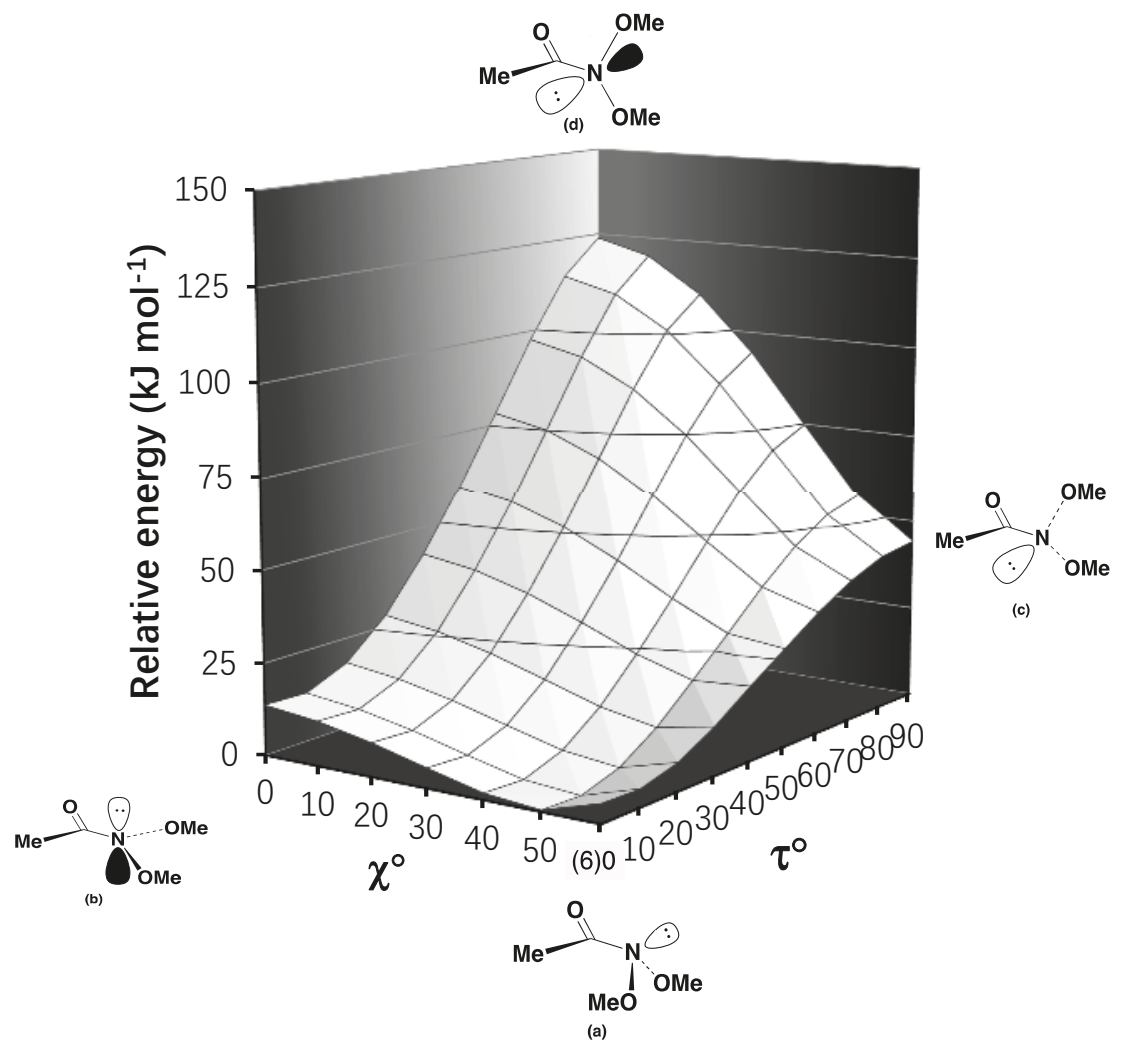

(B)

Figure 5. B3LYP/6-31G(d) energy surfaces for deformation of (A) $N$-methoxy- $N$-methylacetamide $3 \mathbf{b}$ and (B) N,N-dimethoxyacetamide $4 \mathbf{b}$. (a) Untwisted system with $\mathrm{sp}^{3}$ hybridised nitrogen; (b) planar untwisted structure; (c) $90^{\circ}$ rotated structure with $\mathrm{sp}^{3}$ hybridisation at nitrogen; and (d) the fully twisted moiety with $\mathrm{sp}^{2}$ hybridised nitrogen.

In a recent publication, we outlined two concurring isodesmic methods for estimating the amidicity of amides and lactams [4]. Carbonyl substitution, nitrogen atom replacement (COSNAR), developed by Greenberg evaluates the energy stabilisation when the target amide is generated from corresponding ketone and amine according to isodesmic Equation (1) [57-59]. Steric or substituent effects are conserved throughout the reaction so steric corrections are not required.<smiles>[R]CC([X])[Y]</smiles>

In the second approach, the transamidation method (TA), the energy change is determined when $\mathrm{N}, \mathrm{N}$-dimethylacetamide $\mathbf{1}$ transfers the carbonyl oxygen to a target amine according to Equation (2). The limiting energy increase for formation of fully twisted, unstrained 1-aza-2-adamantanone by the corresponding reaction with 1-azaadamantane, constitutes complete loss of resonance stabilisation $\left(\Delta E_{\mathrm{TA}}=76.0 \mathrm{~kJ} \mathrm{~mol}^{-1}\right)$. However, where heteroatom substituents are present at nitrogen, $\Delta E_{\mathrm{TA}}$ must 
be corrected for any additional inductive destabilisation of the carbonyl $\left(\Delta E_{\text {ind }}\right)$ in the absence of resonance, which we obtain isodemically from reactions such as Equation (3) [33].

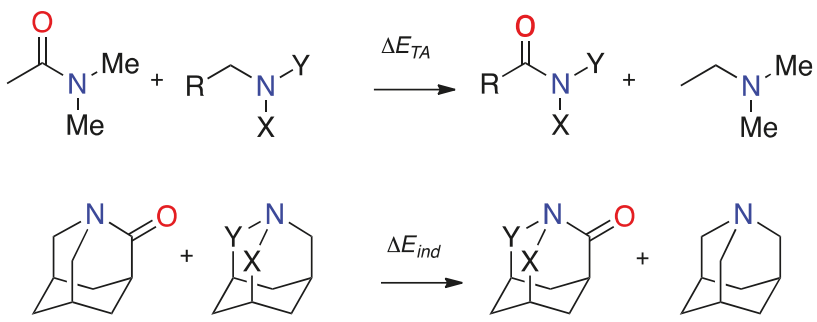

By the TA method, the residual resonance, $\mathrm{RE}_{\mathrm{TA}}$, is given by Equation (4).

$$
\mathrm{RE}_{\mathrm{TA}}=-76.0 \mathrm{~kJ} \mathrm{~mol}^{-1}+\left(\Delta E_{\mathrm{TA}}-\Delta E_{\mathrm{ind}}\right)
$$

In both the TA and COSNAR approaches, zero point energies largely cancel and meaningful results are obtained without the need for frequency calculations [58,60]. RE by both methods, the negative of the traditional representation of resonance stabilisation energy, should correlate $[4,30,33,34,61,62]$ and $\mathrm{RE}$ as a percentage of $-76.0 \mathrm{~kJ} \mathrm{~mol}^{-1}$ (or $-77.5 \mathrm{~kJ} \mathrm{~mol}^{-1}$ in the case of COSNAR) yields the amidicity relative to $N, N$-dimethylacetamide 1 (by definition $100 \%$ ).

The resonance energy and amidicity of $N$-methoxy- $N$-methylacetamide $3 \mathbf{b}$ has been determined with COSNAR (-62.1 kJ mol ${ }^{-1}, 80 \%$ amidicity) and TA (-61.25 $\mathrm{kJ} \mathrm{mol}^{-1}, 81 \%$ amidicity) and accords nicely with the lowest rotational barrier from Figure $5 \mathrm{a}$ of $67.5 \mathrm{~kJ} \mathrm{~mol}^{-1}$. In contrast, for the bisoxyl-substituted acetamide, the RECOSNAR and $\mathrm{RE}_{\mathrm{TA}}$ were determined at $-35.9 \mathrm{~kJ} \mathrm{~mol}^{-1}$, respectively just $47 \%$ or $46 \%$ that of $N, N$-dimethylacetamide [33]. From Figure $5 \mathrm{~b}$ the rotational barrier was $44.4 \mathrm{~kJ} \mathrm{~mol}^{-1}$ and therefore most of the barrier can be accounted for by loss of resonance.<smiles>[R]ON(O)C([R])=O</smiles>

5

a: $R^{1}=\mathrm{Me}, \mathrm{R}^{2}=\mathrm{Et}, \mathrm{R}^{3}=4-\mathrm{NO}_{2} \mathrm{C}_{6} \mathrm{H}_{4}$

b: $\mathrm{R}^{1}=\mathrm{Me}, \mathrm{R}^{2}=4-\mathrm{NO}_{2} \mathrm{C}_{6} \mathrm{H}_{4} \mathrm{CH}_{2}, \mathrm{R}^{3}=\mathrm{Ph}$<smiles>[R7]C(=O)ON(OC)C([R])=O</smiles>

6

a: $\mathrm{R}^{1}=\mathrm{R}^{2}=\mathrm{R}^{3}=4-\mathrm{Bu}^{t} \mathrm{C}_{6} \mathrm{H}_{4}$

b: $\mathrm{R}^{1}=4-\mathrm{Bu}^{t} \mathrm{C}_{6} \mathrm{H}_{4}, \mathrm{R}^{2}=\mathrm{R}^{3}=\mathrm{Ph}$<smiles>CON(OC(C)=O)C(=O)CC(=O)O[Na]</smiles>

7

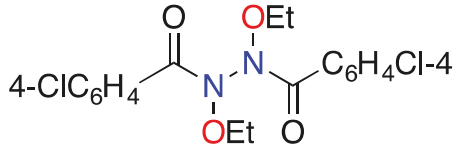

8<smiles>CON(Cl)C(=O)CC(O[Na])O[Na]</smiles>

9

The unusual structure of a number of stable anomeric amides (5-9) has been confirmed by X-ray crystallography (Figure 6) and relevant structural parameters of these are given in Table 1. The X-ray structures of anomeric amides 5-9 provide clear evidence of reduced amide resonance. The data in Table 1 shows that as the combined electron demands of $\mathrm{X}$ and $\mathrm{Y}$ increase, $\mathrm{N}-\mathrm{C}(\mathrm{O})$ bond length and pyramidalisation at nitrogen both increase. The reported average $\mathrm{N}-\mathrm{C}(\mathrm{O})$ bond length in acyclic amides is $1.359 \AA$ (median $1.353 \AA$ ), generated from Cambridge Structural Database (CSD) [29,63], which is significantly shorter than the average $1.418 \AA$ from these seven X-ray structures. While the $(\mathrm{N}) \mathrm{C}=\mathrm{O}$ bond (average $1.207 \AA$ ) contracts slightly compared to simple acyclic amides $(1.23 \AA)$, there is 
little to no correlation seen between change in $(\mathrm{N}) \mathrm{C}=\mathrm{O}$ bond length and degree of lone pair dislocation; this may be attributed to bias towards carbon in the LUMO (Figure 1) [2,26,35,64]. Deviation from the usual $\mathrm{sp}^{2}$ hybridisation at the amide nitrogen $\left(\chi_{\mathrm{N}}=0\right)$ is significant and in line with the electron demands of substituents. $N$-acyloxy- $N$-alkoxyamides $6 \mathbf{a}, \mathbf{6 b}$, and $7\left(\chi_{\mathrm{N}}=65.33^{\circ}, 65.62^{\circ}\right.$ and $59.7^{\circ}$, respectively) are pyramidalised at nitrogen to the extent of, and beyond, what is expected for a pure $\mathrm{sp}^{3}$ hybridisation. The 4-nitrobenzamide 7 is less pyramidal than the benzamides $\mathbf{6 a}$ and $\mathbf{6 b}$ presumably on account of greater positive charge at the carbonyl carbon and attendant increase in nitrogen lone pair attraction. Both $N, N$-dialkoxyamides $5 \mathbf{a}$ and $\mathbf{5 b}\left(\chi_{\mathrm{N}}=58.3^{\circ}\right.$ and $55.6^{\circ}$, respectively) are also strongly pyramidalised. For Shtamburg's $N$-alkoxy- $N$-chloroamide $9, X$-ray data reveals a small $\chi_{\mathrm{N}}$ of $52.5^{\circ}$, similar to $N, N$-dialkoxyamides $5 \mathbf{a}$ and $5 \mathbf{b}$. Both amide nitrogens in hydrazine 34 are the least pyramidalised with $\chi_{\mathrm{N} 1}$ and $\chi_{\mathrm{N} 2}$ of $47^{\circ}$ and $49^{\circ}$, respectively.

Despite high degrees of pyramidalisation in this set of anomeric amides, there is minimal twist about the $\mathrm{N}-\mathrm{C}(\mathrm{O})$ bond $\left(\tau=6.7-15.5^{\circ}\right)$. This indicates that lone pair orbital overlap with the carbonyl $\mathrm{C} 2 \mathrm{p}_{\mathrm{z}}$ orbital, though clearly less effective on electronic and geometric grounds, remains a stabilizing influence (Table 1). As can be seen in the B3LYP/6-31G(d) deformation surface for $N, N$-dimethoxyacetamide $4 \mathbf{b}$ (Figure $5 b$ ), the strongly pyramidal structure requires twist angles $(\tau)$ beyond $20^{\circ}$ before there is significant loss of stabilization.

Table 1. Selected structural data for anomeric amides 5-9 from X-ray structures (Figure 6).

\begin{tabular}{|c|c|c|c|c|c|c|}
\hline Structure & $\mathrm{N}-\mathrm{C}(\mathrm{O}) / \AA$ & $(\mathrm{N}) \mathrm{C}=\mathrm{O} / \mathrm{A}$ & $\theta /^{\circ}$ & $\mathrm{x}_{\mathrm{N}} /^{\circ}$ & $\tau / /^{\circ}$ & Anomeric Twist ${ }^{1} /{ }^{\circ}$ \\
\hline $5 a[33]$ & 1.409 & 1.206 & 331.2 & 58.3 & 6.7 & $\begin{array}{c}\text { C10-O3-N1-O2: } 95.9 \\
\text { C8-O2-N1-O3: }-114.1\end{array}$ \\
\hline $5 \mathbf{b}[33]$ & 1.421 & 1.211 & 334.5 & 55.6 & 13.9 & $\begin{array}{l}\text { C8-O2-N1-O3: -101.6 } \\
\text { C15-O3-N1-O2: }-63.8\end{array}$ \\
\hline 6a [29] & 1.439 & 1.205 & 323.5 & 65.3 & 15.5 & $\begin{array}{l}\text { C18-O3-N1-O1: } 96.2 \\
\text { C7-O1-N1-O3: -141.6 }\end{array}$ \\
\hline $\mathbf{6 b}[29]$ & 1.441 & 1.207 & 324.1 & 65.6 & 13.9 & $\begin{array}{l}\text { C14-O3-N1-O1: } 96.7 \\
\text { C7-O1-N1-O3: -137.6 }\end{array}$ \\
\hline $7[65]$ & 1.411 & 1.203 & 330.3 & 59.7 & -14.0 & $\begin{array}{l}\text { C8-O1-N1-O5: -91.8 } \\
\text { C9-O5-N1-O1: } 116.2\end{array}$ \\
\hline 8(N1) [32] & 1.412 & 1.213 & 343.2 & 47.3 & -8.5 & LP (N2)-N2 -N1-O2: 47.3 \\
\hline $8(\mathrm{~N} 2)$ & 1.410 & 1.207 & 341.1 & 48.9 & -11.4 & LP (N1)-N1-N2-O3: 178.6 \\
\hline $9[65]$ & 1.408 & 1.204 & 337.5 & 52.5 & -13.3 & C8-O2-N1-Cl1: -84.2 \\
\hline
\end{tabular}

Pyramidal nitrogens and corresponding anomeric interactions have also been observed in the structures of a number of urea and carbamate analogues of anomeric amides (10-14) studied by Shtamburg and coworkers and selected structural data are presented in Table 2 [66-69]. Where substituent electronic effects are largely similar as in $\mathbf{1 1 b}$ and $\mathbf{1 3}$, it can be deduced that the stronger conjugative effect of the $\alpha$-nitrogen lone pair in the urea $\mathbf{1 1 b}$, relative to the $\alpha$-oxygen in the carbamate 13, results in significantly less amide resonance interaction and, hence, significant increase in pyramidality at the amide nitrogen. Comparison of the $\mathrm{ONCl}$ structures $\mathbf{9}$ and $\mathbf{1 0 a}$ and $\mathbf{b}$, again indicates greater pyramidality in the ureas where competing acyl nitrogen resonance reduces the anomeric amide resonance interaction. 


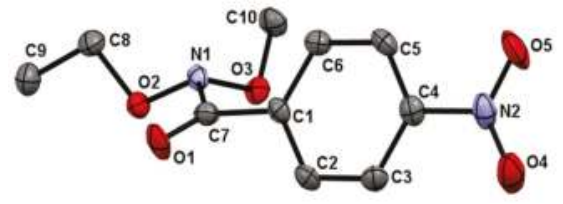

(a)

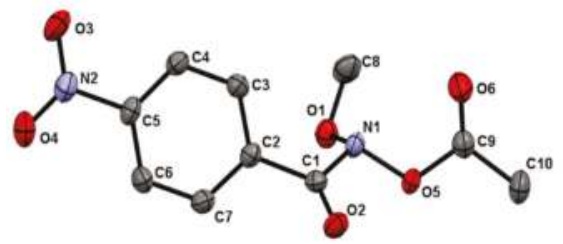

(c)

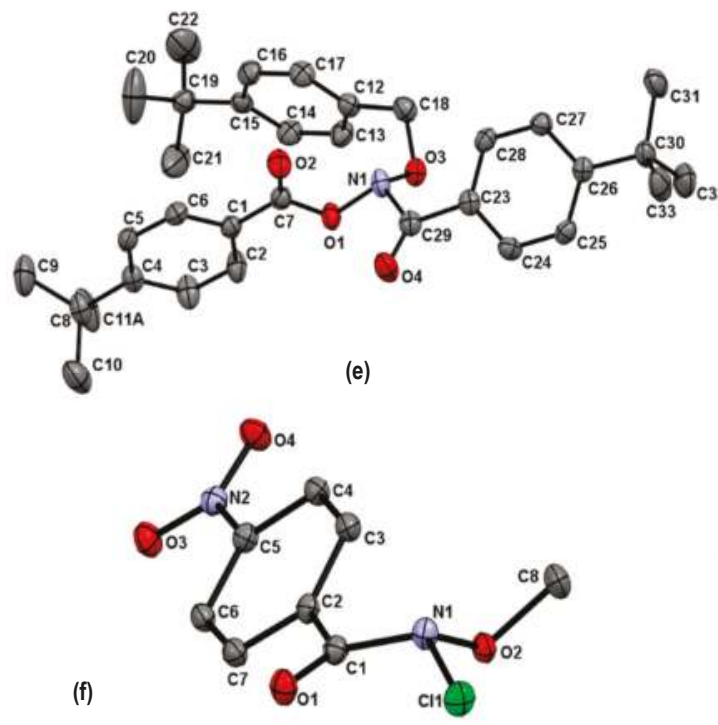

(b)

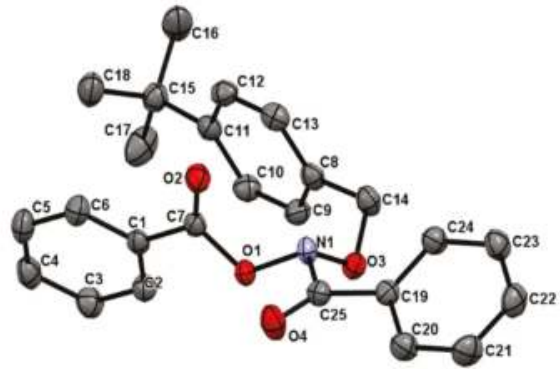

(d)

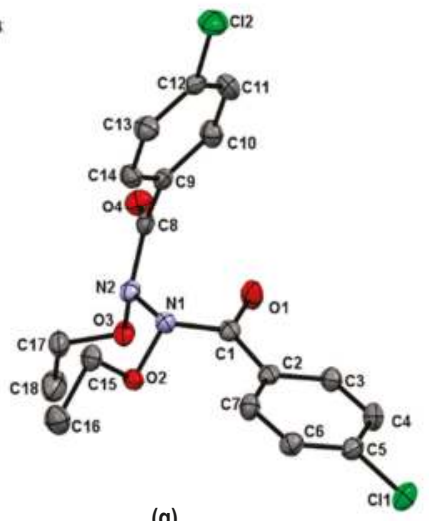

Figure 6. X-ray structures for (a) N-ethoxy- $N$-methoxy-4-nitrobenzamide 5a [33], (b) N-methoxy-N(4-nitrobenzyloxy)benzamide 5b [33], (c) $N$-acetoxy- $N$-methoxy-4-nitrobenzamide $7 \quad$ [65], (d) N-benzoyloxy-N-(4-tert-butylbenzyloxy) benzamide 6b [29], (e) N-(4-tert-butylbenzoyloxy)-N-(4-tertbutylbenzyloxy)-4-tert-butylbenzamide 6a [29], (f) $N$-chloro- $N$-methoxy-4-nitrobenzamide 9 [65], and (g) $N, N^{\prime}-4$-chlorobenzoyl- $N, N^{\prime}$-diethoxyhydrazine 8 [32]. 
<smiles>[R]NC(=O)N(Cl)Cl</smiles>

10

a: $\mathrm{R}^{1}=\mathrm{H}, \mathrm{R}^{2}=\mathrm{Me}$

b: $\mathrm{R}^{1}=4-\mathrm{NO}_{2} \mathrm{C}_{6} \mathrm{H}_{4}, \mathrm{R}^{2}=\mathrm{C}(\mathrm{Me})_{2} \mathrm{CO}_{2} \mathrm{Me}$<smiles>COC(=O)N(OC)C(=O)OC</smiles>

13<smiles>CCON(OC=[Rh])C(N)=O</smiles>

11

a: $R^{1}=M e, R^{2}=E t$

b: $R^{1}=4-C_{C} C_{6} H_{4}, R^{2}=B u$<smiles>CO[N+](C)O[Na]</smiles>

12

a: $\mathrm{R}=4-\mathrm{ClC}_{6} \mathrm{H}_{4}$<smiles>CO[N+](C)(OC)OC</smiles>

14

Table 2. Selected structural data for ureas 10-12 and carbamates 13-14 from X-ray structures.

\begin{tabular}{|c|c|c|c|c|c|c|}
\hline Structure & $\mathrm{N}-\mathrm{C}(\mathrm{O}) / \mathrm{A}$ & $(\mathrm{N}) \mathrm{C}=\mathrm{O} / \AA$ & $\theta /{ }^{\circ}$ & $x_{N} / \circ$ & $\tau /^{\circ}$ & Anomeric Twist ${ }^{2} /{ }^{\circ}$ \\
\hline 10a [66] & $1.443^{1}$ & 1.226 & 329.1 & 59.9 & 8.2 & C-O-N-Cl: -90.9 \\
\hline $10 b[66]$ & $1.472^{1}$ & 1.210 & 325.8 & 61.9 & -13.4 & $\mathrm{C}-\mathrm{O}-\mathrm{N}-\mathrm{Cl}:-100.1$ \\
\hline 11a [67] & $1.426^{1}$ & 1.222 & 333.6 & -57.1 & -6.8 & C-O-N-Oacyl: -104.0 \\
\hline $11 b[68]$ & $1.441^{1}$ & 1.233 & 323.7 & 64.6 & 11.8 & C-O-N-Oacyl: -98.2 \\
\hline 12 [68] & $1.438^{1}$ & 1.220 & 331.8 & 57.4 & 0.8 & $\begin{array}{c}\text { C-O2-N1-O1: }-\mathbf{8 9 . 3} \\
\text { C-O1-N1-O2: } 55.2\end{array}$ \\
\hline 13 [67] & 1.424 & 1.198 & 334.2 & -56.3 & 2.9 & C-O-N-Oacyl: -95.5 \\
\hline $\begin{array}{c}14[69] \\
(\mathrm{N} 1) /(\mathrm{N} 2)^{3}\end{array}$ & 1.408 & 1.194 & 340.0 & 59.8 & -9.4 & LP (N1)-N1-N2-O: 189.2 \\
\hline
\end{tabular}

${ }^{1}$ Anomeric amide bond; ${ }^{2}$ Anomeric alignments in bold-face; ${ }^{3}$ Equivalent nitrogens.

These and other anomeric amides have been modelled at B3LYP/6-31G(d) level in the simplified acetamide system and ground state models of $\mathbf{1 5} \mathbf{a}-\mathbf{d}$ systems display high degrees of pyramidality, little $\mathrm{N}-\mathrm{C}(\mathrm{O})$ twist, long $\mathrm{N}-\mathrm{C}(\mathrm{O})$ bonds, and slightly shortened $(\mathrm{N}) \mathrm{C}=\mathrm{O}$ bonds, in line with the electron demands of substituents and, where applicable, are reasonable approximations of their respective X-ray structure counterparts (Figure 7, Table 3). ONS and $\mathrm{NNCl}$ analogues, $\mathbf{1 5 d}$ and $\mathbf{1 5 e}$, have only been generated as intermediates in reactions but their theoretical structures are in line with those of anomeric systems $15 \mathbf{a}-\mathbf{d} ; \mathrm{N}-\mathrm{C}(\mathrm{O})$ bond lengths and pyramidality at nitrogen $\left(\chi_{\mathrm{N}}\right)$ are broadly in line with the gross electronegativity of substituents at nitrogen. Sulphur, with its low electronegativity, results in a less pyramidal nitrogen, while the $\mathrm{NNCl}$ system $15 \mathrm{e}$ is completely planar (and untwisted) for steric reasons. Nonetheless, its $\mathrm{N}-\mathrm{C}(\mathrm{O})$ bond is comparatively long. The carbamate and the urea 16a $\left(\chi_{\mathrm{N}}=46.3^{\circ}\right)$ and $16 \mathbf{b}\left(\chi_{\mathrm{N}}=49.6^{\circ}\right)$ are both more pyramidal than the corresponding acetamide $15 \mathrm{c}\left(\chi_{\mathrm{N}}=41.8^{\circ}\right)$, presumably as a result of competing resonance from the $\alpha$-oxygen and $\alpha$-nitrogen lone pairs. 


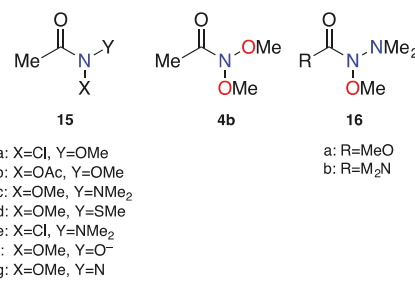

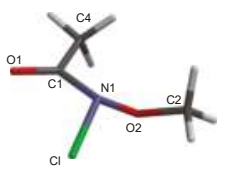

(a)

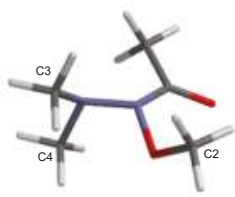

(d)

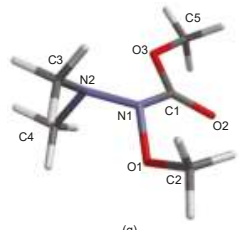

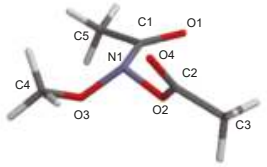
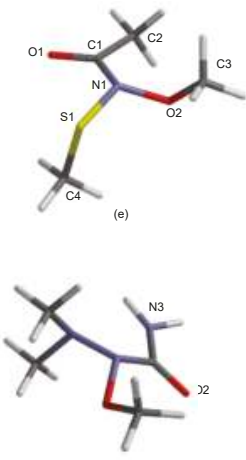
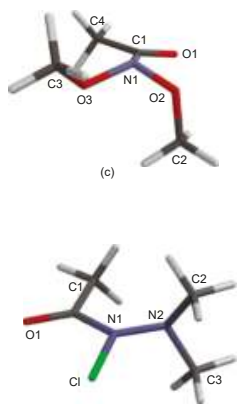

Figure 7. B3LYP/6-31G(d) lowest energy ground state conformers of model anomeric acetamides (a) $N$-chloro- $N$-methoxyacetamide 15a, (b) $N$-acetoxy- $N$-methoxyacetamide 15b, (c) N,N-dimethoxyacetamide $4 \mathbf{b}$, (d) $N$-methoxy- $N$-dimethylaminoacetamide 15 c, (e) $N$-methoxy- $N$ methylthiylacetamide 15d, (f) $N$-chloro- $N$-dimethylaminocetamide 15e, (g) O-methyl $N$-methoxy- $N$ dimethylaminoacetamide 16a, and (h) $N$-methoxy- $N$-dimethylaminourea $\mathbf{1 6 b}$.

Table 3. Selected structural data for B3LYP/6-31G(d) lowest energy conformers of model acetamides $4 b, 15 a-e$, and 16a,b.

\begin{tabular}{|c|c|c|c|c|c|c|c|}
\hline Structure & $\mathrm{N}-\mathrm{C}(\mathrm{O}) / \AA$ & $(\mathrm{N}) \mathrm{C}=\mathrm{O} / \AA$ & $(\mathrm{N}-\mathrm{X}, \mathrm{N}-\mathrm{Y}) / \AA$ & $\theta /{ }^{\circ}$ & $\chi_{N} /^{\circ}$ & $\tau /{ }^{\circ}$ & Anomeric Twist Angles $1 /{ }^{\circ}$ \\
\hline 15a ONCl [34] & 1.432 & 1.207 & $\begin{array}{l}\mathrm{Cl}: 1.787 \\
\mathrm{O} 2: 1.389\end{array}$ & 337.6 & 52.3 & -5.3 & C2-O2-N1-Cl: 88.8 \\
\hline 15b ONOAc [61] & 1.429 & 1.209 & $\begin{array}{l}\text { O2:1.423 } \\
\text { O3:1.395 }\end{array}$ & 332.1 & 58.0 & 2.3 & C4-O3-N1-O2: 101.1 \\
\hline 4b ONO [33] & 1.417 & 1.212 & $\begin{array}{l}\mathrm{O} 2: 1.387 \\
\mathrm{O} 3: 1.412\end{array}$ & 342.9 & 48.1 & 8.5 & $\begin{array}{l}\mathrm{C} 2-\mathrm{O} 2-\mathrm{N} 1-\mathrm{O} 3: \\
\mathrm{C} 3-\mathrm{O} 3-\mathrm{N} 1-\mathrm{O} 2: \\
\mathbf{8 3 . 8}\end{array}$ \\
\hline 15c NNO [62] & 1.404 & 1.217 & $\begin{array}{l}\mathrm{O} 1: 1.430 \\
\mathrm{~N} 2: 1.387\end{array}$ & 346.5 & 41.8 & 5.4 & LP (N2)-N2-N1-O1: 190 \\
\hline 15d ONS [61] & 1.408 & 1.215 & $\begin{array}{l}\mathrm{S} 1: 1.717 \\
\mathrm{O} 2: 1.420\end{array}$ & 352.4 & 31.7 & -4.6 & $\begin{array}{c}\text { C4-S1-N1-O2: }-79 \\
\text { C3-O2-N1-S1: }-86.6\end{array}$ \\
\hline 15e $\mathrm{NNCl}[34]$ & 1.414 & 1.209 & $\begin{array}{l}\mathrm{Cl}: 1.820 \\
\mathrm{~N} 2: 1.351\end{array}$ & 360.0 & 0 & 0 & LP(N2)N2-N1-Cl: 180 \\
\hline 16a NNO [61] & 1.406 & 1.212 & $\begin{array}{l}\text { O1:1.404 } \\
\text { N2:1.383 }\end{array}$ & 342 & 46.3 & 0 & LP (N2)-N2-N1-O1: 169.4 \\
\hline 16b NNO & 1.428 & 1.217 & $\begin{array}{l}\text { O1:1.397 } \\
\text { N2:1.428 }\end{array}$ & 340.0 & 49.6 & -1.7 & LP (N2)-N2-N1-O1: 167.5 \\
\hline
\end{tabular}

${ }^{1}$ Anomeric alignment in bold face. 


\subsection{Resonance Energies and Amidicities}

The resonance energy and the amidicity of anomeric amides $4 \mathbf{b}$ and $15 \mathbf{a}-\mathbf{e}$ have been calculated at the B3LYP/6-31G(d) level by both the TA and COSNAR methods and by the COSNAR method using dispersion corrected M06/6-311++G(d,p). $\Delta E_{\text {COSNAR }}$ (Equation (1)), reaction energies $\left(\Delta E_{\mathrm{TA}}\right)$ (Equation (2)), inductive destabilization corrections $\left(\Delta E_{\text {ind }}\right)$ (Equation (3)), resultant $R E_{\mathrm{TA}}$ (Equation (4)) together with COSNAR, and TA amidicities are presented in Table 4.

Table 4. B3LYP/6-31G(d), B3LYP/6-311++G(d,p), and M06/6-311++G(d,p) derived resonance energies and amidicities of model anomeric acetamides $4 b, 15 a-e$, and 16a.

\begin{tabular}{|c|c|c|c|c|}
\hline Amide $(\mathrm{R}=\mathrm{Me})$ & $\Delta E_{\mathrm{COSNAR}^{1} / \mathrm{kJ} \mathrm{mol}^{-1}}$ & $\Delta E_{\mathrm{TA}} / \mathrm{kJ} \mathrm{mol}^{-1}$ & $\Delta E_{\text {ind }} / \mathrm{kJ} \mathrm{mol}^{-1}$ & $\mathrm{RE}_{\mathrm{TA}}{ }^{1,2} / \mathrm{kJ} \mathrm{mol}^{-1}$ \\
\hline 15a (ONCl) [34] & $-29.6(38)$ & 69.9 & 23.4 & $-29.5(39)$ \\
\hline $15 a^{3}$ & $-27.2(36)$ & & & \\
\hline $15 a^{4}$ & $-34.4(45)$ & & & \\
\hline $\mathbf{1 5} \mathbf{b}$ (ONOAc) [61] & $-39.7(52)$ & 65.3 & 29.7 & $-40.5(53)$ \\
\hline $15 b^{4}$ & $-39.5(52)$ & & & \\
\hline $\mathbf{4 b}(\mathrm{ONO})[35]$ & $-36.0(47)$ & 58.2 & 18.0 & $-36.0(47)$ \\
\hline $4 b^{4}$ & $-39.5(53)$ & & - & \\
\hline $15 c(O N N)[62]$ & $-52.3(69)$ & 35.1 & 10.0 & $-51.0(67)$ \\
\hline $15 c^{4}$ & $-55.7(73)$ & & & \\
\hline 15d (ONS) [61] & $-48.6(64)$ & 26.8 & 5.0 & $-48.6(64)$ \\
\hline $15 d^{4}$ & $-47.3(62)$ & & & \\
\hline 15e (NNCl) [34] & $-28.7(38)$ & 64.5 & 17.6 & $-29.0(37)$ \\
\hline $15 \mathrm{e}^{3}$ & $-28.6(38)$ & & & \\
\hline $15 e^{4}$ & $-48.7(64)$ & & & \\
\hline 16a $(\mathrm{ONN})[61]$ & $-47.7(63)$ & 31.8 & 14.6 & $-50.6(67)$ \\
\hline 1 & $-75.9(100)$ & & & \\
\hline $\mathbf{1}^{4}[34]$ & $-75.9(100)$ & & & \\
\hline
\end{tabular}

The TA and COSNAR methodologies give almost identical resonance energies for all the anomeric amides (4b and 15a-e) at the B3LYP/6-31G(d) level. $\Delta E_{\text {COSNAR }}$ determined at M06 with the expanded basis set yields very similar results to B3LYP/6-31G(d) for N,N-dimethylacetamide $\mathbf{1}$ and the anomeric amides with the exception of $\mathbf{1 5 e}$, where resonance is computed to be worth $49 \mathrm{~kJ} \mathrm{~mol}^{-1}$, just over $60 \%$ that of $N, N$-dimethylacetamide and substantially higher than that predicted from B3LYP/6-311++G(d,p), which was identical to the B3LYP/6-31G(d) value $\left(29 \mathrm{~kJ} \mathrm{~mol}^{-1}\right)$ [34]. The RE parity for 15a and 15e at B3LYP is no longer observed with M06, in line with the lower overall electronegativity of nitrogen and chlorine. These results impute the necessity for inclusion of dispersion corrections in treatments of molecules where anomeric interactions are likely to have a pronounced influence.

It is clear that resonance in anomeric amides is impaired, broadly in line with the gross electronegativity or negative inductive effect of the atoms / groups bonded to nitrogen. Interestingly, the ONN and ONS acetamides, $\mathbf{1 5 c}$ and $\mathbf{1 5 d}$, have very similar resonance energies despite the much lower electronegativity of sulphur. From Bent's rule, the opposite effect would be expected, since s-character in the lone pair orbital should decrease with decreasing electronegativity of X. This is likely to be a manifestation of the role of orbital size since the influence of second period elements is significant; nitrogen increases p-character in the bond to sulphur to effect better overlap with the larger, $3 p$ orbital of sulphur. Consequently, the nitrogen lone pair gains more "s" character relative to the amide nitrogen in the NNO acetamide 15c, resulting in less amide resonance [36,37,70]. Comparing the $\mathrm{M} 06$ values, $\mathrm{ONCl}$ and $\mathrm{ONO}$ systems have about half the resonance of $N, N$-dimethylacetamide while $\mathrm{NNO}, \mathrm{NNCl}$, and ONS systems are computed to preserve some 60 to $70 \%$ of the resonance of $\mathrm{N}, \mathrm{N}$-dimethylacetamide. 


\subsection{The Anomeric Effect}

In addition to their reduced amide resonance, anomeric amides are exemplars of XNY systems featuring an anomeric effect $[26,35]$. There are two possible anomeric interactions designated as $n_{X}-\sigma_{N Y}^{*}$, and $n_{Y}-\sigma_{N X}^{*}$ and where $X$ and $Y$ are different electronegative atoms, one of these interactions will be favoured over the other (Figure 8). By analogy with anomeric carbon centres [26,35,71-73], the relative electronegativities of heteroatoms $\mathrm{X}$ and $\mathrm{Y}$ at nitrogen and the relative sizes of interacting orbitals contribute to the strength of an anomeric interaction. Heteroatoms $\mathrm{Y}$ and $\mathrm{X}$ directly influence the relative energies of $n_{Y}$ and $\sigma^{*} \mathrm{NX}$, which, in turn, affect the net stability gain for the lone pair electrons (Figure 9a).

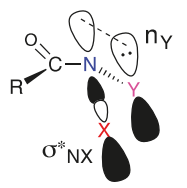

(a)

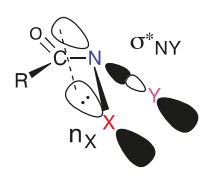

(b)

Figure 8. Two possible anomeric interactions in anomeric amides (a) $n_{Y}-\sigma_{N X}^{*}$ and (b) $n_{X}-\sigma_{N Y}^{*}$.

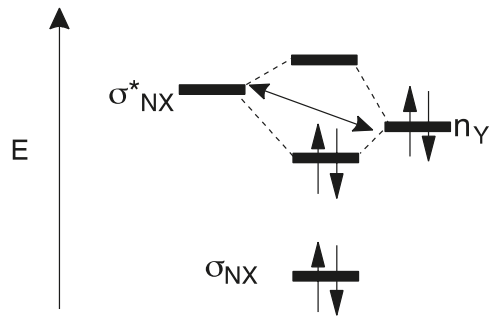

(a)

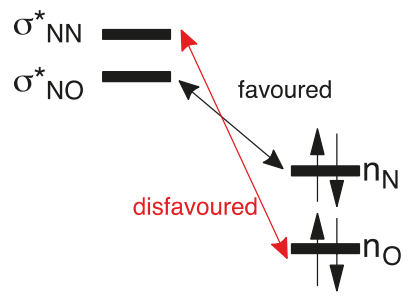

(b)

Figure 9. (a) Stabilisation of a lone pair through a $\mathrm{n}_{Y}-\sigma^{*} \mathrm{NX}$ anomeric interaction and (b) the energetics of the anomeric effect in $\mathbf{1 5 c}$.

As the electronegativity of $\mathrm{X}$ and $\mathrm{Y}$ increases by going across the p-block row on the periodic table, $\sigma^{*} \mathrm{NX}$ (and $\sigma_{\mathrm{NX}}$ ) decreases in energy as does $\mathrm{n}_{\mathrm{Y}}$. Additionally, as $\mathrm{X}$ decreases in electronegativity by going down a p-block group, $\sigma^{*} \mathrm{NX}$ decreases in energy due to reduced orbital overlap $[26,35,36,71,72]$. An optimal anomeric effect can be achieved when $Y$ is an early p-block element and $X$ is a p-block element to the right of $\mathrm{Y}$ on the periodic table; more specifically an anomeric stabilisation will be greater when the energy gap between $n_{Y}$ and $\sigma^{*} \mathrm{NX}$ is lower (Figure 9b) [74,75]. In the unusual case of anomeric amides, where the nitrogen may range between planar $\mathrm{sp}^{2}$ and pyramidal $\mathrm{sp}^{3}$ hybridisation, the geometry of the central nitrogen atom in $\mathrm{XNY}$ systems also plays a role, as pyramidal nitrogen is more conducive to edge-on $\mathrm{n}_{Y}$ and $\sigma^{*} \mathrm{NX}$ overlap than is planar, $\mathrm{sp}^{2}$ hybridised nitrogen (Figure 10a) [26,35]. 


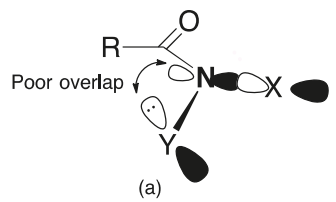

(a)

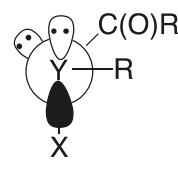

(b)

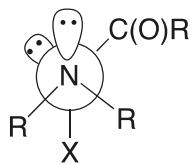

(c)

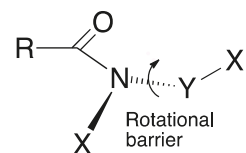

(d)

Figure 10. (a) $\mathrm{sp}^{2}$ hybridised nitrogen hinders overlap with heteroatom $\mathrm{Y}$ in an $\mathrm{n}_{\mathrm{Y}}-\sigma^{*} \mathrm{NX}$ system; (b) optimum conformation in an $n_{Y}-\sigma^{*} \mathrm{NX}$ anomeric interaction; (c) optimum conformation in an $\mathrm{n}_{\mathrm{N}}-\sigma_{\mathrm{NX}}^{*}$ anomeric interaction; and (d) restricted rotation about the $\mathrm{N}-\mathrm{Y}$ bond in an $\mathrm{n}_{\mathrm{Y}}-\sigma_{\mathrm{NX}}^{*}$ anomeric interaction.

Similar to XCY configurations, in an XNY system, a stabilising $n_{Y}-\sigma^{*} \mathrm{NX}$ anomeric effect, for example, can cause the amide to adopt a gauche conformation in which the lone pair of $Y$ is coplanar with the vicinal to C-X bond (Figure 10b) [71,74]. In anomeric amides, when $\mathrm{n}_{Y}$ is divalent oxygen or sulphur, an R-Y-N-X dihedral angle close to $190^{\circ}$ I aligns the p-type lone pair on those atoms with the vicinal $\sigma^{*} \mathrm{NX}$ (Figure 10b). Where the donor is $\mathrm{n}_{\mathrm{N}}$, an optimum anomeric effect would need the lone pair on nitrogen to be antiperiplanar to $X, \mathrm{LP}(\mathrm{N})-\mathrm{N}-\mathrm{N}-\mathrm{X}=180^{\circ}$ (Figure 10c). Consequences of the $n_{Y}-\sigma^{*} N X$ interaction include an increased barrier to rotation about the N-Y bond (Figure 10d), a contraction of the $\mathrm{N}-\mathrm{Y}$ bond, and an extension of the $\mathrm{N}-\mathrm{X}$ bond as electrons from $\mathrm{Y}$ populate the $\sigma^{*} \mathrm{NX}$ orbital.

In each of the X-ray structures in Figure 6 there is clear evidence of these anomeric interactions (Table 1, bold-face torsion angles). On the basis of energetics, the expected anomeric interactions are

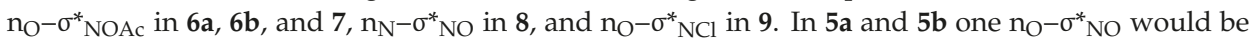
expected to prevail. Dihedral angles about the $\mathrm{N}-\mathrm{O}$ bonds in 5-7 and 9 show a preferred p-type lone pair alignment with the adjacent $\sigma_{\mathrm{NO}}^{*} \sigma^{*}{ }_{\mathrm{NOAc}}$, or $\sigma^{*} \mathrm{NCl}$ bond. In hydrazine 8 , the lone pair on $\mathrm{N} 1$ is almost perfectly aligned with the N2-O3 bond while the N2 lone pair makes an angle of only $47^{\circ}$ to the N1-O2 bond (1.403 $\AA$ ), which is shorter than the anomerically destabilised bond N2-O3 (1.411 $⿱$ ). The structure is asymmetrical with a donor N1 and recipient N2. Similar anomeric interactions are observable in ureas 10-12 and carbamates $\mathbf{1 3}$ and $\mathbf{1 4}$ (Table 2).

All computed structures exhibit an anomeric interaction (Table 3, bold-face torsion angles) and, besides the ONO system where one $\mathrm{n}_{\mathrm{O}}-\sigma^{*} \mathrm{NO}$ prevails, an anomeric $\mathrm{n}_{\mathrm{O}}-\sigma^{*} \mathrm{NX}$ prevails in $\mathrm{ONCl}$, ONOAc, and ONS in line with expectations based on electronegativity. The size of the sulphur p-orbital and lower energy of the $\sigma^{*} \mathrm{NS}$ renders an $n_{S}-\sigma^{*} \mathrm{NO}$ anomeric interaction less likely than a $\mathrm{n}_{\mathrm{O}}-\sigma^{*}{ }_{\mathrm{NS}}$ stabilisation. Where nitrogen is present, the $\mathrm{n}_{\mathrm{N}^{-} \sigma^{*} \mathrm{NO}}$ and $\mathrm{n}_{\mathrm{N}^{-}-\sigma_{\mathrm{NCl}}^{*}}$ interactions are clearly in evidence.

The anomeric effects not only dictate stereochemistry at nitrogen but, as will be seen, combined with reduced amide resonance, they have a profound impact upon spectroscopic properties and the reactivity of anomeric amides.

\subsection{Spectroscopic Properties of Anomeric Amides}

Spectroscopic properties of anomeric amides are strongly influenced by reduced resonance due to electronegativity of substituents at nitrogen. Infrared and ${ }^{13} \mathrm{C}$ NMR data for a diverse range of ONCl, ONOAcyl $[26,31,35]$, and ONO systems [35,55] have been reported as well as for a number of ONN $N, N^{\prime}$-dialkoxy- $N, N^{\prime}$-diacylhydrazines [76-78]. Representative infrared carbonyl stretch frequencies in solution for stable anomeric amides (Table 5) are significantly higher (1700 to $\left.1750 \mathrm{~cm}^{-1}\right)[32,47,55,79-81]$ than those of their precursor hydroxamic esters (1650 to $1700 \mathrm{~cm}^{-1}$ ) and primary $\left(1690 \mathrm{~cm}^{-1}\right)$, secondary (1665 to $\left.1700 \mathrm{~cm}^{-1}\right)$, and tertiary (1630 to $1670 \mathrm{~cm}^{-1}$ ) alkylamides $[26,35,82]$. While there is a slight tightening of the $(\mathrm{N}) \mathrm{C}=\mathrm{O}$ bond, the increase in $v_{\mathrm{C}=\mathrm{O}}$ has been attributed primarily to electronic destabilisation of single-bond resonance form of the carbonyl as electron density is pulled towards the electronegative heteroatoms on nitrogen, resulting in a 
more ketonic carbonyl bond [2,64]. Likewise, anomeric amides exhibit more ketonic carbonyl ${ }^{13} \mathrm{C}$ chemical shifts $\left(\mathrm{CDCl}_{3}\right)$, with downfield shifts of approximately $8.0 \mathrm{ppm}$ from their hydroxamic ester precursors. Deshielding of the carbonyl carbon is an expected consequence of the electron-withdrawing substituents. However, like acid chlorides and anhydrides, the carbonyls resonate upfield of ketones, relative to which the electron density at the carbonyl is increased on account of greater double bond character.

Table 5. Typical spectroscopic data for stable anomeric alkanamides and arylamides $(\mathrm{RC}(\mathrm{O}) \mathrm{NXY})$, and their hydroxamic ester precursors.

\begin{tabular}{cccccc}
\hline System & $\mathbf{X}$ & $\mathbf{Y}$ & $\mathbf{R}$ & Amide $\mathbf{v} / \mathbf{c m}^{-\mathbf{1}}\left(\delta^{\mathbf{1 3}} \mathbf{C}\right)$ & $\begin{array}{c}\text { Hydroxamic Ester } \\
\mathbf{v} / \mathbf{c m}^{-\mathbf{1}}\left(\boldsymbol{\delta}^{\mathbf{1 3}} \mathbf{C}\right)\end{array}$ \\
\hline 2a [79] & $\mathrm{Cl}$ & $\mathrm{OBu}$ & $\mathrm{Me}$ & $1740^{1}(175.3)$ & $1678(167.9)$ \\
2a [35] & $\mathrm{Cl}$ & $\mathrm{OBu}$ & $\mathrm{Ph}$ & $1719(174.2)$ & $1654(165.7)$ \\
2b [79] & $\mathrm{OAc}$ & $\mathrm{OBu}$ & $\mathrm{Me}$ & $1746(176.2)$ & $1678(167.9)$ \\
2b [80] & $\mathrm{OAc}$ & $\mathrm{OBu}$ & $\mathrm{Ph}$ & $1732(173.9)$ & $1654(165.7)$ \\
2c [81] & $\mathrm{OBu}$ & $\mathrm{OBu}$ & $\mathrm{Me}$ & $1707(174.1)$ & $1678^{1}(167.9)$ \\
2c [55] & $\mathrm{OMe}$ & $\mathrm{OMe}$ & $\mathrm{Ph}$ & $1711(174.3)$ & $1683(166.4)$ \\
2d [76] & 4-MeBnONAc & $4-\mathrm{MeBnO}$ & $\mathrm{Me}$ & $1734 / 1700(171.3)$ & $1693(168.0)$ \\
2d [76] & $\mathrm{BzNOEt}$ & $\mathrm{OEt}$ & $\mathrm{Ph}$ & $1708(170.0)$ & $1685(166.5)$ \\
\hline \multicolumn{7}{c}{}
\end{tabular}

Common primary, secondary, and tertiary amides have significant cis-trans isomerisation barriers for rotation about the $\mathrm{N}-\mathrm{C}(\mathrm{O})$ bond, due to the stabilising effect of amide resonance in their ground state [2]. Restricted rotation through lone pair overlap with the adjacent carbonyl $\mathrm{C} 2 \mathrm{p}_{\mathrm{z}}$ orbital, as illustrated in Figure 1, often results in observation of different chemical shifts of cis and trans conformers in their ${ }^{1} \mathrm{H}$ NMR spectra, from which barriers to isomerisation can be deduced $[83,84]$. The computed surface for $N, N$-dimethylacetamide in Figure 3 indicates that the barrier (difference between the completely planar and the fully rotated-pyramidal forms) is of the order of 71-75 $\mathrm{kJ} \mathrm{mol}^{-1}$. Hydroxamic esters have slightly less resonance and amidicity, and the rotation barrier for $N$-methoxy- $N$-methylacetamide from Figure $5 \mathrm{a}$ is approximately $67 \mathrm{~kJ} \mathrm{~mol}^{-1}$. Many hydroxamic esters have broadened ${ }^{1} \mathrm{H}$ NMR signals at ambient temperatures. Anomeric amides with lower resonance should have lower cis-trans isomerisation barriers as exemplified in the model $\mathrm{N}, \mathrm{N}$-dimethoxyacetamide in Figure 5b. Accordingly, the isomerisation barrier in bisoxyl-substituted amides $\mathbf{2 b}$ and $\mathbf{2 c}$ are too low to be measured by usual dynamic NMR methods. All proton signals of $N, N$-dimethoxy-4-toluamide remained sharp down to $180 \mathrm{~K}$ (in $d_{4}$-methanol) and the ${ }^{1} \mathrm{H}$ NMR signals for $N$-acetoxy- $N$-benzyloxybenzamide remained isochronous down to $190 \mathrm{~K}$ (in $d_{8}$-toluene) [26]. The barrier for $N$-benzyloxy- $N$-chlorobenzamide 18 could likewise not be determined by dynamic NMR [35].

Figure 11 illustrates the dramatic difference between ${ }^{1} \mathrm{H}$ NMR spectra of $N$-butoxyacetamide and its $N$-chloro- or $N$-acetoxyl derivatives as a consequence of reduced resonance in the anomeric structures, which clearly have much lower isomerization barriers. At room temperature, the anomeric amides are in the fast exchange region as opposed to the slow exchange in the hydroxamic ester. Earlier theoretical studies by Glover and Rauk support this assertion [27,28]. For example, a comparison of formamide $\mathbf{1 7} \mathbf{a}, N$-methoxyformamide $\mathbf{1 7} \mathbf{b}$, and $N$-chloro- $N$-methoxyformamide 17d, calculated at the B3LYP/6-31G(d) level, showed little reduction in the cis-trans isomerisation barrier of $73.2 \mathrm{~kJ} \mathrm{~mol}^{-1}$ in formamide, to $67-75 \mathrm{~kJ} \mathrm{~mol}^{-1}$ in $N$-methoxyformamide. However, the introduction of a second electronegative heteroatom, $\mathrm{Cl}$, reduced the barrier to only $32.2 \mathrm{~kJ} \mathrm{~mol}^{-1}$, indicating that monosubstitution alone is insufficient to impact upon the isomerisation barrier [27]. A theoretical isomerisation barrier for $N$-methoxy- $N$-(dimethylamino)formamide, which, by analogy with typical NNO systems, should retain $\sim 70 \%$ the resonance in $N, N$-dimethylacetamide, was computed to be higher at $52.7 \mathrm{~kJ} \mathrm{~mol}^{-1}$ [28]. Such an amide isomerisation barrier in the hydrazine, $N, N^{\prime}$-diacetyl- $N, N^{\prime}$-di(4-chlorobenzyloxy)hydrazine 20d, was measurable at $\Delta G^{\ddagger} 278=54.0 \mathrm{~kJ} \mathrm{~mol}^{-1}$, in line with this theoretical barrier [27]. 


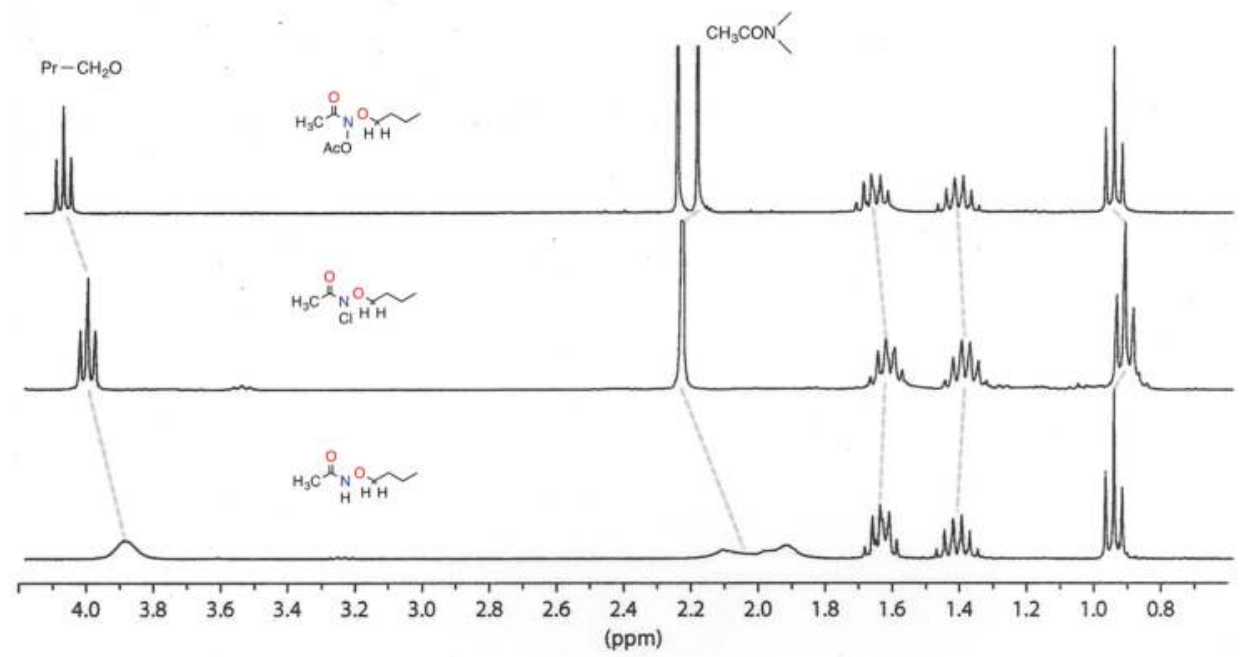

Figure 11. $300 \mathrm{MHz}{ }^{1} \mathrm{H}$ NMR spectra $\left(300 \mathrm{~K}, \mathrm{CDCl}_{3}\right)$ of $\mathrm{N}$-butoxyacetamide, and anomeric amides $\mathrm{N}$-butoxy- $\mathrm{N}$-chloroacetamide and $\mathrm{N}$-acetoxy- $\mathrm{N}$-butoxyacetamide.

The intrinsic barrier to inversion at nitrogen in bisheteroatom-substituted amides is expected to be much lower than those of analogous amines. The transition state for inversion in anomeric amides is expected to be planar, where the nitrogen lone pair can interact with the carbonyl $2 p_{z}$ orbital generating stabilisation [35]. For $\mathrm{N}, \mathrm{N}$-dimethoxyacetamide (Figure $5 \mathrm{~b}$ ) this barrier is represented by the energy of structure (b), while the difference in energy between fully twisted structures (d) and (c) represents the much larger barrier to inversion in the corresponding anomeric amine. Several theoretical estimates put these barriers in anomeric amides at about $10 \mathrm{~kJ} \mathrm{~mol}^{-1}$ [28].<smiles>[Y]N(C)C=O</smiles>

17<smiles>O=C(c1ccccc1)N(Cl)Oc1ccccc1</smiles>

18<smiles>[R]C(=O)N(OCC)N(OCC)C(C)=O</smiles>

19 a: $\mathrm{R}=4-\mathrm{MeOC}_{6} \mathrm{H}_{4}$

b: $\mathrm{R}=4-\mathrm{MeC}_{6} \mathrm{H}_{4}$

c: $\mathrm{R}=\mathrm{C}_{6} \mathrm{H}_{5}$

d: $\mathrm{R}=4-\mathrm{ClC}_{6} \mathrm{H}_{4}$

e: $\mathrm{R}=4-\mathrm{NO}_{2} \mathrm{C}_{6} \mathrm{H}_{4}$<smiles>CC(=O)N(O)N(O)C(C)=O</smiles>

20

a: $\mathrm{R}=4-\mathrm{MeOC}_{6} \mathrm{H}_{4} \mathrm{CH}_{2}$

b: $\mathrm{R}=4-\mathrm{MeC}_{6} \mathrm{H}_{4} \mathrm{CH}_{2}$

c: $\mathrm{R}=\mathrm{C}_{6} \mathrm{H}_{5} \mathrm{CH}_{2}$

d: $\mathrm{R}=4-\mathrm{ClC}_{6} \mathrm{H}_{4} \mathrm{CH}_{2}$

e: $\mathrm{R}=4-\mathrm{NO}_{2} \mathrm{C}_{6} \mathrm{H}_{4} \mathrm{CH}_{2}$

In anomeric systems, strong $n_{Y}-\sigma^{*} \mathrm{NX}$ interactions should increase the bond order of the $\mathrm{N}-\mathrm{Y}$ bond, which should impose barriers to rotation about those bonds. For $N$-chloro- $N$-methoxyformamide $17 \mathrm{~d}$, the $\mathrm{N}-\mathrm{O}$ and $\mathrm{N}-\mathrm{C}(\mathrm{O})$ rotation barriers have been estimated at the B3LYP/6-31G(d) level at 44.7 and $29.2 \mathrm{~kJ} \mathrm{~mol}^{-1}$, respectively [27], while the theoretical barrier to rotation about the $\mathrm{N}-\mathrm{N}$ bond in $N$-methoxy- $N$-dimethylaminoformamide $17 \mathrm{e}$ was computed at $\sim 60 \mathrm{~kJ} \mathrm{~mol}^{-1}$ [28]. Experimental measurements for both anomerically induced barriers have been made. An N-O anomeric rotational barrier of $\Delta G^{\ddagger}=43 \mathrm{~kJ} \mathrm{~mol}^{-1}$ has been determined for $N$-chloro- $N$-benzloxybenzamide 18 , where the benzylic methylenes become diastereotopic at $217 \mathrm{~K}$ in $d_{8}$-toluene, but as no amide isomerisation could be detected, that barrier must be significantly lower [26]. An anomerically induced rotational barrier for $\mathrm{N}-\mathrm{N}^{\prime}$ bond in a number of $\mathrm{N}, \mathrm{N}$-diacyl- $\mathrm{N}, \mathrm{N}$-dialkoxyhydrazines $19 \mathbf{a}-\mathbf{e}$ and $20 \mathrm{a}-\mathbf{e}$ has been measured in dynamic ${ }^{1} \mathrm{H}$ NMR studies [32]. Methylene signals of $N, N^{\prime}$-diethoxy 19a-e and $N, N^{\prime}$-dibenzyloxy groups $20 \mathrm{a}-\mathbf{e}$, which were diastereotopic at room temperature, as a consequence of restricted rotation 
about the $\mathrm{N}-\mathrm{N}^{\prime}$ bond, coalesced at higher temperatures $\left(\mathrm{T}_{\mathrm{c}}=316-346 \mathrm{~K}\right)$ from which rotational free energy barriers of the order of $60-70 \mathrm{~kJ} \mathrm{~mol}^{-1}$ could be determined [32], which compare favourably with the theoretically calculated $N-N^{\prime}$ rotational barrier for $17 \mathrm{e}$ of $60 \mathrm{~kJ} \mathrm{~mol}^{-1}$ [28].

\section{Reactivity of Anomeric Amides}

The reduced resonance and attendant pyramidalisation at the amide nitrogen together with anomeric properties of these unusual molecules results in a plethora of amide reactivity, some known, and now better understood, and others that are unique to anomeric amides. The destabilisation of the amide bond, coupled with the substitution pattern, facilitates reactivity at the amide nitrogen in which the amides are usually transformed from one anomeric amide form to another. Moreover, it can induce a novel process, known as the HERON reaction (Named at the Third Heron Island Conference on Reactive Intermediates and Unusual Molecules, Heron Island 1994.), in which the amide bond is broken to form acyl derivatives and heteroatom-stabilised nitrenes. This reaction is facilitated by weakened amide resonance, but is driven by $n_{Y}-\sigma^{*} \mathrm{NX}$ anomeric destabilisation of the $\mathrm{N}-\mathrm{X}$ bond.

\subsection{Reactivity at the Amide Nitrogen}

Due to their characteristic, diminished amide resonance and anomeric destabilisation, this class of amide has been shown to undergo $\mathrm{S}_{\mathrm{N}} 2$ reaction at nitrogen, and elimination of $\mathrm{N}$-substituents leading to $\mathrm{S}_{\mathrm{N}} 1$-type processes. Several congeners undergo thermolytic homolysis to give alkoxyamidyl radicals.

\subsection{1. $\mathrm{S}_{\mathrm{N}} 2$ Reactions}

In $\mathrm{XNY}$ systems, a moderate $\mathrm{n}_{\mathrm{Y}}-\sigma^{*} \mathrm{NX}$ negative hyperconjugation leads, through neighbouring group participation, to weakening of the $\mathrm{N}-\mathrm{X}$ bond, which can encourage $\mathrm{S}_{\mathrm{N}} 2$ reactions at nitrogen $[26,31,35]$. The increased electrophilicity of nitrogen in $N$-acyloxy- $N$-alkoxyamides 21 leaves them vulnerable to attack by arylamines (Scheme 1 i) [42,44,47,51], azide (Scheme 1 ii) [54], hydroxide (Scheme 1 iii) [45], and thiols (Scheme $1 \mathrm{iv)}$ [52], the outcomes from which are anomerically substituted intermediates 22-24 and 26 that ultimately may undergo HERON reactions. Furthermore, $N$-acyloxy- $N$-alkoxyamides 21 themselves may be synthesised in $\mathrm{S}_{\mathrm{N}} 2$ reactions between $\mathrm{N}$-alkoxy- $\mathrm{N}$-chloroamides 25 and sodium carboxylates (Scheme 1 vi) $[43,45,46,48,51,80,85]$. $N$-alkoxy- $N$-chloroamides 25 also react bimolecularly with azide generating reactive $N$-alkoxy- $N$-azidoamides 26 (Scheme $1 \mathrm{v}$ ) [54].

Reactions of 21 systems with amines and thiols have been modelled at the AM1, HF /6-31G(d), and $\mathrm{pBP} / \mathrm{DN}^{*}$ levels, which reveal significant charge separation in the transition states and alkoxynitrenium ion character (Figure 12) [86]. These reactions should be favoured by electron-donor substituents on the nucleophile and electron-acceptor substituents on the acyloxyl group.

The $\mathrm{S}_{\mathrm{N}} 2$ reaction of $\mathrm{N}$-methylaniline with a wide range of $\mathrm{N}$-acyloxy- $\mathrm{N}$-alkoxyamides 21 has been studied (Scheme $1 \mathrm{i}$ ), and relative rate constants, Arrhenius activation energies, and entropies of activation are in accord with a transition state with significant charge separation $[31,44,51,87]$. $E_{\mathrm{A}}{ }^{\prime} \mathrm{s}$ are of the order of 40 to $60 \mathrm{~kJ} \mathrm{~mol}^{-1}$. Entropies of activation $\left(-90-160 \mathrm{~J} \mathrm{~K}^{-1} \mathrm{~mol}^{-1}\right)$ are more negative than found in $\mathrm{S}_{\mathrm{N}} 2$ reactions of alkyl halides, owing to a greater degree of solvation in the charge separated transition state [88]. In addition, the rates for reactions $\mathrm{i}$, iii, and iv with a series of NAA's bearing $N$ - $p$-substituted benzoyloxyl leaving groups correlated with Hammett $\sigma$ constants with positive slope (i, $\varrho=1.7$, iii, $\varrho=0.6$, and iv, $\varrho=1.1$ ) [44,45,52]. In addition, a series of anilines reacted bimolecularly and rate constants correlate with Hammett $\sigma^{+}$constants $(\varrho=-0.9)$ [44]. In most respects, the $\mathrm{S}_{\mathrm{N}} 2$ reactions are electronically and geometrically reminiscent of those at carbon centres and are accelerated by electron-donor groups on the nucleophile and electron-withdrawing groups on the leaving group. The amide carbonyl facilitates $\mathrm{S}_{\mathrm{N}} 2$ reactivity in line with enhanced reactivity in phenacyl bromides [89]. In particular, bimolecular reaction rates are radically impeded with branching $\alpha$ to the carbonyl [50], which is analogous to the resistance to $\mathrm{S}_{\mathrm{N}} 2$ reactions of $\alpha$-halo ketones bearing substituents at the $\alpha^{\prime}$ position $[90,91]$. 

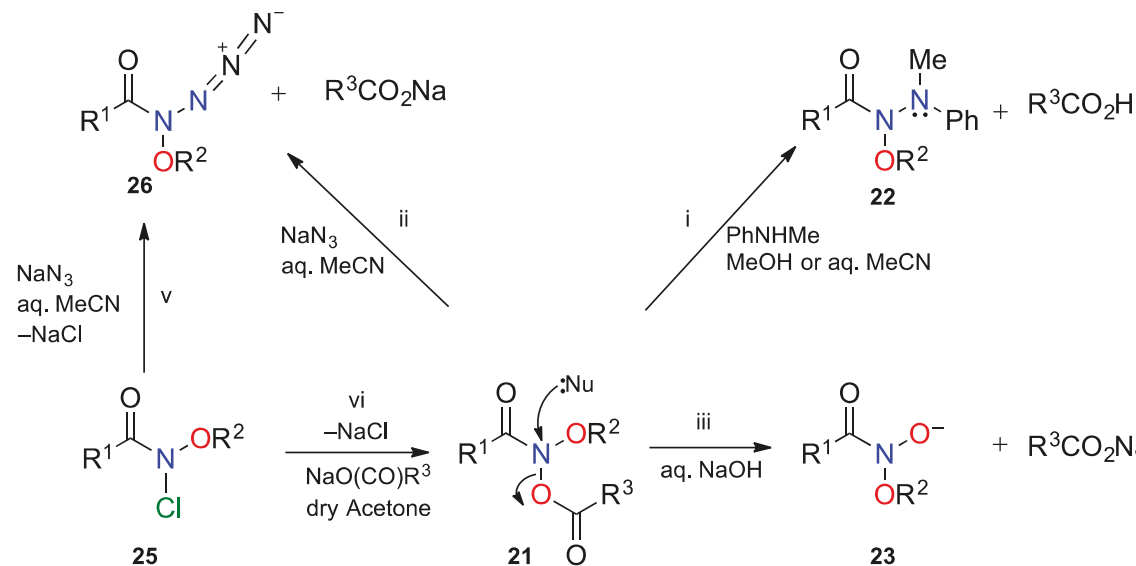
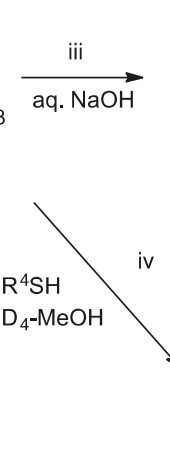

Deoxyribose

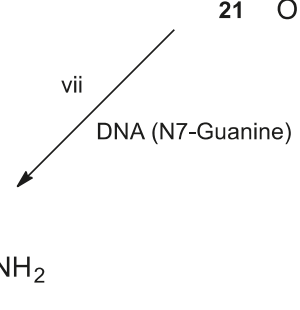

27<smiles>[R]ON([R2])C([R])=O</smiles>

24

Scheme 1. $\mathrm{S}_{\mathrm{N}} 2$ reactions of $N$-acyloxy- $N$-alkoxyamides 21 with: (i) arylamines; (ii) azide; (iii) hydroxide; (iv) thiols; (vii) DNA and reaction of $N$-alkoxy- $N$-chloroamides 25 with (v) azide and (vi) sodium carboxylates.

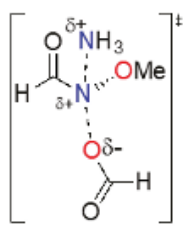

(a)

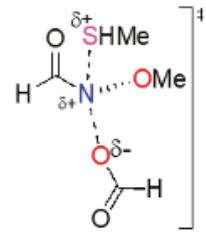

(b)

Figure 12. HF /6-31G* predicted charge separation in transition states for reactions of $N$-formyloxy- $N$ methoxyformamide with (a) ammonia and (b) methanethiol.

Anomeric substitution at nitrogen in $N$-acyloxy- $N$-alkoxyamides $\mathbf{2 1}$ renders this class of amides as direct-acting mutagens. Mutagenicity towards S. typhimurium in the Ames reverse mutation assay does not require premetabolic activation [92,93]. Our DNA damage studies on plasmid DNA at physiological $\mathrm{pH}$, as well as extensive structure-activity relationships [31,38-41,43,45,46,48-50,79,80], point to binding of NAA's 21, intact, into the major groove of DNA, where an $\mathrm{S}_{\mathrm{N}} 2$ reaction occurs at the most nucleophilic centre, the electron-rich N7 in guanine (Scheme 1 vii) [94-97]. All three side chains $\left(R^{1}, R^{2}\right.$, and $\left.R^{3}\right)$ of 21 have an impact upon both DNA damage profiles as well as mutagenicity levels. An $\mathrm{S}_{\mathrm{N}} 1$ mechanism, yielding electrophilic $N$-acyl- $N$-alkoxynitrenium ions, was ruled out since only $\mathrm{R}^{1}$ and $\mathrm{R}^{2}$ would influence binding and reactivity. Moreover, mutagenic activity is radically reduced when there is branching $\alpha$ to the carbonyl in parallel with the impaired $S_{N} 2$ reactivity $[40,50,51]$. The mutagenic activity of $N$-acyloxy- $N$-alkoxyamides 21 has been used recently to show how hydrophobicity and intercalating side chains impact upon DNA binding $[38,39]$. 


\subsubsection{Elimination Reactions}

In an anomeric amide where $n_{Y^{-}}-\sigma^{*} N_{X}$ is a strong interaction, where $X$ has a high electron affinity and $\mathrm{Y}$ is a strong electron donor, polarisation can lead to elimination of $\mathrm{X}^{-}$, leaving a Y-stabilised nitrenium ion 28 (Scheme 2) [98]. The stronger the anomeric effect, the more readily the elimination is expected to occur. In the case of $\mathrm{N}$-alkoxy- $\mathrm{N}$-chloroamides 25 , elimination can be facilitated by Lewis acid complexation with $\mathrm{X}$ and by the use of polar solvents [35]. For example, treatment of $N$-chloro- $N$-(2-phenylethyloxy)- 29a and $N$-chloro- $N$-(3-phenylpropyloxy)amides $29 \mathbf{b}$ with silver tetrafluoroborate in ether, initiates a ring closing reaction to form $\mathrm{N}$-acyl-1H-3,4-dihydro-2,1-benzoxazines 30a and $N$-acyl-1,3,4,5-tetrahydrobenzoxazepines $30 \mathbf{b}$, respectively, via chlorine elimination to form nitrenium ions (Scheme 3). $\mathrm{N}$-acyl- $\mathrm{N}$-alkoxynitrenium ions are strongly stabilised by delocalisation of the positive charge onto oxygen $[98,99]$. This methodology has been used widely since its discovery in 1984 by Glover [100,101] and Kikugawa [102-108]. In addition, treatment of $N$-alkoxy- $N$-chloroamides 25 with silver carboxylates in diethyl ether, allows the nitrenium ion to be scavenged by carboxylate in a versatile reaction which has been used to synthesise a range of $N$-acyloxy- $N$-alkoxyamides 21 [48,80].

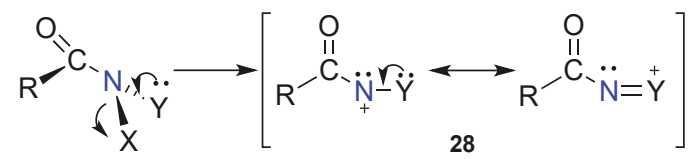

Scheme 2. Nitrenium ion formation by elimination of $X$ due to a strong $n_{Y}-\sigma^{*} N X$ interaction.

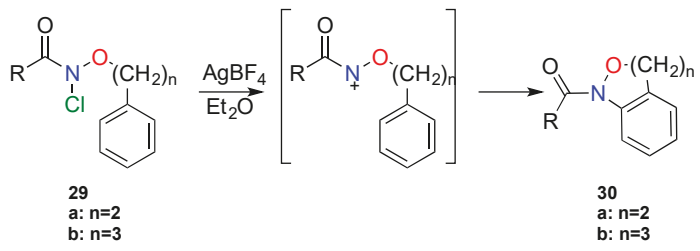

Scheme 3. Cyclisation by silver ion catalysed elimination reactions.

Elimination of chloride in the alcoholysis of $\mathbf{2 5}$ to give nitrenium ion provided a synthetic pathway to $\mathrm{N}, \mathrm{N}$-dialkoxyamides 5 (Scheme 4) [55,56]. We recently reported a more versatile synthesis effected by PIFA oxidation of hydroxamic esters 31 in appropriate alcohol, which proceeds through a reactive phenylbistrifluoroacetate derivative 32 [30,55]. Similar hypervalent iodine oxidations have been used in nitrenium ion cyclisations onto aromatic rings [105].

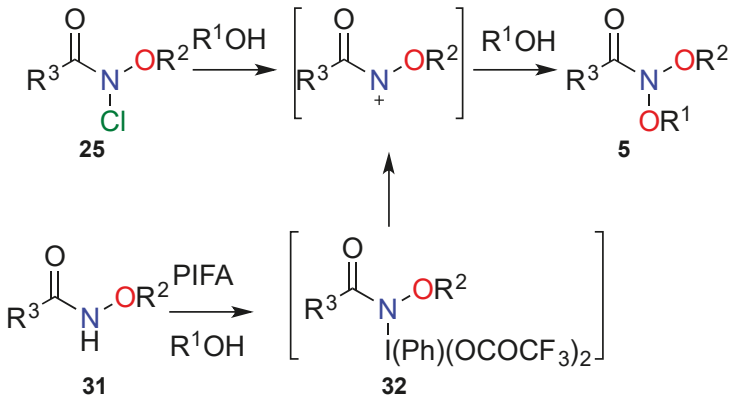

Scheme 4. $N$-Acyl- $N$-alkoxynitrenium ion mediated syntheses of $N, N$-dialkoxyamides 5 .

$\mathrm{N}$-Alkoxy-N-benzoylnitrenium ions 34 are generated through $\mathrm{A}_{\mathrm{A} 1} 1$ acid-catalysed solvolysis of $\mathrm{N}$-acetoxy- $\mathrm{N}$-alkoxybenzamides 33 (Scheme 5) [46,48,49]. Acetoxyl, upon protonation with a catalytic 
amount of mineral acid, is eliminated from $N$-acetoxy- $N$-alkoxybenzamides 33 and the nitrenium ions are trapped by water to form $\mathrm{N}$-alkoxyhydroxamic acids $\mathbf{3 5}$. The anomeric $\mathbf{3 5}$ undergoes secondary reactions to form a range of products.<smiles>CC(=O)ON(O)C(=O)O</smiles>

33

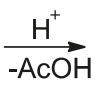<smiles>O=C([AlH2])NOCCO</smiles>

34<smiles>O=C([Al]O)N(O)O</smiles>

35

Scheme 5. Acid catalysed hydrolysis of $N$-acetoxy- $N$-butoxybenzamides.

The elimination reactions of $N$-alkoxy- $N$-chloroamides 25 and the acid-catalysed solvolysis reactions of 33, both of which proceed through intermediacy of $\mathrm{N}$-acyl- $\mathrm{N}$-alkoxynitrenium ions, can better be re-evaluated in terms of anomeric destabilisation in combination with their reduced amidicities.

\subsection{The HERON Reaction}

\subsubsection{HERON Reactions of $N$-Amino-N-Alkoxymides}

A novel reaction of suitably constituted anomeric amides is the HERON (Heteroatom Rearrangement On Nitrogen) reaction [56,109-113]. In such amides, when the $X$ heteroatom of an anomerically destabilised $\mathrm{N}-\mathrm{X}$ bond is a poor leaving group, the amide can undergo a concerted rearrangement involving the migration of $\mathrm{X}$ to the carbonyl carbon and the ejection of a Y-stabilised nitrene (Scheme 6).

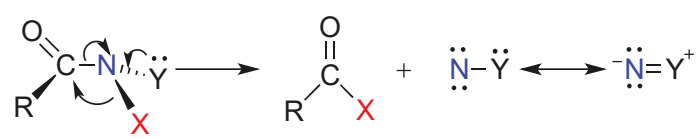

Scheme 6. The heteroatom rearrangement on nitrogen (HERON) reaction of an anomeric amide.

The HERON reaction was discovered by Glover and Campbell during research into $\mathrm{S}_{\mathrm{N}} 2$ reactivity of $\mathrm{N}$-acyloxy- $\mathrm{N}$-alkoxyamides 21 , specifically the reaction between $\mathrm{N}$-acetoxy- $\mathrm{N}$-butoxybenzamide and $\mathrm{N}$-methylaniline according to Scheme $1 \mathrm{i}[47,111]$. In a polar solvent such as methanol, $\mathrm{N}$-methylaniline attacks the amide nitrogen, replacing the acetoxyl side chain to form an unstable intermediate, $N$-butoxy- $N$-( $N^{\prime}$-methylanilino)benzamide 36 , which undergoes the HERON reaction to form butyl benzoate 37, and an aminonitrene, 1-methyl-1-phenyldiazene 38 (Scheme 7 i). Aminonitrenes are highly reactive intermediates with a singlet ground state, which persist long enough under reaction conditions to dimerise to tetrazenes [114-117], in this case, 39 (Scheme 7 ii) [44,47]. $N, N^{\prime}$-Diacyl- $N, N^{\prime}$-dialkoxyhydrazines 40 , the only forms of $N$-alkoxy- $N$-aminoamides $\mathbf{2 d}$ to have been isolated, undergo tandem HERON reactions to form two equivalents of ester $\mathbf{4 1}$ and a molecule of nitrogen; the $\mathrm{N}$-acyl- $\mathrm{N}$-alkoxyaminonitrenes $\mathbf{4 2}$, formed in this HERON reaction, rapidly undergo a second rearrangement to form a molecule of nitrogen and ester before dimerisation of the $\mathrm{N}$-acyl- $\mathrm{N}$-alkoxyaminonitrene can occur (Scheme 8) [56,76]. Step ii can also be regarded as a HERON process, driven by a high energy electron pair on 1,1-diazene, a charge separated form of aminonitrene. Barton and coworkers studied the decomposition at about the same time, and both groups established the operation of three-centre mechanisms using asymmetric hydrazines [77]. In addition, Barton found its concerted nature facilitated the formation of a range of highly hindered esters and, recently, 
Zhang has utilised the reaction to generate hindered esters from $N, N^{\prime}$-dialkoxy- $N, N^{\prime}$-diacylhydrazines, synthesised through $\mathrm{N}$-bromosuccinimide (NBS) oxidation of hydroxamic esters [118].

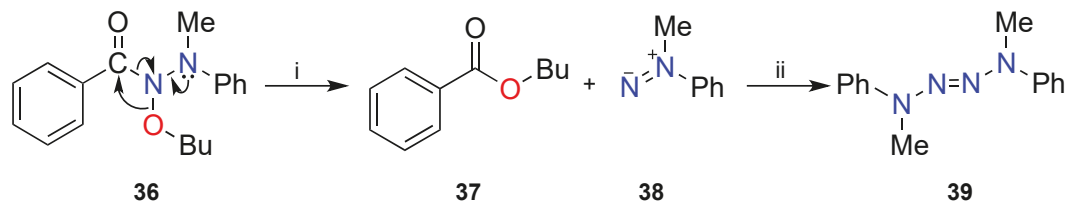

Scheme 7. The first HERON reaction of $N$-butoxy-N-(N'-methylanilino)benzamide 36.

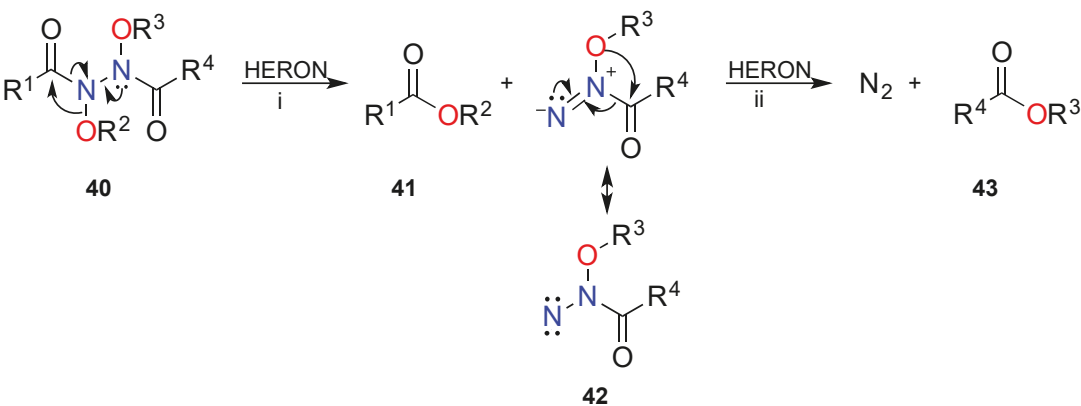

Scheme 8. Tandem HERON reactions of $N, N^{\prime}$-diacyl- $N, N^{\prime}$-dialkoxyhydrazines 40.

\subsubsection{Theoretical and Experimental Validation of the HERON Reaction}

The HERON reaction of $\mathbf{2 2}$ and $\mathbf{4 0}$ has been modelled and validated computationally. Initially, AM1 modelling predicted that the three-centre reaction in the first HERON (Scheme 7 i) had an energy barrier of $184 \mathrm{~kJ} \mathrm{~mol}^{-1}$, while that of the second step was very low $\left(25 \mathrm{~kJ} \mathrm{~mol}^{-1}\right)[56,77]$. An extensive AM1 study of HERON reactions of $N$-amino- $N$-alkoxyacetamides predicted a similar barrier of $159 \mathrm{~kJ} \mathrm{~mol}^{-1}$ in the gas phase, but a lower barrier of $126 \mathrm{~kJ} \mathrm{~mol}^{-1}$ in solution [111]. The same study also predicted lower barriers with electron-donor groups on the amino nitrogen. In a more rigorous study at the B3LYP/6-31G(d) level [76], Glover et al. modelled the HERON reaction of $N$-methoxy- $N$ dimethylaminoformamide 17e, a model representative of $N-\left(N^{\prime}\right.$-methylanilino)- $N$-butoxybenzamide 36 , and $N, N^{\prime}$ - diacyl- $N, N^{\prime}$-dialkoxyhydrazines 40 , for which HERON reactions had been experimentally observed. It was confirmed that the $\mathrm{n}_{\mathrm{N}}-\sigma^{*} \mathrm{NO}$ anomeric destabilisation resulted in migration of the methoxyl group with an activation barrier of $90 \mathrm{~kJ} \mathrm{~mol}^{-1}$ and the reaction was exothermic by $23 \mathrm{~kJ} \mathrm{~mol}^{-1}$. Similar diasteromeric transition states were located, but the transition state accessible from the lowest energy (syn) conformer of $\mathbf{1 7} \mathbf{e}$ was found to be that depicted in Figure 13a. Importantly, modelling showed that amide resonance in the transition state was largely lost, as migration occurs in a plane perpendicular to the carbonyl, twisting the nitrogen lone pair away from alignment with the $\pi^{*} \mathrm{C}=\mathrm{O}$ orbital. Anomeric destabilisation, however, remained along the reaction coordinate, driving the reaction forward. The $\mathrm{N}-\mathrm{C}(\mathrm{O})$ bond is largely intact at the transition state but breaks as the $\mathrm{O} 2-\mathrm{C} 1$ bond forms in an internal, $\mathrm{S}_{\mathrm{N}}$ 2-like reaction at the amide carbon. Significantly, a tetrahedral intermediate is avoided by this process. Subsequent high level calculations on the decomposition of anomeric hydrazines by Tomson and Hall, yielded similar energetics for the HERON process [119]. 


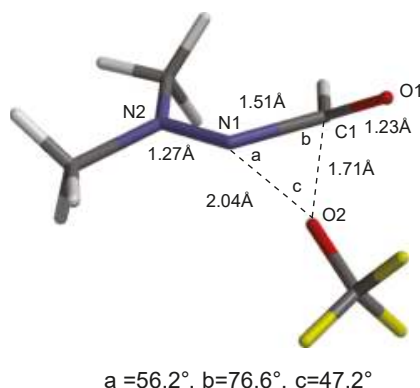

(a)

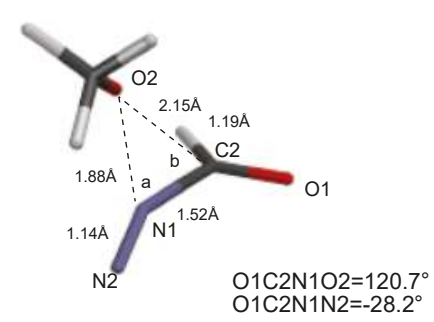

$a=78^{\circ}, b=59^{\circ}$

(b)

Figure 13. Twisted HERON transition states of (a) $N$-methoxy- $N$-dimethylaminoformamide 17e and (b) 1-formyl-1-methoxydiazene $44\left(\mathrm{R}^{1}=\mathrm{H}, \mathrm{R}^{2}=\mathrm{Me}\right)$ at B3LYP/6-31G(d) level $[53,76]$.

Analysis of charge separation in the B3LYP/6-31G(d) transition state revealed a partial positive charge of +0.5 on amino group, partial negative charge of -0.3 on the migrating methoxyl group and little change in charge at the carbonyl. This indicated that HERON in these NNO systems could be assisted by polar solvents, electron-donating groups on the stationary amino substituent, and electron-withdrawing groups on the migrating oxygen substituent. The activation barriers and charge separation in the transition state were validated experimentally by Arrhenius studies and Hammett correlations from thermal decomposition of a range of substituted hydrazines 19a-e and 20a-e in mesitylene (Table 6) [76]. In 19, the donor ability of $\mathrm{n}_{\mathrm{N}}$ is increased by electron-rich aroyl groups, leading to enhanced reaction rates and a negative Hammett $\sigma^{+}$correlation $\left(\varrho=-0.35, R^{2}=0.978\right)$ (Figure 14a). However, acceptor benzyloxy substituents in $\mathbf{2 0}$ facilitate the migration, leading to a positive Hammett $\sigma$-correlation $\left(\varrho=1.02, R^{2}=0.911\right)$ (Figure $\left.14 b\right)$. Rate constants were lower in 20 on account of a negative impact at the donor nitrogen. Donor groups, on the other hand, have little impact on the carbonyl in $\mathbf{1 9 .}$

Table 6. Hammett reaction constants, Arrhenius activation energies, entropies of activation, and rate constants for HERON decomposition of 19a-e and 20a-e [76].

\begin{tabular}{|c|c|c|c|c|}
\hline Series & System & $E_{\mathrm{A}} / \mathrm{kJ} \mathrm{mol}^{-1}$ & $\Delta S^{\ddagger} / \mathrm{J} \mathrm{K}{ }^{-1} \mathrm{~mol}^{-1}$ & $10^{6} \cdot k_{298} / \mathrm{s}^{-1}$ \\
\hline \multirow{5}{*}{ Series 19: $\sigma^{+}$reaction constant $\varrho=-0.35^{1}$} & $19 a$ & $99.2(4.3)$ & $-21.2(13)$ & 5.56 \\
\hline & $19 b$ & $100.7(8.2)$ & $-19.6(25)$ & 3.72 \\
\hline & $19 c$ & $100.4(5.1)$ & $-23.8(15)$ & 2.52 \\
\hline & $19 d$ & $107.7(1.7)$ & $0.9(5)$ & 2.50 \\
\hline & $19 e$ & $104.0(1.7)$ & $-15.4(5)$ & 1.57 \\
\hline \multirow{6}{*}{ Series 20: $\sigma$ reaction constant $\varrho=+1.02^{1}$} & & & & $10^{8} \cdot k_{298} / \mathrm{s}^{-1}$ \\
\hline & $20 a$ & $111.4(0.9)$ & $-21.1(2)$ & 4.02 \\
\hline & $20 b$ & $125.9(1.0)$ & 24.5 (3) & 2.76 \\
\hline & $20 c$ & $114.1(3.9)$ & $-8.7(11)$ & 6.21 \\
\hline & $20 d$ & $125.1(8.5)$ & $27.4(24)$ & 5.44 \\
\hline & $20 \mathrm{e}$ & $98.8(0.3)$ & $-46.4(1)$ & 31.9 \\
\hline
\end{tabular}

${ }^{1}$ Hammett correlations using $k_{298 K}$. 


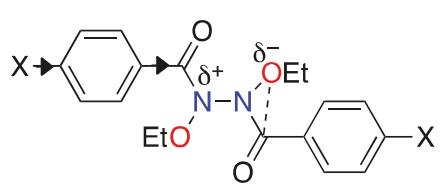

(a)

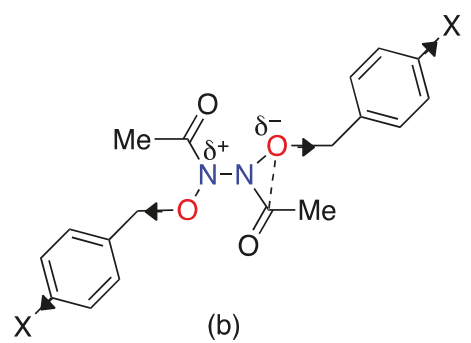

(b)

Figure 14. Influence on the HERON transition state of (a) electron-rich benzoyl groups in 19 and (b) electron-deficient benzyloxy groups in $\mathbf{2 0 .}$

\subsubsection{HERON Reaction of 1-Acyl-1-Alkoxydiazenes}

The second step in the thermal decomposition of $N, N^{\prime}$-dialkoxy- $N, N^{\prime}$-diacylhydrazines 40 , 19, and 20 has also been modelled at both B3LYP/6-31G(d) and CCSD(T)//B3P86 level using $N$-formyl- $N$-methoxydiazene, and was found to have an extremely small $E_{\mathrm{A}}$ of between 5 and $12 \mathrm{~kJ} \mathrm{~mol}^{-1}$ and to be highly exothermic $\left(\Delta E=-400 \mathrm{~kJ} \mathrm{~mol}^{-1}\right)[53,119]$. We encountered this process from the reaction of $N$-acyloxy- $N$-alkoxyamides 21 with azide (Scheme 1 ii), which generates ester and two molecules of nitrogen [54]. The reaction of $N$-acyloxy- $N$-alkoxyamides with azide was originally conceived in an attempt to trap and determine the lifetimes of $\mathrm{N}$-acyl- $\mathrm{N}$-alkoxynitrenium ions, by analogy with the determination of lifetimes of arylnitrenium ions in water $[120,121]$. However, $\mathrm{N}$-Alkoxy- $\mathrm{N}$-azidoamides $\mathbf{2 6}$ are highly unstable intermediates, losing nitrogen to generate 1-acyl-1-alkoxydiazenes $\mathbf{4 4}$, which react further to nitrogen and ester Scheme 9. The transition state for this reaction of $N$-formyl- $N$-methoxydiazene, modelled at the B3LYP/6-31G(d) level, is depicted in Figure 13b. Once again, the methoxyl group migrates in a plane orthogonal to the $\mathrm{N} 1-\mathrm{C} 2-\mathrm{O} 1$ plane in an earlier transition state with little $\mathrm{N}-\mathrm{C}(\mathrm{O})$ bond cleavage, which occurs in concert with $\mathrm{O} 2-\mathrm{C} 2$ bond formation, again avoiding a tetrahedral intermediate. The reaction of azide with $\mathrm{N}$-chloro- $\mathrm{N}$-alkoxyamides 25 proved to be an excellent means of generating highly hindered esters [54] —not surprisingly, in light of the very low $E_{\mathrm{A}}$ and extreme exothermicity born out of the entropically favourable generation of two highly stable molecules (methyl formate and nitrogen) [53,119]. Overall, the decomposition of $N$-azido- $N$-methoxyformamide to two molecules of nitrogen and methylformate was computed to be exothermic by some $575 \mathrm{~kJ} \mathrm{~mol}^{-1}$ [53]. Yields of esters prepared by this method are given in Table 7.

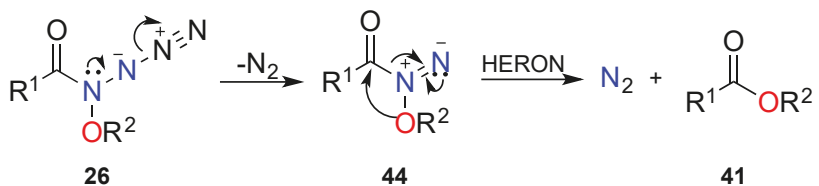

Scheme 9. Decomposition and HERON reaction of $N$-alkoxy- $N$-azidoamides 26. 
Table 7. Ester $41\left(\mathrm{R}^{1} \mathrm{COOR}^{2}\right)$ formation from the reaction of $N$-alkoxy- $N$-chloroamides $25\left(\mathrm{R}^{1} \mathrm{CONClOR}^{2}\right)$ with sodium azide in aqueous acetonitrile.

\begin{tabular}{ccc}
\hline $\mathbf{R}$ & $\mathbf{R}^{\prime}$ & Isolated Crude Yield/\% \\
\hline $\mathrm{Ph}$ & $\left(\mathrm{CH}_{3}\right)_{3} \mathrm{C}$ & 87 \\
$\left(\mathrm{CH}_{3}\right)_{3} \mathrm{C}$ & $\left(\mathrm{CH}_{3}\right)_{3} \mathrm{C}$ & 30 \\
1-adamantyl & $\left(\mathrm{CH}_{3}\right)_{3} \mathrm{C}$ & 82 \\
$\left(\mathrm{CH}_{3}\right)_{3} \mathrm{C}$ & cyclohexyl & 97 \\
$\mathrm{Ph}$ & $\left(\mathrm{CH}_{3}\right)_{2} \mathrm{CH}$ & 92 \\
$\mathrm{Ph}$ & $\mathrm{PhCH}_{2}$ & 93 \\
$\mathrm{CH}_{3}$ & $\mathrm{PhCH}_{2}$ & 92 \\
$\mathrm{p}-\mathrm{NO}_{2} \mathrm{C}_{6} \mathrm{H}_{4}$ & $\mathrm{Et}$ & 94 \\
$\mathrm{Ph}$ & $\mathrm{Et}$ & 94 \\
\hline
\end{tabular}

Both Barton and recently Zhang have shown that the thermal decomposition of $N, N^{\prime}$-dialkoxy$N, N^{\prime}$-diacylhydrazines is a source of hindered esters. The avoidance of a tetrahedral intermediate in both HERON steps of these reactions, and which is a limiting structure in Fisher esterification, is critical. This, and the clear role of anomeric substitution at nitrogen in both reducing amidicity, as well as promoting the rearrangement, are paramount.

\subsubsection{HERON Reactions of Anionic Systems}

Hydroxide substitution of the acyloxyl side chain from a range of $\mathrm{N}$-acyloxy- $\mathrm{N}$-alkoxybenzamides 21, at room temperature in aqueous acetonitrile, generated esters and their hydrolysis products [45]. Rate data and crossover experiments pointed to an $\mathrm{S}_{\mathrm{N}} 2$ reaction at nitrogen and the intramolecular nature of the reaction, implicating a HERON process. The hydroxamic acid intermediates $\mathbf{4 5}$ from initial attack (Scheme 1 iii) would be converted to their conjugate base 23 under basic reaction conditions, generating a strong $\mathrm{n}_{\mathrm{O}-}-\sigma^{*} \mathrm{NO}$ anomeric destabilisation of the $\mathrm{N}-\mathrm{O}$ bond (Scheme 10). A HERON migration of the alkoxyl side chain to the carbonyl carbon results in the formation of alkyl benzoate and the ejection of the nitric oxide anion (Scheme 10, $\mathrm{R}^{1}=\mathrm{Ph}$ ). This route to esters from hydroxamic acids in equilibrium with $\mathbf{2 3}$ was earlier invoked to explain non-crossover ester formation in the $\mathrm{A}_{\mathrm{Al}} 1$ solvolysis of $N$-acyloxy- $N$-alkoxyamides at low acid concentrations (Scheme 5) $[45,46,48,49]$.

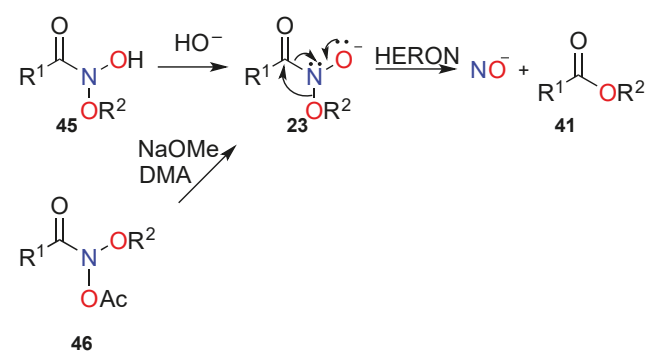

Scheme 10. HERON reaction of hydroxamate anion 23.

The HERON reaction was also invoked by Shtamburg and coworkers to account for formation of ethyl benzoate $41\left(R^{1}=P h, R^{2}=E t\right)$ when $N$-acetoxy- $N$-ethoxybenzamide $46\left(R^{1}=P h, R^{2}=E t\right)$ was treated with methoxide in aprotic media. Anion $23\left(R^{1}=P h, R^{2}=E t\right)$ leading to the HERON reaction was generated by methoxide addition at the ester carbonyl (Scheme 10), while methoxide attack at the amide carbonyl lead to the formation of methyl benzoate [122].

Dialkyl azadicarboxylates, widely used in the Mitsonobu reaction, decompose vigorously with methoxide in methanol [123,124]. 47a afforded methyl isopropyl carbonate 49a and isopropyl formate 50a in a 1:1 ratio by ${ }^{1} \mathrm{H}$ NMR, and diethyl azadicarboxylate $47 \mathrm{~b}$ behaved similarly, though volatile ethyl formate $\mathbf{5 0 b}$ was less prevalent in the reaction mixture (Scheme 11) [112,125]. Since the nitrogens 
in 47 are the overwhelming contributors to the LUMO of azadicarboxylates [112], the most probable route to these products is methoxide addition at nitrogen and a facile HERON reaction of the anionic adducts 48. Calculations based on the HERON reaction of dimethyl azodicarboxylate $5 \mathbf{c}$, gave an $E_{\mathrm{A}}$ of $27 \mathrm{~kJ} \mathrm{~mol}^{-1}$ and exothermicity of $59 \mathrm{~kJ} \mathrm{~mol}^{-1}$, at the B3LYP/6-31G*//HF/6-31G(d) level [112].

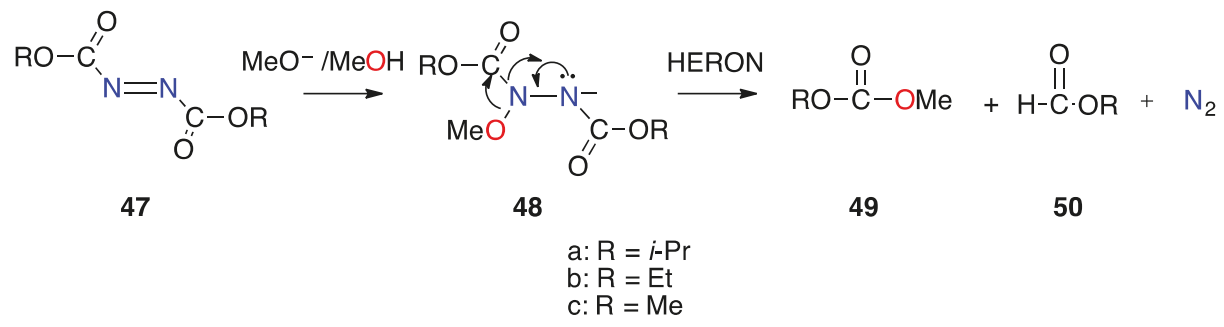

Scheme 11. Amide anion induced HERON reaction in reactions of azadicarboxylates with methoxide.

\subsubsection{HERON Reactions of $N$-Alkoxy-N-Aminocarbamates}

By analogy with the HERON reactions of $N$-acyloxy- $N$-alkoxyamides, several carbamates have been shown to undergo a similar reaction (Scheme 12). $N$-Acetoxy-O-alkyl- $N$-benzyloxycarbamates 51a-c and $N$-methylaniline reacted bimolecularly in $\left[\mathrm{D}_{4}\right]$-methanol to produce the corresponding carbonates 53 and tetrazene 39, presumably through HERON reaction of the N-methylanilino intermediate 52 [126].<smiles>CNc1ccccc1</smiles>

51

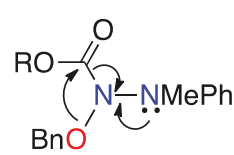

52<smiles>CCPOC(=O)OCc1ccccc1</smiles>

53
39

$$
\begin{aligned}
& a: R=M e \\
& b: R=E t \\
& c: R=B n
\end{aligned}
$$

Scheme 12. HERON reactions of $N$-alkoxy- $N$-aminocarbamates.

\subsubsection{HERON Reactions of $N$-Acyloxy-N-Alkoxyamides}

Based on RE's of models $15 \mathrm{c}$ and 16a in Table 4, the amidicity of NNO systems such as $N$-alkoxy- $N$-aminoamides $\mathbf{2 d}$ or $N$-alkoxy- $N$-aminocarbamates such as $\mathbf{5 2}$, is likely to be reduced by modest amounts (60-70\% that of $N, N$-dimethylacetamide), yet these systems undergo HERON reactions at room temperature, as do the 1,1-diazenes $2 \mathbf{h}$ and hydroxamates $\mathbf{2 g}$. However, all have in common a strong anomeric destabilisation of the $\mathrm{N}-\mathrm{O}$ bond through high energy electron pairs on the donor atom, $\mathrm{n}_{Y}$, and high electronegativity of oxygen. $\mathrm{n}_{\mathrm{O}}-\sigma^{*}$ NO systems such as $N$-acyloxy-N-alkoxyamides $\mathbf{2} \mathbf{b}$ and $N, N$-dialkoxyamides $\mathbf{2}$ c, on the other hand, should have lower RE's (amidicities approximately 50\% that of $N, N$-dimethylacetamide), yet they are thermally stable at room temperature on account of a weaker $\mathrm{n}_{\mathrm{O}}-\sigma^{*} \mathrm{NO}$ anomeric interaction. However, at elevated temperatures, $N$-acyloxy- $N$-alkoxyamides $\mathbf{2 b}$ also undergo HERON reactivity [85].

A tandem mass spectrometric analysis by electrospray ionisation, used in characterising mutagenic $N$-acyloxy- $N$-alkoxyamides 21 (Scheme 13), produced, in addition to sodiated parent compound 54, three characteristic sodiated ions, a sodiated alkoxyamidyl radical, 55, which was generally most prevalent, a sodiated anhydride, 56, and a minor cation due to sodiated ester, 57, which was absent in the ionisation of aliphatic amides. While the fragments formed in parallel 
with each product ion, 58-60, were undetectable, under these conditions the source of anhydrides must be an intramolecular process and the HERON rearrangement at elevated temperature was implicated. Furthermore, the relative amounts of sodiated anhydride and ester reflected the expected bias towards an $\mathrm{n}_{\mathrm{O}}-\sigma^{*} \mathrm{NOAc}$ anomeric stabilisation with attendant weakening of the $\mathrm{N}-\mathrm{OAc}$, rather than the N-OR, bond [112]. A B3LYP/6-31G(d) computational study of migration tendencies in $N$-formyloxy- $N$-methoxyformamide predicted high $E_{\mathrm{A}}$ 's for migration of both formyloxyl and methoxyl in the gas phase (162 and $182 \mathrm{~kJ} \mathrm{~mol}^{-1}$, respectively) [112]. While acyloxyl, rather than alkoxyl, migration would be energetically more favourable, in solution at room temperature and particularly in polar media, the HERON reaction would not be competitive with $S_{N} 2$ and $S_{N} 1$ reactions at nitrogen.

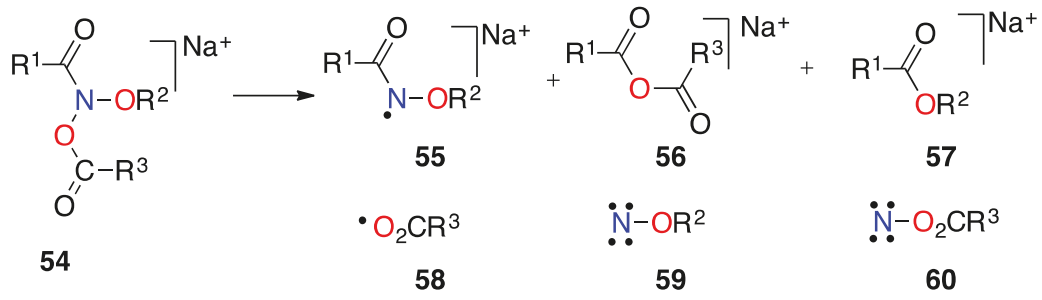

Scheme 13. Fragments from collision induced electrospray ionisation-mass spectrometric (ES-MS) analysis of $\mathrm{N}$-acyloxy- $\mathrm{N}$-alkoxyamides 21.

However, in toluene at $90{ }^{\circ} \mathrm{C}, \mathrm{HERON}$ reactions of 21 have been detected in competition with a homolytic decomposition pathway, and analysis of the complex reaction mixtures provides further support for the driving force behind the HERON process (Scheme 14) [85]. Homolysis of the N-OAc bond in 61 gave relatively long-lived alkoxyamidyl radicals $\mathbf{6 2}$, which in solvent cage reactions with product radicals generated dioxazole 63 , or upon escaping the solvent cage dimerise to hydrazines leading to the expected thermal decomposition esters. The HERON reaction of $\mathbf{6 1}$ generates anhydrides 65 and alkoxynitrenes 66. Anhydrides, which in the case of symmetrical benzoic anhydride from 61a and mixed benzoyl heptanoyl anhydride from $\mathbf{6 1 b}$ were relatively stable, react further to give esters 68 and 69 with alcohols 67 generated in the reaction mixture, the source of which was the alkoxynitrenes, the other HERON product. Critical evidence for the HERON process derived from products of alkoxynitrenes 66, which (1) could be trapped by oxygen; (2) dimerised to hyponitrites; or, (3) underwent characteristic rearrangements leading aldehydes, nitriles, and alcohols. Competition between the HERON and homolytic reaction pathways was evident in a comparison of products from 61c-e. The polarity of these HERON transition states would require a build-up of positive charge on the donor alkoxyl oxygen, $\mathrm{n}_{\mathrm{O}}$. This would be stabilised by electron-donor para substituents on the benzyloxy group, but destabilised by electron-withdrawing para substituents. In accord with this, 61c and 61e generated dioxazole and esters. Little dioxazole was formed from $\mathbf{6 1 d}$ in which the methoxyl group would lower the energy of the HERON transition state, but would have little impact on the non-polar transition state for homolysis of the N-OAc bond (Figure 15). 


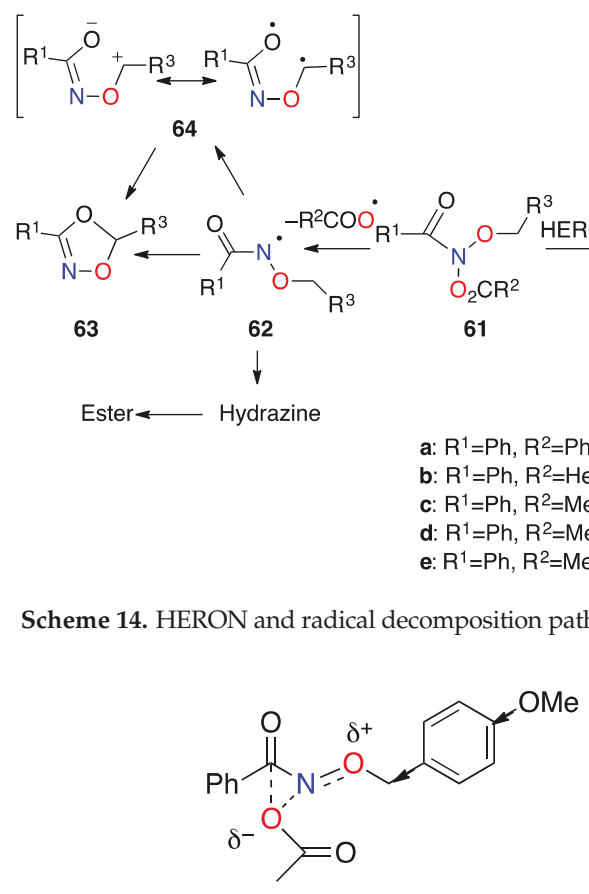

(a)

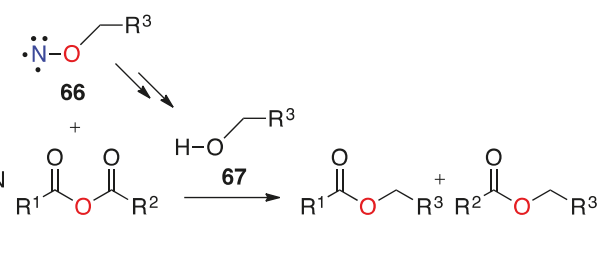

65

68

69

Figure 15. (a) Stabilisation of the HERON transition state for $N$-acyloxy-N-alkoxyamides by para methoxyl group and (b) destabilisation by a para nitro group.

\subsubsection{HERON Reactions of $N, N$-Dialkoxyamides}

Like $\mathrm{N}$-acyloxy- $\mathrm{N}$-alkoxyamides $\mathbf{2} \mathbf{b}, \mathrm{N}, \mathrm{N}$-dialkoxyamides $\mathbf{2 c}$ possess low amidicity and they are thermally unstable, but require higher temperatures (typically $155^{\circ} \mathrm{C}$ in mesitylene). However, their reaction proceeds exclusively by homolysis. Secondary products from alkoxynitrenes, which would be produced by the HERON pathway, were not observed for acyclic $N, N$-dialkoxyamides. Rather, they produce alkoxyamidyl radicals, which dimerise to $N, N^{\prime}$-dialkoxy- $N, N^{\prime}$-diacylhydrazines and ultimately esters. In addition, they can be trapped by hydrogen donors and solvent derived radicals [55].

On the other hand, room temperature HERON reactivity was found to occur exclusively in several alicyclic ONO systems [30]. Cyclic $N, N$-dialkoxyamides, $N$-butoxy-3(2H)-benzisoxazolone 73, $\mathrm{N}$-butoxyisoxazolidin-3-one 74, and $\mathrm{N}$-butoxytetrahydro-2H-1,2-oxazin-3-one 75, can be synthesised by PIFA oxidation of the salicamide $70, \beta^{-}$and $\gamma$-hydroxyhydroxamic esters, 71 and 72 , respectively, by analogy with the synthesis of acyclic $N, N$-dialkoxyamides (Scheme 4) [55]. Only $N$-butoxy-3(2H)benzisoxazolone 73 is stable; $\mathrm{N}$-butoxyisoxazolidin-3-one $\mathbf{7 4}$ and $\mathrm{N}$-butoxytetrahydro-2H-1,2-oxazin-3-one 75 both react at room temperature and the reactions can be monitored by ${ }^{1} \mathrm{H}$ NMR and mass spectrometry (Scheme 15). The $\gamma$-oxazinolactam undergoes quantitative ring opening to a diastereomeric mixture of the stable hyponitrite $\mathbf{7 6}$, which must arise from dimerization of alkoxynitrene 77 , a known reaction of alkoxynitrenes. The $\delta$-oxazinolactam, on the other hand, undergoes a quantitative ring contraction to the $\gamma$-valerolactone 78 with production of butoxynitrene $\mathbf{7 9}$. Both are clearly HERON reactions [30].

The $E_{\mathrm{A}}$ for both HERON reactions must be radically lower than that for acyclic $N, N$-dialkoxyamides. Analysis of the B3LYP/6-31G(d) optimised ground state structures of $N$-methoxy- $\gamma$-oxazinolactam 81 (Figure 16b) and $N$-methoxy- $\delta$-oxazinolactam 82 (Figure 16c) provide insight into this unusual difference 
in reactivity. Firstly, the model $\gamma$-oxazinolactam is strongly pyramidal at nitrogen $\left(\chi_{\mathrm{N}}=64.6^{\circ}\right)$ and significantly twisted $\left(\tau=-36^{\circ}\right)$, with attendant loss of amide character. The $\mathrm{N}-\mathrm{C}(\mathrm{O})$ bond is very long compared to $N, N$-dimethoxyacetamide $4 \mathbf{b}$ (1.417 $\AA$, Table 3$)$. The COSNAR and TA resonance energies for 81 are -20 and $-19 \mathrm{~kJ} \mathrm{~mol}^{-1}$, respectively, translating to amidicities of only $26 \%$ and $25 \%$. Torsion angles close to $90^{\circ}$ indicate that the endo and exo oxygen lone pairs are ideally aligned for maximum $\mathrm{n}_{\mathrm{O}}-\sigma^{*} \mathrm{NO}$ stabilisation. Low amidicity and a strong stereoelectronic effect would favour either reaction but, clearly, ring opening would be more favourable than ring contraction, which would give a highly strained $\beta$-lactone.<smiles>CCCCOC(=O)c1ccccc1O</smiles>

70

PIFA

$\mathrm{CH}_{3} \mathrm{CN}$

$\checkmark$ r.t.<smiles>CCCOn1oc2ccccc2c1=O</smiles>

73<smiles>CCCCOC(=O)CC(C)O</smiles>

71

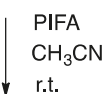

r.t.

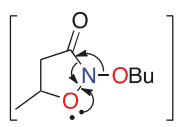

74<smiles>C=[Te]</smiles><smiles>CCC(CC(=O)O[Na])ON</smiles>

77<smiles>[Z20]C(O)CCC(=O)NOCCN</smiles><smiles>CCN1OC(C)CCC1C1CCCCC1</smiles>

75<smiles>[3H][3H]</smiles><smiles>CC1CCC(=O)O1</smiles>

78

Scheme 15. HERON reactions of $\gamma$-oxazinolactam 71 and $\delta$-oxazinolactam 72.<smiles>COn1oc2ccccc2c1=O</smiles>

80

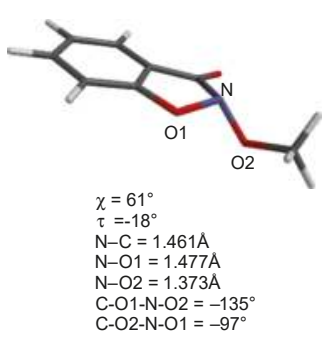

(a)

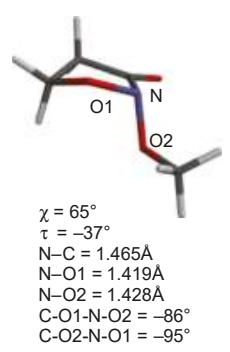

(b)<smiles>CON1OCCC1=O</smiles>

81<smiles>CON1OCCCC1=O</smiles>

82

Figure 16. Ground state structures of models (a) $N$-methoxybenzisoxazolone 80, (b) $N$-methoxy- $\gamma$ oxazinolactam 81 , and (c) chair and (d) boat $N$-methoxy- $\delta$-oxazinolactam 82. 
The B3LYP /6-31G(d) structure of the model $\delta$-oxazinolactam $82\left(\chi_{N}=61^{\circ}\right.$ and $\left.\tau=13^{\circ}\right)$ matches the experimental ( ${ }^{1} \mathrm{H}$ NMR) chair conformation of 75 which has a chiral nitrogen. It is also more pyramidal at nitrogen and slightly more twisted than the alicyclic $N, N$-dimethoxyacetamide $4 \mathrm{~b}\left(\chi_{\mathrm{N}}=48^{\circ}\right.$ and $\tau=9^{\circ}$, Figure $7 c$, Table 3$)$, but its resonance and amidicity $\left(\mathrm{RE}_{\mathrm{COSNAR}}=-38 \mathrm{~kJ} \mathrm{~mol}^{-1}\right.$, amidicity $49 \%$, and $\mathrm{RE}_{\mathrm{TA}}=-37 \mathrm{~kJ} \mathrm{~mol}^{-1}$, amidicity $47 \%$ ) is almost identical to the open chain form. However, only an $\mathrm{n}_{\mathrm{O}(\text { exo })}-\sigma^{*} \mathrm{NO}($ endo $)$ anomeric alignment is evident; with a torsion angle of $171^{\circ}$, the $\mathrm{n}_{\mathrm{O}(\text { endo })}-\sigma^{*} \mathrm{NO}($ exo $)$ interaction is completely switched off. The endo $\mathrm{N}-\mathrm{O}$ bond is nearly $0.1 \AA$ longer than the exo $\mathrm{N}-\mathrm{O}$ bond (the endo bond is marginally shorter than the exo bond by $0.01 \AA$ in $\gamma$-oxazinolactam and $\mathrm{N}-\mathrm{O}$ bonds differ by $0.02 \AA$ in $N, N$-dimethoxyacetamide). Ring opening and ring contraction are computed to have about the same $E_{\mathrm{A}}$ and $\Delta H^{\ddagger}$ at B3LYP/6-31G(d) [30]. It is evident that the ring contraction of the $\delta$-oxazinolactam to $\gamma$-butyrolactone is largely driven by a strong, conformationally imposed anomeric effect, a remarkable impact of anomeric substitution at an amide nitrogen [30]. While the computed transition state for ring opening of model $N$-methoxy- $\delta$-oxazinolactam is marginally lower in energy, the required $\mathrm{n}_{\mathrm{O}(\text { endo) }}-\sigma^{*} \mathrm{NO}($ exo) is only accessible from the boat conformation of the $\delta$-oxazinolactam (Figure 16d). Experimentally, accessing this conformation in 75 by nitrogen inversion could be energetically unfavourable, owing to steric hindrance between the axial 4-methyl and $N$-butoxy groups. However, even in the boat conformation, the strong $\mathrm{n}_{\mathrm{O}(e x o)}-\sigma^{*} \mathrm{NO}($ endo $)$, which favours ring contraction is still evident.

The $\gamma$-lactam in benzisoxazolone is stable at room temperature, though model $\mathbf{8 0}$ has a moderately suitable anomeric alignment for migration of $\mathrm{O} 2$. However, the $\mathrm{n}_{\mathrm{O}(\text { endo })}-\sigma^{*} \mathrm{NO}($ exo $)$ interaction is probably weakened by conjugation of the $\mathrm{O}_{\text {endo }}$ p-type lone pair onto the aromatic ring. Ring contraction driven by a favourable $\mathrm{n}_{\mathrm{O}(e x o)}-\sigma^{*} \mathrm{NO}(e n d o)$ interaction would be disfavoured.

\subsubsection{N-Alkoxy-N-Alkylthiylamides}

The combination of sulphur and oxygen attachment to amide nitrogen in $N$-methoxy- $N$ methylthiylacetamide $\mathbf{1 5 d}$ results in a similar reduction in amide resonance to that of $N$-methoxy-Ndimethylaminoacetamide 15c, namely about $64 \%$ vs. $67 \%$ (Table 4 ). However, the reaction of $\mathrm{N}$-acyloxy- $\mathrm{N}$-alkoxyamides 21 with biological thiols, glutathione, and methyl and ethyl esters of cysteine, which resulted in $\mathrm{S}_{\mathrm{N}} 2$ displacement of carboxylate, produced exclusively hydroxamic esters 83 and disulphides 84 [52] (Scheme 16). The driving force for HERON reactivity is not only reduced resonance, but the anomeric effect. Instead of HERON reactions, the intermediate $\mathrm{N}$-alkoxy- $\mathrm{N}$-alkylthiylamides 24 undergo an $\mathrm{S}_{\mathrm{N}} 2$ reaction at sulphur by thiol. The distinction between reactivity modes for NNO and SNO systems lies in the $n_{\mathrm{S}}-\sigma^{*} \mathrm{NO}$ anomeric interaction, which is much weaker than the $\mathrm{n}_{\mathrm{N}}-\sigma^{*} \mathrm{NO}$ of $N$-alkoxy- $N$-aminoamides.<smiles>[R]ON(O[R10])C([R7])=O</smiles>

21

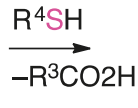

$R$ 24

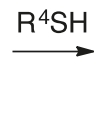

$\mathrm{R}^{1} \mathrm{OR}^{\mathrm{NH}}+$

83

\section{$R^{4} S_{S R}{ }^{4}$}

84

Scheme 16. Reaction of $N$-acyloxy- $N$-alkoxyamides with alkylthiols.

\subsection{Driving Force for the HERON Reaction}

The most accessible transition states for HERON migration of methoxyl in a number of model anomeric amides, $N$-methoxy- $N$-dimethylaminoacetamide 15c, $N, N$-dimethoxyacetamide 4 b, $N$-acetoxy- $N$-methoxyacetamide $\mathbf{1 5}$ b, and $O$-methyl- $N$-methoxy- $N$-dimethylaminocarbamate $16 \mathbf{a}$, ring opening of $N$-methoxy- $\gamma$-oxazinolactam 81 , and ring contracting of $N$-methoxy- $\delta$-oxazinolactam 82, each of which represents a class of neutral anomeric amides known to undergo HERON reactions, as well as for methoxyl migration in $N$-methoxy- $N$-methylthiylacetamide 15d, $\mathrm{N}$-methoxyacetohydroxamate $\mathbf{1 5 f}$, and 1-acetyl-1-methoxydiazene $\mathbf{1 5 g}$, have been derived at the 
B3LYP/6-31G(d) level as part of several studies [30,61,62]. Transition state geometries of $\mathbf{4 b} \mathbf{b}, \mathbf{1 5} \mathbf{b}-\mathbf{d}, \mathbf{f}$ and $\mathbf{g}, \mathbf{1 6 a}, \mathbf{8 1}$, and 82 are presented in Figure 17.

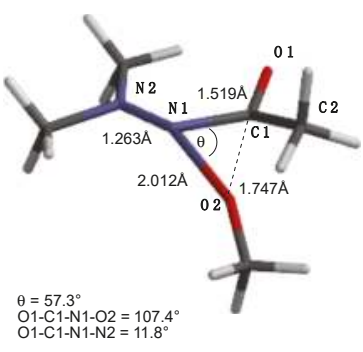

(a)

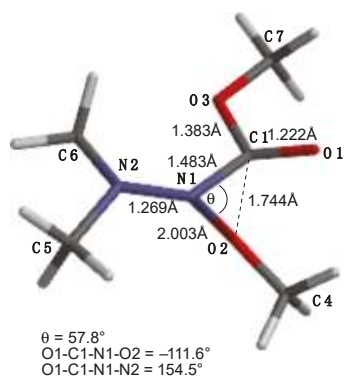

(d)

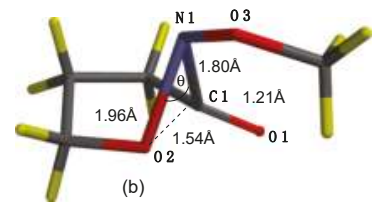

$\theta=48.0^{\circ}$
$\mathrm{O} 1-\mathrm{C} 1-\mathrm{N} 1-\mathrm{O} 2=-112.8^{\circ}$
$\mathrm{O} 1-\mathrm{C} 1-\mathrm{N} 1-\mathrm{O} 3=-21.9^{\circ}$

(g)

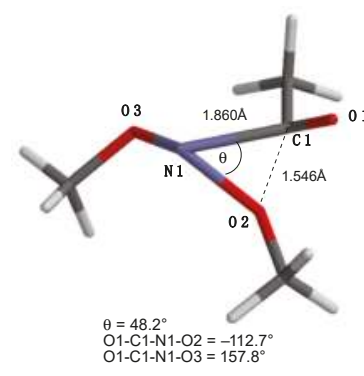

(b)

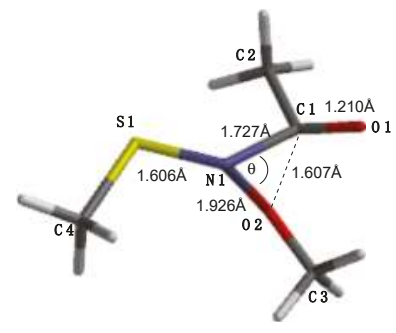

$\theta=51.9^{\circ}$

$\mathrm{O} 1-\mathrm{C} 1-\mathrm{N} 1-\mathrm{O} 2=-113.2^{\circ}$
$\mathrm{O} 1-\mathrm{C} 1-\mathrm{N} 1-\mathrm{O} 3=154.3^{\circ}$

(e)

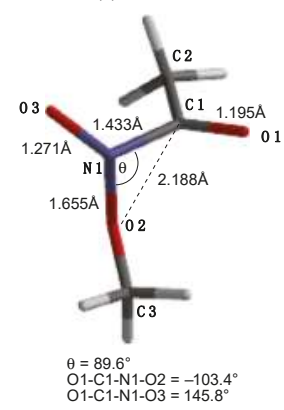

(h)

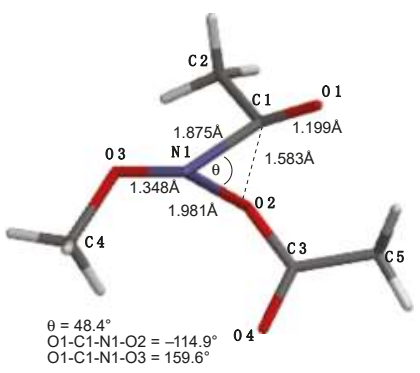

(c)

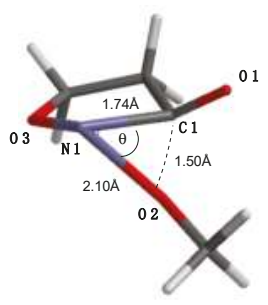

$\theta=44.6^{\circ}$

$\mathrm{O} 1-\mathrm{C} 1-\mathrm{N} 1-\mathrm{O} 2=-119.5^{\circ}$

(f)

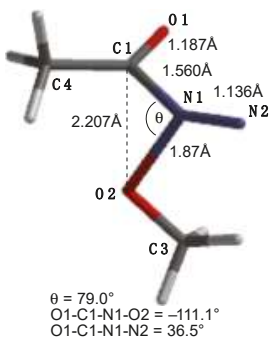

(i)

Figure 17. B3LYP/6-31G(d) optimised transition states of favoured HERON reactions of (a) N-methoxy- $N$-dimethylaminoacetamide $15 \mathbf{c}$, (b) N,N-dimethoxyacetamide $4 \mathbf{b}$, (c) $\mathrm{N}$-acetoxy- $\mathrm{N}$-methoxyamide 15b, (d) O-methyl- $N$-methoxy- $N$-dimethylaminocarbamate 16a, (e) $N$-methoxy- $N$-methylthiylacetamide 15d, (f) $N$-methoxy- $\gamma$-oxazinolactam 81 (ring opening), (g) $N$-methoxy- $\delta$-oxazinolactam 82 (ring contraction), (h) $N$-methoxyacetohydroxamate $\mathbf{1 5 f}$ and (i) 1-acetyl-1-methoxydiazene $\mathbf{1 5 g}$.

In all the transition state complexes, the migrating oxygen does so in a plane largely orthogonal to the N1-C1-O1 plane and the donor atom $\mathrm{n}_{Y}$, driving the migration, is largely in the N1-C1-O1 plane. As a consequence, the amide nitrogen lone pair lies close to the plane and amide resonance is largely lost in the transition state. The resonance energy, RE is therefore a component of the overall $E_{\mathrm{A}}$, the balance being the energy required for the rearrangment under anomeric assistance, $E_{\text {rearr }}$, and must reflect the relative nature of the $n_{X}-\sigma^{*}$ NO driving force. It is therefore possible to approximate 
the influence of the anomeric substituents on the resonance interaction on the one hand, and on the migration process, on the other. Table 8 gives the $E_{\mathrm{A}}, \mathrm{RE}_{\mathrm{TA}}$, and net $E_{\text {rearr }}$ data for these transition states.

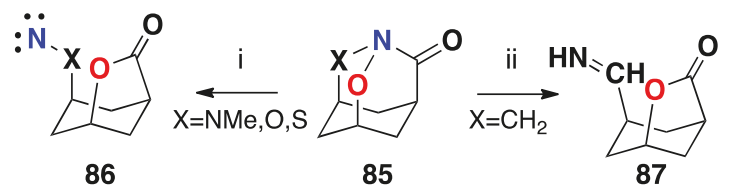

a: $X=N M e ; b: X=O ; c: X=S ; d: X=\mathrm{CH}_{2}$

Scheme 17. HERON migrations of alkoxyl in the absence of resonance.

Table 8. B3LYP/6-31G $(\mathrm{d})$ activation energies $\left(E_{\mathrm{A}}\right)$, resonance energies $\left(\mathrm{RE}_{\mathrm{TA}}\right)$, and rearrangement energies $\left(E_{\text {rearr }}\right)$ for HERON reactions of model anomeric amides and tricyclic anomeric amides; all values in $\mathrm{kJ} \mathrm{mol}^{-1}$.

\begin{tabular}{|c|c|c|c|c|}
\hline Migratory Mode & $E_{\mathrm{A}}$ & $\mathrm{XNY}^{1}$ & $\mathrm{RE}_{\mathrm{TA}}{ }^{2}$ & $E_{\text {rearr }}$ \\
\hline $\mathrm{MeO}$ from anti $\mathbf{1 5 c}$ & 95.0 & ONN & -51.5 & 43.5 \\
\hline $\mathrm{MeO}$ from $4 \mathbf{b}$ & 156.5 & ONO & -35.9 & 120.5 \\
\hline $\mathrm{MeO}$ from syn 16a & 92.4 & ONN & -50.7 & 41.8 \\
\hline $\mathrm{AcO}$ from syn $15 \mathrm{~b}$ & 181.0 & AcONO & -40.5 & 140.5 \\
\hline $\mathrm{MeO}$ from syn $\mathbf{1 5 b}$ & 207.9 & ONOAC & -40.5 & 167.4 \\
\hline $\mathrm{AcO}$ from anti $\mathbf{1 5 b}$ & 181.5 & AcONO & -40.5 & 141.0 \\
\hline $\mathrm{MeO}$ from anti $\mathbf{1 5 b}$ & 182.8 & ONOAC & -40.5 & 142.3 \\
\hline $\mathrm{MeO}$ from anti $\mathbf{1 5 d}$ & 174.1 & ONS & -48.6 & 125.4 \\
\hline $\mathrm{MeO}$ from $\mathbf{1 5 f ^ { 3 }}$ & 48.0 & $\mathrm{ONO}^{-}$ & -32.4 & 15.6 \\
\hline $\mathrm{MeO}$ from $15 \mathrm{~g}$ & 8.8 & ONNitrene & -14.8 & -6.0 \\
\hline Ring opening 81 & 113.0 & ONO & -19.2 & 93.8 \\
\hline Ring contraction 82 & 145.2 & ONO & -36.7 & 108.4 \\
\hline Ring opening of 82 & 136.4 & ONO & -36.7 & 99.7 \\
\hline Scheme 17 i $X=\mathrm{NMe}$ & 59.0 & ONN & 0.0 & 59.0 \\
\hline Scheme 17 i $\mathrm{X}=\mathrm{O}$ & 146.9 & ONO & 0.0 & 146.9 \\
\hline Scheme 17 i $\mathrm{X}=\mathrm{S}$ & 152.7 & ONS & 0.0 & 152.7 \\
\hline Scheme 17 ii $\mathrm{X}=\mathrm{CH}_{2}$ & 242.7 & $\mathrm{ONCH}_{2}$ & 0.0 & 242.7 \\
\hline Scheme $18 \mathrm{i}$ & 133.5 & AcONO & 0.0 & 133.5 \\
\hline Scheme 18 ii & 161.5 & ONOAC & 0.0 & 161.5 \\
\hline
\end{tabular}

${ }^{1} \mathrm{n}_{\mathrm{Y}}$ donor to $\sigma_{\mathrm{NX}}^{*} ;^{2}$ Transamidation data (COSNAR data very similar); ${ }^{3} \mathrm{HF} / 6-31 \mathrm{G}(\mathrm{d})$ values.

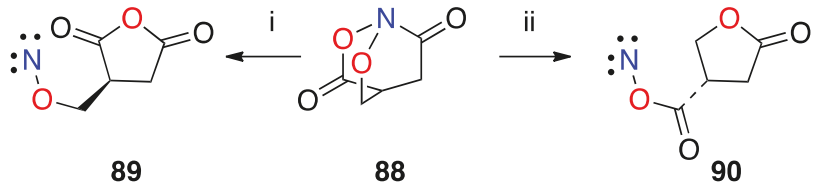

Scheme 18. HERON reactions of $N$-acyloxy- $N$-alkoxyamide in absence of resonance.

Methoxyl migration in the NNO systems 15c and 16a ( $E_{\mathrm{A}}$ 's 95 and $92 \mathrm{~kJ} \mathrm{~mol}^{-1}$ respectively) have similar RE's of around $-50 \mathrm{~kJ} \mathrm{~mol}^{-1}$, and therefore $E_{\text {rearr }}$ of approximately $40 \mathrm{~kJ} \mathrm{~mol}^{-1}$. The change in charge on the carbonyl carbon in the HERON transition state is negligible [76], so replacement of methyl by methoxyl has little bearing on the rearragement energies. ONO in $4 \mathbf{b}$ and ONOAc in $\mathbf{1 5 b}$ migrations have much higher $E_{\mathrm{A}}$ 's despite the lower amide resonance energy. The large difference lies in the $E_{\text {rearr }}$ which is nearly $100 \mathrm{~kJ} \mathrm{~mol}^{-1}$ less favourable and a reflection of the relative efficacy of the $\mathrm{n}_{\mathrm{N}}-\sigma^{*}$ NO vs. the weaker $\mathrm{n}_{\mathrm{O}^{-}} \sigma^{*}$ NO anomeric interaction. The difference of about $80 \mathrm{~kJ} \mathrm{~mol}^{-1}$ between methoxy migration in the ONS 15d and ONN acetamides 15c lies, again, in the much weaker $\mathrm{n}-\sigma^{*}$ NO anomeric effect. This can be accounted for by size mismatch due the larger $3 p$ orbitals of the sulphur. Both HERON reactions of the cyclic forms of $N, N$-dialkoxyamides 81 and 82 have 
substantially lower overall $E_{\mathrm{A}}$ 's than $N, N$-dimethoxyacetamide $4 \mathbf{b}$. After $R E$ has been taken into account, $E_{\text {rearr }}$ values indicate that in the cyclic forms, reorganisation to the HERON transition state is easier. Better stereoelectronic control in the cyclic system accounts for this.

The RE of the 1,1-diazene $\mathbf{1 5 g}$, is computed to be about the same as the overall $E_{\mathrm{A}}$ for its HERON reaction. This is a very early transition state in keeping with the exothermicity of the process. $E_{\text {rearr }}$ is essentially zero on account of the high energy electron-pair on the amino nitrene and the $E_{\mathrm{A}}$ is essentially equivalent to the RE that must be sacrificed. Likewise, the hydroxamate $\mathbf{1 5 f}$ bears a very high energy electron pair on the anomeric donor oxygen. While the resonance energy is similar to that of $\mathrm{N}, \mathrm{N}$-dimethoxyacetamide, the $E_{\text {rearr }}$ is small. This too is a very early transition state.

Overall, the decreasing order of $E_{\text {rearr }}$ of XNY systems based on the deconvolution in Table 8, which can be regarded as the order of decreasing effectiveness of an $n_{Y}-\sigma^{*} N X$ interaction and destabilisation of the $\mathrm{N}-\mathrm{OMe}$ bond, is AcONO $>\mathrm{ONS} \sim \mathrm{ONO}>\mathrm{ONN}>\mathrm{ONO}^{-}>$ONNitrene. The order of $\mathrm{RE}_{\mathrm{TA}}$ is $\mathrm{ONN}>\mathrm{ONS}>\mathrm{AcONO}>\mathrm{ONO}>\mathrm{ONO}^{-}>\mathrm{ONNitrene}$ and the overall activation energies decrease in the order AcONO $>$ ONS $>\mathrm{ONO}>\mathrm{ONN}>\mathrm{ONO}^{-}>$ONNitrene. Clearly, the dominant influence in HERON reactivity is the strength of the anomeric effect rather than the decrease in amidicity.

Rearrangement energies, $E_{\text {rearr }}$ 's, obtained by the deconvolution method represent activation energies in the absence of resonance. Relative $E_{\text {rearr }}$ 's can be compared to relative $E_{\mathrm{A}}$ 's for intramolecular rearrangement in fully twisted amides, heteroatom-substituted 1-aza-2-adamantanones 85 (Scheme 17) and 2-quinuclidone 88 (Scheme 18) and the $E_{\mathrm{A}}$ 's are also presented in Table 8. $\Delta E_{\mathrm{A}}{ }^{\prime} \mathrm{s}$ relative to migration of oxygen (Scheme 17i) in $85 \mathbf{b}$, for $85 \mathrm{a}$, and $85 \mathrm{c}$ are -88 and $5.8 \mathrm{~kJ} \mathrm{~mol}^{-1}$, respectively, which correlate well with the respective differences in $E_{\text {rearr }}$ of the respective acetamides, namely -77 and $5 \mathrm{~kJ} \mathrm{~mol}^{-1}$. Similarly, the difference in the ease of migration of alkoxyl to form 90 and acyloxyl to form 89 in 88 (Scheme 18i,ii) is $28 \mathrm{~kJ} \mathrm{~mol}^{-1}$ and the difference between the corresponding $E_{\text {rearr }}$ form the syn conformer of $15 \mathrm{~b}$ is $27 \mathrm{~kJ} \mathrm{~mol}^{-1}$.

No transition state can be found for migration of alkoxyl group in hydroxamic ester $\mathbf{3 b}$. However, 85d can be rearranged to lactone 87 (Scheme 17ii) with concomitant rearrangement of the nitrene product to the imine. The difference between $E_{\mathrm{A}}$ for this process and the rearrangement of $85 \mathrm{a}$ is $184 \mathrm{~kJ} \mathrm{~mol}^{-1}$. If this translates to the difference in $E_{\text {rearr }}$ between twisted $\mathrm{N}$-methoxy- $\mathrm{N}$-methylacetamide $\mathbf{3} \mathbf{b}$ and $\mathrm{N}$-methoxy- $\mathrm{N}$-dimethylaminoacetamide $\mathbf{1 5} \mathbf{c}$, for which $E_{\text {rearr }}$ is $43.5 \mathrm{~kJ} \mathrm{~mol}^{-1}$, the rearrangement of 3 to methyl acetate and methylnitrene would have an activation energy of about $233 \mathrm{~kJ} \mathrm{~mol}^{-1}$ from twisted $3 \mathbf{b}$ or, adding in the RE for $3 \mathbf{b}$ of $62 \mathrm{~kJ} \mathrm{~mol}^{-1}, 295 \mathrm{~kJ} \mathrm{~mol}^{-1}$ from conjugated 3. It is clear that hydroxamic esters do not rearrange to esters and alkylnitrenes and the role of anomeric (bisheteroatom) substitution in the HERON reaction is vital.

\section{Conclusions}

In this review we have outlined the theoretical and structural properties and the reactivity of the class of anomeric amides. Much of the data from this, and several other groups, is relatively recent and, while several compilations on the subject have appeared in the literature, a focus on the perturbation of the amide structure is befitting this special edition. The fairly recent accrual of structural data from our laboratory and that of Shtamburg has provided experimental verification of the unusual properties of bisheteroatom-substituted amides. Coupled with extensive computational results, the effect of heteroatoms at nitrogen on amide resonance and conformation at the amide nitrogen can be better understood and predicted, in particular the role played by electronegativity of the bonded atoms and orbital interactions. Ensuing from the work is a clearer understanding of the energetic consequences of distortion of the amide linkage. It is clear that spectroscopic properties of various congeners are dictated by two principle concepts: the first is impaired resonance owing to change in hybridisation bought about by orbital interactions that have their foundation in Bent's, and more recently Alabugin's theories of orbital interactions. Of particular importance is the reassignment of $2 \mathrm{~s}$ character to the amide nitrogen lone pair orbital, as consequence of both electronegativity and 
orbital overlap considerations. Secondly, the participating atoms in this purturbation of regular amide bonding possess intrinsic orbital interactions by virtue of both their electronegativity and their lone pairs. The anomeric interaction bought about by $n_{Y}-\sigma^{*} N X$ overlap is pronounced in anomeric amides. What is clear is that the electronegativity induces a shift to less resonance through pyramidalisation and lowering the energy of the amide nitrogen lone pair and the anomeric interaction is better served by this shift to $\mathrm{sp}^{3}$ character. Stronger electronegativity serves to reduce resonance as well as to promote the anomeric interaction.

Regarding reactivity, it is abundantly clear that both resonance impairment and strength of the anomeric effect are definitive, but the anomeric effect dominates in promoting both $\mathrm{S}_{\mathrm{N}} 2$ and elimination reactions at the amide nitrogen. Most significant is the anomeric driving force for the HERON reaction, notably in systems such as $N$-amino- $N$-alkoxyamides (NNO systems) where the energetics for anomeric weakening of the $\mathrm{N}-\mathrm{O}$ bond are optimised, and in cyclic systems such as the $N$-alkoxy- $\gamma$ and $\delta$-oxazinolactams where conformation and configuration appear to favour and enhance anomeric overlap. The HERON reaction is unique to this class of amides and has no equivalence in the literature. It operates in the opposite sense to the well-known Curtius, Hoffman, and Lossen rearrangements in which an acyl substituent migrates from the carbonyl to the nitrogen. Finally our studies of the HERON and those of Barton and coworkers, shed light on the well-known decomposition reactions of $N, N^{\prime}$-dialkoxy- $N, N^{\prime}$-diacylhydrazines. The HERON mechanism that operates in these decompositions and in those of the 1-acyl-1-alkoxydizenes is critical to the synthesis of highly hindered esters.

Conflicts of Interest: The authors declare no conflict of interest.

\section{References}

1. Greenberg, A.; Breneman, C.M.; Liebman, J.F. The Amide Linkage: Structural Significance in Chemistry, Biochemistry and Materials Science; John Wiley \& Sons, Inc.: Hoboken, NJ, USA, 2003.

2. Wiberg, K.B. Origin of the Amide Rotational Barrier. In The Amide Linkage. Structural Significance in Chemistry, Biochemistry and Materials Science; Greenberg, A., Breneman, C.M., Liebman, J.F., Eds.; John Wiley \& Sons, Inc.: New York, NY, USA, 2003; p. 33.

3. Wiberg, K.B.; Breneman, C.M. Resonance interactions in acyclic systems. 3. Formamide internal rotation revisited. Charge and energy redistribution along the $\mathrm{C}-\mathrm{N}$ bond rotational pathway. J. Am. Chem. Soc. 1992, 114, 831-840. [CrossRef]

4. Glover, S.A.; Rosser, A.A. Reliable determination of amidicity in acyclic amides and lactams. J. Org. Chem. 2012, 77, 5492-5502. [CrossRef] [PubMed]

5. Dunitz, J.D. X-ray Analysis and Structure of Organic Molecules; Cornell University Press: London, UK, 1979.

6. Winkler, F.K.; Dunitz, J.D. The non-planar amide group. J. Mol. Biol. 1971, 59, 169-182. [CrossRef]

7. Szostak, M.; Aube, J. Chemistry of bridged lactams and related heterocycles. Chem. Rev. 2013, 113, 5701-5765. [CrossRef] [PubMed]

8. Szostak, M.; Aube, J. Medium-bridged lactams: A new class of non-planar amides. Org. Biomol. Chem. 2011, 9, 27-35. [CrossRef] [PubMed]

9. Kirby, A.J.; Komarov, I.V.; Feeder, N. Spontaneous, millisecond formation of a twisted amide from the amino acid, and the crystal structure of a tetrahedral intermediate. J. Am. Chem. Soc. 1998, 120, 7101-7102. [CrossRef]

10. Kirby, A.J.; Komarov, I.V.; Feeder, N. Synthesis, structure and reactions of the most twisted amide. J. Chem. Soc. Perk. Trans. 2001, 2, 522-529. [CrossRef]

11. Kirby, A.J.; Komarov, I.V.; Kowski, K.; Rademacher, P. Distortion of the amide bond in amides and lactams. Photoelectron-spectrum and electronic structure of 3,5,7-trimethyl-1-azaadamantan-2-one, the most twisted amide. J. Chem. Soc. Perk. Trans. 1999, 2, 1313-1316. [CrossRef]

12. Kirby, A.J.; Komarov, I.V.; Wothers, P.D.; Feeder, N. The most twisted amide: Structure and reactions. Angew. Chem. Int. Ed. 1998, 37, 785-786. [CrossRef] 
13. Morgan, J.; Greenberg, A. Novel bridgehead bicyclic lactams: (a) Molecules predicted to have O-protonated and $N$-protonated tautomers of comparable stability; (b) hyperstable lactams and their O-protonated tautomers. J. Chem. Thermodyn. 2014, 733, 206-212. [CrossRef]

14. Tani, K.; Stoltz, B.M. Synthesis and structural analysis of 2-quinuclidonium tetrafluoroborate. Nature 2006, 441, 731-734. [CrossRef] [PubMed]

15. Yamada, S. Chemistry of highly twisted amides. Rev. Heteroat. Chem. 1998, 19, 203-236.

16. Yamada, S. Sterically Hindered Twisted Amides. In The Amide Linkage: Structural Aspects in Chemistry, Biochemistry, and Material Science; Greenberg, A., Breneman, C.M., Liebman, J.F., Eds.; John Wiley \& Sons, Inc.: Hoboken, NJ, USA, 2000; pp. 215-246.

17. Yamada, S. Structure and reactivity of an extremely twisted amide. Angew. Chem. 1993, 105, 1128-1130. [CrossRef]

18. Cow, C.N.; Britten, J.F.; Harrison, P.H.M. X-ray crystal structure of 1,6-diacetyl-3,4,7,8-tetramethyl-2, 5-dithioglycoluril a highly twisted acetamide. J. Chem. Soc. Chem. Commun. 1998, 1147-1148. [CrossRef]

19. Anet, F.A.L.; Osyani, J.M. Nuclear magnetic resonance spectra and nitrogen inversion in 1-acylaziridinies. J. Am. Chem. Soc. 1967, 89, 352-356. [CrossRef]

20. Boggs, G.R.; Gerig, J.T. Nitrogen inversion in N-Benzoylaziridines. J. Org. Chem. 1969, 34, 1484-1486. [CrossRef]

21. Ohwada, T.; Achiwa, T.; Okamoto, I.; Shudo, K.; Yamaguchi, K. On the planarity of amide nitrogen. Intrinsic pyramidal nitrogen of N-acyl-7-azabicyclo 2.2.1 heptanes. Tetrahedron Lett. 1998, 39, 865-868. [CrossRef]

22. Otani, Y.; Nagae, O.; Naruse, Y.; Inagaki, S.; Ohno, M.; Yamaguchi, K.; Yamamoto, G.; Uchiyama, M.; Ohwada, T. An Evaluation of amide group planarity in 7-azabicyclo[2.2.1]heptan amides. Low amide bond rotation barrier in solution. J. Am. Chem. Soc. 2003, 125, 15191-15199. [CrossRef] [PubMed]

23. Otani, Y.; Futaki, S.; Kiwada, T.; Sugiura, Y.; Ohwada, T. Synthesis of non-planar peptides bearing the 7-azabicyclo[2.2.2] heptane skeleton, and possible self-organized structures. Pept. Sci. 2005, 41, 173-174.

24. Ohwada, T.; Ishikawa, S.; Mine, Y.; Inami, K.; Yanagimoto, T.; Karaki, F.; Kabasawa, Y.; Otani, Y.; Mochizuki, M. 7-Azabicyclo[2.2.2] heptane as a structural motif to block mutagenicity of nitrosomines. Biorg. Med. Chem. 2011, 19, 2726-2741. [CrossRef] [PubMed]

25. Allen, F.H.; Kennard, O.; Watson, D.G.; Brammer, L.; Orpen, A.G.; Taylor, R. Tables of bond lengths determined by $\mathrm{x}$-ray and neutron diffraction. Part 1. Bond lengths in organic compounds. J. Chem. Soc. Perkin Trans. 2 1987, 12, S1-S19. [CrossRef]

26. Glover, S.A. Anomeric amides-Structure, properties and reactivity. Tetrahedron 1998, 54, 7229-7272. [CrossRef]

27. Rauk, A.; Glover, S.A. A computational investigation of the stereoisomerism in bisheteroatom-substituted amides. J. Org. Chem. 1996, 61, 2337-2345. [CrossRef]

28. Glover, S.; Rauk, A. Conformational stereochemistry of the HERON amide, N-methoxy-Ndimethylaminoformamide: A theoretical study. J. Org. Chem. 1999, 64, 2340-2345. [CrossRef]

29. Gillson, A.-M.E.; Glover, S.A.; Tucker, D.J.; Turner, P. Crystal structures and properties of mutagenic $N$-acyloxy- $N$-alkoxyamides_"Most pyramidal" acyclic amides. Org. Biomol. Chem. 2003, 1, 3430-3437. [CrossRef] [PubMed]

30. Glover, S.A.; Rosser, A.A.; Taherpour, A.; Greatrex, B.W. Formation and HERON reactivity of cyclic N,N-dialkoxyamides. Aust. J. Chem. 2014, 67, 507-520. [CrossRef]

31. Glover, S.A. N-Acyloxy-N-alkoxyamide-Structure, properties, reactivity and biological activity. Adv. Phys. Org. Chem. 2007, 42, 35-123.

32. Glover, S.A.; Mo, G.; Rauk, A.; Tucker, D.J.; Turner, P. Structure, conformation, anomeric effects and rotational barriers in the HERON amides, $N, N^{\prime}$-diacyl- $N, N^{\prime}$-dialkoxyhydrazines. J. Chem. Soc. Perkin Trans. 2 1999, 2053-2058. [CrossRef]

33. Glover, S.A.; White, J.M.; Rosser, A.A.; Digianantonio, K.M. Structures of N,N-Dialkoxyamides-Pyramidal anomeric amides with low amidicity. J. Org. Chem. 2011, 76, 9757-9763. [CrossRef] [PubMed]

34. Glover, S.A.; Rosser, A.A.; Spence, R.M. Studies of the structure, amidicity and reactivity of $N$-chlorohydroxamic esters and $N$-chloro- $\beta, \beta$-dialkylhydrazides: Anomeric amides with low resonance energies. Aust. J. Chem. 2014, 67, 1344-1352. [CrossRef]

35. Glover, S.A. N-Heteroatom-Substituted Hydroxamic Esters. In The Chemistry of Hydroxylamines, Oximes and Hydroxamic; Rappoport, Z., Liebman, J.F., Eds.; Wiley: Chichester, UK, 2009; pp. 839-923. 
36. Alabugin, I.V.; Bresch, S.; Manoharan, M. Hybridization trends for main group elements and expanding the Bent's rule beyond carbon: More than electronegativity. J. Phys. Chem. A 2014, 118, 3663-3677. [CrossRef] [PubMed]

37. Bent, H.A. An appraisal of valence-bond structures and hybridization in compounds of the first-row elements. Chem. Rev. 1961, 61, 275-311. [CrossRef]

38. Glover, S.A.; Schumacher, R.R. The effect of hydrophobicity upon the direct mutagenicity of $\mathrm{N}$-acyloxy- $\mathrm{N}$-alkoxyamides-Bilinear dependence upon LogP. Mutat. Res. 2016, 795, 41-50. [CrossRef] [PubMed]

39. Banks, T.M.; Clay, S.F.; Glover, S.A.; Schumacher, R.R. Mutagenicity of $N$-acyloxy- $N$-alkoxyamides as an indicator of DNA intercalation Part 1: Evidence for naphthalene as a DNA intercalator. Org. Biomol. Chem. 2016, 14, 3699-3714. [CrossRef] [PubMed]

40. Glover, S.A.; Schumacher, R.R.; Bonin, A.M.; Fransson, L.E. Steric effects upon the direct mutagenicity of $\mathrm{N}$-acyloxy-N-alkoxyamides-Probes for drug-DNA interactions. Mutat. Res. 2011, 722, 32-38. [CrossRef] [PubMed]

41. Andrews, L.E.; Banks, T.M.; Bonin, A.M.; Clay, S.F.; Gillson, A.-M.E.; Glover, S.A. Mutagenic $N$-acyloxy-N-alkoxyamides-Probes for drug-DNA interactions. Aust. J. Chem. 2004, 57, 377-381. [CrossRef]

42. Banks, T.M.; Bonin, A.M.; Glover, S.A.; Prakash, A.S. Mutagenicity and DNA damage studies of $\mathrm{N}$-acyloxy- $\mathrm{N}$-alkoxyamides-The role of electrophilic nitrogen. Org. Biomol. Chem. 2003, 1, 2238-2246. [CrossRef] [PubMed]

43. Bonin, A.M.; Banks, T.M.; Campbell, J.J.; Glover, S.A.; Hammond, G.P.; Prakash, A.S.; Rowbottom, C.A. Mutagenicity of electrophilic $N$-acyloxy- $N$-alkoxyamides. Mutat. Res. 2001, 494, 115-134. [CrossRef]

44. Campbell, J.J.; Glover, S.A. (Synopsis) Bimolecular reactions of mutagenic $N$-(acyloxy)- $N$-alkoxybenzamides with aromatic amines. J. Chem. Res. 1999, 8, 474-475. [CrossRef]

45. Glover, S.A.; Hammond, G.P.; Bonin, A.M. A comparison of the reactivity and mutagenicity of $\mathrm{N}$-benzoyloxy-N-benzyloxybenzamides. J. Org. Chem. 1998, 63, 9684-9689. [CrossRef]

46. Bonin, A.M.; Glover, S.A.; Hammond, G.P. Reactive intermediates from the solvolysis of mutagenic O-alkyl $\mathrm{N}$-acetoxybenzohydroxamates. J. Chem. Soc. Perkin Trans. 2 1994, 6, 1173-1180. [CrossRef]

47. Campbell, J.J.; Glover, S.A. Bimolecular reactions of mutagenic $N$-acetoxy- $N$-alkoxybenzamides and N-methylaniline. J. Chem. Soc. Perk. Trans. 2 1992, 10, 1661-1663. [CrossRef]

48. Campbell, J.J.; Glover, S.A.; Hammond, G.P.; Rowbottom, C.A. Evidence for the formation of nitrenium ions in the acid-catalysed solvolysis of mutagenic $N$-acetoxy- $N$-alkoxybenzamides. J. Chem. Soc. Perkin Trans. 2 1991, 2067-2079. [CrossRef]

49. Campbell, J.J.; Glover, S.A.; Rowbottom, C.A. Solvolysis and mutagenesis of $N$-acetoxy- $N$ alkoxybenzamides-Evidence for nitrenium ion formation. Tetrahedron Lett. 1990, 31, 5377-5380. [CrossRef]

50. Andrews, L.E.; Bonin, A.M.; Fransson, L.E.; Gillson, A.-M.E.; Glover, S.A. The role of steric effects in the direct mutagenesis of $\mathrm{N}$-acyloxy- $\mathrm{N}$-alkoxyamides. Mutat. Res. 2006, 605, 51-62. [CrossRef] [PubMed]

51. Cavanagh, K.L.; Glover, S.A.; Price, H.L.; Schumacher, R.R. $\mathrm{S}_{\mathrm{N}} 2$ Substitution reactions at the amide nitrogen in the anomeric mutagens, $N$-acyloxy- $N$-alkoxyamides. Aust. J. Chem. 2009, 62, 700-710. [CrossRef]

52. Glover, S.A.; Adams, M. Reaction of $N$-acyloxy- $N$-alkoxyamides with biological thiols. Aust. J. Chem. 2011, 64, 443-453. [CrossRef]

53. Glover, S.A.; Rauk, A. A computational investigation of the structure of the novel anomeric amide $\mathrm{N}$-azido- $\mathrm{N}$-methoxyformamide and its concerted decomposition to methyl formate and nitrogen. J. Chem. Soc. Perk. Trans. 2 2002, 0, 1740-1746. [CrossRef]

54. Glover, S.A.; Mo, G. Hindered ester formation by $\mathrm{S}_{\mathrm{N}} 2$ azidation of $N$-acetoxy- $N$-alkoxyamides and $\mathrm{N}$-alkoxy- $\mathrm{N}$-chloroamides-Novel application of HERON rearrangements. J. Chem. Soc. Perk. Trans. 2 2002, 10, 1728-1739. [CrossRef]

55. Digianantonio, K.M.; Glover, S.A.; Johns, J.P.; Rosser, A.A. Synthesis and thermal decomposition of N,N-dialkoxyamides. Org. Biomol. Chem. 2011, 9, 4116-4126. [CrossRef] [PubMed]

56. Buccigross, J.M.; Glover, S.A.; Hammond, G.P. Decomposition of $N, N$-diacyl- $N, N$-dialkoxyhydrazines revisited. Aust. J. Chem. 1995, 48, 353-361.

57. Greenberg, A. The Amide Linkage as a Ligand: Its Properties and the Role of Distortion. In The Amide Linkage. Structural Significance in Chemistry, Biochemistry and Materials Science; Greenberg, A., Breneman, C.M., Liebman, J.F., Eds.; John Wiley \& Sons, Inc.: New York, NY, USA, 2003; pp. 47-83. 
58. Greenberg, A.; Moore, D.T.; DuBois, T.D. Small and medium-sized bridgehead lactams: A systematic ab initio molecular orbital study. J. Am. Chem. Soc. 1996, 118, 8658-8668. [CrossRef]

59. Greenberg, A.; Venanzi, C.A. Structures and enrgetics of two bridgehead lactams and their $N$ - and O-protonated froms: An ab initio molecular orbital study. J. Am. Chem. Soc. 1993, 115, 6951-6957. [CrossRef]

60. Hehre, W.J.; Radom, L.; Schleyer, P.; Pople, J.A. Ab Initio Molecular Orbital Theory; John Wiley \& Sons: New York, NY, USA, 1986.

61. Glover, S.A.; Rosser, A.A. The role of substituents in the HERON reaction of anomeric amides. Can. J. Chem. 2016, 94, 1169-1180. [CrossRef]

62. Glover, S.A.; Rosser, A.A. HERON reactions of anomeric amides: Understanding the driving force. J. Phys. Org. Chem. 2015, 28, 215-222. [CrossRef]

63. Allen, F.H. The cambridge structural database: A quarter of a million crystal structures and rising. Acta Crystallogr. Sect. B Struct. Sci. 2002, 58, 380-388. [CrossRef]

64. Wiberg, K.B.; Rablen, P.R.; Rush, D.J.; Keith, T.A. Amides. 3. Experimental and theoretical studies of the effect of the medium on the rotational barriers for $N, N$-dimethylformamide and $N, N$-dimethylacetamide. J. Am. Chem. Soc. 1995, 117, 4261-4270. [CrossRef]

65. Shtamburg, V.G.; Tsygankov, A.T.; Shishkin, O.V.; Zubatyuk, R.I.; Uspensky, B.V.; Shtamburg, V.V.; Mazepa, A.V.; Kostyanovsky, R.G. The properties and structure of $N$-chloro- $N$-methoxy-4-nitrobenzamide. Mendeleev Commun. 2012, 22, 164-166. [CrossRef]

66. Shtamburg, V.G.; Shishkin, O.V.; Zubatyuk, R.I.; Kravchenko, S.V.; Tsygankov, A.V.; Mazepa, A.V.; Klots, E.A.; Kostyanovsky, R.G. N-Chloro-N-alkoxyureas: Synthesis, structure and properties. Mendeleev Commun. 2006, 16, 323-325. [CrossRef]

67. Shishkin, O.V.; Zubatyuk, R.I.; Shtamburg, V.G.; Tsygankov, A.V.; Klots, E.A.; Mazepa, A.V.; Kostyanovsky, R.G. Pyramidal amide nitrogen in $\mathrm{N}$-acyloxy- $\mathrm{N}$-alkoxyureas and $\mathrm{N}$-acyloxy- $\mathrm{N}$-alkoxycarbamates. Mendeleev Commun. 2006, 16, 222-223. [CrossRef]

68. Shtamburg, V.G.; Shishkin, O.V.; Zubatyuk, R.I.; Kravchenko, S.V.; Tsygankov, A.V.; Shtamburg, V.V.; Distanov, V.B.; Kostyanovsky, R.G. Synthesis, structure and properties of $N$-alkoxy- $N$-(1-pyridinium)urea salts, $\mathrm{N}$-alkoxy- $\mathrm{N}$-acyloxyureas and $\mathrm{N}, \mathrm{N}$-dialkoxyureas. Mendeleev Commun. 2007, 17, 178-180. [CrossRef]

69. Shtamburg, V.G.; Shishkin, O.V.; Zubatyuk, R.I.; Shtamburg, V.V.; Tsygankov, A.V.; Mazepa, A.V.; Kadorkina, G.K.; Kostanovsky, R.G. Synthesis and structure of $N$-alkoxyhydrazines and $N$-alkoxy- $N^{\prime}, N^{\prime}, N^{\prime}$-trialkylhydrazinium salts. Mendeleev Commun. 2013, 23, 289-291. [CrossRef]

70. Alabugin, I.V.; Bresch, S.; dos Passos Gomez, G. Orbital hybridization: A key electronic factor in control of structure and reactivity. J. Phys. Org. Chem. 2015, 28, 147-162. [CrossRef]

71. Alabugin, I.V. Stereoelectronic Effects: A Bridge between Structure and Reactivity, 1st ed.; John Wiley \& Sons: Chichester, UK, 2016.

72. Alabugin, I.V.; Zeidan, T.A. Stereoelectronic effects and general trends in hyperconjugative acceptor ability of $\sigma$ bonds. J. Am. Chem. Soc. 2002, 124, 3175-3185. [CrossRef] [PubMed]

73. Rauk, A. Orbital Interaction Theory of Organic Chemistry; John Wiley \& Sons, Inc.: New York, NY, USA, 1994; p. 102.

74. Eliel, E.L.; Wilen, S.H.; Mander, L.N. Stereochemistry of Organic Compounds; John Wiley \& Sons, Inc: New York, NY, USA, 1994; pp. 753-1191.

75. Epiotis, N.D.; Cherry, W.R.; Shaik, S.; Yates, R.L.; Bernardi, F. Structural Theory of Organic Chemistry; Springer: Berlin, Germany, 1977.

76. Glover, S.A.; Mo, G.; Rauk, A. HERON rearrangement of $N, N^{\prime}$-diacyl- $N, N^{\prime}$-dialkoxyhydrazines-A theoretical and experimental study. Tetrahedron 1999, 55, 3413-3426. [CrossRef]

77. De Almeida, M.V.; Barton, D.H.R.; Bytheway, I.; Ferriera, J.A.; Hall, M.B.; Liu, W.; Taylor, D.K.; Thomson, L. Preparation and thermal decomposition of $N, N^{\prime}$-diacyl- $N, N^{\prime}$-dialkoxyhydrazines: Synthetic applications and mechanitic insights. J. Am. Chem. Soc. 1995, 117, 4870-4874. [CrossRef]

78. Cooley, J.H.; Mosher, M.W.; Khan, M.A. Preparation and reactions of $N, N^{\prime}$-diacyl- $N, N^{\prime}$-dialkoxyhydrazines. J. Am. Chem. Soc. 1968, 90, 1867-1871. [CrossRef]

79. Banks, T.M. Reactivity, Mutagenicity and DNA Damage of N-Acyloxy-N-Alkoxyamides. Ph.D. Thesis, University of New England, Armidale, Australia, 2003.

80. Gerdes, R.G.; Glover, S.A.; Ten Have, J.F.; Rowbottom, C.A. N-Acetoxy-N-alkoxyamides-A new class of nitrenium ion precursors which are mutagenic. Tetrahedron Lett. 1989, 30, 2649-2652. [CrossRef] 
81. Taherpour, A. University of New England, Armidale, New South Wales, Australia. Personal communication, 2012.

82. Williams, D.H.; Fleming, I. Spectroscopic Methods in Organic Chemistry, 3rd ed.; McGraw Hill Ltd.: Maidenhead, UK, 1980.

83. Jackman, L.M. Rotation about Partial Double Bonds in Organic Molecules. In Dynamic Nuclear Magnetic Resonance Spectroscopy; Jackman, L.M., Cotton, F.A., Eds.; Academic Press: Cambridge, MA, USA, 1975.

84. Günther, H. NMR Spectroscopy—Basic Principles, Concepts, and Applications in Chemistry, 2nd ed.; John Wiley \& Sons Ltd.: Chichester, UK, 1995.

85. Johns, J.P.; van Losenoord, A.; Mary, C.; Garcia, P.; Pankhurst, D.S.; Rosser, A.A.; Glover, S.A. Thermal decomposition of $N$-acyloxy- $N$-alkoxyamides-A new HERON reaction. Aust. J. Chem. 2010, 63, 1717-1729. [CrossRef]

86. Glover, S.A. $\mathrm{S}_{\mathrm{N}} 2$ reactions at amide nitrogen-Theoretical models for reactions of mutagenic $N$-acyloxy- $N$-alkoxyamides with bionucleophiles. Arkivoc 2002, 2001, 143-160. [CrossRef]

87. Campbell, J.J.; Glover, S.A. (Microfiche) Bimolecular reactions of mutagenic $N$-(acyloxy)- $N$-alkoxybenzamides with aromatic amines. J. Chem. Res. 1999, 8, 2075-2096.

88. Isaacs, N.S. Physical Organic Chemistry, 2nd ed.; Longman Scientific and Technical: New York, NY, USA, 1995; p. 422.

89. Forster, W.; Laird, R.M. The mechanism of alkylation reactions. Part 1. The effect of ubstituents on the reaction of phenacyl bromide with pyridine in methanol. J. Chem. Soc. Perk. Trans. 2 1982, 2, 135-138. [CrossRef]

90. De Kimpe, N.; Verhé, R. The Chemistry of $\alpha$-Haloketones, $\alpha$-Haloaldehydes and $\alpha$-Haloimines; John Wiley \& Sons: Chichester, UK, 1988; p. 38.

91. Thorpe, J.W.; Warkentin, J. Stereochemical and steric effects in nucleophilic substitution of $\alpha$-halo ketones. Can. J. Chem. 1973, 51, 927-935. [CrossRef]

92. Maron, D.M.; Ames, B.N. Revised methods for salmonella mutagenicity tests. Mutat. Res. 1983, 113, $173-215$. [CrossRef]

93. Mortelmans, K.; Zeiger, E. The ames salmonella/microsome mutagenicity assay. Mutat. Res. 2000, 455, 29-60. [CrossRef]

94. Pullman, A.; Pullman, B. Electrostatic effect of macromolecular structure on the biochemical reactivity of the nucleic acids. Significance for chemical carcinogenesis. Int. J. Quantum Chem. Symposia 1980, 18, 245-259. [CrossRef]

95. Kohn, K.W.; Hartley, J.A.; Mattes, W.B. Mechanism of sequence selective alkylation of guanine-N7 positions by nitrogen mustards. Nucleic Acids Res. 1987, 15, 10531-10544. [CrossRef] [PubMed]

96. Warpehoski, M.A.; Hurley, L.H. Sequence selectivity of DNA covalent modification. Chem. Res. Toxicol. 1988, 1, 315-333. [CrossRef] [PubMed]

97. Prakash, A.S.; Denny, W.A.; Gourdie, T.A.; Valu, K.K.; Woodgate, P.D.; Wakelin, L.P.G. DNA-directed alkylating ligands as potential antitumor agents: Sequence specificity of alkylation by aniline mustards. Biochemistry 1990, 29, 9799-9807. [CrossRef] [PubMed]

98. Glover, S.A.; Scott, A.P. MNDO properties of heteroatom and phenyl substituted nitrenium ions. Tetrahedron 1989, 45, 1763-1776. [CrossRef]

99. Schroeder, D.; Grandinetti, F.; Hrusak, J.; Schwarz, H. Experimental and ab initio MO studies on [H2,N,O]+ ions in the gas phase: Characterization of the isomers $\mathrm{H} 2 \mathrm{NO}+, \mathrm{HNOH}+$ and $\mathrm{NOH} 2+$ and the mechanism of unimolecular dehydrogenation of [H2,N,O]+. J. Phys. Chem. 1992, 96, 4841-4845. [CrossRef]

100. Glover, S.A.; Goosen, A.; McCleland, C.W.; Schoonraad, J.L. $N$-alkoxy-N-acylnitrenium ions as possible intermediates in intramolecular aromatic substitution: Novel formation of $\mathrm{N}$-acyl-3,4-dihydro-1H-2,1-benzoxazines and N-acyl-4,5-dihydro-1H-2,1-benzoxazepine. J. Chem. Soc. Perkin Trans. 1 1984, 2255-2260. [CrossRef]

101. Glover, S.A.; Rowbottom, C.A.; Scott, A.P.; Schoonraad, J.L. Alkoxynitrenium ion cyclisations: Evidence for difference mechanisms in the formation of benzoxazines and benzoxazepines. Tetrahedron 1990, 46, 7247-7262. [CrossRef]

102. Kikugawa, Y.; Kawase, M. Electrophilic aromatic substitution with a nitrenium ion generated from $\mathrm{N}$-chloro- $\mathrm{N}$-methoxyamides. Application to the synthesis of 1-methoxy-2-oxindoles. J. Am. Chem. Soc. 1984, 106, 5728-5729. [CrossRef] 
103. Kawase, M.; Kitamura, T.; Kikugawa, Y. Electrophilic aromatic substitution with $N$-methoxy- $N$-acylnitrenium ions generated from $N$-chloro- $N$-methoxy amides: Syntheses of nitrogen heterocyclic compounds bearing a N-methoxy amide group. J. Org. Chem. 1989, 54, 3394-3403. [CrossRef]

104. Kikugawa, Y.; Shimada, M.; Kato, M.; Sakamoto, T. A new synthesis of N-alkoxy-2-ethoxyarylacetamides from $N$-alkoxy- $N$-chloroarylacetamides with triethylamine in ethanol. Chem. Pharm. Bull. 1993, 41, 2192-2194. [CrossRef]

105. Miyazawa, E.; Sakamoto, T.; Kikugawa, Y. Syntheis of spirodienones by intramolecular ipso-cyclization of $\mathrm{N}$-methoxy-(4-halegenophenyl)amides using [hydroxy(tosyloxy)iodo]benzene in trifluoroethanol. J. Org. Chem. 2003, 68, 5429-5432. [CrossRef] [PubMed]

106. Kikugawa, Y.; Kawase, M.; Miyake, Y.; Sakamoto, T.; Shimada, M. A convenient synthesis of eupolauramine. Tetrahedron Lett. 1988, 29, 4297-4298. [CrossRef]

107. Kikugawa, Y.; Shimado, M.; Matsumoto, K. Cyclization with nitrenium ions generated from N-methoxy- or $\mathrm{N}$-allyloxy- $\mathrm{N}$-chloroamides with anhydrous zinc acetate. Synthesis of $\mathrm{N}$-hydroxy- and $\mathrm{N}$-methoxynitrogen heterocyclic compounds. Heterocycles 1994, 37, 293-301. [CrossRef]

108. Kikugawa, Y. Uses of hydroxamic acids and $N$-alkoxyimidoyl halides in organic synthesis. Rev. Heteroat. Chem. 1996, 15, 263-299.

109. Greenstein, G. The Merck Index: An Encyclopedia of Chemicals, Drugs, and Biologicals, 14nd ed.; O'Neil, M.J., Heckelman, P.E., Koch, C.B., Roman, K.J., Eds.; Emerald Group Publishing Limited: Whitehouse Station, NJ, USA, 2006; p. 40.

110. The Heron Reaction-Merck Index Named Reaction Index. Available online: https:/ /www.rsc.org/MerckIndex/reaction/r197/ (accessed on 30 October 2018).

111. Buccigross, J.M.; Glover, S.A. Molecular orbital studies of $\mathrm{N}$ to $\mathrm{C}$ migrations in $\mathrm{N}, \mathrm{N}$-bisheteroatom-substituted amides-HERON rearrangements. J. Chem. Soc. Perk. Trans. 2 1995, 595-603. [CrossRef]

112. Glover, S.A.; Rauk, A.; Buccigross, J.M.; Campbell, J.J.; Hammond, G.P.; Mo, G.; Andrews, L.E.; Gillson, A.-M.E. Review: The HERON reaction: Origin, theoretical background and prevalence. Can. J. Chem. 2005, 83, 1492-1509. [CrossRef]

113. Glover, S.A. Development of the HERON reaction: A historical account. Aust. J. Chem. 2017, 70, 344-361. [CrossRef]

114. Hinsberg, W.D., III; Dervan, P.B. Synthesis and direct spectroscopic observation of a 1,1-dialkyldiazene. Infrared and electronic spectrum of N-(2,2,6,6-tetramethylpiperidyl)nitrene. J. Am. Chem. Soc. 1978, 100, 1608-1610. [CrossRef]

115. Hinsberg, W.D., III; Dervan, P.B. Kinetics of the thermal decomposition of a 1,1-dialkyldiazene, N-(2,2,6,6-tetramethylpiperidyl)nitrene. J. Am. Chem. Soc. 1979, 101, 6142-6144. [CrossRef]

116. Hinsberg, W.D., III; Schultz, P.G.; Dervan, P.B. Direct studies of 1,1-diazenes. Syntheses, infrared and electronic spectra, and kinetics of the thermal decomposition of $N-(2,2,6,6$-tetramethylpiperidyl)nitrene and N-(2,2,5,5-tetramethylpyrrolidyl)nitrene. J. Am. Chem. Soc. 1982, 104, 766-773. [CrossRef]

117. Schultz, P.G.; Dervan, P.B. Synthesis and direct spectroscopic observation of $\mathrm{N}$-(2,2,5,5-tetramethylpyrrolidyl)nitrene. Comparison of five- and six-membered cyclic 1,1-dialkyldiazenes. J. Am. Chem. Soc. 1980, 102, 878-880. [CrossRef]

118. Zhang, N.; Yang, R.; Zhang-Negrerie, D.; Du, Y.; Zhao, K. Direct conversion of $N$-alkoxyamides to carboxylic esters through tandem NBS-mediated oxidative homocoupling and thermal denitrogenation. J. Org. Chem. 2014, 78, 8705-8711. [CrossRef] [PubMed]

119. Thomson, L.M.; Hall, M.B. Theoretical study of the thermal decomposition of $N, N^{\prime}$-diacyl- $N, N^{\prime}-$ dialkoxyhydrazines: A comparison of HF, MP2, and DFT. J. Phys. Chem. A 2000, 104, 6247-6252. [CrossRef]

120. Novak, M.; Glover, S.A. Generation and trapping of the 4-biphenylyloxenium ion by water and azide: Comparisons with the 4-biphenylylnitrenium ion. J. Am. Chem. Soc. 2004, 126, 7748-7749. [CrossRef] [PubMed]

121. Novak, M.; Rajagopal, S. N-arylnitrenium ions. Adv. Phys. Org. Chem. 2001, 36, 167-254. [CrossRef]

122. Shtamburg, V.G.; Klots, E.A.; Pleshkova, A.P.; Avramenko, V.I.; Ivonin, S.P.; Tsygankov, A.V.; Kostyanovsky, R.G. Geminal systems. 50. Synthesis and alcoholysis of $N$-acyloxy- $N$-alkoxy derivatives of ureas, carbamates, and benzamides. Russ. Chem. Bull. 2003, 52, 2251-2260. [CrossRef]

123. Crawford, R.J.; Raap, R. The Synthesis and reaction of $N, N$-dicarboalkoxy- $N, N$-dialkoxyhydrazines and some observations on carbalkoxylium ions. J. Org. Chem. 1963, 28, 2419-2424. [CrossRef] 
124. Fahr, E.; Lind, H. Chemisry of a-carbonyl azo compounds. Angew. Chem. 1966, 5, 372-384. [CrossRef]

125. Mo, G. Properties and Reactions of Anomeric Amides. Ph.D. Thesis, University of New England, Armidale, Australia, 1999.

126. Cavanagh, K.L.; Glover, S.A. Heron reactivity of N-acetoxycarbamates with anilines. Unpublished work.

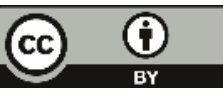

(C) 2018 by the authors. Licensee MDPI, Basel, Switzerland. This article is an open access article distributed under the terms and conditions of the Creative Commons Attribution (CC BY) license (http:/ / creativecommons.org/licenses/by/4.0/). 


\title{
Amide Bond Activation of Biological Molecules
}

\author{
Sriram Mahesh, Kuei-Chien Tang and Monika Raj * \\ Department of Chemistry and Biochemistry, Auburn University, Auburn, AL 36849, USA; \\ mzs0154@auburn.edu (S.M.); kzt0026@tigermail.auburn.edu (K.-C.T.) \\ * Correspondence: mzr0068@auburn.edu; Tel.: +1-334-844-6986 \\ Academic Editor: Michal Szostak \\ Received: 7 September 2018; Accepted: 9 October 2018; Published: 12 October 2018
}

\begin{abstract}
Amide bonds are the most prevalent structures found in organic molecules and various biomolecules such as peptides, proteins, DNA, and RNA. The unique feature of amide bonds is their ability to form resonating structures, thus, they are highly stable and adopt particular three-dimensional structures, which, in turn, are responsible for their functions. The main focus of this review article is to report the methodologies for the activation of the unactivated amide bonds present in biomolecules, which includes the enzymatic approach, metal complexes, and non-metal based methods. This article also discusses some of the applications of amide bond activation approaches in the sequencing of proteins and the synthesis of peptide acids, esters, amides, and thioesters.
\end{abstract}

Keywords: peptide bond cleavage; amide bond resonance; twisted amides; enzymes; metal complexes; catalysts

\section{Introduction}

The amide bond is one of the most abundant chemical bonds and widely exists in many organic molecules and biomolecules [1-6]. Nature has used amide bonds to make these important biomolecules because of the high stability of amide bonds towards various reaction conditions (acidic and basic conditions), high temperature, and the presence of other chemicals [7]. The high stability of amide bonds is attributed to its tendency to form a resonating structure, which provides a double bond character to the amide CO-N bond (Figure 1) [8-10]. The resonance of these amide bonds forms a planar structure and hinders the free rotation around the CO-N bond, thus, it is responsible for 3D structures adopted by proteins and other biomolecules. These 3D structures of biomolecules are responsible for various important biological functions.

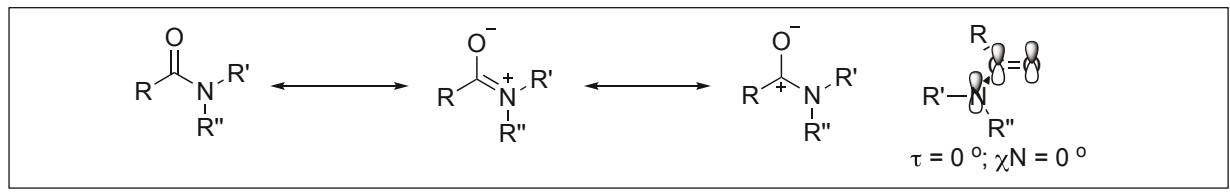

Figure 1. Classical amide bond resonance.

Hansen et al. carried out the rate studies on the hydrolysis of amide bonds at various $\mathrm{pH}$ conditions [11]. The study concluded that at $\mathrm{pH} 7$, the rate of hydrolysis is due to the direct attack of water on peptide and measured as $\mathrm{kH}_{2} \mathrm{O}$. The rate constant showed that the half-life of the amide bonds is 267 years, similar to the value determined by Radzicka and Wolfenden [12]. This study also showed that the rates of acid $\left(\mathrm{kH}_{3} \mathrm{O}^{+}\right)$and base hydrolysis $\left(\mathrm{kOH}^{-}\right)$are identical, therefore, the rate of the hydrolysis of the peptide bond is dominated by $\mathrm{kH}_{2} \mathrm{O}$ throughout the $\mathrm{pH}$ range from $\mathrm{pH}$ 5-9. 
Recently, various methods have been reported in the literature to activate the amide bonds towards a variety of nucleophiles or electrophiles for the synthesis of other organic compounds. This includes the use of enzymes, metal complexes, and non-metal based methods [13-15]. One widely reported approach for the activation of amide bonds involves the distortion of amide bonds, thus, the amide bond is no longer able to form a resonating structure, loses its double bond character, and becomes more susceptible to nucleophilic or electrophilic attack. A higher distortion of the amide bond from the planar structure makes it more reactive, as evidenced by various twisted amide bonds present in cyclic nonplanar bridged lactams, as demonstrated by Stoltz [16,17], Kirby [18-20], and others [21-23] (Figure 2). One of the special cases to achieve maximum rotational inversion of the amide bond so that it remains in the twisted conformation is the use of $N$-acyl-glutarimides [24-29] and N,N-substituted amide bonds $[30,31]$ (Figure 2). It is this strong distortion of amide bonds that provides amide bonds with a high reactivity toward a variety of nucleophiles and electrophiles.

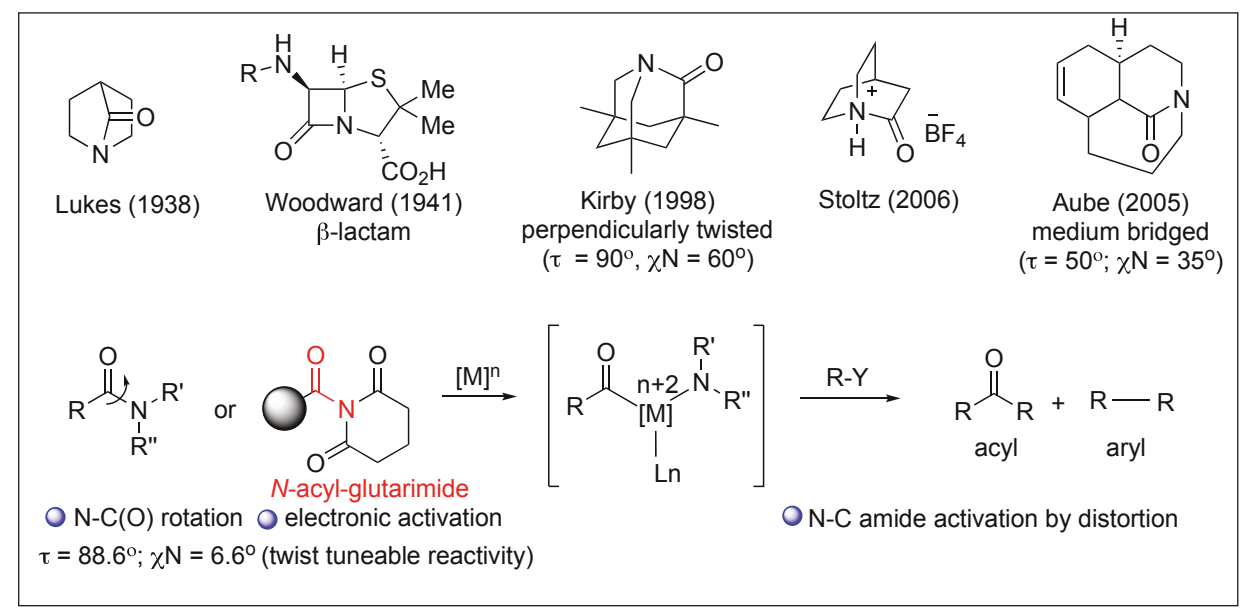

Figure 2. Twisted amides for activation of amide bonds.

There are already some excellent review articles in the literature covering the reactivity of twisted/activated amide bonds for the synthesis of the variety of different organic molecules such as ketones, esters, acids, and alcohols, by cross-coupling reactions [24-31]. The main focus of this review is to summarize the methods for the activation of less reactive amide bonds present in biomolecules such as peptides, proteins, glycopeptides, nucleotides in DNA and RNA and various other peptide bioconjugates, toward attack by various nucleophiles. This task was accomplished by various methods such as by using biological molecules, metal complexes, and non-metal based methods and is discussed below.

\section{Biomolecules for the Activation of Amide Bonds-The Enzyme-Directed Hydrolysis of Amides}

We have summarized different kinds of enzymes, their mechanisms of hydrolysis of unactivated peptide bonds, and the point of cleavages in Table 1. 
Table 1. Enzymatic directed hydrolysis of peptide bonds.

\begin{tabular}{|c|c|c|c|c|}
\hline Entry & Enzyme & Method of Hydrolysis & Point of Cleavage & Ref. \\
\hline 1 & $\begin{array}{c}\text { Serine and } \\
\text { Cysteine Proteases }\end{array}$ & $\begin{array}{l}\text { Oxyanion binding hole with } \\
\text { catalytic triad }\end{array}$ & - & {$[32-37]$} \\
\hline 2 & Metallo-endopeptidase & $\begin{array}{c}\text { Thermolysine with } \mathrm{Zn}^{2+} \text { binds to } \\
\text { His } 142 \text {, His } 146 \text {, Glu } 166\end{array}$ & $\begin{array}{c}\text { Internal peptide bonds on the } \\
\text { N-terminal side of large } \\
\text { hydrophobic amino acids }\end{array}$ & {$[38-51]$} \\
\hline 3 & Metalloexopeptidase & $\begin{array}{l}\text { Carboxypeptidase } \mathrm{A} \text { with } \mathrm{Zn}^{2+} \\
\text { through Lewis acid activation }\end{array}$ & $\begin{array}{l}\text { C-terminus comprising large } \\
\text { hydrophobic amino acids }\end{array}$ & {$[52-54]$} \\
\hline 4 & O-GlcNAc transferase & $\begin{array}{l}\text { Glycosylation followed by enzyme } \\
\text { catalyzed pyroglutamate formation }\end{array}$ & $\mathrm{N}$-terminal glutamic acid & {$[55,56]$} \\
\hline 5 & Nicotinamidase & $\begin{array}{l}\text { Enzyme Chelation to } \mathrm{Zn}^{2+} \text { and } \\
\text { catalytic triad }\end{array}$ & Nicotinamide & {$[57-60]$} \\
\hline 6 & Flavoenzyme & $\begin{array}{l}\text { Flavin hydroperoxide intiated } \\
\text { oxidative mechanism }\end{array}$ & $\begin{array}{l}\text { Unactivated amide bond } \\
\text { in uracil }\end{array}$ & [61-63] \\
\hline 7 & Antibody Fab-BL 125 & $\begin{array}{l}\text { Catalyzes unactivated primary } \\
\text { amide bond hydrolysis }\end{array}$ & $\begin{array}{l}\text { Primary amide bond of L-isomer } \\
\text { of peptides }\end{array}$ & {$[64,65]$} \\
\hline 8 & RNA & $\mathrm{Mg}^{2+}$ catalyzed mechanism & $\begin{array}{l}\text { Unactivated alkyl amide of } \\
\text { DNA analog }\end{array}$ & [66] \\
\hline
\end{tabular}

\subsection{Serine Proteases}

Amide bonds are widely present in proteins due to their high stability and the tendency of amide bonds to exist in resonating structures, which is one of the key factors responsible for secondary structures adopted by proteins and their biological activities. Nature has developed some methods for the cleavage of highly stable amide bonds to control their functions. One such approach is the use of enzymes (serine proteases), which have active sites, and binding pockets for binding to particular amino acids followed by the activation of amide bonds for hydrolysis. These enzymes exist in various families such as trypsin, chymotrypsin, elastase, subtilisin, etc., but have a similar catalytic site containing oxyanion binding hole with Ser, His and Asp triad [32,33]. Some of the proteases have catalytic dyads with two amino acids at the active site, however, triads are the most common.

All these enzymes based on the binding pocket prefer to bind to particular amino acids but the mechanism by which they hydrolyze the amide bond is similar. During the catalysis, these enzymes form an oxyanion hole made up of three amino acids-His, Asp, and Ser-which work in a synergistic manner to break the amide bond (Figure 3). First, the side chain of Asp makes a hydrogen bond with histidine, thus making it more nucleophilic. Second, histidine forms a strong H-bond with the hydroxyl group of serine and abstracts the proton from the hydroxyl group $(\mathrm{OH})$ of serine which in turn attacks amide bond to form a tetrahedral transition state (TS). This TS eventually collapses resulting in the hydrolysis of the amide bond by acid-base catalysis. Wells et al. demonstrated the importance of these residues at the active site by mutating it to alanine [32,33]. They showed that any mutation in the catalytic triad greatly reduces the turnover number which is a consequence of the changes in the enzyme mechanism. Residues in the catalytic triad function in a strongly synergistic manner and contribute a factor of $2 \times 10^{6}$ to the rate enhancement. The study concluded that enzymes increase the rate of amide bond hydrolysis at by least $10^{9}$ to $10^{10}$ times that of the non-enzymatic hydrolysis of amide bonds. 


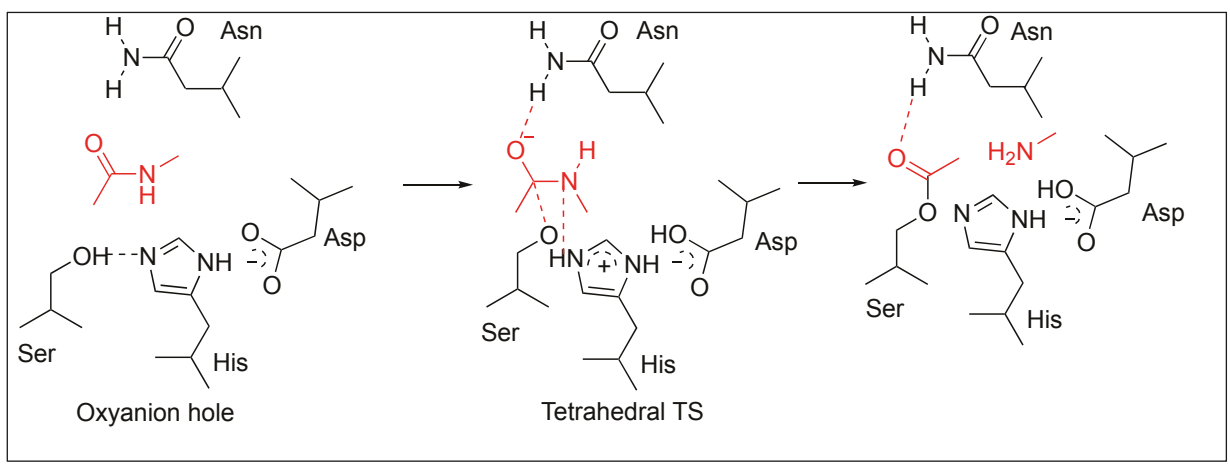

Figure 3. General pathway of serine proteases directed amide bond hydrolysis.

\subsection{Cysteine Proteases}

Cysteine proteases (CPs) hydrolyze the peptide bonds with maximum efficiency at pH 4-6.5 [14]. The thiol group of cysteine protease is susceptible to oxidation so the environment of the enzyme is reducing in nature. Till now 21 families of CPs have been discovered [34-37]. CPs form a triad at the active site during the hydrolysis of the peptide bond made up of Cys-His-Asn residues. First, Asn forms the hydrogen bond with His, then His abstracts the proton from Cys to generate a nucleophilic thiolate ion $\left(\mathrm{S}^{-}\right)$similar to enolate ion generated by serine proteases (Figure 3). Next, the thiolate ion $\left(\mathrm{S}^{-}\right)$attacks the carbonyl group of the peptide resulting in the formation of a tetrahedral intermediate TS followed by the hydrolysis of the amide bond [34-37].

\subsection{Metalloproteases}

Metalloproteases are members of a class of proteases that require a metal ion cofactor at the active site for the hydrolysis of peptide bonds [38]. The most common metal ion cofactor present in metalloproteases is the zinc ion $\left(\mathrm{Zn}^{2+}\right)$ [39]. Other transition metals such as $\mathrm{Co}^{2+}$ and $\mathrm{Mn}^{2+}$ are capable of restoring the functions in zinc-metalloproteases where the $\mathrm{Zn}^{2+}$ core has been removed [39]. Metalloproteases are divided into two major families: metalloendopeptidases and metalloexopeptidases. The names of these families are based on the site of the hydrolysis of the peptide bonds [40,41]. Metalloendopeptidases cleave the internal amide bonds whereas metalloexopeptidases cleave the amide bonds present at the C- or N-terminus of peptides.

\subsubsection{Metalloendopeptidase: Thermolysin}

Thermolysin (TLN) catalyzes the cleavage of the internal peptide bond at the amino-side of large hydrophobic amino acids, such as leucine, isoleucine, or phenylalanine. TLN and TLN-like proteins require $\mathrm{Zn}^{2+}$ as a metal ion cofactor for the cleavage of amide bonds [42-47].

TLN-mediated hydrolysis of the peptide bond is a two-step process (Figure 4) [48-51]. The active site of TLN contains three residues-His142, His146, Glu166 - and a water molecule, which are bound to the $\mathrm{Zn}^{2+}$ ion. First, the carbonyl group of the peptide coordinates with $\mathrm{Zn}^{2+}$ and displaces the hydrogen of a water molecule to form an H-bond with Glu143 and the oxygen of the water molecule remains associated to the $\mathrm{Zn}^{2+}$ ion, resulting in the formation of the enzyme-substrate complex (ES). Second, the oxygen of the water attached to $\mathrm{Zn}^{2+}$ attacks the carbonyl carbon of the peptide, resulting in the formation of transition state 1 (TS1). TS1 is stabilized by the formation of the H-bond with Asp226 and His231 at the carbonyl oxygen of the peptide followed by the formation of intermediate gem-diolate (INT) by the breakage of hydroxyl $\mathrm{OH}$ bond of water. The amide of the peptide forms a hydrogen bond with the $\mathrm{H}$ of $\mathrm{H}_{2} \mathrm{O}$. Third, the carbonyl bond rearrangement in TS2 leads to the breakage of the amide bond $(\mathrm{CONH})$ of the peptide and releases the N-terminal peptide. The rate-determining 
studies showed that the collapse of a zwitterionic tetrahedral intermediate (INT) is a rate-limiting step (Figure 4).

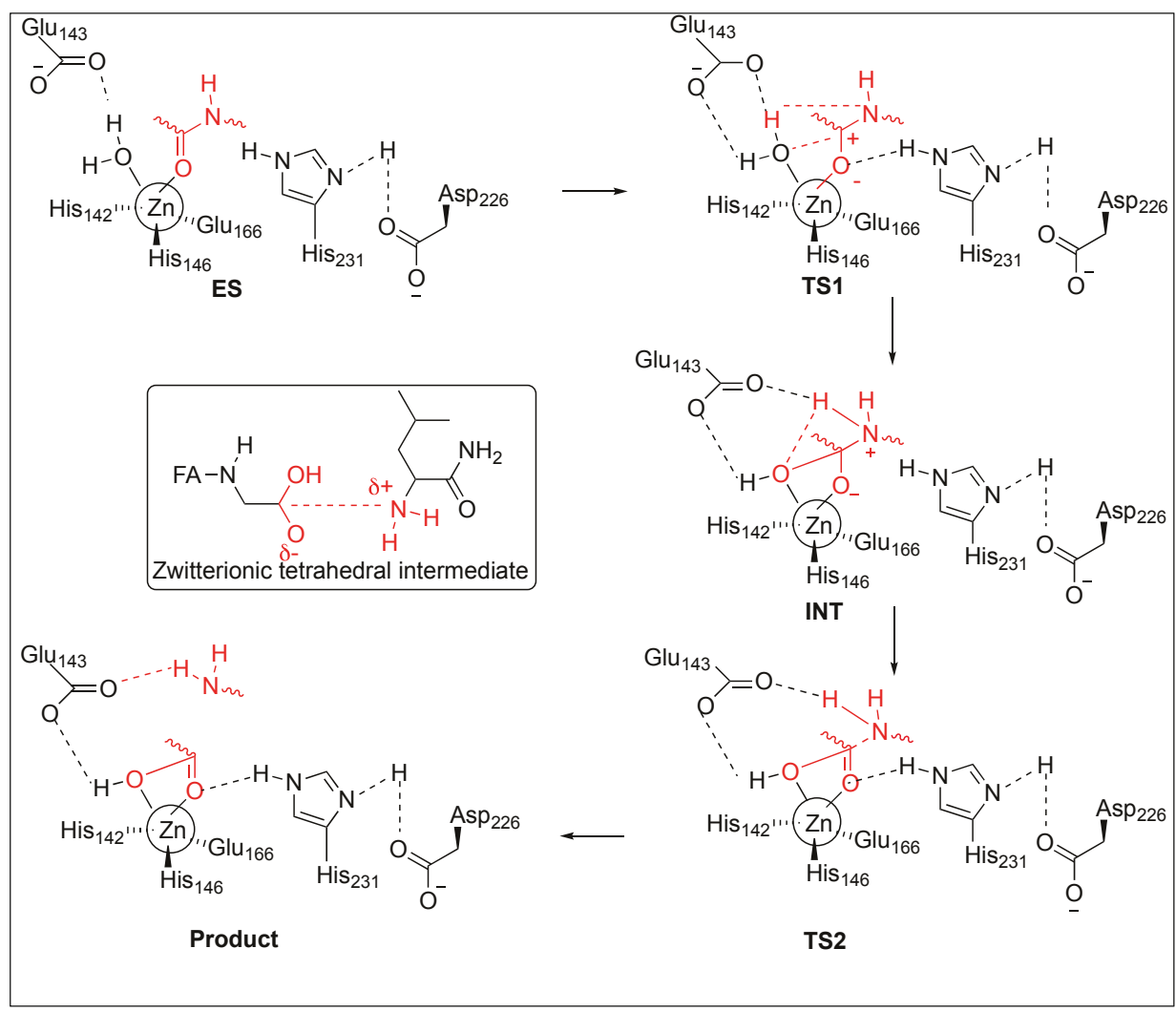

Figure 4. Thermolysin Mechanistic pathway.

\subsubsection{Metalloexopeptidase: Carboxypeptidase A}

Carboxypeptidase A (CPA) is a $35 \mathrm{kDa}$ metalloenzyme and contains a $\mathrm{Zn}^{2+}$ ion cofactor in its active site [52-54]. CPA is an exopeptidase, which catalyzes the hydrolysis of amide bonds present at the C-terminus comprising large hydrophobic side chains. Two different mechanisms have been proposed for the cleavage by these metalloproteases (Figure 5) which showed the importance of Lewis acid catalysis for the activation of amide bonds $[53,54]$. One involves the Lewis-acid activation of the carbonyl group of the amide bond by $\mathrm{Zn}^{2+}$, followed by the attack of water (Figure 5). The second involves the Lewis-acid activation of $\mathrm{H}_{2} \mathrm{O}$ by $\mathrm{Zn}^{2+}$ ions followed by the attack of the hydroxide ion of the water on the carbonyl group of the amide bond (Figure 5). 


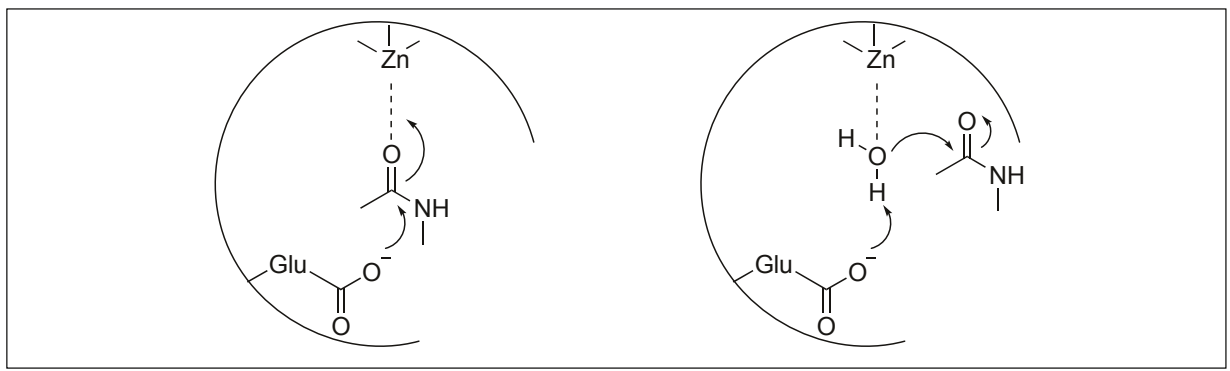

Figure 5. Mechanisms of carboxypeptidase A.

\subsubsection{Glutamate Glycosylation for Amide Bond Cleavage}

Human enzyme O-GlcNAc transferase (OGT) is essential for the cleavage of amide bonds in host cell factor-1 (HCF-1). HCF-1 cleavage takes place at the N-terminal glutamic acid by the glycosylation which is catalyzed by enzyme OGT. Mechanistic studies showed that the glycosylation of the glutamate side chain (intermediate 1, Figure 6) leads to the formation of an enzyme-catalyzed internal pyroglutamate formation (intermediate 2, Figure 6) with the amidic nitrogen of the peptide backbone chain, which then undergoes spontaneous hydrolysis (Figure 6) [55]. Detailed mechanistic studies showed that the rate of conversion of glycopeptide to internal pyroglutamate was an order of magnitude slower than observed in the presence of OGT, thus, it was concluded that both the first and second steps occurred while the peptide is bound to OGT (Figure 6). Hydrolysis likely occurs after dissociation from the enzyme. It has also been reported that glycosylation on Thr next to glutamate also prevents the cleavage at the glutamate $(\mathrm{Glu})$ because of the steric hindrance and thus the enzyme is unable to carry out the glycosylation of glutamate [56].

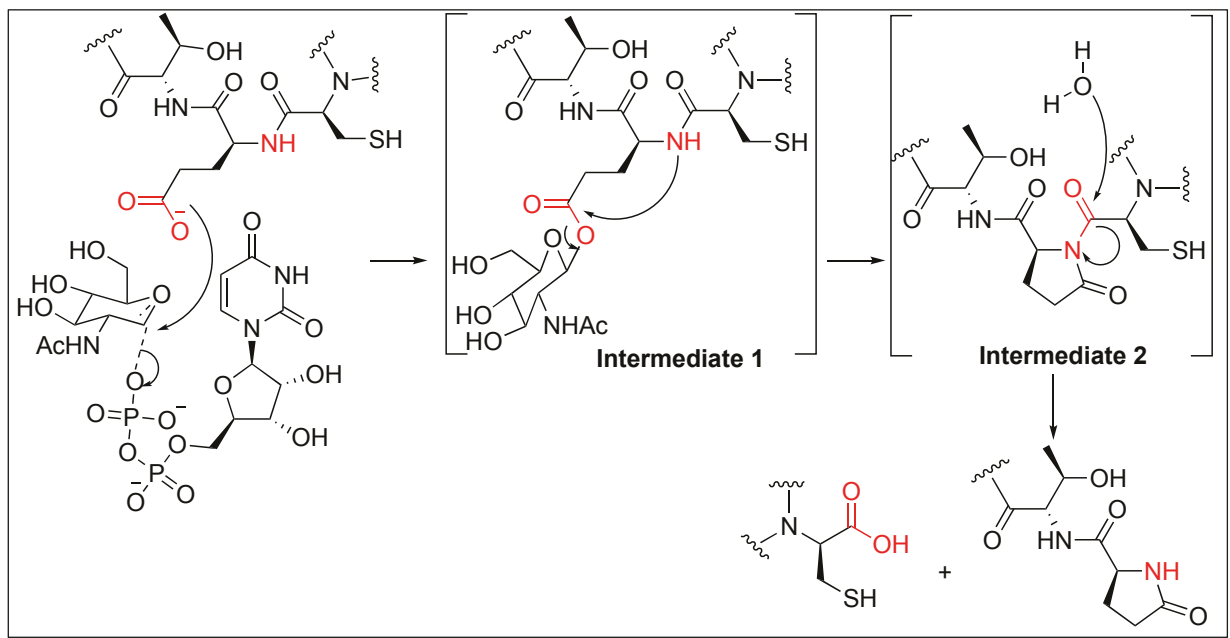

Figure 6. Glycosylation pathway.

\subsubsection{Nicotinamidase (Pnc1) for the Hydrolysis of the Amide Bond of Nicotinamide}

Nicotinamidases catalyze the cleavage of nicotinamide, which is a critically important part of $\mathrm{NAD}^{+}$and $\mathrm{NADH}$, to nicotinic acid and ammonia (Figure 7). A detailed study showed that both the carbonyl oxygen and the ring nitrogen of nicotinamide are critical for binding to the nicotinamidases and reactivity [57-60]. 


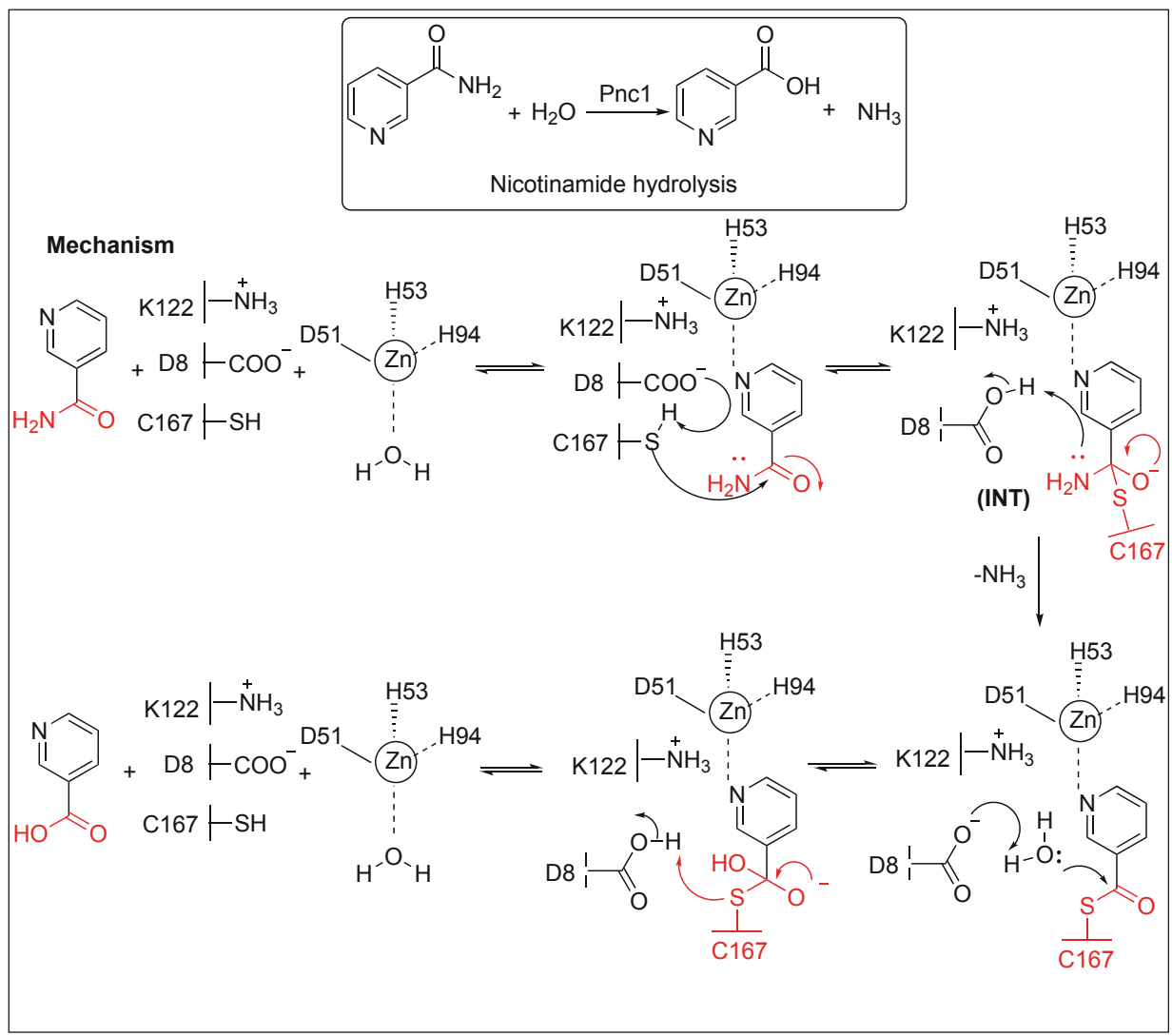

Figure 7. Mechanistic pathway of Pnc1 for hydrolysis of nicotinamide.

Three residues-Asp51, His53, and His94-in nicotinamidase (Pnc1) directly coordinate with $\mathrm{Zn}^{2+}$ at the active site and three other residues act as a catalytic triad (Cys167, Asp8, and Lys122) (Figure 7). In the first step, the substrate binds to the $\mathrm{Zn}^{2+}$ by nitrogen of pyridine ring and displaces the water molecules ligated to the $\mathrm{Zn}^{2+}$. Next, Asp8 removes the proton from Cys167, forming a thiolate, which, in turn, react with the amide carbonyl carbon of nicotinamide, leading to the formation of a tetrahedral intermediate (INT). The tetrahedral intermediate collapsed, resulting in the breakage of the amide bond and release of the ammonia. This is followed by the release of the nicotinic acid from the active site of the enzyme by acid-base catalysis.

\subsubsection{Flavoenzyme-Mediated Hydrolysis of the Amide Bond}

Begley et al. demonstrated the role of flavoenzyme in the cleavage of the unactivated amide bond in uracil, a building block for RNA (Figure 8) [61-63]. The detailed mechanistic analysis showed that the reaction takes place through the oxidative mechanism that is initiated by the addition of a flavin hydroperoxide to the $\mathrm{C}^{*}$ carbonyl of uracil, forming a tetrahedral intermediate (INT) (Figure 8). This is followed by the collapsing of the tetrahedral intermediate (INT), leading to the cleavage of an amide bond in uracil. This was the first example where such chemistry was shown by flavin hydroperoxides. 


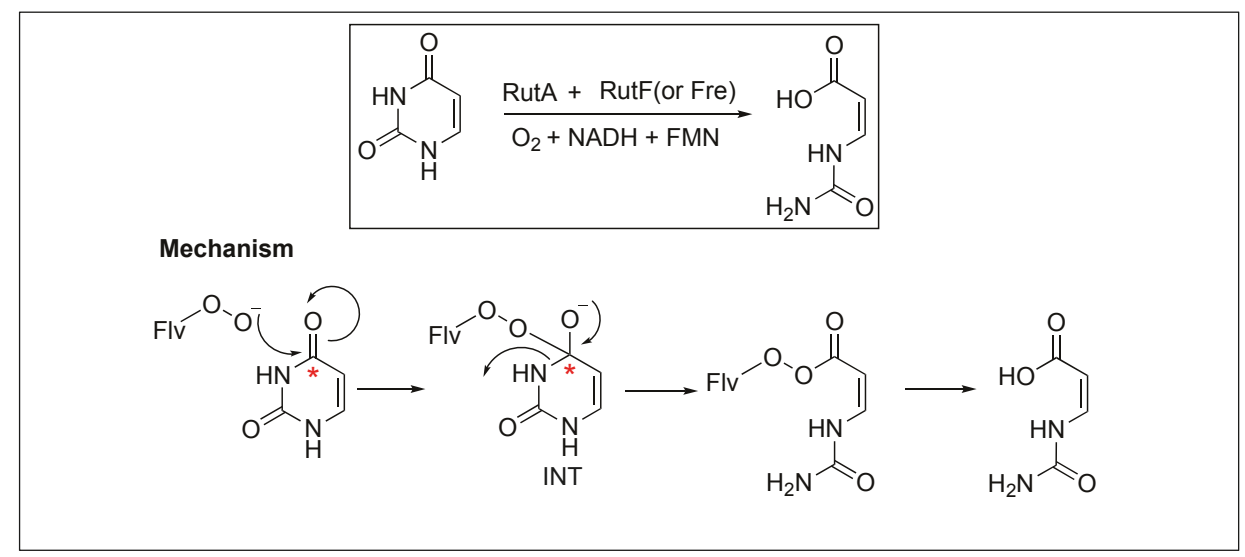

Figure 8. Flavoenzyme-mediated hydrolysis of amide bond.

\subsubsection{Primary Amide Bond Hydrolysis by Antibodies}

The antibody Fab-BL125 catalyzes the hydrolysis of the unactivated primary amide bond of the L-isomer of peptides to generate free peptide acid (Figure 9). The antibody showed high regio- and diastereoselectivity since the D-proline primary amide diastereoisomer did not undergo any hydrolysis. The antibody Fab-BL125 decreases the half-life of the peptide from 17.5 years to only $3.9 \mathrm{~h}$. Such an antibody was obtained by using the $\alpha$-amino boronic acid Hapten by a direct selection strategy from the antibody combinatorial libraries $[64,65]$.<smiles>[R]O[R16](=O)[O-]</smiles>

Figure 9. Antibody Fab catalyzed primary amide bond hydrolysis.

\subsubsection{RNA-Assisted Cleavage of Amide Bonds}

A group I RNA obtained by in vitro evolution catalyzes the cleavage of unactivated alkyl amides of DNA analog. This includes substrates with an amide bond that joins either two DNAs, or a DNA with a short peptide. The RNA increases the rate of hydrolysis by more than $10^{3}$ in comparison to the uncatalyzed reaction. The RNA-catalyzed amide bond cleavage was entirely dependent on $\mathrm{Mg}^{2+}$ where $\mathrm{Mg}^{2+}$ acts as a Lewis acid thus activating the carbonyl group of the amide bond for 
the nucleophilic attack by the hydroxy group of RNA (Figure 10). No amide bond cleavage was detected in the presence of other metal ions such as $\mathrm{Zn}^{2+}, \mathrm{Ca}^{2+}$, or $\mathrm{Sr}^{2+}$. A trace amount of amide bond cleavage was observed in the presence of $\mathrm{MnCl}_{2}$ which is in contrast to the RNA and DNA cleavage reactions [66].

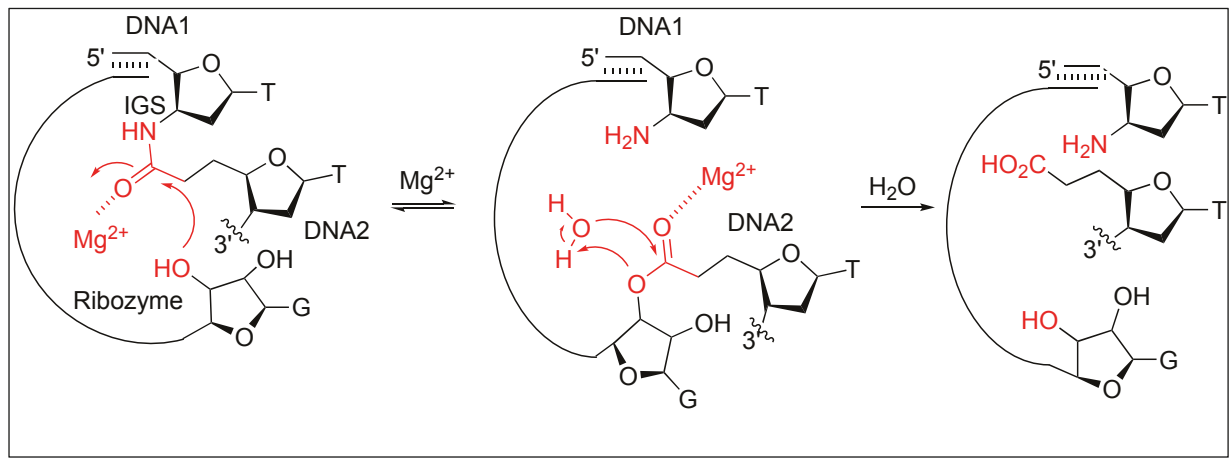

Figure 10. RNA catalyzed amide bond cleavage.

To determine the generality of the amide bond cleavage by RNA, a series of substrates were explored. If a short DNA is attached to a peptide or an amino acid by using an amide bond, the immediate cleavage at the amide bond was observed in the presence of the RNA. The cleavage of the amide bond between the amino acid residues was not observed.

\section{Metal Complexes for the Activation of Amide Bonds}

We have summarized different kinds of metal-based complexes, their mechanisms of hydrolysis of unactivated peptide bonds and point of cleavages in Table 2.

Table 2. Metal catalyzed hydrolysis of peptide bonds.

\begin{tabular}{|c|c|c|c|c|}
\hline Entry & Metal Complex & Method of Hydrolysis & Point of Cleavage & Ref. \\
\hline 1 & Simple metal ions & Lewis acidity of metal ion & C-terminal of peptide & [67-72] \\
\hline 2 & $\begin{array}{c}\text { Zr POMs, } \\
\text { Zr MOF-808 }\end{array}$ & Lewis acidity of metal ion & C-terminal of peptide & [73-82] \\
\hline 3 & $\mathrm{Mo}(\mathrm{VI})$ & $\begin{array}{l}\text { Lewis acidity of metal ion and formation of } \\
\qquad 5 \text { membered ring }\end{array}$ & C-terminal side of Asp & {$[81,82]$} \\
\hline 4 & $\mathrm{Co}(\mathrm{III})$ & N-terminal amine intiated tertiary complex & C-terminal of peptide & [83-88] \\
\hline 5 & Mo(II) & Favorable six-membered chelate ring & C-terminal side of Cys & [89] \\
\hline 6 & $\mathrm{Pd}(\mathrm{II}), \mathrm{Pt}(\mathrm{II})$ & $\begin{array}{l}\text { Carboxylic group of amino acid and side chain of } \\
\text { amino acid anchoring metal complex }\end{array}$ & $\begin{array}{l}\text { C-terminal side of Met, His, Cys } \\
\text { and S-MeCys }\end{array}$ & [90-98] \\
\hline 7 & $\operatorname{Pd}(0)$ & Methionine side chain anchoring metal complex & $\begin{array}{l}\text { Second amide bond upstream } \\
\text { from Met }\end{array}$ & [99-102] \\
\hline 8 & $\mathrm{Co}(\mathrm{III})$ and $\mathrm{Cu}(\mathrm{II})$ & $\begin{array}{l}\text { Lewis acidity activation and PNA for selectivity } \\
\text { towards a particular protein }\end{array}$ & $\begin{array}{c}\mathrm{Mb}=\text { Leu } 89-\text { Ala } 90 \\
\mathrm{PDF}=\text { Gln } 152-\text { Arg } 153 \\
\mathrm{BSA}=\text { Solvent exposed portion }\end{array}$ & [103-111] \\
\hline 9 & $\mathrm{Ni}(\mathrm{II})$ & Non Lewis acid based N,O acyl rearrangement & N-terminal side of Ser/Thr & {$[112,113]$} \\
\hline 10 & Sc(III) & Lewis acid based N,O acyl rearrangement & N-terminal side of Ser/Thr & [114] \\
\hline
\end{tabular}

Another approach for the cleavage of peptide bonds involves the use of metal complexes. This metal complex has potential applications in the field of chemical biology, biochemistry, and bioengineering. A variety of metal ion complexes has been utilized for testing the reactivity with substrates such as peptides, and proteins [67]. Most of the metal catalyzed reactions reported so far are based on the activation of amide carbonyl or water by the Lewis acid mechanism of the metal 
ion. Another metal ion hydrolysis mechanism involves the formation of a square planar complex of the metal ions $\mathrm{Cu}(\mathrm{II}), \mathrm{Ni}(\mathrm{II})$, or Pd(II) with the Ser/Thr-His or Ser/Thr-Xaa-His sequence leading to the $\mathrm{N} \rightarrow \mathrm{O}$ rearrangement of the acyl moiety resulting in the cleavage of the peptide bond (Figure 11). In this section, we will provide few examples of both Lewis acid and the $\mathrm{N} \rightarrow \mathrm{O}$ acyl rearrangement for the cleavage of peptide bonds.

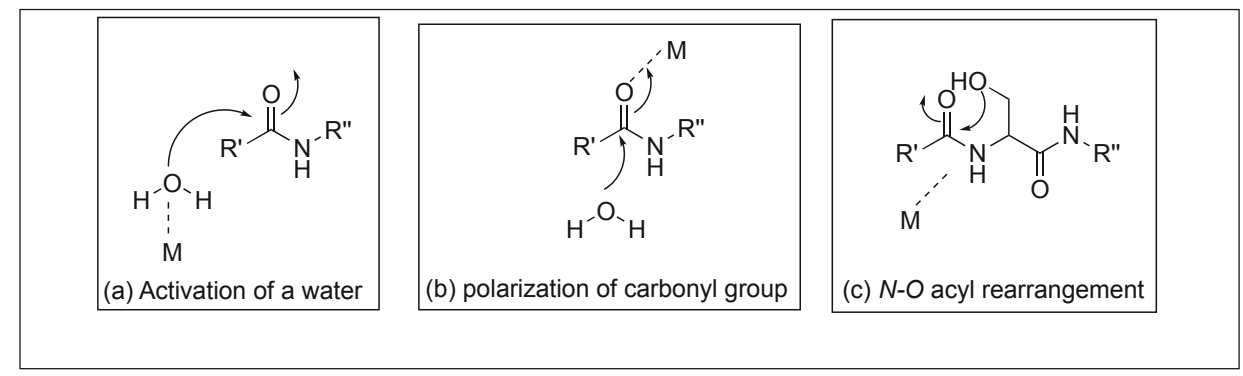

Figure 11. Metal-assisted peptide bond hydrolysis.

\subsection{Lewis Acid Mediated Hydrolysis}

\subsubsection{Simple Metal Ions}

Yashiro et al. reported that the rate of hydrolysis of peptide bonds increases by almost all the metal ions and the highest conversion was observed for Zn(II) [68-72]. The active intermediate was metal complexes where metal binds to both the carbonyl group and the N-terminal amino group of the peptide bond. Cleavage of the peptide bond in the presence of the metal takes place through the mechanism in Figure 11b.

\subsubsection{Oxo Metal Ions}

Parac-Vogt et al. proved that polyoxometalates oxo-metal compounds such as $\mathrm{MoO}_{2}{ }^{-4}$, $\mathrm{WO}_{2}{ }^{-4}$, $\mathrm{CrO}_{2}{ }^{-4}$, and $\mathrm{VO}_{2}{ }^{-4}$ cleave the peptide bonds in various dipeptides [73-77]. They have shown that these oxo-metal compounds also hydrolyze the amide bonds in their regular oligomeric forms, polyoxometalates (POMs). A POM is a unit where one or more atoms can be replaced by a metal center leading to the change in the coordination properties of POM. POMs were utilized for the $\mathrm{Zr}(\mathrm{IV})$ - and $\mathrm{Ce}(\mathrm{IV})$-assisted peptide bond hydrolysis because they are homogenous in nature $[78,79]$.

Zirconium Complex Mediated Hydrolysis of Peptide Bonds

Parac-Vogt et al. reported the hydrolysis of peptide bonds catalyzed by a polyoxometalate complex for the first time. They demonstrated the role of metal-substituted Wells-Dawson type polyoxometalates $\mathrm{K}_{15} \mathrm{H}\left[\mathrm{Zr}\left(\alpha_{2}-\mathrm{P}_{2} \mathrm{~W}_{17} \mathrm{O}_{61}\right)_{2}\right] \cdot 25 \mathrm{H}_{2} \mathrm{O}$ for the hydrolysis of peptide bonds in diglycine, triglycine, tetraglycine, and pentaglycine (GG), yielding glycine as a final product (Figure 12) [80]. A detailed mechanistic investigation by NMR showed that the free amino terminus and both carbonyl functionalities of GG interact with polyoxometalates $\mathrm{K}_{15} \mathrm{H}\left[\mathrm{Zr}\left(\alpha_{2}-\mathrm{P}_{2} \mathrm{~W}_{17} \mathrm{O}_{61}\right)_{2}\right] \cdot 25 \mathrm{H}_{2} \mathrm{O}$ either by the formation of metal ion coordination complex or by the non-covalent interactions of the protonated amino group with the negatively charged surface of POMs, thus responsible for the activation of amide bonds towards hydrolysis. These POMs selectively cleave the C-terminal amide bond of glycylglycyl amide $\left(\mathrm{GGNH}_{2}\right)$, resulting in the formation of GG. No free glycine amide $\left(\mathrm{GNH}_{2}\right)$ was detected during the course of the reaction. 


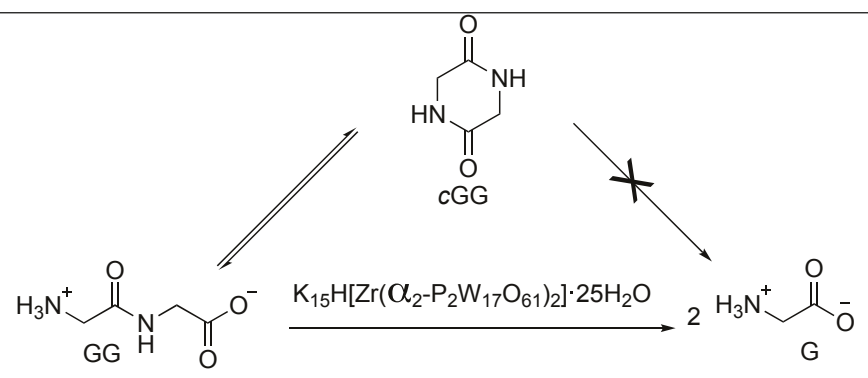

Figure 12. Peptide hydrolysis catalyzed by a polyoxometalate complex.

Recently, Vogt et al. utilized the MOF-808, a Zr(IV)-based metal-organic complex for the hydrolysis of the peptide bond in a wide range of peptides and proteins such as hen egg white lysozyme (HEWL) under physiological conditions [81,82]. The MOF-88 is heterogeneous in nature and is thus a reusable catalyst. The experimental studies and calculations showed that MOF- 808 hydrolyzed the Gly-Gly bond by the formation of the active complexes with two adjacent $\mathrm{Zr}(\mathrm{IV})$ centers of the $\left\{\mathrm{Zr}_{6} \mathrm{O}_{8}\right\}$ core by coordination with amide oxygen and the amine nitrogen atoms. The catalytic efficiency of MOF-808 towards the hydrolysis of peptides is dependent on the bulkiness and nature of the side chain amino acid residues. Dipeptides with small or hydrophilic residues undergo cleavage faster as compared to those with bulky and hydrophobic residues.

\section{Asp-Xaa Selective Hydrolysis of the Peptide Bond by Oxo-Metal Ions}

It has been reported that oxomolybdate(VI) catalyzes the cleavage of various peptides containing aspartic acid (Asp) with cleavage at the C-terminal side of the Asp residue. This is due to the attack of the side chain of the Asp on the amidic carbonyl which is activated by the coordination with oxomolybdate(VI), resulting in the formation of the five-membered ring and simultaneous cleavage of the amide bonds (Figure 13) [81,82].

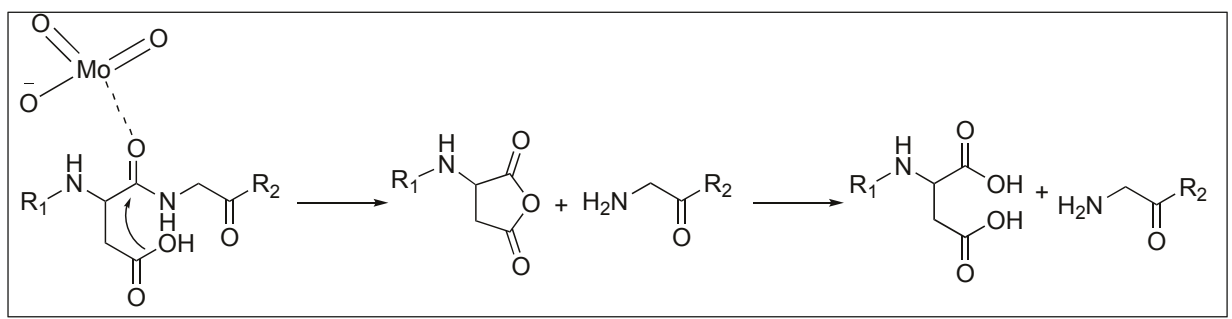

Figure 13. Oxomolybdate(VI) catalyzed cleavage of peptide bonds.

\section{Various Other Metal Complexes}

The Westheimer and Trapmann groups showed that the metal complexes containing Co(II), $\mathrm{Cu}(\mathrm{II})$, and $\mathrm{Ni}(\mathrm{II})$ ions cleave various dipeptides [83,84]. Out of various metal complexes, the $\mathrm{Co}(\mathrm{III})$ complex $\left[\mathrm{Co}(\text { trien }) \mathrm{OH}\left(\mathrm{H}_{2} \mathrm{O}\right)\right]^{2+}$ is one of the widely studied metal ion complexes and carried out the rapid hydrolysis of the peptide bond [85-88]. The detailed mechanistic investigation showed that first, the metal complex $\left[\mathrm{Co}(\text { trien }) \mathrm{OH}\left(\mathrm{H}_{2} \mathrm{O}\right)\right]^{2+}$ forms a tertiary complex with a dipeptide by the replacement of an equatorially coordinated water molecule in the octahedral Co(III) complex by the N-terminal amine of the peptide. This mode of coordination brings the axially bound hydroxyl group in close proximity to the peptide carbonyl resulting in the hydrolysis of the peptide bond (Figure 14). 


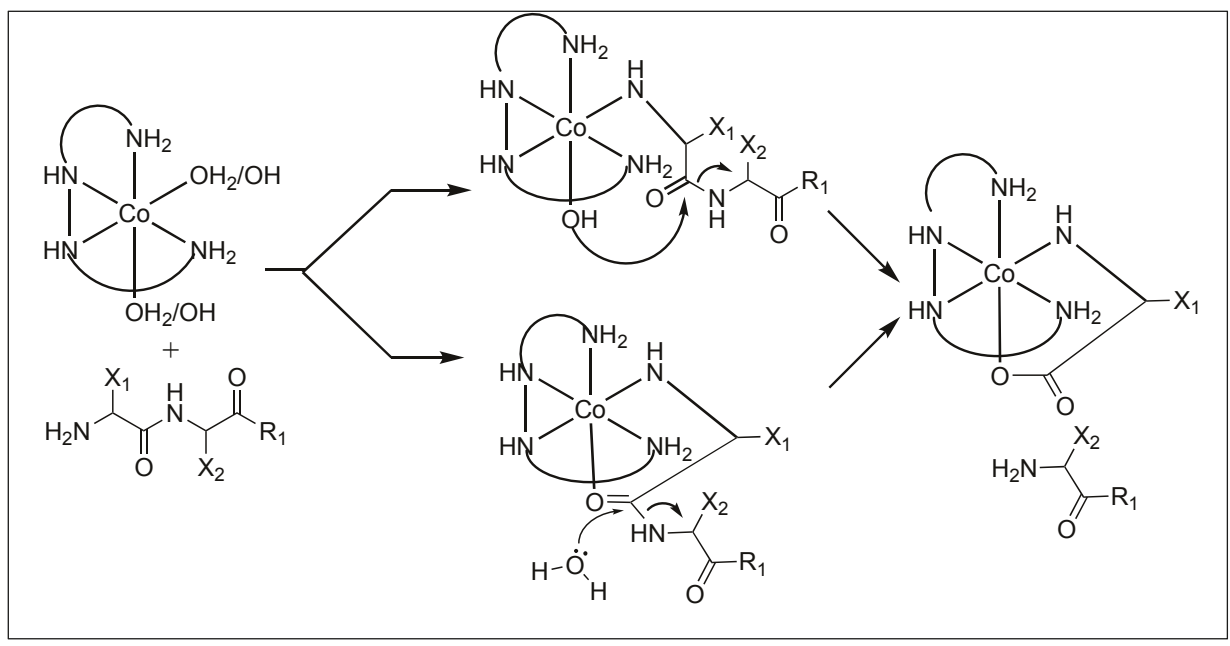

Figure 14. Co(III) Complex catalyzed peptide hydrolysis.

Anchoring at Cys Side Chains: Molybdocene

Erxleben et al. showed that molybdocene dichloride, $\mathrm{Cp}_{2} \mathrm{MoCl}_{2}$, cleaves the amide bond at the C-terminal side of cysteine to generate Cys-Gly from Gly-Cys-Gly [89]. The cleavage is highly selective for the $\mathrm{C}$-side of Cys because it leads to the formation of the favorable six-membered ring. The mechanism of this reaction is illustrated in Figure 15 [89].

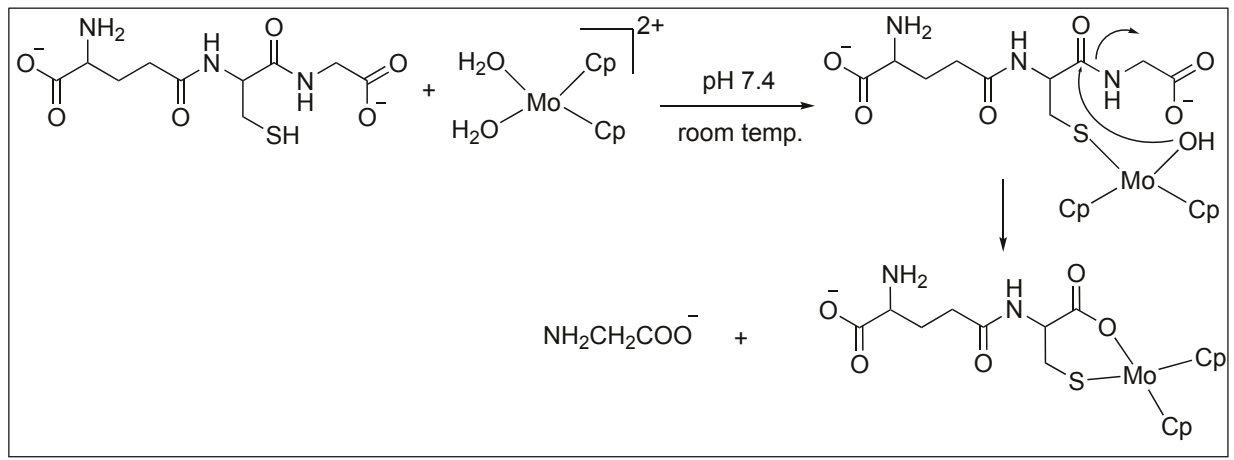

Figure 15. Mo catalyzed peptide hydrolysis.

3.1.3. Anchoring at Met, His, and Cys Side Chains: Palladium(II) Complexes for the Cleavage of Amide Bonds

Figure 16 shows the examples of platinum(II) and palladium(II) complexes which are known for the cleavage of amide bonds under mild conditions. These platinum(II) and palladium(II) complexes attach to the sulfur atom of cysteine, $S$-methylcysteine, and methionine in peptides, thus, promoting the selective cleavage of the unactivated amide bonds at the C-side of the amino acid (Figure 16) [90-92]. 


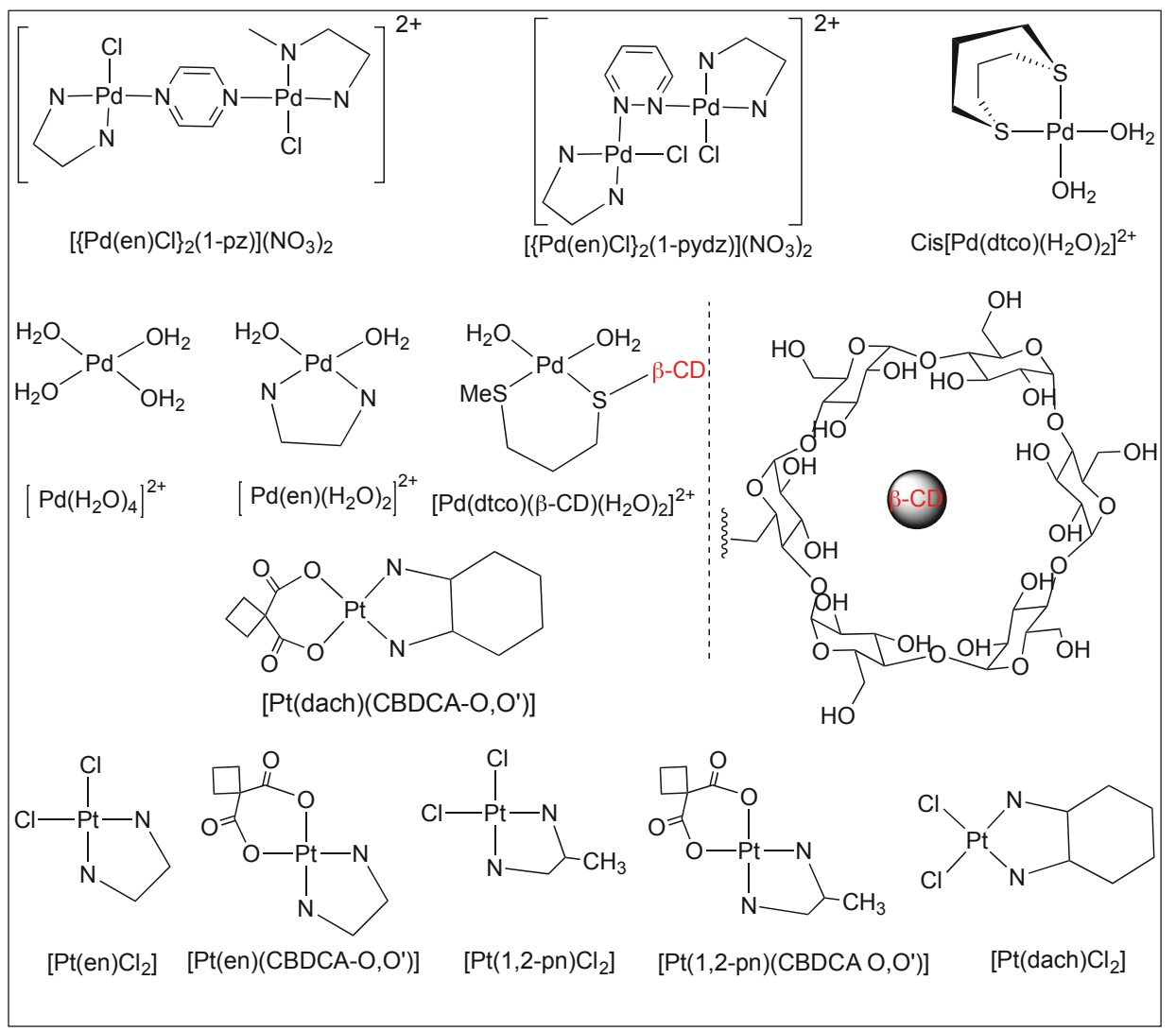

Figure 16. Pd and Pt complexes for activation of amide bonds.

Pyrazine and Pyridazine Palladium(II)-Aqua Dimers

The complete hydrolysis of the amide bonds of peptides $\mathrm{N}$-acetylated-L-histidylglycine (Ac-L-His-Gly) and -L-methionylglycine (Ac-L-Met-Gly) at the C-terminal side of Met and His in the $\mathrm{pH}$ range $2.0<\mathrm{pH}<2.5$ was catalyzed by two dinuclear palladium(II) complexes, [ $\left.\{\mathrm{Pd}(\mathrm{en}) \mathrm{Cl}\}_{2}(\mathrm{l}-\mathrm{pz})\right]\left(\mathrm{NO}_{3}\right)_{2}$ and $\left[\{\mathrm{Pd}(\mathrm{en}) \mathrm{Cl}\}_{2}(\mathrm{l}-\mathrm{pydz})\right]\left(\mathrm{NO}_{3}\right)_{2}$ at $37^{\circ} \mathrm{C}$. The hydrolysis is assisted by the formation of complexes between the side chains of methionine and histidine and the metal complexes (Figure 17) [93-95].

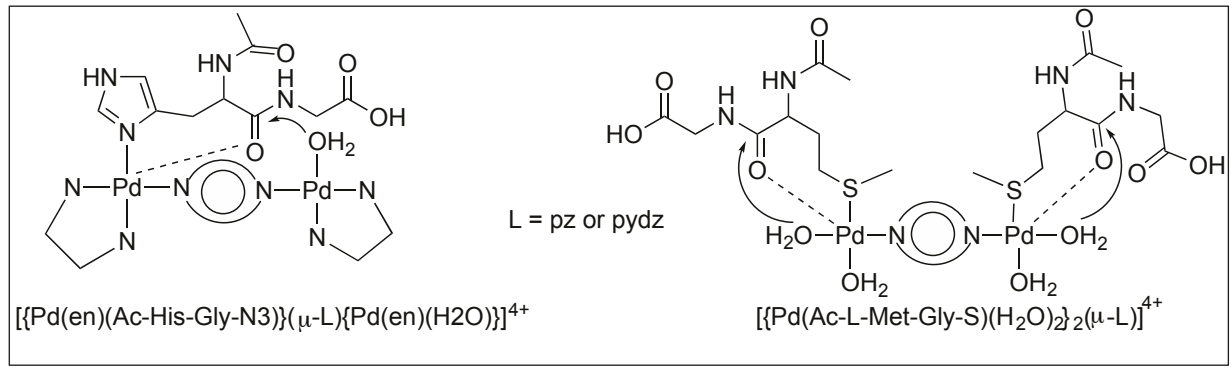

Figure 17. Pd(II) aqua dimers. 
Platinum Complexes for the Cleavage of the Amide Bond

${ }^{1} \mathrm{H}-\mathrm{NMR}$ investigation of the cleavage reactions between various $\mathrm{Pt}(\mathrm{II})$ complexes of the type $\left[\mathrm{Pt}(\mathrm{L}) \mathrm{Cl}_{2}\right]$ and $\left[\mathrm{Pt}(\mathrm{L})\left(\mathrm{CBDCA}-\mathrm{O}, \mathrm{O}^{\prime}\right](\mathrm{L}=\right.$ ethylenediamine-en; $( \pm)$-trans-1,2-diaminocyclohexane-dach; $( \pm)-1,2$-propylenediamine-1,2-pn and CBDCA is the 1,1-cyclobutanedicarboxylic anion) and the $\mathrm{N}$-acetylated-L-methionylglycine dipeptide (MeCOMet-Gly) were reported by Djuran and co-workers [93-96]. The comparison of the rate studies of these Pt complexes for the cleavage of $\mathrm{N}$-acetylated-L-methionylglycine dipeptide (MeCOMet-Gly) showed that the rate of hydrolysis decreases with the increase in the steric bulk of the CBDCA and chlorido Pt(II) complexes (en > 1,2-pn $>$ dach) (Figure 18).

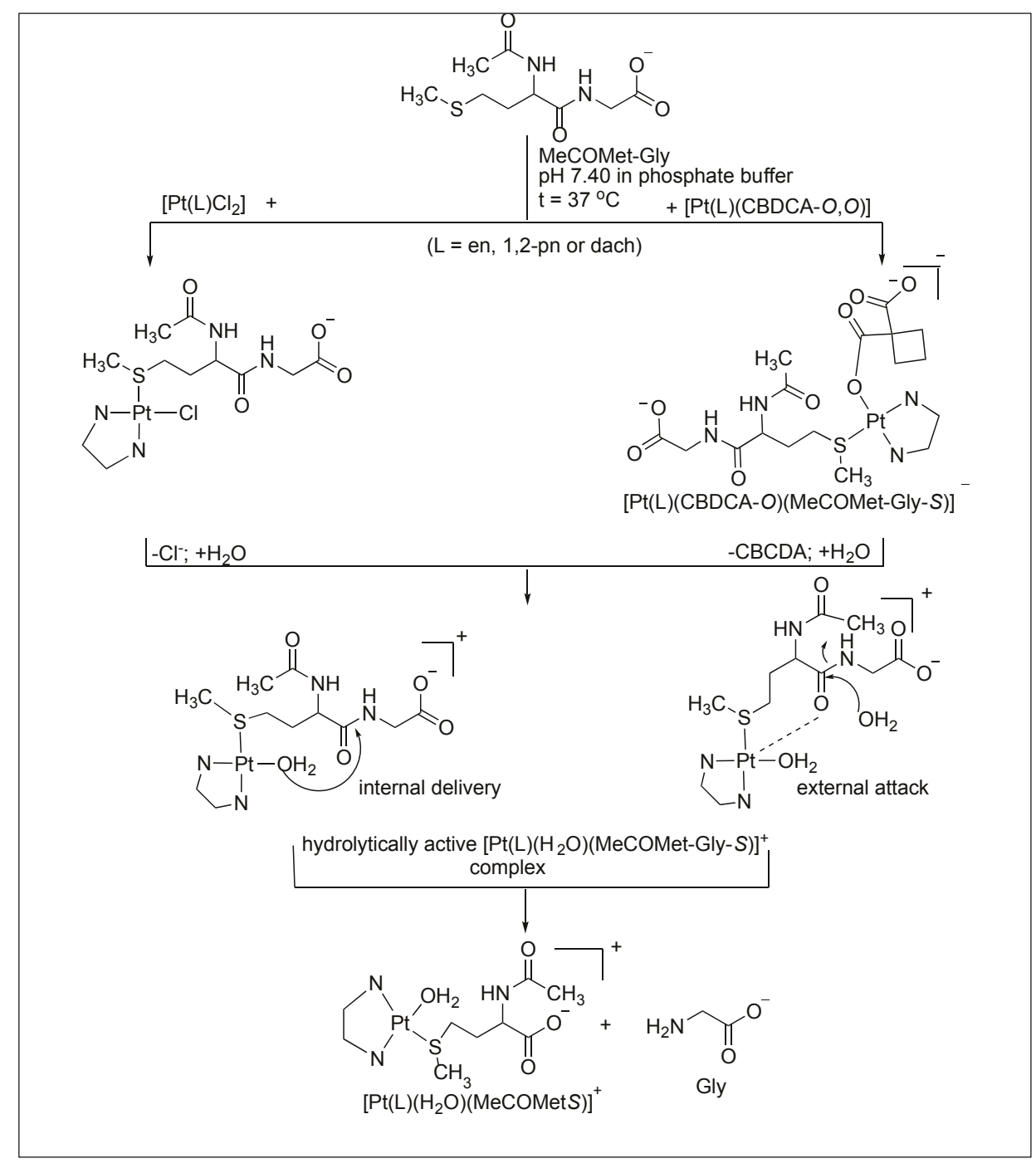

Figure 18. Hydrolytic reactions of Pt complexes. 
Later, these $\left[\mathrm{Pd}(\mathrm{en})\left(\mathrm{H}_{2} \mathrm{O}\right)_{2}\right]^{2+}$ and $\left[\mathrm{Pt}(\mathrm{en})\left(\mathrm{H}_{2} \mathrm{O}\right)_{2}\right]^{2+}$ complexes were used for the cleavage of tetrapeptide (MeCOMet-Gly-His-GlyNH $\mathrm{H}_{2}$ ) in the $\mathrm{pH}$ range of $1.5-2.0$ and at $60{ }^{\circ} \mathrm{C}$. The study showed that these complexes are highly selective for the cleavage of the amide bond at the C-terminal side of methionine (Figure 19) [97]. The high selectivity for the Met-Gly amide bond compared to the other amides is due to the high affinity of the $\mathrm{Pt}(\mathrm{II})$ and $\mathrm{Pd}(\mathrm{II})$ ions for the sulfur atom on Met. Two different mechanisms for the cleavage of tetrapeptide at the C-terminus of Met residue by Pd complexes have been proposed. One involves the direct coordination of the Pd complex with Met followed by the cleavage. The second involves the formation of macrochelate with both His and Met followed by the hydrolysis of the amide bond.

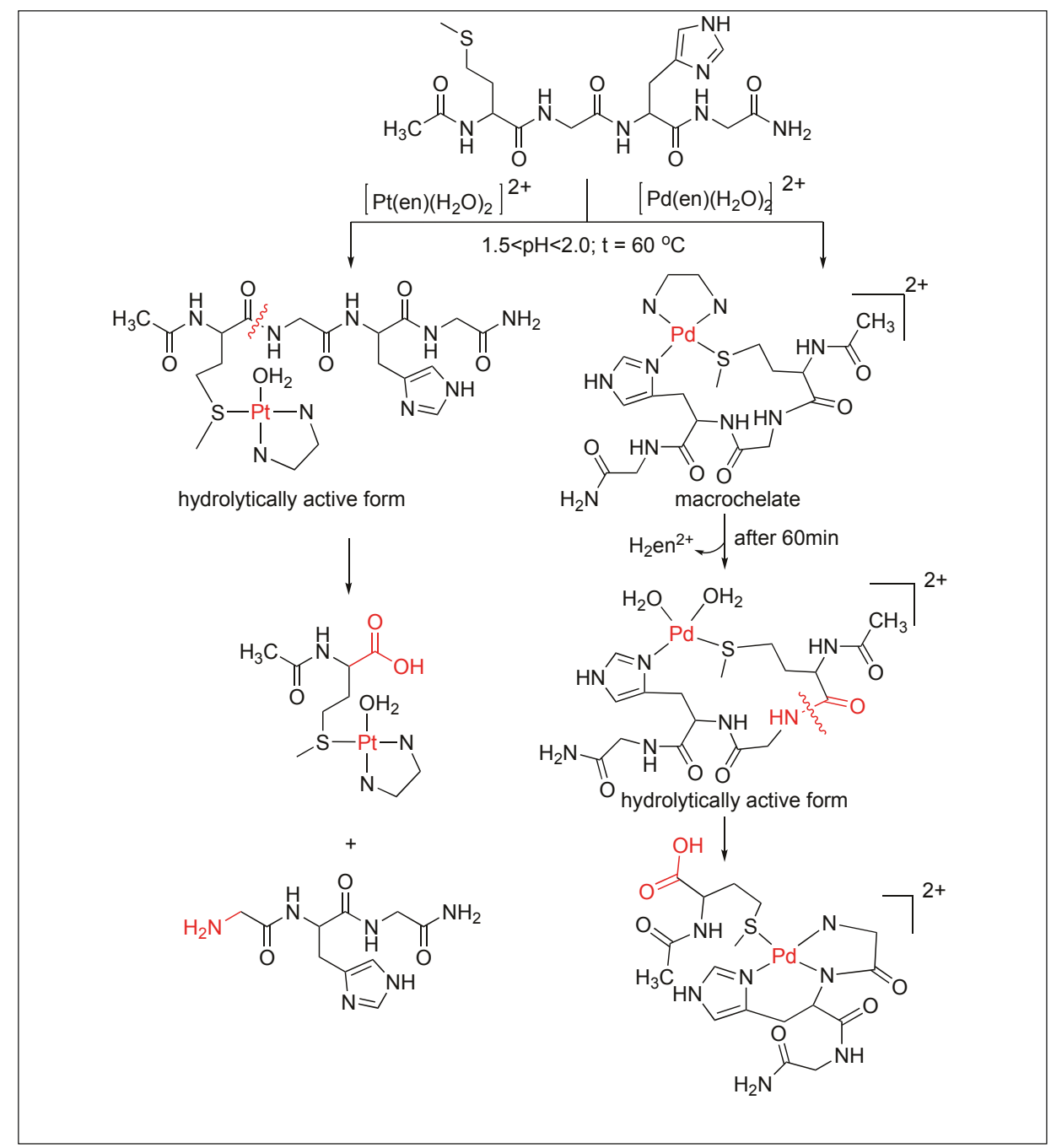

Figure 19. Hydrolytic reactions of $\mathrm{Pd}$ and $\mathrm{Pt}$ complexes.

$\mathrm{Cis}\left[\mathrm{Pd}(\mathrm{dtco})\left(\mathrm{H}_{2} \mathrm{O}\right)_{2}\right]^{2+}$ leads to the selective cleavage of the amide bond at the C-terminal of Met (Figure 20) [98]. Coordination of the metal complex promotes hydrolysis by two different mechanisms. The first involves the formation of a six-membered complex by the chelation of a metal atom with 
both the sulfur of Met and the carbonyl of the amide bond, thus, activating the amide bond toward cleavage by an external attack from water. This mechanism is favorable in the case of platinum(II) promoters and substrates with smaller anchoring side chains. Second, the mechanism involves the chelation of metal with sulfur only, followed by the internal attack of water molecules to the amide bond. This mechanism is favorable with palladium(II) promoters and substrates with longer anchoring side chains (Figure 20) [98].

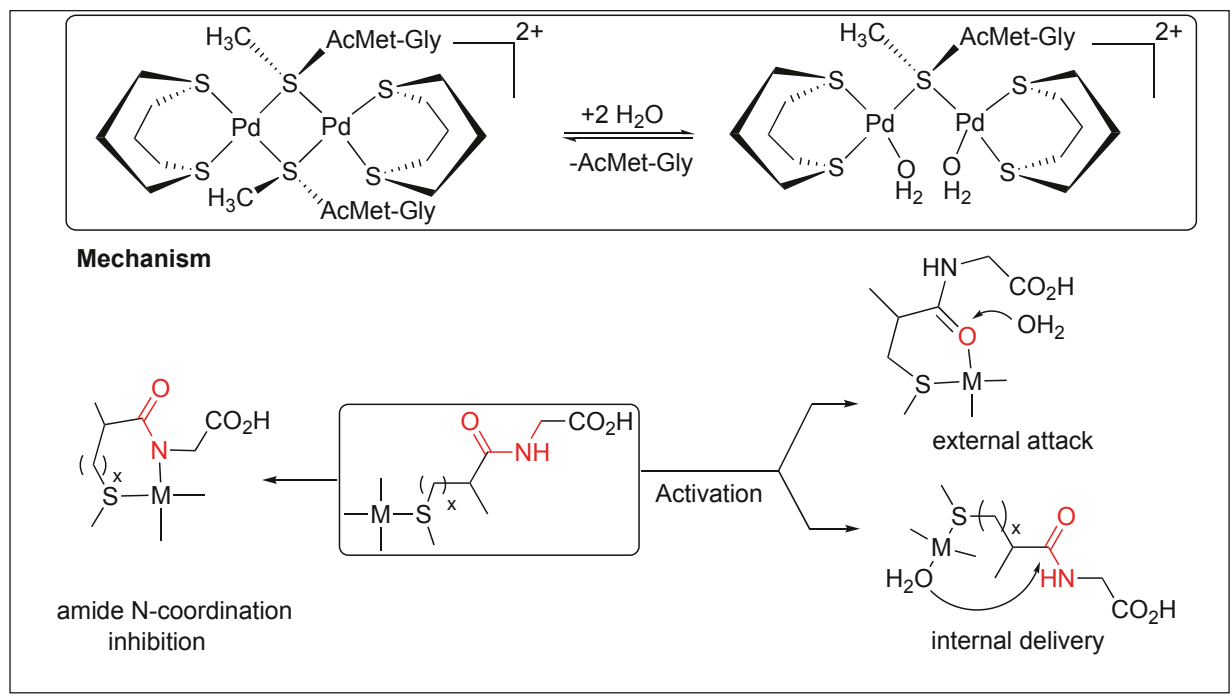

Figure 20. $\left[\mathrm{Pd}(\mathrm{dtco})\left(\mathrm{H}_{2} \mathrm{O}\right)_{2}\right]^{2+}$ mediated hydrolysis of amide bond.

Kostic et al. utilized the $\mathrm{Pd}\left(\mathrm{H}_{2} \mathrm{O}\right)_{4}$ complex for the cleavage of decapeptide (Ac-AKYGGMAARA) under acidic conditions ( $\mathrm{pH}$ 2.3) at $60{ }^{\circ} \mathrm{C}$ [99]. The cleavage of the peptide bond took place at the Gly residue next to Met on the $\mathrm{N}$-terminal side and generated two fragments after $24 \mathrm{~h}$. $\operatorname{The} \operatorname{Pd}\left(\mathrm{H}_{2} \mathrm{O}\right)_{4}$ complex binds to the $\mathrm{S}$ of the Met residue leading to the formation of two different complexes under the reaction conditions (active and inactive), which are in equilibrium with each other (Figure 21). The active complex led to the formation of two fragments through hydrolysis but the inactive complex did not undergo any hydrolysis. The coordination of two amide nitrogen atoms in the inactive complex quench the Lewis acidity of $\operatorname{Pd}(\mathrm{II})$, thus no hydrolysis was observed.

Next, Kostic et al. used this metal complex $\operatorname{Pd}\left(\mathrm{H}_{2} \mathrm{O}\right)_{4}$ for the cleavage of the amide bond under neutral conditions in different peptide substrates such as Gly-Met, Sar-Met, and Pro-Met. This study showed that the rate of hydrolysis at a neutral $\mathrm{pH}$ is slow compared to that at a low $\mathrm{pH}$ [44]. Interestingly, the complete cleavage of Sar-Met and Pro-Met was observed but no cleavage was observed for Gly-Met at a neutral $\mathrm{pH}$. This is due to the difference in the equilibrium position of the Gly-Met compared to that of Pro-Met. In Gly-Met, equilibrium is more shifted towards the inactive form at neutral $\mathrm{pH}$ due to the ability of Gly to form a strong coordinate bond with Pd. In contrast, for the peptide containing Sar-Met or Pro-Met, the equilibrium is shifted towards the hydrolytically active form because they are unable to form a strong coordination with Pd due to the tertiary amide of the Pro or Sar residue (Figure 22). 


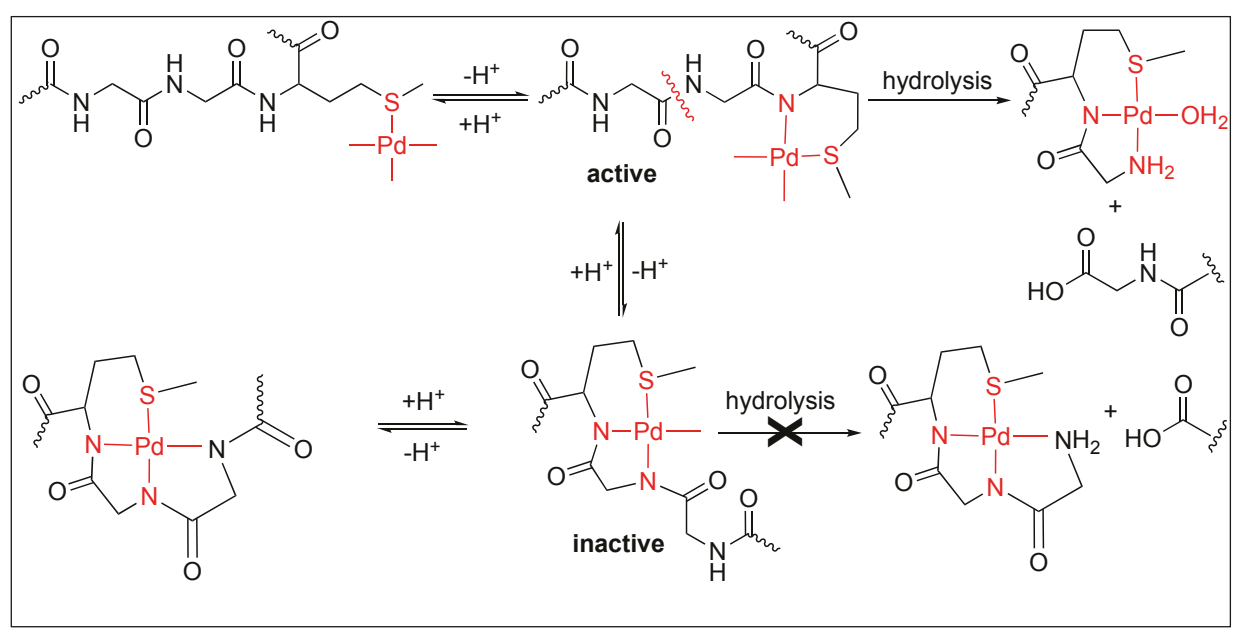

Figure 21. $\left[\mathrm{Pd}\left(\mathrm{H}_{2} \mathrm{O}\right)_{4}\right]^{2+}$ mediated hydrolysis of amide bond.

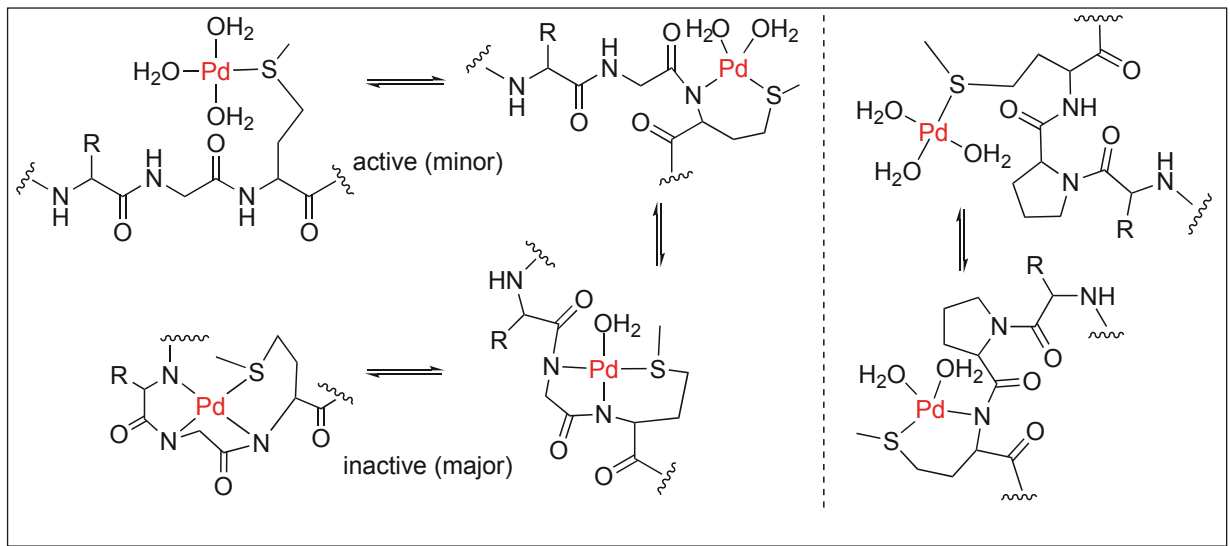

Figure 22. Pd triggered $\mathrm{pH}$ dependent hydrolysis of amide bond.

In the case of Gly-Pro-Met, the hydrolysis of the amide bond can take place either through the external or internal attack of water molecules depending upon the cis/trans conformation adopted by proline (Figure 23). The ROESY NMR studies showed that the hydrolysis of the Gly-Pro-Met peptide takes place by the external attack of water on trans-Gly-Pro [100].

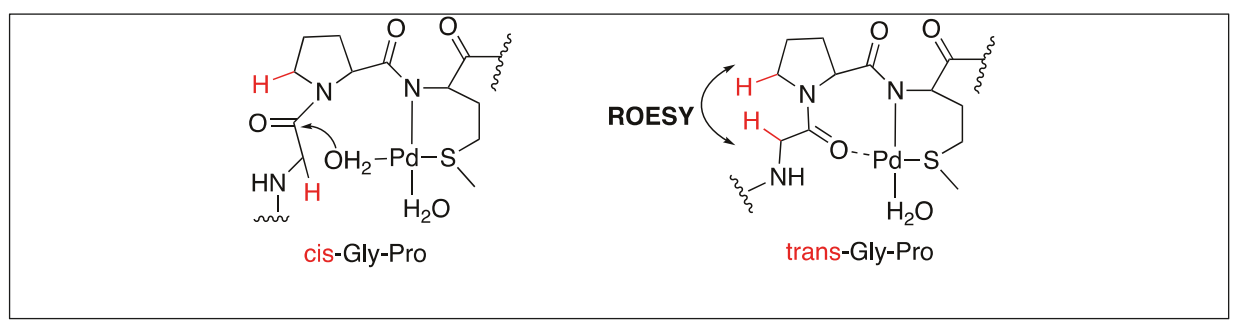

Figure 23. Cis/Trans conformations of Pd complexes. 
Overall, the $\mathrm{Pd}\left(\mathrm{H}_{2} \mathrm{O}\right)_{4}$ complex is residue selective under acidic conditions and cleaves the second amide bond upstream from the Met residue. However, the same complex is sequence-specific under neutral conditions and cleaves the amide bond only at the Pro-Met or Sar-Met residue with no cleavage observed at Gly-Met peptide (Figure 24).

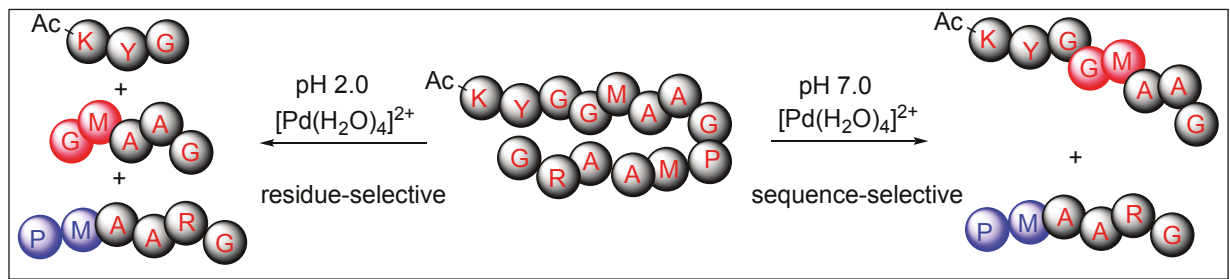

Figure 24. $\mathrm{pH}$ selective Pd catalyst for the hydrolysis.

Next, the same group utilized the $\mathrm{Pd}(\mathrm{en})\left(\mathrm{H}_{2} \mathrm{O}\right)_{2}$ complex for the acidic hydrolysis of the B-chain of bovine insulin containing two histidine residues. These complexes promoted the cleavage of the second amide bond upstream from histidine. The detailed mechanistic analysis showed the selective cleavage by the coordination of the Pd complexes with the histidine side chain and amidic nitrogen followed by the internal attack of water on the amide bond (Figure 25) [101].

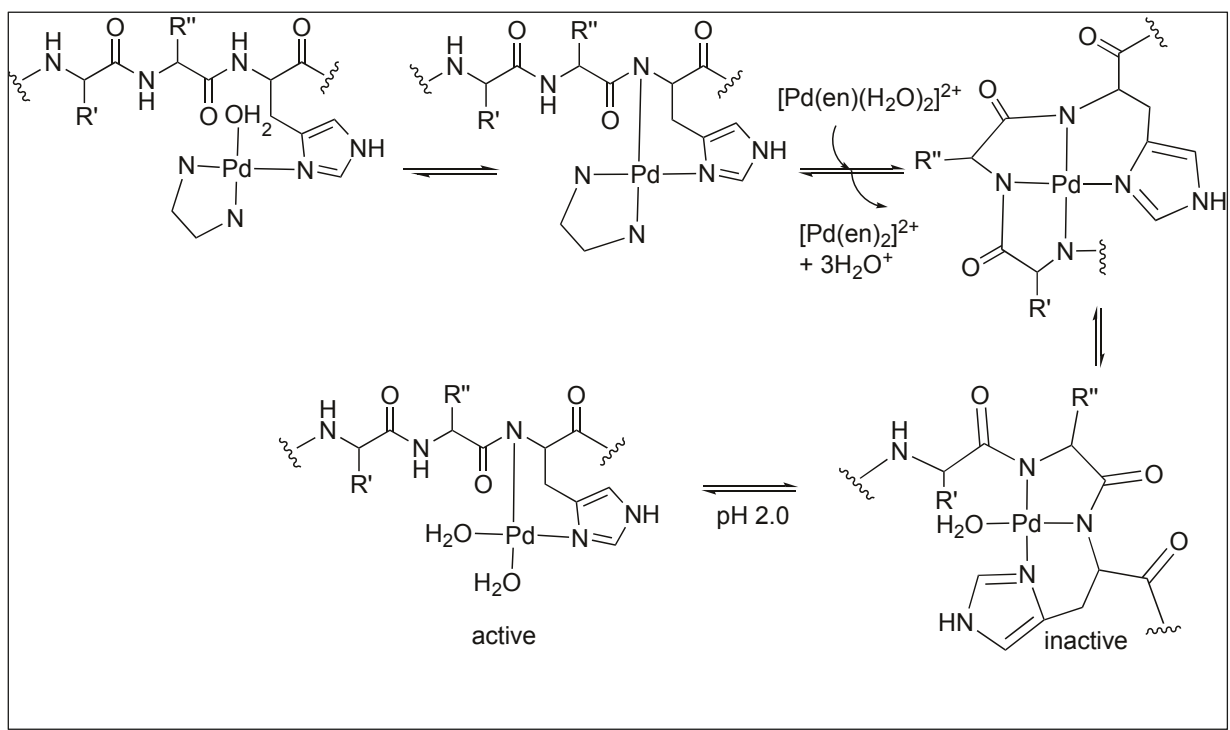

Figure 25. Acidic hydrolysis of amide bonds.

Next, they used the $\beta$-cyclodextrin Pd complex for the cleavage of the amide bond at the first amide bond upstream from the Pro-Phe sequence. The role of the $\beta-C D$ complex was to bind to the hydrophobic residue (Phe) in an aqueous medium followed by the activation of the amide carbonyl group by the metal coordination, and the attack by the external water molecule leading to the cleavage of the amide bond (Figure 26) [102]. 


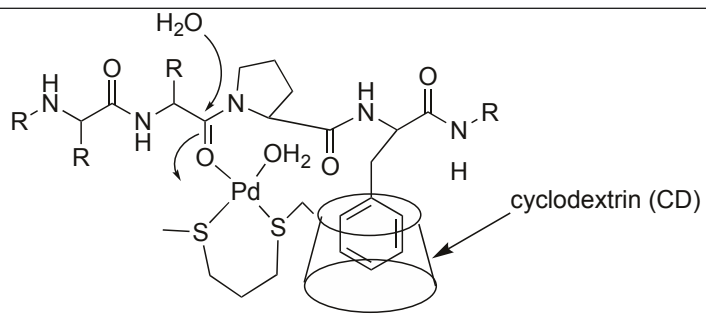

Figure 26. $\beta$-Cyclodextrin Pd-complex.

\subsubsection{Artificial Metal Proteases}

Suh et al. designed metal complexes for the cleavage of amide bonds in proteins at specific locations [103-107]. These metal complexes are highly selective with their protein partners similar to some natural proteases. They also demonstrated that the catalytic rate of hydrolysis increased by the formation of the complex between the substrate and catalyst. This is achieved by increasing the multinuclear metal centers, which provide extra metal centers as substrate binding sites. They showed that the rate of hydrolysis of the myoglobin protein increased with the increase in the number of metal centers in the mono (half-life for hydrolysis $24 \mathrm{~h}$, Figure 27), dinuclear (half-life for hydrolysis $3.5 \mathrm{~h}$ ), and tetranuclear metal centers (half-life for hydrolysis $1.3 \mathrm{~h}$ ) [103].

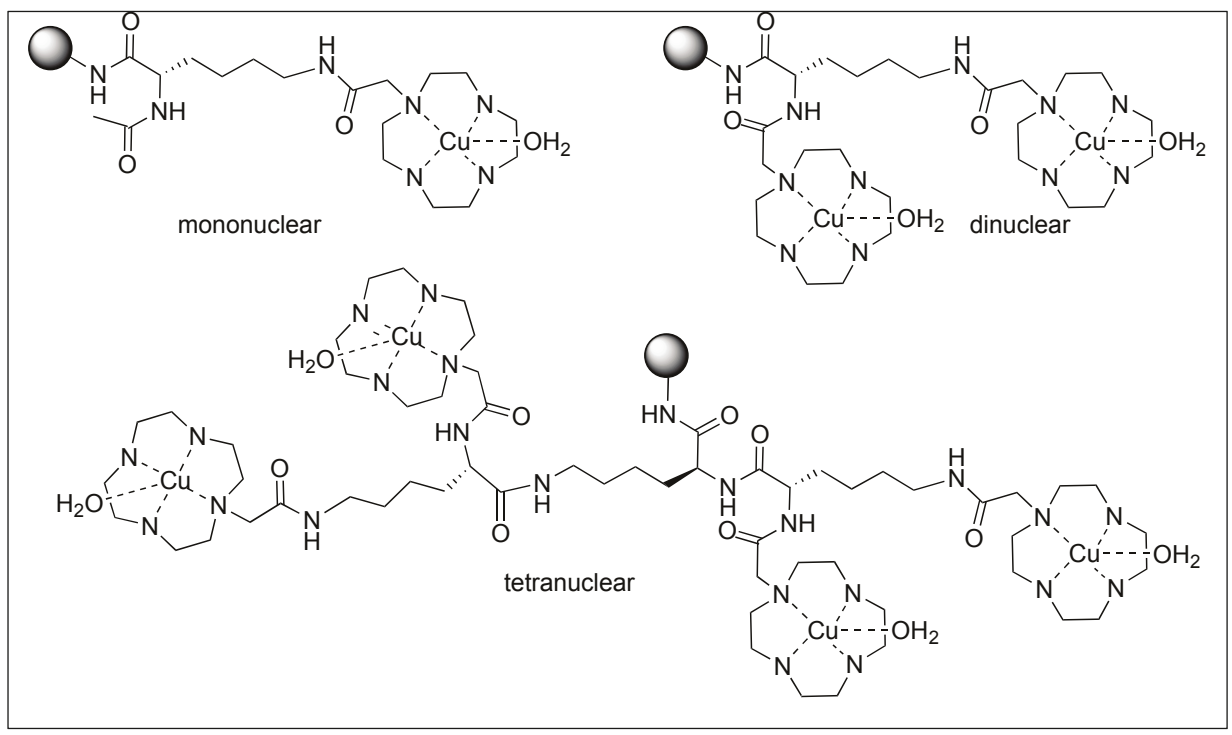

Figure 27. Artificial metal complexes with different numbers of metal centers.

They showed that the selectivity towards a specific protein was achieved by the addition of organic pendants such as peptide nucleic acid (PNA), which are responsible for selective binding to a particular protein. Overall, the goal of this research was to synthesize peptide-cleavage agents selective for the hydrolysis of pathogenic proteins responsible for Alzheimer's disease, type 2 diabetes mellitus, and Parkinson's disease. 
Aldehyde Pendant for the Cleavage of Proteins

Ammonium groups are abundant on the surface of proteins and form imine with aldehyde faster than the peptide bond cleavage and, through this process, brings the reactive metal catalytic center in close proximity to the protein/peptide chain (Figure 28). The rapid formation of imine makes the attack of the metal center on the peptide bond an intramolecular process, thus, increases the rate of hydrolysis. Based on this concept, several artificial metalloproteases have been developed by incorporating an aldehyde handle close to the metal center and has been successfully been applied for the faster cleavage of peptide bonds [104].

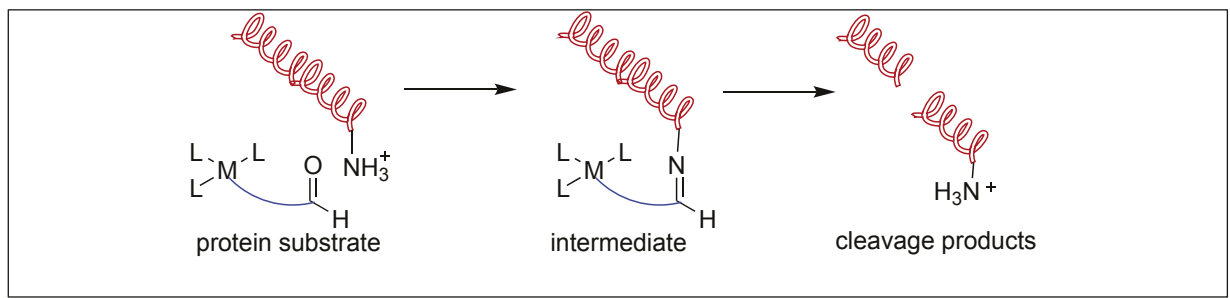

Figure 28. Aldehyde pendant mediated cleavage of peptide bonds.

Mb-Selective Artificial Protease

The catalyst for the cleavage of myoglobin $(\mathrm{Mb})$ was designed by attaching the cyclen metal complex containing $\mathrm{Cu}$ (II) or $\mathrm{Co}(\mathrm{III})$ to the peptide nucleic acid (PNA) monomers, which act as binding sites for the Mb (Figure 29) [105]. Varieties of linkers were inserted between the PNA binding site and the catalytic cyclen site for the formation of Mb-cleaving catalysts. MALDI-TOF MS showed that the cleavage of the peptide backbone chain of $\mathrm{Mb}$ takes place at Leu89-Ala90. Various chelating ligands were tested for determining the activity of the Mb-cleaving catalyst but only cyclen and its triaza-monooxo analog showed efficient catalytic activity.

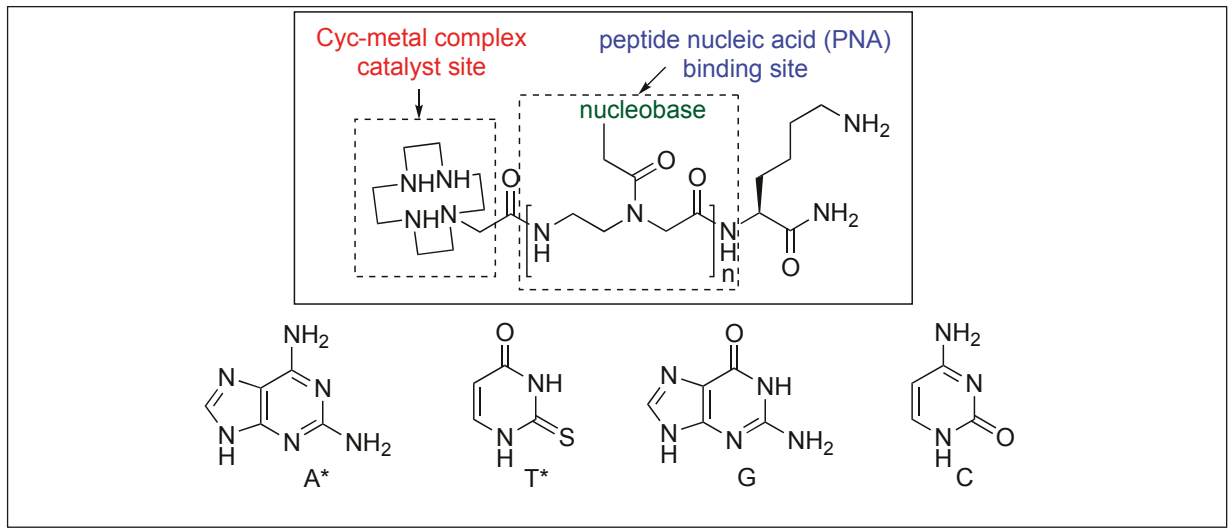

Figure 29. Catalyst design for protein cleavage.

Mechanism: The first step involves the binding of the carbonyl group of the amide to the Co(III) metal center to form a CS complex (Figure 30). The selectivity of one amide carbonyl over the rest of the amidic carbonyls is based on the other half of the catalyst, which is responsible for the recognition of a particular protein and a particular site. This Co(III) carbonyl coordination activates the amidic carbonyl for a nucleophilic attack by the hydroxide ion on the metal center, resulting in the formation of tetrahedral intermediate T. This is followed by the collapse of the tetrahedral intermediate (T), 
resulting in the breakage of the amide bond to generate a peptide amine and corresponding peptide acid [106].

Suh and co-workers showed that the cleaving capability of the $\mathrm{Co}(\mathrm{III}) / \mathrm{Cu}(\mathrm{II})$ complexes of cyclen increased by the replacement of one nitrogen atom of cyclen with an oxygen atom. The Co(III)-oxacyclen complexes (1-oxa-4,7,10-triazacyclododecane Co(III)) cleaved the proteins such as BSA, HEWL, Mb, and bovine serum-globulin with a 4-14 times higher catalytic efficiency compared to the Co(III)-cyclen complexes [106].

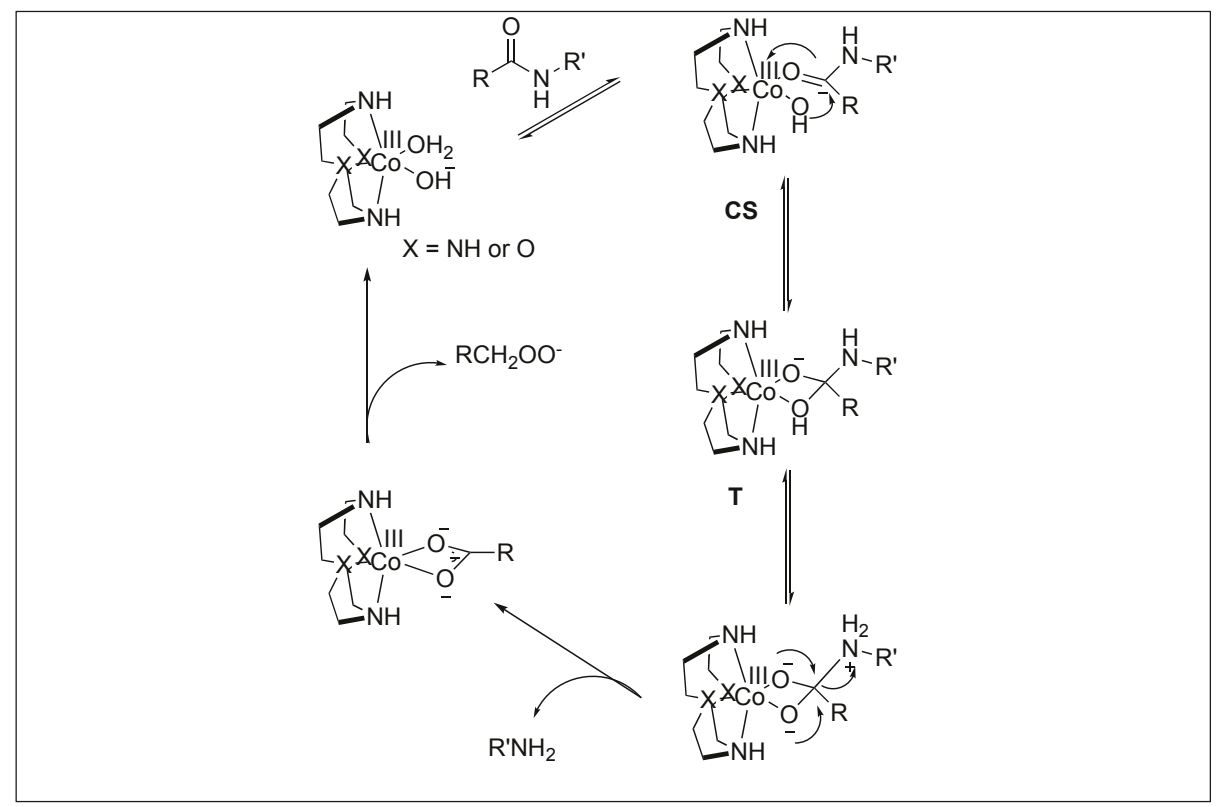

Figure 30. Mechanism of Co(III)-metal complexes.

\section{PDF-Selective Artificial Protease}

The catalyst for the cleavage of the protein, peptide deformylase (PDF), was obtained in a selective manner by screening the library of catalysts (Figure 31). The catalyst cleaved the backbone peptide chain of the PDF at position Gln152-Arg153. Docking simulations showed that multiple interactions were responsible for the formation of a complex between the catalyst and PDF. Fifteen other proteins were examined, but none of them underwent cleavage by this $\mathrm{Co}$ (III) complex, which further confirmed the highly selective nature of these metal complexes [107].

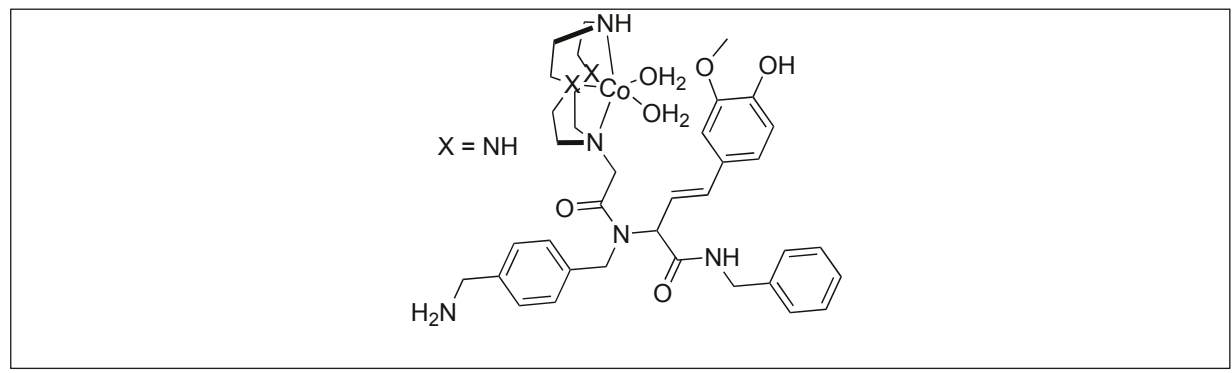

Figure 31. Metal-assisted catalyst for PDF. 


\section{AmPs-Selective Artificial Protease}

AmPs are amyloidogenic peptides or proteins which lack active sites and are related to diseases such as Alzheimer's and type 2 diabetes. Based on the above concept, Suh et al. synthesized various other metal complexes for the selective cleavage of amide bonds in these proteins. The main advantage of this work is that such amyloidogenic proteins cannot be targeted by conventional approaches due to the lack of an active site (Figure 32) [108-110].

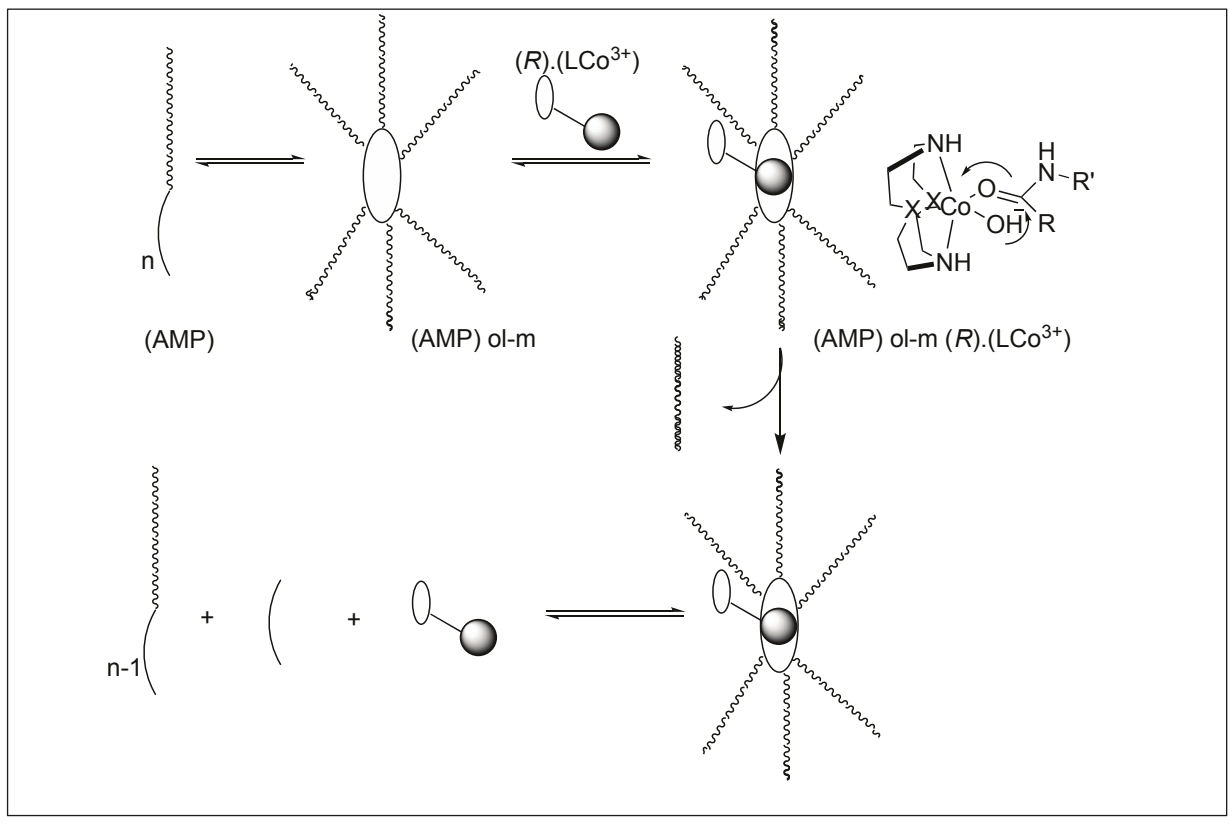

Figure 32. Metal complexes for the cleavage of amyloidgenic peptides.

Soares et al. utilized mononuclear copper(II) complexes $\left[\mathrm{Cu}\left(\mathrm{HL}^{1}\right) \mathrm{Cl}_{2}\right]$ and $\left[\mathrm{Cu}\left(\mathrm{L}^{1}\right) \mathrm{Cl}\right]$ for the cleavage of unactivated amide bonds of the proteins bovine serum albumin (BSA) and Taq DNA polymerase, under mild $\mathrm{pH}$ and temperature conditions (Figure 33). The cleavage occurred at the specific site on the solvent- exposed portions of the protein to generate particular proteolytic fragments [111].

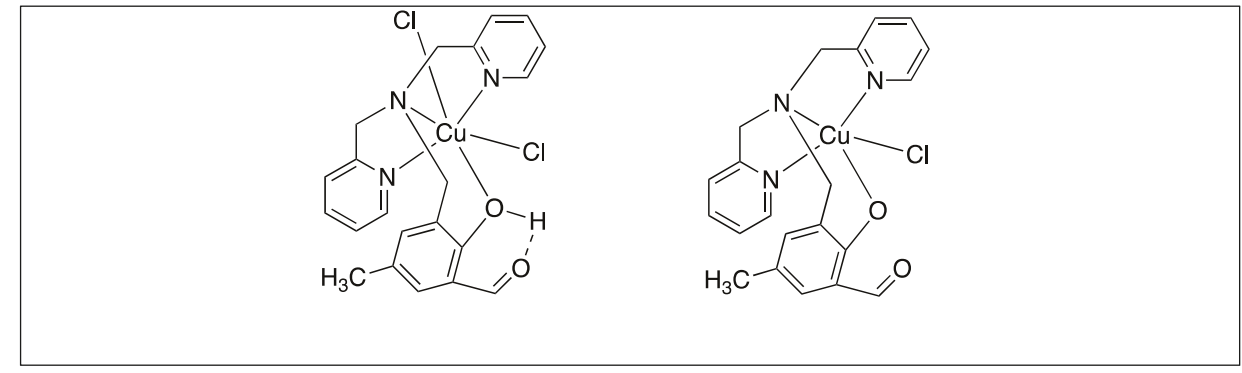

Figure 33. Cu complexes for activation of amide bonds. 


\subsection{The Non-Lewis Acid Reaction Mechanisms Based on the $N \rightarrow O$ Rearrangement}

In some cases, metal catalysts showed a high rate of hydrolysis of the peptide backbone chain at the $\mathrm{N}$-terminus of the serine and threonine residues. Such a cleavage was catalyzed by the $\mathrm{N} \rightarrow \mathrm{O}$ rearrangement and does not employ the Lewis acid properties of the metal atom. Based on the proposed mechanism, the first step involves the formation of the $\mathrm{Ni}$ (II) complex with $4 \mathrm{~N}$ of the backbone amide chain and the side chain of the His residue with the (Ser/Thr)-Xaa-His sequence (Figure 34). The second step involves the $\mathrm{N} \rightarrow \mathrm{O}$ rearrangement from the side chain of the Ser or Thr that transfers the N-terminal R1 moiety from the peptide bond to form an ester bond. This is followed by the hydrolysis of the resulting ester, leading to the formation of two reaction products, the R1 peptide acid and the $\mathrm{Ni}(\mathrm{II})$ complex with the peptide [112,113].

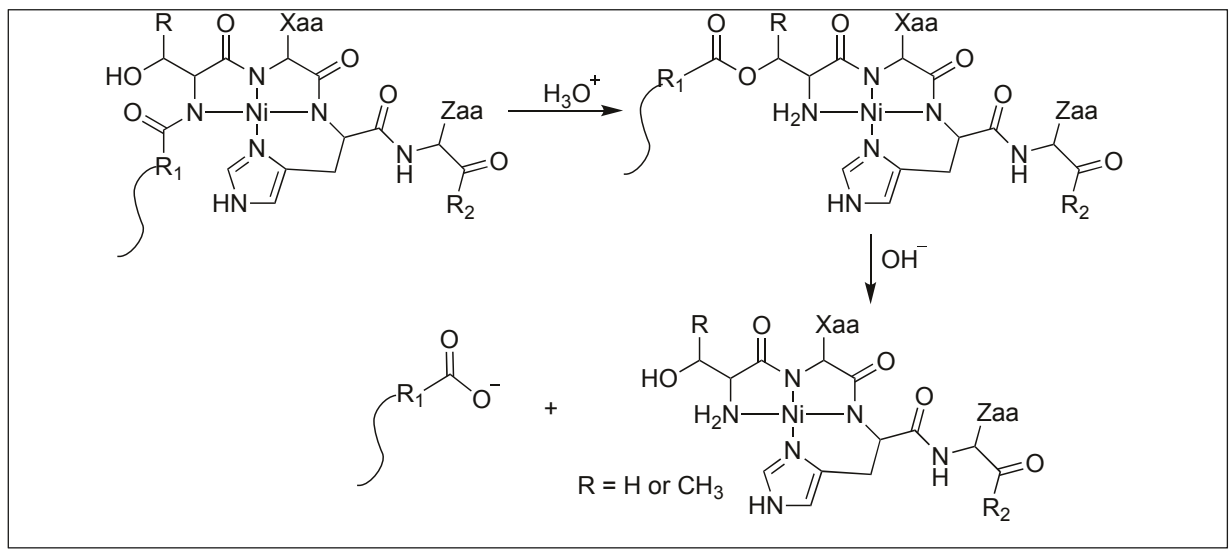

Figure 34. Non lewis acid mediated N, O Acyl rearrangement.

Scandium(III) Triflate-Promoted Serine/Threonine Selective Peptide Bond Cleavage

Kanai et al. reported the hydrolysis of the peptide bond at the N-terminus of Ser/Thr residue by using scandium triflate. This chemical cleavage relies on Sthe c triflate mediated $\mathrm{N}$ to $\mathrm{O}$ acyl rearrangement followed by the subsequent hydrolysis of the ester by heating it at $80-100{ }^{\circ} \mathrm{C}$ (Figure 35). Complete hydrolysis took place in 18-20 h. The authors have used this approach for the cleavage of various peptides including posttranslationally modified (PTM) peptides and the cleavage of native protein A $31-42$, which is closely related to Alzheimer's disease [114].

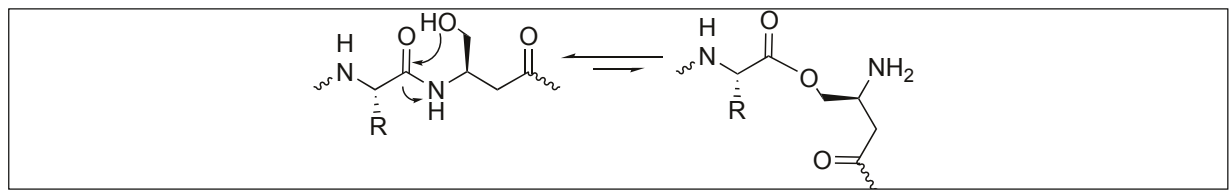

Figure 35. N, O Acyl rearrangement.

\section{Organic Molecules for Activation of Amide Bonds}

We have summarized different kinds of nonmetal-based methods, their mechanisms of hydrolysis of unactivated peptide bonds and the point of cleavages in Table 3. 
Table 3. Organic molecules based hydrolysis of peptide bonds.

\begin{tabular}{|c|c|c|c|c|}
\hline Entry & Organic Molecules & Method of Hydrolysis & Point of Cleavage & Ref. \\
\hline 1 & $\begin{array}{c}\text { Phenyl } \\
\text { isothiocyanate }\end{array}$ & $\begin{array}{l}\text { Through } 5 \text { membered cyclic } \\
\text { phenylisothiocyanate intermediate }\end{array}$ & $\begin{array}{l}\text { N-terminal side } \\
\text { of peptide }\end{array}$ & [115] \\
\hline 2 & Cyanogen bromide & Through 5 membered iminolactone & C-terminal side of Met & [116] \\
\hline 3 & $\begin{array}{l}\text { 2-Nitro-5-thiocyano } \\
\text { benzoic acid }\end{array}$ & Through 5 membered thialactone & N-terminal side of Cys & [117] \\
\hline 4 & 2-iodosobenzoic acid & Through iminospirolactone & C-terminal side of Trp & {$[118,119]$} \\
\hline 5 & TBC & Through Oxindole & C-terminal side of Trp & {$[118,119]$} \\
\hline 6 & $\mathrm{~N}$-amidination & Through 5 membered cyclic amidine ring & $\begin{array}{l}\mathrm{N} \text {-terminal side } \\
\text { of peptide }\end{array}$ & [120] \\
\hline 7 & $\begin{array}{l}\text { Protecting goups } \\
\quad \text { (Table } 4 \text { ) }\end{array}$ & Lactonization strategy & $\begin{array}{l}\text { C-terminal side } \\
\text { of peptide }\end{array}$ & [121-127] \\
\hline 8 & $\begin{array}{l}\mathrm{H}_{2} \mathrm{O}_{2} \text { responsive } \\
\text { protecting groups }\end{array}$ & Lactonization strategy & $\begin{array}{l}\text { C-terminal side } \\
\text { of peptide }\end{array}$ & [128] \\
\hline 9 & PyBroP & $\begin{array}{l}\text { Glutamic acid selective activation through } \\
\text { pyroglutamyl imide }\end{array}$ & N-terminal side of Glu & {$[129,130]$} \\
\hline 10 & DIB & $\begin{array}{l}\text { Hofmann rearrangement mediated } \\
\quad N \text {-acylurea intermediate }\end{array}$ & N-terminal side of Asn & [131] \\
\hline 11 & DSC & Cyclic urethane amide activation & $\begin{array}{l}\text { N-terminal side of Ser, } \\
\text { Thr, Cys and Glu }\end{array}$ & [132-136] \\
\hline 12 & $o$-NBnoc & $\begin{array}{l}\text { A photo responsive amide cleavage } \\
\text { through succinimide ring }\end{array}$ & C-terminal side of Asn & [137-142] \\
\hline 13 & $\begin{array}{l}\text { Cu-organo radical } \\
\text { conjugate }\end{array}$ & $\begin{array}{l}\text { Aerobic chemoselective oxidation of Ser } \\
\text { followed by oxalimide formation }\end{array}$ & N-terminal side of Ser & [143] \\
\hline 14 & $\mathrm{TFA} / \mathrm{H}_{2} \mathrm{O}$ & $\mathrm{N}$-acyl group mediated oxazolinium specie & $\begin{array}{l}\text { C-terminal side } \\
\text { of peptide }\end{array}$ & [144] \\
\hline 15 & Hydrazine hydrate & $\begin{array}{l}\text { Hydrazinolysis accelarated by addition of } \\
\text { ammonium salts }\end{array}$ & N-terminal of peptide & [145] \\
\hline 16 & $N$-Mecysteine & Through oxazolinium ion & $\begin{array}{l}\text { C-terminal side } \\
\text { of } N \text {-MeCys }\end{array}$ & [146] \\
\hline 17 & Acylated N-MeAib & Through oxazolinium ion & $\begin{array}{l}\text { C-terminal side } \\
\text { of } N \text {-MeAib }\end{array}$ & [147] \\
\hline
\end{tabular}

\subsection{N-Terminal Cleavage of Amide Bonds}

\subsubsection{Edman's Degradation}

This approach utilizes phenyl isothiocyanate for the cleavage of the peptide bond at the N-terminus. Phenyl isothiocyanate reacted with an uncharged N-terminal amino group, under mildly alkaline conditions, to form a cyclic phenylisothiocyanate derivative, which undergoes cleavage as a thiazolinone derivative under acidic conditions (Figure 36). We proposed that the activation of an amide bond is due to the formation of the five-membered cyclic phenylisothiocyanate intermediate which creates a twist in the amide bond, thus preventing the amidic nitrogen from forming a resonating structure and making it susceptible towards hydrolysis [115]. 


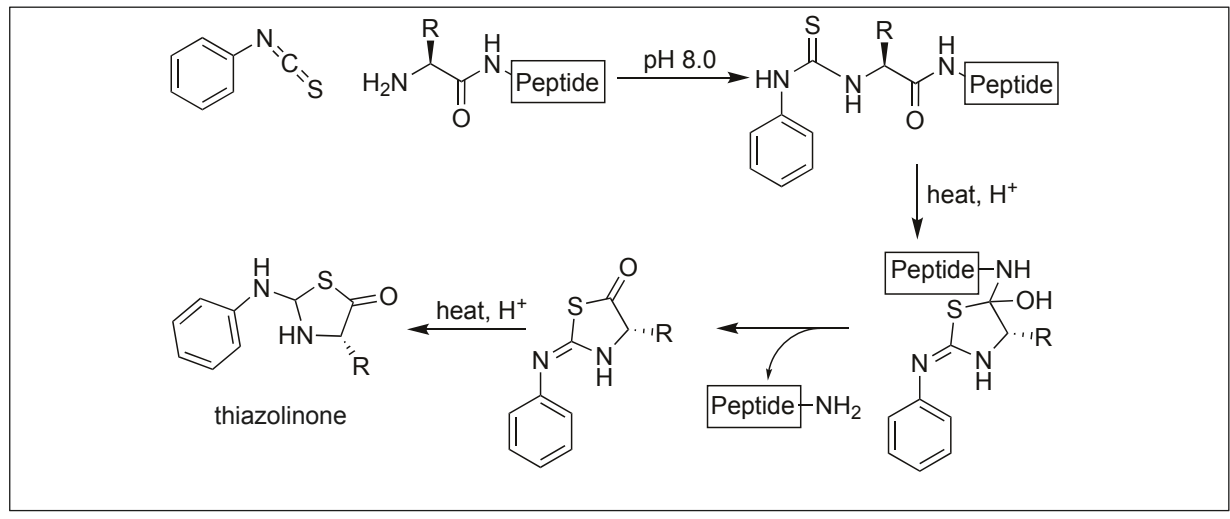

Figure 36. Edman's degradation approach for cleavage of peptide bonds.

\subsubsection{Cyanogen Bromide for Cleavage at Met Residue}

Cyanogen bromide led to the cleavage of the peptide bond at the C-terminus of the methionine residue in a selective manner. The first step involves the nucleophilic attack of the sulfur of methionine on cyanogen bromide (Figure 37) [116]. This displaces the bromide from cyanogen bromide, followed by the attack of the amide carbonyl on the cyano group, resulting in the formation of the five-membered ring, iminolactone, comprising a double bond in the ring between nitrogen and carbon. This double bond results in a rigid ring conformation, thus activating the amide bond towards cleavage at the C-terminus of Met, resulting in the generation of homoserine lactone. This approach has widely been utilized for the sequencing of proteins [116].

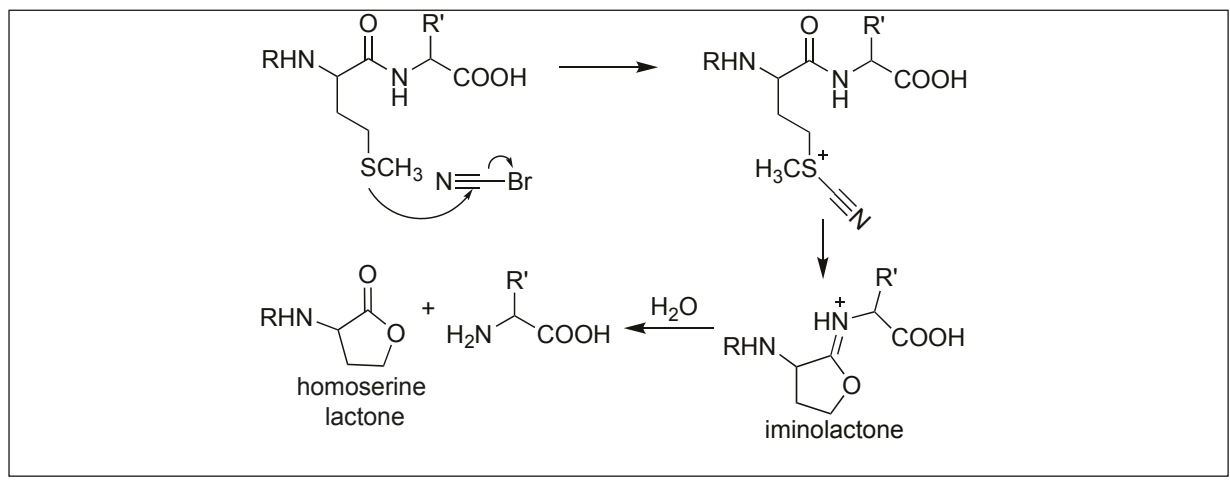

Figure 37. Cyanogen bromide for selective cleavage at Met.

\subsubsection{2-Nitro-5-Thiocyano Benzoic Acid for Cleavage at Cys}

2-Nitro-5-thiocyano benzoic acid led to the hydrolysis of the amide bond at the $\mathrm{N}$-terminal side of the cysteine residue. The first step is the cyanylation of the side chain of cysteine on a peptide by 2-nitro-5-thiocyano benzoic acid, which is followed by the attack of the cysteine amidic nitrogen to the cyano group on the side-chain of cysteine, resulting in the formation of the 5-membered thiolactone ring. This, in turn, activates the amide bond towards hydrolysis under basic conditions (Figure 38). This is again due to the inability of cysteine amidic nitrogen in a thiolactone to form a resonating structure with the carbonyl of peptide bond [117]. 


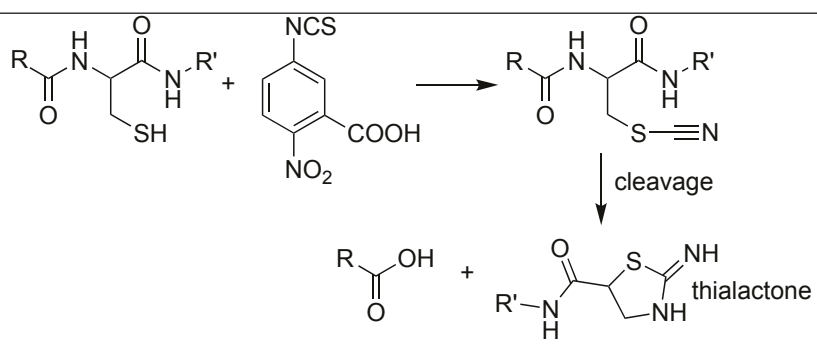

Figure 38. 2-nitro-5-thiocyano benzoic acid selective cleavage at Cys.

\subsubsection{2-Iodosobenzoic Acid for Cleavage at Trp}

2-Iodosobenzoic acid has been used for the hydrolysis of the amide bond at the C-terminal side of the Trp residue. The mechanism of the cleavage is a two-step process. The first step involves the oxidation of the side-chain of tryptophan by 2-iodosobenzoic acid followed by the nucleophilic attack from the neighboring carbonyl group of the amide bond, leading to the formation of an iminospirolactone which hydrolyzes the peptide chain in the presence of water (Figure 39) $[118,119]$.

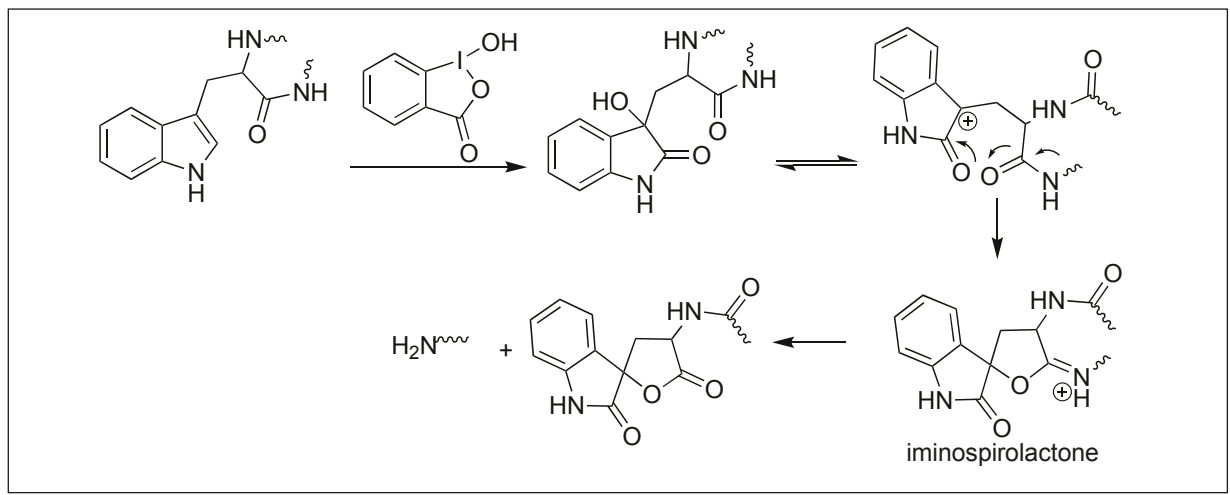

Figure 39. Iodosobenzoic acid for hydrolysis.

\subsubsection{TBC for Cleavage at Trp}

Tryptophanyl peptide bonds underwent selective cleavage by 2,4,6-tribromo-4methylcyclohexadienone (TBC) at the C-terminus (Figure 40). Tyrosyl and histidyl peptide bonds which are usually cleaved by other brominating agents (such as $\alpha$-bromosuccinimide, $\alpha$-bromoacetamide, etc.) are stable to this reagent. Additionally, other amino acids, which are sensitive to oxidation, react with TBC but do not cleave the peptide bonds. This method was successfully applied to a variety of peptides and proteins [118,119].

According to the reaction mechanism suggested by Patchornik et al. (1960), oxidative bromine participates in the modification-cleavage reaction $[118,119]$. Two equivalents of bromine first brominate the indole nucleus followed by a spontaneous debromination through a series of oxidation and hydrolysis reactions (Figure 40). These reactions led to the formation of an oxindole derivative, which cleaves the peptide bond. 


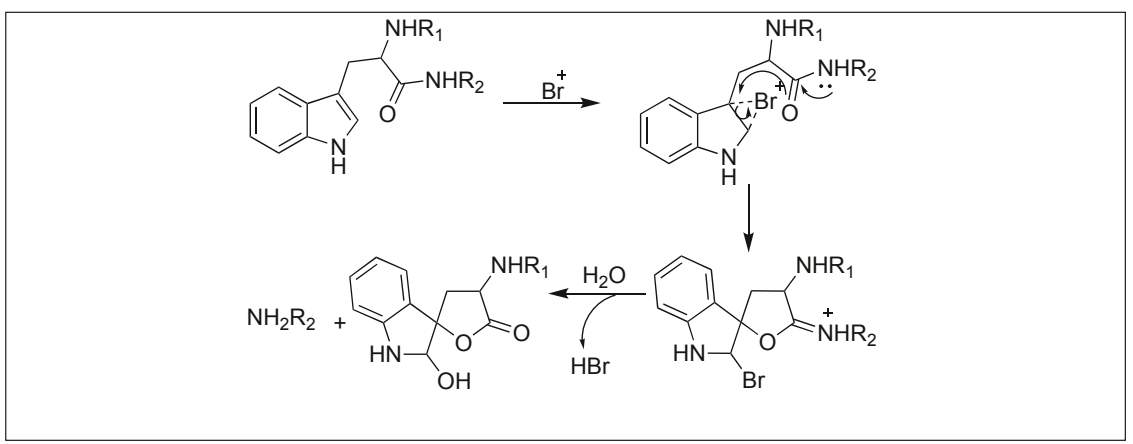

Figure 40. TBC for selective cleavage at Trp residue.

\subsection{N-Amidination for Cleavage of the N-Terminal Amide Bond}

Hamada et al. reported the cleavage of the amide bonds by the $N$-amidination of peptides. The $N$-amidination of peptides leads to the formation of a cyclic moiety which resulted in the cleavage of the amide bond at room temperature (Figure 41) [120]. The rate of cleavage was slow under ambient conditions (PBS buffer, $\mathrm{pH} 7.4$ ) at $37^{\circ} \mathrm{C}$ with $\mathrm{t}_{1 / 2}=35.7 \mathrm{~h}$, but a rapid cleavage was observed under basic conditions $(2 \% \mathrm{NaOH} \mathrm{aq})$ with $\mathrm{t}_{1 / 2}=1.5 \mathrm{~min}$. To evaluate the broad applicability of this cleavage reaction, a series of peptides with different amino acids at the N-terminus such as the Lys, Glu, Ser, Cys, Tyr, Val, and Pro residues were cleaved with $t_{1 / 2}$ values from $1 \mathrm{~min}$ to $10 \mathrm{~min}$. A slightly slow cleavage was observed with bulky amino acids at the terminus such as Val or Pro, which might be hindering the path of cyclization.

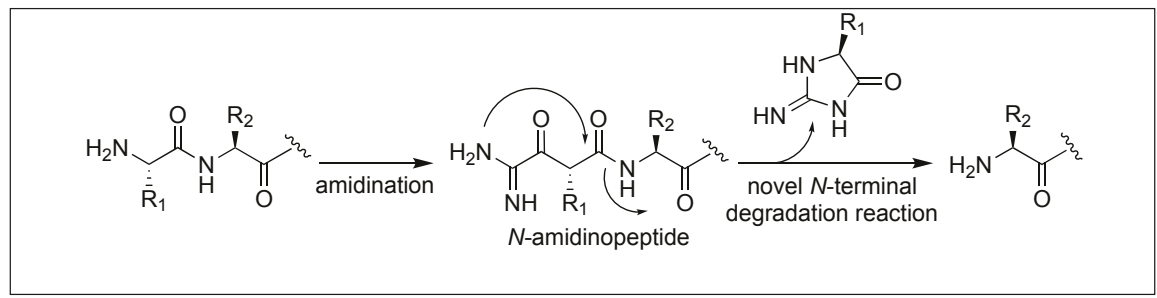

Figure 41. N-amidination strategy.

$\mathrm{N}$-amidinated peptide with a Cys residue at the $\mathrm{N}$-terminus also generated a five-membered ring, thiazolidine by path $b$ (intermediate B) which did not lead to any cleavage, therefore, the $t_{1 / 2}$ of the peptide with Cys at the $\mathrm{N}$-terminus in $2 \% \mathrm{NaOH}$ aq at $37^{\circ} \mathrm{C}$ was $3.4 \mathrm{~min}$ (slower than with other amino acids at the N-terminus) (Figure 42) [120].

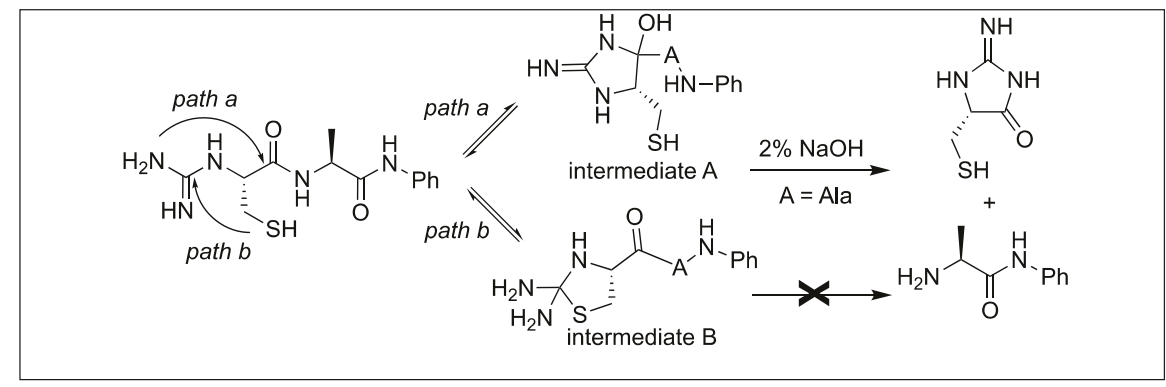

Figure 42. N-amidination strategy with $\mathrm{N}$-terminal cysteine. 


\subsection{Lactonization Mediated Cleavage of Amide Bonds}

Otaka et al. developed an auxiliary with special protecting groups (PGs), which is capable of forming a lactone with the carbonyl of an amide bond, resulting in the cleavage of the amide bond (Table 4) [121-128]. Depending on the nature of the protecting groups, an amide bond cleavage can be initiated in peptides by using different responsive reagents for the deprotection of PGs (Table 4). Table 4 showed various PGs and the corresponding responsive reagents for their deprotection. The thiol responsive reagent was applied for the cleavage of the PNA/DNA complex using thiol-responsive protecting groups [121-128].

Table 4. Lactonization mediated cleavage of amide bonds.

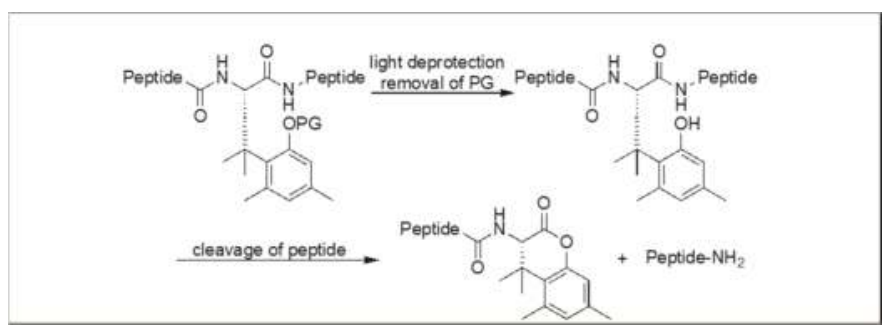

\begin{tabular}{ccccc}
\hline Reagent/Condition & PG & R1 & R2 & R3 \\
\hline & & $\mathrm{NO}_{2}$ & $\mathrm{H}$ & $\mathrm{H}$ \\
Ultraviolet Near-infrared & $\mathrm{NO}_{2}$ & $\mathrm{OMe}$ & $\mathrm{OMe}$ \\
Fluoride hypoxia & 4-nitrobenzenesulfonyl & - & $\mathrm{OTBDPS}$ & $\mathrm{H}$ \\
& phosphate & - & - & $\mathrm{H}$ \\
\hline Thiol & $\mathrm{RO}_{2}$ & - \\
\hline Phosohatase & & $\mathrm{H}$ & - \\
\hline
\end{tabular}

\subsection{Hydrogen Peroxide-Induced Amide Bond Cleavage}

Later, the hydrogen peroxide $\left(\mathrm{H}_{2} \mathrm{O}_{2}\right)$-responsive protecting group was introduced to the amino acid. This protecting group contains a boronate or boronic acid moiety which underwent deprotection in oxidative stress because of the release of hydrogen peroxide followed by the formation of lactone and the cleavage of the peptide bond (Figure 43) [128].

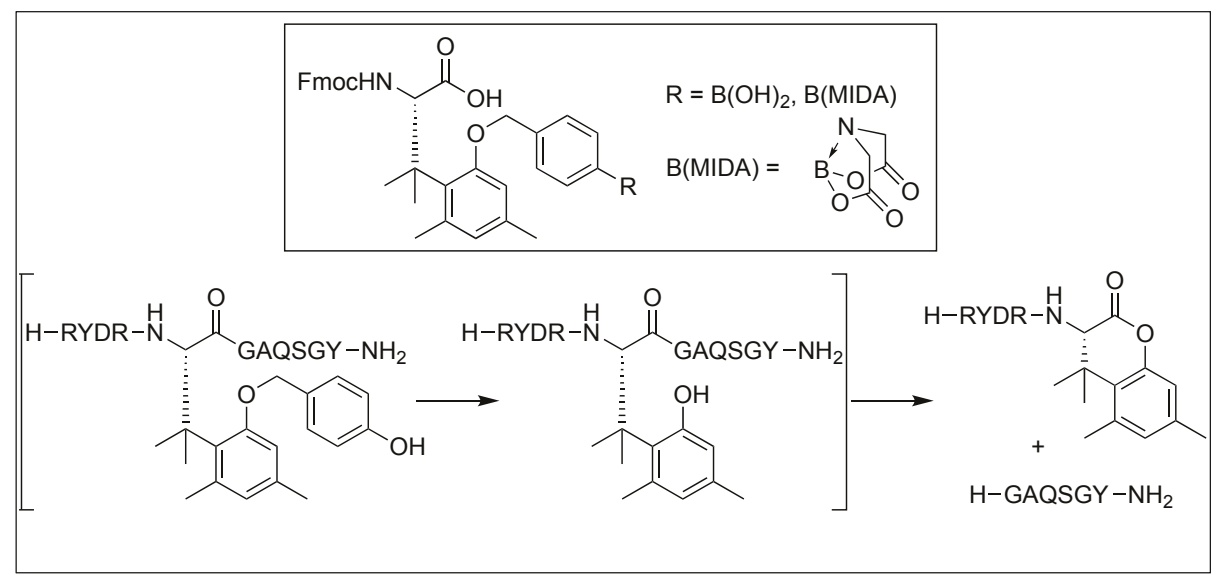

Figure 43. Hydrogen peroxide responsive probes. 


\subsection{Glutamic Acid Specific Activation of Amide Bonds}

We have also reported a new method for the site-specific cleavage of peptide bonds at glutamic acid under physiological conditions $[129,130]$. The method involves the activation of the backbone peptide chain at the N-terminal side of glutamic acid by the formation of a pyroglutamyl imide (pGlu) moiety using bromotripyrrolidinophosphonium hexafluorophosphate (PyBroP) (Figure 44). This activation increases the susceptibility of the peptide bond toward various nucleophiles including thiol and water (Figure 44). We showed that this pyroglutamyl imide activated peptide chain underwent the complete cleavage of the peptide bond under neutral buffer conditions ( $\mathrm{pH}$ 7.5). It was observed that the rate of hydrolysis increase under basic $\mathrm{pH}$ conditions $(\mathrm{pH}=10.5)$. Although the Asp has a carboxylic group on the side chain, no cleavage was observed under the reaction conditions. Jensen et al. exposed the pGlu activated peptide bond towards thiol, resulting in the formation of peptide thioesters $[129,130]$. A noted feature about this approach is that it leads to the formation of epimerization free peptide acids and peptide thioesters. This method is highly specific and exhibits a broad substrate scope including the cleavage of bioactive peptides with unnatural amino acids, which are unsuitable substrates for enzymes.

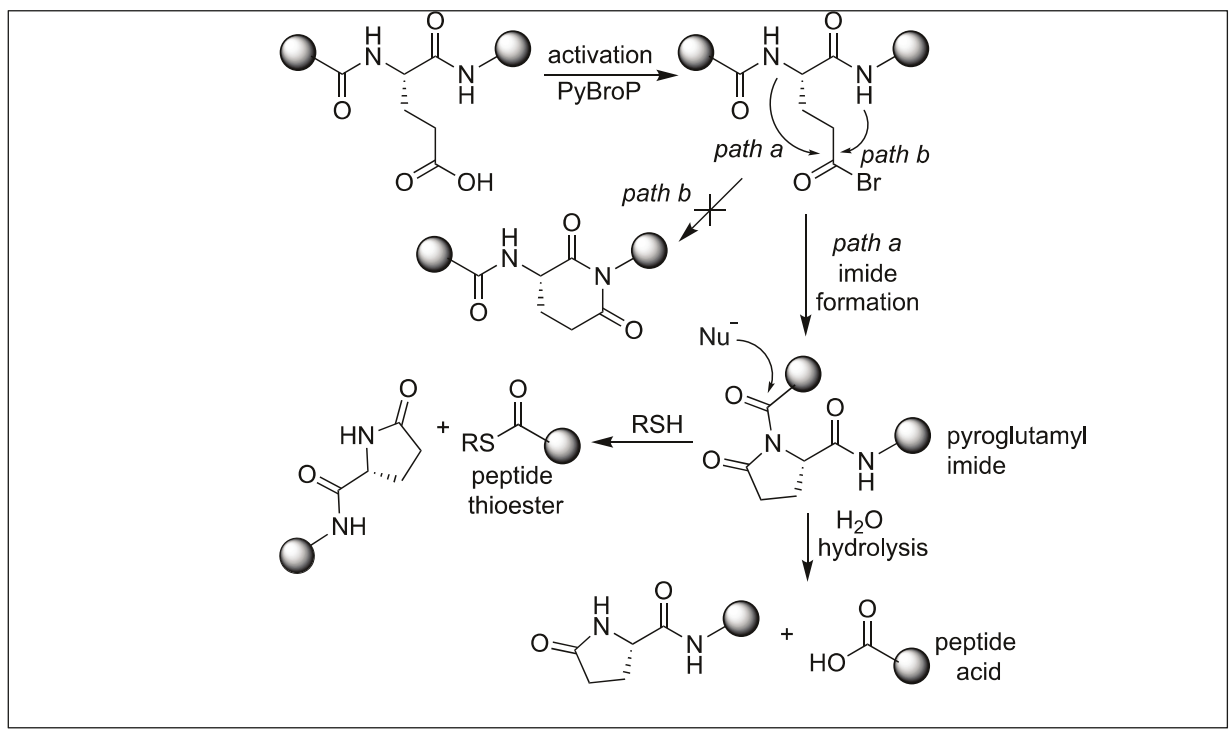

Figure 44. Glutamic acid selective activation of peptide bonds.

\subsection{Asparagine Selective Cleavage of Amide Bonds}

Kanai et al. described the method for the site-selective chemical activation of peptide bonds for hydrolysis at the asparagine residue using diacetoxyiodobenzene (DIB) [131]. The reaction of the side-chain of Asn with DIB leads to the formation of isocyanate by Hofmann rearrangement. This is followed by the attack of the N-terminal amidic nitrogen of the peptide backbone chain, affording a five-membered $\mathrm{N}$-acylurea intermediate, thus activating the amide bond towards hydrolysis (Figure 45). Asn-selective peptide bond cleavage was proceeded in an aqueous neutral solution at $37{ }^{\circ} \mathrm{C}$ and exhibited a broad substrate scope. The Gln-site was not cleaved under the reaction conditions. Specifically, this method is applicable to peptides containing unnatural amino acids and/or posttranslational modifications where enzymatic cleavage is not very efficient. 


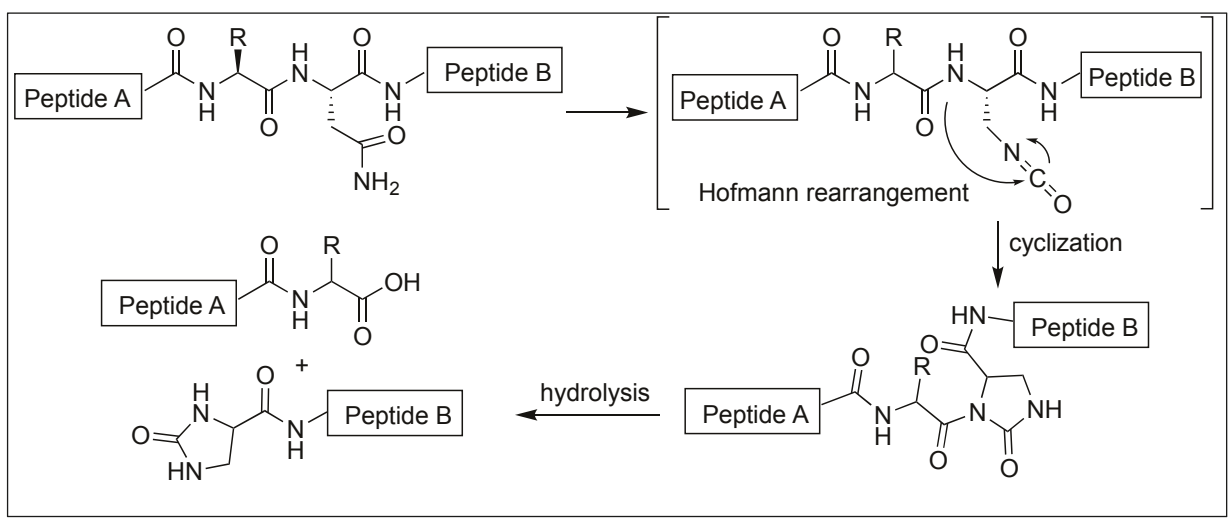

Figure 45. Asparagine selective cleavage of peptide bonds.

\subsection{Cyclic Urethane Mediated Activation of Amide Bonds}

We have developed a method for the cleavage of the amide backbone chain at the N-terminal side of Ser, Thr, and Cys by the formation of a five-membered cyclic urethane moiety [132]. The formation of the cyclic urethane moiety with an amide backbone makes the amidic carbonyl group susceptible to nucleophilic attack. This is presumably due to the twist in the backbone amide chain caused by the cyclic urethane moiety. Thus, it was no longer able to form a resonating structure. To achieve this goal, we screened various carbonylating reagents and a maximum conversion to cyclic urethane moiety was achieved with $\mathrm{N}, \mathrm{N}$-disuccinimidyl carbonate (DSC). We proposed that the hydroxymethyl group of the side chain of Ser reacted with DSC to generate an activated intermediate, A, which then undergoes nucleophilic displacement by the amidic nitrogen on the $\mathrm{N}$-side of serine through the path to generate a five-membered cyclic urethane intermediate B (Figure 46). The formation of the cyclic urethane intermediate B makes the amide bond susceptible to nucleophilic attack and led to the cleavage of the amide bond in neutral aqueous conditions (room temp, $\mathrm{pH} 7.5,12 \mathrm{~h}$ ). There is a possibility of nucleophilic displacement of the intermediate A by the amidic nitrogen through path $\mathrm{b}$. This could lead to the formation of six-membered ring $B^{\prime}$, but we did not observe the formation of any six-membered ring as analyzed by NMR studies.

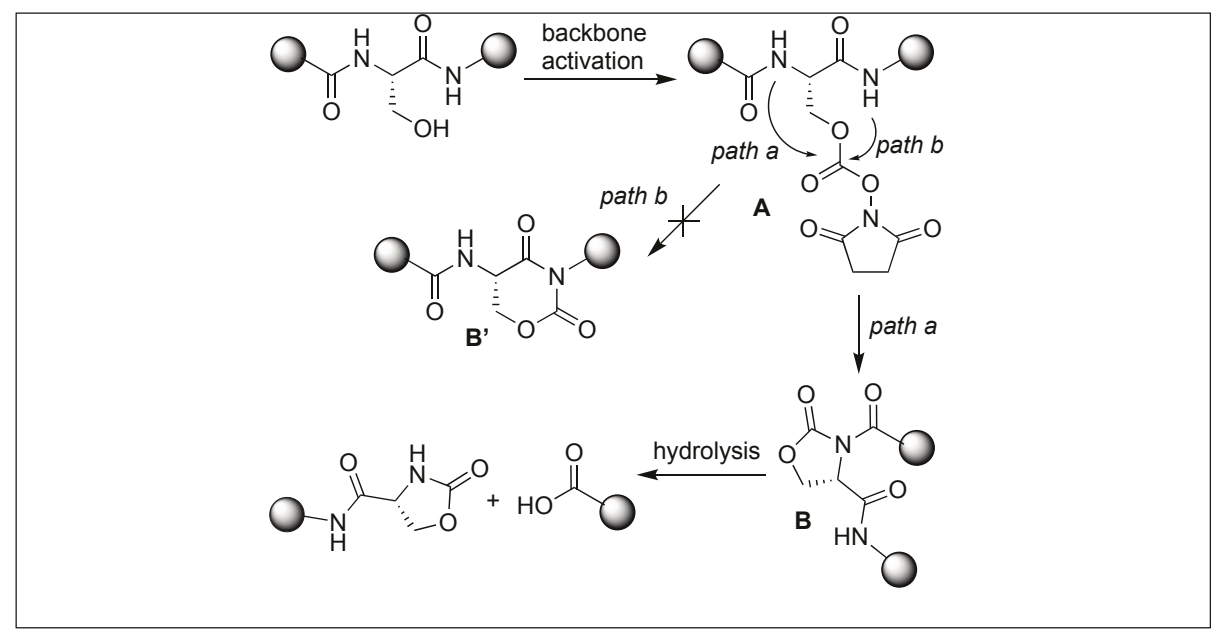

Figure 46. Cyclic urethane mediated activation of peptide bond. 
The side chain of Glu on reaction with DSC also led to the formation of a pyroglutamyl imide moiety with an amide backbone chain, thus making it susceptible to nucleophilic attack (Figure 47) [132]. We have used this approach for the selective hydrolysis of peptides/proteins at the N-terminus of Ser, Thr, Cys, and Glu. This method cleaved various bioactive peptides containing posttranslational modifications (e.g., $\mathrm{N}$-acetylation and -methylation) and mutations (D-and $\beta$-amino acids), which are not suitable substrates for enzymes, thus exhibited a broad substrate scope. We have also used this approach for the synthesis of a variety of functionalized C-terminal peptides such as esters, amides, alcohols, and thioesters (Figure 48) by exposing the cyclic urethane activated peptide towards various nucleophiles such as alcohols, amines, reducing agents, and thiols $[133,134]$. The attractive feature of this approach is that it leads to the formation of epimerization free C-functionalized peptides.

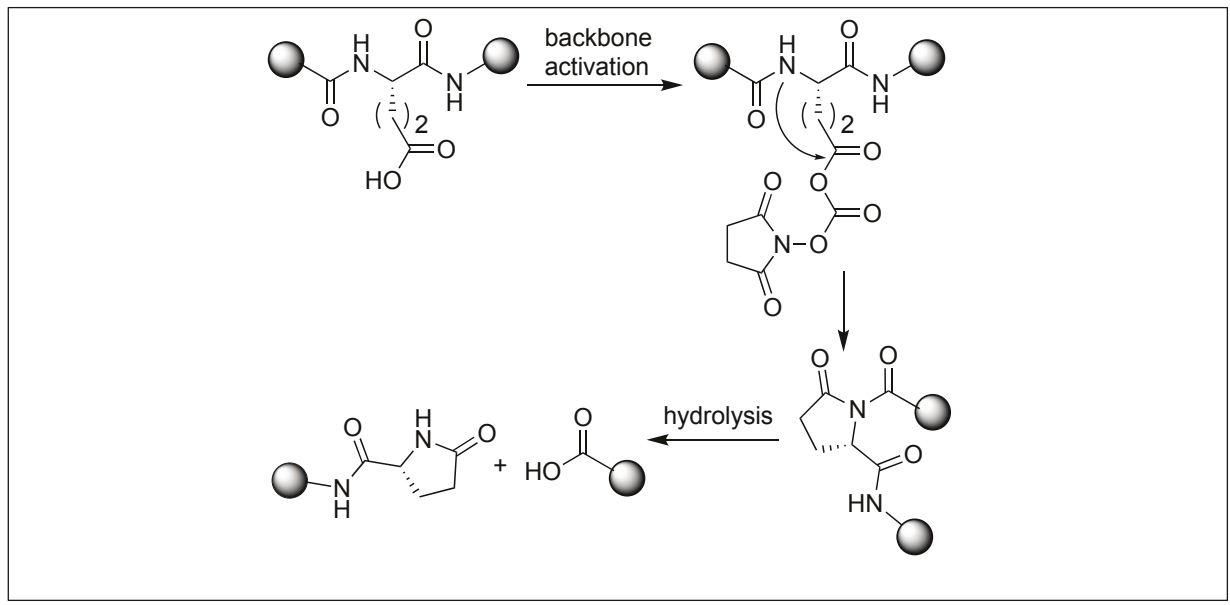

Figure 47. Pyroglutamyl imide mediated activation of peptide bond.

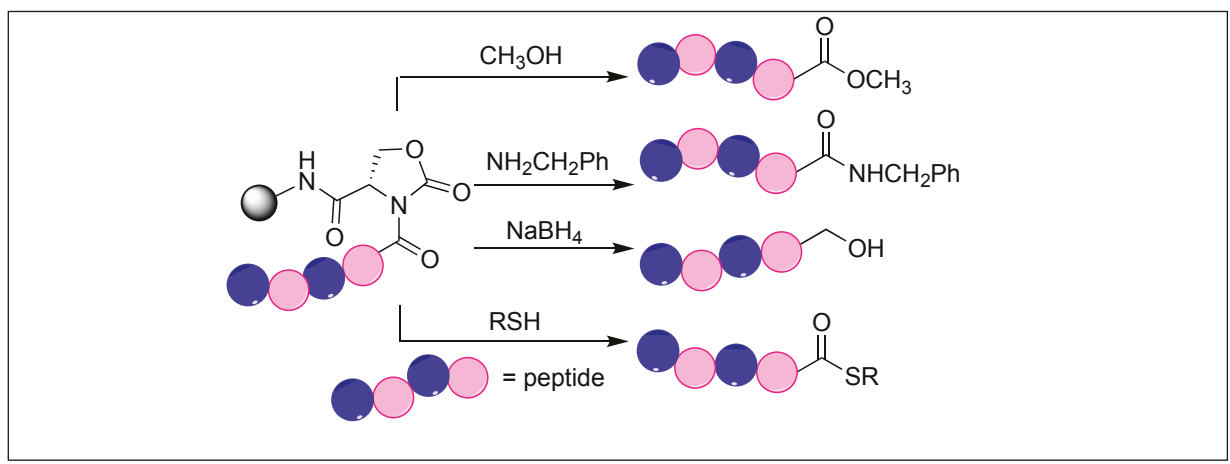

Figure 48. Cyclic urethane mediated synthesis of C-terminal peptides.

Later, this cyclic urethane amide-activation approach was applied for the cleavage of a variety of cyclic and lasso peptides obtained from nature to determine their sequence, which is difficult to be determined by conventional approaches (Figure 49) $[135,136]$. We have also applied this method for the synthesis of a peptide-based molecular machine (rotaxanes) for the first time (Figure 50) $[135,136]$. 


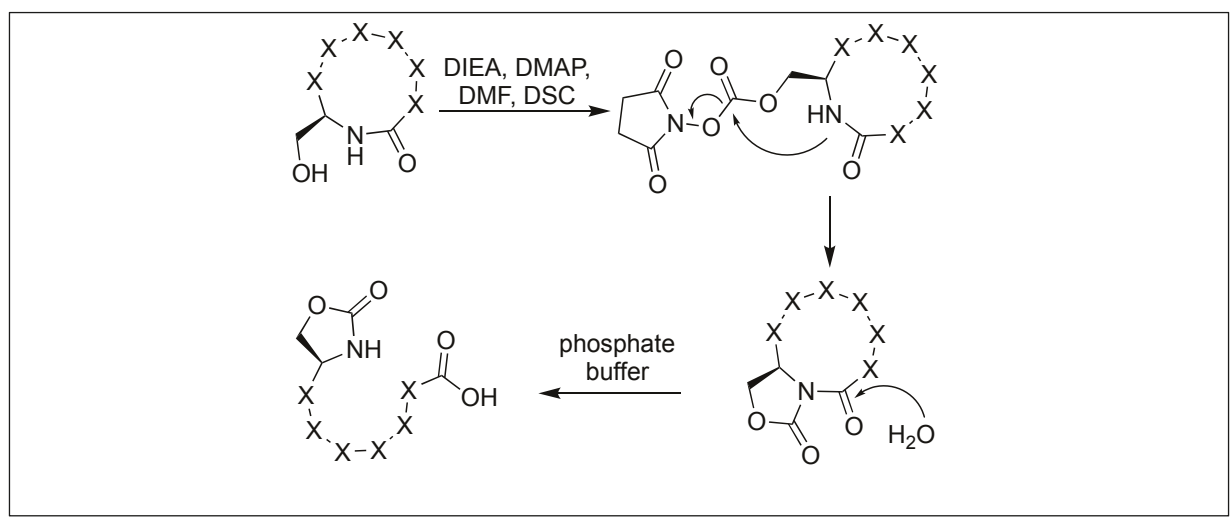

Figure 49. Cyclic urethane for cleavage of cyclic peptides.

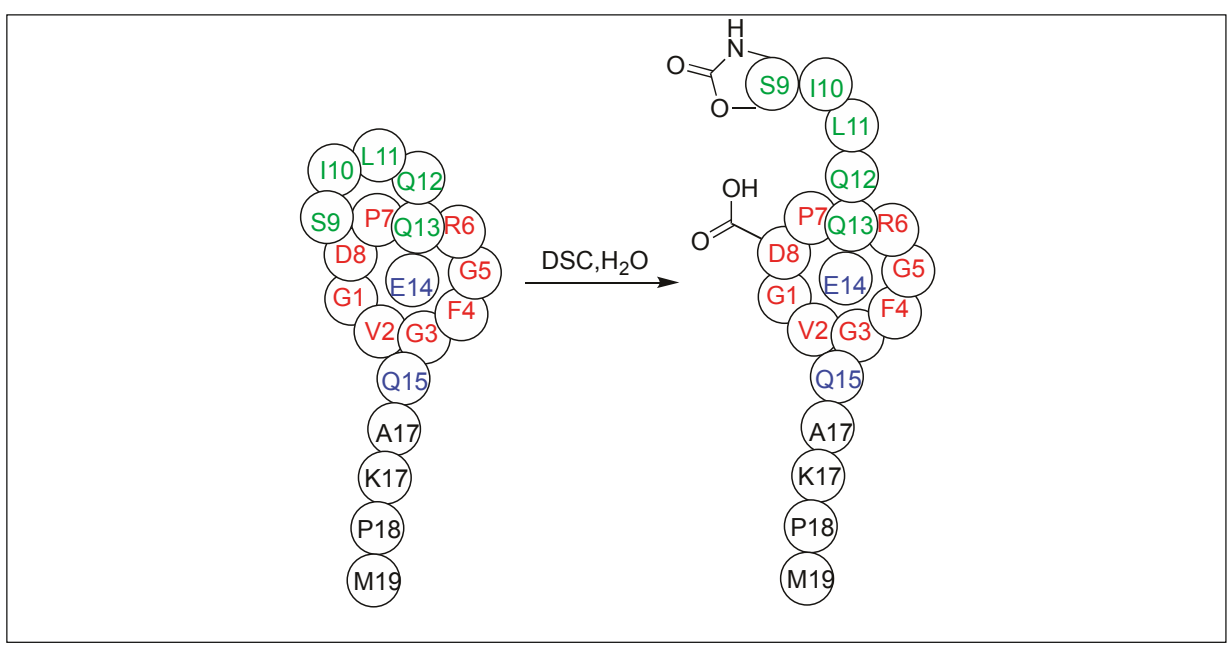

Figure 50. Synthesis of rotaxane from lasso peptide.

\subsection{Intein-Inspired Amide Cleavage Chemical Device}

A photoresponsive device was developed for the cleavage of the amide bond at the C-terminus of the Asn residue [137]. This approach was inspired by intein-mediated protein splicing and its chemical environment was mimicked by the incorporation of geminal dimethyl groups and a secondary amine on the asparagine scaffold.

The secondary amine acts as an intramolecular base, which enhances the nucleophilicity of the amide nitrogen (Figure 51). The geminal dimethyl groups led to a Thorpe-Ingold effect, which enhances the intramolecular attack, thus assisting in the formation of the succinimide ring [138-140]. The $o$-nitrobenzyloxycarbonyl (o-NBnoc) masks the basic character of the secondary amine [141,142], thus leading to the photo triggered cleavage of an amide bond by the deprotection of the secondary amine unit containing the $o$-nitrobenzyloxycarbonyl group. 


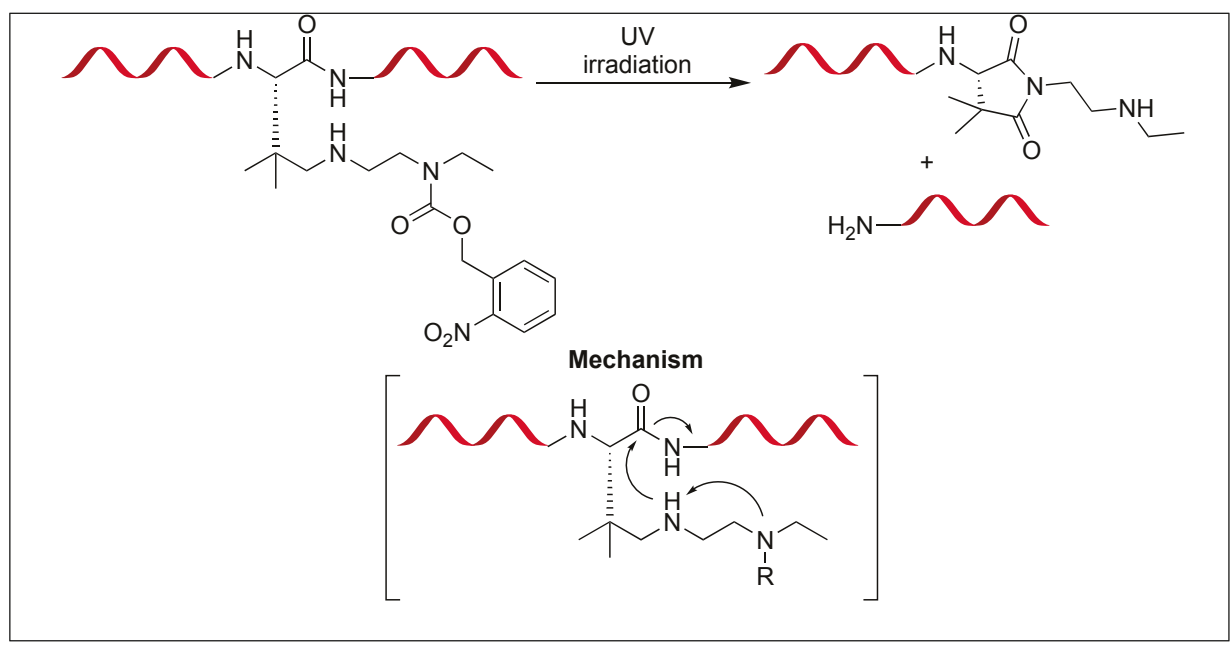

Figure 51. Intein-inspired amide bond cleavage.

\subsection{Serine-Selective Aerobic Cleavage of Peptides}

Kanai et al. reported a use of the water-soluble copper-organoradical conjugate for the selective cleavage of the peptide bond at the N-terminus of a serine residue under mild conditions and at room temperature [143]. They used this approach for the selective cleavage of a variety of different peptides/proteins containing D-amino acids or sensitive disulfide pairs.

Ser-selective cleavage of the peptide bond was initiated by the aerobic chemoselective oxidation of the hydroxymethyl moiety of Ser to a formyl group (A) (Figure 52). This produced a $\beta$-formyl glycineamide intermediate $\mathbf{B}$ which, on further oxidation, led to the formation of oxalamide $\mathbf{C}$ by undergoing oxidative deformylation. Oxalamide $\mathbf{C}$ then underwent hydrolysis under mild conditions because the carbonyl groups of the oxalamide are more electrophilic than those of simple amides, resulting in the formation of the cleaved fragments $\mathbf{D}$ and $\mathbf{D}^{\prime}$. By using molecular oxygen as a terminal oxidant, water and a $\mathrm{C} 1$ molecule (possibly $\mathrm{HCO}_{2} \mathrm{H}$ ) become stoichiometric side products. This strategy is widely distinct from Lewis acid, promoted by the Ser-selective peptide hydrolysis through N-to-O rearrangement.

\subsection{Hydrolysis of Amide Bonds by the Formation of Oxazolinium Specie: Function of Acyl Protecting Group}

Peptides containing a simple $N$-acyl group activates the amide bond four bonds away from an acyl group for cleavage under acidic conditions [144]. First, TFA leads to the protonation of amide carbonyl followed by the nucleophilic attack from the oxygen of the acyl carbonyl to generate a five-membered oxazolinium specie $\mathbf{A}$ in the peptide chain. Second, the collapse of the oxazolinium intermediate $\mathbf{A}$ leads to the cleavage of an unactivated amide bond (Figure 53).

The nature of the aromatic group, $\mathrm{G}$, was responsible for the rate of hydrolysis of the peptide bond. Electron-donating groups increase the rate of hydrolysis whereas electron withdrawing substituents decrease it (Figure 53). 


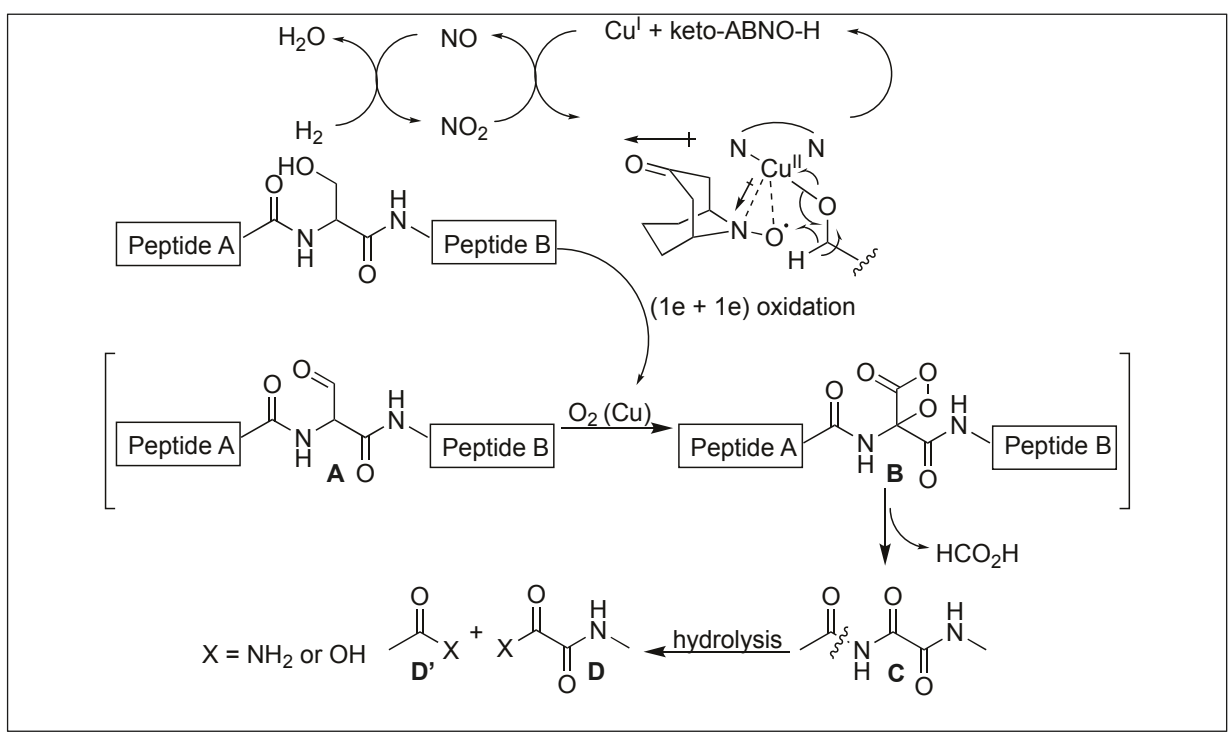

Figure 52. Serine selective aerobic cleavage of peptide bonds.

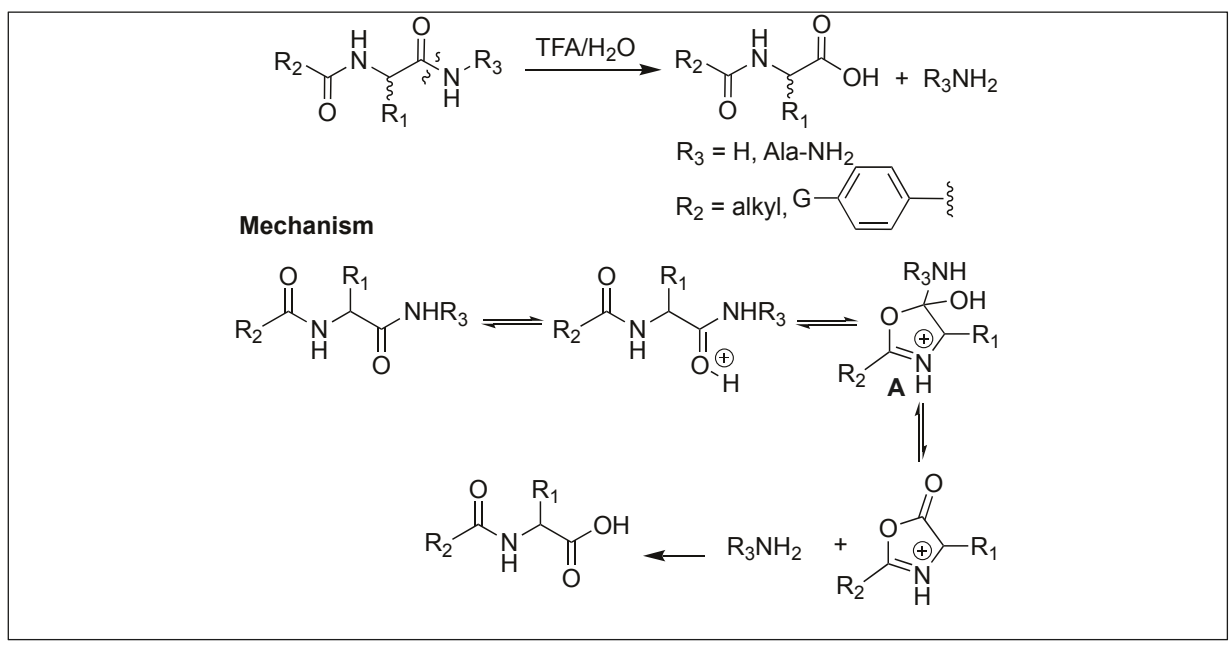

Figure 53. Oxazolinium species formation.

\subsection{Hydrazinolysis for the Cleavage of Amide Bonds}

The hydrazinolysis of unactivated amide bonds was accelerated by the addition of ammonium salts. The reaction proceeds at $50-70{ }^{\circ} \mathrm{C}$ to give peptide cleavage products and exhibits a broad substrate scope that out-performs existing amide bond cleavage reactions [145]. This approach was applied for the cleavage of the peptide bonds without racemization at the $\alpha$-position of the amino acids (Figure 54). It was also applied to the cleavage of the $N$-acetyl group from the amino sugar. 


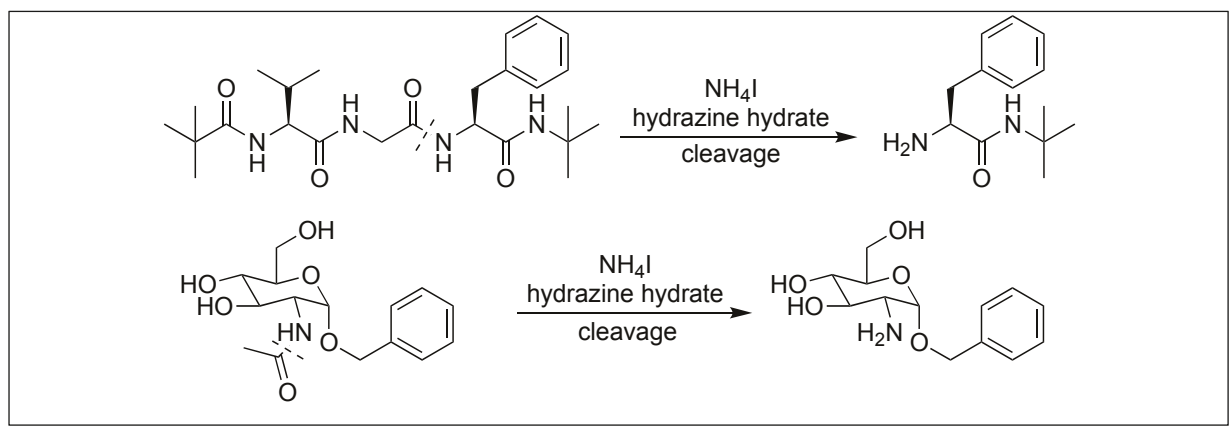

Figure 54. Hydrazinolysis for the cleavage of peptide bonds.

\subsection{Amide Bond Cleavage of the N-Methylcysteinyl Peptide}

Tam et al. developed a selective bi-directional peptide bond cleavage approach utilizing $N$-methylcysteine (MeCys) in the Xaa-MeCys-Yaa peptides (Xaa and Yaa, non-cysteine residues) [146]. Under strong acidic conditions, peptide Xaa-MeCys-Yaa led to the formation of an oxazolinium intermediate, resulting in the cleavage of the Xaa-MeCys bond. The oxazolinium intermediate was later trapped by thiocresol (TC) to form a Xaa-MeCys-TC thioester (Figure 55). The replacement of $\mathrm{MeCys}$ by Cys residue did not result in the peptide bond cleavage, suggesting the important role of $\mathrm{N}$-methylation in MeCys residue for the formation of oxazolone.

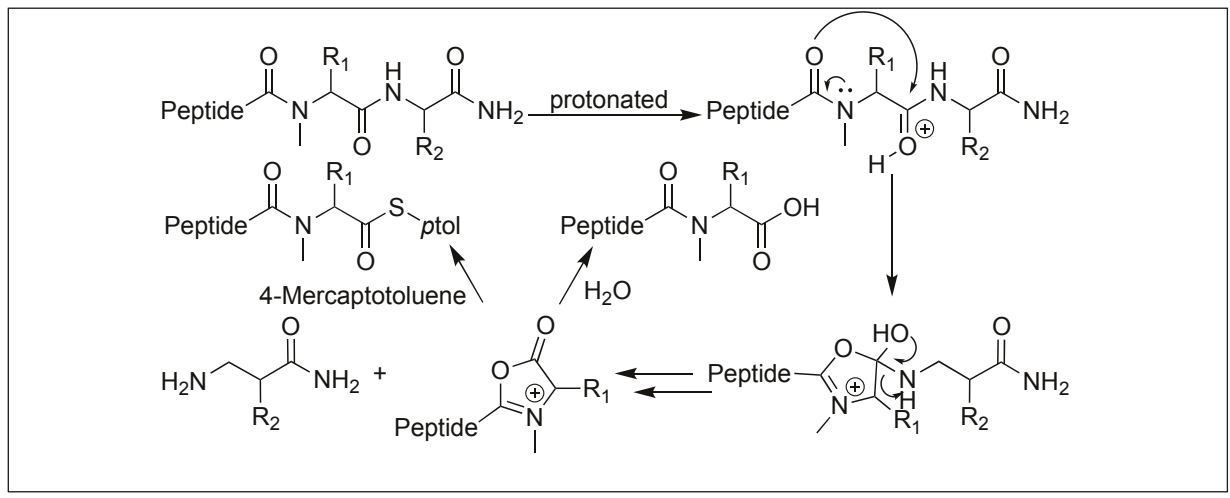

Figure 55. N-methylcysteinyl peptide cleavage.

\subsection{N-MeAib Induced Unusual Cleavage of Amide Bonds}

Peptides containing acylated $N$-methyl-aminoisobutyryl (NMeAib) residues showed unusual cleavage of amide bonds under acidic conditions. The cleavage takes place at the C-terminal side of the NMeAib residue (Figure 56) [147]. X-ray diffraction studies of the NMeAib containing molecules showed that the oxygen atom of the carbonyl group of the preceding residue is close to the carbonyl carbon of the NMeAib residue, thus acting as an internal nucleophile forming a tetrahedral intermediate. Once this tetrahedral intermediate was formed, lone pair electrons on the nitrogen of the phenylalanine were no longer be able to form resonating structures with the carbonyl group of NMeAib. In fact, the phenylalanine nitrogen becomes a proton acceptor like the amines, which resulted in the cleavage of the amide bond followed by the removal of phenylalanine and the formation of an oxazolinium ion intermediate, which further reacts with water to form a carboxylic acid product. 


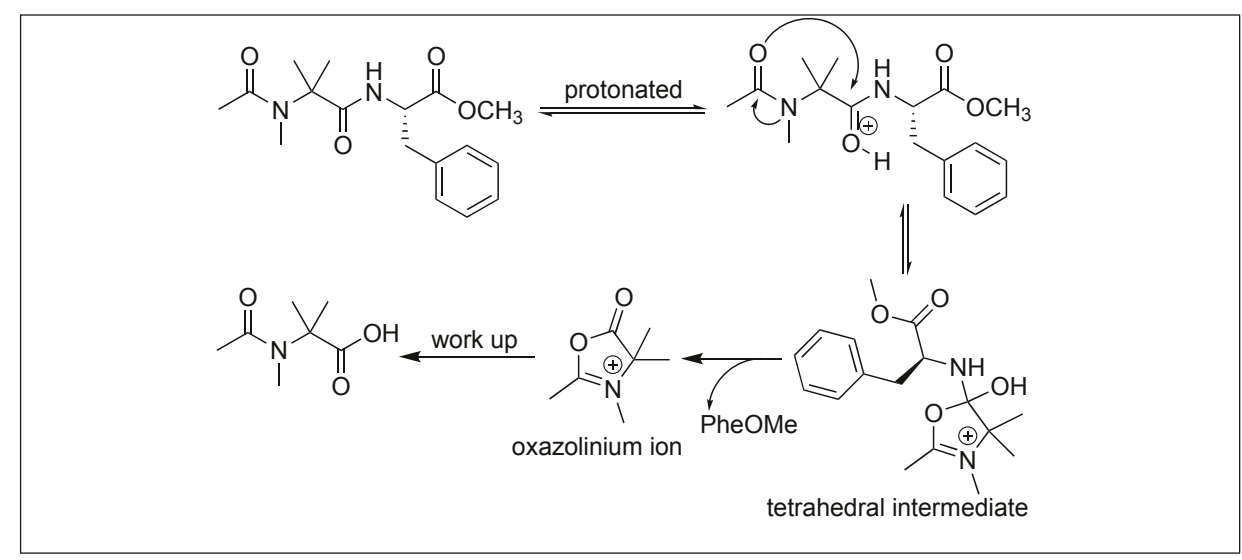

Figure 56. N-Me Aib mediated amide bond cleavage.

\section{Conclusions}

This mini-review highlights the methods for the activation of unactivated amide bonds in biomolecules. This review further highlights the application of these methods in the sequencing of proteins and the synthesis of peptide acids, thioesters, alcohols, and amides. These studies showed that there is still a lot to learn from enzymes catalyzed pathways and how we can develop enzyme mimetics for catalyzing the cleavage of unactivated and highly stable amide bonds at particular residues in a selective manner. We assume that these enzyme mimetics can have potential applications in various fields.

Author Contributions: M.R., S.M. and K.-C.T. collected the literature references. M.R., S.M. and K.-C.T. contributed to the manuscript writing.

Funding: This research was supported by start up funds granted to M.R. by Auburn University.

Conflicts of Interest: The authors declare no conflicts of interest.

\section{References}

1. Greenberg, A.; Breneman, C.M.; Liebman, J.F. The Amide Linkage: Structural Significance, Shemistry, Biochemistry and Material Science; Wiley: New York, NY, USA, 2000.

2. Brunton, L.; Chabner, B.; Knollman, B. Goodman and Gilman's the Pharmacological Basis of Therapeutics; MacGraw-Hill: New York, NY, USA, 2010.

3. Brown, D.G.; Bostrom, J. Analysis of Past and Present Synthetic Methodologies on Medicinal Chemistry: Where Have All the New Reactions Gone? J. Med. Chem. 2016, 59, 4443-4458. [CrossRef] [PubMed]

4. Pattabiraman, V.R.; Bode, J.W. Rethinking amide bond synthesis. Nature 2011, 480, 471-479. [CrossRef] [PubMed]

5. Hughes, A.B. Amino Acids, Peptides and Proteins in Organic Chemistry; Wiley-VCH: Weinheim, Germany, 2009.

6. Kaspar, A.A.; Reichert, J.M. Drug future directions for peptide therapeutics development. Discov. Today 2013, 18, 807-817. [CrossRef] [PubMed]

7. Thorner, J.; Emr, S.D.; Abelson, J.N. Applications of chimeric genes and hybrid proteins part A: Gene expression and protein purification. Methods Enzymol. 2000, 326, 601-617.

8. Kemnitz, C.R.; Loewen, M.J. Amide Resonance correlates with a breadth of C-N rotation barriers. J. Am. Chem. Soc. 2007, 129, 2521-2528. [CrossRef] [PubMed]

9. Mujika, J.I.; Mercero, J.M.; Lopez, X. Water-promoted hydrolysis of a highly twisted amide: Rate acceleration caused by the twist of the amide bond. J. Am. Chem. Soc. 2005, 127, 4445-4453. [CrossRef] [PubMed]

10. Wang, B.; Cao, Z. Acid-catalyzed reactions of twisted amides in water solution: Competition between hydration and hydrolysis. Chem.-Eur. J. 2011, 17, 11919-11929. [CrossRef] [PubMed] 
11. Smith, R.M.; Hansen, D.E. The pH-rate profile for the hydrolysis of a peptide bond. J. Am. Chem. Soc. 1998, 120, 8910-8913. [CrossRef]

12. Radzicka, A.; Wolfenden, R. Rates of uncatalyzed peptide bond hydrolysis in neutral solution and the transition state affinities of proteases. J. Am. Chem. Soc. 1996, 118, 6105-6109. [CrossRef]

13. Arnau, J.; Lauritzen, C.; Petersen, G.E.; Pedersen, J. Current strategies for the use of affinity tags and tag removal for the purification of recombinant proteins. Protein Express. Purif. 2006, 48, 1-13. [CrossRef] [PubMed]

14. Hoyer, D.; Cho, H.; Schultz, P.G. New strategy for selective protein cleavage. J. Am. Chem. Soc. 1990, 112, 3249-3250. [CrossRef]

15. Schepartz, A.; Cuenoud, B. Site-specific cleavage of the protein calmodulin using a trifluoperazine-based affinity reagent. J. Am. Chem. Soc. 1990, 112, 3247-3249. [CrossRef]

16. Tani, K.; Stoltz, B.M. Synthesis and structural analysis of 2-quinuclidonium tetrafluoroborate. Nature 2006, 441, 731. [CrossRef] [PubMed]

17. Hayashi, M.; Bachman, S.; Hashimoto, S.; Eichman, C.C.; Stoltz, B.M. Catalytic anti-Markovnikov transformations of hindered terminal alkenes enabled by aldehyde-selective Wacker-type oxidation. J. Am. Chem. Soc. 2016, 138, 8997-9000. [CrossRef] [PubMed]

18. Kirby, A.J.; Komarov, I.V.; Wothers, P.D.; Feeder, N. The most twisted amide: Structure and reactions. Angew. Chem. Int. Ed. 1998, 37, 785-786. [CrossRef]

19. Kirby, A.J.; Komarov, I.V.; Feeder, N. Spontaneous, millisecond formation of a twisted amide from the amino acid, and the crystal structure of a tetrahedral intermediate. J. Am. Chem. Soc. 1998, 120, 7101-7102. [CrossRef]

20. Kirby, A.J.; Komarov, I.V.; Feeder, N. Synthesis, structure and reactions of the most twisted amide. J. Chem. Soc. Perkin Trans. 2001, 2, 522-529. [CrossRef]

21. Szostak, M.; Aube, J. Chemistry of bridged lactams and related heterocycles. Chem. Rev. 2013, $113,5701$. [CrossRef] [PubMed]

22. Artacho, J.; Ascic, E.; Rantanen, T.; Karlsson, J.; Wallentin, C.J.; Wang, R.; Wendt, O.F.; Harmata, M.; Snieckus, V.; Warnmark, K. Twisted amide analogues of Troger's base. Chem. Eur. J. 2012, 18, 1038-1042. [CrossRef] [PubMed]

23. Bashore, C.G.; Samardjiev, I.J.; Bordner, J.; Coe, J.W. Twisted amide reduction under Wolff-Kishner conditions: Synthesis of a benzo-1-aza-adamantane derivative. J. Am. Chem. Soc. 2003, 125, 3268. [CrossRef] [PubMed]

24. Meng, G.; Szostak, M. Sterically controlled Pd-catalyzed chemoselective ketone synthesis via N-C cleavage in twisted amides. Org. Lett. 2015, 17, 4364-4367. [CrossRef] [PubMed]

25. Meng, G.; Szostak, M. General olefin synthesis by the palladium catalyzed Heck reaction of amides: Sterically controlled chemoselective N-C activation. Angew. Chem. Int. Ed. 2015, 54, 14518-14522. [CrossRef] [PubMed]

26. Shi, S.; Meng, G.; Szostak, M. Synthesis of biaryls through nickel catalyzed Suzuki-Miyaura coupling of amides by carbon-nitrogen bond cleavage. Angew. Chem. Int. Ed. 2016, 55, 6959-6963. [CrossRef] [PubMed]

27. Shi, S.; Szostak, M. Efficient synthesis of diaryl ketones by nickel-catalyzed Negishi cross-coupling of amides by carbon-nitrogen bond cleavage at room temperature accelerated by a solvent effect. Chem.-Eur. J. 2016, 22, 10420-10424. [CrossRef] [PubMed]

28. Meng, G.; Szostak, M. Rhodium-catalyzed C-H bond functionalization with amides by double C-H/C-N bond activation. Org. Lett. 2016, 18, 796-799. [CrossRef] [PubMed]

29. Meng, G.; Szostak, M. Palladium-catalyzed Suzuki-Miyaura coupling of amides by carbon-nitrogen cleavage: General strategy for amide N-C bond activation. Org. Biomol. Chem. 2016, 14, 5690-5707. [CrossRef] [PubMed]

30. Hie, L.; Fine Nathel, N.F.; Shah, T.K.; Baker, E.L.; Hong, X.; Yang, Y.F.; Liu, P.; Houk, K.N.; Garg, N.K. Conversion of amides to esters by the nickel-catalysed activation of amide C-N bonds. Nature 2015, 524, 79-83. [CrossRef] [PubMed]

31. Li, X.; Zou, G. Acylative Suzuki coupling of amides: Acyl nitrogen activation via synergy of independently modifiable activating groups. Chem. Commun. 2015, 51, 5089-5092. [CrossRef] [PubMed]

32. Kraut, J. Serine proteases: Structure and mechanism of catalysis. Annu. Rev. Biochem. 1977, 46, 331-358. [CrossRef] [PubMed]

33. Carter, P.; Wells, J.A. Dissecting the catalytic triad of a serine protease. Nature 1988, 332, 564-568. [CrossRef] [PubMed] 
34. Verma, S.; Dixit, R.; Pandey, K.C. Cysteine proteases: Modes of activation and future prospects as pharmacological targets. Front. Pharmacol. 2016, 7, 107. [CrossRef] [PubMed]

35. Otto, H.H.; Schirmeister, T. Cysteine proteases and their inhibitors. Chem. Rev. 1997, 97, 133-171. [CrossRef] [PubMed]

36. Rawlings, N.D.; Barrett, A.J. MEROPS: The peptidase database. Nucleic Acids Res. 1999, 27, 325-331. [CrossRef] [PubMed]

37. Coulombe, R.; Grochulski, P.; Sivaraman, J.; Menard, R.; Mort, J.S.; Cygler, M. Structure of human procathepsin L reveals the molecular basis of inhibition by the prosegment. EMBO J. 1996, 15, 5492-5503. [CrossRef] [PubMed]

38. Hooper, N.M. Families of zinc metalloproteases. FEBS Lett. 1994, 354, 1-6. [CrossRef]

39. Hase, C.C.; Finkelstein, R.A. Bacterial extracellular zinc containing metalloproteases. Microbiol. Rev. 1993, 57, 823-837. [PubMed]

40. Barrett, A. J. Proteinases in Mammalian Cells and Tissues; Elsevier/North-Holland Biomedical Press: Amsterdam, The Netherlands, 1977; pp. 181-208.

41. Garrett, R.H.; Grisham, C.M. Biochemistry; University of Virginia: Charlottesville, VA, USA, 2010; p. 103.

42. Hausrath, A.C.; Matthews, B.W. Thermolysin in the absence of substrate has an open conformation. Acta Crystallogr. 2002, 58, 1002-1007. [CrossRef]

43. Endo, S. Studies on protease produced by thermophilic bacteria. J. Ferment. Technol. 1962, 40, 346.

44. Kooi, C.; Sokol, P.A. Differentiation of thermolysins and serralysins by monoclonal antibodies. J. Med. Microbiol. 1996, 45, 219-225. [CrossRef] [PubMed]

45. De Kreij, A.; Venema, G.; van den Burg, B. Substrate specificity in the highly heterogeneous M4 peptidase family is determined by a small subset of amino acids. J. Biol. Chem. 2000, 275, 31115-31120. [CrossRef] [PubMed]

46. Titani, K.; Hermodson, M.A.; Ericsson, L.H.; Walsh, K.A.; Neurath, H. Amino-acid sequence of thermolysin. Nat. New Biol. 1972, 238, 35-37. [CrossRef] [PubMed]

47. Ooshima, H.; Mori, H.; Harano, Y. Synthesis of aspartame precursor by thermolysin solid in organic solvent. Biotechnol. Lett. 1985, 7, 789-792. [CrossRef]

48. Holmquist, B.; Vallee, B.L. Metal substitutions and inhibition of thermolysin: Spectra of the cobalt enzyme. J. Biol. Chem. 1974, 249, 4601-4607. [PubMed]

49. Vallee, B.L.; Auld, D.S. Zinc coordination, function, and structure of zinc enzymes and other proteins. Biochemistry 1990, 29, 5647-5659. [CrossRef] [PubMed]

50. Hangauer, D.G.; Monzingo, A.F.; Matthews, B.W. An interactive computer graphics study of thermolysin-catalyzed peptide cleavage and inhibition by $N$-carboxymethyl peptides. Biochemistry 1984, 23, 5730-5741. [CrossRef] [PubMed]

51. Pelmenschikov, V.; Blomberg, M.R.A.; Siegbahn, P.E.M. A theoretical study of the mechanism of peptide hydrolysis by thermolysine. J. Biol. Inorg. Chem. 2001, 7, 284-298. [CrossRef] [PubMed]

52. Kilshtain, A.V.; Warshel, A. On the origin of the catalytic power of carboxypeptidase A and other metalloenzymes. Proteins 2009, 77, 536-550. [CrossRef] [PubMed]

53. Quicho, F.A.; McMurray, C.H.; Lipscomb, W.N. Similarities between the Conformation of Arsanilazotyrosine 248 of Carboxypeptidase A $a$ in the Crystalline State and in Solution. Proc. Nat. Acad. Sci. USA 1972, 69, 2850-2854. [CrossRef]

54. Wu, S.; Zhang, C.; Xu, D.; Guo, H. Catalysis of Carboxypeptidase A: Promoted-Water versus Nucleophilic Pathways. J. Phys. Chem. B 2010, 114, 9259-9267. [CrossRef] [PubMed]

55. Lazarus, M.B.; Jiang, J.; Kapuria, V.; Bhuiyan, T.; Janetzko, J.; Zandberg, W.F.; Vocadlo, D.J.; Herr, W.; Walker, S. HCF-1 is cleaved in the active site of O-GlcNAc transferase. Science 2013, 342, 1235-1239. [CrossRef] [PubMed]

56. Janetzko, J.; Trauger, S.A.; Lazarus, M.B.; Walker, S. How the glycosyltransferase OGT catalyzes amide bond cleavage. Nat. Chem Biol. 2016, 12, 899-901. [CrossRef] [PubMed]

57. Smith, C.S.; Anderson, M.A.; Hoadley, K.A.; Keck, J.L.; Cleland, W.W.; Denu, J. M. Structural and kinetic isotope effect studies of nicotinamidase (Pnc1) from saccharomyces cerevisiae. Biochemistry 2012, 51, 243-256. [CrossRef] [PubMed] 
58. Fyfe, P.K.; Rao, V.A.; Zemla, A.; Cameron, S.; Hunter, W.N. Specificity and mechanism of acinetobacter baumanii nicotinamidase: Implications for activation of the front-line tuberculosis drug pyrazinamide. Angew. Chem. Int. Ed. 2009, 48, 9176-9179. [CrossRef] [PubMed]

59. Hu, G.; Taylor, A.B.; McAlister-Henn, L.; Hart, P.J. Crystal structure of the yeast nicotinamidase Pnc1p. Arch. Biochem. Biophys. 2007, 461, 66-75. [CrossRef] [PubMed]

60. Du, X.; Wang, W.; Kim, R.; Yakota, H.; Nguyen, H.; Kim, S.H. Crystal structure and mechanism of catalysis of a pyrazinamidase from Pyrococcus horikoshii. Biochemistry 2001, 40, 14166-14172. [CrossRef] [PubMed]

61. Mukherjee, T.; Zhang, Y.; Abdelwahed, S.; Ealick, S.E.; Begley, T.P. Catalysis of a flavoenzyme-mediated amide hydrolysis. J. Am. Chem. Soc. 2010, 132, 5550-5551. [CrossRef] [PubMed]

62. Massey, V. Activation of molecular oxygen by flavins and flavoproteins. J. Biol. Chem. 1994, 269, 22459. [PubMed]

63. Vaughn, H.L.; Robbins, M.D. Rapid procedure for the hydrolysis of amides to acids. J. Org. Chem. 1975, 40, 1187. [CrossRef]

64. Gao, C.; Lavey, B.J.; Lo, C.L.; Datta, A.; Wentworth, P., Jr.; Janda, K.D. Direct selection for catalysis from combinatorial antibody libraries using a boronic acid probe: Primary amide bond hydrolysis. J. Am. Chem. Soc. 1998, 120, 2211-2217. [CrossRef]

65. Martin, M.T.; Angeles, T.S.; Sugasawara, R.; Aman, N.I.; Napper, A.D.; Darsley, M.J.; Sanchez, R.I.; Booth, P.; Titmas, R.C. Antibody-catalyzed hydrolysis of an unsubstituted amide. J. Am. Chem. Soc. 1994, 116, 6508-6512. [CrossRef]

66. Dai, X.; de Mesmaeker, A.; Joyce, G.F. Cleavage of an amide bond by a ribozyme. Science 1995, 267, 237-241. [CrossRef] [PubMed]

67. Wezynfeld, N.E.; Frączyk, T.; Bal, W. Metal assisted peptide bond hydrolysis: Chemistry, biotechnology and toxicological implications. Coord. Chem. Rev. 2016, 327-328, 166-187. [CrossRef]

68. Yashiro, M.; Sonobe, Y.; Yamamura, A.; Takarada, T.; Komiyama, M.; Fujii, Y. Metal-ion-assisted hydrolysis of dipeptides involving a serine residue in a neutral aqueous solution. Org. Biomol. Chem. 2003, 1, 629-632. [CrossRef] [PubMed]

69. Suh, J.H. Model studies of metalloenzymes involving metal-ions as Lewis acid catalysts. Acc. Chem. Res. 1992, 25, 273-279. [CrossRef]

70. Wybon, C.C.D.; Mensch, C.; Hollanders, K.; Gadais, C.; Herrebout, W.A.; Ballet, S.; Maes, B.U.W. Zn-catalyzed tert-Butyl nicotinate-directed amide cleavage as a biomimic of metallo-exopeptidase activity. ACS Catal. 2018, 8, 203-218. [CrossRef]

71. Yashiro, M.; Takarada, T.; Miyama, S.; Komiyama, M. Cerium(IV)-cyclodextrin complex for peptide hydrolysis in neutral homogeneous solutions. J. Chem. Soc. Chem. Commun. 1994, 15, 1757-1758. [CrossRef]

72. Kita, Y.; Nishii, Y.; Higuchi, T.; Mashima, K. Zinc-catalyzed amide cleavage and esterification of beta-hydroxyethylamides. Angew. Chem. Int. Ed. 2012, 51, 5723-5726. [CrossRef] [PubMed]

73. Ho, P.H.; Stroobants, K.; Parac-Vogt, T.N. Hydrolysis of serine-containing peptides at neutral $\mathrm{pH}$ promoted by [MoO4]2-oxyanion. Inorg. Chem. 2011, 50, 12025-12033. [CrossRef] [PubMed]

74. Absillis, G.; Parac-Vogt, T.N. hydrolytic activity of vanadate toward serine-containing peptides studied by kinetic experiments and DFT theory. Inorg. Chem. 2012, 51, 9902-9910. [CrossRef] [PubMed]

75. Cartuyvels, E.; Absillis, G.; Parac-Vogt, T.N. Questioning the paradigm of metal complex promoted phosphodiester hydrolysis: [Mo7O24]6-polyoxometalate cluster as an unlikely catalyst for the hydrolysis of a DNA model substrate. Chem. Commun. 2008, 85-87. [CrossRef]

76. Absillis, G.; Cartuyvels, E.; Van Deun, R.; Parac-Vogt, T.N. Hydrolytic cleavage of an RNA-Model phosphodiester catalyzed by a highly negatively charged polyoxomolybdate [Mo7O24]6-Cluster. J. Am. Chem. Soc. 2008, 130, 17400-17408. [CrossRef] [PubMed]

77. Absillis, G.; Van Deun, R.; Parac-Vogt, T.N. Polyoxomolybdate promoted hydrolysis of a DNA-model phosphoester studied by NMR and EXAFS spectroscopy. Inorg. Chem. 2011, 50, 11552-115560. [CrossRef] [PubMed]

78. Takarada, T.; Yashiro, M.; Komiyama, M. Catalytic hydrolysis of peptides by cerium(IV). Chem. Eur. J. 2000, 6, 3906-3913. [CrossRef]

79. Kassai, M.; Ravi, R.G.; Shealy, S.J.; Grant, K.B. Unprecedented acceleration of zirconium(IV)-assisted peptide hydrolysis at neutral pH. Inorg. Chem. 2004, 43, 6130-6132. [CrossRef] [PubMed] 
80. Absillis, G.; Parac-Vogt, T.N. Peptide bond hydrolysis catalyzed by the Wells-Dawson Zr( $\alpha 2-P 2 W 17 O 61) 2$ polyoxometalate. Inorg. Chem. 2012, 51, 9902-9910. [CrossRef] [PubMed]

81. Ho, P.H.; Stroobants, K.; Moelants, E.; Proost, P.; Parac-Vogt, T.N. Selective hydrolysis of hen egg white lysozyme at Asp-X peptide bonds promoted by oxomolybdate. J. Inorg. Biochem. 2014, 136, 73-80.

82. Ly, H.G.T.; Fu, G.; Kondinski, A.; Bueken, B.; De Vos, D.; Parac-Vogt, T.N. Superactivity of MOF-808 toward peptide bond hydrolysis. J. Am. Chem. Soc. 2018, 140, 6325-6335. [CrossRef] [PubMed]

83. Meriwether, L.; Westheimer, F.H. Metal ion promoted hydrolysis of glycine amide and of phenylalanylglycine amide. J. Am. Chem. Soc. 1956, 78, 5119. [CrossRef]

84. Bamann, E.; Hass, J.G.; Trapmann, H. Metallionenkatalytische zerlegung der (-CO-NH-)-bindung in peptiden und N-Acetyl-aminosäuren. Arch. Pharm. 1961, 294, 569-580. [CrossRef]

85. Collman, J.P.; Buckingham, D.A. Hydrolytic cleavage of N-terminal peptide bonds by a cobalt chelate. J. Am. Chem. Soc. 1963, 85, 3039-3040. [CrossRef]

86. Buckingham, D.A.; Coliman, J.P.; Happer, D.A.R.; Marzilli, L.G. Hydrolysis of N-terminal peptide bonds and amino acid derivatives by the $\beta$-hydroxoaquotriethylenetetraminecobalt(III) ion. J. Am. Chem. Soc. 1967, 89, 1082-1087. [CrossRef] [PubMed]

87. Bentley, K.W.; Creaser, E.H. Qualitative determination of N-terminal amino acids of peptides and proteins with cobalt (3) chelates. Bfochem. J. 1973, 135, 507-511. [CrossRef]

88. Kimura, E. Sequential hydrolysis of peptides with $\beta$-hydroxoaquo triethylenetetraminecobalt(III) ion. Inorg. Chem. 1974, 13, 951-954. [CrossRef]

89. Erxleben, A. Interaction of molybdocene dichloride with cysteine-containing peptides: Coordination, regioselective hydrolysis, and intramolecular aminolysis. Inorg. Chem. 2005, 44, 1082-1094. [CrossRef] [PubMed]

90. Burgeson, I.E.; Kostic', N.M. Selective hydrolysis of unactivated peptide bonds, promoted by platinum(II) complexes anchored to amino acid side chains. Inorg. Chem. 1991, 30, 4299-4305. [CrossRef]

91. Rajkovic, S.; Zivkovic, M.D.; Djuran, M.I. Reactions of dinuclear platinum(II) complexes with peptides. Curr. Protein Pept. Sci. 2016, 17, 95-105. [CrossRef] [PubMed]

92. Parac, T.N.; Kostic, N.M. New selectivity and turnover in peptide hydrolysis by metal complexes. A palladium(II) aqua complex catalyzes cleavage of peptides next to the histidine residue. J. Am. Chem. Soc. 1996, 118, 51-58. [CrossRef]

93. Živković, M.D.; Rajković, S.; Glišić, B.D.; Drašković, N.S.; Djuran, M.I. Hydrolysis of the amide bond in histidine- and methionine-containing dipeptides promoted by pyrazine and pyridazine palladium(II)-aqua dimers: Comparative study with platinum(II) analogues. Bioorg. Chem. 2017, 72, 190-198. [CrossRef] [PubMed]

94. Rajkovic, S.; Asanin, D.P.; Zivkovic, M.D.; Djuran, M.I. Synthesis of different pyrazine-bridged platinum(II) complexes and ${ }^{1} \mathrm{H}$ NMR study of their catalytic abilities in the hydrolysis of the Nacetylated L-methionylglycine. Polyhedron 2013, 65, 42-47. [CrossRef]

95. Asanin, D.P.; Zivkovic, M.D.; Rajkovic, S.; Warzajtis, B.; Rychlewska, U.; Djuran, M.I. Crystallographic evidence of anion $\cdots \pi$ interactions in the pyrazine bridged $\left\{[\mathrm{Pt}(\mathrm{en}) \mathrm{Cl}]_{2}(\mu-\mathrm{pz})\right\} \mathrm{Cl}_{2}$ complex and a comparative study of the catalytic ability of mononuclear and binuclear platinum(II) complexes in the hydrolysis of N-acetylated L-methionylglycine. Polyhedron 2013, 51, 255-262.

96. Živković, M.D.; Asanin, D.P.; Rajkovic, S.; Djuran, M.I. Hydrolysis of the amide bond in N-acetylated L-methionylglycine catalyzed by various platinum(II) complexes under physiologically relevant conditions. Polyhedron 2011, 30, 947-952. [CrossRef]

97. Rajkovic, S.; Zivkovic, M.D.; Kallay, C.; Sóvágó, I.; Djuran, M.I. A study of the reactions of a methionine- and histidine-containing tetrapeptide with different $\mathrm{Pd}(\mathrm{II})$ and $\mathrm{Pt}(\mathrm{II})$ complexes: Selective cleavage of the amide bond by platination of the peptide and steric modification of the catalyst. Dalton Trans. 2009, 39, 8370-8377. [CrossRef] [PubMed]

98. Zhu, L.; Kostie, N.M. Toward artificial metalloproteases: Mechanisms by which platinum(II) and palladium(II) complexes promote selective, fast hydrolysis of unactivated amide bonds in peptides. Inorg. Chem. 1992, 31, 3994-4001. [CrossRef]

99. Milovic, N.M.; Kostic, N.M. Palladium(II) complexes, as synthetic peptidases, regioselectively cleave the second peptide bond "upstream" from methionine and histidine side chains. J. Am. Chem. Soc. 2002, 124, 4759-4769. [CrossRef] [PubMed] 
100. Milovic, N.; Kostic, N. Palladium(II) complex as a sequence-specific peptidase: Hydrolytic cleavage under mild conditions of X-Pro peptide bonds in X-Pro-Met and X-Pro-His segments. J. Am. Chem. Soc. 2003, 125, 781-789. [CrossRef] [PubMed]

101. Milovic, N.M.; Kostic, N.M. Interplay of terminal amino group and coordinating side chains in directing regioselective cleavage of natural peptides and proteins with palladium(II) complexes. Inorg. Chem. 2002, 41, 7053-7063. [CrossRef] [PubMed]

102. Milovic, N.M.; Badjic, J.D.; Kostic, N.M. Conjugate of palladium(II) complex and $\beta$-cyclodextrin acts as a biomimetic peptidase. J. Am. Chem. Soc. 2004, 126, 696-697. [CrossRef] [PubMed]

103. Yoo, C.E.; Chae, P.S.; Kim, J.E.; Jeong, E.J.; Suh, J. Degradation of myoglobin by polymeric artificial metalloproteases containing catalytic modules with various catalytic group densities: Site selectivity in peptide bond cleavage. J. Am. Chem. Soc. 2003, 125, 14580-14589. [CrossRef] [PubMed]

104. Yoo, S.H.; Lee, B.J.; Kim, H.; Suh, J. Artificial metalloprotease with active site comprising aldehyde group and $\mathrm{Cu}(\mathrm{II})$ Cyclen complex. J. Am. Chem. Soc. 2005, 127, 9593-9602. [CrossRef] [PubMed]

105. Jeon, J.W.; Son, S.J.; Yoo, C.E.; Hong, I.S.; Suh, J. Toward protein-cleaving catalytic drugs: Artificial protease selective for myoglobin. Bioorg. Med. Chem. 2003, 11, 2901-2910. [CrossRef]

106. Kim, H.; Jang, B.; Cheon, Y.; Suh, M.; Suh, J. Proteolytic activity of Co(III) complex of 1-oxa-4,7,10triazacyclododecane: A new catalytic center for peptide-cleavage agents. J. Biol. Inorg. Chem. 2009, 14, 151-157. [CrossRef] [PubMed]

107. Chae, P.S.; Kim, M.-S.; Jeung, C.-S.; Lee, S.D.; Park, H.; Lee, S.; Suh, J. Peptide-cleaving catalyst selective for peptide deformylase. J. Am. Chem. Soc. 2005, 127, 2396-2397. [CrossRef] [PubMed]

108. Suh, J.; Chei, W.S.; Lee, T.Y.; Kim, M.G.; Yoo, S.H.; Jeong, K.; Ahn, J.Y. Cleavage agents for soluble oligomers of human islet amyloid polypeptide. J. Biol. Inorg. Chem. 2008, 13, 693-701. [CrossRef] [PubMed]

109. Lee, T.Y.; Suh, J. Target-selective peptide-cleaving catalysts as a new paradigm in drug design. Chem. Soc. Rev. 2008, 38, 1949-1957. [CrossRef] [PubMed]

110. Suh, J. Progress in designing artificial proteases: A new therapeutic option for amyloid diseases. Asian J. Org. Chem. 2014, 3, 18-32. [CrossRef]

111. De Oliveira, M.C.B.; Scarpellini, M.; Neves, A.; Terenzi, H.; Bortoluzzi, A.J.; Szpoganics, B.; Greatti, A.; Mangrich, A.S.; de Souza, E.M.; Fernandez, P.M.; et al. Hydrolytic protein cleavage mediated by unusual mononuclear copper(II) complexes: X-ray structures and solution studies. Inorg. Chem. 2005, 44, 921-929. [CrossRef] [PubMed]

112. Kopera, E.; Krężel, A., A.; Protas, A.M.; Belczyk, A.; Bonna, A.; Wysłouch-Cieszynska, A.; Poznanski, J.; Bal, W. Sequence-specific Ni(II)-dependent peptide bond hydrolysis for protein engineering: Reaction conditions and molecular mechanism. Inorg. Chem. 2010, 49, 6636-6645. [CrossRef] [PubMed]

113. Ariani, H.H.; Polkowska-Nowakowska, A.; Bal, W. Effect of D-amino acid substitutions on Ni(II)-assisted peptide bond hydrolysis. Inorg. Chem. 2013, 52, 2422-2431. [CrossRef] [PubMed]

114. Ni, J.; Sohma, Y.; Kanai, M. Scandium(III) triflate-promoted serine/threonine-selective peptide bond cleavage. Chem. Commun. 2017, 53, 3311-3314. [CrossRef] [PubMed]

115. Edman, P.; Begg, G.A. Protein sequenator. Eur. J. Biochem. 1967, 1, 80-91. [CrossRef] [PubMed]

116. Gross, E. The cyanogen bromide reaction. Methods Enzymol. 1967, 11, 238.

117. Degani, Y.; Patchornik, A. Cyanylation of sulfhydryl groups by 2-nitro-5-thiocyanobenzoic acid. High-yield modification and cleavage of peptides at cysteine residues. Biochemistry 1974, 13, 1. [CrossRef] [PubMed]

118. Mahoney, W.C.; Smith, P.K.; Hermodson, M.A. Fragmentation of proteins with o-iodosobenzoic acid: Chemical mechanism and identification of $o$-iodoxybenzoic acid as a reactive contaminant that modifies tyrosyl residues. Biochemistry 1981, 20, 443-448. [CrossRef] [PubMed]

119. Burstein, Y.; Patchornik, A. Selective chemical cleavage of tryptophanyl peptide bonds in peptides and proteins. Biochemistry 1972, 11, 4641-4650. [CrossRef] [PubMed]

120. Hamada, Y.A. Novel N-terminal degradation reaction of peptides via $\mathrm{N}$-amidination. Bioorg. Med. Chem. Lett. 2016, 26, 1690. [CrossRef] [PubMed]

121. Yamamoto, J.; Denda, M.; Maeda, N.; Kita, M.; Komiya, C.; Tanaka, T.; Nomura, W.; Tamamura, H.; Sato, Y.; Yamauchi, A.; et al. Development of a traceable linker containing a thiol-responsive amino acid for the enrichment and selective labelling of target proteins. Org. Biomol. Chem. 2014, 12, 3821-3826. [CrossRef] [PubMed] 
122. Yamamoto, J.; Maeda, N.; Komiya, C.; Tanaka, T.; Denda, M.; Ebisuno, K.; Nomura, W.; Tamamura, H.; Sato, Y.; Yamauchi, A.; et al. Development of a fluoride-responsive amide bond cleavage device that is potentially applicable to a traceable linker. Tetrahedron 2014, 70, 5122-5127. [CrossRef]

123. Shigenaga, A.; Ogura, K.; Hirakawa, H.; Yamamoto, J.; Ebisuno, K.; Miyamoto, L.; Ishizawa, K.; Tsuchiya, K.; Otaka, A. Development of a reduction-responsive amino acid that induces peptide bond cleavage in hypoxic cells. ChemBioChem 2012, 13, 968-971. [CrossRef] [PubMed]

124. Shigenaga, A.; Hirakawa, H.; Yamamoto, J.; Ogura, K.; Denda, M.; Yamaguchi, K.; Tsuji, D.; Itoh, K.; Otaka, A. Design and synthesis of caged ceramide: UV-responsive ceramide releasing system based on UV-induced amide bond cleavage followed by O-N acyl transfer. Tetrahedron 2011, 67, 3984-3990. [CrossRef]

125. Shigenaga, A.; Yamamoto, J.; Sumikawa, Y.; Furuta, T.; Otaka, A. Development and photo-responsive peptide bond cleavage reaction of two-photon near-infrared excitation-responsive peptide. Tetrahedron Lett. 2010, 51, 2868-2871. [CrossRef]

126. Shigenaga, A.; Yamamoto, J.; Hirakawa, H.; Ogura, K.; Maeda, N.; Morishita, K.; Otaka, A. Development of thiol-responsive amide bond cleavage device and its application for peptide nucleic acid-based DNA releasing system. Tetrahedron Lett. 2010, 51, 2525. [CrossRef]

127. Shigenaga, A.; Tsuji, D.; Nishioka, N.; Tsuda, S.; Itoh, K.; Otaka, A. Synthesis of a stimulus-responsive processing device and its application to a nucleocytoplasmic shuttle peptide. ChemBioChem 2007, 8, 1929-1931. [CrossRef] [PubMed]

128. Kita, M.; Yamamoto, J.; Morisaki, T.; Komiya, C.; Inokuma, T.; Miyamoto, L.; Tsuchiya, K.; Shigenaga, A.; Otaka, A. Design and synthesis of a hydrogenperoxide-responsive amino acid that induces peptide bond cleavage after exposure to hydrogen peroxide. Tetrahedron Lett. 2015, 56, 4228-4231. [CrossRef]

129. Nalbone, J.M.; Lahankar, N.; Buissereth, L.; Raj, M. Glutamic acid selective chemical cleavage of peptide bonds. Org. Lett. 2016, 18, 1186-1189. [CrossRef] [PubMed]

130. Tofteng, A.P.; Sørensen, K.K.; Conde-Frieboes, K.W.; HoegJensen, T.; Jensen, K.J. Fmoc solid-phase synthesis of C-terminal peptide thioesters by formation of a backbone pyroglutamyl imide moiety. Angew. Chem. Int. Ed. 2009, 48, 7411-7414. [CrossRef] [PubMed]

131. Tanabe, K.; Taniguchi, A.; Matsumoto, T.; Oisaki, K.; Sohma, Y.; Kanai, M. Asparagine-selective cleavage of peptide bonds through hypervalent iodine-mediated Hofmann rearrangement in neutral aqueous solution. Chem. Sci. 2014, 5, 2747-2753. [CrossRef]

132. Elashal, H.E.; Raj, M. Site-selective chemical cleavage of peptide bonds. Chem. Commun. 2016, 52, 6304-6307. [CrossRef] [PubMed]

133. Elashal, H.E.; Cohen, R.D.; Raj, M. Fmoc solid-phase synthesis of C-terminal modified peptides by formation of a backbone cyclic urethane moiety. Chem. Commun. 2016, 52, 9699-9702. [CrossRef] [PubMed]

134. Elashal, H.E.; Sim, Y.E.; Raj, M. Serine promoted synthesis of peptide thioester precursor on solid support for native chemical ligation. Chem. Sci. 2017, 8, 117-123. [CrossRef] [PubMed]

135. Elashal, H.E.; Cohen, R.D.; Elashal, H.E.; Raj, M. Oxazolidinone-mediated sequence determination of one-bead one-compound cyclic peptide libraries. Org. Lett. 2018, 20, 2374-2377. [CrossRef] [PubMed]

136. Elashal, H.E.; Cohen, R. D.; Elashal, H.E.; Zong, C.H.; Link, A.J.; Raj, M. Cyclic and lasso peptides: Sequence determination, topology analysis, and rotaxane formation. Angew. Chem. Int. Ed. 2018, 57, 6150-6154. [CrossRef] [PubMed]

137. Komiya, C.; Aihara, K.; Morishita, K.; Ding, H.; Inokuma, T.; Shigenaga, A.; Otaka, A. Development of an intein-inspired amide cleavage chemical device. J. Org. Chem. 2016, 81, 699-707. [CrossRef] [PubMed]

138. Jung, M.E.; Piizzi, G. Gem-Disubstituent effect: Theoretical basis and synthetic applications. Chem. Rev. 2005, 105, 1735-1766. [CrossRef] [PubMed]

139. Bachrach, S.M. The gem-dimethyl effect revisited. J. Org. Chem. 2008, 73, 2466-2468. [CrossRef] [PubMed]

140. Beesley, R.M.; Ingold, C.K.; Thorpe, J.F. CXIX-The formation and stability of spiro-compounds. Part I. spiro-compounds from cyclohexane. J. Chem. Soc. Trans. 1915, 107, 1080-1106. [CrossRef]

141. Bochet, C.G. Photolabile protecting groups and linkers. J. Chem. Soc. Perkin Trans. 2001, 2, 125-142.

142. Brieke, C.; Rohrbach, F.; Gottschalk, A.; Mayer, G.; Heckel, A. Light-controlled tools. Angew. Chem. Int. Ed. 2012, 51, 8446-8476. [CrossRef] [PubMed]

143. Seki, Y.; Tanabe, K.; Sasaki, D.; Sohma, Y.; Oisaki, K.; Kanai, M. Serine-selective aerobic cleavage of peptides and a protein using a water-soluble copper-organoradical conjugate. Angew. Chem. Int. Ed. 2014, 53, 6501-6505. [CrossRef] [PubMed] 
144. Samaritoni, J.G.; Copes, A.T.; Crews, D.K.; Glos, C.; Thompson, A.L.; Wilson, C.; O'Donnell, M.J.; Scott, W.L. Unexpected hydrolytic instability of N-acylated amino acid amides and peptides. J. Org. Chem. 2014, 79, 3140-3151. [CrossRef] [PubMed]

145. Shimizu, Y.; Noshita, M.; Mukai, Y.; Morimoto, H.; Ohshima, T. Cleavage of unactivated amide bonds by ammonium salt-accelerated hydrazinolysis. Chem. Commun. 2014, 50, 12623-12625. [CrossRef] [PubMed]

146. Qiu, Y.; Hemu, X.; Liu, D.X.; Tam, J.P. Selective bi-directional amide bond cleavage of N-methylcysteinyl peptide. Eur. J. Org. Chem. 2014, 20, 4370-4380. [CrossRef]

147. Creighton, C.J.; Romoff, T.T.; Bu, J.H.; Goodman, M. Mechanistic studies of an unusual amide bond scission. J. Am. Chem. Soc. 1999, 121, 6786-6791. [CrossRef]

(c) 2018 by the authors. Licensee MDPI, Basel, Switzerland. This article is an open access article distributed under the terms and conditions of the Creative Commons Attribution (CC BY) license (http://creativecommons.org/licenses/by/4.0/). 


\title{
Direct Transamidation Reactions: Mechanism and Recent Advances
}

\author{
Paola Acosta-Guzmán, Alejandra Mateus-Gómez and Diego Gamba-Sánchez * \\ Laboratory of Organic Synthesis Bio- and Organocatalysis, Chemistry Department, Universidad de los Andes, \\ Cra. 1 No 18A-12 Q:305, Bogotá 111711, Colombia; pa.acostag@uniandes.edu.co (P.A.-G.); \\ a.mateus@uniandes.edu.co (A.M.-G.) \\ * Correspondence: da.gamba1361@uniandes.edu.co; Tel.: +571-3394949 \\ Academic Editor: Michal Szostak \\ Received: 24 August 2018; Accepted: 13 September 2018; Published: 18 September 2018
}

\begin{abstract}
Amides are undeniably some of the most important compounds in Nature and the chemical industry, being present in biomolecules, materials, pharmaceuticals and many other substances. Unfortunately, the traditional synthesis of amides suffers from some important drawbacks, principally the use of stoichiometric activators or the need to use highly reactive carboxylic acid derivatives. In recent years, the transamidation reaction has emerged as a valuable alternative to prepare amides. The reactivity of amides makes their direct reaction with nitrogen nucleophiles difficult; thus, the direct transamidation reaction needs a catalyst in order to activate the amide moiety and to promote the completion of the reaction because equilibrium is established. In this review, we present research on direct transamidation reactions ranging from studies of the mechanism to the recent developments of more applicable and versatile methodologies, emphasizing those reactions involving activation with metal catalysts.
\end{abstract}

Keywords: transamidation; amide; amine; catalyst; catalysis

\section{Introduction}

The amide functionality has been recognized as one of the most important functional groups, not only because of its widespread presence in Nature (in proteins, peptides, and alkaloids, among others) [1] but also because of the vast number of synthetic structures bearing this group [2]. It is estimated that approximately $25 \%$ of the existing pharmaceuticals contain an amide bond as part of their structures [3] and that approximately $33 \%$ of the new drug candidates are "amides" [4], thus making amidation reactions some of the most performed chemical processes in the pharmaceutical industry and in drug discovery activities [5].

Traditional methods to synthesize amides suffer from significant issues, principally the use of stoichiometric amounts of activating reagents with the consequent production of waste or the use of corrosive and troublesome reagents such as acyl chlorides or anhydrides. As a consequence, the ACS Green Chemistry Institute assessed the amide bond formation with good atom economy as one of the biggest challenges for organic chemists [6]. In recent years, amide bond synthesis by nontraditional methods has been reviewed, and some alternatives are available to perform acylations on nitrogen [7-10]. Among those unconventional methods, the transamidation reaction appears to be a useful strategy.

The acyl exchange between an amide and an amine has been known since 1876 with the studies carried out by Flescher [11]; however, the method was pretty limited. For approximately one hundred years, the transamidation reaction was almost unexplored, and only a few successful examples were published [12-15]. The biggest drawback of this method was the use of high temperatures and very long reaction times. The first catalytic transamidation was performed using carbon dioxide [14]; 
however, the quantity used makes it not properly a catalyst but rather a promoter; additionally, the yields were always lower than $67 \%$. It was not until 1994 that a modern and complete study on a direct transamidation was published by Bertrand and coworkers [16]. Their work was based on the use of aluminum chloride as a promoter, and the method was limited to the use of aliphatic amines since low yields were obtained with aromatic amides. Chemists noticed the importance and the potential of the direct transamidation reaction and developed some useful and general methods performed under the influence of different types of catalysts. Today, heterogeneous, metallic, acidic and basic catalysts are available to perform transamidation reactions. In this review article, we will begin with the mechanistic studies for transamidation of primary and secondary amides, followed by studies of the reaction with tertiary amides and some other mechanistic studies using proline as a catalyst. In the following sections, we will present a set of selected examples of direct transamidation reactions catalyzed by metals as well as some alternative catalysts.

\section{Mechanistic Studies}

In transamidation, an alternative strategy to prepare amides, the direct exchange of the amine moiety in an amide can occur only under the influence of a suitable catalytic or stoichiometric activating agent because of the poor electrophilic nature of amides. Depending on the reaction conditions, the structure of the amide, and the activating agent employed, the reactivity of these amides differs from reaction to reaction; however, it follows the regular pattern that the primary amides are more active than the secondary and tertiary amides. Nevertheless, some activating agents capable of activating secondary amides have been described in the literature with considerable success [10]. The order of reactivity shown before implies that the structure of the amide is the most important constraint in transamidation processes. Another very important factor is the acidic nature of the N-H function, which could hamper the process by simply inactivating the catalytic species. Considering these facts, understanding how this process occurs represents one of the main challenges for the organic chemistry community [8].

In this sense, Stahl and coworkers [17-19] studied the mechanism of the transamidation reaction catalyzed by metals, focusing on the reaction between a secondary amine and a secondary amide (Scheme 1). They evaluated the behavior of nucleophilic alkali-metal amides, Lewis acidic metal complexes, transition metals and different amides. The authors found that metallic complexes of titanium and aluminum could catalyze the transamidation reaction due to their relatively low basicity; furthermore, metallic complexes of titanium $\left[\mathrm{Ti}\left(\mathrm{NMe}_{2}\right)_{4}\right]$ and aluminum $\left[\mathrm{Al}\left(\mathrm{NMe}_{2}\right)_{6}\right]$ could catalyze the transamidation reaction due to an increase in electron density in the metal center. This effect is related to the reduced basicity of the ligand, which increases the Lewis acidic character of the metal.

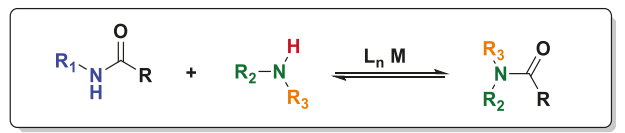

Scheme 1. Transamidation of a secondary amide with a secondary amine.

Based on the previous information, the author carried out a complete mechanistic study, which included the determination of the deuterium kinetic isotope effect, the rate law and the identity of the catalyst resting state. With the results obtained in the kinetic studies, they proposed a catalytic mechanism to explain the transamidation process (Scheme 2). They suggested that in the first step, the secondary amide reacts with the precatalyst to yield metal-amidate complex I. Once this complex is formed, it enters the catalytic cycle by a bimolecular reaction with a primary amine to generate adduct II. After that, a proton transfer between the nitrogen atoms is proposed to reach intermediate III. Later, an intramolecular nucleophilic attack of the amido-ligand to the carbonyl of the amide forms metallacycle IVa. This intermediate is the most important species in the catalytic cycle because it embodies the bifunctional role of the metal center via activation of both the amine and amide substrate. 
However, this intermediate can either revert the cycle to complex III or continue the catalytic cycle by isomerization to form $\mathbf{I V b}$. The isomerization proceeds by transition state $\mathbf{V}$, where the metal is linked to both nitrogen atoms, thus changing the nitrogen coordinated to the metal center and providing exchanged intermediate $\mathbf{I V b}$. This product is easily converted into VI, and finally, the breakdown of intermediate VI promoted by a second molecule of amide leads to the formation of the desired amide and the liberation of an amine molecule that is responsible, in most of the cases, for the equilibrium displacements; in other words: it is the driving force of this reaction [18-20].

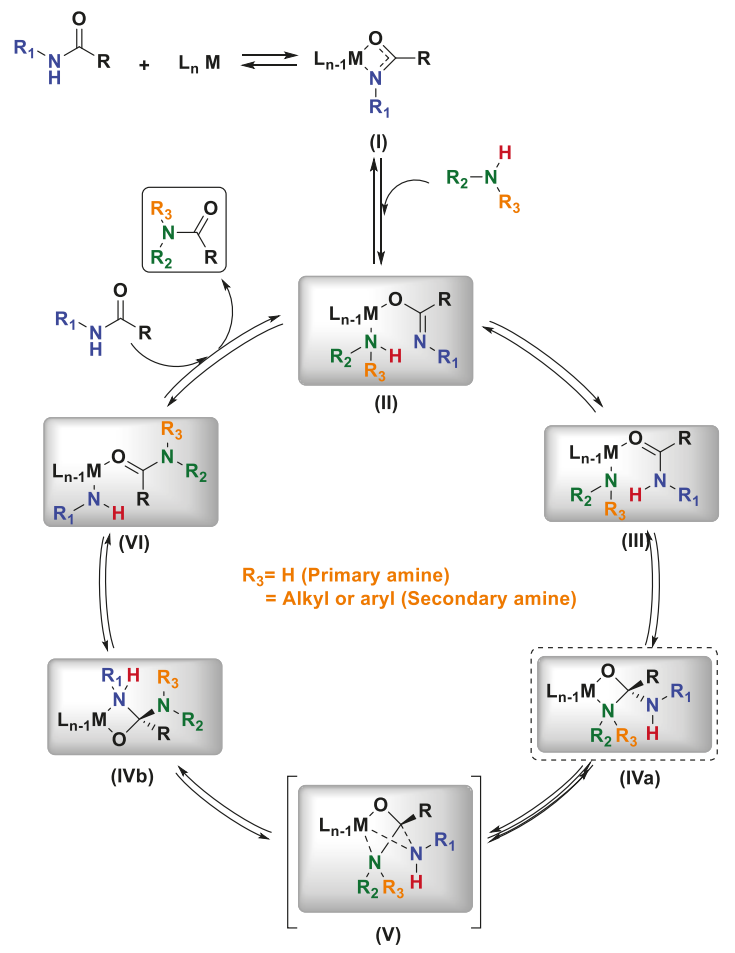

Scheme 2. Proposed catalytic cycle for transamidation reactions between primary or secondary amides with primary amines.

Careful analysis of the proposed mechanism suggests that tertiary amides are unsuitable reagents for the transamidation reaction. This is because of the absence of an $\mathrm{N}-\mathrm{H}$ bond and the consequently different reactivity between these amides and bases. However, successful examples of transamidation reactions with tertiary amides have been described in the literature, suggesting that tertiary amides should follow a different mechanistic pathway. Stahl and coworkers confronted this issue and developed a new study focused on the mechanistic details of the transamidation reaction between tertiary amides and secondary amines employing kinetic, spectroscopic, and computational studies (Scheme 3). According to their results, the first step occurs when the amide interacts with the metal complex to form intermediate I, where the simultaneous activation of the electrophile (amide) and the nucleophile (amine) by the metal center is clear. After that, an intramolecular attack of the amido ligand to the coordinated amide gives rise to metal-stabilized tetrahedral intermediate IIa, which can interconvert to its isomeric intermediate IIb by a simple cleavage and coordination sequence through intermediate III. In the last step, a new amine/amido pair coordinated to the metal IV is formed, from which it is possible to obtain the desired product [21,22]. 


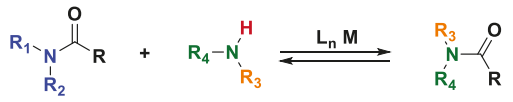

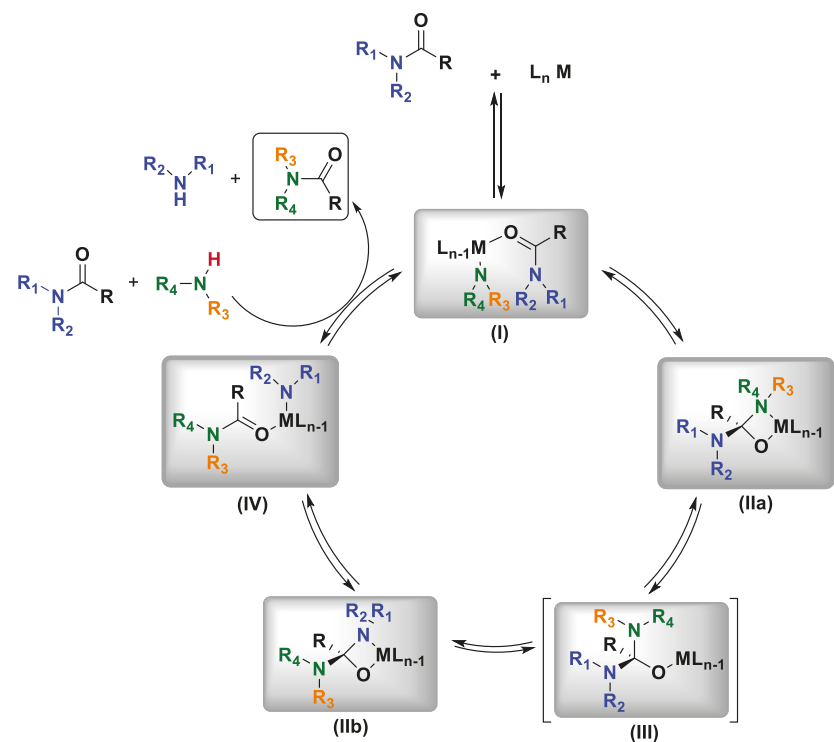

(IIb)

Scheme 3. Proposed catalytic cycle for transamidation reaction between tertiary amides with secondary amines.

Comparing the transamidation processes for secondary amides and tertiary amides makes some similarities evident. First, the mechanisms exhibit not only that there are obvious structural similarity between the intermediates but also that the key step in both processes is the intramolecular nucleophilic attack of the amido ligand on a metal-coordinated amide. Regarding the differences between the two transamidation processes, perhaps the most important one is the identity of the catalyst resting state, implying substantial differences in the kinetic properties of both reactions since the transamidation reaction of secondary amides follows first-order kinetics with regards to the metal and amine involved and the amide follows zero-order kinetics. Contrary to that, for the tertiary amide, the rate law is zero-order for the amine, is half- to first-order for the metal and varies from zero-order to saturation behavior for the amide. The transamidation of primary amides is easier than the cases described before because ammonia is produced in the reaction medium, thus making the reaction simpler and usually better yielding. Concerning the mechanisms, each research team describes its own proposal, typically based on the Stahl studies. In our opinion, slight differences between metals should exist, and as a consequence, the reaction mechanism for the transamidation of primary amides should be pretty similar to that described for secondary amides. Additionally, the large number of non-metal-catalyzed transamidation reactions makes the investigation of their mechanisms interesting. Unfortunately, only one computational study on the reaction catalyzed by L-proline has been described; mechanisms with other catalysts remain unexplored.

The organocatalyzed transamidation reaction has been described as a greener methodology compared with the metal-catalyzed version of this reaction. L-Proline has received much attention due to its dual role as a ligand and a catalyst in other reactions. In view of the above perceptions, L-proline was described as a useful catalyst for the transamidation reaction. Adimurthy and coworkers [23] found that various amides react with a variety of amines in the presence of L-proline as a catalyst. The reaction scope included benzylamines with electron-rich and deficient substituents and alkyl 
aromatic, aliphatic, and secondary amines, which reacted with remarkable ease. Specifically, the reactions of benzylamine with primary amides showed good yields compared to reactions with secondary and tertiary amides. The authors also demonstrated that the reactions have a high degree of functional group tolerance. The mechanistic study carried out to explain the role of L-proline and to disclose why the transamidation can be efficiently catalyzed by proline was reported by Xue and coworkers some years after the reaction was described. They used density functional theory (DFT) calculations to achieve a reasonable proposal.

The transamidation of acetamide with benzylamine was selected as the model system. The calculations revealed that the reactions catalyzed by L-proline follow a stepwise mechanism, which involves a first step where the activation of the amide takes place through a proton transfer from L-proline to the carbonyl group of the amide to form intermediate imidine I. Subsequently, a nucleophilic addition of benzylamine to the imidine intermediate occurs to form II. After eliminating one molecule of ammonia, a hydrolysis of intermediate III produces the target product. This study allowed the researchers to identify the hydrolysis reaction as the rate-determining step (RDS) in the catalytic cycle with the largest energy barrier $\left(26.0,26.8\right.$ and $29.7 \mathrm{kcal} / \mathrm{mol}$ in toluene, ethanol and $\mathrm{H}_{2} \mathrm{O}$ respectively) (Scheme 4) [24].

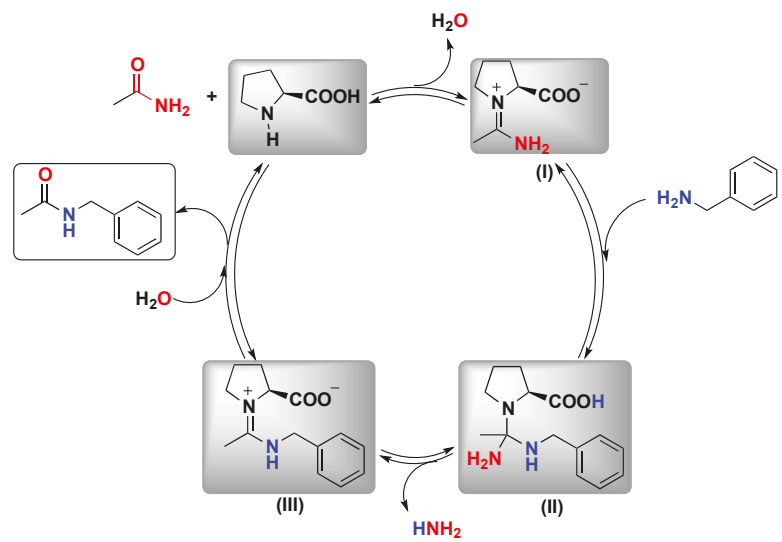

Scheme 4. Proposed mechanism to explain the transamidation reaction catalyzed by L-proline.

As already mentioned, the mechanistic studies on the transamidation reaction are quite limited; however, the metal-catalyzed version presumably follows similar mechanisms independent of the metal identity, with the mechanistic pathway depending on the type of amide reacting. Concerning the non-metal-catalyzed version, some examples are described in the literature, but among them, only L-proline has received enough attention that a mechanistic study was carried out. Nevertheless, the summary of mechanistic studies presented in this section is sufficient to understand the principles and particularities of transamidation reactions. In the following chapters, we will present some selected examples of transamidations and discuss their particularities and issues.

\section{Metal-Catalyzed Direct Transamidations}

Since the pioneering work reported by Stahl and coworkers [18-22], several metal catalysts have been described for direct transamidation reactions. Among them, one of the most commonly used is iron(III), particularly in the form of simple Fe(III) salts, supported in clay or even as nanoparticles. The first study was reported in 2014 by Shimizu and coworkers [25]; they used Fe(III) supported in montmorillonite to perform the direct transamidation of primary amides (Scheme 5). The authors showed that the reaction can be performed under solvent-free conditions with a slight excess of amine at $140{ }^{\circ} \mathrm{C}$. 


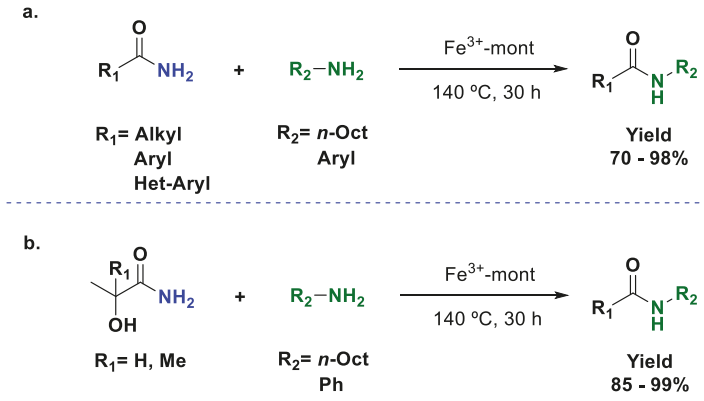

Scheme 5. (a) Transamidation of amides (alkyl, aryl, Het-aryl) with amines catalyzed by $\mathrm{Fe}^{3+}{ }^{-}$mont.

(b) Transamidations of $\alpha$-hydroxyamides with amines.

Unfortunately, the scope of the reaction is limited; only primary amides and primary amines can be used (Scheme 5a). Additionally, the method is limited to the use of liquid starting materials since at least one of the two reagents has to be a liquid, thus making this method unsuitable for a large number of reagents. A few examples with free $\alpha$-hydroxy amides were described (Scheme $5 b$ ). Typically, reactions carried out under solvent-free conditions are seen as good examples of green chemistry principles; however, the transamidation reaction has to be seen from another perspective. As we mentioned before, amidation reactions are one of the most performed processes in drug discovery and the pharmaceutical industry, and the structure of amides used in those fields are somehow complex, meaning they are usually polyfunctional compounds with more than 20 carbon atoms or, in some cases, amino acid derivatives. As a consequence, a good method to synthesize amides has to be amenable to all the structures mentioned before, and solid reagents are highly desirable even if the use of a solvent becomes imperative. This has served us as inspiration to develop a more general method for direct transamidations using Fe(III) [26]. Our method is based on the use of simple Fe(III) salts. In fact, we demonstrated that any Fe(III) salt can be used as a catalyst for this reaction; the sole condition is the presence of water, which has a complementary catalytic role in this process. Water can be added or obtained from hydrated salts, the identity of which is only limited by the availability of the reagents. Technical grade toluene is also a suitable solvent. Consequently, this method is one of the cheapest reported in the literature (Scheme 6).

a.

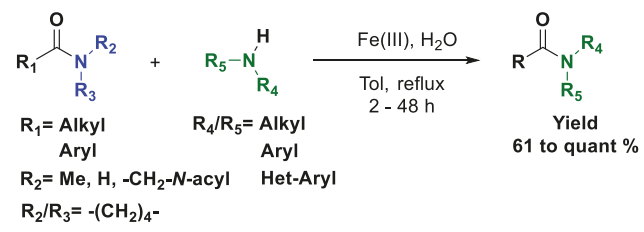

.

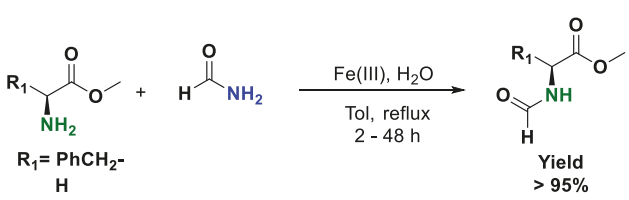

c.

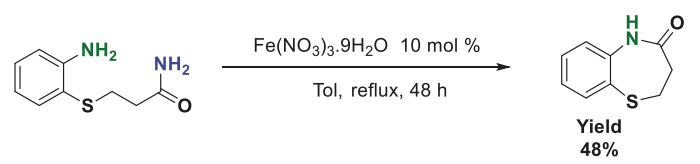

Scheme 6. Transamidation catalyzed by Fe(III) and water of (a) carboxamides. (b) $\alpha$-amino esters. (c) Synthesis of 2,3-dihydro-5H-benzo[b]-1,4-thiazepin-4-one by intramolecular transamidation. 
The reaction scope is very good since the reaction can be performed not only with an excess of amides or amines but also with stoichiometric quantities. The reaction time depends on the amide used, but it is usually shorter with primary amides and longer with secondary and tertiary amides. We also described the transamidation of secondary amides where the liberated amine is not a gas or a volatile liquid and showed that $\mathrm{Fe}(\mathrm{III})$ /water is a suitable catalyst in those cases. It should be noted that no previous functionalization of the secondary amide was needed (Scheme 6a). Finally, the reaction was described with some amino acids as the amino source (Scheme $6 \mathrm{~b}$ ), and one intramolecular example was provided (Scheme 6c). A few years later, magnetic nanoparticles were used in direct transamidation reactions, with some advantages and issues. The method described by Thale [27] using $\mathrm{Fe}_{3} \mathrm{O}_{4}$ has the same problem that all transamidations performed under solvent-free conditions show. The loading of the catalyst is also high $(20 \mathrm{wt} . \%)$, and only primary amines are used as nucleophiles. However, this particular method has some advantages: the catalyst is easily recovered and can be used in several reactions without loss of activity. It is also simple to prepare, and the reaction can be performed with DMF as an example of a tertiary amide. On the other hand, the method described by Heidari and Arefi [28] has a better substrate scope and uses smaller quantities of catalyst. Unfortunately, the preparation process for the catalyst is more complicated and uses simple iron salts as precursors; this is potentially problematic since the authors did not quantify the free salts in their catalyst, and it is possible that some remaining salts are responsible for the transformation, on the other hand if the simple salts are good and suitable catalysts for this reactions, prepare a catalysts that do not provide very different results using them a starting materials consumes time unnecessarily. The recovery of the catalyst was also described, but the identity of the catalytic species is still unclear; both Heidari and Thale attribute the catalytic activity to the metal center.

It is clear that the transamidation reaction is an equilibrium, and as such, when ammonia or gaseous amines are liberated in the reaction media, the reaction is easier. On the other hand, when the liberated amine is a liquid, the reaction becomes more complicated. Stahl and Gellman et al. [29] faced this problem and developed a method applicable to $\mathrm{N}$-aryl amides. In this case, $\mathrm{Ti}\left(\mathrm{NMe}_{2}\right)_{4}$ and $\mathrm{Sc}(\mathrm{OTf})_{3}$ were suitable catalysts affording good yields and acceptable selectivities to the cross-product. The reaction was performed with nonpolar solvents and at low temperatures. However, the best results were obtained with an excess of aliphatic amines (Scheme 7a); the use of stoichiometric aromatic amines produced mixtures of products (Scheme $7 \mathrm{~b}$ ).

a.

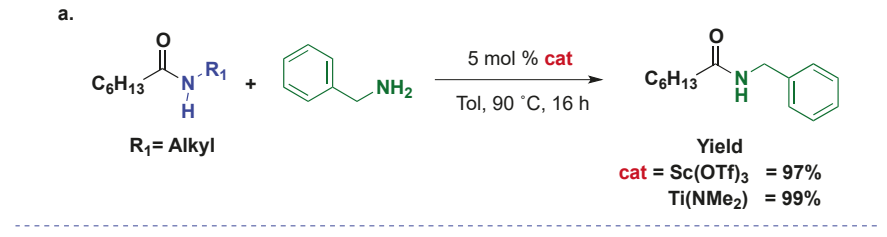

b.

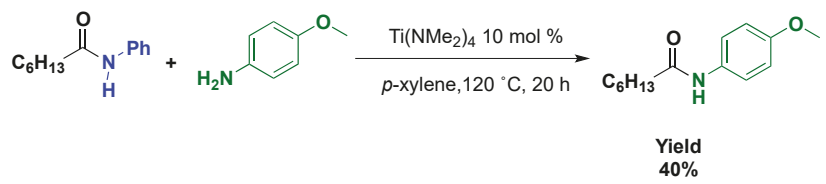

Scheme 7. Catalytic transamidation of (a) $N$-alkyl heptylamines with benzylamine and (b) $N$-aryl amides with aryl amines.

The reactions described before have some common characteristics: they are all performed in nonpolar solvents, and an excess (at least 1 equiv.) of one of the reagents is needed to obtain complete conversions and good yields. One interesting development was the use of $\mathrm{Cu}(\mathrm{OAc})_{2}$ as a catalyst described by Beller and coworkers [30], who used tert-amyl alcohol as the solvent and 0.3 excess 
equivalents of amine. The reaction is limited to the use of primary amides but has a very good substrate scope, as it tolerates free $\mathrm{OH}$ groups in the substrate and can be performed with chiral reagents (amides or amines) without racemization. The sole problem is the use of sealed tubes since high pressures are a safety issue in organic chemistry laboratories.

As the reader can notice, several efforts have been made to have more active and general catalysts for transamidations. Simple metal salts have been proven as suitable catalysts for this transformation, however, the use of more developed metal catalysts may have some advantages. In particular, the use of sulfated tungstate proved to be effective with $\alpha, \beta$-unsaturated amides [31]. These substrates can be potentially complicated because of the presence of two reactive sites. Once the amide forms the complex with the metal center, the carbonyl is more electrophilic, but the $\beta$ position suffers a similar activation; as a consequence, Michael additions are competitive reactions. In the case of sulfated tungstate, no Michael product was observed (Scheme 8a). The catalyst was also active with $\alpha$-amino acid esters, as observed in Scheme $8 \mathbf{b}$.

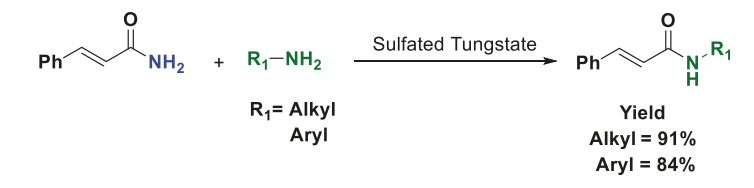

b.

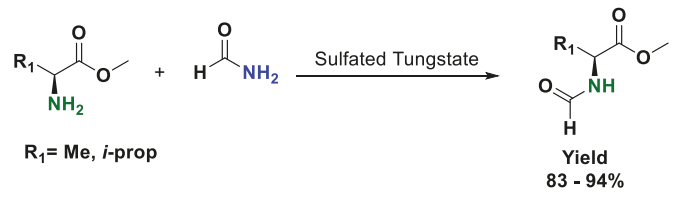

Scheme 8. Transamidation reactions in the presence of sulfated tungstate of (a) cinnamide with alkyl and aryl amines and $(\mathbf{b}) \alpha$-amino esters with formamide.

The use of tertiary amides is typically exemplified with DMF, and very few examples with other tertiary amides have been described. Fortunately, the use of $\mathrm{Pd}(\mathrm{OAc})_{2}$ with 2,2'-bipyridine (bpy) as the ligand can be used for the transamidation of tertiary amides [32]. This catalyst afforded very good yields with aromatic amines, which are easily oxidized and consequently gave lower yields than their aliphatic partners (Scheme 9). The biggest issue of this method is the use of a large excess of amine: 10 equivalents are required. However, the reaction can be performed on a gram scale with excellent results.

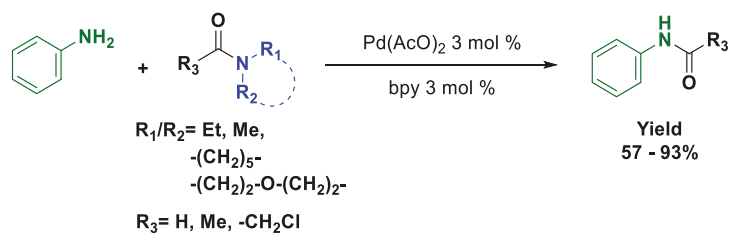

Scheme 9. Transamidation of DMF derivatives with aniline.

Very recently, Hu and coworkers [33] described a reductive transamidation of tertiary amides (very challenging substrates) with nitrobenzenes promoted by manganese. Presumably, the manganese acts not only as a reducing agent by producing the amine in situ but also as an activating agent for the amide. This was proven by adding some metals usually found as impurities of manganese, such as palladium or nickel. Additionally, this metal has also been described as a useful catalyst in a new method of transamidations, such as a reaction where the amide is activated by the use of BOC or tosyl 
groups to increase their reactivity. There are some amazing recent publications in this field, but this are not within the scope of this review article. The reaction performed by Hu et al. showed very good substrate scope and, to the best of our knowledge, is the sole general method for direct transamidation of tertiary amides.

From the previous examples, it is clear that the transamidation reaction is a powerful alternative in amide synthesis. The use of metal catalysts has shown tremendous growth in the last few years, and many researchers have developed a vast variety of catalysts using metallic centers. We selected the most general and simplest methods to discuss in this review article. Nevertheless, other less important catalysts have to be superficially mentioned, including manganese oxide $\left(\mathrm{MnO}_{2}\right)$, which was used under solvent-free conditions [34] with a limited substrate scope but with good yields. The use of lanthanides has also been described; in particular, a bimetallic lanthanum alkoxide [35], and immobilized Ce(III) [36] were used as heterogeneous catalysts with the associated advantages, such as easy catalyst recovery and low catalyst charge, but also with the normal issues, such as the catalyst preparation and activation. Some more innovative catalysts have been prepared and used successfully in transamidation. Mesoporous niobium oxide spheres [37] and $N$-heterocyclic carbene ruthenium (II) complexes [38] are some of the most general and easy to use catalysts with the best substrate scope. Very recently, the use of $\mathrm{Co}(\mathrm{AcO})_{2} \cdot 4 \mathrm{H}_{2} \mathrm{O}$ was described [39] with an excellent substrate scope, but there are no special considerations to mention here.

Some of the catalysts presented in this section can be used with ureas, with phthalimide and, in very few cases, with thioureas. The activation of those substrates has proven more difficult than amides, even though the $\mathrm{C}-\mathrm{N}$ bond has similar features to them. In addition, no details are provided about the application of transamidation reactions with ureas and phthalimides since it is outside the scope of this review. Concerning the catalysts, the development of nonmetallic catalysts has received comparable attention and will be discussed in the next chapter.

\section{Other Catalysts}

In an effort to develop safe, environmentally benign, economical, and energy saving chemical reactions, the design and synthesis of recyclable catalysts have become an important objective. In this context, innovative catalysts for transamidations have been developed. One of the most active catalysts is the recyclable polymer-based metallic Lewis acid catalyst developed by Cui and coworkers [40]. This catalyst, which is based on $\mathrm{HfCl}_{4} / \mathrm{KSF}$-polyDMAP, is recyclable and was described for transamidations of different amide/amine pairs (Scheme 10). The authors chose $\mathrm{HfCl}_{4}$ because it is active in the direct condensation of carboxylic acids and alcohols and because the Hf(IV) salts are easily manipulated and applicable in large-scale reactions. During the optimization process, the authors tried an HF/KSF system and found it suitable for transamidations with mainly nonpolar or low polarity solvents. Interestingly, this study led them to discover that by using mixtures of solvents such as acetonitrile/water and acetonitrile/ $\mathrm{NH}_{3}$, the yield was increased. The use of $\mathrm{HfCl}_{4} / \mathrm{KSF}$ with polyDMAP or $\mathrm{NH}_{3}$ afforded even better yields; presumably, the reaction rate is increased as a result the change in Lewis acidity when polyDMAP and $\mathrm{NH}_{3}$ coordinate to the metal center (Hf). This catalytic system was applied to a variety of aliphatic amides and benzylamines with excellent results. Additionally, the $\mathrm{HfCl}_{4} / \mathrm{KSF}$-polyDMA catalyst can be easily recovered and reused in the same reaction at least five times without loss of activity. However, the catalytic system has some limitations when other aliphatic amines are used.

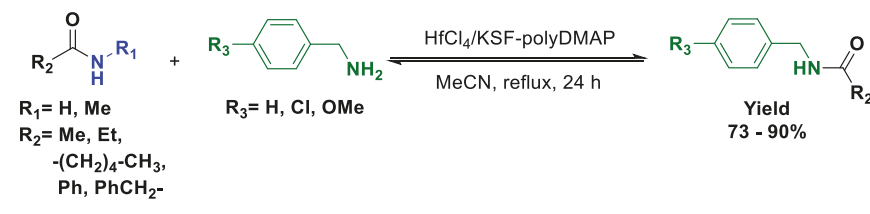

Scheme 10. Transamidation reaction catalyzed by $\mathrm{HfCl}_{4} / \mathrm{KSF}-$ polyDMAP. 
The use of stoichiometric boron reagents for amidation reactions has also been reported several times in the literature [8]. Borate esters were used by Sheppard et al. [41] to activate amides in transamidations. They evaluated different boron reagents and found that $\mathrm{B}(\mathrm{OMe})_{3}$ and $\mathrm{B}\left(\mathrm{OCH}_{2} \mathrm{CF}_{3}\right)_{3}$ show the best behavior in carboxamidation and transamidation processes. This $\mathrm{B}\left(\mathrm{OCH}_{2} \mathrm{CF}_{3}\right)_{3}-$ mediated transamidation reaction gave secondary amides in good yields; unfortunately, the main focus of this study was direct carboxamidation, and consequently, very few examples of transamidations were provided. A big issue in this is the use of stoichiometric amounts of the boron reagent. Consequently, the development of new methods that use catalytic amounts of boron reagents is highly desirable.

Nguyen et al. [42] developed the first transamidation using substoichiometric amounts of boron derivatives. In that research, the authors studied boric acid-catalyzed transamidations of amides and phthalimide. Different solvents were tested in an attempt to increase the reaction conversion. As is typical for this kind of reaction, nonpolar solvents such as toluene or xylene showed good results; however, a higher conversion was observed when the reaction was performed under solvent-free conditions. Additionally, the presence of water (1-2 equivalent) helped promote the transamidation process. Different substrates were used successfully and good yields were obtained in most cases. Secondary amines such as morpholine or piperidine proved to be less reactive and higher temperatures were needed in order to obtain acceptable yields. The most important advantage of this method compared with the other reports is the applicability on primary, secondary and tertiary amides (Scheme 11a).

$$
\text { a. }
$$

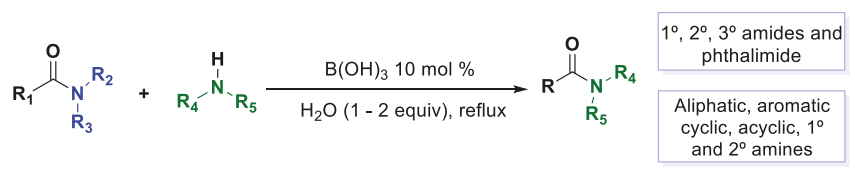

b.
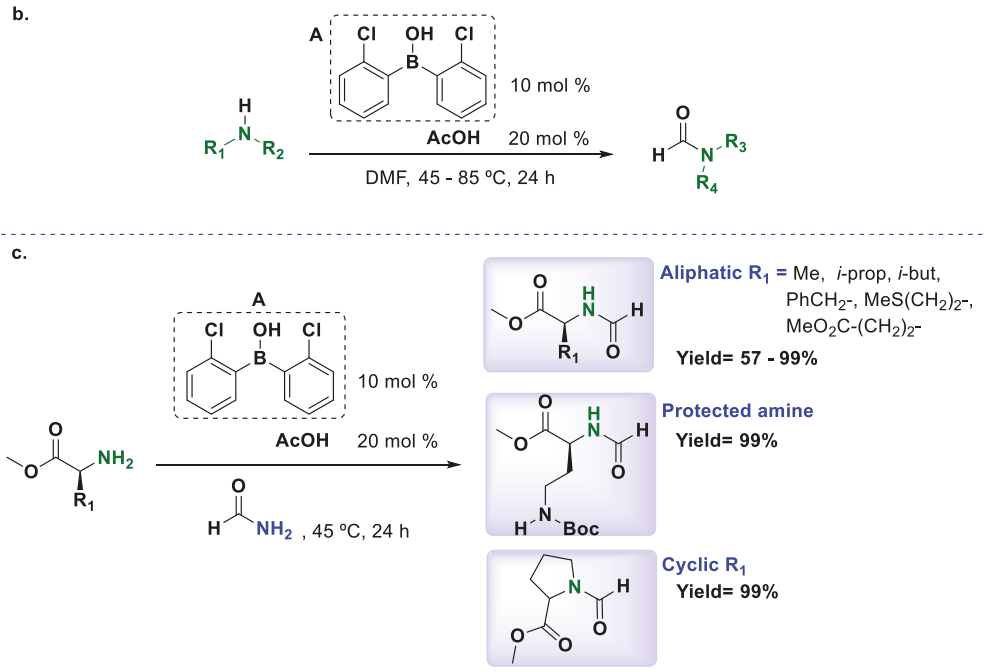

Scheme 11. (a) Boron-mediated transamidation of primary, secondary and tertiary amides with different kinds of amines. (b) Formylation of amines catalyzed by a boronic acid. (c) Transamidation catalyzed by boron between $\alpha$-amino esters and formamide.

However, the high temperatures needed to carry out this method have limited the reaction to using stable achiral amides. To circumvent this problem, Blanchet and coworker [43] exploited the 
remarkable efficiency of boronic acids as catalysts for the transamidation of DMF with amines under lower temperatures (Scheme 11b). Many tests were carried out, and the results demonstrated that the combination of $10 \mathrm{~mol} \%$ of boronic acid $\mathbf{A}$ and $20 \mathrm{~mol} \%$ of acetic acid was the best combination to promote the transamidation reactions (Scheme 11b). The authors proposed a cooperation between both acids and that a Lewis acid-assisted Bronsted acid (LBA) catalytic system could be involved. Excellent yields were found in all cases, and the process showed very good behavior with primary and secondary amines as well as $\alpha$-amino esters. Nonetheless, to perform the reaction with chiral substrates, the DMF solvent was changed to formamide in order to keep racemization at a low level (Scheme 11c).

The activation of primary amides to promote transamidations using catalytic amounts of hydroxylamine was reported by Williams and coworkers [44]. They screened different catalysts and found that the hydroxylamine salt produced the best results. The study, performed in order to compare the differences between base-free and acid salts, demonstrated that the use of salts has a positive effect on the conversion of primary amides into secondary amides. The optimal conditions for this transformation were toluene at a temperature of $105^{\circ} \mathrm{C}$ and the amount of $\mathrm{NH}_{2} \mathrm{OH} \cdot \mathrm{HCl}$ varied according to the substrate. The reaction was successful with a wide range of functional groups, including halogens, alkenes, alkynes, free phenolic hydroxyl groups, and heterocycles. Other important observations in the application of this methodology were that the Boc protecting group was unaffected under the typical reaction conditions (Scheme 12a) and that amino acid esters can be $\mathrm{N}$-acylated without loss of the ester functionality (Scheme 12b). The highest conversion was generally seen with aliphatic amides; in some cases, only $10 \mathrm{~mol} \%$ of $\mathrm{NH}_{2} \mathrm{OH} \cdot \mathrm{HCl}$ was necessary to reach full conversion in short reaction times. However, the transamidation of secondary amides using this methodology is not effective.
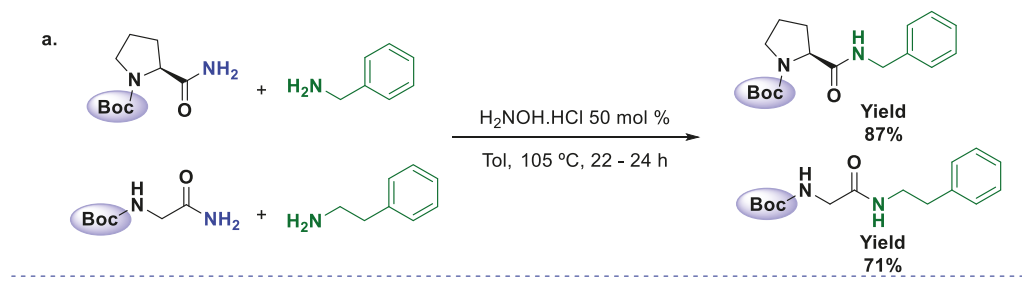

b.

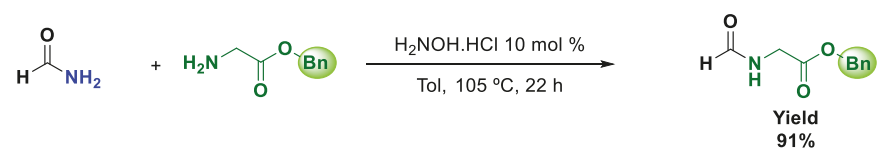

Scheme 12. Hydroxylamine hydrochloride as a catalyst of the transamidation reaction of (a) substrates with a Boc protecting group and (b) $\alpha$-amino esters with a benzyl group.

Hypervalent iodine compounds have undergone impressive developments, and their uses are increasing in many applications in organic synthesis. This progress served as inspiration to Singh and coworkers [45] to propose the first iodine (III)-catalyzed transamidation reaction. The best results were obtained when the reaction was done in the presence of $5 \mathrm{~mol} \%$ of (diacetoxyiodo)benzene (DIB) under microwave heating $\left(60-150{ }^{\circ} \mathrm{C}\right)$ without any solvent. Gratifyingly, this methodology showed a very good substrate scope with good to excellent yields. A careful analysis of the crude reaction mixtures was performed since the catalyst used is an oxidant and products derived from Hoffman rearrangements were observed. In addition, the use of stoichiometric amounts of catalyst promoted nitrene formation and increased the number of byproducts, but by using catalytic amounts, the transamidation reaction was favored.

As mentioned earlier in this manuscript, the use of organocatalysts has also been described in transamidation reactions. The study reported by Adimurthy [23], where the process was carried out in 
the presence of L-proline as an inexpensive catalyst (10 mol \%) under solvent-free conditions, suffers from some weaknesses, principally the need for the temperature to be higher than $80^{\circ} \mathrm{C}$ and the complete inactivity other amino acid catalysts.

Continuing with the revision of inexpensive catalysts in transamidation reactions, benzoic acid was recently used by $\mathrm{Xu}$ and coworkers [46], showing very good activity in transamidations. The reaction, performed in xylene at $130{ }^{\circ} \mathrm{C}$, showed very good functional group tolerance, and many substrates demonstrated good reactivity. Among them, the use of heterocyclic amides (nicotinamide, furan-2- and thiophene-2-carboxamide) with heterocyclic amines should be noted (see Scheme 13a). Unfortunately, this method is not effective with aromatic amines, with which it only afforded moderate yields. The main advantages of this methodology are the availability of the catalysts and the excellent selectivity observed. The authors performed a couple of experiments using mixtures of benzamide with 3-aminobenzylamine and benzamide with tryptamine, showing that only one product was formed in each case and thus making this a potential method for the protection of primary amines (Scheme 13b).

a.

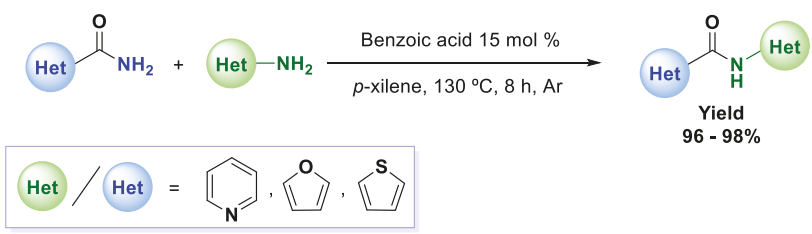

b.
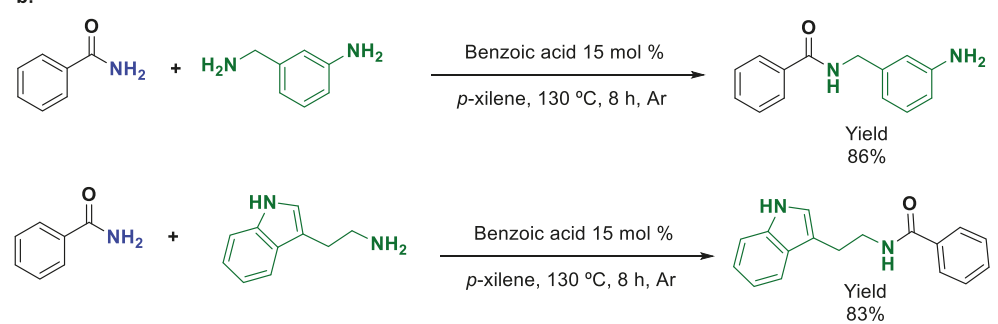

Scheme 13. (a) Benzoic acid as a catalyst of the transamidation reactions of heterocyclic amides and heterocyclic amines. (b) Selectivity of the transamidation reaction using benzoic acid as a catalyst.

In addition to these metal-free strategies for transamidation, the use of $\mathrm{K}_{2} \mathrm{~S}_{2} \mathrm{O}_{8}$ in aqueous media was recently described [47]. The reaction can be performed under the influence of microwaves or conventional heating. The study included the screening of other peroxides, such as $\mathrm{H}_{2} \mathrm{O}_{2}, \mathrm{TBHP}$, $m C P B A$ and oxone, finding that $\mathrm{K}_{2} \mathrm{~S}_{2} \mathrm{O}_{8}$ was the best reactant for the transamidation reaction. Unfortunately, stoichiometric amounts of the promoter are required to achieve complete conversions. This method was applied successfully to L-phenylalanine methyl ester hydrochloride with DMF as the formylating reagent, obtaining the $N$-formyl amino acid ester in $95 \%$ yield without any change in the configuration and optical purity, making this method possibly advantageous with chiral substrates (Scheme 14a). The authors showed an application in the synthesis of some very important molecules, such as phenacetin, paracetamol, lidocaine and piperine (Scheme 14b).

Recently, Das and coworkers [48] developed a new $\mathrm{H}_{2} \mathrm{SO}_{4}-\mathrm{SiO}_{2}$ catalytic system for the direct transamidation of carboxamides, describing a new methodology which complements those previously outlined in this article. Due to the easier ability to manipulate the catalysts, it is described as ecofriendly and low cost. The reaction is performed using $5 \mathrm{~mol} \% \mathrm{H}_{2} \mathrm{SO}_{4}-\mathrm{SiO}_{2}$ at $70{ }^{\circ} \mathrm{C}$ under solvent-free conditions, and the products were obtained without any purification. 
a.

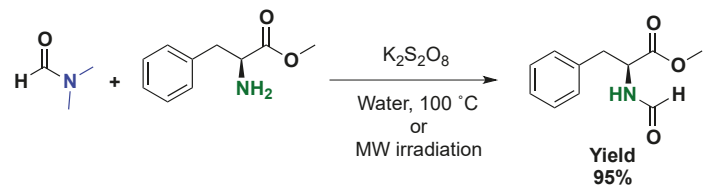

b.

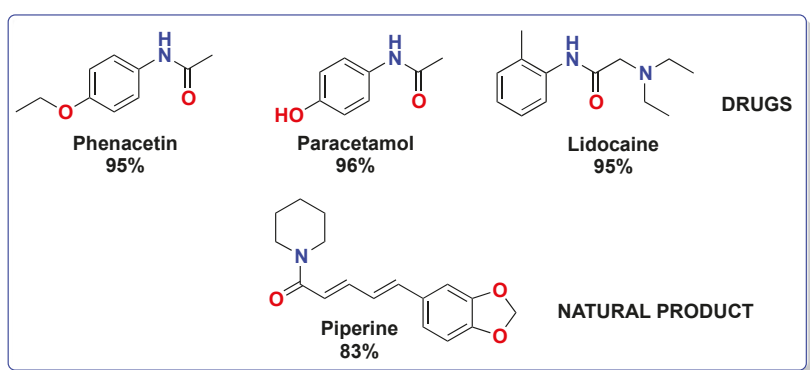

Scheme 14. (a) $N$-Formylation of $\alpha$-amino esters promoted by $\mathrm{K}_{2} \mathrm{~S}_{2} \mathrm{O}_{8}$. (b) Natural products and drugs obtained by transamidation reactions using $\mathrm{K}_{2} \mathrm{~S}_{2} \mathrm{O}_{8}$.

The catalytic system was explored using tertiary amides with substituted aromatic, heteroaromatic, and aliphatic/alicyclic primary amines and some secondary amines as well. The most important application of this methodology was in the synthesis of $N$-aryl/heteroaryl pivalamides, which are an important kind of compound in organic synthesis due to their use as directing groups in many transition-metal catalyzed reactions (Scheme 15a). Furthermore, following this optimized transamidation protocol, the authors reported the synthesis of procainamide, a drug used for the treatment of cardiac arrhythmias (Scheme 15c).
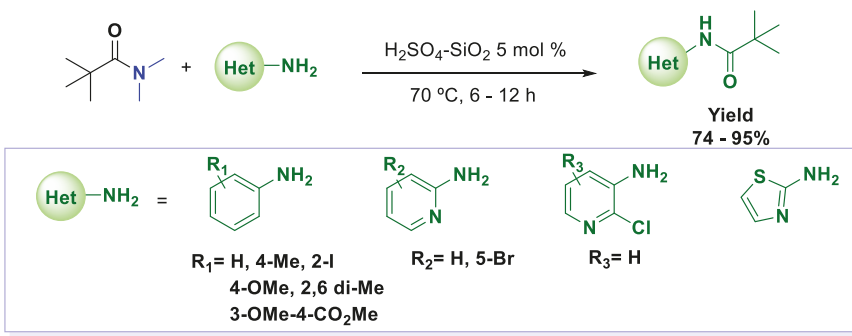

b.

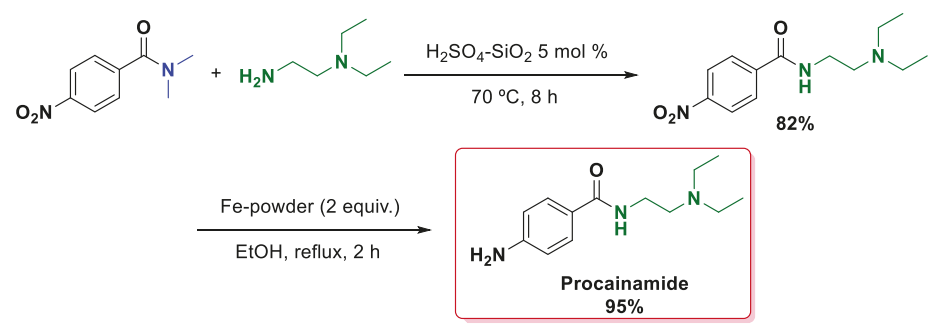

Scheme 15. (a) Synthesis of $\mathrm{N}$-aryl/heteroaryl pivalamides via transamidation catalyzed by $\mathrm{H}_{2} \mathrm{SO}_{4}-\mathrm{SiO}_{2}$. (b) Synthesis of procainamide. 
The examples cited in this section make it clear that the transamidation reaction under metal-free conditions is an attractive alternative because of its environmentally friendly and inexpensive nature. Other less relevant reports for metal-free transamidations are also described in the literature. Among them, new catalytic systems using ionic liquids [49], OSU-6 (a modified silica) [50], $\mathrm{Fe}_{3} \mathrm{O}_{4}$-guanidine acetic acid nanoparticles [51], chitosan [52], graphene oxide [53] and nanosized zeolite beta [54] have shown good results and a good substrate scope. However, they do not have any special consideration that make a more detailed discussion necessary.

\section{Conclusions}

The amide moiety is one of the most important functional groups in organic, pharmaceutical and biological chemistry. Its synthesis has been the focus of many researchers; alternative methods to obtain amides are still needed, and this field is in continuous growth. Currently, alternative activation methods for amides are among the most innovative and recent methods; however, the simple activation of the $\mathrm{C}-\mathrm{N}$ bond in amides by coordination with metals or by interaction with small molecules is an important alternative in amide bond synthesis. Herein, we surveyed the direct activation of amides in transamidation reactions and presented selected examples in this field. We hope this overview will not only that help researchers and serve as inspiration in their future work, but also that they will find it useful in understanding some recently described transamidation processes.

Author Contributions: P.A.-G. wrote more than $70 \%$ of the manuscript and contributed to editing the schemes and researching cited papers; A.M.-G. drew the schemes and contributed to the editing and research of the cited papers, as well as the discussion; D.G.-S. wrote approximately $30 \%$ of the manuscript and made major revisions and edits.

Funding: Financial support was provided by Fondo de Investigaciones de la Facultad de Ciencias de la Universidad de los Andes, convocatoria 2018-2019 para la Financiación de Programas de Investigación "Use of threonine as chiral auxiliary".

Acknowledgments: P.A.-G. and A.M.-G. acknowledge the Universidad de los Andes and particularly the Chemistry Department for providing fellowships. D.G.-S. kindly acknowledges the Chemistry Department of Universidad de los Andes for logistical support.

Conflicts of Interest: The authors have no conflicts of interest to declare.

\section{References}

1. Humphrey, J.M.; Chamberlin, A.R. Chemical synthesis of natural product peptides: Coupling methods for the incorporation of noncoded amino acids into peptides. Chem. Rev. 1997, 97, 2243-2266. [CrossRef] [PubMed]

2. Greenberg, A.; Breneman, C.M.; Liebman, J.F. The Amide Linkage: Structural Significance in Chemistry, Biochemistry, and Materials Science; Wiley-Interscience: New York, NY, USA, 2000.

3. Ghose, A.K.; Viswanadhan, V.N.; Wendoloski, J.J. A knowledge-based approach in designing combinatorial or medicinal chemistry libraries for drug discovery. 1. A qualitative and quantitative characterization of known drug databases. J. Comb. Chem. 1999, 1, 55-68. [CrossRef] [PubMed]

4. Carey, J.S.; Laffan, D.; Thomson, C.; Williams, M.T. Analysis of the reactions used for the preparation of drug candidate molecules. Org. Biomol. Chem. 2006, 4, 2337-2347. [CrossRef] [PubMed]

5. Roughley, S.D.; Jordan, A.M. The medicinal chemist's toolbox: An analysis of reactions used in the pursuit of drug candidates. J. Med. Chem. 2011, 54, 3451-3479. [CrossRef] [PubMed]

6. Constable, D.J.C.; Dunn, P.J.; Hayler, J.D.; Humphrey, G.R.; Leazer, J.J.L.; Linderman, R.J.; Lorenz, K.; Manley, J.; Pearlman, B.A.; Wells, A.; et al. Key green chemistry research areas-a perspective from pharmaceutical manufacturers. Green Chem. 2007, 9, 411-420. [CrossRef]

7. Lundberg, H.; Tinnis, F.; Selander, N.; Adolfsson, H. Catalytic amide formation from non-activated carboxylic acids and amines. Chem. Soc. Rev. 2014, 43, 2714-2742. [CrossRef] [PubMed]

8. Lanigan, R.M.; Sheppard, T.D. Recent developments in amide synthesis: Direct amidation of carboxylic acids and transamidation reactions. Eur. J. Org. Chem. 2013, 2013, 7453-7465. [CrossRef] 
9. Ojeda-Porras, A.; Gamba-Sánchez, D. Recent developments in amide synthesis using nonactivated starting materials. J. Org. Chem. 2016, 81, 11548-11555. [CrossRef] [PubMed]

10. de Figueiredo, R.M.; Suppo, J.-S.; Campagne, J.-M. Nonclassical routes for amide bond formation. Chem. Rev. 2016, 116, 12029-12122. [CrossRef] [PubMed]

11. Fleischer, A. Ueber bildung von azoverbindungen. Ber. Bunsen-Ges. Phys. Chem. 1876, 9, 992-995. [CrossRef]

12. Galat, A.; Elion, G. The interaction of amides with amines: A general method of acylation. J. Am. Chem. Soc. 1943, 65, 1566-1567. [CrossRef]

13. Pettit, G.; Kalnins, M.; Liu, T.; Thomas, E.; Parent, K. Notes-potential cancerocidal agents. III. Formanilides. J. Org. Chem. 1961, 26, 2563-2566. [CrossRef]

14. Yoshio, O.; Noboru, M.; Eiji, I. Transacylation from acid amides to amines catalyzed by carbon dioxide. Bull. Chem. Soc. Jpn. 1968, 41, 1485.

15. Kraus, M.A. The formylation of aliphatic amines by dimethylformamide. Synthesis 1973, 1973, 361-362. [CrossRef]

16. Bon, E.; Bigg, D.C.H.; Bertrand, G. Aluminum chloride-promoted transamidation reactions. J. Org. Chem. 1994, 59, 4035-4036. [CrossRef]

17. Thomson, R.K.; Zahariev, F.E.; Zhang, Z.; Patrick, B.O.; Wang, Y.A.; Schafer, L.L. Structure, bonding, and reactivity of Ti and $\mathrm{Zr}$ amidate complexes: DFT and X-ray crystallographic studies. Inorg. Chem. 2005, 44, 8680-8689. [CrossRef] [PubMed]

18. Hoerter, J.M.; Otte, K.M.; Gellman, S.H.; Stahl, S.S. Mechanism of Al(III)-catalyzed transamidation of unactivated secondary carboxamides. J. Am. Chem. Soc. 2006, 128, 5177-5183. [CrossRef] [PubMed]

19. Kissounko, D.A.; Hoerter, J.M.; Guzei, I.A.; Cui, Q.; Gellman, S.H.; Stahl, S.S. Ti ${ }^{\mathrm{IV}}$-mediated reactions between primary amines and secondary carboxamides: Amidine formation versus transamidation. J. Am. Chem. Soc. 2007, 129, 1776-1783. [CrossRef] [PubMed]

20. Kissounko, D.A.; Guzei, I.A.; Gellman, S.H.; Stahl, S.S. Titanium(IV)-mediated conversion of carboxamides to amidines and implications for catalytic transamidation. Organometallics 2005, 24, 5208-5210. [CrossRef]

21. Hoerter, J.M.; Otte, K.M.; Gellman, S.H.; Cui, Q.; Stahl, S.S. Discovery and mechanistic study of Al(III)-catalyzed transamidation of tertiary amides. J. Am. Chem. Soc. 2008, 130, 647-654. [CrossRef] [PubMed]

22. Stephenson, N.A.; Zhu, J.; Gellman, S.H.; Stahl, S.S. Catalytic transamidation reactions compatible with tertiary amide metathesis under ambient conditions. J. Am. Chem. Soc. 2009, 131, 10003-10008. [CrossRef] [PubMed]

23. Rao, S.N.; Mohan, D.C.; Adimurthy, S. L-proline: An efficient catalyst for transamidation of carboxamides with amines. Org. Lett. 2013, 15, 1496-1499. [CrossRef] [PubMed]

24. Yang, X.; Fan, L.; Xue, Y. Mechanistic insights into L-proline-catalyzed transamidation of carboxamide with benzylamine from density functional theory calculations. RSC Adv. 2014, 4, 30108-30117. [CrossRef]

25. Ayub Ali, M.; Hakim Siddiki, S.M.A.; Kon, K.; Shimizu, K. Fe ${ }^{3+}$-exchanged clay catalyzed transamidation of amides with amines under solvent-free condition. Tetrahedron Lett. 2014, 55, 1316-1319. [CrossRef]

26. Becerra-Figueroa, L.; Ojeda-Porras, A.; Gamba-Sánchez, D. Transamidation of carboxamides catalyzed by Fe(III) and water. J. Org. Chem. 2014, 79, 4544-4552. [CrossRef] [PubMed]

27. Thale, P.B.; Borase, P.N.; Shankarling, G.S. Transamidation catalysed by a magnetically separable $\mathrm{Fe}_{3} \mathrm{O}_{4}$ nano catalyst under solvent-free conditions. RSC Adv. 2016, 6, 52724-52728. [CrossRef]

28. Arefi, M.; Heydari, A. Transamidation of primary carboxamides, phthalimide, urea and thiourea with amines using $\mathrm{Fe}(\mathrm{OH})_{3} @ \mathrm{Fe}_{3} \mathrm{O}_{4}$ magnetic nanoparticles as an efficient recyclable catalyst. RSC Adv. 2016, 6, 24684-24689. [CrossRef]

29. Eldred, S.E.; Stone, D.A.; Gellman, S.H.; Stahl, S.S. Catalytic transamidation under moderate conditions. J. Am. Chem. Soc. 2003, 125, 3422-3423. [CrossRef] [PubMed]

30. Zhang, M.; Imm, S.; Bahn, S.; Neubert, L.; Neumann, H.; Beller, M. Efficient copper(II)-catalyzed transamidation of non-activated primary carboxamides and ureas with amines. Angew. Chem. Int. Ed. 2012, 51, 3905-3909. [CrossRef] [PubMed]

31. Pathare, S.P.; Jain, A.K.H.; Akamanchi, K.G. Sulfated tungstate: A highly efficient catalyst for transamidation of carboxamides with amines. RSC Adv. 2013, 3, 7697-7703. [CrossRef]

32. Gu, D.-W.; Guo, X.-X. Synthesis of $N$-arylcarboxamides by the efficient transamidation of DMF and derivatives with anilines. Tetrahedron 2015, 71, 9117-9122. [CrossRef] 
33. Cheung, C.W.; Ma, J.A.; Hu, X. Manganese-mediated reductive transamidation of tertiary amide. J. Am. Chem. Soc. 2018, 140, 6789-6792. [CrossRef] [PubMed]

34. Yedage, S.L.; D'Silva, D.S.; Bhanage, B.M. $\mathrm{MnO}_{2}$ catalyzed formylation of amines and transamidation of amides under solvent-free conditions. RSC Adv. 2015, 5, 80441-80449. [CrossRef]

35. Sheng, H.; Zeng, R.; Wang, W.; Luo, S.; Feng, Y.; Liu, J.; Chen, W.; Zhu, M.; Guo, Q. An efficient heterobimetallic lanthanide alkoxide catalyst for transamidation of amides under solvent-free conditions. Adv. Synth. Catal. 2017, 359, 302-313. [CrossRef]

36. Zarei, Z.; Akhlaghinia, B. Ce(III) immobilised on aminated epichlorohydrin-activated agarose matrix - "green" and efficient catalyst for transamidation of carboxamides. Chem. Pap. 2015, 69, 1421-1437. [CrossRef]

37. Ghosh, S.C.; Li, C.C.; Zeng, H.C.; Ngiam, J.S.; Seayad, A.M.; Chen, A. Mesoporous niobium oxide spheres as an effective catalyst for the transamidation of primary amides with amines. Adv. Synth. Catal. 2014, 356, 475-484. [CrossRef]

38. Nirmala, M.; Prakash, G.; Viswanathamurthi, P.; Malecki, J.G. An attractive route to transamidation catalysis: Facile synthesis of new $o$-aryloxide- $N$-heterocyclic carbene ruthenium(II) complexes containing trans triphenylphosphine donors. J. Mol. Catal. A Chem. 2015, 403, 15-26. [CrossRef]

39. Ma, J; Zhang, F.; Zhang, J; Gong, H. Cobalt(II)-catalyzed N-acylation of amines through a transamidation reaction. Eur. J. Org. Chem. 2018. [CrossRef]

40. Shi, M.; Cui, S.C. Transamidation catalyzed by a recoverable and reusable PolyDMAP-based hafnium chloride and montmorillonite KSF. Synth. Commun. 2006, 35, 2847-2858. [CrossRef]

41. Starkov, P.; Sheppard, T.D. Borate esters as convenient reagents for direct amidation of carboxylic acids and transamidation of primary amides. Org. Biomol. Chem. 2011, 9, 1320-1323. [CrossRef] [PubMed]

42. Nguyen, T.B.; Sorres, J.; Tran, M.Q.; Ermolenko, L.; Al-Mourabit, A. Boric acid: A highly efficient catalyst for transamidation of carboxamides with amines. Org. Lett. 2012, 14, 3202-3205. [CrossRef] [PubMed]

43. El Dine, T.M.; Evans, D.; Rouden, J.; Blanchet, J. Formamide synthesis through borinic acid catalysed transamidation under mild conditions. Chem. Eur. J. 2016, 22, 5894-5898. [CrossRef] [PubMed]

44. Allen, C.L.; Atkinson, B.N.; Williams, J.M. Transamidation of primary amides with amines using hydroxylamine hydrochloride as an inorganic catalyst. Angew. Chem. Int. Ed. 2012, 51, 1383-1386. [CrossRef] [PubMed]

45. Vanjari, R.; Kumar Allam, B.; Nand Singh, K. Hypervalent iodine catalyzed transamidation of carboxamides with amines. RSC Adv. 2013, 3, 1691-1694. [CrossRef]

46. Wu, J.-W.; Wu, Y.-D.; Dai, J.-J.; Xu, H.-J. Benzoic acid-catalyzed transamidation reactions of carboxamides, phthalimide, ureas and thioamide with amines. Adv. Synth. Catal. 2014, 356, 2429-2436. [CrossRef]

47. Srinivas, M.; Hudwekar, A.D.; Venkateswarlu, V.; Reddy, G.L.; Kumar, K.A.A.; Vishwakarma, R.A.; Sawant, S.D. A metal-free approach for transamidation of amides with amines in aqueous media. Tetrahedron Lett. 2015, 56, 4775-4779. [CrossRef]

48. Rasheed, S.; Rao, D.N.; Reddy, A.S.; Shankar, R.; Das, P. Sulphuric acid immobilized on silica gel $\left(\mathrm{H}_{2} \mathrm{SO}_{4}-\mathrm{SiO}_{2}\right)$ as an eco-friendly catalyst for transamidation. RSC Adv. 2015, 5, 10567-10574. [CrossRef]

49. Fu, R.; Yang, Y.; Chen, Z.; Lai, W.; Ma, Y.; Wang, Q.; Yuan, R. Microwave-assisted heteropolyanion-based ionic liquids catalyzed transamidation of non-activated carboxamides with amines under solvent-free conditions. Tetrahedron 2014, 70, 9492-9499. [CrossRef]

50. Nammalwar, B.; Muddala, N.P.; Watts, F.M.; Bunce, R.A. Efficient conversion of acids and esters to amides and transamidation of primary amides using OSU-6. Tetrahedron 2015, 71, 9101-9111. [CrossRef]

51. Maryam, K.M.; Marzban, A.; Elahe, Y.; Sepideh, A.; Meghdad, K.; Kobra, A.; Akbar, H. Guanidine acetic acid functionalized magnetic nanoparticles: Recoverable green catalyst for transamidation. ChemistrySelect 2016, 1, 6328-6333.

52. Rao, S.; Mohan, D.; Adimurthy, S. Chitosan: An fficiente recyclable catalyst for transamidation of carboxamdes with amines under neat condition. Green Chem. 2014, 16, 4122-4126. 
53. Bhattacharya, S.; Ghoh, P.; Basu, B. Graphene oxide (GO) catalyzed transamidations of aliphatic amides: An efficient metal-free procedure. Tetrahedron Lett. 2018, 59, 899-903. [CrossRef]

54. Durgaiah, C.; Naresh, M.; Swamy, P.; Srujana, K.; Rammurthy, B.; Narender, N. Transamidation of carboxamides with amines over nanosized zeolite beta under solvent-free conditions. Catal. Commun. 2016, 81, 29-32. [CrossRef]

(C) 2018 by the authors. Licensee MDPI, Basel, Switzerland. This article is an open access article distributed under the terms and conditions of the Creative Commons Attribution (CC BY) license (http://creativecommons.org/licenses/by/4.0/). 
Review

\title{
Transition-Metal-Free Activation of Amide Bond by Arynes
}

\section{Hideto Miyabe}

School of Pharmacy, Hyogo University of Health Sciences, Minatojima 1-3-6, Chuo-ku, Kobe 650-8530, Japan; miyabe@huhs.ac.jp; Tel.: +81-78-304-3094

Received: 3 August 2018; Accepted: 24 August 2018; Published: 27 August 2018

\begin{abstract}
Highly reactive arynes activate the $\mathrm{N}-\mathrm{C}$ and $\mathrm{C}=\mathrm{O}$ bonds of amide groups under transition metal-free conditions. This review highlights the insertion of arynes into the $\mathrm{N}-\mathrm{C}$ and $\mathrm{C}=\mathrm{O}$ bonds of the amide group. The insertion of arynes into the $\mathrm{N}-\mathrm{C}$ bond gives the unstable four-membered ring intermediates, which are easily converted into ortho-disubstituted arenes. On the other hand, the selective insertion of arynes into the $\mathrm{C}=\mathrm{O}$ bond is observed when the sterically less-hindered formamides are employed to give a reactive transient intermediate. Therefore, the trapping reactions of transient intermediates with a variety of reactants lead to the formation of oxygen atom-containing heterocycles. As relative functional groups are activated, the reactions of arynes with sulfinamides, phosphoryl amides, cyanamides, sulfonamides, thioureas, and vinylogous amides are also summarized.
\end{abstract}

Keywords: amide; arynes; insertion; activation; heterocycles; organic synthesis; multi-component coupling reaction

\section{Introduction}

In recent years, the use of arynes as highly reactive and strained intermediates in organic synthesis has attracted substantial attention [1-15]. Arynes have been extensively utilized in transition-metal-catalyzed reactions $[16,17]$. The development of ortho-trimethylsilyl aryltriflates 1 as mild aryne precursors led to growing activity in this field (Scheme 1) [18]. Arynes A can be generated in situ from triflate $\mathbf{1}$ and fluoride ion under mild reaction conditions. Therefore, the aryne chemistry using aryltriflates $\mathbf{1}$ has achieved some remarkable success, particularly in the transition metal-free reactions.
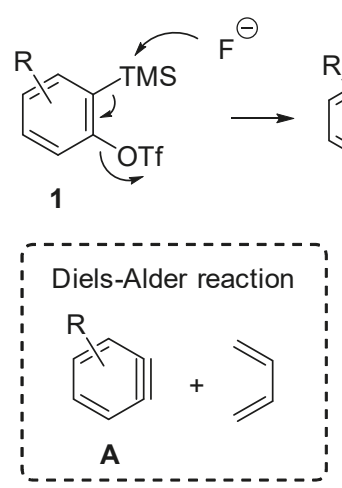<smiles>[R]c1ccc(C[N]CC)cc1</smiles>

A<smiles></smiles>

B<smiles>[R]c1ccc([N])c(F)c1</smiles>

2

Scheme 1. Transition metal-free reaction of arynes. 
Most of transition metal-free reactions proceed through the addition of nucleophiles to arynes $\mathbf{A}$ and the subsequent trapping of intermediates $\mathbf{B}$ with electrophiles to give multi-substituted arenes with structural diversity and complexity. The transition metal-free concerted reactions, such as the Diels-Alder reaction, [2 + 2] cycloaddition reaction, and dipolar cycloaddition reaction, are also synthetically useful $[6,7,11,12]$.

When the nitrogen atom of amides acts as nucleophiles toward arynes, the insertion of arynes into the $\mathrm{N}-\mathrm{C}$ bond is induced to give the $\mathrm{N}-\mathrm{C}$ insertion products 3 , via the formation of four-membered ring intermediates, $\mathbf{C}$ (Scheme 2). In contrast, insertion into the $\mathrm{C}=\mathrm{O}$ bond is promoted by the nucleophilic addition of the oxygen atom of amides to arynes (Scheme 3 ). In the $\mathrm{C}=\mathrm{O}$ insertion reaction, the four-membered ring intermediates $\mathbf{D}$ and ortho-quinone methides $\mathbf{E}$ are highly reactive $[19,20]$; thus, a variety of further transformations using $\mathbf{D}$ or $\mathbf{E}$ have been developed as multi-component coupling reactions [9]. As shown in Section 3 with the $\mathrm{C}=\mathrm{O}$ bond activation, the suitable amides for $\mathrm{C}=\mathrm{O}$ insertion are the sterically less-hindered formamides, such as $N, N$-dimethylformamide (DMF).

\section{Insertion into $\mathrm{N}-\mathrm{C}$ bond of amides}

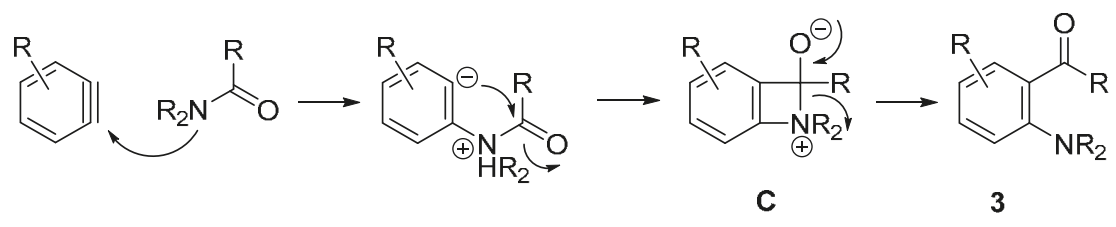

Scheme 2. Activation of amide N-C bond by arynes.

\section{Insertion into $\mathrm{C}=\mathrm{O}$ bond of formamides}

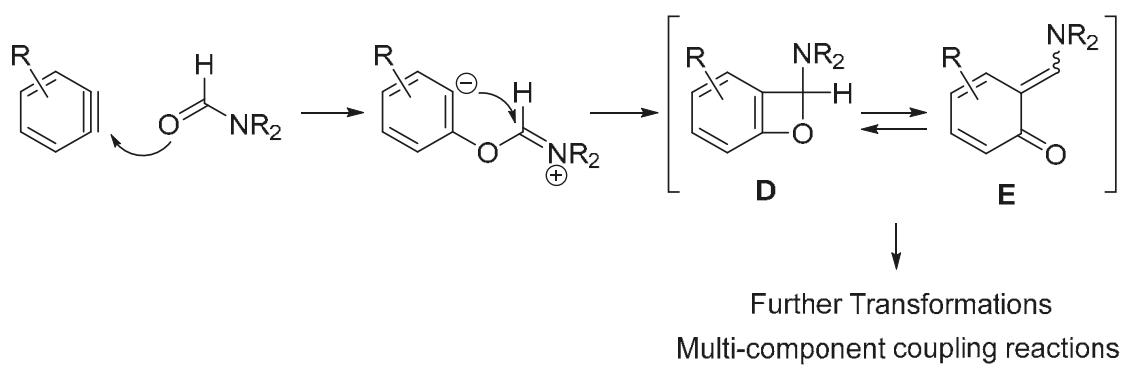

Scheme 3. Activation of amide $\mathrm{C}=\mathrm{O}$ bond by arynes.

\section{N-C Bond Activation}

At first, the insertion of arynes into the $\mathrm{N}-\mathrm{C}$ bond of the amide group was reported in the reaction of ureas with arynes [21]. In the presence of CsF, treatment of 3-methoxy-2-(trimethylsilyl) phenyl triflate 4 as an aryne precursor with 1,3-dimethyl-2-imidazolidinone (DMI) 5 gave 1,4-benzodiazepine derivative 6 in $77 \%$ yield (Scheme 4). Under similar reaction conditions, $N, N^{\prime}$-dimethylpropyleneurea (DMPU) 7 worked well to give 1,5-benzodiazocine derivative 8 . The insertion of aryne into the $\mathrm{N}-\mathrm{C}$ bond of acyclic $N, N, N^{\prime}, N^{\prime}$-tetramethylurea 9 also proceeded. In these reactions, aryne is generated by the reaction of triflate 4 with the fluoride anion of CsF. The sequential transformation is achieved via a route involving the addition of the urea nitrogen atom to an aryne, followed by the intramolecular nucleophilic attack on the carbonyl carbon atom. The resulting four-membered ring intermediate readily undergoes ring opening to afford the $\mathrm{N}-\mathrm{C}$ insertion products 6,8 , and 10 . 

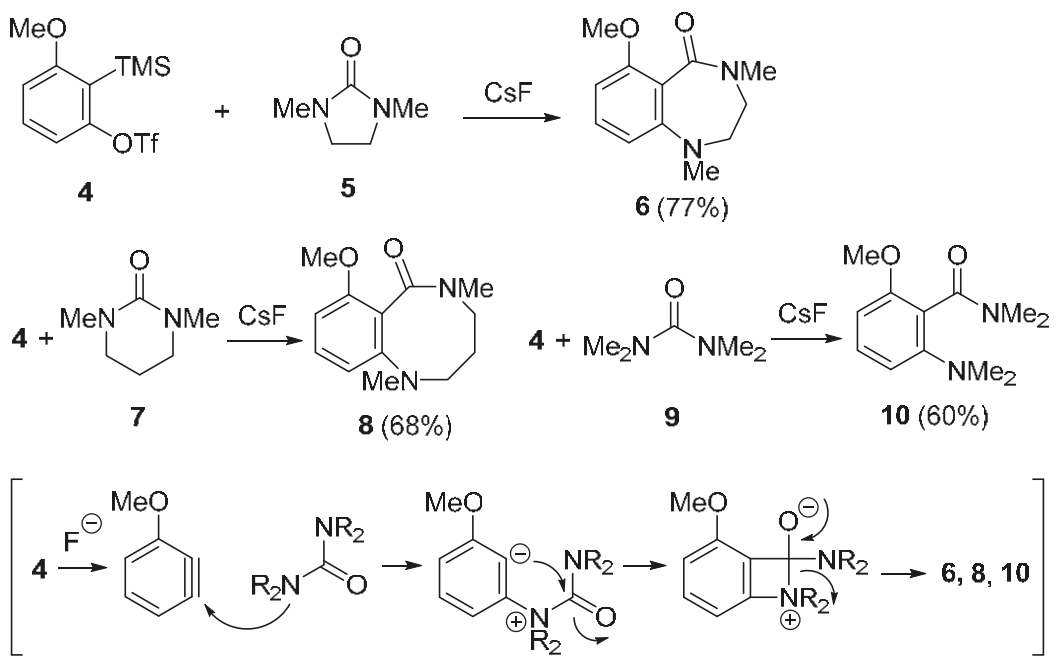

Scheme 4. Reaction of ureas with aryne.

The reaction of pyridynes with ureas was studied [22]. In the presence of CsF, the reaction of 4-triethylsilyl-3-trifluoromethanesulfonyloxypyridine $\mathbf{1 1}$ as a 3,4-pyridyne precursor with DMI 5 gave pyridodiazepine derivatives $\mathbf{1 2}$ and $\mathbf{1 3}$ in 86\% yield and a ratio of 65:35 (Scheme 5). High regioselectivity was obtained by using the 3,4-pyridyne precursor 14 having a methoxy group at the 2-position to give the product 15, selectively. The use of DMPU 7 instead of DMI 5 led to the formation of the corresponding pyridodiazocine, $\mathbf{1 6}$. When 1-methyl-2-oxazolidone 17 was employed, the selective insertion into the $\mathrm{N}-\mathrm{C}$ bond of $\mathbf{1 7}$ proceeded to give pyridooxazepine 18 .<smiles>CCN1CCN([14CH3])c2cnccc2C1=O</smiles>

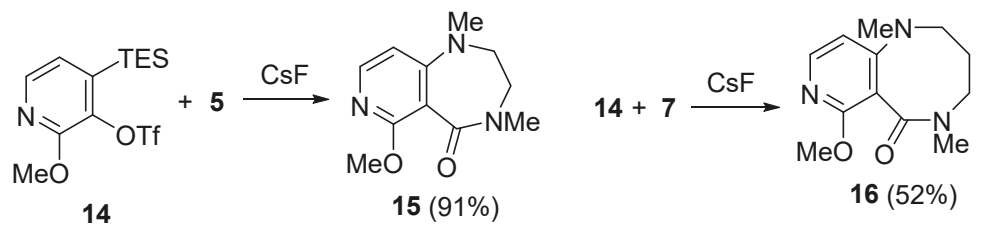<smiles>CCOC(=O)N1CCOC(=O)c2c1ccnc2OC</smiles>

Scheme 5. Insertion of pyridynes into N-C bond. 
The reaction of DMI 5 with 4,5-benzofuranyne precursor 19 was also studied (Scheme 6) [23]. The $\mathrm{N}-\mathrm{C}$ insertion product 20 was regioselectively obtained in $90 \%$ yield as a result of the initial attack of DMI 5 at $\mathrm{C} 5$ of 4,5-benzofuranyne.<smiles>CS(=O)(=O)c1c(O)ccc2occc12</smiles>

19<smiles>CN1CCN(C)C1=O</smiles>

5<smiles>CN1CCN(C)c2ccc3occc3c2C1=O</smiles>

$20(90 \%)$

Scheme 6. Insertion of 4,5-benzofuranyne into N-C bond.

It is reported that silylaryl bromides and iodides can be used as aryne precursors under the conditions similar to those employed for silylaryl triflates, such as precursors 4, 11, and 19 [24]. The utility of silylaryl bromides $21 \mathrm{a}-\mathrm{c}$ was demonstrated in the $\mathrm{N}-\mathrm{C}$ bond reaction (Scheme 7). In the presence of tetramethylammonium fluoride (TMAF), 1-bromo-3-methoxy-2-(dimethylsilyl) benzene 21a reacted with DMPU 7 to give 22a in 64\% yield. Silylaryl bromides 21b and 21c also worked well.<smiles>[R]c1cccc(Br)c1[Hg]C</smiles>

21a: $\mathrm{R}=\mathrm{MeO}$

21b: $\mathrm{R}=\mathrm{H}$

21c: $\mathrm{R}=\mathrm{Cl}$<smiles>CN1CCCN(C)C1=O</smiles>

7

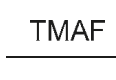<smiles>[R]c1cccc2c1C(=O)N(C)CCC2</smiles>

22a $(64 \%)$

22b (55\%)

22c $(51 \%)$

Scheme 7. Reaction of silylaryl bromides 21a-c with DMPU 7.

The insertion of arynes into the $\mathrm{N}-\mathrm{C}$ bond of $\mathrm{N}$-phenyltrifluoroacetamides proceeded effectively [25]. In the presence of $\mathrm{CsF}$, the reaction of $\mathrm{N}$-phenyltrifluoroacetamide 24a with triflate $\mathbf{2 3}$ as an aryne precursor gave the $\mathrm{N}-\mathrm{C}$ insertion product 25a in $77 \%$ yield (Scheme 8 ). The substituted $\mathrm{N}$-aryltrifluoroacetamides $\mathbf{2 4} \mathbf{b}-\mathbf{d}$ also afforded the corresponding products $\mathbf{2 5} \mathbf{b}-\mathbf{d}$ in good yields. Since the $\mathrm{CF}_{3}$ group on amides is critical to the success of these transformations, they propose the reaction mechanism involving the abstraction of the hydrogen on amide nitrogen by fluoride anion as a base. The products $25 \mathbf{a}-\mathbf{d}$ are obtained via the attack of amide nitrogen anion to aryne, the intramolecular trapping process with the carbonyl carbon atom, and the four-membered ring opening. 
<smiles>CS(=O)(=O)c1ccccc1[O+]</smiles>

23<smiles>[R]c1ccc(NC(=O)C(F)(F)C(F)(F)F)cc1</smiles>

24a: $\mathrm{R}=\mathrm{H}$

24b: $\mathrm{R}=\mathrm{Cl}$

24c: $\mathrm{R}=\mathrm{MeO}$

24d: $\mathrm{R}=\mathrm{EtO}_{2} \mathrm{C}$<smiles>[R]c1ccc(Nc2ccccc2C(=O)C(F)(F)F)cc1</smiles>

25 a $(77 \%)$

25b (86\%)

25c $(78 \%)$

25d $(60 \%)$

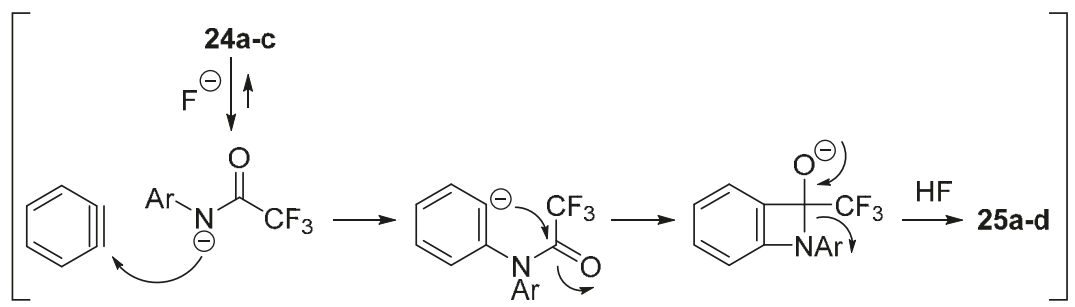

Scheme 8. Reaction of $N$-phenyltrifluoroacetamides with aryne.

To develop the amide insertion reaction having broad utility, the reaction of $N$-pivaloylaniline 26a with triflate 23 was investigated by changing solvents and fluoride sources [26]. Employing tetrabutylammonium triphenyldifluorosilicate (TBTA) as a fluoride source, amide 26a underwent the $\mathrm{N}-\mathrm{C}$ insertion in toluene at $50{ }^{\circ} \mathrm{C}$ to afford the tert-butylketone $27 \mathrm{a}$ in $64 \%$ yield (Scheme 9 ). Exploration of substrate scope showed that $N$-phenyl derivatives $\mathbf{2 6 b}$ and $\mathbf{2 6 c}$ were similarly efficient substrates.<smiles></smiles>

23<smiles>[R]C(=O)Nc1ccccc1</smiles>

26a: $\mathrm{R}=t-\mathrm{Bu}$

26b: $\mathrm{R}=\mathrm{Ph}$

26c: $\mathrm{R}=m-\mathrm{Tol}$
TBAT<smiles>[R]C(=O)c1ccccc1Nc1ccccc1</smiles>

27 a $(64 \%)$

27 b $(81 \%)$

$27 \mathrm{c}(88 \%)$

Scheme 9. Reaction of $N$-phenyltrifluoroacetamides with aryne.

Additionally, this reaction was applied to the synthesis of acridones and acridines (Scheme 10). The one-step synthesis of acridone 29 was achieved by the reaction of ortho-halobenzamide 28, with triflate 23 under microwave irradiation at $120^{\circ} \mathrm{C}$ in the presence of TBAT. Acridone 29 was formed via a route involving the $\mathrm{N}-\mathrm{C}$ insertion, followed by the intramolecular $\mathrm{S}_{\mathrm{N}} \mathrm{Ar}$ reaction. In contrast, acridine 31 was synthesized by a one-pot procedure using $\mathrm{BF}_{3} \cdot \mathrm{OEt}_{2}$ via a route involving the $\mathrm{N}-\mathrm{C}$ insertion of amide 30 into aryne, followed by a $\mathrm{BF}_{3}$-mediated Friedel-Crafts acylation and dehydration. 
23<smiles>O=C(Nc1ccccc1)c1ccccc1F</smiles>

28 TBAT<smiles>O=c1c2ccccc2n(-c2ccccc2)c2ccccc12</smiles>

$29(92 \%)$<smiles>CCOC(=O)c1ccc(NC(=O)c2cccc(Br)c2)cc1</smiles>

1) TBAT

2) $\mathrm{BF}_{3} \cdot \mathrm{OEt}_{2}$<smiles>CCOC(=O)c1ccc2c(c1)C(c1cccc(Br)c1)c1ccccc1N2</smiles>

Scheme 10. Synthesis of acridone and acridine.

The reaction of $\beta$-lactam 32 with aryne gave acridone 29 in $50 \%$ yield by employing 3.5 equivalents of the aryne precursor 23 in the presence of CsF (Scheme 11) [27]. In this transformation, 2,3-dihydroquinolin-4-one 33 is formed as an intermediate as a result of $\mathrm{N}-\mathrm{C}$ bond insertion of aryne into $\beta$-lactam 32. In fact, 33 reacted under the same reaction conditions to give acridone 29 in $77 \%$ yield. The conversion of $\mathbf{3 3}$ into $\mathbf{2 9}$ will proceed through the $\mathrm{N}$-arylation of $\mathbf{3 3}$ with second aryne, the subsequent cyclization, the extrusion of ethylene, and the final $\mathrm{N}$-arylation with third aryne.
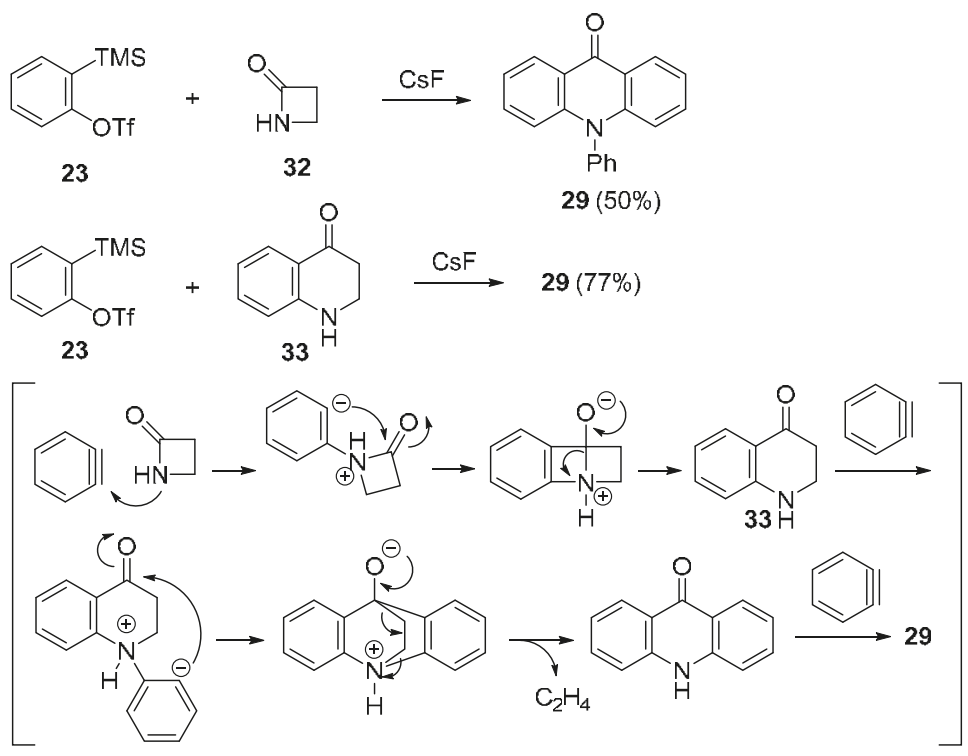

Scheme 11. Reaction of $\beta$-lactam with aryne leading to acridone.

The insertion of arynes into the $\mathrm{N}-\mathrm{C}$ bond of imides was investigated [28]. The formation of simple $N$-arylated products could be suppressed when the reactions of imides $34 a-\mathbf{d}$ with triflate $\mathbf{2 3}$ were carried out in toluene at $60^{\circ} \mathrm{C}$ in the presence of TBAT (Scheme 12). The desired N-C insertion products $35 \mathrm{a}-\mathbf{d}$ were selectively obtained. Additionally, this reaction was applied to the one-pot synthesis of quinolone 36 through Camps cyclization using $\mathrm{KOH}$ and 18-crown-6. 

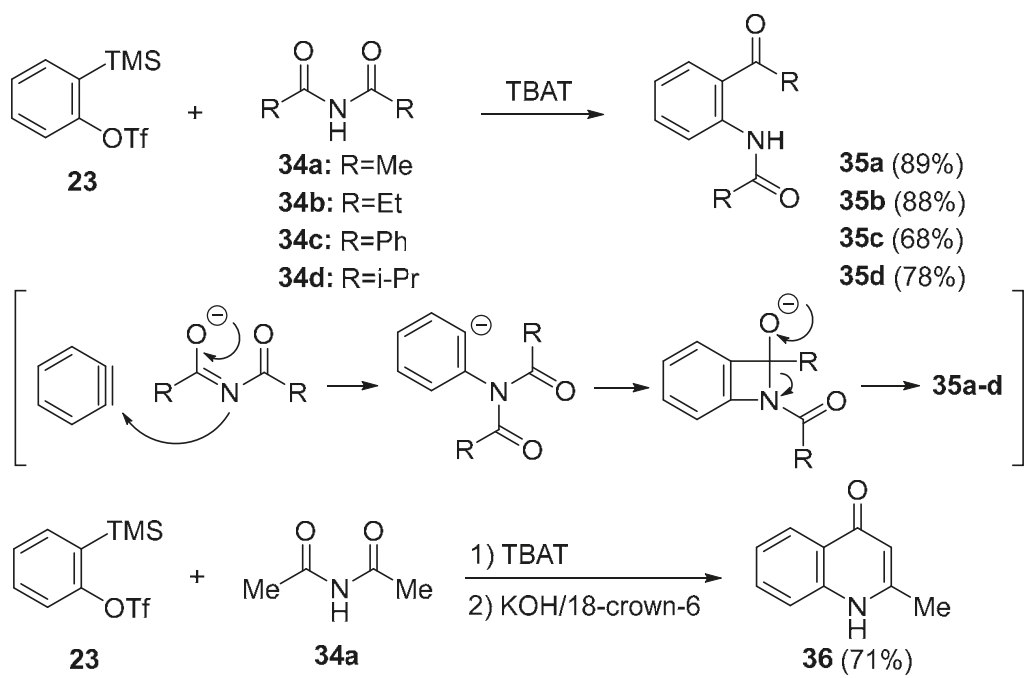

Scheme 12. Reaction of imides with aryne.

\section{3. $\mathrm{C}=\mathrm{O}$ Bond Activation}

At first, the insertion of arynes into the $\mathrm{C}=\mathrm{O}$ bond of the amide group was reported [29]. Aryne, generated from precursor 37 , reacted with $N, N$-dimethylformamide (DMF) to give salicylaldehyde 38 in $32 \%$ yield (Scheme 13$)$.

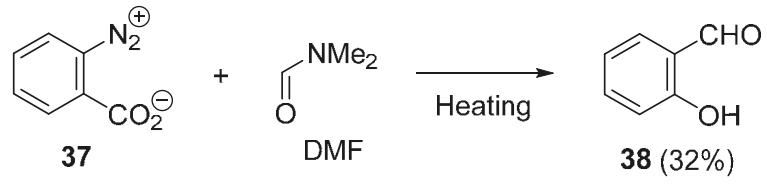

Scheme 13. Reaction of $N, N$-dimethylformamide with aryne.

When the bulky $\mathrm{N}, \mathrm{N}$-dimethylacetamide (DMA) was used, competitive insertion into the $\mathrm{C}=\mathrm{O}$ and $\mathrm{N}-\mathrm{C}$ bonds of DMA was observed [30]. In the presence of TBAF, treatment of 4 with DMA gave the $\mathrm{C}=\mathrm{O}$ insertion product 39 in $34 \%$ yield, and the $\mathrm{N}-\mathrm{C}$ insertion product 40 in 10\% yield (Scheme 14). This result indicates that the sterically less-hindered formamides are the suitable nucleophiles for $\mathrm{C}=\mathrm{O}$ insertion. The insertion into the $\mathrm{C}=\mathrm{O}$ bond will proceed via the stepwise mechanism involving the addition of the oxygen atom of amide to an aryne, followed by the intramolecular nucleophilic attack on the iminium. 

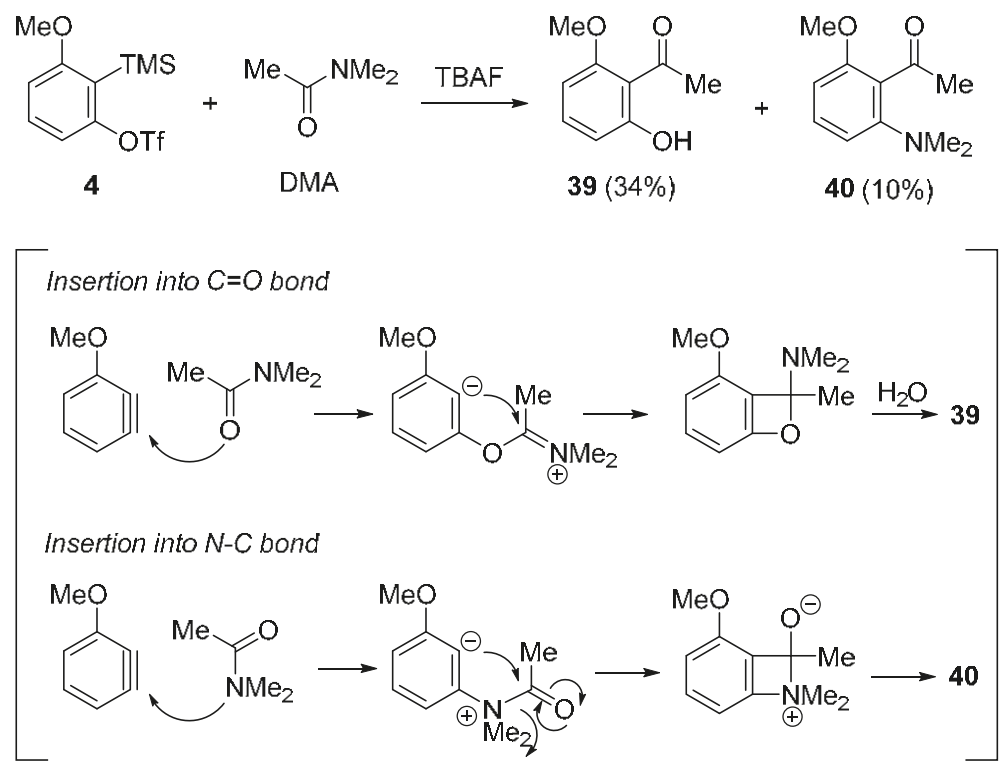

Scheme 14. Reaction of $N, N$-dimethylacetamide with aryne.

The sequential reaction involving the trapping process of transient intermediates with organometallic reagents was studied [30,31]. After a solution of triflate 4 in DMF was stirred in the presence of $\mathrm{CsF}$, a solution of $\mathrm{Et}_{2} \mathrm{Zn}$ in hexane was added to the reaction mixture (Scheme 15). The desired aminophenol 41 was obtained in $71 \%$ yield. Diethyllzinc also trapped the transient intermediate generated from triflate 4 and formamide 42 , to give the aminophenol 43 by a one-pot procedure.<smiles>COc1cccc(OC)c1S(C)(=O)=O</smiles>

4<smiles>CNC(=O)O[Na]</smiles>

DMF<smiles>CCC(c1c(O)cccc1OC)N(C)C</smiles>

$41(71 \%)$<smiles>COc1cccc(OC)c1S(C)(=O)=O</smiles>

4<smiles>O=CN1CCCCC1</smiles>

42 $\underset{\text { b) } \mathrm{Et}_{2} \mathrm{Zn}}{\mathrm{TBAF}}$<smiles>CCC(c1c(O)cccc1OC)N1CCCCC1</smiles>

$43(40 \%)$

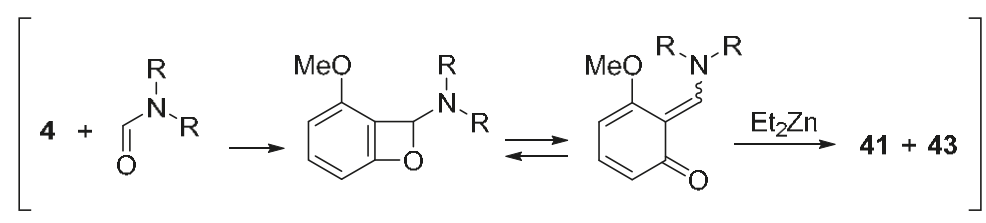

Scheme 15. Reaction for trapping the transient intermediates. 
Three-component sequential coupling of arynes, DMF, and diaryliodonium salts was studied [32]. In the presence of KF, a three-component coupling reaction was found using triflate 23 and diphenyliodonium triflate 44 in DMF-facilitated 2-phenoxybenzaldehyde 45 in 87\% yield (Scheme 16). In this transformation, diphenyliodonium triflate 44 acted as an electrophile by trapping the oxygen atom of a transient intermediate.
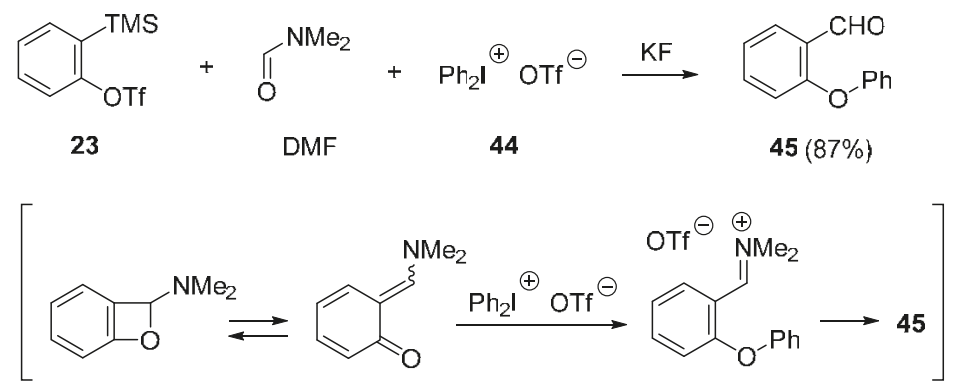

Scheme 16. Trapping reaction using diphenyliodonium salt.

The 2:1 coupling reaction of two molar amounts of aryne and one molar amount of DMF was reported (Scheme 17) [33]. Initially, the reaction of precursor 23 and DMF gives salicylaldehyde 38 via the hydrolysis of a transient intermediate. 9-Hydroxyxanthene 46 is formed by the reaction of salicylaldehyde 38 with aryne.
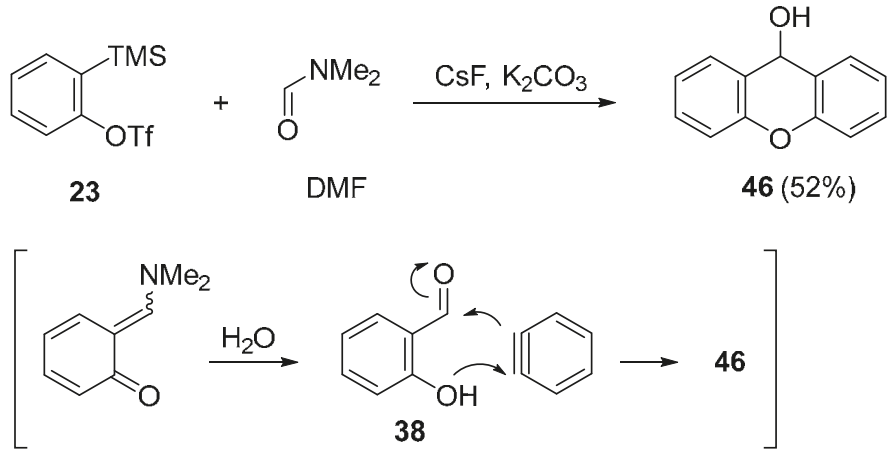

Scheme 17. 2:1-Coupling reaction.

The trapping reactions of transient intermediates generated from arynes precursors and DMF with a variety of reactants have been widely studied as being synthetic approaches to oxygen atom-containing heterocycles [34-43]. The synthesis of $2 \mathrm{H}$-coumarin derivatives was also studied [34-36]. Three-component coupling reactions leading to chromene $\mathbf{4 8}$ was achieved by the use of acetate $\mathbf{4 7}$, having an aryl group as a nucleophile for trapping the unstable intermediate (Scheme 18). In the presence of $\mathrm{KF}$, the reaction of triflate 23 and acetate 47 was carried out in DMF at $80{ }^{\circ} \mathrm{C}$ to give the coumarin 48 in $95 \%$ yield [35]. The synthesis of 2-aryliminochromene skeleton of biologically active compounds was studied by using a three-component coupling reaction [36]. A transient intermediate, generated from triflate 23 and DMF, could be trapped by $N, S$-keteneacetal 49 to give the biologically important arylimino- $2 \mathrm{H}$-chromene-3-carboxamide 50 in $81 \%$ yield. The synthesis of $4 \mathrm{H}$-chromene derivatives was also achieved by using a three-component coupling reaction involving the hetero Diels-Alder reaction between transient intermediates and dienophiles [37]. 
<smiles>CCOc1ccccc1N(C)SC</smiles>

23
$+\prod_{\mathrm{O}}^{\mathrm{NMe}_{2}}+$

DMF<smiles>CCOC(=O)CBr</smiles>

47: Ar=2-pyridyl<smiles>O=c1oc2ccccc2cc1Br</smiles>

$48(95 \%)$

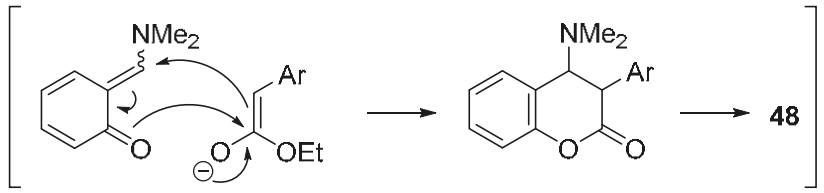

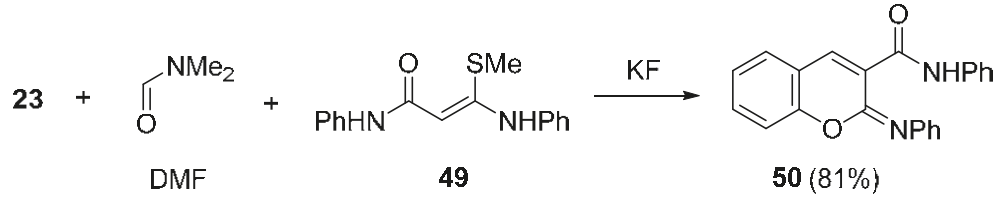

Scheme 18. Synthesis of coumarin derivatives.

The synthesis of benzofurans was also studied [38-40]. The use of $\alpha$-halogenated enolate, generated from $\alpha$-chloromalonate 51 and $\mathrm{Et}_{2} \mathrm{Zn}$, led to the formation of benzofuran 52 (Scheme 19) [38]. In the presence of $\mathrm{CsF}$, treatment of aryne precursor 4 and $\alpha$-chloromalonate 51 with $\mathrm{Et}_{2} \mathrm{Zn}$ in DMF gave 52 in $59 \%$ yield. In this transformation, $\alpha$-chloromalonate acts as a nucleophilic and electrophilic one carbon-unit for trapping a transient intermediate. Benzofuran 52 will be formed via a route involving the retro-aldol type reaction. The simple one-pot synthesis of benzofurans was also reported [40]. When 2-bromoacetophenone $\mathbf{5 3}$ was used as a nucleophilic and electrophilic reactant, benzofuran $\mathbf{5 4}$ was obtained in $79 \%$ yield.<smiles>COc1cccc(OC)c1S(C)(=O)=O</smiles>

4<smiles>CNC=O</smiles>

DMF<smiles>CC(=O)C(Cl)C(C)=O</smiles>

51<smiles>COc1cccc2oc(C(C)=O)cc12</smiles>

$52(59 \%)$<smiles>CCOC(=O)C(CC)C(C)=O</smiles>

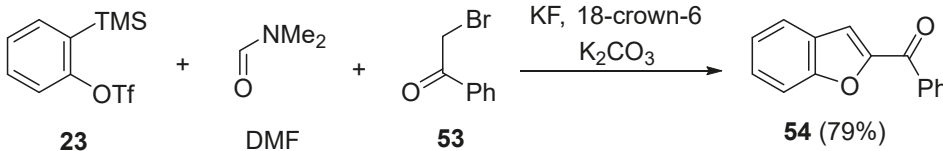

Scheme 19. Synthesis of benzofurans. 
Additionally, the trapping reaction of transient intermediates was successfully applied to a four-component coupling reaction for the convenient synthesis of xanthene derivatives [34,41,42].

\section{Activation of Relative Bonds}

The insertion of arynes into the N-S bond of sulfinamides was studied [25]. In the presence of $n$-Bu ${ }_{4} \mathrm{NF}$, the reaction of $\mathrm{N}$-phenyltrifluoromethanesulfinamides $55 \mathrm{a}-\mathrm{c}$ with triflate $\mathbf{2 3}$ as an aryne precursor gave the corresponding $\mathrm{N}-\mathrm{S}$ insertion products 56a-c in good yields (Scheme 20).<smiles>COc1ccccc1S(C)(=O)=O</smiles>

23<smiles>[R]c1ccc(NS(=O)C(F)(F)F)cc1</smiles>

55a: $\mathrm{R}=\mathrm{H}$

55b: $R=1$

55c: $\mathrm{R}=\mathrm{MeO}$<smiles>[R]c1ccc(Nc2ccccc2S(=O)C(F)(F)F)cc1</smiles>

$56 \mathrm{a}(80 \%)$

56 b $(81 \%)$

56 c $(91 \%)$

Scheme 20. Reaction of $N$-phenyltrifluoromethanesulfinamides with aryne.

The insertion of arynes into the $\mathrm{P}-\mathrm{N}$ bonds of arylphosphoryl amides was studied [44]. In the presence of KF and 18-crown-6, the reaction of diphenylphosphinic amides $57 \mathrm{a}-\mathrm{c}$ with triflate 23 was carried out at $80^{\circ} \mathrm{C}$ in a sealed tube (Scheme 21). The ortho-aniline-substituted arylphosphine oxides $58 \mathrm{a}-\mathrm{c}$ were obtained in moderate yields. This transformation proceeded through the addition of the nitrogen atom of $57 \mathrm{a}-\mathrm{c}$ to an aryne, the intramolecular trapping, and the four-membered ring opening. Additionally, the $\mathrm{P}-\mathrm{N}$ insertion product 58a was converted to ortho-amine-substituted arylphosphine 59 in $96 \%$ yield by the reduction using $\mathrm{HSiCl}_{3}$.
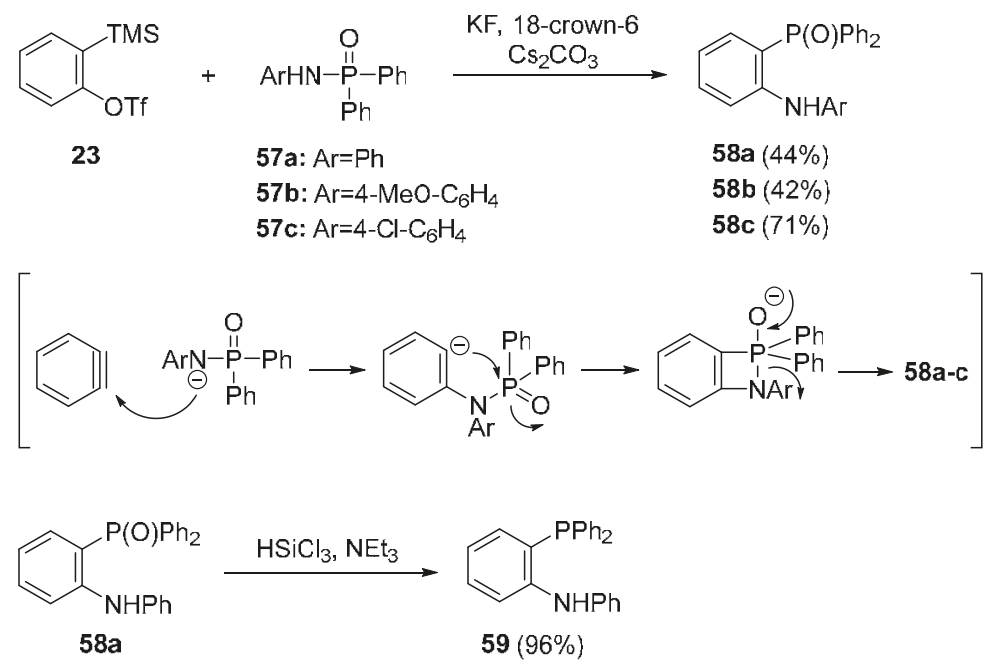

Scheme 21. Reaction of diphenylphosphinic amides with aryne. 
The insertion of arynes into the $\mathrm{N}-\mathrm{C}$ bonds of aryl cyanamides was reported [45]. In the presence of CsF, triflate 23 reacted with aryl cyanamides 60 a-e to give the 1,2-bifunctional aminobenzonitriles 61a-e in good yields (Scheme 22). This N-C bond insertion also proceeds via the formation of the four-membered ring intermediates.

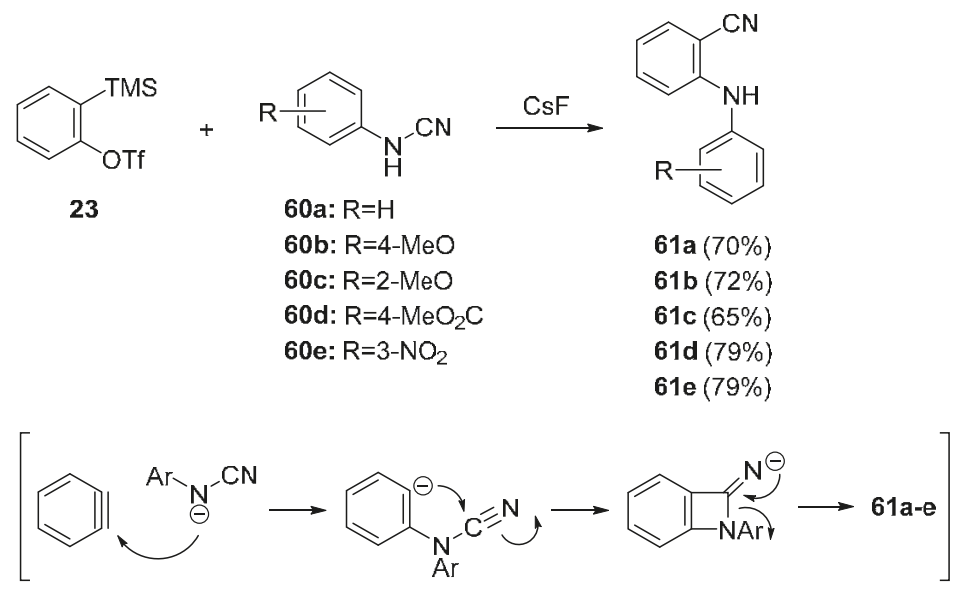

Scheme 22. Reaction of aryl cyanamides with aryne.

The synthesis of biaryl compounds was achieved by using the reaction of aryl sulfonamides with arynes [46]. In the presence of KF and 18-crown-6, aryl sulfonamides 62a-c having an electron-withdrawing group reacted with aryne to afford 2-amino-biaryls 63a-c (Scheme 23). This reaction involves the addition of sulfonamides to aryne, and the subsequent Smiles-type ipso-substitution with sulfur dioxide $\mathrm{SO}_{2}$ extrusion.

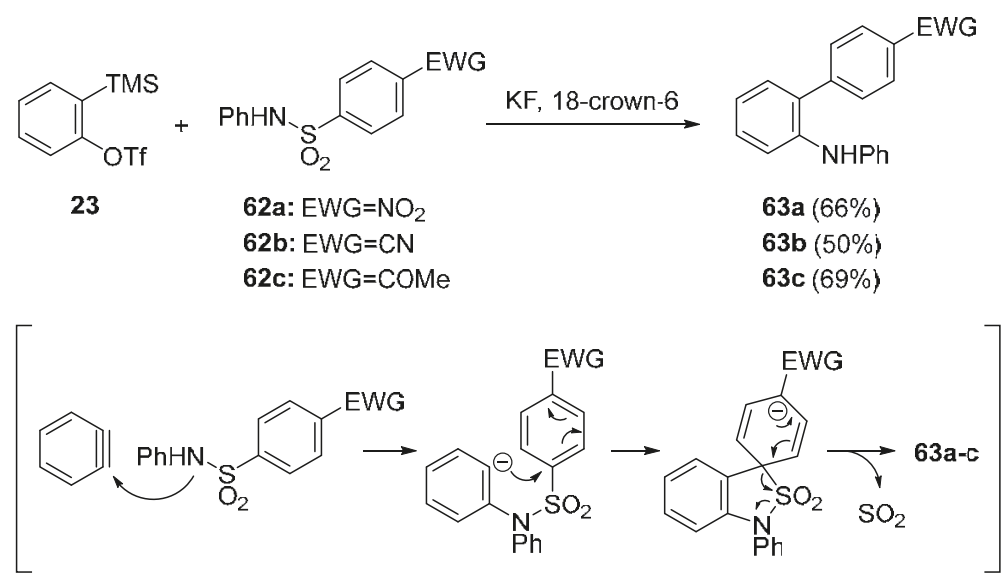

Scheme 23. Reaction of aryl sulfonamides with aryne.

Formal $\pi$-insertion into the $\mathrm{C}=\mathrm{S}$ bond was observed in the reaction of thioureas with aryne [47]. When a solution of triflate $\mathbf{2 3}$ and thiourea $\mathbf{6 4}$ in toluene/MeCN was heated in the presence of CsF, amidine $\mathbf{6 5}$ was formed in $70 \%$ yield, accompanied with the simple S-arylated product $\mathbf{6 6}$ in $20 \%$ yield (Scheme 24). The sequential transformation leading to 65 was started by the reaction of the sulfur 
atom of $\mathbf{6 4}$ with an aryne, which was followed by intramolecular trapping to give a four-membered ring intermediate. The amidine 66 was obtained via the four-membered ring opening and subsequent $S$-arylation by an aryne.
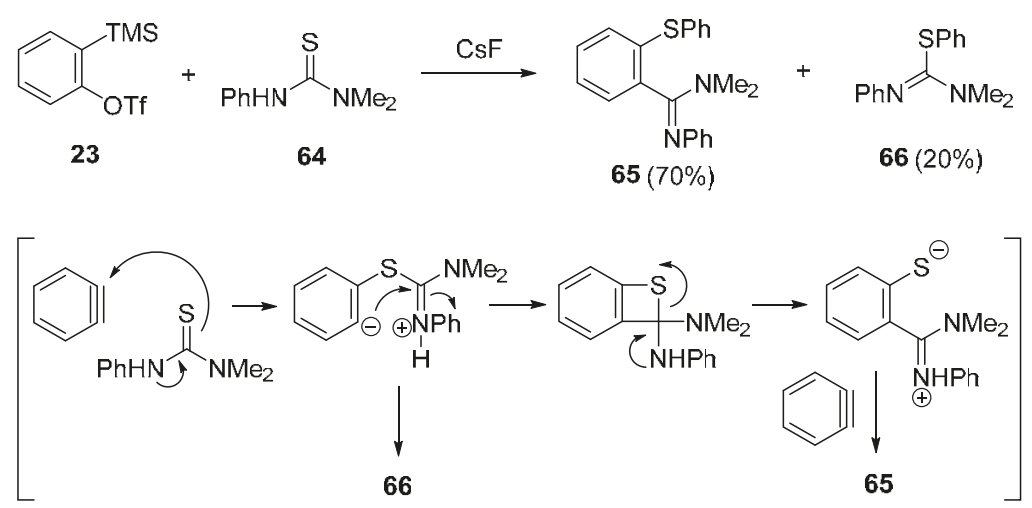

Scheme 24. Reaction of thiourea with aryne.

The $\mathrm{C}=\mathrm{C}$ double bond of vinylogous amide derivatives reacted with aryne $[48,49]$. In the presence of $\mathrm{CsF}$, the reaction of vinylogous amide derivatives $67 \mathbf{a}-\mathbf{b}$ with aryne gave the carbonyl compounds $\mathbf{6 8} \mathbf{a}-\mathbf{b}$ in good yields (Scheme 25). This transformation proceeded via the [2+2] cycloaddition between aryne and $67 \mathrm{a}-\mathrm{b}$ and the four-membered ring opening. The bulky vinylogous amides $69 \mathrm{a}-\mathrm{c}$ having ester, ketone, or cyano group as an electron-withdrawing group reacted well with aryne to give the corresponding products $70 \mathrm{a}-\mathrm{c}$ in good yields.

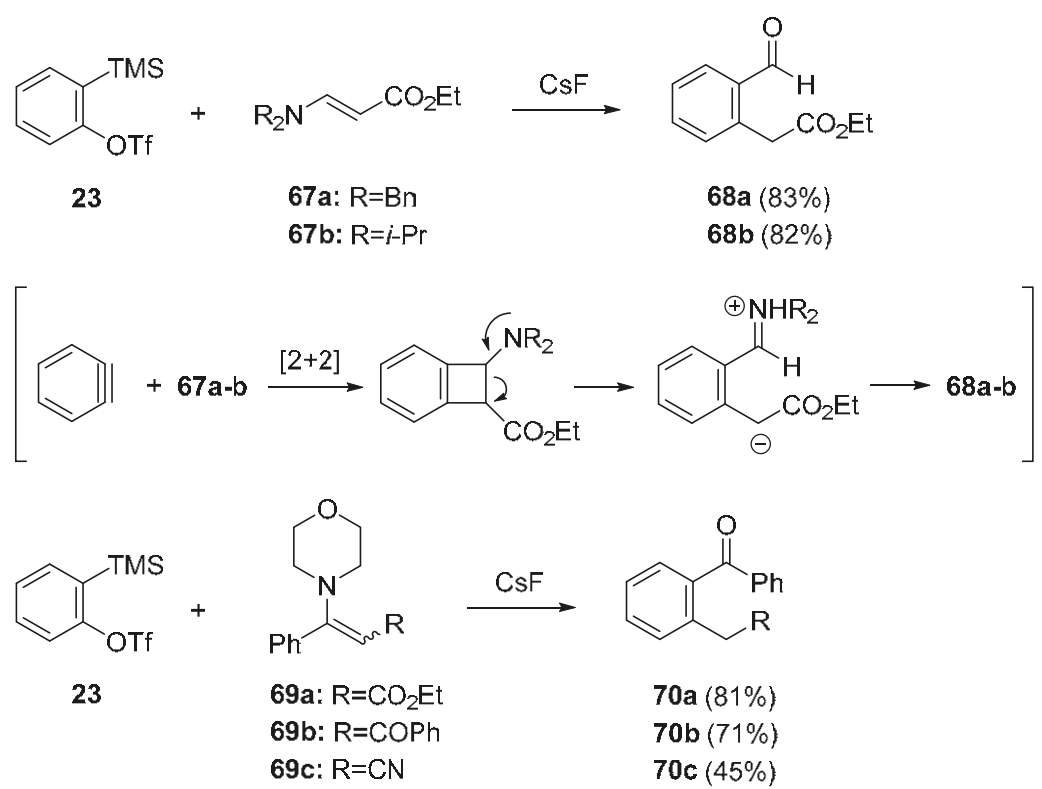

Scheme 25. Reaction of vinylogous amides with aryne. 


\section{Concluding Remarks}

Arynes are highly reactive intermediates that can activate the $\mathrm{N}-\mathrm{C}$ and $\mathrm{C}=\mathrm{O}$ bonds of an amide group under transition-metal-free conditions. As described above, the insertion of arynes into the N-C bond has been studied as a powerful method for preparing ortho-disubstituted arenes. In contrast, the selective insertion of arynes into the $\mathrm{C}=\mathrm{O}$ bond proceeds when sterically less-hindered formamides are employed. Moreover, the trapping reactions of transient intermediates with a variety of reactants, leading to the multi-component coupling reaction, disclosed a broader aspect of the utility of N-C bond insertion for the synthesis of oxygen atom-containing heterocycles. I hope that this review will inspire new creative contributions to organic chemists.

Funding: This research received no external funding.

Conflicts of Interest: The author declares no conflict of interest.

\section{References}

1. Saito, S.; Yamamoto, Y. Recent advances in the transition-metal-catalyzed regioselective approaches to polysubstituted benzene derivatives. Chem. Rev. 2000, 100, 2901-2915. [CrossRef] [PubMed]

2. Wenk, H.H.; Winkler, M.; Sander, W. One century of aryne chemistry. Angew. Chem. Int. Ed. 2003, 42, 502-528. [CrossRef] [PubMed]

3. Pellissier, H.; Santelli, M. The use of arynes in organic synthesis. Tetrahedron 2003, 59, 701-730. [CrossRef]

4. Peña, D.; Pérez, D.; Guitián, E. Aryne-mediated synthesis of heterocycles. Heterocycles 2007, 74, 89-100. [CrossRef]

5. Yoshida, H.; Ohshita, J.; Kunai, A. Aryne, ortho-quinone methide, and ortho-quinodimethane: Synthesis of multisubstituted arenes using the aromatic reactive intermediates. Bull. Chem. Soc. Jpn. 2010, 83, 199-219. [CrossRef]

6. Bhunia, A.; Yetra, S.R.; Biju, A.T. Recent advances in transition-metal-free carbon-carbon and carbonheteroatom bond-forming reactions using arynes. Chem. Soc. Rev. 2012, 41, 3140-3152. [CrossRef] [PubMed]

7. Tadross, P.M.; Stoltz, B.M. A comprehensive history of arynes in natural product total synthesis. Chem. Rev. 2012, 112, 3550-3577. [CrossRef] [PubMed]

8. Gampe, C.M.; Carreira, E.M. Arynes and cyclohexyne in natural product synthesis. Angew. Chem. Int. Ed. 2012, 51, 3766-3778. [CrossRef] [PubMed]

9. Miyabe, H. Synthesis of Oxygen Heterocycles via Aromatic $\mathrm{C}-\mathrm{O}$ Bond Formation Using Arynes. Molecules 2015, 20, 12558-12575. [CrossRef] [PubMed]

10. Goetz, A.E.; Shah, T.K.; Garg, N.K. Pyridynes and indolynes as building blocks for functionalized heterocycles and natural products. Chem. Commun. 2015, 51, 34-45. [CrossRef] [PubMed]

11. Bhojgude, S.S.; Bhunia, A.; Biju, A.T. Employing arynes in Diels-Alder reactions and transition-metal-free multicomponent coupling and arylation reactions. Acc. Chem. Res. 2016, 49, 1658-1670. [CrossRef] [PubMed]

12. Karmakar, R.; Lee, D. Reactions of arynes promoted by silver ions. Chem. Soc. Rev. 2016, 45, 4459-4470. [CrossRef] [PubMed]

13. García-López, J.-A.; Greaney, M.F. Synthesis of biaryls using aryne intermediates. Chem. Soc. Rev. 2016, 45, 6766-6798. [CrossRef] [PubMed]

14. Shi, J.; Li, Y.; Li, Y. Aryne multifunctionalization with benzdiyne and benztriyne equivalents. Chem. Soc. Rev. 2017, 46, 1707-1719. [CrossRef] [PubMed]

15. Diamond, O.J; Marder, T.B. Methodology and applications of the hexadehydro-Diels-Alder (HDDA) reaction. Org. Chem. Front. 2017, 4, 891-910. [CrossRef]

16. Guitián, E.; Pérez, D.; Peña, D. Palladium-catalyzed cycloaddition reactions of arynes. Top. Organomet. Chem. 2005, 14, 109-146. [CrossRef]

17. Worlikar, S.A.; Larock, R.C. Pd-catalyzed reactions involving arynes. Curr. Org. Chem. 2011, 15, 3214-3232. [CrossRef]

18. Himeshima, Y.; Sonoda, T.; Kobayashi, H. Fluoride-induced 1,2-elimination of $o$-trimethylsilylphenyl triflate to benzyne under mild conditions. Chem. Lett. 1983, 12, 1211-1214. [CrossRef] 
19. Bai, W.-J.; David, J.G.; Feng, Z.-G.; Weaver, M.G.; Wu, K.-L.; Pettus, T.R.R. The domestication of ortho-quinone methides. Acc. Chem. Res. 2014, 47, 3655-3664. [CrossRef] [PubMed]

20. Van De Water, R.W.; Pettus, T.R.R. $o$-Quinone methides: Intermediates underdeveloped and underutilized in organic synthesis. Tetrahedron 2002, 58, 5367-5405. [CrossRef]

21. Yoshida, H.; Shirakawa, E.; Honda, Y.; Hiyama, T. Addition of ureas to arynes: Straightforward synthesis of benzodiazepine and benzodiazocine derivatives. Angew. Chem. Int. Ed. 2002, 41, 3247-3249. [CrossRef]

22. Saito, N.; Nakamura, K.; Shibano, S.; Ide, S.; Minami, M.; Sato, Y. Addition of cyclic ureas and 1-methyl-2oxazolidone to pyridynes: A new approach to pyridodiazepines, pyridodiazocines, and pyridooxazepines. Org. Lett. 2014, 15, 386-389. [CrossRef] [PubMed]

23. Shah, T.K.; Medina, J.M.; Garg, N.K. Expanding the strained alkyne toolbox: Generation and utility of oxygen-containing strained alkynes. J. Am. Chem. Soc. 2016, 138, 4948-4954. [CrossRef] [PubMed]

24. Mesgar, M.; Daugulis, O. Silylaryl halides can replace triflates as aryne precursors. Org. Lett. 2016, 18, 3910-3913. [CrossRef]

25. Liu, Z.; Larock, R.C. Intermolecular C-N addition of amides and S-N addition of sulfinamides to arynes. J. Am. Chem. Soc. 2005, 127, 13112-13113. [CrossRef] [PubMed]

26. Pintori, D.G.; Greaney, M.F. Insertion of benzene rings into the amide bond: One-step synthesis of acridines and acridones from aryl amides. Org. Lett. 2010, 12, 168-171. [CrossRef] [PubMed]

27. Fang, Y.; Rogness, D.C.; Larock, R.C.; Shi, F. Formation of acridones by ethylene extrusion in the reaction of arynes with $\beta$-lactams and dihydroquinolinones. J. Org. Chem. 2012, 77, 6262-6270. [CrossRef] [PubMed]

28. Wright, A.C.; Haley, C.K.; Lapointe, G.; Stoltz, B.M. Synthesis of aryl ketoamides via aryne insertion into imides. Org. Lett. 2016, 18, 2793-2795. [CrossRef] [PubMed]

29. Yaroslavsky, S. Reaction of aryldiazonium salts with dimethylformamide. Tetrahedron Lett. 1965, 6, $1503-1507$. [CrossRef]

30. Yoshioka, E.; Kohtani, S.; Miyabe, H. Sequential reaction of arynes via insertion into the $\pi$-bond of amides and trapping reaction with dialkylzincs. Org. Lett. 2010, 12, 1956-1959. [CrossRef] [PubMed]

31. Yoshioka, E.; Miyabe, H. Insertion of arynes into the carbon-oxygen double bond of amides and its application into the sequential reactions. Tetrahedron 2012, 68, 179-189. [CrossRef]

32. Liu, F.; Yang, H.; Hu, X.; Jiang, G. Metal-free synthesis of ortho-CHO diaryl ethers by a three-component sequential coupling. Org. Lett. 2014, 16, 6408-6411. [CrossRef] [PubMed]

33. Okuma, K.; Nojima, A.; Nakamura, Y.; Matsunaga, N.; Nagahora, N.; Shioji, K. Reaction of benzyne with formamides and acetylimidazole. Bull. Chem. Soc. Jpn. 2011, 84, 328-332. [CrossRef]

34. Yoshioka, E.; Kohtani, S.; Miyabe, H. A multicomponent coupling reaction induced by insertion of arynes into $\mathrm{C}=\mathrm{O}$ bond of formamide. Angew. Chem. Int. Ed. 2011, 50, 6638-6642. [CrossRef] [PubMed]

35. Yoshida, H.; Ito, Y.; Ohshita, J. Three-component coupling using arynes and DMF: straightforward access to coumarinsvia ortho-quinone methides. Chem. Commun. 2011, 47, 8512-8514. [CrossRef] [PubMed]

36. Wen, L.-R.; Man, N.-N.; Yuan, W.-K.; Li, M. Direct construction of 2-aryliminochromenes from arynes, N,S-keteneacetals, and DMF. J. Org. Chem. 2016, 81, 5942-5948. [CrossRef] [PubMed]

37. Yoshioka, E.; Tamenaga, H.; Miyabe, H. [4 +2] cycloaddition of intermediates generated from arynes and DMF. Tetrahedron Lett. 2014, 55, 1402-1405. [CrossRef]

38. Yoshioka, E.; Tanaka, H.; Kohtani, S.; Miyabe, H. Straightforward synthesis of dihydrobenzofurans and benzofurans from arynes. Org. Lett. 2013, 15, 3938-3941. [CrossRef] [PubMed]

39. Yoshioka, E.; Miyabe, H. Three-component coupling reactions of arynes for the synthesis of benzofurans and coumarins. Molecules 2014, 19, 863-880. [CrossRef] [PubMed]

40. Neog, K.; Das, B.; Gogoi, P. 2,3-Diaroyl benzofurans from arynes: sequential synthesis of 2-aroyl benzofurans followed by benzoylation. Org. Biomol. Chem. 2018, 16, 3138-3150. [CrossRef] [PubMed]

41. Yoshioka, E.; Kohtani, S.; Miyabe, H. 2,3,4,9-Tetrahydro-9-(3-hydroxy-1,4-dioxo-1H-dihydronaphthalen-2-yl)8-methoxy-3,3-dimethyl-1H-xanthen-1-one. Molbank 2015, 2015, M841. [CrossRef]

42. Yoshioka, E.; Nishimura, M.; Nakazawa, T.; Kohtani, S.; Miyabe, H. Multicomponent coupling reaction using arynes: Synthesis of xanthene derivatives. J. Org. Chem. 2015, 80, 8464-8469. [CrossRef] [PubMed]

43. Gorobets, E.; Parvez, M.; Derksen, D.J.; Keay, B.A. Generation of benzyne species from diphenylphosphoryl derivatives: Simultaneous exchange of three functional groups. Chem. Eur. J. 2016, 22, 8479-8482. [CrossRef] [PubMed] 
44. Shen, C.; Yang, G.; Zhang, W. Insertion of arynes into arylphosphoryl amide bonds: One-step simultaneous construction of C-N and C-P bonds. Org. Lett. 2013, 15, 5722-5725. [CrossRef] [PubMed]

45. Rao, B.; Zeng, X. Aminocyanation by the addition of N-CN bonds to arynes: Chemoselective synthesis of 1,2-bifunctional aminobenzonitriles. Org. Lett. 2014, 16, 314-317. [CrossRef] [PubMed]

46. Holden, C.M.; Sohel, S.M.A.; Greaney, M.F. Metal free bi(hetero)aryl synthesis: A benzyne Truce-Smiles rearrangement. Angew. Chem. Int. Ed. 2016, 55, 2450-2453. [CrossRef] [PubMed]

47. Biswas, K.; Greaney, M.F. Insertion of arynes into thioureas: A new amidine synthesis. Org. Lett. 2011, 13, 4946-4949. [CrossRef] [PubMed]

48. Li, R.; Wang, X.; Wei, Z.; Wu, C.; Shi, F. Reaction of arynes with vinylogous amides: Nucleophilic addition to the ortho-quinodimethide intermediate. Org. Lett. 2013, 15, 4366-4369. [CrossRef] [PubMed]

49. Li, R.; Tang, H.; Fu, H.; Ren, H.; Wang, X.; Wu, C.; Wu, C.; Shi, F. Arynes double bond insertion/nucleophilic addition with vinylogous amides and carbodiimides. J. Org. Chem. 2014, 79, 1344-1355. [CrossRef] [PubMed]

(C) 2018 by the author. Licensee MDPI, Basel, Switzerland. This article is an open access article distributed under the terms and conditions of the Creative Commons Attribution (CC BY) license (http:/ / creativecommons.org/licenses/by/4.0/). 
Review

\title{
Recent Uses of $N, N$-Dimethylformamide and $N, N$-Dimethylacetamide as Reagents
}

\author{
Jean Le Bras and Jacques Muzart* \\ Institut de Chimie Moléculaire de Reims, CNRS-Université de Reims Champagne-Ardenne, B.P. 1039, \\ 51687 Reims CEDEX 2, France; jean.lebras@univ-reims.fr \\ * Correspondence: jacques.muzart@univ-reims.fr; Tel.: +33-3-26913237
}

Academic Editor: Michal Szostak

Received: 13 July 2018; Accepted: 31 July 2018; Published: 3 August 2018

\begin{abstract}
N, N$-Dimethylformamide and $N, N$-dimethylacetamide are multipurpose reagents which deliver their own $\mathrm{H}, \mathrm{C}, \mathrm{N}$ and $\mathrm{O}$ atoms for the synthesis of a variety of compounds under a number of different experimental conditions. The review mainly highlights the corresponding literature published over the last years.
\end{abstract}

Keywords: $\mathrm{N}, \mathrm{N}$-dimethylformamide; DMF; $\mathrm{N}, \mathrm{N}$-dimethylacetamide; DMAc; amination; amidation; thioamidation; formylation; carbonylation; cyanation; insertion; cyclization

\section{Introduction}

The organic, organometallic and bioorganic transformations are extensively carried out in $\mathrm{N}, \mathrm{N}$-dimethylformamide (DMF) or $\mathrm{N}, \mathrm{N}$-dimethylacetamide (DMAc). These two polar solvents are not only use for their dissolution properties, but also as multipurpose reagents. They participate in a number of processes and serve as a source of various building blocks giving one or more of their own atoms (Scheme 1).

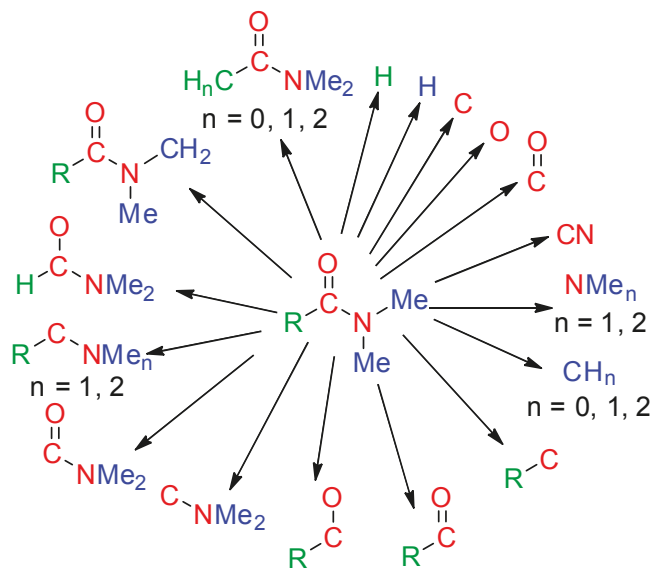

Scheme 1. Fragments from DM $(\mathrm{R}=\mathrm{H}$ or $\mathrm{Me})$ used in synthesis.

In 2009, one of us reviewed the different roles of DMF, highlighting that DMF is much more than a solvent [1]. Subsequently, this topic has been documented by the teams of Jiao [2] and Sing [3]. For of a book devoted to solvents as reagents in organic synthesis, we wrote a chapter summarizing 
the reactions consuming DMF and DMAc as carbon, hydrogen, nitrogen and/or oxygen sources [4]. This book chapter tentatively covered the literature up to middle 2015. The present mini-review focuses on recent reactions which involve DM (DM = DMF or DMAc) as a reagent although some key older papers are also included for context. Processes which necessitate the prerequisite synthesis of DM derivatives such as the Vilsmeier-Haack reagents [5] and DMF dimethyl acetal [6] are not surveyed, but a few reactions of the present review involve the in-situ formation of a Vilsmeier-type intermediate (Vilsmeier-type reagents have been extensively used. Search on 26 June 2018 for "Vilsmeier" with SciFinder led to 4379 entries). Color equations, based on literature proposals, are used to easily visualize the DM atom origin. When uncertainty is expressed by the authors or suspected by us, the atom is typed in italic. Mechanistic schemes are not reported, but Scheme 2 [7-35] summarizes different proposed reactions of DM with the corresponding literature references, where DM acts as either a nucleophilic or electrophilic reagent, or leads to neutral, ionic or radical species. The review is divided in Sections depending on the DM fragment(s) which is (are) incorporated into the reaction product.

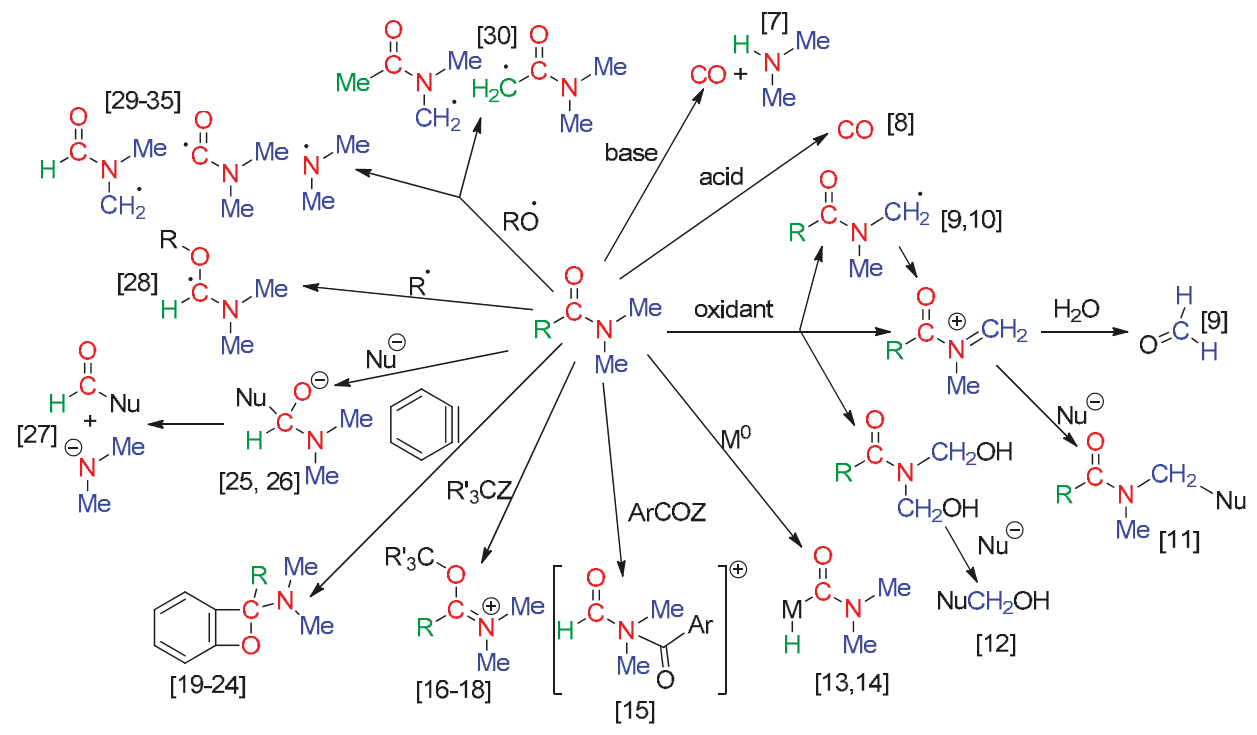

Scheme 2. Reactions of DM ( $\mathrm{R}=\mathrm{H}$ or $\mathrm{Me})$.

\section{C Fragment}

Aerobic carbonylation under nickel/copper or palladium/silver synergistic catalysis occurred efficiently using the Me group of DMF as the $\mathrm{C}$ source, affording cyclic carbonylated compounds, via the directing group-assisted activation of a $\mathrm{C}\left(\mathrm{sp}^{2}\right)-\mathrm{H}$ or $\mathrm{C}\left(\mathrm{sp}^{3}\right)-\mathrm{H}$ bond (Equations (1) and (2) [36], Equations (3) and (4) [37]). Shifting from DMF to DMAc greatly decreased the yields (Equations (1) and (3)). 


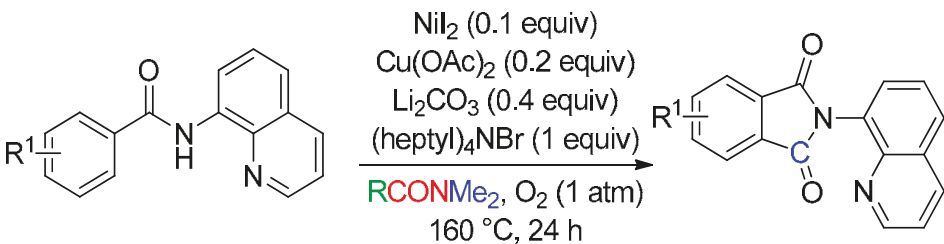

$$
\begin{aligned}
& \mathrm{R}^{1}=\mathrm{H}, \mathrm{R}=\mathrm{H}(79 \%), \mathrm{Me}(38 \%) \\
& \mathrm{R}=\mathrm{H}, 15 \text { examples: } 52-87 \%
\end{aligned}
$$

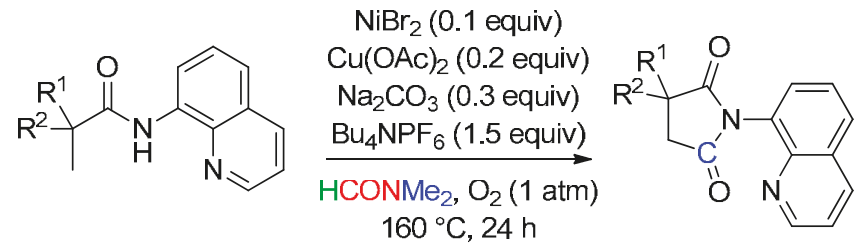

$R^{1}, R^{2} \neq H, 12$ examples: $61-81 \%$
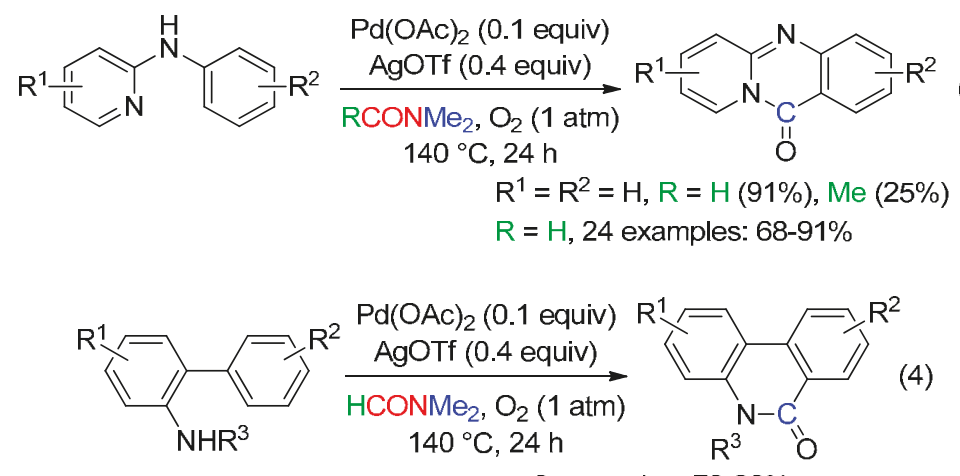

The Me group of DMF was also involved in the cyanation of the $\mathrm{C}\left(\mathrm{sp}^{2}\right)-\mathrm{H}$ bond of arenes catalyzed with an heterogeneous copper catalyst (Equation (5)) [38].

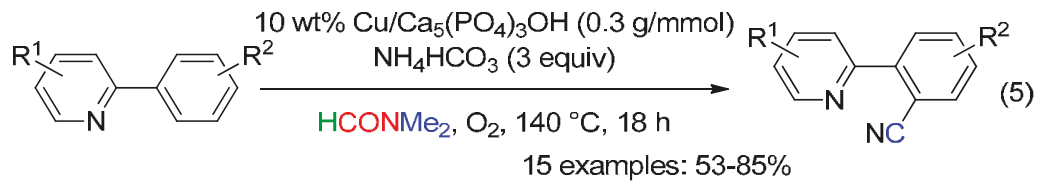

\section{CH Fragment}

Treatment of indole at $130{ }^{\circ} \mathrm{C}$ with suprastoichiometric amounts of $\mathrm{CuI}, t-\mathrm{BuOOH}$ and $\mathrm{AcOH}$ in DMAc under air afforded the corresponding C3-formylation product (Equation (6)) [39]. Such a reaction also occurred with $\mathrm{N}$-methylindole using $\mathrm{CuI}$ and $\mathrm{CF}_{3} \mathrm{CO}_{2} \mathrm{H}$ in DMAc under oxygen [40]. The $\mathrm{CH}$ fragment came from the $\mathrm{NMe}_{2}$ moiety $[39,40]$. In DMF, both procedures led to $\mathrm{C} 3$-cyanation (see below, Equation (25)). 


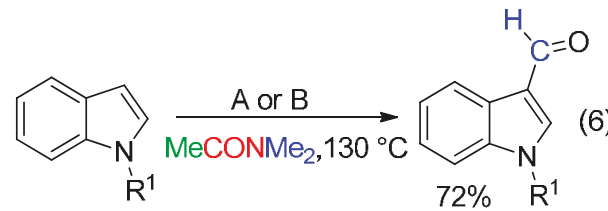
A. $\mathrm{R}^{1}=\mathrm{H}$; Cul (1.2 equiv), $t$-BuOOH (2 equiv),
$\mathrm{AcOH}$ (8 equiv), air, $48 \mathrm{h:} 72 \%$
B. $\mathrm{R}^{1}=\mathrm{Me}$; Cul (1 equiv), $\mathrm{CF}_{3} \mathrm{CO}_{2} \mathrm{H}$ (1.2 equiv)
$\mathrm{O}_{2}(1 \mathrm{~atm}), 36 \mathrm{h:} 42 \%$

Cycloadditions leading to symmetrical tetrasubstituted pyridines using the Me group of DMF as the $\mathrm{CH}$ source have been carried out using either ketoxime carboxylates with $\mathrm{Ru}$ catalysis (Equation (7)) [41], or arones with both iodine and ammonium persulfate mediation (Equation (8)) [42].
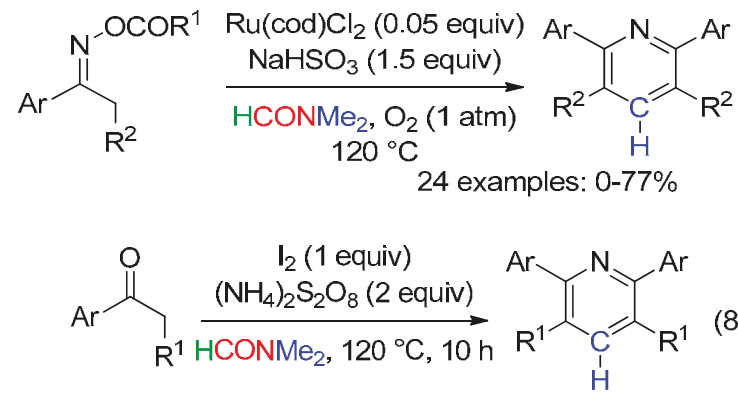

15 examples: $71-89 \%$

2,4-Diarylpyridines were also synthetized from Ru-catalyzed reaction of acetophenones with ammonium acetate and DMF as source of the $\mathrm{N}$ and $\mathrm{CH}$ atoms, respectively (Equation (9)) [43].

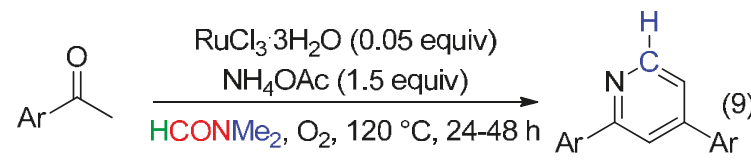

18 examples: $35-80 \%$

With sodium azide as the nitrogen source, DMAc was superior to DMF to deliver the $\mathrm{CH}$ fragment of the copper-catalyzed domino reactions of aryl halides which led to imidazo [1,2-c]quinazolines, quinazolinones or imidazo[4,5-c]quinolones (Equations (10)-(12)) [44]. 
<smiles></smiles>

Cul (0.2 equiv),
$\begin{gathered}\mathrm{RCONMe} \text {, air } \\ \text { TsOOH (1 equiv) } \\ 130^{\circ} \mathrm{C}, 10 \mathrm{~h}\end{gathered}$

$$
\begin{aligned}
& R^{1}=R^{2}=H, R=H(63 \%), M e(82 \%) \\
& R=M e, 19 \text { examples: } 57-82 \%
\end{aligned}
$$

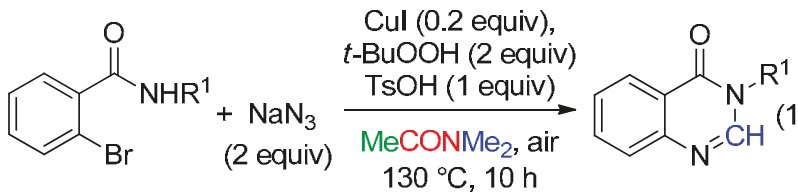

8 examples: $37-71 \%$

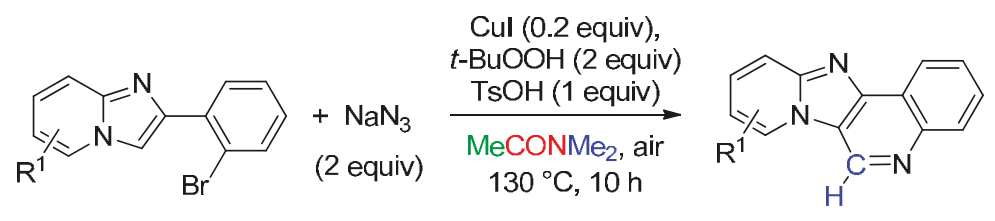

3 examples: $42-52 \%$

In contrast to the above examples, the Cu-catalyzed cyclization leading to $6 \mathrm{H}$-chromeno[4,3b]quinolin-6-ones (Equation (13)) with incorporation of a $\mathrm{CH}$ belonging to DMF occurred with low yield when $t$ - $\mathrm{BuOOH}$ was the oxidant. Shifting to $t$-butyl perbenzoate allowed an effective reaction [45]. For the synthesis of 4-acyl-1,2,3-triazoles from $\mathrm{Cu}$-catalyzed cycloaddition to acetophenones (Equation (14)), $\mathrm{K}_{2} \mathrm{~S}_{2} \mathrm{O}_{8}$ was superior to $t-\mathrm{BuOOH},(t-\mathrm{BuO})_{2}$ and $\left(\mathrm{PhCO}_{2}\right)_{2}$ [46]. Yields decreased with DMAc instead of DMF (Equations (13) and (14)).

$$
\begin{aligned}
& \begin{array}{c}
\mathrm{Cu}(\mathrm{OAC})_{2} \mathrm{H}_{2} \mathrm{O} \text { (0.15 equiv) } \\
\mathrm{PhCO}_{3} t-\mathrm{Bu} \text { (3 equiv) } \\
\mathrm{NaHSO}_{3} \text { (1.2 equiv) } \\
\mathrm{KOAC}^{2} \text { (1 equiv) } \\
\begin{array}{c}
\mathrm{RCNMe}_{2}, \mathrm{O}_{2} \text { (balloon) } \\
130^{\circ} \mathrm{C}, 10 \mathrm{~h}
\end{array}
\end{array} \\
& R^{1}=R^{2}=H, R=H(73 \%), M e(53 \%) \\
& R=H, 20 \text { examples: } 56-81 \%
\end{aligned}
$$

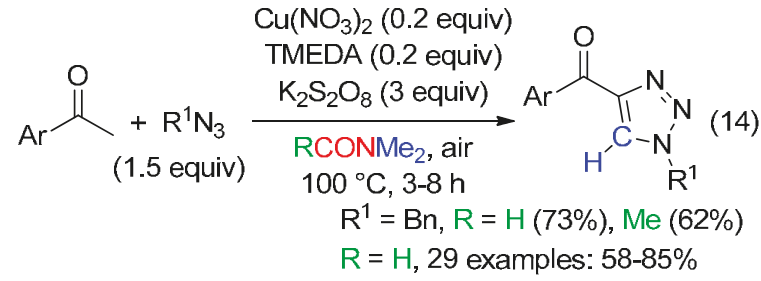

The insertion of a $\mathrm{CH}$ from the $\mathrm{NMe}_{2}$ of $\mathrm{DM}$ under metal-free conditions has been reported for the synthesis of cyclic compounds such as: 
- $\quad$ pyrimidines from $t$-BuOOH-mediated reaction between acetophenones, amidines and DMF (Equation (15)) [47],

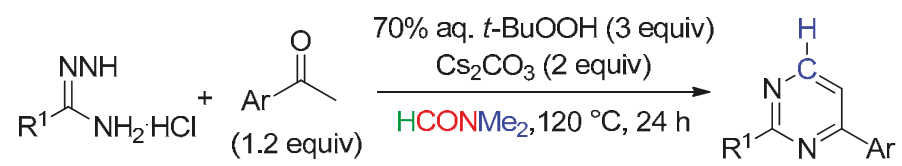

$\mathrm{R}^{1}=\mathrm{Ar}, \mathrm{Me}$, cyclopropyl

22 examples: $36-74 \%$

substituted phenols also from three components cycloadditions (Equation (16)) [48],<smiles>[R1]CC(=O)CC([R7])=O</smiles><smiles>O=[N+]([O-])C=C(Cl)Cl</smiles>

(1.7 equiv)<smiles></smiles>
$100^{\circ} \mathrm{C}, 10 \mathrm{~h}$<smiles>[R]Cc1c(C([R])=O)cc(C([R])=O)c(O)c1[R]</smiles>

$\mathrm{R}^{1}$

$$
\mathrm{R}^{1}=\mathrm{H}, \mathrm{R}^{2}=\mathrm{Me}, \mathrm{R}=\mathrm{H}(77 \%), \mathrm{Me}(34 \%)
$$

$\mathrm{R}=\mathrm{H}, 16$ examples: $35-77 \%$

- $\quad$ 3-acylindoles from 2-alkenylanilines (Equation (17)) [49],

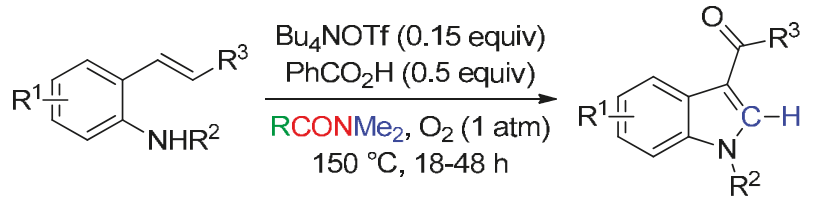

$$
\begin{aligned}
& R^{1}=H, R^{2}=T s, R^{3}=P h, R=H(81 \%), M e(28 \%) \\
& R=H, 28 \text { examples: } 0-81 \%
\end{aligned}
$$

- $\quad$ benzimidazoles and benzothiazole from o-phenylenediamine or 2-aminobenzenethiol through carbon dioxide-mediated cyclization (Equation (18)) [50].

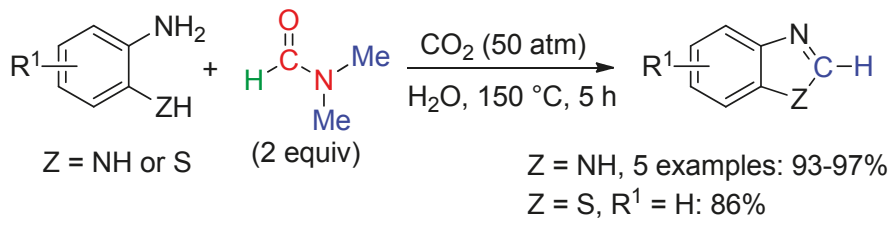

\section{4. $\mathrm{CH}_{2}$ Fragment}

The coupling of indoles or imidazo[1,2-a]pyridines to afford heterodiarylmethanes with DMF as the methylenating reagent occurred in fair to high yields with a $\mathrm{Cu}^{\mathrm{I}}$ catalyst associated to $t-\mathrm{BuOOH}$ [51] or $\mathrm{K}_{2} \mathrm{~S}_{2} \mathrm{O}_{8}$ [52] (Equations (19)-(21)). Use of DMAc was less efficient. 

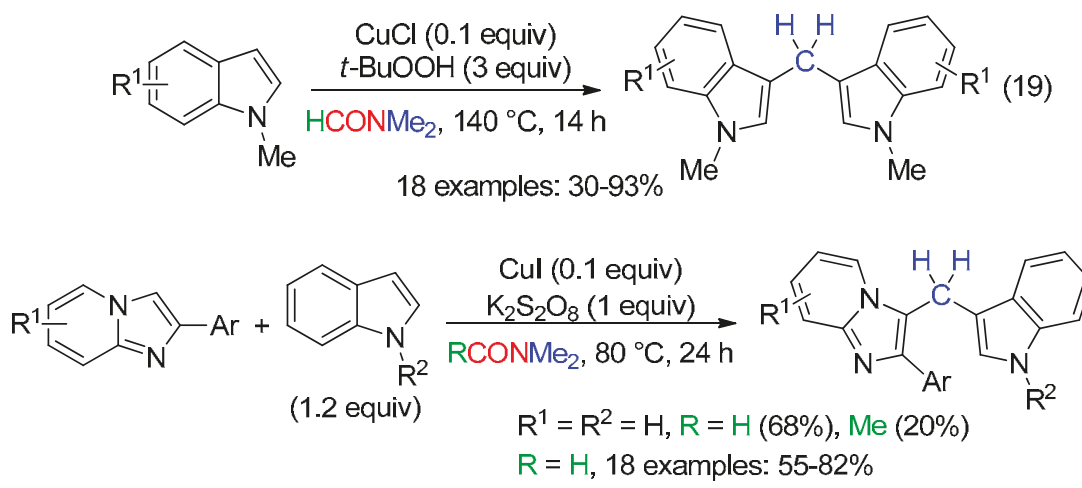

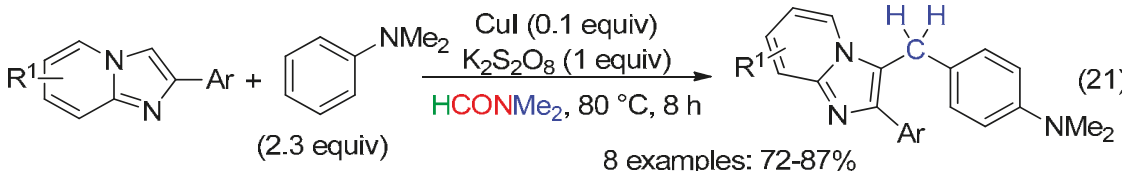

8 examples: $72-87 \%$

In DMAc, the $\mathrm{I}_{2} / t-\mathrm{BuOOH}$ association catalyzed the formation of methylene-bridged bis-1,3-dicarbonyl compounds from aryl $\beta$-ketoesters or $\beta$-ketoamides (Equation (22)). Lower yields were obtained with $\mathrm{I}_{2} / \mathrm{K}_{2} \mathrm{~S}_{2} \mathrm{O}_{8}$ in DMAc or DMF [9]. Subjection 1,3-diphenylpropane-1,3-dione or ethyl 3-oxobutanoate to the $\mathrm{I}_{2} / \mathrm{t}$ - $\mathrm{BuOOH} / \mathrm{DMAc}$ did not afford the bridged compounds.

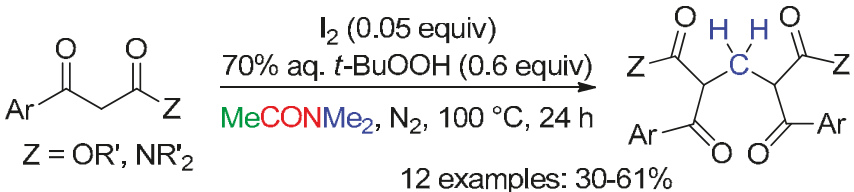

A Mannich reaction leading to $\beta$-amino ketones with DMF as the formaldehyde source has been reported in the presence of $t$-BuOOH and catalytic amounts of an $N$-heterocyclic carbene, $\mathrm{SnCl}_{2}$ and $\mathrm{NEt}_{3}$ (Equation (23)) [11].

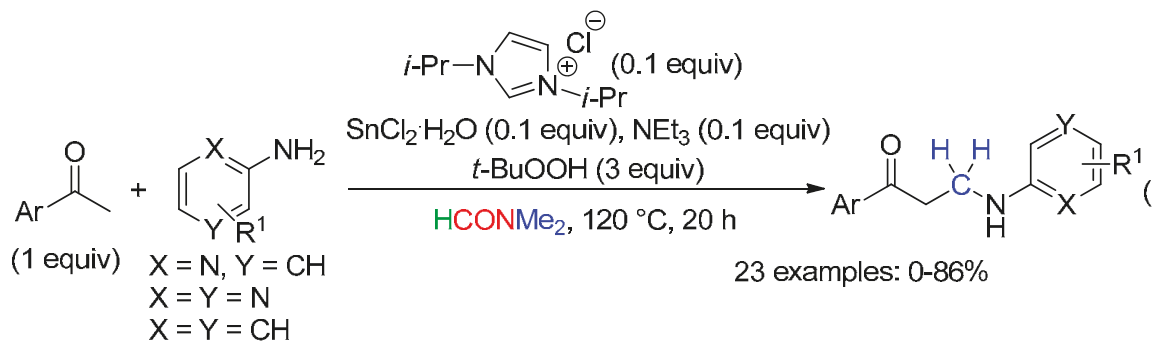

The study of an unexpected reaction due to the oxidation of DMAc with aqueous $t-\mathrm{BuOOH}$ (Equation (24)) showed the formation of $\mathrm{MeCONMe}\left(\mathrm{CH}_{2} \mathrm{OH}\right)$ and $\mathrm{MeCON}\left(\mathrm{CH}_{2} \mathrm{OH}\right)_{2}$, these unusual species delivering the methylene group [12]. 


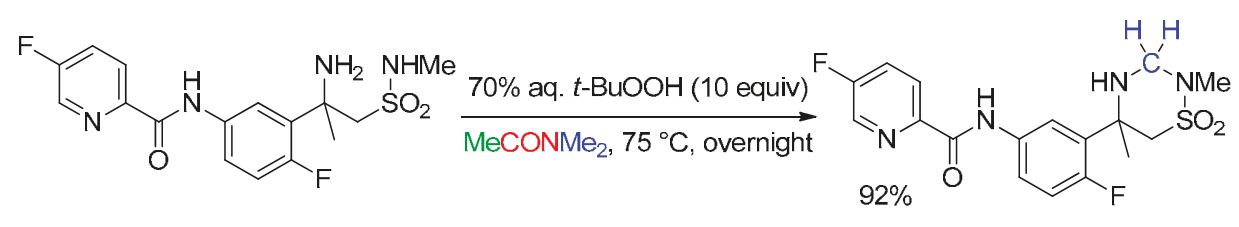

\section{NC Fragment}

While CuI under oxidative and acidic conditions led, in DMAc, to the C3-formylation of indole and $N$-methylindole (Equation (6)), reactions in DMF led to C3-cyanations (Equation (25)) [39,40]. Cyanation of electron-rich arenes and benzaldehydes was also carried out (Equation (26)) [39]. Monitoring the course of the reaction indicated a cyanation arising via the formyl compounds [39,40]. Moreover, 3-iodo indole could also be involved in the formation of the cyano product [40].

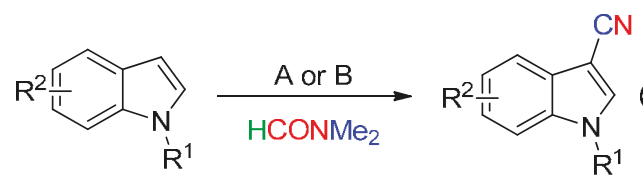

A. $\mathrm{R}^{1}=\mathrm{H}$; Cul (1.2 equiv), $t$ - $\mathrm{BuOOH}$ (2 equiv), $\mathrm{AcOH}$ (4 equiv), air, $120-130^{\circ} \mathrm{C}, 48 \mathrm{~h}$; 15 examples: $30-86 \%$

B. $\mathrm{R}^{1}=\mathrm{Me}$; Cul (1 equiv), $\mathrm{CF}_{3} \mathrm{CO}_{2} \mathrm{H}$ (1.2 equiv), $\mathrm{O}_{2}(1 \mathrm{~atm})$, $130-150{ }^{\circ} \mathrm{C}, 36-96 \mathrm{~h}$; 15 examples: $25-90 \%$

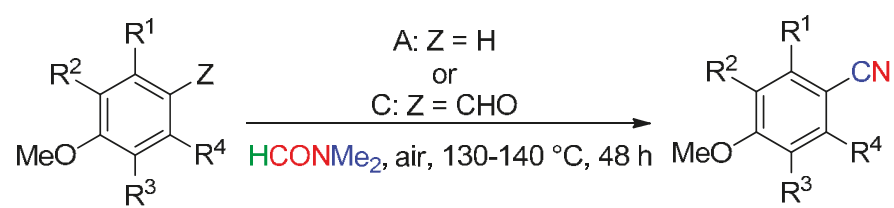

A. Cul (1.2 equiv), $t$ - $\mathrm{BuOOH}$ ( 2 equiv), $\mathrm{AcOH}$ (4 equiv)

$R^{1}=R^{4}=$ OMe, $R^{2}=R^{3}=H: 80 \% ; R^{1}=M e, R^{2}=H, R^{3}=R^{4}:$ OMe: $35 \%$;

$R^{1}=R^{2}=R^{3}=H, R^{4}=$ OMe: $51 \%$

C. $\mathrm{Cu}\left(\mathrm{NO}_{3}\right)_{2} 3 \mathrm{H}_{2} \mathrm{O}$ (1 equiv), $t$ - $\mathrm{BuOOH}$ (2 equiv), $\mathrm{AcOH}$ (8 equiv)

$R^{1}=R^{2}=R^{3}=R^{4}=H: 70 \% ; R^{1}=R^{4}=H, R^{2}=R^{3}=$ OMe: $90 \%$

Laser ablation of silver nitrate in DMF led to silver cyanide (Equation (27)) [53].

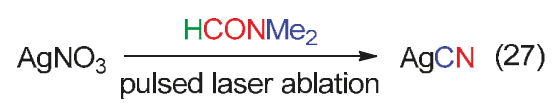

\section{6. $\mathrm{NMe}_{2}$ Fragment}

This chapter is divided in sections corresponding to the type of function reacting with DM.

\subsection{Aryl Halides}

Refluxing chloropyridines in DM or DMAc afforded the corresponding aminopyridines (Equation (28)) [25]. The amination of aryl chlorides and 3-pyridinyl chloride with DMF occurred at room temperature in the presence of potassium $t$-butoxide and a carbenic palladium catalyst (Equation (29)) [27]. 


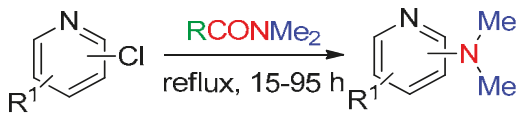

$\mathrm{R}=\mathrm{H}, 5$ examples: $69-78 \%$

$\mathrm{R}=\mathrm{Me}, 4$ examples: $47-69 \%$

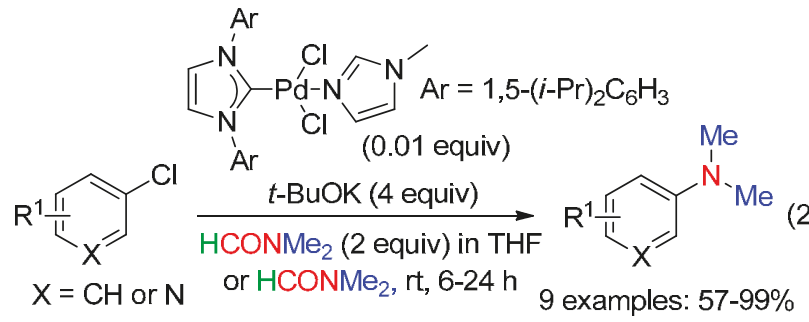

\subsection{Alkylarenes}

Oxidation of methylarenes and ethylarenes at $80^{\circ} \mathrm{C}$ in DMF using catalytic amounts of both $\mathrm{I}_{2}$ and $\mathrm{NaOH}$ [31] or $n-\mathrm{Bu}_{4} \mathrm{NI}$ [32] associated to aqueous $t-\mathrm{BuOOH}$ under air led to benzylic oxidation and incorporation of the $\mathrm{NMe}_{2}$ fragment to afford benzamides (Equation (30)) or $\alpha$-ketoamides (Equation (31)).
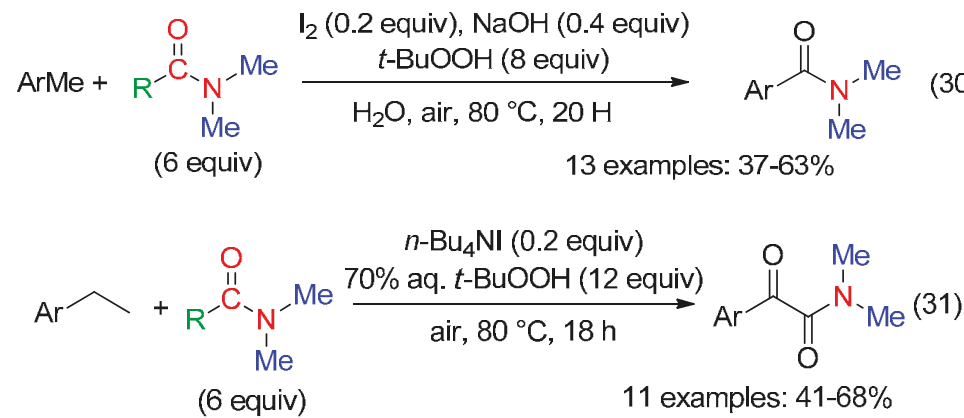

\subsection{Alkenes}

Hydrocarbonylation of terminal alkenes and norbornene followed by acyl metathesis with DM occurred under Pd catalysis, $\mathrm{CO}$ pressure and in the presence of ammonium chloride or $\mathrm{N}$-methyl-2-pyrrolidone hydrochloride (NMP.HCl) (Equations (32) and (33)) [54]. From alkenes, the selectivity towards linear and branched products depended on the catalytic system (Equation (32)). DMF and DMAc afforded similar results. 


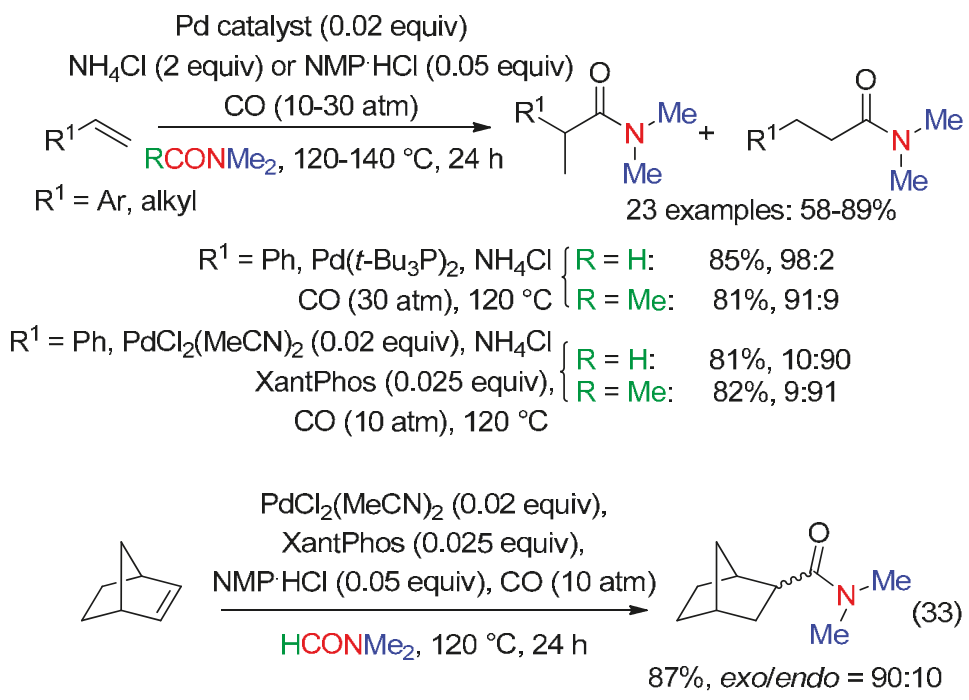

\subsection{Acids}

Copper, palladium and ruthenium catalysts associated to oxidants and DMF were used for the amidation of cinnamic acids [29] and carboxylic acids [55] (Equations (34) and (35)). $\mathrm{N}, \mathrm{N}$-Dimethylbenzamide was one of the products obtained from the $\mathrm{Cu}^{\mathrm{II}}$-catalyzed oxidation of flavonol [56].

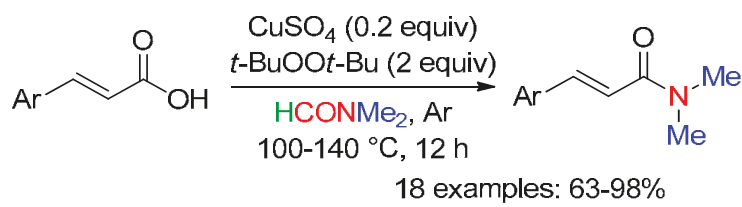

$$
\begin{aligned}
& \text { Ru catalyst (0.05 equiv) } \\
& \begin{array}{l}
\text { or } \mathrm{Pd}(\mathrm{OAc})_{2}(0.1 \text { equiv) } \\
\mathrm{K}_{2} \mathrm{~S}_{2} \mathrm{O}_{8}(2 \text { equiv) }
\end{array} \\
& \mathrm{R}^{1}=\mathrm{Ar} \text {, alkyl, } \mathrm{RuCl}_{2} \text { (p-cymene), Xantphos (0.1 equiv): } \\
& \mathrm{R}^{1}=\mathrm{Ph}, \mathrm{RuCl}_{3} \cdot 3 \mathrm{H}_{2} \mathrm{O}: 64 \%
\end{aligned}
$$



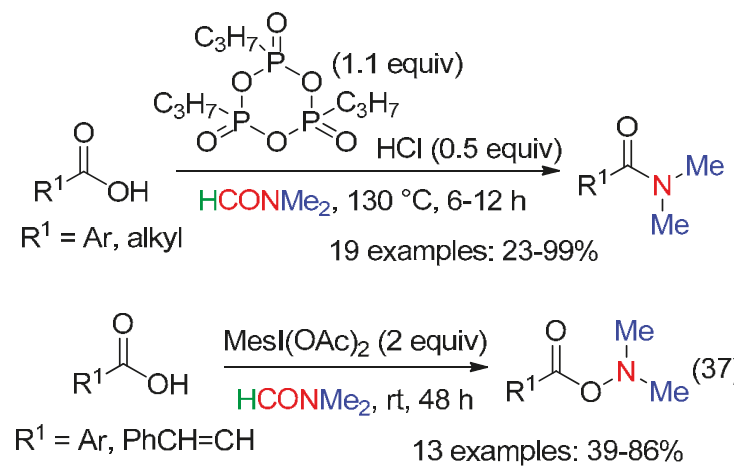

Treatment of arylacetic and cinnamic acids with base, sulfur and DMF at $100-120{ }^{\circ} \mathrm{C}$ led to decarboxylative thioamidation (Equations (38) and (39)) [7]. Inhibition of the process in the presence of TEMPO or BHT indicated a radical involvement in the transformations.
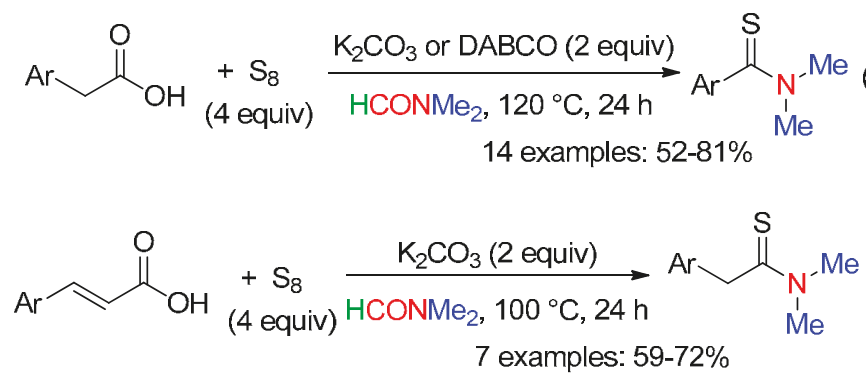

\subsection{Carbonylated Compounds}

Reaction of 2-arylquinazolin-4(3H)-ones with $\mathrm{TsCl}$ and $t$-BuOK in DM provided the corresponding 4-(dimethylamino)quinazolines in good yields, especially in DMF (Equation (40)). These reactions occurred via the formation of the 2-aryl-4-(tosyloxy)quinazolines [57].

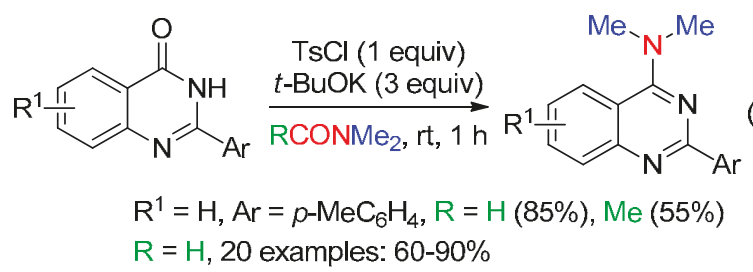

Various amides have been synthetized from aldehydes and DMF using $t-\mathrm{BuOOH}$ and a recyclable heterogeneous catalyst-a carbon-nitrogen embedded cobalt nanoparticle denoted as Co@C-N600 (Equation (41)) [33]. The same transformation of benzaldehydes was subsequently reported using $\mathrm{Co} / \mathrm{Al}$ hydrotalcite-derived catalysts [58].

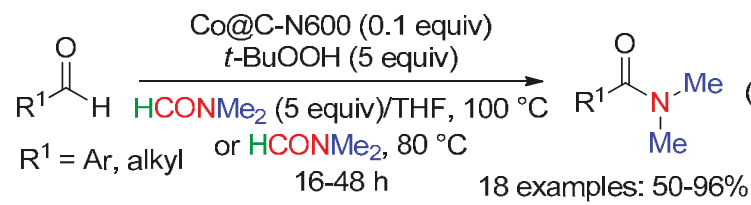


Copper oxide and iodine mediated the reaction of acetophenones with sulfur and DMF to afford $\alpha$-arylketothioamides (Equation (42)) via the formation of $\alpha$-iodoacetophenones [59].

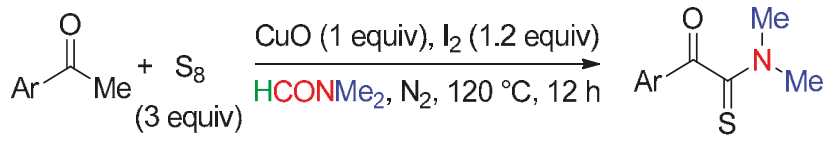

17 examples: $59-85 \%$

Elemental sulfur and the $\mathrm{NMe}_{2}$ moiety of DMF or DMAc was also used for the DBU-promoted synthesis of thioamides from aldehydes (Equation (43)) or arones (Equation (44)) [60], the latter undergoing an efficient Willgerodt-Kindler reaction [61,62].
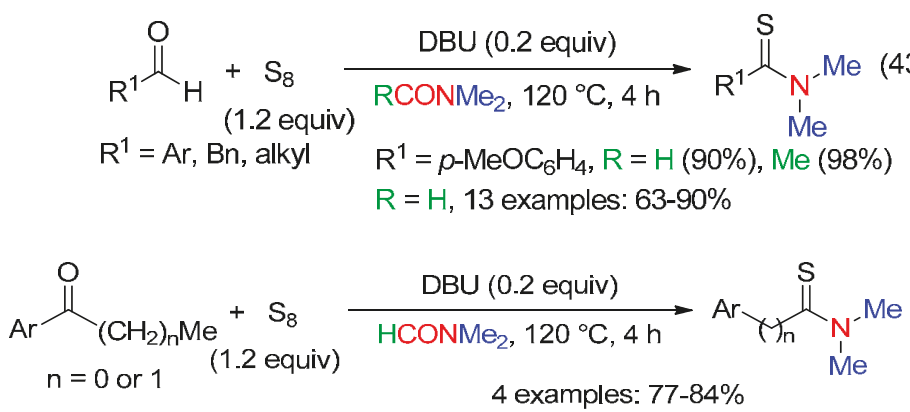

\subsection{Benzyl Amines}

The recyclable $\mathrm{Co} / \mathrm{Al}$ catalysts used above in DMF for the amidation of benzaldehydes also led to benzamides from benzylamines and $t-\mathrm{BuOOH}$ (Equation (45)). These transformations would involve benzaldehydes as intermediates [58].

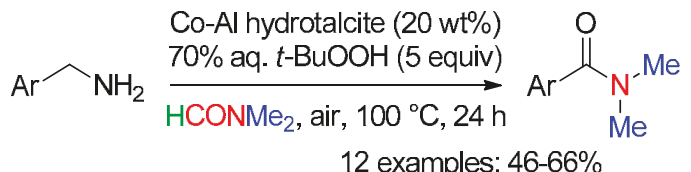

\subsection{Nitriles}

$\mathrm{NaOH}$ mediated, at room temperature, the efficient reaction of the $\mathrm{CN}$ group of 4-oxo-2,4diphenylbutanenitrile with DMF to afford the corresponding $\gamma$-ketoamide (Equation (46)) [63]. Such compounds were also obtained from the domino reaction of chalcones with malononitrile and $\mathrm{NaOH}$ in DMF [63].<smiles>CC(=O)O[Na]</smiles><smiles>CN(C)C(=O)C(CC(=O)c1ccccc1)c1ccccc1</smiles>

\subsection{Sulfur Compounds}

Sulfonamides were synthetized:

- $\quad$ from thiophenols, DMF and air via an oxygen-activated radical process mediated by copper salts and cinnamic acid (Equation (47)) [64], 


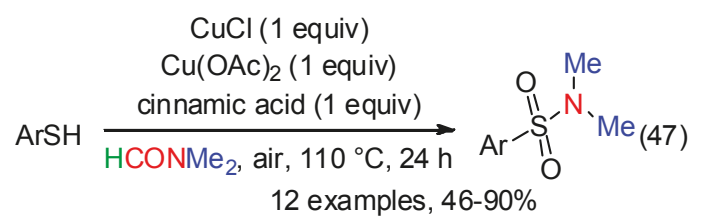

or reaction of sodium sulfonates with $N$-iodosuccinimide and DMF pretreated with $t$-BuOK (Equation (48)) via, probably, sulfonyl iodides (Equation (49)) [65].
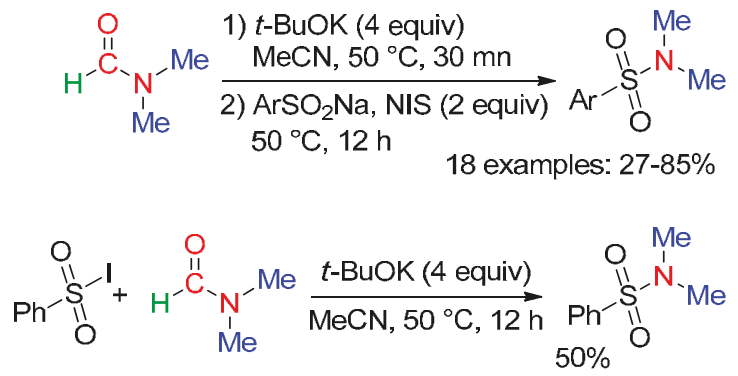

\section{O Fragment}

DMF delivered its oxygen atom to 1,2-cyclic sulfamidates via nucleophilic displacement at the quaternary center to afford, after hydrolysis, an aminoalcohol (Equation (50)) [17].

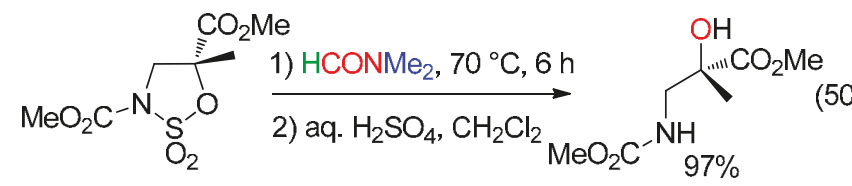

DMF was also the oxygen source leading to an imidazolinone from the reaction with the Cu-carbene complex and the borate salt depicted in Equation (51) [66].

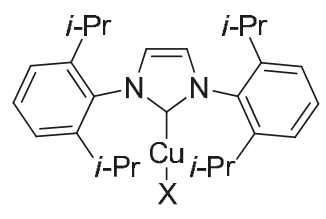
$\underset{\mathrm{HCONMe}_{2}, \mathrm{Ar}, 30^{\circ} \mathrm{C}, 10 \mathrm{~h}}{\stackrel{\left[\mathrm{CF}_{3} \mathrm{~B}(\mathrm{OMe})_{3}\right] \mathrm{K}(6 \text { equiv. })}{\longrightarrow}}$

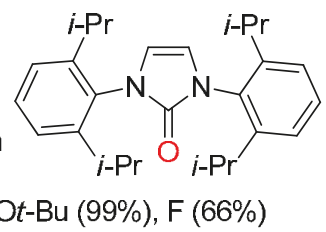

The $\mathrm{I}_{2} / \mathrm{CuO}$ association allowed the $\alpha$-hydroxylation of arones in abstracting, via the $\alpha$-iodoarone, the oxygen atom of DMF (Equation (52)) [18].

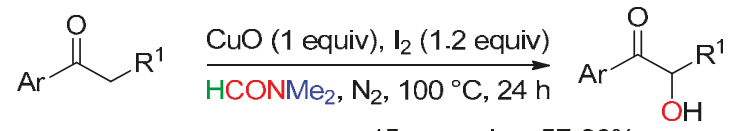

15 examples: $57-86 \%$ 


\section{8. $\mathrm{C}=\mathrm{O}$ Fragment}

With DMF as the CO surrogate, quinazolinones have been prepared at $140-150{ }^{\circ} \mathrm{C}$

- $\quad$ via $\mathrm{C}\left(\mathrm{sp}^{2}\right)-\mathrm{H}$ bond activation and annulation using $\mathrm{Pd} / \mathrm{C}$ [67] or $\mathrm{Pd}(\mathrm{OAc})_{2}$ [8], in the presence of $\mathrm{K}_{2} \mathrm{~S}_{2} \mathrm{O}_{8}, \mathrm{CF}_{3} \mathrm{CO}_{2} \mathrm{H}$ and $\mathrm{O}_{2}$ (Equation (53)),

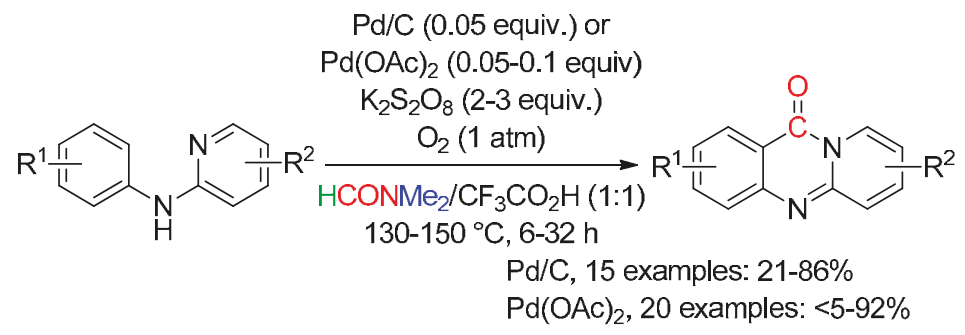

or carbon dioxide-mediated cyclization of 2-aminobenzonitrile (Equation (54)) [50]. This latter reaction would involve a Vilsmeier-Haack type intermediate and did not occur with DMAc.

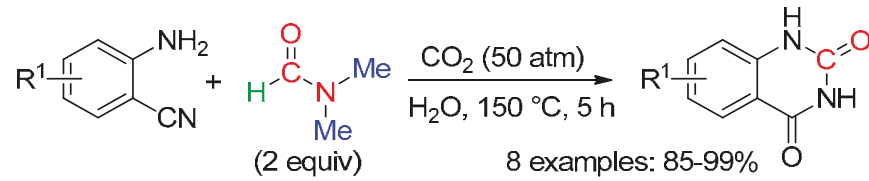

A carbonylative Suzuki-type reaction leading to diarylketones arose in DMF under Ni catalysis at $100{ }^{\circ} \mathrm{C}$ (Equation (55)), IPr = bis(2,6-diisopropylphenyl)imidazol-2-ylidene) [13], or Pd catalysis and UV light assistance at room temperature (Equation (56)) [68].

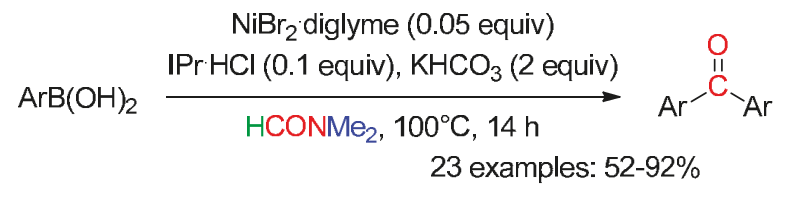

$$
\begin{aligned}
& \mathrm{Pd} \text { (phen) } \mathrm{Cl}_{2} \text { ( } 0.03 \text { equiv) }
\end{aligned}
$$

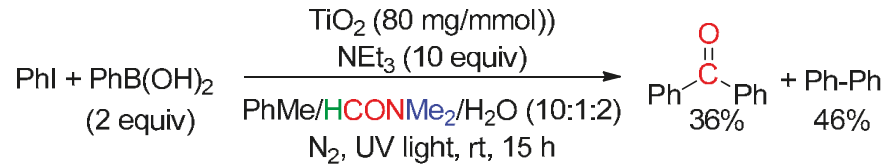

Catalytic amounts of a ruthenium pincer complex and $t$-BuOK led, at $165^{\circ} \mathrm{C}$, to symmetric and unsymmetric $N, N^{\prime}$-disubstituted ureas from primary amines and DMF (Equation (57)) [69].

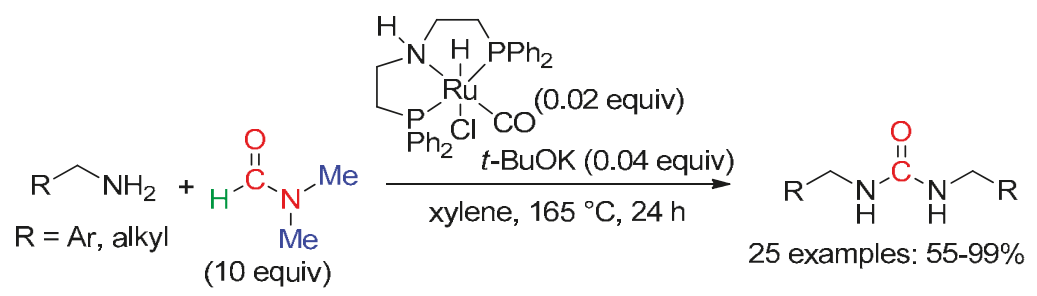


At $120^{\circ} \mathrm{C}$ under $\mathrm{CuBr}_{2}$ catalysis, $\mathrm{o}$-iodoanilines reacted with potassium sulfide and DMF, leading to benzothiazolones (Equation (58)) [70].

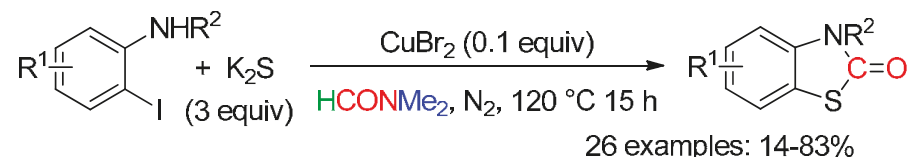

\section{9. $\mathrm{C}=\mathrm{ONMe}_{2}$ Fragment}

Potassium persulfate-promoted the reaction of pyridines with DMF to provide $N, N$ dimethylpicolinamides (Equation (59)) [71], while the oxidative carbamoylation of isoquinoline $\mathrm{N}$-oxides, with also DMF, was catalyzed by $\mathrm{Pd}^{\mathrm{II}}$ in the presence of ytterbium oxide as base and tetrabutylammonium acetate, the latter mediating the N-O reduction (Equation (60)) [72].
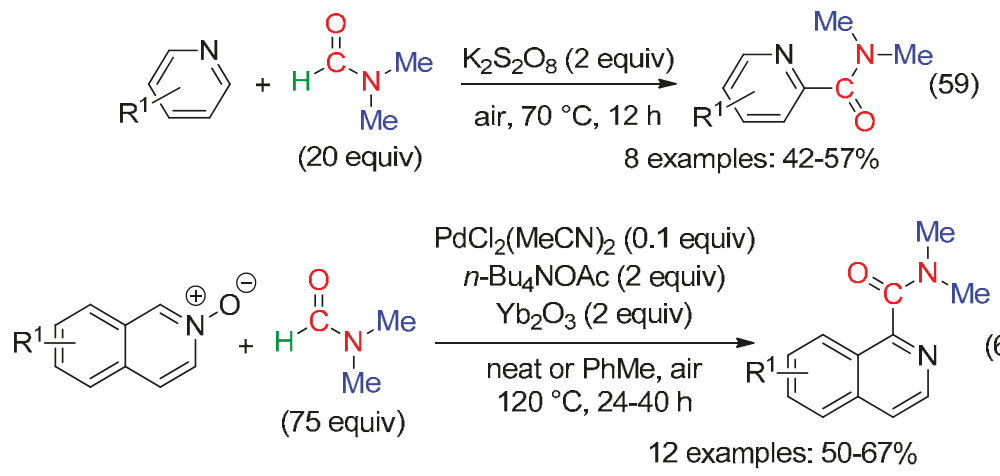

Alkynylation of DMF leading to $N, N$-dimethylamides was produced with peroxides and either an hypervalent alkynyl iodide under Ag catalysis (Equation (61)) [73], or a terminal alkyne under Cu catalysis (Equation (62)) [34].
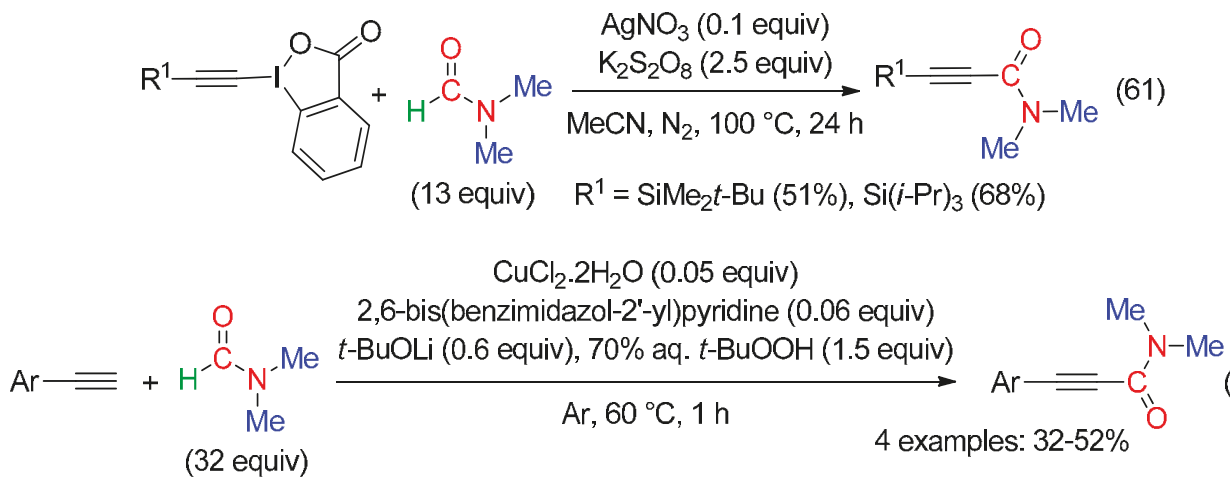

A peroxide was also used for the carbamoylation of 4-arylcoumarin with DMF (Equation (63)) [74]. 


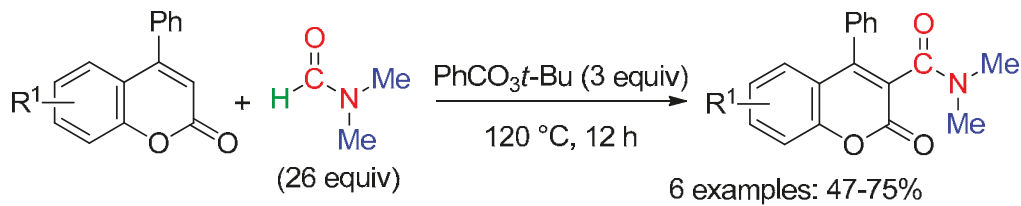

$\alpha$-Ketoamides were obtained from the domino reaction of toluenes with DMF using $(t-\mathrm{BuO})_{2}$, $\mathrm{Cs}_{2} \mathrm{CO}_{3}$ and catalytic amounts of $n$-Bu $\mathrm{NI}$ (Equation (64)) [75].

$$
\begin{aligned}
& n-\mathrm{Bu}_{4} \mathrm{NI} \text { (0.1 equiv) }
\end{aligned}
$$

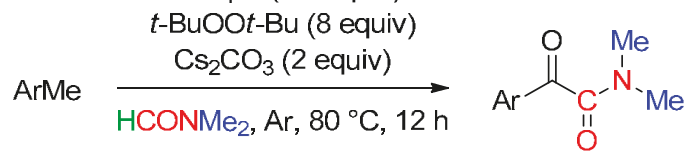

13 examples: $0-85 \%$

At $100{ }^{\circ} \mathrm{C}$ in DMF, $\mathrm{Cu}$ catalyst associated to $t$ - $\mathrm{BuOOH}$ led to unsymmetrical ureas from 2-oxindoles (Equation (65)) [76]. The peroxide would mediate the cleavage reaction, and was the oxygen source of the benzylic carbonyl. That resulted in a ketoamine which undergone the $\mathrm{Cu}$-catalyzed reaction with $\mathrm{DMF} / \mathrm{t}-\mathrm{BuOOH}$, leading to the urea.

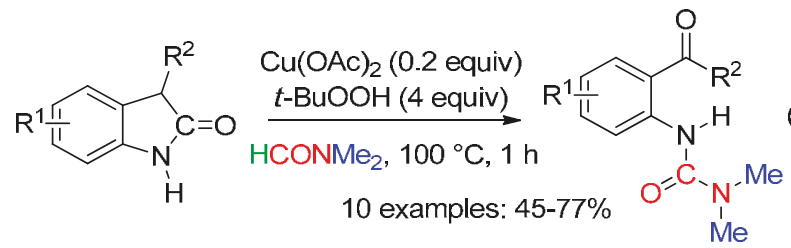

\section{H Fragment}

Semihydrogenation of diaryl alkynes occurred under Ru (Equation (66)) [77] and Pd [78] catalysis with DMF and water as hydrogen source.

$$
\mathrm{Ar}^{1}=\mathrm{Ar}^{2} \frac{\mathrm{AcOH}\left(1.5 \text { equiv), } \mathrm{H}_{2} \mathrm{O}(2 \text { equiv })\right.}{\mathrm{HCONMe}_{2}, 145^{\circ} \mathrm{C}, 24 \mathrm{~h}}
$$

9 examples: $40-98 \%$, ZIE $=75: 25-99: 1$

Cobalt porphyrins catalyzed the hydrogenation transfer from DMF to the $\mathrm{C}\left(\mathrm{sp}^{3}\right)-\mathrm{C}\left(\mathrm{sp}^{3}\right)$ bond of [2.2]paracyclophane (Equation (67)) [79]. DMF was also involved in the Ni-catalyzed intramolecular hydroarylations depicted in Equation (68) [14]. 

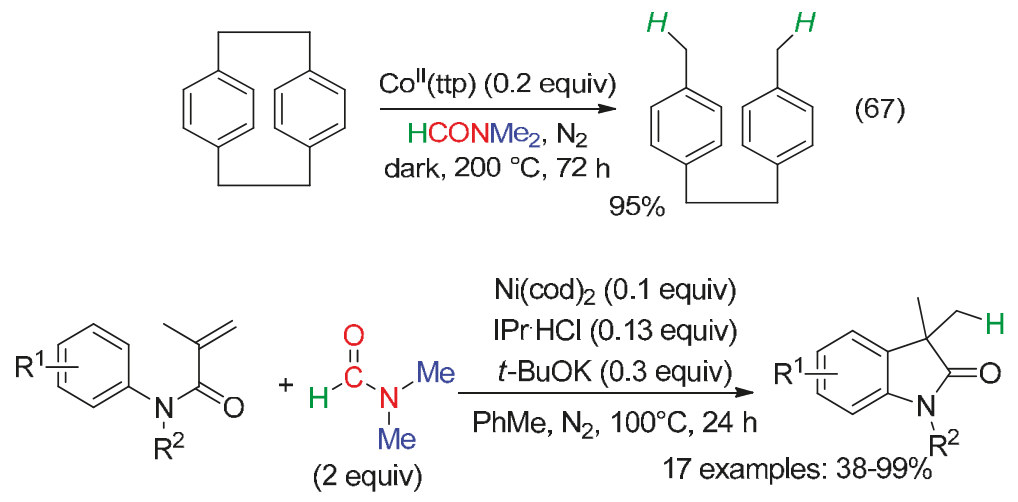

\section{RC Fragment}

New metal-catalyzed and metal-free conditions involving the $\mathrm{CH}$ of the formyl group of DMF have been reported for cyclizations leading to heterocycles (Equations (69) [80-82] and (70) [83]).

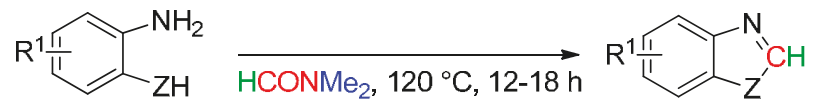

$$
\begin{aligned}
& \mathrm{Zn}(\mathrm{OAc})_{2} 2 \mathrm{H}_{2} \mathrm{O}\left(0 . 0 5 \text { equiv), } \left\{\begin{array}{l}
\mathrm{Z}=\mathrm{NR}^{2}, 12 \text { examples: } 0-95 \% \\
Z=\mathrm{S}, \mathrm{R}^{1}=\mathrm{H}: 83 \%
\end{array}\right.\right. \\
& \text { poly(methylhydrosiloxane) (5 equiv) [80] }\left\{\begin{array}{l}
Z=S, R^{1}=\mathrm{H}: 83 \% \\
Z=0,2 \text { examples: } 70-81 \%
\end{array}\right. \\
& \begin{aligned}
\mathrm{B}\left(\mathrm{C}_{6} \mathrm{~F}_{5}\right)_{3} \text { (0.05 equiv), } \mathrm{H}_{2} \mathrm{SiEt}_{2} \text { or } \\
\mathrm{HSi}(\mathrm{OEt})_{3} \text { (5 equiv), } \mathrm{CO}_{2}(1 \mathrm{~atm})[81]
\end{aligned}\left\{\begin{array}{l}
Z=\mathrm{NR}^{2}, 17 \text { examples: } 68-99 \% \\
Z=\mathrm{S}, 10 \text { examples: } 68-99 \% \\
Z=O, R^{1}=\mathrm{H}: 70 \%
\end{array}\right. \\
& \mathrm{PhSiH}_{3} \text { (4 equiv) [82] }\left\{\begin{array}{l}
Z=N R^{2}, 13 \text { examples: } 31-95 \% \\
Z=S, R^{1}=\mathrm{H}: 83 \%
\end{array}\right.
\end{aligned}
$$

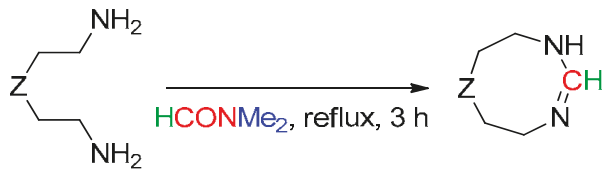

$$
\mathrm{Z}=\mathrm{CH}_{2}(95 \%), \mathrm{NH}(94 \%), \mathrm{HNCH}_{2} \mathrm{CH}_{2} \mathrm{NH}(92 \%)
$$

2-Methylbenzimidazoles were obtained from $\mathrm{PhSiH}_{3}$-assisted delivery of the CMe of DMAc to benzene-1,2-diamines (Equation (71)) [82].

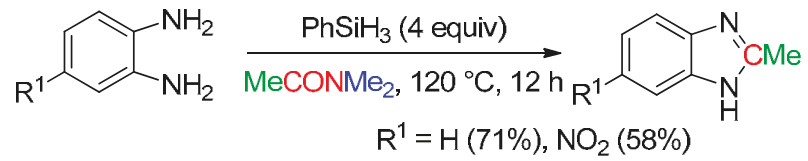

Addition of $p$-tolyllithium to DMF followed by reaction with hydroxylamine hydrochloride afforded 4-methylbenzaldehyde oxime (Equation (72)). The latter underwent cycloaddition with diphenylphosphoryl azide or, in the presence of Oxone ${ }^{\circledR}$, with diethylacetylene dicarboxylate to provide the corresponding 5-aryltetrazole or 3-arylisoxazole, respectively [84]. 


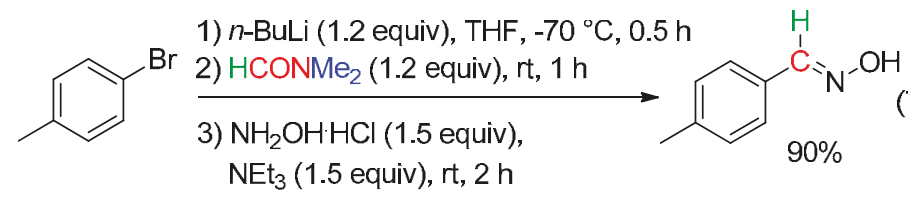

\section{2. $\mathrm{RCNMe}_{2}$ Fragment}

Dihydropyrrolizino[3,2-b]indol-10-ones were isolated in fair to high yields from a $\mathrm{Cs}_{2} \mathrm{CO}_{3}-$ promoted domino reaction leading to the formation of three bonds with incorporation of the HCNMe of DMF. Such a reaction-type with incorporation of the MeCNMe also occurred in DMAc but with a low yield (Equation (73)) [26].

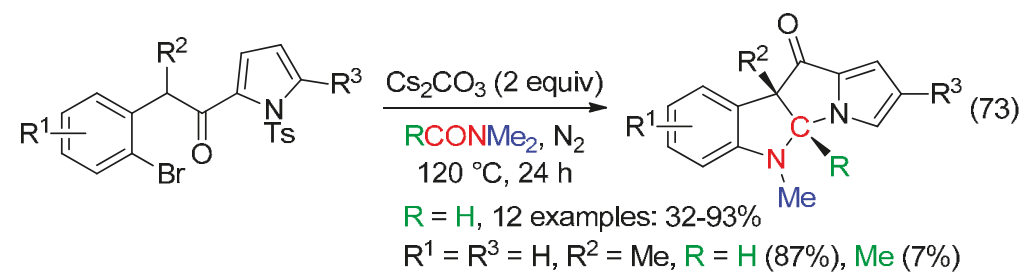

\section{RC-O Fragment}

A 1:1 mixture of $\mathrm{CuO}$ and $\mathrm{I}_{2}$ led the $\alpha$-formyloxylation or $\alpha$-acetoxylation of methylketones by DMF or DMAc, respectively (Equation (74)). $\alpha$-Iodoketones would be the intermediates as indicated by the reaction of 2-iodo-1-(4-methoxyphenyl)ethanone (Equation (75)). Traces of water delivered the carbonyl oxygen [16].
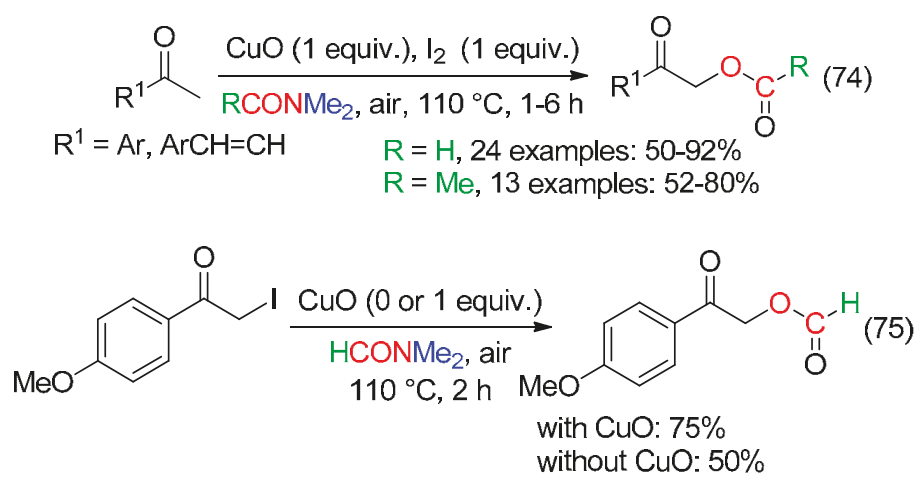

Stereoinversion of the secondary alcohols of a number of carbocyclic substrates was carried out via their triflylation followed by treatment with aqueous DMF (Equation (76)) and subsequent methanolysis [85]. A one pot stereoinversion process was reported.

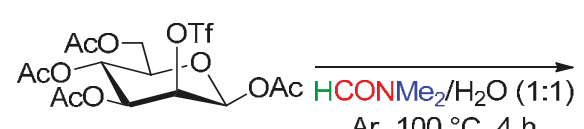

Ar, $100^{\circ} \mathrm{C}, 4 \mathrm{~h}$

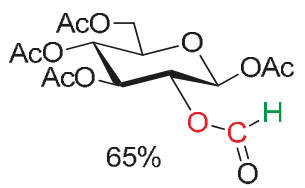


The formyl group of DMF was involved in the triflic anhydride-mediated domino reaction depicted in Equation (77) [86].

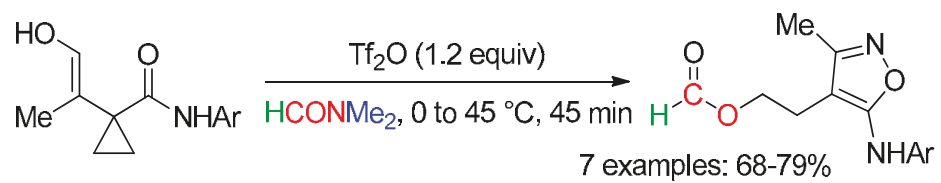

Chloroformyloxylation and chloroacetoxylation of olefinic substrates were performed with $\mathrm{PhICl}_{2}$ and either wet DMF or DMAc (Equation (78)) [87]. Styrenes suffered also difunctionalization using aryl diazonium salts and Ru photocatalysis in wet DM (Equation (79)) [28].

$$
\begin{aligned}
& \mathrm{R}^{1} \mathrm{R}_{+}^{2}+\mathrm{PhICl}_{2} \frac{\text { wet } \mathrm{RCONMe}}{\text { air, } \mathrm{rt}} \\
& \mathrm{R}^{1}=\mathrm{Ar} \text {, alkyl; } \mathrm{R}^{2}=\mathrm{Ph} \text {, alkyl, } \mathrm{CO}_{2} \mathrm{Me}, \mathrm{CONR}{ }_{2}, \mathrm{COAr} \\
& \mathrm{R}=\mathrm{H}, 12 \text { examples: } 60-95 \%, \mathrm{dr}=65: 35-96: 4 \\
& \mathrm{R}=\mathrm{Me}, 3 \text { examples: } 83-90 \%, \mathrm{dr}=88: 12-95: 5
\end{aligned}
$$

$$
\begin{aligned}
& \underset{\text { (4 equiv) }}{\mathrm{Ar}^{1} \sim \mathrm{R}^{1}+\mathrm{Ar}^{2} \mathrm{~N}_{2} \mathrm{BF}_{4}+\mathrm{H}_{2} \mathrm{O}} \stackrel{\begin{array}{c}
{\left[\mathrm{Ru}(\mathrm{bpy})_{3} \mathrm{Cl}\right]_{2}\left(\mathrm{H}_{2} \mathrm{O}\right)_{6}(0.02 \text { equiv) }} \\
\text { visible light }(450 \mathrm{~nm})
\end{array}}{\begin{array}{c}
\text { degassed mixture } \\
\text { RCONMe }
\end{array}} \\
& \mathrm{R}=\mathrm{H}, 22 \text { examples: trace- } 76 \% \\
& \mathrm{Ar}^{1}=\mathrm{Ph}, \mathrm{R}^{1}=p-\mathrm{ClC}_{6} \mathrm{H}_{4}, \mathrm{R}=\mathrm{H}(76 \%), \mathrm{Me}(52 \%)
\end{aligned}
$$

\section{4. $\mathrm{RC}=\mathrm{O}$ Fragment}

Metal-catalyzed or $\mathrm{CO}_{2}$-mediated $\mathrm{C}-\mathrm{N}$ and $\mathrm{N}-\mathrm{H}$ bond metathesis reactions between primary or secondary amines and DM provided the transamidation products, that is formamides or acetamides (Equation (80)) [88-91].

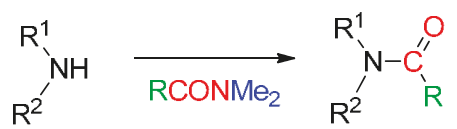

$\mathrm{R}^{1}=\mathrm{Ar}$, alkyl, Bn; $\mathrm{R}^{2}=\mathrm{H}$, alkyl, Bn

$\mathrm{CO}_{2}$ (1 bar), $100{ }^{\circ} \mathrm{C}, 24-48 \mathrm{~h}$ [88]: $\mathrm{R}=\mathrm{H}, 23$ examples: $68-99 \%$

$\mathrm{CeO}_{2}$ (cat), $150{ }^{\circ} \mathrm{C}, 24 \mathrm{~h}$ [89]: $\mathrm{R}=\mathrm{H}, 17$ examples: $49-99 \%$

$\mathrm{Nd}_{2} \mathrm{Na}_{8}\left(\mathrm{OCH}_{2} \mathrm{CF}_{3}\right)_{14}(\mathrm{THF})_{6}\left(0.04\right.$ equiv) $\left\{\mathrm{R}=\mathrm{H}, \mathrm{R}^{1}=\mathrm{H}, \mathrm{R}^{2}=\mathrm{Bn}(78 \%),\left(\mathrm{CH}_{2}\right)_{10} \mathrm{Me}(76 \%)\right.$

$\mathrm{Ar}, 120^{\circ} \mathrm{C}, 5-10 \mathrm{~h}[90] \mathrm{R}=\mathrm{Me}, \mathrm{R}^{1}=\mathrm{H}, \mathrm{R}^{2}=\mathrm{Bn}(86 \%),\left(\mathrm{CH}_{2}\right)_{10} \mathrm{Me}(83 \%)$

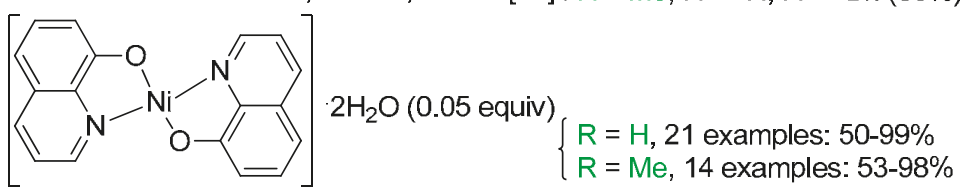

imidazole (3 equiv), $150{ }^{\circ} \mathrm{C}, 2-6 \mathrm{~h}$ [91]

Formylation of aromatic substrates resulted from their treatment with LDA [92] or $n$-BuLi [93] and, subsequently, DMF (Equation (81)). 


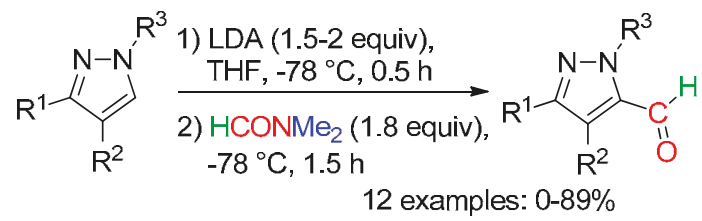

Graphene oxide reacted with DBU and DM to afford, in presence of trace of water, N-(3-(2oxoazepan-1-yl)propyl)formamide or the corresponding acetamide (Equation (82)) [94].

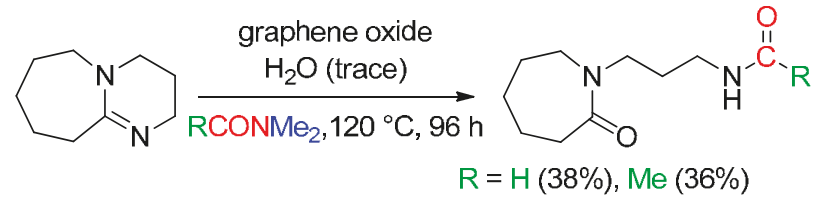

\section{5. $\mathrm{RC}=\mathrm{ON}\left(\mathrm{CH}_{2}\right)$ Me Fragment}

$\mathrm{N}$-Amidoalkylation of imidazoles and 1,2,3-triazoles with DM effectively arose under various experimental conditions (Equations (83) [95] and (84) [10]).

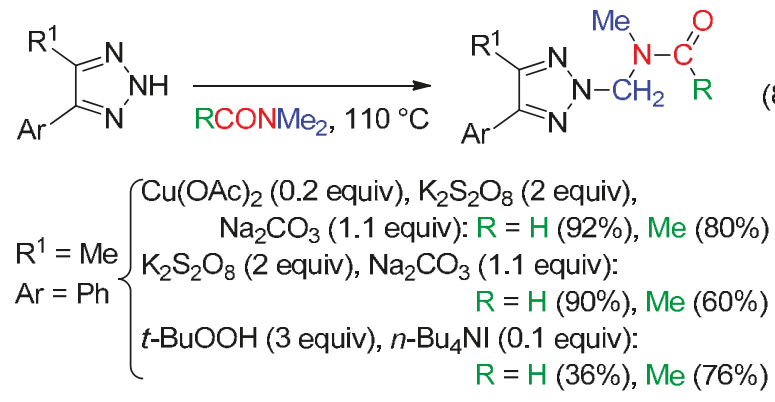

$\mathrm{Cu}(\mathrm{OAc})_{2}$ (0.2 equiv), $\mathrm{K}_{2} \mathrm{~S}_{2} \mathrm{O}_{8}$ (2 equiv), $\mathrm{Na}_{2} \mathrm{CO}_{3}$ (1.1 equiv), 34 examples: $47-94 \%$

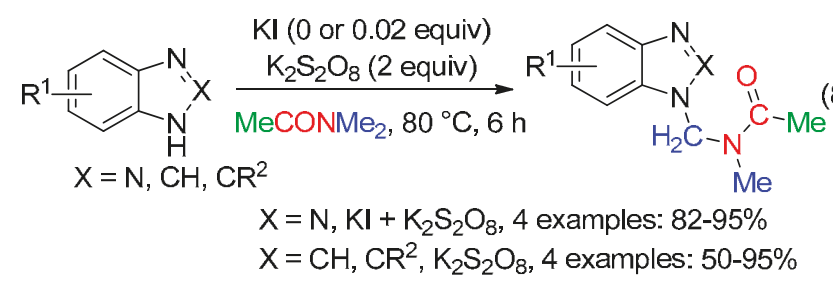

\section{6. $\mathrm{HC}-\mathrm{ONMe}_{2}$ Fragment}

Catalysis with $\mathrm{Mo}(\mathrm{CO})_{6}$ of the reduction of DMF with triethylsilane afforded a siloxymethylamine (Equation (85)), which was used as a Mannich reagent [96].

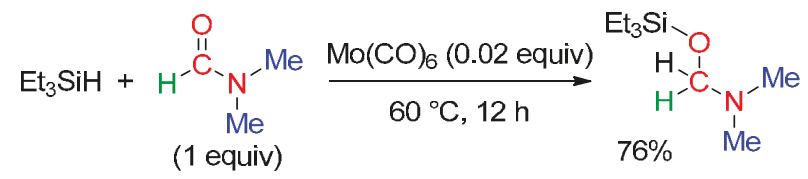




\section{RC and O Fragment}

Arynes, which are easily obtained from, for example 2-(trimethylsilyl)phenyl trifluoromethanesulfonate, undergone a [2+2] cyclization with DM giving a benzoxetene and its isomer, the orthoquinone methide (Scheme 3). Trapping of these intermediates provides various products, which contain the formyl or acetyl CH part and the O atom of DM (Equations (86) [19], (87) [20], (88) [21] and (89) [97]), or the $\mathrm{HCNMe}_{2}$ and O fragments of DMF (see Section 18).

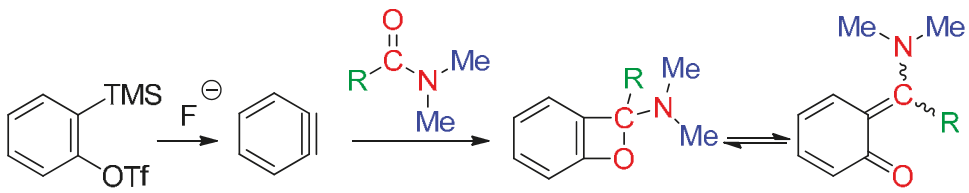

Scheme 3. Aryne formation and reaction with DM.

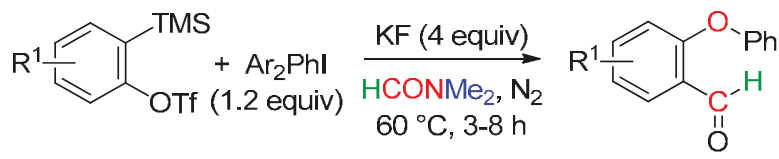

22 examples: $56-96 \%$

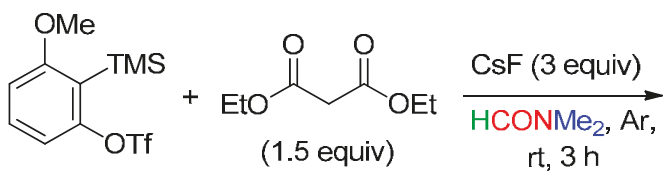<smiles>CCOC(=O)c1c(OC)c2c(OC)cccc2oc1=O</smiles>

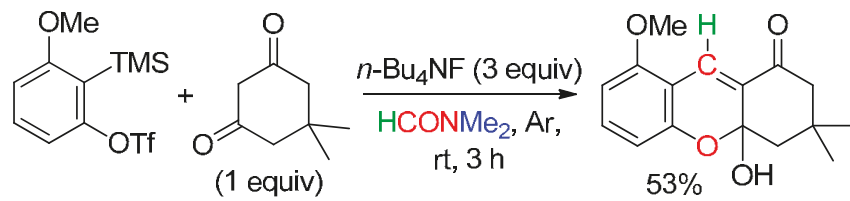

At $115{ }^{\circ} \mathrm{C}$ in wet toluene, the hexadehydro-Diels-Alder of tetraynes depicted in Equation (89) was in-situ followed by [2 +2$]$ cycloaddition reaction with DM leading to multifunctionalized salicylaldehydes and salicylketones [97].

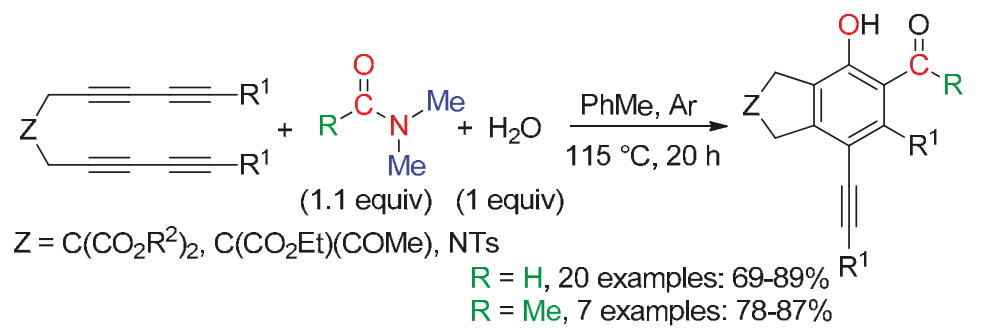

\section{8. $\mathrm{RCNMe}_{2}$ and $\mathrm{O}$ Fragment}

All atoms of DMF were inserted in the polyfunctionalized compounds produced from domino reactions involving formation of arynes, cycloaddition with DMF and subsequent trapping 
with $\alpha$-chloro $\beta$-diesters (Equation (90)) [22], aroyl cyanides (Equation (91)) [23] or diesters of acetylenedicarboxylic acid (Equation (92)) [24].
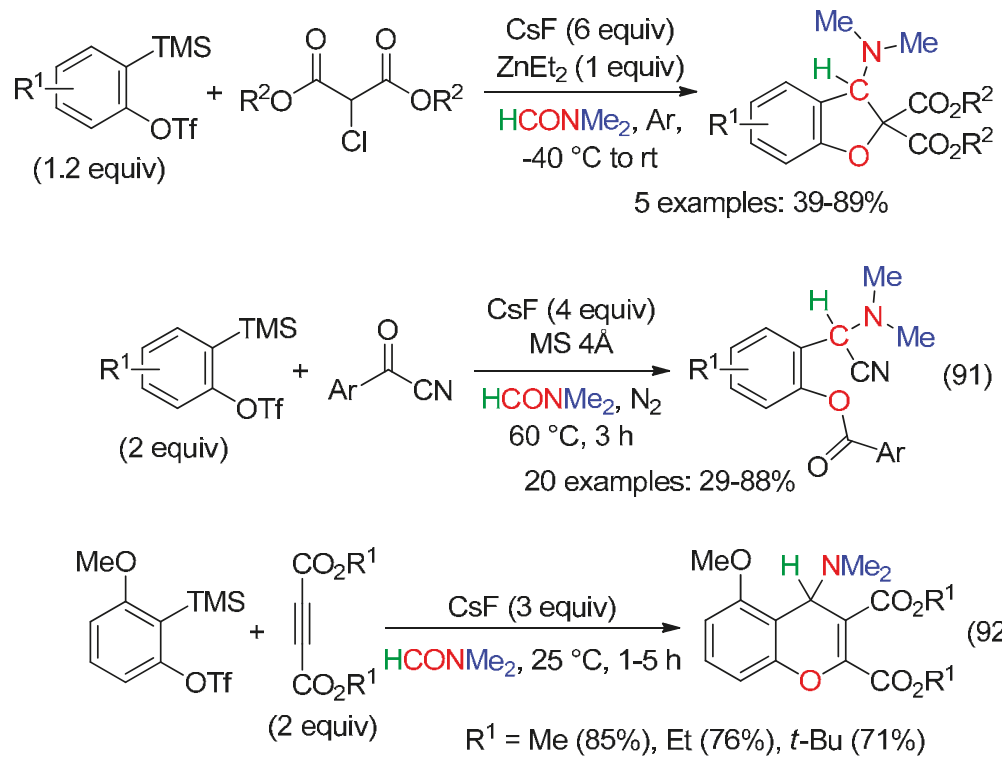

\section{9. $\mathrm{HC}=\mathrm{O}$ and $\mathrm{HC}$ Fragment}

Lithium thioanisole biscarbanion reacted with two molecules of DMF to afford benzo[b]thiophene-2-carbaldehyde (Equation (93)) [98].

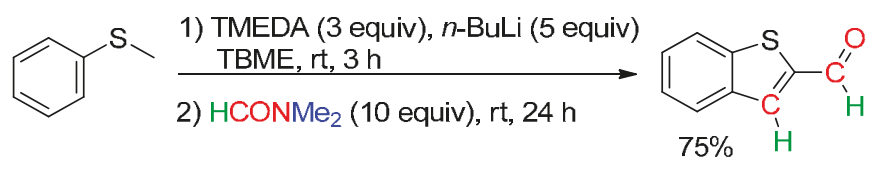

\section{0. $\mathrm{H}$ and $\mathrm{NMe}_{2}$ Fragment}

The reaction of DMF with sodium and subsequent addition of terminal activated alkynes afforded the corresponding hydroamination compounds (Equation (94)) [99].

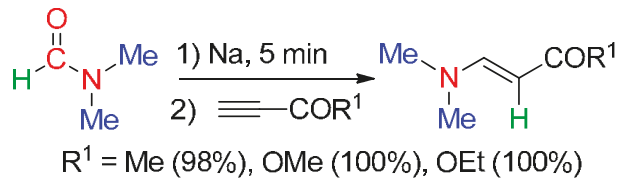

\section{1. $\mathrm{H}$ and $\mathrm{C}=\mathrm{ONMe}_{2}$ Fragment}

Semicarbazides have been synthetized from additions, mediated with $(t-\mathrm{BuO})_{2}$ and catalytic amounts of both $\mathrm{NaI}$ and $\mathrm{PhCOCl}$, of the $\mathrm{H}$ and $\mathrm{CONMe}_{2}$ moieties of DMF to the extremities of the $\mathrm{N}=\mathrm{N}$ bond of azoarenes (Equation (95)) [100]. The role of $\mathrm{NaI}$ and $\mathrm{PhCOCl}$ is not clear and, furthermore, exchange of NaI for imidazole led to formylhydrazines (Equation (96)) [100]. The corresponding acetylhydrazine was not formed in DMAc (Equation (96)). The $(t-\mathrm{BuO})_{2} / \mathrm{NaI} / \mathrm{PhCOCl} / \mathrm{DMF}$ system 
led to the addition of $\mathrm{H}$ and $\mathrm{CONMe}$ to the $\mathrm{N}=\mathrm{C}$ bond of $\mathrm{N}$-benzylideneaniline but with low yield (Equation (97)) [100].

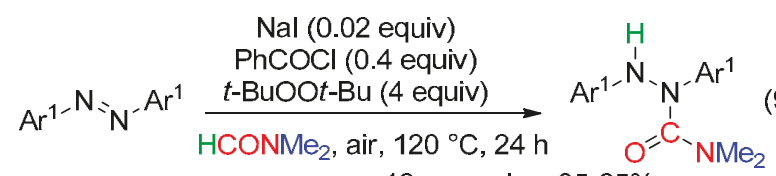

$$
\begin{aligned}
& 12 \text { examples: } 35-65 \%
\end{aligned}
$$

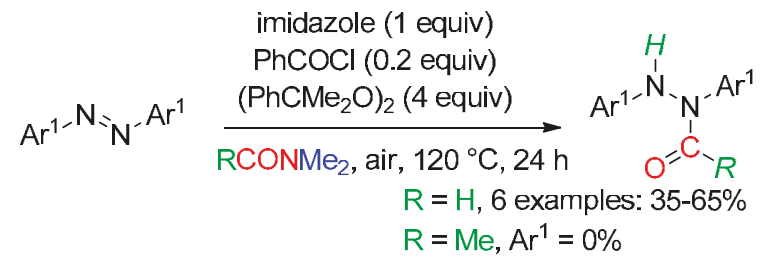

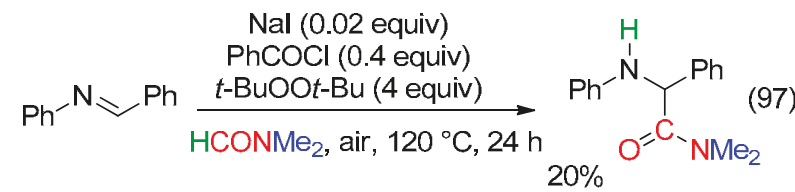

The Ru-catalyzed hydrocarbamoylative cyclization of 1,6-diynes proceeded in DMF to afford cyclic $\alpha, \beta, \delta, \gamma$-unsaturated amides (Equation (98)) [101-103].

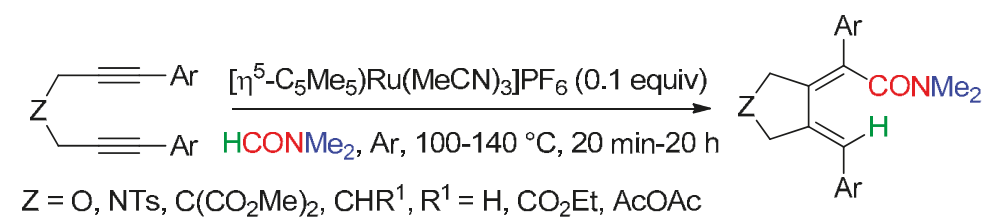

18 examples: $15-86 \%$

\section{2. $\mathrm{H}, \mathrm{C}=\mathrm{ONMe}_{2}$ and $\mathrm{NMe}_{2}$ Fragment}

$\operatorname{Re}_{2}(\mathrm{CO})_{8}\left[\mu-\eta^{2}-\mathrm{C}(\mathrm{H})=\mathrm{C}(\mathrm{H}) \mathrm{Bu}\right](\mu-\mathrm{H})$ undergone reaction with DMF leading to hexenyl $/ \mathrm{CONMe} 2$ and $\mathrm{CO} / \mathrm{HNMe}_{2}$ exchange of ligands (Equation (99)) [104].

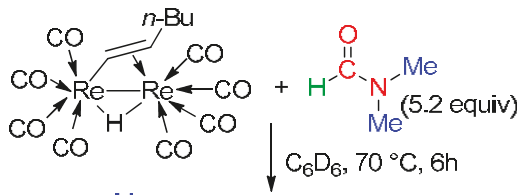
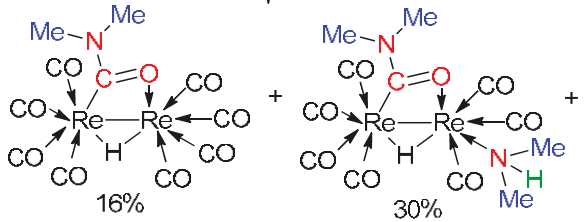

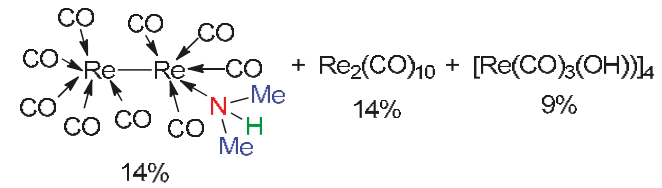




\section{3. $\mathrm{C}=\mathrm{ONMe}_{2}$ and $\mathrm{CH}$ Fragment}

Couplings between amidines, styrenes and fragments of two molecules of DMF in the presence of $t-\mathrm{BuOOH}$ and a $\mathrm{Pd}^{\mathrm{II}}$ catalyst provided pyrimidine carboxamides (Equation (100)) [105]. DMAc may also be the $\mathrm{CH}$ source as exemplified with the formation of the $\mathrm{N}, \mathrm{N}$-diethyl-2,4diphenylpyrimidine-5-carboxamide when $N, N$-diethylformamide was the source of the amide moiety (Equation (101)).

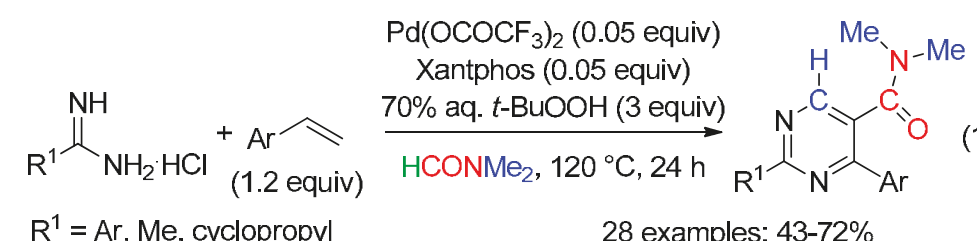

$\mathrm{R}^{1}=\mathrm{Ar}, \mathrm{Me}$, cyclopropyl

28 examples: $43-72 \%$

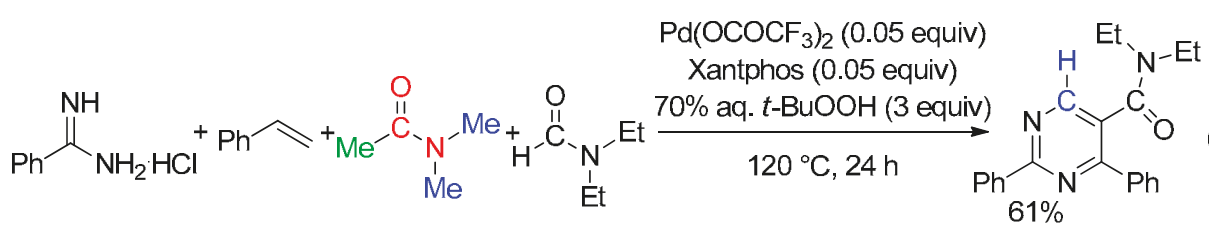

\section{Reducing or Stabilizing Agent}

DMF is a powerful reducing agent of metal salts, hence its use for the preparation of metal colloids [106]. In wet DMF, $\mathrm{PdCl}_{2}$ led to carbamic acid and $\mathrm{Pd}(0)$ nanoparticles (Equation (102)) [107]. The latter have been associated with the metal-organic framework $\mathrm{Cu}_{2}(\mathrm{BDC})_{2}(\mathrm{DABCO})(\mathrm{BDC}=1,4-$ benzenedicarboxylate), leading to a catalytic system with high activity and recyclability for the aerobic oxidation of benzyl alcohols to aldehydes [108] and Suzuki-Miyaura cross-coupling reactions [107].

$$
\mathrm{PdX}_{2}+\mathrm{HCONM}_{2}+\mathrm{H}_{2} \mathrm{O} \longrightarrow \mathrm{Pd}(\mathrm{O})+\mathrm{HOCONMe}_{2}+2 \mathrm{HX}
$$

In addition, DMF can act as stabilizing agent of metal colloids to afford effective and recyclable catalysts, based for examples:

on iron for the hydrosilylation of alkenes (Equation (103)) [109],

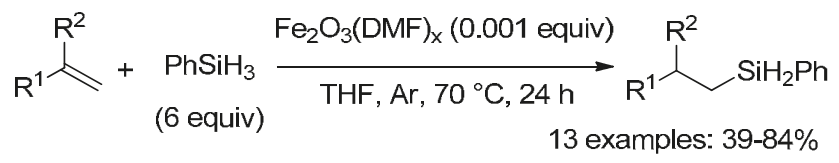

on palladium for the synthesis of 2,3-disubstituted indoles from 2-halooanilines and alkynes (Equation (104)) [110],

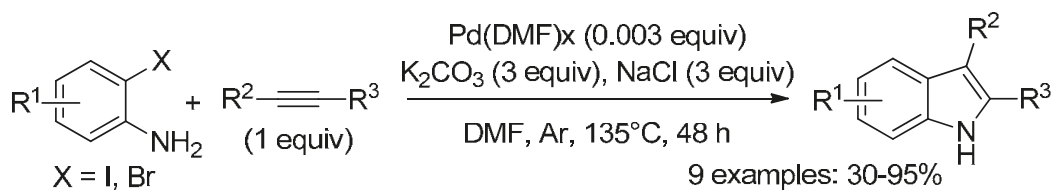


- $\quad$ on copper for Sonogashira-Hagihara cross-coupling reactions (Equation (105)) [111],

$$
\begin{aligned}
& \mathrm{Cu} \text { (DMF)x (0.002 equiv) }
\end{aligned}
$$

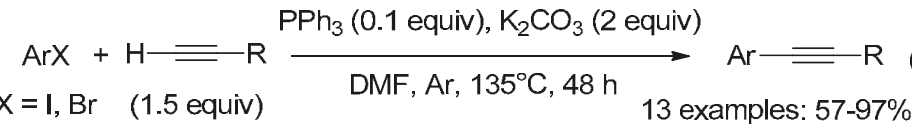

- $\quad$ on iridium for methylation of alcohols (Equation (106)) and amines (Equation (107)), using methanol as the $\mathrm{C} 1$ source [112].
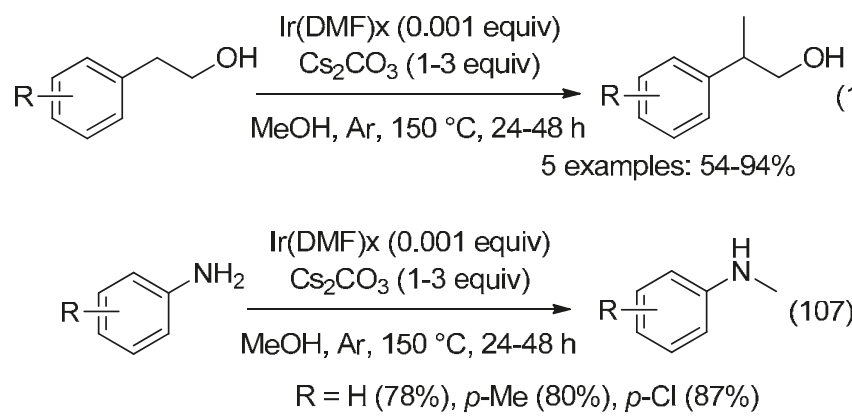

Thermal decomposition of DMF leads to $\mathrm{CO}$, which reacts with water under $\mathrm{CuFe}_{2} \mathrm{O}_{4}$ catalysis to produce hydrogen [113]. In the presence of 2-nitroanilines, this water gas shift reaction was part of a domino reaction involving the reduction of the nitro group followed by cyclisation into benzimidazoles using a $\mathrm{CH}$ from the $\mathrm{NMe}_{2}$ of DMF (Equation (108)) [113]. Such cyclisation is above documented under different experimental conditions (Equation (18)) [50].

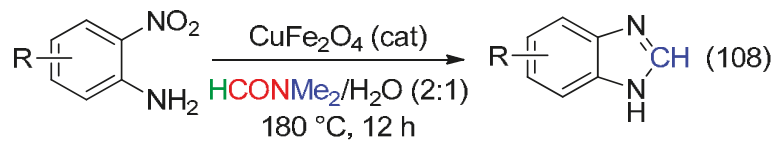

\section{Conclusions}

This minireview highlights recent uses of DMF and DMAc as sources of building blocks in various reactions of the organic synthesis. We assume that new uses of these multipurpose reagents will be reported.

Author Contributions: J. Muzart collected the literature references. J. Muzart and J. Le Bras contributed to the manuscript writing.

Funding: This research received no external funding.

Conflicts of Interest: The authors declare no conflicts of interest.

\section{References}

1. Muzart, J. N,N-Dimethylformamide: Much more than a solvent. Tetrahedron 2009, 65, 8313-8323. [CrossRef]

2. Ding, S.; Jiao, N. N,N-Dimethylformamide: A multipurpose building block. Angew. Chem. Int. Ed. 2012, 51, 9226-9231. [CrossRef] [PubMed]

3. Batra, A.; Singh, P.; Singh, K.N. Cross dehydrogenative coupling (CDC) reactions of $N, N$-disubstituted formamides, benzaldehydes and cycloalkanes. Eur. J. Org. Chem. 2016, 2016, 4927-4947. [CrossRef] 
4. Le Bras, J.; Muzart, J. N,N-Dimethylformamide and N,N-dimethylacetamide as carbon, hydrogen, nitrogen and/or oxygen sources. In Solvents as Reagents in Organic Synthesis, Reactions and Applications; Wu, X.-F., Ed.; Wiley-VCH: Weinheim, Germany, 2017; pp. 199-314.

5. Kolosov, M.A.; Shvets, E.H.; Manuenkov, D.A.; Vlasenko, S.A.; Omelchenko, I.V.; Shishkina, S.V.; Orlov, V.D. A synthesis of 6-functionalized 4,7-dihydro[1,2,4]triazolo[1,5-a]pyrimidines. Tetrahedron Lett. 2017, 58, 1207-1210. [CrossRef]

6. Borah, A.; Goswami, L.; Neog, K.; Gogoi, P. DMF dimethyl acetal as carbon source for $\alpha$-methylation of ketones: A hydrogenation-hydrogenolysis strategy of enaminones. J. Org. Chem. 2015, 80, 4722-4728. [CrossRef] [PubMed]

7. Kumar, S.; Vanjari, R.; Guntreddi, T.; Singh, K.N. Sulfur promoted decarboxylative thioamidation of carboxylic acids using formamides as amine proxy. Tetrahedron 2016, 72, 2012-2017. [CrossRef]

8. Chen, J.; Feng, J.-B.; Natte, K.; Wu, X.-F. Palladium-catalyzed carbonylative cyclization of arenes by C-H bond activation with DMF as the carbonyl source. Chem. Eur. J. 2015, 21, 16370-16373. [CrossRef] [PubMed]

9. Guo, S.; Zhu, Z.; Lu, L.; Zhang, W.; Gong, J.; Cai, H. Metal-free Csp ${ }^{3}-\mathrm{N}$ bond cleavage of amides using tert-butyl hydroperoxide as oxidant. Synlett 2015, 26, 543-546. [CrossRef]

10. Zhu, Z.; Wang, Y.; Yang, M.; Huang, L.; Gong, J.; Guo, S.; Cai, H. A metal-free cross-dehydrogenative coupling reaction of amides to access $N$-alkylazoles. Synlett 2016, 27, 2705-2708.

11. Alanthadka, A.; Devi, E.S.; Selvi, A.T.; Nagarajan, S.; Sridharan, V.; Maheswari, C.U. N-Heterocyclic carbene-catalyzed Mannich reaction for the synthesis of $\beta$-amino ketones: $N, N$-dimethylformamide as carbon source. Adv. Synth. Catal. 2017, 359, 2369-2374. [CrossRef]

12. Zewge, D.; Bu, X.; Sheng, H.; Liu, Y.; Liu, Z.; Harman, B.; Reibarkh, M.; Gong, X. Mechanistic insight into oxidized $\mathrm{N}, \mathrm{N}$-dimethylacetamide as a source of formaldehyde related derivatives. React. Chem. Eng. 2018, 3, 146-150. [CrossRef]

13. Li, Y.; Tu, D.-H.; Wang, B.; Lu, J.-Y.; Wang, Y.-Y.; Liu, Z.-T.; Liu, Z.-W.; Lu, J. Nickel-catalyzed carbonylation of arylboronic acids with DMF as CO source. Org. Chem. Front. 2017, 4, 569-572. [CrossRef]

14. Lu, K.; Han, X.-W.; Yao, W.-W.; Luan, Y.-X.; Wang, Y.-X.; Chen, H.; Xu, X.-T.; Zhang, K.; Ye, M. DMF-promoted redox-neutral Ni-catalyzed intramolecular hydroarylation of alkene with simple arene. ACS Catal. 2018, 8, 3913-3917. [CrossRef]

15. Bannwart, L.; Abele, S.; Tortoioli, S. Metal-free amidation of acids with formamides and T3P®. Synthesis 2016, 48, 2069-2078.

16. Zhu, Y.-P.; Gao, Q.-H.; Lian, M.; Yuan, J.-J.; Liu, M.-C.; Zhao, Q.; Yang, Y.; Wu, A.-X. A sustainable byproduct catalyzed domino strategy: Facile synthesis of $\alpha$-formyloxy and acetoxy ketones via iodination/nucleophilic substitution/hydrolyzation/oxidation sequences. Chem. Commun. 2011, 47, 12700-12702. [CrossRef] [PubMed]

17. Mata, L.; Avenoza, A.; Busto, J.H.; Peregrina, J.M. Chemoselectivity control in the reactions of 1,2-cyclic sulfamidates with amines. Chem. Eur. J. 2013, 19, 6831-6839. [CrossRef] [PubMed]

18. Liu, W.; Chen, C.; Zhou, P. N,N-Dimethylformamide (DMF) as a source of oxygen to access $\alpha$-hydroxy arones via the $\alpha$-hydroxylation of arones. J. Org. Chem. 2017, 82, 2219-2222. [CrossRef] [PubMed]

19. Liu, F.; Yang, H.; Hu, X.; Jiang, G. Metal-free synthesis of ortho-CHO diaryl ethers by a three-component sequential coupling. Org. Lett. 2014, 16, 6408-6411. [CrossRef] [PubMed]

20. Yoshioka, E.; Kohtani, S.; Miyabe, H. Three-component coupling reactions of arynes for the synthesis of benzofurans and coumarins. Molecules 2014, 19, 863-880. [CrossRef] [PubMed]

21. Yoshioka, E.; Kohtani, S.; Miyabe, H. 2,3,4,9-Tetrahydro-9-(3-hydroxy-1,4-dioxo-1H-dihydronaphthalen-2yl)-8-methoxy-3,3-dimethyl-1H-xanthen-1-one. Molbank 2015, 2015, M841. [CrossRef]

22. Yoshioka, E.; Tanaka, H.; Kohtani, S.; Miyabe, H. Straightforward synthesis of dihydrobenzofurans and benzofurans from arynes. Org. Lett. 2013, 15, 3938-3941. [CrossRef] [PubMed]

23. Zhou, C.; Wang, J.; Jin, J.; Lu, P.; Wang, Y. Three-component synthesis of $\alpha$-amino- $\alpha$-aryl carbonitriles from arynes, aroyl cyanides, and N,N-dimethylformamide. Eur. J. Org. Chem. 2014, 2014, 1832-1835. [CrossRef]

24. Yoshioka, E.; Tamenaga, H.; Miyabe, H. [4+2] Cycloaddition of intermediates generated from arynes and DMF. Tetrahedron Lett. 2014, 55, 1402-1405. [CrossRef]

25. Kodimuthali, A.; Mungara, A.; Prasunamba, P.L.; Pal, M. A simple synthesis of aminopyridines: Use of amides as amine source. J. Braz. Chem. Soc. 2010, 21, 1439-1445. [CrossRef] 
26. Zhang, Q.; Song, C.; Huang, H.; Zhang, K.; Chang, J. Cesium carbonate promoted cascade reaction involving DMF as a reactant for the synthesis of dihydropyrrolizino[3,2-b]indol-10-ones. Org. Chem. Front. 2018, 5, 80-87. [CrossRef]

27. Chen, W.-X.; Shao, L.-X. N-Heterocyclic carbene-palladium(II)-1-methylimidazole complex catalyzed amination between aryl chlorides and amides. J. Org. Chem. 2012, 77, 9236-9239. [CrossRef] [PubMed]

28. Yao, C.-J.; Sun, Q.; Rastogi, N.; Koenig, B. Intermolecular formyloxyarylation of alkenes by photoredox Meerwein reaction. ACS Catal. 2015, 5, 2935-2938. [CrossRef]

29. Yan, H.; Yang, H.; Lu, L.; Liu, D.; Rong, G.; Mao, J. Copper-catalyzed synthesis of $\alpha, \beta$-unsaturated acylamides via direct amidation from cinnamic acids and $N$-substituted formamides. Tetrahedron 2013, 69, 7258-7263. [CrossRef]

30. Salamone, M.; Milan, M.; DiLabio, G.A.; Bietti, M. Reactions of the cumyloxyl and benzyloxyl radicals with tertiary amides. Hydrogen abstraction selectivity and the role of specific substrate-radical hydrogen bonding. J. Org. Chem. 2013, 78, 5909-5917. [CrossRef] [PubMed]

31. Du, B.; Sun, P. Syntheses of amides via iodine-catalyzed multiple $\mathrm{sp}^{3} \mathrm{C}-\mathrm{H}$ bonds oxidation of methylarenes and sequential coupling with $N, N$-dialkylformamides. Sci. China Chem. 2014, 57, 1176-1182. [CrossRef]

32. Du, B.; Jin, B.; Sun, P. The syntheses of $\alpha$-ketoamides via $n$-Bu $\mathrm{u}_{4} \mathrm{NI}$-catalyzed multiple $\mathrm{sp}^{3} \mathrm{C}$-H bond oxidation of ethylarenes and sequential coupling with dialkylformamides. Org. Biomol. Chem. 2014, 12, 4586-4589. [CrossRef] [PubMed]

33. Bai, C.; Yao, X.; Li, Y. Easy access to amides through aldehydic C-H bond functionalization catalyzed by heterogeneous Co-based catalysts. ACS Catal. 2015, 5, 884-891. [CrossRef]

34. Wu, J.-J.; Li, Y.; Zhou, H.-Y.; Wen, A.-H.; Lun, C.-C.; Yao, S.-Y.; Ke, Z.; Ye, B.-H. Copper-catalyzed carbamoylation of terminal alkynes with formamides via cross-dehydrogenative coupling. ACS Catal. 2016, 6, 1263-1267. [CrossRef]

35. Zhang, C.; Yue, Q.; Xiao, Z.; Wang, X.; Zhang, Q.; Li, D. Synthesis of $O$-aroyl- $N, N$-dimethylhydroxylamines through hypervalent iodine-mediated amination of carboxylic acids with $N, N$-dimethylformamide. Synthesis 2017, 49, 4303-4308.

36. $\mathrm{Wu}, \mathrm{X}$.; Zhao, Y.; Ge, H. Direct aerobic carbonylation of $\mathrm{C}\left(\mathrm{sp}^{2}\right)-\mathrm{H}$ and $\mathrm{C}\left(\mathrm{sp}^{3}\right)-\mathrm{H}$ bonds through $\mathrm{Ni} / \mathrm{Cu}$ synergistic catalysis with DMF as the carbonyl source. J. Am. Chem. Soc. 2015, 137, 4924-4927. [CrossRef] [PubMed]

37. Rao, D.N.; Rasheed, S.; Das, P. Palladium/silver synergistic catalysis in direct aerobic carbonylation of $\mathrm{C}\left(\mathrm{sp}^{2}\right)-\mathrm{H}$ bonds using $\mathrm{DMF}$ as a carbon source: Synthesis of pyrido-fused quinazolinones and phenanthridinones. Org. Lett. 2016, 18, 3142-3145.

38. Boosa, V.; Bilakanti, V.; Gutta, N.; Velisoju, V.K.; Medak, S.; Ramineni, K.; Jorge, B.; Muxina, K.; Akula, V. $\mathrm{C}-\mathrm{H}$ bond cyanation of arenes using $\mathrm{N}, \mathrm{N}$-dimethylformamide and $\mathrm{NH}_{4} \mathrm{HCO}_{3}$ as a $\mathrm{CN}$ source over a hydroxyapatite supported copper catalyst. Catal. Sci. Technol. 2016, 6, 8055-8062.

39. Zhang, L.; Lu, P.; Wang, Y. Copper-mediated cyanation of indoles and electron-rich arenes using DMF as a single surrogate. Org. Biomol. Chem. 2015, 13, 8322-8329, Correction in Org. Biomol. Chem. 2016, 14, 1840. [CrossRef] [PubMed]

40. Xiao, J.; Li, Q.; Chen, T.; Han, L.-B. Copper-mediated selective aerobic oxidative C3-cyanation of indoles with DMF. Tetrahedron Lett. 2015, 56, 5937-5940. [CrossRef]

41. Zhao, M.-N.; Hui, R.-R.; Ren, Z.-H.; Wang, Y.-Y.; Guan, Z.-H. Ruthenium-catalyzed cyclization of ketoxime acetates with DMF for synthesis of symmetrical pyridines. Org. Lett. 2014, 16, 3082-3085. [CrossRef] [PubMed]

42. Liu, W.; Tan, H.; Chen, C.; Pan, Y. A method to access symmetrical tetrasubstituted pyridines via iodine and ammonium persulfate mediated [2+2+1+1]-cycloaddition reaction. Adv. Synth. Catal. 2017, 359, 1594-1598. [CrossRef]

43. Bai, Y.; Tang, L.; Huang, H.; Deng, G.-J. Synthesis of 2,4-diarylsubstituted-pyridines through a Ru-catalyzed four component reaction. Org. Biomol. Chem. 2015, 13, 4404-4407. [CrossRef] [PubMed]

44. Nandwana, N.K.; Dhiman, S.; Saini, H.K.; Kumar, I.; Kumar, A. Synthesis of quinazolinones, imidazo[1,2-c] quinazolines and imidazo[4,5-c] quinolines through tandem reductive amination of aryl halides and oxidative amination of $\mathrm{C}\left(\mathrm{sp}^{3}\right)-\mathrm{H}$ bonds. Eur. J. Org. Chem. 2017, 2017, 514-522. [CrossRef] 
45. Weng, Y.; Zhou, H.; Sun, C.; Xie, Y.; Su, W. Copper-catalyzed cyclization for access to 6H-chromeno[4,3-b]quinolin-6-ones employing DMF as the carbon source. J. Org. Chem. 2017, 82, 9047-9053. [CrossRef] [PubMed]

46. Liu, Y.; Nie, G.; Zhou, Z.; Jia, L.; Chen, Y. Copper-catalyzed oxidative cross-dehydrogenative coupling/oxidative cycloaddition: Synthesis of 4-acyl-1,2,3-triazoles. J. Org. Chem. 2017, 82, 9198-9203. [CrossRef] [PubMed]

47. Zheng, L.-Y.; Guo, W.; Fan, X.-L. Metal-free, TBHP-mediated, [3+2+1]-type intermolecular cycloaddition reaction: Synthesis of pyrimidines from amidines, ketones, and DMF through $\mathrm{C}\left(\mathrm{sp}^{3}\right)-\mathrm{H}$ activation. Asian J. Org. Chem. 2017, 6, 837-840. [CrossRef]

48. Wang, F.; Wu, W.; Xu, X.; Shao, X.; Li, Z. Synthesis of substituted phenols via 1,1-dichloro-2-nitroethene promoted condensation of carbonyl compounds with DMF. Tetrahedron Lett. 2018, 59, 2506-2510. [CrossRef]

49. Wang, J.-B.; Li, Y.-L.; Deng, J. Metal-free activation of DMF by dioxygen: A cascade multiple-bond-formation reaction to synthesize 3-acylindoles from 2-alkenylanilines. Adv. Synth. Catal. 2017, 359, 3460-3467. [CrossRef]

50. Rasal, K.B.; Yadav, G.D. Carbon dioxide mediated novel synthesis of quinazoline-2,4(1H,3H)-dione in water. Org. Process Res. Dev. 2016, 20, 2067-2073. [CrossRef]

51. Pu, F.; Li, Y.; Song, Y.-H.; Xiao, J.; Liu, Z.-W.; Wang, C.; Liu, Z.-T.; Chen, J.-G.; Lu, J. Copper-catalyzed coupling of indoles with dimethylformamide as a methylenating reagent. Adv. Synth. Catal. 2016, 358, 539-542. [CrossRef]

52. Mondal, S.; Samanta, S.; Santra, S.; Bagdi, A.K.; Hajra, A. N,N-Dimethylformamide as a methylenating reagent: Synthesis of heterodiarylmethanes via copper-catalyzed coupling between imidazo[1,2-a]pyridines and indoles/N,N-dimethylaniline. Adv. Synth. Catal. 2016, 358, 3633-3641. [CrossRef]

53. Lee, S.; Jung, H.J.; Choi, H.C.; Hwang, Y.S.; Choi, M.Y. Solvent acting as a precursor: Synthesis of AgCN from $\mathrm{AgNO}_{3}$ in $\mathrm{N}, \mathrm{N}$-DMF solvent by laser ablation. Bull. Korean Chem. Soc. 2017, 38, 136-139. [CrossRef]

54. Zhou, X.; Zhang, G.; Gao, B.; Huang, H. Palladium-catalyzed hydrocarbonylative C-N coupling of alkenes with amides. Org. Lett. 2018, 20, 2208-2212. [CrossRef] [PubMed]

55. Bi, X.; Li, J.; Shi, E.; Wang, H.; Gao, R.; Xiao, J. Ru-catalyzed direct amidation of carboxylic acids with $N$-substituted formamides. Tetrahedron 2016, 72, 8210-8214. [CrossRef]

56. Sun, Y.-J.; Li, P.; Huang, Q.-Q.; Zhang, J.-J.; Itoh, S. Dioxygenation of flavonol catalyzed by copper(II) complexes supported by carboxylate-containing ligands: Structural and functional models of quercetin 2,4-dioxygenase. Eur. J. Inorg. Chem. 2017, 2017, 1845-1854. [CrossRef]

57. Chen, X.; Yang, Q.; Zhou, Y.; Deng, Z.; Mao, X.; Peng, Y. Synthesis of 4-(dimethylamino)quinazoline via direct amination of quinazolin-4(3H)-one using $\mathrm{N}, \mathrm{N}$-dimethylformamide as a nitrogen source at room temperature. Synthesis 2015, 47, 2055-2062. [CrossRef]

58. Gupta, S.S.R.; Nakhate, A.V.; Rasal, K.B.; Deshmukh, G.P.; Mannepalli, L.K. Oxidative amidation of benzaldehydes and benzylamines with $\mathrm{N}$-substituted formamides over a Co/Al hydrotalcite-derived catalyst. New J. Chem. 2017, 41, 15268-15276. [CrossRef]

59. Liu, W.; Chen, C.; Zhou, P. Concise access to $\alpha$-arylketothioamides by redox reaction between acetophenones, elemental sulfur and DMF. ChemistrySelect 2017, 2, 5532-5535. [CrossRef]

60. Liu, W.; Chen, C.; Liu, H. Dimethylamine as the key intermediate generated in situ from dimethylformamide (DMF) for the synthesis of thioamides. Beilstein J. Org. Chem. 2015, 11, 1721-1726. [CrossRef] [PubMed]

61. Amupitan, J.O. An extension of the Willgerodt-Kindler reaction. Synthesis 1983, 1983, 730. [CrossRef]

62. Nooshabadi, M.; Aghapoor, K.; Darabi, H.R.; Mojtahedi, M.M. The rapid synthesis of thiomorpholides by Willgerodt-Kindler reaction under microwave heating. Tetrahedron Lett. 1999, 40, 7549-7552. [CrossRef]

63. Wei, E.; Liu, B.; Lin, S.; Liang, F. Multicomponent reaction of chalcones, malononitrile and DMF leading to $\gamma$-ketoamides. Org. Biomol. Chem. 2014, 12, 6389-6392. [CrossRef] [PubMed]

64. Huang, X.; Wang, J.; Ni, Z.; Wang, S.; Pan, Y. Copper-mediated S-N formation via an oxygen-activated radical process: A new synthesis method for sulfonamides. Chem. Commun. 2014, 50, 4582-4584. [CrossRef] [PubMed]

65. Bao, X.; Rong, X.; Liu, Z.; Gu, Y.; Liang, G.; Xia, Q. Potassium tert-butoxide-mediated metal-free synthesis of sulfonamides from sodium sulfinates and N,N-disubstituted formamides. Tetrahedron Lett. 2018, 59, 2853-2858. [CrossRef] 
66. Zeng, W.; Wang, E.Y.; Qiu, R.; Sohail, M.; Wu, S.; Chen, F.X. Oxygen-atom insertion of NHC-copper complex: The source of oxygen from N,N-dimethylformamide. J. Organomet. Chem. 2013, 743, 44-48. [CrossRef]

67. Chen, J.; Natte, K.; Wu, X.-F. Pd/C-catalyzed carbonylative C-H activation with DMF as the CO source. Tetrahedron Lett. 2015, 56, 6413-6416. [CrossRef]

68. Feng, X.; Li, Z. Photocatalytic promoting dimethylformamide (DMF) decomposition to in-situ generation of self-supplied CO for carbonylative Suzuki reaction. J. Photochem. Photobiol. A Chem. 2017, 337, 19-24. [CrossRef]

69. Krishnakumar, V.; Chatterjee, B.; Gunanathan, C. Ruthenium-catalyzed urea synthesis by N-H activation of amines. Inorg. Chem. 2017, 56, 7278-7284. [CrossRef] [PubMed]

70. Yang, Y.; Zhang, X.; Zeng, W.; Huang, H.; Liang, Y. Copper catalyzed three-component synthesis of benzothiazolones from $o$-iodoanilines, DMF, and potassium sulfide. RSC Adv. 2014, 4, 6090-6093. [CrossRef]

71. Mete, T.B.; Singh, A.; Bhat, R.G. Transition-metal-free synthesis of primary to tertiary carboxamides: A quick access to prodrug-pyrazinecarboxamide. Tetrahedron Lett. 2017, 58, 4709-4712. [CrossRef]

72. Yao, B.; Deng, C.-L.; Liu, Y.; Tang, R.-Y.; Zhang, X.-G.; Li, J.-H. Palladium-catalyzed oxidative carbamoylation of isoquinoline $\mathrm{N}$-oxides with formylamides by means of dual $\mathrm{C}-\mathrm{H}$ oxidative coupling. Chem. Commun. 2015, 51, 4097-4100. [CrossRef] [PubMed]

73. Wang, H.; Guo, L.-N.; Wang, S.; Duan, X.-H. Decarboxylative alkynylation of $\alpha$-keto acids and oxamic acids in aqueous media. Org. Lett. 2015, 17, 3054-3057. [CrossRef] [PubMed]

74. Singh, S.J.; Mir, B.A.; Patel, B.K. A TBPB-mediated C-3 cycloalkylation and formamidation of 4-arylcoumarin. Eur. J. Org. Chem. 2018, 2018, 1026-1033. [CrossRef]

75. Fan, W.; Shi, D.; Feng, B. TBAI-catalyzed synthesis of $\alpha$-ketoamides via $\mathrm{sp}^{3} \mathrm{C}-\mathrm{H}$ radical/radical cross-coupling and domino aerobic oxidation. Tetrahedron Lett. 2015, 56, 4638-4641. [CrossRef]

76. Chen, W.-T.; Bao, W.-H.; Ying, W.-W.; Zhu, W.M.; Liang, H.; Wei, W.-T. Copper-promoted tandem radical reaction of 2-oxindoles with formamides: Facile synthesis of unsymmetrical urea derivatives. Asian J. Org. Chem. 2018, 7, 1057-1060. [CrossRef]

77. Li, J.; Hua, R. Stereodivergent ruthenium-catalyzed transfer semihydrogenation of diaryl alkynes. Chem. Eur. J. 2011, 17, 8462-8465. [CrossRef] [PubMed]

78. Li, J.; Hua, R.; Liu, T. Highly chemo- and stereoselective palladium-catalyzed transfer semihydrogenation of internal alkynes affording cis-alkenes. J. Org. Chem. 2010, 75, 2966-2970. [CrossRef] [PubMed]

79. Tam, C.M.; To, C.T.; Chan, K.S. Carbon-carbon $\sigma$-bond transfer hydrogenation with DMF catalyzed by cobalt porphyrins. Organometallics 2016, 35, 2174-2177. [CrossRef]

80. Nale, D.B.; Bhanage, B.M. N-substituted formamides as C1-sources for the synthesis of benzimidazole and benzothiazole derivatives by using zinc catalysts. Synlett 2015, 26, 2835-2842. [CrossRef]

81. Gao, X.; Yu, B.; Mei, Q.; Yang, Z.; Zhao, Y.; Zhang, H.; Hao, L.; Liu, Z. Atmospheric $\mathrm{CO}_{2}$ promoted synthesis of $N$-containing heterocycles over $\mathrm{B}_{(}\left(\mathrm{C}_{6} \mathrm{~F}_{5}\right)_{3}$ catalyst. New J. Chem. 2016, 40, 8282-8287. [CrossRef]

82. Zhu, J.; Zhang, Z.; Miao, C.; Liu, W.; Sun, W. Synthesis of benzimidazoles from o-phenylenediamines and DMF derivatives in the presence of $\mathrm{PhSiH}_{3}$. Tetrahedron 2017, 73, 3458-3462. [CrossRef]

83. Simion, C.; Gherase, D.; Sima, S.; Simion, A.M. Serendipitous synthesis of a cyclic formamidine. Application to the synthesis of polyazamacrocycles. C. R. Chim. 2015, 18, 611-613. [CrossRef]

84. Kobayashi, E.; Togo, H. Facile one-pot preparation of 5-aryltetrazoles and 3-arylisoxazoles from aryl bromides. Tetrahedron 2018, 74, 4226-4235. [CrossRef]

85. Ochiai, H.; Niwa, T.; Hosoya, T. Stereoinversion of stereocongested carbocyclic alcohols via triflylation and subsequent treatment with aqueous $N, N$-dimethylformamide. Org. Lett. 2016, 18, 5982-5985. [CrossRef] [PubMed]

86. Yu, M.; Zhang, Q.; Wang, J.; Huang, P.; Yan, P.; Zhang, R.; Dong, D. Triflic anhydride mediated ring-opening/recyclization reaction of $\alpha$-carbamoyl $\alpha$-oximyl cyclopropanes with DMF: Synthetic route to 5-aminoisoxazoles. Synthesis 2016, 48, 1934-1938. [CrossRef]

87. Liu, L.; Zhang-Negrerie, D.; Du, F.; Zhao, K. $\mathrm{PhICl}_{2}$ and wet DMF: An efficient system for regioselective chloroformyloxylation/ $\alpha$-chlorination of alkenes $/ \alpha, \beta$-unsaturated compounds. Org. Lett. 2014, 16, 436-439. [CrossRef] [PubMed]

88. Wang, Y.; Zhang, J.; Liu, J.; Zhang, C.; Zhang, Z.; Xu, J.; Xu, S.; Wang, F.; Wang, F. C-N and N-H bond metathesis reactions mediated by carbon dioxide. ChemSusChem 2015, 8, 2066-2072. [CrossRef] [PubMed] 
89. Wang, Y.; Wang, F.; Zhang, C.; Zhang, J.; Li, M.; Xu, J. Transformylating amine with DMF to formamide over $\mathrm{CeO}_{2}$ catalyst. Chem. Commun. 2014, 50, 2438-2441. [CrossRef] [PubMed]

90. Sheng, H.; Zeng, R.; Wang, W.; Luo, S.; Feng, Y.; Liu, J.; Chen, W.; Zhu, M.; Guo, Q. An efficient heterobimetallic lanthanide alkoxide catalyst for transamidation of amides under solvent-free conditions. Adv. Synth. Catal. 2017, 359, 302-313. [CrossRef]

91. Sonawane, R.B.; Rasal, N.K.; Jagtap, S.V. Nickel-(II)-catalyzed N-formylation and $N$-acylation of amines. Org. Lett. 2017, 19, 2078-2081. [CrossRef] [PubMed]

92. Lindsay-Scott, P.J.; Charlesworth, N.G.; Grozavu, A. A flexible strategy for the regiocontrolled synthesis of pyrazolo[1,5-a]pyrazines. J. Org. Chem. 2017, 82, 11295-11303. [CrossRef] [PubMed]

93. Nakagawa-Goto, K.; Kobayashi, T.; Kawasaki, T.; Somei, M. Lithiation of 1-alkoxyindole derivatives. Heterocycles 2018. [CrossRef]

94. Ramírez-Jiménez, R.; Franco, M.; Rodrigo, E.; Sainz, R.; Ferritto, R.; Lamsabhi, A.M.; Aceña, J.L.; Cid, M.B. Unexpected reactivity of graphene oxide with DBU and DMF. J. Mater. Chem. A 2018, 6, 12637-12646. [CrossRef]

95. Deng, X.; Lei, X.; Nie, G.; Jia, L.; Li, Y.; Chen, Y. Copper-catalyzed cross-dehydrogenative $N^{2}$-coupling of $\mathrm{NH}$-1,2,3-triazoles with $\mathrm{N}, \mathrm{N}$-dialkylamides: $\mathrm{N}$-amidoalkylation of $\mathrm{NH}$-1,2,3-triazoles. J. Org. Chem. 2017, 82 , 6163-6171. [CrossRef] [PubMed]

96. Gonzalez, P.E.; Sharma, H.K.; Chakrabarty, S.; Metta-Magaña, A.; Pannell, K.H. Triethylsiloxymethyl- $\mathrm{N}, \mathrm{N}$-dimethylamine, $\mathrm{Et}_{3} \mathrm{SiOCH}_{2} \mathrm{NMe}_{2}$ : A dimethylaminomethylation (Mannich) reagent for O-H, S-H, P-H and aromatic C-H systems. Eur. J. Org. Chem. 2017, 2017, 5610-5616. [CrossRef]

97. Hu, Y.; Hu, Y.; Hu, Q.; Ma, J.; Lv, S.; Liu, B.; Wang, S. Direct access to fused salicylaldehydes and salicylketones from tetraynes. Chem. Eur. J. 2017, 23, 4065-4072. [CrossRef] [PubMed]

98. Zhu, R.; Liu, Z.; Chen, J.; Xiong, X.; Wang, Y.; Huang, L.; Bai, J.; Dang, Y.; Huang, J. Preparation of thioanisole biscarbanion and $\mathrm{C}-\mathrm{H}$ lithiation/annulation reactions for the access of five-membered heterocycles. Org. Lett. 2018, 20, 3161-3165. [CrossRef] [PubMed]

99. Zeng, R.; Sheng, H.; Rao, B.; Feng, Y.; Wang, H.; Sun, Y.; Chen, M.; Zhu, M. An efficient and green approach to synthesizing enamines by intermolecular hydroamination of activated alkynes. Chem. Res. Chin. Univ. 2015, 31, 212-217. [CrossRef]

100. Liu, D.; Mao, J.; Rong, G.; Yan, H.; Zheng, Y.; Chen, J. Concise synthesis of semicarbazides and formylhydrazines via direct addition reaction between aromatic azoarenes and $N$-substituted formamides. RSC Adv. 2015, 5, 19301-19305. [CrossRef]

101. Mori, S.; Shibuya, M.; Yamamoto, Y. Ruthenium-catalyzed hydrocarbamoylative cyclization of 1,6-diynes with formamides. Chem. Lett. 2017, 46, 207-210. [CrossRef]

102. Yamamoto, Y.; Okude, Y.; Mori, S.; Shibuya, M. Combined experimental and computational study on ruthenium(II)-catalyzed reactions of diynes with aldehydes and $N, N$-dimethylformamide. J. Org. Chem. 2017, 82, 7964-7973. [CrossRef] [PubMed]

103. Yamamoto, Y. Theoretical study on ruthenium-catalyzed hydrocarbamoylative cyclization of 1,6-diyne with dimethylformamide. Organometallics 2017, 36, 1154-1163. [CrossRef]

104. Adams, R.D.; Dhull, P. Formyl C-H activation in $N, N$-dimethylformamide by a dirhenium carbonyl complex. J. Organomet. Chem. 2017, 849-850, 228-232. [CrossRef]

105. Guo, W.; Liao, J.; Liu, D.; Li, J.; Ji, F.; Wu, W.; Jiang, H. A four-component reaction strategy for pyrimidine carboxamide synthesis. Angew. Chem. Int. Ed. 2017, 56, 1289-1293. [CrossRef] [PubMed]

106. Pastoriza-Santos, I.; Liz-Marzán, L.M. N,N-Dimethylformamide as a reaction medium for metal nanoparticle synthesis. Adv. Funct. Mater. 2009, 19, 679-688. [CrossRef]

107. Akbari, S.; Mokhtari, J.; Mirjafari, Z. Solvent-free and melt aerobic oxidation of benzyl alcohols using $\mathrm{Pd} / \mathrm{Cu}_{2}(\mathrm{BDC})_{2} \mathrm{DABCO}-\mathrm{MOF}$ prepared by one-step and through reduction by dimethylformamide. RSC Adv. 2017, 7, 40881-40886. [CrossRef]

108. Tahmasebi, S.; Mokhtari, J.; Naimi-Jamal, M.R.; Khosravi, A.; Panahi, L. One-step synthesis of Pd-NPs@Cu $\mathrm{Cu}_{2}(\mathrm{BDC})_{2} \mathrm{DABCO}$ as efficient heterogeneous catalyst for the Suzuki-Miyaura cross-coupling reaction. J. Organomet. Chem. 2017, 853, 35-41. [CrossRef]

109. Azuma, R.; Nakamichi, S.; Kimura, J.; Yano, H.; Kawasaki, H.; Suzuki, T.; Kondo, R.; Kanda, Y.; Shimizu, K.-I.; Kato, K.; et al. Solution synthesis of $N, N$-dimethylformamide-stabilized iron-oxide nanoparticles as an efficient and recyclable catalyst for alkene hydrosilylation. ChemCatChem 2018, 10, 2378-2382. [CrossRef] 
110. Onishi, K.; Oikawa, K.; Yano, H.; Suzuki, T.; Obora, Y. N,N-Dimethylformamide-stabilized palladium nanoclusters as a catalyst for Larock indole synthesis. RSC Adv. 2018, 8, 11324-11329. [CrossRef]

111. Oka, H.; Kitai, K.; Suzuki, T.; Obora, Y. N,N-Dimethylformamide-stabilized copper nanoparticles as a catalyst precursor for Sonogashira-Hagihara cross coupling. RSC Adv. 2017, 7, 22869-22874. [CrossRef]

112. Oikawa, K.; Itoh, S.; Yano, H.; Kawasaki, H.; Obora, Y. Preparation and use of DMF-stabilized iridium nanoclusters as methylation catalysts using methanol as the $C 1$ source. Chem. Commun. 2017, 53, 1080-1083. [CrossRef] [PubMed]

113. Rasal, K.B.; Yadav, G.D. One-pot synthesis of benzimidazole using DMF as a multitasking reagent in presence $\mathrm{CuFe}_{2} \mathrm{O}_{4}$ as catalyst. Catal. Today 2018, 309, 51-60. [CrossRef]

(C) 2018 by the authors. Licensee MDPI, Basel, Switzerland. This article is an open access article distributed under the terms and conditions of the Creative Commons Attribution (CC BY) license (http:/ / creativecommons.org/licenses/by/4.0/). 

MDPI

St. Alban-Anlage 66

4052 Basel

Switzerland

Tel. +41616837734

Fax +41 613028918

www.mdpi.com

Molecules Editorial Office

E-mail: molecules@mdpi.com www.mdpi.com/journal/molecules

-.....

(2)

-

Q

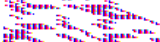

ont 

MDPI

St. Alban-Anlage 66

4052 Basel

Switzerland

Tel: +41 616837734

Fax: +41 613028918 